\title{
A Comparative Grammar of
}

the Early Germanic Languages

3

\section{R.D. Fulk}

John Benjamins Publishing Company 
A Comparative Grammar of the Early Germanic Languages 


\section{Studies in Germanic Linguistics (SiGL)}

ISSN 2452-2120

This series aims to provide a unified home for the highest quality monographs and edited scholarly volumes of empirically grounded research on Germanic languages past and present. The series welcomes formal, functional, and quantitative studies in any established subfield of linguistic inquiry (e.g., syntax, semantics, phonology, morphology, sociolinguistics, historical linguistics, psycholinguistics, and language acquisition).

Contributions that engage two or more Germanic languages in their studies are particularly desirable. In addition to an empirical focus on Germanic, volumes in this series should also contribute to theories of language structure, language use, language change, language acquisition, and language processing.

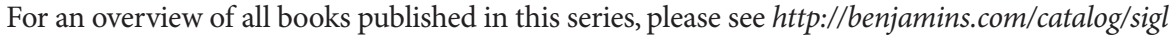

\section{Editors}

Michael T. Putnam

Penn State University

\section{Editorial Board}

Tor A. Åfarli

Norwegian University of

Science \& Technology

Birgit Alber

University of Verona

Hans C. Boas

University of Texas at Austin

Joshua R. Brown

University of Wisconsin-Eau

Claire

Elizabeth Coppock

Boston University

Ulrike Demske

University of Potsdam

David Fertig

University at Buffalo

Elly van Gelderen

Arizona State University

Tracy Alan Hall

Indiana University

\section{Volume 3}

Holger Hopp

University of Braunschweig

Marjo van Koppen

Utrecht University

Carrie N. Jackson

Penn State University

Janne Bondi Johannessen

University of Oslo

Winfried Lechner

University of Athens

Ida Larsson

University of Oslo

Mark L. Louden

University of Wisconsin -

Madison

Helge Lødrup

University of Oslo

Marc van Oostendorp

Meertens Institute / Leiden

University
Laura Catharine Smith

Brigham Young University
Pia Quist

University of Copenhagen

Joseph C. Salmons

University of Wisconsin -

Madison

Florian Schäfer

Humboldt University, Berlin

Halldór Ármann Sigurðsson

Lund University

John R. te Velde

Oklahoma State University

Höskuldur Thráinsson

University of Iceland

Ida Toivonen

Carleton University

Marit Westergaard

University of Tromsø

Susi Wurmbrand

University of Connecticut

C. Jan-Wouter Zwart

University of Groningen

A Comparative Grammar of the Early Germanic Languages

by R.D. Fulk 


\section{A Comparative Grammar of the Early Germanic Languages}

R.D. Fulk

John Benjamins Publishing Company

Amsterdam/ Philadelphia 
The paper used in this publication meets the minimum requirements of the American National Standard for Information Sciences - Permanence of Paper for Printed Library Materials, ANSI z39.48-1984.

Open access to this work was funded in part by the College of Arts and Sciences at Indiana University, Bloomington, by the kindness of Paul Gutjahr, Associate Dean for Arts and Humanities, and by the Office of the Vice Provost for Research, Ed Comentale, Associate Vice Provost, through the Retired Faculty Grant-in-Aid Program.

DOI 10.1075/sigl.3

Cataloging-in-Publication Data available from Library of Congress: LCCN 2018030754 (PRINT) / 2018031862 (E-BOOK)

ISBN $9789027263124 \quad$ (нB)

ISBN $9789027263131 \quad$ (Е-BOOK)

(C) 2018 -John Benjamins B.V.

The electronic edition of this book is Open Access under a CC BY-NC-ND 4.o license. https://creativecommons.org/licenses/by-nc-nd/4.0

This license permits reuse, distribution and reproduction in any medium for non-commercial purposes, provided that the original author(s) and source are credited. Derivative works may not be distributed without prior permission.

This work may contain content reproduced under license from third parties. Permission to reproduce this third-party content must be obtained from these third parties directly.

Permission for any reuse beyond the scope of this license must be obtained from John Benjamins Publishing Company, rights@benjamins.nl

John Benjamins Publishing Company · https://benjamins.com 


\section{Contents}

List of figures $\quad$ xii

List of abbreviations $\quad$ xiii

Preface xiv

CHAPTER 1

Introduction

1.1 Early Germanic phonology and morphology: general bibliography $\mathbf{1}$

1.2 The Indo-European background of Germanic $\mathbf{1}$

1.3 Distinguishing characteristics of Germanic 4

1.4 The position of Germanic within the Indo-European family $\mathbf{5}$

1.5 Substrate influence upon Germanic 9

1.6 The reconstruction of Proto-Germanic 11

1.7 Germanic loanwords in Finnish $\mathbf{1 2}$

1.8 The three branches of Germanic $\mathbf{1 2}$

1.9 The grouping of the three Germanic branches $\mathbf{1 4}$

1.10 The development of Northwest Germanic and the Ingvaeonic problem $\mathbf{1 7}$

1.11 East Germanic 19

1.12 Provenance of the Goths 22

1.13 The Runic records $\mathbf{2 3}$

1.14 North Germanic 24

1.15 West Germanic 25

1.16 Old English 26

1.17 Old Frisian $\mathbf{2 8}$

1.18 Old Saxon 29

1.19 Old Low Franconian $\mathbf{3 0}$

1.20 Old High German 30

PHONOLOGY

CHAPTER 2

Prosodic Features and the Syllable

2.1 The Proto-Indo-European lexical accent $\mathbf{3 5}$

2.2 Lexical accent in Proto-Germanic $\mathbf{3 6}$

2.3 Quantity in early Germanic $\mathbf{3 8}$

2.4 Syllable division in early Germanic $\mathbf{3 9}$

2.5 Prokosch's law $\mathbf{4 1}$

CHAPTER 3

The Vowels of Proto-Indo-European and Proto-Germanic

3.1 The vowels of Proto-Indo-European $\mathbf{4 3}$

3.2 The short vowels in early Germanic $\mathbf{4 6}$

3.3 The long vowels in early Germanic $\mathbf{4 7}$

3.4 The diphthongs in early Germanic $\mathbf{4 9}$

3.5 The sources of $\bar{e}_{2} \quad \mathbf{5 1}$ 
3.6 Ablaut in Proto-Germanic $\mathbf{5 2}$

3.7 Summary tables of Indo-European vowel developments $\mathbf{5 3}$

CHAPTER 4

Changes of Stressed Vowels in Germanic

4.1 Compensatory lengthening upon loss of a nasal consonant

55

4.2 Shortening in closed syllables $\mathbf{5 5}$

4.3 Redistribution of the Proto-Germanic short mid and high vowels: lowering $\mathbf{5 5}$

4.4 Redistribution of the Proto-Germanic short mid and high vowels: raising $\mathbf{5 7}$

4.5 Changes of stressed vowels in Gothic $\mathbf{5 9}$

4.6 Changes of stressed vowels in the Northwest Germanic protolanguage $\mathbf{6 0}$

4.7 Front mutation $\mathbf{6 1}$

4.8 Back mutation $\mathbf{6 7}$

4.9 Changes of stressed vowels and diphthongs in Proto-Norse $\mathbf{7 0}$

4.10 Changes of stressed vowels and diphthongs in the protolanguage of West Germanic $\mathbf{7 1}$

4.11 Changes of stressed vowels in North Sea Germanic $\mathbf{7 2}$

4.12 Changes of stressed vowels and diphthongs in Anglo-Frisian $\mathbf{7 2}$

4.13 Changes of stressed vowels in early Old English $\mathbf{7 3}$

4.14 Changes of stressed vowels in Old Frisian $\mathbf{7 5}$

4.15 Changes of stressed vowels in Old Saxon $\mathbf{7 6}$

4.16 Changes of stressed vowels in Old Low Franconian $\mathbf{7 6}$

4.17 Changes of stressed vowels in Old High German 77

4.18 Summary table of Germanic stressed vowels 77

CHAPTER 5

\section{The Germanic Vowels in Syllables of Lesser Stress}

5.1 General remarks $\mathbf{7 9}$

5.2 Short vowels of final syllables $\mathbf{7 9}$

5.3 Bimoric vowels and diphthongs of final syllables $\mathbf{8 2}$

5.4 Trimoric vowels and diphthongs $\mathbf{8 4}$

5.5 Changes of medial vowels in the early preliterary period $\quad \mathbf{8 7}$

5.6 Later preliterary changes of medial and final vowels $\mathbf{9 0}$

5.7 Vowels in prefixes $\mathbf{9 6}$

5.8 Sievers' law 97

CHAPTER 6

\section{Consonants}

6.1 The Proto-Indo-European consonants 99

6.2 The glottalic theory $\mathbf{1 0 0}$

6.3 Laryngeal consonants in Germanic $\mathbf{1 0 1}$

6.4 Grimm's law $\mathbf{1 0 2}$

6.5 Exceptions to Grimm's law $\mathbf{1 0 5}$

6.6 Verner's law $\mathbf{1 0 7}$

6.7 The chronology and dating of Grimm's and Verner's laws $\mathbf{1 1 0}$

6.8 Geminates in Proto-Germanic $\mathbf{1 1 2}$ 
6.9 Geminate obstruents and Kluge's law $\mathbf{1 1 4}$

6.10 The Verschärfung $\mathbf{1 1 7}$

6.11 Further consonant changes common to all the Germanic languages $\mathbf{1 2 0}$

6.12 Consonant changes in Gothic $\mathbf{1 2 2}$

6.13 Gothic $p l-\mathbf{1 2 3}$

6.14 Consonant changes in Proto-Norse $\mathbf{1 2 3}$

6.15 West Germanic consonant gemination $\mathbf{1 2 6}$

6.16 Other consonant changes in the West Germanic protolanguage $\mathbf{1 2 9}$

6.17 Consonant changes in North Sea Germanic and Anglo-Frisian 130

6.18 Consonant changes in Old English 131

6.19 Consonant changes in Old Frisian 132

6.20 Consonant changes in Old Saxon $\mathbf{1 3 3}$

6.21 The High German Consonant Shift $\mathbf{1 3 3}$

6.22 Other consonant changes in Old High German $\mathbf{1 3 6}$

\section{MORPHOLOGY}

CHAPTER 7

Nouns

7.1 Noun formation in Proto-Indo-European and Germanic 141

7.2 The inflections of Proto-Indo-European root-stems $\mathbf{1 4 2}$

7.3 The inflectional categories of Germanic nouns $\mathbf{1 4 3}$

7.4 Accent and ablaut in nouns $\mathbf{1 4 4}$

7.5 Vocalic stems $\mathbf{1 4 4}$

$7.6 a$-stem nouns $\mathbf{1 4 4}$

7.7 The simple $a$-stems $\mathbf{1 4 5}$

7.8 Origin and development of $a$-stem inflections $\mathbf{1 4 6}$

7.9 The $j a$-stems $\mathbf{1 5 0}$

7.10 The $j a$-stems in Gothic $\mathbf{1 5 0}$

7.11 The $j a$-stems in Northwest Germanic $\mathbf{1 5 1}$

7.12 The $w a$-stems $\mathbf{1 5 3}$

7.13 The $\bar{o}$-stems $\mathbf{1 5 4}$

7.14 The simple $\bar{o}$-stems $\mathbf{1 5 4}$

7.15 Origin and development of $\bar{o}$-stem inflections $\mathbf{1 5 5}$

7.16 The $j \bar{o}$-stems $\mathbf{1 5 6}$

7.17 Origin and development of $j \bar{o}$-stem inflections $\quad \mathbf{1 5 7}$

7.18 The $w \bar{o}$-stems $\quad \mathbf{1 5 7}$

7.19 The $i$-stems $\mathbf{1 5 8}$

7.20 The masculine and neuter $i$-stems $\mathbf{1 5 8}$

7.21 Origin and development of masculine and neuter $i$-stem inflections

7.22 The feminine $i$-stems $\mathbf{1 6 1}$

7.23 Origin and development of feminine $i$-stem inflections $\quad \mathbf{1 6 2}$

7.24 The $u$-stems $\mathbf{1 6 3}$

7.25 Origin and development of $u$-stem inflections $\quad \mathbf{1 6 4}$

7.26 The consonantal stems $\mathbf{1 6 5}$

7.27 The root-stems $\mathbf{1 6 5}$

7.28 Origin and development of the root-stems and their inflections $\mathbf{1 6 7}$

7.29 The $n$-stems $\mathbf{1 6 8}$ 
7.30 The an-stems $\mathbf{1 6 8}$

7.31 Origin and development of an-stem inflections $\mathbf{1 6 9}$

7.32 The $\bar{o} n$-stems $\mathbf{1 7 1}$

7.33 Origin and development of $\bar{o} n$-stem inflections $\mathbf{1 7 2}$

7.34 The $\bar{i} n$-stems $\mathbf{1 7 2}$

7.35 The $r$-stems $\mathbf{1 7 3}$

7.36 Origin and development of $r$-stem inflections $\quad \mathbf{1 7 4}$

7.37 The $s$-stems $\mathbf{1 7 6}$

7.38 Origin and development of $s$-stem inflections $\quad \mathbf{1 7 7}$

7.39 The $n d$-stems $\mathbf{1 7 8}$

7.40 Origin and development of $n d$-stem inflections $\mathbf{1 7 8}$

7.41 The dental stems $\mathbf{1 7 9}$

7.42 The heteroclitic stems $\mathbf{1 8 0}$

\section{CHAPTER 8}

Pronouns

8.1 Types of pronouns in Proto-Germanic $\mathbf{1 8 1}$

$$
\text { I. PERSONAL PRONOUNS }
$$

8.2 Personal pronouns of the first person $\mathbf{1 8 1}$

8.3 Personal pronouns of the second person $\mathbf{1 8 5}$

8.4 Reflexive pronouns $\mathbf{1 8 8}$

8.5 Possessive adjectives $\mathbf{1 8 8}$

II. ANAPHORIC PRONOUNS

8.6 Anaphoric pronouns in Proto-Indo-European $\mathbf{1 9 0}$

8.7 Anaphoric pronouns in Germanic $\mathbf{1 9 0}$

III. Demonstrative Pronouns

8.8. Demonstrative pronouns in Germanic 193

8.9 Demonstrative pronouns in Proto-Indo-European 193

8.10 The inherited demonstrative pronoun in Germanic $\mathbf{1 9 4}$

8.11 Distal demonstrative pronouns in Germanic $\mathbf{1 9 8}$

8.12 Proximal demonstrative pronouns $\mathbf{1 9 8}$

IV. REMAINING TYPES OF PRONOUNS

8.13 Interrogative pronouns $\mathbf{2 0 1}$

8.14 Relative pronouns $\mathbf{2 0 3}$

8.15 Indefinite pronouns $\mathbf{2 0 4}$

CHAPTER 9

Adjectives

9.1 Adjective inflection in Proto-Indo-European and Proto-Germanic 208

I. INDEFINITE (STRONG) ADJECTIVES

9.2 The unmarked strong declension of monosyllabic heavy stems $\mathbf{2 0 9}$

9.3 Variant stem types in the unmarked strong declension $\mathbf{2 1 2}$

9.4 The $j a$ - and $j \bar{o}$-stems $\mathbf{2 1 3}$

9.5 The $w a$ - and $w \bar{o}$-stems $\mathbf{2 1 4}$

9.6 The $i$ - and $u$-stems 215 


\section{DEFINITE (WEAK) ADJECTIVES}

9.7 Definitions, distribution, derivation $\mathbf{2 1 6}$

9.8 Inflectional patterns $\mathbf{2 1 6}$

9.9 The declension of participles $\mathbf{2 1 8}$

III. COMPARISON OF ADJECTIVES

9.10 The comparative degree $\mathbf{2 1 8}$

9.11 The superlative degree $\mathbf{2 1 9}$

9.12 Distribution of suffixes $\mathbf{2 1 9}$

9.13 Suppletive comparison $\mathbf{2 2 0}$

CHAPTER 10

\section{Numerals}

\section{CARDINALS}

10.1 The numerals 1-4 222

10.2 The numerals 5-10 $\mathbf{2 2 6}$

10.3 The numerals 11-19 227

10.4 The lower decads, 20-60 228

10.5 The upper decads, 70-120 $\mathbf{2 3 0}$

10.6 The higher cardinals $\mathbf{2 3 2}$

$$
\text { II. ORDINALS AND VARIA }
$$

10.7 'First', 'second', and 'third' 233

10.8 'Fourth' to 'twelfth' $\mathbf{2 3 3}$

10.9 The higher ordinals $\mathbf{2 3 4}$

10.10 Varia 235

CHAPTER 11

Adverbs, Prepositions, Conjunctions

11.1 Monomorphemic adverbs $\mathbf{2 3 7}$

11.2 The composition of adverbial stems $\mathbf{2 3 7}$

11.3 Regular comparison of adverbs $\mathbf{2 3 9}$

11.4 Suppletive comparison $\mathbf{2 4 0}$

11.5 Prepositions $\mathbf{2 4 0}$

11.6 Conjunctions $\mathbf{2 4 1}$

CHAPTER 12

Verbs

I. The PROTO-INDO-EUROPEAN BACKGROUND OF THE GERMANIC VERB

12.1 Categories and aspects of verbs in Proto-Indo-European $\mathbf{2 4 2}$

12.2 Verb tenses and stems in Proto-Indo-European $\mathbf{2 4 4}$

12.3 Primary, secondary, and derived verbs in Proto-Indo-European $\mathbf{2 4 5}$

12.4 Personal inflections of verbs in Proto-Indo-European 249

12.5 The middle voice in Proto-Indo-European 250

12.6 The moods of Proto-Indo-European $\mathbf{2 5 1}$

12.7 Non-finite verb forms $\mathbf{2 5 2}$

12.8 Particles and the Proto-Indo-European verb 253 


\section{GERMANIC VeRB MORPHOLOGY}

12.9 The general nature of the restructuring of the Germanic verb system $\mathbf{2 5 4}$

12.10 Morphological restructuring of root, stem, and inflection in ProtoGermanic 255

\section{STRONG VERBS}

A. Stem formation

12.11 The general nature of strong verbs $\mathbf{2 5 5}$

12.12 Productivity $\mathbf{2 5 6}$

12.13 Derivation of Proto-Germanic ablaut patterns: classes I-III 257

12.14 Derivation of Proto-Germanic ablaut patterns: classes IV-V 257

12.15 Derivation of Proto-Germanic ablaut patterns: class VI $\mathbf{2 5 8}$

12.16 Derivation of Proto-Germanic ablaut patterns: class VII $\mathbf{2 6 0}$

12.17 Verner's law in strong verbs $\mathbf{2 6 1}$

12.18 Aorist presents $\mathbf{2 6 3}$

12.19 Strong verbs with so-called weak presents $\mathbf{2 6 5}$

12.20 Preterites of class VII in Northwest Germanic $\mathbf{2 6 6}$

12.21 Contracted verbs $\mathbf{2 7 0}$

12.22 The verba pura $\mathbf{2 7 1}$

\section{B. Inflection}

12.23 A comparative paradigm of strong verb inflection $\mathbf{2 7 2}$

12.24 Inflection of the present indicative active in Proto-Germanic $\mathbf{2 7 4}$

12.25 Inflection of the preterite indicative in Proto-Germanic $\mathbf{2 7 7}$

12.26 Inflection of the present subjunctive active in Proto-Germanic 279

12.27 Inflection of the preterite subjunctive in Proto-Germanic $\mathbf{2 8 1}$

12.28 Inflection of the imperative in Proto-Germanic $\mathbf{2 8 2}$

12.29 The passive and middle inflections $\mathbf{2 8 3}$

12.30 Formation and inflection of non-finite strong verb forms $\mathbf{2 8 4}$

12.31 Characteristics of the seven strong classes in the individual early Germanic languages $\mathbf{2 8 5}$

\section{WEAK VERBS}

12.32 The nature of weak verbs $\mathbf{2 9 1}$

12.33 Origin of the dental suffix $\mathbf{2 9 2}$
A. Weak verbs of class 1

12.34 Stem formation 294

12.35 Inflection $\mathbf{2 9 5}$

12.36 Variation in the stem $\mathbf{2 9 6}$

12.37 Verbs without $*_{-} i$ - in the preterite $\mathbf{2 9 9}$

12.38 Development of the inflections of the present stem $\mathbf{3 0 1}$

12.39 Development of inflections of the preterite stem $\mathbf{3 0 3}$

B. Weak verbs of class 2

12.40 Stem formation $\mathbf{3 0 4}$

12.41 Inflection $\mathbf{3 0 5}$

12.42 Morphological variation $\mathbf{3 0 6}$

12.43 Historical development $\mathbf{3 0 6}$

C. Weak verbs of class 3

12.44 Stem formation $\mathbf{3 0 8}$ 
12.45 Inflection $\mathbf{3 0 8}$

12.46 Morphological variation $\mathbf{3 1 0}$

12.47 Historical development $\mathbf{3 1 0}$

D. Weak verbs of class 4

12.48 Stem formation $\mathbf{3 1 3}$

12.49 Inflection $\mathbf{3 1 3}$

12.50 Historical development $\mathbf{3 1 4}$

V. PRETERITE-PRESENT VERBS

12.51 Stem formation $\mathbf{3 1 6}$

12.52 Inflection and forms $\mathbf{3 1 6}$

12.53 Inventory by corresponding strong class $\mathbf{3 1 7}$

12.54 Historical development $\mathbf{3 2 1}$

VI. ATHEMATIC VERBS

12.55 Inventory $\mathbf{3 2 3}$

12.56 The verb 'be' $\mathbf{3 2 3}$

12.57 Historical development of 'be' $\mathbf{3 2 5}$

12.58 The verb 'will' $\mathbf{3 2 8}$

12.59 Historical development of 'will' $\mathbf{3 2 8}$

12.60 The verb 'do' 330

12.61 Historical development of 'do' $\mathbf{3 3 1}$

12.62 The athematic verb 'go' $\mathbf{3 3 4}$

12.63 Historical development of 'go' 335

12.64 The athematic verb 'stand' $\mathbf{3 3 6}$

References 


\section{List of figures}

Fig. 1. The Indo-European Stammbaum of Schleicher.

Fig. 2. The Gothic alphabet, with numerical values and transliterative equivalents.

Fig. 3. The Elder Futhark, with equivalents in transcription.

Fig. 4. Reflexes of Proto-Indo-European vowels in Proto-Germanic.

Fig. 5. The general direction of front mutation in the early Germanic languages.

Fig. 6. The High German shift of voiceless stops at its greatest extent.

Fig. 7. New High German Dialects. 


\section{List of abbreviations}

\begin{tabular}{|c|c|c|c|}
\hline acc. & accusative & num. & numeral \\
\hline act. & active & NWGmc. & Northwest Germanic \\
\hline adj. & adjective & OCS & Old Church Slavonic \\
\hline adv. & Adverb & $\mathrm{OE}$ & Old English \\
\hline Alban. & Albanian & $\mathrm{OEN}$ & Old East Norse $(\S 1.14)$ \\
\hline CG & Central German $(§ 1.20)$ & OFris. & Old Frisian \\
\hline comp. & comparative & $\mathrm{OHG}$ & Old High German \\
\hline conj. & conjunction & OIcel. & Old Icelandic \\
\hline dat. & dative & OIr. & Old Irish \\
\hline dem. & demonstrative & $\mathrm{ON}$ & Old Norse \\
\hline EWS & Early West Saxon $(§ 1.16$ & OLF & Old Low Franconian \\
\hline & n. 1) & OPruss. & Old Prussian \\
\hline esp. & especially & opt. & optative \\
\hline fem. & feminine & orig. & original(ly) \\
\hline gen. & genitive & OS & Old Saxon \\
\hline Gk. & Greek & OWN & Old West Norse $(\S 1.14)$ \\
\hline Gmc. & Germanic & part. & participle \\
\hline Go. & Gothic & pass. & passive \\
\hline IE & Indo-European & PDE & Present-Day English \\
\hline imp. & imperative & PGmc. & Proto-Germanic \\
\hline ind. & indicative & PIE & Proto-Indo-European \\
\hline inf. & infinitive & pl. & plural \\
\hline instr. & instrumental & pp. & past/passive participle \\
\hline intrans. & intransitive & pres. & present \\
\hline Lat. & Latin & pret. & preterite \\
\hline Lith. & Lithuanian & pron. & pronoun \\
\hline loc. & locative & refs. & references \\
\hline LWS & Late West Saxon $(\S 1.16$ & sg. & singular \\
\hline & n. 1) & $\mathrm{sj}$. & subjunctive \\
\hline masc. & masculine & Skt. & Sanskrit \\
\hline ME & Middle English & superl. & superlative \\
\hline MHG & Middle High German & trans. & transitive \\
\hline neut. & neuter & UG & Upper German $(\S 1.20)$ \\
\hline NGmc. & North Germanic & vb. & verb \\
\hline NHG & New High German & voc. & vocative \\
\hline NLG & New Low German & WGmc. & West Germanic \\
\hline nom. & nominative & WS & West Saxon \\
\hline
\end{tabular}




\section{Preface}

The present work was undertaken in response to the recognition that there exists no introduction of very recent date to the comparative study of the earliest Germanic languages and the reconstruction of Proto-Germanic suitable for student use (see $§ 1$ ). It is especially remarkable that there exists none in English of more recent date than 1939. Later works generally have less comprehensive aims. Moreover, even the available handbooks tend to offer limited bibliographical guidance, with the result that their prescriptions seem, at times, oracular, though in fact there are relatively few topics in early Germanic linguistics that are uncontroversial. Accordingly, the aim of this book is twofold: to provide students with an overview of early Germanic phonology and inflectional morphology and to furnish such bibliographical references as may be required in the pursuit of further research on any given topic. Naturally, given the enormous volume of published research in this area, bibliographical coverage is constrained; the aim was, rather, to provide students with sufficient references to locate the totality of the relevant literature by referral to more specialized studies. The older literature, in particular, is often left uncited in the assurance that it will be readily discoverable by reference to more recent work.

One generalization that may be gleaned from the following pages is that, as remarked above, there is hardly any topic in early Germanic linguistics about which scholarship is entirely unanimous. An effort has thus been made to refer the reader to alternative views, often without favoring a particular analysis. It would, however, be unhelpful to present every competing explanation as equally probable, and so usually it will be plain which the present writer finds most plausible. Nonetheless, it is not the aim of the present work to offer the last word on any given topic. Moreover, few new analyses are offered. It is the author's hope that this handbook will be used instead to enable future studies to probe competing hypotheses for their relative probability and to establish what is most credible, even if the preferences indicated herein prove to be unfounded.

Like most comparable works in Indo-European linguistics, the present manual confines itself to considerations of phonology and inflectional morphology, without any systematic attempt to explain derivational morphology. There are already available some excellent guides to derivational morphology in Germanic; for references to these, see $\S 1$.

The typescript was submitted to the editors at the end of July 2017, and the referees' reports were returned in the middle of March 2018. With few additions, the bibliography remains as it was nearly a year ago, since the author's present circumstances rendered it impracticable to attempt in any concerted fashion to bring it up to date. An exception is that references to Ringe 2006a have for the most part been replaced by references to the revised edition (Ringe 2017), though it was not feasible to do more with the revised edition than to update citations.

One referee for the press recommended that transliterations be supplied for Greek words. Students should be advised that it is not feasible to undertake the study of early Germanic phonology without prior acquaintance at least with the Greek alphabet, if not greater familiarity with the language. Those in need of guidance may consult any grammar of Ancient Greek (e.g. Sihler 1995) or, for the most basic information, any one of a number of Web pages devoted to the topic may be referred to, for example https://en.wikipedia.org/wiki/Greek_orthography. 
A book such as this could not have been compiled without the generous assistance of many individuals. Grateful acknowledgment must go first to Mary Richards, now emerita of Delaware, who probably does not remember the occasion, many years past, on which she planted the germ of an idea out of which this project sprouted. The author's sincerest thanks are also extended to the board of the John Simon Guggenheim Memorial Foundation for providing the fellowship in 2013-14 that enabled work to begin on this project. It is to be hoped that the final result adequately, if belatedly, repays the debt. Anatoly Liberman, who lent vigorous support in the (otherwise anonymous) fellowship selection process, has over the years been a generous interlocutor and an inspiration. Colin J. Grant provided welcome assistance on some particular points (see $\$ 6.15 \mathrm{n} .8$ ). Kari Ellen Gade, who has been the author's closest colleague and a sustaining influence over the years, lent much-appreciated encouragement and practical support.

Warmest thanks are due to David Fertig, who identified himself as one of the two referees who vetted the typescript for the publisher and who provided a meticulous, substantial, and singularly helpful set of recommendations, from which the book has benefited immensely. Any remaining deficiencies are, of course, attributable solely to the author. At John Benjamins, the editors of the Studies in Germanic Linguistics series, B. Richard Page, Mike Putnam, and Laura Catharine Smith, have provided invaluable help. The Acquisitions Editor at Benjamins, Anke de Looper, showed patience and latitude in the face of the challenges that a book such as this poses to the Studies in Germanic Linguistics series, and for that, sincere gratitude is due her.

Finally, it should be apparent on every page of this book that it owes its existence to the intellectual care devoted to comparative Germanic and Indo-European linguistics by countless teachers - most, though not all, long since reduced to words on a page- - from whose instruction the author has benefited these many years. It is his great privilege to have known not a few of them.

R.D.F.

New York City

May 2018 



\section{Introduction}

\subsection{Early Germanic phonology and morphology: general bibliography}

Handbooks of early Gmc. in general, with varying attention to the reconstruction of PGmc., include Ramat 1981, van Coetsem \& Kufner 1972, Krahe \& Meid 1969 (succeeding Loewe 1933), Guchmann et al. 1962-6, Prokosch 1939, Hirt 1931-4, Boer 1924, Kluge 1913, Paul 1900-9, Dieter 1900, and Streitberg 1896. Euler 2013 is devoted to the WGmc. protolanguage and its development into the attested older languages. Ringe 2017, not a grammar but a narrative, traces developments from PIE to PGmc.; likewise Ringe \& Taylor 2014 from PGmc. to OE, both with copious lists illustrating sound changes. More theoretical is Voyles 1992. Hutterer 1975 may be useful for general external history. Of these, Paul 1900-9 and Hirt 1931-4 are notable for attempting to provide extensive bibliographical coverage of individual topics.

Specifically devoted to PGmc. phonology is Noreen 1894. For an excellent guide to derivational morphology, see Krahe \& Meid 1969: III, and on both inflectional and derivational morphology, see Bammesberger 1986a (verbs) and 1990 (nominals). The derivational morphology of Gmc. nominals is also covered thoroughly in Kluge 1926, and specifically for Gothic in Casaretto 2004. For bibliography on Gmc. morphology, consult Seymour 1968. For the Gmc. lexicon, some useful sources are Kroonen 2013a, Orel 2003, and Torp \& Falk 1909. On PGmc. syntax, see Walkden 2014, Hopper 1975, Lehmann 1972.

A very substantial bibliography will be found in Markey, Kyes, \& Roberge 1977. The most thorough bibliographical source covering the period from 1948 to the present is the annual Linguistic bibliography for the year ..., with supplement for the years 193947.

See further $\S \S 1.11-20$ for general bibliography on the individual languages.

\subsection{The Indo-European background of Germanic}

The Germanic languages are a subgroup of the Indo-European family of languages. ${ }^{1}$ It is a well-defined subgroup, showing a number of distinctive traits that differentiate it from other IE languages, such as the results of Grimm's law ( $\$ 6.4)$, the development of a distinction between the strong and weak inflection of adjectives (\$9.7), and the rise of verb preterites marked by a dental suffix $(\$ 12.32){ }^{2}$ In conceptualizing the relation between Germanic and other IE languages, the comparative method whereby Proto-Indo- 
European has been reconstructed very nearly demands a genealogical model like a family tree, with each language or language group represented by a node on a branching diagram. Such a representation as a branching tree, or Stammbaum, was first proposed by Schleicher (1860: 81), as shown in Figure 1. In such a model, the protolanguage is assumed to have developed dialects which eventually diverged sufficiently to be regarded as separate languages, which in turn underwent the same process repeatedly. An assumption underlying such a Stammbaum is thus that once languages diverge in this manner, each develops separately, without the influence of one upon another. It has frequently been pointed out that this is not a realistic model of language development, for a variety of reasons, the most obvious of which is that languages do not generally develop in isolation, but changes may affect more than one language at once, proceeding diatopically in a wave-like pattern (as described in the so-called Wellentheorie 'wave theory', first posited by J. Schmidt 1872). ${ }^{3}$ An example of this is umlaut, which affected West Germanic after the rise of recognizably different West Germanic languages, perhaps affecting Old English first (§4.7). Changes may also affect different languages in identical ways, often because related languages contain identical structures that are ripe for particular kinds of alterations (in the 'drift' model first proposed by Sapir 1921: 160-82). Tree diagrams do encode

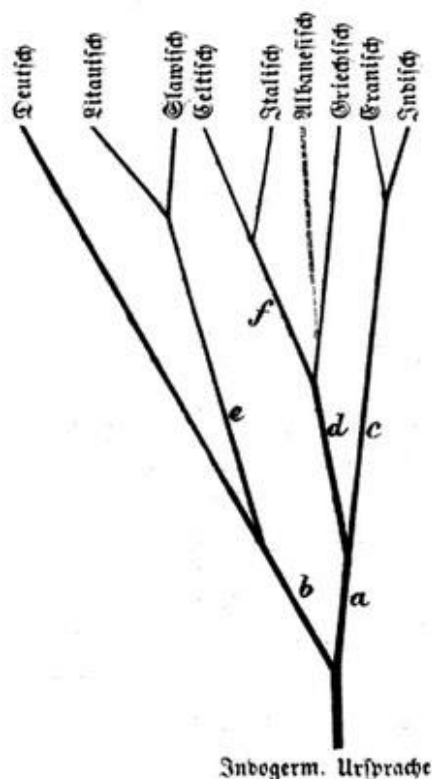

Fig. 1. The Indo-European Stammbaum of Schleicher (1860: 81). Here PIE lies at the base of the tree, and the uppermost branches represent the living IE language families known to Schleicher (Germanic, Baltic, Slavic, Celtic, Italic, Albanian, Hellenic, Iranian, Indic). The letter a marks a branch labeled Asiatic-South European, b North European, c Asiatic, d South European, e BaltoSlavic, f Italo-Celtic. 
useful information in a convenient, memorable form. For example, Schleicher's tree reveals at a glance that there are greater similarities between the Baltic and the Slavic languages than are detectable between these and any other language group. But trees also by their nature make specific claims about issues that may in fact be controversial, such as the robustness of the affinity between Italic and Celtic, and the precise relation of Albanian to the other IE languages. The proper position of Germanic within such a tree is particularly difficult to determine. ${ }^{4}$ When the wave theory and the Stammbaum theory are viewed properly, however, i.e. as necessarily inadequate models of language development, the two are not fundamentally incompatible: "the former is a model of how soundchanges can spread; the other a model of the general results of successive sound-changes" (Hines 1995: 35-6). ${ }^{5}$

The Stammbaum model (or 'cladistic model' in some recent treatments) also appears to proceed from the premise that any protolanguage was at first uniform in nature, whereas the study of modern languages shows that protolanguages are likely from the start to have had dialects, perhaps both regional and social. Moreover, some such dialects might be difficult to classify as belonging to just one of two languages with which it shares features. These observations have some relevance to the much-disputed question of when and where Proto-Indo-European was spoken. ${ }^{6}$ A particular complication is that the Anatolian languages are so markedly different from the other Indo-European languages that on any branching tree their divergence should be placed well before the differentiation of the remaining languages, and so the problem of identifying the date and place of IE origins depends on how the relation of Anatolian is to be recognized.

Although there is no scholarly consensus about these issues, the predominant view now is that the IE languages originated in the steppeland of Ukraine and southern Russia, in the so-called Pontic area north of the Black and Caspian Seas, in the second half of the fourth millennium BCE. ${ }^{7}$ Although many parts of Europe and Asia are compatible with the place of origin suggested by the reconstructible PIE vocabulary of flora and fauna, what is known of PIE burial practices and wheeled vehicles is especially associable with steppeland cultures of that period known as 'kurgan peoples' for their use of funerary tumuli known as 'kurgans', a term based on the Russian word for such.

The chief competing hypothesis today is that of Renfrew (1987, along with Gamkrelidze \& Ivanov 1995), who would place the IE homeland in Anatolia and the Caucasus in the seventh millennium BCE, as part of an argument that it was agriculture rather than warfare that made the Indo-Europeans so successful. This hypothesis is not as widely credited by archaeologists and linguists. ${ }^{8}$ The linguistic objection has often been raised that it is difficult to reconcile with lexical evidence such as the shared IE vocabulary of wheeled vehicles. Such vehicles seem first to have been used in the second half of the fourth millennium, supporting the steppeland hypothesis, though Renfrew (e.g., 2002: 89) has responded that after the differentiation of the IE language branches they could all have borrowed the relevant terms along with the technology. It has been argued, moreover, that Renfrew's alternative, earlier dating can be associated with the period during which Anatolian developed as a discrete branch (Gray \& Atkinson 2003, Atkinson et al. 2005). ${ }^{9}$

On the distinction between centum- and satem-languages, see $\S 6.1$. 
1. After a dearth of long standing, recent years have seen the appearance of a number of introductory works in English for the study of Indo-European. For an excellent grammatical introduction to PIE, consult Szemerényi 1996; also Lehmann 1993, Meier-Brügger 2003 (with especially useful references to relevant literature), Clackson 2007, Adrados et al. 2010, and Beekes 2011. For introductions to the IE languages and PIE culture, see Baldi 1983, Ramat \& Ramat 1998, Mallory \& Adams 2006, Voyles \& Barrack 2009, and Fortson 2010. The most detailed grammars of PIE are in German: see Kuryłowicz et al. 1968-2015, and the dated but still useful Brugmann \& Delbrück 1897-1916. Still useful also is Krahe 1966-9. For a survey of the IE languages, see Kausen 2012. For lexicon, see Pokorny 1959-69, and, specifically for verbs, Rix 2001; for nomina, Wodtko et al. 2008.

2. For succinct accounts of major distinguishing features of the Germanic subgroup, see H.F. Nielsen 1989: 28-32, Polomé 1997, Fulk 2008. Krahe \& Meid (1969: I, 43-4) list eleven distinctive features of Germanic: 1. fixing of the accent on initial syllables, 2. Grimm's law, 3. development of syllabic resonants to /u/ plus resonant, 4. coalescence of $a$ and $o$ as $a$, and of $\bar{a}$ and $\bar{o}$ as $\bar{o}, 5$. loss of final consonants and vowels under the Auslautgesetze 'laws of finals', 6. systematization of ablaut, 7. case syncretism in nouns and pronouns, 8 . rise of the $n$-stem nouns, 9. rise of the opposition between strong and weak adjectives, 10 . simplification of the verb system, 11. rise of weak preterites. See also Wiik 1997, and see further $§ 1.3$ infra.

3. A third approach, the Entfaltungstheorie 'developmental theory' of Höfler (1955-56, supported by, e.g., Penzl 1988a, 1988b), calls for more carefully calibrated reconstruction within the framework of the Stammbaumtheorie and posits nondistinctive features in the protolanguage developing in divergent fashion in the daughter languages (hence their Entfaltung).

4. See especially Ringe, Warnow, \& Taylor 2002, and cf. Gray \& Atkinson 2003, with discussion in Clackson 2007: 10-15.

5. Seebold 1986: 173-5 defends the primacy of the Stammbaum model over models of linguistic convergence.

6. For a wide-ranging discussion of the scholarship on the date and place of IE origins, see Mallory 1989. More concise, with more recent information, is Fortson 2010: $\S \S 2.50-73$.

7. This hypothesis depends vitally on the findings of the Lithuanian archaeologist Marija Gimbutas: see especially Gimbutas 1997. For wide-ranging discussion of the lexical evidence, see Mallory \& Adams 1997, and of the archaeological evidence, Anthony 2007.

8. One important archaeological critique of Renfrew's argument is that of Gimbutas (1997: 338-44). For an enlightening overview of various theories about the original home and early movements of the Indo-Europeans, see Polomé 1993.

9. Current debate deals with the question whether certain modern IE languages (including English) should be derived from known earlier states of those languages, as recorded in preserved written form, or from forms of those languages assumed to have differed from the formalized, presumably more artificial written records; the former position supports the steppeland hypothesis (see, e.g., Chang et al. 2015, responding, in part, to Bouckaert et al. 2012), the latter the Anatolian hypothesis (see Wade 2015). Whether or not there was any Anatolian migration into Europe in the seventh millenium BCE (for reasons to doubt, see Fortson 2010: §2.71), genetic evidence supports the migration of steppeland peoples into what is now Germany in the third millennium BCE: see Haak et al. 2015, Novembre 2015.

\subsection{Distinguishing characteristics of Germanic}

Hirt (1931-4: §20) lists nineteen characteristics of the Gmc. language family that distinguish it from other IE language groups. The following is based loosely on his list (see also $§ 1.2$ n. 2.):

(1) Change of the PIE pitch accent to a stress accent and shift of place to a fixed position in the word ( $\$ 2.2$ infra).

(2) Shift of consonant values governed by Grimm's law (\$6.4).

(3) The rise of geminate consonants ( 66.8$)$.

(4) Neutralization of the contrast between PIE $o$ and $a$, as well as stressed $H(\S 3.2)$. 
(5) The realization of PIE syllabic sonorant consonants as $u+$ sonorant (\$3.2).

(6) Systematization of ablaut, e.g. final severance of any connection between ablaut alternations and accent, and the use of ablaut to distinguish verb tenses (\$3.6).

(7) Changes to final syllables under the 'laws of finals' (\$§5.1-6).

(8) Fusion of stem formatives with inflections, with the attendant transference of grammatical information to the inflection, e.g. gender in nouns (\$7.1).

(9) Reduction of the eight or nine nominal cases of PIE to four or five (\$7.3).

(10) Extensive changes to the pronominal system, especially as the result of analogy $(\S \S 8.2-15)$.

(11) Increased productivity of the class of $n$-stems and the rise of weak adjectives $(\S \S 7.29,9.7)$.

(12) Innovations in the inflection of strong adjectives, distinguishing their declension from that of nouns (\$9.2).

(13) Unproductivity of PIE patterns of stem formation in the present tense of verbs $(\S 12.9)$.

(14) Loss of the $s$-aorist and the imperfect (\$12.9).

(15) Conversion of the PIE perfect to the Gmc. preterite (§12.9).

(16) Merger of the aorist with the perfect in the formation of the Gmc. preterite (possibly: §12.25).

(17) Loss of various non-finite verb formations, and especially the rise of a uniform infinitive formation $(\S 12.30)$.

(18) Loss of perfect and middle participles.

(19) Influence of unstressed vowels upon stressed (§§4.3-4), though most such changes postdate the PGmc. period.

To this list may be added some others, including the following:

(20) The rise of new preterite formations in weak and preterite-present verbs ( $\S 12.32$ $3)$.

(21) Reduction of the verb moods of PIE to three, with the etymological optative assuming the functions of the subjunctive (\$12.9).

(22) An increasing tendency toward unproductivity in nominal classes other than the PIE $o-, \bar{a}$-, and $n$-stems ( $§ 7.1)$.

(23) Unproductivity in strong verbs, with later narrowing of productivity chiefly to the second weak class $(\S \S 12.12,12.32)$.

\subsection{The position of Germanic within the Indo-European family}

Unlike Schleicher's Stammbaum (§1.2), modern reconstructions commonly represent the main branches of the IE family tree as proceeding directly from PIE, as if PIE broke all at once into so many different varieties. The Indo-Iranian and Balto-Slavic branches are the exceptions, each representing a period of common development before the two constituent language groups of each went their separate ways. The histories of the IE daughter languages in the various branches themselves suggest that this is not a plausible 
view of the rise of the daughter languages, since their Stammbäume show many intermediate branchings, and such should therefore be expected between PIE itself and the rise of the major language families within it. Yet in most cases it is exceedingly difficult to specify with assurance particular affinities between IE branches, and this is especially true in connection with Germanic. Such similarities as are discoverable between Germanic and any other particular IE branch are not generally impressive and may not be common inheritances from the mother language but the result of later contact between neighboring peoples or of substrate influence $(\S \S 1.4-5)$ or, in some cases, of convergent but independent developments. ${ }^{1}$

Nonetheless, it is commonly assumed that the earliest Germanic formed part of a northern European IE linguistic continuum that produced the Celtic, Italic, and Germanic, and perhaps the Balto-Slavic, language groups. ${ }^{2}$ This continuum is sometimes referred to as 'Northwest Indo-European', in consequence of the research of Meillet (1908: 23) into the vocabulaire du nord-ouest. Celtic, Italic, and Germanic are generally agreed to belong to this grouping; there is much greater disagreement about whether Baltic and Slavic should be included in the group (see Euler 1997: 103-4 for references). ${ }^{3}$

Among the languages of Europe, some especially close parallels to distinctive features of Germanic are to be found in Balto-Slavic. ${ }^{4}$ The most striking of these is the use of $-m$ - in the dative (instrumental) plural of nouns where *-bh-is reflected in other IE branches $(\S \S 7.2,7.8$ n.17). Other shared features include trimoric vowels of disputed origin in certain inflections, such as the nom. sg. of masc. and neut. $n$-stems (see Jasanoff 2002: 37-8), the neutralization of the PIE a/o distinction (though in opposite directions), present participles in *-nt-jo- (in West Germanic), inchoative verbal suffix - $n$-, and adjectives in *-isk- (e.g. Go. gudisks 'divine', Lith. dañgiškas 'heavenly', OCS slověnbskb 'Slavic'). Lexical commonalities have been studied in detail (see, e.g., Porzig 1954: 139-47, Stang 1972, Mańczak 1985b), and although the project of discerning affinities on the basis of shared vocabulary is fraught with difficulties, it does seem likely that many lexical connections between Germanic and Balto-Slavic are quite ancient. ${ }^{5}$ Euler (1997: 110-11, with references) summarizes specifically Baltic morphological parallels, such as comparatives containing *-is-, as in Go. mins 'less', OPruss. massais 'fewer' (see especially Schmid 1989, with further references), and parallels in the formation of the dual pronouns, e.g. Lith. (Samogitian) vè-du, Go. wit 'we two'. Among the numerals, OE forma 'first' is parallel to OPruss. pirmas 'first', both with a distinctive - $m$ - suffix; and there are similarities between the Germanic and Baltic numerals ' 11 ' and '12'; but on the problems associated with the connection, see Bednarczuk 1999: 44. Schmid (1986: 164-5) points out how ablaut patterns in Baltic verbs parallel those in most Gmc. strong verb classes, extending even to the lengthened grade in the preterite of the fourth and fifth classes: to Go. niman 'take', pret. pl. nēmum, cf. Lith. lemia 'break', pret. lemè, and to Go. bidjan 'request', pret. 3 pl. bèdun, cf. Lith. slepia 'conceal', pret. sleppe. He also notes the twofold adjective inflection of Germanic and Balto-Slavic and parallels in regard to the influence of pronominal inflection on adjective formation. ${ }^{6}$

The question of ties between Germanic, on the one hand, and Italic and Celtic, on the other, is not entirely separable from the fraught question of the relations between the latter two, but it is now generally agreed that the sharing of features is due to language contact beginning ca. $1500 \mathrm{BCE}$, though a few features could stem from an earlier period 
of unity among Germanic, Italic, and Celtic, such as conversion of the PIE pitch accent to a stress accent, use of the suffix *-tüt- (as in Lat. juven-tūt- 'youth', OIr. betha 'life', gen. bethad $<{ }^{*} g^{w} i u o-t \bar{u} t$-, Go. ajukdūps 'eternity'), and the development of *-tt- to *-ts$>$-ss-, e.g. in Lat. vīsus 'seen', cf. OIr. fiuss 'knowledge' and OHG gi-wissi 'certain' (but cf. K.H. Schmidt 1986: 233). ${ }^{7}$ It is also largely consensus that ethnic Italic speakers migrated from northern Europe, and from that point in time lexical borrowings between the Germanic and Celtic branches (the former usually borrowing from the latter) become prominent, perhaps because the Germanic and Celtic groups had earlier been separated by the Italic. ${ }^{8}$ Thus, Italo-Germanic contact stems from the Bronze Age (cf. Lat. aes, Go. aiz 'copper, bronze', from * aios, also shared with Indo-Iranian with the meaning 'iron'), whereas Celto-Germanic contact stems from the Iron Age (cf. Gaulish ìsarno-, Go. eisarn, etc., shared with no other IE branch). A considerable number of fairly basic lexical items are shared between Italic and Germanic. ${ }^{9}$ One exclusively Italo-Germanic isogloss is the use of *-no- to form distributive numerals from adverbs, e.g. Lat. bin̄ 'twofold' < *duis-noi; cf. bis 'twice'), OIcel. tvennr <*twiz-naz. Another is the use of the suffix *-ne to indicate direction from, as in Lat. superne 'from above', Go. ütana 'from without' (Krahe 1954: 72). Cf. also the use of the directional suffix *-tr-in Lat. extrā 'outside', Go. haprō 'whence', etc., and the existence of $\bar{\imath} n$-stems beside $\bar{o} n$-stems, e.g. in Umbrian natine (Lat. natiōne, reformed analogically) and Go. managei 'multitude'. There are also striking parallels between Latin and Germanic in connection with the Gmc. weak classes of verbs, e.g., in the third class, Go. pahan 'be silent', ana-silan 'be silent', to which cf. Lat. tacēre, silère (see Szemerényi 1996: §9.4.1.5). Also notable is the parallel between Gmc. preterites with a long vowel in the fourth and fifth strong classes and Lat. perfects, e.g. Go. sètum, Lat. sēdimus 'we sat', though there are parallels also in Baltic (Euler 1997: 106). ${ }^{10}$ Scholarship on Celto-Germanic isoglosses is summarized by K.H. Schmidt (1984; 1991: 139-47), focusing on shared vocabulary, which he divides into five strata, the earliest of which includes the administrative terms Go. reiks 'ruler' (borrowed before the application of Grimm's law from Celtic *rīg- < PIE *rēg-) and OE ombeht 'attendant' (cf. Gaulish ambactus in Caesar, with $a m b$ - from PIE * $h_{2} m b h i-$ ), shown by their form to have undergone Celtic phonological developments before being borrowed into Germanic. ${ }^{11}$ The initial stress of Germanic has also been postulated as a feature derived from close contact with Celtic (Polomé 1992b: 58-9). See further Polomé 1983, Untermann 1989.

Germanic bears, as well, some affinities to Illyrian and Venetic, two European IE languages attested only fragmentarily. For example, in Germanic and Illyrian, possessive pronouns are formed with a suffix $*_{-} n o-$, as in OHG $m \bar{i} n$, $d \bar{i} n$, $\sin$ (see $\S 8.5$ on the origin of the Gmc. forms), and to Venetic acc. sg. mexo 'me' cf. Go. mik, both formed by analogy to the corresponding nominative pronoun (H.F. Nielsen 1989: 25). On Germanic and Hellenic, see Polomé 1986b.

Although the standard view is that Germanic vastly simplified the IE verb system that it inherited, it has sometimes been argued that the relative simplicity of the Gmc. system, with a simple contrast between present and preterite (i.e., without a trace of the future or the imperfect, or, in the view of some, e.g. Hiersche 1984: 96 and Polomé 1993: 47, of the aorist, though cf., e.g., Bammesberger 1988a) and no subjunctive mood (since the Gmc. subjunctive reflects the PIE optative), is a sign of the archaic nature of 
Germanic, aligning it with Anatolian, which has a similarly unelaborated verb system. The assumption thus is that IE features like the imperfect and the subjunctive developed in PIE after the Anatolian and Germanic branches had broken away, at an early date. ${ }^{12}$ The degree of credence lent this hypothesis by scholars usually depends upon the degree of credence lent the glottalic theory of PIE consonantism (§6.2), according to which Germanic is supposed to point to a more archaic inventory of PIE obstruents than nearly all other IE subgoups. K.H. Schmidt (1991: 136) objects to this analysis, observing that the Gmc. preterite, unlike the Anatolian, is based on the PIE perfect, and perhaps the aorist, and that Anatolian attests to a morphological aspectual system that the evidence of Vedic shows to be ancient (a view strongly contradicted by Ringe 1998).

1. K.H. Schmidt (1991: 129-39) offers a convenient summary of views on the genesis of Germanic and the Germanic peoples, with references; see also H.F. Nielsen 1989: 18-28, Euler \& Badenheuer 2009: 16-53. For references to studies of the relations among Italic, Celtic, Germanic, Baltic, and Slavic, see Euler 1997: 103. For an elementary survey of Gmc. relations, see Ernst \& Fischer 2001: 60-108. Several of the chapters in Askedal \& Nielsen 2015 are relevant.

2. See, e.g., Krahe 1954, Porzig 1954, Polomé 1985, 1993, Schmid 1986, Euler 1997, and Oettinger 1997. Although in our present state of knowledge the geographic homeland of the Germanic peoples in prehistory is only marginally relevant to the early history of Germanic, and it cannot be determined with any certainty on an archaeological basis, it is commonly assumed to have lain along the southern coasts of the North Sea and the Baltic, roughly between the Rhine and the Vistula, including the Cimbric peninsula, and probably also in southern Scandinavia (though some see the Germanic presence in Scandinavia as a later development, e.g. von Petrikovits 1985, Udolph 1994: 925-6, Elert 1997). The archaeological evidence was until relatively recently believed to suggest association with the more circumscribed Jastorf culture, located between the Weser and the Oder ca. 600-300 BCE, and probably also the neighboring Harpstedt culture to the west between the Weser and the Rhine, with considerable expansion to the east and south by ca. 100 BCE (Mallory 1989: 86-7); but now the association is generally considered less secure (see the refs. in H.F. Nielsen 2000: $362 \mathrm{n}$. 3). For informative discussion of these and other views, and especially in response to the theory of polygenesis proposed by Ament 1986, see K.H. Schmidt 1991, Polomé 1992b, H.F. Nielsen 2000: 299-368, esp. 299-303.

3. Not to be confused with Northwest Indo-European is the concept of Old European, a linguistic continuum posited for much of ancient Europe on the basis of shared lexical and morphological elements in the hydronymy across much of the continent: see Krahe 1954, Schmid 1986, 1987, Udolph 1994. On the critical reaction to such argumentation, see H.F. Nielsen 2000: 302-3.

4. On the history of scholarship relating to Balto-Slavic and Germanic connections, see Lötzsch 1987.

5. Stang 1972 attempts to show that some of the earliest lexical items shared by Germanic and Balto-Slavic antedate the use of metals. The foundational work on connections between Germanic and Balto-Slavic is Leskien 1876. For a succinct discussion, with examples, see Euler 1997: 112-14. Although Schmid (1986) argues, in part on the basis of similarities in ablaut patterns, that Germanic and Baltic (but not Slavic) share a common path of development, K.H. Schmidt (1991: 138-9) counters that the commonalities are due to later language contact. Much other work on lexical relations between Germanic and Balto-Slavic is unpersuasive. See further Bednarczuk 1982-3, Birnbaum 1984, Dyen 1990, Mańczak 1985b, 1986 b (but cf. Polomé 1982a: 734-5), Rot 1988, Schmalsteig 1994.

6. In addition, Polomé (1997: 200) mentions "inflectional similarities in the causatives" and "the $j$-adjectives."

7. To the contrary, Euler (1997) argues that the connections between Germanic and Italic are no less important than those between Germanic and Baltic, and those between Germanic and Slavic are considerably less salient. By contrast, Mańczak (2000) attempts to show that the lexical connections between languages, which Euler regards as less significant than morphological parallels, are more important.

8. The main components of this analysis were laid down by Krahe 1954. For a survey of research in this area, see K.H. Schmidt 1986.

9. A few examples: Lat. lingua (Old Lat. dingua), Go. tuggō 'tongue'; Lat. caput, OIcel. hofuð 'head'; Lat. collus, Go. hals 'neck'; Lat. līmus 'mud', OE lām 'loam'; Lat. aqua, Go. ahsa 'water'; Lat. grāman < *ghrasmen-, Go. gras 'gras' (see Krahe \& Meid 1969: I, §4, with further examples). 
10. For a response to a peculiar hypothesis aligning North Germanic with Latin and East and West Germanic with Osco-Umbrian, see Seebold 1986: 174-5.

11. On more recent Gallo-Roman loans in Gmc., from the first half of the first millennium CE, see Guinet 1982.

12. See, e.g., Polomé 1982a, 1982b, 1987b: 234-5, 1997, Lehmann 1985, Seebold 1986: 172-7, and the references in §6.2. This view is implicitly contradicted by Hoffmann (1955), who finds that Go. qimip, OHG quimit, etc. 'comes', must derive formally from a PIE aorist subjunctive.

\subsection{Substrate influence upon Germanic}

According to the prevailing view, Indo-Europeans in central Europe first migrated north in the first half of the third millennium BCE, and they were successful because of technological innovations they carried with them, particularly in connection with warfare (see, e.g., Gimbutas 1997: 240-68, 321-31, also Polomé 1987b, and cf. §1 supra). It is natural to assume that in such a situation the language of the Indo-Europeans was adopted by the peoples they conquered (see, e.g., Meid 1984), and therefore it should be expected that some of the distinctive traits of the individual IE branches and languages should be derivable from pre-IE languages spoken in Europe. Quite a number of Germanic terms for flora and fauna and products made from them have no plausible IE source, and this is an area in which it should be expected that local terms already in use should have been retained (see, e.g., Polomé 1986a: 665-70, 1992a, Bandle et al. 2002-5: I, 572-93, Kroonen 2013b). For the same reason, many place names must be pre-IE, especially in the area of hydronymy. ${ }^{1}$ The study of substrate influence upon Germanic, however, is laden with difficulties, not least of which is that little or nothing is known for certain about the presumed substrate languages (or language?) involved. ${ }^{2}$ Their features can be divined only by identifying them with features of Germanic that mark it as different from other IE branches, and yet this leads to circular reasoning, since it is generally impossible to be certain that any given unusual Gmc. feature does not have some origin other than substrate influence.

Nonetheless, certain features do suggest substrate influence upon Germanic. Salmons (1992) discusses three such features, though he also raises questions about their validity. One is the confusion of $/ \mathrm{a} / \mathrm{and} / \mathrm{o} /$ in languages of the northern European linguistic continuum, as evidenced by perceived borrowings (e.g. *ablu 'apple') from a substrate language in which no distinction between the two vowels was maintained (see Hamp 1979, and cf. Adams 1985, arguing that 'apple' is an IE word). Another feature is unusual word structure. It is a peculiarity of PIE that biconsonantal roots in the language do not generally contain two plain voiced stops, e.g. no *deg- (\$6.2). A possible Gmc. example is OIcel. kati 'small ship', NLG kat 'small vehicle' (Orel 2003: 211). A third feature is roots containing $* b$, especially in initial position, as this sound probably was not part of the PIE consonantal inventory, at least in initial position ( $\$$ 6.1-2, but cf. Meid 1984: 107). Examples are OHG pfluog 'plow' < *blog- and OIcel. skip 'ship' <*skib-. Orel 2003 in fact lists $32 \mathrm{Gmc}$. etyma with initial $p$-. Boutkan $(1998,1999)$, on the other hand, proposes to explain unusual suffixal ablaut alternations as a substrate effect, e.g. *-иð- beside *-ið- in OE hēafod, OIcel. hofuð vs. Go. háubip, OS hōbid 'head'. 
Although there has been widespread disagreement about the extent of the substrate vocabulary in Gmc., most scholars regard the incidence as particularly high in this branch: e.g., Markey (1988a: 7-8; cf. Kallio 1997: 127) estimates that such constitutes 28 percent of the Germanic 'core' vocabulary. ${ }^{3}$ Given the obstacles to establishing substrate influence, it should not be surprising that the endeavor has produced some especially speculative and fanciful attempts. ${ }^{4}$ In this respect it is prudent to heed the advice of Polomé (1989: 54-5) about what criteria should be taken into account before lexical borrowings are posited:

(a) the lexical items under consideration must either belong to the basic vocabulary of the language or relate to the type of cultural activities that characterize the civilization of the pre-Indo-European population or describe specific elements relevant to the ecology of the area; (b) there must be clear evidence that the terms belong to the archaic vocabulary of the Northern European languages under investigation and that they can not plausibly be explained as part of their IndoEuropean heritage; (c) the vocabulary tentatively identified as 'non-Indo-European' must be screened for possible ancient borrowings from neighboring language families or 'Wanderwörter'; ${ }^{[5]}$ d) the terms must be analyzed linguistically to look for any discrepant phonological and/or morphological features that would point to their non-Indo-European background.

Despite much fruitless discussion, the etymology of Latin Germani is unknown (see, e.g., K.H. Schmidt 1991: 132-3). Quite possibly the term is not Germanic in origin, or it originally applied to a small group of Germanic speakers, but it was always a Latin term, not natively applied to themselves by speakers of Germanic languages (see Meid 1986: 210-11, Wagner 1986a).

1. See, e.g. Krahe 1954, 1964, Udolph 1990. For a summary of Krahe's views, as well as a summary of criticisms leveled against them, see H.F. Nielsen 1989: 19-22.

2. Wiik (1995, 1997, and elsewhere) has argued that such Gmc. features as initial stress, Grimm's law, and Verner's law are due to a Uralic substrate, but the arguments are implausible: see Kallio 1997. Substrate vocabulary plays a role in the 'Nordwestblock-Hypothese' of Hans Kuhn, elaborated in many of his publications (e.g. Hachmann et al. 1962), of a culture neither Celtic nor Germanic along the North Sea coast up to the Iron Age: for discussion and partial support, see Meid 1986, and for an overview of the evidence, see Nowak 2011. Schrijver (2014) attempts to remedy the problem of the unknown substrate by focusing chiefly on relatively recent prehistory and on languages in which the substrate can be identified on historical grounds with some confidence, e.g. Celtic for English and Romance for Dutch, though he also locates the origin of Germanic in a Finnic substrate speaking IE (2014: 158-96). See Schrijver 2004 on NWGmc. and Saami. The literature on Celtic influence on English is especially extensive: see, e.g., Filppula \& Klemola 2009, with references.

3. On the other hand, Polomé (1987b: 236), interpreting the findings of Bird 1982, finds that in the entries in Pokorny 1959-69, Germanic has the highest incidence of inherited IE vocabulary of any IE branch and the highest level of co-occurrence with other branches. See also Scardigli 1987.

4. For bibliography, see Schrodt 1976 and Vennemann 1984a, the latter arguing for a non-IE superstrate, an idea dismissed by Markey (1986: 254 n. 6). An example of a lexical study with notable methodological shortcomings is Gysseling 1987, critiqued by Polomé 1989. Several unconvincing attempts have been made to explain Grimm's law, and other non-lexical distinguishing features of Germanic, as due to a substrate, e.g. Devleeschouwer 1985-6: 28-9.

5. Author's note: As Polomé explains, Wanderwörter are "words that have spread with the object, like the native American designations of products of the New World, e.g. potato, tomato, chocolate, etc.: a classical example is 'hemp' (ON hampr, OE hennep, OS hanap, OHG hanaf) which entered Germanic before initial * $k$ became $h$ - (cf. OCS konopljá, Lith. kanapës, OPruss. knapios, Alban. kanep, Gk. kánnabis [whence Lat. 
cannabis]) - the term being assumed to have been borrowed from an undetermined eastern language (taken over from the Scythians or the Thracians by the Germanic peoples)" (Polomé 1993: 45).

\subsection{The reconstruction of Proto-Germanic}

The hypothetical language from which the Germanic languages descend is referred to as Proto-Germanic. The methods used to reconstruct Proto-Germanic are in some respects different from those used to reconstruct PIE. The latter is arrived at by comparison of the IE languages and the reconstructed protolanguages from which the attested IE languages derive, with minor elaboration on the basis of internal reconstruction. ${ }^{1}$ The shape of Proto-Germanic, on the other hand, must be determined not only by these methods but also by taking into account known features of PIE. For example, the alternations governed by Verner's law (\$6.6) cannot be explained solely on the basis of what is observable in the Germanic languages themselves; Verner relied upon patterns of accentuation in Sanskrit verbs to explain the alternations, and thus he reconstructed for Proto-Germanic a pattern of alternating accent not reconstructible (or at least not recognizable) from the evidence afforded by the Germanic languages alone.

It must be kept in mind, as well, that there is something unrealistic about the way protolanguages are generally reconstructed. Under the comparative method, related languages are compared in order to arrive at a unitary reconstruction of a uniform language such as the Stammbaum theory invites $(\$ 1.2)$, whereas all natural languages show internal variation, which may correlate, for example, to sociolects and regional dialects. It is best, therefore, not to lose sight of the fact that Proto-Germanic as reconstructed is an abstraction and must not be assumed to represent in all its details any actual prehistoric language, no matter how close an approximation it may be to that. For this reason and others, some scholars prefer to discard the idea of a 'Proto-Germanic' language and refer only to Common Germanic, by which is meant a stage in the development of the Germanic languages when all dialectal and sociolectal varieties were still mutually intelligible. $^{2}$

Another layer of abstraction to be recognized is particularly evident in regard to phonology. The comparative method allows the reconstruction of a phonemic system whose members, for the sake of convenience, are represented by phonetic symbols, though the phonetic associations of such symbols may be too definite for reconstructed phonemes. Phonemes are by their nature abstractions, being mental categories into which actual speech sounds are grouped. Reconstructed phonemes are even more abstract, since the range of actual sounds they may have encompassed is largely irrecoverable. For example, the reflexes of the phoneme reconstructed as PIE $* \bar{e}$ are identifiable in the modern Gmc. languages, e.g. Mod.Icel. /au/, NHG /a/, PDE /i/, and from these may be reconstructed a PGmc. phoneme, but it cannot be known for certain what precise range of sounds the reconstructed phoneme represents. When Penzl (1988a: 2, and elsewhere), among others, posits non-phonemic umlaut variants for the Gmc. protolanguage itself (cf. Liberman 1991: 125), or for the NWGmc. protolanguage (Penzl 1988b: 502-3), this may be the most economical way to account for the existence of phonemic umlaut variants in 
the attested languages, but it is by no means inevitable that any such variants should have existed in Proto-Germanic, especially since there is no trace of them in Gothic (despite claims to the contrary, answered by Cercignani 1980a; see also Wienold 1967, and cf. Antonsen 2002: 252-3). The point is not that phonetic detail ought not to be built into any reconstruction of the proto-language, but that such detail is considerably more conjectural than the more abstract system of phonemic oppositions to be reconstructed. Penzl's objection (1988a: 3-4) that only structure is generally recoverable, and not the kind of sub-phonemic detail demanded by the glottalic theory ( $\$ 9.2)$, is thus not fully valid, though it is true that such detail renders the theory more speculative than reconstructions that delineate phonemic oppositions without invoking any considerable degree of detail.

1. An example of such internal reconstruction is Szemerényi's law (see Szemerényi 1996: §6.2.7.1, and see further Kümmel 2015), according to which the lengthened grade found in the nom. sg. of some IE consonantstem classes (those ending in a nasal, a liquid, or a postvocalic dental, including $s$ ) represents compensatory lengthening upon loss of final ${ }^{*} s$, or $*_{-} h_{2}$, e.g. *suesōr 'sister' < *suesors. Comparison to other stem classes leads to the expectation that $*_{-s}$ should originally have appeared in forms like this one, but it can be reconstructed only on the basis of considerations internal to PIE rather than to comparative evidence. Cf. Kotin 2012: 136. Szemerényi himself points out that he was not the first to posit this change, but in the subsequent literature it is commonly given his name.

2. The meanings assigned in the literature to the terms Urgermanisch and Gemeingermanisch have been notably various. For a survey of usage, see Hutterer 1975: 74-6. On this topic see also Lane 1978, with useful observations on the relation between methodological rigor and abstractness of reconstruction.

\subsection{Germanic loanwords in Finnish}

A considerable number of words were borrowed from Germanic into the Finnic languages of the Baltic region, as attested chiefly by Finnish, evidencing extensive cultural influence. Some such words must have been borrowed at an early date, since they preserve features that antedate changes assignable to PGmc. For example, Finnish rengas 'ring' derives from PGmc. *xreygaz (> Go. hrings, OIcel. hringr), antedating the PGmc. raising of $* e$ in this word $(\$ 4.4)$ as well as the reduction or loss of inflectional $-a z$, preserved as such in the Gmc. languages only in Runic. Some further examples of borrowing are Finnish kuningas 'king' < PGmc. *kuningaz > OE cyning; Finnish tiuris 'beast' from PGmc. *diuriz > OE dēor. For a comprehensive lexicon of such borrowings, see Hahmo et al. 1991-2012. For wide-ranging discussion, with references to the extensive literature, see Koivulehto 1999 (an anthology); also useful is Fromm 1957-8. ${ }^{1}$ For an overview, see Koivulehto 2002.

1. An argument for dating Germanic loans into Finnish prior to the First Consonant Shift ( $§ 6.4)$ is offered by Koivulehto \& Vennemann 1996. On dating, see also Ritter 2002.

\subsection{The three branches of Germanic}

Within the Gmc. family of languages there are three broadly recognizable groups: East, North, and West Germanic. The East Gmc. languages are all extinct, and aside from 
Gothic and Crimean Gothic, only Vandalic and Burgundian are attested with any security, though only in the most fragmentary state. The North Gmc. languages are those of both continental and insular Scandinavia, along with the languages of Scandinavian colonizers. The remaining languages comprise West Germanic, a group that in the present day includes High and Low German, Yiddish, Luxembourgish, Pennsylvania German, Dutch, Afrikaans, Frisian, English, and Scots.

Given the fragmentary nature of the evidence aside from Gothic $(\S 1.11)$, then, it is not possible to identify features that can with assurance be called distinctively East Germanic. A few of the many features that distinguish Gothic from the NGmc. and WGmc. languages, however, may be indicated: (a) retention of reduplication in the seventh class of strong verbs, without innovatory replacements for these $(\$ 12.20)$; (b) genitive plural inflection in $-\bar{e}$ in all noun classes except feminine $\bar{o}-, \bar{o} n-$, and $e i n$-stems (cf. OHG OS -o, OE ON - $a, \S 7.8$ ); (c) dat. pl. ending -am (PIE *-omis, North and West Gmc. $-u m$ ) in $a$-stem, $n d$-stem, and masc. and neut. $n$-stem nouns; (d) acc. pl. endings -ans, -ins, -uns; (e) vocative case in nouns; (f) dual forms in verbs; (g) inherited synthetic passive forms in the present tense (\$12.29); (h) $3 \mathrm{sg}$. imp. forms of verbs; (i) coalescence of PGmc. * $i$ and $* e(\$ 4.5)$; (j) the loss of alternations under Verner's law in verbs $(\S 6.6)$; and $(\mathrm{k})$ fairly transparent compounding in the formation of weak preterites, e.g. 3 pl. pret. dōmidèdun 'judged' (Penzl 1985: 161). Gothic also lacks umlaut and other Fernassimilationen (distance assimilations) in vowels ( $\S 4.3-4,4.7-8)$; and PGmc. $\bar{e}_{1}$ fails to be lowered. ${ }^{1}$

North Germanic is distinguished from the other two branches by features including the following: (a) (probably) stressed NGmc. $\bar{x}>\bar{a}$ (\$4.6, but unstressed $e$, later $i, \S 5.6)$; (b) $a i>æ i(>$ OIcel. ei, §4.9); (c) non-initial $h$ is lost except before $s(\S 6.14)$; (d) initial $*_{j}$ is lost $(\S 6.4$, though a new initial $j$ arises by stress shift in diphthongs, $\S \S 4.8-9)$; (e) $w$ is lost before back vowels and their umlauts, even when $r$ intervenes (§6.4); (f) final $l d$, $n d, \eta g$ yield $l t, n t, \eta k$, later $l t, t t, k k(\S 6.4)$; (g) $n$ is lost, with compensatory lengthening of the preceding vowel, before $s(\$ 4.9$, though this also occurs in NSGmc., $\S 4.11)$; (h) there arose a middle voice marked by the suffix $-s k,-m k$ (and variants) from the reflexive pronouns sik, mik (\$12.29); (i) there arose a definite article hinn, placed before adjectives or after nouns, to which it was later suffixed ( $\$ 8.11)$; (j) pretonic syllables, including verb prefixes, were lost (§5.7).

Features setting West Germanic apart from East and North Germanic include these: (a) consonant gemination $(\$ 6.15$, though velars are geminated also in North Germanic, §6.14); (b) formation of the $2 \mathrm{sg}$. pret. of strong verbs with $-i(\mathrm{OE}-e ; \S 12.25)$; (c) loss of the nom. sg. ending *-az in masc. $a$-stems (§7.8); (d) change of PGmc. /ð/ to /d/ (§6.16); (e) loss of /w/ internally after velar consonants, as in OHG OS OE singan 'sing' : Go. siggwan, OIcel. syngva; (f) loss of weak verbs in -nan as a recognizable class $(\S 12.48)$; (g) gerunds in *-anja- $(\S 12.30)$; (h) nom. sg. masc. *-o(n) in the $n$-stems; (§7.31); (i) formation of abstract nouns with the suffixes OHG -heit, -schaft, and -tum and cognates; and (j) retention of *dōn 'do' as an independent verb. For further examples (not all of them unassailable), see Voyles 1971 and the other works cited by Stiles (2013: 15 n. 16).

1. This is apparently a general EGmc. characteristic, as $\bar{e}$ appears as $i$ in elements of certain Burgundian and Vandalic personal names, e.g. -mir(is), -rid (= Go. -mērs, -rēeps). 
2. This rule is complicated by the divergent developments of * $x^{w}$ in OE sēon 'see' $<{ }^{*} \operatorname{sex}^{w} a n a^{n}$ and pret. pl. $s \bar{a} w o n<{ }^{*} \bar{e} z^{w} u n(p)$. That the loss of postconsonantal $w$ was a late development ascribable to the individual languages is shown by the velar stop (rather than affricate) in the OE ja-stems picce 'thick', mirce 'dim' (Luick 1914-40: §637 Anm. 4).

\subsection{The grouping of the three Germanic branches}

After much controversy, there seems now to have emerged a fairly broad consensus that East Germanic branched off from Proto-Germanic with the departure of East Germanic speakers (Goths and others) from the Baltic littoral, an event dated to some period between the first century $\mathrm{BCE}$ and the second and third centuries $\mathrm{CE}$. The remaining dialect continuum then corresponds to what is commonly called Northwest Germanic, ${ }^{1}$ out of which North and West Germanic are to be derived. There is little agreement, however, about how North and West Germanic developed out of this continuum: see $\S 1.10$.

That the North and West Gmc. languages should derive from a Northwest Gmc. protolanguage is by no means an inevitable assumption, and indeed, a number of nineteenth-century scholars, including Müllenhoff 1900: 108-32, Scherer 1995 [1868], and Zimmer 1876, believed that North and East Gmc. share enough features that they should be assumed to derive from a Northeast Gmc. protolanguage - a supposition no doubt influenced by the widespread belief that the Goths originated in Scandinavia (see $\S 1.12)$. The idea of East and North Gmc. unity was revived by Schwarz (1951; similarly Jungandreas 1949: 30), whose refinement of the hypothesis is to suppose that North Sea Germanic originally was closely allied with the Gotho-Nordic group, but by the third century CE it was linguistically aligned with the Gmc. dialects of the continent. ${ }^{2}$ The following are among the similarities that have been remarked between East and North Germanic:

(a) The rise of stop articulation in the Verschärfung, whereby PGmc. *-jj-> Go. $-d d j-$, OIcel. -ggj-, and PGmc. ${ }^{*}-w w->$ Go. OIcel. - $g g w$-. See $§ 6.10$.

(b) Retention of the ending $-t<$ PIE *-tha in the 2 sg. pret. ind. of strong verbs (vs. WGmc. -i), as in Go. OIcel. bart vs. OS, OHG bāri, OE b̄̄re 'bore': see $\$ 12.25$.

(c) The inflection of present participles as $\bar{\imath} n$-stems, rather than as jō-stems, as in West Germanic (\$9.9).

(d) The extensive preservation of inchoative verbs with a nasal infix, e.g. Go. fullnan 'become full' and OIcel. stirðna 'become stiff'. See $§ 12.48$.

(e) The use of the analogical ending PGmc. *-jau in the 1 sg. pret. sj., e.g. Go. bērjáu, OIcel. bæra 'bore' (cf. OS, OHG bāri, OE bǣre < PIE *-īm). See $\$ 12.26$.

(f) Absence of any reflex of PGmc. *dō-anan 'put, do' as an independent verb (cf. Go. táujan 'do', OIcel. gørva 'do').

(g) The development of $* \bar{u}$ to $\bar{o}$ before a vowel in Gothic and East Norse, e.g. Go. bauan, Old Swedish bóa 'dwell'; cf. OIcel. búa.

(h) PGmc. *-ngw-is retained (i.e., it does not lose $w$, as in WGmc.).

(i) The ending of the nom. sg. of masc. $a$-stem nouns is retained (Go. $-s$, OIcel. $-r<$ PGmc. *-az), though it is lost in WGmc. 
(j) There are no short forms of the verbs 'stand' and 'go' (cf. OHG stān/stēn, gān/gēn beside stantan, gangan; but short forms are found in East Norse, e.g. Danish stå, gå).

(k) There are no gerunds of the type OE tō sāwenne, OHG zi sāwenne 'for sowing'.

(1) There are no forms of the $1 \mathrm{sg}$. pres. ind. of 'to be' in $b$-: to Go. im, OIcel. em, cf. OE bēo $(m)$, OS bium, OHG bim.

(m) A few items of vocabulary show agreement of East and North Germanic as against West Germanic (see Schwarz 1971), including Go. watō, -ins, OIcel. vath vs. OE wæter 'water' (a PIE heteroclitic stem; but there is some evidence for the retention of the $r$-form in skaldic poetry: see \$7.42); Go. fön, gen. funins, OIcel. funi, vs. OHG füir, fur, OS fiur, OE fȳr (another PIE heteroclite); Go. sauil, OIcel. sól vs. OE sunne 'sun'; Go. himins, OIcel. himinn 'heaven' (cf. OE heofon, OHG himil); and Go. leitils, OIcel. lítill 'little' (cf. OE lȳtel <*lūtilaz).

These similarities are more suggestive than probative: for example, (a) is not unlikely to represent independent developments in North and East Germanic (see $\$ 6.10$ ), and (b) may represent a change in West Germanic after the separation of North and West Germanic. If (e) were undisputed, it would constitute fairly good evidence, but there are significant reasons to doubt (see $\S 12.26 \mathrm{n}$. 3). But the relevance of these similarities to the problem of determining the affinities of Gothic is diminished if the matter is not observed strictly from the standpoint of a Stammbaum analysis of Germanic affiliations, but allowance is made for areal changes spreading across related dialects of Germanic (see $§ 1.2)$.

Some further possible shared features are itemized by Euler (2002: 12). Schwarz (1951) lists 25 commonalities between Gothic and Old Norse in support of his theory. The idea of East and North Germanic unity has garnered some support (e.g. Schirmunski 1965, Lehmann 1966), but it has also provoked much criticism, especially by Kuhn (1952, 1955-6; see also Markey 1976), ${ }^{3}$ who argues that commonalities that are not shared inheritances are either independent innovations or changes originating in a speech community extending across the Baltic before the migration of the Goths to the Black Sea. As for differences between North(west) Germanic (in Runic form) and Gothic, the following have been noted (see Noreen 1970: $\$ 4$ ): (a) preservation of the inflectional vowel in the nom. and acc. sg. of $a$ - and $i$-stem nouns, e.g. Runic pewar 'servant', staina 'stone', -gastir 'visitor': Go. *pius, stáins, gasts; (b) gen. sg. in -as in a-stems, e.g. Runic godagas (name, with $\bar{o}$ ): Go. dagis 'day'; (c) preservation of $-\bar{e}$ as such in the dat. sg. of $a$-stems, e.g. Runic -kurne 'grain': Go. kaúrna; (d) gen. and dat. sg. in -an in an-stems, e.g. Runic -halaiban 'bread': cf. Go. an-stem dat. sg. ahin 'mind'; (e) dat. sg. in -iu in $u$ stems, e.g. Runic kuni-mu[n]diu (name) : cf. Go. dat. sg. sunáu 'son'; (f) nom. pl. in -iR in $r$-stems, e.g. Runic dohtriR 'daughters' : Go. dohtrjus; (g) 1 sg. weak pret. in -ō, e.g. Runic tawido 'made’: Go. tawida (see $\$ 12.39$ infra on this). Most of these differences, however, could be explained plausibly as due to changes specific to Gothic subsequent to the development of a supposed Northeast Germanic into separate North and East Germanic branches.

There are some commonalities of Gothic and West Germanic (particularly High German) that set them apart from North Germanic, but they are few, the most salient 
being the following: (a) the use of Go. haban 'have' and its cognates to express possession, as against OIcel. eiga; (b) the equivalence of Go. is and OHG er 'he', as opposed to OIcel. hann (but OE OS $h \overline{\bar{e}}$, OF $h \bar{\imath}$ ); (c) agreement in demonstrative pronouns in the gen. and dat. sg. feminine and gen. plural: OHG dera, deru, dero, respectively, like Go. pizōs, pizai, pizō (fem.), vs. OIcel. peirar, peiri, peira (see Schwarz 1951, Rösel 1962 for further examples). But all of these may be regarded as archaisms retained from ProtoGermanic, so they need not be credited as evidence for East and West Germanic unity. ${ }^{4}$

More significant are the similarities between North and West Germanic that set them apart from East Germanic. The most important of these (some of which were mentioned above, $\$ 1.8$ ) include the following: (a) development of $\bar{e}_{1}$ (PIE $\left.* \bar{e}\right)$ to $* \bar{x}(\S 4.6)$; (b) development of early PGmc. unstressed $*_{o}$ to $u$ before $m$, as in the dat. pl. inflection -um (Go. -am; §5.2); (c) replacement of the reduplicated preterite (\$12.20); (d) development of unstressed $a i$ and $a u$ to $\bar{x}$ and $\bar{o}$, respectively (\$5.6); (e) umlaut (\$4.7); (f) phonemicization of $[\mathrm{o}]>/ \mathrm{o} /$; (g) rhotacism (§6.6); (h) loss of the inherited synthetic middle voice (\$12.29); (i) gemination before $/ \mathrm{j} /$ (restricted in North Germanic to $/ \mathrm{g} /$ and $/ \mathrm{k} /$ ); (j) gen. pl. ending *-onô in the $\bar{o}$-stems; (k) change of /x/ to a labial consonant between a back vowel and a coronal sonorant consonant (Go. aúhns 'oven' : OE ofen) and of $/ \mathrm{\gamma} /$ to $/ \mathrm{w} /$ between a back vowel and $m$ (Go. bagms 'tree' : OE bēam); ${ }^{5}$ and (1) proximal demonstratives, e.g. OE p $\breve{\bar{e} s}$ beside $s \check{\bar{e}}$, OIcel. sjá/pessi beside sá (Hamp 1985; H.F. Nielsen 1976). ${ }^{6}$ Some further ways in which East Germanic differs were listed above (§1.8), though they have little bearing on the question of the relations between North and West Germanic. Schwarz (1951) would explain the commonalities of NWGmc. as due to relatively late influence of WGmc. upon NGmc., though of course this will not account plausibly for features (a) and (b). As pointed out by Kuhn (1955-6), the language of early Runic inscriptions does not allow any pronounced differentiation of North and West Germanic, the divide between which he would therefore date to the fifth century, whereas Isakson (2000) dates the divide to the sixth. ${ }^{7}$ It may be, as some have charged (see Makaev 1962: 122; 1996: 20-4; but cf. Antonsen 2002: 297-314), that the language of inscriptions in the Elder Futhark is artificially conservative, or that it is a koine (see Krause 1968: §32, Düwel 1983: 15-16; cf. H.F. Nielsen 2000: 287), but even if one accepts such arguments, no very marked differentiation between North and West Germanic can plausibly have occurred before the third century, and most scholars maintain that the emergence of differentiating characteristics should be dated ca. 500. See Antonsen 1967, E. Haugen 1970: 48, Markey 1976, Penzl 1988a, 1988b, 1989, 1996, Klein 1992: 223-4, but cf. Grønvik 1981: Chap. 3, idem 2010; Laur 1990; Stiles 2013: 8; see also several of the essays in Askedal et al. 2010. For accounts of the differing views on this question, see H.F. Nielsen 1989: 5-12, 2000: 56-69.

For an exceptionally extensive accounting of features shared among the different branches of Gmc., see H.F. Nielsen 2000: 203-40; also Grønvik 1998b: 67-82 and the contributions to Bandle et al. 2002-5: 2.553-72. Stiles (2013) furnishes a concise bibliographical account of scholarly views.

1. Antonsen (1965: 31) objects to this terminology, preferring simply 'Germanic' because the departure of the Goths should not have had any effect on the mother tongue. For a response to the objection, see H.F. Nielsen 1989: 95. For some nineteenth-century studies supporting the idea of West Germanic as a protolanguage, see Schleicher 1860, Förstemann 1869: 163-4, 185-6, Bezzenberger 1880: 152-5, and Streitberg 1896: §13. K.M. 
Nielsen (1975) offers a negative assessment, Voyles (1968, 1981), Findell (2012), and Ringe (2012) positive ones.

2. For further discussion of affinities between North Germanic and North Sea Germanic, with references, see Laur 1988: 125-6; also Antonsen 1975: 26 (assuming a unity of North Gmc. and Ingvaeonic that he refers to as Northwest Gmc.), H.F. Nielsen 1975, 1994c, 2004, Seebold 2004.

3. For criticisms of Schwarz's hypothesis, see Brinkmann 1951, Philippson 1954, Rosenfeld 1955c, Adamus 1962, and Schützeichel 1976. See also Penzl 1988b: 498, with further references.

4. Snyder (1989) supports the idea of close affinities between East and West Germanic on the basis of a statistical analysis of nouns and adjectives with $l$-and $r$-suffixes.

5. But cf. W. Laur 1990: 218, assuming PGmc. *baumaz.

6. See Antonsen 1975: 26 and Stiles 2013: 8-9 for some further commonalities. Some of the studies in Marold \& Zimmermann 1995 are also relevant.

7. On the possible early development of PGmc. $\bar{e}_{1}$ to NGmc. $\bar{a}$, see $\S 4.6$. See further below $(\S 1.10)$ on alternative views about NWGmc.

\subsection{The development of Northwest Germanic and the Ingvaeonic problem}

The question how the North and West Germanic languages developed out of Northwest Germanic has been much debated. According to the older view, prevalent in the nineteenth century, Northwest Germanic simply split into two protolanguages, a Scandinavian one and a continental one, but such an assumption has been repeatedly disputed. ${ }^{1}$ The question is thus largely equivalent to the question whether the assumption of a single WGmc. protolanguage is valid. Karstien (1930: 1127b), for example, supposes that innovations common to West Germanic actually postdate the rise of Ingvaeonic. A particularly influential view is that of Maurer (1952; similarly Frings 1932), who rejects the idea of a West Germanic aboriginal unity, replacing it with three discrete culture groups, North Sea Germanic (OE, OF, OS), Weser-Rhine Germanic (Franconian), and Elbe Germanic (Alemannic, Bavarian, Lombardic), corresponding to the tripartite division of Germanic Mannus-groups into Ingaeuones, Istaeuones, and Herminones outlined in cap. 2 of Tacitus's Germania. Maurer's chief contribution to the debate is his employment of historical and archaeological evidence, yet this is also its greatest weakness, since there is no good reason to assume that ethnic and cultural differences necessarily correspond to linguistic ones: see particularly H.F. Nielsen 2004. On this analysis, some of the characteristic WGmc. features itemized in $\S 1.8$ would have to be explained as later developments spreading among related West Germanic languages, a circumstance that has occasioned much criticism of views like Maurer's, especially by Kuhn (1944: 8-9); see further the essays in Naumann 2004 and Harm 2013.

In a tradition going back to Müllenhoff (1900), a great many studies of the development of West Germanic assume a tripartite division into Ingvaeonic, Istaevonic, and Erminonic branches, on the basis of the distinction drawn by Tacitus. ${ }^{2}$ This is probably not a sound assumption, on a variety of grounds. As noted above, ethnic distinctions need not imply linguistic ones. Moreover, it is to be doubted whether the language of the earliest Runic inscriptions can conclusively be identified as North Germanic instead of Northwest Germanic (see $\$ 1.9$ ad fin.), and so the ethnic distinction drawn by Tacitus at the end of the first century CE must be assumed to have antedated any now-detectable 
linguistic difference by several centuries. ${ }^{3}$ In addition, although Ingvaeonic can be defined fairly narrowly on a linguistic basis (see below), practically nothing is known about Istaevonic or Erminonic, so that much guesswork is inevitably involved in any tripartite division.

Particularly important for the question of West Germanic unity are the position and composition of Ingvaeonic or North Sea Germanic, the latter term now tending to prevail over the former. ${ }^{4}$ The majority view is that the North Sea Germanic group includes not only English and Frisian but also Old Saxon, and the reason Old Saxon is less plainly allied to this group is that the language lost some of its Ingvaeonic features under Franconian influence starting about $700 \mathrm{CE}$, due to Frankish political domination. Some do not regard Old Saxon as a member of this group (e.g. Rösel 1962), but Stiles (2013: 19-21) catalogues the effects of High German influence on the changing language, and why it must be regarded as Ingvaeonic. A. Campbell (1947) identifies the following Ingvaeonic features as definitive: (a) fronting of WGmc. $\check{a}$ except before nasal consonants (§4.12); (b) development of WGmc. *au to $\bar{a}$ (in OFris., not in OE or OS: §4.14); (c) palatalization of velar stops before front vowels (\$6.17); (d) loss of nasal consonants before fricatives $(\$ 4.11) ;{ }^{5}$ (e) failure to participate in the High German Consonant Shift (§6.21); and (f) elimination of distinctions of person in the plural of verbs (e.g. §12.24). ${ }^{6}$ The distribution of these features across the group is uneven: for example, Old Saxon lacks feature (a) and shows only traces of (c), and in regard to (b), Old English has $\bar{e} a$ rather than $\bar{a}$, whereas literary OS has $\bar{o}$.

In the view of some (e.g. Schwarz 1952: 276 and Rösel 1962: 46-7), North Sea Germanic was originally more closely allied with North Germanic and only later acquired affinities to West Germanic. The dominant view, however, is that North Sea Germanic is simply a dialect of West Germanic. ${ }^{7}$ There is less agreement about whether the distinctive features of North Sea Germanic developed on the Continent before the departure of the Anglo-Saxons or later, as cultural exchange continued across the North Sea, the latter being the influential view of Kuhn (1955-6). By contrast, in the view of Antonsen (1975: 26-8), there existed by ca. 100 CE distinctions among East, South, and Northwest Germanic, with Ingvaeonic becoming distinct from the last about a century later. The most detailed studies (Markey 1976: 36-71, H.F. Nielsen 1985: 148-54, 255-7; but see also Fulk 1998a: 154) suggest that only a few of the distinctive features of Ingvaeonic developed before the departure of the Anglo-Saxons.

1. Such is also the view of, e.g., Kuhn 1955-6 and of many handbooks. For a thorough review of the literature, see H.F. Nielsen 1989: 67-107.

2. Tacitus's term Ingaeuones is generally assumed to be an error for Inguaeones (the name used by Pliny) under the influence of the term Istaeuones. For archaeological evidence in support of this tripartite division, see Mildenberger 1986.

3. In response to the attempt of Jungandreas (1974) to establish four dialect areas of Germanic in the first century CE, see Hofstra 1976.

4. For arguments in favor of using the term 'North Sea Germanic' to designate the present-day languages, see Laur 1984, with references; for an opposing view, Stiles 2013: 10 n. 8.

5. But cf. Hermann (1978: 300-1), arguing that this change also affected North Germanic, though earlier there had occurred assimilations like [n $\theta]>[\mathrm{n}:]$ that prevented its application in most of the original environments.

6. Markey (1976: 36-71) identifies thirty-six features as typically Ingvaeonic, among the most important of which is loss of $*_{-z}$ in monosyllabic pronouns like OE dat. mё (cf. OHG mir). Another feature left out of 
consideration in Campbell's list is use of $h \breve{e}$ for the third person sg. masc. pronoun. See also the lists in Stiles 2013: 18, 21-3.

7. For an account of the history of ideas about West Germanic, see Stiles 2013, emphasizing the importance of chronology and diatopic variation for establishing the validity of assumed WGmc. unity. His conclusion is that most Ingvaeonic innovations postdate the period of WGmc. unity, but a few, being shared with NGmc., must antedate the rise of WGmc. as a separate branch. For an account of the external history of Germanic as it pertains to the grouping of the Gmc. languages, see Seebold 2013.

\subsection{East Germanic}

On the basis of ethnographic information supplied primarily by Pliny the Elder and Tacitus ( $1^{\text {st }}$ cent. $\left.\mathrm{CE}\right)$ and Ptolemy $\left(2^{\text {nd }}\right.$ cent. $\left.\mathrm{CE}\right)$, which are the earliest sources, a number of named early Germanic groups are to be counted among the East Germanic peoples. ${ }^{1}$ They at one time inhabited the lands south of the Baltic Sea, east of the Elbe, as far as the Vistula, an area later to be called Pomerania. Usually included in this group are Goths (among whom are probably to be counted Gepids, Greuthingi, and Thervingi), Bastarnae, Burgundians, ${ }^{2}$ Heruli, Rugii, Scirii, Silingi, and Vandals. No East Germanic language survives to the present day, and only the Goths have left extensive remains of their language. Of the remainder, the only evidence for East Germanic languages is isolated words, almost exclusively names in Burgundian and Vandalic. ${ }^{3}$

The Gothic language is known chiefly on the basis of the surviving fragments of a Bible translation made from Greek by Ulfilas (Go. Wulfila, ca. 310-383), bishop of those Christian Visigoths settled in Moesia by Constantine (though Ratkus 2018 argues against the sole authorship of Ulfilas). Five manuscripts together preserve, in a fragmentary state, the four gospels, a number of epistles, portions of Nehemiah, a few words from Genesis, a fragment of a Gothic calendar, and eight fragments of a commentary on John referred to by the Gothic title assigned in modern times, Skeireins ('Explanation'). There are also Gothic names preserved in various sources, and a few stray words, including some runic inscriptions. ${ }^{4}$ In addition to these remains, in 2010 there was discovered in Bologna a palimpsest of a Gothic manuscript containing a collection of passages from the Bible and from Skeireins, some of them not otherwise preserved, as well as a few words of narrative that do not derive from scripture: for description and text, see Finazzi \& Tornaghi 2013, with an improved transcript in Falluomini 2014.

The Gothic records are written in an alphabet reportedly devised by Ulfilas (see Figure 2), based chiefly on Greek characters, with resort to Latin and runic characters

$\begin{array}{cccccccccccccc}\lambda & \text { в } & \Gamma & \mathrm{d} & \mathrm{E} & \mathrm{u} & \mathrm{z} & \mathrm{h} & \psi & \mathrm{I}, \ddot{\mathrm{I}} & \mathrm{k} & \lambda & \mathrm{M} & \mathrm{N} \\ 1 & 2 & 3 & 4 & 5 & 6 & 7 & 8 & 9 & 10 & 20 & 30 & 40 & 50 \\ \mathrm{a} & \mathrm{b} & \mathrm{g} & \mathrm{d} & \mathrm{e} & \mathrm{q} & \mathrm{z} & \mathrm{h} & \mathrm{p} & \mathrm{i} & \mathrm{k} & 1 & \mathrm{~m} & \mathrm{n}\end{array}$

$\begin{array}{ccccccccccccc}\mathrm{g} & \mathrm{n} & \Pi & \mathrm{u} & \mathrm{k} & \mathrm{s} & \mathrm{T} & \mathrm{\gamma} & \mathrm{F} & \mathrm{x} & \odot & \text { \& } & \uparrow \\ 60 & 70 & 80 & 90 & 100 & 200 & 300 & 400 & 500 & 600 & 700 & 800 & 900 \\ \mathrm{j} & \mathrm{u} & \mathrm{p} & - & \mathrm{r} & \mathrm{s} & \mathrm{t} & \mathrm{w} & \mathrm{f} & \mathrm{x} & \mathrm{h} & \mathrm{o} & -\end{array}$

Fig. 2. The Gothic alphabet, with numerical values and transliterative equivalents. 
where necessary. In the figure, the first row represents the Gothic character, the second its value when used as a numeral (agreeing to the extent possible with the numerical use of alphabetic characters in Greek), and the third its standard transliteration in studies of Gothic. The character İ is used only initially and to represent a heterosyllabic vowel, as in fra-itip 'devours'. The characters $u$ and $\uparrow$ are used only as numerals (90 and 900, respectively), and $x$ occurs only in the name Xristus.

In this spelling system the vowels $a$ and $u$ are ambiguous as to quantity, and therefore they have been marked in this book with a macron when etymologically long. ${ }^{5}$ The tense vowels $\bar{e}, \bar{o}$, and $e i$ are, at least historically, always long, the last having the value /i:/, and $i$ is always short. Among the digraphs, $i u$ is a falling diphthong, whereas $a i$ and $a u$ are ambivalent: they are usually assumed to represent $/ \varepsilon /$ and $/ 0 /$ (perhaps ranging allophonically to [e] and [o], sounds otherwise representing a gap in the vowel inventory), respectively, when they are derived from simple vowels (see §4.5), in which event they are conventionally marked ai and aú by grammarians; but they may also be derived from PGmc. $a i$ and $a u$, in which event they are marked $a ́ i$ and $a ́ u$, probably with the values / $\varepsilon: /$ and $/ \mathrm{s} / /$, to judge by Ulfilas's spelling of biblical names and by fourth-century Latin spellings of Gothic names, though the matter has been much contested. ${ }^{6}$ On the value of $a i$ and $a u$ not marked with an acute, see $\S 4.5$. The character $\varphi(w)$ is used also to represent Gk. $v$ and $o r$ (both $/ \mathrm{y}(:) /$ by the fourth century) in borrowed words, e.g. swnagogge

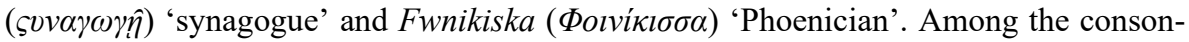
ants, $q$ and $h$ are labialized velars $/ \mathrm{k}^{\mathrm{w}} /$ and $/ \mathrm{x}^{\mathrm{w}} /$ (the latter perhaps with allophone $\left[\mathrm{h}^{\mathrm{w}}\right]$, $\S 6.11)$. The characters $b, d, g$ represent voiced stops initially and after nasal consonants (and in gemination, §6.9), otherwise voiced fricatives, except that they are stops also after (probably) any consonant. ${ }^{7}$ On the model of Greek spelling, $/ \mathrm{nk}, \mathrm{\eta k}{ }^{\mathrm{w}}, \mathrm{\eta g} /$ are written $g k$, $g q, g g$, though the last may also represent the product of the Verschärfung (§6.10), as in bliggwan 'beat' (cf. OHG bliuwan, and compare Go. siggwan 'sing' < PGmc. *singwana $\left.^{n}\right)$.

A Gothic enclave persisted in Crimea into the modern era, referred to in various sources from the ninth century to the eighteenth. The only substantial witness to the Crimean Gothic language is a 1562 letter, published in 1589, from the Flemish ambassador Ogier Ghiselin de Busbecq, listing about eighty words and the lyrics of a song; see Tischler 1978 on some further witnesses. Some Crimean Gothic inscriptions of the ninth or tenth century have recently been deciphered (conjecturally: see Vinogradov \& Korobov 2015, 2016), but their fragmentary state adds little of substance to what is known of the language. Because Crimean Gothic shows no trace of the lowering of $i$ and $u$ before $r$ and $h$, Cercignani (1980a: 211-12) advises that it not be regarded as a lineal descendant of Bible Gothic.

Some useful grammars of Gothic are Wright 1954, Mossé 1956, Kieckers 1960, Krahe 1967, Krause 1968, Binnig 1999, and Braune 2004b. Kotin 2012 explores the language in depth but is not usable as a grammar. See Lehmann 1986 for a comprehensive etymological dictionary; another dictionary is Köbler 2014e. For the standard edition of the Gothic Bible, see Streitberg 2000. On Crimean Gothic, see Stearns 1989, also Grønvik 1983. For bibliography, see C.T. Petersen 2002.

1. For an ethnographic overview, see Bremer 1900: 819-27; on the sources, see Wrede 1886: 12-35. 
2. At one time resident on the Danish island of Bornholm, ON Borgundar holmr.

3. On the Burgundian names, see Wackernagel 1868; on the Vandalic, Wrede 1886.

4. Most of these 'Gothica minora' are edited by Massmann 1841. They are also included as an appendix in the latest recension of Streitberg's edition of the Bible fragments (2000). For an exact accounting of the remains, see Braune 2004b: §§E5-19.

5. On the history of shifting views about whether phonemic length was a feature of Gothic vowels, see Moulton 1987.

6. Compare, e.g., Go. dat. Lauidjái 'Lois' (rendering Gk. $\Lambda \omega i ̈ \delta l$ ) and Lat. Ostrogoti, earlier Austro-. For a bibliographical summary of the different proposals, see d'Alquen 1974: 19-29. Marchand (1973: 102), for example, finds it 'highly improbable' that $\langle\mathrm{ai}\rangle$ or $\langle\mathrm{au}\rangle$ could represent more than one sound.

7. This conclusion is drawn on the basis of the failure of these consonants to be written as voiceless fricatives in positions in which fricatives would be expected to be devoiced, as with -swarb 'wiped' ( 3 sg.) and alds 'age'; cf. also dags 'day'.

\subsection{Provenance of the Goths}

The historical records of classical antiquity show plainly that Goths were present in great numbers on the northern shore of the Black Sea by the middle of the third century CE. By the end of the fourth century they comprised two groups, the Ostrogoths, living east of the Dniester, to the Dnieper and beyond, and the Visigoths, to be found between the Dniester and the Danube. ${ }^{1}$ It is from these Pontic areas that they were dislodged by the arrival of the Huns in 375. How the Goths arrived at the Black Sea, and where they originated, are matters of debate. The usual assumption, and the one still credited by the considerable majority of scholars, has been that the account given in the sixth-century Getica of Jordanes is trustworthy at least in general outline: according to this account, the Goths migrated, perhaps about $100 \mathrm{BCE}$, from Scandinavia (Scandza) to the banks of the Vistula. ${ }^{2}$ Their area of settlement on the southern coast of the Baltic is called by Jordanes Gothiscandza (presumably *Gutisk-andja 'Gothic end', Much 1967: 487, but cf. Svennung 1972: 28: *Guti-Skandia 'Gothic Scandinavia'), and it has commonly been assumed that this is the origin of the names of the cities of Gdańsk (NHG Danzig) and Gdynia on the Polish coast, though the derivations cannot be proved. In accordance with the account of Jordanes, the Goths have usually been identified with the Gutones first mentioned by Pliny the Elder ca. $65 \mathrm{CE}$ as living on the shore of (apparently) the Baltic Sea. ${ }^{3}$ On this reasoning the Goths have also commonly been associated with the island of Gotland and with the region of south-central Sweden called Götaland (named after the ON Gautar, OE Géatas), from which areas they are assumed to have migrated originally. ${ }^{4}$

In more recent times the account of Jordanes, recorded so many centuries after the purported departure from Scandinavia, has been called into question, in part on archaeological grounds (see von Petrikovits 1985, Polomé 1992b: 57-8). In a series of studies, Mańczak has argued that the vocabulary of Gothic has considerably more in common with that of Upper German than with that of Swedish, and the origin of the Goths is thus to be sought in the southernmost parts of Germania rather than in Scandinavia. ${ }^{5}$ In support of this analysis have been offered arguments about the greater historical plausibility of migrations eastward to the Black Sea and northward to the Vistula than from the Vistula 
to the Black Sea (see Kortlandt 2001, with references). Euler (1985) examines Scandinavian Runic inscriptions to determine that some do show evidence of Gothic phonological and morphological features, so that the presence of Goths in Scandinavia is not to be doubted, though whether this is because they originated there or migrated there from the mouth of the Vistula is not a question that can be settled on the basis of such inscriptions. But if migration from the Vistula to the Black Sea is improbable, as has been claimed, migration to Scandinavia seems even less plausible, especially given the coincidence that the area to which they must be assumed to have migrated on this account is precisely that from which Jordanes says that they set out. At all events, the name of the Goths is so common in place-names in Sweden - and place-names are often among the most archaic evidence - that it is difficult to believe that the Gothic presence in Scandinavia could have been a late development (see Strid 2014).

1. Ostro- is to be related to Lat. aurora, Gk. ë $\omega \varsigma$, Skt. uṣāh, Lith. aušrà 'morning light' (hence 'east'), and Visi- to Lat. vesper, Gk. ह̈ $\sigma \pi \varepsilon \rho \varsigma^{\prime}$ 'evening'. The Goths are generally associated with the archaeological remains of the Černjahov culture in what is now Ukraine: see Heather \& Matthews 1991: 51-101, Heather 1996: 1850. For a concise account of the standard view, with extensive references, see Green 1998: 164-8.

2. See Hachmann 1970: 136-43, 458, Wolfram 1979: 34-5. This analysis is lent support by similarities between material remains of the Cernjahov culture of Ukraine and of the Wielbark culture of the Polish coast. The Goths have lent their name to a number of places in present-day Sweden, including Gotland, Götaland, and Göteborg (Gothenburg).

3. In his Geography, of ca. $150 \mathrm{CE}$, Ptolemy, drawing on earlier sources, identifies the Гov $\tau \alpha \iota$ as living in

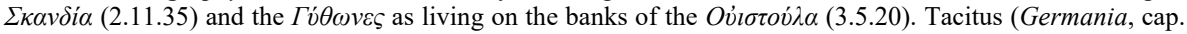
43), ca. $98 \mathrm{CE}$, likewise places the Gotones on the Continent near the Baltic.

4. For extensive references to the scholarship supporting Jordanes' account, see Penzl 1985. Mottausch (1994: $133 \&$ n. 23) and Strid (2010) also provide references. Kotin (2012: 13) mistakenly attributes to Krause (1968: 42-3) the view that the East Germanic peoples (rather than the Vandals alone) originated in northern Jutland.

5. See Mańczak 1982, 1984a, 1986a, 1987b, and the reply to the last by Salmons (1987). Phonological evidence is adduced by Grønvik (1995, critiqued by Nilsson 1996: 55-6; cf. Mańczak 1998). For criticisms of Mańczak's methodology, see Penzl 1985: 154-8.

\subsection{The Runic records}

Although a few runic inscriptions are generally regarded as Gothic (see §1.11; also Ebbinghaus 1990, Peterson 1998) - and certainly Ulfilas knew the Runic alphabet, since he incorporated some of its characters into the Gothic alphabet - the majority are of Scandinavian provenance and evince specifically NGmc. linguistic characteristics; on the Continental Runic inscriptions, see Findell 2012, who catalogues 90 such inscriptions. But the earliest inscriptions in Runic, Gothic inscriptions aside, reflect a stage of linguistic development in which North and West Gmc. forms cannot yet be distinguished (see §1.9)..$^{1}$ These are recorded in a form of the Runic alphabet referred to as the Elder Futhark, named after its first six characters, the order of which is assured by various alphabetic inscriptions, including those on the Kylver Stone (ca. 400) and on the Vadstena Bracteate (ca. 500). The 24 characters of the Elder Futhark are presented in Figure 3 (though variant forms of individual runes are not uncommon: see Antonsen 1975: 6-10), with their usual equivalents in transliteration. (Transliterations of inscriptions in Runic are conventionally presented in boldface.) Here $\mathbf{p}$ is always voiceless, and $\mathbf{b}, \mathbf{d}, \mathbf{g}$ are alternately stops and 


\begin{tabular}{|c|c|c|c|c|c|c|}
\hline$k$ & $\Lambda$ & $p$ & F & $R$ & $<$ & $X$ \\
\hline f & $\mathbf{u}$ & p & $\mathbf{a}$ & $\mathbf{r}$ & $\mathbf{k}$ & $\mathbf{g}$ \\
\hline $\mathrm{N}$ & $t$ & I & 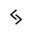 & 5 & h & Y \\
\hline $\mathbf{h}$ & $\mathbf{n}$ & $\mathbf{i}$ & $\mathbf{j}$ & * & $\mathbf{p}$ & $\mathbf{z} / \mathbf{R}$ \\
\hline$\uparrow$ & $B$ & $M$ & 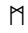 & T & $\diamond$ & W \\
\hline t & b & e & $\mathbf{m}$ & I & y & d \\
\hline
\end{tabular}

Fig. 3. The Elder Futhark, with equivalents in transcription.

fricatives by position ( $\S 6.5$ ). On the value of $\mathbf{R}$ (which many prefer to transliterate as $\mathbf{z}$, and which must be so transliterated in the earliest inscriptions), see $\S 6.14$. Vowels may be long or short. The value of the rare rune $\int$ is disputed; highly plausible is the argument of Antonsen (1975: 3-6, with references) that it was originally PGmc. $\bar{e}_{l}(/ \overline{\mathrm{e}} /$ in his notation) and that it came to be used for a number of other sounds once the reflex of $\bar{e}_{1}$ developed to $\mathrm{N}(\mathrm{W})$ Gmc. $\bar{a}$ in stressed syllables and $\bar{e}$ in unstressed and consequently came to be represented by other runes. Due to loss of $j$ in the rune-name *jāran 'year' (> OIcel. $a ́ r)$, in late inscriptions $\triangleleft(\mathbf{j})$ is sometimes used to represent $a$, and in that event it is transcribed A. There also occur non-etymological, epenthetic vowels, rendered superscript in transcriptions, as in wor ${ }^{\mathbf{a}} \mathbf{h t o}=$ Go. waúrhta 'made' and $\mathbf{- w o l}^{\mathbf{A}} \mathbf{f} \mathbf{R}$ ' $w o l f$ '.

Beginning as early as ca. 750 the Elder Futhark was gradually replaced in Scandinavia by the Younger, of just 16 runes, even though the number of vowel phonemes expanded notably at about the time of its introduction. ${ }^{2}$ In OE, on the other hand, the Elder Futhark was modified and added to, producing the Old English Futhorc (with o for earlier a due to the NSGmc. change of the rune-name *ansuz 'god' to $\overline{o s}, \S 4.11)$, an alphabet of as many as 33 runes. Inscriptions in the Younger Futhark and in the OE Futhorc play a relatively minor role in tracing the histories of North Germanic and OE, though earlier Anglo-Frisian inscriptions in the Elder Futhark are of some linguistic significance: see, e.g. Bammesberger 1991a, H.F. Nielsen 1991, 1996, R.I. Page 1996.

The dating of inscriptions in Runic is hardly secure, involving epigraphic, archaeological, and linguistic considerations, and so disagreements in the relevant literature are inevitable. See, e.g., Krause 1971: 16-17, Antonsen 2002: 149-67. Much has been written about the disputed origins of runes: see, e.g., Antonsen 1982, Moltke 1985, Morris 1988, Odenstedt 1991, Vennemann 2013, Fairfax 2014, and for an overview of scholarship, Antonsen 2002: 93-117. For general studies and introductions to runology, see Düwel 1983, 1998, Antonsen 2002, Looijenga 2003, Askedal et al. 2010, M.P. Barnes 2012. For grammars of Runic, see Krause 1971 (with an abridged corpus of 127 inscriptions derived from the comprehensive corpus of Krause 1966), Antonsen 1975. On Runic as evidence for language history, see, e.g., Bammesberger 1994b, 1996, Grønvik 1998a, b, H.F. Nielsen 1998b, 2000, 2009, Spurkland 1998, Schulte 2000a, 2003, Antonsen 2002, Mees 2006, Stiles 2012.

Although early Runic is in some respects even more conservative than Gothic, it is too fragmentarily attested to furnish useful paradigms, and thus, in this book Runic evidence is adduced in connection with morphology only when strictly relevant. 
1. In his corpus of 121 inscriptions, ranging in date from ca. $150 \mathrm{CE}$ to ca. 650 , Antonsen (1975) finds a few with distinct diatopic linguistic features: 5 EGmc. or Go., 8 WGmc. or NSGmc., 15 NGmc., 5 East Norse, 1 West Norse; the remainder show no dialectal differentiation.

2. On the Younger Futhark see, e.g., M.P. Barnes 2009, Schulte 2009, 2011.

\subsection{North Germanic}

The earliest runic inscriptions date to ca. $150 \mathrm{CE}$. At what point in time inscriptions begin to appear that can be identified as specifically North Germanic (as opposed to yet earlier inscriptions of a NWGmc. character) is a matter of debate (see \$1.9), but it would appear that by the late fifth century at the latest some inscriptions may be identified as linguistically Proto-Norse (see H.F. Nielsen 2000). ${ }^{1}$ Dialectal differentiation does not begin to appear in this Runic corpus until the Viking Age (ca. 800-ca. 1050), at which point East and West Norse may be distinguished, the former evincing minor but separate Swedish and Danish characteristics already during this period, the latter separate Norwegian and Icelandic characteristics beginning in the twelfth century. ${ }^{2}$ Old Gutnish, spoken on the island of Gotland in the Baltic, differs in certain respects from East Norse, and also from West Norse, and it has been argued that it is most closely related to Gothic ${ }^{3}$ (as the name of the island might imply), though it is normally accounted a dialect of Old Swedish. None of the few runic inscriptions from Iceland can be dated earlier than ca. 1200 , and so they are of little linguistic use. The earliest Icelandic manuscript evidence is from the end of the twelfth century, but manuscript evidence does not become plentiful until the second half of the thirteenth.

The weightiest respects in which Old East Norse differs from Old West Norse are these (Noreen 1970: §8): (a) front and back umlaut frequently fail, e.g. OEN vāre 'were' (sj.), $\bar{\imath}$ ga $r$ 'yesterday', land 'lands' (nom./acc.pl.) : OWN væri, i gær, lond; (b) syllablefinal OWN $\bar{u}$ corresponds to OEN $\bar{o}$, e.g. OEN kō 'cow', gnōa 'rub' : OWN kú, gnúa; (c) $\bar{i}, \bar{e}, \bar{y}$ fail to form rising diphthongs with a following vowel, e.g. OEN seea 'see', fiande 'enemy', bȳar 'farmstead' (gen. sg.) : OWN sjá, fjandi, bjár; (d) the change of $m p, n k, n t$ to $p p, k k, t t$, respectively, is far less regular, e.g. OEN krumpin 'stunted', ænkia 'widow', bant 'bound' (pret.) : OWN kroppinn, ekkja, batt; (e) the OEN endings nom. pl. -iar, $-i æ r$, acc. $-i a,-i æ$ of masc. $i$ - and $j a$-stems correspond to OWN nom. $-i r,-i$, e.g. OEN drængiar, -ia 'fellows' : OWN drengir, $-i$; (f) OEN suffixed def. art. dat. pl. -umin for OWN -unum; (g) some distinctive OEN pronouns, e.g. iak, iæk 'I', $v \bar{\imath}(r)$ 'we', $\bar{\imath}(r)$ 'you' (pl.), rel. sum: OWN ek, vér, (p)ér, sem; (h) weak forms corresponding to OWN preterites in -r- (class VII), e.g. OEN sāpe: OWN sera 'sowed'; (i) mediopassives in -as(s), e.g. OEN kallas(s) : OWN kallask 'are called'.

Unless specified otherwise, in this book the term 'Runic' (thus capitalized) is used in connection with forms of a Proto-Norse character attested in runic inscriptions. The term 'Old Norse' is used in connection with forms in either runic or manuscript attestation that postdate the Proto-Norse period (i.e., appearing after ca. 800), and the term may be used indifferently in respect to East and West Norse forms. Most cited forms of the historical period are designated 'Old Icelandic' rather than 'Old Norse', reflecting their actual provenance. ${ }^{4}$ OIcel. forms are cited in this book in standardized orthography of the 
classical period (i.e. ca. 1200-ca. 1350) unless otherwise stated, e.g. with high vowels in unstressed syllables $(-u(m),-i(r)$ rather than earlier $-o(m),-e(r))$; $\partial$ rather than $p$ except initially in free morphemes; and $a$ for ${ }^{5} .^{5}$

Noreen 1970 is a comprehensive grammar of Old West Norse; for Old Icelandic see also Heusler 1967, Gutenbrunner 1951, Wessén 1958. More concise are R. Iversen 1973, Ranke \& Hofmann 1988, O.E. Haugen 2013a, b. For Old Swedish and Old Gutnish, see Noreen 1904; for Old Danish, Brøndum Nielsen 1950-7. For collective treatments of all the North Germanic languages, see Wessén 1968, Bandle et al. 2002-5. The most comprehensive and complete dictionary of Old Norse/Icelandic is Fritzner 1954. A new, comprehensive dictionary of prose (currently A-EM) is in preparation. ${ }^{6}$ Other dictionaries: de Vries 1962 (etymological), Cleasby \& Vigfusson 1957, and Zoëga 1910.

1. The loss of final $*_{-z}$ in kaba (for kamba) on the Frienstedt comb (ca. 250-300) is a specifically WGmc. development (see Schmidt, Nedoma, \& Düwel 2011), but there is no need to assume that the change had affected all of WGmc. by the date of its deposit. Compare the mother-goddess names Vatvims, Aflims, and Gabims in Ubian inscriptions (dat. pl., $1^{\text {st }}-3^{\text {rd }}$ centuries; Much 1887, and cf. Ringe \& Taylor 2014: 46). Other Runic evidence is more difficult to interpret, e.g. alugod (Værløse clasp, Zealand, ca. 200), of which the second constituent could reflect $*_{z} \partial \partial a z$ (so Antonsen 1975: 75), though it could also be a voc. (so Krause 1971: 174).

2. On the development of the Scandinavian languages out of Proto-Norse, see Bandle 1973, Bandle et al. 2002-5. Some of the earliest differences to arise between Old Norwegian and Old Icelandic, mostly strong tendencies rather than absolute differences, are the following (Noreen 1970: §9): (a) failure of back mutation in ONorw., e.g. dat. pl. sakum 'cases' (OIcel. sokum); (b) unstressed high vowels in ONorw., e.g. the inflections $u(m)$ and $-i(r)$ (OIcel. $-o(m)$ and $-e(r)$ before ca. 1200); (c) loss of initial $h$ before sonorant consonants in ONorw., e.g. loupa 'leap, run', níga 'sink', ringr 'ring' (OIcel. hlaupa, hniga, hringr); (d) change of $b n$ to $m n$, e.g. ONorw. svemn, OIcel. svefn 'sleep'; (e) pronouns mit beside vit 'we' (dual), mér beside vér 'we' (pl.), hvarr beside hværr 'which, each' (OIcel. vit, vér, hverr); (f) 2 pl. verb ending - $r$ beside -ð, -t, e.g. ONorw. grípir, -ið, -it 'grasp' (OIcel. gripeð, -et before ca. 1200) and ONorw. gripur, -uð, -ut 'grasped' (OIcel. gripoð, -ot before ca. 1200).

3. So, e.g., Wessén 1968: 115-17. The chief source for Old Gutnish is Guta saga (13 ${ }^{\text {th }}$ cent.). Examples of distinctive Old Gutnish features are these: (a) The umlaut of PGmc. *au is oy, as in droyma 'dream' (OEN drø̄ma, OWN dreyma); (b) PGmc. *ai remains unchanged, as in paim 'them' (dat.; OEN pēm, OWN pæim); (c) as in OWN, PGmc. *au remains unchanged, as in auga 'eye' (OEN øga, OWN auga).

4. The distinction between Old Norse and Old Icelandic is of especial importance in connection with English language history, since citing an Old Icelandic form as if it were an Old Norse form would inevitably lead to misrepresentations about Norse loanwords in English, e.g. PDE though $<\mathrm{ON} *$ pōh (OIcel. pó).

5. The standardized spelling used here is thus that of most modern editions of OIcel. literary texts, e.g. those in the Íslenzkt fornrit series (1933-). For further features distinguishing the language of the classical period from the earlier period (ca. 870-ca. 1200), not all of them indicated in standardized orthography, see Noreen 1970: $§ 10$, using a slightly more archaic normalized orthography.

6. Ordbog over det norrøne prosasprog / A Dictionary of Old Norse Prose (Copenhagen, 1986-), with unedited material available on-line: http://onp.ku.dk/english/ (last accessed 12 June 2017).

\subsection{West Germanic}

As noted above $(\$ 1.10)$, no scholarly consensus has been reached about the origin and the internal and external relations of the West Germanic languages. The ethnic groups identifiable as West Germanic that are mentioned in Greek and Roman sources tended to migrate considerable distances during the Migration Period (die Völkerwanderung, ca. $300-$ ca. 700), with the consequence that their original linguistic affinities may have been altered over time by alignment with the groups with which they came into contact. ${ }^{1}$ An 
example of this is the Lombards (Langobards), who established a kingdom in northern and central Italy in the sixth century. They are of uncertain affinities, formerly thought an East Germanic or a North Sea Germanic group, though the few attested words in Lombardic, preserved in inscriptions and in Latin sources, plainly evidence the effects of the High German Consonant Shift (§6.21; see van der Rhee 1976, Petracco Sicardi 1977, Torgilsvedt 2009). In the first century CE they were counted among the Suevi by Tacitus and Strabo, the latter of whom locates them astride the Elbe, whereas Paulus Diaconus says that they originated in Scandinavia. See further Hutterer 1975: 336-41, and for linguistic analysis and an overview of scholarship, Tischler $1989 .{ }^{2}$

Certainly Anglo-Frisian, comprising English and Frisian, is recognizable as a subgroup of WGmc., and its affinities to Old Saxon are sufficient to render the term North Sea Germanic (or Ingvaeonic) useful as a way of grouping Old Saxon with the AngloFrisian group, regardless of the precise historical circumstances that led to the sharing of features within this group. ${ }^{3}$ For a list of distinctive NSGmc. features, see $\S 1.10$. The remaining WGmc. languages may be said to form two groups, distinguished by the extent to which they show the effects of the High German Consonant Shift (§6.21). The shift characterizes High German (Hochdeutsch) but not Low Franconian, of which Dutch (including Flemish) is now the chief variety. Naturally, the varieties of Low German (Niederdeutsch or Plattdeutsch) descended from Old Saxon, like other Ingvaeonic languages, remain unaffected by the High German Consonant Shift, but they share a number of features with Low Franconian that the other Ingvaeonic languages do not share.

1. In general, the movement of West Germanic peoples was to the south and west, occupying lands formerly held by Celts, as demonstrated by archaeological finds, the testimony of classical authors, and, especially, the Celtic origins of much of the hydronymy of southern and western Germany.

2. Further overviews of scholarship on Lombardic: Scardigli 1978, van der Rhee 1978, Restelli 1984.

3. On Anglo-Frisian as a possible protolanguage, see Pietersen 1978, H.F. Nielsen 1985, 1994a, 1998a, Bremmer 1982, 2008, Stiles 1995, Fulk 1998a, Kortlandt 2008, Repanšek 2012, Versloot 2014. On the position of OS within Gmc., see Dal 1983, H.F. Nielsen 1994b, Krogh 1996.

\subsection{Old English}

Bede (d. 735) asserts that beginning in the middle of the fifth century Britain was invaded by Angles, Saxons, and Jutes. Archaeological evidence largely confirms the identification, though other ethnic groups must also have been involved (as Bede himself seems to say elsewhere), and the invasion no doubt began early in the fifth century rather than the middle (see J. Campbell 1982). And so Bede probably had reliable sources about the ethnicities of the invaders, and he was not simply extrapolating from the political situation of his own day, when the English north of the Thames were called Engle and spoke dialects different from those south of the Thames (and in Middlesex and Essex), where the Seaxan lived; and the Germanic peoples of Kent and the Isle of Wight, said to have been settled by Jutes, maintained a separate identity. The preserved dialects of Old English are West Saxon, Kentish, Mercian, and Northumbrian, the last two of which are particularly closely related and are referred to collectively as Anglian. The earliest texts 
in English are runic inscriptions, attested beginning in the fifth century; the earliest manuscripts are from ca. 700, though some texts (such as the laws of Æthelberht of Kent) must have been composed earlier, despite being preserved only in late copies. Old English continued to be copied with some fidelity in certain areas as late as the thirteenth century, though most texts of the twelfth century are commonly regarded as Middle English, a language characterized by the reduced vocalism of inflections, the influx of vocabulary from Old Norse and French, and extensive changes to the system of vowels.

West Saxon is attested in Early and Late varieties. ${ }^{1}$ The former is attested fragmentarily in charters, the earliest of which to show distinctive WS features dates to the middle of the ninth century, but the chief witnesses originated in the reign of King Alfred 'the Great' (r. 871-99), whose program of translating Latin texts into English was intended to reinstill the literacy that had become scarce as a consequence of Scandinavian incursions into Britain. Another consequence of those invasions was the eventual unification of the English under the rule of a single, West Saxon king, with the result that Late West Saxon (beginning about 950) became the standard literary language for all of England, with the vast majority of the OE corpus preserved in that dialect. Late West Saxon is preserved in two sorts: (a) a managed variety (Standard Late West Saxon, or Ælfrician West Saxon, on which see, e.g., Gretsch 2006) promulgated by Æthelwold, bishop of Winchester from 963 to 984 , and his student Ælfric, with fairly uniform spelling practices and some distinctive vocabulary, and (b) a variety showing an admixture of phonological and lexical features characteristic of other dialects, probably due to the imperfect 'translation' of texts from other dialects (chiefly Mercian) into West Saxon (on which see Fulk 2009a, with references).

The most substantial sources of information on the other OE dialects are glosses. Kentish is fragmentarily attested, almost exclusively in glosses and charters. Evidence for Mercian (of the Central and West Midlands) is much more substantial, including collected glossses of ca. 700 and continuous glosses on the Vespasian Psalter (of the first half of the ninth century, though the language seems rather more archaic) and a large portion of the Rushworth Gospels (of the late tenth century). Northumbrian (the dialect of the North), for which no charters survive, is attested in a small amount of eighth- and (probably) ninth-century poetry, and in the form of names in a confraternity book begun in the ninth century; the only texts of any length are continuous glosses of the late tenth century, by which time the inflectional morphology of the dialect has lost countless earlier distinctions. For a summary of the chief characteristics of the non-Saxon dialects, with exemplary texts, see Fulk 2014: 118-31.

OE $f, s, p, \partial$ (the last two used indifferently in regard to phonetic value) are voiced between voiced sounds, otherwise voiceless, the variants being allophonic. According to environment, $c, g, s c, c g$ are palatal or velar: although there is some disagreement (see Minkova 2003, with references), it is most commonly held that $c$ represents [k] when not palatalized and affricated to [t]; $g$ when not palatalized represents [g] initially and after $n$, but [d] after $n$ when palatalized, [j] elsewhere when palatalized, and [y] in all other environments; ${ }^{2} s c$ represents [ $]$ ] everywhere except internally before or finally after a back vowel, where it is [sk]; and $c g$ is usually the palatal affricate [d]], rarely the velar geminate $[\mathrm{g}:] .{ }^{3} \mathrm{OE} h$ is $[\mathrm{h}]$ initially, otherwise $[\mathrm{x}] .{ }^{4}$ There is much disagreement about the values 
of the diphthongal digraphs $\breve{\bar{e} a}, \check{\bar{e}}$, $\breve{\bar{l}}$, $\breve{\bar{l}}$ : see Hogg 1992: $\S \S 2.19-37$ for discussion and references, and see $\$ 4.8$ infra.

Some important resources for the study of OE phonology and morphology may be mentioned. The most useful grammars are Bülbring 1902, Sievers 1903, Luick 1914-40 (phonology), Wright \& Wright 1925, Girvan 1931, Brunner 1965, A. Campbell 1977, Hogg 1992 (phonology), and Hogg \& Fulk 2011 (morphology). On the development of OE out of PGmc., see also Lass 1994, Ringe \& Taylor 2014. The largest dictionary is Bosworth \& Toller 1882, supplemented by Toller 1921 and A. Campbell 1972, though in some respects more useful is Clark Hall 1960. The Dictionary of Old English (currently A-H: Cameron et al. 2016) is largely unconcerned with historical matters, but its database is invaluable, especially in the on-line version, with global search capacity: Healey 2009.

Unless specified otherwise, OE forms cited in this book are EWS, for reasons explained in Fulk 2009b.

1. Here the practice is followed of capitalizing 'Late' and 'Early' in connection with West Saxon in acknowledgment that the later variety it is not precisely a lineal descendant of the earlier (so, e.g., Hogg 1992), for reasons explained succinctly in A. Campbell 1977: $§ 301$.

2. But final $g$ after any sound but a nasal is an analogical spelling, the actual value being [x], e.g. burg beside burh 'fortress'.

3. For an account of the various palatalizing environments, which are not uniform for all these sounds (and some of the details of which are in dispute), see Hogg 1992: $\$$ 7.15-43, with references.

4. Possibly $h l, h r, h n, h w$ represent voiceless sonorants, though etymologically they are clusters, and in poetry they alliterate with $h$ and with one another.

\subsection{Old Frisian}

At one time the Frisians dominated the North Sea coast from the area of Bruges to the border of present-day Denmark, though today their language is spoken in just three districts within that area, Friesland in the Netherlands, Saterland in Germany (south of Ostfriesland, Niedersachsen), and the districts of Nordfriesland and the (main) island of Heligoland (NHG Helgoland), also in Germany (on the west coast of SchleswigHolstein). The earliest Frisian preserved takes the form of some twenty brief runic inscriptions of the period ca. 500-ca. $800 \mathrm{CE}$, along with a few words in Latin texts. Aside from glosses in a fragmentary psalter of ca. 1200, and a few more recently discovered words from the $12^{\text {th }}$ cent. (see Langbroek 2015), the earliest manuscripts containing Old Frisian date to about 1300 , the latest to about 1600 , almost exclusively in the form of legal texts. Old Frisian thus is coeval with the middle or early modern periods of other WGmc. languages, though its inflectional morphology in particular has more in common with the older periods of those languages. It is a useful witness to the early history of West Germanic, though not generally as useful as OE, OS, and OHG. It is, accordingly, cited less frequently in this book than those languages, usually only when it provides information not afforded by those. A distinction may be drawn between two dialects, Old East Frisian and Old West Frisian, from regions separated by the Lauwers, but the difference is also chronological, the former being attested almost exclusively in manuscripts of the period ca. 1275-ca. 1475, the latter of the period ca. 1475-ca. 1600. 
Forms cited in this book derive from the former, unless marked otherwise. On the remains of Old North Frisian, see Steller 1928: 3.

Grammars of Old Frisian include van Helten 1890 (Old East Frisian), Steller 1928, and Bremmer 2009; Siebs 1901, Markey 1981, and Munske et al. 2001 cover the entire history of the language. For a dictionary of Old Frisian, see Köbler 2014a; the etymological dictionary of Boutkan \& Siebenga (2005), based on the first Rüstring manuscript of ca. 1300 (of which Boutkan 1996 is a grammar), is useful; there is also a concise dictionary: Holthausen 1985.

\subsection{Old Saxon}

The Continental Saxons occupied Saxonia (Old Saxony), an area of northwest Germany bounded roughly by the Elbe and the Ems to the east and west, more or less equivalent to the modern states of Lower Saxony, Westphalia, and Saxony-Anhalt, i.e. with a southern border extending approximately on a line from Merseburg west to Essen. The earliest texts are two ninth-century poems, Heliand and the fragmentary Genesis (ed. Behagel 1984); there are also some less substantial prose texts and glosses preserved (ed. Wadstein 1899), along with words in Latin charters. From ca. 1100 the language is called Middle Low German and is characterized by the reduction of unstressed vowels to [ə]. Distinct dialects cannot be established for OS, the way they can for OHG, and in fact the extant records show a remarkable mixture of forms and variant spellings, often within a single text, perhaps some of it due to dialect mixture (resulting from the recopying of texts by scribes of different habits and linguistic backgrounds) and to the influence of Old Frisian, Old English, and Old High German sources and scribes. The language of the two poems differs from that of the prose texts in certain respects, the most salient of which is that the dat. sg. pronominal/adjectival ending in masc. and neuter forms is commonly - $u$ ) m, -on, as in im 'him' and hèlagon 'holy', beside imu, hèlagumu, the latter being the usual forms in prose. Intervocalic $h$ is also much better preserved in the early verse texts. The relations between orthography and sounds are similar to those of OE, though there are no affricates in native words, and there is greater variability of spelling, especially of diphthongs and unstressed vowels. ${ }^{1}$ Unlike in OE, final stops are probably voiceless.

The most useful grammars and studies of Old Saxon are Gallée 1993, Holthausen 1921, Cordes 1973, Cathey 2000, and Schuhmann 2014. ${ }^{2}$ For a highly innovative learner's grammar, see Rauch 1992. For lexicons, see Tiefenbach 2010, Köbler 2014d, and Sehrt 1925 (the last solely for poetry). For bibliography, see Gallée 1993: 349-404. See further Cordes \& Möhn 1983.

1. Variability in the representation of unstressed vowels was explained by Twaddell (1963) as due to a mismatch between the five vowels of the Latin alphabet and a four-vowel inventory in OS unstressed syllables, /i, u, æ, å/. This analysis was subsequently refined, especially by Klein (1977).

2. Also to be noted is Donhauser et al. 2011, a database of Old Saxon, Old High German, and Old Low Franconian offering extensive morphological and syntactic annotation that can be searched to provide answers to many of the questions for which grammars are regularly consulted. 


\subsection{Old Low Franconian}

This is the ancestor of the Limburgic dialect of Dutch. The only witness to the language is a now-lost interlinear gloss on the Psalter, preserved fragmentarily and often unreliably in several transcripts made ca. 1600 , probably representing a southeastern dialect of the language, but with an admixture of Central Franconian forms. The Middle Dutch period begins ca. 1100. Because Old Low Franconian is preserved so fragmentarily and imperfectly, its evidential value for the development of West Germanic is severely limited.

For text and grammar, see Cowan 1957 and Kyes 1969; on Donhauser et al. 2011, see $\S 1.18$ n. 2. For dictionaries, see Kyes 1983, Schutz 2007-14, and Köbler 2014c the last two on line. Robinson 1992: 199-221 offers an informative overview. Donaldson 1983 covers the entire history of Dutch. See further Bremmer \& Quak 1992, Quak \& van der Horst 2002; also J. Smith 1976, van Bree 1977, Quak 1981, Mees 2002, de Vaan 2014.

\subsection{Old High German}

High German represents those varieties of German regularly affected to some degree by the High German Consonant Shift (\$6.21). OHG, roughly 750-1050, is generally divided into two dialect groups, Franconian (Fränkisch) or, less commonly, Central German (Mitteldeutsch, comprising East Franconian and West Central German, the latter includeing Rhine Franconian and Middle Franconian, the latter ill attested in the OHG period) and Upper German (Oberdeutsch, including Bavarian and Alemannic, the latter now comprising Swabian and High and Low Alemannic). It is only after the OHG period that East Franconian comes to be regarded as belonging to the Upper German group, at which point the term 'Franconian' is no longer synonymous with 'Central German'. It is also after the OHG period that the Thuringian and Upper Saxon areas of East Central German were colonized by Germanic speakers. The distinction between Central and Upper German is drawn on the basis of the extent to which they are affected by the High German Shift: Central German is bounded on the north by the Benrath line and on the south by the Speyer line (on which see $\S 6.21$ ), though it should be recognized that these lines are drawn on the basis of modern dialects and give only a rough impression of OHG dialect areas, East Franconian being particularly ill classified on this basis. In OHG times the dialects are represented by the usage in scriptoria of religious houses in the respective areas: Würzburg, Bamberg, and Fulda for East Franconian; Mainz, Lorsch, Speyer, and Frankfurt for Rhine Franconian, along with Weissenburg, which represents the South Rhine Franconian dialect; Trier, Echternach, Cologne, and Aachen for Middle Franconian; Regensburg, Freising, Tegernsee, Salzburg, Mondsee, and Passau for Bavarian; and St. Gall, Reichenau, and Murbach for Alemannic. ${ }^{1}$

Aside from a few terms, such as names in Latin texts and words in runic inscriptions, ${ }^{2}$ the earliest evidence for OHG dates to the second half of the eighth century and comprises chiefly glosses. The most important of the eighth-century texts are the Wessobrunn Prayer (ca. 770-90, Bavarian), the St. Gall Vocabulary (ca. 790, Alemannic), the Abrogans, a manuscript of glossae collectae beginning with Lat. abrogans : 
dheomodi 'humble' (ca. 790 in the St. Gall manuscript, with other manuscripts from the early ninth century, Bavarian), and the Isidor, a translation of Isidore of Seville's Tractatus de fide catholica contra Judaeos (ca. 790-800, somewhere west of Cologne, hence Middle Franconian). Important ninth-century texts include an interlinear translation of the Benedictine Rule (ca. 800, Alemannic), Muspilli, a fragmentary poem about the end of times (ca. 800, Bavarian), the Mon(d)see-Vienna Fragments of a homiliary (ca. 825, Bavarian), the Murbach Hymns (ca. 825, Reichenau, hence Alemannic), the anonymous translation of Tatian's harmony of the gospels (ca. 825, Fulda, hence East Franconian), and Otfrid's Evangelienbuch (ca. 863-71, South Rhine Franconian, but ca. 900 in the Freising manuscript, a Bavarian recension). Also important are the translations of Notker Labeo (Boethius, Aristotle, Psalms, ca. 1000: Alemannic). Isidor and Notker are particularly important for the study of OHG vocalism, since they indicate vowel length, the former by doubling, the latter with a circumflex. Length is indicated less regularly by doubling in the Benedictine Rule, and occasionally (mainly in stressed syllables) by doubling or diacritics in some other texts: see Gabriel 1969 for a thorough survey of the Upper German sources.

The most salient differentiating characteristic of OHG is its consonant system, altered by the High German Consonant Shift (\$6.21), which resulted in new affricates and a new geminate fricative $z z$, on the value of which see $\$ 6.21 \mathrm{n}$. 1. But it is also characterized by some unusual morphological characteristics, some of them innovative, such as the regularization of weak verb stems, some conservative, such as its retention of separate plural inflections for all three persons in verbs, the only WGmc. language to retain this feature.

The most useful resources on OHG phonology and morphology are Baesecke 1918, Schatz 1927, and Braune 2004a; on Donhauser et al. 2011, see $\$ 1.18$ n. 2. For grammars of individual dialects, see Franck 1971 (Franconian) and Schatz 1907 (Bavarian). A general introduction to $\mathrm{OHG}$ and $\mathrm{MHG}$ is Russ 1978; other histories of the language include Scherer 1995 [1868], Waterman 1976, Wells 1987, Polenz 2009, Sanders 2010, Salmons 2012. Dictionaries: Schützeichel 2006, Köbler 2014b. ${ }^{3}$ Two comprehensive dictionaries are in preparation: see Karg-Gasterstädt et al. 1968- and Lloyd et al. 1988-. Still useful is Graff 1840. For an assessment of the state of scholarship, see Davis 1999.

1. On OHG dialects, along with the grammars cited below, and the references given there, see Moriciniec 1984.

2. Worthy of mention in this regard is the inscription in runes on the Pforzen buckle ( $6^{\text {th }}$ cent.), representing a full line of $\mathrm{OHG}$ verse.

3. There is another on-line lexicon at http://awb.saw-leipzig.de/cgi/WBNetz/wbgui_py?sigle=AWB (last accessed 21 March 2018). 

PHONOLOGY 



\section{Prosodic Features and the Syllable}

\subsection{The Proto-Indo-European lexical accent}

A distinction is often drawn between languages with stress accent (or 'expiratory' or 'dynamic' accent in the older literature), as with English, German, and Russian, and those with pitch (or tone, or 'musical') accent, as with Lithuanian and Japanese. ${ }^{1}$ In the stress type, the primary features of the accented syllable are greater volume and duration, as well as higher pitch, though the relative importance of these properties varies from one stress language to another; and the lesser expiratory force expended on unaccented syllables tends to lead to weakening (i.e., centralization) or loss of the vowels in them. Unaccented syllables tend to be much better preserved in languages with pitch accent, such as ancient Greek and Vedic Sanskrit, wherein the primary feature of the accent is variation (not merely elevation) in pitch (i.e., the rate of vibration of the vocal cords), though stress may also be involved. It is generally agreed that the PIE accent was of the latter type at the end of the PIE period, though at an earlier time it must have been of the former type, as this is surely the origin of alternations between weak and full grades in ablaut (see §3.1).

A distinction with more significant consequences for Germanic linguistics regards the position of the accent: in many languages the place of the accent within the word is entirely predictable on the basis of a mechanical set of rules. This, for example, is the case in Welsh and Polish, where the accent in words of more than one syllable is on the penult, and in French, where it is on the ultima (if, in fact, any syllable in French receives greater stress), and in Latin, where the accent falls on the ultima if it is a heavy syllable, otherwise on the penult. Such an accent is said to be bound. In languages in which the position of the accent is not predictable, or not entirely predictable, such as English and Spanish, the accent is said to be free. It is apparent that the PIE accent was free, a situation best preserved in Vedic Sanskrit, which is thus often of fundamental value in determining the position of the accent in PIE for a given reflex. ${ }^{2}$

In Greek, Sanskrit, and Lithuanian, a bimoric vowel or a diphthong may bear the accent on either the first or the second mora. Thus, for example, the accent is on the first mora of $\omega$ in Gk. $\alpha \dot{\tau} \tau \hat{\omega} v$ 'themselves' (gen.) but on the second in $\dot{\varepsilon} \gamma \omega$ ' 'I'. It has very often been assumed that the same opposition between circumflex and acute accent must have obtained in PIE, but since it is now generally agreed that the chief source of the circumflex accent, the loss of laryngeal consonants (\$3.1), took place in the IE daughter languages rather than in PIE itself, this cannot have been the case. ${ }^{3}$

Across languages, words serving primarily grammatical functions, such as conjunctions and prepositions, tend to be unaccented. For prosodic purposes these are

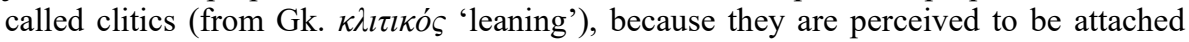
prosodically to a stressed word: they are proclitics if the stressed word follows, enclitics if it precedes. 
Some words, most notably some pronouns, occupy a middle tier, being sometimes accented and sometimes not. Doublets of this sort can have some important consequences in Germanic: see $\S 8.1$. Finite verbs, in particular, are shown by Gmc. alliterative meters to group with words of this middle tier (see Kuhn 1933). Finite verbs in fact do appear to have been accentually less prominent than nouns, adjectives, and non-finite verb forms, at least in independent clauses, in Proto-Indo-European. The evidence for this is of various kinds. In the manuscripts of Vedic Sanskrit, finite verbs in primary clauses are written without accent, as long as they do not begin a clause or a poetic line, and in Greek the accentuation of verbs resembles that of clitic strings rather than that of nouns (Fortson 2010: 109). In the older Germanic languages, particularly, verbs in primary clauses normally appear as the second element, and this is the same position occupied by unstressed sentence particles in some other IE languages (a phenomenon known as Wackernagel's law: see Wackernagel 1892, Collinge 1985: 217-19).

In general, the PIE accent in thematic formations (including some nouns, adjectives, and verbs) is static, appearing on the same syllable throughout the paradigm, though there are exceptions. In athematic formations the accent is usually dynamic, shifting its position within the paradigm. In general, the dynamic accent appears in a leftward position in the nom. acc. of nomina and the sg. of verbs, otherwise in a rightward position. See Clackson 2007: 79-88 for a succinct account of the attested patterns of variation, and see $\$ 7.4$ on the accentuation of nouns.

1. It has been pointed out that this terminology is inaccurate, and the distinction is better described as that between an accent distributed across an entire syllabic phoneme and one limited to a single mora of the phoneme: see Szemerényi 1996: §5.2, with references. The precise nature of the distinction is of no importance in the context of early Gmc. grammar. Languages with tone accent are not the same as tonal languages, such as Chinese and Yoruba, in which every syllable may have a discrete tone, whereas tone accent is usually confined to a single syllable in a word. It should be said that the identification of prosodic types is fraught with difficulties practical and terminological. For an informative discussion, see Hyman 2006. 'Stress' and 'pitch' must be understood as relative rather than absolute descriptors in regard to accent types.

2. The term 'free' should not be taken to imply that in a given word any syllable, chosen at random, might be accented. Rather, in every word there was a proper place for the accent, but the place was not predictable (or not entirely predictable) by rule, nor was it limited to any particular part of the word by general rule.

3. In Greek, circumflexion also arose due to loss of intervocalic $*_{s}$, $*_{y}(i)$, and $* w$, and by morphological processes.

\subsection{Lexical accent in Proto-Germanic}

In Proto-Germanic, the accent inherited from PIE was altered fundamentally, changing from a free pitch accent to a bound stress accent. ${ }^{1}$ From the evidence of Verner's law (§6.6) it may be deduced that the accent was still free after the First Sound Shift (§6.4), and most suppose that it had become a stress accent, on the assumption that this is likelier to explain the voicing that took place under Verner's law. ${ }^{2}$ Conversion to a bound accent must have taken place at a later time. On the dating of Verner's law, see $\$ 6.7$.

When the accent shifted in Proto-Germanic, in most lexical categories it came to rest on the initial syllable of the word, as in Italic and Celtic. It was the fixing of the stress accent on the initial syllable that began the extended process of the reduction and loss of inflectional syllables. ${ }^{3}$ The prefix $*_{3} a-*_{3} i$ - is never stressed, but other prefixes on nouns and adjectives were usually stressed, though there are isolated exceptions. For example, words bearing the privative prefix un- usually alliterate with words bearing 
vocalic initials in OE poetry, though exceptions are to be found. ${ }^{4}$ The chief exception to the rule of initial stress is that verb roots receive primary stress, leaving prefixes unstressed or with a lesser degree of stress. ${ }^{5}$ The chief evidence for root-stress in verbs is of two kinds: alliterative patterns in verse and vowel reductions in prefixes. The usual explanation for the different accentuation of verbs, first proposed by Loewe (1933; already in the $1^{\text {st }}$ ed., 1905: 1.33), is that at the time of the accent shift, prefixes were not yet univerbated with verbs but stood in front of them as proclitics, a property inherited from PIE. Evidence for this analysis may be derived from Gothic, in which other parts of speech may stand between such particles and the verb root, as in $3 \mathrm{sg}$. at-uh-pan-gaf 'and then delivered' (-uh- 'and', -pan- 'then') and us-nu-gibip 'render therefore' (-nu'therefore'). It is for this reason that verbs derived from prefixed nouns have initial stress rather than root stress, as with $\mathrm{OE}$ and-swarian 'answer' (verb; cf. and-swaru 'answer' (noun)).

In addition to primary, full stress, there is secondary stress on the second constituents of compound nouns and adjectives, as with Go. árma-hairts, OE éarm-hèort 'merciful'. ${ }^{6}$ Another kind of subordinate stress is found in quasi-compounds (including dithematic personal names), i.e. compounds not composed of two free morphemes, such as Go. and-wairps 'present'. As the meter of OE poetry demonstrates, these did not normally bear ictus (and thus, presumably, stress) on the second constituent except when another syllable followed, hence OE nórð-weard 'north' (adj.), but nom. pl. nórðwèrde. ${ }^{7}$ The difference in degree of stress on the second constituents of compounds and quasi-compounds is proved by the complete resistance of vowels and diphthongs under the former to be reduced, whereas vowel reductions often do apply to the latter, as with compounds that lose their transparency, e.g. OE fultum 'aid', early fulteam. This degree of stress on quasi-compounds is commonly referred to as tertiary stress. ${ }^{8}$ That there really is a degree of stress on the middle syllables of quasi-compounds is demonstrated by instances in which there is no vowel reduction, as in OE ān-fealdes 'simple' (gen. sg.) and wīs-dōmes 'of wisdom', since diphthongs and long vowels ought not to appear in fully unstressed syllables. Diphthongs and long vowels in the unstressed syllables of words like OE nord-weard and $\bar{a}$-feald are probably due to the influence of the inflected cases (see Fulk 2002: 82 n. 3). The nature of stress can hardly have been uniform across the Germanic languages, ${ }^{9}$ but the metrical similarities of the surviving alliterative poetry in North and West Germanic languages suggest a tiered system of stress relations like that in Old English, e.g. OIcel. pann er saklauss var 'him who was blameless' (Sólarljód 22, with non-ictic -lauss) beside vitlaussi mjok 'very foolish' (Helreið Brynhildar 5, with ictic-laus-).

1. For an overview of early Gmc. prosodics, see Bennett 1972.

2. But cf. Polomé 1994: 18. Alternatives to this analysis have occasionally been proposed. Boer (1916: 110; 1924: 123-4) argues that Proto-Germanic retained a pitch accent for a time after developing the stress accent, and that voicing occurred between the two accents, so that Verner's law may be dated later than the accent shift. (For references to some studies proposing similar ideas, see Boutkan 1995b: 105.) Prokosch (1939: §20a n.) objects that this leaves Verner's law effects in final position unaccounted for and ignores the natural connection between voicing and stress (as seen in, e.g., the distinction between Mod.Eng. exact, exert with /gz/ and exercise, execute with /ks/). Bennett (1972: 100-2) proposes that after the accent shift the PGmc. fricatives had fortis and lenis allophones, the former occurring initially and "medially or finally if the nearest preceding parent vowel or other syllabic had already borne primary accent" (101). This again links medial and final voicing to pitch accent rather than stress, and it fails to account for the problem with the standard analysis that motivates Bennett's search for an alternative, the unexpected initial voicing in PGmc. *za- $<$ PIE *kom-. David Fertig has kindly called attention to the dissertation of a former student of his in which it is found that preceding and following pitch may have an effect upon the perception of voicing in fricatives 
(Cornish 2007), thus calling into question the assumption that the Gmc. accent was a stress accent at the time that Verner's law applied.

3. Initial stress is necessary but not sufficient to explain the reduction of final syllables: e.g., E. Haugen (1969: 107) points out that Finnish, with an initial stress accent, does not reduce final syllables. In view of the preservation of long vowels in medial syllables in Gothic, Kotin (2012: 34) argues that stress in that language had not yet shifted entirely to the initial syllable.

4. For example, the prefix un- alliterates at more than 40 places in Beowulf, whereas the consonantal initial of the word to which it is attached alliterates three or four times (at lines 1756, 2000, 2863, probably 2921).

5. That verb prefixes were not entirely unstressed is best illustrated by Gothic prefixes like fair- and faur -, given that the vowels ai and aú do not occur in unstressed syllables of native Go. words. Yet variation in the spelling of the OHG equivalent (fur-, for-, fir-, fer-) can be attributed to low stress.

6. In various publications Anatoly Liberman has advocated the view that 'stress' is an epiphenomenon to the variety of vowels permitted in a given syllable (see, e.g., Liberman 1982: 24-6, 1994, perhaps most explicitly 2010: 382-4), an analysis with roots in the Prague Circle (Trubetskoy, Jakobson, and their adherents). One implication of such an analysis is that it is mistaken to refer to 'degrees of stress'. It may in fact be possible to reduce the four apparent degrees of stress in Old English to two (see Fulk 1992: 183-234), but certainly it simplifies the discussion of Germanic stress to have recourse to more than two levels of stress, even if 'stress' in such a discussion is to be understood as an abstraction, not necessarily referring to expiratory force (or other features of stress accent) but to other factors that may involve, e.g., morphology and metrical conventions.

7. For example, the meter demands that there be no ictus on -lēas in sēcean wynlēas wīc (Beowulf 821a) but that -lèas- bear ictus in pāra pe tìrlēases (843a). For a list of exceptional verses in Beowulf, see Fulk 1992: \$210. It should be noted than when the second constituent of a quasi-compound follows an unstressed syllable, it is receives ictus regardless of whether it is inflected, hence, e.g., OE énde-lèas 'endless'.

8. Some regard even uninflected quasi-compounds like OE furlang 'furlong' and hettend 'enemy' as bearing tertiary stress: see Hogg 1996, with references. This would explain how there can be a long vowel or a diphthong in the final syllable of an uninflected quasi-compound, though it renders the metrical treatment of such words difficult to explain. On the difficulty of drawing prosodic conclusions from metrical observations, see Minkova 1996. It should be plain that OE plays a central role in discussions of Gmc. stress. This is largely because of the size of the OE poetic corpus and the morphological conservatism of OE relative to ON. Relevant studies of (chiefly) OE stress include Moulton 1977, Suphi 1988, McCully \& Hogg 1990, McCully 1992, Colman 1994, Hogg 1996, Gąsiorowski 1997, Hutton 1998a, b, and Russom 2001.

9. For instance, it is generally believed that the restoration of syncopated vowels and the appearance of svarabhakti vowels in Old Saxon indicate a lower degree of primary stress than in the other Gmc. languages (see Suzuki 2004: 11-23, with references), and in Old High German, long vowels appear in syllables that are fully unstressed in cognates, e.g. -èn in habēn 'have' (OIcel. -a, Go. OE OS -an).

\subsection{Quantity in early Germanic}

The earliest Gmc. languages are to be regarded as mora-counting languages. ${ }^{1}$ High German aside, starting ca. 1200 there appear the earliest signs of conversion to isochronous languages, in which all stressed syllables are heavy, taking the form V.C or VC.C (where the point marks the syllable boundary), by lengthening of vowels in open syllables and shortening in closed. ${ }^{2}$ The term 'isochrony' thus refers to uniformity of syllable quantities. A number of Scandinavian languages remain isochronous to this day, including Icelandic, Faroese, and Standard Swedish and Norwegian. The earliest Gmc. languages, by contrast, had both light and heavy stressed syllables, as well as overlong ones, as in Go. bandwjan 'signify', brōprjus 'brothers', and OE wæstmb̄̄re 'fruitful'. Rather than standardizing syllable quantities, then, the earliest Gmc. counted morae and tended to preserve moric quantities. This explains early Gmc. instances of compensatory lengthening of vowels, as in *fayxana ${ }^{n}>{ }^{*} f \bar{a}^{n} x a n a^{n}>$ Go. fähan 'take' 
and *ib-hiez $>$ OE îfig 'ivy'. Another effect of mora-counting is the alternations governed by Sievers' law, whereby PIE $\underline{i}$ is nuclearized after a heavy sequence but not a light, producing oppositions like Go. nom. sg. harjis 'army' : hairdeis 'herdsman' ( 55.8 , and see Kleiner 1999b). Mora-counting is evident as well in a variety of early IE verse traditions, including Gmc., where a stressed light syllable plus another, regardless of the latter's weight, is metrically equivalent to a heavy syllable: see $\$ 2.4$ on resolution.

1. See, e.g., Liberman 1982: 57, idem 1990a, b. There is no consensual definition of a mora. It may be conceived as a unit of length, either vocalic or consonantal, equivalent to the duration of a short vowel. Moric count begins at the syllable peak and includes all segments in the syllable coda. The first syllable of Go. manags 'large' is monomoric (since $n$ belongs to the onset of the second syllable), of hardus 'hard' bimoric, of acc. hardjana trimoric, etc. (though not all would agree that the last is not divided har.djana: see \$2.5).

2. As a consequence of the High German Consonant Shift ( $\$ 6.21)$, some light syllables became heavy due to the conversion of stops to affricates, and some regard this development as part of the process of conversion to isochronous status.

\subsection{Syllable division in early Germanic}

Conclusions about how syllables were divided in early Gmc. are based on several factors, including scribal practice as regards the division of words at line ends, historical changes in vowel quantities, and the meters of alliterative verse.

Scribal practice in Go. manuscripts is remarkably consistent as regards how words are divided at line ends. In simplices, a word-medial consonant or consonant cluster is divided in such a way that just one consonant begins a new line: typical divisions are thus ha/bái, swis/tar, paúr/nuns, tal/zeinái, ans/tái. An exception to the rule is that a cluster of obstruent plus sonorant consonant usually is not divided: examples are fa/dreinam, win/tráu, af/tra. A cluster with a final glide, however, follows the more general rule, e.g. fulshn/ja, waúrst/wa (Vennemann 1987b: 170-83; Barrack 1998: 24 6). ${ }^{1}$ Division of simplices in $\mathrm{OE}$ manuscripts is similar to this, the usual practice again being not to divide an obstruent from a sonorant, with the exception of certain clusters (e.g. $t l, d l, b l, s r$ ) which do not occur word initially. ${ }^{2}$

The lengthening of vowels in open syllables that affected the Gmc. languages in the later Middle Ages provides only partial support for the manuscript evidence for syllabification. The plainest evidence comes from Icelandic and Faroese, where the change was exceptionally regular. Vowels remained short when followed by more than one consonant, the only exceptions occurring before clusters of voiceless stop plus $r$ : Mod. Icel. skopra 'roll', betri 'better', and akrar 'fields' all have long vowels. Before l, however, there is no lengthening, as in epli 'apple', katlar 'kettles', and miklan 'large' (acc. sg. masc.), all with a short vowel. Moreoever, there is no lengthening before fricative plus sonorant consonant, as in aðra 'other' (acc. sg. fem.), klifra 'climb', seðlar 'banknotes'. More striking is that a cluster of voiceless stop plus glide permits lengthening, as in sitja 'sit', vökva 'water' (verb), contradicting the pattern of word division in Gothic. ${ }^{3}$

Alliterative verse yields some evidence. In most meters a stressed light syllable may not bear the ictus alone, but it must be 'resolved' with another syllable to do so (Sievers 1893: §9.1). For example, OE fiftiges wìd is an acceptable verse, having a heavy initial syllable and thus four metrical positions, whereas theofones helm would not be an acceptable verse, having a light initial syllable that must be resolved with the following syllable, producing a verse of fewer than the requisite four positions. This is 
usually explained on the assumption of syllabification as heo.fo.nes. ${ }^{4}$ Yet in verse, despite the evidence of word division in manuscripts, clusters like $t r$ cannot be tautosyllabic: compare ond pæs betran forð, in which the first syllable of betran can only be heavy. ${ }^{5}$ Skaldic poetry presents some especially puzzling evidence. The results of Open Syllable Lengthening in Icelandic and Faroese plainly show that the first syllable of words like OIcel. betri was light, yet a certain formal requirement of skaldic verse known as Craigie's law demands a different conclusion. A monosyllable ending in a consonant is, by most accounts, necessarily a heavy syllable, since the final consonant must belong to the coda. ${ }^{6}$ Yet dróttkvætt meter treats a monosyllable like fjol in position 4 as if it were light, since a verse like Ragnarr ok fjol sagna is licit, whereas $\dagger$ Ragnarr ok fjolð sagna would not be (Gade 1995: 29-30). Likewise, an antevocalic long vowel cannot be a lift unless it is resolved with the following syllable: thus, for example, búa is metrically equivalent to gefa, implying that $b u^{\prime}$ - is a light syllable. This is especially puzzling because $\nmid b u a$, with a short root vowel, is an impossibility (see \$2.5). Moreover, internal rhymes (hendingar) in dróttkvætt are treated as if intervocalic consonants, and even consonant clusters, belonged to the syllable coda, for example ríoviggs lagar skídum; meldr i móður holdi; pá varð fastr við fóstra. ${ }^{7}$

The various sorts of evidence thus do not provide any definitive answer to the question how early Gmc. syllables were divided. It is nonetheless true that certain probabilities can be established on the basis of patterns of syllabification observable in natural languages. Consonant sounds can be ranked on a strength scale, indicating their relative sonority, and generalizations (syllable contact laws) then formulated about preferred and dispreferred syllabifications on the basis of the relative sonority of sounds in contact. ${ }^{8}$ Yet the syllabifications that are a crucial factor in certain sound changes are the very ones for which no such syllable preference law can be formulated with assurance: for example, neither si.tja- nor sit.ja- can be regarded as universally preferred, the former being the syllabification in Icelandic and Faroese, the latter being that required to account for WGmc. consonant gemination. Other sorts of evidence need to be adduced in such instances, as will become apparent in the discussion of Sievers' law ( 55.8 infra . In regard to Gothic syllable division, see further below on Prokosch’s law $(\$ 2.5)$.

1. For a critique of the use of word division to determine syllable division in Go., see Riad 2004. Further studies of Go. and early Gmc. syllable structure include Vennemann 1987b, Frey 1989, Salmons 1990, Murray 1991, Fullerton 1992, Pierce 2002, 2004, 2006.

2. See Lutz 1985, 1986 (interpreting Wetzel 1981); also Suzuki 1985, 1986, Barrack 1998: 26-7.

3. See Stefán Einarsson 1945: 3-6. For Faroese, see Lockwood 1955: 8-9. OE word division is indecisive in these respects: clusters like $f l, p r$ do not strongly favor division either before or after the first consonant (Lutz 1985: 234), and WGmc. consonant gemination eliminated most of the evidence regarding glides.

4. See $\S 2.5$ on Prokosch's law. To the contrary, Kuryłowicz (1949, supported by Liberman 1982: 46, 226; 1994: 238-40) argues that in early Gmc. not only a morpheme but a stressed syllable could not end in a short vowel, and this explains resolution and Prokosch's law. Naturally, this requires a rather different idea about syllabification.

5. To be sure, such evidence is not incontestable, since the prehistoric OE loss of $i$ in the reflex of *batizacannot be dated with any assurance (see $\S 5.6$ ), and even if it were sufficiently early, retention of the older, resolved value would be characteristic of linguistically conservative OE poetic tradition.

6. It is possible, however, that, from the standpoint of metrical phonology, the final consonant in a monosyllable is extrametrical. Such an explanation might be invoked to explain, for instance, why there is no breaking before $r$ in OE wer 'man', though there is in weor. ¿an 'become'. 
7. Liberman (2010: 406) remarks about such rhymes that "perhaps they correlated with the morphological type of Old Germanic, as Brink (2004: 87-93) suggested; perhaps they were inherited from the protolanguage."

8. See in particular Murray \& Vennemann 1983, Murray 1988, Vennemann 1988b, Barrack 1998.

\title{
2.5 Prokosch's law
}

The preference for a bimoric syllable rime (i.e., nucleus plus coda) in languages (like PGmc.) with stress accent has been given the name 'Prokosch's law'. One formulation of the law is thus the following:

\begin{abstract}
In stress accent languages an accented syllable is the more preferred, the closer its syllable weight is to two moras, and an unaccented syllable is the more preferred the closer its weight is to one mora. (The optimal stressed syllable is bimoric, the optimal unstressed syllable is unimoric.) ${ }^{1}$
\end{abstract}

As a consequence of the law, when PGmc. acquired a stress accent (\$2.2), monomoric stressed morphemes became dispreferred, and in a word ending in a stressed short vowel, lengthening of the vowel took place. Examples are OIcel. $p \dot{u}$, OE $p \bar{u}$, OS this, OHG $d \bar{u}$ 'you (sg.)' (cf. Gk. $\sigma \dot{v}$, Lith. tù), OIcel. sá, OE $s \bar{e}$ 'this, the' (cf. Go. $s a$ ), and Go. $n \bar{e}$ 'no', ON né 'not' (poetic), OE $n \bar{e}$ 'nor' (cf. Skt. $n a ́$ 'not'). Yet short vowels could remain (or re-develop) in unstressed forms, e.g. -tu in ON skaltu 'you (sg.) shall' and the preverbal particle Go. $n i, \mathrm{OE} n e$ 'not'. It is to be conceded, however, that doublets of such words with long and short vowels probably existed already in PIE (so, e.g., Sihler 1995: 38; see Johansson 1890: 125-6), and so lengthening is more securely attested in words that lost a final consonant in Gmc., e.g. PGmc. dat. sg. *mez $>\mathrm{OE} m \bar{e}$ 'me' (cf. Go. mis, OHG mir, and compare how loss of $-z$ does not cause lengthening in unstressed syllables), PGmc. *in > OIcel. $i$ 'in', PIE *suod $>$ PGmc. *swa, Go. swa 'so', but stressed $s w \bar{e}$ 'just as', OIcel. svá, OE swā 'so', ${ }^{2}$ and PGmc. ${ }^{*} s^{*}{ }^{w}(e)>$ OIcel. sá 'saw' (cf. Go. sah).

A further implication of Prokosch's law is that the initial syllable of a word such as Go. kuni 'race' or OIcel. fara 'go' is of a dispreferred type, and this has consequences for Germanic phonology, inasmuch as it may be said that the initial syllable in such words, in a sense, attracts to it the second syllable to form a "foot," a single prosodic unit. ${ }^{3}$ This is evident, for example, in the operation of high vowel deletion in the WGmc. languages, particularly OE (\$5.6), whereby a light syllable plus another of any weight (which may be called a 'resolved' sequence of syllables) is functionally equivalent to a heavy syllable, after which a final high vowel is lost, hence, e.g., *weorodu > weorod 'troop' and *hwatostu $>$ hwatost 'keenest', but faru 'journey' and (Mercian) héafudu 'heads'. Resolved and heavy syllables are also functionally equivalent in the operation of Sievers' law ( $\$ 5.8)$. The equivalence is observed as well in the meters of alliterative verse, in which a light syllable must be resolved with another syllable under primary stress to form a metrical position sufficient to bear ictus (see \$2.4).

Prokosch's law plainly operated in prehistoric OE, as shown by the evidence of Sievers' law (§5.8). Under the definition of Prokosch's law quoted above, it should be expected to have applied to all the early Gmc. languages, since they all had stress accent. That the law applied is not as plain in regard to Gothic: Riad (1992) regards the law as crucial to understanding Gothic syllabification, whereas Calabrese (1994) rejects this view. Pierce (2013) offers strong evidence in support of Riad's position. The usual 
assumption, however, has been that lengthening under Prokosch's law is limited to the NWGmc. languages and does not apply to Gothic: so, e.g., Kuryłowicz 1949, Pascual 2016: 290-1; cf. Goering 2016: 280-9, idem forthcoming.

1. Vennemann 1988b: 30 . The way that the principle is formulated by Prokosch (1939: $\S 50)$ is considerably less precise. But Prokosch also says that "after a long syllable, or after two syllables (which phonetically, or metrically, amounts to the same thing) $[i$ and $u]$ disappear sooner than after a short syllable. This law, which seems to express a general trend of Germanic towards accented syllables of two morae, is clearly preserved" $(\S 49 \mathrm{c})$.

2. Orthography does not prove a short vowel in Go. swa (or $s a, p u$, etc.), but stressed $s w \bar{e}$ can be the result only of lengthening of PGmc. *swa (cf. PIE *sūōd), and certainly the vowel is short in $n i$ (see below). It is thus to be assumed that this lengthening did take place in Gothic, as should be expected if the formulation of Prokosch's law quoted above is valid. (Otherwise Ringe \& Taylor 2014: 65.) For a different derivation of OE $s w \bar{a}$, see Hollifield 1985. The loss of unstressed $i$ in Go. $i$-stems but preservation of $u$ in $u$-stems seems to point to variable loss, presumably conditioned by syllable weight, with later paradigm regularization, thus providing evidence of the same sort of results of the law evident in WGmc.: see Prokosch 1939: §49c.

3. This insight belongs originally to Kuryłowicz (1949). The idea of the 'Germanic foot' derives from Dresher \& Lahiri 1991, adding Sievers' law (§5.8) to the list of dependent phonological processes. For a critique and refinement of Dresher \& Lahiri's position, and of responses to it, see Barrack 1998: 164-6. For an introduction to metrical phonology, see Hogg \& McCully 1987. 


\section{The Vowels of Proto-Indo-European and Proto-Germanic}

\subsection{The vowels of Proto-Indo-European}

Vowel alternations in PIE are referred to as ablaut or vowel gradation, which may be qualitative or quantitative. The most fundamental alternation is the qualitative one between $e$ and $o$, which may be observed in forms like Gk. $\varphi \varepsilon ́ \rho \omega$ 'bear' < *bher- : $\varphi \rho \rho \alpha ́$ 'bearing' <*bhor-. The $e$-grade of a root like *bher- is to be regarded as the unmarked form or the dictionary form; sometimes the appearance of the $o$-grade alternant may appear to be related to the placement of the accent on a different syllable, as in the example given, though often no straightforward explanation is apparent, and doubt has been cast on the role of accent in this regard (see Szemerényi 1996: §6.3). As regards quantitative ablaut, $e$-grade and $o$-grade are both varieties of the full grade. In zerograde the vowel disappears altogether, as with *-bhr- in Gk. $\dot{\varepsilon} \kappa \phi \rho \varepsilon \dot{\varepsilon} \omega$ 'bring out'. When zero-grade causes a sonorant consonant $(l, r, n, m, i, u)$ to appear between obstruents, or next to an obstruent at the beginning or end of a word, the sonorant must be syllabic ( $l$, $r, n, m, i, u$, respectively), as in Old Irish breth 'bearing' $<* b h r t-$ The difference between the nonsyllabic sonorant in *bhr-and the syllabic one in *bhrt- is thus purely phonotactic, and for this reason both are commonly referred to as examples of zerograde. In certain instances, however, it is useful to have terminology to distinguish the two, and then the latter may be called the reduced grade; together, the zero and reduced grade are sometimes called the weak grade, as they are in this book. ${ }^{1}$ Another quantitative alternation produces the lengthened grade, as in Gk. $\varphi \omega ́ \rho<* b h \bar{o} r$ 'thief', which may have either $e$ - or $o$-quality (or $a$-quality, as explained below). Lengthened grade is frequently explicable on a phonological basis as compensatory lengthening, as in this instance, where the root vowel has been lengthened upon loss of final $*_{-s}$ (see $\S 1.6 \mathrm{n}$. 1). Frequently, however, the origin is obscure, as in Lat. sēdès 'seat' (cf. OS sittian 'sit' $<$ PGmc. *sit-j-ana ${ }^{n}<$ PIE *sed-).

Only in a circumscribed number of words does it appear necessary to reconstruct a PIE root vowel $a$ rather than $e$ or $o$. An example is *nas-, as in Skt. nás 'nose', OIcel. nes 'headland' < *nasja-, with a long ablaut alternant *nās- in Lat. nāris 'nostril' and OE nōse 'promontory'. For evidence that $i$ could be a phonemic vowel and not solely an allophone of $i$, , see Mayrhofer in Kuryłowicz et al. 1986-2015: I, 160-1, 168.

In older reconstructions of PIE there is posited a vowel $\partial$, called schwa (or schwa primum), reflected, where preserved, as $i$ in Indo-Iranian and as $a$ everywhere else (though it develops further to $o$ in Slavic; about Greek see below). ${ }^{2}$ The standard view now instead is that this represents a syllabic consonant referred to as a laryngeal consonant (though there is no consensus about its actual phonetic value), which may be represented as $H$, indicating, abstractly, any syllabic laryngeal consonant. ${ }^{3}$ The grounds for regarding $\partial$ as a consonant were at first structural. For example, Saussure (1879) 
observed that whereas a combination of vowel plus sonorant consonant in the full grade becomes a syllabic sonorant in weak grade (e.g. $o$-grade *pondh- in Gk. perf. $\pi \dot{\varepsilon} \pi o v \theta \alpha$ 'I have suffered' : weak-grade *-pndh-in aorist $\tilde{\varepsilon} \pi \alpha \theta o v)$, a root with a long vowel where full grade should be expected produces $a$ in the weak grade (e.g. full-grade *-st $\bar{a}$ - in Gk.

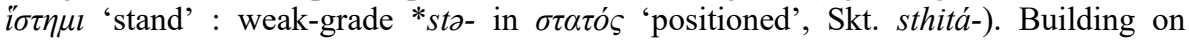
Saussure's discoveries, Möller (1911) observed that the vowel a thus behaves the way a consonant does, and the vowel $\bar{a}$ in ${ }^{*} s t \bar{a}$ - might thus better be analyzed as vowel plus $H$ (hence *staH-), a consonant to which he first applied the term 'laryngeal' (laryngal). It is particularly plain from Greek evidence that weak-grade $a$ corresponds to three different long vowels, $\bar{e}, \bar{a}$, and $\bar{o}$, in forms where a simple $e$-grade vowel should be expected to appear, as in the present indicative of verbs. If $H$ can explain the length in these vowels, it can also be employed to explain the three different vowel qualities or 'colorations' if it is assumed that $H$ actually represents three different consonants. The three are now commonly represented as $h_{l}$ (producing $e$-coloration), $h_{2}$ ( $a$-coloration) and $h_{3}$ (o-coloration), though $H$ may be retained to represent any of the three when the distinction is of no importance. ${ }^{4}$ In Greek alone does a laryngeal perhaps retain its colorizing quality when syllabified, so that the three laryngeals are reflected as $\alpha, \varepsilon$, and $o$, respectively, when they correspond to what used to be represented as $\partial .{ }^{5}$ Except when a laryngeal stood before a vowel, its loss resulted in the lengthening also of $i$ and $u$, though without producing any coloration, as in Skt. pivan- 'fat' <*piH-uon- and OE brū 'brow' <*bhruH-. Other syllabic sonorants might be lengthened, as well, as in Lat. (g)nātus 'born' < * ğñntós (cf. Go. kunds). When a laryngeal originally stood before a vowel, it might color the vowel, but its loss would not result in any lengthening of the vowel, as in *hes- $t i>$ Lat. est 'is', * $h_{2} e \hat{g}_{-}>$Lat. ago 'do', and * $h_{3} e k^{w_{-}}>$Gk. ó $\psi o \mu \alpha l$ 'I shall see'. Saussure's theory was dramatically confirmed by Kuryłowicz (1927) after Hittite was deciphered and discovered to preserve a consonantal reflex of $h_{2}$, and most likely of $h_{3}$, as well, as in * $h_{2}$ ent- in Hitt. hant-s 'forehead' (cf. Lat. ante 'in front') and * $h_{3}$ erbh- in Hitt. harapp- 'become separated' (cf. Lat. orbus 'orphan'; o becomes $a$ in Hittite). Regardless of the date at which Hittite branched off from the IE group (see $\S 1.2$ ), it is now generally assumed that the loss of laryngeal consonants was not a PIE phenomenon but took place independently in the daughter languages. Thus, technically, many long vowels formerly reconstructed for PIE must be assumed to have arisen in the post-PIE period, and long syllabic sonorant consonants should not be reconstructed for the protolanguage. No very consistent treatment has been adopted in the present book: long vowels of laryngeal origin and long syllabic resonants are frequently treated as if they arose in PIE, in the conviction that the older notation is not infrequently less opaque, and readers will recognize shorthand reconstructions for what they are. Long syllabic sonorants, for example, are included in the inventory of PIE vowels below.

In weak grade it should be expected that the vowel would disappear entirely between two obstruents, and this is very commonly the case, as with weak grade $*_{-} p t->$ in Lat. neptis 'granddaughter, niece' (cf. lengthened grade *-pōt- in Lat. acc. sg. nepōtem 'grandson, nephew'). However, in many environments in which zero grade between two obstruents should be expected, instead a vowel appears, as in past participles, e.g. Gk. $\pi \varepsilon \pi \tau o ́ \varsigma$, Lat. coctus 'cooked' from expected *pkw-tos (cf. full grade in Gk. $\pi \varepsilon ́ \tau \tau \omega$, Lat. coqū 'cook'). The unexpected vowel appears most commonly, but not consistently, in a morphological environment in which syllabicity can be explained as due to analogy: ${ }^{6}$ in the given example, since reduced rather than zero grade is the norm in past participles (technically, verbal adjectives) of verb roots containing a sonorant consonant (as with 


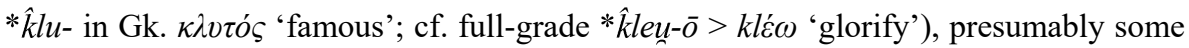
variety of reduced vocalism was introduced analogically into the root of forms like ${ }^{*} p k^{w}$-tos. This reduced vowel is referred to as schwa secundum and is usually represented by a subscript $e$, or sometimes by $b$, hence ${ }^{*} p_{e} k^{w}$-tos or ${ }^{*} p b k^{w}$-tos. The value of this sound is often thought to have been, at least originally, [ə], but these alternative representations of it came into use because at the time it was first posited, the graph $\langle\partial\rangle$ was already in use to represent a syllabic laryngeal. The alternative representations are actually preferable for their abstractness, since it cannot be known whether the vowel, when introduced analogically, was not sometimes a full grade vowel from the start, or whether the analogical formations arose in PIE itself. It should be noted that quite a few scholars reject the idea of schwa secundum, e.g. Szemerényi (1996: §4.1.11). ${ }^{7}$

On the analysis presented here, originally there were no diphthongs in PIE, but once quantitative ablaut lost its phonological conditioning, except before a vowel, $i$ and $u$ would have combined with a preceding vowel to form diphthongs, hence $a i, e i$, oi, $a u$, $e u$, ou. Long diphthongs also occurred rarely due to lengthening or contraction, and later by the loss of laryngeals. Again, long and short diphthongs are included in the inventory of PIE vocoids below to facilitate comparison among the daughter languages. from PIE:

The following vocoids may thus be assumed to have been inherited by Germanic

$$
\begin{aligned}
& a, e, o, i, u, h_{1}, h_{2}, h_{0}, e \\
& \bar{a}, \bar{e}, \bar{o}, \bar{l}, \bar{u} \\
& n, m, r, l \\
& \bar{n}, \bar{m}, \bar{r}, \bar{l} \\
& \text { ai, ei, oi, au, eu, ou } \\
& \bar{a} i, \bar{e} i, \bar{o} i, \bar{a} u, \bar{e} u, \bar{o} u
\end{aligned}
$$

1. To call the syllabic and nonsyllabic sonorants both examples of zero grade is to treat the two sets as in allophonic variation with each other, which originally they were. When ablaut ceased to be phonologically conditioned, however, the distinction became phonemic.

2. On whether ə (i.e., $H_{0}$ ) ever produces $u$ in Germanic, see $\$ 5.5$ ad fin.

3. For an enlightening account of laryngeal consonants, their traces in the IE languages, and various theoretical approaches to them, see Lindeman 1987.

4. The precise number of laryngeals posited for PIE varies, but the majority of scholars work with three.

5. It is perhaps likelier, though, that a syllabic laryngeal always develops to $\alpha$ in Greek, and the three short vowels are instead due to the analogical influence of the corresponding long vowels: so, e.g., Szemerényi 1996: §4.1.11. See Lindeman 1987: §§86-7 for discussion and references, and cf. Sihler 1995: 99-100.

6. In a form like * $k^{w} t u r-$ 'four' (as in Gk. $\tau \rho \dot{\alpha} \pi \varepsilon \zeta \alpha$ '(four-footed) table'), the alternant * $k^{w}$ etuor- (as in Lat. quattuor 'four') perhaps arose in constructions in which the word followed a word-final consonant, creating an even more awkward consonant cluster. Hence, the assumption that schwa secundum had the value [ə] is not unreasonable.

7. One might prefer to think of $e_{e}$ as pure abstraction, representing processes of analogical restoration of vocalism in the IE branches, if not in the protolanguage itself. But since, for example, verbal adjectives like ${ }^{*} p k^{w}$-tós, without the schwa, are never attested as simplices (one might have expected the initial consonant cluster to have been simplified in that case), it really is necessary to assume some sort of vocoid in such forms in the protolanguage. That is all $e$ need be taken to represent, though differences among the daughter languages as to its reflex do raise the possibility of a sound distinct from any other in PIE. 


\subsection{The short vowels in early Germanic}

In the stressed syllables of Proto-Germanic there occurred the unconditioned change of $o$ to $a$, and of $H$ to $a$. The short syllabic sonorant consonants of PIE, $n, m, r, l$, , developed to PGmc. un, um, ur, ul, respectively. The fate of schwa secundum varies by environment: between obstruents (and, usually, between a resonant and an obstruent) it appears as a full-grade vowel $e$, whereas in front of an antevocalic resonant it develops to $u$, just as syllabic resonants develop to $u$ plus resonant. On the standard view, the remaining short vowels retain their PIE values in Proto-Germanic except as the result of certain conditioned changes explained in $\S \S 4.1-4$. Examples of the short vowels:

PIE $a$, Gmc. $a$ : PIE *sal- 'salt' > Gk. $\dot{\alpha} \lambda \varsigma$, Lat. sal, Go. OIcel. OS salt, OHG salz; PIE *kan- 'sing' > Lat. canō, Welsh canu 'sing', Go. OE OFris. hana, OHG OS

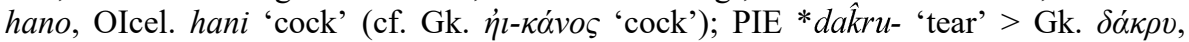
Welsh deigr, Go. tagr, OHG zahar.

PIE $e$, Gmc. e: PIE *kkel- 'conceal' > Lat. celō, OIr. celid, OE OS OHG helan; $\mathrm{PIE} *$ medhu- > Gk. $\mu \dot{\varepsilon} \theta v$ 'wine', Lith. medùs 'honey', OE medu, OFris. mede, OHG

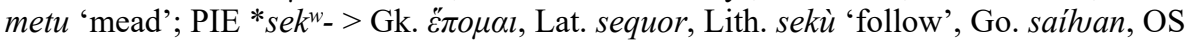
OHG sehan 'see'.

PIE $o>$ Gmc. $a:{ }^{1}$ PIE *uogh $->$ Gk. $\delta \chi \varepsilon ́ \omega$ 'lead, guide', OCS voziti 'drive, guide, lead', Go. ga-wagjan 'move, shake', also OE OS wagian, OHG wagōn 'move'; PIE

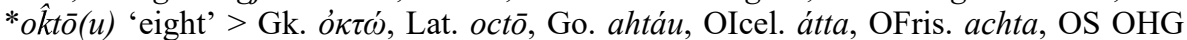
ahto; PIE *bholgh- > OIr. bolg 'bag', OPruss. balsinis 'pillow', Go. balgs 'leather bag', OHG balg 'bag'.

PIE $i$, Gmc. $i$ : PIE *pisk- 'fish' > Lat. piscis, Go. fisks, OIcel. fiskr, OE OHG

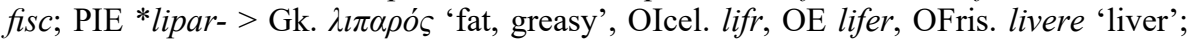
PIE * $\left(h_{3}\right) m i g h->$ Gk. ó $\mu i \gamma \lambda \eta$ 'cloud', Lith. miglà 'fog', OIcel. mistr, OE mist 'mist' (Gmc. *mix-st-).

PIE $u$, Gmc. $u$ : PIE *dhubh- > Gk. $\tau \dot{\phi} \phi \omega$ 'give off smoke', OIr. dub 'black', OIcel. dupt 'powder', OHG tuft 'fog'; PIE *dhur-> Skt. (acc. pl.) duráh, Homeric Gk.

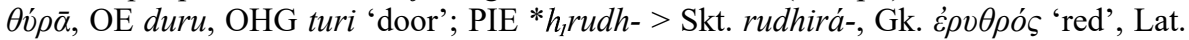
rubor 'redness, blush', OE rudu 'redness, ruddy complexion'.

PIE $h_{1}>$ Gmc. $a$ : PIE full-grade *bheh ${ }_{1^{-}}>* b h \bar{e}$ - in OHG bāen, bājan 'warm with covers, bake bread', reduced-grade * $b h h_{1}$ - in OIcel. bað 'steam bath' OS bath, OHG

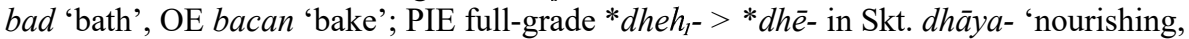

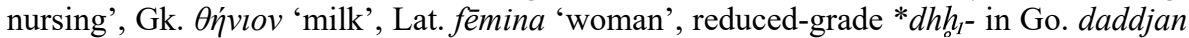
$(<*$ dajjan $)$ 'suckle'; PIE full-grade * ghleh $_{1^{-}}>{ }^{*}$ ghle- in OIcel. glámr 'moon', glær 'bright', reduced-grade * $\hat{\text { gh }} l_{h_{1}}$ - in OIcel. glan 'radiance'.

PIE $h_{2}>$ Gmc. a: PIE full-grade ${ }^{*} s t e h_{2^{-}}>*^{*}$ stā- in Lat. stāre, OS OHG stān

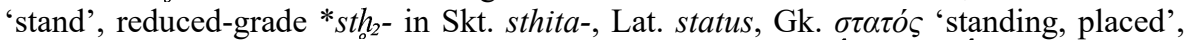
Go. staps, OIcel. staðr, OHG stat 'place'; PIE full-grade $* \hat{k} e h_{2} d->\hat{k} \bar{a} d$ - in Avestan $s \bar{a} d r a-$ 'affliction', Gk. $\kappa \hat{\eta} \delta o \varsigma$ 'sorrow', reduced-grade $\hat{k} h_{2} d$ - in Go. hatis, OIcel. hatr, OHG haz 'hate'; PIE full-grade *deh $h_{2}$ - > $*$ dāp- in Skt. dāpayati 'divides', reducedgrade * $d h_{2} p$ - in Gk. $\delta \alpha \pi \alpha v \alpha \dot{\omega} \omega$ 'consume', OIcel. tafn (*dap-no-) 'sacrificial animal, sacrificial meal'.

PIE $h_{3}>$ Gmc. a: PIE full-grade $* d h h_{3^{-}}>* d h \bar{o}$ - in Skt. dhấr $\bar{a}$ 'cutting edge, sharpness, blade', reduced-grade $* d h h_{3^{-}}$in Gk. $\theta 0 o$ c $\left(<* d h h_{3}\right.$-uos), OE daroð 'spear', daru 'injury'; PIE full-grade *ghreh $3^{-}>$*ghrō- in OIcel. gróa, OE grōwan 'grow', reduced-grade $\mathrm{ghrh}_{\mathrm{o}}$ - in Go. OIcel. OS OHG gras 'grass'; PIE full-grade * $\mathrm{Heh}_{3} g->* \bar{o} g$ - 
in Lith. úoga 'berry', reduced-grade ${ }^{*} \mathrm{Hh}_{3} g$ - in Go. akran, OIcel. akarn, MHG ackeran 'fruit, acorn'.

PIE $_{e}$ (schwa secundum) gives Gmc. $u$ before $r, l, n$, or $m$ (which must be antevocalic, as otherwise there would be no schwa secundum, but $r, l, m, n)$, otherwise a full-grade vowel, usually $e$ : PIE * $g^{w}{ }_{e} m-o->\mathrm{OE}$ cuman 'come' (cf. full grade in Skt. gámati 'goes', zero grade after a vowel in Avestan frā-ymat 'comes forth'); PIE * $\hat{k}_{e} l->$ Gk. $\kappa \alpha \lambda i \dot{\alpha}$ 'cottage', Go. hulundi 'cave' ( $\hat{k}_{e} l-n t \bar{\imath}$; cf. OE OS OHG helan 'conceal', with full grade); PIE ${ }^{*} s_{e} d->$ Skt. sattá-, Lat. sessus, OIcel. setinn, OE seten, OS gi-setan, OHG gi-sezzan 'having sat'; possibly PIE $* l_{e} g h->$ OIcel. leginn, OE legen 'lain' (cf.

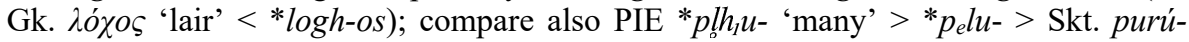

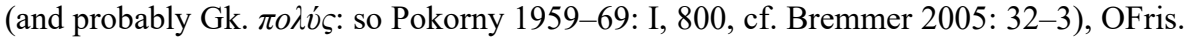
fule, fula.

PIE $n>$ PGmc. un: PIE *bhndh- in Skt. baddháh 'bound' (full grade in bándhuh 'relation'), Go. bundans 'bound'; PIE * $h_{1} d n t$ - in Skt. gen. sg. datá-h, Lat. gs. dent-is 'tooth', Go. nom. sg. *tunpus 'tooth'; PIE *n- privative prefix in Skt. $a$-, Gk. $\dot{\alpha}$-, Lat. in$<$ en-, PGmc. *un-; PIE *knk- in Skt. kákatē 'thirsts', ON hungr 'hunger'.

PIE $m>$ PGmc. um: PIE * $g^{w} m-t-i s$ - in Skt. gáti- $h$ 'movement', Go. ga-qumps 'assembly'; PIE $h_{2} m b h i(-)$ in Skt. abhi-tah 'to both sides', OHG OS umbi, OIcel. umb,

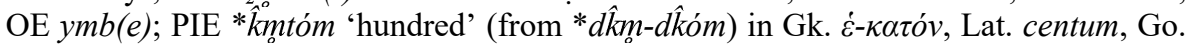
OE hund.

PIE $r$ > PGmc. ur: PIE * bhrgh- in Czech brh 'cave', OE pret. pl. burgon 'save';

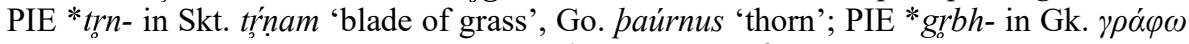
'write', OE cyrf 'slice' < *kurb-iz; PIE *trs- in Skt. tŕsyati 'thirsts', OE purst, OHG durst 'thirst'.

PIE $l>$ PGmc. ul: PIE *mld- in Skt. mrdnāti 'crushes', Lat. mollis 'soft, weak', OE pret. pl. multon 'melt'; PIE *ull $k^{w}-$ 'wolf' in Skt. vŕkah, Lat. lupus, Go. wulfs; PIE *klt- 'incline' in Lat. aus-cultō 'hear attentively' (<*'incline the ear'), Go. hulps, OIcel. hollr, OHG OS OE hold 'gracious, loyal'.

1. This change had not yet taken place when words from Celtic were borrowed into Gmc. on the Continent, e.g. Volcae $>$ OE Wealh-, OHG Walha (ethnic name). In loans from Latin, however, o remains, as in OE scolu 'host' < Lat. schola. See Hirt 1931-4: I, §29.

\subsection{The long vowels in early Germanic}

In the stressed syllables of Proto-Germanic there occurred the unconditioned change of PIE $\bar{a}$ to $\bar{o}$. Otherwise, the long vowels reconstructed for PGmc. (including the long vowels that developed from short vowels plus laryngeal consonants, §3.1) are the same as those reconstructed for PIE, though with some qualitative alterations noted below. The long syllabic sonorant consonants, lengthened chiefly by the loss of laryngeal consonants in the daughter languages (i.e., sonorant plus $H$, producing a long sonorant), developed in Gmc. the same way as the short, perhaps simply by loss of the laryngeal without compensatory lengthening. Examples of the long vowels:

PIE $\bar{a}>$ Gmc. $\bar{o}$ : PIE *bhāgós 'beech' > Lat. fāgus, Gk. $\varphi \eta \gamma o ́ \varsigma$ (Doric $\varphi \bar{\alpha} \gamma o ́ s$ ),

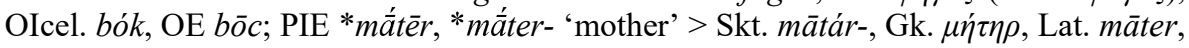

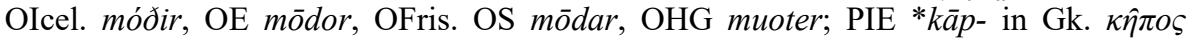

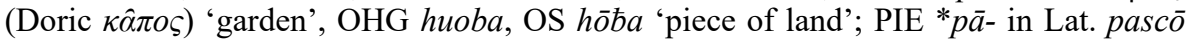
'feed' (cf. Oscan paastores), OIr. ás 'growth', Go.fōdjan, 'feed', OIcel. fóðr, OE fōðor, fōd(d) or, OHG fuotar 'food, fodder'. 
PIE $\bar{e}$, PGmc. $\bar{e}$ (i.e., $\bar{e}_{l}$, which yields NWGmc. $\bar{x}$ or $\left.\bar{a}(\S 4.6)\right):{ }^{1}$ PIE *bhle- in Gk. $\varphi \lambda \dot{v} v \alpha \varphi o \varsigma$ 'idle talk', Go. uf-blēsan 'puff up', OIcel. blása, OHG blāsan 'blow'; PIE *dhe- in Gk. és- $\theta \eta \kappa \alpha$ 'I placed', Lat. fēcì 'I did', Go. ga-dēps, OIcel. dáð, OHG tāt 'deed'; PIE * $g h \bar{e}$ - in Homeric Gk. $\kappa l-\chi \dot{\eta} \mu \varepsilon v \alpha \imath$ (inf.) 'come to', Lat. hèrēs 'heir', OE OS OHG gān, Crimean Go. geen 'go'; PIE *mē- in Gk. $\mu \hat{\eta} \tau \iota \varsigma$ 'discernment', Lat. mētior 'measure', Go. mēl, OIcel. mál, OHG māl 'time'.

PIE ō, Gmc. ō: PIE *bhlō- in Lat. flōreō 'bloom', OE blōwan, OS blōjan, OHG bluojen, bluowen 'bloom'; PIE *dūo(-) ‘two' in Skt. dvà, Homeric Gk. $\delta v ́ \omega$, Go. twōs (fem.); PIE *dhō- 'put' in Gk. $\theta \omega \mu$ ó $\varsigma$ 'heap', Lat. ab-dōmen 'abdomen' (*'part put in hiding'), Go. dōms 'discernment', OIcel. dómr, OE OFris. OS dōm, OHG tuom 'judg-

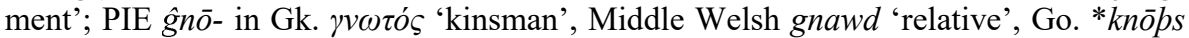
(dat. knōdái) 'tribe, extraction', OHG knōt, knuot 'extraction', OE cnōsl 'family, kin'.

PIE $\bar{\imath}$, Gmc. $\bar{l}$ : PIE * $d \bar{\imath}-t$ - in Armenian $t i$ 'age', OIcel. tíð, OE OS $t \bar{\imath} d$, OHG $z \bar{\imath} t$ 'time'; PIE *līg- in Lith. lýg, lýgus 'like', Go. ga-leiks, OIcel. (g)likkr, OE ge-līc, OS gilīk, OHG gi-līh 'like'; PIE *stī- in Lith. styrstù, stỹrti 'stiffen', Icelandic stírur 'stiffness in the eyes upon waking', East Fris. stīr 'stiff', NHG stier 'fixed'; PIE *sūi- in Gk. $\sigma \bar{l} \gamma \dot{\eta}$ 'silence', OE swìgian, OHG swīgēn 'be silent'.

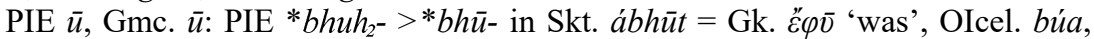
OE būan 'reside' (but cf. \$3.4 n. 5); PIE *bhrū- 'brow' in Skt. bhrūh, Gr. ó $\varphi \rho \hat{v} \varsigma$, OIcel. brún, OE brū; PIE *bhrūg- in Lat. frūctus 'enjoyment', Go. brūkjan, OE brūcan, OS brūkan, OHG brūhhan 'enjoy'; PIE *ghrū- in Lith. grúdau, grúdžiu 'pound, crush (grain)', OE grūt 'groats', MHG grūz 'grit, cereal grains'; PIE * $m \bar{u} s$ 'mouse' > Skt. $m \bar{u} s \underline{-}-$, Gk. $\mu \hat{v} \varsigma$, Lat. $m \bar{u} s$, OIcel. mús, OE OS OHG mūs.

PIE $\bar{n}$ (yielding Skt. $\bar{a}$, Gk. $v \bar{\alpha}$ Lat. $n \bar{a})>$ PGmc. un: PIE * gnnh $h_{3}-t o ́-s>* \hat{g} \bar{n} t o ́ s$ 'known' in Lith. pa-žìntas, Go. kunps, OHG kund, OE cūp; PIE * $\hat{g} n h_{2}-t o ́-s>* \hat{g} \bar{n} t o ́ s$ in Skt. jātáh, Lat. nātus < gnātus 'born', OE heofon-cund 'celestial', OIcel. ás-kunnr 'related to the gods'.

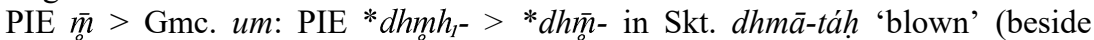
dhami-táh $<* d h_{e} m h_{1}$-tós), OIcel. dý 'quagmire' < PGmc. *dumxjan < PIE *dhmh kion, $^{*}$ likewise in NHG dumpf 'dull'; also, to PIE *gleh bh- * $g l h_{1} b h$ - in Lith. glébiu, glëbti 'embrace' beside glabóti 'preserve', cf. nasalized *glmh ${ }_{1} b h->*^{*} g l \bar{n} b h$ - in OE pret. pl. clumbon 'climb'.

PIE $\bar{r}$ (yielding Skt. $\bar{\imath} r$ or $\bar{u} r$, Gk. $\rho \omega$, Lat. $r \bar{a})>$ PGmc. $u r:$ PIE * ${ }^{\prime} r h_{1} n->* \hat{g} \bar{r} n-$ in Skt. jūrṇa-ḥ, jīrna-ḥ 'brittle', Lat. grānum, Go. kaúrn, OIcel. OHG korn 'grain' (PGmc. *kurna ${ }^{n}$ ).

PIE $\bar{l}$ (yielding Skt. $\bar{r} r$ or $\bar{u} r$, Gk. $\lambda \omega$, Lat. lā) $>$ Gmc. $u l$ : PIE *h $h_{2} u l h_{2}-n-e h_{2}>$

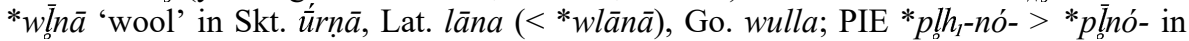
Skt. pūrṇa-, Lat. plēnus, OIr. lán, Lith. pilnas, Go. fulls $(<* f u l n-)$ 'full'; PIE *dl̆h ghó$>* d \bar{l} g h o ́-$ in Skt. dīrghá- 'long', Go. tulgus 'fast, firm' (<*'long, lasting'), OS tulgo 'very', OE tulge 'firmly'; PIE *mlo ${ }_{3} d h->* m \bar{l} d h$ - in Skt. mūrdhán- 'head', Gk. $\beta \lambda \omega \theta \rho o ́ \varsigma$ 'high-growing (of trees)' $(<* \mu \lambda \omega \theta \rho o ́ \varsigma), \mathrm{OE}$ molda 'top of the head' $(<*$ muldō).

On the basis of early borrowings from Latin it can be determined that PGmc. $\bar{e}$ and $\bar{o}$ were open vowels, i.e. / $\varepsilon: /$ and /o:/ (if not /æ:/ and /p:/), not /e:/ and /o:/, e.g. OE clīroc 'cleric' (Lat. clēricus) and Go. Rūmōneis 'Romans' (Lat. Rōmāni), showing that Latin mid vowels were borrowed as high vowels. The latter form also shows that Lat. $\bar{a}$ was borrowed as $\bar{o}$ (and cf. OHG Tuonouwa 'Danube', from Celtic *Dānovios), or that PIE $\bar{a}$ had not yet developed to PGmc. $\bar{o}$ at the time of borrowing. ${ }^{2}$ Presumably, then, after the latter change Latin $\bar{a}$ could be borrowed as an unrounded vowel, as in OE $n \bar{x} p$ 


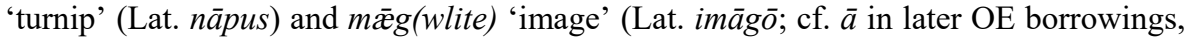
e.g. $p \bar{a} l$ 'pole', from Lat. pālus). ${ }^{3}$ The rise of $\bar{e}_{2}$ (/e:/, §3.5) thus filled a gap in the PGmc. vowel inventory, though it also produced an asymmetry, with no corresponding back vowel /o:/.

1. This vowel is sometimes reconstructed as PGmc. $\bar{x}$ (though for some this is merely a notational convention, and it is assumed to represent the PIE sound unchanged, e.g. Wright 1954: §43), although this requires that it revert to $\bar{e}$ in Gothic, where in fact it appears to have been a close rather than an open sound (see Braune 2004b: $\S 6 \&$ Anm. 1). It may nonetheless have been an open $\bar{e}$ in PGmc., i.e. [ع:]: see Bremer 1886: 5-6. It is commonly represented as $\bar{e}_{1}$, to distinguish it from the vowel discussed in $\S 3.5\left(\bar{e}_{2}\right)$.

2. The latter is the view of Polomé (1987b: 200, idem 1994: 6-7), who would thus date the change of $\bar{a}$ to $\bar{o}$ after Germanic peoples reached the upper Danube in the second century BCE. Silva Bācenis in Caesar may also be relevant.

3. See Kluge 1913: §§14-16, Antonsen 1975: 3-4.

\subsection{The diphthongs in early Germanic}

Out of PIE combinations of tautosyllabic vowel plus glide ( $i$ or $u)$ there developed diphthongs in the IE languages, including Germanic, and perhaps already in late PIE. Most of the changes affecting these diphthongs in PGmc. are paralleled by the regular changes in simple vowels, so that oi and ou become $a i$ and $a u$, respectively, as do $H i$ and $H u$ : compare the development of $o$ and $H$ to $a$ (\$3.2). In addition, PGmc. ei developed to $\bar{i}$, on which see $\S 4.4 \& \mathrm{n}$. 4 . With the possible exception of $\bar{e} i$ from PIE $\bar{e} i$, as well as $\bar{o} u$ from PIE $\bar{o} u$ (but not from $\bar{a} u$ ), the long diphthongs were shortened in ProtoGermanic and then underwent the same developments as the originally short diphthongs. Although undeniable examples are few, PGmc. $\bar{e} i$, on the other hand, is commonly assumed to have lost its off-glide, producing a sound conventionally represented as $\bar{e}_{2}$, on which see $\S 3.5$. If that is the case, in parallel fashion, PIE $\bar{o} u$ likewise developed to PGmc. $\bar{o}$ rather than $a u$, though this view is less widely credited. ${ }^{1}$ The development of PIE $\bar{o} \underline{i}$ in Gmc. stressed syllables cannot be determined conclusively, but system symmetry suggests that it should have become Gmc. ai. ${ }^{2}$ Examples:

PIE $a \underline{i}>>$ PGmc. $a i$ (giving OIcel. OHG ei, OS $\bar{e}, \mathrm{OE} \bar{a}, \mathrm{PDE} o$ ): $\mathrm{PIE} * h_{2} e i g h^{w_{-}}>$

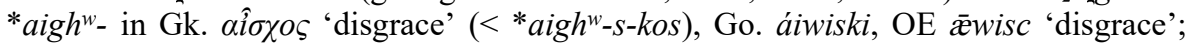
PIE * ghaido- in Lat. haedus 'kid, young goat', Go. gáits, OIcel. geit, OHG geiz, OS gēt, OE gāt 'goat'.

PIE au > PGmc. au (giving OE èa): PIE *saus- in Skt. śoṣa- (assimilated from soșa-) 'dessication', Homeric Gk. avoos 'dry', OE sēar > PDE sere; PIE *kaunos in Latvian kàuns 'disgrace', Go. háuns, OE hēan 'abject'; PIE * $\left(h_{2}\right)$ maurr- in Gk.

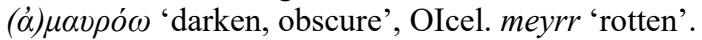

PIE $e \underline{i}>$ PGmc. $\bar{l}$ : PIE *steigh- in Gk. $\sigma \tau \varepsilon i x \omega$ 'walk, go', Go. steigan, OIcel.

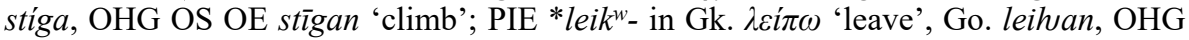
OS līhan 'lend'.

PIE $e u>$ PGmc. $e u$ (giving Go. iu, OIcel. jó, OHG OS io OE ēo), except before $i$ or $j$ in the next syllable (§4.4): PIE *bheudh- in Gk. $\pi \varepsilon \dot{\theta} \theta$ opal 'enquire', Skt. bódhati 'is awake, learns', Go. ana-biudan 'order', OIcel. bjóða, OHG biotan, OS biodan, OE beedan 'offer'; PIE * geuss- in Gk. $\gamma \varepsilon v$ ' $\omega$ 'give a taste of', Go. kiusan, OIcel. kjósa, OHG OS kiosan, OE cēosan 'choose'. 
PIE oi > PGmc. ai (giving OIcel. OHG ei, OS è, OE à): PIE *uoide 'knows'> Skt. véd $a$, Gk. oî̉ $\delta$, Go. wáit, OIcel. veit, $\mathrm{OHG}$ weiz, OS wēt, OE wāt; $\mathrm{PIE}$ * oinos 'one' $>$ Old Lat. oinos (> Lat. ünus), Go. áins, OIcel. einn, OHG ein, OS èn, OE àn.

PIE ou (giving Lat. $\bar{u}$ ) > PGmc. au (giving OHG OS $\bar{o}, \mathrm{OE} \bar{e} a$ ): PIE * hroudhos 'red' > Lat. rūfus, Go. ráups, OIcel. rauðr, OHG rōt, OS rōd, OE rēad; PIE *roup- in Skt. rōpayati 'produces pain, breaks off', Lith. pl. raupaĩ 'measles, pockmarks', Serbian rüpa 'hole', OIcel. rauf 'hole'.

PIE $H_{o} \underline{i}>>$ PGmc. ai (giving OIcel. OHG ei, OS $\bar{e}$, OE $\bar{a}$, PDE $o$ ): PIE $* \hat{k}_{o} h_{1}-\underline{i}-n->$ *k̂kain- in Avestan saēni- 'point', OIcel. hein 'whetstone', PDE hone (< OE hān 'stone'; full-grade *k̂koh $1^{-}>* \hat{k} \bar{o}$ - in Skt. śānah 'whetstone' = Gk. $\kappa \hat{\omega} v o \varsigma$ 'cylinder, pine cone'); PIE *kh $h_{1}$ id $->* k a i d-$ in Go. háitan, OIcel. heita, OHG heizan, OS hētan, OE hātan 'command' (aorist present: $§ 12.18$ ).

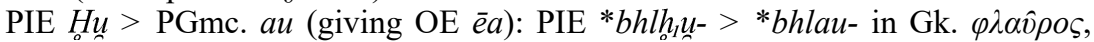
$\varphi \alpha \hat{v} \lambda o \varsigma$ (both dissimilated from * $\varphi \lambda \alpha \hat{v} \lambda o \varsigma$ ) 'worthless, poor, common', Go. bláupjan 'make void', OIcel. blauðr 'weak, cowardly', OE blēað 'timid' (cf. PIE full-grade

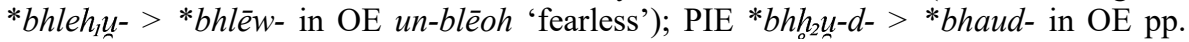
bēaten 'beaten' (cf. full-grade PIE *bheh ${ }_{2} u d->* b h \bar{a} u d-$ in inf. bēatan). ${ }^{3}$

PIE $\bar{a} \underline{i}>$ PGmc. ai (giving OHG ei, OS $\bar{e}$, OFris. $\bar{a} / \bar{e}, \mathrm{OE} \bar{a}$ ): PIE *deh ${ }_{2} \underline{i} \underline{u} e r s>$ *dāinuer 'brother-in-law' in Skt. dēvár-, Lat. lèvir (with Sabine l-), OHG zeihhur, OE tācor (with intrusive Gmc. $k$ : see Fulk 1993: 341-2 for a possible explanation); PIE ${ }^{*} \operatorname{seh}_{2} \underline{l}_{-}>{ }^{*} s \bar{a} i$ - (or perhaps weak-grade *sai-) in Go sáir, OHG OS OFris. sēr (with OHG $e i>\bar{e}$ before $r, \S 4.17)$, OE $s \bar{a} r$ 'pain'; PIE *keh $\underline{i}_{2}->* k \bar{a} i$ - in Skt. kētú- 'optical phenomenon', Go. háidus 'manner', OHG heit, OE hād 'form'.

PIE āu > PGmc. au (giving OHG $\bar{o}, \mathrm{OE} \bar{e} a$ ): PIE *keh ${ }_{2} u->* k a \bar{u} u$ - in Lith. káuju, kóviau, káuti 'strike', with Verschärfung (\$6.10) in OIcel. hoggva, OHG houwan, OE

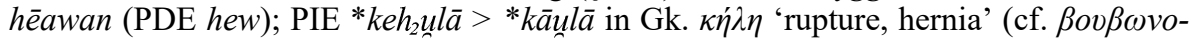
$\kappa \dot{\eta} \lambda \eta$ 'hydrocele'), OIcel. haull, OE hēala, OHG hōla 'hydrocele'; PIE *leh h $_{-}$- > *lāu-

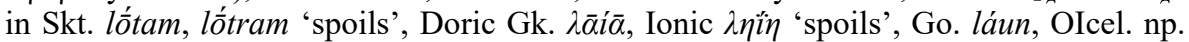

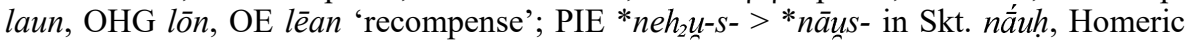

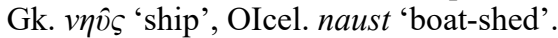

PIE $\bar{e} i>$ PGmc. $\bar{e}_{2}$ (giving OHG ia, ie, ea): The following examples are insecure (see §3.5): PIE lengthened-grade *k̂kèi-r- in Go. OS OE hēr, OIcel. hér, OHG hiar (cf. PIE reduced grade ${ }^{*} \hat{k} i$ - in Lat. cis 'on this side of', Go. hidrē, OE hider $>$ PDE hither $){ }^{4}$ PIE lengthened-grade *uēi-l- in OIcel. vél 'artifice', OE Wèlund, OHG Wialant (name of a mythological craftsman; cf. full-grade PIE *uei-l- in OE wīl > PDE wile); PIE lengthened grade * stēigh- > PGmc. ste $\overline{2}_{2}$ - in OHG stiaga $>$ NHG Stiege 'stair' (cf. PIE fullgrade *steigh-> PGmc. *stīz- in Go. steigan 'climb', as above).

PIE èu > PGmc. eu: PIE *bhleh $u_{1-}>*$ *bhlēu- in OE un-blēoh 'fearless' (as above); PIE * $\left(h_{1}\right)$ eh $h_{1}$ dh- $>* \bar{e} u d h$ - in OIcel. júgr 'udder' (cf. reduced grade in Skt. údhar 'udder'); PIE *ghreh,u-no- > *ghrēu-no- in OIcel. grjón 'groats' (cf. reducedgrade PIE * $g h r h_{1} u_{-}>*^{*} g h r a u-$ in Gk. $\chi \rho \alpha \dot{\omega} \omega$ 'scratch, graze, wound slightly'); PIE * $\hat{g h e h} h_{1} u-m->* \hat{g h} \bar{e} u m$ - in OHG giumo (beside guomo: see below under PIE ōu) 'palate'.

PIE ōi : No indisputable example in a Gmc. stressed syllable is in evidence.

PIE ōu > PGmc. $\bar{o}: 5$ PIE * ghoh ${ }_{1} u-m->*^{3} \overline{o u m}$ - in OE gōma 'inside of mouth', OHG guomo 'palate' (cf. reduced grade in Gk. $\chi \alpha v \lambda l$-ó $\delta o v \tau$ - 'with projecting teeth'); PIE * $g^{w} o h_{1} u d h->* g^{w} \bar{o} u d h$ - in MHG kōt (beside quāt, kāt), NHG Kot 'excrement' (cf. reduced-grade PIE * $g^{w} h_{1} u d h->{ }^{*} g^{w} a u d h$ - in OE cwēad, OFris. quād 'dung'). 
On the shortening of PIE long vowels before a sonorant consonant in a closed syllable (another possible diphthongal shortening), see $\$ 4.2$.

1. OIcel. neuter nom./acc. tvau 'two' has often been thought equivalent to Skt. $d v a \dot{a} u$, thus indicating development of PIE $\bar{o} u$ to Gmc. $a u$ rather than $\bar{o}$ (so, e.g., Prokosch 1939: 104); but the connection is doubtful: see Brugmann \& Delbrück 1897-1916: II, 2.10.

2. The usual example of PIE $\bar{o} i>$ Gmc. ai is OIcel. fleiri 'more', compared to Lat. plūs 'more' $<*$ plōis, in comparison to Old Lat. superl. ploerume (so, e.g., Hirt 1931-4: I, 35). But Lat. plūs is to be derived instead from Old Lat. plous, and superl. ploerume is more likely of analogical origin: see Pokorny (1959-69: I, 800), who more plausibly reconstructs reduced-grade * $p l h_{1}-i s^{-}$(not his notation) underlying fleiri (since PGmc. ai $>$ OIcel. ei). Aside from the Latin forms, there is no evidence for $o$-vocalism among the IE cognates.

3. This is on the assumption that there should be full grade in the infinitive and reduced grade in the past participle, as in other verb classes. But an aorist present is possible: cf. Go. háitan, above.

4. Cf. Ringe 1984, deriving PGmc. *xēr from a lengthened form of *xir (cf. Go. hiri 'come here!').

5. A special development of PGmc. ${ }^{*}-\bar{o} w w$ - is usually assumed, chiefly to account for OIcel. búa 'dwell' (cf. byggja 'settle', with $j$-suffix) and Gmc. cognates: see, e.g., Seebold 1970: 124-8.

\subsection{The sources of $\bar{e}_{2}$}

In addition to the reflex of PIE $* \bar{e}$ (represented as $\bar{e}_{1}$ ), there arose within Gmc. another $\bar{e}$ sound, generally referred to as $\bar{e}_{2}$, which develops to ea, ia, ie in OHG. ${ }^{1}$ In Gothic it occurs only in hèr 'here', fêra 'region, side' (= OHG fiara), mēsa 'table', and Krēks 'Greek', of which the second is etymologically obscure and the last two borrowings from Late Latin. This $\bar{e}_{2}$ fell together with PIE $\bar{e}$ in Gothic but not in the other Gmc. languages, where it remained as $\bar{e}(>\mathrm{OHG} i a$, etc.), as opposed to NGmc. $\bar{a}$, WGmc. $\bar{x}$ or $\bar{a}(\$ 4.6)<\mathrm{PIE} \bar{e}$, as in Go. OE OS hèr, OIcel. hér, OHG hēr, hear, hiar, hier 'here', ${ }^{2}$ with $\bar{e}_{2}$, as opposed to $\bar{e}_{1}$ in Go. lètan, OIcel. láta, OE lātan, OS lātan, OHG lāzan 'let'. The literature on $\bar{e}_{2}$ is extensive, and often speculative. ${ }^{3}$ Although attempts have been made to identify a unitary source, it appears that $\bar{e}_{2}$ must be regarded as the product of polygenesis: ${ }^{4}$

(a) Jellinek (1891b) was the first to derive $\bar{e}_{2}$ from PIE $* \bar{e} i$ (or $* e H i$ in laryngeal terms: see §3.1). Reliable examples are scarce, e.g. OHG stiaga 'stair' < PIE *stēighā, and $\mathrm{OE} c \bar{e} n$, OHG kien- 'torch' < PIE * $\hat{g} e \bar{i}-n$-. Especially because unambiguous examples of $\bar{e}_{2}$ from PIE $\bar{e} i$ are few, it seems suspicious that so little of the evidence is to be found outside of OHG.

(b) $\bar{e}_{2}$ occurs in Latin borrowings, especially into OHG, after the earliest period of borrowing (Polomé 1988: 385-6), as in Lat. thêca 'cover' borrowed as OHG ziahha 'pillow case'; Lat. prēsbyter borrowed as OHG priester 'priest'; Lat. bèta 'beet' borrowed as OE bēte, OHG biaza; Lat. Graecus borrowed as Go. Krēks, OE pl. Crēcas 'Greeks'.

(c) The commonest environment for $\bar{e}_{2}$ is in the preterite of formerly reduplicating verbs in North and West Germanic, as in OIcel. hét, OHG hiaz, OE OS hèt 'was called' and OIcel. lét, OHG liaz, OE OS lèt 'let'. Although there is considerable controversy regarding the origin of the preterite vocalism in such verbs (see $\S 12.20)$, most observers regard it in one way or another as the product of the contraction of the reduplicative vowel /e/ with the root vowel of the verb. For explanations involving laryngeal consonants, see Lehmann 1952: 66-73, 
Connolly 1979, 1999, and cf. Polomé 1988: 384-401, Voyles 1989b, 1999, Müller 2007: 159.

(d) Miscellaneous sources of $\bar{e}_{2}$ include lengthening and lowering of $i$ upon loss of a following anteconsonantal $z$ (a sound that arose in PIE in those rare instances in which $s$ came to stand before a voiced stop), the securest example being OE $m \bar{e} d$, OS mèda, OHG miata 'reward' beside Go. mizdō, OE meord 'reward' < PIE *mizdhó- in Gk. $\mu \iota \sigma \theta o ́ \varsigma$ 'wages', OCS mbzda, 'reward', Skt. mị̄há- 'prize'. If the $\mathrm{OHG}$ demonstrative dé, die corresponds to Go. pái (see §8.10), ai may be supposed to have developed to $\bar{e}_{2}$ in NWGmc. unstressed syllables and then to have been extended to stressed forms of the demonstrative (so Karstien 1921: 53).

(e) Influential has been the hypothesis of van Coetsem $(1956,1970$ : 55-8, 1997) that at least some instances of $\bar{e}_{2}$ are to be derived from PIE ei before a low vowel in the next syllable. This could account for alternations like OHG stiaga 'path' stīgan 'ascend'. See also Knapp 1974, van Loon 1986.

1. To explain how the two $\bar{e}$-sounds failed to coalesce it is sometimes assumed that PIE $\bar{e}$ became PGmc. $\bar{x}$. This is also a step in the direction of $\bar{a}$, the NGmc. and, in part, WGmc. reflex of PIE $\bar{e}$, but this assumption requires that $\bar{x}$ have reverted to $\bar{e}$ in Gothic, and at all events there are other possible values for the PGmc. reflex of PIE $\bar{e}$. The representation $\bar{e}_{1}$ is preferred here for its relative abstractness. See $\S 3.3$ n. 2 .

2. There also occur OS OFris. $h \bar{\imath} r$. The derivation of this word is disputed. It is plainly related to Lat. cis 'on this side', but $\bar{e}_{2}$ has been derived from * $\bar{e} i$ (Jellinek: see below) and by lengthening and lowering of $i$ (Ringe 1984). The latter explanation seems more probable in view of parallel forms, e.g. Go. par 'there', har 'where?'. For references, see Orel 2003: 172, and cf. Jörundur Hilmarsson 1991. For further possible sources, see Hirt 1931-4: I §29.4.

3. In addition to works devoted specifically to the development of the reduplicated preterites in NWGmc. (references in \$12.20), see Sievers 1892: 238-57, Holthausen 1891, van Helten 1896: 438-45, idem 1908, Lehmann 1952: 66-73, Grønvik 1998b: 91-5.

4. See esp. Polomé 1988: 384-401; van Coetsem 1997; Kortlandt 2006a; for the earlier literature, see Streitberg 1896: §79, Hirt 1931-4: I, §29.4.

\subsection{Ablaut in Proto-Germanic}

Whereas PIE ablaut alternations (\$3.1) were not extensively maintained in most IE languages, ablaut came to play an important grammatical role in Gmc., where it differentiates the stems used to form the principal parts of strong verbs, and thus it serves as an indicator of tense and/or number, or participial function. Unsurprisingly, then, ablaut alternations are most plainly observable in strong verbs: see $\S 12.11$ for an overview of the relevant alternations in this grammatical category. Ablaut alternations are evident, however, in other grammatical contexts, as well. One fairly regular correspondence is between strong verb stems with PIE $e$ and derivatives, either verbal or nominal, with PIE $o$. Weak verbs of class 1 provide many examples, e.g. Go. strong ga-nisan 'be saved' beside weak nasjan 'save', strong sigqan 'sink' (intrans.) beside weak sagqjan (trans.), strong af-leipan 'depart' beside OE weak lǣdan 'lead' < *laiðjan < *laibjánan. Similarly, beside strong verb stems with $e$-grade there occur fem. abstract nouns with $o$ grade, e.g. Go. bi-leiban 'remain' beside láiba 'remnant', OE stelan 'steal' beside stalu 'theft', OIcel. rið 'ride' < *rīðanan ${ }^{n}$ beside reið 'course' < *raiðō. Strong verb stems with $e$-grade often have $i$-stem derivatives with weak grade, e.g. Go. qiman 'come' beside qums 'advent', OE strican 'stroke' beside Go. striks 'stroke', OE brecan 'break' 
beside bryce 'breach' < *brukiz. ${ }^{1}$ Many less regular alternations are also discoverable, e.g. Go. liufs 'dear' < *leub- : ga-láubjan 'believe' (o-grade) : lubō 'love' (weak grade); Go. bindan 'bind' : bandi 'band' : ga-bundi 'bond'; OIcel. bera 'bear' : barn 'child' : burdr 'birth'; OE setl 'seat' : ge-sæt 'act of sitting' < *-satan : nest 'nest' < PIE *ni-zd-

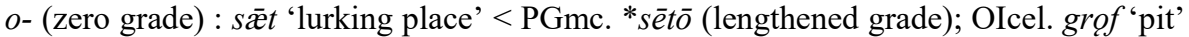

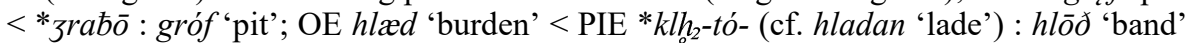
$<* x l o p-<$ PIE *kléh ${ }_{2}-t$.

Ablaut is also evident in derivational suffixes. The reflex of PIE *-on-must originally have alternated with *-en- in the paradigm of OE morgen beside umlauted mergen 'morning'; 2 likewise in $n$-stems, e.g. Go. acc. sg. hanan 'cock' $<* x a n a n u^{n}$ : gen. hanins

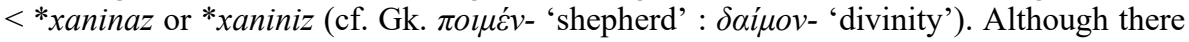
is analogical redistribution of the PIE variants $*_{-} e s-\sim *_{-o s}$ - in Gmc. $s$-stems, variation remained and is attested by alternative stems in the paradigm with and without umlaut in WGmc., e.g. OE (Northumbrian) nom./acc. sg. d̄̄g, pl. dōgor 'day', OHG nom./acc. sg. lamb, pl. lembir 'lamb'. Quantitative alternations are also detectable, as in $r$-stem nouns, e.g. Go. brōpar $<*$ bhrāter- : dat. brōpr $<*$ bhrātri; and in the diminutive suffix *-ing- : *-ung- $\left(<*_{-}\right.$enko- : *-nko-), as in OE cyning : OIcel. konungr 'king'. As for inflectional suffixes, with the resegementation of stems and inflections in PGmc. (§7.1), the theme vowel was incorporated into the inflections, and its ablaut alternations became unrecognizable as such.

For literature on the development of PIE ablaut in Gmc., see Kilbury 1975, Born 1980, Stedje 1987, Lewickij 1996. For an overview of ablaut patterns in PGmc., see Ringe 2017: 253-60.

1. The form *brukiz (rather than the expected *burkiz $<* b h r \hat{g}^{-}$) probably shows metathesis by analogy to *brekan-: see $\S 12.31$ n. 3 .

2. It is necessary to assume lowering of $u$ to $o$ in *murzanaz and subsequent extension of $o$ throughout the paradigm, as otherwise the regular development of *murzin- would be OE myrgen (which does occur twice, in compounded words). Cf. Ringe \& Taylor 2014: 18-20, attributing the alternation of *-in- and *-an-to a NWGmc. phonological change.

\subsection{Summary tables of Indo-European vowel developments}

For comparative purposes it may be useful to summarize in tabular form the main developments of PIE syllabic segments in various IE languages. These tables are generalizations, with many exceptions under given conditions, for which the grammars cited in $\S 1.2 \mathrm{n}$. 1 should be consulted, or grammars of the individual IE languages.

\begin{tabular}{|c|c|c|c|c|c|c|c|}
\hline PIE & PGmc. & Skt. & Gk. & Lat. & Lith. & OCS & OIr. \\
\hline $\mathrm{e}$ & $e, i$ & $\mathrm{a}$ & $\varepsilon$ & e & e & e & $e, i$ \\
\hline o & $\mathrm{a}$ & $\mathrm{a}$ & o & $\mathrm{O}^{1}$ & $\mathrm{a}$ & o & $\mathrm{o}, \mathrm{u}$ \\
\hline $\mathrm{a}$ & $\mathrm{a}$ & $\mathrm{a}$ & $\alpha$ & $\mathrm{a}$ & $\mathrm{a}$ & o & $\mathrm{a}$ \\
\hline $\mathrm{i}$ & $\mathrm{i}$ & $\mathrm{i}$ & 1 & $\mathrm{i}$ & $\mathrm{i}$ & b & $\mathrm{i}, \mathrm{e}$ \\
\hline $\mathrm{u}$ & $\mathrm{u}$ & $\mathrm{u}$ & $v$ & $\mathrm{u}$ & $\mathrm{u}$ & $\mathbf{b}$ & $\mathrm{u}, \mathrm{o}$ \\
\hline$\overline{\mathrm{e}}$ & $\overline{\mathrm{e}}_{1}$ & $\bar{a}$ & $\eta$ & $\overline{\mathrm{e}}$ & $\dot{\mathrm{e}}$ & ě & í \\
\hline$\overline{0}$ & $\bar{o}$ & $\bar{a}$ & $\omega$ & $\bar{o}$ & uo & $\mathrm{a}$ & á \\
\hline $\bar{a}$ & $\bar{o}$ & $\bar{a}$ & $\eta^{2}$ & $\bar{a}$ & $\overline{\mathrm{o}}$ & $\mathrm{a}$ & á \\
\hline$\overline{1}$ & $\overline{1}$ & $\overline{1}$ & $\grave{i}$ & $\overline{1}$ & $\mathrm{y}$ & $\mathrm{i}$ & í \\
\hline$\overline{\mathrm{u}}$ & $\overline{\mathrm{u}}$ & $\overline{\mathrm{u}}$ & $\bar{v}$ & $\overline{\mathrm{u}}$ & $\overline{\mathrm{u}}$ & $\mathrm{y}$ & ú \\
\hline ei & $\overline{1}$ & $\overline{\mathrm{e}}$ & $\varepsilon l$ & $\overline{1}$ & ie, ei & $\mathrm{i}$ & é, ia \\
\hline
\end{tabular}




\begin{tabular}{|c|c|c|c|c|c|c|c|}
\hline PIE & PGmc. & Skt. & Gk. & Lat. & Lith. & OCS & OIr. \\
\hline eu & eu, iu & $\bar{o}$ & $\varepsilon v$ & $\overline{\mathrm{u}}$ & $\mathrm{au}$ & $\mathrm{u}$ & ó, ua \\
\hline oi $\hat{i}$ & ai & $\overline{\mathrm{e}}$ & ol & $\overline{\mathrm{u}}, \mathrm{oe}$ & ie, ai & ě & ái, ói, oe, ae \\
\hline$\hat{\mathrm{ou}}$ & $\mathrm{au}$ & $\bar{o}$ & ov & $\overline{\mathrm{u}}$ & $\mathrm{au}$ & $\mathrm{u}$ & ó, ua \\
\hline $\mathrm{ai}$ & ai & $\overline{\mathrm{e}}$ & $\alpha \imath$ & ae & ie, ai & ĕ & ái, ói, oe, ae \\
\hline aú & $\mathrm{au}$ & $\overline{\mathrm{o}}$ & $\alpha v$ & $\mathrm{au}$ & au & $\mathrm{u}$ & ó, ua \\
\hline$\hat{h_{1}}$ & $\mathrm{a}$ & $\mathrm{i}$ & $\alpha$ & $\mathrm{a}$ & $\mathrm{a}$ & o & $\mathrm{a}$ \\
\hline $\mathrm{h}_{2}$ & $\mathrm{a}$ & $\mathrm{i}$ & $\alpha$ & $\mathrm{a}$ & $\mathrm{a}$ & o & $\mathrm{a}$ \\
\hline $\mathrm{h}_{3}$ & $\mathrm{a}$ & $\mathrm{i}$ & $\alpha$ & a & $\mathrm{a}$ & o & $\mathrm{a}$ \\
\hline$r$ & ur & $r$ & $\alpha \rho, \rho \alpha$ & or & ir & $\mathrm{r} \breve{1}, \mathrm{rŭ}^{3}$ & ri, ar \\
\hline$\hat{1}$ & ul & $\hat{r}$ & $\alpha \lambda, \lambda \alpha$ & ol, ul & il & $\mathrm{l} \breve{\mathrm{i}}, \breve{u u}^{3}$ & li, al \\
\hline$n$ & un & a & $\alpha$ & en & im & $e<$ im & am, em \\
\hline$\stackrel{n}{m}$ & um & $\mathrm{a}$ & $\alpha$ & em & in & $\mathrm{e}<$ in & an, en \\
\hline 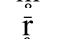 & ur & $\overline{\mathrm{i}}$, ūr & $\rho \bar{\alpha}$ & rā & ir & $\mathrm{ri}, \mathrm{ru}^{3}$ & ri, ar \\
\hline$\frac{\hat{a}}{1}$ & $\mathrm{ul}$ & $\overline{\mathrm{i}} \mathrm{r}, \mathrm{u} \mathrm{r}$ & $\lambda \bar{\alpha}$ & lā & il & lî, lü $\breve{u}^{3}$ & li, al \\
\hline ñ & un & $\bar{a}$ & $v \bar{\alpha}$ & nā & $\mathrm{im}$ & $\mathrm{e}^{2}<\mathrm{im}$ & am, em \\
\hline$\overline{\bar{m}}$ & um & $\bar{a}$ & $\mu \bar{\alpha}$ & mā & in & $\mathrm{e}<$ in & an, en \\
\hline
\end{tabular}

As noted above (\$3.1), some studies assume three reflexes in Greek for the three syllabic laryngeals $(\varepsilon, \alpha, o)$, on the basis of forms like the past participles $\theta \varepsilon \tau \dot{\varsigma} \varsigma$ 'placed'

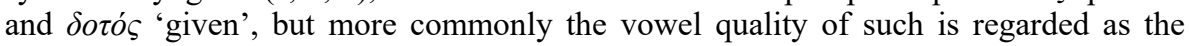
result of analogy to full-grade forms (cf. $\tau i \theta \eta \mu l$ 'place', $\delta i \delta \omega \mu l$ 'give'): so, e.g., Lindeman 1987: 101-2 and Szemerényi 1996: §4.1.11. On the long diphthongs in Gmc., see $\S 3.4$.

Figure 4 summarizes graphically the development of the PIE vowels in PGmc. stressed syllables. Here consonantal laryngeal consonants are treated as if already lost in PIE.

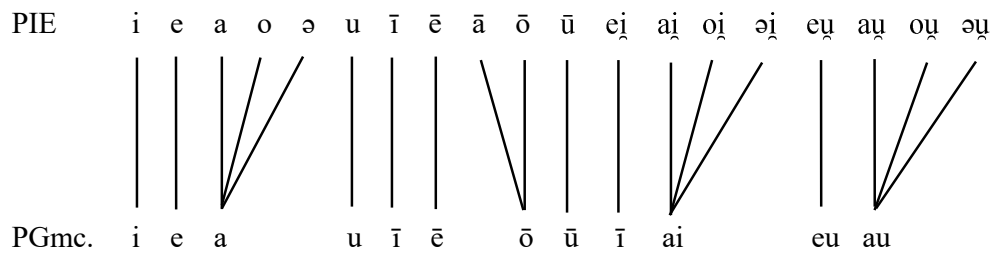

Fig. 4. Reflexes of Proto-Indo-European vowels in Proto-Germanic.

1. But Old Lat. $o l>$ Lat. $u l$.

2. Doric and Aeolic $\bar{\alpha}$.

3. The spellings $r \check{l}, r \breve{u}, l \breve{l}, l \breve{u}$ (transliterations of $p b, p b, \pi b, л b$ ) stand for syllabic sonorants, palatalized and nonpalatalized. 


\section{Changes of Stressed Vowels in Germanic}

\subsection{Compensatory lengthening upon loss of a nasal consonant}

In the PGmc. consonant group * ${ }_{-} \eta x$ - the nasal consonant was lost, with compensatory lengthening of the preceding vowel. The vowels $e$ and $o$ did not occur in this environment. The lengthened vowels may have remained nasalized for a considerable time, well past the close of the NWGmc. period, since $\bar{a}^{n}$ produced this way developed to $\bar{o}$ in Anglo-Frisian (as in OE pret. sg. pōhte, OFris. thöchte 'thought') and did not fall together with OE $\bar{a}<a i$ or OFris. $\bar{a}<a i$, $a u(\$ 4.12)$. In ON the usual reflex of $\bar{a}^{n}$ is $a$. Examples: Go. peihan 'thrive' < PGmc. ${ }^{*} p \imath^{n} x a n a^{n}<{ }^{*}$ pinxana ${ }^{n}<$ PIE *tenk- (cf. OE pp. pungen 'successful' and Lith. tenkù, tèkti 'have enough'); Go. preihan 'throng' < PGmc. *prin'xana ${ }^{n}<{ }^{*}$ pripxana ${ }^{n}$ (cf. OE pringan 'crowd upon', Lith. treñkti 'strike'); Go. fähan 'take' < PGmc. *fän xana ${ }^{n}<*$ fayxana ${ }^{n}<$ PIE *pa-n- $k$ - (cf. OE pp. fangen and Lat. pangō 'compose'); Go. brāhta 'brought' < PGmc. *brānxtē < *brayxtēp (cf. inf.

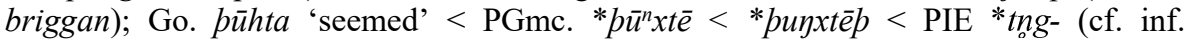
pugkjan, OE pyncan, also Lat. tongeō 'know'); OE OHG fūht 'damp' < PGmc. *fün xtaz $<*$ funxtaz $<$ PIE *pnk-t- (cf. Skt. payka- 'slime').

\subsection{Shortening in closed syllables}

In most IE languages a long vowel followed by a sonorant plus another consonant was shortened, and in PGmc. the same happened. Examples: Go. faírzna, OE fiersn, OS fersna, OHG fersana 'heel' < PIE *pērsn- (cf. Skt. pārșnih 'heel', with shortening in Lat. perna 'ham'); Go. winds, ON vindr, OE OFris. OS wind, OHG wint 'wind' < PIE *uēentos (cf. Skt. vānt- 'blowing', with shortening in Lat. ventus 'wind'). ${ }^{1}$

1. Such shortening is not uncommonly regarded as of a piece with the shortening of long PIE diphthongs in PGmc. (§3.4), e.g. by Hirt (1931-4: §29.7) and Prokosch (1939: §46c). That is, én, êr, etc., are to be regarded as diphthongs, the way they are treated, for instance, in PDE, where shortening of diphthongs before voiceless consonants applies also to the sequence vowel + sonorant consonant, as in grant (vs. grand), like lout (vs. loud).

\subsection{Redistribution of the Proto-Germanic short mid and high vowels: lowering}

After the development of PIE $o$ to PGmc. $a$, there was no short phoneme /o/ in the Germanic protolanguage (but see $\$ 5.5$ on the seeming retention of $/ \mathrm{o} /$ beyond the $\mathrm{PGmc}$. period in certain noninitial syllables). This elimination of $/ \mathrm{o} /$ created an imbalance in the phonemic inventory of Gmc. vowels, because the result was that there was no back vowel corresponding to front /e/ (but see below on this), and it is an oft-observed characteristic of phonological systems across languages, and especially vowel systems, that 
they tend to change in symmetrical fashion, and asymmetrical systems tend to be unstable (see, e.g., McMahon 1994: 28). Unsurprisingly, then, there is abundant evidence that [o] arose again at a fairly early date, as a result of distance assimilation in vowels: when $u$ stood before a mid or low vowel in the next syllable (i.e., /a/ or /o(:)/, since /e/ had been virtually eliminated in unstressed syllables: see §5.5), it was lowered to $o$. That this is a relatively early development is shown by a form like OE scolu, OS skola 'troop, shoal' $<{ }^{*} s k u l \bar{o}$, since final $-\bar{o}$ became $-u$ in the fifth century, to judge by the evidence of Runic inscriptions. ${ }^{1}$ Lowering of $u$ is also discernible in some early Runic inscriptions, e.g. horna (Gallehus horn 2, ca. 400 CE; see Stiles 2012). The change is not demonstrable in Gothic, where $u$ is retained everywhere except before $/ \mathrm{r} /$ and $/ \mathrm{x} /$ $(\S 4.5)$, but it is plainly evident elsewhere in Gmc. It is particularly plain in the past participles of strong verbs of the fourth class, but it is evident in many other grammatical categories, as well. Examples: OIcel. stolinn, OHG OS gi-stolan, OE stolen 'stolen' < PGmc. *stulanaz < *stel-; OHG tor, OE OS dor 'door' < PIE *dhuron (cf. Gk. $\pi \rho o ́ \theta v \rho o v$ 'front door'); OHG bodam, OIcel. botn, OE botm = Gk. $\pi v \theta \mu \eta \dot{v}$ 'bottom' <

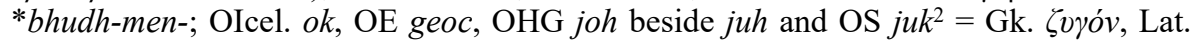
jugum 'yoke' < PIE * ingom; OHG OS OE OFris. gold, OIcel. gull beside goll 'gold' < PGmc. ${ }^{*} z u l p a^{n}$. This lowering is prevented before a tautosyllabic nasal consonant, e.g. in OE pp. wunden 'wound' $<*$ wundanaz and OIcel. sund 'swimming' $<{ }^{*}$ sunda ${ }^{n}$. It appears that it was also prevented by a heterosyllabic nasal, as in OE fruma 'beginning', guma 'man', cuman 'come', though OS and OHG show instances of $o$ beside $u$, e.g. OS gomo beside usual gumo; lowering in OIcel. koma 'come' (cf. OIcel. oblique guma) is due to $a$-umlaut, a specifically Norse development (\$4.8). Lowering is prevented also when $j$ preceded the non-high vowel conditioning the change: cf. OE cnyssan 'knock',

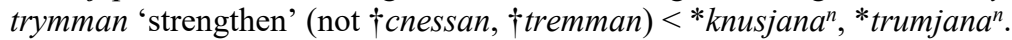

It is plain, as well, that PGmc. $i$ might be lowered to $e$ in parallel fashion before a mid or low vowel in the next syllable. ${ }^{3}$ Undeniable examples are OE OHG nest 'nest' < PIE *nizdos (cf. Skt. nī as in OE niper 'down' plus *-zd- as in full-grade Lat. sedeo 'sit'; and OS OFris. OE wer(-) 'person, man', OIcel. verr 'man' (cf. Lat. vir, Welsh gîwr 'man'). Gothic, once again, stands apart, since PIE $i$ in that language is reflected as ai (probably / $/ \varepsilon /$ or /e/) before $/ \mathrm{r}, \mathrm{x}, \mathrm{x} /$, otherwise $i(\S 4.5)$. The only other secure example in OE is spec 'bacon' beside spic, ${ }^{4}$ but the change is well attested outside of Anglo-Frisian, e.g. OIcel. heðan 'hence' (note the absence of $a$-fracture (\$4.8), and cf. early hiðra 'here' = OE hider, later OIcel. heðra by analogy); OHG quec, OS quec- (beside usual quik) 'live', OFris. quec (beside usual quik) 'cattle' (cf. PIE * $g^{w} i h_{3} u-$ in OE $c w i c u$ 'live', OIr. bith 'world, life'); rare OIcel. stegi beside stigi 'ladder' (cf. stiga 'step', Gk. $\sigma \tau \varepsilon i \chi \chi \omega$ 'walk' < *steigh-); OHG lebara, MLG lever (cf. OIcel. lifr, OE lifer, OFris. livere) 'liver' = Gk. $\lambda \imath \pi \alpha \rho o ́ \varsigma$ 'fat, greasy'. The change is most regular in High German (see Braune 2004a: $\S 31$ ), least regular in English (A. Campbell 1977: §114). Plainly, the results of the lowering of $i$ are much less systematic than those for the lowering of $u$, and in NWGmc., $i$ and $e$ alternated in many words, depending on whether or not a high vowel appeared in the following syllable. This created a situation ripe for analogical change on either an inter- or an intraparadigmatic basis, with leveling away of $e$ being the commonest result. ${ }^{5}$ Because the distribution of $/ \mathrm{i} /$ and /e/ is so different in Gothic, methodologically it is best to assume that the change of $i$ to $e$ is a development of NWGmc., but it is not impossible that the change should have taken place in PGmc., ${ }^{6}$ and indeed, it may have been the irregularities produced by this change that prompted 
the redistribution of the short mid and high vowels in Gothic, though the distribution of the two types there is so nearly perfectly regular (see $\$ 4.5)$ that a purely phonological explanation does seem more probable.

It should be added that it has sometimes been argued that there was no asymmetry in the PGmc. short vowels, rather that $e$ and $i$ were allophones, just as $o$ and $u$ were (so Trager \& Smith 1950: 67, 70; Marchand 1957a; see also Hock 1973). Beeler (1966) shows that this assumption creates problems for the analaysis of ON, since there $e$ cannot have been raised before $u$ in the next syllable (and thus it stood in phonemic constrast with $i$ in that environment), given the facts of $u$-fracture (\$4.8). For discussion and references to further studies pro and con, see Durie 1996, with further evidence against the merger.

1. On the other hand, it would appear that lowering has not yet occurred in the divine name Hludana of Ubian dedicatory inscriptions of ca. 200 CE (Polomé 1994: 9). Ringe, with extensive discussion and copious examples in various grammatical classes, dates this lowering before the loss of WGmc. *az, since it is common in $a$-stem nouns but not root-stems (Ringe \& Taylor 2014: 27-34, at 29).

2. The coöccurrence of forms with $o$ and $u$ is presumably due to alternation within the original paradigm, e.g. acc. sg. *joka ${ }^{n}$ beside gen. pl. *jukum.

3. Kock (1898: 545) argues that this lowering of $i$ is prevented in North Germanic when $g$ or $k$ immediately precedes the vowel, as in gin 'maw' and skip 'ship'. It is also prevented when $j$ or nasal + consonant intervenes $(\$ 4.4)$.

4. A rather probable example, however, is OE gewegan 'fight' (beside wigan; cf. OIcel. vega), pp. forwegen 'killed'. The voicing under Verner's law (cf. Go. weihan) suggests the PGmc. suffixal accent characteristic of aorist presents, hence PGmc. *wizanan (Seebold 1966b: 3-4). Another possible example is ME steken 'pierce' (Seebold 1970: 467-8). On these, see Lloyd 1966: 743-4.

5. Ringe (Ringe \& Taylor 2014: 34-6) takes the position that this lowering is a Franconian change that spread northward irregularly in WGmc., and that in OFris. the change is unrelated, choosing to leave exceptions like OE nest, wer unexplained. By contrast, Lloyd (1966) argues that an allophone [e] of /i/ arose occasionally in Gmc. on the basis of systemic analogy. Cercignani (1980b) explains the rarity of the change outside of High German as due to avoidance of merger of /e/ with/i/; cf. Kylstra 1983.

6. So, e.g., Streitberg 1896: §68; cf. Krahe \& Meid 1969: I, §36; for further references, see Kock 1898: 544 and Hirt 1931-4: I, §34.1.

\subsection{Redistribution of the Proto-Germanic short mid and high vowels: raising}

PIE $e>$ PGmc. $i$ under at least two, possibly three, conditions: (a) before $\check{\bar{l}}$ or $j$ in the next syllable; (b) before a tautosyllabic nasal consonant; (c) before $u$ in the next syllable. The change represented by (c) is not now widely credited as a development of Proto-Germanic: see the discussion below. These changes cannot be illustrated in Gothic, since PGmc. $e$ always yields $i$ in that language (but is lowered again to $e$, or prevented from rising, before $\left./ \mathrm{r}, \mathrm{x}, \mathrm{x}^{\mathrm{w}} / \mathrm{:} \S 4.5\right)$. Examples:

(a) PIE *uen-i-s > OIcel. vinr, OE wine, OS OHG wini 'friend' (cf. PIE *uen- in Lat. Venus); PIE *bher-e-ti $>$ PGmc. *beripi $>*$ biripi $>$ OE biro, OS birid, OHG birit 'bears'; PIE * $m_{e} \hat{g}-e l->$ PGmc. *mek-il- > *mikil-> OIcel. mikill, OE micel, OS mikil, OHG mihhil 'large' (cf. PIE * $m_{e} \hat{g}$ - in Lat. magnus 'large'); PIE *medh-io- $>$ Lat. medius, OIcel. miðr, OE midd, OHG mitti 'middle'; PIE *sed-ino- > OIcel. sitja, OE sittan, OS sittian, OHG sitzen 'sit'; PIE *uegh-ino- > Skt. vahyá- 'vehicle', OIcel. vigg, OE wicg, OS wigg 'horse'.

(b) PIE * (-)bhendh- in Avestan bandayaiti 'binds', Gk. $\pi \varepsilon v \theta \varepsilon \rho o ́ \varsigma$ 'father-in-law' (*'bound by marriage'), Lat. dēfendō 'defend' (*'release from bonds'), Go. OE OS 
bindan, OIcel. binda, OHG bintan 'bind'; PIE *klem- (plus consonant) in Skt. krándati 'bellows', OE hlimman 'make a noise', OHG limmit 'makes a noise'; PIE *reng- in Lith. rëžiu, rëžzi 'tighten, elongate', OE OHG rinc, OS rink 'man'; PIE *tenk- > Lith. tenkù, tèkti 'have enough', PGmc. *peyxana ${ }^{n}>{ }^{*}$ pinxana $^{n}>*^{*}$ pixana $^{n}$ (\$4.1) in Go. peihan, OE pēon, OS thīhan, OHG dīhan 'thrive'.

(c) PIE * pelh $u$ 'many' > OIr. il, OS OHG filu (but cf. OIcel. fjol, OE fela); ${ }^{1}$ PIE *medhu- in Skt. mádhu- 'honey', Gk. $\mu \varepsilon \dot{\theta} \theta$ 'wine', OIr. mid 'mead', OHG mito 'mead' $\left(1 \times\right.$, beside meto, OIcel. mjoðr, OE medu, meodo); PIE * $g^{w} e t u$ - in Skt. játu 'lacquer, gum', OE huuīt-quidu (Épinal Glossary) > hwït-c(w)udu (cf. inflected cwidue(s), Bald's Leechbook) 'mastic'; PIE *suedh- 'custom' in Skt. svadhá, Gk. ě $\theta o s$, and probably OIcel. siðr, OE OS sidu, OFris. side, OHG situ (but with *sedh- rather than *suedh-); PIE *septḿ ' 7 ' underlying PGmc. * sibun (\$10.2), reflected in early OE forms with $i$, e.g. Mercian sifun- (A. Campbell 1977: $§ 682){ }^{2}$

The evidence of Gmc. names in Latin and Greek texts and inscriptions is neither unambiguous nor consistent, but some attestations suggest that (a) and (b) had not yet been completed by the first centuries CE, e.g. inscriptional Nehalennia in the second century, and Segimerus, Segimundus in Tacitus (Polomé 1994: 5-6, 8-9). The evidence for (c) is secure almost exclusively in OHG and OS, where the change applied (or continued to apply) at a relatively late date, since it is found in the $1^{\text {st }}$ pers. $\mathrm{sg}$. ind. of some verbs, e.g. biru '(I) bear', stilu '(I) steal', though $-u$ here developed from $-\bar{o}$, probably in the course of the fifth century $(\$ 4.3)$. There do not appear to be any examples of the change in OIcel. or in Anglo-Frisian other than the possible ones presented here. ${ }^{3}$ According to the older view, revived by Collitz (1905) and Prokosch (1939: §38), PIE $e$ yields Gmc. $i$ except before a non-high vowel in the next syllable, and except when there is later lowering before a non-high vowel. The result would have been extensive alternation of $e$ and $i$ within paradigms and among related forms, as with $o$ and $u(\S 4.3)$, with the consequence that $e$ was restored in most instances in OIcel., OE, and OFris., as it is to some extent in OHG and OS (e.g. OHG fehu np. 'cattle. property' beside fihu). An advantage of this analysis is that the change of /e/ to /i/ in Gothic comes to seem less anomalous; another is that developments of the front and back vowels are made more symmetrical, at least in theory; a third is that it explains the change of PIE ei to Gmc. $\bar{l}$ (§3.4). ${ }^{4}$ The chief disadvantage is that the replacement of $i$ by $e$ in OIcel. and AngloFrisian must be regarded as uncommonly regular for an analogical development. Hirt (1931-4: I, 46; similarly Lloyd 1966) objects that if there is lowering of $i$ to $e$ in OHG gigeban 'given' and other verbs of the fifth strong class, it cannot be explained why there is no lowering in gistigan 'risen' and other verbs of the first strong class. Therefore, the $e$ in gigeban cannot ever have been raised. But this is surely irrelevant, since the evidence for the lowering of $i$ before a non-high vowel in the next syllable is rather solid, especially for OHG: see $\$ 4.3$. It is nonetheless true that the failure of lowering in gistigan still demands to be explained, and Krahe \& Meid (1969: I, §36) plausibly argue that $\bar{l}$ in the present system of verbs of the first class exerted sufficient analogical influence to prevent or reverse the effects of lowering in the participle. ${ }^{5}$ That there did at one time exist alternation between $e$ and $i$ in the past participle in the first class is suggested by the OIcel. participle beðinn (to biða = PDE bide). This seems rather probable, given the high token frequency of biða, which is perhaps the commonest verb of the first class in OIcel., and given the resistance of forms with high token frequency to regularizing analogical changes. ${ }^{6}$ Another possible example is OE forwegen 'killed' (cf. wigan 
'fight' beside gewegan, $\S 4.3$ n. 4). There is frequent lowering of $i$ to $e$ in the pret. pl. and pp. of verbs of class I in OFris. See further Polomé 1994: 28-9 n. 10.

Just as PGmc. $e$ was raised to $i$ before $i$ or $j$ in the next syllable, so under the same conditions $e u$ changed to $i u$. In ON and Anglo-Frisian, under normal circumstances $i u$ would subsequently undergo front umlaut (\$4.7). The further developments of $e u$ are discussed under the treatment of vowels and diphthongs in the individual languages.

1. On this analysis, OE fela (cf. Northumbrian feolu, Gk. $\pi 0 \lambda \dot{\varsigma} \varsigma$ 'many') has final -a probably from an oblique case-form of the original $u$-stem adjective (so A. Campbell 1977: §666), e.g. PGmc. nom. pl. fem. * felôz, in which there would have been no raising of /e/ (or later reversal of that raising). If this is correct, OIcel. fjol must show fracture of $* e$ due to original final $-u$ (as in the nom. acc. sg. of the adjective), with restoration of $e$ in the root, prior to fracture, from oblique cases.

2. Possibly also OE nigon ' 9 ' < PGmc. *ne(w)un(-) (with intrusive 3, §10.2), though Ross \& Berns (1992: 589) explain the raising as originating in the $i$-inflected stem *niwuni-.

3. A possible exception is OIcel. OE OS wit 'we two', which Prokosch (1939: §98d) plausibly explains as having developed from *we-tu (see $\$ 8.2$ infra); but the raising of *e in this word may instead be due to unstressed use of the pronoun $(\$ 5.5)$.

4. Implicit in this analysis is the assumption that these changes also affected the diphthong eu: Prokosch (1939: §39a) thus maintains that "eu appears normally as $e o$ before $a$, as $i u$ elsewhere." The change of $e i$ to $\bar{l}$ was not yet completed in the third century CE if the evidence of Alateiviae, the name of a deity from Xanten, is to be trusted (Polomé 1994: 6).

5. That the vowel $\bar{l}$ of the present system was able to exert influence of this sort is also the premise behind all the most convincing explanations for the long $\bar{u}$ (for expected $u$ ) in the so-called aorist presents of verbs of the second strong class, such as brücan 'enjoy', bügan 'bend', and düfan 'dive': see §12.18.

6. Seebold (1966b: $3 \&$ n. 4) supposes that beðinn is due to confusion with the pp. of biðja 'bid', a confusion paralleled in OE (though only in manuscripts of the late tenth and eleventh centuries, and never in the pp. of the verb). This would be a more convincing analysis if there were other evidence in ON of confusion of biða and biðja and from an early date, seeing as †biðinn does not occur.

\subsection{Changes of stressed vowels in Gothic}

PGmc. $e$ and $i$ fell together as $i$ in Gothic, except that both appear before $r, h, h$ as $a i$ $(/ \varepsilon /)$, in a process commonly referred to as 'breaking', as in stilan 'steal' (OE OS OHG stelan), bairan 'bear' (OE OS OHG beran), pp. laíhans 'lent' (OHG gi-liwan). ${ }^{1}$ Similarly, PGmc. $u$ appears as $u$ in Gothic, but as aú $(/ \mathrm{J} /)$ before $r, h, h,{ }^{2}$ as in pret. $3 \mathrm{pl}$. -budun 'offered' (OE budon, OS budun), pp. -budans 'offered' (OE boden, OHG gibotan), pret. 3 pl. waúrpun 'became' (OE wurdon, OS wurdun).

Before a vowel, PGmc. $\bar{e}$ and $\bar{o}$ develop to / $\varepsilon: /$ and / $/ 2: /$, transcribed as $a i$ and $a u$, without any acute, to distinguish them from the vowels identified in $\S 3.4$. Examples: PGmc. "séana ${ }^{n}>$ Go. saian 'sow'3 and PGmc. 3 sg. pret. *stōiðe $(p)>$ Go. stauida 'judged'.

The diphthongs $e u$ and $i u(\$ 4.4)$ fell together as iu in Gothic, e.g. *keusana ${ }^{n}>$ Go. kiusan 'choose' (cf. OE cēosan) beside *liuxtijana ${ }^{n}>$ Go. liuhtjan 'give light' (cf. OE liehtan).

1. Exceptions are waila 'well' (OE OS wel, OHG wela), aippáu 'or' (OE eppa beside usual oppe, OHG ed(d)o), and hiri, hirjats, hirjip 'come here!', on which see Cercignani 1984, and on hiri in particular, van der Hoek 2007. Raising also fails in reduplicative syllables in verbs of strong class VII, e.g. pret. faifalp 'fold', usually explained as due to the analogical influence of preterites like haiháit 'call', or to weak stress. For alternative explanations, see Cercignani 1979 (with refs.), Ebbinghaus 1991. 
2. It cannot be determined whether $u$ had been lowered to $o$ in PGmc. before a non-high vowel (see $\S 4.3$ ), but if so, the change of PGmc. $o$ and $u$ in Gothic would be entirely parallel to that of the equivalent front vowels.

3. Such is the view, e.g., of Braune (2004b: §22). It is sometimes assumed instead that verba pura such as this should be reconstructed with a medial $j$ (so, e.g., Wright 1954: §77, Krause 1968: §58), thus * sejjanan, but see $\$ 12.22$, where it is argued that such verbs had intervocalic hiatus due to loss of a laryngeal consonant. Even if they did contain $j$ in PGmc., the sound must have been lost in Gothic, as otherwise spellings with $j$ should be expected there, e.g. † $\uparrow \bar{e} j i p$ rather than the attested saiip 'sows' (beside saijip, which is rare and likelier to contain an inorganic insertion than an inherited segment), like bajōps beside bái 'both' (see d'Alquen 1974: 148-54). The same reasoning applies, mutatis mundandis, to assumed $\bar{o}$ rather than $\bar{o} w$ in stauida, etc., where $w$ is never inserted: see Fulk 1993a: 249-51.

\subsection{Changes of stressed vowels in the Northwest Germanic protolanguage}

Whereas PIE $\bar{e}$ appears as $\bar{e}$ in Gothic, in most of the NWGmc. languages it is reflected as $\bar{a}$, though in WS as $\bar{x}$ and in the remaining OE dialects and OFris. as $\bar{e}$. As remarked above (\$3.3), the PGmc. sound is sometimes reconstructed as $\bar{x}$, though also (as in this book) as $\bar{e}$ (i.e., $\bar{e}_{l}$ ). Its reflex in NWGmc. and/or WGmc. is usually posited as either $\bar{a}$ or (as in this book) $\bar{x}$. The uncertainty cannot be eliminated conclusively, but the preponderance of evidence suggests $\bar{x}$ rather than $\bar{a}$. For example, when *swa 'so' undergoes vowel lengthening on the basis of Prokosch's law (\$2.5), the result is OS OHG sō, not $\dagger s \bar{a}$, and in OE and OFris., the languages in which there was fronting of low vowels (§4.12), the result is $s w \bar{a}$ and $s \bar{a}$, respectively. ${ }^{1}$ Thus, in no instance does this new lengthened $\bar{a}$ coalesce with the WGmc. reflex of $\bar{e}_{1}$, rendering $\bar{x}$ the likelier reconstruction for the latter. ${ }^{2}$ On the other hand, the development of the reflex of $\bar{e}_{1}$ to $\bar{o}$ before a nasal consonant in Anglo-Frisian (\$4.12) would seem to favor the reconstruction $\bar{a}$ as the reflex of $\bar{e}_{l}$, but it is hardly impossible that in Anglo-Frisian, $\overline{\mathfrak{x}}^{n}$ as the reflex of $\bar{e}_{l}$ before a nasal consonant should have coalesced with the nasalized reflex of $a$ lengthened by the loss of a nasal consonant before a voiceless fricative in North Sea Germanic $(\$ 4.11){ }^{3}$ The names of Angles and Frisians in Latin sources of the first and second centuries CE are spelt with $\langle\mathrm{e}\rangle$ (which presumably may represent either $\bar{e}$ or $\bar{x}$ ). Elsewhere in West Germanic the change of $\bar{e}$ to $\bar{a}$ begins in Upper German (the earliest instances in names being from the second half of the first century CE for Bavarian) and spreads northward, the earliest Franconian evidence for the change dating to ca. 500, with a few $\langle\mathrm{e}\rangle$ spellings persisting as late as the eighth and ninth centuries, whereas PGmc. $\bar{e}_{1}$ is reflected as $\bar{a}$ already in the earliest North Germanic inscriptions (see Bremer 1886: 12-29). ${ }^{4}$ The assumption of WGmc. $\bar{a}$ rather than $\bar{x}$ leads to some difficulties in reconstructing the chronology of Anglo-Frisian sound changes, as illustrated by A. Campbell 1977: $§ 132$. The asymmetry between long and short vowel systems that results from the assumption of $\bar{x}$ as the reflex of $\bar{e}_{1}$ plausibly explains the divergent developments respecting $a$ and $\bar{x}$ in Anglo-Frisian and elsewhere in NWGmc. (§4.12).

1. OE $s w \bar{x}$ and $s w \bar{e}$ do occur in some dialects, but they can be explained as due to lengthening of re-stressed $*_{s w æ}<s w a$, with Anglo-Frisian Brightening (§4.12), whereas $s w \bar{a}$ must result from lengthening before that change. See $\S 8.13$ n. 6 .

2. Stiles (2004) argues that because the vowel of PGmc. * par 'there', * $x^{w} a r$ 'where', when lengthened in WGmc., coalesced with the reflex of PGmc. $\bar{e}_{l}$, the latter must already have developed to $\bar{a}$ in WGmc. This argument proves inconclusive because if there was no $\bar{a}$ in WGmc. at the time of the lengthening, presumably the lengthened vowel would have been identified with the nearest preëxisting equivalent in value, which may 
have been $\bar{x}$. Similar reasoning pertains to the borrowing of Lat. strāta as OE strāt. At all events, Bremer's evidence (see below) forbids the assumption of a general WGmc. $\bar{a}$ at the time of the lengthening.

3. Or, perhaps likelier, $\bar{x}$ became $\bar{a}$ before a nasal consonant, as might be expected on the basis of comparison to the short vowels, where there was no sequence $x$ plus nasal in Anglo-Frisian, only an (\$4.12).

4. Contradicting the observations of Bremer, however, is the Runic name-element -mariR $\left(<\mathrm{PGmc}\right.$. $\left.{ }^{*} m e \bar{e} r i z\right)$ on the Thorsberg chape from nothern Germany (Anglia, ca. 200). Possibly, though, the chape is of NGmc. origin (see Stiles 2004: 390), or $\langle\mathrm{a}\rangle$ represents $\bar{x}$. That Gmc. $\bar{e}_{1}$ continued to be spelt either $\langle\mathrm{e}\rangle$ or $\langle\mathrm{a}\rangle$ for some time (e.g. ca. 500-ca. 700 in Franconian names) could indicate that the sound was $\bar{x}$ during that period, though it could also be due to conservative spelling traditions. Scholarship on the development of PGmc. $\bar{e}_{1}$ (e.g. Hollifield 1980: 145-50) seems generally unacquainted with Bremer's findings. See further Polomé 1994: 7, Stiles 2004, Kortlandt 2006a. Ringe (in Ringe \& Taylor 2014: 10-13) regards the assumption of NWGmc. $\bar{a}$ as simpler, but that is a matter of perspective, as the supposition of a change PGmc. $\bar{e}>$ NWGmc. $\bar{a}>\mathrm{OE} \bar{x}$ is not as simple as the assumption that OE $\bar{x}$ reflects the NWGmc. vowel unchanged.

\subsection{Front mutation}

Long after the PGmc. change of $e$ to $i$ before $\breve{l}$ or $j$ in the next syllable (§4.4), under the same conditions most other vowels underwent fronting and/or raising in a process of front mutation, more commonly referred to as front umlaut or $i / j$-umlaut, or simply umlaut (a term originating with Jacob Grimm). The process is an assimilatory one inasmuch as it eases articulation: in anticipation of the following high front vowel or glide a vowel takes on some of its qualities, requiring less movement of the tongue at the onset of $\check{\bar{l}}$ or $j$. Alternatively, the process has not infrequently been analyzed as assimilation not of the qualities of $\breve{l}$ or $j$ itself but of the palatal quality lent an intervening consonant by the mutating sound. ${ }^{1}$ There are some disadvantages, though, to this alternative formulation, chief of which is that palatalization of consonants other than velars does not normally lead to phonemic distinctions in the early Gmc. languages, e.g. no $* / \mathrm{n} /:$ : $/ \mathrm{n} /$, so that the assumption of non-phonemic palatalized variants seems speculative. ${ }^{2}$ Likewise, the parallel development of back mutation (\$4.8) can hardly be thought to depend upon rounding/backing of intervening consonants. Further alternatives to the theory of distance assimilation include the supposition of epenethesis, e.g. $*_{\text {-ati- }}>*_{-} a^{i} t i$ - $>*_{\text {-eti-; }}$ the supposition of a process of vowel harmony (interpreting that term broadly); and the theory of umlaut as a result of language contact: on these, see Krygier 1997, with references. ${ }^{3}$

The general trend represented by the umlaut process may be expressed by Fig. 5 , wherein it will be seen that the vowels affected all trend toward the high front position of $\tilde{\bar{l}} / j$. New vowels created by umlaut are placed in round brackets, and of course the change of $e$ to $i$ took place much earlier (\$4.4).

Only East Germanic (including Crimean Gothic) shows no evidence of the effects of umlaut, but the process applied at various times and with varied effects in the

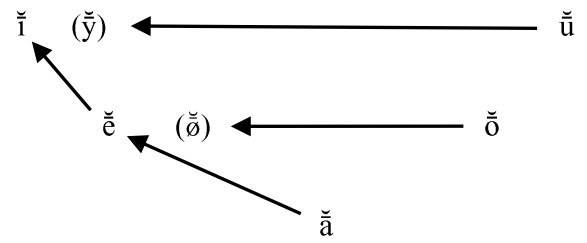

Fig. 5. The general direction of front mutation in the early Germanic languages. 
remaining Gmc. languages, so that it is necessary to assume either a change proceeding across NWGmc. in waves or a change originating in various places due to similar linguistic conditions (see $§ 1.2$ ). In WGmc., umlaut must have occurred earliest in North Sea Gmc., as the southward spread of the change can be observed in High German (see below). In $\mathrm{OE}$ the change is perhaps to be dated to the first half of the sixth century (Luick 1914-40: §350), whereas in Runic there is no reliable evidence for umlaut in the Older Futhark. ${ }^{4}$ In WGmc., outside of Ingvaeonic (i.e., in all dialects of OHG and OLF), only the umlaut of $a$ to $e$ is expressed in the orthography of the older languages; though other vowels must have been umlauted, as well, the change does not affect spelling until the MLG and MHG periods.

Old Icelandic. Two discrete patterns of umlaut are discernible in NGmc., ${ }^{5}$ (1) one in which the change was caused by $i$ or $j$ lost in the early period, and (2) one in which it was caused by preserved $i$ or $j$. In the former pattern (1), umlaut regularly applies to heavy syllables but not usually light, e.g. heavy bekkr 'bench' $<*$ baykiz and pret. heyrði 'heard' < *xauziðē : light acc. sg. stað 'place' < *staðin , nom. nár 'corpse' $<*$ nawiz, and pret. gladdi 'gladden' $<*_{3}$ laðiðé. In the latter pattern (2), umlaut applies to both heavy and light syllables, e.g. heavy kerling '(old) woman' $<*$ karling $\bar{o}$ : light ketill 'cauldron' < *katilaz. In pattern (1) the umlauted vowel was (apparently) phonemicized upon loss of $i$ or $j$, and this explains the different results for heavy and light stems, since presumably $i$ was lost earlier after heavy stems than light, just as in WGmc., e.g. OE giest 'guest' $<*_{3}$ astiz but wine 'friend' $<*$ winiz. Such is the groundbreaking analysis of Kock (1888, though of course without reference to phonemicization), who posited three historical periods:

A. Umlaut in heavy syllables when $i$ (but not $j$ ) disappeared, ca. 600-700;

B. Umlaut in light syllables by a following $i_{R}\left(>_{R}\right.$; see below) or $j$, ca. 700-850;

C. Umlaut by preserved $i$ after both heavy and light syllables, ca. 900-1000.

Implicit in this analysis is thus the assumption that umlaut should have taken place in heavy stems but not light on a purely phonological basis, and this seems unlikely, as there is no apparent phonetic basis for the distinction. ${ }^{6}$ It would therefore seem natural to assume instead that between the loss of $i / j$ in heavy and light stems there was paradigm regularization: in heavy-stem paradigms, where umlaut was no longer phonologically conditioned, the umlauted stem was commonly extended throughout the paradigm, e.g. from the masc. nom. sg. to the gen. sg. and dat. pl., ${ }^{7}$ whereas in light-stem paradigms, where the conditioning remained, the unumlauted stem was extended throughout. That there was indeed umlaut at one time in light stems is shown by the appearance of umlaut in a number of words in which analogical restoration of the unumlauted vowel was not possible, such as gegn 'against' $<$ gegin $<*_{\text {zazina }}$ and mylna 'mill' (borrowed from Lat. molina), as well as mass nouns, which had no plural, e.g. gnyðr 'murmur', $k y l r$ 'gust of cold air' ${ }^{8}$ On this assumption, however, it is difficult to account for light-stemmed preterites of the first weak class without umlaut, e.g. $v a k ð i$, vakti 'roused' (to vekja) <*wakiðē, since there were no forms anywhere in the paradigm that did not originally contain either $i$ or $j$. Conversely, light roots bearing the PGmc. suffix *-ipō always have umlaut, e.g. spekð, spekt 'wisdom', lemd 'lameness' (cf. spakr 'wise', lami 'lame person'), and they, too, would have had suffixal $i$ throughout the paradigm. Yet this latter type could be due to the analogical influence of related forms: cf. speki 'wisdom' < ${ }^{*}$ spakin- and lemja 'to lame'. ${ }^{9}$ Perhaps, then, verb forms like vakði may be explained on the assumption that the reduction and lowering of unstressed $i(\$ 5.6)$ took place before the vowel was lost after light syllables, and the 
umlauted vowel, its fronting no longer conditioned, reverted. ${ }^{10}$ Alternatively, and intriguingly, Liberman (2001: 88) suggests that the failure of umlaut after light stems is related to their different syllabification under Prokosch's law ( $\$ 2.5$; see also Kylstra 1983, Kleiner 1999a), an idea pursued at greater length in Schulte 2004. ${ }^{11}$ Since verbs of the first weak class are usually derived from other parts of speech, Kiparsky (2006) argues that analogy to related forms induced reversion in preterites like talð $i$ 'told' beside the noun tal 'talk'. More persuasive is the explanation of Iverson \& Salmons (2012: 115) that after the earlier syncope, the preterite suffix in heavy stems was no longer $*_{-} i \partial$ - but $*_{-} \partial-$, and this was extended to the light stems. Yet this account, too, leaves some questions unanswered. ${ }^{12}$ To date, no consensual view of these matters has emerged, and this remains a topic that invites further investigation.

Note that $i$ from earlier $\bar{e}$ developed too late to cause umlaut, e.g. faðir 'father' < *faðer $r$. The specific results of $i / j$-umlaut in ON are these:

$a>e$ : PGmc. *sandi(j)iz(i) > sendir 'send' (2 sg.; cf. Go. sandeis); PGmc. * satjana ${ }^{n}>$ setja 'set' (cf. Go. satjan).

$\bar{a}$ (from PGmc. $\bar{e}_{1}$ and $\left.\bar{a}^{n}\right)>æ($ i.e., $/ \mathfrak{x}: /)$ : PNorse 2 sg. *lātiR $>$ lætr 'let' (cf. inf. láta); PNorse *ājan > æja 'bait (a horse)' (cf. pret. áði); PGmc. 2 sg. pres. ${ }^{*} f \bar{a}^{n} x i z>f æ r$ 'get'.

$o>ø$ : As $o$ is to be derived from $u$ by lowering before a non-high vowel in the next syllable, a lowering prevented by $j(\$ 4.3)$, $o$ was not commonly in a position to undergo umlaut. It might be introduced analogically into the relevant position, however, as in nom. pl. doetr 'daughters' $<*$ døhtr $<$ PNorse *doxtriR (cf. Runic dohtriR).

$\bar{o}>\propto($ i.e., $\bar{\emptyset}):$ PGmc. *sōki(j)iz(i) > sœkir 'seek' (2 sg.; cf. Go. sōkeis); PGmc. *dōmijana ${ }^{n}>$ doema 'judge' (cf. Go. dōmjan).

$u>y$ : PGmc. *spurjana ${ }^{n}>$ spyrja 'track' (cf. spor 'footprint' < *spura ${ }^{n}$ ); PGmc. *brunjō > brynja 'coat of mail' (cf. Go. brunjō).

$\bar{u}>\dot{y}:$ PGmc. *mūsiz > mýss 'mice' (cf. sg. mús); PGmc. *funsijana ${ }^{n}>$ fýsa 'urge' (cf. fúss 'willing').

au > ey: PGmc. *xlaupiz(i) > hleypr 'leap' (2 sg.; cf. inf. hlaupa); PGmc. *xauzijana ${ }^{n}>$ heyra 'hear' (cf. Go. háusjan).

iu $>$ ý: PGmc. *briutiz(i)> brýtr 'break' (2 sg.; cf. inf. brjóta); PGmc. *biujōz > pýjar 'bondwomen' (nom. pl.; cf. Go. piujōs).

A similar but somewhat later change, though still pre-literary, is the so-called $R^{-}$ umlaut. $R$ was apparently a palatal consonant $(\$ 6.14)$, and it mutated an immediately preceding back vowel or diphthong, as in gler 'glass' $<*$ glar, kýr 'cow' <*kū , eyra 'ear' < *aurōn, hlýr 'cheek' < *hleuran (OE hlēor), and fem. pl. pær 'they' <* $\bar{a}^{\prime}$. This change is often connected with the so-called $i_{R}$-umlaut, which, unlike the older $i / j$ umlaut, regularly affect vowels in light syllables, e.g. kømr 'comes' < *komiR and ferr 'goes' $<*$ fariR. The likeliest explanation of $i_{R}$-umlaut, however, in accordance with the analysis of $i / j$-umlaut offered above, is that palatal $R$ prevented the lowering of $i$ to $e$, and thus this is simply another variety of $i$-umlaut. Comparable is the later change (palatal mutation) of $a$ to $e$ before $g i$ or $k i$ in which $i$ has developed from earlier $e$ or $æ$ due to the palatal consonant, as in tekinn 'taken' (inf. taka) and genginn 'gone' (inf. ganga).

Old English. Even though, among the Gmc. languages, umlaut occurred first, perhaps, in OE (so, e.g., Hirt 1931-4: I, §33.2), it took place relatively late in the series of vowel changes characteristic of that language, such as fronting of $a$ and breaking $(\S \S 4.12-13) .{ }^{13}$ The results in EWS are these: 
$æ>e$ : PGmc. *bariz > *bæri > bere 'barley' (cf. Go. barizeins 'made of barley'); PGmc. *satjana ${ }^{\prime}>$ settan 'set' (cf. Go. satjan).

$a>x$ : The vowel $a$ did not normally occur in a position where it would be subject to umlaut, having always been fronted to $x$ in the relevant environments (§4.12), but $a$ could be restored on an analogical basis and then umlauted. Examples: PGmc. *farip $(i)>*$ færip, reformed as *farip (cf. inf. faran) > færð (cf. Go. farip); PGmc. *sakja ${ }^{n}$ (acc. sg.) > * sækkja, reformed as *sakkja (cf. OE sacu 'strife') > sæcc 'strife'.

$\bar{a}($ from $a i)>\bar{x}:$ PGmc. $*$ dailiz $>* d \bar{a} l i>d \bar{x} l$ 'portion' (cf. Go. dáils); PGmc. *laizijana ${ }^{n}>$ *lārjan > lāran 'teach' (cf. Go. láisjan).

$o>e$ (Anglian $\alpha$, spelt $\langle\mathrm{oe}\rangle$, or $e$ ): The vowel $o$ did not normally occur in a position where it would be subject to umlaut, since PGmc. $u$ was not lowered to $o$ when $\overline{\bar{l}}$ or $j$ appeared in the next syllable (\$4.3). It might be introduced analogically, however, or it might undergo umlaut in a loanword. Examples: PGmc. *murzinaz reformed as *morzinaz (on the basis of the alternative stem *morzan-, as in OHG morgan) > mergen (cf. OIcel. myrginn, morginn); OE ele 'oil' (Northumbrian ole) from Lat. oleum.

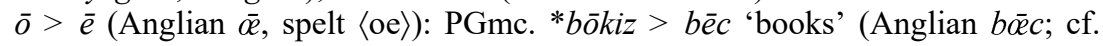
bōcere 'scholar'); PGmc. *sōkijanan $>$ sēcan 'seek' (cf. Go. sōkjan). The same development affects $\bar{o}$ derived from $\bar{a}^{n}(\$ \S 4.1,4.11,4.12)$ : *wēniz $>{ }^{*} w \bar{a}^{n} n i z>{ }^{*} w \bar{n} n i>$ wēn 'expectation' (Anglian wōen); *zansiz $>*_{3} \bar{a}^{n} s i>$ gēs 'geese' (Anglian gōes).

$u>y$ (Kentish e): PGmc. *muniz > myne 'mind' (cf. Go. muns); PGmc. *buзjana ${ }^{n}>$ bycgan 'buy' (cf. Go. bugjan).

$\bar{u}>\bar{y}$ (Kentish $\bar{e})$ : PGmc. *fūlipō > fȳld 'filth' (Kentish fêlp; cf. fül 'foul'); PGmc. *brūki(j)ip(i)> brȳcð 'enjoys' (cf. Go. brūkeip).

ea (breaking of $x, \S 4.13)>$ ie (non-WS e): PGmc. *xalðip(i) > hielt 'holds' (cf. inf. healdan); PGmc. *balpijana ${ }^{n}>$ bieldan 'embolden' (cf. beald 'bold', and see $\$ 6.17$ on *-lp->-ld-). The same development is seen in the WS palatal diphthongization of $æ$ $(\$ 4.13)$, e.g. giest 'guest' $<*_{3}$ easti $<*_{3}$ sti $<*_{3}$ astiz and be-sciered 'deprived' $<$ $*_{\text {-scearid }}<*_{\text {-scærid }}<*_{\text {-skariðaz. }}$

$\bar{e} a($ from $a u)>\bar{l} e$ (non-WS è): PGmc. *lauziz > lìeg 'flame' (Anglian lèg; cf. Go. láuhmuni 'lightning'); PGmc. *bauzijanan > biegan 'bend' (Anglian bēgan; cf. bēag 'ring'). In EWS nīehst(a) $<*$ nēahist- $<*$ nz̄hist- is seen the same development of the breaking of $\bar{x}(\S 4.13)$.

$\breve{\bar{e} O}>\check{\bar{l}} O(>\overline{\bar{e}} O$, but Northumbrian $\check{\bar{l}} O)$ : The diphthongs $e o$ and $\bar{e} O$ should not have occurred before $i$ or $j$ in the next syllable $(\$ 4.4)$, but they could be introduced into the environment for umlaut on an analogical basis. The plainest evidence of this is words in which EWS $\breve{l e}$ might be expected but is not found, e.g. gepēode (also EWS gepiode)

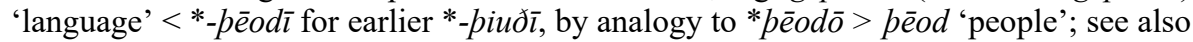
n. 14 and A. Campbell 1977: $\$ 202$.

io (breaking of $i)>$ ie (Northumbrian io, Mercian, Kentish eo): PGmc. *irzijaz > *iorrī > ierre 'angry' (Northumbrian iorre, Mercian eorre; cf. OS irri); ${ }^{14}$ EWS gesiehð 'sees' (Kentish -siohð) $<*$ sioxip $<*$ six ${ }^{w} i p(i)$.

$\bar{i} u$ (from PGmc. iu, §4.4) > ie (non-WS ē): PGmc. *kiusip(i) > ciest 'chooses' (cf. inf. Go. kiusan); PGmc. *liuxtijana ${ }^{n}$ liehtan 'illuminate' (cf. Go. liuhtjan).

Front umlaut could also occur when $i / j$ appeared in the third syllable of words with initial stress, e.g. $\bar{x} m y r g e, \bar{x} m e r g e$ 'embers' $<* \bar{a} m y r j æ<*$ aimurjo $\bar{o}^{n}$ (cf. OHG eimuria): see A. Campbell 1977: §203. 
Old Frisian. Although front umlaut must have produced a variety of sounds in the prehistoric period, they had all fallen together as $\check{\bar{e}}$ by the time of the historical records: ${ }^{15}$ ledza 'lay'.

$$
a>x(\S 4.12)>e: \text { PGmc. *baðjaz > bed 'bed'; PGmc. *lazjana }{ }^{n}>* \text { leggjan }>
$$

$\bar{a}^{n}$ (from PGmc. ay before $x, \S 4.1$, and NSGmc. an before a voiceless fricative, $\S 4.11$, and Anglo-Frisian $\bar{a}$ before a nasal consonant, §4.12) > $\bar{e}$ : PGmc. ${ }^{*}$ fanxip $>$ $f \bar{a}^{n} x i p>$ fèth 'takes'; PGmc. *tanpiz $>*$ tăn biz > têth 'teeth'; PGmc. *wènijana ${ }^{n}>$ *wānjan > wēna 'expect'.

$\bar{o}>\bar{e}$ : PGmc. *blōðijana ${ }^{n}>$ blēda 'bleed'; PGmc. bōtijana ${ }^{n}>$ bèta 'atone'.

$u>y>e$ : PGmc. *kustiz > kest 'choice' (cf. OE cyst); PGmc. *kunjan $>$ kenne 'kind' (cf. OE cynn).

$\bar{u}>\bar{y}>\bar{e}:$ PGmc. *brūðiz > brēd 'bride' (cf. OE brȳd); PGmc. *kūpijanan $>$ kètha 'announce' (cf. OE cỳdan).

$a i>\bar{a}>\bar{x}>\bar{e}$ : PGmc. *laizijanan $>$ lēra 'teach' (cf. OE lāran); PGmc. *dailiz

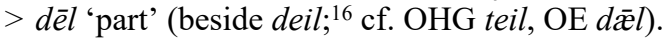

au $>\bar{a}>\bar{e}$ : PGmc. *hauzijana ${ }^{n}>*$ hārjan $>$ hēra 'hear'; PGmc. *laubijana ${ }^{n}>$ lēva 'believe' (cf. Go. ga-laubjan).

PGmc. iu remains unchanged (rather than developing to $i \bar{a}, \S 4.14$ ) in umlaut environments, except that it becomes a rising diphthong, e.g. PGmc. *diupijana ${ }^{n}>$ diūpa 'deepen, dip' (cf. LWS dȳpan $<*$ diepan).

Old Saxon. Only the umlaut of $a$ to $e$ (and $a i$ to $e i$ ) is undeniably indicated in the orthography, and even then forms with $a$ by analogical replacement are frequent beside those with $e$, e.g. mannisk beside mennisk- 'human' and acc. pl. handi beside hendi 'hands'. The evidence of MLG, however, shows that other back vowels and back diphthongs must have been mutated: see, e.g., Lasch 1914: $\S \S 42-60$. Occasional spellings in OS itself could also represent the native umlaut of vowels besides $a$ (see, e.g., Prokosch 1939: $\$ 41 \mathrm{~h}$ ), but other explanations are possible. ${ }^{17}$ Unlike in OE, syncope (\$5.6) antecedes $i$-umlaut in heavy-stemmed verbs, e.g. sanda 'sent' : OE sende (cf. Go. sandida).

Old High German. As with OS, only the early umlaut of $a$ ('primary umlaut') is indicated in the spelling, as $e$, though Notker (late $10^{\text {th }}$ cent.) uses $\langle i u$. for the umlaut of /u/, and MHG evidence shows that other back vowels and back diphthongs must have undergone mutation ('secondary umlaut', which by most accounts includes umlaut of $a$ in environments in which it had earlier been prevented), as the $i$ or $j$ that caused the umlaut evidenced in MHG had been lost or lowered to $e$ already in the OHG period, with signs of weakening as early as the start of the ninth century. ${ }^{18}$ On the basis of rhyme in MHG poetry it may be concluded that the $e$ derived from PGmc. $e$ and the $e$ resulting from the umlaut of $a$ were discrete phonemes, $/ \varepsilon /$ and /e/, respectively, and thus in modern grammars they are often distinguished as $\ddot{e}$ and $e$ (or $e$ ), respectively. ${ }^{19}$ Examples of the umlaut of $a$ are PGmc. *lambiz- > lembir 'lambs' (cf. nom. lamb) and PGmc. *brannijana ${ }^{n}>$ brennen 'burn' (cf. pret. branta). This umlaut of $a$ begins to appear in the OHG records ca. 750 and is carried through by the ninth century, spreading southward. It fails before $h+$ consonant and before consonant $+w$ (as also, in part, in OS), as in mahtīg 'mighty' and garawen $<*^{*}$ zarwijana ${ }^{n}$. Also as in OS, occasional spellings, especially late in the OHG period and early in the MHG, seem to evidence attempts to represent the effects of umlaut: examples are $\bar{a}>\bar{x} / \bar{e}$, as in unsélic 'misfortunate' (12 th cent.); uo (from $\bar{o})>u e$, as in gruene 'green'; $u>\ddot{u}$ (spelt $i, u i, i u$, $y$ ), as in ibilo 'evil' $<* u \hbar i l-\left(11^{\text {th }} / 12^{\text {th }}\right.$ cent.); $\bar{u}>i u$, as in liuten 'make a sound' (cf. lüt 


\section{'sound'; Notker, ca. 1000); and $\bar{o}$ (from $a u$ ) > $\bar{e}$, spelt oi in troistest 'console' (2 sg.; $11^{\text {th }}$ century). Because they are late, such spellings are unlikely to represent Anglo- Frisian orthographic influence.}

1. So, e.g., Scherer 1995: 142-5 and Sievers 1885a: $\$ 41$ Anm. For an overview of developments in the study of umlaut, see Holsinger \& Salmons 1999: 241-5.

2. Cf. Kleiner 1999a: 95. Palatalization of /1/ is probably the best explanation for the failure of diphthongization in OE tellan < Proto-WGmc. *talljan (for expected OE *tiellan < *tealljan: see Barrack 1998: 153-5). Otherwise, however, it should probably be assumed that $/ 1 /$ in the syllable coda was normally velar in prehistoric OE (see §4.13).

3. Howell \& Salmons (1997) argue that front umlaut is most regular when it affects vowels most different in place of articulation from the conditioning sound; hence, $a$ is umlauted first and most regularly, $u$ least regularly.

4. The form niuhagestumr on the Stentoften stone (mid- $7^{\text {th }}$ cent.) has repeatedly been said to show front umlaut in dat. pl. -zestumR 'guests', analogical to nom. sg. ${ }^{*}$ zest $(i)_{R}<*_{3}$ astiR (cf. -gastiR on the Gallehus horn, ca. 400), but it now appears that the inscription should be interpreted as niu ha[n]gestums 'nine steeds': see Santesson 1989: 227b; Schulte 1998: 76-82.

5. For bibliography on ON front umlaut, see Schulte 1998, Iverson \& Salmons 2012. For an intensive study of the Runic evidence for the reduction and syncope of umlaut-causing vowels, see Schulte 2000a; for a concise account, H.F. Nielsen 2000: 261.

6. That umlaut at first affected vowels in heavy syllables but not light is nonetheless an idea that is to be found still in recent literature, e.g. Lahiri 2000: 120 and Voyles 2005: 268, the latter adopting the unorthodox position that "many - if not most" phonological changes are governed from the start by morphosyntactic conditioning.

7. This formulation assumes that the $i$-stem gen. sg. and dat. pl. endings were replaced early by $a$-stem desinences, as otherwise there are no $i$-stem case-forms that can be assumed with confidence not to have undergone umlaut. Replacement of the fem. $i$-stem endings by $\bar{o}$-stem ones must have been far advanced at the time of syncope, since umlaut has been removed entirely from the fem. paradigm.

8. Wadstein 1892. There is also the mythological name Bergelmir, the prototheme of which, as suggested by the context (Vafprúðnismál 29, 35), should mean 'barley' and thus be derived from *bari(z)-: cf. OIcel. barr, OE bere 'barley' ( $i$-stems, originally $s$-stems), Go. barizeins 'made of barley': see Fulk 1989: 317.

9. Analogical change in spek $\partial$, etc., is essentially the view of Schulte (1998: 250-1), who distinguishes usefully among $i-, j$-, and $\bar{i}$-umlaut.

10. So Hesselman 1945: 25-45, esp. 29, and earlier Seip (1919: 86), the latter assuming $i>\curvearrowright$; similarly Reid 1990 , assuming $i>a$. The corpus of Runic inscriptions yields no evidence on this point. Reversion may seem questionable if $i$ had been lost already after heavy stems and the umlauted vowel in such stems therefore had been phonemicized. If the new sounds were regarded as separate phonemes in heavy stems, why not also in light? The alternative of supposing that $i$ was lowered to $e$ after light stems only, and before the loss of $i$ after heavy stems (as seems to be suggested by Gordon 1957: 272), is surely unlikely, as the loss of $i$ after heavy stems shows that the vowel was weakened earlier there.

11. For a synopsis of attempts to explain the failure of umlaut in light radical syllables, see Schulte 1998: 3058.

12. They explain (2012: 117) that with the replacement of *-ið- by $*_{-} \partial-$ - "the motivation for retaining umlaut in ${ }^{+}$telða, now from /tal+ða/, simply disappeared.” A similar, though lightly sketched, explanation was offered by Kleiner (1999a). Yet umlaut should originally have applied to all forms within the paradigm, and so it is difficult to see how the underlying stem could have escaped lexicalization as *tel- rather than *tal-. Another possibility is that reversion in the pret. ind. served to differentiate the ind. from the sj., a difference already eliminated in the heavy stems. But the problem of how the light umlauted stem persisted unlexicalized remains. Some of these issues are treated in Fertig 2013, where comparison is drawn to the disappearance of umlaut in nouns that lost $\mathrm{OHG}-i$ and $\mathrm{MHG}-e$ in the gen. and dat. sg., e.g. OHG dat. sg. anst beside ensti 'favor' and MHG gen./dat. sg. kraft beside krefte 'power'.

13. The argument of Collier (1987) that $i$-umlaut preceded breaking and the WS digraph 〈ie $\rangle$ represents $/ \mathbf{i} /$ cannot be reconciled with the evidence of the ME dialect of the Southwest, in which the reflex of WS ie is a rounded vowel: see $\$ 4.13$. 
14. This word, however, with PGmc. ${ }^{*} r z-$, is something of an exception (due to the geminate), since in Anglian, breaking usually failed before $r$ when $i$ appeared in the next syllable. EWS hierde 'herdsman' (PGmc. *xirdijaz; Northumbrian hiorde, Mercian heorde) probably has the umlaut of eo extended analogically from heord 'herd'. See A. Campbell 1977: $\S \S 154,201$.

15. See further Russ 1996.

16. OFris. ei rather than $\bar{e}$ is common before dental sounds and $l$.

17. Thus, for example, Holthausen (1921) explains forms like andwirdi 'answer' and fisid 'inclined' (for andwurdi, füsid), as scribal errors ( $\$ 88$ Anm. 4), and forms like ēhtin (< PGmc. * $\bar{a}^{n} x t i n a z$ 'regarded') and $m \bar{e} r i$ 'glorious' (< Proto-WGmc. *mǣrja) as possibly due to English or Frisian influence $(\S \S 89,92)$.

18. Braune 2004a: $\S \S 51,56$. This analysis, however, is not universally accepted, as some are of the opinion that umlaut was not phonemicized, or perhaps not even realized allophonically, until late in the OHG period: see, e.g., Kastovsky 1995: 231 n. 8, Voyles 1996 (with refs. to his earlier work, and to opposing views of H. Penzl), Klein 2013: 184. Voyles, in particular, has argued in various studies that umlaut spread on a morphological or morpholexical rather than a phonological basis and thus need not have arisen in OHG before the tenth century. For an overview of the controversy, see Iverson \& Salmons 1996 (arguing that primary umlaut did antecede secondary) and M.R. Barnes 1999. For criticisms of morpholexical approaches, see Holsinger \& Salmons 1999: 245, though their concern is solely the status (phonological or morpholexical) of primary umlaut. Gütter (2011) highlights and discusses twelve names in documents from the period 827-957 which show umlaut of vowels other than $a$.Some further studies relevant to OHG umlaut are van Coetsem \& McCormick 1982, McCray 1983, Kortlandt 1993, Salmons 1994, Iverson, Davis, \& Salmons 1996, Janda 1998, Rauch 1999, Isakson 2002, and Panieri 2012-13.

19. For discussion, see Liberman 1987.

\subsection{Back mutation}

In both North and West Gmc., a back vowel may exert influence upon a front vowel in a preceding syllable. In some instances, especially in NGmc., the process closely parallels front mutation, in that the affected vowel remains monophthongal and assimilates one or more features of the back vowel, but more commonly the result is fracture-that is, development of the front vowel to a back diphthong. These processes are also sometimes referred to as $u$-umlaut (or $u / a$-umlaut) or back umlaut, or labial (or labiovelar) umlaut, though in ON studies these terms are not commonly used to refer to fracture.

Old Icelandic. When $a$ appears in the next syllable, $u$ is lowered to $o$, as in koma 'come' (cf. OE cuman), gen. sonar 'son' (nom. sunr). This change, known as $a$-umlaut, is very commonly reversed on an analogical basis, e.g. guð 'god' beside goð. See Noreen 1970: $§ 61.1$ for details.

Stressed $e$ before $a$ in the next syllable (but not before nasalized $\left.a^{n}\right)^{1}$ undergoes fracture to the falling diphthong $e a$, with subsequent conversion to the rising diphthong $j a$, as with PNorse *berzan > bjarga 'save' (cf. Go. bairgan) and *herta > hjarta 'heart' (cf. Go. hairtō). ${ }^{2}$ In parallel fashion, $e$ before $u$ in the next syllable undergoes fracture to a falling diphthong that may be represented $e o$, later developing at least in West Norse to a rising diphthong $j g$, but $j o$ before a geminate velar stop in OIcel. (e.g. pjokkr 'thick' < NWGmc. *bekkuz) and jó when lengthened (§4.9, e.g. mjólk 'milk'; cf. Go. miluks). ${ }^{3}$ There is thus $u$-fracture in PNorse acc. pl. *skeldu $>$ skjgldu 'shields' and dat. pl. *heltum $>$ hjoltum 'hilts'. There has been disagreement in the literature about the specifics of $u$-fracture. ${ }^{4}$

In addition to these instances of fracture, there is rounding of a stressed non-back vowel or diphthong, often referred to as back umlaut, labial umlaut, or $u / v$-umlaut. ${ }^{5}$ The 
vowels $a$ and $\bar{a}$ are rounded before $u$ in the next syllable; similarly, $e, \breve{\bar{l}}$, and $e i$ are rounded before either $u$ or $w$ :

$a>g$ : PGmc. *pankō > *pakku > pokk 'pleasure' (cf. Go. pagkjan 'think'); PNorse *allum > ollum 'all' (dat. pl.; cf. nom. sg. allr).

$\bar{a}$ (from PGmc. $\bar{e}_{1}$ or $\bar{a}^{n}$ ) > $\dot{o}$ : The $\dot{o}$ produced by this change subsequently fell together with $a$ by about 1250 and is represented thus in normalized orthography; however, $\dot{g}$ is required by the rhymes in some earlier skaldic verse. Examples: PNorse dat. sg. *gātu > gótu, later gátu 'riddle'; PGmc. *ax ${ }^{w} \bar{o}>* \bar{a} u>o ́$, later á 'river' (cf. Go. ahva); PGmc. 1 pl. pres. * făn xum > OIcel. fọm, later analogical fóum, fáum 'take'.

$e>ø$ : This change is infrequently caused by $u$ because $e$ in the relevant position underwent fracture except after $r$ or next to $l$ (see supra). Examples: PNorse *reru $>$

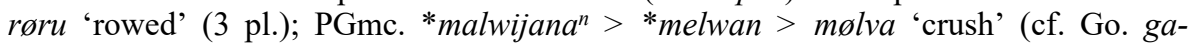
malwjan); PGmc. *stigk ${ }^{w} a n a^{n}>{ }^{*}$ stekkwan (§6.14) > støkkva 'spring' (cf. Go. stigqan).

$i>y$ : NWGmc. ${ }^{*}$ mirkwiz $>{ }^{*}$ mirkuR $>$ myrkr 'darkness'; PGmc. * ${ }^{*}$ igg ${ }^{w} a n a^{n}>$ syngva 'sing' (cf. Go. siggwan)

$\bar{\imath}>\dot{y}$ : PGmc. *tīwaz $>* t \bar{\imath} u R>T y ́ r$ (name of a god; cf. Lat. dīvus 'god'); ${ }^{6}$ PNorse *strīkwan > strýkva (but usually analogical strýkja) 'stroke' (cf. OE strīcan).

ei $>$ ey: PGmc. *aiwa > *eiu > ey 'ever' (cf. Go. ni-áiw 'never'); Proto-West Norse $* k^{w} æ i k^{w}$ - in $k v e y k v a$ 'kindling' (more commonly kveikja).

Changes of this sort could also apply to vowels of lesser stress, e.g. in *-tezuR > -tøgr in pritøgr ' 30 '. According to the standard view, $a$ in a medial syllable was mutated to $Q$, later developing to $u$, as in nom. sg. fem. ${ }^{*}$ zamalo $>*_{\text {zamolu }}>$ gomul 'old'; on the possibility that this might be the result of an earlier change, see $\$ 5.5$. In combination with various consonants, $u$-umlaut could produce further changes, referred to collectively as combinative back mutation, e.g. PGmc. ${ }^{*}$ wèrun $(p)>*^{*}$ wārun $>$ óru 'were' (beside analogically restored vóru, later váru, though óru is required by the poetic form in some skaldic verse: see Hornklofi, Haraldskvæði 2/2) and PNorse *nahtu $>$ nótt 'night' (\$6.14).

As with $i / j$-umlaut $(\$ 4.7)$, there appear to have been two patterns of this back umlaut, (1) whereby the umlaut is always carried through and the $u / w$ is lost in the early period, and (2) whereby the $u / w$ is preserved and the umlaut is usually missing in East Norse. The East Norse results, however, cannot be due to phonological developments only, as there is evidence for the earlier occurrence of pattern (2) in East Norse: see Hreinn Benediktsson 1963, with references.

Old English. A front vowel may be diphthongized by a back vowel in the following syllable, though conditions for this set of developments vary by dialect, the changes being most widespread in Mercian and least in WS, where they are generally limited to the position before a lone labial or liquid consonant $(f, p, w, m, l, r) .{ }^{7}$ With few exceptions (noted below), the change does not occur in closed syllables, and only in Kentish (and Mercian, if the change is not analogically induced) does it take place before a velar consonant. This change is most likely coeval with, or postdates, the earliest manuscript evidence (ca. 700: see the references in Fulk 1992: 347 n. 170).

The product of this change is diphthongs that are orthographically indistinguishable from diphthongs inherited from PGmc., but their subsequent histories show them to have differed from those diphthongs. In poetic meter they are treated like short vowels, whereas diphthongs inherited from PGmc. have the same scansion as long vowels. Despite the typological objections that have been raised, e.g. by Stockwell \& Barritt (1951), it is generally assumed that phonemically long and short diphthongs were 
distinguished in $\mathrm{OE}$, the former marked here with macrons. Indeed, repeated attempts have been made to explain the digraphs produced by back mutation (as well as breaking and diphthongization by initial palatal consonant, \$4.13) as non-diphthongal, but the alternative proposals all face daunting obstacles (see Hogg 1992: $\$ \$ 2.20-30$ for discussion and references). ME spellings of the Southwest like seothen $<$ OE seoppan 'afterward', souen, seoue(ne) < OE seofon 'seven', and hor < OE heora 'their' do not prove that the result of back mutation was an actual back diphthong, but such spellings are also used for the reflexes of OE long diphthongs (e.g. leosen, loese < OE léosan 'lose'), just as the long and short diphthongs are spelt identically in OE, and so the orthographic evidence is hard to dismiss.

The change is caused by $a$ or $u$ (or its allophone $o$ ), whether etymologically long or short:

$x>e a$ in West Mercian only, ${ }^{8}$ though spellings with $e a$ are common in verse. Examples: PGmc. *xabukaz > Mercian OE heafoc (WS hafoc) 'hawk'; PGmc. *xafō > Mercian OE heafu (WS hafu, -o) 'oceans'.

$e>$ eo: PGmc. *xerotaz > OE heorot 'hart'; PGmc. *bebruz > OE beofor 'beaver' (cf. Skt. babhrúh 'reddish-brown; mongoose'). ${ }^{9}$

$i>$ io, which yields $e o$ in all dialects except Northumbrian and, in part, Kentish. Examples are WGmc. *klipōd $\bar{x}>$ Northumbrian OE cliopade (WS cleopode; cf. WS inf. clipian beside analogical cleopian) 'called'; PGmc. *sibun(-) > Northumbrian OE siofu, WS seofon (cf. Go. OHG sibun). The vowel $i$ in the environment for back mutation, and regardless of the following consonant, may undergo so-called combinative back mutation when it follows $w$, as in OE wudu 'wood' $<$ widu (also attested) and swugian beside swigian 'be silent'.

Although back mutation is rare in closed syllables, it does occur in a few forms, the commonest of which are seoððan 'since' and siondon 'are' beside siððan, sindon.

Old Frisian. The vowel $i$ was diphthongized to $i u$, a rising diphthong, before $u$ or $w$ in the next syllable, e.g. niugen '9' < NSGmc. *nizun and diunk 'dark' < WGmc. *dinkwa.

Old Saxon and Old High German. The vowel $e$ is raised to $i$ before $u$ in the next syllable, e.g. OS OHG filu 'many' (cf. OIcel. fjol- < PNorse *felu-), OS OHG sihu '(I) see' (cf. OE sēo < WGmc. * $\operatorname{sex}^{w} u$ ), and OS miluk, OHG miluh 'milk' (cf. OE $\operatorname{meol}(o) c)$. The change often fails even when there is no analogical basis for restoration of e, e.g. OS ebur, OHG ebur 'boar' (cf. OE eofor < PGmc. *eburaz).

1. So, most notably, there is no fracture in verbs of strong classes IV and V because $a^{n}$ remained nasalized after a light stressed syllable (see $\$ 2.5$ on the Germanic foot), hence, e.g., geta 'get' rather than †gjata.

2. This change is attested in Runic inscriptions of the seventh century (Björketorp, Istaby).

3. This is the convincing explanation of Hreinn Benediktsson (1963: 428-31), who argues that when $e$ was diphthongized, its off-glide could be identified with any of the extant back vowels, and $g$ was the sound it was usually identified with in Old Icelandic. The handbooks of OIcel. grammar generally instead assume a change of $j o$ to $j o$ by ca. 1250 on the basis of orthographic evidence (countered by Hreinn).

4. Before Hreinn Benediktsson (1963) offered his analysis there were two prevailing views: (1) that $a$ - and $u$-fracture produced different diphthongs from the start (as Hreinn assumes), and (2) that they both initially produced $e a$, which subsequently underwent back mutation and stress shift to $j o$, just as $a$ is mutated to $g$. Hreinn (1963: 431) demonstrates the unreliability of the orthographic evidence for the latter view. A third view, that fracture is an unconditioned change, initiated by a general diphthongization of $e$ to $i e$ (so Svensson 1944), appears to have gained no adherents.

5. See the exchange of views between S.R. Anderson and G.K. Iverson in Language Sciences 42 (1976), 26-34; also Kuzmenko 1994. 
6. When $u$ is the cause of this change, it must immediately follow $\bar{l}$.

7. For details of the conditions of the change in other dialects, see A. Campbell 1977: $\S \S 205-21$.

8. This is because Mercian is the only dialect in which $æ x$ could occur before a back vowel, due to so-called Second Fronting, whereby $æ>e$ and $a>x$ : for the conditions, see Hogg 1992: $\S 5.87-92$.

9. In a form such as geol(o) ca 'yolk', from WGmc. *jeloko $\hat{o}^{n}, e$ would have been diphthongized to ie by the initial palatal consonant, and this appears to have been converted to io (later eo) by back mutation: see A. Campbell 1977: $§ 220$.

\subsection{Changes of stressed vowels and diphthongs in Proto-Norse}

PGmc. $\bar{e}_{1}$ has become NGmc. $\bar{a}$ already in the earliest NGmc. Runic inscriptions, e.g. in the name-element -marAz on the Ellestad stone (ca. 550-600?). Koivulehto (1986: 286) finds that PGmc. $\bar{e}_{1}$ appears as $a$ already in the earliest loanwords into Finnish, borrowed ca. 300-200 BCE.

In Proto-Norse, $a i$ was fronted to $x i$, later giving OIcel. ei. In the older runic inscriptions it is still represented by ai (there being no separate rune for $\mathfrak{x}$ ), as in staina on the Tune stone (ca. 200-ca. 450) and stain on the Eggjum stone (ca. 700). But under certain conditions it was monophthongized to $\bar{a}$ : (1) $x i>\bar{a}$ immediately before $/ \mathrm{x} /$, which was subsequently lost, as in PGmc. *aix(e)> OIcel. $a$ 'owns' (still Aih on the Maglemose bracteate, ca. 400-ca. 650). The change is perhaps attested as early as ca. 400-ca. 600 on the Åsum bracteate in the form fahi[do] 'color[ed]' and on the Halskov bracteate (ca. 450-550?) in the form fahide. ${ }^{1}$ (2) $x i>\bar{a}$ before $r$ (but not before $R$ ), as in PGmc. *saira $>$ OIcel. sár 'wound' (Go. sáir, OE sār) and PGmc. *airuz > órr, later árr (§4.8) 'messenger’ (Go. áirus, OE ār); cf. PNorse *gaikan > OIcel. geirr 'spear'. (3) $æ i>\bar{a}$ in some medial syllables of lesser stress, §5.6. In addition, Proto-Norse $æ i$ developed to ON $\mathfrak{x}$ (i.e., /æ:/) before $w$ (which might be lost, §6.14), as in *aiwin- > OIcel. ævi 'age' (cf. Go. aíws < *aiwaz) and hræ 'corpse' (cf. Go. hraíw).

Parallel to (1) above there are the changes $\breve{\bar{l}}>\dot{e}, \breve{\bar{u}}>o$, and $a u>o$ before (lost) $/ \mathrm{x} /$, as in *rixtijana ${ }^{n}>$ rétta 'straighten' (cf. OHG rihten), 3 sg. pret. * ${ }^{*} \bar{u}^{n} x t \bar{e}>$ pótti 'seemed' (cf. OE pühte), and *pauh > *pōh (borrowed into OE; cf. ME pōz) > pó 'though' (cf. Go. páuh). The /x/ thus lost may represent the devoicing of $*_{3}(\S 6.14)$, as in *flau $>$ *flauh $>*$ flōh $>$ fló 'flew'. As the example of rétta shows, vowels were lengthened before $x t$ (probably at the time of the lenition of $x$ to h), which subsequently developed to $t$.

Also in Proto-Norse, a nasal consonant was lost before non-final $s, f, r, l$, with nasalization and compensatory lengthening of the preceding vowel. Examples: *ansuz $>\bar{a}^{n}$ suz $>{ }^{*} \bar{o} s u R>$ OIcel. áss 'god' (cf. Latinized Go. anses, OHG ansi-); *fimfilan $>$ *fifila > fifl 'fool'; PNorse *bunraR $>* b \bar{u}^{n} r a R>$ Pórr (name; cf. OE gen. sg. punres 'thunder'); PNorse *anlaibaz > *ālæiநar > Áleifr (name, beside Oláfr, with -eirequired by the rhyme in some skaldic verse, e.g. Sigvatr bórðarson, Vikingarvísur 9/8 and Nesjavisur 4/4). See Krogh 1996: 221-3. Compensatory lengthening attends the loss of various consonants, as in PNorse *biwiR > pir 'maidservant' (cf. Go. piwi), PGmc. *maplan > mál 'speech, affair' (cf. Go. mapl 'market'), PNorse *fjoðriR > fjórir '4' (cf. Go. fidwōr), and PGmc. *axtō > átta '8' (cf. Go. ahtáu).

Some further lengthenings may be mentioned. There is lowering and lengthening of high vowels before $R$ in OWN monosyllables, e.g. dat. *miR > mér 'me'; cf. the short vowel in 3 pl. pret. *kuRun $>* k o r u^{n}>k ø r u$ 'chose' (with $R$-umlaut, $\$ 4.7$; cf. OHG 
churun). There is thus lowering without lengthening otherwise before $R$, as in eru 'are' $<*_{e} u^{n}<*_{i z u n}$. Starting about 1200, back vowels and diphthongs are lengthened before $l$ plus a labial or velar consonant $(m, f, p, g, k)$, rarely a dental, as in hjálmr 'helmet', sjálfr 'self', úlfr 'wolf', bólginn 'swollen', fólk 'people', háls 'neck', skáld 'poet' (requiring a short vowel for the rhyme in early skaldic poetry, e.g. Bragi's exchange with the troll-woman 1/1)

With the loss of postconsonantal $w$, a following $a$ or $e$ might become $o$, and $i$ might become $y$, as in tolf '12' (later tólf; cf. Go. twalif), sofa 'sleep' (cf. OE swefan),

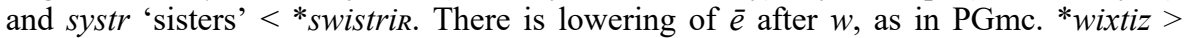
*vēttr (with $i>\bar{e}$, as above) $>$ vættr 'weight'.

There is general shortening of long vowels before geminate consonants, as with nom. sg. neut. gott 'good' : masc. góðr and nom. sg. masc. pinn 'your (sg.)' : dat. binum, though an exception is before $t t<x t$, as in PGmc. *xaxtuz $>$ háttr 'manner'. The diphthong $e i$ became $e$ under such conditions, as in ekki 'not' < * æitt-gi and edda 'grandmother' (cf. poetic eiða 'mother'). The effects of this change are often removed on an analogical basis, e.g. in nom. sg. masc. finn 'fine' (cf. dat. finum), nom. sg. neut. litt 'little' (cf. masc. lítill), and stórr 'large'. Likewise, there is general shortening in closed syllables, including syllables closed as a result of syncope, as with nom. pl. masc. ymsir 'various' (nom. sg. ýmiss), brullaup 'wedding' < brúð-laup, Porsteinn (name, from Pór-), Skirnir (name; cf. skíra 'cleanse'), and mestr 'most' (cf. Go. máists). Once again, however, analogy commonly removes irregularities, e.g. dýrð beside dyrð 'glory' (cf. dýr- 'costly') and árna beside arna 'intercede' (cf. Go. áirinōn 'be an emissary' and OIcel. ár- 'messenger').

In Old West Norse, PGmc. eu develops to eo, whence jó, before dental consonants, $x$, and $m$; otherwise it appears as jú. Examples: PGmc. *keusana ${ }^{n}>$ OIcel. kjósa 'choose', *peuxa ${ }^{n}>$ pjó 'thigh', *xleumaz > hljómr 'sound', but *leuzana ${ }^{n}>$ ljúga 'lie', *leubaz $>$ ljúfr 'dear'. Contrariwise, the back diphthong that developed in preterites of class VII (\$12.20) gives OIcel. jó regardless of what consonant follows, as with hljóp 'sprang', jók 'increased'.

On front and back umlaut, and fracture, see $\$ 4.7-8$. For further details of ProtoNorse vowel developments, consult the grammars cited in $\S 1.14$.

1. The form fahido occurs also on the Rö stone (ca. 400), but there perhaps a for ai is due simply to omission of a rune, given the form saira 'wound' in the same inscription (so Antonsen 1975: 13, 43).

\subsection{Changes of stressed vowels and diphthongs in the protolanguage of West Germanic}

The handbooks (e.g. A. Campbell 1977: §120.2) prescribe that new diphthongs developed when the sequences $-a w j$ - and -iwj- underwent WGmc. gemination ( $\$ 6.15)$, e.g. $*_{\text {strawjana }}{ }^{>}$* strawwjan $>$*strauwjan > EWS *strīegan, Anglian strēgan 'strew', and *niwjaz $>$ *niwwja $>$ *niuwja $>$ OE niewe, OS OHG niuwi 'new'. There are, however, significant reasons to doubt this. ${ }^{1}$ Similar diphthongs developed as a consequence of the Verschärfung (if the Verschärfung did not result from the analogical extension of diphthongs rather than doubling of glides: see $\$ 6.10)$, with or without umlaut, e.g. *klajjō $>* k l a i j \bar{o}>k l \overline{a j} u>$ OE clāg, similarly OFris. klāy, MLG klei, and *trewwō $>*$ treuwu > OE trēow 'faith', OS treuwa, OHG triuwa (cf. Go. triggwa). New diphthongs also arose as a consequence of the WGmc. loss of $w$ before $u(\S 6.16)$, as with 
*prawō $>$ *prawu $>$ *prau $>$ OE prēa 'affliction', or when postvocalic $w$ became final and thus formed a diphthong, as with *trew $a^{n}>*$ treu $>$ OE trēo, OS trio 'tree', or when final $-\bar{o}$ became $-u$ and contracted with a preceding vowel, as with *hi- $\bar{o}$ (with analogical fem. $-\bar{o}$ added to the stem $h i-)>* h i u>$ OE $h \bar{e} o$ 'she'.

1. It is difficult to imagine how $w$ could have remained consonantal in forms like ${ }^{*}$ strawjana $^{n}$ and ${ }^{*}$ niwjaz (cf. Go. stráujan, niujis), and at all events WGmc. *strauwjan should be expected to have developed not to EWS * striegan but to *striewjan $>*$ striewan $(\S 6.15)$. See also $\$ 6.10$ on the unlikelihood of the dismantling of geminates in this fashion. Rather, EWS *striegan may be derived unproblematically from PGmc. * straujana ${ }^{n}$, and $\mathrm{OE}$ niewe may be assumed to have undergone the same sort of paradigm regularization that affected words like OE peeow, gen. pēowes 'servant' (\$7.12).

\subsection{Changes of stressed vowels in North Sea Germanic}

In a change comparable to that seen in PGmc. *fayxana ${ }^{n}>f \bar{a}^{n} x a n a^{n}(\$ 4.1)$, in North Sea Germanic a nasal consonant was lost before any voiceless fricative, with nasalization and compensatory lengthening of the preceding vowel. The change thus affects $m f$, $n s, n p$ and produces $\bar{a}^{n}, \bar{l}^{n}, \bar{u}^{n}$. The first of these yields $\bar{o}$ in Anglo-Frisian (as does $\bar{a}^{n}$ inherited from PGmc.), but either $\bar{a}$ or $\bar{o}$ in OS (whereas PGmc. $\bar{a}^{n}$ is always reflected as $\bar{a}$, as in OS OHG brāhta: OE brōhte, OFris. brochte 'brought'): for details, see Ringe \& Taylor 2014: 142-6. Examples: WGmc. *fimf $>*^{*} \imath^{n} f>$ OE OFris. OS fiff (cf. Go. OHG fimf); WGmc. *zans > OE OFris. MLG gōs, but OHG gans 'goose'; PGmc. *funsaz> OE OS fūs, but OHG funs 'ready'; *anperaz > OE ōðer, OFris. ōther, OS āđar, ōđar, but Go. anpar, OHG ander 'other'. Compare the similar developments in NGmc. (\$4.9).

At least in some instances, final stressed $*-w \bar{o}$ yields $-\bar{u}$, as in OE OFris. OS $h \bar{u}$ 'how' (beside OFris. OS $h u \bar{o}$ ) and OE neut. $t \bar{u}$ 'two'. The same change probably results in OE $c \bar{u}$, OFris. $k \bar{u}$ 'cow' (also OIcel. $k y ́ r$, dat. \& acc. $k \dot{u}$, but OS $c \bar{o}$, OHG kuo), since this derives from PGmc. ${ }^{*} k^{w} \bar{o}-$ (cf. Lat. $b \bar{o} s$, and see Szemerényi 1956, idem 1996: $\S 7.5 .5$; De Decker 2011), and OE neut. $b \bar{u}$ 'both' can be explained as analogical to $t \bar{u}$. The facultative nature of the change in NSGmc. suggests generalization of paradigm alternants. See Lane 1936: 22 for references, and Hollifield 1979 and Schrijver 2004: 201-4 for an alternative analysis assuming development of final $\bar{o}$ to $\bar{u}$ even in a stressed syllable without a preceding labial element. To the contrary, Ringe (2017: 223) suggests a Pre-PGmc. paradigm alternant due to a change ${ }^{*} g^{w} O w_{-}>*^{*} u w->* g \bar{u}-$, whereas Euler (2013: 91-2, following Griepentrog 1995: 238-40, 246) thinks the forms with $\bar{u}$ are by analogy to *s $\bar{u}$ - 'sow'. See also Boutkan 1995b: 44-5.

\subsection{Changes of stressed vowels and diphthongs in Anglo-Frisian}

(N)WGmc. $\bar{x}\left(<\bar{e}_{1}\right)$ appears as $\bar{x}$ in WS, but as $\bar{e}$ elsewhere in Anglo-Frisian. ${ }^{1}$ An exception is before nasal consonants, where it is reflected everywhere as $\bar{o}$, presumably from earlier $\bar{a}^{n}$, as in OE OFris. mōna 'moon' (cf. Go. mēna, OIcel. máni, OS OHG $m \bar{a} n o$ ) and 3 pl. pret. OE c(w)ōmon, OFris. kōmen 'came' (cf. Go. qēmun, OS quāmun).

Parallel to these developments in the long vowels are changes affecting $a$ : (1) Before a nasal consonant it was nasalized. In OFris. and in some dialects of OE the resulting $a^{n}$ was subsequently rounded, hence OFris. OE (Mercian) noma 'name', lomb 'lamb', hond 'hand', long 'long'. '2 (2) Elsewhere, $a$ was fronted to $æ$. In the absence of 
further conditioning (see below) it remained as such in OE, whereas it is reflected in OFris. as e. Examples: OE fæder 'father', dæg 'day', læt 'slow, late', OFris. feder, dei, let (cf. Go. fadar, dags, lats). This fronting is commonly referred to as Anglo-Frisian Brightening. Except in umlaut environments, PGmc. a remains unchanged in OFris. before /x/ (cf. achta 'eight', sax 'knife', slā 'kill' (<* slaxan)), before checked $l$ (cf. salt 'salt', ald 'old'), between $w$ and checked $r$ (cf. warm 'warm', swart 'black'), and in some unaccented words, e.g. was 'was'. In Anglo-Frisian a notable asymmetry between the long and short vowel inventories of WGmc. (with no short vowel corresponding to $\bar{x}$, no long vowel corresponding to $a$ ) was thus eliminated by the fronting of $a$ to $x$, whereas elsewhere in WGmc. (and NGmc.) it was eliminated by the backing of $\bar{x}$ to $\bar{a}$ (§4.6). See further Kortlandt 2008: 266.

This fronting of $a$ applied also to the diphthong $a u$ in OE, producing $\bar{e} a$, at first a diphthong with a rounded off-glide, as shown by early spellings, e.g. 〈aeodbald〉 (i.e. $\bar{E}$ adbald, name) in Bede, with rounding persisting in late Northumbrian. There probably was no such fronting in the development of $a u$ in OFris., where it produces $\bar{a}$, before which there is no palatalization (\$6.17; see Kortlandt 2006a). Examples: OE ēac 'also', ēage 'eye', bēam 'tree' : OFris. āk, āge, bām (Go. áuk, áugōo, OHG boum), but OE gēac 'cuckoo' (with palatal initial) : OFris. gāk. PGmc. ai appears as $\bar{a}$ in $\mathrm{OE}^{3}$ and is represented by $\langle\mathrm{e}\rangle$ or $\langle\mathrm{a}\rangle$ in OFris., probably [e:] and [æ:], with the cause of the divergent outcomes still debated (see Goblirsch 1991, Hofmann 1995, with references). Examples: OE OFris. gād 'lack', rāp 'rope', fem. \& neut. twā 'two' (cf. Go. gáidw, -ráips, twái), but also OFris. (n)ān '(n)one', hām 'home', klāth 'garb' beside (n)èn, hèm, klēth.

1. The evidence of Insular North Frisian shows that in the dialect out of which it developed the sound was probably $\bar{x}$, as in WS: see Århammar 2001: 750-3.

2. Only in the West Midlands did this rounding persist in OE, and to the present day. The vowel appears to have lost any vestige of its nasal quality elsewhere by the end of the OE period (so A. Campbell 1977: $\S 130$ ).

3. Uncertainty about whether ai became $x i$ in Anglo-Frisian stems from doubts about whether $æ i$ could have developed to OE $\bar{a}$ : so, e.g., A. Campbell 1977: $§ 132$.

\subsection{Changes of stressed vowels in early Old English}

PGmc. eu develops to $\bar{e} o$ in Old English, as in *freusana ${ }^{n}>$ frēosan 'freeze' and *deuzan $>$ déor 'beast'. This èo develops to $\bar{\imath} o, \bar{l} a$ in Kentish.

Front vowels may become back diphthongs before certain consonants, usually in the syllable coda. These are $r, l, h$, and (by some accounts) $w .{ }^{1}$ The standard view is that these consonants were velar, as one might expect on the basis of their modern reflexes, though this is not the only explanation that has been offered. ${ }^{2}$ This so-called breaking (which antedates front umlaut, §4.7) takes place before $r$ and $l$ only in closed syllables (and not when the sonorant is simply word final), whereas $h$ causes breaking in both open and closed syllables. The vowels that undergo breaking are $\breve{\bar{e}, ~} \overline{\bar{e}}, \breve{\bar{l}}$, producing what were presumably otherwise identical long and short diphthongs, though some of the same controversy attends the interpretation of the OE digraphs as in the case of back mutation (\$4.8). The specific environments and results of breaking are these:

Before $r$ plus any consonant other than $j$ (and always before $r r$ ), the short vowels $æ$ and $e$ are broken to $e a$ and eo. Examples are bearn 'child', heard 'hard', weorð 'worthy', steorra 'star' (cf. Go. barn, hardus, waírps, staírnō). In Northumbrian, æ 
often is retracted to $a$ instead, especially after a labial consonant, as in farr 'bull' and ðarf'need'.

Before $l$ plus any consonant, $x$ is broken to $e a$, whereas $e$ is broken to $e o$ in WS only when the consonant after $l$ is $h$. Examples: healp 'helped', healdan 'hold' (Go. halp, haldan) and seolh 'seal' (OHG selah). Breaking also occurs in $\bar{a}$-seolcan 'become languid' and in non-WS seolf 'self'. Breaking of $i$ before $l$ cannot be proved. Before checked $l$ the Anglian dialects show retraction rather than breaking of $x$, as in cald 'cold' and all 'all' (WS ceald, eall).

Before $h$ (i.e. [x] on the standard view) in both open and closed syllables, $\breve{\bar{x}, ~} \overline{\bar{e}}$, and $\check{\bar{l}}$ are broken to $\overline{\bar{e}} a, \check{\bar{e}} O$, and $\check{\bar{l}}$ ( $>\check{\bar{e}} O$ in most dialects). ${ }^{3}$ Examples: *xlaxtraz $>$

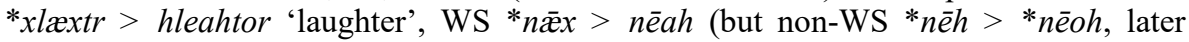
Anglian nēh, Kentish *nīoh); *fextana ${ }^{n}>$ feohtan 'fight'; Peohtas 'Picts'; *ligxtaz > *līxtaz > līoht, lēoht 'light' (adj.; cf. Go. leihts). At the time of breaking, short $i$ occurred in an open syllable only in umlaut environment, e.g. $*_{-\operatorname{sixi}}(i)>{ }^{*}{ }_{-\operatorname{sioxip}}>$ -siehð 'sees'.

Before $w$, $\breve{\bar{x}}$ was retracted to $\breve{\bar{a}}$, as in WS ge-sawen 'seen' and pret. pl. sāwon 'saw'. In open syllables it was also retracted before a back vowel in the following syllable, hence nom. pl. dagas 'days' (sg. dæg) and dat. pl. māgum 'kinsman' (nom. sg. $m \bar{x} g$ ), though $\bar{x}$ is often found for $\bar{a}$.

A source of short diphthongs besides back mutation ( $\$ 4.8)$, as well as breaking, is diphthongization by initial palatal consonants (which precedes front umlaut but not breaking: cf. ceorl 'commoner', not †cierl, from *kerlaz). In Anglo-Frisian, front vowels palatalize an initial velar consonant (\$6.17), producing OE palatal $c, s c, g$, and in WS, $\breve{\overline{\mathscr{Z}}}$ and $\breve{\bar{e}}$ are in turn diphthongized by the initial palatal. Examples are ceaster 'town' $<*$ cæstru $<*$ kastrō (borrowed from Lat. castra); $3 \mathrm{sg}$. geaf 'gave' $<*_{3 æ f}<$ PGmc. *zab(e) (Go. gaf); pl. gēafon 'gave' < *3 $\bar{x} \hbar u n<$ PGmc. *zēbun(p) (Go. gēbun); scieran 'cut' < *skeranan (cf. OIcel. skera); gīe 'you (pl.)' < $*_{z} \bar{e}$. ${ }^{4}$ Similar changes occur less regularly in Northumbrian: see A. Campbell 1977: $\$ 186$ for details. The digraphs in such forms are of disputed significance (see $\$ 4.8$ supra and Hogg 1992: $\S 5.49$ ), but the vocoids resulting from $\overline{\bar{e}}$ and from the umlaut of $\overline{\bar{x}}, \overline{\bar{e}}$ affected by initial palatals are reflected in ME with spellings indicating rounding (e.g. Southwestern ME зиuе < EWS giefan 'give'), strongly suggesting that at least originally the result of this change was a set of back diphthongs (see Fulk 2012: §20 \& Remark 3).

At about the time of the earliest manuscript records, in a process referred to as smoothing, the diphthongs $\breve{\bar{e} a}, \check{\bar{e}}$, dialects before $c, g, h$, which were thus presumably palatal (see Hogg 1992: $\$ 5.93$ for discussion). Subsequently, $\bar{x}$ as the result of smoothing developed to $\bar{e}$, and before $r$ or $l$ plus a back consonant $æ$ became $e$. Examples: wæx 'wax' (WS weax, OS wahs); færh, ferh 'pig' (WS fearh, OHG far(a)h); hēh 'high' (WS hēah, Go. háuhs); werc 'work' (WS weorc, OIcel. verk); flège 'fly' (WS flèoge, OHG flioga); mixen 'dunghill' (WS meoxen $<*$ mixs $(t)$-); fìl 'file' $<* f \imath \imath^{\imath} x l u<* f i \eta x l o ̄$ (WS fēol). Smoothing of $\check{\bar{e} a}$ to $\check{\bar{e}}$ occurred in LWS before or after a velar (palatal) consonant, though the change is expressed only irregularly in the orthography, e.g. LWS ehta 'eight', hēh 'high', ège 'eye', pret. sg. gef 'gave', cēs 'chose', gèer 'year' beside eahta, hēah, etc.

By various means, such as loss of intervocalic $h, w$, or $j$, or analogical refashioning, vowels (and diphthongs) could become contiguous and undergo contraction.

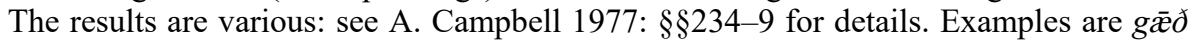
'goes' < *gæ-ip (§12.63); fōn 'take' < *fōhan $<* f \bar{a}^{n} x a n a^{n}$; sēon 'see' $<{ }^{*}$ seohan $<$ 
$*^{*} \operatorname{sex}^{w} a n a^{n} ;$ slēan 'strike' < *sleahan < *slæxan < *slaxana ${ }^{n \cdot 5}$ frēond 'friend' < * fri(j)ōnd- ${ }^{6}$ Compensatory lengthening occurs upon loss of $x$ between voiced sounds, even with an intervening liquid consonant, as in gen. sg. méares (cf. nom. mearh 'horse'), pwēal 'washing' (cf. Go. pwahl), èored 'troop' < *eoh-rād-. Poetic meter sometimes preserves evidence of the state before the application of contraction and compensatory lengthening (see Fulk 1992: 92-121).

In a process referred to as palatal umlaut, $e$ (or $e o$ or io developed from it, where Anglian smoothing did not apply) before $/ \mathrm{x} /$ plus consonant in absolute finality was raised to $i$, as in cniht 'boy', riht 'right', wrixl 'change'. It cannot be determined whether the digraph in siex 'six' represents an actual diphthong.

On front and back umlaut, see $\S \S 4.7-8$. For further details of OE vowel developments (especially changes of the literate period, which are for the most part left unconsidered here), consult the sources cited in $\$ 1.16$.

1. It appears rather that supposed instances of breaking before $w$ can be explained as due to back mutation (§4.8): see Fulk 1993b: 350 n. 6, idem 1992: 146 n. 2. On Gmc. breaking in general, see Roelands 1989, Liberman 1998, Kostakis 2015. On OE breaking in particular, see H.F. Nielsen 1984 (and the refs. there), Strøjer 1984, Kortlandt 1994a, Suzuki 1994; also Hogg 1992: §§5.16-34, with refs.

2. Howell (1991b) argues on the basis of parallels chiefly in German dialects that breaking in OE is instead a consequence of weakening of the relevant consonant. The chief difficulty confronting this view is that $/ \mathrm{x} /$ would appear not to have been weakened in the relevant environments in OE, as shown by later developments, including Anglian smoothing and LWS smoothing (see A. Campbell 1977: §§222-33, 312-14), and development of [x] to [y] and [f] in ME (Jordan 1974: §§196-7). Lutz 1991 likewise explains various vowel developments in the history of English as due to weakening of $/ x /$. Gąsiorowski (2006) argues that the articulation of $\mathrm{OE} / \mathrm{r} /$ was hardly uniform - as might be expected on the basis of modern dialects.

3. At the time of breaking, WS had no $\bar{e}$ in the relevant environments and non-WS no $\bar{x}$.

4. Although WS had $\bar{x}$ where Anglian had $\bar{e}$ at the time of this change, a new $\bar{e}$ had arisen by lengthening under Prokosch's law (\$2.5), hence * $3 \bar{e}$ 'you (pl.)' (> Mercian $g \bar{e})$ by analogy to $w \bar{e}$ 'we’ (§8.3).

5. It is sometimes assumed that in forms like *seohan and *sleahan the loss of $h$ induced lengthening of the preceding vowel before contraction: so, e.g., Hogg 1992: §7.45. Yet there would have been nothing to compensate in terms of syllable weight and structure if, as is usually supposed, $h$ in such forms was in the syllable onset rather than the coda. See Fulk 1992: §101. It should be noted that when contracted forms like sēon demand disyllabic scansion in verse, a heavy initial syllable is never required.

6. Unlike the other examples, frēond is never disyllabic in verse, and at some places the meter demands a monosyllable (i.e., not *frijōnd-), e.g. Beowulf 1385 a.

\subsection{Changes of stressed vowels in Old Frisian}

There is breaking of $e$ and $i$ to $i u$, a rising diphthong, before $/ \mathrm{x} /+/ \mathrm{x}, \mathrm{s}, \mathrm{t} /$, as in *texxō$>$ tiuche 'team, parcel of land', 2 sg. * sixist $>*^{*}$ sixst $>$ siuchst 'see', *fextan $>$ fiuchta 'fight'. Breaking is prevented by $i$ in the following syllable, as in *plixti- $>$ plecht 'duty'. Unlike in OE, $i$-umlaut antecedes breaking in OFris. (see Stiles 1995: 194-5). ${ }^{1}$

As in $\mathrm{OE}$, adjacent vowels contract upon loss of intervocalic $h$ : $-a-a$ - contracts to $-\bar{a}-$, as in WGmc. ${ }^{*}$ slaxan $>$ sla 'strike'; $-e-a$ - contracts to $-i \bar{a}$-, as in ${ }^{*} \operatorname{sex}^{w} a n>s i \bar{a}$ 'see', and $-\overline{\bar{o}}-a-$, whether in verba pura or due to loss of intervocalic $x$, yields $-u \bar{a}$-, as in *do-an $(\S 12.61)>d w \bar{a}$ 'do' and WGmc. *xăn xan $>$ *hōxan $>$ hwā 'hang'.

PGmc. eu develops to a rising diphthong $i \bar{a}$ (cf. Kentish OE, $\$ 4.13$ supra), as in PGmc. *leubaz > liāf 'dear' and *beuðanan $>$ biāda 'offer'.

Palatalization of $3(\$ 6.17)$ resulted in the rise of a new diphthong ei, as in

*waznaz $>$ *wæzn $>$ wein 'cart' and *xuziz $>$ *hyzi $>$ hei 'mind' (\$4.7). 
On front and back umlaut, see $\S \S 4.7-8$. For further details of OFris. vowel developments, consult the sources cited in $\$ 1.17$.

1. On OFris. breaking, see further de Graaf \& Tiersma 1980, Tiersma 1983, 1986, van der Meer 1985. On breaking in general, see also the references in $\$ 4.13 \mathrm{n} .1$.

\subsection{Changes of stressed vowels in Old Saxon}

WGmc. $\bar{x}$ (PGmc. $\bar{e}_{1}$ ) is realized as $\bar{a}$, even before nasal consonants, as in lattan 'let' and māno 'moon'. Unlike in OE and OFris., PGmc. $\bar{a}^{n}$ results in $\bar{a}$, as in wāh 'evil' (cf. OE wōh 'crooked') and brähta 'brought'. PGmc. $\bar{e}_{2}$ is usually reflected as $\bar{e}$, but in some texts the result may be ie (as in Franconian dialects), as in herr, hier 'here' and tieglan 'tile' (Lat. $t \bar{e} g u l a$ ). PGmc. $\bar{o}$ is usually reflected as $\bar{o}$, but it may also be diphthongized to $u o$, as in OHG, as in brōđar, bruođar 'brother' and stōd, stuod 'stood'. PGmc. ai usually results in $\bar{e}$, as in *stainaz > stēn 'stone' and lemm 'loam', but before $j$ it is umlauted to $e i$, as in gen. pl. ei(i)ero 'eggs' ( $\mathrm{OE} \bar{x} g r a<* \bar{a} j-<* a i j-$, and cf. OIcel. eggja) and hneihida (misspelt 〈hnethida〉) 'neighed' (= OE hnägde). PGmc. au becomes $\bar{o}$, as in lōn 'reward' (cf. Go. laun) and rōd 'red' (Go. ráups), though this $\bar{o}$ is rarely spelt $u o$, and $a u$ before $w$ usually remains unchanged, as in thau 'practice' (OE peaw < *bauw-) and skauwon 'view' (OE scēawian). PGmc. eu is reflected as eo, io, later also $e a, i e$, as in breost 'breast', fliogan 'fly'. But eu remains (or is spelt $\langle\mathrm{iu}\rangle$ ) before $w$, as in hreuwan 'rue', eu, iu 'you (pl.)'.

There is often contraction of adjacent vowels upon loss of intervocalic $w(\S 6.16)$ or $h(\$ 6.20)$, and in instances of the removal of hiatus between vowels, though not commonly in poetry. Examples: gimālda beside gimahalda 'said', $v \bar{e}$ beside fehu 'herded animal', and perhaps dōn beside duan, doan, etc. 'do'. ${ }^{1}$ When the first vowel in such sequences was originally long, it is shortened, as shown by the change of eo to io, ia, ie, as in *aiw > * $\bar{e}-u>e o$, io 'ever' (Go. áiw; Holthausen 1921: §108 Anmm. 1-2).

Long vowels are shortened before geminate consonants (as in OE), e.g. ettar 'poison' (OE ātor, attor), ellevan '11' (cf. Go. *áinlif).

Various changes of vowel qualities are encountered on a facultative basis under the influence of neighboring consonants, e.g. farah beside ferah 'life', old beside ald 'old', soster beside suster 'sister': see Holthausen 1921: §§109-14. On the raising of $e$ to $i$ before $u$ in the next syllable, see $\S 4.4$.

1. See $\S 12.61$. The loss of hiatus in originally reduplicating preterites, e.g. 3 sg. pret. lēt 'let' $(<* l-e-\bar{x} t$, $\S 12.20)$, is perhaps earlier; at all events, contraction is carried through consistently even in poetry.

\subsection{Changes of stressed vowels in Old Low Franconian}

The vowels of OLF are similar to those of OS, hence PGmc. $\bar{e}_{1}>\bar{a}$ and PGmc. $\bar{a}^{n}>\bar{a}$. But $a i$ is monophthongized to $\bar{e}$ only before $r$ or $w$ (and possibly before $h(/ \mathrm{x} /)$ or in final position, as in OHG, though no relevant forms are attested), as in sēo 'sea' and mêrra 'more' (Go. sáiws, máiza). Likewise, au becomes $\bar{o}$ only finally or before $h, r$, or an alveolar consonant, as in ōra 'ear' (Go. áusō); otherwise it becomes ou, as in ouga 'eye'. The new $\bar{e}$ and $\bar{o}$ do not undergo the diphthongization regularly suffered by PGmc. $\bar{e}_{2}$ and $\bar{o}$, as in hiera 'here' and fuot 'foot'. These changes are nearly identical to those of OHG. 


\subsection{Changes of stressed vowels in Old High German}

PGmc. iu generally remains as such in OHG, though in Central German before a nonhigh vowel in the next syllable eu develops to io, the usual form beside occasional eo (the earlier form). ${ }^{1}$ In Upper German this change occurs only before an alveolar consonant or $h(/ \mathrm{x} /)$. Examples: inf. beotan 'offer', but $1 \mathrm{sg}$. biutu, imp. biut, and leoht, lioht 'light' (noun), but liuhten 'illuminate' <*liuxtijan. PGmc. eu appears early as eo, more generally as io.

PGmc. $\bar{e}_{2}$ and $\bar{o}$ were diphthongized to ie (ia, ea) and uo (ua,oa), as in hier (hèr, hear, hiar) 'here', mieta 'reward' (Go. mizdō, §3.5), buoh 'book' (Go. bōka), suohhen 'seek' (Go. sōkjan), fuoz 'foot' (Go. fōtus). Diphthongized spellings of $\bar{o}$ start to appear in Franconian in the eighth century, of $\bar{e}$ in the ninth, spreading to Upper German.

PGmc. $a i$ is reflected as $e i$, except that it is monophthongized to $\bar{e}$ before $r, w$, or $h(/ \mathrm{x} /)$, as in $\bar{e} r$ 'early' (Go. áir), èht 'property' (Go. áihts), and gen. sg. snēwes 'snow' (Go. snáiwis); cf. stein 'stone' (Go. stáins), reit 'rode', etc. There is also monophthongization finally in a few interjections, e.g. sē 'look!' (= Go. sái). Comparably, au developed to ou except before $h$ and dental consonants, where it was monophthongized to $\bar{o}$, hence hōh 'high' (Go. háuhs) and tōd 'death' (Go. dáupus), but loufan 'run' (OIcel. hlaupa), ouga 'eye' (Go. áugō). The new monophthongs did not undergo the dipthongization that affected PGmc. $\bar{e}_{2}$ and $\bar{o}$, and whereas $h$ from PGmc. $x$ caused the change, final $h$ from $k$ by the High German Consonant Shift (\$6.21) did not, hence hōh : ouh 'also' (Go. áuk). These changes begin to be expressed in the orthography in the eighth century, first in Franconian, spreading southward. See Taylor 1989, with references.

As in OS and OLF, PGmc. $\bar{a}^{n}$ yields $\bar{a}$ in OHG, as in fähan 'take' $<* f \bar{a}^{n} x a n a^{n}$.

On the raising of $e$ to $i$ before $u$ in the next syllable, see $\S 4.4$.

1. The change fails when the next syllable originally contained $j$, hence diuten 'signify' $<$ WGmc. * piudjan . That is to say, the original conditioning of the PGmc. eu : iu contrast remained relevant.

\subsection{Summary table of the development of Germanic stressed vowels}

The following table summarizes the vowel developments outlined in $\$ \S 4.1-17$, though a number of changes described there cannot conveniently be indicated in the table:

\begin{tabular}{|c|c|c|c|c|c|c|}
\hline PGmc. & Go. & OIcel. & OE (EWS) & OFris. & OS & OHG \\
\hline$a$ & $a$ & $\begin{array}{c}\mathrm{a} \\
\text { e }(\$ 4.7) \\
\text { e }(\$ 4.8) \\
\text { e > }(\$ 4.8) \\
\text { o, ó }(\$ 4.9) \\
\bar{Q}>\text { á }(\$ 4.8)\end{array}$ & $\begin{array}{c}\text { æ, o }(\S 4.12) \\
\mathrm{e}, æ, \mathrm{ie}(\S 4.7) \\
\text { ea }(\S \S 4.12-13) \\
\overline{\mathrm{o}}(\S 4.1) \\
\overline{\mathrm{e}}(\S 4.7)\end{array}$ & $\begin{array}{c}\mathrm{e}, \mathrm{o}(\S \S 4.12,4.14) \\
\overline{\mathrm{o}}(\S 4.1) \\
\overline{\mathrm{e}}(\$ 4.7)\end{array}$ & $\begin{array}{c}\mathrm{a} \\
\mathrm{e}(\$ 4.7) \\
\bar{a}(\$ 4.1)\end{array}$ & $\begin{array}{c}\mathrm{a} \\
\mathrm{e}(\$ 4.7) \\
\bar{a}(\$ 4.1)\end{array}$ \\
\hline e & $\begin{array}{c}\text { i, aí } \\
(\S 4.5)\end{array}$ & $\begin{array}{c}\mathrm{e} \\
\mathrm{i}(\S 4.4) \\
\text { ja, jo, jo, } \\
\text { jó }(\S 4.8) \\
\varnothing(\S 4.8)\end{array}$ & $\begin{array}{c}\mathrm{e} \\
\mathrm{i}(\S 4.4) \\
\text { eo }(\S \S 4.8,4.13) \\
\text { ie }(\S 4.7)\end{array}$ & $\begin{array}{c}\mathrm{e} \\
\mathrm{i}(\S 4.4) \\
\text { iu }(\$ 4.14)\end{array}$ & $\begin{array}{c}\mathrm{e} \\
\mathrm{i}(\S 4.4)\end{array}$ & $\begin{array}{c}\mathrm{e} \\
\mathrm{i}(\S 4.4)\end{array}$ \\
\hline
\end{tabular}




\begin{tabular}{|c|c|c|c|c|c|c|}
\hline PGmc. & Go. & OIcel. & OE (EWS) & OFris. & OS & OHG \\
\hline $\mathrm{a}$ & $\mathrm{a}$ & $\begin{array}{c}\mathrm{a} \\
\mathrm{e}(\S 4.7) \\
\mathrm{q}(\S 4.8) \\
\mathrm{e}>\varnothing(\S 4.8) \\
\mathrm{o}, \mathrm{o}(\S 4.9) \\
\bar{Q}>\mathrm{a}(\S 4.8)\end{array}$ & $\begin{array}{c}\text { æ, o }(\$ 4.12) \\
\text { e, æ, ie }(\$ 4.7) \\
\text { ea }(\$ \S 4.12- \\
13) \\
\bar{o}(\S 4.1) \\
\text { è }(\$ 4.7)\end{array}$ & $\begin{array}{c}\mathrm{e}, \mathrm{o}(\S \S 4.12, \\
4.14) \\
\overline{\mathrm{o}}(\S 4.1) \\
\overline{\mathrm{e}}(\S 4.7)\end{array}$ & $\begin{array}{c}\mathrm{a} \\
\mathrm{e}(\$ 4.7) \\
\overline{\mathrm{a}}(\$ 4.1)\end{array}$ & $\begin{array}{c}\mathrm{a} \\
\mathrm{e}(\S 4.7) \\
\bar{a}(\$ 4.1)\end{array}$ \\
\hline $\mathrm{e}$ & $\begin{array}{c}\text { i, aí } \\
(\S 4.5)\end{array}$ & $\begin{array}{c}\mathrm{e} \\
\mathrm{i}(\S 4.4) \\
\text { ja, jo, jo, } \\
\text { jó }(\$ 4.8) \\
\varnothing(\$ 4.8)\end{array}$ & $\begin{array}{c}\mathrm{e} \\
\mathrm{i}(\S 4.4) \\
\text { eo }(\S \S 4.8, \\
4.13) \\
\text { ie }(\S 4.7)\end{array}$ & $\begin{array}{c}\mathrm{e} \\
\mathrm{i}(\S 4.4) \\
\text { iu }(\$ 4.14)\end{array}$ & $\begin{array}{c}\mathrm{e} \\
\mathrm{i}(\$ 4.4)\end{array}$ & $\begin{array}{c}\mathrm{e} \\
\mathrm{i}(\$ 4.4)\end{array}$ \\
\hline $\mathrm{i}$ & $\begin{array}{c}\text { i, aí } \\
(\S 4.5)\end{array}$ & $\begin{array}{c}\mathrm{i} \\
\text { e }(\S 4.3) \\
\text { y }(\$ 4.8) \\
\text { é }(\$ 4.9)\end{array}$ & $\begin{array}{c}\mathrm{i} \\
\text { eo }(\S \S 4.8, \\
4.13) \\
\text { ie }(\S 4.7) \\
\overline{1}(\S 4.1,4.11)\end{array}$ & $\begin{array}{c}\mathrm{i} \\
\text { iu }(\S \S 4.8, \\
4.14) \\
\overline{1}(\S 4.1,4.11)\end{array}$ & $\begin{array}{c}\mathrm{i} \\
\mathrm{e}(\S 4.3) \\
\overline{1}(\S 4.1, \\
4.11)\end{array}$ & $\begin{array}{c}\mathrm{i} \\
\mathrm{e}(\S 4.3)\end{array}$ \\
\hline $\mathrm{u}, \mathrm{o}$ & $\begin{array}{l}\mathrm{u}, \mathrm{aú} \\
(\S 4.5)\end{array}$ & $\begin{array}{c}\mathrm{u}, \mathrm{o} \\
\mathrm{y}, \varnothing(\S 4.8) \\
\mathrm{o}(\S 4.9)\end{array}$ & $\begin{array}{c}\mathrm{u}, \mathrm{o} \\
\mathrm{y}, \mathrm{e}(\S 4.7) \\
\overline{\mathrm{u}}(\S 4.11)\end{array}$ & $\begin{array}{c}\mathrm{u}, \mathrm{o} \\
\mathrm{e}(\S 4.7) \\
\overline{\mathrm{u}}(\S 4.11)\end{array}$ & $\begin{array}{c}\mathrm{u}, \mathrm{o} \\
\overline{\mathrm{u}}(\S 4.11)\end{array}$ & $\mathrm{u}, \mathrm{o}$ \\
\hline$\overline{\mathrm{a}}^{\mathrm{n}}$ & $\begin{array}{c}\overline{\mathrm{a}} \\
(\S 4.1)\end{array}$ & $\begin{array}{c}\text { á }(\$ 4.1) \\
æ(\S 4.7) \\
\text { ó >á }(\$ 4.8)\end{array}$ & $\begin{array}{l}\overline{\mathrm{o}}(\$ 4.1) \\
\overline{\mathrm{e}}(\$ 4.7)\end{array}$ & $\begin{array}{l}\overline{\mathrm{o}}(\$ 4.1) \\
\overline{\mathrm{e}}(\$ 4.7)\end{array}$ & $\overline{\mathrm{a}}(\S 4.1)$ & $\overline{\mathrm{a}}(\S 4.1)$ \\
\hline$\overline{\mathrm{e}}_{1}$ & $\begin{array}{c}\overline{\mathrm{e}} \\
\mathrm{ai} \\
(\S 4.5)\end{array}$ & $\begin{array}{c}\text { á }(\$ 4.6) \\
æ(\S 4.7) \\
\text { ó>á }(\$ 4.8) \\
\text { ó }(\S 4.9) \\
\end{array}$ & $\begin{array}{c}\bar{x}(\S 4.6) \\
\bar{e} a(\S 4.13) \\
\bar{a}(\S 4.13)\end{array}$ & $\overline{\mathrm{e}}(\S 4.6)$ & $\overline{\mathrm{a}}(\S 4.6)$ & $\overline{\mathrm{a}}(\S 4.6)$ \\
\hline$\overline{\mathrm{e}_{2}}$ & $\overline{\mathrm{e}}$ & é & $\overline{\mathrm{e}}$ & $\overline{\mathrm{e}}$ & $\begin{array}{c}\overline{\mathrm{e}}, \mathrm{ie} \\
(\S 4.15)\end{array}$ & $\begin{array}{c}\text { ie, ia } \\
(\S 4.17)\end{array}$ \\
\hline$\overline{1}$ & $\begin{array}{c}\text { ei } \\
(\S 1.11)\end{array}$ & $\begin{array}{c}1 \\
\text { ý }(\$ 4.8) \\
\text { é }(\$ 4.9)\end{array}$ & $\overline{1}$ & $\overline{1}$ & $\overline{1}$ & $\overline{1}$ \\
\hline$\overline{\mathrm{o}}$ & $\overline{\mathrm{o}}$ & ó & $\overline{\mathrm{o}}$ & $\overline{\mathrm{o}}$ & $\begin{array}{c}\bar{o}, \text { uo } \\
(\S 4.15)\end{array}$ & uo $(\$ 4.17)$ \\
\hline$\overline{\mathrm{u}}$ & $\overline{\mathrm{u}}$ & $\begin{array}{c}\text { ú } \\
\text { ý }(\S 4.7)\end{array}$ & $\begin{array}{c}\overline{\mathrm{u}} \\
\overline{\mathrm{y}}(\S 4.7)\end{array}$ & $\begin{array}{c}\overline{\mathrm{u}} \\
\overline{\mathrm{e}}(\S 4.7)\end{array}$ & $\overline{\mathrm{u}}$ & $\overline{\mathrm{u}}$ \\
\hline ai & $\begin{array}{c}\text { ái } \\
(\$ 1.11)\end{array}$ & $\begin{array}{c}æ i>\text { ei } \\
(\S 4.9) \\
\text { ei }>\text { ey } \\
(\$ 4.8) \\
\text { á }(\$ 4.9)\end{array}$ & $\begin{array}{l}\overline{\mathrm{a}}(\$ 4.12) \\
\bar{x}(\$ 4.7)\end{array}$ & $\begin{array}{c}\overline{\mathrm{e}}, \overline{\mathrm{a}}(\$ 4.12) \\
\overline{\mathrm{e}}(\$ 4.7)\end{array}$ & $\begin{array}{c}\mathrm{e}(\$ 4.7) \\
\text { ei }(\$ 4.7, \\
4.15)\end{array}$ & $\begin{array}{c}\text { ei, } \overline{\mathrm{e}} \\
(\S 4.17)\end{array}$ \\
\hline $\mathrm{au}$ & $\begin{array}{c}\text { áu } \\
(\$ 1.11)\end{array}$ & $\begin{array}{c}\text { au } \\
\text { ey }(\S 4.7) \\
\text { ó }(\$ 4.9)\end{array}$ & $\begin{array}{c}\text { èa }(\$ 4.12) \\
\overline{1} e(\$ 4.7)\end{array}$ & $\begin{array}{c}\overline{\mathrm{a}}(\$ 4.12) \\
\overline{\mathrm{e}}(\$ 4.7)\end{array}$ & $\begin{array}{c}\mathrm{au}, \overline{\mathrm{o}} \\
(\$ 4.15)\end{array}$ & $\begin{array}{c}\overline{\mathrm{o}}, \mathrm{ou} \\
(\$ 4.17)\end{array}$ \\
\hline $\mathrm{eu}$ & $\begin{array}{c}\text { iu } \\
(\S 4.5)\end{array}$ & $\begin{array}{l}\text { jó, jú } \\
(\S 4.9)\end{array}$ & $\begin{array}{c}\text { ēo }(\S 4.13) \\
\overline{1} \text { e, } \overline{1} \mathrm{i}(\$ 4.7)\end{array}$ & iā $(\$ 4.14)$ & $\begin{array}{l}\text { eo, eu } \\
(\S 4.15)\end{array}$ & io $(\S 4.17)$ \\
\hline
\end{tabular}




\section{The Germanic Vowels in Syllables of Lesser Stress}

\subsection{General remarks}

Many uncertainties about vowel development in syllables of lesser stress remain unresolved, even a number of basic issues, and especially matters pertaining to the differentiation of bimoric and trimoric vowels and diphthongs. The general trend in unstressed syllables is for vowels to weaken or disappear, with loss of $a$ earlier than of $i$ or $u$. Likewise, vowels are generally weakened and lost earlier after heavy syllables than light, as a consequence of Prokosch's law (\$2.5). Prokosch himself provides a useful if selfadmittedly overly schematic account of the trend, stating that in the first two or three centuries CE "final syllables lost one mora. About five hundred years later a second mora was lost; another five hundred years later, a third" (1939: §49a). Especially notable are changes in final syllables, for which Auslaut(s)gesetze 'laws of finals' have been formulated, generating a weighty body of scholarship. ${ }^{1}$ Developments in final syllables are difficult to determine for a variety of reasons, including the rarity of attestation of some types of final syllables (especially in Runic), uncertainty as to their form in PIE, uncertainty in any given case as to whether analogy has interfered with phonological development, and notable points of disagreement among the Gmc. languages. In general, however, Prokosch's dictum appears to hold true: Proto-Germanic desinences lost one mora, either a final non-high vowel or a final consonant other than $s / z$ or $r$, and otherwise vowels toward the end of the word should not be expected to have weakened in PGmc. itself. For convenience's sake, vowels in syllables of lesser stress will be referred to in this discussion as unstressed. It must be recognized, however, that not all syllables that did not bear primary accent were stressed to the same degree, as the following discussion will demonstrate, and as was shown in \$2.2. On ablaut in unstressed syllables, see $§ 3.6$.

1. The more salient literature includes Walde 1900, Lane 1963, Hollifield 1980, d'Alquen 1988, Voyles 1988, Boutkan 1995b, Antonsen 2002: 237-60, and Schrijver 2004, with references to many others provided by these. The last five of these represent a trend in the renewed scholarly interest in the laws of finals to attempt to explain developments without recourse to trimoric vowels.

\subsection{Short vowels of final syllables}

On the standard view, all PIE short, unstressed non-high vowels $(e, a, o)$ in absolute finality were lost in PGmc. ${ }^{1}$ Examples: PIE 1 sg. perfect *uoida and 3 sg. *uoide $>$ Go. wáit 'know' (cf. Gk. oî̉ $\alpha$ and oî $\delta \varepsilon$ ); PIE *-eso > Go. -is in gen. sg. dagis 'day' (cf. Gk. gen. sg. $\theta \varepsilon o \hat{v}<* \theta \varepsilon \delta \sigma \sigma o$ 'god'); 2 pl. imp. *bherete $>$ Go. baírip 'bear'. Final high vowels were more resistant to loss, but even they disappear in the post-PGmc. period 
after heavy syllables, already in Go., later elsewhere, as in dat. sg. PGmc. *brōpri 'brother' > Go. brōpr, OE brēerer (where the umlaut confirms retention of final *-i relatively late), rare OIcel. brœðr beside usual, analogical bróður; ${ }^{2}$ and PGmc. *tagru 'tear' > Go. tagr, OE teagor (cf. Gk. $\delta \dot{\alpha} \kappa \rho v$ ). ${ }^{3}$ Compare the retention after light syllables in OE mere 'sea' < *mari < PIE *mori and PGmc. *fexu 'property, goods, livestock' > Go. faihu, OS fehu, OHG fihu, as well as *filu 'much'> Go. OS OHG filu. That the Go. situation is in part the result of analogy is suggested by OE (Anglian) dat. sg. milc < $*^{*}$ milyki $<*^{*}$ miluki 'milk' (or *-î?); by comparison, there is no dat. sg. †mēn(e) $p<$ *mōnapi < *mēnōpi 'month'. Under Prokosch's law (\$2.5) it might be expected that there would be variable loss in trisyllables, e.g. dat. sg. *3umini 'man' $>*^{*}$ umin but *attini 'father', without change after a heavy initial syllable, also $3 \mathrm{sg}$. pres. *faripi $>$ *farip 'goes' but *bi̋ $i p i$ 'awaits', without change. If there ever existed such variation, however, Gothic has generalized the apocopated endings (gumin, attin, farib, beidib), and there is no secure evidence that the other Gmc. languages did not do the same. ${ }^{4}$ Monosyllabic words of lesser stress retained a final short vowel regardless of its height: examples are PIE *ne > PGmc. ${ }^{*} n i>$ Go. OHG $n i$, OE $n e$, OFris. OS $n i, n e$ 'not' and PIE *so > PGmc. *sa > Go. sa, lengthened in OIcel. sá 'this'; cf. loss of the final vowel of the enclitic in Go. $s a-h$ '(and) this' $<*^{*} s o-k^{w} e$.

Vowels originally protected by a final consonant were not regularly lost in PGmc., though only Runic preserves $a$ under such circumstances, as in pp. haitinar 'called' (cf. Go. háitans, OE häten). This $a$ is preserved as well in early loan-words into Finnish (§1.7), e.g. kulta 'gold', borrowed from PGmc. *3ulba ${ }^{n}<$ PIE * $g h l t o m$. Gothic has also lost $i$ before final $s$ in most case-forms of $i$-stems like gasts 'guest' (cf. the umlaut in OIcel. gestr, OE giest), but $u$ is preserved in $u$-stems (e.g. Go. handus 'hand'; cf. the back umlaut in OIcel. hond), showing that there is regularization of stems in opposite fashion in the two stem classes in Gothic: ${ }^{5}$ to analogically reformed $i$-stem qums 'arrival' (cf. OE cyme $<* k^{w} u m i z$ ) cf. hatis 'hatred' (transferred to the $a$-stems; cf. $i$-stem OE hete, OS heti); also fem adj. nawis 'dead', etc. ${ }^{6}$ In most instances the final consonant that prevented loss of the preceding vowel was itself dropped, as is shown by the loss in forms like PIE 3 pl. *bhudhnt $>$ PGmc. *buðun(b)> Go. -budun, OE budon, etc. 'offered'; PIE $o$-stem acc. sg. ${ }^{*}-o m>$ PGmc. ${ }^{*}-a^{n}$ (with nasalization) in Runic staina 'stone' (but OIcel. stein, Go. stáin, OE stān, etc.); cf. PIE $o$-stem acc. pl. *-ons > PGmc. *-ans in Go. stáinans, Runic staba 'runestaves'. There must have been loss of $i$ early, perhaps in PGmc. itself, in the ending *-omiz reflected in the dat. (orig. instr.) pl. of a-stems (and the $1 \mathrm{pl}$. ind. of verbs), since the ending is reflected as -am already in Gothic; cf. Runic -umR $(2 \times)$ on the Stentoften stone (mid- $7^{\text {th }}$ cent.). ${ }^{7}$ The only exceptions to the loss of a lone final consonant after an unstressed vowel are $s / z$ and $r$. Whereas $s / z$ is plainly preserved in NGmc. and in Gothic (and see $\S \S 6.6,6.12$ on the fate of $z$ in Go.), its development in WGmc. is contested, the commonest assumption being that $z$ was lost but $s$ preserved (see §6.16). Examples: PGmc. *dazaz > Go. dags, ON dagr, OE dæg OS dag, OHG tag 'day'; PGmc. *under > Go. undar, OIcel. undir (without umlaut), OE under, OS undar, under, OHG untar. ${ }^{8}$ On the development of final consonants, see further $\S \S 6.12,6.14,6.16$.

When $a$ was lost in a final syllable (after the PGmc. period, but uniformly across the branches of $\mathrm{Gmc}$.), a preceding glide was nuclearized. The process is partly obscured in WGmc. by the analogical extension of geminates within paradigms, but due to Sievers' law (\$5.8), WGmc. high vowels thus generated may in some instances be preserved after heavy stems. Examples are *kunja ${ }^{n}>$ Go. kuni 'kind', OIcel. kyn (< 
*kuni, as shown by the umlaut); *rīkijan $>$ Go. reiki, OIcel. riki, OE rīce, OS rīki, OHG rīchi 'dominion'; *zarwaz > OIcel. gorr (Proto-Norse *zoruR), OE gearu, OS OHG garo 'ready'. The significance of Go. $-w$ in a form like gáidw (OE gād < ${ }^{*}$ zaiðwan $)$ 'want, lack' is disputed: see Krause 1968: $\S 88$, Braune 2004b: $\S 42$. Very likely $-w$ is due to paradigm regularization; cf. skadus 'shadow' ( $u$-stem, originally wa-stem: cf. OE gen. pl. sceadwa, etc.).

1. Antonsen (2007) argues that Runic wraita on the Reistad stone (Norway, ca. 450) is a 1 sg. pret.'wrote', and thus $-a$ was not lost in second syllables in PGmc. The usual interpretation of the word as a noun (and hence with $-a^{n}$ ) is, admittedly, dubitable, but see Ringe 2017: 143, declaring Antonsen's analysis impossible.

2. The evidence of brøð $r$, however, is insecure. Other forms suggest early loss of final $-i$ in Scandinavia after a heavy syllable, as in Runic ist 'is' (Vetteland stone, Norway, mid-4 $4^{\text {th }}$ cent.) from PIE $* h_{l} e s-t i$, and OIcel. umb. Note the absence of umlaut, though the word is difficult, since retention of the final vowel in OE $y m b e$ (but also ymb), OS OHG umbi raises doubts about the direct equivalence of Gk. $\dot{\alpha} \mu \phi i$ 'around' usually assumed (e.g. by Hollifield (1980: 33). On this problem see $\$ 11.5$. The final vowel in such forms perhaps derives from prep. ${ }^{*} b \bar{i}$; rather, Klingenschmitt (1987: 187) explains ymbe, umbi as proclitic, and thus the final vowel was not, in a sense, word final. OIcel. ár 'early' (Go. áir), without umlaut, probably derives from a loc. *ail(e)ri (§6.11 ad fin.); cf. OE $\bar{x} r$, OS OHG $\bar{e} r$, with umlaut, though it is not impossible that the comp. should have been substituted for the positive in WGmc.

3. OE teagor (which is poetic, ultimately Mercian) shows back mutation of $x$, suggesting retention of rounding from lost final $*-u$ late enough to color the final syllabic sonorant consonant as or rather than *er, as might have been expected after the front vowel in the root (\$5.6).

4. A dissenter is Ringe (2002, and in Ringe \& Taylor 2014: 289-96 et passim), but see $\$ 5.6 \mathrm{n} .13$ infra .

5. That is to say, Gothic must originally have lost unstressed $i$ and $u$ before a final consonant after a heavy syllable but not a light. That unstressed $i$ or $u$ before a final consonant was not regularly lost in PGmc. (despite the seeming claim of, e.g. Krahe \& Meid 1969: I, §120; but cf. §122) is demonstrated by, among other considerations, Runic forms like uinir 'friend', -mariR 'famed' (with $\bar{a}$ : name element, Thorsberg chape, ca. 200), and waruR 'enclosure'. Prokosch (1939: §49c) argues rather that $i$ and $u$ were lost already in PGmc. after heavy syllables or after two syllables (though his remark "which phonetically, or metrically, amounts to the same thing" is not quite right, due, ironically, to Prokosch's law: see $\$ 2.5$ ), otherwise preserved. This would explain some matters, for example why $i$ in the inflections of most case-forms of $i$-stems is lost in Gothic (since there must be phonological loss under some circumstances to motivate analogical loss in other environments; but this change appears to be Go. rather than PGmc.), and why there is no umlaut in the sg. of $i$-stems in OS and OHG. The idea faces some rather severe difficulties, however, such as the consistent preservation of $i$ even after heavy stems in Runic $i$-stems as early as 200 (as above), of $i$ after heavy syllables in loanwords into Finnish, e.g. tiuris 'beast' from PGmc. *diuriz (> OE dēor), and the consistent umlaut in $\mathrm{ON}$ and $\mathrm{OE}$ heavy-stemmed $i$-stems, given that the general trend in $i$ - and $u$-stems is replacement of the original inflections by $a$-stem (or $\bar{o}$-stem) inflections (which thus makes it easier to account for the Go. OS and $\mathrm{OHG}$ forms as analogical than the $\mathrm{ON}$ and $\mathrm{OE}$ ones). The nom. pl. $u$-stem ending *-iwiz is sometimes said to have developed to *-iuz already in PGmc. (so., e.g., Heusler 1967: §102; cf. Boutkan 1995b: 83-6), but this need not have been the case. There is valuable material in Streitberg 1896: $\S \S 146-7$, though his conclusion that $i$ (but not $u$ ) in a final syllable was lost already in PGmc. after a heavy syllable appears to be mistaken.

6. Some regard the reduction of $*_{-i s}$ to $*_{-s}$ (and loss of final $*_{-i}$ ) in Go. as unconditional, e.g. Bjorvand 1991: 107, Boutkan 1995b: 59-62, 374-5. Thus, for example, framis 'farther' is to be regarded as analogical to a comp. adj. *framiza-. Neither analysis appears to be capable of definitive proof, but it is worth observing that categorical loss of $i$ would create an imbalance in the phonological development of the high vowels, since $u$, though usually restored, is lost after heavy syllables, as in, e.g., acc. sg. root-stem baúrg $<*$ burz $u^{n}$ (Krause 1968: $§ 69.2 d)$.

7. Was loss in the ultima earlier in a third syllable than a second? So, e.g., Krahe \& Meid 1969: I, §121, calling the change "gemein-germ." Boutkan (1995b) and Antonsen (2002: 241) work with similar assumptions. If PIE $e$ in unstressed syllables is assumed to have become $i$ except before $r(\S 5.5)$, the assumption of earlier loss in third syllables would be the simplest way to explain why in the pres. ind. of strong verbs there is not umlaut throughout the paradigm in North and West Gmc. Certainly, $i$ is preserved in second syllables in Runic, but rather than regular loss in all third syllables there might be expected conditioned loss governed by Prokosch’s law ( $\$ 2.5$; e.g. *dazomz: *stainomiz), with subsequent generalization of the syncopated form. The 
assumption of early loss in third syllables leaves some WGmc. forms with umlaut unexplained, e.g. OE $n d-$ stem nom. plurals like friend 'friend' and hettend 'enemy' (not †hettand).

8. Cf. PGmc. *anperaz > Go. anpar, OIcel. annarr, OE ōðer, OS ōđar, ōđer, āđar, OHG ander, andar 'other'.

\subsection{Bimoric vowels and diphthongs of final syllables}

The bimoric syllabics of PGmc. reflect diphthongs (originally vowel + glide, §3.1) and long vowels derived from PIE, as well as vowels lengthened upon loss of a final or anteconsonantal laryngeal consonant, e.g. PIE $*_{-}-\mathrm{oh}_{2}>*_{-} \bar{o}$ and PIE ${ }^{*}-e h_{1}-t i>$ PGmc. ${ }^{*}-\bar{e} p(i)$. Although they are sometimes grouped with the trimoric vowels (see §5.4), vowels contracted already in PIE from vowel sequences without an intervening laryngeal consonant (e.g. PIE thematic masc. nom. pl. *-ōs $<*_{-o-e s)}$ are almost certainly to be regarded as bimoric.

In absolute finality, PGmc. $\bar{o}$ develops to Go. $a$ but NWGmc. $u$ : cf. Runic $1 \mathrm{sg}$. pres. Wa ritu 'write' on the Järsberg stone (ca. 450) < PGmc. *writto. In NGmc. this $u$ is lost altogether (after causing fracture and $u$-mutation, §4.8), whereas in WGmc. it is lost only after heavy syllables, though it is frequently restored on an analogical basis, especially in OS and OHG. Examples: PGmc. *zebo ' 'gift' > Go. giba, OIcel. gjof, OE giefu; PGmc. *laibō 'remnant' > Go láiba, OIcel. leif, OE läf; ${ }^{1}$ PGmc. pres. 1 sg. *farō 'go' > Go. fara, OIcel. fer (with analogical e), OE (Anglian) færo, fearu, OS OHG faru. Developments in monosyllables of lesser stress are less certain: PIE fem. *sō 'this' gives Go. sō but OIcel. sú (perhaps lengthened from *su: see §8.10); but to PIE *dō> Go. $d u$ 'to' cf. OE OFris. OS tō, OHG zuo; plainly, the mutual influence of stressed and unstressed forms played a role.

For the most part, PGmc. $\bar{o}$ was preserved as such when a consonant originally followed. This $\bar{o}$ is reflected as $\bar{o}$ in Gothic, $a$ in NGmc., and probably $a$ in WGmc. Under such circumstances final $-s / z$ was preserved in PGmc. ( $\$ 6.11)$, and the development of $\bar{o}$ before it may be illustrated by the reflexes of the PIE nom. pl. masc. $o$-stem ending *-ōs $\left(<*_{-}-\right.$-es $)$reflected in Go. dagōs 'days', OIcel. dagar, OE dagas, OS dagos, -as; yet the WGmc. evidence is mostly insecure, due to the possible analogical influence of the acc. pl. inflection (\$7.8). Final $r$ was also preserved, and before it $\bar{o}$ apparently remained in Gothic and developed to $a$ in WGmc. (> OE OFris. $e$ ), as in Go. fidwōr, OE fēower, OS fi(u)war 'four' (Stiles 1985-6); perhaps also *watōr $>$ OE wæter, OS water, watar, OHG wazzar 'water' (cf. Gk. $v \delta \omega \omega \rho)$. When final $n$ (PIE $n, m$ ) originally followed, it was lost and the vowel nasalized, the vowel still reflected as $\bar{o}$ in Runic NWGmc. (e.g. runo on the Einang stone, ca. 350-400), resulting otherwise in $a$ (OE and OFris. $e<x$ ), as with the PIE acc. sg. $\bar{a}$-stem ending $*_{-} e h_{2}-m>*_{-}^{*} \bar{a} n>*_{-} \bar{o}^{n}$, as in Go. giba 'gift', OE giefe, OFris. gife, OS geba, OHG geba. ${ }^{2}$ The same change is seen in monosyllables of lesser stress, except that the Go. reflex is $\bar{o}$, e.g. PIE fem. acc. sg. ${ }^{*} t a h_{2}-m$ 'this' $>* t \bar{a} m>$ PGmc. ${ }^{*} p \bar{o}^{n}>$ Go. $p \bar{o}$ and re-lengthened OIcel. $p \dot{a}$, OE $p \bar{a}$.

In absolute finality, $\bar{e}_{l}(/ \varepsilon: /)$ developed to $a$, which is securely reflected only in Gothic, as in PIE instr. ${ }^{*}-e-h_{1}>*_{-}-\bar{e}$ in Go. dat. stáina (cf. original instr. pee in Go. ni pe haldis 'none the more'; also Go. dat. hammēh 'every' < PIE *-eht-kwe: hamma 'who' $<$ PIE $*_{-} e-h_{l}$, but see $\$ 7.8$ on the $a$-stem dat. sg.). It is perhaps lost altogether in WGmc. endingless locatives ( $\$ 7.8$ under dat. sg., but for alternative explanations see Dahl 1938: 51-5, Braune 2004a: \$193 Anm. 8), and in the gen. of dual and plural personal 
pronouns, e.g. OS üser 'of us' (§8.2). Final $\bar{e}$ in a monosyllable of lesser stress is preserved in Go. $p \bar{e}$ (above; cf. Gk. (Thera) $\tau \eta-\delta \varepsilon$ 'in this way') and OE $\partial \bar{e}$ (as in $n \bar{a} \partial \bar{e}$ raðor 'none the sooner'). When originally protected by a final consonant, $\bar{e}$ is preserved as such in Gothic, with various developments in the other Gmc. languages, as in the PIE ablative ending *-èd > PGmc. *-ē(t) in Go. hidrē 'hither' OIcel. heðra, OE hider, like Go. hadrē, OE hwæder 'whither'. ${ }^{3}$ A possible exception in Gothic is before final $r$, assuming the development PIE * $p h_{2} t \bar{e} r$ 'father' > PGmc. *faðèr > Go. fadar, OIcel. faðir (without umlaut; cf. Runic swestar 'sister', §5.6 n. 4), OE fæder, OS fadar, OHG fatar. Yet now it seems likelier that Go. fadar reflects the stem *faðer-found in the voc. and acc. (cf. Gk. acc. $\pi \alpha \tau \dot{\varepsilon} \rho \alpha$, and see Stiles 1988), given that long vowels protected by a final consonant are generally unshortened in Go.

PIE $\bar{l}$ in absolute finality is reflected as $i$ in Gothic (not ei, hence short). Elsewhere in Gmc. it should have developed the same way as $i$ before a final consonant, being lost everywhere in $\mathrm{ON}$, and after heavy syllables in WGmc., though the evidence is insufficient to prove this. Examples: Go. fem. frijōndi 'friend' (\$7.40), likewise mawi 'girl' <*mazwī, fem. to magus 'boy'. Before an original final consonant, $\bar{\imath}$ preserved its length, to judge by the nom sg. of the $\bar{i}$-stems, e.g. Go. managei, OHG menigi 'multitude': see $\$ 7.34$.

There is no secure evidence for PIE $\bar{u}$ in a Gmc. final, unstressed syllable.

PIE $o i$ and $a i$ are reflected in absolute finality as Go. $a$; in NWGmc. they were monophthongized to $\bar{x}$ (thus falling together with PGmc. $\bar{e}_{1}$ ), as shown by Runic hypercorrect spellings in $a i$ for the reflex of $\bar{e}_{1}$, e.g. talgidai 'carved' (Nøvling clasp, ca. 200: see Antonsen 1975: 5, but cf. Hollifield 1980: 150, H.F. Nielsen 2000: 160-4). This NWGmc. $\bar{x}$ develops to OIcel. $e>i$, OE $æ>e$, OS OHG $a$. Examples: PIE 3 sg. middle *-toi is reflected in Go. háitada 'is called' (OIcel. $1 \mathrm{sg}$. heite > heiti, with PIE $*_{\text {-ai }}$; see $\left.\S \S 12.5,12.29\right)$, OE hātte $<* h \overline{a t t æ .}$ The reflexes of PIE ou and au in absolute finality cannot be determined: Go. $u$-stem vocatives have both $-u$ and -áu.

A developmental distinction needs to be drawn between PIE short and long diphthongs in Gmc. unstressed syllables. ${ }^{4}$ The only very convincing evidence for the distinction, however, is the $u$-stem dat. (originally loc.) sg. inflection, PIE $*_{-} \bar{e} u>$ PGmc. $*_{-} \bar{e} u$ $>$ Go. Runic OHG -iu (\$7.25); cf. PIE *-eu- in $u$-stem nom. pl. PIE *-eu-es $>$ PGmc. $*_{-i w i z}>$ Go. -jus, NWGmc. *-iuz $>*_{-i z}$. To be sure, PIE *-éu and *-eu-es are not directly comparable, but the distinction between, e.g., OHG $-i u$ and $-i$ is suggestive, given that the original extra syllable in the latter ending might have been expected to provide greater protection for the diphthong that developed. The corresponding $i$-stem ending is inconclusive (see \$7.21), and the other examples of PIE long diphthongs generally cited in support of a distinction (e.g. by Krahe \& Meid 1969: I, §129) either develop the same way as short diphthongs or are actually trimoric as the term is defined in $\$ 5.4$.

1. In OS and OHG $\bar{o}$-stems the acc. inflection $-a$ has been substituted for the nom., hence OS geநa, lēta, OHG geba, leiba.

2. OIcel. gjof is modeled on the nom. The original ending is reflected as $-a$ in fem. adjs., e.g. acc sg. spaka 'prescient'.

3. For this reason it is difficult to see how the weak $3 \mathrm{sg}$. pret. suffix can be reconstructed as PIE *dhēt $>$ PGmc. ${ }^{*}-\partial \bar{e}(p)$, yielding Go. $-d a$ and NWGmc. ${ }^{*}-ð \bar{x}>$ OIcel. $-ð i, \mathrm{OE}-d \mathfrak{x}>-d e$, OS $-d a$, OHG -ta. See $\S 12.60$, and cf. NWGmc. $\bar{e}$ or $\bar{x}$ in Runic 3 sg. pret. tawide 'made' (Garbølle Box, Zealand, ca. 400). It is thus tempting to suppose (with Krahe \& Meid 1969: I, $\S \S 47,124$ ) that Go. $a$ is the regular development of bimoric $\bar{e}$ in all final syllables. But if the final vowel of Go. hidre is trimoric in origin, as they suppose, the definition of trimoricity offered below in $\$ 5.4$ cannot be correct unless $-\bar{e}$ is not in origin an ablative ending (so 
Hollifield 1980: 37). The matter cannot be resolved here. But possibly when originally protected by a final nasal consonant, bimoric $\bar{e}$ developed to $\bar{e}$ in Gothic, elsewhere to $a(>\mathrm{OE} æ>e)$, hence PGmc. ${ }^{*} \operatorname{siml} \bar{e}^{n}($ ?) $>$ Go. simle 'formerly', OE sim(b)le 'always', OS sim(b)la.

4. Long diphthongs are technically trimoric, but in the present context long diphthongs are to be regarded as involving PIE lengthened grade rather than later lengthening upon loss of a laryngeal consonant, and so long diphthongs in the present context do not belong to the category of trimoric vowels as defined in $\$ 5.4$. On the other hand, it cannot be proved that the distinction is genuine, since there is no evidence for a trimoric Gmc. $\hat{e} u$ in opposition to merely long $\bar{e} u$.

\subsection{Trimoric vowels and diphthongs}

A persistent problem in the analysis of final syllables is a set of inconsistencies in the development of certain long vowels. For example, the PIE $o$-stem gen. pl. ending *-óm and $\bar{a}$-stem acc. sg. *-ām should both have developed to PGmc. ${ }^{*}-\bar{o}^{n}$, yet they yield Go. $-o$ and $-a$, respectively. Of the various attempts to account for such discrepancies, the one that now enjoys the most favor is the assumption that in PGmc. there were two types of long vowels. Most long vowels were simply bimoric. But when two syllabic segments were separated by a PIE laryngeal consonant, hiatus might remain upon loss of the consonant, delaying contraction. The plainest evidence of this is in Indo-Iranian, where the meters of Vedic Sanskrit and Avestan verse sometimes require that a long vowel be scanned as two syllables. This is relatively common in, e.g., the gen. pl. of all genders, where Vedic $-\bar{a} m$ is not infrequently equivalent to -aam. On the commonest view, the distinction between the reflexes of long vowels and uncontracted vowels is maintained in Gmc., where the two develop differently. In Gmc. linguistics the latter are referred to as trimoric. At one time it was the standard view that the difference between bimoric and trimoric vowels was intonational, the former bearing Stoßton, the latter Schleifton, an opposition that may be characterized as distinguishing even intonation and changing intonation, respectively (on which see $\$ 2.1$ ). This view is no longer current, since Kuryłowicz (1958: 106-368) showed that the intonation oppositions of Greek and Lithuanian cannot have been inherited as such from PIE. Thus, for some scholars the term 'trimoric' is intended literally, denoting vowels three morae in length (so, e.g., Jasanoff 2004). To such an assumption it has been objected that since trimoric vowels are found only in final syllables, the assumption of such vowels requires a greater number of quantitative distinctions in unstressed than in stressed syllables (Schrijver 2004: 199), a typological improbability. Yet that is not necessarily the case, since stressed bivocalic sequences due to loss of an intervening laryngeal consonant must have occurred at some point in the development of Gmc.; there is simply no evidence that they developed differently from other long vowels in stressed syllables, nor should any such difference be expected. It is also possible, however, that trimoric vowels were simply uncontracted vowels which remained uncontracted until unstressed bimoric vowels were shortened, and then trimoric vowels contracted and remained as long vowels for a time. ${ }^{1}$ In reconstructions in this book, trimoric vowels and diphthongs are indicated by a circumflex diacritic, e.g. $\hat{e}, \hat{o}, \hat{o} i$, etc., though other notational devices will be encountered in the literature.

It was once widely agreed that trimoric vowels arose in environments in addition to the perilaryngeal one just described. ${ }^{2}$ The PIE thematic masc. nom. pl. inflection ${ }^{*}-\bar{o} s$ $<*_{\text {-o-es }}$ was regularly regarded as an example (so, e.g., Fulk 1992: 420, Ringe 2017 : 92 ), but it is now to be doubted that vowels arising in this manner were trimoric. ${ }^{3}$ 
Likewise, compensatory lengthening upon loss of a final consonant has sometimes been thought to result in a trimoric vowel: so, e.g., Bammesberger 1990: 167 n. 275, 169. Similarly, Prokosch (1939: §49n) analyzes the trimoricity in the PGmc. gen. sg. inflection *-ôz of the $\bar{o}$-stems as due to compensation for the loss of a final vowel in PIE, i.e. '- $\bar{a}-s o>*_{-} \hat{a} s(\theta \varepsilon \hat{\alpha} \varsigma)$ ' (cf. masc. *-so), but rather the ending is to be analyzed as *-eh-es or $*_{-} e h_{2}-o s$, given that the consonant-stem inflection is $*_{-} e s$ or $*_{-} o s(\S \S 7.2,7.15)$. Very likely trimoric vowels did arise in PGmc. upon the loss of $j$ between unstressed vowels ( $\$ 6.11 \mathrm{ad}$ fin.), though the evidence is not unassailable (see below). On PIE long diphthongs, see $\$ 5.3$ n. 4 .

In addition to the differing developments of bimoric and trimoric vowels, some evidence for trimoric vowels in Gmc. is furnished by the meter of Beowulf, in which originally trimoric vowels, like inflections ending in a consonant, prevent resolution under secondary stress, whereas final, originally bimoric vowels, at least when shortened, demand resolution, a principle now known as Kaluza's law. ${ }^{4}$ The fem. $\bar{o}$-stem gen. sg. inflection (as above), for example, is one that prevents resolution (see Beowulf $2118 \mathrm{a})$.

It will thus be seen that in studies of trimoricity it has commonly been the assumption that the distinction between bimoric and trimoric vowels rests upon whether or not they could be shortened in PGmc., with Gothic providing the most reliable evidence. But it was shown above that bimoric vowels protected by a final consonant were not generally shortened in PGmc., and thus, many endings formerly thought to reflect trimoric vowels can be better explained as preserving length because of the original presence of a final consonant. The distinction is of some significance, since bimoric and trimoric vowels and diphthongs in final syllables closed by a consonant do not always develop identically. An example is Go. $\bar{o}$-stem acc. sg. $-a<*_{-} \bar{o}^{n}<*_{-}-e h_{2} m$ : gen. pl. $-\bar{o}<*_{-} \hat{o}^{n} *_{-}$oHom; another is Go. $3 \mathrm{sg}$. pass. $-d a<$ PGmc. $*_{-}$¿ai $<\mathrm{PIE} *_{-}$-toi :

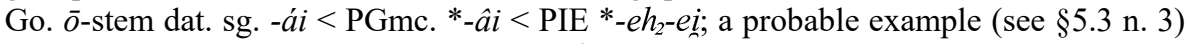
is Go. weak $3 \mathrm{sg}$. pret. $-d a<*_{-}$¿e $p<* d h e h_{1} t$ : adverbial $-\bar{e}$ (as in jáindrē 'thither', hidrē 'hither') $<*$-ê $<*_{-}$eh et. In addition, bimoric and trimoric vowels in absolute finality develop differently, as with Go. $1 \mathrm{sg}$. pres. ind. $-a<$ PGmc. *-ō, but cf. Go. pret. $3 \mathrm{sg}$. saísō < PGmc. *se-zô < PIE *se-sóh ${ }_{1}$-e. Ringe (2017: 91; not his notation) tabulates the different developments of bimoric and trimoric $o$-timbre vowels as follows:

\begin{tabular}{|c|c|c|c|c|}
\hline PGmc. & Go. & ON & OE & OHG \\
\hline$*_{-\bar{O}}$ & $-\mathrm{a}$ & $*_{-u}>\varnothing$ & $-\mathrm{u} \sim \varnothing$ & $-\mathrm{u} \sim \varnothing$ \\
\hline$*_{-} \overline{\mathrm{O}}^{\mathrm{n}}$ & $-\mathrm{a}$ & $-a$ & $-\mathfrak{x}>-e$ & $-\mathrm{a}$ \\
\hline${ }^{*}-\hat{o}, *-\hat{o}^{n}$ & -0 & $-a$ & $-a$ & -0 \\
\hline$*_{\text {-ōz }}$ & -os & -ar & $-æ>-e$ & $-a$ \\
\hline *-ôz & -os & $-a r$ & $-a$ & -0 \\
\hline
\end{tabular}

The most securely attested trimoric vowels and diphthongs of PGmc. (as defined here) and their developments are as follows:

The PIE $o$-stem ablative sg. ending $*_{-} o-h_{l} e d^{5}$ is reflected as an adverbial ending in PGmc. *-ô(t), e.g. Go. ga-leikō 'in like manner', OIcel. likka, OE ge-līce, OFris. līke, OS gi-līko, OHG gi-līhho. PGmc. $\hat{o}$ in the gen. pl. $a$-stem inflection ${ }^{*}-\hat{o}^{n}<$ PIE ${ }^{*}-o H o m$ (?) develops similarly, except that the Go. inflection $-\bar{e}$ is of disputed origin ( $\$ 7.8)$, and in Anglo-Frisian the nasalized (and thus unfronted) vowel remains long relatively late, as shown by the treatment of the inflection as heavy in the meter of Beowulf under Kaluza's law: so, e.g., gen. pl. Go. dagē, OIcel. OE daga, OS dago, OHG tago 'day'. 
A trimoric vowel must be assumed in certain masc. and neut. $n$-stem inflections, e.g. Go. neut. nom. sg. haírtō 'heart', masc. OE nama, OHG namo (cf. PGmc. $-\bar{o}^{n}$ in acc. sg. Go. giba, OE giefe, OFris. gife, OS geba, OHG geba 'gift'). In this instance, however, $\hat{o}$ is certainly not due to loss of an intervocalic laryngeal consonant, and although there are parallels to the trimoricity in Balto-Slavic (see Jasanoff 2002), such forms present a considerable obstacle to explaining Gmc. trimoricity purely on the basis of derivation from PIE. ${ }^{6}$ An example of a trimoric $\hat{o}$ in absolute finality was given above, Go. saísō, OIcel. sera 'sowed' $<*$ se-sóh $e$. The endings of the $1 \& 3 \mathrm{sg}$. pres. sj. of weak verbs of class 2 (Go. $-\bar{o}, \mathrm{OHG}-o$, etc.) give evidence of a trimoric vowel that arose in PGmc. by the loss of intervocalic $j$ (Ringe 2017: 160). A fairly plain demonstration of the different developments of bimoric and trimoric vowels is afforded by the OE $\bar{o}$-stem inflections (§7.15), originally nom. pl. $-a<*_{-} \hat{o} z<\mathrm{PIE} *_{-} e h_{2} e s:$ acc. pl. $-e<*_{-} \bar{o} z<\mathrm{PIE} *_{-} e h_{2} n s$ (Hollifield 1980: 43).

The PIE $i$-stem nom. pl. ending *-ei-es should have developed to PGmc. *-i(j)iz $>*_{-} \hat{z}$, and this accounts well for Go. -eis and ON -ir, though $*_{-} \bar{\imath} z$ would probably produce the same results, and the WGmc. endings are difficult to explain (see \$7.21).

The PIE $\bar{a}$-stem dat. sg. inflection $*_{-} a h_{2}-e i$ gives PGmc. ${ }_{-}-\hat{i} i$, which develops regularly in Gothic (-ái) and in $\mathrm{OE}\left(-e<\right.$ early $\left.-\mathfrak{x}<\mathrm{NWGmc.}{ }_{-\bar{x}} \bar{x}\right)$; on the reflex elsewhere in Gmc., see $\$ 7.15$. Compare the development of final bimoric ai to Go. $a$ in 3 sg. pass. $-d a$. The meter of Beowulf attests to a trimoric vowel in the masc. nom. pl. inflection of adjectives; perhaps the best explanation is that pronominal PGmc. *-ai (PIE *-oi) was added to the ending $-a$ (Brunner 1965: $§ 150.1) .^{7}$

If the analysis of weak verbs of the third class offered by Bennett (1962) is correct, certain forms in the present paradigm of these might be expected to show PGmc. *-âi- <*-a(j)i- < PIE *-holi-e-, e.g. Go. 2 sg. habáis 'have', OE (Anglian) hafas(t), OS habes, -as; but OIcel. hef(i)r is hard to reconcile with this view (\$12.47).

It will be seen, then, that if trimoric vowels result only from the loss of a laryngeal consonant between vocalic segments or the loss of $j$ between unstressed vowels in PGmc., the undeniable examples are few-many fewer than the handbooks generally allow-and undeniable exceptions do occur. ${ }^{8}$ A great many of the supposed discrepant developments of bimoric and trimoric vocoids must instead be due to differences between the development of bimoric vowels in absolute finality and before an original final consonant.

An alternative to the assumption of PGmc. trimoric vowels is the hypothesis that PIE $\bar{a}$ and $\bar{o}$ developed differently in WGmc., and perhaps elsewhere, when unstressed, except in absolute finality, where they both result in PGmc. $\bar{o}$ (Möller 1880, Jellinek 1891a, 1895, van Wijk 1907-8, A.W. Jones 1979; cf. Boutkan 1995b: 105-9). The idea has been revived and defended by Schrijver (2004), with extensive discussion and the theory of a Saami substrate in NWGmc. Earlier it was supposed that the Auslautgesetze could be regularized on the basis of accentual considerations: so, originally, Paul 1879: 178-208, later Hamp 1959, Wagner 1986b: 43-8, d'Alquen 1988.

1. For most purposes it matters little what the precise nature of trimoric vowels was, though certain analyses depend upon a particular specification, e.g. the argument of Jasanoff (2002: 37) that an extra mora was added to final $-\bar{o}$ in Gmc. and Balto-Slavic, creating a trimoric vowel (see $\$ 7.31 \mathrm{n} .4$ ) and the argument of Lane (1963) that trimoric vowels arose only when one of the two vowels involved was long. Similar to Lane's is the view of Ringe (2017: 93, 153-64), though he also credits trimoricity as a result of contractions like PIE $*_{-o-e s}>*_{-} \bar{o}$ s and of word-final vowel plus laryngeal, and he suggests that trimoric vowels may have been glottalized. Similarly, rejection of the theory of trimoricity generally depends upon a particular interpretation of what is meant by trimoricity: for example, Boutkan, who describes trimoricity as a matter of quantity and rejects the theory, nonetheless reconstructs a bivocalic sequence for the gen. pl. (1995b: 140, following F. 
Kortlandt). Although the distinction between bimoric and trimoric vowels remains central to many approaches to the laws of finals, it should be said that the distinction is rejected by many, e.g. Marchand (1973: 102).

2. Hirt (1894: 99-117, summary 115-17) identifies four sources of trimoricity in PIE: contraction (e.g. abl. sg. *-o-ed $\left.>*_{-}^{*} \hat{d}\right)$, loss of a syllable (e.g. $i$-stem gen. sg. *-oiso $>*_{-}^{*} \hat{i s}$ ), compensatory lengthening upon loss of a consonant (e.g. $\bar{a}$-stem acc. pl. $*_{-}-\bar{a} n s>*_{-} \hat{a} s$ ), and some other, unknown factor (e.g. Gk. diphthongal stem voc. $\beta \alpha \sigma l \lambda \varepsilon \hat{v}$ 'king' : nom. $\beta \alpha \sigma l \lambda \varepsilon \dot{v} \varsigma)$.

3. So, e.g., Jasanoff 2004: 22-3. Lane (1963: 165) remarks that although this plural ending *-ōs $(>$ Skt. $-\bar{a} s)$ must occasionally be scanned as disyllabic in Vedic verse, so must a number of endings that cannot be the result of contraction of any sort, and neither they nor this $*_{-} \bar{o} s$ is disyllabic with anything approaching the frequency of the corresponding fem. ending $-\bar{a} s<*_{-}-e h_{2}-e s$. Disyllabic scansion in these other endings thus must be analogical. See also Lindeman 1987: 45-6 on analogical scansions. The meter of Beowulf unfortunately provides no evidence on this score.

4. For example, in the verse wiss wordcwida there must not be metrical resolution of $-c w i d a$ (with $-a<$ PGmc. ${ }^{*}-\hat{o}^{n}$ ), as the verse would otherwise comprise just three metrical positions rather than the requisite four, whereas in the verse $n \bar{y} d$ wracu nīpgrim there must be resolution of - wracu (with $-u<$ Gmc. *-ō) to reduce the verse from five positions to four. For discussion and references, see Fulk 1992: $\S 153-68$, and for subsequent scholarship, Neidorf \& Pascual 2014.

5. So Beekes 2011: $\S 13.2 .9$. Most studies regard the PGmc. vowel (and the Proto-Baltic) as trimoric, though Fortson (2010: §6.45) expresses uncertainty about the laryngeal. See Hollifield 1980: 27-8. Certainly Beekes is not justified in reconstructing the corresponding dat. inflection as $*_{-} o h_{l} e i$ rather than $*_{-} \bar{o} i<*_{-}-e i$. Lane (1963: 167) adduces evidence from Vedic meter for trimoricity in the ablative ending, though there remains room for doubt. On the uncertainties involved in adverbial endings, see Boutkan 1995b: 378-81. As the example illustrates, distinguishing trimoric from bimoric vowels in PGmc. is fraught with difficulties. For an excellent overview of the problem, see Stiles 1988.

6. It is noteworthy in this context that the reflex of the PGmc. $\bar{o}$-stem acc. sg. ending $*_{-} \bar{o}^{n}$ prevents metrical resolution at Beowulf 596a, though it, like the $n$-stem endings here discussed, does not involve loss of an intervocalic laryngeal in the usual reconstruction $\left({ }^{*}-\bar{o}^{n}<*_{-} \bar{a} m<*_{-} e h_{2}-m\right.$, not $\left.*_{-} e h_{2}-m\right)$. This inflection is not commonly disyllabic in Vedic, but the Proto-Baltic ending also points to a trimoric vowel (see Hollifield 1980: 28), and so perhaps the same process that produced a trimoric vowel in the $n$-stem masc. and neut. nom. sg., whatever that process was, also produced trimoricity here.

7. The possibility must be recognized, however, that trimoric and unshortened bimoric vowels were treated identically under Kaluza's law. The (non)resolvable verses in Beowulf relevant to this question are few.

8. For a tabulation of endings containing trimoric vowels according to the handbooks' most liberal interpretation, see Boutkan 1995b: 115-20.

\subsection{Changes of medial vowels in the early preliterary period}

For the most part, in the PGmc. period vowels in syllables of lesser stress underwent the same changes as fully stressed vowels, but some differences are to be remarked.

It is commonly reported that PIE $e$ develops to PGmc. unstressed $i$ except before r: so, e.g., A. Campbell 1977: §331.2; Krahe \& Meid 1969: I, §45. Examples are nom. pl. *lambezo $>*$ lambizu $>$ OHG lembir 'lambs' and pp. * $k^{w}$ umenaz $>*$ kumin $>$ OE cymen 'come', but *afteraz > OE æfter 'after' (without umlaut; cf. Go. aftarō 'in back of', with analogical $-\bar{o}$, and Skt. apataram 'farther off'); also PGmc. *anperaz > Go.

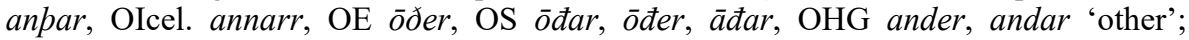
*faðer-> Go. fadar, OIcel. faðir, OHG fater. There are exceptions, however, such as 2 pl. pres. *3rabepe > OIcel. grafid, OHG grabet 'dig' (without umlaut) and gen. sg. *dazes (a) > OHG tages (see $\$ 7.8$ on the inflection), though of course these can be explained as due to substitution of $e$ for $i$ after the PGmc. period, or other analogical developments. Accordingly, some suppose that in unstressed syllables as in stressed there was raising of $e$ only before a high vowel in the next syllable (so, e.g., van Helten 
1891: 460, Hirt 1931-4: 1.41, Boutkan 1995b: 72-89; but see $\$ 4.4$ supra regarding the reliability of this formulation for stressed syllables), as for instance in 2 sg. pres. *3rabesi $>*_{3}$ rabis $(i) /$-iz(i) > OIcel. grefr, OHG grebis 'dig'. Even if the latter is the case, though, it must be assumed that $e$ yields $i$ before final $z$, as in the $s$-stem nom. sg. (so, e.g., Antonsen 2002: 240-1). Yet once again there are exceptions. The PGmc. suffix *-il- causes umlaut wherever it can (OE yfel 'bad', micel 'large', lỳtel 'little', etc.),

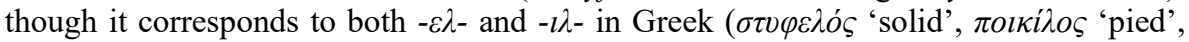
etc.); likewise, PIE *ne 'not' (Skt. ná, Lat. ne- in nesciō 'not know', nefās 'abomination', etc.) gives PGmc. *ni (Go. OFris. OS OHG $n i$, unstressed). It was shown above (§4.4) that the raising of $e$ to $i$ in stressed syllables is subject to many exceptions, probably due to elimination of paradigm alternations, and the same should be expected in unstressed syllables if the change was similarly a type of distance assimilation. The assumption that unstressed $e$ was everywhere raised except before $r$ has in its favor the development of $e$ to $i$ in unstressed monosyllables, e.g. PGmc. *ek> OE $i c$, OS $i k$, OHG ih (OIcel. $e k$ reflects the tonic form), and PIE *ne > PGmc. * $n i$ (above). The evidence is too insecure to draw any firm conclusions at present, but certainly the reflex of PIE $e$ in Gmc. unstressed syllables is most commonly $i$, except before $r{ }^{1}$

As for PGmc. *er, it is sometimes asserted that this changed categorically to *ar in PGmc. or in NWGmc. ${ }^{2}$ Yet the handbooks of ON (e.g. Heusler 1967: $\S 105,113$ ) relate that this change is to be expected only in originally medial syllables: to OIcel. annarr 'other' $<$ *anperaz cf. undir 'under' $<*$ under ( $\$ 5.6$ \& n. 3). Moreover, it is most commonly assumed that PGmc. final *-er remains as such in Anglo-Frisian (so, e.g., Brunner 1965: §44 Anm. 4, A. Campbell 1977: §369), though it is also possible that final *-er changed to *-ar in WGmc., becoming *-ær by Anglo-Frisian Brightening (§4.12), later -er. In support of the latter view, Ringe points out that WGmc. *-ar does, after all, yield OE -er in OE fêower, OFris. fiower, fiuwer 'four' (Ringe \& Taylor 2014: 18). Yet this observation does not demand that OE under be derived from WGmc. *undar. The spelling of 'after' with 〈er〉 in early Northumbrian (in both Cædmon's Hymn and Bede's Death Song) speaks for the usual interpretation, but then early Anglian spellings of 'over' with 〈aer〉 (Leiden Riddle, Épinal Glossary, in the latter beside (er)), must be assumed to show confusion of unstressed vowels. OHG ander 'other', after 'after', however, are hard to explain if *er became *ar in PGmc. (Braune 2004a: $\S \S 64,65$ Anm. 3). The question cannot be settled conclusively, though one's view about this is likely to parallel one's view about whether PGmc. $\bar{e}_{1}$ developed categorically to $\bar{a}$ in NWGmc. (\$4.6).

Although PIE $o$ regularly developed to $a$ in PGmc. stressed syllables (\$3.2), it is usually thought to have remained $o$ longer under certain unstressed conditions. ${ }^{3}$ According to this view, as a connecting vowel in compounds it probably remained rounded before labial consonants, given the evidence of early Germanic names preserved in Latin texts, such as Ario-vistus and Lango-bardi. In NWGmc. it is reflected as $u$ (but Go. $a$ ) before $m$, as with the development of PIE *-omis to PGmc. ${ }^{*}-o-m(i) z$ in dat. pl. Go. stáinam but OIcel. steinum, OE stānum, OS stēnum OHG steinum, and of PIE *-omes to PGmc. ${ }^{*}$-om(i)z in 1 pl. pres. Go. bairam but OIcel. berum (and cf. OHG berumess) 'bear'. ${ }^{4}$ A similar development is commonly said to affect both this same $o$ and also $\bar{o}$, which developed to $u$ and $\bar{u}$, before $u$ in the next syllable. ${ }^{5}$ This change is sometimes regarded as coeval with the other (see, e.g., A. Campbell 1977: §331.6), though the NGmc. evidence is insecure. Examples: PGmc. ${ }^{*}$-on-um $>{ }^{*}$-on $u^{n}>-u n$ in the acc. sg. of masc. $n$-stems, e.g. OS gumon, -un, OHG gomon, -un 'man', OE (North- 
umbrian Runic) galgu 'gallows'; ${ }^{6}$ PGmc. *-ōn-um $>*_{-}^{*} n u^{n}>-\bar{u} n$ in the acc. sg. of fem. $n$-stem nouns, e.g. OHG zungūn 'tongue', OE (Northumbrian) foldu 'earth', eorðu 'earth'. ${ }^{7}$ The ON evidence for these latter changes is almost all capable of alternative explanation, ${ }^{8}$ and perhaps even seemingly convincing examples can be accounted for otherwise, such as agentive nouns in $-u ð r<*_{-} \overline{\partial u z, ~ e . g . ~ O I c e l . ~ m j o t u ð r, ~ O E ~ m e(o) t o d, ~}$ OS metod 'God' (*'deliberator': cf. *metōjana ${ }^{*}>$ Go. mitōn 'plan'; further examples in Kluge 1926: §29). ${ }^{9}$ For details, see van Helten 1891: 460-7, Walde 1900: 167-79. See also below ( $\$ 5.6)$ on $\bar{o}>\bar{u}$ in NWGmc.

There is no scholarly consensus about the development of PIE syllabic laryngeals in Gmc. unstressed syllables. From the equation PIE * dhug $(h) h_{2}$ tér- $>$ Skt. duhitár- = Gk. $\theta v \gamma \alpha \tau \varepsilon \dot{\rho} \rho-=$ Go. daúhtar 'daughter' it would seem that a syllabic laryngeal was simply lost. ${ }^{10}$ Yet it has been questioned whether the laryngeal in this word was actually syllabic in PIE or whether it was vocalized on a dialectal basis (see Fulk 1988: 153; Hackstein 2002). Not infrequently it has been argued that a syllabic laryngeal may under some conditions be reflected as $u$ (so, e.g., Streitberg 1896: §56, Lehmann 1952: 53-5). The hypothesis of Bennett (1978, supported by Ringe 1988: 429) that $H$ was lost in medial syllables but preserved as $u$ in final ones, aside from lacking any straightforward phonological rationale, faces the difficulty that the securest example of PIE $H>$ Gmc. u, OE ened, æned, OHG anut, anot 'duck' < *anuði- (cf. Skt. àtíh, Lith. ántis, Gk. $v \hat{\eta} \sigma \sigma \alpha$ Lat. anas, gen. anatis) is to be reconstructed as an $i$-stem, and thus $H$ would not have appeared in a final syllable in any PGmc. case-form. ${ }^{11}$ By contrast, the likeliest explanation of OE birce 'birch' (< PIE *bherH $\left.\hat{g}_{-}\right)$and its Gmc. cognates is that $H$ has been lost from such forms without a trace: cf. PIE $* b h r H g-$ in Skt. bhürja-. A comprehensive explanation remains to be devised. ${ }^{12}$

1. For discussion and references, see Boutkan 1995a, 1995b: 72-89, who concludes that in NWGmc., $e$ was raised to $i$ only before $i$ or $j$ in the next syllable, or before the reflex of PIE $s$. In the latter study he draws this conclusion on the basis of four inflections: (1) PIE $2 \& 3 \mathrm{sg}$. pres. ind. *-esi, *-eti $>*_{-}^{*} i s,{ }^{*}-i p$; (2) PIE $o$-stem gen. sg. *-éso as reflected in $\mathrm{OHG}-e s$; PIE 2 pl. ind. *-et(H)e as reflected in OHG -et; and (4) PGmc. $n$-stem gen. \& dat. sg. *-ena/es, ${ }^{*}$-eni as reflected in $\mathrm{OHG}-e n$, -in, respectively. Cf. the discussion in Ringe 2017: 147-51 (contra Lloyd 1961), with counterexamples.

2. See, e.g., Stiles 1988: 133, 136 n. 4, Ringe 2017: 150. The relevant article cited by Stiles as forthcoming, however, appears never to have been published.

3. See Eulenburg 1904, responding to Bremer 1903 (where it is argued that all the evidence of personal names may be due to inflectional endings in the classical languages, or to Celtic influence); likewise Banta 1980, Polomé 1994: 4-5. Boutkan (1995b: 90) credits Bremer's argument, but the restriction of preserved $o$ almost entirely to the position before a labial consonant (as pointed out by Eulenburg) raises significant doubts. Still, as Boutkan remarks, the allophones of PGmc. /a/ cannot be known, and it is not necessary to assume the maintenance of a phonemic distinction between PIE $a$ and $o$ in any environment in PGmc., as /a/ may have been rounded in some environments.

4. Beeler (1979) proposes instead that $o$ developed normally to $a$, which was subsequently lost, producing nuclearization of $m$, leading to $-u m$.

5. Boutkan (1995b passim) refers to this raising as van Helten's law: see van Helten 1891: 460-3, and see Hollifield 1984 for a detailed study. The idea is rejected in Ringe \& Taylor 2014: 62-5.

6. Note, however, that Walde (1900: 169) explains Northumbrian $-u$ in such masc. forms as analogical to WGmc. fem. forms with $\bar{u}<\bar{o}$. Streitberg (1893: 49-50) objects to a phonological change $\bar{o}>\bar{u}$ on the ground that $\bar{e}$ does not become $\bar{\imath}$ before $i$, but it must be remembered that the PGmc. (and NWGmc.) inventory of long vowels was asymmetrical.

7. The WGmc. $s$-stems are sometimes invoked in evidence of this change, but on some of the difficulties involved see Hogg \& Fulk 2011: 2.99 nn. 1-2, and cf., e.g., von Unwerth 1910: 11.

8. The handbooks of ON (e.g. Noreen 1970: $§ 148)$ generally prescribe that $u(o)$ in a form like nom. acc. pl. neut. heilug 'holy' $(<*$ xailazo $)$ is developed from $g$, the latter due to back mutation of $a(\S 4.8)$. This would 
place the development of $u$ in such forms well after the close of the NWGmc. period. Inscriptions in the Older Futhark afford no unambiguous evidence, but since PGmc. -er- develops to -ar-in NGmc. (but perhaps not throughout WGmc.: §5.5), the development seen in PGmc. nom. sg. fem. *anperō $>*$ anparu $>*$ annoru $>$ OIcel. gnnur 'other' would seem to date the change to the post-NWGmc. period.

9. The change has not yet occurred ca. $500 \mathrm{CE}$ in the form haukopur on the Vånga stone from Sweden (if in fact -opur, with $\bar{o}$, represents this same agentive suffix).

10. See the references in Szemerényi 1996: §5.3.4 Addendum.

11. See Fulk 1988: 153-4, 170-1. Boutkan (1995b: 94-7) would explain $u$ in *anuð as due to analogy to acc. *anuð-un < *anað-un: see Müller 2007: 75-6.

12. The literature is cited in G. Schmidt 1973: 64-7 and Fulk 1988.

\subsection{Later preliterary changes of medial and final vowels}

Go. $i u$ from earlier $i w$ by loss of a following vowel became $j u$ in unstressed syllables, as in nom. pl. sunjus 'sons' $<*^{*}$ suniwiz. Final $*_{-i} / \hat{\imath}$ was shortened in Gothic, as in acc. hairdi 'herdsman' < *xirðijan , voc. hairdi $<* x i r ð i(j) i{ }^{1}$

Possibly $a i$ was monophthongized to $\bar{x}$ in (N)WGmc. middle syllables, as it was in final (\$5.3), as is suggested by the correspondences of the Go. comparative suffix -aiz- = OHG -er- on adjs. and of Go. libáin- 'life', lubáin- 'hope' = OE lifen 'sustenance', lufen 'hope'. If so, au was probably correspondingly monophthongized to $\bar{o}$, though there is no relevant evidence.

It is commonly assumed that PGmc. $\bar{o}$ yields NWGmc. $\bar{u}$ before tautosyllabic $n$ (so, e.g., Prokosch 1939: §84d, Krahe \& Meid 1969: I, §47). ${ }^{2}$ This assumption seems necessary in order to account for developments in the $\bar{o} n$-stems (§7.33). For discussion, with references, and a vigorous defense, see Hill 2010: 432-43; also Ringe \& Taylor 2014: 63. Certain NGmc. evidence discourages the assumption that this could be a development of the NWGmc. protolanguage, most notably Runic -on for expected *-un in two fifth-century inscriptions, and accordingly Hill concludes that the change, demanded by the $u$-mutation in forms like dat. sg. gotu 'path', is a separate, later development in NGmc. The idea of Panieri (2015) that raising could be caused by $i$ in the following syllable, e.g. OHG dat. sg. zungūn $<*$ tungōn $(i)$, betrays no acquaintance with similar, earlier proposals (see Hill 2010: 440-1). For a review of alternative analyses, see Boutkan 1995b: 289-90.

It is sometimes assumed that $\bar{e}_{1}$ developed to $\bar{a}$ in both unstressed and stressed syllables in NWGmc.: so, e.g. Bazell 1937, Hollifield 1980: 103-4. It was shown above (§4.6) that this is improbable in stressed syllables if Ingvaeonic is regarded as descended from Proto-WGmc. (cf. Antonsen 1975: 27). In unstressed syllables, too, it was more likely $\bar{x}$, represented as e, and perhaps a, in Runic (tawide, swestar: see above, §5.3, and below, n. 4); so also Korlandt 1989: 103-4, 1990: 5-6.

Old Norse. The development of unstressed vowels in NGmc. is especially complex. Most short vowels in final syllables (whether originally final or due to PGmc. loss of a final syllable) are lost, but not before causing front or back mutation, where possible. Unlike in WGmc., short vowels are lost after both heavy and light syllables, though the facts of front umlaut show that $i$ must have been reduced (with lowering) and lost earlier after heavy stems than light (\$4.7). Examples are *dazaR > dagr 'day', acc. sg. * stain $^{n}>$ stein 'stone', *mazuR $>$ mogr 'boy, son', and PNorse *ferup in the expression i fjord 'last year' (cf. Skt. parút, Gk. $\pi \dot{\varepsilon} p v \sigma r)$. However, short vowels were 
preserved before a nasal consonant or $r($ not $R$ ), as in NGmc. 3 pl. pret. * gābun $>$ gáfu 'gave' and PGmc. *ubir(i)> yfir 'over'. Before a nasal consonant in a closed syllable, $a$ develops to $e$ (later $i$ ), as in *wöðanar > Óðinn (name, without $i$-umlaut) and pp. *faranaR > farinn 'gone'; likewise before $g$, as in *ainazan > einigr 'any' (but heilagr 'holy'). As in Go., $e$ before $r$ yields $a,{ }^{3}$ as in hvaðarr 'which of two' (Go. hapar, OE $h w æ \partial e r)$. On the dating of apocope, see Isakson 2000, H.F. Nielsen 2000: 259-61.

Long vowels were shortened in final syllables, as in *swestēr $>$ NGmc. *swestār $>$ syster, later systir 'sister' (showing that $\bar{e}_{1}$ developed differently in stressed and unstressed syllables: see $\S 4.6) ;{ }^{4}$ gen. sg. $\bar{o}$-stem *manôR $>$ manar 'mane'; PGmc. -ai in *haitz $>$ heite, later heiti 'am called', and so forth. In some middle syllables, however, ai developed to $\bar{a}$, as in vitaðr 'known' <*witaiðaR (cf. Go. witáips): see Noreen 1970: $\S 139$ for details. The diphthong iu was also reduced, as in *suniuR $>$ synir 'sons'.

After the loss of vowels in the ultima, as outlined above, an unstressed short vowel was syncopated in what was now the penultima if it was an open syllable or if the syllable was closed only by a cluster $s t$ or $s k$, which thus was treated as a unitary phoneme, the way it is for the purpose of alliteration in early Gmc. verse. Thus, for example, there is syncope in NGmc. acc. sg. masc. *gamalanu ${ }^{n}>$ gamlan 'old' (but nom. sg. gamall $<{ }^{*}$ gamalaR) and nom. pl. masc. ${ }^{*}$ haitanæ $\bar{x}_{R}>$ heitner, later heitnir 'called' (cf. gen. sg. heitins $<*$ haitanas). When this resulted in stem alternations within the paradigm, often one stem was extended throughout, as for example in superlatives in *-ist- (e.g. dat. pl. *jungistom > yngstum 'youngest', with yngst- then extended to the nom. sg., hence yngstr rather than †yngistr).

Under the same conditions, NGmc. $\bar{x}$ and $\bar{l}$ were lost, whereas $\bar{o}$ is reflected as $a$, though again there is much stem uniformization within paradigms. Examples: NGmc. gen. sg. fem. *pazǣnôR > pagnar 'silence' (cf. Go. neut. paháins); acc. sg. fem. gullna 'golden' (cf. Go. gulpeina); 1 sg. pret. hvarfaða 'went about' (cf. Go. harbōda). Under all other conditions, long vowels in medial syllables were shortened, with $\bar{o}$ again yielding $a$. Examples: NGmc. nom. sg. *blindōstaR > blindastr 'blindest'; NGmc. 1 pl. pres. sj. *geち̋̄m(e) > gefem, later gefim 'give'; NGmc. 1 pl. pret. sj. *grō̄ime > grofim 'dig'.

West Germanic. In final unstressed syllables, $a$ and $a^{n}$ were lost regardless of the weight of the preceding syllable, as in PGmc. nom. sg. *dazaz $>* d a z a^{6}>\mathrm{OE} d æ g$, OS dag, OHG tag 'day', acc. sg. PGmc. *dazan $>$ OE dæg, OS dag, OHG tag. When this change resulted in a word-final postconsonantal sonorant (e.g. *wundraz $>{ }^{*}$ wundr), the sonorant remained nonsyllabic for a time, as shown by the meters of alliterative poetry. ${ }^{7}$ Although it is commonly regarded as belonging to the WGmc. protolanguage, nuclearization (vocalization, syllabification) of final sonorants cannot have taken place very early, and it must be assumed to have occurred on a dialectal basis, as suggested also by the divergent results in English and elsewhere (see below). Indeed, in some instances OE spelling suggests that certain final resonants remained nonsyllabic in the historical period, as with botm 'bottom' and $\bar{a} d l$ 'disease'. ${ }^{8}$ Glides which became final in this manner, however, were vocalized early, e.g. PGmc. *xarjaz $>$ WGmc. *hari $>$ OE here, OS OHG heri 'army' and PGmc. *sarwan $>$ WGmc. *saru $>$ OE searo, OS OHG saro 'device, armament'. When thus nuclearized, the resultant high vowels underwent the same development as original high vowels, being lost after heavy syllables, though not infrequently the sound is restored on an analogical basis. Examples are OE $m \bar{x} d$

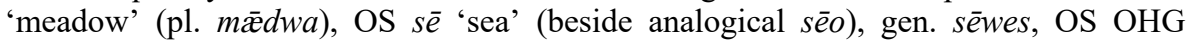
analogical kunni 'kin, kind' (cf. OE cynn $<$ PGmc. ${ }^{*} k u n j a^{n}$ ). In addition to such nuclear- 
ization there is anaptyxis in the WGmc. languages: it is infrequent in $\mathrm{OE}$ (see Hogg 1992: $\S \S 6.34-7)$; in OHG it occurs between a liquid and $h$ (e.g. forahta, forohta beside forhta 'fright') and in some clusters containing $w$ (e.g. garawēr beside garwèr 'ready': see Braune 2004a: §69); ${ }^{9}$ and in OS it is particularly common, occurring in a considerable variety of consonant combinations (see Holthausen 1921: §144). Unlike inherited vowels, such vowels are unstable.

Although the change did not take place in the WGmc. protolanguage itself, the pattern of retention of unstressed high vowels after light syllables but not heavy is plainer in WGmc. than elsewhere, though OS and OHG obscure the original pattern more than OE through analogical change. ${ }^{10}$ In Anglo-Frisian this syncope took place later than the application of $i$-umlaut (cf. OE giest, OFris. iest 'guest') but before $i$ umlaut elsewhere in WGmc. (OS OHG gast). The change does not occur in a closed syllable, nor in a final syllable closed by a consonant, as this would result in unwieldy consonant clusters. Examples: PGmc. *winiz > WGmc. *wini $>$ OE wine, OS OHG wini 'friend'; PGmc. *brūðiz > OE brȳd, OFris. brēe, OS brūd, OHG brūt 'bride'; WGmc.

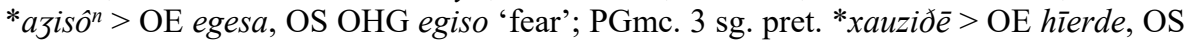
hōrda, OHG hōrta 'heard', but PGmc. pp. *xauziðaz > WGmc. *xaurid(a)> OE hiered, OS -hōrid, OHG -hōrit; PGmc. *sunuz > OE OS sunu, OHG sun, sunu 'son'; PGmc. *xanduz > OE OS hand, OHG hant; WGmc. gen. pl. *eburô ${ }^{n}>$ OE eofora, OHG eburo 'boar'; (Greek-derived) Lat. diabolus borrowed as *diubul- (see A. Campbell 1977: $\S 492)>$ OE dēofol, OS diubal, diubul, OHG tiufal, but OE dat. pl. dēoflum, OS diuநlun, OHG tiuflun (Wessobrunn). Again, a sequence of light syllable plus another of any weight is equivalent to a heavy syllable $(\$ 2.5)$ in regard to this change, as in OE neut.

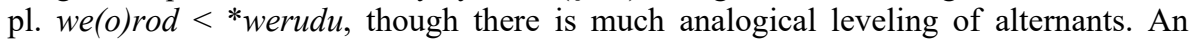
exception to the rule is that, at least in OE, although a medial high vowel in an open syllable might be expected to have been syncopated after a heavy syllable, it is instead preserved before the inflection $-u$, as in OE (Mercian) neut. nom./acc. pl. lỳtelu 'little' $<$ *lütilō and nētenu 'cattle' <*nēatinu < *nautīnō: see Fulk $2010 \mathrm{~b}$.

Ingvaeonic and Anglo-Frisian. In general, in Ingvaeonic and Anglo-Frisian the same changes occurred medially as in stressed syllables. Thus, there is the NSGmc. loss of a nasal consonant before a voiceless fricative, with compensatory lengthening (and later shortening) of the preceding vowel (\$4.11), as with *juzunp-> OE geogup, OFris. iogethe, OS jugud, but OHG jugund 'youth' (cf. Lat. juvent- <*iuHnt-) and the $3 \mathrm{pl}$. pres. ind. inflection *-anp(i)> OE - ap, OFris. -at(h), -et(h), OS - ad, but Go. -and, OHG -ant. As in stressed syllables, Anglo-Frisian $a$ was nasalized before a nasal consonant (but only a tautosyllabic one if the vowel was unstressed), otherwise fronted to $x$ ( $\$ 4.11$, later $e$ : see below), as in OE faran, OFris. fara 'go' and acc. sg. OE naman, OFris. noma, but with fronting in OE masc. $a$-stem gen. sg. -es (early -æs), OFris. -es, and before heterosyllabic $n$ in inflected forms of OE OFris. pp. faren- 'gone' < *faræn$<{ }^{*}$ faran-. ${ }^{11}$ The same change appears to have applied in OS, where the fronted vowel is variously spelt $\langle\mathrm{a}\rangle$ and $\langle\mathrm{e}\rangle$, as with the $a$-stem gen. sg. inflection -as, -es (Klein 1977: $390-537)$. Front mutation is fully operative in unstressed syllables, as in *apalijaz $>$ *apali > OE æðele, OFris. ethele, but OS ađali; OE -ede in æpplede 'embossed' (cf., e.g., OS hringodi 'ringed').

Unaccented non-high vowels (that is, $a$, as well as short vowels derived from it - fronted $x$, umlauted $e$, raised $i$ before palatal consonants - and $e$ preserved before $r$, were lost in all medial open syllables in Anglo-Frisian, regardless of the weight of the preceding syllable, as in acc. sg. masc. OE OFris. gōdne 'good' < ${ }^{*}$-ano $\bar{o}^{n}$ (cf. OS 
gōdan(a), OHG guotan); OE dat. pl. mangum 'many' <*manazum(iz) (cf. nom. sg.

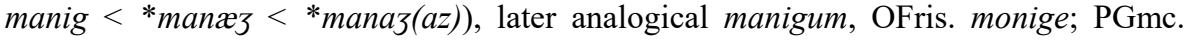
* samanōjana ${ }^{n}>$ OE samnian, OFris. somnia, samenia, OHG samanōn 'gather'; PGmc. *daza-werka ${ }^{n}>$ OE dægweorc, OFris. deiwerch, OHG tagawerk 'day's work'; WGmc. *ala-maxtīzaz > OE xlmihtig, OFris. elmechtich, OS alamahtig, OHG alamahtīg 'almighty'. An exception to the rule appears to occur when $a$, in an open syllable following a heavy syllable, is followed by final $-u$ in the next syllable, as in OE (Mercian) nom. sg. fem. ìdelu 'idle' <*iððalō and ēadigu 'blessed' < *auðagō: see Fulk 2010b.

The nuclearization of final postconsonantal sonorants conforms to a recognizable pattern in $\mathrm{OE}$, and it is possible that the change is Anglo-Frisian, though this cannot be proved, since unstressed short vowels are generally reduced to $e$ in Frisian. In $\mathrm{OE}$ the quality of the syllabic sonorant was at first determined by the quality of the vowel in the preceding syllable: after a front vowel the sonorant was written with preceding $i$ (later $e$ ), otherwise $u$ (later $o$ ). Examples (from names in early Latin texts) are -caestir (later ceaster, borrowed from Lat. castra) and Eorcun- (already beside Earcon-). There is no $i$-umlaut in forms with $i$ before the sonorant, though it cannot be determined whether that is because the change postdates umlaut or because $i$ does not represent an actual vowel but the fronted quality of the syllabic resonant. At all events, in course of time spellings like er and or could be used interchangeably, after front or back vowels, and thus they can represent only syllabic sonorants rather than a sequence of vowel plus sonorant. For further evidence, see Hogg \& Fulk 2011: §6.96.

Old English. All remaining long vowels in unstressed syllables were shortened, but not necessarily at one time. Thus, for example, $\bar{l}$ was shortened early enough medially to be syncopated before most inflections, as in dat. pl. gyldnum 'golden' (cf. Go. gulpeináim) and Anglian dat. pl. nètnum 'cattle' (but cf. acc. pl. nètenu, §5.6); compare the final development in hierde 'herdsman' $<-i<-\bar{l}<*_{-} i j(a z)$, with $\bar{l}$ arising (and being shortened) too late to be syncopated. At least some long vowels were shortened earlier in final syllables, so that $\bar{a}(<a i$, as in stressed syllables, §4.12) developed to $e$ in final syllables but $o$ in medial, and the resulting paradigm allomorphy led to much mixture of stems, as with earfep beside earfop 'difficulty' < *arbaip-; cf. Go. arbáips 'labor'. WGmc. $\bar{x}<\bar{e}_{1}$ is reflected in OE as $e$, as in bōcere 'scholar' $<*$-z̄ri $(z)$.

Breaking did not apply to syllables of low stress, though it is found in certain derivational suffixes, e.g. -weard beside -ward, with alternation due originally to alternate stressed and unstressed forms, e.g. stressed after the unstressed syllable in üteweard 'external', unstressed in tōward beside commoner tōweard 'impending'. Rather than break, $x$ was retracted to $a$ (and later commonly rounded) before $l$ or $r$ plus consonant, as in hläfard, hläford 'lord' < *xlaiba-warðaz and anwald, anwold 'control'.

Old English evinces some salient exceptions to the deletion of medial short vowels treated above (in part under West Germanic). In the notably conservative language of the Mercian gloss on the Vespasian Psalter, both syncope and apocope fail to affect disyllabic stems with a heavy initial syllable when they bear the inflection $-u$ (fem. nom. sg. or neut. nom./acc. pl.), e.g. ìdelu 'idle' and nētenu 'cattle', as opposed to forms bearing other inflections, e.g. ìdlan $<*$ idalanu and nētna $<*_{n} \bar{e} a t \bar{n} n \hat{o}$. Such forms are in almost perfectly consistent contrast to those of originally monosyllabic stems made disyllabic by the nuclearization (syllabification) of a final sonorant, e.g. fācen 'crimes' and wēpen 'weapons' (<*fācnu, *wēpnu). ${ }^{12}$ Also exceptional in WS and (in part) Kentish are $2 \& 3 \mathrm{sg}$. pres. ind. forms of verbs, with syncope occurring after both heavy and (less regularly) light stems, as in WS giefst, giefð 'give' and brȳcst, brȳcð 
'enjoy' (Anglian gefest, gefep, brūcest, brūcep, with analogical removal of $i$-umlaut). The commonest explanation now for such verb forms is that they underwent syncope when followed by a pronoun, the prosodic group acting like a single word, so that the inflectional vowel was in a position to be syncopated. The syncopated forms were then generalized in WS, the unsyncopated in Anglian. ${ }^{13}$ Syncope also affects some superlative adjs. of high frequency in WS, e.g. hiehsta 'highest', gingsta 'youngest' (beside gingesta), due either to treatment of -st- as a unitary phoneme (so that the syllable was open) or to the analogy of comparatives, in which the connecting vowel had been syncopated.

Although, as noted above, high vowels were not at first syncopated in a medial light syllable after an open syllable (e.g. nerede $<*$ nazid $\bar{x})$, already at a prehistoric date there was loss of $i$ in such an environment when the consonant following the vowel was $l$ or $r$, as in gen. sg. masc. micles 'large' $<*$ mikilæs and betra 'better' < *batizô: see Brunner 1965: $\$ 159$ for exceptions. The vowel $u$ remained resistant to the change longer: cf. inflected sweotole 'plain', eofore 'boar'. Loss of $i$ (and $u$ ) before consonants other than $l, r$ is less regular, e.g. eg(e)sa 'fear', ef(e)sian 'shear', heolstor 'darkness' (cf. early pl. helustras); and monosyllabic endingless forms could appear by analogy to inflected ones, e.g. fir(e)n 'crime', meol(o)c 'milk'. Syncope is constant in a few such words, e.g. eln 'ell', hwelc 'which', twelf '12'. It is generally absent when it would create a syllable coda with a disfavored sonority sequence, e.g. wæter 'water', bydel (PDE beadle).

In general, unstressed $æ x$ and $i$ are retained in early texts but are soon reduced to $e$, as in $a$-stem gen. and dat. sg. $-æ s$ and $-æ$, later $-e s$ and $-e$, as well as masc. $i$-stem nom. sg. $-i$, later $-e$. The vowel $a$ remains, whereas $u$ may appear as $u$ or $o$. The front vowels that coalesced as $e$, however, will appear as $i$ in a palatal environment, as in mihtig < *-īz, èadig 'blessed' < *-æz (cf. early dat. pl. èadgum, later analogical $\bar{e}$ adegum, where $g$ is velar), Denisc 'Danish', sārlic 'painful' and so forth.

As in the other WGmc. languages, unstressed vowels tend to weaken and be variously spelt with the passage of time. For further details, and for developments of the literary period, see the grammars cited in $\$ 1.16$. One pattern that may be remarked, however, is the tendency to dissimilate identical or similar vowels in successive unstressed syllables, e.g. -edon for earlier -odon in the 3 pl. pret. of weak verbs of class 3 and -esta for -osta in superlatives (A. Campbell 1977: §385).

Old Frisian. There is the same late development of $-\bar{l}$ in the $j a$-stems as in OE, e.g. *rīkij $\left(a^{n}\right)>$ rīke 'realm'. Most remaining unstressed vowels are reduced to $e$, as in WGmc. *zeלu > ieve 'gift' and nerede 'saved' <*naziðē. Before palatals, this $i$ may or may not be found instead of $e$ (as in OE), as in Rümiska, Rümeska 'Roman' and wellich, wèldech 'potent'. But the ending -um was mostly preserved as such, and WGmc. $\bar{o}$ from a variety of sources is generally reflected as $a$, as in hona 'cock' < *xanôn , mōna 'month' (cf. Go. mēnōps), and achta '8' < PIE *ôktồ(u).

Old Saxon. When a postconsonantal final sonorant is nuclearized, usually $a$ is written before it, occasionally $e$, as in wintar 'winter' (cf. Go. wintrus) and hunger 'hunger' (cf. Go. hührus). But before $m$ usually $o$ is written, occasionally $u$, as in wastom, -um 'growth'.

Non-final short vowels for the most part retain their original quality, as with thiodan 'lord', fadar 'father', egiso 'terror', and sibun '7'. But there is a tendency especially in the non-high vowels to be assimilated to the quality of a following vowel, as in gen. sg. hebenes 'heaven' (nom. heban) and gen. pl. thesoro, -aro 'these' (cf. 
OHG desero). The composition vowel in compounds is most commonly retained but is subject to fluctuation in quality, as in ala-jung 'quite young' beside alo-waldand '(the) Almighty'.

Changes in quality indicate that the remaining unstressed long vowels were shortened both internally and finally, e.g. fiskari 'fisherman' beside dōperi 'baptist' < *-āri; sikur, sikor, from Lat. sēcūrus; dat. sg. daga, dage 'day' < NWGmc. *daz $\bar{x}$.

Old High German. The treatment of unstressed vowels is similar to the treatment in OS. In final syllables, the short vowels $a, e, i, o, u$ generally remain distinct until ca. 900, at which point they start to be confused, gradually tending toward the representation of all of them as $e$, earlier in absolute finality than before a final consonant, and earlier in Upper German than in Central German. In all dialects the opposition between $u$ and $o$ is weakened early in favor of $o$. Already in the earliest texts, in medial syllables the five-vowel opposition tends to be reduced to a three-vowel one, $a, i, u$. As in OS, a syllabified sonorant has usually $a$ written before it, but often $u$ in a labial environment, especially before $m$.

The most remarkable feature of $\mathrm{OHG}$ unstressed vocalism is the retention of long vowels, as indicated especially in the Isidor and Notker (\$1.20). Long vowels corresponding to all five short ones appear in final syllables that are closed by a consonant, whereas the variety of long vowels is reduced in other unstressed syllables. ${ }^{14}$

1. Phonological shortening is the usual assumption, though Wright (1954: §154) notes that if this is correct, weak imperatives like sōkei and hazei must have their vowel by analogy, and he notes the possibility that heavy-stemmed voc. acc. sg. hairdi and such have their vowel by analogy to light-stemmed voc. acc. sg. hari, and there was no final shortening. It should be noted, however, that light-stemmed hazei can be explained only on an analogical basis, and so it is more economical to assume final shortening.

2. Given the history of this idea, it cannot justly be referred to as 'Boutkan's law' (Kortlandt 2006b: 4).

3. Perhaps originally only in medial syllables: cf. undir 'under' <* under, and see $§ 5.5$.

4. The suffixal vowel in Runic swestar (Opedal, Norway, ca. 425) is usually assumed to represent $\bar{x}$ : so, e.g., Krause (1971: 52), who remarks that otherwise OIcel. systir would be difficult to explain; similarly Hollifield 1984: 65. Panieri (2013) argues instead for $\bar{a}$, whereas Stiles (1984, with extensive references) makes a strong case that swestar reflects an old vocative in PIE *-er.

5. But under such circumstances NGmc. $\bar{x}$ yields $a$ before an alveolar consonant, e.g. *- $\bar{x} p->-a \delta$ - in pass. parts. of weak verbs of class 3 , such as sagaðr 'said'.

6. Note, e.g., the loss of final ${ }_{-z} z$ in kaba (for kamba) on the Frienstedt comb (ca. 250-300).

7. Thus, e.g., OE hleahtor 'laughter' < *xlaxtraz must be scanned as a monosyllable at Beowulf 611a, and OS mēđom- 'treasure' < *maipma- at Heliand 3261a, 3772a: see Fulk 1992: §§76-98, idem 2005: 151. Similarly, OIcel. gestr 'guest' < *gastik (and similar words in postconsonantal $-r$ ) remain monosyllabic in Icelandic poetry until the fourteenth century, and $-n$ in vatn 'water' $<{ }^{*} w a t n a^{n}$ remains nonsyllabic to this day in Icelandic and Faroese. But words of this kind in $\mathrm{OE}$ are variably to be scanned with syllabic and nonsyllabic final sonorant consonants, even the same word within a single text, and so it must be recognized that the change is prehistoric, the nonsyllabic scansion at least in some instances a consequence of the conservatism of poetic tradition.

8. It must be borne in mind that syllabicity is not a matter of physiological facts but of native speakers' perceptions. See Fulk 1992: $\S \S 77-8$, with references. For further evidence of the lateness of this change, see Vennemann 1991. The literature shows much confusion on this head, with frequent references to a final postconsonantal sonorant consonant (as in OE fugl 'bird') as 'syllabic' (so, e.g., Boutkan 1995b: 172). WGmc. spelling does not permit a distinction to be drawn between nuclearization and epenthesis in connection with final sonorant consonants: see Hogg 1992: §§6.34-45.

9. On OHG epenthesis, see Wulf 1985, Howell 1991a, Vennemann 1991.

10. Syncope of $i$ after heavy syllables is the norm in OS and OHG only in the preterite of weak verbs of the first class. The morphological distribution of the change allows Kiparsky (2009) to argue that such preterites lost $i$ because they remained prosodic compounds (of stem plus 'do') in OHG. Plainly, however, $u$ was 
syncopated in a form like OHG tiuflun 'devils', and, equally plainly, analogical restoration did affect such forms, producing, e.g., gen. tiufales beside nom. tiufal. See, e.g., Schatz 1927: §94. The loss of high vowels described here is the standard view, rejected by Antonsen (2002: 237-60), who denies that umlaut occurred earlier in $\mathrm{OE}$ than in $\mathrm{OHG}$ and argues that the root-stems were a productive class in Gmc.

11. In such forms the vowel of the suffix -en- should have been lost before a vocalic inflection (see below). It must be assumed that before that loss the fronted $x$ was extended to cases in which the following $n$ was tautosyllabic (e.g. nom. sg. masc. faren), and after the syncope in open syllables the disyllabic stem was extended analogically throughout the paradigm.

12. For discussion, see Fulk 2010b.

13. This explanation originates with Walde (1900: 125 n. 1). For discussion and references, see Fulk 1992: $\S \S 320-2$. Objections and an alternative analysis covering all these exceptions to medial vowel deletion have been offered by Ringe (2002, and in Ringe \& Taylor 2014: 289-96 et passim), but see the counter-objections of Bermúdez-Otero (2015: 13-14). Alternative analyses also face the difficulty that there does not seem to be any plausible explanation how Mercian could correctly have distributed the inflection in otherwise identical paradigms like those of $\bar{i} d e l u$ and fäcen if the former represented an analogical restoration rather than a phonological result.

14. The relevant inflections with final long vowels are nom. acc. pl. of masc. $a$-stems $(-\bar{a})$, nom. acc. pl. of $\bar{o}-$ stems $(-\bar{a})$, nom. acc. sg. \& pl. of $\bar{\imath} n$-stems $(-\bar{l})$, weak pret. sj. $1-3$ sg. (-tī in Alemannic), and perhaps pres. sj. 1 $\& 3 \mathrm{sg}$. ( $-\bar{e}$ once in the Benedictine Rule). At least some of these long vowels may have been analogically induced by related forms, especially $-\bar{l}$ in the fem. abstract nouns (e.g. hōhi by analogy to gen. pl. hōhinno, dat. pl. hōhim: so Russ 1978: 58-9). For a list of all relevant inflections, see Gabriel 1969: 105-8.

\subsection{Vowels in prefixes}

Like prepositions, with which they are often identical, prefixes might be stressed (as in nouns) or unstressed (verbs: §2.2). Under Prokosch's law, prepositions with final vowels should show vowel lengthening when stressed. ${ }^{1}$ The lengthened vowels could then be extended to the corresponding stressed prefixes. Thus, for example, ${ }^{*} b i>\mathrm{OE} b e$ or, when stressed, $b \bar{\imath}$, and to the verbs be-gān 'traverse' and be-nemnan 'name' may be compared the nouns bigenga 'inhabitant' and binama 'pronoun', though many nouns show variable lengthening or none in the prefix, e.g. OHG b̆̈jiht 'witness' (NHG Beichte; cf. OHG bi-jehan 'attest'). As in some other grammatical categories (see, e.g., $\S 2.5$ n. 2), Gothic appears to have generalized the short vowels, having only bi(-), never †bei(-).

Aside from such lengthening, vowels in PGmc. monosyllabic prefixes underwent the same changes as stressed vowels. Thus, for example, there are the Gothic forms and(a)- (prep. and 'throughout'; cf. Gk. öv $v \alpha$ 'opposite'), faúr(a)- (prep. faúr(a) 'before'; cf. Lat. por-), $u f$ - (prep. uf 'under'; cf. Gk. vió 'under'), and so forth. Later the vowels in unstressed prefixes weaken, as with OE ge- (early gi-), of-pyncan 'displease' (stressed in æx-punca 'source of offense') and op-gān 'escape' (stressed in üpgenge 'evanescent'). Occasionally such vowels are lost in the individual WGmc. languages, as with OE blinnan 'cease' < WGmc. *bi-linnan, ${ }^{2}$ OE OS bütan 'except' < *bi-ütan, MHG gloube 'belief' < OHG gi-loubo and NHG bleiben 'remain' < OHG bi-līban. Occasional forms of a similar nature are to be found in OIcel., e.g. greiða 'arrange' (cf. Go. garáidjan) and frýja 'defy' (cf. Go. fra-wrōhjan). But usually prefixes of both verbs and nouns are lost altogether in North Germanic. The former presence of a prefix is not infrequently detectable in verse, where the meaningless particle of or $u m$ replaces it, as required by meter (see Kuhn 1929). New prefixed forms arose, however, with stress on 
the prefix, e.g. af-ráð 'payment' (cf. ráða af 'get off') and fram-ganga 'advance' (noun; cf. ganga fram 'go forward').

1. A preposition was stressed when it did not stand immediately before its object, as shown by the meters of alliterative verse.

2. So also with $\mathrm{OE} * n i$, proclitic to verbs, as in nis 'is not' and næbbe 'have not'.

\subsection{Sievers' law}

According to Sievers (1877-8: 129), in Indic, $i$ or $u$, when it bears no accent (not even the svarita, comparable to the Greek circumflex), is a consonant after a light syllable, a vowel after a heavy, regardless of which other syllable bears the accent. ${ }^{1}$ Thus, for example, there is $y$ after a light syllable in Skt. ávya but $i$ in mártia. He proposed that the same variation can explain certain inflectional alternations in Gmc., such as that between the Go. ja-stems gen. sg. harjis 'army' and hairdeis 'herdsman', from *koriéso and *kerdhiiéso. The conditioning and scope of the law have been much debated (as has its status as derived from PIE itself). ${ }^{2}$ For a time there prevailed a virtual orthodoxy based on the elaborations of the law formulated by Edgerton (1934, 1943, 1962), who regarded the law as exceptionally regular, applying also to liquid and nasal consonants (e.g. *-atra- in alternation with *-atrra-), and resulting automatically not just in the nuclearization of the relevant segment after heavy syllables but denuclearization after light, e.g. *-at-iy-a- > *atya- (in Edgerton's notation), the latter development referred to in the literature as the 'converse of Sievers' law'. But Sievers was aware of the many exceptions to the law in Sanskrit, and current scholarship tends to treat the law more conservatively, recognizing the extent to which (de)nuclearization is morphologically regulated.

In Gmc. only $i / j$ (and not $u / w$ ) attests to alternations of this type, and evidence for it is not found in all the environments in which it might be expected. For example, although Go. masc. $j a$-stems like harjis and hairdeis attest to the variation, $j \bar{o}$-stems do not-there is no inflectional difference between, e.g., bandi 'band' and mawi 'maiden' - and denuclearization has subsequently applied after heavy syllables, giving, e.g., nom. pl. háirdjōs rather than $\dagger-i j o ̄ s$ (see Kortlandt 1986). Even in ja-stem nouns the law does not apply without exception, e.g. gen. sg. arbjis 'heritage' for expected *arbeis, and andbahtjis beside andbahteis 'service'. ${ }^{3}$ The alternation is also detectable in weak verbs of the first class, e.g. 3 sg. pres. ind. nasjip 'saves' beside sōkeip 'seeks', with PGmc. *-jib and $*_{-i}(j) i b$, respectively, though here, too, there are exceptions, including imp. sg. - ei after both heavy and light stems, and exclusively -ei- in verbal derivatives like naseins 'salvation' and hazeins 'praise'. Verb stems of more than one syllable group with the heavy monosyllables in this respect (e.g. mikileip 'magnifies', swögateip 'sighs', and siponeip 'is a disciple'), but there is OE evidence that this is a Go. innovation, and originally a disyllable with a light initial syllable patterned with the heavy stems, whereas a disyllable with a heavy initial syllable patterned with the light. Thus, WGmc. gemination occurs in OE $j a$ - and $j \bar{o}$-stems like fæestenn 'evening' < *fastunjaz and hæftenn 'captivity' < *xaftunjō, but not byrele 'cup-bearer' < *burilijaz or acc. sg. gydene 'goddess' < *3uðinijo $\bar{o}^{n}$ (Dahl 1938: 74-81; Erdmann 1972; Barrack 1998). ${ }^{4}$ The different effect of the two types of disyllables on a following segment is paralleled by the effect of the two in respect to OE high-vowel apocope, whereby, for 
example, the nom./acc. neuter inflection $-u$ is retained in words like Mercian hēafudu 'heads', parallel to fatu vessels, but lost in words like weorod 'hosts', parallel to word 'words' (see §5.6 supra). Failure of breaking in OE tellan 'tell' (for expected †tiellan < *taljan), as opposed to fiellan 'fell' <*feallijan, with a PGmc. geminate, may also be explained on this basis (Barrack 1998: 151-5).

In the course of the development of West Germanic the distinction between *-ijand $*_{-j}-$ was eliminated in favor of the latter, certainly not in Proto-WGmc. itself, given NSGmc. changes to weak verbs (Ringe \& Taylor 2014: 156-7). In Runic, however, -ijoccurs regularly after heavy syllables, as in holtijaz 'Holt's son' (or 'from Holt'?; Gallehus horn, ca. 400) and asm. makija 'sword' (with $\bar{a}$; Vimose chape; $3^{\text {rd }}$ cent.); but although, conversely, the suffix is $-\mathbf{j}$ - in harja (name; Vimose comb, $3^{\text {rd }}$ cent.) and swaba-harjar (name; Rö stone, ca. 400), it is -ij- in harija (name; Skåäng stone, ca. $500)$, and always in the name-element -warijar $(3 \times$, e.g. staina-warijar on the Rö stone). ${ }^{5}$ In OIcel., a reflex of the original alternation remains, inasmuch as when the following vowel is lost, postconsonantal $*_{-j}-$ is also lost, whereas $*_{-} i j$ - is reflected as $-i(-)$ : to $j \bar{o}$-stem acc. sg. ben 'wound' compare heiði 'heath'. On the other hand, if the following vowel is preserved, $j$ remains, whereas $*_{-} i j$ - is lost except after velar consonants: to gen. sg. benjar cf. heiðar, but eggjar 'blade'.

Sievers' law has been explained variously as a product of syllable contact laws or footing in metrical phonology: see $\S \S 2.4-5$, and for a critique of both approaches, Y. Kim 2001. For prosodic approaches and approaches on the basis of syllable structure subsequent to the overview of Barrack (1998), see Kiparsky 1998, Pierce 2006 (to which cf. Barrack 2010); see further Schulte 2000b.

1. "[U]nbetontes (nicht svaritiertes) $i$ oder $u$ vor einem vocal ist consonant nach kurzer, vocal nach langer silbe ohne rücksicht auf die sonstige accentlage des wortes." Prokosch (1939: §33b) sees this variation as due to different syllabification, e.g. Go. sat-jis, har-jis, stō-jis : sō-keis, miki-leis, hair-deis, so that "interconsonantic $-j i-=i i$ was contracted to $\bar{\imath}$." Although such syllabification has been advocated for PGmc., it is hard to reconcile with the orthographic and phonological evidence of some early Gmc. languages: see \$2.4.

2. For the literature, see Seebold 1972: 25-175 and, more succinctly, Collinge 1985: 159-74. Debates about the law are particularly relevant to Gmc. syllabification: see $\$ 2.4$. As for derivation of the law from PIE, Koivulehto (1986) finds evidence in early Gmc. loanwords in Finnish that at the time of borrowing, $j$ was not automatically syllabic after a heavy syllable, given the change of dental consonant plus $j$ to $* \check{-c} \check{c}$ - $>$ Finnish -ts-, as in ratsas 'riding' (cf. OE rǣede 'ready for riding' < *raiðijaz). Boutkan (1995b: 203) points out that Runic holtijaz would not have had the structure in PIE to produce nuclearization (PIE * $k l d-i-$ ); further examples in Ringe 2017: 144-5.

3. For other exceptions, see Seebold 1972: 74-8; cf. Kiparsky 2000, with an Optimality Theory account. At all events, a form like harjis must be formed analogically (see §7.10), and certainly Go. alternations under Sievers' law can be regarded only as relics of a once-active phonological process (Schuhmann 2011).

4. Words like fæestenn may also appear with a non-geminate consonant, but this is due to degemination between unstressed vowels in late OE (see A. Campbell 1977: §457). Barrack (1998: 221-239) collects the data showing that, conversely, gemination never occurs in $j a$-stems like byrele, and it is vanishingly rare in $j \bar{o}-$ stems like gyden. Adamczyk (2001) was apparently unaware of Barrack's work. It should be added, it is possible that some of the words collected by Barrack have their geminate from a source other than WGmc. consonant gemination: e.g., to OE fæstenn, OS fastunnia cf. Go. fastubni '(observance of) fast', and see $\$ 6.11$ infra. Most of the evidence, however, cannot be explained this way.

5. For a comprehensive list of such Runic forms, see Syrett 1994: 80-1; for an attempt to make sense of them, see Syrett 1998. Bammesberger (2007) argues that -warijar contains a long vowel. 


\section{Consonants}

\subsection{The Proto-Indo-European consonants}

The following represents a fairly standard reconstruction of the PIE consonant system as laid out in current handbooks:

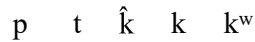

$$
\begin{aligned}
& \text { (b) } \mathrm{d} \hat{\mathrm{g}} \mathrm{g} \mathrm{g}^{\mathrm{w}} \\
& \text { bh dh gh gh } \mathrm{gh}^{\mathrm{w}} \\
& \mathrm{m} n \mathrm{r} \\
& \mathrm{h}_{1} \underset{\mathrm{i}}{\mathrm{h}_{2}} \mathrm{~h}_{3}
\end{aligned}
$$

The consonant $/ \mathrm{b} /$ is marginal, as it probably did not occur at all in initial position in PIE. Among the oral stops, a phonemic distinction is to be drawn between plain voiced stops $/ \mathrm{b}, \mathrm{d}, \hat{\mathrm{g}}, \mathrm{g}, \mathrm{g}^{\mathrm{w}} /$ and their aspirated equivalents $/ \mathrm{bh}, \mathrm{dh}, \mathrm{gh}, \mathrm{gh}, \mathrm{gh}^{\mathrm{w}} / .{ }^{1}$ Also to be distinguished are palatals $/ \hat{\mathrm{k}}$, $\mathrm{g}, \mathrm{gh} /$, velars $/ \mathrm{k}, \mathrm{g}, \mathrm{gh} /$, and labiovelars $/ \mathrm{k}^{\mathrm{w}}, \mathrm{g}^{\mathrm{w}}, \mathrm{gh}^{\mathrm{w}} /$ : although generally this tripartite distinction is reduced to, at most, a bipartite one in the IE languages, ${ }^{2}$ the three series are recoverable because in some languages the palatal and velar varieties are collapsed into one category (the so-called centum-group, to which Gmc. belongs - named after the Latin reflex of PIE *k̂ntóm 'hundred') and in others the velars and labiovelars (the satem-group, named after Avestan satam 'hundred'). The distinction between the two groups was once thought to demarcate an important historical division of PIE into two language families, though now it is plain that although the isogloss does probably represent some shared developments among IE languages, to a great extent the distinction is a matter of convergent developments in related but discrete languages. ${ }^{3}$

The reconstructions $\underline{i}$ and $u$ are generally in allophonic relation to $i$ and $u$, but see Mayrhofer in Kuryłowicz et al. 1986-2015: I, 160-1, 168 for evidence of phonemic $i$. The voiced aspirates /bh, dh, gh, gh, $\mathrm{gh}^{\mathrm{w}} /$ are not attested as such in any IE language, though the murmured consonants $b h, d h$, etc. of Indic, which reflect them (and probably represent their actual PIE value), are transcribed similarly. On the laryngeal consonants $/ h_{1}, h_{2}, h_{3} /$, see $\S 3.1$.

1. A separate series of voiceless aspirates /ph, th, $\mathrm{kh}, \mathrm{kh}, \mathrm{kh}^{\mathrm{w}} /$ was at one time a common assumption to explain the voiceless murmured consonants of Indic, as well as certain Armenian phenomena, but these are now standardly regarded as (in origin) allophones of the voiced aspirates. The glottalic theory (see below) has prompted some to return to the earlier view (e.g. Joseph 1985, Gramkrelidze \& Ivanov 1995; see also Szemerényi 1996: §§6.7.1.4-7), but cf. Kuryłowicz 1956: 375-82, showing that nearly all of the relevant evidence is due to secondary developments. The issue is of no real relevance to $\mathrm{Gmc}$. grammar.

2. Melchert (1987, 1989: 23-32), however, has shown that separate reflexes of $/ \hat{k}, \mathrm{k}, \mathrm{k}^{\mathrm{w} /}$ are discernible in Luvian, and perhaps of $/ \hat{\mathrm{g}}, \mathrm{g}, \mathrm{g}^{\mathrm{w}} /$ in Lycian. 
3. So, for example, Tocharian, in Central Asia, belongs (probably) with the majority of European languages in this respect, even though it is the easternmost of the IE languages, whereas Balto-Slavic is grouped with the Indo-Iranian languages. The centum-group includes the westernmost IE languages, including Hellenic, Italic, Celtic, and Germanic, whereas the satem-group includes Indo-Iranian and Balto-Slavic, and probably Armenian and Albanian, though the facts are disputed.

\subsection{The glottalic theory}

Jakobson (1958; so earlier Walde 1897: 468) pointed out the typological improbability of the reconstruction of the PIE consonant system outlined in $\S 6.1$. One problem is the rarity of $b$ in PIE reconstructions, a peculiarity for which there is no straightforward explanation, whereas languages lacking $p$ (such as Proto-Celtic) are well attested (as remarked by Pedersen 1951: 10-11). ${ }^{1}$ It is also typologically odd to reconstruct a language with voiced aspirates but not voiceless. Accordingly, it was proposed by Gamkrelidze \& Ivanov $(1973 ; 1995)$ and Hopper $(1973)$ that these peculiarities can be explained if instead of the voiced series $b, d, g$, etc., there is reconstructed a voiceless series of glottalized stops (i.e., ejectives) $p^{\prime}, t^{\prime}, k^{\prime}$, etc. ${ }^{2}$ The remaining series ( $p, t, k$, etc., and $b h, d h, g h$, etc.) may then be reconstructed either as voiced and voiceless series with aspiration in free variation (i.e. $p(h), t(h), k(h)$, etc., and $b(h), d(h), g(h)$, etc., respectively), or (according to Hopper) simply as $p, t, k$, etc., and $b, d$, g, etc.). This reconstruction is also offered in explanation of the peculiarity of PIE root structure that roots consisting of two plain voiced stops under the older reconstruction are prohibited, e.g. $\dagger$ bed-, $\uparrow d e g-$, etc. The prohibition can be attributed to the well-attested phenomenon of avoidance of successive ejectives in languages that have such.

Although the glottalic theory enjoyed no small degree of support at one time, it is not now generally accepted in IE studies. One problem is that ejectives such as those reconstructed are not found in any historical IE language but Ossetic (a language of Iran), where they are instead to be attributed to the influence of neighboring Caucasian languages. The chief implication of the glottalic theory for Germanic linguistics is that it permits Germanic (along with Armenian) to be regarded not as a highly innovative branch in its consonantism but as an exceptionally conservative one, whereas the IE languages usually regarded as hewing closest to the PIE consonant system, especially Sanskrit and Greek, turn out to do nothing of the sort. That Germanic should have remained so conservative while the European languages in closest proximity to it in prehistoric times all altered the inherited obstruents in similar ways is difficult to credit. And yet although the glottalic theory is not now widely supported, there is a considerable degree of concurrence that the reconstruction of PIE obstruents represented in $\$ 6.1$ is implausible and awaits replacement by a creditable reconstruction. ${ }^{3}$ Nonetheless, it need not be the case that such an alternative reconstruction is what must be assumed for the latest stages of PIE, since it is of course possible that the typological peculiarities of PIE mentioned above are the consequence of an earlier obstruent system that had already changed before any of the extant IE families had developed individuating characteristics. That is to say, it is not a given that any IE language should directly reflect that earlier state of affairs rather than a later-developed obstruent system similar to that arrived at (in §6.1) by the comparative method. The supposition that Germanic is an especially archaic branch of IE is at all events unsupported by its verb system, which appears to be a simplification of that reconstructed for late PIE (\$12.9), showing no marked resemblance to the Hittite verb system. ${ }^{4}$ 
Prior to the glottalic theory, there were attempts to address the improbability of the reconstructed PIE consonant inventory by assuming that the voiced aspirates were actually fricatives: so Walde 1897, Prokosch 1918-19, 1939: §18, Peeters 1971. Other solutions are surveyed by Huld (1986).

1. Although there is disagreement in the literature, Szemerényi (1996: §6.7.1.8 \& n. 1; so also Polomé 1994: $33 \mathrm{n}$. 24) remarks that the distribution of $b$ word internally is normal, and this is typologically odd, given its absence from initial position - certainly a problem not solved by the glottalic theory. Melchert (1994: 93) offers examples of medial PIE $b$ reflected in Anatolian. For possible explanations for the non-occurrence of initial $b$, see Ringe 2017: 19.

2. In ejectives, closure and release of the oral and glottal points of closure are simultaneous, producing the sensation of a click.

3. See, e.g., Salmons 1993 and Beckwith 2007. See also the papers in Vennemann 1989.

4. For a comparison of the Anatolian and late PIE verb systems, see Clackson 2007: 129-51.

\subsection{Laryngeal consonants in Germanic}

At the time when the study of PIE laryngeal consonants was still in the process of gaining the status of orthodoxy (see §3.1), a variety of studies suggested that laryngeals might have been preserved relatively late into the PGmc. period. The only proposal for the influence of laryngeal consonants in specifically Gmc. developments that is now widely credited pertains to the Verschärfung (though even this analysis is hardly secure), and the commonest view of the matter now is that it is not laryngeals but the hiatus left by the early loss of laryngeals that is responsible for this gemination of glides: see $\S 6.10$. (On the derivation of $\bar{e}_{2}$ from a laryngeal source, see $\S 3.5$; Polomé 1988: 384-401; 1994: 21-4.) Some other proposals regarding laryngeal consonants are these:

(a) In certain environments a laryngeal may be reflected as a velar consonant (Austin 1946, Lehmann 1952: 47-52, Cowgill 1965 passim, Connolly 1977: 351-2, Ringe 2017: 86-8, but cf. Polomé 1988: 401-4, idem 1994: 23-4, Voyles 1989b: 41-2 (with further references), Fulk 1993b: 341-2, Kortlandt 1997), as in OIcel. $n o k k v i$, OE naca 'boat' (cf. Lat. nāvis $<* n^{2} h_{2} u$-); OIcel. kvikr, OHG quec 'alive' (but Go. *qius, qiwa-; cf. Skt. jī̌áh < ${ }^{*} g^{w} i h_{3} u-$ ); and OHG zeihhur, OE tācor

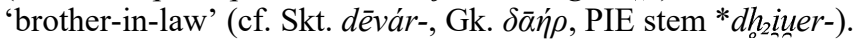

(b) The reflex of PIE a (i.e., $H$ in laryngeal notation) did not always develop to Gmc. $a$ or, in unstressed syllables, Ø. For discussion, see $§ 5.5$ ad fin.

(c) Certain preterites in - $r$ - in $\mathrm{OHG}, \mathrm{OE}$, and OIcel. have been assigned a laryngeal cause (Lehmann 1952: 56-61; idem 1954; Connolly 1983), e.g. OHG ki-screrot to scrōtan 'cut', OE leort to lǣtan 'let', and OIcel. snera to snúa 'turn'; cf. §12.20. Cf. van Coetsem 1956: 68; Müller 2007: 157-8.

(d) The seemingly sporadic change of PGmc. $*_{i}$ to $e$, as in PIE *slibro- $>$ OE slipor, OHG sleffar 'slippery', has been claimed to take place only in the presence of a laryngeal: see Connolly 1977, 1999; cf. Polomé 1988: 386-9, Voyles 1989b: 3841, idem 1999.

(e) Lühr (1976) and Ritter (1984) argue that the gemination of certain sonorant consonants other than glides may be due to laryngeals, e.g. OS thimm 'dark' (cf. Skt. támisra- 'dark night') and Go. OHG OE spinnan 'spin' (cf. Lith. pinù, pinti 
'braid'). See also Seebold 1970: 290 and Eichman 1973 on Go. kunnan, kann and cognates.

(f) It has been argued that certain exceptions to Verner's law ( 66.6$)$ are to be explained by the preservation of laryngeal consonants into Proto-Germanic: see Connolly 1980.

(g) Hansen (2015) argues that PIE initial $* h_{2} i$ - and $* h_{2} u$ - may yield Gmc. $a i$ - and $a u$-.

\subsection{Grimm's law}

The oral stop consonants of PIE underwent a systematic change of manner of articulation commonly known as the First Consonant Shift, as described under the terms of Grimm's law. ${ }^{1}$ Though many qualifications are necessary (on which see $§ 6.5$ ), in broad outline it may be said that the PIE stops developed as follows in PGmc.:

\begin{tabular}{|c|c|c|c|c|c|c|c|c|c|c|c|c|c|}
\hline & PI & & & & & & & & & & \multicolumn{3}{|c|}{ PGmc. } \\
\hline $\mathrm{t}$ & $\hat{\mathrm{k}}$ & $\mathrm{k}$ & $\mathrm{k}^{\mathrm{w}}$ & $\rightarrow$ & $\mathrm{p}$ & $\mathrm{t}$ & $\mathrm{k}$ & $\mathrm{k}^{\mathrm{w}}$ & $\rightarrow$ & $\mathrm{f}$ & $\mathrm{p}$ & $x$ & \\
\hline d & $\hat{\mathrm{g}}$ & $\mathrm{g}$ & $\mathrm{g}^{\mathrm{w}}$ & $\rightarrow$ & b & $\mathrm{d}$ & $\mathrm{g}$ & $\mathrm{gw}^{\mathrm{w}}$ & $\rightarrow$ & $\mathrm{p}$ & $\mathrm{t}$ & K & \\
\hline $\mathrm{dh}$ & gh & $\mathrm{gh}$ & $\mathrm{gh}^{\mathrm{w}}$ & $\rightarrow$ & bh & $\mathrm{dh}$ & gh & $\mathrm{gh}^{\mathrm{w}}$ & $\rightarrow$ & $b$ & ð & 3 & \\
\hline
\end{tabular}

That is to say, the voiceless stops became voiceless fricatives, the voiced stops were devoiced, and the aspirated voiced stops became voiced fricatives. (The middle step shows the coalescence of the PIE palatal stops with the plain velars: see $\$ 6.1$. $)^{2}$ There is thus (roughly) no change in place of articulation, and of voicing only in the series of PIE voiced unaspirated stops. The PGmc. results are displayed with the characters usually employed in the reconstruction of PGmc. words; as with the PIE consonants, the likeliest phonetic values are not always ascertainable. For example, $b$ was certainly a voiceless fricative, but it could have been either dental or alveolar (probably not postalveolar); the series $x, k, 3$ is called velar, but palatal or uvular articulation, at least under some circumstances, cannot be ruled out; and $f$, though the character connotes labiodentalality, was likelier bilabial $[\phi]{ }^{3}$ The PIE labiovelars remained unitary phonemes after the shift (PGmc. $x^{w}, k^{w}, 3^{w}$ ), though later they became diphonematic: see $\S \S 6.5$ ad fin., 6.11 for discussion. Examples of these changes are as follows:

PIE $p>$ PGmc. $f$ : PIE * por- > Go. OE OS OHG faran, OIcel. fara 'go' (cf. Gk. $\pi о \rho \varepsilon v ́ \omega$, Lat. portō 'convey'); PIE * pōd-/ped-> Go. fōtus, OIcel. fótr, OE OS fōt, OHG

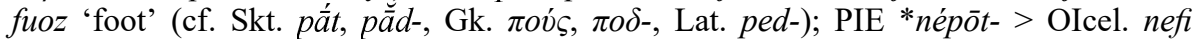
'kinsman', OE nefa 'nephew, grandson', OS neᄒьo 'nephew, grandson', OHG nevo 'nephew, kinsman' (cf. Skt. nápāt 'offspring, son, grandson', Lat. nepōs); PIE *k̂klep- > Go. hlifan 'steal' (cf. Gk. $\kappa \lambda \dot{z} \pi \tau \omega$, Lat. clepō 'steal'); PIE *apo 'from, away' > Go. OIcel. OS af (cf. Skt. ápa, Gk. ö $\pi o, \alpha \dot{\alpha} \pi o ́)$.

PIE $t>$ PGmc. $p$ : PIE *tong- > Go. pagkjan 'think', OIcel. pekkja 'recognize', OE pencan, OS thenkian, OHG denken 'think' (cf. Lat. tongeō 'know'); PIE *trei- > Go. prija (nom. neut.), OIcel. prír, OE prīe, OS thria, OHG drī 'three' (Skt. tráyah, Gk. $\tau \rho \varepsilon \hat{\imath} \varsigma$, Lat. trēs); PIE *mnt-> Go. munps, OIcel. munnr, muðr, OE mūð, OS mūđ, OHG mund 'mouth' (cf. Lat. mentum 'chin'); PIE *uert- > Go. waírpan, OIcel. verða, OE weorðan, OS werđan, OHG werdan 'become' (cf. Skt. vártati, Lat. vertō ‘turn').

PIE $\hat{k}>$ PGmc. $x$ : PIE $* \hat{k}$ mtóm $>$ Go. OE OS hund, OHG hunt 'hundred' (Skt. śatám, Lat. centum); PIE k̂klutós with lengthening in PGmc. *xlūðaz > OE OFris. OS

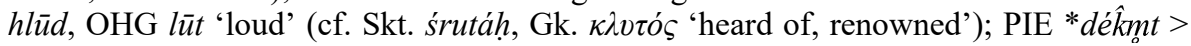


Go. taíhun, OIcel. tíu, OE tīen, OS tehan, OHG zehan 'ten' (Skt. dáśa, Gk. dék $\alpha$ ); PIE *pekku- > Go. faihu, OIcel. fé, OE feoh, OS fehu, OHG fehu, fihu 'herded animal' (Skt. páśu-, Lat. pecū).

PIE $k>$ PGmc. $x$ : PIE *kap-ōl- in OE hafola 'head' (Skt. kapấla-); PIE *kar- in Go. hardus, OIcel. harðr, OE heard, OS hard, OHG hart 'hard' (cf. Skt. karkara-

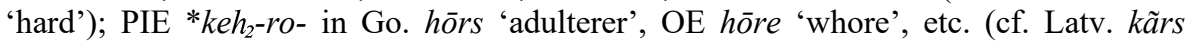
'desirous', Lat. cārus 'dear'); PIE *ueik- in Go. weihan 'fight' (cf. Lith. veikiù, veîkti 'work', Lat. vincō 'conquer'); PIE *leuk - in Go. liuhap, OE lēoht, OS OHG lioht 'light' (noun; cf. Skt. rōká-, Lat. lūx).

PIE $k^{w}>$ PGmc. $x^{w}$ : PIE $k^{w}$ oter-/ $k^{w}$ eter- $>$ Go. hapar, OIcel. hvaðarr, OE

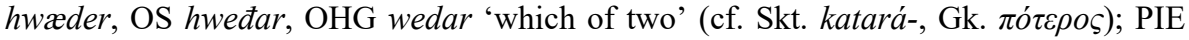
${ }^{*} k^{w}$ od $>$ Go. ha, OIcel. hvat, OE hwæt, OS hwat, OHG (h)waz 'what' (cf. Skt. kád, Lat. quod); PIE *sek ${ }^{w}$ - in Go. saíhuan, OIcel. sjá, OE sēon, OS OHG sehan 'see' (cf. Lat.

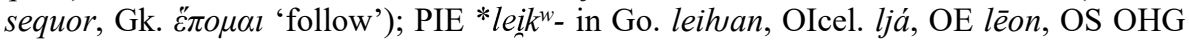
lìhan 'lend' (cf. Gk. $\lambda \varepsilon i \pi \omega$, Lat. re-linquō 'leave').

PIE $b>$ PGmc. $p:{ }^{4}$ PIE *bend- $n$ - in OIcel. pinni, OE OS pinn 'pin', OHG $p$ fin 'nail' (cf. OIr. benn 'prong, horn' < *bnd-no- or *bend-no- and Welsh bannog 'horned'); PIE *bu-s- in OIcel. posi, OE pusa, posa, OHG pfoso 'bag' (cf. Gk. $\beta v ́ \omega$ 'stuff full' < * $\beta \dot{v} \sigma \omega)$; PIE *dheub- in Go. diups, OIcel. djúpr, OE dèop, OS diop, OHG tiof 'deep' (cf. weak grade in Lith. dubùs, OIr. domain, Welsh $d w f n(* d h u b-n i-)$ ); PIE *slēb- in Go. slēpan, OE slǣpan, OS slāpan, OHG släfan (cf. Lith. (Samogitian) slãbnas and OCS slabъ 'weak').

PIE $d>$ PGmc. $t$ : PIE * deik $k$ - in Go. ga-teihan, OIcel. tjá 'tell, show', OE tēon,

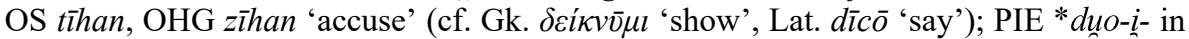
Go. masc. twái, OIcel. tveir, OE fem. twā, etc. 'two' (cf. *d(u)ūo in Skt. $d v \bar{a}$, Homeric Gk. $\delta \dot{v} \omega$, Lat. duo); PIE *sed- in Go. sitan, OIcel. sitja, OE sittan, OS sittian, OHG sizzen 'sit' (cf. Skt. sad-, Lat. sedeō); PIE *med- in Go. mitan, OIcel. meta, OE OS metan, OHG mezzan 'measure, assess' (cf. Gk. $\mu \varepsilon ́ \delta o \mu \alpha l$, Lat. meditor 'consider').

PIE $\hat{g}>$ PGmc. $k$ : PIE * gnneu- in Go. kniu, OE cnēo(w), OS OHG kneo, knio 'knee' (cf. PIE * $\hat{g} o n u$ - in Skt. jấnu, Gk. yóvv); PIE * $\hat{g}_{n} h_{3^{-}}$in Go. OHG kunnan, OIcel.

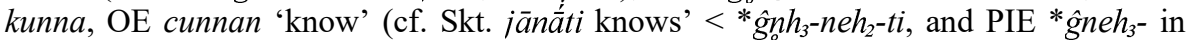
Lat. nōscō); PIE $h_{2}$ egrros > Go. akrs, OIcel. akr, OE æcer, OS akkar, OHG akar, ackar

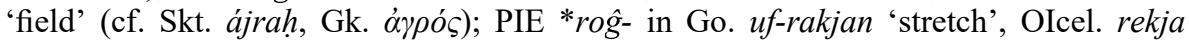
'spread out', OE reccan 'stretch' (cf. Skt. rjyati 'stretches', Lat. rogō 'request' $(<*$ 'stretch out the hand')).

PIE $g>$ PGmc. $k$ : PIE * gal- in OIcel. kalla, OE ceallian 'call', OHG kallōn 'chatter' (cf. Welsh galw 'call', and *gal-gal- in OCS glagolati 'speak'); PIE *gloi- in

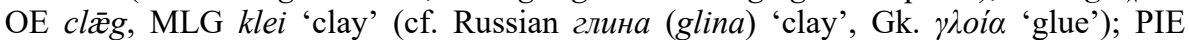
*heug- in Go. áukan, OIcel. auka, OE èacian, OS ōkian, OHG ouhhōn 'increase' (cf. Lith. áugu, áugti 'grow', Lat. augēo 'increase'); PIE *tog- in OIcel. pak, $\mathrm{OE} p æ c, \mathrm{OHG}$

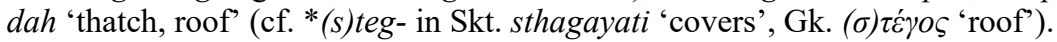

PIE $g^{w}>$ PGmc. $k^{w}(>k w)$ : PIE $g^{w} e m-/ g^{w} e m$ - in Go. qiman, OIcel. koma, OE cuman, OS kuman, OHG queman, coman 'come' (cf. Gk. Baivw 'go' $\left(<{ }^{*} g^{w} m i \bar{o}\right)$, Lat. veniō 'come'); PIE * $g^{w} e n$ - in Go. qinō, OE cwene, OS OHG quena 'woman' (cf. OIr. ben, OCS žena); PIE *nogw- in Go. naqaps, OIcel. nøkkviðr, OE nacod, OHG nackut, nachut 'naked' (cf. Skt. nagnáh, Lith. núogas); PIE hrregw- in Go. riqis 'darkness', OIcel. $r ø k(k) r$, $r o k k r$ 'twilight' (cf. Skt. rájanī- 'night', Gk. č $\rho \varepsilon \beta o \varsigma$ 'underworld'); PIE * $h_{l} e n g^{w}$ - in OIcel. $ø k k r$ 'lump, tumor' and økkvinn 'thick, clodded' (cf. Gk. $\dot{\alpha} \delta \dot{\eta} v$ 'gland' 
$\left(<* h_{1} n g^{w} \bar{e} n\right)$, Lat. inguen 'groin'). It cannot be determined whether $k^{w}$ was already indistinguishable from $k w$ in PGmc., but even though Ulfilas uses a single character, $\langle\mathrm{u}\rangle$ $(q)$, to represent the reflex of PIE $g^{w}$, this could be in imitation of Latin $\langle q\rangle$. The generally preferred derivation of the Go. dual pronoun igqis is from *ink- with analogical addition of $w$, borrowed from pl. izwis ( 88.3$)$, demanding the assumption that Go. $q$ was indistinguishable from $/ \mathrm{kw} /$. Certainly, the labial feature of PIE labiovelars is not infrequently reflected as a separate segment in West and North Gmc., as in OE cwicu 'alive' $<$ Pre-PGmc. ${ }^{*} k^{w} i k^{w} a z$; probably also OIcel. song 'sang' < *saygu < PGmc. * ${ }^{*} a \eta g{ }^{w}(e)$, and certainly nøkkviðr 'naked' (as above; cf. Go. naqaps).

PIE $b h>$ PGmc. $b$ (but $b$ in initial position probably already in PGmc.): PIE *bher- in Go. baíran, OIcel. bera, OE OS OHG beran 'bear' (cf. Skt. bhárati, Lat. ferō); PIE *bhuh $2^{-}$(possibly; cf. $\$ 3.4$ n. 5) in Go. bauan, OIcel. búa, OE OHG būan

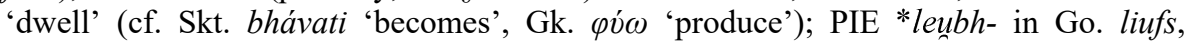
OIcel. ljúfr, OE lēof, OS liof, OHG liob 'dear' (cf. Skt. lúbhyati 'yearns', Lat. libet, older lubet 'pleases'); PIE * gerbh- in OE ceorfan, OHG kerban 'carve' (cf. Gk. $\gamma \rho \alpha \dot{\varphi} \varphi \omega$ $<* g r b h-)$.

PIE $d h>$ PGmc. $\partial$ (but probably $d$ initially already in PGmc.): PIE *dhrs- in Go. ga-daúrsan, $\mathrm{OE} *$ durran, dear, $\mathrm{OHG}$ *-turran, gi-tar 'dare' (cf. Skt. dhrsnốti 'is bold', Gk. (Lesbos) $\theta \dot{\varepsilon} \rho \sigma o \varsigma$ 'bravery'); PIE *dhur- in OIcel. dyrr 'doorway', Go. daúr, OE dor, OS dor, dur, OHG tor 'door' (cf. Gk. (Homeric) $\theta \dot{v} \rho \bar{\alpha}$, Lith. acc. pl. duris); PIE *medhios > Go. midjis, OIcel. miðr, OE midd, OS middi, OHG mitti 'in the middle' (cf. Skt. mádhyah, Lat. medius); PIE *medhu(-) in OIcel. mjoðr OE meodu 'mead' (cf. Skt. mádhu 'sweet drink', Gk. $\mu \dot{\varepsilon} \theta v$ 'wine').

PIE ghh > PGmc. 3: PIE * hhans- > OIcel. gás, OE gōs, OS gās, gōs, OHG gans 'goose' (cf. Skt. hamsáh 'goose, swan', Gk. $\chi \dot{\eta} v$ 'goose'); PIE * ghaiso- in OIcel. geirr,

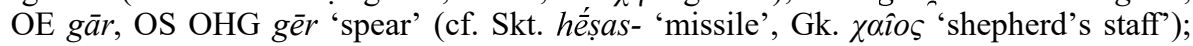
PIE *wegh- in Go. ga-wigan 'stir', OIcel. vega 'lift', OE OS OHG wegan 'move, carry' (cf. Skt. váhati 'goes', Lat. vehō 'convey'); PIE *loighh- in Go. bi-láigōn 'lick' (cf. Gk. $\lambda \varepsilon^{\prime} \chi \omega$, reduced grade in Skt. lihati).

PIE gh > PGmc. 3: PIE * ghostis > Go. gasts, OIcel. gestr, OE giest, OS OHG gast 'guest, stranger' (cf. Lat. hostis 'enemy', OCS gostb 'guest'); PIE * ghleu- in OIcel.

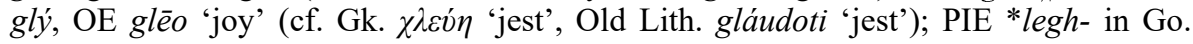

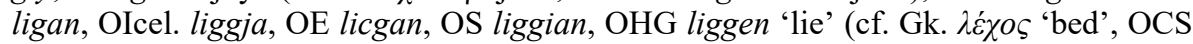
ležati 'lie', OIr. lige 'bed, grave'); PIE *(s)teigh- in Go. steigan, OIcel. stíga, OE OS OHG stīgan 'climb, ascend' (cf. Gk. $\sigma \tau \varepsilon i ́ \chi \omega$, OIr. tíagu 'go', reduced grade in Skt. stighnōti 'ascends').

PIE $g h^{w}$. There is no scholarly agreement about the development of $g h^{w}$ in Gmc., except that it is plainly delabialized before $u$ : PIE $g h^{w}>$ PGmc. 3 before $u$, as in PIE ${ }^{*} g h^{w} n-t i-s$ (as in Skt. hatih 'blow') > PGmc. * ${ }_{n} u n p->$ OIcel. guðr (and later, analogical gunnr), OE gūo, OS gūđea, OHG gund- 'war'. Otherwise, examples are too sparse and etymologies too insecure to afford certainty. It is the argument of Seebold $(1967,1980)$ that initial $g h^{w}$ otherwise produces Gmc. $b$, for example in PIE $* g h^{w} r-n-w$ - $>$ Go. OS OHG brinnan, OIcel. brenna, OE beornan 'burn (intrans.)' (cf. Skt. ghrnồti 'burns'; but see the criticisms of Polomé 1994: 20-1). This argument appears to have persuaded few (so Ringe 2017: 127-33 and Hartmann 2013); ${ }^{5}$ the literature in opposition is surveyed by Polomé (1987a). PGmc. *warm- (OIcel. varmr, OE wearm, OS OHG warm 'warm')

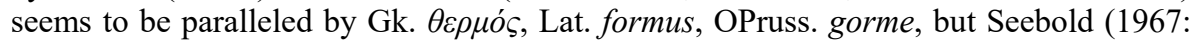
108-9) is not alone in supposing that it should be tied to Hittite war- 'burn'. Seebold's 
other conclusions (1967) may be summarized as follows: (a) Postvocalic $g h^{w}$ appears before liquids and nasals as $w$. Examples: PIE *negh $h^{w}-r->$ OIcel. nýra, OHG nioro

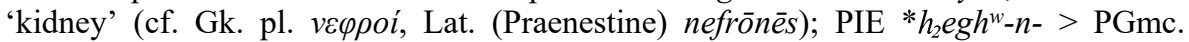
*aun- > OE éanian 'yean' (cf. Gk. d́ $\mu v o ́ s$, Lat. agnus 'lamb'). (b) Intervocalic $g h^{w}>$ PGmc. $3^{w}$, developing further to $w$ after $e$ or ai, otherwise to 3. Examples: PIE *(s)noigh ${ }^{w}$ - > PGmc. *snaiw- in Go. snáiws, OIcel. snjór, snær, OE snāw, OHG sneo 'snow' (cf. Lat. weak grade niveus 'snowy', nasalized ninguit 'it snows', Gk. (Homeric) veí $\varphi \varepsilon l$ 'it snows'); possibly PIE * $h_{1} o g h^{w}-i$ - > PGmc. *azi- in OS egi-thassa, OHG egidehsa 'lizard' (cf. Gk. ó $\phi i \varsigma$, Skt. áhi- 'snake'). (c) PIE ghw and $\hat{g} h w$ appear to have developed the same way as $g h^{w}$, though the evidence is scant. A possible example is OE wèðe, OS wōđi 'pleasant' <* $\hat{g} h w \bar{t} t j o-$ (Seebold 1967: 110). Kortlandt (1997) argues that labiovelars became labial obstruents before or after a sonorant consonant. Johnsen (2011) finds that PGmc. $3^{w}$ develops to $w$ before $i$, but 3 before $j$. For a tabulation of opinions from 1896 to recent times, see Hartmann 2013: 1-2.

1. The IE and Gmc. correspondences were described by Jacob Grimm in letters to Karl Lachmann of 25 Nov. 1820 and (in detail) 1 April 1821, and a full exposition published in 1822 in the second edition of Vol. 1 of his Deutsche Grammatik. Building on the work of earlier observers, Rasmus Rask, in his Undersögelse om det gamle nordiske eller islandske sprogs oprindelse (1818), had previously worked out the correspondences with Latin and Greek consonants later systematized and described by Grimm as a shift. Grimm acknowledged his debt to Rask in the preface to the first volume of the first edition of his Deutsche Grammatik. For a succinct discussion of the relations between Rask's and Grimm's analyses, see Prokosch 1939: §15, observing that Rask's observations could in no sense be termed a law.

2. Although it seems likely, it cannot be proved that this coalescence occurred before rather than after the shift; the chronology has left no distinctive trace in the Gmc. languages.

3. This may be judged from its source in PIE $p$, from the use of $\langle\mathrm{p}\rangle$ to represent it in OIcel. before $t$, as in eptir 'after', probably also the change of $n$ to $m$ in Go. OHG fimf, OIcel. fimm 'five', and from the parallel sound $\hbar$, for the bilabiality of which there is evidence in OE until the ninth century (§6.6), though certainly $\mathrm{OE} f$ was labiodental before that.

4. As remarked above $(\S 6.1)$, it is dubitable whether there was any word-initial $b$ in PIE. The forms provided here are accepted by Pokorny (1959-69). Their relative obscurity inspires little confidence.

5. However, Normier (1977: 185) supposes that PIE $g h^{w}$ always results in Gmc. $b$.

\subsection{Exceptions to Grimm's law}

The commonest exceptions to Grimm's law are governed by Verner's law, on which see $\S 6.6$.

It should be noted that already in the Pre-PGmc. period a voiced stop, whether aspirated or not, was devoiced before $t$ or $s$, with loss of aspiration, where relevant. Thus, for example, ${ }^{*} g t,{ }^{*} g h t>* k t$, and ${ }^{*} g s,{ }^{*} g h s>* k s$. The change can be seen in, e.g., Lat. perf. nūpsī, pp. nūptus to nūbō 'wed' (PIE *(s)neubh-); Skt. loc. pl. pat-sú beside loc. sg. pad-i 'on foot'; and Lat. perf. junxī, pp. junctus to jungō 'join' (PIE *iu-n-g-). A sequence $* t$ thus produced developed to PGmc. ${ }^{*} s s$, on which see $\S 6.8$. In the other clusters, the voiceless first consonant became a fricative in PGmc., as was normal under Grimm's law, but not the second. Examples: Go. ga-skafts 'creation' (cf. skapjan 'create'); OHG gift 'gift' beside geban 'give'; OE weft 'weft' beside wefan 'weave' (cf. Skt. ubhnátti 'ties together'); OE wæfs (also wæsp, wæps) 'wasp' (PIE *uobhs-; cf. Lith. vapsvà 'wasp', Avestan vawžaka- 'scorpion'); Go. pret. waúrhta to waúrkjan 'work, 
make'; Go. maihstus 'dung' beside OIcel. míga 'urinate' (PIE *meigh -, as in Skt. méhati 'urinates').

Grimm's law fails to apply to a PIE voiceless stop preceded by $s$. Examples: PIE *spr-n- in OIcel. sporna 'spurn, tread on', OE spurnan, spornan, OS OHG spurnan (cf.

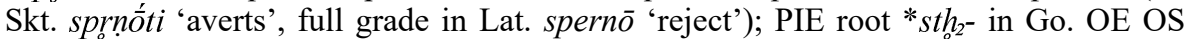
standan, OIcel. standa, OHG stantan 'stand' (cf. Lat. stō 'stand', Skt. sthitáh 'standing'); PIE * ghostis > Go. gasts (as above, §6.4); PIE superlative formation *-is-

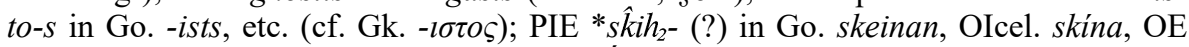
scīnan, OS OHG skinan 'shine' (cf. Gk. $\sigma \kappa i \grave{\alpha}$, Tocharian B skiyo 'shadow', and cf. Skt.

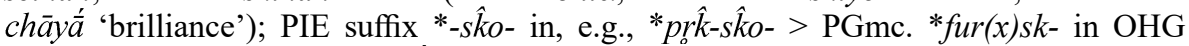
forsca 'question' = Skt. prcchá; PIE *skabh- in Go. OS OHG skaban, OIcel. skafa, OE sc(e)afan 'shave' (cf. Lat. scabō 'shave', Latvian skabrs 'sharp'); PIE *pisk- in Go. fisks, OIcel. fiskr, OE OHG fisc, OS fisk 'fish' (cf. Lat. piscis, full grade in OIr. ìasc, gen. èisc); there are no examples of PIE $s k^{w}$ in Gmc.

Similarly, when PIE $p$ or a velar consonant $\left(\hat{k}, k, k^{w}\right)$ shifted to a fricative under Grimm's law, a following voiceless stop (only $t$ occurs) failed to undergo the usual change, and the labiovelar lost its labiality. Examples: PIE *kap-tó-s > Go. -hafts, OIcel. haptr, OE hæft, OS OHG haft 'captive' (= Lat. captus, OIr. cacht); PIE *ôktó̀(u)

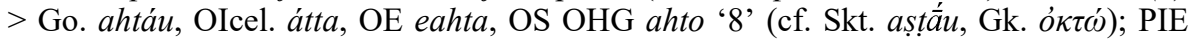
*slak-t- in OIcel. sláttr 'mowing', OE slieht 'blow', OS man-slahta 'murder', OHG slachta 'massacre' (cf. Go. slahan 'strike', Middle Irish slacc 'sword'); PIE *nok ${ }^{w}-t->$ Go. nahts, OIcel. nátt, OE neaht, niht, OS OHG naht 'night' (cf. Lat. nox, acc. noctem 'night', OIr. i-nnocht 'tonight', Skt. naktam 'by night', Hittite neku-).

The PIE voiced aspirates $b h, d h, \hat{g} h, g h, g h^{w}$ are reflected as voiced stops rather than fricatives after a nasal consonant. Examples are the following: PIE $* h_{2} m b h i>\mathrm{OE}$ $y m b$ 'about' (= Skt. abhí, Gk. $\alpha \mu \varphi i)$; PIE * gombh- in OIcel. kambr, OE camb, OHG

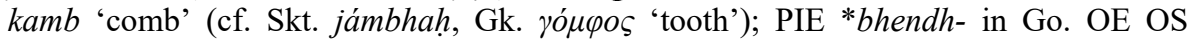
bindan, OIcel. binda, OHG bintan 'bind' (cf. Avestan bandayaiti 'binds', with PIE *bhndh- in Skt. badhnáti 'binds'); ${ }^{1}$ PIE *bhlendh- in Go. blinds, OIcel. blindr, OE OS blind, OHG blint 'blind' (cf. Lith. blendžiù, blẹsti 'sleep', Latv. blendu 'see poorly'); PIE * dngh $\hat{g}$ - in Go. tuggō, OIcel. OS tunga, OE tunge, OHG zunga 'tongue' (cf. Old Lat. dingua, Lat. lingua, OIr. teng; Skt. jihvă and Avestan hizvā 'tongue' attest to PIE $\hat{g} h$ in the word, though the onset of each is unetymological); PIE * $h_{2}$ engh- in Go. aggwus, OIcel. ongr, øngr, OE enge, OS OHG engi 'narrow' (cf. Gk. پ’ $\gamma \chi \omega$, Lat. angō 'press tight'); PIE * ghongh- in Go. gagg, OIcel. gangr, OE OS OHG gang 'going, way' (cf. * ghhengh- in Skt. jáyghā 'shin', Lith. žengiù, žeñgti 'stride'); PIE *dlh ${ }_{2}-n$-gh- in Go. laggs, OIcel. langr, OE OS OHG lang 'long' (cf. Lat. longus, Middle Persian drang); PIE *sengh ${ }^{w}$ - in Go siggwan, OIcel. syngva, OE OS OHG singan 'sing' (cf. *songh ${ }^{\text {- }}$ - in Gk. $\dot{\prime} \mu \varphi \eta ́$ 'divine voice, prophecy', Middle Welsh de(h)ongl 'explain'); PIE *lnghw- in

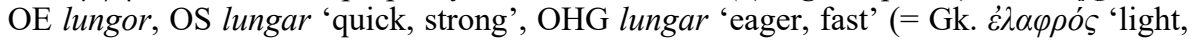
quick'; cf. non-nasalized Lat. levis 'light' <*leghw-).

The PIE voiced aspirates $b h, d h$ are nowhere reflected as fricatives in initial position, only as stops. Examples: PIE *bherHg- in Go. bairhts, OIcel. bjartr, OE beorht, OS OHG beraht 'bright' (cf. Skt. bhrājatē 'shines'); PIE *bhrăter- in Go. brōpar, OIcel. bróđir, OE brōpor, OS brōđar, OHG bruoder 'brother' (cf. Skt. bhrátar-); PIE *dhrs- in Go. ga-daúrsan, OE *durran, dear 'dare' (cf. Skt. dhrș-nó-ti 'dares'); PIE *dhun- in OIcel. dynr, OE dyne, OHG tuni 'din' (cf. *dhuen- in Skt. dhvánati 'sounds'). By contrast, PIE initial $\hat{g} h$, $g h$ must have developed to fricatives and remained as such 
in PGmc., given forms like OE giefan (with initial /j/; cf. ME yiven), OFris. ieva, NLG

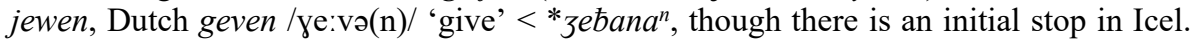
gefa, NHG geben; Go. giban is ambiguous. Possibly $l \delta>l d$ already in PGmc., since it is nowhere verifiably reflected as $l \partial$, and $l \partial$ that arose by syncope in PNorse developed somewhat differently ( $\$ 6.14)$. There was no change of $\partial$ after $r$ in PGmc., however: cf. OIcel. pp. orðinn 'become' $<*$ wurðanaz.

On the development of PGmc. consonants in gemination, see $\S \S 6.8-9$.

It has sometimes been supposed that PIE labiovelars become plain velars before back vowels in PGmc. ${ }^{2}$ This is unlikely, given forms like Go. hōpan 'boast', hōta 'threat, reprimand', ga-qumps 'gathering', OE *hwōsan 'cough', hwōstan 'cough' cwème 'pleasing' (< PGmc. ${ }^{*} k^{w} \bar{o} m i$-). There are nonetheless adjustments to labiovelars both in the PGmc. period and afterward according to environment. (a) Before the application of Grimm's law, PIE $k^{w}$ became $p$ ( $>$ Gmc. $f$ ) when it appeared in the same root as another labial consonant. Examples: PIE * $k^{w} e t u \bar{o} r->$ Go. fidwōr '4' (cf. Skt. catvắrah, Lat. quattuor); ${ }^{3} \mathrm{PIE} *{ }^{*}$ pénk $^{w} e>$ Go. OHG fimf, OIcel. fimm, OE OS fif '5' (cf. Skt. páñca, Gk. $\pi \dot{v} v \tau \varepsilon$, Lat. quinque); PIE *ulk $k^{w} o s>$ Go. wulfs, OIcel. úlfr, OE OS wulf, OHG wolf 'wolf' (cf. Skt. vŕkah, Lat. lupus, Lith. vi $\left.\tilde{l n}_{k} a s\right) .{ }^{4}$ (b) Although PIE $k^{w}$ and $g^{w}$ are reflected as labiovelar $h, q$ in Gothic, the orthography suggesting preservation of their status as unit phonemes (but cf. Wagner 2006 and $\$ 6.4$ supra), there is no labialized $g$ in Gothic, so that PGmc. $3^{w}$ perhaps should be assumed to have developed to 3 or $w(\$ 6.4)$ already in PGmc. ${ }^{5}$

1. Under Grassmann's law, the first of two voiced aspirates in a PIE root is deaspirated in Sanskrit, as also in Greek.

2. It has been claimed (e.g. by Streitberg 1896: §117) that this change occurs also before IE $o$ in PGmc., but that is hardly possible in view of forms like OIcel. hvatr 'keen', hvalr 'whale', and Go. hapo 'spume' and saíhan 'see'. The delabialization in Go. OS OHG hals, OIcel. háls, OE heals 'neck' $<* k^{w}$ olsos antedates PGmc.: see Solmsen 1897: 547. There is delabialization in the Go. suffix - $u$ ) $h$ 'but, and' (cf. Lat. -que); the usual assumption is that the change is limited to final position under low stress, which would also explain the failure of $u$ to develop to aú before $h$ in this form. But Mottausch (2001) argues cogently that the distribution of the variants $-h$ and $-u h$, the latter occurring only after a consonant other than a liquid, is best explained on the assumption that the variants are purely phonological developments of PIE $*-k^{w} e$.

3. This sound change was first posited by Kluge (1886: 560$)$. Alternatively, $f$ - in Gmc. ' 4 ' could be by analogy to '5' (so Prokosch 1939: §99a, Voyles 1987: 492; first proposed by Zupitza 1896: 7). Bennett (1969) attributes such changes to contamination or borrowing from Celtic. Ringe (2017: 140-1) reserves judgment on the validity of the supposed sound change. Stiles (1985-6: 6.85) cites exceptions to the rule (e.g. Go. qiman 'come'), but he sensibly observes that since the change is not phonologically random but always involves the change of a labiovelar to a labial, it is probably a genuine, if somewhat opportunistic, phonological change.

4. Sen (2000) argues rather that PIE $k^{w}$ became $p$ before $e$ in Pre-PGmc., explaining Go. wulfs as reflecting a stem * $w l p$ - that arose in the vocative (though this word can hardly have been used commonly in direct address).

5. On exceptions to Grimm's law, and to the High German Consonant Shift $(\$ 6.21)$, see further the exchange among N. Davidsen-Nielsen, H.F. Nielsen, and J.E. Rasmussen in Acta Linguistica Hafniensia 16.4556 (1976), 17.86-97 (1982), 18.201-19 (1983).

\subsection{Verner's law}

The most notable exception to Grimm's law is the appearance of PGmc. voiced fricatives where voiceless ones might have been expected, for example $\delta$ for $p$ in Go. OS fadar, OIcel. faðir, OE fæder, OHG fater 'father' (cf. Skt. pitár-, Gk. $\pi \alpha \tau \eta \dot{\rho} \rho$, Lat. pater). 
The first to publish the correct explanation was Karl Verner (1877): ${ }^{1}$ when the immediately preceding syllable peak did not bear the PIE accent, a PIE voiceless stop ( $p, t$, $k, k^{w}$, assuming prior coalescence of palatals and velars) between voiced sounds is reflected as a voiced fricative (PGmc. $\hbar, \delta, 3,3^{w}$ ) rather than a voiceless one. ${ }^{2}$ These voiced fricatives thus fell together with the PGmc. reflexes of PIE aspirated voiced stops and developed in precisely the same way. In addition, under the same conditions $s$ was voiced to $z$, which, outside of Gothic, developed, where preserved, to $r$ by rhotacism, a development with parallels in Latin, e.g. gen. generis 'kind' $<*$ genh $h_{1}$-es-. The evidence for this analysis is plainest in strong verbs, which (outside of Gothic) continue to show paradigm alternations on this basis, whereas paradigm alternations due to the change were mostly eliminated in other grammatical categories before the literary period. And among strong verbs the evidence is plainest in the first three classes, in which the attested Gmc. alternations are paralleled by the accentuation of verbs in Sanskrit. That is to say, in Sanskrit normally the accent falls on the root in the perfect sg. (the PIE perfect being the chief source of the Gmc. pret.) but on the inflection in the dual and plural, and also in perfect participles. The accent in pres. forms is more various, but root accent is common. Accordingly, in at least the first three classes of Gmc. strong verbs there is to be found no voicing under Verner's law in the present stem (including the inf. and pres. part.) and the pret. sg. ind. (hence in the first two principal parts), ${ }^{3}$ whereas there is voicing in the pret. pl., the pret. $\mathrm{sj}$., and the pass. participle (the latter two principal parts). Comparison may be drawn between the alternation of accent seen in Skt. $3 \mathrm{sg}$. pres. ind. várt-ati 'turns', $3 \mathrm{sg}$. perf. ind. va-várt-a, 1 pl. va-vrt-imá, perf. pass. part. vart-āná- and the corresponding forms of OS snīđan 'cut', kiosan 'choose', and tiohan 'draw':

$\begin{array}{llll}\text { Pres. } 3 \text { sg. } & \text { snīđid } & \text { kiusid } & \text { tiuhiđ } \\ \text { Pret. } 3 \text { sg. } & \text { snēđ } & \text { kios } & \text { tioh } \\ \text { Pret. pl. } & \text { snidun } & \text { kurun } & \text { tugun } \\ \text { Pp. } & \text { gi-snidan } & \text { gi-koran } & \text { gi-togan }\end{array}$

Due to the general voicing of fricatives between voiced sounds outside of Gothic $(\S \S 6.14,6.16)$, along with limitations imposed by use of the Latin alphabet, alternation of $f$ and $b$ is not demonstrable in the same fashion. However, the reflexes of the two sounds are to an extent distinguished as $f$ and $b$ in the earliest OE texts, though whether the distinction was by then one of voicing or of labiodental vs. bilabial articulation is contested (see Brunner 1965: $\$ 191$ Anm. 1, with references). Neither is the alternation of $x^{w}$ and $3^{w}$ directly observable in verbs, due to later developments of these sounds (§6.4), but it may be inferred from, e.g., OE inf. sēon $\left(<{ }^{*} \operatorname{seohan}<{ }^{*} \operatorname{sex}^{w} a n a^{n}\right)$ 'see', pret. 3 sg. seah : WS pret. pl. sāwon $\left(<*_{s} \bar{x} w u n<*^{*} \bar{e}^{w} u n(p)\right)$, pp. sewen $\left(<*^{*} \operatorname{sez}^{w}\right.$ an- $)$, but Anglian pret. pl. ségon, pp. segen. ${ }^{4}$ In NGmc. only the alternation of $s$ and $r$ is observable (as in OIcel. kjósa 'choose' : pret. 3 pl. kuru, køru), but that between $x$ (which was lost when not word-initial) and 3 may be inferred (as in pret. 3 sg. sló 'struck' : pl. slógu). Further alternations may be inferred after $n$ or $l$ in two verbs: pret. 3 sg. fann 'found' (<*fanp) : pl. fundu; pret. 3 sg. olli 'caused' (*wulpē) : pp. valdinn. Verner's law failed to apply to fricatives in voiceless consonant clusters ( $s p, s t, s k, s s, f t$, $f s, x s, x t)$.

In Gothic, alternations under Verner's law have been eliminated almost entirely by substitution of the voiceless alternant for the voiced, though in words in which there was little or no alternation the voiced consonant remains, as in fadar 'father' < PIE * $\mathrm{ph}_{\mathrm{o}}$ ter- and gen. sg. riqizis 'darkness' $<{ }^{*} h_{1}$ rég ${ }^{w} e s-$ (but nom. riqis due to final fortition, 
$\S 6.12) .^{5}$ Variants may be observed, however, in related forms, e.g. fahēps 'gladness' beside faginōn 'be glad'; hührus 'hunger' beside huggrjan 'be hungry'; filhan 'conceal' beside fulgins 'hidden' (adj., originally pp.); jūhiza 'younger' (<*juyx-iz-, §4.1) beside juggs 'young'. The only words in which paradigm allomorphy persists are the pret.pres. verbs *paúrban 'need' (1 sg. pres. parf, pl. paúrbum) and *áigan 'have' (1 \& $3 \mathrm{sg}$. áih $7 \times$ beside áig $1 \times$; pres. part. áigands $5 \times$ beside áihands $1 \times)$. Given that the voiced variant occurs in words in which there would have been little or no alternation, naturally it is the standard view that Verner's law was once regular in EGmc., but its effects were eliminated in Gothic on an analogical basis, though it has also been argued that Gothic reflects a stage of PGmc. in which the variants had not yet developed fully. ${ }^{6}$ It should be recognized that the elimination of the effects of Verner's law in Gothic is by no means exceptionless. It is not plain, for instance, why Gothic has hazjan but nasjan; Liberman (2010: 409-18, with discussion and references) suggests sentence stress as the cause.

Alternations like those in strong verb paradigms were termed grammatischer Wechsel, purportedly by Jacob Grimm, and certainly by Adolf Holzmann (1870: 171, $229,342)$, apparently with grammatisch in the sense of Greek $\gamma \rho \alpha \dot{\mu} \mu \alpha$ 'letter of the alphabet', so that the original meaning of the phrase was 'alternation of letters' rather than 'grammatical alternation' (so, e.g., Lechner 2008-9: 6). But grammatical alternation is also observable on a comparative rather than a paradigmatic basis. A number of Gothic words show generalization of a stem with root accent, whereas the other Gmc. languages show the reverse generalization: such are Go. dáups 'dead' (<*dáupa-), but OE déad, OS dōd, OHG tōt (*dauðá-); Go. alpeis 'old', but OE eald, OS ald, OHG alt; ${ }^{7}$ Go. ga-nōhs 'enough' but OE ge-nōg-, OS gi-nōg, OHG gi-nuog; Go. áusō 'ear', but OIcel. eyra, OE éare, OS OHG ōra. Neuter $a$-stems afford a number of examples of differentiated leveling, due to accent shift in the nom./acc. plural (collective: §7.3), e.g. OIcel. gler 'glass' but OE glæs, OS OHG glas; OE OS blōd, OHG bluot 'blood' but Go. gen. sg. blöpis. Alternations are also frequently in evidence when a PIE verb root forms more than one Gmc. present type, e.g. Go. class I (orig. with nasal infix?) weihan, OHG wìhan 'fight' (= Lat. vincō?) : OIcel. class V vega 'fight'; Go. strong verb with weak pres. hafjan 'raise' (= Lat. capiō 'take') : weak verb haban 'have'; Go. strong leihan, OIcel. ljá, OE lēon, OS OHG līhan 'lend' : OIcel. weak leiga 'hire'; Go. strong (intrans.) fra-wairpan : weak (trans.) fra-wardjan 'spoil'; OHG strong gi-fehan 'rejoice' : weak feginōn; Go. class V (with $n$-suffix) fraíhnan 'ask' : OHG weak class 3 fragēn; OHG class I zīhan 'accuse' : weak class 2 zeigōn 'show'. There is thus a fairly regular correspondence between strong verbs and causatives to the same root (with suffixal accent: §12.3), as with OE ge-nesan 'survive' : nerian 'save'; OS līđan 'go' : lēdian 'lead'; OHG hāhan 'hang' (<*xayxana ${ }^{*}$, intrans.) : hengen (trans.); OE rīsan 'rise' : rǣran 'raise' $\left(<*\right.$ raizijana $\left.{ }^{n}\right)$. Similarly, verbs and related nouns may give evidence of alternations, e.g. OE staðol 'foundation' : standan 'stand'; OE lèosan 'lose' : lyre 'loss'; Go. fāhan 'take' : OIcel. fengr 'booty'. Such correspondences are especially notable between strong verbs and deverbal fem. abstract nouns in PIE *-á (as with Gk.

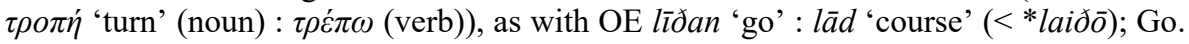
pret.-pres. láis 'know how' : OE lār 'instruction, lore' $(<*$ laizō); Go. preihan 'press upon' $\left(<*\right.$ priyxana $\left.^{n}\right)$ : OIcel. prong 'crowd'. For a succinct catalogue of grammatical classes in which Verner's law should have applied in PGmc., see Ringe 2017: 244-8, highlighting causative verbs of weak class 1 (PIE suffix *-éie/o-), e.g. OE lǣran 'teach' $<$ laizijana $^{n}$; weak inchoative verbs (with PIE accent on suffix *-néh ${ }_{2}$ - or the inflection), e.g. OE liornian 'learn' <*liznō-; masc. $n$-stem agentives with weak grade of the root, 
e.g. OE heretoga 'military general' <*-tuzô (cf. têon 'lead' <*téuxana ${ }^{n}$ ); some $a$-stem neuters expressing action or result, e.g. OE gehror 'destruction' <*-xruzan (cf. hrēosan 'fall'); and $\bar{o}$-stems of similar meaning (cf. OE lād : lìðan above).

The formulation of Verner's law given above_-voicing took place when the immediately preceding syllable peak did not bear the PIE accent-precludes voicing of initial fricatives if the domain of the rule is the word. There is one apparent exception, however: almost certainly the unstressed prefix $*_{3} a$ - is cognate with Lat. co(n)-, demanding the assumption of voicing; the meaning 'with' is inferrable from correspondences like Go. ga-máins 'common' (cf. Lat. com-mūnis), ga-qiman 'assemble' (cf. Lat. con-veniō), ga-haftjan 'join' (cf. Lat. con-cipiō), and ga-juka 'companion' (cf. Lat. con-jugō) ${ }^{8}$ compare also, without voicing, Franconian OHG (Lex Salica) ham- in Latinized ham-èdii 'co-swearer' and hamallus 'assembly co-member'. Other prefixes show no such voicing, e.g. Go. fair-, faúra-, fra-, paírh-.

On Verner's law see further Rooth 1974, with full bibliography, and subsequently Collinge 1985: 203-16 and Liberman 2010; also Moulton 1954, Milroy 1982, Mańczak 1990, 1999, B.R. Page 1998, Schaffner 2001, Mottausch 2011.

1. Eduard Sievers perceived the correct explanation earlier and wrote to Wilhelm Braune about it in 1874 . Although Sievers was too gracious ever to have mentioned the letter, the relevant portion was later published by Osthoff (1886: 13 n. 2).

2. Comparison is frequently drawn to the regularity in English that intervocalic $x$ is voiced as $/ \mathrm{gz} /$ when the accent follows, as in exist, exert, examine. The parallel is imprecise, since either $/ \mathrm{ks} / \mathrm{or} / \mathrm{gz} /$ may appear in many words when the accent precedes, as in exit, exile, but cf. exercise, execute, with $/ \mathrm{ks} /$ only. Comparison may be drawn as well to the opposition absolve : absolute, and to the Middle English voicing of fricatives in unstressed words, e.g. of : off. See Liberman 2010: 408. Voicing under Verner's law is a type of lenition: voicing requires less effort between voiced sounds, since the vibrations of the vocal folds are continuous rather than interrupted. It is unsurprising that a variety of lenition should be restricted to positions of low accentual salience, but such need not be the case: voicing under Verner's law is only a limited variety of a more general change that applied later in the Gmc. languages, the voicing of all nongeminate fricatives between voiced sounds.

3. Voicing would not originally have affected the pret. 2 sg. ind., where it is not found in NGmc., but WGmc. has adopted for the $2 \mathrm{sg}$. the same stem found in the plural: see $\S 12.25$.

4. OFris. has pret. pl. sēgon, pp. sēn, indicating that WS and Anglian have extended paradigm variants in opposed directions.

5. To Go. aqizi 'axe' cf. OIcel. $\varnothing x, \varrho x$, OE (Mercian) æxes, OS acus, OHG achus. PIE patterns of accentuation in $s$-stems (and thus alternations under Verner's law) are a matter of controversy: see $\$ 7.37$.

6. The latter is the view of Prokosch (1912, 1939: §20) and Hirt (1931-4: I, §91 Anm. 2, §93). Suzuki (1994) discusses the literature and attributes the removal of the voicing effects to final fortition (unpersuasively). On the law in Gothic, see Wood 1895, Haraldur Bernharðsson 2001, Woodhouse 2003, with references.

7. In words like 'old' the evidence of OHG is crucial, since medial *-lp-changed to -ld-in NSGmc. (\$6.17), as with OE OS gold 'gold' but OIcel. gull, OHG gold (not † golt), Go. dat. sg. gulpa.

8. See esp. Bennett 1968.

\subsection{The chronology and dating of Grimm's and Verner's laws}

Grimm's law specifies a type of sound change known as a chain shift, whereby a change in value in one sound or set of sounds precipitates a change or series of changes in another sound or set. Two types of chain shifts have been posited, push chains and drag chains. ${ }^{1}$ In a push chain, a phoneme or set of phonemes is said to change in such a way as to impinge upon the domain of another, causing the latter to change in value. For ex- 
ample, given two phonemes $/ \mathrm{t} /$ and $/ \mathrm{d} /$, if the former begins to take on voicing as a quality it may result in a change of the latter (e.g. fricativization) in order to maintain the phonemic distinction: $/ \mathrm{t} /$ may thus become $/ \mathrm{d} /$, and the original $/ \mathrm{d} / \mathrm{may}$ become $/ \mathrm{d} / .^{2}$ In a drag chain, one phoneme develops a new value and another changes to fill the gap supposedly left by the other. For example, if /d/ becomes a fricative / $/ /, / t /$ may be voiced to /d/. Grimm's law has been analyzed as a push chain by Kretschmer 1932: 274, Luick 1914-40: $§ 618.4$, Noske 2012; as a drag chain by (it would appear) Grimm 1848: 393 (see also Hirt 1931-4: I, §§52-5, Prokosch 1939: §16), Kiparsky 1971. Given the reconstruction of PIE obstruents represented above $(\$ 6.1)$, the two analyses are not equally probable. If a push chain is assumed, the change of PIE $b, d, g, g^{w}$ (assuming prior neutralization of the $\hat{g}: g$ opposition) to voiceless stops would have prompted the change of the voiceless stops $p, t, k, k^{w}$ to fricatives. Reasons might then be devised for the change of the voiced aspirates $b h, d h, g h, g h^{w}$ to fricatives (and, in some environments, stops), but such a change could not be ascribed to any direct push-chain effect. If a drag chain is assumed, the fricativization of PIE $p, t, k, k^{w}$ would have invited the devoicing of PIE $b, d, g, g^{w}$, which in turn would have permitted the development of $b h$, $d h, g h, g h^{w}$ to either stops or fricatives (depending on environment), the distinction having no phonemic significance within the new PGmc. system of obstruents. The latter analysis thus makes of Grimm's law a genuine chain shift as regards all the affected sounds, whereas the former does not. Moreover, the push chain model would appear to demand spontaneous devoicing of the PIE voiced stops, even though this would represent, improbably enough, a variety of unconditioned fortition. Yet this reveals little, since the Gmc. shift in consonant values almost certainly was not as simple as either model suggests (see n. 2), and the precise values of the PIE obstruents involved cannot be determined. ${ }^{3}$

It should be observed that whereas a push chain demands simultaneous shifting of all affected phonemes, a drag chain allows the relevant shifts to have occurred over perhaps a considerable period of time. This suggests a possible source of dating evidence. Yet as Prokosch (1939: §17) remarks,

The only concrete arguments consist in loan words and proper names, but the dating of the former is generally uncertain, and the possibility of sound substitution exists in both types of words. E.g., names like Cimbri, Teutones, with L[at]. c $t$ for Germanic spirants, do not indicate that the consonant shift had not yet taken place at the time of the Cimbrian migration; rather, these consonants are either Roman or Celtic substitutions. ${ }^{4}$

Yet Prokosch's own idea (so, earlier, e.g., Hirt 1931-4: I, §65) that borrowings like Go.

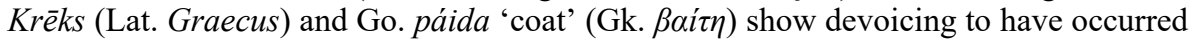
late in the shift faces similar objections. ${ }^{5}$ Even so, estimates of the date of the shift, which rely on evidence such as this, vary widely, from the second millennium BCE (so Kluge 1913: $\S 33$ Anm. 1) to the end of the first century BCE (so Euler \& Badenheuer 2009: 64-73). The commonest view is that the shift is to be dated to the first millennium BCE, perhaps toward its middle. ${ }^{6}$

Given the reconstruction of the PIE consonants represented above (§6.1), Grimm's law should be assumed to antecede Verner's law, hence, e.g., PIE $t>$ PGmc. $p$ $>\delta$, as otherwise the unlikely sequence of development would be PIE $t>d h>\delta$. Alternative arguments mostly depend upon one or another version of the glottalic theory (§6.2), ${ }^{7}$ and although it must be conceded that the phonological motivation for Grimm's law is hard to discern under the standard reconstruction of the PIE obstruent inventory, 
no version of the glottalic theory yet proposed is cogent enough, nor is the the problem exigent enough, to compel credence. Verner's law is further to be dated prior to the PGmc. accent shift (\$2.2). ${ }^{8,9}$

1. Or, regrettably, 'pull chains'. The two types are not equally credited in the literature: "Drag chains are supported by a good deal of empirical evidence, in terms of observable sequences of events. No such empirical support seems to exist for push chains" (Hock 1986: §8.4). There is, however, good evidence that the Great Vowel Shift of English unfolded in push-chain fashion: see Lass 1999: 74-7.

2. It may seem absurd to suppose that / $t$ / would spontaneously change to /d/ in all environments, given that phonemic systems are sets of structured oppositions. Rather, since voicing of stops is a common sort of lenition, it may be supposed that in such a development $/ t /$ is voiced in leniting environments, and conditions in the system of consonants are such as to prompt the opposed phoneme /d/ to undergo development to a fricative in order to prevent loss of phonemic contrast in just those same environments, resulting eventually in its change to a fricative in other environments. Likewise, the idea of a sound leaving a gap to be filled in a drag chain is difficult to reconcile with the insight that phonemes are sets of sounds defined by their opposition to other sets rather than sounds delimited on an absolute basis. Chain shifts cannot be the seemingly simple, straightforward developments described here, since they involve changes not in simple sounds but in systems of sounds, i.e. phonemes comprising perhaps numerous allophones. They thus are not likely to represent wholesale, uniform shifting of all allophonic values but piecemeal redistribution of allophones. But specifics of this kind in a change as historically remote as the First Sound Shift are irrecoverable. On the mechanisms of the First (and, in some cases, Second, §6.21) Sound Shift, in which aspiration is generally thought to have played a crucial role, see further Fourquet 1948, Schrodt 1989, Draye 1990a, Lauttamus 1992, Paddock 19967, Goblirsch 2005: 18-101, idem 2015, with further references.

3. See the remarks in $\S 6.4$. As an illustration of the difference that precise specification makes, note that Prokosch's analysis (1939: §16), derived from Grimm's, relies upon the supposition that the PIE voiced aspirates were actually fricatives - though it is implausible that such should have developed to murmured stops in Indic.

4. Prokosch's remarks here effectively undermine the arguments of Euler \& Badenheuer (2009: 13, 66-7) and Euler (2013: 50) for a late dating of the change of voiceless stops to fricatives. Cf. Mottausch 2015: 285, objecting that if these names contained unshifted consonants, the First Sound Shift would have to be dated improbably late.

5. It is possible that PGmc. had no voiced stops in initial or intervocalic position, only voiced fricatives, and thus, voiceless stops were adopted as nearest equivalents. See further Kluge 1913: §33, Hirt 1931-4: I, §65.

6. Much 1893: 63 dates the change to the third century BCE, Bethge 1900: 176 to the period 1000-400 BCE, and Meyer 1901: 126 and Kossinna 1936 to about the year 400 BCE. Polomé (1994: 9-11) discusses the evidence of Germanic names in Latin and Greek sources and concludes that they shed no reliable light on the date of the shift.

7. See, e.g., Ramat 1981: 37-40, Vennemann 1984b: 21; Kortlandt 1988: 5-6; Gamkrelidze 1990; Koivulehto \& Vennemann 1996 (cf. Liberman 2010: 401-2); Noske 2012; see also below on Kluge's law, §6.9. Glottalic approaches to the First Sound Shift have also met with much criticism: see, e.g., Draye 1986, Merlingen 1986 (advocating implosives rather than ejectives; cf. Woodhouse 1997), Moulton 1986, Penzl 1986b, Sanjosé Messing 1986, von Stechow 1986, Meid 1987, Voyles 1989a, Marchand 1991.

8. See Polomé 1987b: 219-20, with refs. On alternatives to this analysis, see §2.2 n. 2; also Vykypěl 2001.

9. Ringe $(2017: 125,234)$ would date Verner's law after the PGmc. loss of final non-high vowels on the basis of its failure to apply in Go. OHG uns <*unswé. But it is difficult to believe that the loss of final vowels did not postdate the change of the PIE pitch accent to the Gmc. stress accent, and regardless of the nature of the PGmc. accent at the time Verner's law applied (see §6.6), it is hard to countenance the supposition that a final syllable bearing the accent would have been lost.

\subsection{Geminates in Proto-Germanic}

In general, geminate consonants were rare in PIE, arising only on a morphological basis when a suffix began with the same consonant that ended the preceding morpheme. 
Geminates that arose this way appear usually to have been simplified, for example $2 \mathrm{sg}$. pres. ind. *h,es-si 'are' > *esi > Skt. ási, Gk. $\varepsilon \hat{i}$.

An exception is -tt-, which arose by the addition of a $t$-suffix to a form ending in $t$ or $d$. The resulting $t t$ is usually said to have developed to $t^{s} t$ (or $t^{b} t$ ) in PIE. It is reflected as $t t$ in Skt., $t s>s s$ in Celtic, $s t$ in most other IE languages (including Avestan), but $s s$ in Latin and Gmc., and in Gmc. it is degeminated to $s$ after a long vowel, a diphthong, or a consonant. Examples: PIE *mit-to- $>$ *mitsto- 'mis-' in Go. missa-, OIcel. OE OS mis-, OHG missa-, missi- (OIr. mí-, mis(s)-; cf. OHG mīdan 'avoid' < *mīpan- < *meit-on-); PIE *uid-tó-s (> *uitstós) 'seen' in Skt. vittáh, Gk. ö$\imath \sigma \tau o \varsigma$, Lat. vissus (with analogical lengthening), OE OS wiss, OHG gi-wissi 'certain' (cf. the degemination in OE wisse, OHG wissa 'manner' < *ueid-to-); PIE *sed-t- in Skt. sattáh 'seated', Lat. sessiō 'session', OIcel. OE sess 'seat'. Forms that arose early in PGmc. are treated similarly, e.g., to the pret.-pres. verb Go. wáit 'knows' (etc.), pret. Go. OS OHG wissa, OIcel. vissa, OE wisse (beside wiste, with analogical re-addition of the dental suffix). Naturally, as the last example shows, irregularities created by this change are frequently removed on the basis of analogy, e.g., beside OIcel. hlass 'cartload' (cf. hlaða 'lade' < PIE *klh $h_{2}$-tó-), OE hlæst, OHG (h)last, with re-addition of the abstract-forming suffix seen in OE forst, frost 'frost' (cf. frēosan 'freeze') and cost 'choice' (cf. cēosan 'choose'). ${ }^{1}$ Similarly, PIE *ts yields Gmc. $s(s)$, as in Greek and Latin. Examples: PIE *-bhudh- + -s- $^{-}>$PGmc. *-buts- $>-b u s^{-}$in Go. ana-busns 'command' (cf. ana-biudan 'command' and -sn- in ga-rēhsns 'appointed time' beside rahnjan 'count'); PIE * $h_{1}$ rudh- + -s- > PGmc. * rutsman- > OHG rosomo 'rust' (cf. Gk. है $\rho \varepsilon v \theta o s$, Lat. rubor 'redness').

There is a tendency in Gmc. for assimilation to occur in consonant groups containing a sonorant consonant, giving rise to new geminate sonorants $l l, n n, m m$, and perhaps $r r$ :

Gmc. $\boldsymbol{l l}$. Notably, *-ln- yields -ll-, as in PIE *plh $h_{-}-n o ́->$ PGmc. *ful-n-> Go. fulls, OIcel. fullr (etc.) 'full' (cf. Skt. prnàti 'fills', with infixed $n$, Lat. plènus 'full'); PIE *pelh $h_{2}-n->$ PGmc. ${ }^{*}$ fel- $n->$ Go. -fill (in prūtsfill 'leprosy'), OIcel. fjall, OE fell (etc.) 'hide' (cf. *pelh $h_{2}>$ Gk. $\pi \dot{\varepsilon} \lambda \alpha \varsigma$ 'hide'); PIE *h $h_{2} u l h_{2}-n-e h_{2}>$ PGmc. *wul-n- > Go. wulla, OE wull (etc.) 'wool' (cf. Skt. ùrṇā, Lat. lāna 'wool'). Likewise, PGmc. *-ðlprobably yields $-l l$-, and when *- $*$ - is the result of Verner's law, - $l l$ - may be in variation with - pl- (Sievers 1895): PGmc. *staðlaz > OE steall (etc.) 'position' : *stapulaz $>\mathrm{OE}$ staðol (etc.) 'foundation'; PGmc. *waðlō- > OE weallian, OHG wallōn 'wander' : *wap(u)l- in OE waðol 'wandering', OHG wadal 'migration'. Perhaps also there is a change of PGmc. *-zl- to -ll- (Kluge 1882: 521-5; cf. *-zn-, *-zm- below): PGmc. *knuzlijana ${ }^{n}>$ OIcel. knylla 'beat', OE cnyllan 'toll', MHG knüllen 'beat' : *knusjana ${ }^{n}$ $>$ OE cnyssan, OHG knussen 'strike'; PGmc. *xruz-l- > OIcel. hrolla 'shudder' : *xreusanan ${ }^{\prime}$ OIcel. hrjósa 'shudder'.

Gmc. nn. PIE *-nu- develops to Gmc. -nn-, as in PGmc. *punw-> OIcel. punnr, but ja-stems OE pynne, OHG dunni 'thin' (cf. Lat. tenuis, with full grade); PGmc. *manw-> Go. manna, OE OS OHG man(n) 'person' (cf. Skt. mánu- 'person'). Verbs with an $n$-infix are a notable source: PGmc. * brinwana ${ }^{n}>$ Go. OS OHG brinnan, OIcel. brinna, OE beornan, birnan 'burn' (cf. Lat. ferveo 'boil, seethe', without infix); PGmc. *rinwana ${ }^{n}$ Go. OE OS OHG rinnan 'run' (cf. Skt. rṇóti, rnváti 'moves'). Go. kunnan, OIcel. kunna, etc. 'know' perhaps shows a geminate as the result of infixation of $n$ in a stem already containing $n$, assuming PIE * $g_{n} n-n-h_{1^{-}}$(so Pokorny 1959-69: I, 376; cf. $\S 6.3$ supra). PGmc. ${ }^{*}-z n$ - also develops to $-n n-$, though never in Gothic: PGmc. ${ }^{*}$ razna ${ }^{n}$ 
'house' > Go. razn, OIcel. rann, OE arn; PGmc. *twiznaz > OIcel. tvinnr, tvennr, OE twinn 'twofold, twin' (cf. Lat. binn̄ <*duisnoi); perhaps the PGmc. suffix *-asnō, *-aznō, as in Go. hláiwasnōs 'graves', arhazna 'arrow', if this is reflected in OE byrgen $(n)$ 'grave'; probably *lizn- is a WGmc. innovation in OE leornian, OFris. lerna, lirna, OS lìnon, OHG lirnēn, lernēn 'learn'. NWGmc. -nn- can also result from the loss of an intervening consonant, as in OHG zannēn 'bare one's teeth' $(<*$ tan $p-n-;$ cf. zand 'tooth') and OE sinnan 'mind, heed', OHG fir-sinnan 'recover one's senses' $<*$ sin $p-n$ (cf. Lat. sentiō 'perceive').

Gmc. mm. The securest source of $-m m$ - is PGmc. *-zm-, as in Go. dat. sg. pamma (cf. Skt. tásmāi) and Go. im 'am' < *imm(i) < PIE * $h_{1} e s-m i{ }^{2}$ Probably *-mzhad the same result, as in OS thimm <*pimz- (cf. Lith. tamsùs 'dark'). There is assimilation of *-nm- to -mm- in OE hamm, OHG hamma 'ham' (cf. PIE *kneh $-m$ - in Gk. $\kappa v \eta ́ \mu \eta$ 'shank', OIr. cnāim 'bone'). Possibly PIE *-bm-develops to Gmc. -mm-, as in OIcel. dammr 'dam', Go. faúr-dammjan 'dam up' (cf. OIcel. dapi 'puddle' (nickname), OHG tapfar 'heavy', OCS debelb 'thick': Schröder 1898: 66).

Gmc. $r \boldsymbol{r}$. Geminate $-r r$ - is found in all the early Gmc. languages, including Go. (qairrus 'gentle', andstaúrran 'murmur against', fairra 'far off'), but there is no consensus about its source. To judge by some doublets, ${ }_{-}-r n$ - is a source: compare OE steorra, OS OHG sterro : Go. staírnō, OIcel. stjarna, OHG sterno 'star'; also Go. fairra, OHG ferro 'far off': Go. fairneis, OHG firni 'old'. It may be that -rr- arose under Kluge's law (see below), yet the exceptions are so much more numerous than examples of -rr- (Go. paúrnus 'thorn', barn 'child' gairnjan 'desire', kaúrn 'grain', haúrn 'horn', etc.) that suspicions about this explanation are natural.

On the gemination of glides due to the Verschärfung, see $\S 6.10$.

1. Kögel (1880: 196) argues that such instances of $s t$ for expected $s s$ result from placement of the PIE accent on the preceding vowel, though this can hardly be proved, and the phonological motivation is difficult to discern. See Kluge 1886: 150, and for an exhaustive treatment of the subject, Görtzen 1998. Krahe \& Meid (1969: III, §128.2) prefer to see an opposition like OIcel. hlass : OE hlæst as due to an original difference in suffixation, though they admit the possibility of analogical readdition of the $t$-suffix. Ringe (2017: 247-8) suggests a separate sound change of PGmc. dental $+t$ to st. Other instances of $-t t$ - that arose in Gmc. (§6.9) remain as such. See the lengthy discussion in Hill 2003: 78-217.

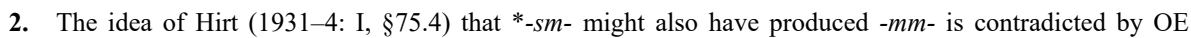
bōs(u)m, OFris. bōs(e)m, OS bōsom, OHG buosum 'bosom' < *bōsmaz, OE prosm 'vapor', besma 'broom', etc., though, to be sure, these could be WGmc. innovations. Certainly, ${ }^{*}-m s-$ did not yield -mm-: cf. Dutch dijzig 'cloudy, dark' < *bimsiza- : OS thimm < *bimz-.

\subsection{Geminate obstruents and Kluge's law}

In addition to the geminate resonants (and ss) discussed above, geminate obstruents are well attested in all the early Gmc. languages except for Gothic, where examples are few and almost certainly not derived directly from PIE: aside from personal names in historical records, the instances are just sakkus 'sack' (of Semitic origin, probably borrowed from Greek, though elsewhere in Gmc. borrowed from Lat. saccus: see the OED), smakka 'fig' (surely a loan; cf. OCS smokva), atta 'father' (a hypocorism, probably borrowed (Gk. ó $\tau \tau \alpha$, Lat. atta); cf. the derivative Attila), and skatts 'money' (OE sceatt, NHG Schatz; a concept not native to the early Gmc. economy, ${ }^{1}$ and so most likely borrowed, though the source is unknown: see Orel 2003: 336, and cf. OCS skotb 'herded animal'). ${ }^{2}$ It is thus difficult to disagree with the assessment of Prokosch (1939: 
§31a): "there is no Gothic evidence for the Gmc. lengthening of stops." 3 Voiceless geminate stops are not uncommon in the other Gmc. languages, and Kluge (1884) explains the majority of them as due to assimilation of a following $n$ contained in an accented nasal suffix, as in these examples of $n$-stem nouns ${ }^{4}$ and verbs assumed originally to have borne a nasal suffix *-néh $2^{-}$(as in Skt. grbhṇáti 'seizes' < *ghrbh-néh ${ }_{2}$-ti: see $\S 12.3):^{5}$

OIcel. ruppa, MLG roppen, OHG ropfōn 'pluck' < PIE *rup-néh-, as in Lat. rumpō 'break'

OE læppa 'lappet, piece, lobe', OFris. lappa, OS lappo 'cloth, rag' < PIE *lob$n e ́ h_{2}$ (cf. Gk. $\lambda o \beta o ́ \varsigma$ 'lobe')

ME lappen 'lap' (verb) < PIE *labh-néh $h^{-}$, as in Lat. lambō 'lick' (cf. Gk. $\lambda \alpha \varphi v ́ \sigma \sigma \omega$ 'devour' <*labh-)

OE cnotta 'knot' < PIE * gnu-t-néh $2^{-}$; cf. OHG knodo 'knob' < PGmc. *knupan-; also Lith. gniutúoti 'squeeze, clutch'

OHG krazzōn 'scratch' < PIE * grod-né $h_{2}$; cf. OIcel. krota 'engrave' < * grd-

Possibly OE hættian 'scalp' < PIE * $k h_{2} d h-n e ́ h_{2}-;$ cf. OE hōd 'hood'

Possibly OE fricc(e) $a$ 'herald', jan-stem reformed from PIE * prek-néh ${ }_{2}$; cf. Go. fraíhnan 'ask'

OE paccian 'pat' < PIE *tag-néh $h_{2}^{-}$; cf. Lat. tangō 'touch'

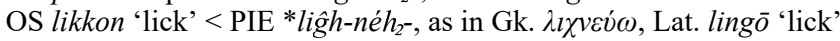

By contrast, when the accent precedes the PIE obstruent there is no assimilation. Probable examples, given their e-grade vocalism, are OIcel. regn 'rain', svefn 'sleep', OE pegn 'thegn'. Although much analogical disruption must be assumed, Kluge's findings also provide a means of accounting for the coöccurrence of the stems *ob-and *upp(the latter, strikingly, unreflected in Gothic) in certain forms derived from prepositions, e.g. OS adv. oban(a), uppan, OHG obana, üffana 'above' (cf. Gk. vió 'under'), due ultimately to variation in the ablative suffix *-an- (Kroonen 2011: 82-92). As the examples above illustrate, ${ }^{*} t t$ arising in this fashion did not develop to Gmc. ss, as PIE * $t t$ $\operatorname{did}(\$ 6.8)$.

It will be noted that the etymologies of these words with geminate oral stops are not nearly as secure as those of some of the geminate sonorant consonants examined above. Accordingly, scholarly opinions about the validity of Kluge's explanation diverge widely: e.g., Prokosch calls it "the standard view" (1939: §22), whereas Ringe says that the idea is "doubtful at best" (2006a: 115; cf. Ringe 2017: 136-40, rejecting it altogether). The commonest explanation for such geminates is that they are expressive in origin (so, e.g., Trautmann 1906, Fagan 1989), and indeed, geminates are very common in hypocorisms (e.g. OE Céol(l)a for Céol(-mund, -nop, etc.) and $\bar{E} a d(d) a$ for $\bar{E} a d(-r e d$, -weard, etc.)) and in intensive and iterative verbs, e.g. OHG tocchōn 'exert oneself', brocchōn 'crumble', zwecchōn 'seize, pluck' (cf. zwigōn 'pluck'), etc. Of expressive origin appear to be diminutives in reference to animals, e.g. OE ticcen, OHG zicchī, zikkīn 'kid' (cf. OHG ziga 'goat') and OIcel. krabbi, OE crabba, MLG krabbe 'crab' (cf. OHG crebiz). But the categories in which an ablauting $n$-suffix most commonly appears, $n$-stem nouns and certain weak verbs, are also the categories in which expressivity might most be expected to have played a role, since hypocorisms are generally $n$-stems, and weak verbs in general are commonly intensive or iterative. ${ }^{6}$ Much then depends upon examples in which expressivity must be excluded as an explanation, such as the doublet OS oban(a), uppan 'above', which are infrequent and resistant to explanation on a purely phonological basis, since much analogical change must be assumed. Still, the expressive basis for gemination in many $n$-stem nouns and 
weak verbs is difficult to perceive (e.g. OE cnotta 'knot' and læppa 'lobe'; Lühr 1988 collects examples), and in view of such instances, the degree to which NWGmc. forms with geminate obstruents are to be found in $n$-stem nouns and in verbs (presumably) with $n$-suffix, as predicted by Kluge, is impressive. Thus, although Kluge's account demands much conjecture, it cannot justly be called improbable, and in fact in some instances it does seem the most plausible explanation.

Yet even if Kluge's account is admitted, significant problems remain. Given the reconstruction of the PIE obstruents represented above $(\$ 6.1)$, it is difficult to see why the voiced aspirates should have been devoiced only when geminated. To explain this it has been proposed that Kluge's law applied before the devoicing of voiced stops under Grimm's law (so already Kluge 1884: 172 and, e.g., Prokosch 1939: §22, Lühr 1980: 259, Scheungraber 2014: 133, assuming that devoicing of the PIE voiced stops was the final development in the consonant shift, and the other changes under Grimm's law preceded the application of Kluge's law), and thus, for example, there was the development PIE * ghn after unaccented vowel $>*^{*} g g$ (Kluge's law) ${ }^{7}>*^{*} k k$ (Grimm's law). It was pointed out above $(\S 6.7)$ that the devoicing of PIE voiced stops under a push chain analysis of Grimm's law is difficult to account for; the same must be said of voiced geminates in either a push chain or a drag chain. The identical treatment under Kluge's law of PGmc. voiced fricatives whether derived from PIE voiced aspirates or from voiceless stops (i.e., under Verner's law) has been taken as evidence that Verner's law antecedes both Kluge's and Grimm's laws (so Kortlandt 1991), though this requires an alternative reconstruction of the PGmc. consonant inventory in line with the glottalic theory (§6.2). Dating Kluge's law to PGmc. also means that the effects of the law should be evident in Gothic. But it was pointed out above that geminate obstruents are exceedingly few in Gothic and are found probably only in borrowed words and in names; moreover, although some counterexamples to the law in Gothic are likely to show root accent, in others this is not so plain, e.g. aúhns 'oven' (cf. Gk. i ivó ৎ 'oven', and see Orel 2003: 433, Casaretto 2004: 325-6).

If Kluge's law is to be credited, it should be assumed that when a geminate arose after a long vowel or a diphthong, it was degeminated. This, after all, is what happened to geminates that arose by other means, e.g. Go. un-weis 'unlearned', OE OS OHG wīs 'wise' $<*$ ueid-to- and OHG pret. muosa 'must' $<*$ mōssa $<$ PGmc. *mōt-t-. This assumption allows it to be explained why certain Gmc. voiceless stops correspond to the reflexes of PIE voiced aspirates (rather than non-aspirates) or voiceless stops in other IE languages. Kluge's examples (1884: 182-4) include Go. heits, OIcel. hvitr (etc.) 'white', as if from PIE *kueit-nó- (cf. Skt. śvetá-, śvitna-, śvitnyá- 'white'); others

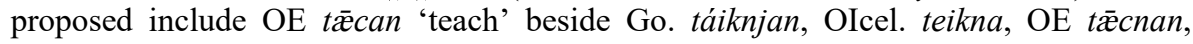
OHG zeihinen 'show' (cf. Gk. $\delta \varepsilon i ́ \kappa v \bar{v} \mu l$ 'show') and OE scēap, OS skāp, OHG scāf 'sheep' (cf. PGmc. *skat- in Go. OHG skaban, OIcel. skafa (etc.) 'shave, shear'). Some of these examples, however, demand the assumption that Kluge's law applied in PGmc., with later elimination of its effects in Gothic.

Voiced geminates in Gmc. are less frequent, e.g. OE frogga 'frog', docga 'dog', sceacga 'rough hair'; Kluge (1884: 176-7) explains them as having arisen on an analogical basis, by contamination of stems in alternation like *knaba- $*$ knappa-.

1. See Tacitus, Germania $\mathrm{v}, \mathrm{xv}$.

2. Kroonen (2011: 80-2) adds hypocoristic personal names found outside of Bible Gothic: Ibba, Faffo, Mammo, Oppa, Riggo, Wacca. 
3. Marchand (1957c) offers cogent arguments against assigning this change to the PGmc. period. For attempts to establish that Kluge's law is a PGmc. phenomenon and that the geminates it produced were later mostly eliminated in Gothic, or simply not represented in the Gothic Bible, see Kroonen 2011: 110-12, Scheungraber 2014: 139-42.

4. Kluge's assumption is that in the $n$-stems gemination would have occurred in the weakest cases, i.e. those with zero grade of the *-en-suffix (gen. sg., acc. pl. (?), and gen. pl. in PIE, though traces of zero grade in the suffix in Gmc. are found only in the gen. pl.: §§7.30-1). For bibliography, see Lühr 1988, Kroonen 2011.

5. Lühr (1988) classifies the verbs not as nasal presents but as factitives based on verbal adjectives in PIE *-no-; see also West 1990. The nouns are surveyed by Kroonen (2011), the verbs by Scheungraber (2014: $129-58,277-82)$, the latter of whom (170-2, with refs. to earlier literature) concludes that derivation from verbal adjectives is untenable, and only derivation from verbs with nasal suffix may be credited.

6. For a glottalic approach to expressive gemination, see Hopper 1990.

7. Note that on this reasoning it must be assumed that PIE $g h$ developed to PGmc. $g$ (rather than 3 ) not just after $n$ but also before it, though Kluge (1884: 175) would have the stop articulation develop after the rise of the geminates. For counterarguments to Kluge's ordering of Grimm's and Verner's laws, see Ringe \& Taylor 2014: 512-14.

\subsection{The Verschärfung}

The Germanic languages show reflexes of what would appear to have been geminate glides $* / \mathrm{jj}$, ww/ after a short vowel in some words in which extra-Germanic cognates show non-geminates, e.g. OHG zweiio 'of two' beside Skt. dváyōh. In North Germanic the geminates developed to $\langle\mathrm{ggj}$, ggv $\rangle$, respectively, and in Gothic to $\langle\mathrm{ddj}, \mathrm{ggw}\rangle$, as in ON tveggja, Go. twaddje 'of two' <*twajj-. Further examples: ${ }^{1}$

\section{With */jj/:}

Go. daddjan, Old Swedish dæggia 'suckle'; cf. Skt. dháyati 'sucks'.

OIcel. Frigg (name of deity), OHG Frīja; cf. Skt. priyá- 'loved one'.

Go. -waddjus, OIcel. veggr, OE wāg, wāg 'wall'; cf. Skt. váyati 'weaves'.

\section{With */ww/:}

OIcel. byggja, byggva 'settle'; cf. Skt. bhávati 'becomes'

Go. glaggwō 'meticulously', OIcel. gloggr, gløggr, OE glēaw, OS glau, OHG

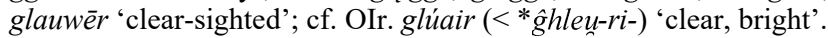

OIcel. hoggva, OE hēawan, OS hauwan, OHG houwan 'hew'; cf. Lith. káuju, kóviau, káuti 'hit'

The two processes, of gemination in Germanic and of the development of obstruents in North and East Germanic, are both referred to indifferently as 'the Verschärfung'; the older term 'Holtzmann's law' (after Holtzmann 1835: 862, 1836, 1870: 29, 42-3, 109) is now rarely encountered. In what follows, the gemination will be examined first, then the development of obstruents.

1. The gemination appears not to have affected every intervocalic glide after a stressed vowel: to OIcel. Frigg (name) cf. Go. frijōn 'love', and to hoggva cf. Go. hawi 'hay'; cf. also the class of words like OS treo 'tree', dat. trewe in West Germanic (OIcel. tré). Three chief kinds of explanations for the gemination have been offered: (a) accentual; (b) laryngeal; (c) morphological. ${ }^{2}$ No explanation has yet been generally agreed upon, but the laryngeal account currently enjoys the most favor. All explanations face the difficulty that secure etymologies for the relevant words are not numerous. 
(a) Early attempts at explanation, influenced by the explanatory success of Verner's law, appealed to the position of the PIE accent, as Holtzmann himself had supposed. Most such attempts argued that the change was conditioned by a following accented syllable (Bechtel 1885; Trautmann 1906, 1925; Mikkola 1924; Hirt 1931-4: 1.113), though Kluge (1879: 127-30,1913) argued for a preceding accent. Uncertainty about the place of the accent, combined with the failure of any alternation in regard to the gemination in Go. strong verbs like bliggwan, blaggw, bluggwum, bluggwans, in which the place of the accent ought to have varied, eventually brought scholars to reject such explanations. ${ }^{3}$ Subsequent attempts to relate the phenomenon to the Germanic and/or the PIE accent have been sporadic and have not won acceptance. ${ }^{4}$

(b) H.L. Smith (1941) was the first to relate the gemination to PIE laryngeal consonants, and the idea has subsequently evolved in several different directions. The precise role of any laryngeal involved is a matter of disagreement: some, with Smith (and see esp. Lehmann 1952: 63 and Davis \& Iverson 1996b), see it as lengthening an adjacent glide due to assimilation of the laryngeal (a change which Lindeman 1964 would date to the PIE period; cf. Beekes 1972), whereas others see the laryngeal as leaving a hiatus upon its disappearance, to be filled in Germanic by a homorganic glide. ${ }^{5}$ A particular disagreement concerns whether the laryngeal must follow the glide (so Jasanoff 1978a) or precede it (so Polomé 1949, 1959, 1970), ${ }^{6}$ or whether either arrangement is allowable (so in part Lehmann 1952: 36-46). This particular uncertainty has occasioned some heavy criticism of laryngeal approaches (see esp. Beekes 1972), a situation that Jasanoff (1978a, supported by Rasmussen 1990) aims to set right by assuming that laryngeal plus glide could undergo metathesis. While Jasanoff's seems the best laryngeal analysis, its chief demerit is that it requires a great deal of analogical interference in order for the phonological rule to apply regularly, especially in regard to

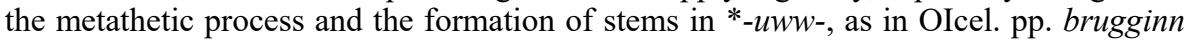
'brewed'. Moreover, the word with the plainest etymology, OIcel. tveggja, proves an ill match with any laryngeal hypothesis: Jasanoff (1978a: 83-4, in reliance upon Lühr 1976: 73) would derive it from a PIE gen. dual *duoi-Hou (not his notation), but Rasmussen (1990: 436-7) points out that the ending *-Hou is locative rather than genitive. For counterarguments to laryngeal explanations, see van Coetsem 1949, Zgusta 1955: 198-201, Beekes 1972, Voyles 1989b: 23-32, Polomé 1994: 21-4.

(c) A morphological solution is proposed by Kuryłowicz (1967, Kuryłowicz et al. 1968-2015: 2.329-33), whereby a form like $C u w V$-, conceived as a reduced grade of $C e w V$ - under Edgerton's formulation of Sievers' law (\$5.8) or as due to loss of a laryngeal consonant in $\mathrm{CuHV}$-, was given an analogically induced new full grade $\mathrm{CeuwV}$-. Another morphological explanation ${ }^{7}$ ascribes the gemination to paradigm regularization, whereby an alternation between diphthongal forms like masc. nom. *twai, dat. *twaimiz and non-diphthongal gen. *twajôn resulted in the extension of the diphthong in the former to the latter, giving *twaijon. This process is paralleled at a later date in $\mathrm{OE}$ nouns with diphthongal stems, where alternation between nom. *peu > péo 'servant' with gen. * pewas $>$ * pewes resulted in extension of the diphthong of the former to the latter and of the $w$ of the latter to the former, giving nom. peow, gen. péowes. This accounts well for verbs with Verschärfung, given original alternations like inf. * brewana ${ }^{n}$ 'brew' beside $1 \& 3$ sg. pret. *brau, but it is more speculative as an explanation for some nouns, such as OIcel. hogg 'blow' and OE trēow, which must be regarded as analogical to related verbs or as due to change of inflectional class. An advantage of morphological solutions is that the Verschärfung appears to be too irregular to be the 
result of phonological change. A more concrete advantage is that since "the dismantling of geminates is a very unusual change (apparently violating the Obligatory Countour Principle)" (Ringe \& Taylor 2014: 65-6), it seems more plausible to suppose that WGmc. reflects the original situation, with a dipthong before a glide (i.e., the Verschärfung is not the result of gemination), and East and North Gmc. have innovated, turning a sequence like *aij- into *-ajj-. That WGmc. did not undergo the same change is perhaps not unrelated to the facts of WGmc. consonant gemination (\$6.15).

It should be noted that a number of forms with $* / \mathrm{jj} /$ can be explained as due to suffixation, e.g. weak Go. daddjan 'suckle' $<*$ dai-j-ana ${ }^{n}$ and OIcel. Frigg $<*$ frij-jō $<$ * frī-jō: see Voyles 1989b, Rasmussen 1990. This lends support to the just-remarked evidence that the WGmc. situation is more original.

2. The second stage of the Verschärfung, represented by the rise of obstruents in North and East Germanic, has occasioned controversy about both (a) the phonetic values of the new obstruents and (b) the motivation for the change:

(a) It is debated whether Go. - $d d j$ - and OIcel. -ggj- might represent the same sequence of sounds (presumably involving a palatal stop), a matter that is related to the question whether the second phase of the Verschärfung comprises independent developments in East and North Germanic (the usual assumption: see, e.g., Cathey 1970, Markey 1988b: 322, H.P. Petersen 2002) or a change that took place either before the separation of the two branches (so Davis \& Iverson 1996b) or at a stage of greater proximity between the two (see Suzuki 1991b). These two sequences of sounds are usually assumed to represent a (geminate) stop followed by a glide (see, e.g., Y. Tanaka 1970), though Hammerich (1955: 178) argues that at least originally the fortition of [j:] resulted in [d]], somewhat as Latin [j] developed to Italian [d]], regardless of what Go. $-d d j$ - and OIcel. - ggj- might actually represent. As for Gothic - ggw-, it has been debated whether -gg- here might not represent [yg], as elsewhere (so Marchand 1959: 442, 1973: 56-7, Bennett 1964, Snædal 2011; but see Brosman 1971 for counterevidence), though it is usually assumed to represent [g:] in products of the Verschärfung.

(b) As for the motivation for the East and North Germanic developments, Polomé (1949) argues that the sound(s) represented by $\langle g g\rangle$ developed when the accent inherited from PIE was on the following vowel, as with Verner's law. Rasmussen (1989; see also Rowe 2003) posits a PGmc. development of [jj] and [ww] to [jyj] and [wyw], with subsequent loss of the fricative in West Germanic; and indeed, several analyses posit a fricative at least at an intermediate stage. Davis \& Iverson (1996b) instead suppose that at the time it was lost, the laryngeal left its place to be filled by a glide, and at the same time its feature [consonantal] spread to the preceding glide, producing a stop. The West Germanic languages suggest instead that stop articulation is not to be traced to Proto-Germanic, as do some early Germanic loan-words in Finnish and the word niuwila in runes on the fifth-century Næsbjærg bracteate (see, e.g., Marchand 1973: 87, Koivulehto 1977).

1. For an assemblage of 42 possible examples, see Rasmussen 1990: 436-41. Most commentators, however, work with far fewer examples: e.g., Kuryłowicz (1967: 448-9) accepts no more than 18. Collinge 1985: 93101 offers a good, concise summary of the scholarship.

2. A fourth variety of explanation, that the gemination is expressive in nature (Meillet 1922: 78), has, not surprisingly, met with no support; cf. Jasanoff 1978a: 77.

3. Accentual explanations were rejected by Paul 1879-80: 7.165, Streitberg, Michels, \& Jellinek 1936: 323 6, and Lehmann 1952: 39. 
4. See van Coetsem 1949, Y. Tanaka 1970. Some of the laryngeal explanations referred to under (b) also invoke accentual support.

5. So Jasanoff 1978a, Polomé 1988: 404-5, Suzuki 1991b; see also Cathey 1970: 57, and see Müller 2007: 91-2 for discussion. Whether loss of the laryngeal without automatic lengthening of the glide would produce an impossible syllable structure (see Davis \& Iverson 1996b) is debatable, as it may be assumed that the vowel plus glide sequence of PIE produced a Gmc. diphthong before the loss of the laryngeal.

6. This raises the problem that the sequence *-VHR- is commonly thought to be reflected as $-\bar{V} R$ - in Germanic. Analyses of this kind thus usually appeal to the placement of the accent to distinguish forms with and without Verschärfung.

7. See Fulk 1993b. A somewhat different analysis of a few forms as due to paradigm regularization is offered by Voyles (1989b: 27-8).

\subsection{Further consonant changes common to all the Germanic languages}

PGmc. *-m- $ð->-n d-$, as in PIE *k̂ntóm 'hundred'> PGmc. *xumðan > Go. OE OS hund, OHG hunt; Go. OIcel. OE sund 'swimming' (cf. OE swimman); PGmc. *skam-ðō 'disgrace' > Go. skanda, OE sc(e)and, OHG scanta (cf. Go. skaman 'be ashamed').

With the devoicing of PIE voiced stops under Grimm's law, an immediately preceding $z$ was devoiced to $s$, as in OE OHG nest $<$ PIE *ni-zd-os (> Lat. nìdus 'nest', with zero grade of the PIE root *sed- 'sit') and Go. asts, OHG ast 'bough' = Gk. ö $\zeta o \varsigma$, Armenian ost 'bough' < PIE * $h_{3} e-z d$-os (again from *sed-). Before the reflex of a PIE voiced aspirated stop, however, PGmc. $z$ remained, developing for the most part to $r$ outside of Gothic (§6.6), as in *kuzdh- > Go. huzd, OE OS hord, OHG hort 'hoard'; *mizdhó- > Go. mizdō, OE meord (but also mēd, with $\left.\bar{e}_{2}(\$ 3.5)\right)^{1}$ 'reward' (cf. Avestan

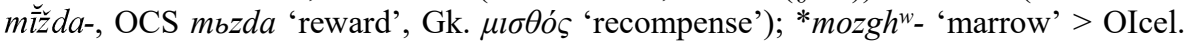
mergr, OE mearh, OS OHG marg (cf. Avestan mazga-, OCS mozgz).

PGmc. $w$ was lost (and $k^{w}$ delabialized, if it had not already developed to $k w$ in PGmc., §§6.5 ad fin., 6.11) before $u$, as in Go. niun ' 9 ' < *niwun < PIE *néun (cf. Skt. náva, Lat. novem), PGmc. * ${ }^{*} w u m-\delta-a^{n}>$ OIcel. OE sund 'swimming' and $* k^{w} u m a n a^{n}>$ OIcel. koma, OE cuman, OS kuman 'come'. An exception is when $w$ is initial, as in Go. wulla 'wool'. But $w$ could be restored to reduce paradigm allomorphy, e.g. Go. pret. swultun (inf. swiltan 'die'), pret. qumun (inf. qiman 'come'), OE pp. swungen beside sungen (inf. swingan 'beat').

PGmc. antevocalic $x$ may have become $h$ in initial position already in PGmc. (so, e.g., Ringe 2006a: 215; otherwise Ringe 2017: 244), since it is nowhere reflected as [x]. ${ }^{2}$ However, initial $x^{w}$ - is unlikely to have become $h^{w}$ - in PGmc., given its fortition to [kv] in Modern Icelandic and Faroese, and given medieval Scottish and northern English spellings like $q u h-, q h w-, c h u-$, and similar, usually interpreted as representing [xw]. On the PGmc. loss of $y$ before $x$, with compensatory lengthening of the preceding vowel, see $\S 4.1$.

All PIE final consonants after an unstressed vowel in a word of more than one syllable were lost in PGmc. except for $s / z$ and $r$. Examples of obstruent loss are thus limited to dental consonants, since no other obstruents but $s$ occurred finally in PIE polysyllables. The loss may be illustrated in Gothic: PIE *bhidh-ngt $>$ bidun 'awaited' (3

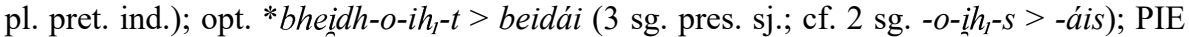
abl. * $k^{w}$ oteréd $>$ hadrē 'whither'; PIE *nepōt- > OE nefa, OS neбo, OHG nefo 'nephew, grandson' (cf. Skt. nápāt 'descendant'). For examples of the treatment of final $\mathrm{s} / \mathrm{z}$ and $r$, see $\S 5.2$, and see below, $\S 6.16$, on $s / z$ in West Germanic. ${ }^{3}$ A final nasal consonant 
was also lost in PGmc., with nasalization of the preceding vowel, which in some cases resulted in different treatment of the resulting nasalized and non-nasalized vowels: see, e.g., §4.8. Before their loss, however, all final nasal consonants became $n$, as shown by instances in which a final particle was added, leading to preservation of $n$, as in acc. $\mathrm{sg}$. masc. Go. pana, OE pone 'the, that' < PIE *tom (as in Skt. tám, to sá, Lat. is-tum) plus particle $-a<$ PGmc. ${ }^{*}-\bar{o}^{n}$. The loss of a final nasal consonant is attested in a variety of morphological categories, including the acc. sg. of all genders, nom. sg. neuter, gen. pl. of all genders, nom. sg. of $n$-stems, and the $1 \mathrm{sg}$. pres. and pret. sj. of verbs.

As for monosyllables, a final nasal in a monosyllable was lost only after a long vowel: to Go. han, OS hwan 'when' (= Lat. cum, Old Lat. quom) cf. acc. sg. fem. Go. $p \bar{o}$, OIcel. $p a ́$, OE $p \bar{a}$ 'the, this' (= Skt. $t \bar{a} m$, Gk. $\tau \eta^{\prime} v$ ). An oral dental consonant was also preserved at the end of a monosyllable, at least after a short vowel, as in Go. OIcel. OS at, OE æt, OHG $a z$ 'at' (cf. Lat. $a d$ ) and OIcel. hvat, OE hwæt, OS hwat, OHG (h)waz 'what' (cf. Lat. quod; but cf. Go. ha, on which see \$8.13). It cannot in fact be said with assurance that any final consonant was lost in monosyllables, except $n$ after a long vowel. Yet Go. swa 'so, thus' and its Gmc. cognates are perhaps to be derived from *sūōd (Orel 2003: 398): cf. Old Lat. suad 'thus'.

Insertion of a transitional consonant between certain sounds may ease articulation, and the process may be instigated by changes in the articulation of PIE sounds due to substrate influence $(\S 1.5)$. PIE * $s r$, when not affected by Verner's law, develops to Gmc. str, as in some other IE languages, including the Slavic branch. Examples: PIE * sroum- > OIcel. straumr, OE strēam, OS strōm, OHG stroum 'stream' (cf. Gk. $\dot{\rho} \varepsilon \hat{v} \mu \alpha$ 'stream', OIr. srúaim 'river'); OE Ėastron 'Easter' (cf. Lith. aušrà 'dawn', Skt. usrá'matutinal'); possibly Go. swistar, OIcel. systir, etc. 'sister' (cf. Skt. svásar-, weak stem svasr-, Lat. sōror; see Ringe \& Taylor 2014: 515). Similarly, * $m r$ may develop to $m b r$, as in Go. timbrjan (beside more usual timrjan), OIcel. timbra, OE timbran, OS timbrian, OHG zimberen 'build' (cf. Gk. $\delta \varepsilon \mu \omega$ 'build'). ${ }^{4}$ The reason for the appearance of $s$ and $f$ in forms with the PGmc. suffix *- $p$-, as in Go. ansts, OE est 'favor', (cf. OE unnan 'grant'), OHG kunst 'art' (cf. kunnan 'know'), kumft 'arrival', numft 'robbery', is not plain (see Hirt 1931-4: I, §77), but it is probably not due to insertion of a transitional consonant. ${ }^{5}$

In the cluster $m n$, the first consonant tends to lose its nasality by dissimilation, though the results are hardly regular, and the reverse change (of $\hbar n$ to $m n$ ) is well attested in NWGmc. ${ }^{6}$ Fairly secure examples include the Go. suffix -ubni $\sim-u f n i$ (e.g. witubni 'knowledge', wundubni 'wound'; on the alternation, see $\S 6.12$; but to fastubni '(observance of) fast' cf. OE fæstenn, OS fastunnia), comparable to Lat. -umnia in calumnia (and see further Kluge 1926: §150); OE heofon, OS heban 'heaven' (cf. Go. himins, OIcel. himinn and the alternative stem in $l$ by heteroclisis, OFris. himel, himul, OS OHG himil).

There was probably loss of $j$ between unstressed vowels (except between $i$ and a back vowel: cf. Runic holtijaz), as this assumption best explains the development of weak verbs of classes 2 and 3 : see $\$ 12.43$ and n. $2, \S 12.47$. A fairly convincing example (in an unstressed word) is PIE loc. *aieri (cf. Avestan ayarz 'day') > PGmc. *a(j)iri) > Go. áir 'early'. Guơun Pórhallsdóttir (1993) finds that this change affects $j$ even after stressed vowels, as in PIE * aies- 'bronze' > PGmc. *a(j)iz- > Go. áiz $(1 \times$, for expected *áis, §6.12), OIcel. eir, OE $\bar{a} r$, OS OHG êr; cf. §6.10 on the Verschärfung. 
1. Similar loss of $z$, with compensatory lengthening, can be seen in OE twin 'linen' (cf. NHG Zwirn), OS linon 'learn' (cf. OE liornian, leornian), Middle Dutch hēde 'hards of flax' (cf. OE heorde), and possibly OE $h \bar{a} d$-, if it has the meaning 'hair' in hād-swēpe 'bridesmaid' (cf. OIcel. haddr 'woman's hair' < *hazðaz, $\$ 6.12$ infra, and see Holthausen 1974: 143). The alternative results have not been adequately explained; presumably it is the result of paradigm alternation. For further examples, see Ringe \& Taylor 2014: 84-5.

2. It is notable that whereas in names in Latin and Greek sources Gmc. initial $/ \mathrm{x} /$ is usually represented by Lat. $C, C h$, or $H$, Gk. $K$ or $X$, as early as the third century there appear forms with vocalic initials, e.g. Asdingi,

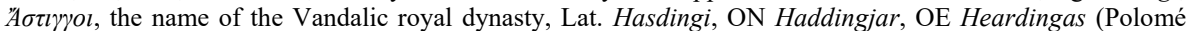
1994: 10-11). Ringe (2017: 244) mentions, as evidence for the preservation of initial [x], Frankish names transcribed with $\mathrm{Ch}$ - and borrowings into French like flank 'flank' < Franconian *xlank-.

3. An exception to the retention of final $z$ is in reflexes of PGmc. ${ }^{*}$-omiz, appearing in the dat. pl. of $a$-stems (and the 1 sg. pres. ind. of verbs) as Go. -am (but Runic -umR: see $\$ 7.8$ ad fin.).

4. Compare the similar, later developments in PDE thimble, bramble, thunder, etc. (OE pȳmel, brēmel (rarely brembel), punor). See further Osthoff in Osthoff \& Brugmann 1878-1910: V, 125.

5. It may be that interdental $b$ was assimilated to the place of articulation of the preceding consonant, and the suffix (in the form $t$ after a fricatve) re-added.

6. E.g. OIcel. nafn 'name' : Go. namō and OIcel. safna, samna 'collect' : saman 'together'; the etymologies of OE stefn, stemn 'voice' (Go. stibna), hrafn, hramn 'raven', and efn, emn 'even' (Go. ibns) are rather insecure, though the last is a fairly probable example.

\subsection{Consonant changes in Gothic}

There is devoicing of Go. final fricatives (final fortition, Auslaut(s)verhärtung), as well as of fricatives before final $s$. Examples: pret. gaf (inf. giban 'give'), hláifs 'loaf' (gen. hláibis), pret. bap (inf. bidjan 'pray'), gōps 'good' (gen. gōdis), riqis 'darkness' (gen. riqizis). Presumably the same change affected $g$, but it is not expressed in the orthography, no doubt because $g$ and $h$ contrasted in all other environments, whereas other pairs of voiced and voiceless fricatives did not contrast consistently: cf. mag 'can', baúrgs 'city' (not †mah, †baúrhs). On the basis of non-alternation in forms like pret. -swarb (inf. *-swairban 'wipe'), halbs 'half', waúrd 'word', alds 'age' it may be inferred that voiced fricatives (other than $z$ ) had become stops after liquid consonants ( $r$, $l$ ) in Gothic, as they had in PGmc. after nasals (but cf. 2 sg. parft, inf. *paúrban 'need').

Voicing dissimilation affects Go. fricatives in such wise that a suffixal fricative is voiced if the last preceding consonant is voiceless, but devoiced if that preceding consonant is voiced, in a development known as Thurneysen's law. Thus, there is voicing of the bilabial fricative in fastubni '(observance of) fast', witubni 'knowledge', but not in wundufni 'wound', waldufni 'dominion'. The alternation is most plainly observable in the suffixes -ubni/ufni, -ōdus/ōpus, -uzi/usi, -zna/sna, -ida/ipa, and the $s$-stem suffix -iz/is-, but many exceptions are to be found: see Collinge 1985: 183-91 for literature and discussion, and more recently Suzuki 1992, Woodhouse 1998b.

Final $s$ might come to follow $s$ as a result of syncope, in which event the geminate was simplified, as in wairs 'worse' $<*$ wirss $<*$ wirsiz. Likewise, after $r$, final $s$ was lost after a light syllable, as in wair 'man' and anpar 'other' (cf. swèrs 'honored'), though in adjectives it was restored analogically after a stressed vowel to differentiate genders, as in ga-faúrs 'well-behaved'.

Alternations due to Verner's law were eliminated in Gothic: see §6.6. On the apparent gemination of $j, w$, and on the change $j j, w w>d d j, g g w$, see $\S 6.10$. 


\subsection{Gothic $p l-$}

There are a number of words in Gothic with root-initial $p l$-: for a list, see Salmons \& Iverson 1993: 88 or Davis \& Iverson 1994: 155-6. The plainest case is pliuhan 'flee', the Gmc. cognates of which all have root-initial $f$-, as with OIcel. flýja, OE fleoon, OFris. fliā, OS OHG fliohan. Not all instances of $f$ - in other Gmc. languages, however, correspond to Go. $b l-$ : e.g., to OE $f \bar{o} d$ 'flood' cf. Go. flōdus. It has sometimes been maintained that in forms with $p l$-, this must be the original cluster, ${ }^{1}$ and indeed, the change of $/ \theta \mathrm{l} /$ to $/ \mathrm{fl} /$ is considerably more natural than the reverse (Kjellmer 1995; cf. M.J. Jones 2002). But some of the relevant words have fairly secure extra-Germanic cognates in PIE *pl-, the plainest case again being Go. pliuhan: cf. Gk. $\pi \lambda \dot{\varepsilon} \omega<*$ pleuō 'swim', Lat. pluit 'rains', etc. ${ }^{2}$ Since the Gothic forms in $b l$ - are restricted to a limited number of texts, Davis \& Iverson (1994, 1996a; cf. Woodhouse 1995, 1998a, Nilsson 1996: 53-5) argue that the change of / $/ 1 /$ to / fl/ is a dialectal development. ${ }^{3}$ To the contrary, Salmons \& Iverson (1993) make the case that the alternation between the two clusters is due to lexical diffusion. Woodhouse (2000) interestingly observes that in the forms with Go. $p l$ - the following vowel reflects PIE $e$-grade or reduced grade, whereas $o$-grade is found with $f$-: examples are plaúhs 'flight' (cf. OIcel. flugr) <*plukós : flahta 'lock of hair' (cf. Lat. plectō) $<*$ plokk-t-. The claim, however, that the consonant alternation is conditioned by ablaut faces some unresolved difficulties, in part of a chronological nature. ${ }^{4}$

1. See, e.g., Kieckers 1960: 48, Hirt 1931-4: I, 82, Woodhouse 1995, 1998a; cf. Davis \& Iverson 1996a.

2. See Zupitza 1896: 131, Nordmeyer 1935, Prokosch 1939: §29d, M.J. Jones 2002.

3. Similarly, earlier, Nordmeyer 1935. Cf. Marchand 1956: 149-50.

4. Cf. the argument of Matzel (1962) that the change is due to the combined influence of $-l$ - and stem-final $h, h s$, or $q$.

\subsection{Consonant changes in Proto-Norse}

Before the end of the PNorse period, PGmc. $z$ must no longer have been simply the voiced equivalent of $s$, as otherwise it should be expected to have been devoiced to $s$ word finally (as explained below). It is most commonly transcribed as Runic R. Eventually it developed to $r$, but in Runic it is generally distinguished from $r$ (rune R) by the use of a separate rune ( $\Psi$ ); the two, however, apparently had fallen together at least in some environments in East Norse, given the hypercorrection in $\mathbf{A f}^{\mathrm{a}} \mathbf{t R}$ (Istaby stone, Sweden, $1^{\text {st }}$ half of the $7^{\text {th }}$ cent.; cf. Go. aftra 'back, again'). ${ }^{1}$ The sound must have been palatal, given that it could produce umlaut in a preceding vowel $(\S 4.7) .^{2}$ Before $z$ could develop to $r$, it was assimilated to a following $\partial$ or $n$, as in OIcel. gaddr 'goad' (Go. gazds, but OE $g \bar{a} d$ : see $\$ 6.11 \mathrm{n}$. 1) and rann (Go. razn). When $R$ came into contact with another consonant due to syncope, it could be assimilated to it: thus, always with $s$, as in lauss 'loose' < *laus- $<$ *lausaz; after $l$ or $n$, except when it ended a light, stressed syllable, as in heill 'whole' < *hail-R, litill 'little' < *ititl-R, fallinn 'fallen' $<*$ fallin-R, but dalr 'valley', vanr 'usual'. But $-r$ is frequently restored after $n n$, as in punnr 'thin'.

In initial position, PGmc. 3 became a stop, probably at an early date, as in OIcel. gull 'gold', gefa 'give', gjalda 'repay'. So also $\bar{b}$ and $\partial$ if this change had not occurred already in PGmc. (§6.5). 
Initial $j$ was lost categorically, as in *jēran $>$ ár 'year', *jungaz $>$ ungr 'young', a change that can be dated on the basis of the use of the rune $*$, which originally represented $j$, to represent a vowel (A), the earliest instance being on the Vallentuna dice (ca. 600: see H.F. Nielsen 2000: 256-7). Otherwise, $j$ is preserved only when syllableinitial (i.e., after a light syllable) or after a velar obstruent: to selja 'deliver', nom. pl. niðjar 'kinsmen', sœkja 'seek', pykkja 'seem' cf. deila 'distribute' (Go. dáiljan), senda 'send' (Go. sandjan). There was also loss of $j$ before all front vowels, including those resulting from front umlaut, except for $æ$. Initial $w$ was lost before rounded vowels (but not $g$ or $\phi$, developed from $a$ and $a$ ), even when $r$ intervened, as in ormr 'serpent' (Go. waúrms), óðr 'mad' (Go. wōds, 1×, for expected *wōps: §6.12), yrkja 'make' (Go. waúrkjan), хpa 'shout' (Go. wōpjan), róta 'disarrange' (OE wrōtan); the loss of $w$ before other instances of initial $r$ is later, as shown by the alliteration in some early verse. Internal $w$ was lost under similar conditions, as in sœtr 'sweet' (cf. OE swōt), hósti 'cough' (OE hwōsta). Medial $w$ was also lost after a heavy syllable unless preceded by a velar consonant, as in benda 'betoken' (Go. bandwjan), ótta 'early morning' (Go. ühtwō), but syngva 'sing', sokkva 'sink'. There was also loss of $w$ before $u$, as in boð 'battle' <*baðu<*baðwō (gen. boðvar, wō-stem), a change that may belong to Proto-NWGmc. (see $\S 6.16$ ). On the date of the loss of $j$ and $w$, see Isakson 2000.

Medially, voiceless fricatives other than $s$ were lenited wherever this was not prevented by an adjacent voiceless consonant. For $f$ and $p$ this meant voicing, as in PGmc. *wulfaz > úlfr 'wolf' (where $<\mathrm{f}>=\hbar$, but still wul(a)f- in Runic), *brōper- > bróðir 'brother', and *werpana ${ }^{n}>$ verða 'become'. ${ }^{3}$ For $x$, lenition meant a change to $h$, which was subsequently lost, though the sound is usually preserved in Runic, with loss securely attested only in wurte, wortaa, worte (East and West Norse, ca. 500-550) < *worxte 'made'. ${ }^{4}$ Loss of final $h$ is not in evidence until late in the tenth century; cf. *pōh (> OIcel. pó) 'though' (Go. páuh), borrowed into OE (> ME pōz). Vowels were lengthened before $x t(\$ 4.9)$, which developed to $t t$ at about the end of the PNorse period. Examples: átta '8' (Go. ahtáu), máttr 'might' (Go. mahts), réttr 'straight' (Go. raíhts), sótt 'sickness' (Go. saúhts).

Medially and finally there was voicing assimilation in consonant clusters, as in nom./acc. sg. neut. ljúft 'dear' (with [f]; cf. nom. sg. masc. ljúfr, with a voiced labial),

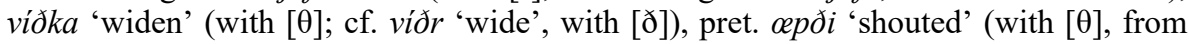

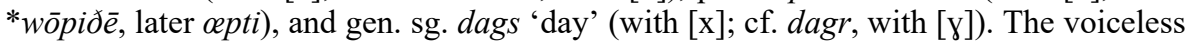
fricatives so produced frequently become stops, especially next to another fricative, by dissimilation, as in pret. fýsti 'urged' $<* f \bar{y} s-p i<* f u n s i ð \bar{e}(p)$, and in gen. sg. e(i)nskis 'no, none' $<*$ eins-zi-s. But fricatives in clusters with uniform place of articulation become stops (excluding $s$, which has no corresponding stop in Gmc.), at least after a stressed vowel, as in motti 'moth' (OE moppe), pret. gladdi 'gladdened' < *3lað-ið-è( $(p)$ and nom./acc. sg. neut. glatt 'glad' $<*$ glað-t. In addition, after a heavy syllable, $l ð$ that arose by syncope developed to $l d$, as in pret. deildi 'distributed' $<*$ dail-iðe $(p)$ and fylldi 'filled' < *full-iðé( $(p)$; but $\partial$ remained until about 1300 after a light syllable, as in malði 'ground' and valði 'chose'; compare halda 'hold', falda 'fold', with PGmc. *-lð- (§6.5). In addition, there was loss of $\partial$ before $n$ and sometimes $r$, as in beina 'assist' (related to beiða 'request'), Skáney 'Skåne' (OE Scedenig), nom. masc. fjórir '4' < *fjoðrir (and cf. the change to 3 between back vowels in neut. fjogur $<*$ feuður $<$ PNorse *feðuru, likewise in Old Norwegian laugur-dagr 'Saturday' ('bath-day'), with laugur- < lauður(cf. OE lēaðor 'soap', PDE lather). 
There is total assimilation to the sonorant consonant in the clusters $n p, l p, \delta l::^{5}$ finna 'find' (Go. finpan), sannr 'true' (with analogical re-addition of $-r$; cf. OE sōp < *sanpaz), hollr 'gracious' (again with $-r$ by analogy; cf. Go. hulps), ellri 'older' (Go. alpiza), á milli, earlier á miðli 'in the middle'. By most accounts, internally, nn produced by this means, or of any other source, changed to $\partial$ before $r$, as in acc. pl. masc. aðra 'other' < *annran(n) (Go. anparans) and maðr 'person' (dat. sg. manni; cf. OE man(n)), though Hale \& Reiss (2008: 238-43) argue for an analogical explanation. Geminates also result when a velar obstruent stands between a stressed short vowel and $j$, as in leggja 'lay' (Go. lagjan), gen. sg. bekkjar 'brook' (cf. OHG bah); but analogy has much disrupted the original distribution, so that geminate - $g g$ - and nongeminate $-k$ are commonly generalized (cf. liggr beside ligr 'lies', lykja 'shut in', rekja 'spread out', vekja 'wake up', etc.). ${ }^{6}$ There is also gemination of $k$ between a short vowel and $w$, as in slokkva 'extinguish' (< PGmc. *slakwjanan ${ }^{n}$, røk(k)r, rokkr 'darkness' (Go. riqis), and nøkkviðr 'naked' (OE nacod). Postconsonantal geminates are simplified, as in fagr 'beautiful' <*fagr-r, and jarl 'earl' < *jarl-l.

The sequence $n+$ voiceless stop became a voiceless geminate stop, and if the preceding vowel was $i$, it was lowered to e. Examples: kleppr 'lump' (cf. Old Swedish klimper), spretta 'cause to spring' (cf. MHG sprinzen), drekka 'drink' (cf. OE drincan).

A final obstruent after a stressed vowel was devoiced. Thus, pret. *gab 'gave' produces Runic gaf (cf. 1 sg. pres. gibu). Voiced stops appeared only after nasals and in gemination (except that $d$ occurred after $l$ : see above), and after devoicing, a preceding nasal was assimilated to the final stop (as above), hence imp. *bind 'bind', *gang 'go', *geald 'repay' > *bint, *gank, *gealt > bitt, gakk, gjalt, and pret. *band, *ging, *gald > batt, gekk, galt. Such preterites are generally well preserved, but relative uniformity of the stem in the present paradigm induced analogical imperatives like bind, gang, gjald. The assimilation of a nasal to a following voiceless stop also occurred internally, as in kappi 'champion' (cf. OE cempa), spretta 'spring' (MHG sprinzen 'break forth'; on the lowering of $i$ to $e$, see above), pekkja 'know' (Go. pagkjan).

There is widespread loss of final $n$, as in halda 'hold' (Go. haldan), acc. pl. gest 'guests' $<*$ gastinn $<*_{3}$ astinz; also when a vowel following in PNorse was lost, provided the preceding vowel was not short, as in pl. augu 'eyes' (Go. áugōna), 3 pl. sj. bindi (Go. bindáina), but acc. sg. masc. gōðan (Go. gōdana), innan 'from within' (Go. innana), with similar developments in unstressed words, e.g. $i$ 'in' (Go. in), frá 'from' (Go. fram), á 'on' (Go. ana).

On the loss of internal nasal consonants, with compensatory lengthening of the preceding vowel, see $\S 4.9$. On the development of $j j$ and $w w$, see $\S 6.10$. The handbooks (see $§ 1.14$ ) provide more detailed information about these and other changes.

1. But see the cautionary remarks of H.F. Nielsen (2000: 257-8). Antonsen (1975: 17) regards East Norse hideR- and hAidR- (cf. OIcel. heiðr 'clear') as further examples of this confusion, but given the coöccurrence of $\mathrm{OE} h \bar{a} d r$ - and $h \bar{x} d r$-, this is likelier to be in origin an s-stem (the usual analysis of the Runic forms, e.g. that of Krause 1971: §98): see Brunner 1965: §288 Anm.

2. Heusler (1967: §144) proposes that its articulation involved approach of the back of the tongue to the hard palate, accompanied by vibration of the tongue tip, whereas $r$ was supradental. Painter \& Dery (2014, with refs.), on the basis of an acoustic experiment, would identify the sound as $[z]$ at the time of umlaut.

3. The earliest examples of the confusion of $p$ and $\partial$ are in Runic inscriptions of the $8^{\text {th }}$ cent., uipR 'against' and upin (OIcel. Óðinn): see H.F. Nielsen 2000: 258-9.

4. Possibly also welA- (with $\bar{e}$ : Stentoften stone, Sweden, $1^{\text {st }}$ half of $7^{\text {th }}$ cent.), if OIcel. véla 'deceive' reflects *wixla- (so Antonsen 1975: 86). 
5. Heusler (1967: §158) regards $m m$ for earlier * $m f$ in OIcel. fimm ' 5 ' as a phonological development (in final position only?), even though it is unparalleled; $m f$ otherwise develops to $f$, with compensatory lengthening of the preceding vowel (see $\$ 4.9$ supra). More commonly the retention of $m$ in fimm is regarded as due to analogy, either to fimtán '15' or to the ordinal (see Prokosch 1939: §99a, Noreen 1970: §298.2).

6. Heusler (1967: $\S 187$ Anm. 1) dates this gemination after the syncope of the $7^{\text {th }} / 8^{\text {th }}$ cent. in forms like $*_{\text {sakja }}>*_{\text {seki }}>$ sekr 'outlaws', since such forms without gemination are required in the paradigm to explain the analogical degemination in a form like inf. sekja.

\subsection{West Germanic consonant gemination}

In the WGmc. protolanguage there was consonant doubling before sonorant consonants, though the regularity with which the change is attested varies according to the nature of the sonorant and of the geminated consonant, as well as of the length of the preceding vowel. ${ }^{1}$ Before $j$ the change regularly applies to any consonant other then $r$ (including $r$ $<z$ ) after a short vowel (and thus also not after a diphthong), though exceptions to this rule are characteristic of OHG, as discussed below. ${ }^{2}$ This $j$ is preserved in OS and generally written $\langle\mathrm{i}\rangle$; in the earliest OHG records it is usually written $\langle\mathrm{i}\rangle$ before $e$ or $u$, but $\langle\mathrm{e}\rangle$ before $a$ or $o$, and it disappears in the course of the $9^{\text {th }}$ century. Elsewhere in WGmc. it is lost after heavy syllables and thus can appear only after $r$, which failed to geminate before it. Gemination is regular before $j$, infrequent before $r, l$, rare before $w, m$. For a detailed survey, see Simmler 1974. Examples of gemination before $j$ are the following:

OE scieppan, OS skeppian, OHG scepfen: Go. skapjan, OIcel. skepja 'create'

OE sibb, OS sibbia, OHG sipp(e)a : Go. sibja 'relationship'

OE settan, OS settian, OHG sezzen : Go. satjan, OIcel. setja 'set'

OE biddan, OS biddian, OHG bitten : Go. bidjan, OIcel. biðja 'bid, request'

OE sæcc, OHG secka: Go. sakjō 'strife'

OE lecgan, OS leggian, OHG leggen : Go. lagjan, OIcel. leggja (\$6.14) 'lay’

OE fremman, OS fremmian, OHG fremmen: OIcel. fremja 'further, promote'

OE wennan, OS gi-wennian, OHG gi-wennen : OIcel. venja 'accustom'

OE sellan, OS gi-sellian, OHG sellen : Go. saljan, OIcel. selja 'hand over'

But $r(<$ PGmc. $r, z)$ remains ungeminated, with preservation of $j$ (or its reflex) ${ }^{3}$ after the light syllable, as in OE OS ferian, OHG ferien (but also ferren: see below), Go. farjan, OIcel. ferja 'travel, transport' and OE OS nerian, OHG nerien (also nerren), Go. nasjan 'save'. Examples of gemination before $r, l$ include the following:

OE snot(t)or, OHG snottar ${ }^{4}$ : Go. snutrs, OIcel. snotr 'wise'

OFris. ekker, OS akkar, OHG ackar (but OE æcer) : Go. akrs, OIcel. akr 'field'

OE (Northumbrian) æhher (but WS èar, OS ahar, OHG ehir) : Go. ahs, OIcel. ax 'ear (of grain)'

OE (Northumbrian) tæher (= tæhher, but WS tēar, OHG tahar) : Go. tagr, OIcel. tár 'tear'

OE æppel, OS appul, OHG apful : Crimean Go. apel 'apple'

Before $r, l$ the change is restricted to voiceless stops, except that $x$ may be geminated in Northumbrian. The OE forms without gemination are best explained as originating in the nom. sg., on the assumption that gemination took place only when a vowel followed the sonorant consonant; hence, e.g., PGmc. nom. sg. *akraz > WGmc. *akr, with later nuclearization of $-r(\S 5.6)$, but WGmc. dat. sg. *akr- $\bar{x}>* a k k r \bar{x}$, with generalization of the former stem in OE, of the latter elsewhere. ${ }^{5}$ 
Gemination is caused by $w$ only in the clusters $k w, h w$, i.e. clusters derived from PGmc. labiovelars, and the evidence derives almost exclusively from $\mathrm{OHG}$, as in $\mathrm{OHG}$ nackot 'naked' (cf. Go. naqaps, OE nacod, MLG naket), OHG acchus, OS accus 'axe' (beside OHG achus, OS acus = Mercian OE æces), and rare OHG sehhan beside sehan 'see' (Go. saíhan). ${ }^{6}$ Gemination before $m$ occurs in LWS $m \bar{a} p p m$ beside $m \bar{a} p m$ 'treasure' (Go. máipms). Thus, gemination before $w$ and $m$ is probably not to be ascribed to WGmc. as a whole, though Simmler 1974: 329-41 accepts the former as WGmc., not the latter.

Exceptions to the general pattern of WGmc. gemination are to be found in $\mathrm{OHG}$. First, forms with geminate $r r$ appear, chiefly in Alemannic, but also in Franconian, e.g. ferro 'ferryman', dat. pl. herrun 'hosts', gi-burren 'supervene' beside ferio, heriun, giburien. There are good reasons to believe that this change is peculiar to OHG, i.e. that it is not a WGmc. change later eliminated elsewhere. ${ }^{7}$

Second, OHG geminates are to be found after long vowels and diphthongs, almost exclusively in Upper German. ${ }^{8}$ Examples: teillen beside teilen, OE d̄̄lan, OS dēlian, Go. dáiljan, OIcel. deila 'distribute'; OHG auckan beside ougen, OE ìewan, ēawan, OS ōgian, Go. áugjan, OIcel. eygja 'show'; OHG gen. ke-rāttes beside nom. gi-

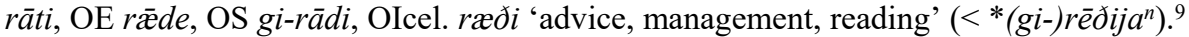
Such forms disappear from the later language, leaving only nongeminates after long vowels. At one time there was a fairly broad consensus that gemination applied after long vowels and diphthongs throughout WGmc., but that everywhere but in Upper German, degemination subsequently applied to geminates so produced: so, e.g., Prokosch 1939: $§ 30$, Krahe \& Meid 1969: I, §84, culminating in the exhaustive study of Simmler (1974), who found sufficient evidence outside of Upper German to convince him that the change was general in WGmc. Now there is much greater diversity of opinion: see Braune 2004a: $\$ 96$ Anm. 1 for references. A notable difficulty is that in accordance with Sievers' law, $j$ should have been nuclearized to $i j$ after a heavy syllable and thus incapable of inducing gemination, and $i j$ cannot have been denuclearized in the WGmc. protolanguage, given the evidence of $\mathrm{OE}$ forms like gydene 'goddess', without gemination (§2.5). A further difficulty stems from the observation that gemination does occur after a long vowel outside of OHG, but it is securely and widely attested only before $r$ or $l$ (probably with shortening of the vowel): cf. OE hluttor beside hlütor, OS OHG hluttar 'pure, clear' (beside (later) OHG (h)lūtar; cf. Go. hlütrs); OE lyttel beside lȳtel, OS luttil, OHG luzzil 'little' (cf. Go. leitils, OIcel. litill). The question arises why geminates should have been so thoroughly eliminated outside of Upper German in stems with original $j$, but not in these stems. It seems likelier that geminates after long vowels are found before $r, l$ because, unlike $j$, these sonorants were not nuclearized under Sievers' law. It may be assumed, then, that in a form like WGmc. *xlütr the vowel was shortened in the closed syllable, whereas in gen. *xlütras the syllable boundary fell between the vowel and consonant, and the tautosyllabic stem *xlüt-was then extended from the nom. to elsewhere in the paradigm. ${ }^{10}$ Such a development was not possible before $j$, since, e.g., PGmc. * ${ }^{*} \bar{e} \partial i j a z>$ WGmc. ${ }^{*} r \bar{x} \partial \bar{\imath}$. It should be mentioned, as well, that there appears to have been gemination after a long vowel in two OE weak verbs lacking original * $i$ - in the preterite $(\$ 12.37)$, recc(e)an 'care' (pret. rōhte) and læcc(e)an 'seize' (pret. lāhte, lāhte), and the result was not later degemination but vowel shortening. One significant factor that set the pattern for $\mathrm{OHG}$ geminates after long vowels was probably the High German consonant shift $(\$ 6.21)$, which converted some etymological non- 
geminates to geminates after long vowels, e.g. släf(f)an 'sleep', heiz(z)an 'call', dat. pl. boohhum, buochum 'books'.

It has long been recognized that gemination must have been motivated by syllable division (so, e.g., Prokosch 1939: §30), and most modern accounts, beginning with Murray \& Vennemann 1983, explain the patterns of change as governed by syllable contact laws, i.e. by a hierarchy of consonant sonority or, conversely, strength (see $\S 2.4$ ), regulating syllabification. Such accounts serve well to explain some aspects of gemination, such as why only voiceless stops were geminated before $r, l$ in WGmc., given that voiceless stops are the least sonorous consonants. They are less persuasive at explaining other aspects of the change, such as why $r$ is not usually geminated, especially in view of the gemination of $w$, which is more sonorous than $r$ on most sonority scales reconstructed for WGmc. For discussion of this last problem, with extensive references to the literature, see Suzuki 1989, Hall 2004.

Gemination before $j$ antedated the Second Sound Shift (\$6.21), as shown by forms like OHG setzen 'set' (OS settian) and skepfen 'create' (OS skeppian): cf. ezzan 'eat', släf(f)an 'sleep' (OS etan, slāpan). Such gemination is attested in Runic kunni (= $\mathrm{OE}$ cynn) on one of the Weser rune-bones, certainly West Germanic and to be dated probably to the fourth or fifth century (see Antonsen 2002: 315-28; also Findell 2012: $343,481-3$, with references). Some would date the change to as early as $200 \mathrm{CE}$, though H.F. Nielsen (2000: 243, 373, with refs.) favors a date in the fourth century.

1. The literature on gemination is extensive. For references to earlier studies, see Simmler 1974. Subsequent work includes Guinet 1981, Murray 1986, 1998, Seynnaeve 1987, Wagner 1989, Draye 1990b, Ham 1997-8, Denton 1998, Goblirsch 1999, Callender 2007.

2. A further exception, or seeming exception, is that the PGmc. sequence *-awj- is reflected without a geminate in NSGmc., e.g. OE hieg, OS hōi 'hay' < *hauj-; cf. the gemination in OHG houwi. On this problem see $\S 4.10 \& \mathrm{n} .1$.

3. Unmistakable signs of nuclearization of $j$ appear in WS, in spellings like generige (see Hogg \& Fulk 2011: §6.80), with similar developments in OS (Holthausen 1921: §171). On the fricativization of $j$ after $r$ in OHG, see n. 7 infra.

4. Note that OHG -tr- does not undergo the High German Consonant Shift (§6.21).

5. Krahe \& Meid (1969: I, §85) suppose rather that OE æcer resulted when $*_{-} r$ developed to *-er before gemination could take place; but this is unlikely, given that many postconsonantal final sonorants must be treated as still nonsyllabic in OE poetic meter (see §5.6), and thus æcer cannot be a very old form.

6. The form OE hweohhol 'wheel' is not infrequently cited in the handbooks, though a search for such a form produced no results. A. Campbell (1977: §408) cites hweohhol in evidence of OE gemination (before $w$ ? $l$ ? the stem is PIE * $k^{w} e k^{w} l o-$; cf. weak grade in Gk. $\kappa \hat{v} \kappa \lambda o \varsigma$ 'circle'), but Brunner (1965: §228) cites it as an example of the LWS gemination seen in, e.g., gen. sg. miccles beside micles 'large'; cf. not infrequent OE (-)hweohle(s).

7. It seems likely that $j$ had become a voiced fricative after OHG $r$, seeing as words like nerian 'save' are never spelt †nerean, though in $9^{\text {th }}$-cent. texts -ean is a common spelling for -jan after other consonants; and spellings like nergen are especially frequent. Likewise, though postconsonantal $j$ is still preserved in early texts, as attested by spellings like willeo 'volition' and gisellio 'companion', there are no spellings like †nerrian, with $i$ after geminate $r r$. See Braune 2004a: $\$ 118$ Anm. 3. This development perhaps sheds light on problematic OE hergian 'harry' < *xarjōjanan': see Hogg \& Fulk 2011: §6.118 n. 2.

8. Colin J. Grant kindly provided the projections from his paper 'The interaction of Sievers' Law and West Germanic Gemination in Upper German', 22 ${ }^{\text {nd }}$ Germanic Linguistics Annual Conference, University of Iceland, Reykjavík, 20 May 2016, from which the following discussion has benefited. Among other matters, Grant specifically discusses the obstacle that Sievers' law presents to the assumption of general WGmc. gemination after long vowels. 
9. Apparently, gemination could also apply to UG consonants after a nasal consonant, leading to doublets like MHG swinken swingen 'swing' and High Alemannic länten länden 'land': see Scheungraber 2013.

10. A detailed argument along these lines, to the effect that $\mathrm{OE}$ orthographic geminates are primarily an indication of syllabification rather than consonant length, is offered in Fulk 1998b, including a discussion of vowel shortening before geminates.

\subsection{Other consonant changes in the West Germanic protolanguage}

PGmc. $\partial$ developed to WGmc. $d$. Examples: OE fæder, OS fadar, OHG fater : OIcel. faðir 'father'; OE bēodan, OS biodan, OHG biotan : OIcel. bjóða 'bid, ask'; OE OS bìdan, OHG bìtan : OIcel. biða 'wait'.

It was once a common view that both $s$ and $z$ when final were lost in WGmc. (or that final $s$ developed to $z$ in WGmc. and was then lost), and even now this analysis has not been entirely abandoned. ${ }^{1}$ Under this hypothessis, apparent exceptions to the loss of $*_{-s}$ can be explained in various fashion: e.g., OE nom. pl. dagas 'days' (= Go. dagōs, OIcel. dagar) is often thought to reflect PGmc. ${ }^{*}$ dazōsiz, or similar, ${ }^{2}$ and so it may be supposed that the WGmc. loss of final ${ }_{-s}$ antedated the loss of $*_{-} i z$ in this form. Other exceptions are not so easily explained. ${ }^{3}$ The prevailing view, however, has always been that in WGmc. ${ }^{*}-s$ was preserved and ${ }^{*} z$ was lost. ${ }^{4}$ An exception to the rule is that ${ }^{*} z$ is retained and develops to $-r$ in light monosyllables in OHG and OLF (in the latter of which, e.g., wi coöccurs with wir 'we'). ${ }^{5}$ Given the coöccurrence of forms in the same inflectional classes with root and suffix accent in PIE (cf., e.g., Gk. ï $\pi \pi 0 \varsigma$ 'horse' beside $\pi о \tau \alpha \mu o ́ \varsigma$ 'river'), there must have been extensive variance between final ${ }_{-S}$ and $*_{-z}$ in PGmc. in words otherwise inflected identically. It appears that ${ }_{-} z$ was more commonly the variant that was generalized, with notable exceptions, though the evidence of Gothic is ambiguous. Leveling of one or the other variant in an inflectional class, however, must not have been completed in PGmc., or even in the WGmc. protolanguage, to judge by the divergent developments seen in, e.g., OHG nom. pl. tag $\bar{a}$ (= OIcel. dagar < $*$ dazōz) and OE dagas, OS dagos, -as $<*$ dazōs; likewise in OE 2 sg. sj. fare (= OIcel. farir $<*$ faraiz) and OS fares, OHG farēs $<*$ farais.

In all the WGmc. languages, as in North Gmc., there was lenition of medial fricatives wherever it was not prevented by an adjacent voiceless consonant. ${ }^{6}$ Lenition amounts to voicing of $f, b, s$, but $x$ is lenited to $h$ (if, in fact, the change of $x$ to $h$ is part of the same sound change, which seems most probable). The change does not apply to geminates, e.g. OE sippan 'after(ward)' <**īp-pon and lāssa 'less' < PGmc. *lais-iz$\hat{o}^{n}$, with voiceless geminates. This change must not be dated to the NWGmc. period, and it must postdate the WGmc. change of PGmc. $\partial$ to $d$, since $b$ lenited to $\partial$ does not become $d$. It is best regarded as a change that took place in each of the WGmc. languages, since, for example, $x$ appears not to have been lenited in forms like OE slieht

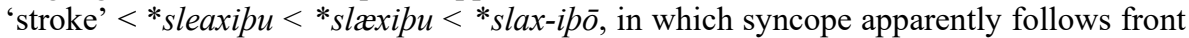
umlaut, which in turn must follow the specifically OE change of breaking of $x$ to ea (but see the discussion of problems related to verbs in $\S \S 12.38,12.43$ ). Moreover, the usual assumption is that $x$ had not yet been lenited when breaking occurred (§4.13), yet the results of breaking in OE and OFris. are not identical.

Although $w$ was lost before $u$ in PGmc. (\$6.11), the sequence *-wu-could arise again, and in such instances $w$ was again lost, though it could be restored analogically to reduce paradigm allomorphy. Examples are OE fēa 'few' $<*_{f a u}<* f a w u<* f a w \bar{o}$, 
beadu 'battle' < *badwu < *baðwō, and dat. pl. smerum 'grease' (Lorica Glosses) beside analogical smeorwum. This change may have occurred in Proto-NWGmc. (see $\S 6.14)$. Note that although postconsonantal $j$ is for the most part lost in the WGmc. languages (\$6.15), $w$ was preserved in the WGmc. protolanguage even after heavy syllables when followed by a vowel, as in OE gen. sg. lǣswe 'pasture'. An exception is that $w$ is lost after a heavy syllable when it follows a velar consonant, as in OE OS OHG singan 'sing' (cf. Go. siggwan, OIcel. syngva, and see $§ 1.8$ n. 2). Moreover, after the Proto-WGmc. period, postconsonantal $w$ appears to have been lost in OS and OHG after a heavy syllable, as there are no heavy-stemmed consonant-final $w a$ - or $w \bar{o}$-stems in these languages. On this and some other environments in which $w$ was lost, the grammars cited in $\S \S 1.15-20$ should be consulted.

1. Such is the view of Braune (1876: 156), Hirt (1894: 527-8), Streitberg (1896: §214), Walde (1900: 130), van Helten (1902: 534), Prokosch (1939: §49d), and Bammesberger (1986a: 47-8). Boutkan (1995b: 43-51), with references to earlier, similar views (e.g. Meillet 1922: 82), argues that PIE final $s$ always yielded PGmc. $z$, regardless of the place of the accent. Some forms that lend strong support to his position, because they are hard to explain as analogical, are $\mathrm{OE} s \bar{u}$ 'sow', $c \bar{u}$ 'cow', and $m \bar{a}$ 'more'. See further Mańczak 1996.

2. So Hirt 1894: 528 , but see $\$ 7.8$.

3. Boutkan (1995b: 46) identifies six such exceptional endings in WGmc.: (1) OS consonant stem gs. -as, -es; (2) pres. sj. 2 sg. OS -es, OHG -ēs; (3) pret. sj. 2 sg. OS -is, OHG -iss; (4) o-stem nom. pl. OE -as, OS -os; (5) OHG 1 pl. -mès; weak pret. 2 sg. OE OS -des, OHG -tōs.

4. First to express this view was perhaps Paul (1879-80: VI, 550). Representative are the views of Luick (1914-40: §629), Krahe \& Meid (1969: I, §§115-16), and Ringe (in Ringe \& Taylor 2014: 43-4). On the date of this loss, see above, $§ 5.6$ n. 6 .

5. H.F. Nielsen (2000: 249; so earlier Luick 1914-40: §629.1) assumes loss of $-z$ in unstressed monosyllables but retention in stressed, and that $\mathrm{OHG}$ has generalized the latter variant, the other WGmc. languages the former. Ringe (in Ringe \& Taylor 2014: 86) rejects this idea because of the loss of $*_{-} z$ in stressed monosyllables like OE $m \bar{a}$ 'more' < *maiz and $c \bar{u}$ 'cow' (cf. OIcel. kýr). He thus argues that final $z$ was lost categorically in WGmc., except that it is preserved in monosyllables in the southern part of the WGmc. Sprachraum, and he offers explanations for the apparent OHG exceptions. OS (like OHG) shows retention in merr 'more', perhaps under OHG influence.

6. For discussion and a review of the literature, see Goblirsch 2005: 83-96.

\subsection{Consonant changes in North Sea Germanic and Anglo-Frisian}

Medial NSGmc. *-lb- changes to - $l d-$, which is later extended to final position. Examples: OE OFris. OS gold: Go. gulp, OIcel. gull, OHG gold $(<* 3 u l b, \S 6.22)$ 'gold'; OE OFris. wilde, OS wildi : Go. wilpeis, OIcel. villr, OHG wildi 'wild'; OE OFris. OS hold : Go. hulps, OIcel. hollr, OHG hold 'gracious, loyal'. A few forms with final -lp are still to be found in early OE, e.g. Balth- (in names: 'bold'), -felth (in place-names: 'field': see Brunner 1965: §201 Anm. 2, misconstrued in Braune 2004a: §162 Anm. 1).

NSGmc. $n$ is lost before a voiceless fricative, with compensatory lengthening (and nasalization) of the preceding vowel, as in OE müð, OS mü (beside mund) : Go. munps, OIcel. munnr, muðr, OHG mund 'mouth'. See $\S 4.11$ for further examples.

In NSGmc. and neighboring dialects there is metathesis of $*_{-s l} l$ to $-l s$ - between unstressed vowels, as with OE dat. sg. Ead-gilse (name: 'wealth-hostage') <*-zīslē; cf. OIcel. Gisli (name). See de Vaan 2012.

It cannot be determined for certain whether palatalization of velars by front vowels occurred in the Anglo-Frisian protolanguage or independently in English and Frisian, but it is not unlikely that it did occur early (see Fulk 1998a: 145-8, with refs.). 
It may in fact have taken place in the Ingvaeonic protolanguage, given certain OS spellings (\$6.20). If so, it must be assumed that the subsequent change of affrication (or 'assibilation': $\S \S 6.18-19)$, which is found in OE and OFris. but not OS, did not affect all palatal stops, or that some palatal stops reverted to velars before affrication could occur. The fricative 3 was palatalized initially before a front vowel, medially before (not after) a front vowel, and in the syllable coda after one. This palatalized 3 eventually became $j$ or the off-glide of a front diphthong. Examples: OE gieldan, OFris. ielda 'pay'; OE gēotan, OFris. iāta 'pour'; OE hyge, OFris. hei 'thought' (cf. OS hugi); OE dæg, OFris. dei 'day'; OE bregdan, OFris. breida 'pull'; but OE siggan, OFris. pres. sigga 'sink', with the velar sound. As a result, OE shows paradigm alternation, e.g. hälig, hālge holy' with the palatal sound and $h \bar{a} \lg u(m)$ with the velar. Unless palatalization is dated later than the Anglo-Frisian period, it must be assumed that Frisian has almost entirely eliminated such alternations (cf. OFris. hēlich, hēlega), an exception being ielda : pp. gulden. As for the velar stops, it is impossible to be certain that they were palatalized unless they were later affricated, and affricates are not distributed identically in the two languages: see $\S \S 6.18-19$, and see further van der Rhee 1977.

In a fashion complementary to the voicing of fricatives between voiced sounds in the WGmc. languages, there was fortition (devoicing) of final fricatives in the Ingvaeonic languages. Examples are pret. OE geaf, OFris. ief, OS gaf 'gave' <* $3 a b$; OE burh, burg, OS burg, burch 'fortress', ${ }^{1}$ OFris. berch, dat. berge 'mountain'. This change probably occurred independently in OE, OFris., and OS, given that $b$ is still used finally in early OE texts to represent the reflex of PGmc. $\hbar$, whereas PGmc. $f$ is represented by $f$, e.g. $o b$ 'from', salb 'ointment' : wulf 'wolf', fif 'five' (see Brunner 1965: §191, and cf. A. Campbell 1977: §446). It is possible, however, that the distinction marks an opposition between bilabial and labiodental articulation rather than a voicing difference (so, e.g., Luick 1914-40: $\S 651.2$ ). But since the use of $h$ for etymological 3 is at first rare and then increases over the course of the OE period (A. Campbell 1977: §446), final devoicing is probably a convergent development in the Ingvaeonic languages.

1. Such OE and OS spellings with $g$ (which are the norm in OS) rather than (c) $h$ are due to the influence of inflected forms, e.g. OE OS burga. Note that PGmc. $z$ and $\delta$ had already changed to $r$ and $d$, so that devoicing did not apply.

\subsection{Consonant changes in Old English}

The palatal variety of 3 merged with $j$ by ca. 950 at the latest (see Minkova 2003: 11320). Certain palatal varieties of $k$ and $g$ likewise became the affricates $/ \mathrm{t} /$, usually spelt $\langle\mathrm{c}\rangle$, and /dz/, usually spelt $\langle\mathrm{cg}\rangle$, or simply $\langle\mathrm{g}\rangle$ after $n$, assuredly by ca. 1000 , but not all the palatal stops assumed above (\$6.17) to have arisen in Anglo-Frisian were affricated in OE. Palatalized $k$ is always affricated initially, as in ceald 'cold', ceorl 'churl', cirice 'church'. There was no palatalized $g$ in initial position, since PGmc. 3 was still a fricative initially at the time of palatalization, the velar variety becoming a stop in WS probably ca. 950 . Medially before vowels and finally, palatal stops were affricated only after $\breve{l}$ (but not before a back vowel) or when the preceding vowel had undergone front umlaut, meaning that the stop had earlier been followed by $\breve{\bar{l}}$ or $j .{ }^{1}$ Note that the palatal stop $g$ occurred only after a nasal consonant or in gemination. Examples: dīc 'ditch, dike' (but not in dat. pl. dīcum), finc 'finch', wyrc(e)an 'work' $<*$ wurkijana ${ }^{n}$, dat. pl. bencum 'benches' < *baykijum; leng 'longer' < *layg-iz, ecg 'edge' < *aggju < *azjō, 
meng(e)an 'mix' $<*$ maygijana ${ }^{n}$. There must then have been reversion to velarity in the remaining sounds assumed in $\$ 6.17$ to have been palatalized in Anglo-Frisian, e.g. bæc 'back', gen. sg. freces 'bold'. Certainly there was reversion when syncope rendered the palatal sound anteconsonantal, as in $s \bar{e} c p$ 'seeks' (but with an affricate in inf. sécan; cf. PDE seek: beseech), gen. sg. micles 'large' (but with an affricate in micel $<*$ mikilaz). As for PGmc. ${ }^{*} s k$, this developed eventually to $/ \mathrm{J} /$ (perhaps [ $\left.\int \mathrm{]}\right]$ intervocalically) even in many non-palatal environments. It is preserved as $/ \mathrm{sk} /$ only medially before a back vowel or finally after one, as in dat. pl. Deniscum 'Danish' and tüsc 'tusk, tooth'; otherwise it is palatal, as in Denisc, sculan 'shall' (but /sk/ in scōl 'school', borrowed from Lat.), scop 'poet'.

The sound $h$, the lenition of $x$, was lost between voiced sounds in OE, as in séon 'see' < *seohan and gen. sg. mēares (beside nom. mearh 'horse'), the latter, gen. form with compensatory lengthening. For further examples and discussion of the resulting changes in proximate vowels, see $\$ 4.13$. This change has significant consequences in some morphological categories, especially verbs: see $\$ 12.21$. Although this loss likewise occurred in OFris., it cannot plausibly be dated to the Anglo-Frisian period

Whereas WGmc. gemination before $r, l$, affected only voiceless stops, the change was extended to other obstruents in OE. Above were mentioned xhher and māppm (§6.15); OE $d$ (the only voiced stop that could occur between a vowel and $r, l$ ) was also affected, as in $æ t g x d(d) r e$ 'together', probably with vowel shortening in næddre 'adder'

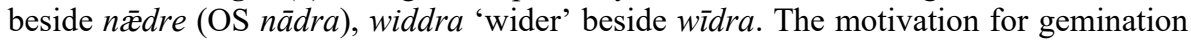
in some such forms with an etymologically long vowel is obscure, since words like $n \bar{x} d r e$ and widra were never uninflected, and thus the gemination cannot be explained the way that WGmc. gemination in OE hluttor, lyttel was explained above (\$6.15). Perhaps the paradigm alternation hlütor $\sim$ hluttr-, with later mixture of stems, leading to forms like hluttor and reintroduced hlütr-, gave rise to analogical alternations in similar stems. In OE there also arose new geminates due to the creation of new clusters of stop plus liquid due to late syncope, hence bet(t)re 'better' (Go. batiza), gen. sg. mic(c)les 'large' (Go. nom. mikils).

A number of other OE consonant changes, such as metathesis (esp. of $r$; see Nakao 1986), epenthesis (see B.R. Page 1997), deletion in clusters, and simplification of geminates between unstressed vowels, are less regular, may be dialectically restricted, and have fewer consequences for morphology. The handbooks cited in $\$ 1.16$ may be consulted for details.

1. As the phrase "had earlier been" implies, the assumption here is that affrication took place late, long after the loss of such umlauting segments in many environments, and therefore palatals other than those eventually affricated had reverted to velars by the time of affrication.

\subsection{Consonant changes in Old Frisian}

The affricates derived from the palatal varieties of Anglo-Frisian $k, g$ are $t s, d z$, respectively. The distribution of affricates in OFris. and $\mathrm{OE}$ is similar but not identical: compare OFris. kāp 'purchase' (from Lat. caupo 'shopkeeper'), tsiurke 'church' (<

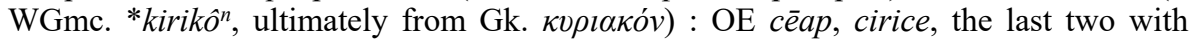
only affricates. Almost certainly, then, affrication took place independently in the two languages, though palatalization may still be assumed for the Anglo-Frisian period, with subsequent, minor changes in the distribution of palatals. Most affricates in OFris. 
correspond to OE affricates, e.g. OFris. tsiāk 'cheek' (OE cēace), sprētse 'speech' (OE sprǣce), sedza 'say' (OE secgan), mendza 'mix' (OE meng(e)an). Unlike in OE, PGmc. *sk remains as such in all positions, e.g. skeft 'shaft' (OE sceaft), fisk 'fish' (OE fisc), flāsk 'flesh' (OE flāsc).

As in OE, there is lenition and later loss of $x$ between voiced sounds in OFris., with resulting contraction of neighboring vowels ( $\$ 4.14)$.

Final - $n$ was usually lost, as in lidza 'lie', $d w \bar{a}$ 'do', nom. pl. tunga 'tongue', hwona 'whence', binna 'inside'. It is retained in cardinal numbers, e.g. èn, àn 'one', si(u)gun 'seven' and at the end of a weak-inflected initial constituent of a compound, e.g. Sunnandei 'Sunday'.

As in OE, there is metathesis of $r$ with a short vowel, with movement in either direction, e.g. gers 'grass' (Go. gras), bren 'child' (beside bern; OE bearn).

\subsection{Consonant changes in Old Saxon}

Voiced stops are devoiced in syllable-final position (and thus also word-finally), as shown by occasional spellings like dump beside dumb 'dumb'; so also giwalt 'control', punt 'pound', thinclīk 'parliamentary'.

As in OE, there is loss of $h$ between voiced sounds, but $h$ may still be retained in early texts, e.g. acc. sg. masc. höhan in the Heliand, later hoan.

Spelling evidence also indicates that velar consonants were palatalized before front vowels. The sequence $k e$ is not seldom written kie, as in kiennian 'know', gihwilīkies 'any', kiēsur 'emperor'. Likewise, palatalization of initial 3 is indicated in ieldan 'pay' and ie-givan 'given', by the occasional representation of the prefix gi- as $i$-, and by infrequent medial loss before $i$, as in gein beside gegin 'against' and eislik beside egislikk 'terrible'. Compare also inverted spellings like giungaro beside iungaro 'disciple'. It is generally assumed that initial velar 3 has become a stop in OS.

\subsection{The High German Consonant Shift}

The most salient aspect of the OHG consonant system is a shift in the value of stops as extensive as the shift under Grimm's law; the High German shift is thus often referred to as the Second Sound Shift. The second shift, however, is less unconditioned than the first appears to have been, its results varying by position in the word, by geminate or nongeminate status of the consonant, and by dialect. The general pattern is that a PGmc. voiceless stop is reflected as an affricate before a vowel, i.e. initially, after a medial sonorant consonant, or when geminate (either medially or finally); otherwise it is reflected as a fricative, i.e. after a vowel medially or finally. Or to put this in reverse fashion, a PGmc. voiceless stop is usually reflected as a fricative after a vowel (medially or finally), though it is reflected as an affricate initially, after a medial sonorant consonant, or in gemination. The shift of the voiceless stops at its greatest extent may be tabulated as in Figure 6. Here $p f, p h$ represents an affricate /pf/. In initial position, $z$ represents an affricate /ts/, which is also the shifted value medially or finally of the geminate $t t$ and of $t$ after a sonorant consonant; otherwise, in medial or final position the shifted value of $t$, spelt $z(z)$, represents a voiceless fricative, the value of which is not precisely determinable. ${ }^{1}$ Initial, medial, and final $c h, k h$ represents an affricate $/ \mathrm{kx} /$ or $/ \mathrm{kh} /$, which is also 


$\begin{array}{lcccccc}\text { Position } & \mathbf{p} & \text { pp } & \mathbf{t} & \mathbf{t t} & \mathbf{k} & \mathbf{k k} \\ \text { Initial } & \mathrm{pf}, \mathrm{ph} & & \mathrm{z} & & \mathrm{ch}, \mathrm{kh} & \\ \text { Medial } & \mathrm{f}, \mathrm{ff} & \mathrm{pf}, \mathrm{ph} & \mathrm{z}, \mathrm{zz} & \mathrm{zz}, \mathrm{tz} & \mathrm{h}, \mathrm{hh}, \mathrm{ch} & \mathrm{cch} \\ \text { Final } & \mathrm{f} & \mathrm{pf}, \mathrm{ph} & \mathrm{z} & \mathrm{z}, \mathrm{tz} & \mathrm{h} & \mathrm{ch}\end{array}$

Fig. 6. The High German shift of voiceless stops at its greatest extent.

the value of the shifted geminate and of $k$ after a sonorant consonant; otherwise, in medial or final position the shifted value of $k$ is $/ x(:) /$. The nongeminate voiceless stops are shifted to geminate voiceless fricatives in non-initial position; and the geminate is regularly degeminated finally and before consonants. After long vowels, degemination is much less regular, becoming more uniform over time. There is no shift after a fricative $s, f, h$, e.g. sprehhan 'speak', haspil 'reel', scama 'shame', miscen 'mix', stein 'stone', ist 'is', naht 'night', luft 'air'. Likewise, PGmc. $t$ remains unshifted in the consonant cluster $t r$, as in trüēn 'believe', and medially $t$ is geminated before $r(\$ 6.15)$, as in snottar 'wise' (Go. snutrs).

The results of the shift of voiceless stops, as well as of the other changes discussed below, are most extensive in the southernmost part of Upper Germany, with decreasing incidence to the north. The change of medial and final $p, t, k$ to the fricatives $f(f), z(z), h(h)$ is common to all dialects, as is the affrication of $t$ to $z(/ \mathrm{ts} /){ }^{2}$ The affrication of $p(p)$ to $p f$ is found only in UG and East Franconian, except that it occurs in Rhine Franconian after a liquid, e.g. helpfan 'help', werpfan 'cast', later helfan, werfan. The shift of $k(k)$ to an affricate occurred only in UG; the affricate (c) ch, $k h$ occurs today only in the south of Switzerland and Austria (with simplification to a fricative as far north as Freiburg), though it appears to have been used throughout the UG area in OHG times. Examples:

p(p): As affricate: OHG pfenning 'penny' (but Middle Franconian penning), skepfen 'create' (skeppen), helpfan 'help' (> helfan, but Middle Franconian helpan), chapf 'height', to which cf. OS penning, skeppian, helpan, OE cæppe 'cap'. As fricative: OHG släf(f)an 'sleep', skif 'ship' : OS slāpan, skip.

t(t): As affricate: OHG ziohan 'draw', setzen 'set', herza 'heart', holz 'wood' : OS tiohan, settian, herta, holt. As fricative: OHG ezzan 'eat', hwaz 'what' : OS etan, hwat.

k(k): As affricate: OHG khorn, chorn 'grain' (UG; CG korn), wec(c)hen 'waken' (UG; CG wecken), t(h)enchen, denchen 'think' (UG; CG th)enken, denken), star(a)ch 'strong' : OS korn, wekkian, thenkian, stark. As fricative: OHG mahhōn 'make', ih 'I' : OS makon, ik.

As elsewhere in WGmc., PGmc. $\partial$ became (at first) OHG $d$; in addition, the other voiced fricatives, $b, 3$, became stops $b, g$ in all positions. ${ }^{3}$ These stops $b, d, g$ could then shift to $p, t, k$, but to a different extent in different dialects. The stop $d$ is shifted to $t$ in all dialects except Middle and Rhine Franconian, as in dohter 'daughter', bidden 'bid', biodan 'offer', otherwise OHG tohter, bitten, biotan. The stops $b$ and $g$, on the other hand, are frequently written $p, k$ in UG, especially initially, and particularly in Bavarian, but starting in the $9^{\text {th }}$ cent. in Alemannic and in the $10^{\text {th }}$ in Bavarian they start to be written $b, g$ except where geminated, though the older spellings are still to be found, as well, as late as the $16^{\text {th }}$ century. Early UG forms thus include peran 'bear', kepan 'give', stīcan 'ascend', sippa 'kinship', (h)rucki 'back', later beran, geban, stīgan, sippa, rucki. The usual assumption, then, is that in Upper German there was no voicing contrast in 
obstruents, only contrasts of length and of manner of articulation (stop : fricative : affricate; see Kraehenmann 2003: 61-7). The handbooks cited in $\S 1.20$ should be consulted for details, and for discussion of what the phonological significance of these UG orthographic changes might be.

The results of the High German shift were mapped in the $19^{\text {th }}$ cent. and played a significant role in the differentiation of NHG dialects represented in Figure 7. The isoglosses plotted there have plainly shifted some since OHG times (see $\$ 1.20$ ), but for the most part the modern diatopic distribution of the results of the shift appears to be congruous with the $\mathrm{OHG}$ and (much more secure) $\mathrm{MHG}$ evidence. Line A in the figure represents the Benrather Linie (named after a village that is now a district of Düsseldorf), marking the northernmost limit of the shift (machen : maken); line B represents the Speyerer Linie (named after the city of Speyer; sometimes also called the Main line, after the river), marking the border between Upper and Central German (Apfel : Appel).

Several aspects of the shift have generated considerable controversy, especially the shift of the voiceless stops. The commonest assumption (as proposed by Braune 1874b: 49-50) is that the shift began with aspiration of voiceless stops, with subsequent conversion of aspirates to affricates, which then after vowels were simplified to fricatives, hence, e.g., $p>p^{h}>p f(>f f)$. Alternative views are summarized concisely by Braune (2004a: $\$ 90$ Anmm. 2-3). The date of the shift's origin and the manner of its spread, two closely related issues, are matters of greater controversy. The view of the

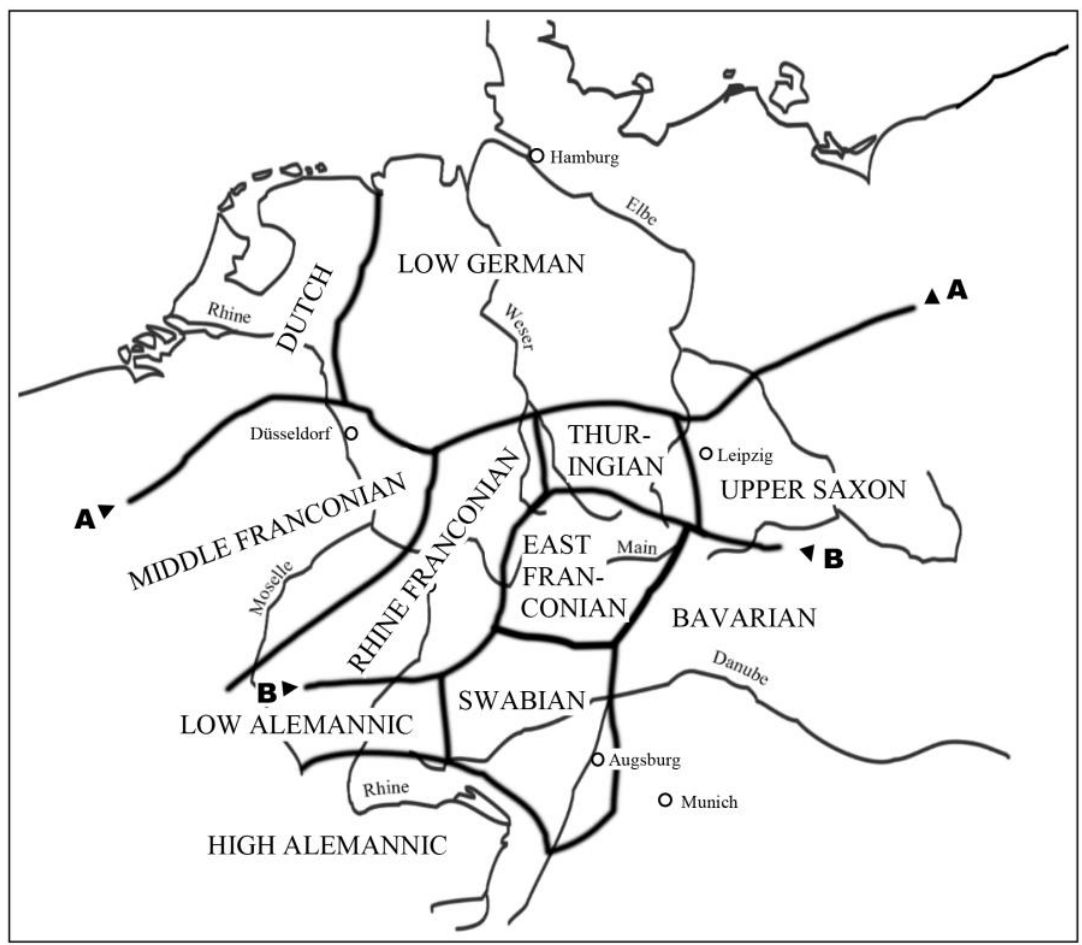

Fig. 7. New High German Dialects. Line A represents the Benrath line, differentiating High and Low German; line B represents the Speyer line, distinguishing Upper and Central German. See also $\$ 1.20$. 
majority, again established by Braune (1874b), is that the shift originated in UG, in the area where its effects are most extensive, and as it spread northward it gradually affected fewer sounds. The pattern of spread would thus be like that for the change of $p$ to $d$, which can be traced over the course of the OHG period (\$6.22). Yet it has also been argued that the change spread from north to south, or from the west; or that the shift was polygenetic in origin, arising in more than one related dialect (the Entfaltungstheorie, originating with Höfler 1955-56); or that the change initially produced the same results in all $\mathrm{OHG}$ dialects, but that there was a creeping 'creolization' of CG dialects under NSGmc. influence (so Vennemann 1987a: 48-53, and elsewhere); or that it originated in a Gallo-Romance substrate (Lange 2003, Schrijver 2011). See Goblirsch 2005: 13781 for summary, discussion, and bibliography pertaining to these issues, and subsequently Callender 2012, 2017. The shift has been dated as early as the $1^{\text {st }}$ cent. BCE, but the majority view is that it occurred in the $6-8^{\text {th }}$ centuries $\mathrm{CE}$; for a summary of views, see Vennemann 1994a. Vennemann (e.g. 1984b) has also argued in various publications that the shift can best be explained on the basis of the glottalic theory (\$6.2), advocating very early dating and a centuries-long process of adaptivity and sound substitutions to account for application of the shift to Lat. loans, e.g. Zürich, from Lat. Turicum. ${ }^{4}$ For a thorough review of scholarship on all aspects of the shift, see Schwerdt 2000.

1. This sound is distinguished in spelling from the reflex of PGmc. $s$ until late in the MHG period. The latter was probably postalveolar, given that it has become $/ \mathrm{J} /$ initially before a consonant, and given that $\mathrm{OHG}$ texts from Freising represent Slovene $/ \int, z /$ as $\langle\mathrm{s}\rangle$ and $/ \mathrm{s}, \mathrm{z} /$ as $\langle\mathrm{z}\rangle$ (Braune 1874a). In that event, perhaps $z$ was simply [s], reduced from [ts]. For discussion and references, see Penzl 1986a: 38-9. Although $\langle\mathrm{z}(\mathrm{z})\rangle$ may usually stand for either the fricative or the affricate, in Isidor the sounds are distinguished, the affricate being represented by $\langle\mathrm{z}\rangle(\langle\mathrm{tz}\rangle$ when geminated), the fricative by $\langle\mathrm{zss}\rangle$ ( $\langle\mathrm{zs}\rangle$ when final). Likewise, in some manuscripts the affricate is represented by $\langle c\rangle$ (Braune 2004a: §157). And of course the fricative and the affricate are distinguishable on the basis of modern reflexes.

2. But Middle Franconian preserves final stops in the words dat, it, wat, the inflection -et, and (in part) $u p$.

3. An exception is Middle Franconian, where the development of $b$ agrees with that in OS: except initially, after $m$, and in gemination, where it had already developed to $b$, it remained $b$ except when devoiced (i.e., next to a voiceless sound or finally); hence gevan 'give', pret. gaf, otherwise CG geban, gab.

4. Vennemann's position has met with much criticism: see Braune 2004a: $\$ 90$ Anm. 6 for bibliography. A supporter is L.C. Smith (1996); an opponent is Schwerdt 2000: 177-89; see further Schwerdt 2002.

\subsection{Other consonant changes in Old High German}

As noted in $\S 6.21$, unlike in Ingvaeonic, PGmc. $\hbar$ and 3 become stops $b$ and $g$ in all positions in OHG, except in Middle Franconian, and in UG these are commonly represented as $\langle\mathrm{p}\rangle$ and $\langle\mathrm{k}, \mathrm{c}\rangle$.

The reflex of PGmc. $p$ is usually spelt $\langle\mathrm{d}\rangle$ (also $\langle$ th, $\mathrm{dh}\rangle$ ) already in the earliest Bavarian texts, and the gradual spread of the change east- and northward is traceable in the OHG records, appearing finally in Middle Franconian in the $11^{\text {th }}$ century. In this last dialect, then, it fell together with $d$ from PGmc. $\partial$, which was not shifted to $t$ in Middle Franconian, as in UG and East Franconian, and variably in Rhine and South Rhine Franconian. Presumably, $b$ passed through the stage $\partial$ in the process of becoming OHG $d$, and this is apparently what relatively infrequent spellings with $d h$ represent. Examples: dorn 'thorn' (Go. paúrnus), bruoder 'brother' (Go. brōpar), ander 'other' (Go. anpar), tōd 'death' (Go. dáups). When geminate, however, $p p$ (like $d d$, §6.21) becomes $t t$, as in smitta 'smithy' (OE smibpe). 
Devoicing of final voiced stops (final fortition, Auslaut(s)verhärtung) is frequently in evidence in Franconian, especially in Isidor and Tatian, rarely in Otfrid; yet it is hardly universal, and $d$ from PGmc. $p$ is always written $d$. Due to the development of the voiced stops in UG, the extent of devoicing cannot be reliably gauged.

Notker evinces a pattern of voicing alternations in initial stops under sandhi conditions, a pattern known as Notkers Anlaut(s)gesetz 'Notker's law of initials'. He uses $\langle\mathrm{b}, \mathrm{d}\rangle$ (the latter from $p$ ) and $\langle\mathrm{g}\rangle$ to represent stops when the preceding word ends in a vowel or a sonorant $r, l, m, n$; otherwise he writes $\langle\mathrm{p}, \mathrm{t}, \mathrm{k}\rangle$, i.e. either when the preceding word ends in an obstruent (etymologically either voiced or voiceless), or at the start of a sentence. OHG $t$ derived from PGmc. $d$ does not participate in the alternation. The usual explanation is that OHG $b, d, g$ are voiceless lenes, and writing $\langle\mathrm{p}, \mathrm{t}, \mathrm{k}\rangle$ (usually representing voiceless fortes) expresses neutralization of the contrast between lenis and fortis stops after an obstruent. It naturally follows that $\mathrm{OHG} t(<d)$, a fortis, would show no alternation. For discussion of this and alternative views, with a bibliographical overview, see B.R. Page 2013; also Luxner 2015. 

MORPHOLOGY 



\section{Nouns}

\subsection{Noun formation in Proto-Indo-European and Germanic}

In the IE protolanguage, nouns were inflected for (probably) eight cases (nominative, vocative, accusative, genitive, ablative, dative, locative, instrumental; perhaps also allative) and three numbers (singular, dual, plural), as in Sanskrit. Each nominal form was composed of stem plus inflection, e.g. stem *pod-plus case inflection ${ }^{*}-m={ }^{*}$ pod$m>$ Gk. acc. sg. $\pi \delta \delta \alpha \alpha$ 'foot'. The stem might be a simple root, as in the example given, or the stem might be a root plus one or more suffixes, e.g. * $\hat{g} e n h_{1}-e s-$ in Lat. gen. sg. generis 'family' (cf., with different suffixes, Lat. gen. sg. gen-ti-s 'nation', co-gnā-t-us 'related by birth') and * genhh-e-tōr- in Lat. gen. sg. genitōris 'progenitor'. The commonest class of nouns comprised masc. and neut. stems ending in a vocalic suffix of the form *-e- or (more commonly) *-o- (which might or might not be attached to a consonantal suffixal onset), a suffix called the 'theme vowel' or 'thematic vowel' (a conveniently abstract term, given the alternation $e / o$ ), and hence the category is referred to as

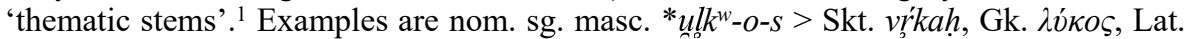
lupus 'wolf' and neut. *ing-o-m > Hittite yukan, Skt. yugám, Gk. soyóv, Lat. jugum 'yoke'. Stems without the theme vowel are all said to belong to athematic classes, except that $\bar{a}$-stems are an ill fit with either category. ${ }^{2}$ The different PIE stem classes will be examined below in connection with the Germanic classes descended from them.

By the time of late PIE some of the transparency of the distinction between stem and inflection had been lost (see, e.g., Kastovsky 1995: 228). In part this is because inflections, though similar, were not identical across stem classes: e.g., the nom. sg. masc. and fem. inflection ${ }^{*} s$ was not used in the $r$-, $\bar{a}$-, and $\bar{l}$-stems, and the nom./acc. sg. neut. inflection *- $m$ was used in $o$-stems but not $s$-stems. More significant, in many stem classes the juncture between stem and inflection had become obscured: e.g., the dat. sg. ending $*_{-} e i$ had in the thematic stems melded with the theme vowel $*_{-o}-$ to give the unitary inflection *-oi $i$, with the result that, at least in the dative, the stem could no longer be said to end in the theme vowel. By the time of the earliest attested Germanic languages this fusing of inflections and stem endings has proceeded so far that the original points of juncture are no longer plainly recognizable: for example, among the $n$-stems in Gothic the inflection has attracted to itself what was originally the -en-/-onsuffix attached to the stem, so that acc. sg. masc. *men-on-m has become Go. mēn-an 'moon', in which the original inflection has been lost altogether, and what was originally a stem-forming suffix has become an inflection. The result was a declensional system in which inflections differed a great deal from one noun class to another. Such changes ought to have terminological consequences for the analysis of Germanic: if - an in ménan is an inflection, the category is no longer literally the class of $n$-stems, since most such stems do not end in - $n$ - (nom. $a h-a$ 'mind', att- $a$ 'father', etc.). However, some stem classes in Germanic retain their PIE characteristics: $r$-stems, for instance, do 
still have stems ending in $-r$-. Noun classes in Germanic are thus not wholly classifiable, synchronically, on the basis of either stem formation or the suffixes attached to the stems. Accordingly, it is both convenient and conventional to retain the stem-categories of PIE in reference to Germanic ( $r$-stems, $s$-stems, etc.), making only such adjustments as are required by Gmc. phonology (e.g., $a$-stems rather than $o$-stems, due to the change of PIE $* o$ to Gmc. $a$, and $\bar{o}$-stems rather than $\bar{a}$-stems, since PIE $* \bar{a}>$ Gmc. $\bar{o}$ ).

1. There is much confusion, especially in the earlier literature, about what the term 'thematic stems' means. In current IE linguistics it refers only to $o$-stems, though in some works it is used to refer also to $\bar{a}$-stems, in others also to all vocalic stems (i.e., stems ending in a vowel in PIE, hence including $i$ - and $u$-stems, and sometimes, again, $\bar{a}$-stems, supposing early loss of laryngeals), in still others to all but root-stems (since all but root-stems bore a 'theme', i.e. a suffix, in PIE).

2. The PIE $\bar{a}$-stems are in origin athematic, inasmuch as they originally added athematic inflections to a stem ending in $h_{2}$. Yet, like $o$-stems, they have a fixed accent throughout the paraadigm. Current handbooks, unlike many earlier ones, explicitly limit thematic inflection to the $o$-stems (so, e.g., Szemerényi 1996: $\S 7.1 .4 .6$, Fortson 2010: 84 ), yet they do not expressly classify $\bar{a}$-stems with athematic stems.

\subsection{The inflections of Proto-Indo-European root-stems}

Although, as noted above, inflections were not uniform across noun classes in PIE, general patterns of declension are observable. To clarify the origins of the Gmc. endings, it will be useful beforehand to illustrate the inflections borne by PIE root-stem nouns, i.e. nouns in which the stem was an unsuffixed root, since these inflections were generally the basis for the inflections found in other stem classes, by the combination of the root-stem endings with suffixal elements in other classes. In the oldest inflectional classes, masc. and fem. nouns are declined identically, i.e. as uters (as opposed to neuters); only later in PIE did separate inflections for some feminine nouns arise. The dual endings are insufficiently relevant to Germanic to be treated here. The following is a typical reconstruction of the uter root-stem inflections:

\begin{tabular}{|c|c|c|}
\hline & singular & plural \\
\hline nominative & $-s$ & -es \\
\hline vocative & $\varnothing$ & -es \\
\hline accusative & $-m$ & $-n s$ \\
\hline genitive & -és/-ós & -(oH)óm (?) \\
\hline ablative & -és/-ós & -bh(i)ós, -mós \\
\hline dative & -éi & -bh(i)ós, -mós \\
\hline locative & $-1 ́$ & -sú \\
\hline instrumental & -éh $/$-óh & -bhís, -mís \\
\hline
\end{tabular}

The endings $-m,-n s,-i$ become syllabic ( $-m,-n s,-i)$ when they follow a consonant. The neuter inflections are slightly different: in most classes the bare stem is used in the nom., voc., and acc. sg., whereas the same cases in the plural add $*_{-} \bar{a}<*_{-} e h_{2}$, which appears originally to have been a collective ending related to the nom. sg. inflection of $\bar{a}$-stems: see Clackson 2007: 100-4. Uter nom. sg. $-s$ is lost in some consonant-stem nouns, with compensatory lengthening of the root vowel, as in Gk. $\pi \alpha \tau \dot{\eta} \rho<\operatorname{PIE} * p h_{2} t \bar{e} r$ $<{ }^{*} h_{2} h_{2}$ ter-s (Szemerényi's law: $\S 1.6 \mathrm{n} .1$ ). This pattern was then extended analogically to many other consonant-stems, i.e. ones without a stem-final sonorant consonant. The alternative endings containing ${ }^{*}-m$ - in the abl., dat., and instr. pl. are reflected in the Germanic and Balto-Slavic languages, and there is no generally accepted explanation for the substitution of *-m- for *-bh-: for discussion, see K.H. Schmidt 1963; also, for 
references, Szemerényi 1996: $§ 7.1 .4 .3$ n. 5 and $§ 7.2 .1$, with n. $7 .{ }^{1}$ The shape of the gen. pl. is much contested: some (e.g. Prokosch 1939: 232, 239, Szemerényi 1996: §7.2.1) assume that the original ending was $*_{-o m}$, and this was replaced in Skt., Gk. and some others by the $o$-stem ending $*_{-} \bar{o} m<*_{-}-$-om or (more likely) the $\bar{a}$-stem ending $*_{-} e h_{2}$ $o m$, in large part because the Slavic ending points to *om (see further Kortlandt 1978); others (e.g. Jasanoff 1983, 2002: 36) suppose that the ending was *-o-om or *-oHom, as suggested by, among other things, the accentuation of Gk. $-\hat{\omega} v$ and the disyllabic scansion of Vedic Skt. $-\bar{a} m$ in roughly a third of instances. ${ }^{2}$

The origins of some aspects of these inflections can be determined with some probability. The ${ }^{*} s$ found in most cases of the plural is likely to be a plural marker abstracted from the nom. plural. In that event, acc. pl. *-ns is probably from ${ }^{*}-m-s$, i.e. as a pluralization of the sg. $*_{-} m$. The loc. sg. is based on the hic et nunc particle $*_{i}$, and the plural cases in *bh derive from the postposition *bhi, reflected in PDE as $b y$.

1. Schmid (1986: 165) offers analogy to the pronominal inflection as an explanation; Beekes (2011: 30-1) asserts that the dat. pl. ending was *-mus, the instr. *-bhi.

2. *-oHom would have to be a late development, given the peculiar ablaut; the sometimes heated debate over this ending is thus to a great extent simply over whether the required analogical change took place in late PIE or afterward.

\subsection{The inflectional categories of Germanic nouns}

Dual number is not retained as an inflectional category among nouns in any Germanic language, though it is preserved in pronouns and verbs (the latter in Gothic only, where the 3 dual is lost), and perhaps in ' 2 ' and 'both'. ${ }^{1}$ More significant is that the eight cases of PIE are reduced to six in PGmc.: nominative, vocative, accusative, genitive, dative, and instrumental. The dative combines the functions of the PIE dative, ablative, and locative, and all three types of case endings appear to have contributed to the morphology of the dative of Gmc. nouns, although the locative is the chief source of dat. sg. endings in Germanic. ${ }^{2}$ No Gmc. language preserves all six of these PGmc. cases: in the inflection of nouns, only Gothic and (probably) early Runic preserve the vocative, ${ }^{3}$ and Gothic, Old Norse, and Anglo-Frisian substitute the dative for the instrumental, only the singular of the instrumental being preserved as a distinct case form elsewhere. In addition, however, a few relic forms of these cases survive in the singular, chiefly in West Germanic: see $\$ 7.8$ under dat. sg. The nom. acc. neuter plural is in origin a collective form in ${ }^{*}-e h_{2}$ with rightward-shifted accent. Such collectives came to be regarded as plurals in the individual IE languages, though their collective origin is indicated by, e.g., the Latin and Greek rule that neuter plural subjects take a singular verb. In Gmc. the accent shift sometimes resulted in consonant alternations under Verner's law (examples in §6.6).

1. The Gmc. syntactic rule that an adj. referring to two persons of different sexes is inflected neuter is often said to be a reflex of the homophony of the masc. nom./acc. dual and the neut. nom./acc. pl. as ${ }_{-}-\bar{o}$ in PGmc.: so, e.g., Hirt 1931-4: II, 12.

2. But see especially the discussion of the $a$-stem dat. sg., $\$ 7.8$.

3. The Go. vocative (sg. only) does not in fact retain discrete inflections: in Gothic $a-, i-, u$-, and $n d$-stems (including $j a$ - and $w a$-stems), the vocative singular is identical to the accusative, e.g. skalk 'servant', gast 
'guest', sunu 'son', frijōnd 'friend', respectively (the nom. adds $-s$ ). Otherwise it is identical to the nominative. For the Runic forms, see Krause 1971: 116, 118.

\subsection{Accent and ablaut in nouns}

In thematic stems, the PIE accent fell on the same syllable throughout the paradigm. This could be the first syllable (the so-called acrostatic pattern) or it could be the theme vowel (mesostatic). In athematic nouns, on the other hand, the accent was usually mobile. For example, the suffix could appear with accented full-grade vowel *e/o in the nom. voc. acc. sg. dual and pl. and, in some categories, the loc. sg (the so-called strong or direct cases), ${ }^{1}$ though commonly the vowel was lengthened in the nom. sg. of uter nouns; in the remaining, weak or oblique cases there was weak grade of the suffix and accent on the inflection. Hence, e.g., there may be reconstructed PIE $r$-stem nom. sg. ${ }^{*} p h_{2} t-\bar{e} r<* p h_{0} t-e ́ r-s$ 'father', acc. * $p h_{2} t-e ́ r-m$, gen. * $p h_{2} t-r$-ós. This is the so-called hysterokinetic (or hysterodynamic) pattern of accentuation. There are also to be found athematic stems following the amphikinetic pattern (or simply kinetic in root-stems), with accented root in the strong cases and accented inflection in the weak, as with nom. sg. *pónt-oh $h_{2}-s>$ Skt. panthāh 'path' (with $-t h-<{ }^{*}-t h_{2}$ - extended from the weak cases), gen. sg. *pnt- $h_{2}-e ́ s>$ patháh. In the proterokinetic type, the root is accented in the strong cases and the suffix in the weak, as with PIE nom. sg. * $g^{w} e ́ n-h_{2}$ 'woman' > OIr. ben, PIE gen. * $g^{w} n-e ́ h_{2}-s>m n a ́$. In athematic nouns there do occur acrostatic types, with the characteristic that although the accent is fixed, there is ablaut alternation between the strong and weak stems. An example of this is heteroclitic PIE strong stem $* i e k^{w}-r-$ 'liver', reflected in Gk. $\hat{\eta} \pi \alpha \rho$, weak stem *iék $k^{w} n$ - reflected in Skt. gen. yáknah̆. See further Clackson 2007: 79-111 on the PIE patterns, and on Germanic, Schaffner 2001, Mottausch 2011. Most ablaut alternations in nominal stems were eliminated in PGmc., though ablaut persisted in inflections.

1. Some regard the acc. pl. as weak: e.g., to Clackson 2007: 79 cf. Fortson 2010: 114-15, and cf. the anstem acc. pl. Skt. räjñah (§7.31).

\subsection{Vocalic stems}

IE noun stems are conventionally classed as vocalic or consonantal, depending on whether the stem ended in a vowel or a consonant. The vocalic stems in Gmc. are the $a$ stems (including the $j a$ - and $w a$-stems), the $\bar{o}$-stems (including the $j \bar{o}$ - and $w \bar{o}$-stems), the $i$-stems, and the $u$-stems.

\section{6 $a$-stem nouns}

The $a$-stems, or thematic stems, reflecting the PIE $o$-stems, are all masculine and neuter, with minor differences of inflection between the two. This is a highly productive class: when masc. and neut. nouns defect from other stem classes, it is usually to this class. The class includes simple $a$-stems, in which $a$ (PIE thematic $o$ ) was added to the stem, as well as $j a$-stems and $w a$-stems, in which the theme vowel was preceded by a glide, 
which was usually suffixal. The PIE accent is on the same syllable throughout the paradigm, usually on the root, though the theme vowel could instead be accented, as

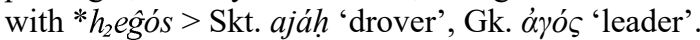

\subsection{The simple $a$-stems}

This class includes only masculine and neuter nouns. Masculine paradigms of $a$-stems in the major early Gmc. languages may be illustrated by Go. wulfs 'wolf' and its cognates:

\begin{tabular}{|c|c|c|c|c|c|c|}
\hline & & Go. & OIcel. & OE & OS & OHG \\
\hline & nom. & $\begin{array}{l}\text { wulfs } \\
\text { pulf }\end{array}$ & úlfr & wulf & wulf & wolf \\
\hline & acc. & $\begin{array}{l}\text { wulf } \\
\text {. }\end{array}$ & $\begin{array}{l}\text { úlf } \\
\text { úlfs }\end{array}$ & $\begin{array}{l}\text { wulf } \\
\text { wulfes }\end{array}$ & $\begin{array}{l}\text { wult } \\
\text { wulfes }\end{array}$ & wolfes \\
\hline & & wulfa & úlfi & woulfe & wulfe & wolfe \\
\hline & instr. & wйла & & wati & wulfu & wolfu \\
\hline pl. & $\begin{array}{l}\text { voc. } \\
\text { nom. }\end{array}$ & $\begin{array}{l}\text { wulf } \\
\text { wulfōs }\end{array}$ & úlfar & wulfas & wulfos & wolfă̆ \\
\hline & acc. & wulfans & úlfa & wulfas & wulfos & wolfă \\
\hline & gen. & wulfē & úlfa & wulfa & wulfo & wolfo \\
\hline & dat. & wulfam & úlfum & wulfum & wulfum & wolfum \\
\hline
\end{tabular}

Neuter nouns are declined similarly, the exceptions being in the nom. and acc. of both sg. and pl., as illustrated by forms of the word for 'word' (a heavy stem; on the light stems, see below):

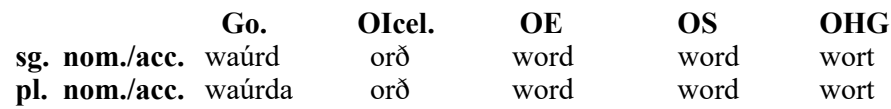

Inflectional variants:

Gothic. Final $-s$ in the nom. sg. masc. is lost if the stem ends in /r, s/, as with nom. wair 'man', freihals 'freedom'.

Old Icelandic. Final $-r$ in the nom. sg. is assimilated to a preceding /n, s, 1/, as in himinn 'heaven', iss 'ice', jokull 'glacier'; if such assimilation produces a postconsonantal geminate, the geminate is simplified, as with hrafn 'raven', jarl 'earl'; so also aldr 'age' $<*$ ald $r-r$.

West Germanic. Light-stemmed neuters take the ending $-u(-o)$ in the nom. acc. pl. in OE and OS, e.g. OE scipu 'ships' (cf. word), OS grabu 'graves'. In OE and OFris. there occur some rare instr. singulars in -um, which Bammesberger (2001) identifies as dual in origin. Beside OS nom. acc. pl. -os there occurs $-a,-e$, borrowed from pronouns. The quantity of final $\langle\mathrm{a}\rangle$ in the OHG nom./acc. pl. masc. is disputed, though most regard the long variant as a dialectal development. ${ }^{1}$ The spelling of vowels in inflections is far from uniform, especially in OS and OHG.

1. See Braune 2004a: $\S 193$ Anm. 4 for references; but cf. under nom. pl. in $\S 7.8$. Note that Braune regards $-\breve{a}$ as the correct reflex of ${ }^{*}-\bar{o} z$. See further Shields 2006 , regarding $-\bar{a}$ as analogical to the $\bar{o}$-stem inflection. 


\subsection{Origin and development of $a$-stem inflections}

The following issues may be noted:

Nom. sg. The masculine nouns reflect PGmc. *-az< PIE *-o-s; cf. Skt. áśvah, Gk. ï $\pi$ $\pi$, Lat. equus < *ékuos 'horse'. It is generally assumed that the variant *-az due to the voicing of */s/ under Verner's law (\$6.6) analogically replaced *-as in the type with accent on the theme vowel, which is particularly common in PIE $o$-stem adjectives

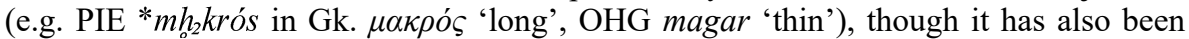
proposed that every postvocalic final ${ }_{-}-S$ was voiced to $*_{-z}$ in PGmc., regardless of the accent (so, e.g., Bammesberger 1990: 40, Boutkan 1995b: 43-51; cf. \$6.16 supra). The vowel is lost independently in Go. and ON (cf. Runic pewar 'servant', ca. 400, with loss already in EGmc. awings, Vimose sheathplate, Fyn, $3^{\text {rd }}$ cent.), and in $\mathrm{ON},{ }^{*}-z$ (R in Runic, distinct from r) undergoes rhotacism (\$6.6), whereas in Gothic it is devoiced (§6.12). The ending is lost altogether in WGmc. As for the neuter nouns, they reflect PGmc. ${ }^{*}-a^{n}<*_{-} a n<\mathrm{PIE}{ }^{*}-o-m$ : cf. thematic Skt. -am, Gk. -ov, Lat. -um.

Acc. sg. PGmc. ${ }^{*}-a^{n}<*_{-a n}<\mathrm{PIE} *_{-o-m}$. The stage -an is attested by the acc. sg. masc. pronoun Go. pan-a, OE pon-e, from PGmc. *ban < PIE *to-m (Skt. tám, Gk. tóv) plus ${ }^{*}-\bar{o}^{n}$ (probably: see $\S 8.10$ ).

Gen. sg. OE and Runic forms point to PGmc. ${ }^{*}$-as,${ }^{1}$ which is usually explained as reflecting PIE *-ó-so, where the place of the accent prevents voicing of $* / \mathrm{s} /$ under Verner's law, though certainly then analogy must be invoked, since it is hardly plausible that thematic genitives were always so accented. PIE *-o-so is supported by Old Prussian deiwas < *deiu-o-so 'of a god', but the IE languages more usually reflect

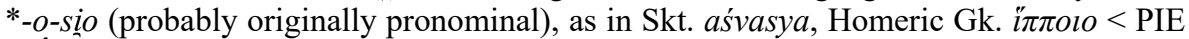
*ek ku-o-sio 'horse'. ${ }^{2}$ But OHG and OS -es point rather to PIE *-e-so (the ending -as is less common in OS, and OHG -as is a late, chiefly Bavarian development: see Braune 2004a: §193 Anm. 1), as does Go. -is. This *-e-so could reflect a PIE ablaut variant in nouns, as is often assumed, though the evidence for such an alternant outside of Gmc. is exiguous. Accordingly, Beekes (1988, with refs.) argues that the pronominal ending was PIE *-e-so in the pronoun $k^{w}$-é-so 'whose?', and this supplanted the ending on $a$ stem nouns in PGmc. ${ }^{3}$ This would explain why */s/ was never voiced: in pronouns like ${ }^{*} x^{w} e ́ s\left(<* k^{w} e ́ s o\right)$ there was no opportunity for Verner's law to apply. On this view, in NGmc. and $\mathrm{OE}$, where *-as is reflected, the vocalism is an analogical innovation postdating PGmc.: cf. OE demonstrative pæs < PIE *toso. Beekes' analysis would also explain why the Gmc. ending reflects *-eso rather than *-esio: cf. OCS česo 'of which?'. Alternatively, Ringe (2006b: 175-6, idem 2017: 226) argues that the *-as found outside of Gothic and OHG reflects the PGmc. ending, derived not from the PIE $o$-stem inflection but from pronominal gen. PIE *tósio, thus explaining why Verner's law does not produce $*_{-z}$ in the genitive. OS $\mathrm{OHG}$-es is then to be explained as analogical to the gen. pronouns ${ }^{*} e s$ and ${ }^{*} x^{w} e s$. Another fact to be accounted for is that $\mathrm{OS}$ and $\mathrm{OHG}$-es do not cause umlaut (e.g. OHG tages 'day'). Yet this observation would not be decisive in favor of Ringe's position even if it were universally agreed that PIE $e$ yields PGmc. $i$ in unstressed syllables except before $r{ }^{4}$ Although it does not appear to be possible to prove whether it is *-as or *-es that was the PGmc. inflection, the historically dominant position that there was no PGmc. $e$ in unstressed syllables except before $r$ does, all things considered, favor the assumption of original *-as, though, to be sure, the fate of unstressed $e$ aside, Ringe's does appear to be the more 
complicated account. ${ }^{5}$ Mottausch (2011: 167) explains *-as as having acquired the vowel found elsewhere in the paradigm. See further Bjorvand 1991.

Dat. sg. Go. dat. sg. $-a$ in the $a$-stems perhaps derives from PIE instr. *-e (i.e., $*_{-}-h_{1}$ ), given comparison to the relic instr. $p \bar{e}$ (as in ni $p \bar{e}$ haldis 'none the more', bi-pe 'while', jap- $p \bar{e}$ 'and if', $p \bar{e}-e i$ 'that, because'; also Go. dat. hammēh 'every' < PIE ${ }^{*}-e h_{1}-k^{w} e$ vs. hamma 'who' < PIE $\left.*_{-} e-h_{1}\right),{ }^{6}$ with development of unstressed $-\bar{e}$ to $-a$, though it would also be possible to derive Go. $-a$ from a posited reduced form of the PIE dat. ${ }^{*} \bar{o}$ (beside usual $*_{-} \bar{o} \underline{i}<*_{-}-$-e $\underline{i}$ : see Krahe \& Meid 1969: II, §4; cf. Bammesberger 1990: 42). ${ }^{7}$ The same ending $*_{-} \bar{e}$ perhaps underlies endingless locatives in WGmc., e.g. OE OS OHG hüs: see Dahl 1938: 51-5, Hogg \& Fulk 2011: §2.18, but cf. Boutkan 1995b: 382-3. The WGmc. dat. sg., however, most likely derives from PGmc. dat. ${ }_{-} a i<*_{-} \bar{o} .{ }^{8}$ The idea of Prokosch (1939: §79e) that this is an unnecessarily complicated derivation, since datives in other Gmc. classes derive from locatives, faces the difficulty of explaining forms like early $\mathrm{OE} f \bar{a} c n i$ that are instrumental in function but, apparently, locative in form, with $-i$ from thematic PIE *-ei (cf. early OE dat. sg. hrōfx 'roof' with -æ, probably from PGmc. dat. *-ai< PIE $*_{-}-\bar{i}<_{-} *_{-o-e} i$ ), though such forms usually lack umlaut. ${ }^{9}$ There is thus some reason to doubt the idea of Hollifield (1980: 160) that $\bar{e}$ in Go. hammēh reflects PGmc. ai, further reduced to $a$ in hamma; this also leaves Go. $p \bar{e}$ (etc.) unexplained: cf. pái 'they' (masc.) < PIE *toi. It is nonetheless very commonly assumed that the Gmc. dat. reflects the PIE loc. ${ }^{*}$-oi: see Euler 2013: 69, with references. Runic $-\bar{e}$ (woduride, walhakurne) can reflect either $*_{-} \bar{e}$ or $*_{-a i} ;{ }^{10}$ note that although $\bar{e}_{1}$ developed to $\bar{a}$ in stressed syllables early in NGmc. (§4.6), this was not so in unstressed syllables: cf., e.g., * swestēr > PNorse ${ }^{*}$ swest $\bar{x} r>$ OIcel. syster, later systir 'sister' (§5.6 \& n. 4). See further Kotin 2012: 142-4. Pervasive uncertainties remain.

Instr. sg. In early texts in $\mathrm{OHG}$ and in OS there appear forms reflecting instrumental singular endings, e.g. OHG wortu 'word' and OS hoђu 'court', with $-u<$ PIE $*_{-} \bar{o}\left(\right.$ i.e., $\left.{ }^{*}-o-h_{l}\right) .{ }^{11}$ There must be assumed analogical restoration of the inflection after heavy stems (Gallée 1993: 197).

Voc. sg. In masc. nouns the ending in PIE was *-e (i.e. the bare theme vowel); cf. Gk. iٓ $\pi \pi \varepsilon$, Lat. eque 'horse'. In neuter nouns, however, the vocative was probably identical to the nominative, as in Greek. This ending *-e is lost everywhere in Germanic, and this resulted in the loss of any distinction between vocative and nominative in WGmc. A distinction was preserved in Gothic, however (where the nom. ended in $-s),{ }^{12}$ and in early Runic, as attested by the vocatives alawid and alugod (personal names, the latter from ca. 200; cf. nom. in -(a)R, as above).

Nom. pl. In masc. nouns the PIE ending was $*_{-} \bar{o} s<*_{-} o-e s$ (cf. athematic PIE

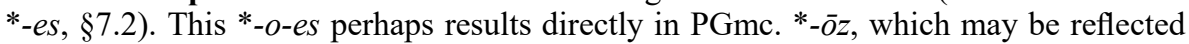
in OIcel. -ar, OHG - $\bar{a}$, and Go. $-\bar{o} s .{ }^{13}$ However, OE OS -as (cf. OFris. -ar, -er, -a, -an) require a different explanation, as $*_{-z}$ should have been lost in WGmc. Possibly PGmc. $*_{-} \bar{o} z$ and $*_{-} \bar{o} s$ were variants under Verner's law (\$6.6), with generalization of one or the other in the different Gmc. languages (unless final $*_{-} s$ was always voiced to $*_{-} z$ : see under nom. sg. above). Alternatively, comparison has been drawn to Indo-Iranian -āsas (see Beekes 1989 for refs.), implying PIE *-oses (i.e. normal *-o-es with re-addition of the athematic ending *-es), which could account for all the Gmc. endings (including -ar in Frisian — so van Helten 1889: 282 - though this could be a borrowing from ON: see Markey 1981: 14, but cf. Boutkan 1995b: 188-91, H.F. Nielsen 2000: 253-4) except OHG: see Bammesberger 1990: 43-4. The OHG variant - $a$ with short vowel is likely to 
be analogical to the acc. pl. (so Krahe \& Meid 1969: II, §4; see also Hollifield 1980: 43-4), as the nom. and acc. pl. influence each other throughout WGmc. declension. ${ }^{14}$ But Prokosch (1939: §49n note) offers the very different idea that acc. pl. *-ans developed to ${ }^{*}-\bar{a}^{n} S$ in NSGmc. (see $\S 4.11$ ), resulting utlimately in OE OS -as, to which the nom. pl. inflection is analogical. Stiles (1988: 139 n. 18), elaborating an idea of Bjorvand (1987: 186-7), argues that ${ }^{*} z$ was devoiced by analogy to the gen. sg. for the purpose of contrast with the fem. ending. Ringe proposes that after the loss of final ${ }^{*} z$, the $s$-particle that spread through the paradigm of the proximal demonstrative pronoun (§8.12) was added to the remaining *- (Ringe \& Taylor 2014: 162-3). For discussion and references, see Boutkan 1995b: 187-93, favoring the assumption of PGmc. *-ōsez. As for the neut., the PIE ending was $*_{-} \bar{a}$ (see $§ 7.2$ ); this develops to PGmc. ${ }_{-}^{*} \bar{o}$, which gives, in normal fashion, $-a$ in Gothic and $-u$ elsewhere. This final $-u$ is always lost in NGmc., though not without causing $u$-umlaut or fracture, e.g. in OIcel. nom. pl. born 'children', fjoll 'mountains'. In WGmc. this $-u$ was preserved only after light syllables, e.g. OE scipu 'ships', OS graђu 'graves', but in OHG the endingless variant was generalized, the ending $-u$ being preserved only in some Alemannic diminutives, e.g. chindiliu 'little children', and in $j a$-stems (see §7.11).

Acc. pl. PIE masc. ${ }^{*}-o$ - $n s$ gives PGmc. ${ }^{*}$-anz, which develops regularly in Go. and OHG. In ON there must be assumed a development *-anz $>*_{-}$-ann $>*_{-}-a n>-a$ (not attested earlier than ca. 600 in Runic); cf. $n$-stem gen. sg. kepan (name; Belland stone, ca. 500) <*-anz; cf. Antonsen 1975: 19. The ending OE -as, OS -os is by analogy to the nom. pl. (cf. above under nom. pl. for the converse development in OHG). OS has also occasionally $-a,-e$, which Holthausen (1921: §265.4) is probably right to regard as analogical to pronominal declension, though Boutkan (1995b: 192) prefers to see it as a "special development" of the acc. pl. The neut. inflection was identical to the nom. pl. neuter.

Gen. pl. PIE *-o-Hom should have developed to PGmc. *- $\hat{o}^{n}$. This accounts well for all the Gmc. forms except Go. $-\bar{e}$, which has been the topic of a great deal of controversy: see Ringe 2006b: 170-8 for an extensive survey of approaches. Some purely phonological explanations involve the supposition of qualitative ablaut in PIE (see, e.g., Möller 1880: 489, Loewe 1933: 2.9, and the references in Morgenroth 1965), though Gothic is the only IE language thought to show the variant with the front vowel, so that this account is difficult to credit. Others posit sound changes in Gmc. that are possible but not widely accepted. ${ }^{15}$ Morphological solutions seem likelier, the most widely credited of which is the idea of van Helten (1893: 570-3, 1909: 273-5) that the $e$ quality of the Gothic ending arose by analogy to the e-quality of the gen. sg. *-es (in consonant-stems) and *-eso (in $a$-stems). This (as pointed out by Prokosch 1939: §791) would explain why $-\bar{e}$ is not the ending in the Gothic $\bar{o}$-stems (as well as the $\bar{o} n$-stems and $\bar{i} n$-stems), where the gen. sg. ending is $-\bar{o} s$. Another morphological solution is that of Brugmann (1914: 272-4), positing origin in the PIE neuter nom. sg. ending *-êeio-m of some adjectives (unfortunately unattested in Gmc.). The hypotheses of Morgenroth (1965: 333-6), Lehmann (1967: 109-11), and Kuryłowicz (Kuryłowicz et al. 19682015: 2.87 Anm. 8; see also Fullerton 1983: 119-27) show some similarity to that of van Helten, somewhat more abstractly assuming that $-\bar{e}-$ arose in Gothic as part of a pattern of frontness/backness oppositions between the vocalism of feminine and nonfeminine inflections. Some other morphological solutions assume that $-\bar{e}$ is based on a different case ending, e.g. a supposed instr./abl. sg. (Sehrt 1930: 98-100) or abl. sg. (Eska 1988; see also Wood 1923: 107-8), ${ }^{16}$ whereas Kortlandt (2007) sees the Go. 
ending as originating in the $i$-stems, with *-ei-om developing to - $e$ rather than the $-e i$ or $-i$ that Ringe (2006b: 173) says should be expected. See further Kotin 2012: 140-2.

Dat. pl. To PIE athematic instr. pl. *-bhis corresponds the desinence *-mis reflected in Gmc. and Balto-Slavic: see the references in $\$ 7.2$. Thematic ${ }_{-o-m i s}{ }^{17}$ develops to -um everywhere in Gmc. except in Gothic, where it gives -am: see §5.5.

1. OS -as also occurs on occasion. The vowel is still preserved in Runic hnabdas (Bø stone, ca. 500).

2. Ringe (2017: 141), conveying the opinion of W. Cowgill, explains PGmc. *-as as reflecting PIE *-osio on the assumption that a postconsonantal sonorant consonant rendered final by the loss of a final vowel was lost in PGmc.

3. To the suggestion that PGmc. *-esa could have developed from PIE *-esio, Roberge (1988: 143-4, with references) raises telling objections; cf. Szemerényi 1996: §7.6.2. Cf. also Hollifield 1980: 34.

4. The point would not be decisive because there remains the possibility that umlaut was analogically removed from the genitive forms, and because OHG -es is not actually an impediment to Beekes' position even if it is assumed that PGmc. unstressed $e$ became $i$ : if *-es is by analogy to * $x^{w} e s$ (with $e$ retained under stress), it may have arisen after the change of $e$ to $i$ ceased to apply, and at all events the analogical influence of the pronoun need not be assumed to have ceased after the initial change. Boutkan $(1995 \mathrm{~b}: 72-89,178)$ is one who supposes that the raising of unstressed $e$ occurred on a limited basis and would not have occurred in PGmc. *-es(a).

5. Ringe does not actually posit direct analogy to the reflexes of PGmc. ${ }^{*} e s$ and ${ }^{*} x^{w} e s$, rather the spread of *-es from these to pronominal *bes, followed by extension of *-es to adjectives, followed by extension to nouns, the last two steps (apparently) occurring independently in Gothic and OHG.

6. Cf. also Gk. (Thera) $\tau \eta-\delta \varepsilon$ 'in this way', with $\eta<*^{*} h_{1}$ : so Sihler 1995: $257-8$; instr. $*_{-}-\bar{e}$ is rejected by Ringe (2017: 225 n. 49).

7. That there was a development of PIE dat. ${ }^{*}-\bar{o} i$ to PGmc. ${ }^{*}-\bar{o}$ was first proposed by Wiedemann (1892). The issue has been much disputed: see A.W. Jones 1979: 118-23 for discussion and references.

8. The more usual reconstruction is *-ôi (cf. the inflection on Gk. dat. sg. $\theta \varepsilon \hat{\varphi}$ ' 'god'), but see $§ 5.4$. Derivation from the PIE loc. ${ }^{*}$-oi is also possible.

9. Gothic preserves an old locative in the conjunction pei 'that' (cf. Doric Gk. $\tau \varepsilon \hat{\imath}-\delta \varepsilon$ 'here'). Beekes (1985: 127) suggests that $*_{-} e i$ is pronominal in origin.

10. Runic instances of -ai instead of -e are uncertain: see Krause 1971: 116.

11. Traces of the instrumental case are found also in the singular of some pronouns and adjectives in WGmc.: see $\S \S 8.10,9.2$ infra.

12. The only attested Go. $a$-stem vocatives are skalk 'servant' and piudan 'king'.

13. On the earlier reconstruction PGmc. ${ }^{*}-\hat{o} z<\mathrm{PIE} *_{-o-e s,}$, see $\S 5.4$. There are, of course, other possible explanations for PGmc. ${ }^{*}-\hat{o} z$ (if indeed the vowel was trimoric, as is usually assumed, and if ${ }^{*}-o$-es contracted to ${ }^{*}-\bar{o} s$, with a bimoric vowel, already in PIE, as Jasanoff (2004) contends), e.g. that $-z$ in PGmc. ${ }^{*}-\bar{o}-z$ was replaced by the athematic ending ${ }_{-}-e z$, giving PGmc. ${ }_{-}^{*}-\bar{o}-e z>*_{-} \hat{o} z$.

14. So also H.F. Nielsen 2000: 253. To the contrary, Braune (2004a: $\$ 193$ Anm. 4, in agreement with Wagner 1986b), identifies $-a$ as the reflex of ${ }^{*}-\bar{o} z$, and $-\bar{a}$ as an Alemannic innovation.

15. See, e.g., Osthoff 1878: 240-1, 289-90, Mahlow 1888: 105-10, Wiedemann 1892: 483-4, Pisani 1930: 67, Must 1952, Bech 1969: 56, 62-4, Kortlandt 1978: 291, Boutkan 1995b: 109, 249-50.

16. Shields $(1979,1997)$ also offers morphological solutions, though on the basis of some unconventional reconstructions of PIE morphology. See further Kuryłowicz et al. 1968-2015: 2.87 Anm. 8.

17. The thematic ending was PIE *-ōis, giving Skt. -ais, shortened in Gk. -olৎ, but the Gmc. thematic ending is formed by adding athematic PIE *-mis (pronominal in origin? see $\S \S 7.2,8.9$ ) to the theme vowel. Loewe (1918) instead regards *-mis as the proper PIE instr. pl. inflection. Some would reconstruct a PIE dat. pl. *-omus and derive the Gmc. ending from this: so, e.g., van Helten 1890: 21, Loewe (op. cit.), Boutkan 1995b: 197, Beekes 2011: 212. 


\subsection{The $j a$-stems}

These were formed in PIE by the addition of the theme vowel to both verb and noun stems in $*_{-i-}$ (or the ablaut alternant $*_{-} e \underline{i-}$, chiefly in denominal adjectives, as in Lat. aureus 'golden'), which was usually suffixal. The PIE nouns with *-i-o- and *-ei-o- ultimately fell together in Germanic as $j a$-stems, but the development of the Gmc. suffix was different according to whether the preceding syllable was heavy or light, ${ }^{1}$ giving PGmc. *-ija- and *-ja-, respectively, under Sievers' law (\$5.8).

1. According to the usual formulation, polysyllabic stems behave like heavy stems in regard to Sievers' law in Gmc., but see $\$ 2.5$ on the challenge to this view offered by Dahl (1938) and others.

\subsection{The $j a$-stems in Gothic}

The difference between heavy and light stems is most pronounced in Gothic, where the heavy masc. stems may be typified by hairdeis 'herdsman' and the light by harjis 'army':

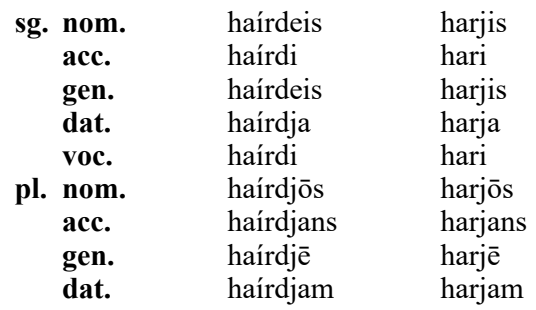

The endings are thus identical to those for Go. dags, but with preceding $-j$ - throughout the plural, in the dat. sg., and in the gen. sg. of the light stems; more remarkable divergences from the simple $a$-stem paradigm are to be found in the sg. in the nom., acc., voc., and, among the heavy stems, the genitive.

There is some controversy over how to account for the nom. and gen. singular. Heavy-stemmed nom. -eis is usually explained as deriving from PGmc. ${ }_{-}-i j a z>{ }^{*}-i j z>$ $*_{-i i z}>-\bar{l} s$. Such a development is plausible enough, but it demands the assumption that light-stemmed nom. -jis have been formed by analogy to gen. -jis (since nom. and gen. are identical in the heavy-stemmed nouns, both bearing the inflection -eis), and Barrack (1998: 102-4) objects that the nom. should not be expected to have been reformed by analogy to the genitive, since the genitive is more marked and far less frequent than the nominative. He supports the view of Sievers (1877-8: 129) that instead there was raising of $*_{a}$ in $*_{-i j a z}>*_{-i j e z}>*_{-i j i z}>*_{-i i z}$, noting that although $*^{*} a$ is not elsewhere raised after $* j$, the combined effect of $* j$ and following $* z$ could have caused raising. But considering that stem-final $-j$ - heavily predominates in the paradigm of harjis, as Barrack concedes, the gen. need not be considered the only analogical influence upon the nominative. ${ }^{1}$ It is quite possible that original *haris acquired the stem harj- by analogy to the rest of the paradigm. In fact, if PGmc. *-ji- was always reduced to $*_{-i}$, even after a consonant (see §12.38), then the gen. sg. must also be analogical. The development of the remaining cases is straightforward: 
Acc. sg. PGmc. heavy $*_{-i j a} a^{n}$ probably did not lose intervocalic $*_{j}$ (so Krahe \& Meid 1969: II, §6; cf. §6.11 supra, ad fin.); ${ }^{*}-a^{n}$ was lost, as in the simple $a$-stems, and the remaining final $*_{-j}$ on light stems was syllabified.

Gen. sg. PGmc. heavy *-ijis loses intervocalic *j, giving *-iis $>$-īs; light $*_{\text {-jis }}$

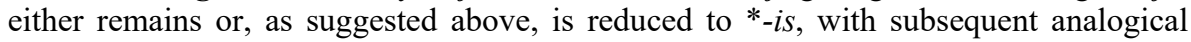
restoration of $j$, as in the nom.

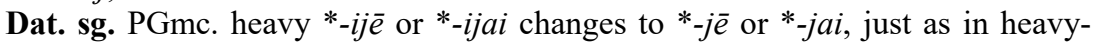
stemmed verbs of weak class $1(\$ 12.38)$; it thus falls together with light $*_{-j e}$ or $*_{-j a i}$, which develops normally to -ja.

Voc. sg. PGmc. heavy *-ije loses final $*_{-} e$, then $*_{-} i j$ develops to $*_{-} i i>*_{-} \bar{l}$ and is shortened; yet Wright (1954: §154) cites the imp. sg. of heavy-stemmed verbs of the first weak class as evidence that there was no shortening of $*_{-} \bar{l}$ in Gothic (but see $\S 12.38$ n. 8 for an alternative explanation). Light $*_{-j e}$ loses final $*_{-} e$ and then $*_{-j}$ is syllabified. For a different explanation of the voc. endings, see Ringe 2017: 142.

PI. Developments are comparable to those in the dat. singular.

In Gothic neuters the heavy and light ja-stems are declined identically. Only the nom. sg. and the nom. and acc. plural should be expected to have borne endings different from the corresponding masc. endings in PGmc., giving Go. nom. sg. $-i$ and nom. and acc. pl. -ja. The only irregularity is that the heavy- and light-stemmed gen. sg. ending should be expected to have been differentiated, as in the masc. nouns, whereas -jis (instead of -eis) is used for both types in the neuters. The simplest explanation is that the light-stemmed inflection has been extended to the heavy stems, a plausible change because it has the effect of eliminating alternations under Sievers' law in the neuters, creating a uniform paradigm. ${ }^{2}$

1. Prokosch (1939: 306, n. 1 to $\S 80$ ) provides references to some alternative views. See also Barber 2013: 13-14.

2. For a different explanation, based on the argument that Gothic eliminated most stems ending in a short vowel, see Kiparsky 2000; but see also $§ 9.4$ n. 1 .

\subsection{The $j a$-stems in Northwest Germanic}

There are differences between heavy- and light-stemmed ja-stems in NWGmc., though they are not as transparently conditioned by Sievers' law as in Gothic. The heavy masc. stems may be exemplified by OIcel. hirðir 'herdsman' and its cognates:

\begin{tabular}{|c|c|c|c|c|c|}
\hline & & OIcel. & OE & OS & OHG \\
\hline & nom. & hirðir & hierde & hirdi & hirti \\
\hline & acc. & hirðis & hierde & hirdi & hirti \\
\hline & gen. & hirði & hierdes & hirdies & hirtes \\
\hline & dat. & hirði & hierde & hirdie & hirtie \\
\hline & instr. & & & hirdiu & hirtiu \\
\hline pl. & nom. & hirðar & hierdas & hirdios & hirte \\
\hline & acc. & hirða & hierdas & hirdios & hirte \\
\hline & gen. & hirða & hierda & hirdio & hirteo \\
\hline & dat. & hirðum & hierdum & hirdium & hirtum \\
\hline
\end{tabular}

In OIcel., - j- appears before a back vowel at the end even of heavy stems if the preceding consonant is velar: to gen. pl. hirða cf. mækja 'swords'. There is considerable 
variety in the spelling of inflections in $\mathrm{OS}$ and $\mathrm{OHG}$, e.g. dat. sg. OS -ea, $-i a, \mathrm{OHG}-e$; dat. pl. OS -ion, -eon, OHG -un, -on, -im, -in.

Heavy-stemmed neuters are declined the same way, except in the nom. sg. and the nom./acc. plural, as exemplified by OIcel. riki 'kingdom' and its cognates:

$\begin{array}{lcccc} & \text { OIcel. } & \text { OE } & \text { OS } & \text { OHG } \\ \text { sg. nom. } & \text { ríki } & \text { rīce } & \text { rīki } & \text { rīchi } \\ \text { pl. nom./acc. } & \text { ríki } & \text { rīcu } & \text { rīki } & \text { rīchi }\end{array}$

The light masc. and neut. stems are declined the same way as the heavy in OS and $\mathrm{OHG}$, except that in OS, the nom./acc. sg. of stems that do not end in $/ \mathrm{r} /$ may be inflectionless, e.g. neut. nom. bed beside beddi 'bed' (on which see further below). ${ }^{1}$ The inflections in OIcel. and OE may be exemplified by masc. OIcel. niðr 'kinsman', OE secg 'man', here 'army', neut. OIcel. kyn 'kin', OE cynn 'kin':2

\begin{tabular}{|c|c|c|c|c|c|}
\hline & \multicolumn{3}{|c|}{ masc. } & \multicolumn{2}{|c|}{ neut. } \\
\hline & OIcel. & OE & OE & OIcel. & OE \\
\hline sg. nom. & niðr & secg & here & kyn & cynn \\
\hline acc. & nið & secg & here & kyn & cynn \\
\hline gen. & niðs & secges & herges & kyns & cynnes \\
\hline dat. & nið & secge & herge & kyni & cynne \\
\hline pl. nom. & niðjar & secgas & hergas & kyn & cynn \\
\hline acc. & niðja & secgas & hergas & kyn & cynn \\
\hline gen. & niðja & secga & herga & kynja & cynna \\
\hline dat. & niðjum & secgum & hergum & kynjum & cynnum \\
\hline
\end{tabular}

$\mathrm{OE}-c g$ - in secg represents the West Germanic gemination of $*_{3}$ before $*_{j}$, the latter of which was then lost after the heavy syllable thus created. Since $r$ was not geminated $(\S 6.15), j$ remains in the paradigm of here, where it is often spelt $\langle\mathrm{g}\rangle$ before a vowel, whereas word-finally it is vocalized to $i>e .^{3}$

Thus, in OIcel., the vocalized $*_{-i j-}$ in the heavy stems is reflected as $-i(-)$ in the singular, where it stands either before a consonant or in finality, ${ }^{4}$ but it is lost in the plural, where it stood before a vowel (and is assumed to have become non-syllabic, though it is still syllabic after heavy syllables in early Runic, e.g. gen. sg. holtijaz); in the light stems, to the contrary, the non-vocalic variant $*_{-j}-$ is lost in the singular but preserved in the plural.

In OE, nom. sg. $-e$ in the heavy stems reflects early $-i<*_{-}-\bar{\imath} *-i j(a z)$, with shortening having occurred too late for the vowel to be apocopated. Light-stemmed nom. sg. secg is for expected ${ }^{*}$ sege $<{ }^{*}$ sazi $<{ }^{*}$ sazjaz. ${ }^{5}$ The geminate of the other cases was extended at an early date to the nom., though perhaps not as early in OHG as elsewhere in WGmc.: for details see Dal (1934), who assumes that the acc. sg. is also analogically reformed, though Dahl (1938; so also Hogg 1979: 68-73) supposes that WGmc. acc. $*_{\text {sazzjan }}$ would have developed before the loss of the final vowel.

In Old Saxon, poetry has forms like nom. sg. segg 'man' and acc. bed 'bed', whereas later texts have seggi, beddi, with analogical extension of the ending of heavy stems, e.g. nom. acc. hirdi. OHG generally has the latter type ((h)rucki 'back', tilli 'dill'), though a few alternative forms are attested, e.g. hewi beside houwi 'hay', beti beside betti 'bed', seemingly attesting to forms like the original *sege posited for OE (above). 
1. The nom./acc. forms in $-i$ are later creations by analogy to the heavy stems. OS stems ending in $/ \mathrm{r} /$ (only neut. heri 'army', swiri 'cousin') retain $-i /-e$ in the nom./acc., as in $\mathrm{OE}$, as do stems of more than one syllable. Masc. segg 'man' has gone over to the $i$-stems.

2. OE secg of course is not technically a light stem, but the stem *sez- (assuming that $-j$ - had been reanalyzed as belonging to the inflection) was light before the onset of WGmc. gemination (§6.15).

3. Cf. the spelling -heri in early glossaries. The claim of Prokosch (1939: $\S 80 \mathrm{~b}$, followed by Krahe \& Meid 1969: II, 15-16) that $j$ is preserved and spelt $\langle\mathrm{e}\rangle$ or $\langle i\rangle$ in early light-stemmed plurals is unreliable: in spellings like gen. pl. 〈secgea $\rangle$, the $\langle\mathrm{e}\rangle$ is a diacritic indicating the palatal nature of the preceding sound: see Hogg 1992: $\S 2.68$.

4. The only exception is the rare neut. dat. sg. kyn, beside usual kyni. The endingless form must be older, since all strong neuter nouns in OIcel. have $-i$ in the dat. sg., whereas $-i$ fails also in masc. $i$-stems and $r$-stems.

5. The assumption of original * sege is supported by OE mene 'necklace', a neut. $j a$-stem tranferred to the $i$ stems; probably also dili 'dill' (cf. OS dilli) in the Corpus Glossary, acc. sg. dile in EWS, as well as a few OHG forms like beti beside betti 'bed' noted below (Dal 1934, Braune 2004a: §201 Anm. 4). It is also implied by the appearance of geminates in some $i$-stems, e.g. OE gen. sg. hysses to nom. hyse 'warrior', best explained on the assumption that the nom. of $j a$-stems resembled that of $i$-stems (Dahl 1938: 84-6). Boutkan (1995b: 209-13) offers an alternative analysis whereby there was the development $*$ mannja ${ }^{n}>*_{m e n n}>$ *men, with analogical addition of the final vowel. His analysis of the $j a$-stems (assuming a development comparable to nom. sg. $j \bar{o}$-stem *synnju $>*$ *synnu $>$ synn 'sin') requires the assumption that the apocope of $-a(z)$ and of $-i$ represent the same phonological development, though they are usually regarded as widely separated in time: Luick (1914-40: 3350 ), e.g., dates the former to the $2^{\text {nd }}$ or $3^{\text {rd }}$ cent., the latter to the beginning of the $7^{\text {th }}$ in OE, i.e. less than a century before the appearance of the earliest OE manuscripts. The dating of the latter is controversial (see Fulk 1992: $\S \S 402-4$ ), but since the umlaut in OE caused by unapocopated $*_{-i}$ postdates the period of Anglo-Frisian unity (Fulk 1998a: 153), Luick's position seems likely.

\subsection{The wa-stems}

These nouns, with stems ending in PIE $* u$ before the theme vowel, were originally formed like the $j a$-stems but with $*_{-} w$ - where the $j a$-stems had $-j$ - This $w$ remains before vowels, but in finality it is often vocalized to $u$ and may undergo further developments, as summarized below. Typical are the paradigms of Go. pius 'servant', OIcel. horr 'flax', OE bearu 'grove', OS skado 'shadow', OHG horo 'dirt', all masc. except the last, which is neuter:

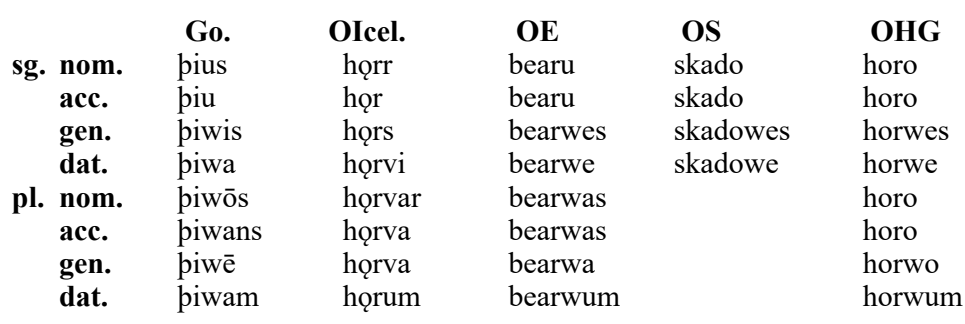

The following details are relevant:

Gothic. Few of these forms are actually attested, though the paradigm is reconstructible on the basis of comparison to other $w a$-stems nouns in Gothic. The vocalization of $w$ seen in the nom./acc. sg. does not occur in heavy stems, e.g. snáiws 'snow'. The light-stemmed neuters are like nom./acc. sg. kniu 'knee', nom./acc. pl. kniwa, the heavy like nom./acc. sg. gáidw 'lack', pl. gáidwa. 
Old Icelandic. Final $*-w\left(\right.$ from $\left.*-w a^{n}\right)$ is vocalized and then lost (after mutating the root vowel), as in the acc. sg.; so also in the nom./acc. sg. and pl. of neuter nouns, e.g. hogg 'blow', bol 'misfortune'. Medially, ${ }^{*} w$ is lost before $-u m$ in dat. pl. horum.

West Germanic. There are no light-stemmed masc. nouns of the type in OHG to be compared with the OE and OS forms. Just a few OS plurals are attested: acc. knio, cneo 'knee', bu 'farm', gen. beuwo 'harvest', dat. kneohon 'knee'. Before $u$, WGmc. $w$ should have been lost, as in OIcel; hence, OE dat. pl. bearwum is analogical, as are OE nom./acc. pl. neut. searu 'devices' (replacing *saru $<*^{*}$ sarwu $<*^{*}$ sarwō). Since this loss preceded OE breaking, the diphthong in such forms, and in forms such as nom. sg. bearu, must be due not to breaking but to analogy to the cases retaining $w$ (see Hogg \& Fulk 2011: $\S \S 2.28 \mathrm{a}, 2.31 .1)$. Stems with an original long vowel or diphthong before $*_{-} w$ - should have lost the $*_{-} u$ to which this was vocalized when final, but there is almost always analogical restoration of $-w /-u /-o$ in such forms, e.g. OE $s n \bar{a} w$ 'snow' beside rare snā $<*$ snāu $<*$ snaiwaz, OHG hleo 'shelter' beside lēe, gen. sg. hlēwes. Short non-back vowels formed a diphthong with final $*_{-} u<*_{-} w$, e.g. OS treo 'tree' beside gen. -treuues. In $\mathrm{OE}$, the diphthong so formed was usually extended to the inflected forms, and the $-w$ - of the inflected forms to the uninflected, so that gen. *pewes 'servant' was re-formed as pēowes, and nom. pēo as pēow: for details, see Fulk 1992: 146-52.

\subsection{The $\bar{o}$-stems}

This class in Gmc. reflects the so-called PIE $\bar{a}$-stems (since PIE $\bar{a}$ gives Gmc. $\bar{o}$ ), which are all feminine. The same class is reflected in the Latin first declension, e.g. lingua 'tongue' (earlier $*_{-} \bar{a}$ ), and in Greek feminines of the first declension, e.g. $\chi \omega \dot{\omega} \rho \bar{\alpha}$ 'land', $\tau \bar{\imath} \mu \eta^{\prime}$ 'honor' (with $\eta$ from $\bar{\alpha}$, as preserved in Doric). The IE vowel $-\bar{a}$ - that characterizes stems of this class must derive from earlier $-e h_{2^{-}}$, to which, originally, the case endings of athematic nouns were added directly, though there is no ending $*_{-s}$ in the nom. sg., perhaps because it was assimilated to the preceding laryngeal. Parallel to the situation in the $a$-stems, this category includes two major subclasses, $j \bar{o}$-stems and $w \bar{o}$-stems.

\subsection{The simple $\bar{o}$-stems}

There is no distinction in any language between nom. and voc. in this class, nor between dat. and instr. The light-stemmed type may be typified by the paradigm of Go. giba 'gift' and its cognates:

$\begin{array}{llllll} & \text { Go. } & \text { OIcel. } & \text { OE } & \text { OS } & \text { OHG } \\ \text { sg. nom. } & \text { giba } & \text { gjơf } & \text { giefu } & \text { geba } & \text { geba } \\ \text { acc. } & \text { giba } & \text { gjǫf } & \text { giefe } & \text { geba } & \text { geba } \\ \text { gen. } & \text { gibōs } & \text { gjafar } & \text { giefe } & \text { geba } & \text { gebā } \\ \text { dat. } & \text { gibái } & \text { gjǫf } & \text { giefe } & \text { gebu } & \text { gebu } \\ \text { pl. } \text { nom. } & \text { gibōs } & \text { gjafar } & \text { giefa } & \text { geba } & \text { gebā } \\ \text { acc. } & \text { gibōs } & \text { gjafar } & \text { giefa } & \text { geba } & \text { gebā } \\ \text { gen. } & \text { gibō } & \text { gjafa } & \text { giefa } & \text { gebono } & \text { gebōno } \\ \text { dat. } & \text { gibōm } & \text { gjơfum } & \text { giefum } & \text { gebum } & \text { gebōm }\end{array}$

Inflectional variants:

Old Icelandic. Nouns like gjof $<*$ gebu show $u$-fracture in the nom., acc., and dat. sg. and in the dat. pl. (in all which cases nouns like grof 'pit' show $u$-mutation) and 
$a$-fracture in the rest of the paradigm (see §4.8). Nouns in -ing (e.g. kerling 'old woman', dat. -ingu) and a few others bore the inflection $-u$ in the dat. sg. before apocope, as did many personal names, e.g. Ingibjorg $<*$-berzu, which additionally bore the same inflection in the acc. singular. ${ }^{1}$ A number of $\bar{o}$-stem nouns in OIcel. are declined also (somewhat later) as $i$-stems.

West Germanic. Nom. sg. $*_{-} \bar{o}>-u$ was lost after heavy and resolved stems (§5.6), giving, e.g., OE lār 'instruction' beside light giefu. However, in OS and OHG the acc. sg. ending ${ }^{*}-\bar{o}^{n}>-a$ was extended to the nominative, e.g. OS OHG lèra 'instruction' (compare how the $a$-stem nom. and acc. are formally identical), though there are a few early exceptions, e.g. OS tharf 'need', OHG scouwunc 'inspection' and, retaining $-u$ and even extending it to the accusative, some OHG nouns in -ung- and -id-, such as ladungu 'invitation' and grätidu 'diligence'. As with the $a$-stems, there is considerable variability in the form of the inflections in OS and OHG, e.g. gen. sg. $-u,-o$, dat. pl. -on, -un. In OE, the etymological endings should be nom. pl. - $a$, acc. pl. -e (see Hollifield 1980: 42-3); WS has generalized the former to the latter case (though $-e$ is still found occasionally in EWS), the Anglian dialects the reverse. In WGmc., the gen. pl. inflection of the $n$-stems replaces the original ending - $a$ in OS and OHG, whereas in WS -ena is found chiefly in poetry, and usually only after light stems, so that the usual inflection $-a$, though identical to the original inflection, is probably an analogical reintroduction, given the linguistic conservatism of verse. Compare Skt. gen. pl. aśvānām 'mares'. EWS gief- shows diphthongization by initial palatal consonant (\$4.13), corresponding to LWS gyf-, gif-, Anglian gef-, geof-.

1. Boutkan (1995b: 228) explains this $-u$ as adopted from the $n$-stems, Myrvoll (2015) as reflecting PNorse *-ūn, bearing the ending PIE *-mi found also in Balto-Slavic instrumentals.

\subsection{Origin and development of $\bar{o}$-stem inflections}

The following inflections require comment:

Nom. sg. PIE *-a (from earlier $*_{-} a h_{2}$, perhaps from $*_{-} e h_{2} h_{2}<*_{-} e h_{2}-s$ ) $>$ PGmc. $*_{-} \bar{o}$, yielding NWGmc. * ${ }_{-} u$, as in Runic lapu 'invitation', OIcel. loð.

Acc. sg. PIE *-ām (earlier $*_{-} e h_{2}-m$ ) produces PGmc. ${ }^{*}-\bar{o}^{n}$, which develops regularly to $-a$ in Go. and to $\mathrm{OE}-e$, OS $-a / e, \mathrm{OHG}-a$. It is usually assumed that in NGmc. the nom. inflection was extended to the accusative, causing $u$-mutation in the appropriate stems before its loss, though Kortlandt (2005: 2) argues that the original ending, reflected as Runic -o, caused $u$-umlaut and was subsequently lost. This assumption demands an unusual analysis of the corresponding adj. ending $-a(\$ 9.2)$.

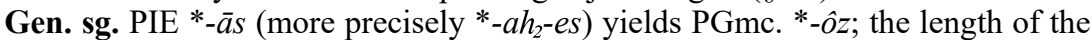
vowel of $\mathrm{OHG}-\bar{a}$ is thus to be deduced, as there is no direct evidence (Braune 2004a: $\S 207$ Anm. 3, contra Krahe \& Meid 1969: II, §10). OE gen. sg. - e (for etymological - $a$, as in ermða 'misery', Vespasian Psalter) is by analogy, perhaps to the original acc. pl. inflection (so Flasdieck 1930: 60; cf. Boutkan 1995b: 227, Kortlandt 2005: 3), since the two inflections are identical in the other chief class of fem. nouns, the fem. $n$-stems (§7.14). It has been asserted instead that the PGmc. inflection was ${ }^{*}-\bar{o} z$, with a bimoric vowel, and OE - $e$ is thus etymological (Ringe \& Taylor 2014: 59).

Dat. sg. PIE *-āi (more precisely *-eht-ei) gives PGmc. *-ôi, which develops regularly in Gothic and in $\mathrm{OE}$. The other languages reflect $*_{-} u<^{*} \bar{o}$, which may be 
either a shorter form of the PIE dative inflection (\$7.8) or, more probably, an original instrumental, in either event from PIE $*-\bar{a}$.

Nom. pl. PIE *-ās (more precisely $*_{-} a h_{2}-e s$ ) yields PGmc. *-ôz, which develops the same way as the gen. sg. inflection.

Acc. pl. PIE *-ās $<*_{-} \bar{a} n s$ (cf. Skt. acc. pl. aśvāh 'mares') is usually assumed to have developed the same way as the nom. pl. inflection. However, early OE and Anglian $-e$ is best derived from PGmc. ${ }^{*}-\bar{o} z$, with a bimoric rather than trimoric vowel. See Stiles 1988: 131, Bammesberger 1990: 105. To what extent the identity of nom. and acc. forms in the other languages is the product of analogy is difficult to determine: see Syrett 1994: 123-32 for discussion and references, and Schrijver 2004: 207-9 for an alternative analysis (to which cf. Kortlandt 2005: 3-4).

Gen. pl. PGmc. *- $\hat{o}^{n}$ develops to $-\bar{o}$ in Gothic, $-a$ elsewhere. Note the Gothic opposition between $-\bar{e}$ in the $a$-stems and $-\bar{o}$ in the $\bar{o}$-stems.

Dat. pl. PIE *-a-mis yields PGmc. *-ôm (with trimoric vowel perhaps by analogy to the gen. pl.), which develops regularly in all languages.

\subsection{The jō-stems}

In Gmc. these bear the same relation to the $\bar{o}$-stems that the $j a$-stems do to the $a$-stems. The light-stemmed nouns of this type are inflected the same way as the simple $\bar{o}$-stems in all the Gmc. languages. (As a consequence, some grammars distinguish between light and heavy stems as $j \bar{o}$ - and $i \bar{o}$-stems, respectively.) Only in the nom. sg. of heavy stems in Gothic and NGmc. does the inflection differ from that of the $\bar{o}$-stems. The pattern may be illustrated by Go. bandi 'band', OIcel. heiðr 'heath', and the WGmc. words for 'rod':

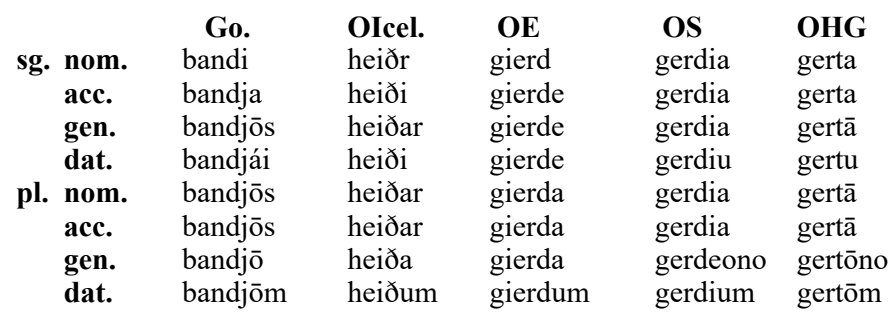

The light-stemmed type, however, is inflected the same way as the $\bar{o}$-stems, e.g. Go. nom. acc. wrakja 'persecution', OIcel. nom. acc. sg. ben 'wound', OE nom. synn 'sin', acc. synne. Go. mawi 'girl', inflected like a heavy stem, is heavy in origin (*mazw-), as is probably piwi (see Lehmann 1986, s.v.). Inflectional variants:

Old Icelandic. After a light root, stem-final $/ \mathrm{j} /$ is preserved before back vowels, e.g. gen. sg. benjar 'wound', dat. pl. eggjum 'edges' (the latter root light before gemination) : nom. sg. ben, egg. Also in the light stems, the dat. sg. inflection may be either $-u$ or null, e.g. dat. sg. ben, dregg 'yeast', eggju, helju 'death'. In the heavy stems, $j$ is preserved before back vowels only after a velar consonant.

West Germanic. In OHG, nouns in WGmc. *-innjō in the nom. (and sometimes acc.) sg. may be inflectionless, as with kuningin 'queen', as may dithematic names and the noun thiu 'maid' (cf. Go. piwi, gen. piujos), and this is the original situation for the light-stemmed nouns. The reflex of $*_{-j}$ - in OS may be spelt either $\langle i\rangle$ or $\langle\mathrm{e}\rangle$. This ele- 
ment may also be preserved before all endings in OHG in texts of the eighth century, and similarly spelt, e.g. nom. sg. suntea, suntia 'sin'. In such early texts there are also forms in simple -e, e.g. nom. acc. gen. sg., nom. acc. pl. sunte, where -e reflects *-ja, formed by analogy to the $\bar{o}$-stems. Otherwise, only the presence of umlaut (and gemination) distinguishes these from $\bar{o}$-stems in WGmc.

\subsection{Origin and development of $j \bar{o}$-stem inflections}

Although stems in nom. $*_{-i} \bar{a}<*_{-} \underline{i} e h_{2}$ do occur in the IE languages (e.g. Skt. vidyáa 'knowledge', Gk. (Ionic) $\dot{\alpha} \lambda \eta \theta$ cin 'truth' <*-esia $\bar{a}$ ), these are all secondary formations. For expected $*_{-} i \bar{a}<*_{-} i e h_{2}$, PIE had instead the reduced grade nom. $*_{-}-\bar{\imath} *_{-} i h_{2}$ (cf. Skt. pálikni 'cow for the first time with calf'), perhaps with the variant *-i $h_{2}$ : cf. Gk. $\tau \rho \dot{\alpha} \pi \varepsilon \zeta \alpha$ 'table' $<*\left((\right.$ te)trapedia $) .{ }^{1}$ This was the chief means of forming feminine alternants to athematic stems, e.g. Skt. dēvi 'goddess' (cf. masc. dyauh), including fem. forms of pres. parts., e.g. Skt. bhárantī 'bearing' (like Go. fem. frijōndi 'friend' (i.e., 'loving (one)', with $-i$ for normal $-e i$ because the word was no longer recognized as a participle). ${ }^{2}$ The lack of an inflectional $-s$ in the nom. indicates the connection between such forms and the PIE $\bar{a}$-stems. Another type bore consonant-stem inflections on an ac-

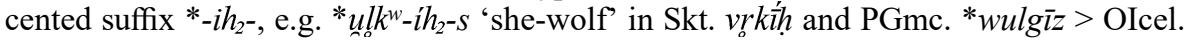
$y \lg r$, inflected like heiðr (but with $j$ after the stem-final velar consonant when a back vowel follows).

Nom. sg. PIE $*_{-} \bar{\imath}<*_{-} i h_{2}$ (or perhaps PGmc. ${ }_{-} i<$ PIE $*_{-i} i h_{2}$, with PGmc. loss of the final syllabic laryngeal ( $\$ 5.5 \mathrm{ad}$ fin.) and vocalization of $i$ ) is reflected in Gothic as $-i$, and the ending undergoes regular loss in OE after a heavy syllable, whereas in OS and $\mathrm{OHG}$ the ending of the pure $\bar{o}$-stems replaces it. In OIcel. it was replaced by the nom. sg. inflection of the fem. $i$-stems of the nauðr type (\$7.22), except in names in -dis or -unn. In OE, the nom. sg. of light stems is properly inflectionless, by loss of $*_{-j}-$ after the heavy syllable created by WGmc. gemination in, e.g., *bannjo $>*$ bennju $>*$ bennu, producing OE ben $(n)$ 'wound' by loss of *-u after the heavy syllable (\$5.6).

Acc. sg. Again there occur reduced-grade variants, PIE *-ìm (cf. Skt. dēvīm) and ${ }^{*}-i h_{2} m$ (cf. Skt. vrkyàm 'she-wolf', Gk. $\tau \rho \alpha \dot{\pi} \pi \varepsilon \zeta \alpha \nu$ ), but the Gmc. forms reflect the fullgrade ending of the simple $\bar{o}$-stems added to stem-final $*_{-j-}$.

The rest of the $j \bar{o}$-stem inflections surviving in Germanic were in full-grade form in PIE, and so it is unsurprising that they resemble the inflections of pure $\bar{o}$-stems.

1. Full-grade *-īa- occurred in the oblique cases of the sg., e.g. Skt. gen. dēvyāḥ: see, e.g., Szemerényi 1996: \$7.7.3.

2. The original ending $*_{-} \bar{\imath}$ is nonetheless fossilized in the Go. fem. inflections on pres. parts., which have been reformed as $\bar{i}$-stems. For this reason the idea of Boutkan (1995b: 231-5) that the normal PGmc. ending reflected PIE $*_{-i n} h_{2}$ rather than ${ }^{*}-i h_{2}$ seems unlikely (though he also assumes a development $*_{-j} a>*_{-i} i a *_{-} \overline{\text { ) }}$.

\subsection{The $w \bar{o}$-stems}

These are inflected the same way as the simple $\bar{o}$-stems, and so all that need be remarked is the treatment of the stem-final $w$. This is retained in Gothic in all cases, e.g. nom. sg. bandwa 'sign', gen. sg. bandwōs, etc. In NGmc. and WGmc., $w$ is lost before $u$ (which may be from $\bar{o}, \S 5.3$ ), and this results in paradigms like OIcel. nom. sg. or 'ar- 
row' < PGmc. *arwō, gen. sg. grvar. In OE, $w$ in final position is vocalized, whereupon, like $u$ from other sources, it is apocopated after a heavy syllable, hence lās 'pasture' < *lesswō : sinu 'sinew' <* sinwō. Where it was lost before $u$ it is commonly restored by analogy, hence OE dat. pl. lēswum (beside earlier lēsum), sinwum, though especially in early texts, in many forms $w$ is lost even when it does not stand before $u$, e.g. acc. sg. $m \bar{x} d e$ 'meadow'. In OS and OHG, postconsonantal $w$ is lost everywhere, so that $w$ is preserved only in forms like OS dat. pl. brāwon 'brows' (beside brāhon), OHG nom. sg. drawa, drowa, drouwa, drō 'menace'. ${ }^{1}$ In OS gen. pl. frato $(h) o$ 'trappings' may be seen anaptyxis before $w$ (cf. OE frætwa), which was subsequently lost.

1. These are comparable to OE prēa 'menace' < *brau < WGmc. *brawu (§6.16 ad fin.) beside OE clawu 'claw', with the stem claw- re-introduced from, e.g., gen. sg. clawe.

\subsection{The $i$-stems}

In PIE these were of all genders, inflected alike, whereas in PGmc. there were originally few $i$-stems of neuter gender (of which PGmc. *mari (or *mariz?) 'sea' is a secure example), most of the attested examples in WGmc. having been transferred to this class from others, especially the $s$-stems. In Germanic there arose inflectional differences between the masc. and fem. nouns, since in all the Gmc. languages there is a tendency toward analogical reformation under the influence of the $a$ - and $\bar{o}$-stems. On a phonological basis, in WGmc. there arose differences between the inflection of heavy and light stems, due to the loss of high vowels after heavy syllables (§5.6). In PIE these exhibited proterokinetic accentuation, i.e. accent on the root in the strong cases, otherwise on the suffix.

\subsection{The masculine and neuter $i$-stems}

The inflection of the heavy-stemmed type may be illustrated by the paradigms of Go. gasts 'guest' and its cognates: ${ }^{1}$

$\begin{array}{llllll} & \text { Go. } & \text { OIcel. } & \text { OE } & \text { OS } & \text { OHG } \\ \text { sg. nom. } & \text { gasts } & \text { gestr } & \text { giest } & \text { gast } & \text { gast } \\ \text { voc. } & \text { gast } & & & & \\ \text { acc. } & \text { gast } & \text { gest } & \text { giest } & \text { gast } & \text { gast } \\ \text { gen. } & \text { gastis } & \text { gests } & \text { giestes } & \text { gastes } & \text { gastes } \\ \text { dat. } & \text { gasta } & \text { gest } & \text { gieste } & \text { gaste } & \text { gaste } \\ \text { instr. } & & & & \text { gastiu } & \text { gastiu } \\ \text { sg. nom. } & \text { gasteis } & \text { gestir } & \text { giestas } & \text { gesti } & \text { gesti } \\ \text { acc. } & \text { gastins } & \text { gesti } & \text { giestas } & \text { gesti } & \text { gesti } \\ \text { gen. } & \text { gaste } & \text { gesta } & \text { giesta } & \text { gestio } & \text { gesteo } \\ \text { dat. } & \text { gastim } & \text { gestum } & \text { giestum } & \text { gestium } & \text { gestim }\end{array}$

Inflectional variants:

Old Icelandic. Stems ending in a velar consonant retain $j$ before inflectional back vowels, e.g. gen. pl. bekkja, dat. pl. bekkjum beside nom. sg. bekkr 'bench'. Such may also have gen. sg. in -ar, hence bekkjar beside bekks; the $-s$ form is borrowed from the $a$-stems, as is the $-i$ in dat. sg. gest $i$ beside gest.

West Germanic. There is, as in other classes, considerable variability in the spelling of the inflections in OS and OHG, e.g. OS dat. pl. gestiun, gestion, gesteon, 
OHG gestin, gesten. Also in OS and OHG, umlaut fails in the nom. acc. sg. because of the loss of $-i$ after heavy syllables ( $\$ 5.6)$, whence the unmutated vowel may have spread to the other cases of the singular (if these indeed originally underwent umlaut: see below), since this serves to heighten the contrast between singular and plural. In OE, $i$ umlaut was earlier (§5.6), so that it preceded loss of $-i$ after heavy syllables.

In Gothic there is no distinction in the inflection of light and heavy $i$-stems. The inflection of the light stems in the other languages may be illustrated by paradigms of OIcel. vinr 'friend' and its cognates:

\begin{tabular}{|c|c|c|c|c|c|}
\hline & & OIcel. & OE & OS & OHG \\
\hline & nom. & vinr & wine & wini & wini \\
\hline & acc. & vin & wine & wini & wini \\
\hline & gen. & vinar & wines & win(i)es & wines \\
\hline & dat. & vin & wine & wini, win(i)e & wine \\
\hline $\mathbf{s g}$ & instr. & vinir & $\begin{array}{l}\text { Wine } \\
\text { wine winas }\end{array}$ & $\begin{array}{l}\text { Wini(u) } \\
\text { wini winios }\end{array}$ & wini \\
\hline & acc. & vini & wine, winas & wini, winios & wini \\
\hline & $\begin{array}{l}\text { gen. } \\
\text { dat. }\end{array}$ & $\begin{array}{l}\text { vina } \\
\text { vinum }\end{array}$ & $\begin{array}{l}\text { wina, winiga } \\
\text { winum }\end{array}$ & $\begin{array}{l}\text { winio } \\
\text { winiun }\end{array}$ & $\begin{array}{l}\text { winio, wino } \\
\text { winim }\end{array}$ \\
\hline
\end{tabular}

Nom. pl. OE wine and OS wini are the original forms; OE - $e$ is found only in early or poetic texts and on ethnic names, e.g. Dene 'Danes', with analogical extension to heavy stems, e.g. Seaxe 'Saxons' (without umlaut). OE winas and OS winios have been reformed under the influence of the $a$-stems. Likewise, OE wina and OHG wino show substitution of the $a$-stem inflection; the earlier forms are OE winiga (very rare, and paralleled only by Deniga 'Danes') and OHG winio: see Fulk 1992: 243-5. Unlike wini, most OHG light $i$-stems in have been altered analogically to inflect like heavy stems, with removal of umlaut in the sg., e.g. nom. sg. slag 'stroke': see Boutkan 1995b: 2423 for lists of forms with and without $-i$ and/or umlaut and a conspectus of explanations.

Neuter $i$-stems, which remain distinct only when light-stemmed, are preserved only in OE and OS, where they are declined like the masculines, but with $-u$ in the nom. and acc. pl., e.g. OE speru 'spears', OS urlagu 'wars'. A possible neuter $i$-stem in OHG is indicated by dat. sg. meri 'sea' (Sievers 1877-8: 107, Krahe \& Meid 1969: II, §14), though this is indistinguishable from the fem. dative. Go. marei 'sea' shows reformation of an original neuter as a fem. $\bar{l} n$-stem.

1. Not all these forms are actually attested, though all the given inflections themselves are.

\subsection{Origin and development of masculine and neuter $i$-stem inflections}

In PIE, stem-final weak-grade $*_{-} i$ - appeared in the nom. acc. sg. and throughout the plural except for the nom. voc.; elsewhere this stem formative took the full-grade form $*_{-}^{*} i-$, and in the loc. sg. the lengthened grade *-eit. To these stem-forms were added the usual athematic inflections $(\S 7.2)$.

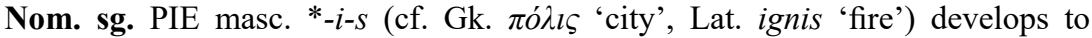
PGmc. ${ }^{*}-i z$, which is reflected as -iR in Runic, e.g. in names in -gastiR. This develops regularly in all dialects. PIE neut. ${ }^{*}-i-m$ develops the same way as the acc. (below).

Voc. sg. The PIE vocative ending was probably *-ei (i.e. an endingless form with full grade of the $i$-suffix), as reflected in Skt. agne 'fire': cf. the parallel in the $u$-stems (e.g. Go. sunau 'son', §§7.24-5), and see Szemerényi 1996: §7.5.1. As in Greek (cf. 
$\pi \delta \lambda_{l}$ ), this must have been replaced in Germanic by $*_{-} i$, by analogy to the $a$-stems, where the voc. is identical to the bare stem of the nom. and accusative. This $*_{-} i$ is then lost by regular phonological development in Gothic (\$5.2). Another possibility is that PGmc. $*_{-} \bar{l}$ was replaced by the $a$-stem voc. inflection $*_{-} e$ (without change to $*_{-} i$ : so Boutkan 1995b: 244). Only Gothic maintains a distinction between nom. and voc.

Acc. sg. PIE masc. and neut. $*_{-i-m}$ develops to $*_{-} i^{n}$ and is lost altogether after heavy syllables in the Gmc. languages, leaving its trace only in the $i$-umlaut of the root vowel in OIcel. and OE. After light syllables it is preserved in WGmc. (becoming $-e$ in $\mathrm{OE})$ but lost phonologically in NGmc. (\$5.6). In Gothic it is lost on a morphological basis, since the inflection on light stems was replaced analogically by that on the heavy.

Gen. sg. In PIE the stem-final $\underline{i}$ was preceded by a full-grade vowel; hence, the stem ended in $*_{-}-\underline{i}$ - or $*_{-o i-}$ (see, e.g., Szemerényi 1996: §7.5.1, Fortson 2010: 120), to which the zero-grade form ${ }^{*}-s$ of the gen. inflection was added. If it was the former that was inherited, this should have developed to ${ }^{*}-\bar{l} s$ or ${ }^{*}-\bar{l} z$ in PGmc. (see $\$ \S 3.4,6.6$ ), but in that event the Gothic and $\mathrm{OHG}$ inflections tell against the supposition of a long vowel, so that it is safest to assume replacement by the corresponding $a$-stem inflection. (Otherwise Ringe 2017: 311.) If this was at an early date (and otherwise it must have happened at different times in the Gmc. branches), the $i$-umlaut of the root vowel in OIcel. and OE must be analogical. If it was PIE *-ois that was inherited, this would explain the Go. fem. ending (see below, §7.22), and possibly the North and West Gmc. light-stem masc. endings. On the merits of the competing explanations of ON -ar on the light stems either as reflecting etymological *-aiR or as analogical, see Syrett 1994: 93104, favoring the latter; Stiles (1984: 10-12) and Boutkan (1995b: 244-6) conclude otherwise. See further Grønvik 1981: 63-5, 205-6. OS winies cannot directly reflect the so-called open-inflected variant of the PIE $i$-stem gen. sg. *-i-os (as in Skt. ávyah 'sheep': see Szemerényi 1996: $§ \S 7.5 .2-3$ ), as this should have produced gemination of the preceding consonant (though such could have been leveled out); more likely OS has simply generalized wini- as the stem, as in the case of the dat. pl. (see below).

Dat. sg. The PIE suffix plus inflection was probably *-ei-ei, as in Skt. agnayē, parallel to the $u$-stem inflection *-eu-ei (see $§ 7.23$ ), as this may plausibly be assumed to produce, by haplology, the $*_{-} e \underline{i}$ that underlies Lat. ignī, OCS gosti 'guest' and others. This $*_{-} e i$, if assumed for Gmc. as well, would produce PGmc. $*_{-} \bar{l}$, and this would explain the endingless dative of OIcel., as well as early OE spellings in $-i$ (beside $-x$, the latter borrowed from the $a$-stems: see A. Campbell 1977: $\$ 601)$. It could also explain OS wini (so Krahe \& Meid 1969: II, §13, though deriving the ending from PIE loc. *-ei or instr. ${ }^{*}-\vec{l}$ ), though this could also be the result of generalization of the stem wini- (as with the gen. sg. above), with analogical addition to this in some instances of the $a$-stem inflection in its variant spellings. ${ }^{1}$ All the remaining Gmc. forms can be explained as reformed by analogy to the $a$-stems. Yet the Gmc. dat. sg. usually reflects the PIE locative, and so Antonsen (1972: 138) proposes the derivations PIE *-ei- $i>$ PGmc. *$i(j) i>$ NWGmc. $*_{-} \hat{\imath}$ and PIE $*_{-o i-i}>$ PGmc. $*_{-} a(j) i>$ Go. $-a i$ (though the Go. inflection is actually $-a$, which may result from PGmc. *-ai but probably not*-âi: see $§ 5.4)$.

Instr. sg. Krahe \& Meid (1969: §13) see the PIE instr. *-i underlying OE -e, OS $-i$. But the OE instr. is never distinguished from the dat. in nouns, so that analogy to the dat. must not be ruled out. OS OHG - $i u$ shows analogical addition of the $a$-stem inflection to the stem in $-i-$.

Nom. pl. The masc. inflection is PIE *-ei-es (cf. Skt. agnayah) $>$ PGmc. *-i(j)iz, which is usually assumed to have developed to $*_{-} \hat{\imath} z$. This accounts for the Go. and 
OIcel. inflections, but WGmc. presents some difficulties, since OHG $-i$ is certainly short (Braune 2004a: $\$ 215$ Anm. 4), and the meter of Beowulf tells against deriving -e from a trimoric vowel unless trimoric high vowels were shortened earlier than trimoric nonhigh vowels (on which see Fulk 1992: 421-2). The likeliest explanation is that the nom. inflection is analogical to the accusative (Prokosch 1939: 246), yet even so, $i$ ought to have been lost after a heavy syllable (§5.6), so that the OS and OHG endings in the heavy stems are probably best explained as analogical to the ending in light stems. ${ }^{2} \mathrm{An}$ alternative solution is to assume that WGmc. ${ }^{*} i$ represents a generalization of the reflex of the PIE so-called open-inflected type of $i$-stem nom. pl. *-i-es, though the evidence for the survival of the open-inflected type in Gmc. is sparse: see Szemerényi 1996: $\S \S 7.5 .2-3$, especially regarding Go. kinnus 'cheek' and manna 'man'. The ending $-u$ on $\mathrm{OE}$ and OS neuters must be regarded as analogical to the $a$-stem ending.

Acc. pl. PIE masc. *-i-ns develops regularly in Germanic (cf. §7.8), except that $\mathrm{OE}$ winas beside earlier wine and OS winios beside earlier wini are analogical to the nom.

Gen. pl. The PIE inflection was perhaps *-i-(oH)om. The development of this in Gothic is subject to some of the same uncertainties that attend the development of the $a$ -

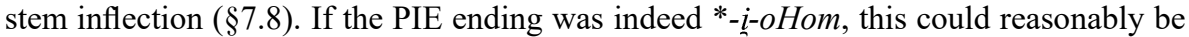
supposed to have resulted in forms like OIcel. bekkja, OE winiga 'friends', and OS winio; if it was instead $*_{-} \underline{i}$-om, the reflex of PIE $*_{-i-}$ - may have remained part of the stem, with replacement of the inflection by the $a$-stem inflection.

Dat. pl. PIE instr. *-i-mis develops regularly as the dat. inflection in Go. and OHG, whereas the other languages show the analogical influence of the $a$-stems. On the supposition that this change is attested already on the seventh-century Stentoften stone, see $\$ 4.7$ n. 4 .

1. In Abrogans there occur a few light-stemmed OHG datives in - $i$, which Boutkan (1995b: 248) considers original, though such forms are more usually regarded as analogical to the nom. acc. sg. (so, e.g., Braune 2004a: \$217 Anm. 4).

2. Such analogical restoration on the basis of light stems is encountered in some other grammatical categories in OS and OHG, e.g. imp. sg. OS sōki, OHG suochi 'seek' (cf. OE $s \bar{e} c$ ). This analysis is perhaps reinforced by the observation that whereas the $i$-stems were a moribund class in $\mathrm{OE}$, this was not the case in regard to German.

\subsection{The feminine $i$-stems}

The Gmc. inflections of the heavy-stemmed fem. $i$-stems may be illustrated by the paradigms of Go. ansts 'favor' and its cognates:

$\begin{array}{llllll}\text { Go. } & \text { OIcel. } & \text { OE } & \text { OS } & \text { OHG } \\ \text { sg. nom. } & \text { ansts } & \text { ást } & \text { êst } & \text { anst } & \text { anst } \\ \text { voc. } & \text { anst } & & & & \\ \text { acc. } & \text { anst } & \text { ást } & \text { èst(e) } & \text { anst } & \text { anst } \\ \text { gen. } & \text { anstáis } & \text { ástar } & \text { ēste } & \text { ensti } & \text { ensti } \\ \text { dat. } & \text { anstái } & \text { ást } & \text { èste } & \text { ensti } & \text { ensti } \\ \text { pl. nom. } & \text { ansteis } & \text { ástir } & \text { ēsta } & \text { ensti } & \text { ensti } \\ \text { acc. } & \text { anstins } & \text { ástir } & \text { êsta, -e } & \text { ensti } & \text { ensti } \\ \text { gen. } & \text { anstē } & \text { ásta } & \text { ēsta } & \text { enstio } & \text { enstio } \\ \text { dat. } & \text { anstim } & \text { ástum } & \text { êstum } & \text { enstium } & \text { enstim }\end{array}$


Inflectional variants:

Old Icelandic. The alternant óst (cf. also dat. pl. óstum) shows $u$-umlaut by analogy to the $\bar{o}$-stems. Some nouns, e.g. nauð 'necessity', have also a nom. sg. in $-r$ (naudr), which is the older form, those without $-r$ being subject to the influence of the $\bar{o}$ stems. Quite a few OIcel. $i$-stems were originally $\bar{o}$-stems and may therefore have dat. sg. in -u, e.g. rostu 'mile'. Note that there is no umlaut anywhere in the paradigm, indicating early replacement of $i$-stem endings by $\bar{o}$-stem ones in most case-forms and generalization of the stem without umlaut in the remainder.

West Germanic. OE still frequently has an uninflected acc. sg.; forms with acc. sg. $-e$ have it by analogy to the $\bar{o}$-stems. OE attests an early gen. sg. uyrdi (Leiden Riddle) beside analogical forms in -æ. In OS and OHG there are the expected variants, e.g. OS gen. sg. enste, dat. enstiu. One would expect instrumentals (in locative use) like OHG steteo 'place' to be late creations, but they are confined to early texts (Braune 2004a: \$218 Anm. 3). On OS endingless datives and their analogical sources, see van Helten 1910: 468.

In Go. there is no distinction in the inflection of light and heavy fem. $i$-stems; likewise in OIcel. and OE, where the light stems have changed gender or declension. In $\mathrm{OS}$, the oldest light-stemmed fem. $i$-stems have $-i$ throughout the singular and in the nom. acc. plural. In OHG only kuri 'choice' and turi 'door' have $-i$ in the nom. acc. sg.; otherwise, such nouns are inflected the same way as the heavy fem. $i$-stems.

\subsection{Origin and development of feminine $i$-stem inflections}

The PIE fem. inflections were identical to the masc.; differentiation of the two genders in Germanic is due to the analogical influence of the $a$-and $\bar{o}$-stem inflections. As noted above (\$7.22), in North Germanic, the shift of so many fem. $i$-stems to the $\bar{o}$-declension

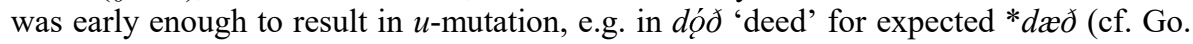
$d \bar{e} p s$ ); correspondingly, the lack of $i$-umlaut in forms like nom. pl. dádir is notable.

Gen. sg. The inflection must reflect the PIE $o$-grade variant *-oi-s, which develops regularly in Go. and OIcel. Euler (2013: 75) thinks an alternant PIE *-ei-s possibly explains the WGmc. forms (he compares the double formation in the gen. sg. of $a$ stems, but see §7.8); Krahe \& Meid (1969: II, §15) compare Oscan -eis. Boutkan (1995b: 34-5, 244-6) argues rather that OE uyrdi 'fate' (Leiden Riddle) proves the development $*_{-a i z}>$ WGmc. $-i$ (as opposed to $*_{-a i}>\mathrm{OE}-e$ ), improbable as that may seem, and this in turn constitutes one of three pieces of evidence for the derivation of Ingvaeonic directly from PGmc. rather than from NWGmc. But so much weight must not be accorded such an isolated form, given the possibility of scribal error. See further Hogg \& Fulk 2011: §2.68. H.F. Nielsen (2000: 244; cf. Grønvik 1998b: 124) admits the possibility that WGmc. *-iz has its vowel by analogy to the dat. sg.

Dat. sg. Go. -ái is commonly identified with the ending on Homeric Gk. $\pi \lambda_{\lambda} \lambda \dot{i}$ (though the Homeric final is syllabic) and derived from a PIE loc. ${ }^{*}-\bar{e} i$ (cf. $u$-stem loc. $*_{-} \bar{e} u$ ). The Go. ending could instead be analogical to the corresponding $\bar{a}$-stem inflection. This would render natural the derivation of the WGmc. ending, PIE *-ê $i>$ PGmc. $*_{-e i}>*_{-}-\bar{l}>$ WGmc. $-i$; but the different development of the corresponding back diphthongs $e u$ and $\bar{e} u$ is undeniable ( $\$ 5.3 \mathrm{ad}$ fin.). No matter the explanation, the inflectionless OIcel. form cannot be a regular phonological development. It is most likely analogical to the $\bar{o}$-stem form.

Acc. pl. OIcel. -ir is borrowed from the nom. 


\subsection{The $u$-stems}

In PIE these were formed the same way as the $i$-stems, but with stem-final $* u / u$ rather than $* i / i$, with the same variety of ablaut grades in the same cases, and all three genders were inflected alike, aside from the neut. nom. sg. and pl., which were, as always, identical to the acc. The masc. and fem. $u$-stems maintain identical inflections in Gmc., but almost no neuters remain, the securest examples being Go. faihu 'cattle, property', OE lī $p$ 'strong drink', and cognates; OIcel. mjoðr 'mead' and Gmc. cognates are masc., but they have neuter IE cognates. Due to the loss of high vowels after heavy syllables (§5.6), in WGmc. there arose an inflectional distinction between light and heavy stems. The $u$-stems were never very numerous in Gmc., and the class is moribund in WGmc. ${ }^{1}$ The declension may be illustrated by the paradigms of Go. sunus 'son' and cognates:

\begin{tabular}{|c|c|c|c|c|c|c|}
\hline & & $\begin{array}{c}\text { Go. } \\
\text { sunus }\end{array}$ & $\begin{array}{l}\text { OIcel. } \\
\text { sunr }\end{array}$ & $\begin{array}{c}\mathbf{O E} \\
\text { sunu }\end{array}$ & $\begin{array}{c}\text { OS } \\
\text { sunu }\end{array}$ & $\begin{array}{l}\text { OHG } \\
\text { sunu }\end{array}$ \\
\hline & acc. & sunu & sun & sunu & sunu & sunu \\
\hline & gen. & sunáus & sonar & suna & sunies & sunes \\
\hline & $\begin{array}{l}\text { dat. } \\
\text { instr. }\end{array}$ & sunáu & syni & suna & suno & $\begin{array}{l}\text { sune } \\
\text { suniu, sunu }\end{array}$ \\
\hline sg. & nom. & sunjus & synir & suna & suni & suni \\
\hline & acc & sununs & sunu & suna & suni & suni \\
\hline & $\begin{array}{l}\text { gen. } \\
\text { dat. }\end{array}$ & $\begin{array}{l}\text { suniwē } \\
\text { sunum }\end{array}$ & $\begin{array}{l}\text { sona } \\
\text { sunum }\end{array}$ & $\begin{array}{l}\text { suna } \\
\text { sunum }\end{array}$ & $\begin{array}{l}\text { sunio } \\
\text { sunum }\end{array}$ & $\begin{array}{l}\text { suneo, suno } \\
\text { sunim }\end{array}$ \\
\hline
\end{tabular}

Inflectional variants:

Gothic. In the singular, $-u$ - and -áu- in endings are occasionally confused, e.g. nom. sunáus, dat. sunu. ${ }^{2}$ A few neuters remain as such in Go., though no plurals to them are attested; they have $-u$ in the nom./acc. sg., as with faíhu 'cattle'.

Old Icelandic. Only masc. nouns remain in this class, the feminines having assimilated to the $\bar{o}$-stems, though relic forms like gen. sg. neut. fjár 'property' ( $a$-stem, to nom. fé) and dat. sg. fem. hendi 'hand' (consonant-stem, to hond) point to original affiliation with the $u$-stems. In the dat. sg. there are alternative, somewhat later forms that are most commonly endingless, showing $u$-mutation or $u$-fracture where possible, e.g. vond beside vendi 'rod', and hjørt beside hirti 'heart', and these are most likely based on the accusative. The alternation of $u$ and $o$ in sunr is due to $a$-umlaut of $u$ (§4.8); the alternation resulted in analogical extension of both stems, resulting in forms like nom. sg. sonr, nom. pl. sønir, gen. pl. suna.

West Germanic. The inflection of the heavy $u$-stems differs from that of the light only in that the nom. and acc. sg. are endingless, due to loss of *- $u$ after a heavy syllable (\$5.6). However, from an early date there is a tendency toward reformation in accordance with the $a$ - and $i$-stems for masculines, the $\bar{o}$-stems for feminines. Likewise, in OE the endings $-a$ and $-u$ are confused from an early date. OS has no light-stemmed feminines, OHG no heavy-stemmed masculines. The gen. sg. in OS and OHG is plainly reformed analogically; there are just a few, early traces of the original ending in OHG, e.g. frido 'peace'. OS fehu and OHG fihu, feho 'property' remain neuters, which may take the endings of $a$-stems in the gen. dat. sg.

1. On the Gothic $u$-stems in particular, see Neri 2003. 
2. The coöccurrence of such alternatives in the sg. only has suggested to some that Go. preserves a subsidiary amphikinetic $u$-stem type, i.e. with accent on the root in the strong cases and on the inflection in the weak. See Braune 2004b: §104 Anm. 2, with references.

\subsection{Origin and development of $u$-stem inflections}

The original endings closely parallel those of the $i$-stems, but with $* u / u$ where the $i$ stems have $* i / i$.

Nom. sg. PIE uter *- $u$-s develops regularly in Germanic. Neuter *- $u$ - $m$ develops like the acc. sg. (below).

Voc. sg. PIE *-ou would regularly produce PGmc. ${ }^{*}-a u>$ Go. -áu $(8 \times)$; the alternative ending $-u$ ( $9 \times$ in native words) thus probably developed parallel to the $i$-stem ending (\$7.21), i.e. as a bare stem. But Ringe (2017: 150-1, after Bazell 1937: 4 and Rasmussen 1983: 207-8 n. 10, 214-15) argues plausibly that PIE * eu yields PGmc. *au in final, unstressed syllables, and thus it is unnecessary to reconstruct a PIE ablaut variant $o$ rather than $e$ to explain the Gmc. $u$-stem inflections.

Acc. sg. PIE $*_{-} u-m$ is regularly lost in OIcel., though the vowel is still to be found in magu 'son' on the fifth-century Kjølevik stone.

Gen. sg. The ending in PIE perhaps varied between *-eu-s and *-ou-s (so Szemerényi 1996: $\$ 7.5 .1$, but cf. the voc. sg. above). If so, the latter adequately explains the attested inflections, excluding the analogical endings of OS and OHG. Instead, Bammesberger (1990: 152) supposes that the diphthong *au spread from the dat. The reconstruction PIE *-oues of Antonsen (1975: 20) is contradicted by Skt. sūnóh. Runic -OR (i.e., $-\bar{o}_{R}$ ) shows monophthongization in PGmc. *-auz.

Dat. sg. The PIE endingless locative $*_{-} \bar{u} u$ regularly gives Go. -áu, OIcel. $-i$ (Runic -iu in kunimu[n]diu, Turkjö bracteate, Sweden, ca. 500), and OHG (instr.) - $-i u .{ }^{1}$ If there was an ablaut alternant PIE *-ōu, this could account for OE suna, OS suno, and the Go. ending could also derive from this. Bammesberger (1990: 153) suggests that PIE $*-\bar{e} u$ might regularly produce the OE and OS endings, though the Runic form illustrates the hazards of this. ${ }^{2}$ It has also been argued that *au- spread from the gen. sg. (the opposite of Bammesberger's position, under gen. sg. above) to the dat. sg. and nom. pl. (Ringe \& Taylor 2014: 57-8).

Nom. pl. PIE *-eu-es (parallel to $i$-stem *-ei-es), as in Skt. -avah, Gk. -els, yields PGmc. *-iwiz for uter nouns. This develops regularly in Gmc., e.g. to *-iwz > Go. -jus, NWGmc. ${ }^{*}-i u z>*_{-}-i z$. This accounts for the inflections listed except OE - $a$ (cf. OFris. $-a$ beside -ar, -an, -en), which is difficult to explain. It is often said to derive from a PIE ablaut variant *-ou-es (so, e.g., Krahe \& Meid 1969: II, §17; A. Campbell 1977: §612; Hollifield 1980: 36), but there is no evidence for such an alternant outside of AngloFrisian. ${ }^{3}$ OHG nom. acc. pl. feho in Notker is probably by analogy to the $a$-stems; cf. Gk. neuter nom. acc. pl. $\ddot{\alpha} \sigma \tau \eta<\ddot{\alpha} \sigma \tau \varepsilon \alpha$ 'cities'. OE neut. wintru appears beside winter; the former is probably analogical (to the light stems?), as the reflex of PIE *-uh should have been lost

Acc. pl. PIE *-uns gives PGmc. *-unz, which develops regularly in East and North Germanic. The WGmc. inflections are analogical to the nom. pl.; that the OS and OHG endings should have been drawn from the $i$-stems, as the gen. (and dat. in OHG) was (Krahe \& Meid 1969: II, §17), is also possible. In the view of Dahl (1938: 182), the three examples of acc. pl. $-u$ in the OE Orosius are doubtful, and yet, even though the 
ending is otherwise always - $a$ before the tenth century, he regards $-u$ as directly reflecting PGmc. *-unz; similarly Boutkan (1995b: 257).

Gen. pl. In PIE *-u- $(o H) o m$, zero-grade *-u- could be replaced by full-grade $*_{-}-u_{-}$, as in Gk. $\pi \dot{\eta} \chi \varepsilon \omega v$ 'cubits' < *bhāgheuōm, and on this basis Gothic -iwe is to be expected. OE $-a$ is by analogy to the $a$-stem ending, whereas the other languages have their inflections from the $i$-stems, since the nom. pl. was identical to that of the $i$-stems, by regular phonological rule. ${ }^{4}$ An exception is that OHG suno is influenced not by the $i$ stems but the $a$-stems.

Dat. pl. PIE instr. pl. *-umis gives PGmc. *-umiz, which develops regularly except in $\mathrm{OHG}$, where the ending is analogical to that of the $i$-stems, as are the alternative OS endings -iun, -ion.

1. That hakupo (Noleby stone, Sweden, ca. 450) is dat. sg. of a $u$-stem (Antonsen 1975: 55-6, Boutkan 1995b: 256) may be doubted: cf. Krause 1971: 157.

2. Antonsen (1989: 287-8) argues instead that we should assume "alternate derivation from the ablauting variants PIE */-ew-i/-ow-i/. Since every Germanic dative form can be derived from the Proto-Indo-European dative/locative ending */-i/ (see Antonsen 1969-70: 75), we can discard the highly improbable development posited in the standard handbooks (e.g., Krahe \& Meid 1969[: I,] §129), whereby a PIE 'long diphthong' */eu/ becomes Go. - $a u$, but Run. -iu, OHG -iu (cf. the completely analogous alternative derivation of the Gmc. gen. sg. Run. -oz, Go. -aus, ON -ar, etc. from PIE */-ow-es/)."

3. Prokosch (1939: §83) invokes analogy to gen. dat. sg., gen. plural. Dahl (1938: 182; similarly Bammesberger 1985) posits an original dual in PIE *-ou-. High-frequency $u$-stem 'hand' would have been used frequently in the dual; so also 'door' (e.g. OE duru), if this was originally a $u$-stem, though the comparative evidence suggests otherwise.

4. Euler (2013: 77) supposes rather that $w$ was assimilated to the preceding $i$, so that the OHG ending is derived phonologically from WGmc. *-ijō.

\subsection{The consonantal stems}

The consonant-stem nouns in Gmc. are the root-stems (including apparently vocalic root-stems like OIcel. kýr 'cow' and sýr 'sow', on which see $\$ 7.28 \mathrm{n} .2$ ), the $n$-stems, the $r$-stems, the $s$-stems, the $n d$-stems, and the dental stems. All except the first were formed in PIE of stems bearing a suffix ending in a consonant. The accent was usually mobile, most commonly on the root or suffix in the strong cases, on the inflection in the weak (\$7.4).

\subsection{The root-stems}

These, also called root-nouns, are masc. and fem. nouns which in PIE attached athematic inflections (\$7.2) directly to the root, without any intervening suffix. In PIE these mostly showed amphikinetic accent, i.e. accent on the root in the strong cases, on the inflection in the weak. A few, however, followed the acrostatic pattern, with accent on the root thoughout, but different ablaut grades of the root vowel in the strong and the weak cases, e.g. strong *pod- in Gk. nom. pl. $\pi o ́ \delta \varepsilon \varsigma$ 'feet' but weak *péd-extended to a strong case in Lat. pedes (Clackson 2007: 81, but cf. Ringe 2017: 57, 59). Griepentrog (1995) identifies 23 root-stems in the early Gmc. languages as original. Masc. and fem. were originally inflected alike, though the two have diverged in Gmc. A great many rootstems have defected to other classes; those that retain root-stem inflections are usually 
nouns of high frequency. In $\mathrm{ON}$, however, the class attracted many nouns of different origin to it. The inflections for masc. root-stems may be illustrated by the paradigm of Go. reiks 'ruler', ' along with the paradigms of OIcel. maðr 'person' and its WGmc. cognates:

\begin{tabular}{|c|c|c|c|c|c|c|}
\hline & & Go. & OIcel. & OE & OS & OHG \\
\hline so & om. & reiks & maðr & $\operatorname{man}(n)$ & $\operatorname{man}(\mathrm{n})$ & $\operatorname{man}(\mathrm{n})$ \\
\hline & acc. & reik & mann & $\operatorname{man}(\mathrm{n})$ & $\operatorname{man}(n)$ & $\operatorname{man}(\mathrm{n})$, mannan \\
\hline & gen. & reikis & manns & mannes & mannes, -as & $\operatorname{man}(\mathrm{n})$, mannes \\
\hline & dat. & reik & manni & $\operatorname{men}(n)$ & $\operatorname{man}(\mathrm{n})$, manne, $-\mathrm{a}$ & $\operatorname{man}(n)$, manne \\
\hline sg. & nom. & reiks & menn & $\operatorname{men}(n)$ & $\operatorname{man}(n), \operatorname{men}(n)$ & $\operatorname{man}(\mathrm{n})$ \\
\hline & acc. & reiks & menn & $\operatorname{men}(\mathrm{n})$ & $\operatorname{man}(n), \operatorname{men}(n)$ & $\operatorname{man}(n)$ \\
\hline & gen. & reikē & manna & manna & manno, -a & manno \\
\hline & dat. & reikam & mǫnnum & mannum & mannum, -un, -on & mannum, -un, -on \\
\hline
\end{tabular}

The masc. nouns are particularly poorly preserved in Gothic, having mostly gone over to other stem classes. Cognate with OIcel. maðr is Go. manna, the paradigm of which combines root-stem (originally $u$-stem: Szemerényi 1996: §7.5.2) and $n$-stem forms (the latter in boldface in the following): nom. sg. manna, acc. mannan, gen. mans (with degemination before $s$ ), dat. mann, nom. and acc. pl. mans beside mannans, gen. manne, dat. mannam. In OE there is a parallel $n$-stem paradigm, nom. sg. manna, etc., but forms other than acc. sg. mannan are infrequent. Weak forms also occur rarely in OIcel. The reason for the co-occurrence of root-stem and $n$-stem forms of this noun is contested, along with the word's IE derivation. ${ }^{2}$

In OIcel., some masc. root-stems have gen. sg. in -ar, e.g. fótar 'foot'. The inflection of the fem. root-stems may be illustrated by the paradigm of Go. baúrgs 'city', along with the paradigms of OIcel. bók and OE $b \bar{o} c$, both 'book', and of OS naht and OHG naht, both 'night':

\begin{tabular}{llllll} 
& Go. & OIcel. & \multicolumn{1}{c}{ OE } & \multicolumn{1}{c}{ OS } & OHG \\
sg. nom. & baúrgs & bók & bōc & naht & naht \\
acc. & baúrg & bók & bōc & naht & naht \\
gen. & baúrgs & bókar & bēc, bōce & nahtes & naht \\
dat. & baúrg & bók & bēc, bōc & naht, nahta & naht \\
& & & & & \\
pl. nom. & baúrgs & bœkr & bēc & naht & naht \\
acc. & baúrgs & bœkr & bēc & naht & naht \\
gen. & baúrgē & bóka & bōca & nahto & nahto \\
dat. & baúrgim & bókum & bōcum & nahtun, -on & nahtum, -un, -on
\end{tabular}

There are no neuters that can properly be called root-stems: on OE scrūd 'garment', see Hogg \& Fulk 2011: §2.3 n. 3; on Go. fōn, see $\$ 7.42$ infra.

1. The acc. sg. is not actually attested, though the form is not in doubt.

2. The word is usually derived either from an $n$-stem PIE *dhgh-m-on- (or similar, from which Go. guma 'man' is also derived), containing an ablaut variant of a root meaning 'earth' (so, e.g., Kroonen 2011: 29), or from a $u$-stem based on the root *men-, as in Skt. mánu- 'person' (so, e.g., Euler 2013: 92): for discussion and references, see Bammesberger 2000, where both of these explanations are regarded as improbable. Bammesberger's own hypothesis is that the word is in origin a root-stem, from which were derived both a thematic variant (as in, e.g., Go. mana-sēps 'humankind') and an $n$-stem in the weak cases of which the geminate arose, e.g. gen. sg. *man-n-az; similarly Mottausch 2011: 73. 


\subsection{Origin and development of the root-stems and their inflections}

Originally, the inflections were the athematic ones listed in \$7.2. The original distribution of endings is better preserved among fem. nouns than masc., and chiefly in Gothic, hence PGmc. nom. sg. *burz-s $>$ *burxs, acc. *burz- $u^{n}$, gen. ${ }^{*}$ burz-iz or ${ }^{*}$-az, dat. (originally loc.) *burz-i, nom. pl. *burz-iz, acc. *burz-unz, gen. *burz- $\hat{o}^{n}$, dat. *burz$u m(i) z$. All these sg. forms develop regularly in Go. except for the acc. (cf. $u$-stem acc. $h a n d u$ 'hand'), which may be explained as endingless by analogy to the $i$-stems. In the plural, as in many classes, the nom. inflection is extended to the acc. (as in all these languages), and Go. fem. -im in the dat. is again by analogy to the $i$-stems (and masc. $-a m$ to the $a$-stems), as may be gen. pl. $-\bar{e}$. The original dat. pl. ending appears in some other consonant-stems, e.g. mēnōpum 'month', but not among the root-stems (cf. Boutkan 1995b: 261-2). Among the masc. nouns in Go., certainly acc. sg. reik and gen. reikis are by analogy to either the $i$-stems or the $a$-stems.

In OIcel., most masc. case-forms are indistinguishable from $a$-stem or $u$-stem forms, the chief exception being the nom. and acc. pl. (the latter replaced analogically by the former), where *mann-iz > *menn-R > menn (cf. foetr 'feet' < *fōt-iz) shows umlaut with a distinctive inflection. The dat. might be expected to show umlaut, as in OE; dat. feti, however (with analogical ending), is the only OIcel. root-stem to show it. ${ }^{1}$ Gen. sg. $-a r$ is borrowed from the $u$-stems, $-s$ from the $a$-stems (in slightly later bynames, e.g. gen. uxafóts 'ox-foot'); the original ending *-iz should give *-r (cf. the fem. stems below). Nom. sg. maðr is usually regarded as a regular phonological development from *mannr; cf. fem. pl. teðr 'teeth' beside analogical tennr (but see §6.14). As for the OIcel. fem. root-stems, most cases are reformed by analogy to the $\bar{o}$-stems, the exceptions being the nom. and acc. plural. In the nom. sg., the reflex of PIE $*_{-S}$ was retained in a few fem. vocalic stems, where the vowel is subject to $R$-umlaut ( $\$ 4.7)$ : kýr 'cow', sýr 'sow', $x r$ 'ewe'. The original gen. sg. ending $-r$ (with umlaut) $<*_{-i z}<\mathrm{PIE} *_{-}$-es is preserved only in gen. sg. kýr 'cow', merkr (to mork 'mark (of silver)'), and a few others listed by Noreen $(1970: \S 416.1){ }^{2}$

In WGmc., the original situation is best preserved in $\mathrm{OE}$, where gen. and dat. sg. $b \bar{e} c$ are the earlier forms, $b \bar{o} c e$ and $b \bar{o} c$ having been formed by analogy (the former to the $\bar{o}$-stems), as is OS dat. sg. nahta (cf. $\bar{o}$-stem dat. geちa beside normal gebu 'gift'). Rare OHG gen. sg. man (= Go. mans) is original, and dat. sg. OE menn, OS OHG man are also archaisms (from *manni).

The nom. sg. of some uter root-stems (and other consonant-stems, those ending in a nasal, liquid, or dental consonant, including $s$ ) should have been subject to consonant loss and compensatory lengthening in PIE under Szemerényi’s law (§1.6 n. 1). For example, Lat. $p \bar{e} s$ 'foot' results from *pess $<*$ pets $<*$ *ped-s, whereas Skt. pất results from analogical restoration of $d$ to ${ }^{*} p \bar{a} d-s$, probably from *pōs. ${ }^{3}$ The variety of ablaut grades to be found in such words thus results in analogical changes in the IE languages to reduce paradigm allomorphy. Whereas Lat. and Gk. have a long vowel only in the nom. sg. of this word, Gmc. has generalized $\bar{o}$ throughout the paradigm. In Gothic the word has acquired $u$-stem inflections (fōtus; likewise *tunpus 'tooth'), probably due to acc. sg. fōtu, pl. fötuns. Thus, the stems of Gmc. root-stems may differ from those of IE cognates, or even within the Gmc. family itself (e.g. Go. tun $p$ - 'tooth' $<* h_{1} d n t-$ : OHG zan $(d)<* h_{l}$ dont-; cf. Lat. dèns, gen. dentis, derived from the zero grade of *h,ed- 'eat', with participial suffix, and see Lass 1986). However, 'tooth' is the only root-stem in which it is provable that ablaut alternations in the root persisted in Gmc. ${ }^{4}$ 
1. The PGmc. dat. (originally loc.) ending $*_{-i}$ should have been lost after the heavy syllable (§5.6), but presumably it was restored by analogy to light-stemmed root-stems, and perhaps to $r$-stems (see §7.36).

2. It may seem odd to refer to vocalic consonant stems, but these would have ended in a consonant in PIE, usually a laryngeal. A possible alternative explanation for a nom. sg. like mork is that it has its back mutation by analogy not to the $\bar{o}$-stems but to the acc. sg. (Prokosch 1939: §87a), or by the combined influence of the two. Note that analogical forms of the nom. sg. appear elsewhere among feminines of this class, e.g. tonn 'tooth' and nótt 'night' (beside nátt), the latter with the combined labial mutation proper to the acc. sg. and dat. pl. (\$4.8).

3. On 'Doric $\pi \dot{\omega} \varsigma$ ' and its unexplained alteration to Gk. $\pi \circ v$ $\varsigma$, see Sihler 1995: 117-18. "The difference in vowel colouring between $\pi o v ́ \varsigma$ and $p \bar{e} s$ is explained by alternation within the paradigm (e.g. nom. *pōs : gen. *ped-ós), or between simple[x] and compound (e.g. *pēs : *su-pōs 'with good feet'), with subsequent generalizing of one or the other timbre" (Szemerényi 1996: §7.2.1).

4. A further, probable example is PGmc. *wrōt- > ON rót 'root' : *wurt- > Go. waúrts, ON urt, OE wyrt, OS wurt, OHG wurz 'plant'.

\subsection{The $n$-stems}

These are commonly referred to as 'weak' nouns, just as with weak adjectives, which are also $n$-stems (see §9.7). ${ }^{1}$ In PIE either there were no fem. $n$-stems or the only gender opposition in this class was between animate and neuter nouns; the category of fem. in Gmc. no doubt arose from substantivized weak fem. adjectives. Neuters in Gmc. are very few in number. To be distinguished are the three types of Gmc. $n$-stems: the anstems, the $\bar{o} n$-stems, and the $\bar{i} n$-stems.

1. The terms stark 'strong' and schwach 'weak' are used in reference to nouns, adjectives, and verbs already in Grimm's Deutsche Grammatik: see, e.g., Grimm 1822-37: I, 597-8, where the terms are defined in reference to declension.

\subsection{The an-stems}

These comprise masc. and neuter nouns. The masculines are very commonly deverbal agentive nouns, e.g. Go. hana 'cock' (cf. Lat. canō 'sing'), blōma 'flower' (cf. OE blōwan 'bloom'). There also occur jan-stems, inflected the same way, e.g. Go. masc. baúrgja 'citizen' (cf. bairrgan 'protect'), neut. sigljō 'seal' (cf. sigljan, from Lat. sigilläre). The masc. inflections may be illustrated by the paradigms of Go. guma 'man' and its cognates:

$\begin{array}{llllll}\text { sg. nom. } & \text { guma } & \text { OIcel. } & \text { OE } & \begin{array}{l}\text { OS } \\ \text { gumi }\end{array} & \begin{array}{l}\text { guma } \\ \text { OHG }\end{array} \\ \text { acc. } & \text { guman } & \text { guma } & \text { guman } & \text { gumon, -an } & \text { gomo } \\ \text { gen. } & \text { gumins } & \text { guma } & \text { guman } & \text { gumen, -an, -on } & \text { gomen, -in } \\ \text { dat. } & \text { gumin } & \text { guma } & \text { guman } & \text { gumen, -an, -on } & \text { gomen, -in } \\ \text { pl. nom. } & \text { gumans } & \text { gum(n)ar } & \text { guman } & \text { gumon, -un, -an } & \text { gomon, -un } \\ \text { acc. } & \text { gumans } & \text { gum(n)a } & \text { guman } & \text { gumon, -un, -an } & \text { gomon, -un } \\ \text { gen. } & \text { gumanē } & \text { gumna } & \text { gumena } & \text { gumono, -uno, -onu } & \text { gomōno } \\ \text { dat. } & \text { gumam } & \text { gum(n)um } & \text { gumum } & \text { gumon, -un } & \text { gomōm }\end{array}$

The plural of OIcel. gumi is actually atypical of the type, which usually lacks $-n$ - in all cases of the plural, having adopted $a$-stem inflections. Rather, in poetry a few $n$-stems referring to persons preserve the original gen. pl. ending $-n a^{1}$ and extend $-n$ - thence to the other cases of the plural. Another masc. type, and a rare one, is represented by Go. 
gen. pl. aúhsnē 'oxen', OIcel. nom. acc. pl. yxn, øxn, gen. yxna, øxna, dat. yxnum, øxnum (nom. sg. uxi, oxi), OE (chiefly Anglian) nom. acc. pl. oxen, exin, exen, gen. oxna, dat. oxnum (nom. sg. oxa). In these the PIE suffix took the form *-en- in the strong cases, rather than ${ }^{*}$-on-.$^{2}$ On Go. manna, see $§ 7.27$.

The neuters are declined similarly in the genitive and dative. The nominative and accusative inflections may be illustrated by forms of Go. áugō 'eye' and its cognates:

Go. OIcel. OE OS OHG

nom. acc.sg. áugō auga ēage ōga, -e ouga

nom. acc. pl. áugōna augu ēagan ōgun, -on, -an ougun, -on

A different type of neuter is represented by Go. nom. acc. pl. namna 'names', i.e. with the ending -na rather than -ōna. Such neuters had PGmc. ${ }^{*}-\hat{o}$ or ${ }^{*}-\hat{o}^{n}$ in the nom. sg., ${ }^{3}$ just as the masc. nouns did, and so they were made masc. in WGmc. (Bammesberger 1990: 167; Jasanoff 2002: 35). Besides namō, only PGmc. *sēmô (OHG sāmo 'seed') and *aykw $\hat{o}$ (OHG ancho 'butter') are of this latter type. On heteroclitic stems like Go. watō, dat. pl. watnam, see $\S 7.42$.

1. As in the $\bar{o} n$-stems, $\S 7.32$. It is otherwise usually replaced by $a$-stem - $a$ (but cf. $\$ 7.31 \mathrm{n} .8$ ); cf. Runic gen. pl. arbijano 'heirs' on the Tune stone, ca. 400.

2. This is the PIE 'hysterokinetic' or 'hysterodynamic' type (\$7.4), in which the final syllable bore the accent: for discussion, see Kroonen 2011: 27-40. Similar is Go. gen. pl. abnē, dat. abnam 'men': see Sen 2002, Johnsen 2005; probably also OIcel. bogna 'bows'. This is not the origin of OE genitives like brögna, which occur in the conservative language of poetry, and which must be assumed to show syncope (for the reasons offered by Brunner 1965: §276 Anm. 4).

3. This ending is unexplained; the PIE ending was ${ }^{*}-n$, reflected in Skt. nāma, Lat. nōmen, OCS imę.

\subsection{Origin and development of $a n$-stem inflections}

These nouns in PIE bore the suffix *-en-/-on-. The Gmc. an-stems mostly reflect the PIE amphikinetic type, with accent on the root in the strong cases (\$7.4), the stem-formative suffix taking the form $*_{-o n-}\left({ }^{*}-\bar{o} n<*_{-o n-S}\right.$ in the nom. sg.), but the form $*_{-}$en- in the loc. sg. (and acc. sg.?), and elsewhere ${ }^{*}-n$ - or $*-n-.^{1}$ The weak grades of the suffix are all replaced by full grades in Gmc. Only Gothic retains significant traces of the original inflections; in the other languages it is mostly the $n$-suffix that has become the inflection. Reconstruction of the development of these nouns presents many difficulties (some of them remarked by Ringe 2017: 306-8); the nouns and the weak adjectives must have exerted considerable mutual analogical influence. But the agreement of Go. and OHG on key points leads to the conclusion that originally *-on- (becoming *-an- or *-un-: see under acc. sg. below) appeared in the acc. sg. and all cases of the plural, whereas *-enappeared in the gen. dat. sg.

Nom. sg. PIE had the endings $*_{-} \bar{o} n\left(<*_{-o n-s}\right), *_{-} \bar{o}\left(<*_{-} \bar{o} n\right),{ }^{2}$ and $*_{-} \bar{e} n\left(<*_{-} e n-s\right)$, but probably not the oft-posited $*_{-\bar{e}}\left(<*_{-} \bar{e}\right.$; see Jasanoff 2002: 34-5). Any of these would account for Go. masc. $-a$. OIcel. $-i$ is commonly derived from ${ }^{*}-\bar{e} n$ (or from analogically created $*_{-} \bar{e}, *_{-} \hat{e}$, or $*_{-} \hat{e}^{n}$; see, e.g., Jasanoff $\left.2002: 31,44\right)$, but the older Runic ending, which is well attested, is -a, and so a morphological refashioning is perhaps to be assumed. ${ }^{3}$ Only $*_{-} \hat{o}$ or ${ }^{*}{ }_{-}{ }^{n}$ will account for the WGmc. masc. forms (continental Runic $-o$ is attested from the end of the $6^{\text {th }}$ cent. in boso (name) and leubo 'beloved man': see Euler 2013: 80), and the origin of the trimoric vowel in these, as elsewhere among the $n$-stems, is perplexing. ${ }^{4}$ Likewise, ${ }^{*}-\hat{o}$ is required to explain Go. neuter $-\bar{o}$, 
whereas the neuter endings in the other languages require $*_{-} \bar{o}^{n}$; PIE neuter $*_{-} \bar{o} n$, however, is to be derived from *-on- $h_{2}$, just as PIE $* p h_{2} t \bar{e} r$ is to be derived from * $p h_{2}$ ter$s\left(\S 1.6\right.$ n. 1; see Jasanoff 2002: 33). ${ }^{5}$ Boutkan (1995b: 285-6) rather assumes analogical extension of $*_{-} \bar{o}(n)$ from the neut. pl.

Acc. sg. The PIE animate ending was *-en-m (see Szemerényi 1996: §7.3.1), but

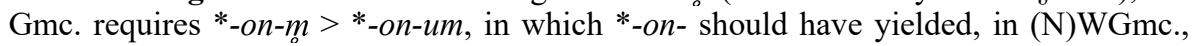
$*_{\text {-un }}$ - before $* u$ in the next syllable, whereas *-on- in EGmc. developed to *-an- $(\S 5.5)$. This accounts for the OS and OHG endings, but OE (and OIcel.? see §5.5) must have extended *an- from other cases to the acc. ${ }^{6}$ (The an-stem acc. unfortunately is not attested in early Runic.) Early Northumbrian galgu $<*_{3}$ alzun $<$ WGmc. ${ }^{*}$ zalzunum on the Ruthwell Cross suggests that OE originally had *-un- in this case. The neuters bore the same inflection as in the nom.

Gen. sg. Only in Skt. is the original weak form of the $n$-suffix preserved, as in gen. sg. räjñah 'king'. The other IE languages generally point to *-en-es or *-en-os, giving PGmc. *-iniz, *-inaz. ${ }^{7}$ This accounts for Go. -ins and OS OHG -en. The OIcel. and $\mathrm{OE}$ endings must derive from forms with the PIE alternant ${ }_{-}$-on-, as in Gk. acc. sg.

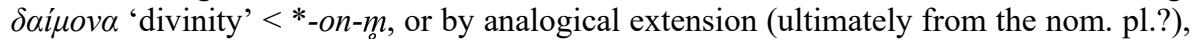
as in the accusative. $\mathrm{OHG}$-in here and in the dat. produces umlaut (e.g. nemin 'name'), though the original root vowel is always restored outside of the earliest texts.

Dat. sg. PIE *-n-ei is to be expected (cf. Skt. dat. rājiñe), but the Gmc. ending is more likely to derive from loc. *-en-i or *-on-i. The former will account for Go. -in, OS $\mathrm{OHG}$-en (CG), -in (UG); the latter (cf. Gk. پ̋ $\kappa \mu o v \imath$ 'thunderbolt') for OIcel. $-a$ and OE -an, assuming early loss of $*_{-} i$ in third syllables ( $\$ 5.2$ n. 7).

Nom. pl. PIE *-on-es gives PGmc. masc. *-aniz, which accounts for the Go. and $\mathrm{OE}$ endings. $\mathrm{OS}$ and $\mathrm{OHG}-\mathrm{on}$, - un are probably analogical to the acc. pl., whereas OIcel. - $a r$ is modeled on the $a$-stem ending. As for the neuter, the cognates point to PIE $*_{-} \bar{o} n-h_{2}$, as in Skt. nāmāni 'names', in which *-ōn- may be a collective suffix (Jasanoff 1980: 376). This should have produced PGmc. *-ona, but $*_{-} a$ in this was replaced by $*_{-} \bar{o}$, borrowed from the $a$-stems, with the NWGmc. development $*_{-} \bar{o} n \bar{o}>*_{-} \bar{o} n u>*_{-} \bar{u} n$.

Acc. pl. Only Skt. preserves the original weak form of the suffix, as in rājñah 'kings'. Gmc. reflects the suffix in $o$-grade, PIE *-on-ns $>$ masc. *-on-unz, in which *-on- should have developed to *-an- in EGmc. and *-un- in (N)WGmc. (see §5.5). This accounts for the OS and OHG endings, whereas the OE ending is analogical to the nom. plural. OIcel. shows the same development as in the acc. singular. Go. -ans may be due to the combined forces of haplology ( $\$ 12.33$ n. 6) in *-an-unz and analogical influence from the nom. plural. The neuter ending was the same as the nominative.

Gen. pl. PIE weak *-n-(oH)om finds expression in forms like Go. aúhsnē (see $\S 7.30$ ) and OE oxna. However, in Gmc. there should be expected the reflex of a fullgrade form of the suffix, *-on-, and this accounts for Go. -ane. The OIcel. ending $-a$, like the nom. pl. ending, seems to be analogical to the $a$-stem ending, ${ }^{8}$ whereas the WGmc. endings reflect $*_{-} \bar{o} n-\hat{o}^{n}$, which is perhaps borrowed from the $\bar{o} n$-stems $(\S 7.32)$, probably via the weak adjectives $(\$ 9.8)$.

Dat. pl. PGmc. *-miz (cf. $a$-stems, §7.8) was attached directly to the suffix *-on-,

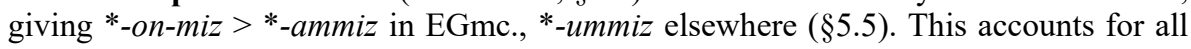
the endings except $\mathrm{OHG}-\bar{o} m$, which was influenced by the $\bar{o} n$-stems, as in the gen. pl.

1. The precise distribution of accentual and ablaut variants is not wholly agreed upon: e.g., to Szemerényi 1996: \$7.3.1 cf. Kroonen 2011: 28. 
2. Loss of *-n may be due to sandhi conditions (Prokosch 1939: §84c).

3. Stiles (1984: 16-17) argues plausibly that masc. Runic -a was extended to the nom. from the oblique cases for the purpose of re-differentiating the masc. and fem. forms (nom. masc. ${ }^{*}-\hat{o}$ and fem. ${ }^{*}-\bar{o}^{n}$ having fallen together as $\left.*_{-} \bar{o}\right)$, since, outside the nom. sg., the feminines had ${ }^{*}-\bar{o} n$ - throughout and the masculines *-an-, the latter having been generalized by analogy to the feminines. Subsequently Runic -a was lost by regular phonological rule, not only in the regular $n$-stems but also in the subcategory of $i j a n$-stems (i.e., janstems with a heavy root syllable), leaving the $n$-stems and the ijan-stems inflected identically, except that in the nom. sg. the latter had $-i$, which was then adopted by the $n$-stems (similarly Boutkan 1995b: 281). Cf. the discussion in Syrett 1994: 134-52. To the contrary, Nedoma (2005: 172-3) and Jón Axel Harðarson (2005: 227-8; see also Ringe \& Taylor 2014: 520) assume that Runic -a actually reflects PIE *-enn.

4. The usual assumption is that *-o and *-ê were the result of loss of the final consonant in PIE, and Bammesberger $(1990: 167$ n. 275,169$)$ defends this view by reference to PGmc. ${ }^{*}$ nefô, reduced from PIE *nepōs. But only Balto-Slavic and Gmc. require the reconstruction of trimoric vowels in this declension, and trimoricity is otherwise to be related to hiatus between vowels (usually through loss of a laryngeal consonant), not length in vowels resulting from compensatory lengthening (but see §5.4 supra). Jasanoff (2002: 37), who intends the term 'trimoric' literally and thus assumes that trimoric vowels were simply overlong, proposes a rule of Gmc. and Balto-Slavic whereby $* \bar{o}$ (but not any other vowel) gained an extra mora in final position. This is a simple solution, but the motive for the change is obscure. Lane (1963, supported in part by Boutkan 1995b: 127, 281) supposes that *-an (from earlier *-an-un) was leveled into the nom. sg. in WGmc., and that this accounts for the attested endings. This entails certain complications, one of which is that *-an-un should have developed to *-un: see §5.5. The form of the suffix *-an-could have been extended, however, from other cases, e.g. nom. pl., though this leaves unexplained the coincidence of Baltic intonation and of what would appear to be a trimoric Gmc. reflex.

5. Prokosch (1939: §84c) remarks a complementarity in the development of the nom. sg. between Go. and

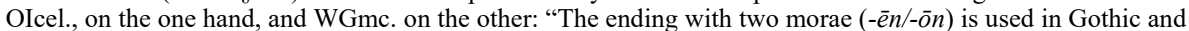
Old Norse with masculines, but in WGmc. with feminines and neuters. On the other hand, the tri-moric ending - $\tilde{o}$ is used in Gothic and Old Norse with feminines and neuters, in WGmc. with masculines (in Old Saxon there is a good deal of variation between the MSS)."

6 To the contrary, it is usually assumed that *-an- spread from the acc. sg. to other cases (e.g. Prokosch 1939: §84d; Bammesberger 1990: 168). Certainly, the spread of *-an-is justly assumed, since it has replaced ${ }^{*}-\bar{o} n$ - in the feminine $n$-stems in $\mathrm{OE}$, but the acc. sg. ending is not likely to be the source, at least in WGmc.

7. Bammesberger (1990: 168) suggests that at least in Gmc., gen. *-en- may be analogical to the dat. suffix (PIE loc.). Boutkan (1995b: 283-4) argues that *-en- remained as such in the gen.

8. However, Prokosch 1939: $\S 84$ d posits the replacement of $-n a$ by $-a$ from stems like hani 'cock', gen. pl. *hanna $>$ hana, facilitated by the disappearance of inflectional $-n$ - from the rest of the paradigm.

\subsection{The ōn-stems}

This class includes feminine nouns only. The inflections may be illustrated by the paradigms of Go. tuggō 'tongue' and cognates:

$\begin{array}{llllll} & \text { Go. } & \text { OIcel. } & \text { OE } & \text { OS } & \text { OHG } \\ \text { sg. nom. } & \text { tuggō } & \text { tunga } & \text { tunge } & \text { tunga, -e } & \text { zunga } \\ \text { acc. } & \text { tuggōn } & \text { tungu } & \text { tungan } & \text { tungun, -on, -an } & \text { zungūn } \\ \text { gen. } & \text { tuggōns } & \text { tungu } & \text { tungan } & \text { tungun, -on, -an } & \text { zungūn } \\ \text { dat. } & \text { tuggōn } & \text { tungu } & \text { tungan } & \text { tungun, -on, -an } & \text { zungūn } \\ \text { pl. nom. } & \text { tuggōns } & \text { tungur } & \text { tungan } & \text { tungun, -on, -an } & \text { zungūn } \\ \text { acc. } & \text { tuggōns } & \text { tungur } & \text { tungan } & \text { tungun, -on, -an } & \text { zungūn } \\ \text { gen. } & \text { tuggōnō } & \text { tungna } & \text { tungena } & \text { tungono } & \text { zungōno } \\ \text { dat. } & \text { tuggōm } & \text { tungum } & \text { tungum } & \text { tungun, -on, -an } & \text { zungōm, -ōn }\end{array}$

A subtype, the $j \bar{o} n$-stems, have $-j$ - before the inflection, which causes umlaut, e.g. OIcel. brynja 'coat of mail', and these have gen. pl. in - $a$ instead of -na, e.g. brynja, unless the stem ended in a velar consonant, e.g. gen. pl. kirkna (to kirkja 'church'). Contracted 
forms are generally uninflected in the sg., e.g. frú 'lady', pl. frúr, and kona 'woman' has gen. pl. kvenna, kvinna, probably based on a stem *kven- to a different noun (Go. qinō, OE cwene, OHG quena: see Jón Axel Harðarson 1989).

\subsection{Origin and development of $\bar{o} n$-stem inflections}

In PIE there was no inflectional distinction between masc. and fem. $n$-stems (if in fact any PIE $n$-stems were fem.), but in PGmc. the two genders became differentiated by the elimination in fem. nouns of the variation in vowel quality and quantity in the stemforming suffix, which was regularized as $*_{-} \bar{o} n-.{ }^{1}$ The likeliest source of the long vowel in this analogical process is the $\bar{o}$-stem nouns. Of those that survive in Gmc., nearly all PIE $\bar{a}$-stem nouns designating persons have become $\bar{o} n$-stems, e.g. PIE $\bar{a}$-stem ${ }^{*} g^{w} e n \bar{a}$ 'woman' (cf. Russian жена (̌̌ena)) > Go. qinō, gen. -ōns (Krahe \& Meid 1969: III, $\S 91)$. There thus arose a correspondence between the masc. proportion $a$-stem $-a-: n$ stem $-a n$ - and the fem. proportion $\bar{o}$-stem $-\bar{o}-: \bar{o} n$-stem $-\bar{o} n$ - that could be exploited and expanded. There may also have been influence of the fem. adjectives upon the nouns (Kuryłowicz 1968). The conversion of $\bar{o}$-stems to $\bar{o} n$-stems must have been a relatively late development, as $\bar{o}$-stem forms are still encountered in $\bar{o} n$-stem nouns in Gothic, e.g. dat. sg. bandwái to ōn-stem bandwō 'sign' (Streitberg 1910: 111).

At first, then, the use of $*_{-} \bar{o} n$ - was the only distinction between masc. and fem. $n$-stems, since they bore the same inflections after the stem-forming suffix. This situation remains little changed in Gothic, the only alterations being the extension of gen. pl. $-\bar{o}$ (to form $-\bar{o} n \bar{o})$ and dat. pl. $-\bar{o} m$ (for original $\left.{ }_{-}-\bar{o} n a m\right)$ from the $\bar{o}$-stems. Although the phonological changes are much disputed, the commonest assumption is that PGmc. ${ }^{*}-\bar{o} n$ - should have changed to NWGmc. *- $\bar{u} n$ - before $u$ in the next syllable $(\$ 5.5)$-i.e., in the acc. sg. and pl. - and before tautosyllabic $n$ at a later date (§5.6) in all the remaining cases except nom. sg. and gen. and dat. pl. This situation is well preserved in OS and OHG. Some analogical reformation has taken place in OIcel.: in the plural, nom. acc. $-u r$ is analogous to - ar (borrowed from the $a$-stems) in the masc. $n$-stems, and the dat. pl. corresponds to the Go. form. PGmc. *-on- $\bar{o}$ should have yielded $\mathrm{ON} *_{-a n a}$; gen. pl. -na may be influenced by masc. forms like yxna (\$7.30; Krahe \& Meid 1969: II, $\S 29)$, but it is likelier to have been influenced by the neuter form, as the original nom. acc. pl. inflection would have agreed with the neut. (Heusler 1967: §233). In OE, the fem. paradigm has been made to conform almost entirely to the masc.; Northumbrian acc. sg. foldu 'earth' and eorðu 'earth' are most likely relics of an earlier inflection like that in Go., though it should be noted that these forms are not necessarily exceptions to the rule of conformity to the masc. paradigm: cf. masc. acc. sg. galgu 'gallows'. Original *-ōn- is reflected also in OE pl. Éastron, -un 'Easter'. For alternative analyses, see Ringe \& Taylor 2014: 163-4.

1. Cf. similarly in Greek, masc. nom. sg. $\dot{\alpha} \gamma \omega \dot{\omega} v$ 'assembly', gen. $\dot{\alpha} \gamma \hat{\omega} v o \varsigma$, etc., and in Latin, nom. sermō 'conversation', acc. sermōnem, etc.

\subsection{The $\overline{i n}$-stems}

Like the $\bar{o}$-stems, this class includes feminine nouns only. The inflections may be illustrated by the paradigms of Go. managei 'multitude' and its cognates, along with OIcel. gørsimi 'treasure': 
Go.

$\begin{array}{ll}\text { sg. nom. } & \text { managei } \\ \text { acc. } & \text { managein } \\ \text { gen. } & \text { manageins } \\ \text { dat. } & \text { managein } \\ \text { sg. nom. } & \text { manageins } \\ \text { acc. } & \text { manageins } \\ \text { gen. } & \text { manageinō } \\ \text { dat. } & \text { manageim }\end{array}$
OIcel.

gørsimi

gørsimi

gørsimi

gørsimi

gørsimar

gørsimar

gørsima

gørsimum
OE

menigu
menigu
menigu
menigu
menigu
menigu
meniga
menigum

\section{OHG}

$$
\begin{aligned}
& \text { menigīin) } \\
& \text { menigī(n) } \\
& \text { menigī(n) } \\
& \text { menigī(n) } \\
& \text { menigīin) } \\
& \text { menigī(n) } \\
& \text { menigīno } \\
& \text { menigīm }
\end{aligned}
$$

It will be seen that the Go. paradigm corresponds precisely to that of the $\bar{o} n$-stems, but with $-e i-(/ \mathrm{i}: /)$ where the other has $-\bar{o}-.^{1}$ The OHG paradigm closely resembles the Gothic, corresponding exactly to the OHG $\bar{o} n$-stem paradigm above (\$7.32). The OHG forms in $-\bar{i} n$ (as opposed to $-\vec{\imath}$ ) are limited to a small number of textual sources: see Braune 2004a: 228 Anm. 1, Boutkan 1995b: 292-3. In OS the inflection of these nouns is indistinguishable from that of fem. $i$-stems, though occasional $j \bar{o}$-stem forms occur, e.g. dat. sg. menigo $(1 \times$ beside usual menigi $)$. In OIcel. the sg. corresponds phonologically to the Go. sg., whereas the pl. inflections are the same as those of the $\bar{o}$ stems. In $\mathrm{OE}$ a few forms, mostly in early or Anglian texts, e.g. acc. gen. dat. sg. strenge, show that originally the OE paradigm was more closely comparable to the OHG one. The substitution of the ending $-u$ for $-e<*-i$ is usually explained as the result of analogy to stems in Gmc. *-ipō, e.g. OE strengpu (see, e.g., A. Campbell 1977: $\S 569(7)$, and cf. Brunner 1965: $\$ 280)$, though the extension of $-u$ within the paradigm of the latter type is difficult to account for, and doubts have been raised (see Bammesberger 1975, and cf. Ringe 2002: $149 \&$ n. 42).

The origin of the suffix *-in- in this class is uncertain, as it is unparalleled in the IE languages. But if, as supposed above (\$7.33), the $\bar{o}$-stems played a significant role in the spread of $*_{-} \bar{o} n$ - throughout the paradigm of the $\bar{o}$-stems, it may be supposed that *-in- was analogously constructed on the basis of the jo-stems, in which the nom. sg. ended in $*_{-} \bar{l}(\$ 7.17)$.

1. In Gothic, the suffix -ein- is found also in feminine abstract nouns derived from weak verbs of the first class, e.g. dáupeins 'baptism' (cf. dáupjan 'baptize'), but these bear different inflections: those of the $i$-stems in most cases, but those of the $\bar{o}$-stems in the nom. gen. plural. Gothic and ON first participles and adjectives in the comparative degree are also inflected as $\bar{i} n$-stems ( $\$ 9.9-10)$.

\subsection{The $r$-stems}

This small class comprises nouns of family relationship, which were formed in PIE with a suffix *-ter- or *-er- in alternating ablaut grades. The inflections may be illustrated by the paradigms of Go. brōpar 'brother' and its cognates:

Go.

sg. nom.

acc.

gen.

dat.

pl. nom.

acc.

gen.

dat. brōpar brōpar brōprs brōpr brōprjus brōpruns brōprē brōprum
OIcel. bróðir bróður bróður bróður brœðr brœðr brœðra brœðrum

\section{OE} brōpor brōpor brōpor brēper brōpor brōpor brōpra brōprum
OS

brōđer, -ar brōđer, -ar brōđer, -ar brōðer gibrōðer, -ar gibrōðer, -ar

brōðrun, -on
OHG bruoder bruoder bruoder bruoder bruoder bruoder bruodero bruoderum, -un 
The other nouns in this class are Go. fadar 'father' (once, in the voc., beside usual atta), *mōdar 'mother', ${ }^{1}$ daúhtar 'daughter', ${ }^{2}$ swistar 'sister', and their cognates. ${ }^{3}$ Note Runic swestar on the (probably) $5^{\text {th }}$-century Norwegian Opedal stone. Beside OIcel. dat. sg. foður 'father' there occurs the (probably more original) by-form $f e \partial r$, which may be extended to the acc. and reformed in gen. feðrs; foður itself is then probably analogical to the gen. acc. sg. (Gutenbrunner 1951: 104). In OHG, muoter is inflected like bruoder, but fater has nom. acc. pl. fateră, and there develop alternative forms modeled on the $a$ stems, gen. sg. fateres, dat. fatere. Similarly, OE fæder always has $a$-stem nom. acc. pl. $f æ d(e) r a s$, and analogical gen. sg. fæd(e)res occurs not infrequently. Umlaut is usually missing from dat. sg. fæder, but cf. Northumbrian feder beside fæder; conversely, umlaut may be extended to cases in which it is not etymological, as in Mercian gen. sg. dehter (spelt with $\langle\mathrm{oe}\rangle$ ). OE mōdor has always nom. acc. pl. mōdru or $m \bar{o} d r a$, and the variation suggests that the origin of the inflection is in a collective neuter plural (see Hogg \& Fulk 2011: §2.93), as PGmc. acc. pl. *-unz should have been lost (otherwise Boutkan 1995b: 275). The lack of umlaut in nom. pl. brōpor (as opposed to dat. sg. brēper) is unexpected. ${ }^{4}$ Of particular interest is Mercian gen. sg. feadur, Northumbrian -fadur, fador, on which see $\$ 7.36$.

1. Go. áipei is used instead of *mōdar, which is entirely unattested, but which is reconstructible from related forms. According to Prokosch (1939: §85), and as might be expected from the vocalism, *mōdar (as well as $\mathrm{OE}$ mōdor, OS mōdar, OHG muoter; OIcel. móðir is ambiguous) derives from PIE *mấtêr , with root accent throughout (cf. Gk. $\mu \dot{\eta} \tau \eta \rho$, Lith. mótè, but cf. Pokorny 1959-69: II, 700), and the apparent effect of Verner's law $(\S 6.6)$ is thus to be attributed to analogy to fadar; cf. Skt. mätár- beside pitár-.

2. Go. aú in daúhtar is due to the following $h(\$ 4.5)$, whereas $o$ in NWGmc. *dohter- is due to lowering of $u$ before the following mid vowel ( $\$ 4.3$; the etymon is PIE *dhug $(h) h_{2} t e r-$, as in Gk. $\left.\theta v \gamma \alpha \dot{\alpha} \tau \rho\right)$, with compensatory lengthening upon loss of $/ \mathrm{x} /$ in OIcel. dóttir (\$4.9).

3. The OHG words swehur 'father-in-law', swigar 'mother-in-law', swägur 'brother-in-law', zeihhur 'husband's brother' and their cognates are not inflected as $r$-stems. On the intrusive consonant in zeihhur (cf. Skt. dêvár-, Gk. $\delta \alpha \dot{\rho} \rho$ ), see Fulk 1993b: 341-2.

4. It cannot be due to full grade of the stem suffix in PGmc. *brōper-iz, with early loss of $i$ in a third syllable (as in dat. pl. $\left.{ }_{-}-m i z, \S 5.2 \mathrm{n} .7, \S 7.8\right)$, unless it is assumed that $e$ was not raised to $i$ before ${ }_{-}-r i-(\S \S 4.4,5.5)$. Umlaut is lacking in the plural throughout WGmc.; the umlaut in NHG Väter, Mütter, Brüder, Töchter is modern and analogical. Umlaut is found in all the NGmc. forms, however: feðr, mœðr, brœðr, dœetr.

\subsection{Origin and development of $r$-stem inflections}

In PIE at least 'father' had a regular alternation between strong and weak cases (\$7.4), with shift of accent between stem and inflection, as in Greek acc. sg. $\pi \alpha \tau \varepsilon \dot{\varepsilon} \rho \alpha$ 'father', gen. $\pi \alpha \tau \rho o ́ \varsigma$. In Go. and OIcel. the weak stem has been extended to all cases but the nom. and acc. sg., whereas in WGmc. it is the strong stem that prevails. If it is assumed that alternation in the place of the accent occurred in all these words, not just 'father', it must be supposed that the consequent alternations in voicing under Verner's law ( $\$ 6.6)$ have been leveled away.

Nom. sg. *brōpēr (< PIE *bhrātēr < *bhrāter-s) may be assumed for PGmc. This would explain OHG bruoder, though the stem *broper- of the acc. and voc. would produce the same result if extended analogically to the nominative. ${ }^{1}$ The usual assumption is that in Go. brōpar, *-er has resulted in -ar (\$5.3), and that *-er also explains OIcel. -ir as well as early Runic swestar, assuming that $\langle\mathrm{a}\rangle$ stands for $/ \mathfrak{a}: /$, which later developed to /e/ in the unstressed syllable, still later merging with /i/. Alternatively, 
Streitberg (1892: 108, idem 1896: $\S \S 160,179)$, followed by some others, has argued that swestar reflects the $*_{-} \bar{o} r$ of PIE *suesōr. Both of these assumptions have been challenged by Stiles, who argues that Go. fidwōr 'four' must be derived from PIE neut. * $k^{w}$ etuṓr rather than the usually assumed masc. $k^{w} e t u o ́ r e s$, with subsequent analogical extension of $\bar{o}$ from the neuter (see Stiles 1985-6: 6.86-8), and therefore shortening in Gothic is not to be expected in *brōpeer; rather, Go. nom. brōpar has acquired the stem of the vocative or, less likely, the acc. (Stiles 1988). He also argues that Runic swestar is unlikely to represent a nom. in $*_{-} \bar{e}$ but a voc. in *-ar (Stiles 1984). Hamp (1990) supports Stiles but posits nom. sg. *brōpe for PGmc. Boutkan (1992, 1995b: 272) argues that Runic swestar reflects the original $*_{-} \bar{o} r$, whereas OIcel. systir reflects the analogical ending $*-\bar{e} r$. The issues are complex and capable of more than one interpretation, but the analysis of Stiles seems quite likely.

Acc. sg. PGmc. *brōper- $u^{n}<$ PIE *bhrāter-m develops normally in Gothic and OIcel., in the latter instance through the series of changes $*_{\text {-eru }}^{n}>*_{\text {-aru }}>*_{\text {-oru }}>{ }_{-u r}$ (see Heusler 1967: §113). The WGmc. developments appear to be natural; on OE -or, see note 1 .

Gen. sg. The Gothic and main NWGmc. forms may be derived regularly from PIE *bhrátr-os or *bhrátr-es. OIcel. faðir has gen. sg. foður, which is usually associated with Skt. pitúr and derived from * $p h_{2}$ trrs, though how such a form arose in PIE is difficult to explain, since the original ending should have been PIE *-r-os (see Szemerényi 1996: §7.3.3, with references, and cf. Stiles 2013: 30). Accordingly, Bammesberger (1983a) argues that the Gmc. and the Skt. forms are analogical creations. Corresponding to foður are the variant Anglian OE forms cited above, feadur, -fadur, fador.

Dat. sg. The Gmc. dat. corresponds to the PIE locative, hence PIE * $p h_{2} t r-i$ 'father' (cf. Gk. $\pi \alpha \tau \rho i$, Lat. ablative patre), in which the loss of final *- $i$ after the heavy syllable was earlier in Go. than elsewhere in Gmc. (§5.2). PIE *bhrátr-i explains all the forms in the paradigms in $\$ 7.35$ except for OIcel. bróður (for expected brœðr, which is rare), which is analogical to the acc. and gen., like dat. foður beside etymological feðr. But doubts have been raised about the retention of *- $i$ in Proto-Norse: see $\$ 5.2$ n. 2.

Nom. pl. PIE *bhrâter-es > PGmc. *brōper-iz develops regularly into the OS and OHG forms (aside from the elimination of voicing of $p$ under Verner's law, if instead *bhrātér-es is assumed, as explained above). OIcel. brœðr results from generalization of the weak grade of the suffix *-r-in PNorse, resulting in *brōpris; cf. Runic dohtrir on the Tune stone of ca. 400. OE fæderas has been analogically reformed on the model of the $a$-stems. Go. brōprjus, with zero grade of the suffix, as in $\mathrm{ON}$, has acquired the $u$-stem ending because the acc. and dat. pl. endings of Go. $r$-stems were indistinguishable from those of $u$-stems.

Acc. pl. PIE *bhrấtr-nns > PGmc. *brōpr-unz produces the Go. form by regular sound change, whereas the NWGmc. forms are analogical to the nom. pl.

Gen. pl. PIE *bhrátr-oHom produces the expected results everywhere except in OIcel., where the umlauted vowel of the nom. pl. is extended throughout the plural, and in $\mathrm{OHG}$, where bruodero may be due to analogical generalization of the stem with *-er(cf. the dat. pl.), or, less likely, it may reflect an original variant with full grade of the suffix: cf. Gk. $\pi \alpha \tau \dot{\varepsilon} \rho \omega \nu$ beside Homeric $\pi \alpha \tau \rho \hat{\omega} v$, Lat. patrum.

Dat. pl. PIE *bhrấtŗ-mis is an instr. form $(\$ 7.2$; cf. Skt. instr. mātŗbhis 'mothers') which may be assumed to give PGmc. *brōpru-miz (with *-ru- rather than *-ur- under the influence of the other weak cases: see $\$ 12.31 \mathrm{n}$. 3). This produces 
regular results, except that the umlauted vowel of the nom. pl. is extended to the dat. in OIcel., and in OHG the stem with -er- has been generalized.

1. By contrast, $\mathrm{OE}$ has -er (as in fæder) or -or (as in brōpor) depending on whether the vowel of the preceding syllable is front or back, due to nuclearization originating in the gen. and dat. sg., according to A. Campbell (1977: §631). Alternatively, Krahe \& Meid (1969: II, §23) suppose that -er in nom. sg. fæder directly reflects PIE *-er $r$, with loss of the vowel after a heavy syllable in all the remaining $r$-stems and subsequent parasiting. But phonological loss of the stem vowel in an uninflected form seems unlikely.

\subsection{The s-stems}

In PIE these were almost all neuter, and in Gmc. they are exclusively so. ${ }^{1}$ They bore the PIE accent on the root in the nom. sg., but otherwise there is wide disagreement about the pattern of accentuation in this class. ${ }^{2}$ The category remains distinct in several IE languages; an example of an $s$-stem is, from PIE * génh $h_{1}-o s$ 'kind, family', gen. * génh $h_{1}$

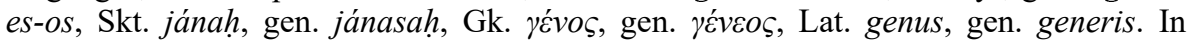
Gmc. the $s$-stems as a noun class remain nowhere very distinct, having conformed to the inflection of more productive classes, though in $\mathrm{OE}$ the coöccurrence of alternative stems in different noun classes attests to the alternations in earlier $s$-stem paradigms. Thus, for example, beside gāst 'spirit', hlāw 'mound', $h r \bar{a} w$ 'corpse' there occur also

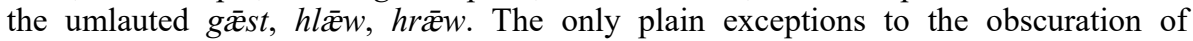
paradigm alternations are to be found in Anglian texts. One exception is dogor 'day': in

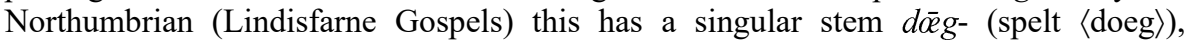
whereas the plural stem is $\operatorname{dog}(o) r-$, the latter used for both sg. and pl. in poetry. ${ }^{3}$ Similarly, the Mercian gloss on the Vespasian Psalter has sg. cælf (with $i$-umlaut) ${ }^{4}$ but pl. calfur, calfer-. In poetic texts, nom. sg. hrē̇ 'glory' occurs beside $h r o \bar{\partial}(o) r(-)$ in the dat. sg. and in the plural. On the basis of such alternations may be reconstructed an original paradigm like the following (see Brunner 1965: §289, Hogg \& Fulk 2011: $\S 2.96)$ :

$\begin{array}{lll} & \text { singular } & \text { plural } \\ \text { nom. } & \text { dōg } & \text { dōgor } \\ \text { acc. } & \text { dōe } & \text { dōgor } \\ \text { gen. } & \text { dōgores } & \text { dōg(o)ra } \\ \text { dat. } & \text { dōgor(e) } & \text { dōgrum }\end{array}$

The two residual signs of $s$-stem inflection are thus variable umlaut of the root vowel and variable appearance of suffixal $r<z$. Aside from the exceptional examples of preserved paradigm alternation noted above, the OE paradigms of original $s$-stems are of two types: (1) The nouns cealf 'calf', lamb 'lamb', and $\bar{x} g$ 'egg' decline as neut. $a$ stems, except that in the plural the inflection is preceded by $-r-$, e.g. nom. acc. cealfru, gen. cealfra, dat. cealfrum. (2) The remainder are declined mostly as neut. $a$-stems but have extended stem-final $-r$ - throughout the paradigm, e.g. nom. sg. hōcor 'derision'. Usually it is the stem without $i$-umlaut that is generalized, though a few nouns show generalization of the umlauted form, e.g. nom. pl. scērero 'shears'. In some instances there is a dual development, e.g. OE $i$-stems sige 'victory', sele 'hall', $h \bar{x} l$ 'salvation' beside $a$-stems sigor, salor, hālor (see A. Campbell 1977: §636). ${ }^{5}$

In Gothic and OIcel., the $s$-stems are declined entirely like $a$-stems, e.g. Go. riqis

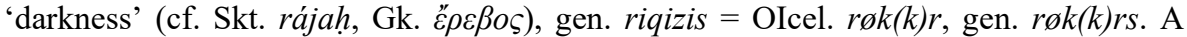
probable exception is gen. sg. hatis (for expected $a$-stem *hatizis) 'hatred' < PIE *-es- 
os (though this is disputed: see Braune 2004b: $§ 94$ Anm. 5): other forms of the word decline on the pattern of $a$-stems. ${ }^{6}$ In OHG and OS, the few remaining $s$-stems decline as $a$-stems, but with $r$-suffix in the plural and, in OHG, umlaut, e.g. OHG lamb 'lamb', nom. pl. lembir $<*$ lambizu $<*$ lambezo, gen. lembiro, dat. lembirum. This method of forming the plural was to become quite productive in German, for reasons sketched by Klein (2013). A few OHG forms with -ir or -ar in the sg. also occur (Braune 2004a: $\S 197$ Anm. 1).

1. The Gmc. material is collected in Kluge 1926: §84, also Schlerath 1995: 259-60. See also Schenker 1971, Casaretto 2000, the latter arguing that the type was productive in Gmc. Adamczyk 2012 traces the decline of the type in OE and OHG.

2. For instance, Clackson (2007: 94) reconstructs nom./acc. sg. *nébhos 'cloud', gen. sg. *nebhés-os, nom./acc. pl. *nebhés- $h_{2}$, whereas Ringe (2017: 62-3) reconstructs root accent throughout, and Beekes (2011: 198) assumes for the $s$-stems accent on the root in the nom. sg., on the suffix in the acc. sg., and on the inflection in the gen. sg. See further Schaffner 2001, Mottausch 2011. There must be assumed an alternating PIE accent, sometimes on the suffix, in order to explain the generalization of $s$ or $z$, alternants under Verner's law, for example $z$ in Go. aqizi 'axe' but $s$ everywhere else in Gmc., e.g. OE (Mercian) æces.

3. The two Northumbrian stems are not uncommonly regarded as belonging to separate paradigms (so, e.g., Cook 1894: 40-1, Klein 2013: $170 \mathrm{n}$. 1), but the complementary distribution by number is unmistakable.

4. In Anglian there is retraction of $æ x$ to $a$ before covered $l$, and this $a$ then may be umlauted to $æ$.

5. Wagner (2011) argues that PGmc. $a$-stem *dazaz 'day' was in origin an $s$-stem, derived from the etymon

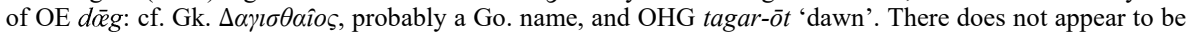
evidence outside of Gmc., however, for quantitative ablaut alternations in the root of $s$-stems.

6. In Go. the $s$-stems have $-s$ - after $h$ or a diphthong, otherwise $-i s-$. For the reason, see Boutkan 1995b: $266-7$.

\subsection{Origin and development of $s$-stem inflections}

The usual pattern in PIE was for the suffix to take the form *-os in the nom. voc. acc. sg. only (cf. the Finnish loanword lammas 'lamb'), elsewhere *-es-, which should produce PGmc. ${ }^{*}-i z$-. Thus, the reconstructed paradigm of OE $d \bar{\alpha} g$ in $\$ 7.37$ shows precisely the opposite of the expected historical distribution of $i$-umlaut, which is found in the nom. acc. sg. only, with the expected loss of final *-iz after the heavy stem. Against the usual IE pattern, then, the reflex of PIE *-os- must have prevailed outside the nom. acc. sg., though how -or- developed from *-os- is a matter of some debate. ${ }^{1}$ The likeliest explanation (that of Bammesberger 1990: 210) is that nom. acc. pl. *dōzazo developed to *dōzr (with rhotacism and syncope of *-a-, followed by apocope of $\left.*_{-} u<*_{-} \bar{o}\right)$, in which $*_{-} r$ was then syllabified to $-u r$, which was subsequently extended to most cases, with subsequent lowering to -or. Yet this explanation, too, faces some difficulties. ${ }^{2} \mathrm{OE}$ gen. sg. dogores was formed by analogy to the $a$-stems, since *-a- should have been lost from the final syllable of PGmc. *dōzazaz, giving *dōzaz > *dōzar, a situation reflected in the Mercian gen. sg. calfur (with analogical replacement of *-ar by -ur, as above). OE dat. sg. doggor is perhaps to be derived from a PIE instr. in $*_{-} \bar{e}$, which ending should have been lost; but a locative in $*_{-i}$ would explain the form if the ending is assumed to have been lost in a third syllable $(\$ 5.2 \mathrm{n}$. 7). The alternative dat. dogore (in poetry beside $d \bar{o} g o r$ ) probably does not reflect the PIE dat. in *-ei reconstructed for this class (note the lack of umlaut) but is analogical to the $a$-stems. 
1. For discussion and references, see Boutkan 1992, Hogg \& Fulk 2011: §2.99 n. 1, Klein 2013: 171-5. Boutkan's analysis, whereby -or(-) always reflects syllabified $r$, is discounted by Hogg \& Fulk (2011: $\$ 2.100$ n. 6), who conclude that $-o r$ in at least some instances must reflect $*_{-} u z-$, a conclusion agreed to by Klein, though no very convincing explanation as to how *-uz- arose has yet been devised (see Schaffner 2001: 58991, Klein loc. cit.).

2. This hypothesis could be tested metrically, since nom. acc. pl. dogor should then be monosyllabic in the meter of Beowulf, where, unfortunately, the relevant cases do not occur. Acc. pl. lomber at Guthlac B 1042 is disyllabic, but the metrical features of this poem are not conservative enough to ensure that the second syllable is not due to parasiting. The Mercian gloss on the Vespasian Psalter perhaps suggests that Bammesberger's explanation is incorrect, since in this text the final sequence PGmc. *-arō yields -eru rather than -ur (as in nom. sg. fem. óderu 'other'), and this must be the etymological outcome rather than the result of ana$\operatorname{logy}$ (see Fulk 2010b). In this text are to be found nom. acc. pl. calfur $(3 \times)$ and lombur $(1 \times)$, but also calferu and lomberu, once each. It is possible, though, that $-r$-, later syllabified, originated elsewhere in the paradigm. The hypothesis that PIE forms in $*_{-u s-}$ and $*_{-} H_{s}$ - should be reconstructed among the $s$-stems reflected in Gmc. is highly questionable: see Fulk 1988: $155-6$ for references.

\subsection{The $n d$-stems}

These are sometimes categorized under the dental stems (\$7.41), which also bore athematic inflections in PGmc., though the development of the two types is different. The inflections may be illustrated by the paradigms of Go. frijōnds 'friend' (cf. frijon 'love') and its WGmc. cognates, along with OIcel. bóndi 'farmer' (cf. búa 'settle'): ${ }^{1}$

\begin{tabular}{|c|c|c|c|c|c|c|}
\hline \multirow{3}{*}{ sg. } & & Go. & OIcel. & OE & OS & OHG \\
\hline & & frijōnds & bóndi & frēond & friund & friunt \\
\hline & c. & frijōnd & bónda & frēond & friund & friunt \\
\hline \multirow{6}{*}{ pl. } & gen. & frijōndis & bónda & frēondes & friundes, -as & friuntes \\
\hline & dat. & $\begin{array}{l}\text { frijōnd } \\
\text { friiōnd }\end{array}$ & bónda & frīend & friunde, $-\mathrm{a}$ & friunt, -e \\
\hline & nom. & frijōnds & bœndr & frīend & friund & friunt \\
\hline & acc. & frijōnds & bœndr & frīend & friund & friunt \\
\hline & gen. & frijōondē & bónda & frēonda & friundo & friunto \\
\hline & dat. & frijōndam & bóndum & frēondum & friundun, -on & friuntum, \\
\hline
\end{tabular}

In WGmc. there occur also analogical forms. Thus, in the nom. acc. pl. are to be found forms analogical to the $a$-stems, OE frēondas (regularly in Anglian), OS friundos, friunda, OHG friuntă . OS OHG dat. sg. $-e$ is also analogical to the $a$-stem ending (dat. sg. friunt is rare in $\mathrm{OHG}$ ), and beside $\mathrm{OE}$ friend there occurs frēonde, the ending -e being universal in stems of more than one syllable such as dat. sg. hettende 'enemy'. OE polysyllabic stems regularly have genitive plural in - $r a$ and frequently nom. acc. pl. in $-e$, both of which endings are borrowed from adjectives.

1. OIcel. bóndi is represented here because in frændi 'kinsman' a single stem vowel has been extended throughout the paradigm, though a rare, archaic, uncontracted pl. friendr is also attested.

\subsection{Origin and development of $\boldsymbol{n d}$-stem inflections}

These are in origin substantivized polysyllabic present participles in PIE *-nt- (cf. Gk.

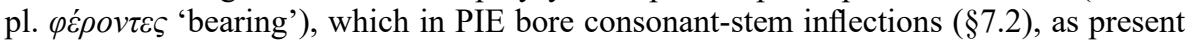
participles still do in Skt., though on a dialectal basis the true participles acquired $a$-and 
$\bar{o}$-stem inflections and were thus distinguished from these nouns in Gmc. ${ }^{1}$ As in the participles, since the vowel before ${ }^{*}-n t$ - was unstressed, PGmc. ${ }^{*}-n p$ - was voiced to *-nð- under Verner's law, with subsequent development to *-nd- $(\S \S 6.5-6)$.

The original set of inflections is best preserved in Gothic, where the nom. acc. dat. sg. and nom. acc. gen. pl. directly reflect the consonant-stem endings (cf. Go. baúrgs 'city', §7.27). Several of these endings, however (nom. acc. sg., gen. pl.) are identical to the $a$-stem endings, and probably on that basis $a$-stem inflections were adopted for the gen. voc. ${ }^{2}$ sg. and the dat. pl.

Umlaut in the nom. pl. in OE and OIcel. (and cf. OIcel. nom. acc. pl. gefendr 'giver' beside nom. sg. gefandi) is the result of the consonant-stem ending $*_{-i z}<$ PIE *-es, with the acc. pl. patterned after this, and in OE there is umlaut in the dat. sg., just as in the root-stems and the $r$-stems $(\$ \S 7.27,7.35)$, due to PGmc. and PIE *-i (locative). OIcel. thus preserves the consonant-stem character of these nouns in the plural, whereas the singular has been made to conform to the declension of the an-stems (\$7.30). Aside from the endingless forms (those which in OE have umlaut), there is nothing to distinguish these nouns from $a$-stems in WGmc., though that is in part due to regular sound change, in part to analogy, the latter having applied in the gen. sg., where *-iz (cf. Go. $-i s)$ should have been lost.

1. Ringe (2017: 224) doubts that there was a class of $n d$-stem nouns in PGmc, supposing that they were still regarded as participles. That is not impossible, but since Go. frijōnds and its Gmc. cognates all have the meaning 'friend' and do not inflect like participles in any Gmc. language, the assumption that PGmc. had $n d-$ stem nouns cannot justly be called rash.

2. The voc. sg. would normally have developed to * frijōn (\$6.11).

\subsection{The dental stems}

Most of these are disyllabic stems ending in $b$, which reflects a PIE $t$-suffix (as in Lat. nepōs, gen. nepōtis 'grandson'); but cf. Go. weitwōds 'witness'. In Gothic and OIcel., in large part, these bear the same inflections as the masc. root-stems, e.g. Go. mènōps, OIcel. mánaðr 'month' (originally an $s$-stem: cf. Gk. $\mu \eta \dot{v}$, gen. $\mu \eta v o ́ \varsigma<* \mu \eta v \sigma o ́ \varsigma$, Lat. mēnsis, but perhaps with PIE nom. *mēnōt: Pokorny 1959-69: I, 731). In WGmc. only the nom. acc. pl. remains distinctively athematic: cf. OE mōnað, OHG mānōt. In WGmc. some dental stems developed in ways similar to the $n$-stems, so that the original athematic inflections were lost in most case-forms, leaving the dental element to serve as an inflection. Only OE preserves this situation recognizably, and in just a few words, as illustrated by nom. acc. sg. ealu 'ale', gen. dat. sg. ealap, gen. pl. ealepa, though analogical forms occur beside these, e.g. Northumbrian gen. sg. alðes. Although mōnap shows its origin in this class only by the nom. acc. pl., $m æ g(e) b$ 'maiden' is uninflected in the gen. dat. sg. and nom. acc. pl., though $-p$ has been extended analogically to the nom. acc. singular. OE nom. acc. sg. hæle 'hero' has nom. pl. hælep (beside hælepas), gen. pl. hælepa, dat. pl. hælepum. In the other WGmc. languages such nouns are declined according to other classes, e.g. OS helid 'hero' as an $a$-stem, OHG magad 'maiden' as an $i$-stem. 


\subsection{The heteroclitic stems}

In PIE there was a class of neuter nouns with stems in $*_{-} r$ - in the nom. and acc. sg., whereas in the other cases the stem was in ${ }^{*}-n-$, as in Lat. femur, gen. feminis 'thigh'. ${ }^{1}$ This irregularity must have survived in some words into PGmc., since the different branches of Gmc. have generalized one or the other stem individually. The plainest example is Go. watō 'water', gen. watins, inflected as a regular neut. an-stem, except that the dat. pl. is watnam (other pl. cases unattested; hence, like gen. pl. aúhsne, $\S 7.30)$; cf. Gk. $v \delta \omega \rho$ 'water', gen. $v \delta \delta \alpha \sigma \varsigma<* h_{2} u d-n$ - with post-PIE dental extension; cf. also Hittite watar (PIE * $h_{2} u o ́ d-r$ ), gen. witenas. NGmc. has also generalized the form of the stem with $-n$ - in OIcel. vatn, a regular $a$-stem, though rare vatr occurs early, as confirmed by the rhyme in some skaldic poetry, e.g. vatr (in one manuscript, but vatn elsewhere) rhyming with vitri in Sigvatr Pórðarson, Lausavisa 19. WGmc. reflects only the stem in -r-, e.g. OE wæter, an $a$-stem. Also notable is Go. fön 'fire', gen. funins, dat. funin (comprising all the attested cases), hence inflected as a root-stem, the only neuter root-stem in Gothic. To this corresponds OIcel. funi, inflected as a masc. an-stem, whereas WGmc. has again generalized the stem in -r-, OE fy̆r, OS OHG fiur (neuter $a$ stems), but cf. the derivative OHG funcho 'spark' and the alternative, disyllabic form OHG fuir (spelt vugir in Muspilli), which is difficult to explain: see Bammesbeger 1990: 205, Ringe 2017: 147, $162 .^{2}$ On the ablaut in heteroclites, see Schindler 1975. On Go. $a b a$ 'man' as a heteroclite, see Johnsen 2005.

1. Schindler (1975) posits separate singular and collective paradigms for such nouns, e.g. nom. acc. sg. ${ }^{*} h_{2} u o ́ d-r$, gen. ${ }^{*} h_{2} u e ́ d-n-n-s$, nom. acc. collective ${ }^{*} h_{2} u e ́ d-\bar{o} r$, gen. ${ }^{*} h_{2} u d-n$-és (though he does not assume an initial laryngeal).

2. On the reconstruction of a heteroclitic $l / n$-stem on the basis of comparison of Go. sauil 'sun' and OE sunne 'sun' (with cognates), see Bammesberger 1990: 206. See also Mottausch 2011: 80-1, Simms 2017. 
CHAPTER 8

\section{Pronouns}

\subsection{Types of pronouns in Proto-Germanic}

The Germanic protolanguage inherited from PIE a system of pronouns including personal pronouns for only the first and second persons, which were declined in three numbers (singular, dual, plural) and in the same cases as nouns (\$7.1), though not all the case forms are securely reconstructible for all pronouns. Personal pronouns were declined without gender distinctions. The function of the personal pronoun for the third person was filled by demonstrative pronouns (which lacked dual forms), particularly the anaphoric pronoun $* i s$, and these were declined in three genders, though in some case forms no more than one gender can be distinguished. It should not be surprising that gender is not distinguished in the personal pronouns: the referents of pronouns of the first and second person are both present in dyadic interaction (or, in the dual and plural, at least one of each must be present), and so specification of gender would not under most circumstances contribute any useful information: for discussion, see Siewierska 2013.

In addition to these, interrogative, relative, possessive, and reflexive pronouns are reconstructible for PIE. Pronouns might be stressed or unstressed in PGmc., and with the usual changes affecting vowels in unstressed syllables there arose alternative forms of one and the same pronoun, and one or the other alternant might then be generalized, for example by extension of unstressed forms to stressed positions. Tonic and enclitic forms are likewise assumed to have been in alternation in PIE. The development of Gmc. pronouns has been particularly heavily influenced by analogical proportions.

\section{Personal Pronouns}

\subsection{Personal pronouns of the first person}

Reconstructing the pronouns of PIE is fraught with difficulties, but a comparison of personal pronouns in Vedic Sanskrit, Old Church Slavonic, Greek, Old Latin, Gothic, and Hittite suggests that the following is a plausible reconstruction of the first person pronoun in PIE, where the colon separates tonic and clitic forms, respectively: ${ }^{1}$

\begin{tabular}{|c|c|c|c|}
\hline & singular & dual & plural \\
\hline nom. & $* h_{1}$ e $\hat{g o H}: * h_{1}$ eĝHom & *ue & * unei \\
\hline c. & ${ }^{*} \mathrm{~h}_{1}$ mé $:{ }^{*} \mathrm{~h}_{1} \mathrm{me}$ & *nnh nue $_{1}$ *nōh & *ñsmé : *nĕ \\
\hline n. & ${ }^{*} \mathrm{~h}_{1}$ méne $: *$ mei/moi & *nōh & *ñnsóm : *nōs \\
\hline $\mathbf{a}$ & $*$ med & ${ }^{*}$ nŏh $_{1}$ & $*_{n}^{n}$ smed \\
\hline at. & *mebhi : *mei/moi, & ${ }^{*}$ nŏh $_{1}$ & *nssmei : *nōs \\
\hline
\end{tabular}


Germanic reflects only the tonic forms. The commonest corresponding forms attested in early Germanic are the following. Note that Old High German preserves no dual pronouns, with the exception mentioned below: ${ }^{2}$

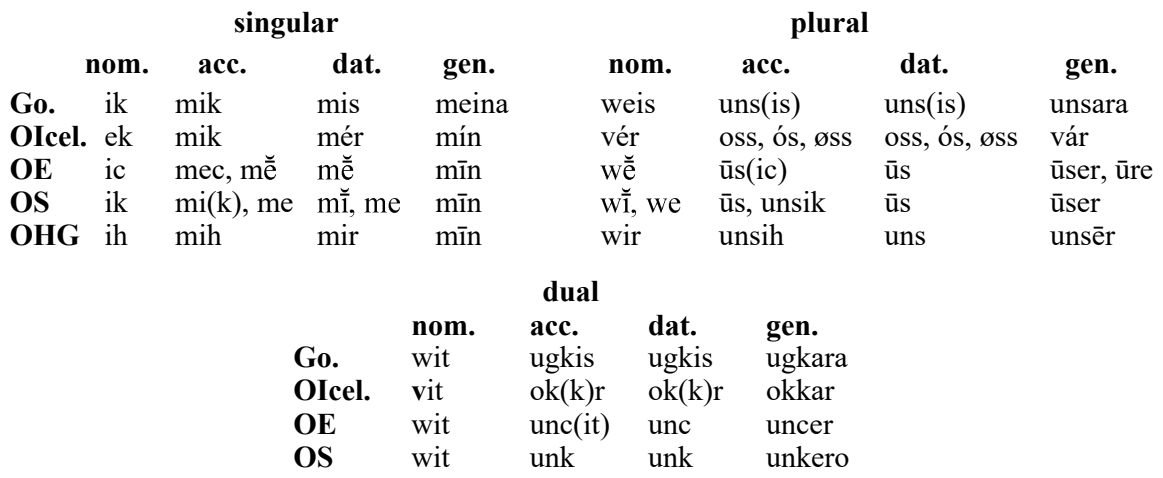

In OE the acc. forms in $-c$ are confined to the Anglian dialects and poetry; dat. and acc. are identical in WS. OS mik is rare but attested in the Heliand. In OHG, beside $1 \mathrm{sg}$. ih there occurs ihha, ihcha, semantically equivalent to Lat. egomet. The Germanic forms may be remarked upon as follows:

Nom. sg. The Gmc. forms $i k$ and $e k$ cannot be derived directly from either PIE

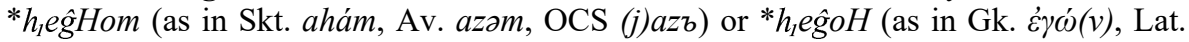
$e g \bar{o})$, since there should not have been raising of $*_{e}$ to $i$ in either reflex, and neither will produce Runic ek, ${ }^{3}$ rather $* e k a$ or $* e k u$. Thus, ${ }^{*} h_{l} e \hat{g H o m}$ adequately explains enclitic -(e)ka, attested in East Norse inscriptions after ca. 600 (Seebold 1984: 21-2). But Gmc. $i k$ and $e k$ are most plausibly to be derived from ${ }^{*} h_{1} e \hat{g}$ (or $* e g h_{2}$ : so Ringe 2017: 163), which must underlie OLith. ěs, OPruss. es, Latvian $e s<* e \hat{k}$, presumably devoiced from *eg before a voiceless initial (Prokosch 1939: §98b). This $* h_{1} e \hat{g}$, as opposed to $* h_{l} e \hat{g}$ $H o m$, explains the raising of the root vowel seen in all the East and West Germanic reflexes, since the monosyllable could be entirely unstressed and thus undergo raising of the vowel (see §5.5), whereas OIcel. ek must reflect *eka<*hlegHom. The coöccurrence of * $h_{1} e \hat{g}$ and $* h_{1} e \hat{g H o m}$ is paralleled in Slavic, where, e.g., OCS $a z ъ$ beside infrequent jazb indicates earlier $* h_{l} \bar{e} \hat{g}$ beside $* h_{1} \bar{e} \hat{g H o m}$, with lengthening.

Acc. sg. Final $-k$ has often been derived from a clitic particle reflected in Greek as $\gamma \varepsilon$ 'at least, for one' (e.g. by Fortson 2010: 150), which is joined to pronouns, as in $\dot{\varepsilon} \mu \varepsilon^{\gamma} \gamma \varepsilon$ ' $m e$ '. This is not improbable, since the particle has an emphasizing function, and the PGmc. form may be assumed to have undergone the development *me-ke $>*_{m e k i}$ $>$ *mik (Hirt 1931-4: II, §69; Seebold 1984: 34). It is also possible, however, that $-k$ has been extended from the nominative, with raising of $*_{e}$ to $*_{i}$ in the monosyllable under low stress. A similar explanation, at all events, seems to be required to account for Hittite acc. dat. loc. amug by comparison to nom. ug (Szemerényi 1996: §8.4.2) and for

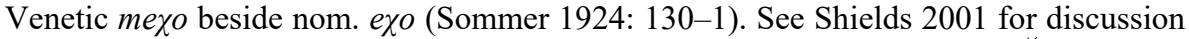
and references. As for the alternative accusative forms of Ingvaeonic, OE $m \overline{\bar{e}}$, OFris. $m \bar{\imath}$, OS $m \breve{l}$ (seldom $m e$ ), it is difficult to explain why the distinction between acc. and dat. forms should have been eliminated. Seebold (1984: 35-6) argues, somewhat diffidently, that there was an oblique enclitic form *me/mi used in PGmc. for acc. and dat. alike, with dedicated acc. ${ }^{*} m i k$ and dat. ${ }^{*} m i z$ reserved for use in contexts in which the distinction was important, and after dat. *miz fell together with this dual-purpose *me in 
WGmc., the alternative acc. *mik came to be regarded as superfluous in most of North Sea Germanic. Likelier perhaps is the possibility of confusion of the two cases in unstressed forms, a confusion then extended to stressed ones: see Howe 1996: 105-11, with discussion and references. See also H.F. Nielsen 2000: 250.

Gen sg. The Gmc. forms probably are to be derived from PGmc. *minne < *meinē, a remodeling of PIE *menē by equation of $*_{-n} \bar{e}$ with the directional suffix reflected in Lat. superne 'from above' and Go. ütana 'from without' (§1.4), leading to replacement of *me- by locative (or enclitic: Szemerényi 1996: $\$ 8.4 .4 \mathrm{e}$ ) *mei, the sense 'mine' thus deriving from 'with me' (Seebold 1984: 49-51). This *-nē gives Go. -na, otherwise $-n$ in Gmc. (\$5.3). With reanalysis, the pronominal stem *min- then became the basis for the possessive Go. meins, OIcel. minn/min-, OE min, etc. To the contrary, Ringe (2017: 236) derives all genitive personal pronouns from possessive adjectives.

Dat. sg. PGmc. *miz, tonic $*_{m e z}$ will account for all the attested forms; OIcel. $m e ́ r$ shows lengthening before Proto-Norse ${ }_{-}$, and OE $m \bar{e}$ (beside $m e$ ) and OS $m \bar{\imath}$ show lengthening in the re-stressed pronoun $(\$ 2.5)$. The origin of $-z$ in the PGmc. form is much disputed, since there is no obvious IE parallel: see G. Schmidt 1978: 135-6 and Seebold 1984: 45-6 for discussion of some proposals, and see below regarding the acc./dat. dual.

Nom. du. PGmc. *wit accounts for all the Gmc. forms. Its final *-t is generally explained as derived from one or another form of 'two' (a construction with parallels: cf. Lith. mùdu (Samogitian vẽdo) and Slovene $m \hat{\imath}-d v a$ ), perhaps PIE *de, as in *de-kmt 'ten' < 'two hands', as argued by Seebold (1984: 25-6, with references; cf. Cowgill 1985: 15 , reconstructing *ué-duo). On the basis of modern dialect forms may be reconstructed OFris. * wit (Siebs 1901: 1353).

Acc./dat. du. The PGmc. stem is plainly *ujk-, in which $k$ is unparalleled outside of Germanic, though $u n$ - regularly derives from PIE *n- (probably for earlier $*_{n}$-: see the acc. pl. below), as in tonic Skt. $\bar{a} v a ́-<* n h_{1}-w e ́-;$ cf. the unreduced grade in Skt. $n a h$, Lat. $n \bar{s} s$. The usual explanation of $*_{-} k$ - is that it is borrowed from acc. sg. *mik (so, e.g., Prokosch 1939: §98d). Seebold (1982) instead argues for the development of $g$ (> PGmc. $k$ ) out of PIE $u$ between a front diphthong and a syllabic liquid, though the evidence for such a change is hardly straightforward. Ringe (2017: 112, 233-4, following Katz 1998: 89-99, 212-17) reconstructs PIE *nh $h_{3} m e ́$, with subsequent substitution of $u$ (borrowed from second-person forms) for $m$ and a velar consonant as reflex of the laryngeal. Also difficult are the desinences, since Go. -is has no close IE parallel, and there is no umlaut of the root vowel in $\mathrm{ON}$ or $\mathrm{OE}$. The standard explanation is that the ending is extended from dat. sg. Go. $m$-is, OIcel. mé-r to the dat. pl., with subsequent extension to the dual, along with elimination of the formal distinction between dat. and acc., as in the plural. Alternatively, -is in Go. may have been borrowed from nom. pl. we-i-s before $e i$ developed to a diphthong and was monophthongized to $\bar{l}$ (Hogg 1992: §3.3). Ringe (2017: 234-5, following Katz 1998: 118-21) supposes that the source of Go. -is is an analogical PIE instr. pl. *ns-mís, which furnished the PGmc. dat. pl., and -is in the other datives (sg. and dual) is analogical to this, with a complex derivation. Anglian OE acc. uncit (beside uncet, WS and Kentish unc) must be dissimilated from *unk-ik (so Stiles 1996; cf. A. Campbell 1977: $\$ 703$ n. 1, deriving -it from the nom. dual, and similarly Bahnick 1973: 153, Seebold 1984: 32): cf. acc. pl. $\bar{u}$ sic (OHG unsih) and second-person acc. pl. éowic, and see the discussion of those forms as regards the origin of $-i c$. Umlaut (along with affrication of $c$ ) has thus been 
analogically reversed in uncit (see Hogg \& Fulk 2011: §5.26 n. 2). Note that OFris. *unk may be reconstructed on the basis of North Frisian unk (Seebold 1984: 32).

Gen. du. Go. *ugkara is unattested but may be inferred from the corresponding pronoun of the second person, igqara. The stem is derived from the PGmc. possessive adj. *uykera-, which in turn was formed by the addition to the pronominal stem *uyk(cf. the acc. and dat. du.) of a suffix *-er- seen also in Go. anpar 'other', hapar 'which of two', a thematization of the PIE suffix *-er- used to form locative adverbs, ${ }^{4}$ e.g. Go. jáinar 'yonder' (cf. jáins 'yon'; so G. Schmidt 1978: 203; see the gen. sg. above on possessive meaning derived from locative). OS unkero shows the ending of the gen. plural. In OHG there is a dual pronoun unkēr attested twice in Otfrid, but only with the qualifier zweio 'two', showing that the dual meaning was no longer transparent; cf., however, OE uncer twēga (Beowulf 2532). See also $\S 8.3$ on MHG duals in the $2^{\text {nd }}$ pers. pronoun.

Nom. pl. The Gmc. forms reflect the PIE stem *ue- recoverable from Skt. vayám, OCS vē, Hitt. wès, Tocharian B wes, Lith. du. vè-dú. Go. weis and OEN vī(r) reflect PGmc. *wiz, probably from *uei $(e) s$, i.e. ue- $\underline{i}$ - plus the the nom. pl. inflection of athematic nouns, whereas the other Gmc. forms reflect *wez, from *ues, with raising to * wiz when unstressed, and lengthening when re-stressed. ${ }^{5}$ There appears to be no very compelling basis for regarding either *wiz or *wez as more original. In the view of some (e.g. Krahe \& Meid 1969: II, §32), the OWN and WGmc. forms may be derived from *wiz, to be regarded as derived from PGmc. ${ }^{*} w \bar{i} z$ by vowel shortening under low stress. How the vowel in *wiz could have been lowered in OE, however, is difficult to explain, since lengthening would then have to have taken place after this lowering, even though such lowering can have occurred only in the historical period, as with acc. sg. mec, early mic. On the preservation of $*_{-z}>-r$ in OHG wir, see $\S 6.16$.

Acc./dat. pl. The stem is PGmc. $*^{*} u n s^{-}<\mathrm{PIE} *{ }_{n} s^{-}$, with ${ }_{n}$ probably for earlier $m$ (cf. $m$ - in the oblique cases of the sg.) by assimilation to the following coronal consonant. The ending Go. -is (probably originating in the dat.: see the discussion of the acc./dat. du.) is facultative, though Dickhoff (1913: 468) finds that unsis is commoner as dat. $(50 \times: 44 \times)$ and $u n s$ as acc. $(16 \times: 77 \times)$. Likewise variable is umlaut in OIcel. øss $<*$ unsiz beside ós $<*$ ons $(\$ 4.9)<*$ uns (Noreen 1970: $\$ 112.1)$, though the usual form is oss. $^{6}$ Anglian OE acc. üsic parallels OHG unsih, with WGmc. *-ik taken over from the acc. singular. OS acc. unsik (without NSGmc. loss of $n, \S 4.11$ ) occurs only in the $10^{\text {th }}$-cent. gospel glosses in the Essen manuscript.

Gen. pl. As in the dual, the Gmc. stem is usually thought to derive from the PGmc. possessive adj., here *unser-, though there is no general agreement as to which case-form of the adj. it represents. ${ }^{7}$ The ending is probably PGmc. *-e (> Go. $-a$, elsewhere lost, §5.3), which can be explained as the same ending seen in the gen. sg. (Seebold 1984: 55). ${ }^{8}$ OS forms in -o have acquired this vowel by attraction to a following substantive with the gen. pl. suffix -o. In OHG unserr the long vowel is usually assumed to have been lengthened by analogy to the nom. sg. of the pronominal inflection of adjectives, e.g. blinter 'blind', though there is no consensus. ${ }^{9}$ This accounts for all the Gmc. forms except OIcel. vár and OE üre. The former is usually taken to represent the borrowed stem of the possessive adj. várr (and see $\S 8.5$ on the derivation of the adj.), though there has also sometimes been posited a form PIE *ue-ro (e.g. by Streitberg 1896: §183), derived from a variant of the dual stem. ${ }^{10}$ As for OE $\bar{u} r e$, this cannot be derived from *unserē by normal means. Perhaps when the NSGmc. possessive adj.

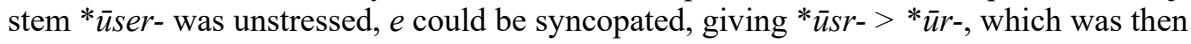


extended to the pronoun (so, tentatively, Hogg \& Fulk 2011: §5.25), though this leaves final $-e$ in the pronoun unexplained. Rather than $\bar{u} r e$, the conservative Mercian dialect of the gloss on the Vespasian Psalter has the $\bar{u} r$ expected on the basis of this explanation. The form $\bar{u} r e$ is also used as a possessive adj.—oddly, since it is thus inflected like a ja-stem, but without umlaut ${ }^{11}$ — whereas Northumbrian (and, frequently, poetry) has $\bar{u} s e r, \bar{u} s r a$, with use of $\bar{u} s e r-, \bar{u} s r-$ (also uss- $<\bar{u} s r-$ ) as the stem of the possessive adjective.

1. Here and throughout this chapter, posited paradigms represent an amalgam of a variety of reconstructions, especially those of Szemerényi 1996: §8.4.1-4, Sihler 1995: 372, and Beekes 2011: 15.3.1. Intensive studies are G. Schmidt 1978 and Katz 1998. The Indo-Iranian forms Skt. ahám, Av. azəm are here assumed to have developed $*$ - $\hat{g} h$ - from $*-\hat{g} H-$.

2. In OS, too, duals not infrequently have plural meaning, foreboding the loss of dual forms.

3. Just twice ik, which Krause (1971: 120) explains as due to WGmc. influence or aberrant orthography or (least plausibly) development in unstressed position, whereas Antonsen 1975: 71) perceives the influence of acc. ${ }^{*} m i k$.

4. Rather, Euler (2013: 110) regards it as a comp. suffix.

5. The coöccurrence of *ue- $i$ - (as in Skt. vay-) and *ue-s- is due to alternate use of pronominal and nominal plural suffixes. The reason OWN vér cannot be derived from PGmc. *wiz is that original $\bar{l}$ appears not to have been lowered before $R$, as in Gliru-Halli 'blinking (or squinting?) Halli'; cf. Faroese glisa 'large, staring eye', glisa 'blink'.

6. Prokosch (1939: $\S 98 \mathrm{c}$, in reliance on Noreen: see Noreen 1970: §112.1) regards oss as a contamination of ós and øss, but oss is the usual form in older texts, and so Heusler (1967: §143) is probably right to regard oss as comparable to Go. unsara, with -sr- (after syncope) developing to -ss-.

7. For a survey of views (ablative, loc./instr., nom./acc. pl. neut.), including some that divorce the form from the poss. adj., see Shields 1985.

8. Sometimes *-o is assumed, instead (e.g. by Prokosch 1939: §98c, Euler 2013: 110-11), but under Prokosch's law (\$2.5 supra) this should be reflected as final -u/o rather than lost in OE üser. See further G. Schmidt 1978: 88 .

9. Johansson (1890), with a summary of alternative views, argues strenuously against this analysis, assuming rather that $-\bar{e} r$ reflects a PIE $r$-case of an instrumental stem with a long vowel comparable to Go. $h \bar{e} r$ 'here', OE $p \bar{x} r$ 'there', $h w \bar{x} r$ 'where' (1890: 133).

10. Seebold (1984: 52-4), rather than treating the pronoun as formed by analogy to the adj., derives it directly from PGmc. He posits a development in PGmc. *unser- $>*$ unsez- $>* \bar{u}$ sez-, followed by assimilation to $* \bar{u} z e z$, and then loss of $z$ by dissimilation, producing $* \bar{u} e z->* \bar{u} e_{R^{-}}>* \bar{u} e r->* \bar{u} a r->$ vár. Although this series of changes is dubitable, assuming as it does the forces of noncontiguous assimilation and dissimilation applying to the same sequence of sounds, it accounts well for the parallel instance of *isern- > *isezn- > járn 'iron'.

11. The most probable conclusion to be drawn from the lack of umlaut is that the possessive adj. üre is simply a borrowing of the gen. pronoun, with adj. inflections added. The idea of Seebold (1984: 54) is that üre derives from *uzzez (derived by the same means as in the case of the Olcel. pronoun, as above, n. 10), which must have been uninflected, as otherwise $*_{-} z$ would not have been lost. Naturally, this complicates the problem of explaining $\bar{u} s e r$. Cf. Ringe \& Taylor 2014: 339, positing a sound change $\overline{u s e r}>\bar{u} r e$ without parallel in OE.

\subsection{Personal pronouns of the second person}

A comparison of personal pronouns in Vedic Sanskrit, Old Church Slavonic, Greek, Old Latin, Gothic, and Hittite suggests that the following is the most plausible reconstruction of the second person pronoun in PIE (Szemerényi 1996: §8.4.1-4, with some modifications; dual forms adapted from Sihler 1995: 373): 


\begin{tabular}{|c|c|c|}
\hline singular & dual & plural \\
\hline$* \mathrm{t} \overline{\bar{u}} / * \mathrm{ti}$ & $*$ inuh $_{1}$ & *iūus/*usmés (usués?) \\
\hline *túé : *te & *uh uné : *ư̆ŏh & *usmé : ūōs \\
\hline *teue : *t(un)ei $/ * t($ un)oi & *uōôh & *ữōsóm/*usóm : unō̄s \\
\hline *tued & *uōôh & *usméd \\
\hline *tébhi : *t(u)ei $/ *$ t(u)oi & *uōoh & *usméi : ūōs \\
\hline
\end{tabular}

Once again, only the tonic forms are reflected in Gmc. The commonest corresponding forms attested in early Germanic are the following. Note that Old High German preserves no dual pronouns:

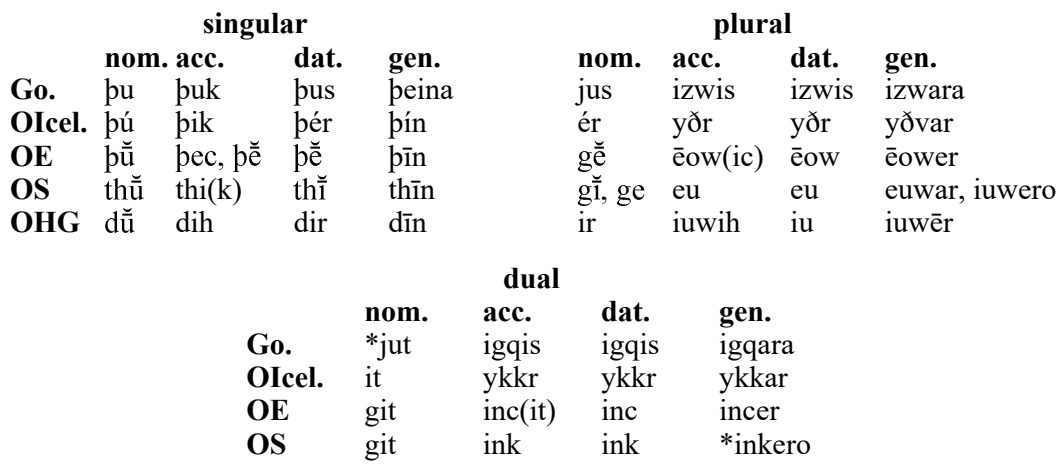

There occur in MHG (Bavarian) some duals ez, enc, and possessive enker, with plural meaning, showing that dual forms existed in OHG (or at least Bavarian) but went unrecorded. These have reflexes in present-day Bavarian (Howe 1996: 244-5, with discussion). Some remarks may be offered on the Gmc. forms:

Nom. sg. Gmc. $p \bar{u}$ may be derived unproblematically from either *tu or $* t \bar{u}$, the former undergoing lengthening as prescribed in $§ 5.2$.

Acc. sg. In their development the given forms are entirely parallel to those of the corresponding pronoun of the first person (§8.2), suggesting PGmc. * pik, except for Go. buk. This is usually explained as having borrowed the vowel of the nom. sg., though Seebold (1984: 36-7) argues that the Go. form is an archaism, and Prokosch (1939: $\S 98 b$ ), in related fashion, tentatively derives Go. $b u$ - from a PIE stem *tue- (producing both *tu and *te): cf. Skt. nom. tvám, abl. tvád, loc. $t v e \hat{e}$, Gk. $\sigma \dot{\varepsilon}<*$ tue (and cf. parallel developments in the reflexive pronoun, §8.4). ${ }^{1}$ If Go. puk is not analogical to the nom., the other Gmc. forms must be analogical to the corresponding pronoun of the first person.

Dat. sg. Go. pus presents the same problem of vocalism as in the acc. singular. Otherwise, the attested forms are to be explained the same way as the dat. sg. of the first person pronoun.

Gen sg. The attested forms developed parallel to the corresponding pronoun of the first person.

Nom. du. Although the Go. form is unattested, the parallel with the nom. pl. (see below) suggests that the PIE stem *iu(h)- might be expected to have been preserved here, too, as *jut, since the other Gmc. forms can readily be explained as reformed by analogy to the nom. du. of the first person pronoun-i.e., $* j u-t$ (from *iu(h)-de, with *-de added as in the corresponding first person form, §8.2) became *ji-t by analogy to *wi-t. The form *jit may also be reconstructed for OFris. on the basis of modern dialect 
forms (Siebs 1901: 1353). On NHG (Bavarian) evidence for *iz in OHG, see Seebold 1984: 17.

Acc./dat. du. Go. igqis and OIcel. $y k k r$ require PGmc. *inkwis (the latter with

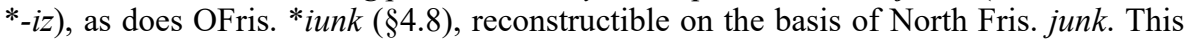
reconstruction will also account for OE inc and OS ink, with loss of $w(>u)$ after the heavy syllable $(\$ 5.6)$. That this stem contains $w$, whereas that of the corresponding pronoun of the first person does not, is most commonly explained as due to the analogical influence of the plural, on the proportion *unsiz: ${ }^{*} u \eta$ kiz $={ }^{*} i z w i z: x$ (so, e.g., Krahe \& Meid 1969: II, §33; cf. Ringe \& Taylor 2014: 519). Less convincing is the attempt of

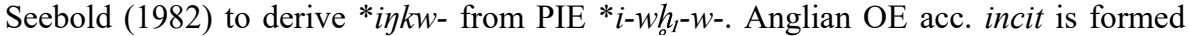
the same way as the corresponding pronoun of the first person. OHG *ink and *inkiz (= $\mathrm{OE}$ inc, incit) are reconstructible on the basis of Bavarian NHG enk, enks (Seebold 1984: 32). ${ }^{2}$ the first person.

Gen du. The attested forms developed parallel to the corresponding pronoun of

Nom. pl. Possibly the final consonant, a plural inflection, was added after the PIE period. The quantity of the vowel in Go. jus cannot be determined, and the comparative IE evidence is inconclusive. The other Gmc. forms almost certainly show replacement of PGmc. *juz by *jiz (cf. developments in the first person pronoun), with lengthening before $R$ in OEN to $*_{j} \bar{l}_{R}$ (giving $\bar{l}(r)$ ). On the basis of the reasoning offered above in regard to the corresponding pronoun of the first person, OE g $\check{\bar{e}}$ must then be regarded as analogical to $w \overline{\bar{e}}$.

Acc./dat. pl. The Gmc. forms show wide discrepancies, and there is no consensus as to how they are to be accounted for. Probably the most plausible explanation is that of Krahe \& Meid (1969: II, §33): the PIE form *ues gave PGmc. *wiz, which, to avoid homophony with the enclitic form of the first person plural (*wiz), was reduplicated to *wiz-wiz, with subsequent loss of initial $w$ by dissimilation, producing Go. izwis. ${ }^{3}$ In the form *izwiz, dissimilation further led to NGmc. *iðwiz (so already Bugge 1855: 251-2), which regularly produces OIcel. $y \partial r$. In WGmc., on the other hand, *izwiz results in *iuwiz, either by change of $*_{-}-w$ - to $*_{-w w}$ - (so first Kluge 1908: 65; see Stiles 1985-6: 6.92 for further references) or with the prior change to *iðwiz seen in NGmc., since Stiles shows that the change of PGmc. *feðwōr 'four' to WGmc. *feuwar also requires the change $*_{-} \partial w->*_{-} w w$ - (though Stiles does not assume NWGmc. *iðwiz). It has also been proposed that WGmc. *izwiz was reduced to *iwiz, again by dissimilation, which accounts adequately for OS eu, OHG iu, but not (pace Krahe \& Meid) OE $\bar{e} o w$ (Northumbrian $\bar{l} o w$ ), which would have to be assumed to have its $w$ by analogy to gen. pl. éower: cf. the discussion of OE wa-stems, §7.12. Alternatively, Prokosch (1939: §98c) suggests that the PGmc. form was *iwiz $(* j u+i z$, as in the corresponding pronoun of the first person, Go. unsis), with insertion of $s$ ( $>z$ by Verner's law) by analogy to the corresponding pronoun of the first person in East and North Germanic. But the structural parallel between *iwiz and *unsiz seems less compelling as a motive for the insertion of $s$ in the former than does the structure of *izwiz for development to *iuwiz in West Germanic. A variety of less plausible solutions is summarized briefly by Seebold (1984: 41-4), whose own attempt to derive the attested forms from a supposed PIE honorific stem *sghw- is less persuasive. Ringe (2017: 235, following Katz 1998: 102-5, 110-12), reconstructs PIE *usué (assuming that, by analogy to the pronoun of the first person, *-ué was replaced by *-mé in Greek and Indo-Iranian), from which initial $u$ was lost in PGmc. under some sandhi conditions, with later addition of 
prothetic $*_{i-}$, followed by a number of other changes. In Anglian OE there is addition of the suffix -ic, derived from mic (later $m e c$ ), with a similar development in OHG (and cf. MLG jük).

Gen pl. The attested forms developed parallel to the corresponding pronoun of the first person, except that in OS and OHG the monophthongal root vowel has been replaced by the diphthong seen in the dat. plural.

1. Yet possibly * sue is by analogy to *tue: so, e.g., Pokorny 1959-69: I, 882.

2. There is some confusion in the discussion of these forms in Euler 2013: 110, where the pronouns of the first and second persons are both said to have $q$ in Gothic.

3. For a different explanation, with references to earlier literature, see Kroonen 2008.

\subsection{Reflexive pronouns}

Reflexive pronouns do not occur in the nominative, since, historically, they refer back to the subject of the clause. They are indifferent as regards gender and number; ${ }^{1}$ in OHG, however, the gen. is used only with a sg. masc. or neut. subject, and the dat. has been replaced by anaphoric pronouns. In North Sea Germanic no reflexive pronouns are preserved (see H.F. Nielsen 2000: 250-1), having been replaced by anaphoric pronouns:

$\begin{array}{llll} & \text { acc. } & \text { dat. } & \text { gen. } \\ \text { Go. } & \text { sik } & \text { sis } & \text { seina } \\ \text { OIcel. } & \text { sik } & \text { sér } & \text { sín } \\ \text { OHG } & \text { sih } & & \text { sin }\end{array}$

In Old Gutnish there also appears a gen. sina, another connection between Go. and that language (§1.14). Throughout early Gmc. there occur reflexive possessive adjectives to the same root, on which see below, $\S 8.5$. The development of these pronouns is entirely parallel to that of the sg. pronouns of the first and second persons. The ultimate source is the PIE reflexive pronoun ${ }^{*} s(u) e$ (acc.) seen also in Gk. $\ddot{\varepsilon}$, as a possessive adj. in Skt. svá-, Lat. suus, and extended in Go. swēs, OE swēs (etc.) '(one's) own'.

1. An exception is that although the usual form of the pronoun in Old Low Franconian is $\operatorname{sig}(7 \times)$ regardless of case and number, there once appears a dat. pl. sil (Kyes 1983: 83), though this is almost certainly an error (so, e.g., Köbler 2014 b s.v.).

\subsection{Possessive adjectives}

To the personal and reflexive pronouns were formed adjectives Go. meins 'my', peins 'your (sg.)', seins (reflexive), unsar 'our', izwar 'your (pl.)', *ugkar 'our (du.)', *igqar 'your (du.)' and cognates:

$\begin{array}{llllllll}\text { Go. } & \text { meins } & \text { peins } & \text { seins } & \text { unsar } & \text { izwar } & \text { ugkar } & \text { igqar } \\ \text { OIcel. } & \text { minn } & \text { pinn } & \text { sinn } & \text { várr } & \text { yðvarr } & \text { okkarr } & \text { ykkarr } \\ \text { OE } & \text { mīn } & \text { pīn } & \text { sīn } & \text { ūre, ūser } & \text { eower } & \text { uncer } & \text { incer } \\ \text { OS } & \text { mīn } & \text { thīn } & \text { sīn } & \text { ūsa } & \text { euwa } & \text { unka } & \text { inka } \\ \text { OHG } & \text { mīnēr } & \text { dīnēr } & \text { sīnēr } & \text { unserēr } & \text { iuwerēr } & & \end{array}$


These are inflected as strong adjectives. There are no dual possessives in OHG, and in Franconian OHG (as in OS, where they are used exclusively) there are shorter forms of the plural pronouns, with inflections added to the stem without the PGmc. suffix *-er-, masc. unsēr, iuwer , neut. unsaz, iuwaz, fem. unsu, iuwu. ${ }^{1}$ Go. *igqar is reconstructed on the basis of dat. sg. fem. igqarai, and *ugkar on the basis of the pronoun ugkis and comparative evidence. The reflexive adjectives are infrequent in NSGmc., losing ground before anaphoric pronouns, and in OFris. and OS they are restricted to sg. masc. and neut. reference.

Go. meins probably contains the reflex of a PIE loc. *mei, which is reflected with a further suffix in Skt. pron. máyi, and which is thematized in Lat. meus $<*$ mei-os. The affinity of the sense 'at me' to 'in my possession' is plain. The $n$-suffix in Gmc. is perhaps akin to that seen in directional forms like Go. hindana 'behind' (cf. hindar 'behind') and OE norðerne 'northern': see the discussion under gen. sg. in §8.2. The vowel $\bar{l}$ was extended to peins and seins, to which the locatives apparently would have been PIE *teu and *seu: see Seebold 1984: 49-51 for details. The most widely credited alternative explanation (originating with Bugge 1855: 244-5) is that the singular possessives are formed with a possessive suffix PIE *-ino-, as in Lat. asininus 'belonging to an ass' (so, e.g., Prokosch 1939: §98e). The dual and plural possessives are formed from the oblique stem of the corresponding pronoun by the addition of a suffix *-ero-, which G. Schmidt (1978: 203) analyzes as a thematization of the suffix -er used to form locative adverbs, e.g. Go. undar, hindar.

On OE üre, üser, see the discussion of the corresponding pronoun, §8.2.

OIcel. várr shows in the oldest texts some striking stem alternations within the paradigm by gender and number: commonest is the stem vór-, vár-, but there also occur ó $r$ - and oss- (consult the handbooks identified in $\S 1.14$ for the precise distribution of the variants), the last occurring almost exclusively in archaic poetry, with (vór- >) várreplacing $o r$ - gradually in the $13^{\text {th }}$ century. Deceptively, then, the paradigm appears to show loss of *w-before rounded vowels $(\S 6.14)$, but the cognates show that this cannot have been the case. Of the stems ór- and oss-, the former is probably from *unRar- $>$ *unnar- > *unnr- > ór- (cf. *bunraR > Pórr), the latter from *unsar-, with ó- from *unbefore $s$ (cf. §8.2): so Heusler 1967: §§143, 147 Anm. 2, 255. ${ }^{2}$ Old Gutnish ōar and Modern Gutnish euar point to *ōar- or *ūar- as the source of ON vár-: cf. the shift of diphthongal nucleus, with lengthening, in PNorse *iulu > OIcel. jól 'Yule' and *iuzar$>$ júgr 'udder'. The most plausible explanation for $* \bar{o} a r$ - is that it is the result of paradigm regularization, with extension of $* \bar{o}$ - (developed from *unn- before $r$ ) to cases in which *unn- remained before an unsyncopated vowel (von Friesen 1901-6: I, 63-5); cf. Seebold's attempt at a purely phonological explanation (above, §8.2).

1. The shorter stem originates in cases with $r$-inflections, e.g. nom. sg. masc. unserēr, gen. pl. unserero, by haplology (Baesecke 1918: 180).

2. Prokosch (1939: §98c) objects to Heusler's explanation but misunderstands it. His own assumption is of the development *unsaro $>* \bar{o} s(a) r u>o ́ r$, but his explanation of the pronoun oss as the result of contamination (see $\S 8.2$ n. 6 supra) seems unlikely on chronological grounds, which means that *unsar- likelier yields oss- than ór- 


\section{Anaphoric Pronouns}

\subsection{Anaphoric pronouns in Proto-Indo-European}

The PIE anaphoric pronoun that formed the basis for the Gmc. pronoun of the third person was perhaps declined as follows (cf. Szemerényi 1996: §8.2.2; Beekes 2011: 229; Sihler 1995: 391-2; Seebold 1984: 62-6):

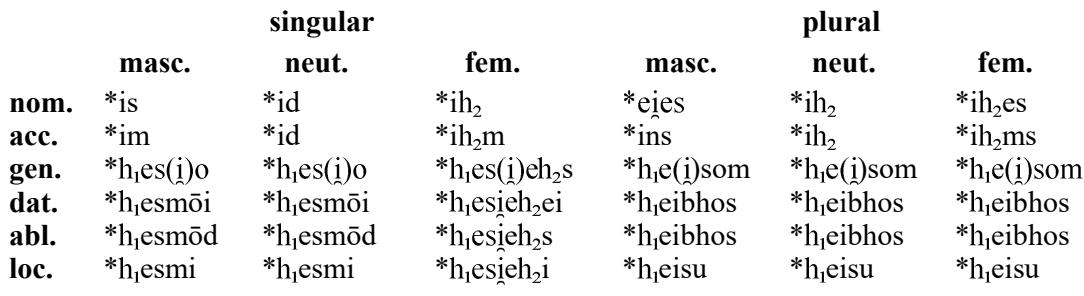

It thus appears that the PIE paradigm was suppletive, with a stem * $i$ - (full grade * $e i$-) in the nom./acc. and ${ }^{*} h_{l} e$ - elsewhere. In the dat./abl. pl., *-bh- corresponds to $-m$ - in Gmc. and Balto-Slavic, and some reconstruct PIE *-m- for anaphoric/demonstrative pronouns: see $\$ 7.2$.

\subsection{Anaphoric pronouns in Germanic}

In Gmc. the anaphoric pronouns inherited from PIE are used as personal pronouns of the third person. As in PIE, they are differentiated for gender, but they lack dual forms. Unlike pronouns of the first and second persons, they have no related possessive adjectives; instead, the genitive is used as a possessive except when the reference is to the subject of the clause (in which event a reflexive pronoun would be used, at least originally).

The pronoun of the third person was declined in early Germanic as follows:

\begin{tabular}{|c|c|c|c|c|c|c|c|c|c|}
\hline & & & & gular & & & plural & & \\
\hline & & nom. & acc. & dat. & gen. & nom. & acc. & dat. & gen. \\
\hline Go. & m. & is & ina & imma & is & eis & ins & im & izē \\
\hline & n. & ita & ita & imma & is & ija & ija & $\mathrm{im}$ & izē \\
\hline & f. & si & ija & izái & izōs & $*_{\mathrm{ij} o \bar{s}}$ & ijōs & im & izō \\
\hline OIcel. & m. & hann & hann & honum & hans & peir & pá & peim & peir(r)a \\
\hline & n. & pat & pat & pví, pí & pess & pau & pau & peim & peir(r)a \\
\hline & f. & hon & hana & henni & hennar & pær & pær & peim & peir(r)a \\
\hline OE & m. & hё & hine & him & his & hì, hie & hì, hie & him & hira, heora \\
\hline & n. & hit & hit & him & his & hēo, hie & hēo, hie & him & heora \\
\hline & f. & hēo & hie & hire & hire & hī, hie & hī, hie & him & hira, heora \\
\hline OS & m. & hě, ȟ̄, hie & $\operatorname{ina}(n)$ & $\operatorname{im}(u)$ & is, es & sia, sea, sie & sia & $\mathrm{im}$ & iro, ira, era \\
\hline & n. & it, et & it, et & $\operatorname{im}(u)$ & is, es & & siu & $\mathrm{im}$ & iro, ira, era \\
\hline & f. & siu, sie & sia, sea & iru, iro & ira, iru & sia, sea, siu & sia, sea & im & iro, era, ira \\
\hline DHG & m. & er & in(an) & $\mathrm{imu}$ & $\sin$ & sie, see, sia & sie, see & $\mathrm{im}$ & iro \\
\hline & n. & & & imu & es & siu & siu & in & iro \\
\hline & f. & siu, š̄ & sia, š̄ & iru & ira & sio & sio & $\mathrm{im}$ & iro \\
\hline
\end{tabular}


In Franconian there occur some forms in $h$ - comparable to the $\mathrm{OE}$ forms, most commonly nom. sg. her (see Howe 1996: 241-2). After the early period in the Gmc. languages there occur enclitic forms of third person pronouns, and Seebold (1984: 60) argues that these were present in the earlier period but remained unrecorded because they did not belong to the standard languages. It seems likelier that they are later developments. Note that in no instance is the postconsonantal glide in forms like PIE fem. abl. sg. * $h_{1}$ esieh $h_{2}$ reflected in Gmc.

Gothic. In all but a few cases the stem has been regularized to $i$-, whether by analogical extension of the nom./acc. stem or by the regular development of PGmc. $e$ to Go. $i$. To this stem are added endings on an analogical basis, for the most part the same pronominal endings found in the paradigm of the demonstrative $s a$ 'this, that' $(\$ 8.10)$. Thus, to masc. acc., dat., gen. sg. ina, imma, is compare pana, pamma, pis; to fem. dat., gen. sg. izái, izōs compare pizái, pizōs, and so forth. Nom. pl. masc. eis is instead comparable to the ending -eis of $i$-stems, a borrowing perhaps motivated by the identity of acc., dat. ins, im to the corresponding $i$-stem endings -ins, -im. Nom. sg. fem. si probably shows extension of $s$ - from the demonstrative, in the paradigm of which only nom. sg. masc. $s a$ and fem. $s \bar{o}$ have initial $s$, making it a distinctive marker. ${ }^{1}$ Acc. sg. fem. ija is comparable to Lat. eam, both with the analogical addition of the reflex of PIE $*_{-} \bar{a} m$ found in the PIE $\bar{a}$-stems (Go. $-a$ ). Likewise, nom./acc. pl. neut. ija is comparable to Lat. ea; in both languages, as in Greek, the nom./acc. pl. of neut. $i$-stems was in ${ }^{*}-i-\bar{a}$ (as in Gk. $\tau \rho i \alpha$, Lat. tria, Go. prija ' 3 ').

Old Icelandic. In ON the original anaphoric pronouns have been abandoned in favor of demonstrative pronouns $(\$ 8.10)$ in the neuter singular and throughout the plural. Remodeling in the rest of the paradigm has been extensive. Either nom. sg. masc. hann $<*$ hāns represents the PIE particle *ke 'here, there' (cf. Lat. cis 'on this side of', Lith. šis, OCS $s b$ 'this') plus the demonstrative *eno-s 'that', a combination seen also in Epic Gk. $\kappa \varepsilon \hat{\imath} v o \varsigma$ 'that (over there)' $<* \hat{k}$-eno-s (the usual older explanation: see, e.g., Prokosch 1939: §94), or the compound is $(* \hat{k} e>) x+*$ ainar $(<\mathrm{PGmc}$. *jainaz, as in Go. jáins 'that'): see, e.g., Rosenfeld 1955a, b, Orel 2003: 205. ${ }^{2}$ The Proto-Norse stem *hān- then spread throughout the masc. and fem. singular, with shortening in most cases, though long vowels are in evidence in some early texts (see Noreen 1970: $\$ 466$ Anm. 1). There are also the usual mutations of $a$ in the stem, e.g. dat. sg. masc. hánum $>$ hónum $>$ honum, similarly nom. sg. fem hon $<*$ hánu, with front mutation in dat., gen. sg. fem. henni, hennar due to the desinences ${ }^{*}-i_{R} a i,{ }^{*}-i_{R} \bar{o} R$ (cf. Go. demonstratives pizái, pizōs). Replacement of the original nom. sg. masc. pronoun may have been motivated by the need to differentiate the pronoun from $* i s / e_{R}$ meaning 'is' and 'who/which'.

West Germanic. All the WGmc. languages but OHG have a nom. sg. masc. pronoun in $h$ - (including OFris. $h \bar{\imath}$, OLF he, hie, her) derived, as in ON, from PIE $* \hat{k} e$, the reflex of which would still have been recoverable with deictic meaning from forms like OS hiu-diga 'today', hèr 'here', and hinan(a) 'hence'. It was added to the nom sg. because PGmc. *iz (Go. is) would have been reduced to WGmc. ${ }^{*} \bar{e}$, which would have been difficult to distinguish from other forms reduced solely to vowels (see n. 1, and see below on remedies for this problem in other case forms in WGmc.), which prompted onset-strengthening by the addition of $h-.^{3} \mathrm{OHG}$ is the exception because final $*_{-} z$ was not lost in monosyllables in that language $(\$ 6.16)$. In OE this $h$ - was subsequently extended throughout the paradigm, and a new nom. sg. fem. form hēo was created either from the masc. stem *hi- with addition of the nom. $\bar{o}$-stem ending $*_{-} u<$ PGmc. ${ }^{*}-\bar{o}$ or 
by analogy to the dem. sēo, formed in the same fashion (§8.10). Just as Go. nom. pl. masc. eis is analogical to the corresponding $i$-stem inflection, a new OE nom./acc. pl. pronoun hie was formed by the addition of the corresponding $i$-stem adj. inflection (OE $-e$ ) to the stem $h i$-found in nearly all other OE case-forms (cf. gen. pl. heora $<$ hiora $<$ hira), producing hie, alongside earlier uter $h \bar{l}$, neuter hēo (cf. Go. masc. eis, neut. ija). This is a development rendered fairly certain by metrical and dialectal evidence (see Hogg \& Fulk 2011: $\$ 5.17$ n. 3). Like OE, OFris. has initial $h$ - throughout the paradigm, except that originally reflexive $\sin$ is used for the gen. sg. masc. and neut.

$\mathrm{OHG}$ er probably derives from PGmc. ${ }^{*} i z$, but why the root vowel was lowered remains obscure; OHG ir is the sole form in use in Isidor. ${ }^{4} \mathrm{OHG}$ nom. sg. fem. š $\breve{\bar{l}}$ is comparable to Go. si, the form with long vowel due to stressed conditions (\$5.2). To siwas added in OS and OHG the ending of the nom. sg. fem. demonstrative OS thiu, OHG diu (\$8.10) (and cf. OLF sia = thia). This pattern of attaching demonstrative inflections to the stem si- was subsequently extended to all those forms which, as comparison to Gothic shows, would have been reduced solely to vowels in WGmc., and thus difficult to distinguish from one another, i.e. the acc. sg. fem. and the nom. and acc. pl. of all genders. Gen. sg. es $<\mathrm{PIE} * h_{1} e-s(i) o$ is retained in the neut. in OHG, whereas the reflexive pronoun is adopted for the masculine. Acc. sg. masc. OS ina, OHG in represent the earlier forms; inan shows addition of the corresponding adj. inflection. The masc./neut. dat. sg. ending $-m u$ in OHG ( $-m$ is the earlier form in OS) is generally traced to a PIE instr. ablaut variant in $*_{-} \bar{o}$ (beside usual $*_{-} \bar{e}$ ), e.g. by Krahe \& Meid (1969: II, §37); cf. Boutkan 1995b: 303-4 and the references in Howe 1996: 255. Spellings in OS are variable as usual, e.g. nom. pl. masc. sia, sie, sea, se. In OHG there occurs in the Lex Salica fragments of ca. 830 an alternative dat. sg. emu, which Euler (2013: 12), comparing Skt. asmái, regards as archaic, though the earliest texts use exclusively imu. It is thus likelier to be analogical to the demonstrative demu $(\$ 8.10)$; see also Szemerényi 1996: §8.2.2 n. 1 .

1. Seebold (1984: 64) speaks of PIE *iə/̄ (his notation) as needing "strengthening" because of its minimal phonological material (what Krahe \& Meid 1969: II, §35 refer to as Einlautigkeit), an idea not infrequently appealed to in the literature. Seebold's solution to the problem of Go. si is instead to reconstruct, on the basis of Celtic and Greek forms, an "archaic" *siz/si , of any gender, which replaced the original pronoun. See Ringe 2017: 233 for another suggestion.

2. Seebold (1984: 64-6) distinguishes *ke 'here' from *ko 'there' and identifies the latter as the source of Gmc. $h$ - in pronouns, though usually the meaning 'there' is assumed to be a later development of *ke (so, e.g., Pokorny 1959-69: I, 609).

3. This explanation, advocated by, e.g., H.F. Nielsen (2000: 249-50), is plainly at odds with that of Euler (2013: 112-13), who reconstructs PGmc. *xai (cf. Klingenschmitt 1987: 173: *xaiz) to account for OE OS hĕ

4. Analogy to the gen. sg. neut. is sometimes invoked (e.g. by Prokosch 1939: §94, Krahe \& Meid 1969: II, $\S 35)$, but why the gen. sg. should have exerted such influence is not obvious. Seebold (1984: 66-9) argues for an etymological distinction of PIE origin between the vocalism of the OHG pronouns mir, dir, wir ir, with $i$, and wer, der, er, with $e$. 


\section{Demonstrative Pronouns}

\subsection{Demonstrative pronouns in Germanic}

Germanic inherited a pronoun ${ }^{*} s o, * t o d,{ }^{*} s \bar{a}$ from PIE, for which no definite deictic implication of relative distance from the speaker or hearer is reconstructible: it seems to have meant alternately 'this, that, the', alternative meanings which its reflex may take, for instance, in NHG. ${ }^{1}$ PGmc. also had a distal deictic reflected in Go. jáins, PDE yon, NHG jener (\$8.11), and apparently in NWGmc. the need was felt for a corresponding proximal demonstrative 'this' (\$8.12). In addition, in NGmc. there arose a new deictic nom. sg. masc. hinn, neut. hit, fem. hin, on which see $\$ 8.11$. Similar modifications of the system of deictics are observable in other IE languages, e.g. the ternary system of Lat. hic 'this here', iste 'that of yours', and ille 'that (yonder)', and of Gk. ovitos 'this

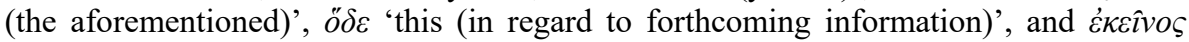
'that'.

1. Compare, e.g., Das Ergebnis wäre das gleiche 'The result would be the same' and D a s Erbebnis wäre ideal $=$ Dieses Ergebnis wäre ideal 'This/That result would be ideal'. The deictic import of the PIE pronoun thus probably pertained to information structure rather than location, i.e. old versus new information.

\subsection{Demonstrative pronouns in Proto-Indo-European}

On the basis of reflexes in Skt., OCS, Lith., Go., and Doric Gk., Szemerényi (1996: $\S 8.2 .1)$ reconstructs the paradigm of the PIE demonstrative 'this, that, the' more or less as follows (and note that he dispenses with laryngeal notation):

\begin{tabular}{|c|c|c|c|c|c|c|c|}
\hline & & ingular & & & & plural & \\
\hline & masc. & neut. & fem. & & masc. & neut. & fem. \\
\hline nom. & $*_{\text {so }}$ & $*_{\text {tod }}$ & *sā & & *toi & $*_{\text {tā }}$ & *tās \\
\hline acc. & *tom & *tod & *tām & & *tōn(s) & $*_{\mathrm{ta}}$ & $* \operatorname{tā}(n) s$ \\
\hline gen. & *tosio & *tosio & *tosiās & & *toisōm & *toisōm & *tāsōm \\
\hline dat. & *tosmōi & *tosmōi & *tosiāāi & & *toibh(i)os & *toibh(i)os & *tābh(i)os \\
\hline abl. & *tosmōôd & *tosmōôd & *tosiầîs & & *toibh(i)os & *toibh(i)os & *tābh(i)os \\
\hline loc. & *tosmi(n) & *tosmi(n) & & & *toinsu & *toînsu & *tāsu \\
\hline & & & & dual & & & \\
\hline & & & masc. & neut. & fem. & & \\
\hline & & nom. & $*$ tō & *toi & *toi & & \\
\hline & & acc. & $*$ tō & *toôi & *tôi & & \\
\hline
\end{tabular}

In the dat. abl. pl., *-bh- corresponds to - $m$ - in Gmc. and Balto-Slavic, and some reconstruct PIE *-m- for anaphoric/demonstrative pronouns: see $\$ 7.2$. The Gmc. dat. pl. derives from *toi-mis $>$ *baimiz, with the same desinence seen in nominal inflection, though $-m$ - probably originates in the masc. neut. sg. of forms like this.

There were thus two stems to the PIE paradigm, one in ${ }^{*} s$ - and one in *t-, the former confined to the nom. sg. masc. and fem. The element ${ }^{*}$-sm- in the oblique cases of the singular (probably related to PIE *sem- 'one' and *som- 'same') may have been an optional element lending emphasis (so Szemerényi 1996: §8.2.1), as it is missing from some forms, e.g. Go. pei 'that' (originally loc.: see below). 


\subsection{The inherited demonstrative pronoun in Germanic}

The PIE demonstrative 'this, that, the' is reflected in Gmc. as follows (with a few alternative forms remarked below):

\begin{tabular}{|c|c|c|c|c|c|c|c|c|c|c|}
\hline & & & & ingular & & & & plu & & \\
\hline & & nom. & acc. & dat. & instr. & gen. & nom. & acc. & dat. & gen. \\
\hline Go. & m. & & pana & pamma & & pis & pái & pans & páim & pizē \\
\hline & n. & pata & pata & pamma & pē & pis & pō & pō & páim & pizē \\
\hline & f. & sō & pō & pizái & & pizōs & pōs & pōs & páim & pizō \\
\hline OIcel. & m. & sá & pann & peim & & pess & peir & pá & peim & peir(r)a \\
\hline & n. & pat & pat & pí, pví & pí, pví & pess & pau & pau & peim & eir(r)a \\
\hline & f. & sú & pá & peir(r)i & & peirar & pær & pær & peim & peir(r)a \\
\hline OE & m. & sĕ & pone & pǣm & pȳ, pē & pæs & bā & $\mathrm{p} \overline{\mathrm{a}}$ & pǣm & pāra \\
\hline & n. & pæt & pæt & pǣm & $\mathrm{p} \bar{y}, \mathrm{p} \overline{\mathrm{e}}$ & pæs & pā & pā & pǣm & pāra \\
\hline & f. & sēo & & pǣre & & pǣre & pā & pā & p̄̄m & pāra \\
\hline OS & m. & thě & thena & themu & thiu & thes & thea & thea & thềm & thero \\
\hline & n. & that & that & themu & thiu & thes & thiu & thiu & thĕm & thero \\
\hline & f. & thiu & thia & theru & & thera & thea & thea & thĕm & thero \\
\hline OHG & m. & der & den & demu & & des & dē & dē & dēm & dero \\
\hline & n. & daz & daz & demu & diu & des & diu & diu & dēm & dero \\
\hline & f. & diu & dea & deru & & dera & deo & deo & dēm & dero \\
\hline
\end{tabular}

Many alternative forms of individual pronouns are to be found in Gmc. outside of Gothic. The handbooks should be consulted for these; the following discussion is limited chiefly to the forms given in these paradigms. ${ }^{1}$

Some Gmc. forms point to $e$ rather than $o$ in the pronominal stem (e.g. Go. pis, pize, pizōs, OS thes, themu, etc.), and this has led some to posit alternation in the stem in PIE; it is likelier, however, that $e$ is a Gmc. innovation, borrowed from the interrogative pronoun ( $\$ 8.13$; but see below on Go. pei), which, as assumed below, exerted other kinds of influence on this paradigm. After PIE acc. sg. masc. *tom had developed to PGmc. * pan, to this was added a particle, the reflex of PIE $*_{-\bar{o}}$ or $*_{-} \bar{o} m$, producing ${ }^{*}$ bano or ${ }^{*}$ bano $\bar{o}^{n}{ }^{2}$ Although the vowel is reduced finally in all the Gmc. languages, it can still be seen in Go. indef. acc. hanōh 'each, every', formed from interrog. ${ }^{*} h^{w} a n \bar{o}$ (> Go. hana 'whom?' parallel to bana) plus -uh (as in nom. hazuh). Although a masc./neut. gen. sg. containing PIE $*_{i}$ is well attested in the IE languages (cf. masc. ${ }^{*}-o$ -

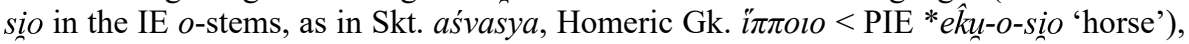
the Gmc. forms lack it (cf. Old Prussian deiwas < *deiu-o-so 'of a god'); yet most of the Gmc. languages reflect *-e-so rather than ${ }^{*}$-o-so, again probably by analogy to the corresponding interrogative pronoun (PIE $k^{w} e ́$-so > OCS česo, Ionic Gk. $\tau \dot{\varepsilon} o$ 'whose?'). The Gmc. dat. sg. is generally assumed to reflect the PIE instr., which is not securely reconstructible for PIE *so; for the etymon of the Gmc. masc./neut. dat. is usually reconstructed *tosmé, on the basis of forms like Go. indef. hammēh 'each, every' (cf. acc. hanōh, above, and on *-zm-> -mm- see $\S 6.8$ ) beside unsuffixed hamma, and the neut. instr. $p \bar{e}$ (in the phrase ni pe haldis 'none the more' (also OE $p \bar{e} m \bar{a}$ 'the more') and some compound conjunctions, e.g. $b i-p \bar{e}$ 'while'). This $p \bar{e}$ is probably old (cf. OCS instr. $t \bar{e}-m b$, also Gk. (Thera) $\tau \eta-\delta \varepsilon$ 'in this way'), in which event pamma may be explained as formed by the addition of instr. ${ }^{*}-\bar{e}$ to the dat. sg. stem inherited from PIE (so, e.g., Krause 1968: §180; cf. the discussion under dat. sg. in §7.8). Likewise, PIE loc. sg. *tosmi appears to have borrowed the dat./abl. stem; Go. complementizer pei 'that' is formally a locative, and it is perhaps more plausible that it should be original 
(cf. Doric Gk. $\tau \varepsilon \hat{\imath}-\delta \varepsilon$ 'here'), not based on an unattested corresponding interrogative pronoun.

With these general Gmc. conditions taken into account, the forms given in the Gmc. paradigms above may be regarded as regular developments of the PGmc. pronouns, with the exception of the forms in individual languages remarked in the following paragraphs.

Gothic. Nom./acc. sg. neut. pata shows extension of final $-a$ from the acc. sg. masc. The alternation between PIE masc. neut. ${ }^{*}-o i$ - and fem. ${ }^{*}-\bar{a}$ - in the plural has led to some paradigm regularization: Go. gen. pl. fem. pizo has borrowed the vowel of the corresponding singular form, and the stem piz- is then extended to the masc. and neuter. In their turn, fem. gen. and dat. sg. pizōs, pizái appear to be analogical to the corresponding interrogative pronouns $(\$ 8.13)$. On the alternation between $-\bar{e}$ and $-\bar{o}$ in the gen. pl., see $\$ 7.8$.

Old Icelandic. There is lengthening in nom. sg. masc. sá under Prokosch's law (§2.5). The fem. nom. sg. either reflects $*_{s \bar{o}}>*_{s u}$ under unstressed conditions, with lengthening when the latter was extended to stressed positions (the usual assumption) or reflects unstressed $*_{s} \bar{o}>*_{s} \bar{u}$, in which the vowel was never shortened (Ringe \& Taylor 2014: 16). PGmc. acc. sg. masc. *ban was altered to pann under the influence of hann (Prokosch 1939: §93). PGmc. acc. sg. fem. ${ }^{*} p \bar{o}^{n}$ was shortened to $p a^{n}$ when unstressed (presumably before $o$ arose as an allophone of $u$, so that the shortening of $\bar{o}$ was $a$; OE shows the same development) with lengthening to $p a ́$ when re-stressed. Dat. sg. peim (like OE $p \bar{x} m$ ) shows extension of the dat. pl. form to the singular, by analogy to the $a$ stem adjectives, in which the two forms are identical. Dat. sg. fem. peiri reflects * paizjoi $i$, perhaps with extension of ai from the corresponding plural form (assuming the diphthong of the masc. and neut. pl. had earlier replaced the PIE monophthong of the fem.), as does OE pāre (with umlaut). But given the agreement of ON and OE on this point, perhaps *paizjôi or *paizôi was the PGmc. form. ${ }^{3}$ The alternative form peirri shows analogical addition of the adj. inflection -ri (orig. pronominal) to the stem peir-; gen. pl. peirra beside peira is to be explained similarly. Gen. sg. masc./neut. pess agrees with Go. pis < * pes, except that $-s$, probably from nominal declension, has been added. ${ }^{4}$

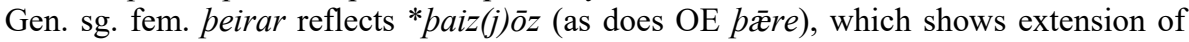
the dipthong from the pl. to the singular. Neut. dat./instr. $p i$ is well attested (also in the compound $p(v) i l i k r$ 'such') but is uncommon relative to $p v i$. The former probably reflects the same locative *tei underlying Go. pei; the latter shows the analogical influence of interrogative $h v i .^{5}$ Nom. pl. masc. peir shows the addition of $-r$ from nominal inflection, as in steinar 'stones'. There is no consensus about the derivation of nom./acc. pl. neut. pau: whereas some derive it directly from a PIE masc. dual *tōu (beside *tō: cf. Skt. $t \bar{a} u$ beside $t \bar{a}$; so, e.g. Ross \& Berns 1992: 563-4), others regard it as a Norse innovation, formed by the addition of $-u$ from neuter nominal inflection (as in born 'children' < *barnu) to the reflex of PIE neut. pl. $t \bar{a} .{ }^{6}$ Nom./acc. pl. fem. pær derives from PGmc. ${ }^{*} p \bar{o} z$, with shortening to ${ }^{*} p a z$ under low stress (cf. the acc. sg., as above), ${ }^{7}$ a form reflected in OE, as well; when this form was extended to stressed positions there was lengthening to ${ }^{*} p \bar{a}_{R}$ (reflected as OEN $p \bar{a} r$ ), which underwent $R^{-}$ mutation (\$4.7) to pær. In PGmc. acc. pl. masc. *bans the final two consonants were lost when the word was unstressed, as in the $a$-stem inflection; extension of the resulting * $p a$ to stressed positions induced lengthening to $p a$, and the same explanation will account for OE $p \bar{a}$, if this is not simply analogical to the nom. 
West Germanic. Despite the claim of some handbooks (e.g. Prokosch 1939: $\S 93)$, OE nom. sg. masc. se cannot be derived from PIE *so with lengthening of the vowel, since the development of unstressed $* x \mathfrak{x}$ to ${ }^{*} s e$ would have taken place too late (on the date, see Fulk 1992: §§415-17) for sē rather than $\uparrow s \bar{x}$ to have been the regular result of re-stressing; rather, it is best regarded as a reformation of the reflex of PGmc. ${ }^{*} s a$ by analogy to $h \bar{e}<* h$-iz (\$8.7; so, tentatively, Girvan 1931: 279). ${ }^{8}$ Nom. sg. fem. sēo (as well as OS thiu, OHG diu, but with substitution of the usual onset found in the rest of the paradigm) is often said to be derived from a by-form of PIE * sā of the form * siā (so, e.g., Prokosch 1939: §93, Krahe \& Meid 1969: II, §37), an adjectival derivative of the nom. uter stem in *s- (see Brugmann \& Delbrück 1897-1916: II, 2, §322 for reflexes). Perhaps more plausible is that, like hēo (§8.7), it should be based on the masc. stem, in this instance *si- (in *siz) with the addition of the WGmc. nom. inflection of $\bar{o}$ stems, ${ }^{*}-u<$ PGmc. ${ }^{*}-\bar{o}<$ PIE ${ }^{*}-\bar{a}$ (Girvan 1931: 279). ${ }^{9}$ As noted above, quite a few OE forms parallel those of OIcel., but not of Go., OS, or OHG; OFris. agrees for the most part with $\mathrm{OE}$ in this respect. Acc. sg. fem. $p \bar{a}(<* b a z<* b \bar{o} z$; cf. OFris. thā $)$, dat. sg. masc./acc. $p \bar{x} m$ (later also $p \bar{a} m$, with the vowel found in all other pl. forms transferred to the dat. pl. and thence to the sg.; cf. OFris. tha $(m))$, dat. sg. fem. pāre $(<*$ paizjôi; cf.

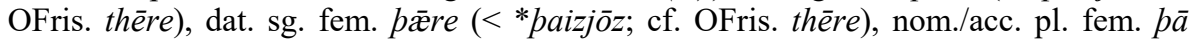
(like acc. sg. fem. $p \bar{a})$, and acc. pl. masc. $p \bar{a}\left(<* b a<{ }^{*} b a n s ;\right.$ cf. OFris. thā $)$ all developed like the corresponding OIcel. forms, as discussed above. ${ }^{10}$ Also parallel to OIcel. instr. (orig. loc.) sg. neut. $p v i$ appears to be OE $p \bar{y}$. There is no consensual explanation for this form; perhaps the best rationale is that it is analogical to interrog. $h w \bar{y}$ (just as OIcel. pvi is analogical to $h v i),{ }^{11}$ if the explanation offered in $\$ 8.13$ for the equally perplexing $h w \bar{y}$ is reliable. The alternative instr. $p \bar{e}$ is comparable to Go. $p \bar{e}$. There is also an instr. pon which, in addition to its usual functions, is used in comparative constructions (e.g. pon $m \bar{a}$ ' the more') and in adverbial phrases, e.g. for pon pe 'because' and siððan 'after(ward)' <*sīp pon. It is of uncertain derivation, ${ }^{12}$ but it is usually compared to Go. pan, used as a rel. particle, a demonstrative, and a conj.; and for the semantics cf. Go. pana-máis 'still, further' (= OE pon mā, OS than mēr, OHG dana meer; so Girvan 1931: 279); cf. also Go. han (= OE hwon) with the meaning 'how much' when used with comparatives. Unlike the gen. sg. elsewhere in Gmc., OE $p \mathfrak{x}$ derives not from PIE *teso but the ablaut variant *toso (cf. Gk. $\tau o \hat{v}<*$ tos $(i) o$ ); OFris. thes is ambiguous.

OS thĕ and thiu are constructed the same way as OE s $\overline{\bar{e},}$ sēo, but initial th- has been generalized in the paradigm; OHG nom. sg. masc. der is analogical to er (§8.7) and $(h)$ wer (§8.13), either directly or as an unstressed shortening of * ${ }^{*} \bar{e}-r$ (see $\$ 9.2$ on the origin of the adj. inflection $-\bar{e} r$ ), whereas fem. diu is formed as in OS. Acc. sg. masc. OS thena and OHG den (: Go. pana, OIcel. pann, OE pone) have imported $e$ from the rest of the masc. paradigm; likewise dat. sg. masc./neut. OS themu, OHG demu (Go. pamma), perhaps with degemination of $-\mathrm{mm}$ - under low stress, though Prokosch (1939: $\S 93)$ suggests alternatively that these may be compared to inherited forms without $-s-$, e.g. Lith. dat. tamui, OCS tomb, OCS instr. têmъ. Perhaps it is likelier still that *pemmu was reduced analogically to * beти because in * ветти it would appear, by comparison to, e.g., dat. sg. imu (to $\mathrm{OHG} e r$ ), that the stem was *bem- rather than *be-, which would have been anomalous within the paradigm. Instr. sg. neut. OS thiu, OHG diu are sometimes derived from a by-form PIE *tio- (Krahe \& Meid compare Skt. nom. sg. neut. tya-t, 1969: II, §37; similarly Ross \& Berns 1992: 563 for the pl.), but it is perhaps likelier that these are constructed by analogy to $i$-stem instrumentals $(\$ 7.20)$, or, even 
likelier, that the commonest $a$-stem instr. ending $-u$ was added to the masc./neut. stem OS the-, OHG $d e$-, and while the form remained disyllabic, $e$ was raised to $i$ before $u$ in the next syllable (\$4.4). For masc. nom./acc. pl. OS thea are also found thia, thie, and the , the last equivalent to $\mathrm{OHG} d \bar{e}$ (also diphthongized to die, dea, dia), both apparently representing unstressed developments of PGmc. *pai. Unless PIE *tio- is to be invoked, the other OS forms can be explained as formed by the addition of the adj. endings $-e,-a$ to the stem the-, with $i$ in thia introduced from neut. nom./acc. pl. thiu (to which compare the instr. sg. above). There occurs an OHG nom./acc. pl. neut. dei, found only in the earliest UG texts, perhaps analogical to zwei '2'; cf. Ross \& Berns 1992: 564. The gen. and dat. pl. forms of OS and OHG correspond to the Go. ones. There is much variation in the spelling of these pronouns, especially in OS, with the forms of one gender extended to another on an occasional basis.

1. For discussion of the pl. of this pronoun in Gmc., see Ross \& Berns 1992: 562-5.

2. The source of this $*_{-} \bar{o}$ or $*_{-} \bar{o}^{n}$ is disputed. For example, Wright (1954: §261) compares it to the Skt. prep. $\bar{a}$ 'up to', which takes the acc., whereas Krahe \& Meid (1969: II, §37) analyze it as lengthened grade of the suffix seen in Skt. id-am, Lat. id-em 'it'. There is discussion in Boutkan 1995b: 297-300 (with conclusions largely agreeing with those of A.W. Jones 1979), deriving the added ending from the fem. acc. sg. of PGmc. *is (§8.7).

3. Thus, e.g., Ringe (2017: 232) assumes PGmc. gen. * paizōz as a refashioning of the reflex of PIE *tósieh ${ }_{2} s$ by metathesis of ${ }_{-s i} i$ - under the influence of the diphthong of the masc. neut. plural.

4. Without this change, pes would have been anomalous, as gen. $-s$ otherwise never occurs after a stressed short vowel, and the alternative solution of lengthening the vowel would have increased paradigm allomorphy. The alternative form pes does occur, but it is generally regarded as a reduction of pess, like pan for pann (Noreen 1970: \$469 Anm. 3). Prokosch (1939: §93) suggests instead that pess was formed by analogy to pann. Krahe \& Meid (1969: II, §37) regard pess as analogical to pessa (§8.12 infra)

5. Krahe \& Meid (1969: II, §37) distinguish dat. pvi from instr. $p v e ́$, the latter comparable to Go. instr. $p \bar{e}$. This may be etymologically correct: OIcel. hvé does occasionally mean 'why', as normally does $h v i$, but it usually means 'how'. Paul (1879: 215) proposes that $p i$ should be derived from ${ }^{*} p \bar{e}(=$ Go. instr. $p \bar{e})$ : for further references, see Boutkan 1995b: 303, where it is proposed that $p i$ is analogical to $h v i$.

6. For discussion, with references, see Hiersche 1963. If the ON pronoun is dual in origin, so also may be Go. $p \bar{o}$ (as advocated by Hiersche). Cowgill (1985: 14-15) rejects both analyses, regarding bau as analogical to tvau.

7. For alternative analyses, see Schrijver 2004: 204-6.

8. Krahe \& Meid (1969: II, §37; similarly Euler 2013: 114) derive $s \check{\bar{e}}$ from PIE *so plus a deictic particle $i$

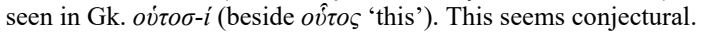

9. As frequently in tracing the development of Gmc. pronouns, in choosing between alternatives like these it is necessary to weigh the probability of the preservation of archaisms of limited attestation elsewhere in IE against the degree of transparency of mophological structure viz-à-viz the posited analogical model, as well as the degree of relatedness of the model.

10. OE nom. pl. $p \bar{a}$ may be etymological, or it may be analogical to the acc. Neuter nom./acc. pl. $p \bar{a}$ is by analogy to this, since PGmc. ${ }^{*} p \bar{o}$ would have developed to $* b \bar{u}$ in NWGmc. and become indistinguishable from the second person pronoun (Cowgill 1985: 15).

11. This is perhaps what Lass (1994: 144) means when he says that there is probably some relation between the two. His idea that the alternative form $h w \bar{\imath}$ is somehow "legitimate," however (a view shared with Krahe \& Meid 1969: II, §42), is improbable, as $h w \bar{\imath}$ appears to represent an unrounding of $h w \bar{y}$ (so, e.g., A. Campbell 1977: §316), appearing rarely in Alfredian texts, and none earlier. A possible (but speculative) alternative explanation is that $b \bar{y}$ is developed from ${ }^{*} b \bar{u}$ (parallel to $h \bar{u}$ ) with the addition of the masc./neut. instr. adj. ending $*_{-} i$ (\$9.2): so Girvan 1931: 279. More plausibly, $p \bar{y}$ could be analogical to $h w \bar{y}$ formed of $h \bar{u}+i$, though this would render the resemblance to OIcel. $h v i$ entirely happenstance. 
12. The fullest study is Dal 1932, concluding that the form originates in a pronominal 'prosecutive' in PIE *-no which assumed ablative function in PGmc., taking on other functions in time.

\subsection{Distal demonstrative pronouns in Germanic}

Already in PGmc. there was formed a distal deictic 'that, yon', reflected as Go. jáins (declined like an $a / \bar{o}$-stem adj.), OE *geon (attested just once, EWS dat. sg. fem. geonre), ${ }^{1}$ OFris. iena, MLG jene, OHG jenêr. The etymology is difficult to establish because these forms show notable disagreement: Go jáins would appear to reflect PGmc. *jainaz; OE geon appears to reflect PGmc. *janaz, or possibly PGmc. *jainaz > *jān with subsequent shortening to $o$ under low stress; ${ }^{2}$ the remainder would appear to reflect PGmc. *jenaz, but possibly they, too, could reflect *jainaz under low stress (with the addition of the usual adj. endings in MLG and OHG). ${ }^{3}$ Neither is there a consensus about how *jainaz (assuming this is the correct reconstruction) was formed: the chiefly credited possibilities are that it represents a PIE demonstrative particle *ie- plus the pronominal stem *eno- (so, e.g., Prokosch 1939: §93d, assuming an ablaut difference between Go. and WGmc.) and that it represents PIE *i- (reduced form of *ie-) plus *oino'one' (so, e.g. Orel 2003: 205 for Go., but favoring the former explanation for WGmc.). The competing explanations thus parallel those for OIcel. hann (§8.7). The rarity of this pronoun in $\mathrm{OE}$ probably indicates that $\mathrm{OE} p æ t$, when it did not develop into an article, had acquired a distal dimension, as in PDE.

A consideration in favor of the assumption of PGmc. *jainaz is that with the loss of initial $j$ in PNorse, the word would have become indistinguishable from the word for 'one', and this explains why there arose a replacement in $\mathrm{ON}$, a new distal pronoun nom. masc. hinn, neut. hit, fem. hin, inflected with all the same desinences as the possessive pronouns minn, binn (\$8.5, but with nom. acc. sg. neut. hit rather than hitt, a rare form) added to the particle $h i-<\mathrm{PIE} * \hat{k} e(\S 8.7)$. As a pronoun it means 'that' (emphatic) or 'the other'; otherwise it is a def. article, in the earliest texts not yet postposed (as in all the modern NGmc. languages) with loss of initial $h$.

1. There is, however, an $\mathrm{OE}$ adverb, either (depending on an editorial decision) geon or geonofer '(over) yonder', which appears in the legal text Dunsæte.

2. On unstressed $a i>\mathrm{OE} o$, see $\S 5.6$. Under such an explanation it is unnecessary to assume that the form shows EWS -on- for -an-, as unstressed status is sufficient to explain $o$ for $a$; no matter what the source of the vowel, PDE yon would be difficult to explain if the OE vowel were stressed.

3. Ingeniously, Pokorny (1959-69: I, 320) explains the WGmc. forms as derived from PIE *i-onio- (with initial $* i$ - derived from the rel. pron., though the lack of umlaut in OE geon would be anomalous, and the lack of any gemination of $n$ in WGmc.), and Go. jáins as derived from PGmc. *janj- with metathesis under the influence of áins 'one'.

\subsection{Proximal demonstrative pronouns}

In Gothic there is a pronoun meaning 'this' which is found only in a few set expressions: himma daga 'on this day, today', und hina dag 'to this day', und hita (nu) 'till now, hitherto', fram himma 'from now, henceforth'. These forms are transparently composed of $h i-$, reflecting the PIE particle * $k$ e, originally with hic et nunc reference (as above, §8.7), and the same endings found on the demonstrative $s a$. It is often supposed 
that these are relics of a once complete PGmc. paradigm (so, e.g., Euler 2013: 116), but if that were the case it would be difficult to understand both why so few forms are attested in Gothic and why outside of Gothic there arose new pronouns meaning 'this', especially on the assumption that the paradigm of this supposed pronoun paralleled closely that of PGmc. *sa. It seems likelier, then, that these developments are the result of an imbalance of deictics in PGmc., on the assumption that there was no pronoun to contrast specifically with *jainaz 'that', and forms like himma are an innovation specific to East Germanic. The commonest forms of 'this' outside of Gothic are these:

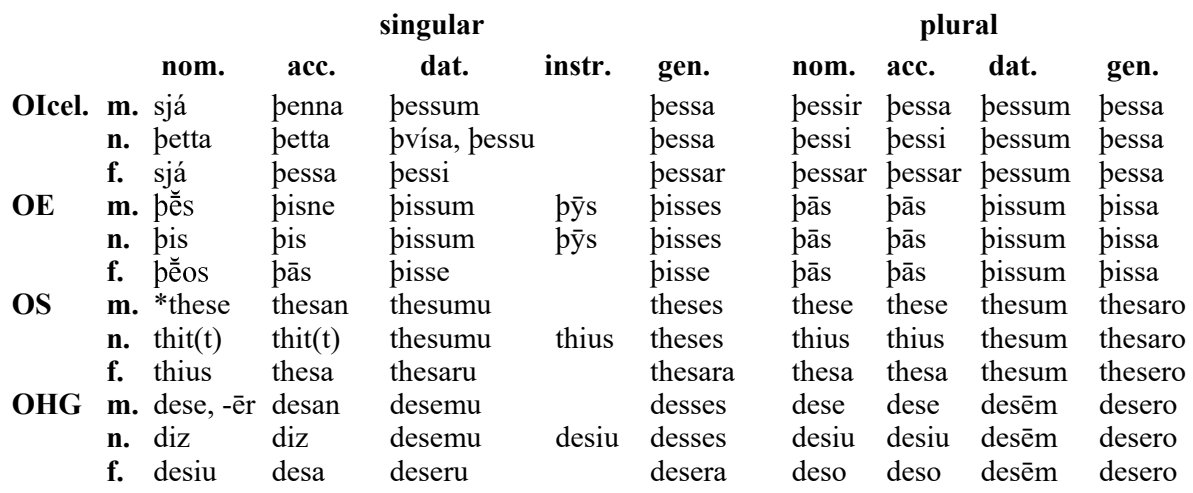

The differences between the OE forms and those of OS and OHG are remarkable, and those between NGmc. and WGmc. are so stark as to suggest polygenesis; nonetheless, almost certainly these forms all have a common origin. Runic inscriptions in the Younger Futhark (i.e., after ca. 750) frequently evince demonstratives from the paradigm of $s a ́$ (§8.10) with what is usually regarded as a following emphatic particle $-s i(-s e,-s)$ or $-a$ attached, e.g. nom. sg. sasi, fem. susi, neut. patsi or pita (see Noreen 1970: $\$ 470$ Anm. 1). This pattern of original inflection of the first component of the compound is observable also in OHG nom. sg. masc. de-se, gen. des-se, the latter an older form (Muspilli 103) to which a final inflection was added later (desses: Braune 2004a: $\$ 288$ Anm. 3d). The earlier form of the deictic s-suffix is difficult to determine, in part because of the alternation between $-s i$ (WGmc. $-s e$ ) and $-s$. Probably the most plausible explanation is that originally this pronoun was formed by iteration. ${ }^{1}$ That is to say, nom. sg. masc. *sa (\$8.10) was iterated as * $s a$-sa, perhaps with the later addition of the hic et nunc particle ${ }^{*}-i$ (cf. Lat. quī, quae $<{ }^{*} k^{w} O-i,{ }^{*} k^{w} \bar{a}-i$ ). A significant advantage of the idea of iteration is thus that it explains the otherwise mysterious rise in NWGmc. of a new $s$-particle of which there is no trace in Gothic. ${ }^{2}$ It also explains admirably the origin of the geminate $t$ in the neuter forms OIcel. petta, OS thitt (cf. OHG diz, where $-z$ $=-t z<*$-tt: Braune 2004a: $\$ 289$ Anm. 3b), assuming original *pat-pat $>{ }^{*}$ patta, with later change of root vowel by intraparadigmatic analogy. A similar course of development will also account for $\mathrm{ON}$ acc. sg. masc. penna, assuming original *pan-pan, since PGmc. *-np-> ON -nn- (§6.14). With the reduction of final vowels, reanalysis of $-s$ - in the nom. sg. masc. and fem. resulted in its extension as a suffix through most of the paradigm. This explanation may also account for the origin of the alternative particle $-a$ in ON. Noreen (loc. cit.) compares it to Go. -uh ( $\$ 8.10$ supra), though more commonly it is related to the particle PIE *-om added to Go. pana, pata (\$8.10; so, e.g., Krahe \& 
Meid 1969: II, §38). Rather, if iteration is assumed, final - $a$ in a form like penna may be regarded as etymological, starting from NWGmc. *pan-pan.

The subsequent development of these forms is governed by thoroughgoing analogical restructuring, prompted in large part by the lexicalization of suffixed forms, so that non-final inflection in a form like acc. sg. masc. pan-si was no longer recognizable as such, and new inflections were, to a great extent, added to the end of the relevant forms, especially in WGmc. Given the assumption of these early changes, most of the forms given above are transparent refashionings, though a few require further comment.

Old Norse. Masc. and fem. nom. sg. sjá is most commonly explained as analogically induced, with - $a$ borrowed from forms like penna and petta and lengthened under stress. ${ }^{3}$ This makes good sense, since the result is $-a$ in the nom. and acc. of all genders (or perhaps all sg. forms before the addition of new endings, e.g. to gen. sg. fem. pessar, and later yet pessar(r)ar). Later there arose pessi and similar forms alongside sjá, thus reducing stem variation within the paradigm. Dat. sg. neut. pvisa and pessu both appear in early texts, though both are plainly analogical formations, the former by the addition of $-s a$ to the corresponding form of pat, the latter by the addition of the usual dat. sg. neut. ending $-u$ to the stem pess- that prevails in the paradigm.

West Germanic. The stems with initial $s$ have exchanged it for $p$, regularizing the paradigm. In OE, most forms have the stem piss- (reduced to pis- when a vowel does not follow), with the same endings found on adjectives; gen. dat. sg. fem. pisse and

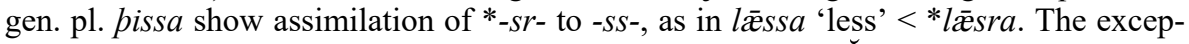
tions are all plainly composed of the corresponding form of $s \check{\bar{e}}$ plus a suffix $-s$ (though again with $p$ - for $s$ - in the nom.). These exceptions resisted replacement by new analogical forms based on the stem piss-probably because such replacement forms would have eliminated grammatical contrasts within the paradigm, reducing most forms to pisse or pissa. There are many analogical by-forms in OE, e.g. gen./dat. sg. fem. pisre, pissere, dat. pl. pisum. Old Frisian generally agrees with OE, with a stem thiss- in most case forms, but it also shows a notable agreement with $\mathrm{OS}$ and $\mathrm{OHG}$ in regard to nom./acc. sg. neut. thit.

The OS and OHG forms mostly represent the WGmc. stem *pes- (as in ON) with the endings of adjectives or of the demonstrative OS the that depart from this pattern are older. Such is nom. sg. masc. OS * these (to be assumed on the basis of MLG dese) and OHG dese, on which final -e, as a reflex of the vowel or diphthong of the iterated form posited above (*sa-sa-i?), can hardly be explained as analogical. Likewise, neut. OS thit $(t)$ and OHG diz reflect a geminate, due to original iteration (as explained above) comparable to that in ON petta, and OS instr. thius is comparable in structure to OE $p \bar{y} s$, whereas OHG desiu has substituted the stem in WGmc. *pes-. OHG gen. sg. masc. neut. desses for earlier desse was explained above. As always in $\mathrm{OHG}$ and (esp.) OS, there is considerable spelling variation, e.g. dat. sg. fem. OS thesaru, -aro, -oro, -ero, -ara.

The reason for the discrepancy between Anglo-Frisian *piss- and, elsewhere in WGmc., *pes- is not plain. The geminate in *piss- can be accounted for as resulting from *-sr- (as explained above), but the reason for the raised vowel in *biss- and *bittis not obvious, especially if WGmc. * pitt- is to be derived (ultimately) from *pat-pat. This could be a case of simple dissimilation to *pit-pat (see $\$ 12.33$ n. 6). Or it may be that *bitt- is by analogy to the corresponding anaphoric pronoun, with subsequent spread of the vowel to *biss-. Cf. Klingenschmitt 1987: 184, Ringe \& Taylor 2014: 102, with other proposals. 
1. This is the proposal of Klingenschmitt (1987: 185-9), though the version of the idea presented here differs in some respects from his.

2. This is a weighty reason to prefer the idea of iteration to the otherwise attractive idea that the $s$-suffix should be compared to -se in Lat. ipse (so, e.g., Prokosch 1939: §93b).

3. Probably to be reconstructed is *se-a $>s j a ́$. The stem *se- is not paralleled in the paradigm of $s a ́$; perhaps $e$ is introduced analogically, since it is the vowel that prevails in the paradigm of sjá.

\section{Remaining Types of Pronouns}

\subsection{Interrogative pronouns}

In PIE there was an interrogative pronoun uter * $k^{w i s}$ 'who?', neuter * $k^{w} i d$ 'what?', with the same inflections (masc. and neut.) as *is (§8.7), reflected as Lat. quis, quid, Hitt. $k w i s, k w i d, \mathrm{Gk} . \tau i \varsigma, \tau i$. Beside this there was an adjective stem inflected in three genders in the nom. and acc. (otherwise undifferentiated for gender), masc. ${ }^{*} k^{w} O,{ }^{1}$ neut. ${ }^{*} k^{w} o d$, fem. ${ }^{*} k^{w} e h_{2}$, with the same inflections as $*^{*}(\S 8.10)$, reflected as Skt. masc. $k \dot{a}-h$, fem. $k \bar{a}$, Lat. masc. quī $\left(<k^{w} O-i\right)$, fem. quae $\left(<k^{w} \bar{a}-i\right)$, neut. quod. Although these were inflected in the sg. and pl., only sg. forms are reflected in Germanic. Accordingly, the PIE sg. forms were these (see Sihler 1995: 397, Szemerényi 1996: §8.3.1, Beekes 2011: 230):

\begin{tabular}{|c|c|c|c|c|c|}
\hline & \multicolumn{2}{|c|}{ pronoun } & \multicolumn{3}{|c|}{ adjective } \\
\hline & uter & neuter & masc. & neuter & feminine \\
\hline nom. & $* \mathrm{k}^{\mathrm{w}}$ is & $* \mathrm{k}^{\mathrm{w}} \mathrm{id}$ & $* \mathrm{k}^{\mathrm{w}} \mathrm{O}$ & $* \mathrm{k}^{\mathrm{w}} \mathrm{od}$ & $* \mathrm{kwoh}_{2}$ \\
\hline acc. & $* \mathrm{k}^{\mathrm{w}} \mathrm{im}$ & ${ }^{*} \mathrm{k}^{\mathrm{w}} \mathrm{id}$ & $* \mathrm{k}^{\mathrm{w}} \mathrm{om}$ & $* \mathrm{k}^{\mathrm{w}} \mathrm{od}$ & $* \mathrm{k}^{\mathrm{w}} \mathrm{Oh}_{2} \mathrm{~m}$ \\
\hline gen. & \multicolumn{2}{|c|}{${ }^{*} \mathrm{k}^{\mathrm{w}} \mathrm{es}(\mathrm{i}) \mathrm{o}$} & \multicolumn{2}{|c|}{$* \mathrm{k}^{\mathrm{w}}$ osio } & ${ }^{*} \mathrm{k}^{\mathrm{w}} \mathrm{OSieh}_{2} \mathrm{~S}$ \\
\hline at. & \multicolumn{2}{|c|}{${ }^{*} \mathrm{k}^{\mathrm{w}}$ esmei } & & ${ }^{*} \mathrm{k}^{\mathrm{w}} \mathrm{OSieh}_{2} \mathrm{i}$ \\
\hline & \multicolumn{2}{|c|}{$* \mathrm{k}^{\mathrm{w}} \mathrm{esmi}$} & \multicolumn{2}{|c|}{$\begin{array}{l}{ }^{*} \mathrm{k}^{\mathrm{w}} \text { osme1 } \\
* \mathrm{k}^{\mathrm{w}} \mathrm{osmi}\end{array}$} & \\
\hline
\end{tabular}

The reflexes of these are often intermixed, as they are in Gmc., and in the various languages they serve different functions, which may include interrogative, indefinite, and relative use. ${ }^{2}$ The Gmc. interrogative pronouns are generally derived from the PIE adjective stem, the gen. sg. masc./neut. being the most notable exception:

\begin{tabular}{|c|c|c|c|c|c|c|}
\hline \multirow{3}{*}{ Go. } & & nom. & acc. & dat. & gen. & instr. \\
\hline & m. & huas & huana & hamma & huis & \\
\hline & n. & ha & ha & huamma & his & huē \\
\hline & f. & hū & huō & huizái & *huizōs & \\
\hline OIcel. & mf. & hverr & hvern & hveim & hvess & \\
\hline & n. & hvat & hvat & hví & hvess & \\
\hline OE & mf. & hwā & hwone & hwǣm & hwæs & \\
\hline & n. & hwæt & hwæt & hwǣm & hwæs & hwȳ, hwon \\
\hline OS & mf. & hwē & hwena & hwem(u) & hwes & \\
\hline & n. & hwat & hwat & hwem(u) & hwes & hwī \\
\hline OHG & $\begin{array}{l}\text { mf. } \\
\text { n. }\end{array}$ & $\begin{array}{l}\text { (h)wer } \\
\text { (h)waz }\end{array}$ & $\begin{array}{l}\text { (h)wen(an) } \\
\text { (h)waz }\end{array}$ & $\begin{array}{l}\text { (h)wemu } \\
\text { (h)wemu }\end{array}$ & $\begin{array}{l}\text { (h)wes } \\
\text { (h)wes }\end{array}$ & (h)wiu \\
\hline
\end{tabular}


Thus, only Gothic has separate fem. forms, ${ }^{3}$ which are probably not a Gothic innovation (as is often supposed, e.g. by Prokosch 1939: §97a and Euler 2013: 118), as the vowel of dat. hizái appears to derive from the pronominal rather than the adjectival stem, serving as a model for the spread of the vowel to the paradigm of *so $(\S 8.10)$ and to the $\bar{o}$-stem inflection in adjectives $(\S 9.2){ }^{4}$ The archaic nature of Go. with respect to these pronouns is also suggested by a relic of the plural preserved in a compound of this pronoun, hazuh 'each' (\$8.15): insandida ins twans hanzuh 'he sent them forth two and two' (Luke 10:1, also Mark 6:7; cf. PIE acc. pl. masc. * $k^{w}$ ons). The PIE gen. sg. was probably not $* k^{w}$ esio but $* k^{w}$ eso (cf. OCS česo), and this seems the likeliest source of the gen. sg. inflection Go. -is, OS OHG -es of $a$-stem nouns and adjectives $(\S \S 7.8$, 9.2). In Go. and WGmc. these forms are also used as indefinite pronouns meaning 'someone, anyone; something, anything', whereas ON hverr can mean 'any' only when used as an adjective. A few forms in the individual languages invite comment:

Gothic. Endingless nom./acc. neut. $h a$ is possibly an archaism: final $-d$ in the corresponding demonstrative PIE *tod is probably from earlier $t$, assuming that *tod reflects an iterated form *to-to (Szemerényi 1996: $\S 8.2 .1$; note that final *- $t$ developed to $*_{-} d$ in PIE itself: Szemerényi 1996: $\left.\$ 5.4 .5\right)$, and if that is the case, the interrogative pronoun could have $*_{-} d$ (as in Lat. quod $=$ OIcel. hvat) only by analogy to *tod. Krahe \& Meid (1969: II, §42), suggest, alternatively, that ha reflects * $x^{w} a m$, with substitution of the usual nom./acc. ending on neuter $a$-stem nouns (cf. Skt. neut. kim beside masc. $k a ́ h$, fem. $k \dot{a}$ ); but a final nasal in a monosyllable was not generally lost except after a long vowel $(\S 6.11) .{ }^{5}$ Otherwise, the Go. forms developed the same way as $s a(\$ 8.10)$, except with final $-s$ in the nom. sg. masc. (probably not present in PIE, as explained above).

Old Norse. The nom. and acc. masc. forms fell out of use, perhaps due to coalescence with hvar 'where?' and *hvan 'when?', with replacements supplied from the paradigm of the corresponding adj. hverr 'which' (§8.13). Dat. sg. hveim (= OE hwæ $\bar{x}$ ) is parallel to peim (explained in $§ 8.10$ ) There also occurs hvé, formally an instr., with the meaning 'how?'.

West Germanic. OE $h w \bar{a}$ (OFris. $h w \bar{a}$ ) can reflect PGmc. ${ }^{*} x^{w} a z$, with loss of ${ }^{*}-z$ and lengthening before $a$ could be fronted in Anglo-Frisian. ${ }^{6}$ The OE forms are otherwise parallel to those of $s \overline{\bar{e}}(\S 8.10)$. There is no consensus as to how OE $h w \bar{y}$ is to be explained. Perhaps the likeliest explanation is that it developed early from *hwi (attested as such only in later texts, and so probably representing there an unrounding of $h w \bar{y}$; cf. OS $h w \bar{\imath}$, ON $h v i$ ), formally a locative with PIE *-ei. Such a change is to be contemplated under low stress only (which is why there is no early *hwy $l$, a LWS form only, for hwīl 'while' et sim.): cf. the change of *ni willan to nyllan 'will not' in prehistoric times. Krahe \& Meid (1969: §42) suggest instead a contamination of $h w \bar{\imath}$ and (formally instr.) $h \bar{u}$ 'how' $<* h w \bar{o}$.

OS $h w \bar{e}$ shows the influence of $h \overline{\bar{e}}$, and $\mathrm{OHG}(h)$ wer of er (§8.7). The influence of the anaphoric pronoun is in fact exerted throughout the paradigm, with substitution of the stem hwe- (: pe-) in most forms, along with other parallels, e.g. OHG instr. (h)wiu. $\mathrm{OHG}$ acc. sg. masc. wenan (for earlier (h)wen) shows the analogical influence of anaphoric inan. On OS OHG $-m u$, see the discussion of the anaphoric pronoun ( 88.7$)$, and cf. the demonstratives OS themu, OHG demu. For alternative spellings, the handbooks should be consulted.

Further interrogatives. Common to all the Gmc. languages is an interrogative 'which (of two)?', Go. hapar, OIcel. hvárr, OE hwæðer, OS hweđar, OHG (h)wedar, 
derived from * $x^{w} a z$ 'who' by the addition of the same suffix seen in, e.g., Go. anpar

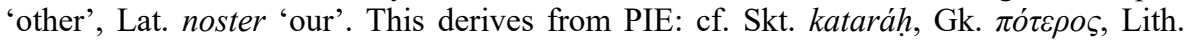
katràs. Apparently PGmc. in origin, but without a parallel in WGmc., is Go. harjis (inflected like a ja-stem adj., but always with nom. sg. neut. -ata), OIcel. hverr 'which (of more than two)?', probably a compound of * $x^{w}$ ar (Go. har, OIcel. hvar, but with lengthening in OE $h w \bar{x} r$, OS $h w \bar{a} r$, OHG $(h) w \bar{a} r)$ and the reflex of the PIE rel. pron. *io-s (§8.14; J. Schmidt 1889: 43). Go. hi-leiks, OIcel. hvilikr, OE hwelc, hwilc, OFris. hwelk, hwe-lik, OS hwi-lik, OHG (h)we-līh 'of what sort?', 'which?' is a compound of the reflex of PIE * $k^{w} i$ - 'who, what?' (above) and PGmc. *likkaz 'similar' (Go. ga-leiks, OIcel. likr, etc.) $;^{7}$ on variation in the vowel of the first syllable, see the discussion of Go. swa-leiks (\$8.15 and n. 3).

1. Although most reflexes point to ${ }^{*} k^{w} O s$, the parallel to ${ }^{*}$ so suggests masc. ${ }^{*} k^{w} O$, as does Lat. $q u \bar{\imath}<{ }^{*} k^{w} O-i$, with the hic et nunc particle $-i$ added, as in quae $<* k^{w} \bar{a}-i$ (cf. also quoque 'also').

2. Probably already in PIE, clitic forms of these were used as indefinites (Ringe 2017: 69).

3. In LWS there occur indef. gen. dat. fem. gehwēre, gehwäre 'each (one)', which disrupts the meter of poetry at various places, showing that it is a late scribal substitution for (the equivalent of WS) gehwām.

4. On syntactic constraints on the use of the fem. forms in Gothic, see Matzel 1982-3, favoring inheritance of the fem. from PIE.

5. Prokosch (1939: §97a; so also Orel 2003: 199, Euler 2013: 119) assumes, rather, that Go. ha reflects an unaccented form with final $*_{-} t$ in PGmc. But the assumption that final consonants were lost in Go. in unstressed monosyllables after a short vowel is dubitable: see $\$ 6.11$. Ringe (2017: 168) argues rather that ha is analogical to the neut. nom. acc. sg. of the strong adj.

6. There is a parallel in OE $s w \bar{a}<$ PGmc. *swa (§2.5); cf. the objections of Hollifield (1985). That there can be lengthening in OE $s w \bar{a}$ is shown by the alternative forms $s w \bar{x}, s w \bar{e}$, with lengthening after the fronting of $a$ in re-stressed ${ }^{*} s w a$. This seems to be the only likely explanation, as the alternatives (see A. Campbell 1977: $\S 125$ n. 1) cannot account for Northumbrian $s w \bar{x}$. Cf. Stiles 2004: 390 n. 7, and see further Ringe \& Taylor 2014: 152 .

7. More commonly it is said that *-likkaz here is a derivative of PGmc. *līkan 'body', itself a derivative of *likkaz (cf. Lith. lýg, lýgus 'like'): so, e.g., Krahe \& Meid 1969: III, §168. That is, *likka takes the meaning 'shape, form' $\rightarrow$ 'kind' and serves as the second constituent of exocentric compounds; hence, * $x^{w} i$-lìkaz originally meant '(of) what kind?'. The assumed formal and semantic development is simpler if it is supposed that *-lik $k$ - was an adj. all along, and the original meaning of * $x^{w} i-l i k k a z$ was 'like what?'. This also lends more transparent sense to forms like Go. waira-leikō 'like a man, in manly fashion' and OE fêondlic 'hostile', with semantic bleaching as the second constituent became widely productive, e.g. in OIcel. hlogiligr 'laughable', harðliga 'forcibly'. See further §11.2 infra.

\subsection{Relative pronouns}

Although there was a relative pronoun in PIE, formed to the stem *ie- $\sim$ *io- and declined like an $a / \bar{o}$-stem adj. (cf. Homeric Gk. ös, ஜ̈, ö, Skt. yáh, yá, yad), it is not reflected in Gmc., except probably as the initial of PGmc. distal *jainaz (§8.11) and as the second constituent of PGmc. * $x^{w} a r-j a z$ 'which (of more than two)?' (\$8.13). The Gmc. languages individually developed new relative constructions. In $\mathrm{ON}$, uninflected er (early also es, variants under Verner's law) ${ }^{1}$ and sem were used as relatives, also at 'that' in a limited number of constructions, e.g. pá at = pá er 'when'. Of these, es, er is perhaps identical to Go. iz-ei (see below); sem probably derives from samr 'same' 2 and acquired independent status as a relative from reanalysis of constructions like svá sem 'so as, just as' and slikt sem 'such as'; and at is a reduction of pat, identical to Go. pat$e i$ (see below), having lost initial $p$ - in constructions like * peir vissu pat, pat . . 'they 
knew it that' (cf. OE pætte 'that' < pat pe). In OE, indeclinable pe was used as a relative particle; it is perhaps identical to Go. pei (§8.10), in origin a loc. of $s a{ }^{3}$ More com-

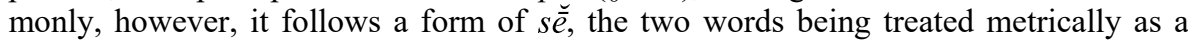
single, unstressed word. ${ }^{4}$ The demonstrative šё is also used alone as a fully declined relative pronoun, unless such constructions are simply paratactic. OS and OHG are like $\mathrm{OE}$, with rel. particles $\mathrm{OS}$ the, $\mathrm{OHG}$ de used alone, or in combination with a demonstrative, or by use of a demonstrative alone.

Go. $e i$ (cf. Gk. $\varepsilon i$ 'if', $\varepsilon \hat{i}-\tau \alpha$ 'then'), originally a loc. of anaphoric $i s,{ }^{5}$ could be used alone as an indeclinable rel. particle, but usually it was combined with a preceding pronoun. For relatives of the first and second persons it was attached to the corresponding personal pronoun, e.g. ikei '(I) who', puei '(you sg.) who', pukei '(you) whom', izwizei '(to you pl.) whom'. For the rel. of the third person it was attached to the corresponding form of $s a$, with elision from the end of the demonstrative of a final short unstressed vowel, but not a long vowel or an original diphthong (e.g. bana $+e i>$ panei, pamma $+e i>$ pammei, but saei, pizeeei, pizáiei). There is also voicing of $s$ when it becomes nonfinal, hence $p i s+e i>$ pizei. There is as well a form peeei, neut. instr. in origin, used only as a conj. '(because, for) that', and a form patei, neut. acc. in origin, used as a complementizer 'that' (= ON at, OE pæt, OS that, OHG daz).

1. Cf. Runic SAR (= OIcel. sá er) on the Björketorp stone (Sweden, $1^{\text {st }}$ half of the $7^{\text {th }}$ cent.).

2. So, e.g., Ásgeir Blöndal Magnússon (1989: 804), who cites the corresponding forms Faroese sum, Old Danish sem, sæm, sum, som, Old Swedish sum, som.

3. Most handbooks regard the vowel of $\mathrm{OE} p e$ as short, but it is sometimes thought to have had an alternative form $p \bar{e}$ (so, e.g., Brunner 1965: §340) on the assumption that it could be stressed when its antecedent did not stand immediately before it.

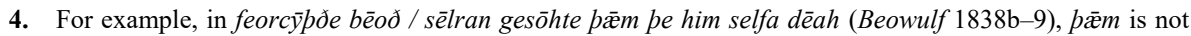
clause-initial and so would be stressed, spoiling the meter, if it were not joined to the unstressed particle. Of course, that $p \bar{x} m$ and $p e$ are separate words, rather than a compound $p \bar{x} m-p e$, is merely the assumption of editors.

5. Cf. WGmc. unstressed rel. * $p e=$ Go. $p e i$.

\subsection{Indefinite pronouns}

Common to all the Gmc. languages are certain indefinite adjectives that may be used as pronouns and are inflected as adjectives. One is Go. sums, OIcel. sumr, OE OS OHG sum 'some, a certain (one)', inflected as a strong adj. The word for 'one' (Go. áins, OIcel. einn, OE àn, OS èn, OHG ein) may also be a pronoun 'one, a certain one'. Similar are 'other' (Go. anpar, OIcel. annarr, OE ōðer, OS ōđar, OHG ander = Skt. ántara- 'other'; likewise Go. aljis 'other'; ' cf. Lat. alius 'other'), 'all' (Go. alls, OIcel. allr, OE eall, OS OHG al <*al-n-az), 'many' (Go. manags, OE manig, OS OHG manag; but ON mangr is late), 'few' (Go. *fáus, masc. pl. fawái, OIcel. fár, OE fēa, OS $f a o$, OHG $f \bar{o}(h), f a o$ ), and 'self' (non-reflexive: Go. silba, OIcel. sjálfr, OE self(a), OS self, selb-, OHG selb). ${ }^{2}$ Parallel to Go. hi-leiks (etc., §8.13) is Go. swa-leiks, OIcel. slikr, OE swelc, swilc, OFris. sulih, sulik, selik, OS sulik, OHG sulīh 'such', based on *swa 'so, thus' (Go. swa, OIcel. svá, etc.). ${ }^{3}$ Compare also OIcel. pvilikr 'such' (with dat./instr. of pat as first constituent), OE pyslic (cf. instr. pyys to bēes) beside puslic (cf. pus 'thus'), also pyllic, pullic 'such'. On Go. has, ha and cognates as indefinite pronouns, see §8.13. On 'both’ (Go. bái, bajōps, OIcel. báðir, etc.), see §10.1. Further 
Gmc. indefinites, like some of the foregoing, are generally compounds of pronouns examined above, their morphology almost without exception varying by branch or language.

'Each, every, any'. There is in Go. a particle -uh, cognate with Lat. -que 'and', though the source of $-u$ - is disputed (see Lehmann 1986: 374, and cf. Mottausch 2001). It was added to the pronouns has (\$8.13), harjis (above), and hapar (above) to form the distributives hazuh 'each, every', harjizuh 'each, every', and haparuh 'each of two'. In declination, the vowel of $-u h$ is elided after a vowel or a diphthong, and $s$ becomes $z$ between vowels; and it may be seen from the datives hammēh, harjammēh (vs. unsuffixed hamma, harjamma) that suffixation took place early enough to prevent reduction of originally final $\bar{e}$ to $a$. These pronouns are declined only in the sg., with the sole exception of acc. pl. hanzuh (§8.13). To harjizuh could be prefixed áin- 'one' to form áinharjizuh 'each one, everyone'.

In NWGmc. the collective prefix $*_{3 a-}, *_{3} i$ - (as in OE gebrōoor 'brethren') was added to some pronouns to form indefinites; subsequently all pretonic syllables were lost in NGmc. ( $\$ 5.7)$, with the result that some pronouns became indistinguishable from

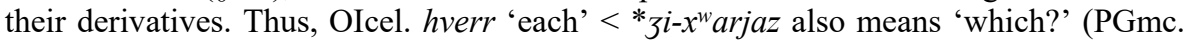
* $x^{w}$ arjaz), though occasionally poetic meter seems to demand the prefixed form. ${ }^{4}$ So also hvárr 'each (of two)' < * $3 i$ - $x^{w}$ aperaz also means 'which (of two)?' (PGmc. * $x^{w} a$ paraz). Comparable WGmc. formations are OE ge-hwā, OS gi-hwe 'each (one), every (one)'; OE ge-hwelc, OS gi-hwilik, OHG gi-(h)welīh 'each (one), every (one)'; $\mathrm{OE}$ ge-hwæðer, OS gi-hweđar, OHG gi-(h)wedar 'each (of two)'. For ge-, OE frequently has $\bar{x} g-(<* \bar{a}-z i-)$ in these pronouns, $\bar{x} g h w \bar{a}$, $\bar{x} g h w i l c, \bar{x} g h w æ \partial e r$ (and cf. OS io-gi-hwe, io-gi-hwelīk, io-hweđar); also (ge)welhwilc 'everyone'; cf. also samhwilc 'some'. ${ }^{5}$ This same prefix appears in PGmc. *aiw-zi-līk-az 'each', reflected as OE $\bar{x} l c,{ }^{6}$ OFris. ellik, e(l)k, OHG eo-gi-līh. OE ǣnig, OFris. ēnich, OS ènig 'any' (< PGmc. *ainīzaz) derive from *ainaz 'one'.?

'Either, one of two'. OIcel. uses the compound hvár(r)tveggja to mean 'either' and annarr hvárr to mean 'one of two' (with hvárr < *hvaðarr). OE uses prefixed ge$h w æ \partial e r$ and $\bar{x} g-h w æ \partial e r^{8}$ indifferently to mean 'either, one of two, each, both'; cf. OFris. āhwedder 'one of two, someone', iāhweder (and äider) 'each (of two)' < AngloFrisian *zi-a-hwæðer-; OS è-di-hweđar (cf. èn 'one' and MHG eintweder; -di- is of uncertain derivation) and ōđarhweđar 'one of two'.

Privative pronouns. Various strategies were devised to negate pronouns. In Gothic, the usual negative particle attached to pronouns is -hun, suffixed to has 'who', manna 'person', and áins 'one', always with the neg. particle ni preceding, to produce ni hashun 'no one' (nom. sg. masc. only), ni mannahun 'no one' (sg. only), ni áinshun, ni áinhun 'no one, nothing' (inflected for three genders, in sg. only). Go. -hun appears to be cognate with Skt. cana 'anyone, anything', as in the closely comparable construction ná kaś-caná 'no one' (where kaś- = Go. has). Cognate with -hun, but with a different ablaut grade and voicing under Verner's law, is *-zin, a suffix that plays an important role in $\mathrm{ON}$ and is also observable in WGmc. ${ }^{9}$ It is detectable in OIcel. engi 'no (one), none' < PNorse *æin-gi(n), neut. ekki<*æint-gi(n), a word that developed like the proximal demonstrative pronoun $(\$ 8.12)$, i.e. with the suffix originally added to the inflected pronoun, and then later with final inflections added, e.g. dat. pl. engum; cf. gen. sg. e(i)nskis with double inflection. The suffix is also used to form hvár(r)gi 'neither (of two)' and hver(r)gi 'each, every one' (rarely 'none'; neut. hvatki), ${ }^{10}$ with either internal or final inflection, e.g. dat. pl. hvárungi, hverjungi beside hvár(i)gum, 
hverigum, as well as man(n)gi 'no one' (cf. Go. ni mannahun) and vættki 'nothing' (from vættr 'wight, being' < *wext-; cf. Go. ni waihts, OE nāwiht, nāuht, nāht, OS OHG neo-wiht, ni-wiht 'nothing'). The suffix is used in WGmc. to form an adverb OE hwergen 'elsewhere', OS hwergin, OHG io-wergin (> NHG irgend) 'somewhere, anywhere' (cf. io 'ever'). As the example of OE nāwiht (<*ne $\bar{a}$-wiht) shows, privative pronouns were also formed by prefixation of the neg. particle ne, as in OIcel. neinn, OE nān, OS nēn 'no, none', derived from 'one'. Similar are OE (non-WS) nǣnig 'not any';

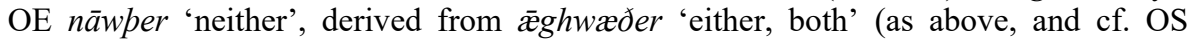
neweđar); OS OHG neo-, nio-man 'no one' <* ne-aiw-mann-. To Go. nih 'and not, not even' (= Lat. neque) there corresponds the OHG prefix nih-in nih(h)ein 'no, none', also noh(h)ein with an ablaut variant of the prefix, and the derivative adjectives nihheinig, nohheinig; OS nigēn, negēn probably does not contain the same prefix with voicing under Verner's law (so Krahe \& Meid 1969: II, §47) but reflects *ni zi-ain- (so Holthausen 1921: §347).

Varia. Gothic uses the expressions (sa)hazuh saei and sahazuh izei (nom. sg. masc. only) to mean 'who(so)ever', and patahah pei (acc. sg. neut. only) to mean 'what(so)ever'; the same idea is conveyed by prefixing pis to hazuh saei (masc. pishazuh saei, neut. pishah pei or pishah patei), declined only in the singular.

North and West Gmc. use a negated form of the verb *wait 'know' to form an indefinite pronoun: the OIcel. adj. nekkverr, nøkkverr 'some, a certain' (also nekkvarr, $n ø k k v a r r$ ), inflected early like hverr, derives from *net-k hverr $<$ PNorse (West Norse) *ne wæit ek hwerr, and the pronoun and adj. nekkvat, nøkkvat 'something' (also early nakkvat), inflected like hvat, from *ne wæit ek hwat, with mixture of the two from early times. Similar are OE pron. nāthwelc 'someone' $<*_{n e}$ wät ic hwelc and nāthwā, nāthwæt 'someone, something'; also MHG neizwēr 'someone'.

In addition to sumr and nekkverr, ON uses the expression einn hverr (fem. ein hver, neut. eitt hvert) to mean 'someone, each one', already in the oldest manuscripts sometimes given as a compound with invariant ein-; there is also a pronoun eitthvat 'something'. OIcel. hvat-vetna 'anything whatever, everything' has an inflected first constituent and an invariant second, an irregular gen. pl. to vættr 'wight, being'.

Throughout WGmc., man (from mann 'person') is used as an impersonal pronoun (as subject only) comparable to French on, forming clauses equivalent to agentless passive constructions. Another WGmc. construction is *aiw-wihtiz 'aught, anything' in OE āwiht, āuht, āht, OS OHG io-wiht (cf. OIcel. vættki, hvat-vetna, above); but OE OS OHG wiht could also be used alone to mean 'anything'. Also WGmc. is the construction with 'so ... so' and an intervening indefinite pronoun, e.g. OE $s w \bar{a} h w \bar{a} s w \bar{a}$ 'whoever', swā hwilc swā 'whoever', swā hwæðer swā 'whichever' (of two; not infrequently simply swā hwæðer or contracted swæðer), OS sō hwē sō, sō hweđar sō, OHG sō welīh $s \bar{o}(=\mathrm{OE}$ swā hwilc swā).

$\mathrm{OE}$ adds invariant -hwugu (-hwegu, -hwigu) to inflected hwæt (hwæthwugu 'something') and hwilc (hwilchwugu 'someone') to form indefinite pronouns. OE (se) $i l c a$ '(the) same' derives from *iz-likk-az (where $i z-=$ Go. is, Lat. is). This *iz-produces $\bar{l}$ - 'same', as in OE $\bar{l}$ dæges, OFris. ìdiges 'on the same day', OE $\bar{\imath}$ sìes 'immediately'. Possibly $\bar{l}$ - was not shortened in ilca before the end of the OE period (so, e.g., Holthausen 1974: 187), though it may have been shortened earlier under low stress.

To Go. aíppáu 'or, else' there corresponds the OHG prefix eddes-, ettes- (later et(t)e-), used to form pron. eddeswer 'someone, anyone', adj. eddeswelīh 'some, any', as well as adj. eddeslīh (NHG etlich); probably late OE öðerhwīle 'sometimes' 
represents a folk etymologization of the same prefix (cf. the confusion of the reflexes of OE oppe 'or' and $\bar{\partial}$ 'er 'other' in ME). There is also an OHG prefix theh-, deh- of unknown provenance from which is constructed a compound of ein: deh(h)ein, theh(h)ein, thihhein, dohein, thohhein 'someone', with derivative adj. thihheinīg, dohheinīg, apparently formed as a complement to nih(h)ein, noh(h)ein (above). The strong adj. gilìh 'like' is sometimes used with the gen. pl. of a substantive to mean 'any, some', as in manno gilīh 'someone'.

1. Also in compounds: Runic alja-, OE el-, OS OHG eli-.

2. On the etymology, see Euler 2013: 118; on 'self' and reflexivity, see Markey 1982.

3. The variation $e \sim i$ in $\mathrm{OE}$ hwilc and swelc may be due to the mutual influence of the two words upon each other, but $h w e l c$ can also be explained as etymological, since forms like OHG walīh beside welìh suggest a reconstruction parallel to Go. ${ }^{*}$ haleiks, with substitution of adjectival ha- for pronominal hi- and umlaut (Braune 2004a: 292 Anm. 1).

4. A probable example is er mér $i$ heðin hvern (Hávamál 73/3).

5. Perhaps sam- is a full-grade ablaut variant of sum; Holthausen (1974: 269), comparing PDE somewhat, thinks sum- is what is intended, which seems unlikely, but cf. OHG sumilīh 'some'.

6. Cf. Mercian $y l c$, with obscure vocalism. The phrase $\bar{x}$ fre $\bar{x} l c$ (> PDE every) comes into use late in the period.

7. Etymologically distinct from Go. áinaha 'only, sole' (pace Orel 2003: 8), to which corresponds OE ānga.

8. From Anglo-Frisian *ā-zi-hwæðer-> PDE either; * $\bar{a}-=\mathrm{OE} \bar{a}$ 'ever' < *aiw-; cf. Go. áiws 'age, eternity', Lat. aevum 'age'.

9. Because of the back mutation in, e.g., gen. sg. fem. øngrar beside engrar 'no, none', the suffix must have contained PGmc. $x^{w} \sim 3^{w}$, and so it is probably related to Lat. -que 'and'.

10. The suffix did not originally have negative meaning but indefinite, as shown by Skt. cana and by the necessity of using $n i$ with it in Gothic. But it was used in so many privative constructions that negative sense could be transferred to it, especially with the loss of pretonic *ni in ON. 


\section{CHAPTER 9}

\section{Adjectives}

\subsection{Adjective inflection in Proto-Indo-European and Proto-Germanic}

PIE adjectives had stems corresponding to those of the classes of nouns, i.e. o-, io-, uo$\bar{a}-, i \underline{a}-, u \bar{a}, i-, u-$, and a limited variety of consonant-stems. ${ }^{1}$ To these were attached the same inflections taken by the corresponding noun stems. Most adjectives were inflected like $o$-stems when masc. or neut. and like $\bar{a}$-stems when fem.; other stem classes did not distinguish masc. from fem. inflections, though these uters were distinguished from neuters in some case forms. PIE adjectives took on suffixes to form the comparative and superlative degrees, and these are reflected in the Gmc. comparison of adjectives, along with some other suffixes expressing properties of degree whose original function is more difficult to ascertain $(\S \S 9.11,10.7)$.

Four significant changes in PGmc. disrupted the regularity of this system of adjective inflection: (1) Just as in the nouns, in late PIE the distinction between stem and inflection was beginning to undergo obscurement, and in PGmc. this process was greatly accelerated, with the result that many stem-final segments came to be analyzed as inflectional. Thus, for example, as illustrated by the paradigm in $\S 9.2$, PGmc. $a$ stems no longer recognizably had stems ending in $a$, which segment instead had become part of the inflection; more radically, the suffix used to form $n$-stems was re-analyzed as part of the inflection, or as the sole inflection in some cases (§9.8), as with Go. acc. sg. masc. - an < PIE suffix *-on-plus inflection *-m, the reflex of the latter of which (PGmc. *-um) was lost. (2) In all the Gmc. languages (and presumably already in PGmc.) there is a tendency for adj. stems other than $a-\bar{o} \bar{o}$, and $n$-stems to lose their distinctiveness and acquire the inflections of $a$ - and $\bar{o}$-stems, so that even in Go., though a few case-forms may remain distinctive, most of the idiosyncratic inflections have been replaced analogically. (3) In a number of case forms, the nominal inflections employed by $a$ - and $\bar{o}$-stems were replaced by pronominal inflections, as discussed in $\S 9.2$. (4) Adjectives inflected as $n$-stems came to be associated with definite constructions (as defined in \$9.7), and as a result, nearly any adjective could be inflected as an $n$-stem. The remaining stem classes were thus associated with indefinite constructions. This is the origin of the distinction between the so-called strong and weak adjectives of Gmc.

1. Aside from the $n$-stem (weak) adjectives, the only significant consonant-stem adjectives in Gmc. are present participles ( $\$ 9.9$, not inflected identically to root-stem nouns). Other types were infrequent in PIE: Beekes (2011: 219) finds only rare instances of PIE adj. suffixes ending in $k, t, s, h_{2}$, and $n$, never $r, l, m$. But possessive adjective compounds (bahuvrīhi, exocentric) were very commonly formed of adj. or noun plus

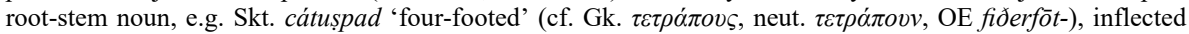
like a root-stem noun. For an etymological dictionary of inherited Gmc. adjectives, see Heidermanns 1993. 


\section{Indefinite (strong) adjectives}

\subsection{The unmarked strong declension of monosyllabic heavy stems}

Just as in PIE, in which masc. and neut. adjectives were most commonly inflected as $o$ stems and fem. as $\bar{a}$-stems, the PGmc. reflexes of these remained the norm in indefinite constructions (as defined in §9.7), except that inflections of pronominal origin came to replace some of the original nominal inflections. It should be plain from the discussion below that the influence of pronominal inflection on the paradigms of strong adjectives was not solely a PGmc. phenomenon, but it continued in force in the individual languages. The usual patterns of inflection may be illustrated by the paradigms of Go. laggs 'long' and its cognates in the oldest Gmc. languages:

\section{Go. OIcel. OE $\quad$ OS OHG PGme.}

m. sg. nom. laggs langr lang lang lang, langēr *-az

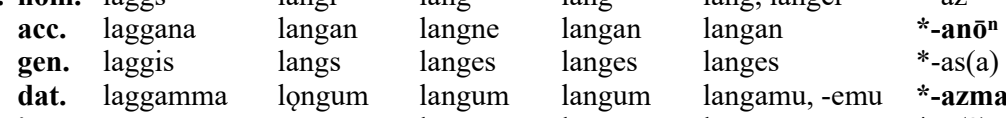

instr. lange langu

n. sg. nom. lagg, laggata lang acc. lagg, laggata langt lang lang gen. laggis langs langes langes dat. laggamma lǫngu langum langum instr. lange langu

f. sg. nom. lagga

acc. lagga

gen. laggáizōs

dat. laggái

m. pl. nom. laggái

acc. laggans

gen. langáizē

dat. laggáim

n. pl. nom. lagga

acc. lagga

gen. laggáizē

dat. laggáim

f. pl. nom. langōs

acc. langōs

gen. langáizō

dat. langáim

$\begin{array}{llll}\text { lọgg } & \text { lang } & \text { lang } & \text { lang, langiu } \\ \text { langa } & \text { lange } & \text { langa, -e } & \text { langa } \\ \text { langrar } & \text { langre } & \text { langera } & \text { langera } \\ \text { langri } & \text { langre } & \text { langeru } & \text { langeru } \\ \text { langir } & \text { lange } & \text { lange, -a } & \text { lang, lange } \\ \text { langa } & \text { lange } & \text { lange, -a } & \text { lange } \\ \text { langra } & \text { langra } & \text { langaro } & \text { langero } \\ \text { lọngum } & \text { langum } & \text { langum } & \text { langēm } \\ \text { lọng } & \text { lang } & \text { lang } & \text { lang, langiu } \\ \text { lọng } & \text { lang } & \text { lang } & \text { langiu } \\ \text { langra } & \text { langra } & \text { langaro } & \text { langero } \\ \text { lọngum } & \text { langum } & \text { langum } & \text { langēm } \\ \text { langar } & \text { langa } & \text { langa, -e } & \text { lang, lango } \\ \text { langar } & \text { langa } & \text { langa, -e } & \text { lango } \\ \text { langra } & \text { langra } & \text { langaro } & \text { langero } \\ \text { lọngum } & \text { langum } & \text { langum } & \text { langēm }\end{array}$

*-1 (?) langu

$\begin{array}{ll}\text { lang, langaz } & *-a^{\text {n }},{ }^{*} \text {-at- } \\ \text { lang, langaz } & *-a^{\text {n }}, * \text {-at- }\end{array}$

langes

langamu, -emu

$*$-as(a), *-es(a)

*-azmai

$*-\overline{1}(?)$

$*_{-\overline{0}}$

$*_{-} \overline{\mathrm{o}}^{\mathrm{n}}$

*-(a)izōz

*-(a)izai

*-ai

$*$-anz

${ }^{*}-\operatorname{aiz}(\mathbf{j}) \overline{\mathbf{0}}^{\mathbf{n}}$

*-aimiz

$*_{-\overline{0}}$

$*_{-\overline{0}}$

${ }^{*}$-aiz $(\mathbf{j}) \overline{\mathbf{0}}^{\mathbf{n}}$

*-aimiz

*-ōz

*-ōz

$*_{-a i z}(\mathbf{j}) \overline{\mathbf{0}}^{\mathrm{n}}$

*-aimiz

The PGmc. forms in boldface are borrowed from pronominal forms: compare especially the paradigm of Go. $s a$ and cognates ( $\$ 8.10)$. The remainder reflect PIE $a$ - and $\bar{o}$-stem endings. In Go., nom./acc. sg. neut. -ata (pronominal in origin: cf. pata §8.10, and see Ratkus 2015) is less frequent than the zero-inflection, and the form is almost always attributive. ${ }^{1}$ Likewise, in $\mathrm{OHG}$, the alternative endings nom. sg. masc. $-\bar{e} r$, pl. -e, nom./acc. sg. neut. $-a z$, pl. -iu (Franconian -(i)u), nom. sg. fem. -iu (Franconian -(i)u), pl. $-o$, are pronominal in origin, and in attributive use the sg. pronominal endings alternate indiscriminately with nominal inflections, whereas in the pl., nominal forms 
are rare; in predicative use the nominal forms are commoner. ${ }^{2}$ The $\mathrm{OE}$ inflections are those generally found in EWS, whereas in LWS the nom./acc. plural inflection is usually $-e$ for all genders. PGmc. ${ }^{*}-\bar{o}$ became ${ }^{*}-u$ in North and WGmc., and this is preserved as such (or lowered to $-o$ ) in OE after light stems in the nom. sg. fem. and the nom./acc. pl. neuter, e.g. light-stemmed hwatu 'active' (nom. sg. masc. $h w æ t$ ), beside heavy lang, with $u$-mutation of roots in $a$ in the corresponding forms of Old Icelandic. OS and OHG show the usual, expected spelling alternants, e.g. OS acc. sg. masc. -an, -on, -en and OHG dat. sg. fem. -eru, -ero, but also OS dat. sg. masc. -ити, -оти, -етu, -emo, etc., beside -um, -un, etc.

Since the origin and development of the nominal and pronominal inflections are discussed elsewhere $(\S \S 7.8,7.15,8.10)$, just a few adjectival forms require comment:

Nom. sg. masc. Although $\mathrm{OHG}-\bar{e} r$ (like neut. $-a z$ ) is plainly pronominal (cf. $d e r, d a z, \S 8.10$ ), there is no consensus as to why $-\bar{e} r$ has a long vowel. Comparison can be drawn to the possessive pronouns (Franconian) unsēer, iuweer (\$8.5), which Johansson (1890, with a summary of prior scholarship) argues have $-\bar{e} r$ by analogy to the identical gen. forms of the corresponding personal pronouns (§8.2); but $-\bar{e} r$ in the latter can be explained as etymological only on a speculative basis. The most commonly accepted explanation is that of Sievers (1875: 122; so, e.g., Krahe \& Meid 1969: II, §50), that der is a weakened form of earlier ${ }^{*} p \bar{e} r$, to the latter of which the ending $-\bar{e} r$ is analogical.

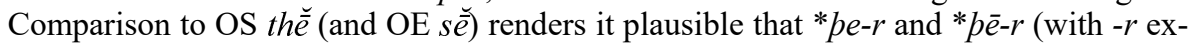
tended from $e r$ 'he') should once have coöccurred in OHG, the latter eventually driven out by the continued analogical influence of er. Boutkan (1995b: 296-7) tentatively proposes that $\bar{e}$ in $-\bar{e} r$ is analogical to the dat. plural.

Dat. sg. masc. Beside OS -um there are many variants, e.g. -u(n), -етu, -omo, and similar endings with different vocalism; likewise OHG -ети, -ето, -ати, -ото, the forms with $e$ no doubt by analogy to pronouns. The ending -um in OIcel. and OE (and in part in OS) is probably analogical to the corresponding plural noun inflection (note that dat. sg. and pl. of pronominal OIcel. sá, OE sē also agree in these languages, §8.10): so Prokosch 1939: §95, but cf. Krahe \& Meid 1969: II, §37, and see further Stiles 2013: 22-3. OHG -ети (for more original -ати, -ато) is by analogy to dat. sg. demu (§8.10).

Dat. sg. neut. OIcel. $-u$ is usually assumed to be instr. in origin, like OS OHG instr. sg. $-u$, though it is not plain why $-u$ was not apocopated: cf., e.g., nom. sg. grof 'pit' < PGmc. *3räō. Boutkan (1995b: 302-3) argues that $-u$ may be analogical to the vowel in *hu (Old Swedish $h \bar{u}$ 'how').

Instr. sg. masc. \& neut. Certainly OS OHG $-u$ is the same desinence found in $a$ stem nouns. OE $-e$ appears to be the reflex of the ending $-i$ of $a$-stem nouns found in some early texts in instr. function and reflecting PGmc. ${ }_{-}^{*} \bar{\imath}<$ PIE loc. ${ }_{-}^{*} e i(\S 7.8 ; \mathrm{A}$. Campbell 1977: §640). If so, the umlaut that it should have caused must have been leveled out of the paradigm.

Nom. pl. masc. Go. retains -ái (which should have changed to $-a$ ) by analogy to the pronoun pái. ON -ir reflects *-eir by analogy to peir 'they', tveir 'two', which in turn have $-r$ by analogy to the corresponding nominal inflection (Sievers 1875: 114; on alternative explanations, see Syrett 1994: 92-3). In WGmc., the acc. pl. inflection has been replaced by the nom. pl., as in nouns (outside of OHG: §7.8).

Nom./acc. pl. neut. OHG $-i u$ is analogical to the corresponding ending of pronominal der ( $\$ 8.10)$, dese (\$8.12), etc.

Nom. sg. fem. OHG $-i u$ is entirely parallel in origin to the identical neuter inflection (supra). 
Acc. sg. fem. OIcel. $-a$ reflects the original inflection ${ }^{*}-\bar{o}^{n}$, whereas in the $\bar{o}$-stem nouns (§7.15) the corresponding inflection has been made identical to that of the nom. sg. Rather, Kortlandt (2005: 2) regards $-a$ as pronominal in origin.

Gen. sg. fem. According to Sievers (1875: 111-14), Go. -áizōs has borrowed -ái- from the gen. \& dat. pl., with similar developments in OS and OHG, and $i$ in PGmc. *-izos was syncopated in ON and OE. It is notable, however, that there is no trace of umlaut in the gen. or dat. sg. fem. in NWGmc.; it is usually assumed to have been leveled out (e.g. by Prokosch 1939: §90). Rather, it has been argued that the ending was already *-aizozz in PGmc., and that $a i$ in this and other endings in *-aiz- (dat. sg. fem., gen. pl. all genders) was replaced by $e$ by analogy to the anaphoric pronoun and others similarly inflected. See Stiles 2013: 31-2, Ringe \& Taylor 2014: 22-3. In addition to explaining the lack of umlaut, the latter hypothesis obviates the need to assume early shortening of $a i>\bar{e}>e$ in OS and OHG.

Dat. sg. fem. According to Sievers (1875: 111), Go. -ái is by analogy to the nominal inflection, and again ON and OE may be assumed to have lost $i$ from PGmc. *-izai, with analogical removal of umlaut, though OS and OHG have $e<*_{\text {-ai- leveled }}$ from the plural. But see under gen. sg. fem. above. In OS OHG -eru the final diphthong of PGmc. has been replaced by the dat. ending of the substantive $\bar{o}$-stems.

Gen. pl. The PGmc. diphthong *ai is etymological in the corresponding masc. and neut. pronouns, with analogical extension to the fem. form. In the view of Sievers (see above), $\mathrm{ON}$ and $\mathrm{OE} i$, later lost, has been taken over from the fem. sg. and extended to the masc. and neut. inflections, though once again analogy must be assumed to have eliminated umlaut. ${ }^{3}$ These contrary analogical changes are not simple and obvious, and so the view that $a i$ has been replaced by $e$ (see above under gen. sg. fem.) is to be preferred.

Dat. pl. The original inflection *-aimiz is reflected in Go. and OHG, whereas the other Gmc. languages have substituted the ending -um found in $a$-stem nouns.

The distinction in Gmc. between strong and weak adjective inflection is paralleled in Balto-Slavic (see §9.7), where adjectives in indefinite constructions are inflected like nouns, and those in definite constructions are compounds of the adjective plus a pronominal element. The earliest approaches to explaining the Gmc. development of adjectives relied on comparison to Balto-Slavic, and hence the influx of pronominal endings into Gmc. strong inflection was likewise most commonly understood to be a matter of compounding of the thematic adj. stem with a pronominal stem PGmc. *ja- plus its normal pronominal inflections. Yet the Balto-Slavic compounds are definite, whereas the Gmc. adjectives with pronominal inflections are indefinite, and it is not plain why the attachment of pronouns to indefinite adjectives should have occurred at all. Ever since the critique of the compounding theory by Sievers (1875), preference has been accorded his alternative view, that Gmc. has simply borrowed many of the indefinite inflections from pronouns. ${ }^{4}$ Sievers $(1875: 107-9)$ points out that in Skt. quite a few words that are adjectival in origin sometimes take pronominal inflections, since they may be used in pronominal function (i.e., they are substantivized), e.g. néma'another' and púrva- 'foremost'. It is in fact common in IE languages for words of this sort to acquire pronominal inflections, e.g. nom./acc. sg. neut. Gk. $\ddot{\alpha} \lambda \lambda o=$ Lat. aliud 'other', reflecting pronominal *-od (cf. Skt. tád 'it', and compare the nominal inflections Gk. -ov, Lat. -um, Skt. -am), in comparison to nom. sg. masc. Gk. $\ddot{\alpha} \lambda \lambda o \varsigma$, Lat. alius, with non-pronominal ${ }^{*}$-os, though Sievers himself argues that such mixture of inflections was to be found already in PIE. It is natural enough to assume, then, that the Gmc. strong adjectives that first acquired pronominal inflections were adjectives like 
indefinites and numerals (i.e., pronominal adjectives), such as 'some', 'any', 'such', and 'one', which were normally inflected as adjectives but which could be used in pronominal function. ${ }^{5}$ Explaining the precise distribution of nominal and pronominal endings in Gmc. strong adjectives thus becomes a matter of lesser import, seeing as the competing forces of analogical influence in the direction of both pronominal and adjectival use remained in effect throughout the history of the Gmc. languages, with the result that new pronominal inflections were added to adjectival paradigms after the PGmc. period, e.g. OHG nom. sg. masc. $-\bar{e} r$ and nom./acc. sg. neut. $-a z{ }^{6}$

1. Ringe (2017: 314-15) observes that although Go. -ata, ON -t, and OHG -az have the same pronominal source, they must have been borrowed independently in the three languages, given that Go. -ata is borrowed from the specifically Go. form of the pronominal ending. This is probably correct, though of course it is possible that the pronominal ending was extended to adjectives in PGmc. and subsequently reformed in Go. in tandem with the addition of $-a$ to the pronoun.

2. The endingless forms in the plural are not etymological but arose in predicative use.

3. The reflex of PGmc. medial *-ai- is not normally syncopated in $\mathrm{ON}$ and OE: cf., e.g., OIcel. erfiði, OE earfepe 'labor' < *arbaip-. The circumstance that *ai was preceded by *e in a form like *anperaiz $\hat{O}^{n}$ 'other' should have rendered it less, not more, susceptible to syncope.

4. Compounding has again been advocated by Birkhan (1974) and Haudry (1981); cf. Bammesberger 1990: $226-7$.

5. Compare the analysis of Prokosch (1939: §89b): "It is not impossible that this transfer of pronominal endings to the 'strong' adjective declension was at least part due to the fact that 'weak' adjectives are usually preceded by pronominal forms: on the pattern of pana blindan guman there may have been formed blindana guman; pata blindō barn may have been the starting point for blindata barn."

6. Sievers $(1875: 111,114)$ in fact argues that PGmc. pronominal inflections could be replaced in the individual languages by nominal ones. See further McFadden 2003.

\subsection{Variant stem types in the unmarked strong declension}

Certain stem alternations are to be observed in indefinite adjectives.

Gothic. Voiced fricatives are usually devoiced finally and before final $-s$, as in frōps 'wise', gōps 'good', liufs 'dear', saps 'full' (gen. frōdis, gōdis, liubis, sadis), but láus 'empty', gen. láusis.

Old Norse. In OIcel., $r$ at the start of an inflection was dropped when added to a stem ending in postconsonantal $r$, e.g. nom. sg. masc vitr 'wise', fagr 'beautiful', gen. sg. fem. vitrar, fagrar; cf. nom. sg. masc. súrr 'sour', gen. sg. fem. súrrar. Such an $r$ was assimilated to a preceding $l$ or nongeminate $n$, as in nom. sg. masc. heill 'hale', kœnn 'wise', gen. sg. fem. heillar, kœnnar (acc. sg. masc. heilan, kœnan), but sannr, sannrar 'true'. Disyllabic stems ending in a single consonant generally show syncope in the stem-final syllable before inflections beginning with a vowel, as illustrated by the paradigm of gamall 'old':

$\begin{array}{llcllll} & \text { masc. } & \begin{array}{c}\text { singular } \\ \text { neut. }\end{array} & \text { fem. } & \text { masc. } & \begin{array}{c}\text { plural } \\ \text { neut. }\end{array} & \text { fem. } \\ \text { nom. } & \text { gamall } & \text { gamalt } & \text { gomul } & \text { gamlir } & \text { gomul } & \text { gamlar } \\ \text { acc. } & \text { gamlan } & \text { gamalt } & \text { gamla } & \text { gamla } & \text { gomul } & \text { gamlar } \\ \text { gen. } & \text { gamals } & \text { gamals } & \text { gamallar } & \text { gamalla } & \text { gamalla } & \text { gamalla } \\ \text { dat. } & \text { gomlum } & \text { gomlu } & \text { gamalli } & \text { gomlum } & \text { goqmlum } & \text { gǫmlum }\end{array}$

Exceptions to the rule are stems in -ligr and weak second participles in -aðr, which show no syncope. In accordance with the change that produced forms like batt 'bound' 
$<$ *band (§6.14), sannr has nom./acc. sg. neut. satt. Stems ending in a vowel likewise have $-t t$ in the nom./acc. sg. neut., e.g. fátt to fár 'few', and $a$ or $u$ at the start of an inflection is elided after such stems, hence acc. sg. masc. fán, fem. fá, but nom. pl. masc. fáir. Possessive adjectives and adjectives in -inn, including strong second participles, have $-n$ rather than $-a n$ in the acc. sg. masc., and to this $-n$ is assimilated a preceding $l$, hence acc. fundinn 'found', pinn 'your', einn 'one', várn 'our', mikinn 'large' (nom. mikill), lítinn 'small' (nom. litill).

Old English. Disyllabic stems with a heavy initial syllable followed by a light regularly show syncope before a vocalic inflection other than $-u$, as illustrated by the paradigm of hälig 'holy':

\begin{tabular}{|c|c|c|c|c|c|c|}
\hline \multicolumn{4}{|c|}{ singular } & \multicolumn{3}{|c|}{ plural } \\
\hline & masc. & neut. & fem. & masc. & neut. & fem. \\
\hline nom. & hālig & hālig & hāligu & hālge & hāligu & hālge, -a \\
\hline acc. & hāligne & hālig & hālge & hālge & hāligu & hālge, -a \\
\hline gen. & hālges & hālges & hāligre & hāligra & hāligra & hāligra \\
\hline $\begin{array}{l}\text { dat. } \\
\text { instr. }\end{array}$ & $\begin{array}{l}\text { hālgum } \\
\text { hālge }\end{array}$ & $\begin{array}{l}\text { hālgum } \\
\text { hālge }\end{array}$ & hāligre & hālgum & hālgum & hālgum \\
\hline
\end{tabular}

The syncopated vowel is usually restored by analogy in LWS, but the meter in poetry often indicates the earlier value (e.g. Beowulf 336b: Ne seah ic elpeedige). Syncope of original non-high vowels is also regular after a light syllable (e.g. manges $<*$ manazas beside nom. manig $<*$ managaz), whereas the change less regularly affects high vowels (§5.6). Disyllabic stems with a light initial syllable originally apocopated the inflection $-u$, but it is frequently restored, e.g. yfelu beside $y f e l$ 'wicked'. Syncope and the alternation of front and back vowels resulted in consonantal alternations within paradigms, e.g. [j] (vel sim., §§6.17-18) in hālge but [४] in hālgum, and [t'] (vel sim., ibid.) in micel 'large' but $[\mathrm{k}]$ in micles, the latter due to anteconsonantal deaffrication (§6.18). Alternation between $x$ and $a$ was originally regulated by whether or not a back vowel followed, but in the historical period $a$ appears in open syllables, otherwise $æ$, e.g. blæc 'black', gen. blaces. Stems with final $h$ lose this before vowels, resulting in either contraction or compensatory lengthening (§4.13), e.g. hēah 'high', pweorh 'crooked', gen. hēas, pwēores. These regularities are much altered by analogical developments, especially in the later period.

Old Saxon. There should in Old Saxon have been patterns of apocope (but not syncope) like those in OE, but they have been eliminated: heavy and light stems are alike inflectionless in the nom. sg. fem. and nom./acc. pl. neut., e.g. ald 'old', hol 'hollow', though the neuters may also have $-e,-a$ by analogy to the uters. The only regular paradigm variation in regard to syncope is that disyllabic adjectives like hêlag 'holy', with a heavy initial syllable and a light second, have acc. sg. masc. -na, whereas all others have -an. There is no comparable alternation in OHG.

\section{$9.4 \quad$ The $j a$ - and $j \bar{o}$-stems}

For the most part, in Go. these adjectives add the same inflections found on $a$ - and $\bar{o}$ stem adjectives to a stem ending in $j$, hence, e.g., acc. sg. masc. midj-ana 'middle', gen. midj-is, dat. midj-amma. In the nom./acc. sg. neut., where the $a$-stems may be endingless, $j$ in the $j a$-stems is vocalized to $i$, hence midi, wilpi 'wild' beside midjata, wilpjata. An exception is nom. sg. midjis, parallel to the noun harjis (\$7.10, q.v. in regard to the 
origin of the desinence). Also, just as in the $j a$-stem nouns, a distinction is maintained between light stems like midjis and heavy like wilpeis: wherever the former has -jis, the latter has -eis (nom. sg. masc., gen. sg. masc.), with the possible exception of the gen. sg. neut. (cf. $\$ 7.10$ ad fin.). ${ }^{1}$ Likewise, to nom. sg. fem. midja cf. wilpi, comparable to $j \bar{o}$-stem nouns like bandi 'band' (\$7.16).

In $\mathrm{ON}$ the inflection of the $j a$ - and $j \bar{o}$-stem adjectives is indistinguishable from that of $a$ - and $\bar{o}$-stems, except that $-j$ - is preserved before back vowels after a light syllable or after a velar consonant, hence miðr 'middle', rikr 'powerful', villr 'wild', gen. sg. masc. miðs, riks, vills, nom./acc. sg. neut. mitt $(<*$ miðt), rikt, villt, acc. sg. masc. miðjan, rikjan, villan, dat pl. miðjum, rikjum, villum. The $-j$ - element is reflected as $-i-$, however, even after a heavy stem ending in a non-velar consonant, in certain compounds, e.g. villi-sauðr 'wild sheep'.

The originally light-stemmed $j a$ - and $j \bar{o}$-stem adjectives in OE (of which none with a stem ending in $r$ is preserved) are inflected the same way as $a$ - and $\bar{o}$-stem adjectives, with a stem-final geminate except where degemination takes place before a consonantal inflection, e.g. midd, middes, midne, midra, with apocope of $-u$ in the nom. sg. fem. and nom./acc. pl. neut., hence midd. The heavy-stemmed adjectives of this class are also inflected like the $a$ - and $\bar{o}$-stems, except that wherever the latter are endingless, the former bear the inflection $-e\left(<*_{-} i\right.$, from $j$ syllabified upon loss of the inflection), e.g. nom. sg. masc. wilde, acc. wildne, gen. wildes. In addition, as in the corresponding noun class, $-u$ is not apocopated after a heavy syllable, hence nom. sg. fem. and nom./acc. pl. wildu.

In OS and OHG there is no distinction between the inflection of originally light and heavy $j a$-and $j \bar{o}$-stems: both are inflected the same way as $a$ - and $\bar{o}$-stem adjectives, but with $-i$ wherever the latter are endingless. In addition, OS retains $-i$ - elsewhere in the paradigm, though it may be spelt $-e-$.

1. David Fertig has kindly supplied the information that the gen. sg. neut. of heavy ja-stem adjectives appears to be unattested in Gothic. The wilpeis cited as gen. sg. neut. by Kiparsky (2000: 21-2) seems to be due to a misunderstanding of an example given by W. Streitberg. The syntactic context (Romans 11:17) demands a weak adj., in which event the form is presumably a scribal error for wilpeins, and at all events it must be masc. rather than neut.

\subsection{The $w a-$ and $w \bar{o}$-stems}

The few stems of this class that are preserved in Go. have the same inflections as the $a$ and $\bar{o}$-stem adjectives attached to stems ending in $w$. Aside from forms of triggws 'true', the only surviving forms are lasiws 'weak' (for expected *lasius, stem lasiw-), nom. pl. qiwái (to *qius 'alive'), fawái (to *fáus 'little'), and usskawái (to *usskáus 'vigilant').

In ON these bear the usual adjective inflections, with stem-final $-v-\left(<*_{-} w-\right)$ preserved only before non-rounded vowels. When a root vowel is subject to back mutation, it is mutated throughout the paradigm. Examples: nom. sg. masc. folr 'pale', tryggr 'true', gen. fols, tryggs, acc. folvan, tryggvan.

Only light stems remain distinctive in $\mathrm{OE}$, where the usual adjective inflections are added to stems in $-w$-, which becomes $u(>o)$ finally or before a consonantal inflection, e.g. nom. sg. masc. gearu, acc. gearone, gen. gearwes. Such stems without a consonant before $-w$ - usually have $-w$ - throughout the paradigm, e.g. nom. sg. masc.

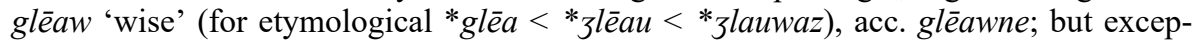
tional is dat. pl. fêam 'few' $(<*$ faum $<*$ fawum(i)z, beside analogical fêawum), also 
nom./acc. pl. neut. fêa $<* f a u<* f a w u<* f a w \bar{o}$. The situation is similar in OS and OHG: cf. OS nom. sg. masc. garo, $-u$, gen. garowes, $\mathrm{OHG}$ garo, gar(a)wes; but unlike in OE, $w$ is not extended throughout the paradigm in stems like OS OHG glau 'wise', acc. glauwan. Throughout WGmc., stems like *braygwaz 'narrow' (cf. ON prongr), with $-w$ - after a heavy consonantal stem, lose $-w$ - entirely, hence MLG dranc.

\subsection{The $i$ - and $u$-stems}

These remain distinctive in Gothic only, and even there the number of forms peculiar to this category has been curtailed. Most case forms have adopted ja- and jo-stem inflection, including nearly all those forms in which the light and heavy $j a$ - and $j \bar{o}$-stems are inflected identically, and so all plural forms. ${ }^{1}$ The remaining distinctive forms are the nom. sg. of all genders (e.g. $i$-stem masc. and fem. hráins 'clean', neut. hráin, never *hráinjata; u-stem masc. and fem. hardus 'hard', neut. hardu beside analogical hardjata), the acc. sg. neut. (hráin; hardu and analogical hardjata), and the $i$-stem gen. sg. masc. and neut. (hráinis; the case is unattested among $u$-stem adjectives). The remaining distinctive inflections are thus identical to the corresponding inflections of $i$ and $u$-stem nouns, except that there are no neuter $i$-stem nouns attested in Gothic.

In $\mathrm{ON}$ the $i$ - and $u$-stem adjectives have generally lost their distinctiveness. The former are mostly indistinguishable from $a$ - and $\bar{o}$-stems; only the Finnish loanword tiuris (OIcel. dýrr 'beast') and the name element NWGmc. -mariR (Thorsberg chape, ca. 200; OE mǣre, OIcel. mærr 'renowned'), as well as the lingering effect of front umlaut, attest to retention of $i$ in the prehistoric period. But some $j a$ - and $j \bar{o}$-stem adjectives with a stem ending in a velar consonant were originally $i$-stems, e.g. fleygr 'able to fly' and adjectives in -fengr, such as OIcel. brádfengr 'hot, hasty'. The $u$-stems have almost entirely fallen together with the $a$ - and $\bar{o}$-stems, e.g. harðr 'hard' (Go. hardus), with loss of $u$ early enough to prevent back mutation. But $u$-stems ending in a velar consonant have become $w a$ - and $w \bar{o}$-stems, from which they differ only in that they evince by-forms with and without front mutation, e.g. $\varrho n g r$ beside $ø n g r$ 'narrow' (cf. Go. aggwus, acc. aggwjana).

In WGmc., $i$-stem adjectives are inflected identically to $j a$ - and $j \bar{o}$-stems, with only non-gemination in a few $\mathrm{OE}$ light stems indicating the original distinction, hence OE bryce 'brittle', freme 'excellent', gemyne 'mindful', swice 'deceitful'. 2 The WGmc. $u$-stem adjectives are mostly inflected as $a$ - and $\bar{o}$-stems (e.g. OE OS hard, OHG hart), with just a few relic forms otherwise surviving, including OE nom. sg. (all genders) cwicu, cucu 'alive' (beside cwic), acc. sg. masc. cucone, cucune, etc. (beside cwicne, cucne), nom. sg. (all genders) wlacu 'tepid' (beside wlæc), and indeclinable noun and adj. OE (Northumbrian) feolu, OS OHG filu 'many, much'. Some $u$-stems are inflected as $j a$ - and jō-stems (cf. Go. aggw-, aggwj- above), including OE egle 'troublesome', enge 'narrow' (OS engi), myrge 'pleasant', smylte 'tranquil' (beside smolt), strenge 'strong' (beside strang; OHG strengi beside strang), swār(e) 'heavy' (OHG swāri beside swār), swète 'sweet' (beside swōt), pyrre 'dry', and compounds in -wintre 'years old'; also OHG herti 'hard' (beside hart). Compare also OE adv. tulge 'strongly' (OS tulgo) to Go. adj. tulgus 'firm'.

1. Snædal (2002) argues that Go. $i$-stem adjectives are $j a$-stems in origin.

2. It may be that origin as $i$-stem adjectives is indicated by the endingless forms adv. (ge)fyrn 'formerly' noun and adv., and (rarely) indeclinable adj. lyyt 'little': so A. Campbell 1977: §654. 


\section{Definite (weak) adjectives}

\subsection{Definitions, distribution, derivation}

Definite or 'weak' adjectives bear a PIE $n$-suffix and are for the most part identical to the corresponding forms of $n$-stem nouns, with the exceptions noted below (§9.8). ${ }^{1}$ They are used in constructions in which the noun that they modify is definite, i.e. contextually specified, non-hypothetical, or otherwise not introduced as a new entity in terms of information structure. Thus, definite adjectives accompany nouns modified by a definite specifier, i.e. a definite determiner (demonstrative or possessive) or a definite quantifier, or (often: see Stiles 1984: 23-6) those used in direct address. They are used also in the comparative degree, even though, for example, "a higher purpose" (as opposed to "the higher purpose") would appear to be indefinite. The definite declension is also common in the superlative degree, and it is the rule with ordinal numerals above 'second' and, with exceptions in WGmc., active participles. In WGmc. poetry the definite form may appear even without a specifier, especially when the adj. is used as a substantive, as is the rule in Gothic. Most pronominal adjectives are declined only strong, but a few are only weak, including Go. sama 'same' and silba 'self', though ON sjálfr is always strong. Usage is thus not identical in all the Gmc. languages; the handbooks should be consulted for details.

In the classical languages there is a pattern of forming proper names as epithets derived from adjectives (or nouns) by the addition of *-ōn-, hence, e.g., Lat. Catō, -ōnis 'the sly one' to catus 'sly', Rufō, -ōnis 'the redhead' to rufus 'red', Gk. $\Sigma \tau \rho \alpha \dot{\alpha} \beta \omega v$ to $\sigma \tau \rho \alpha \beta o ́ \varsigma$ 'squinting', and $\Sigma i ́ \mu \omega v$ to $\sigma u o^{\prime} \varsigma$ 'snub-nosed' (see Schwyzer 1977: 487, 637; Jasanoff 2002: 40). Certainly, there are Gmc. weak nouns derived the same way, e.g. Go. weiha 'priest' beside weihs 'holy', OE pearfa 'pauper' beside pearf 'in need', gefā 'foe' <*-fāha beside $f \bar{a} h$ 'hostile' The individualizing nature of the $n$-suffix thus parallels the particularizing function of the Gmc. definite declension, and it is generally thought that the class of weak adjectives arose in some such model. ${ }^{2}$ The distinction between strong and weak inflection, though not inherited from PIE, is paralleled in some other IE languages, most notably in Balto-Slavic, where indefinite adjectives are inflected like nouns of the same class, whereas definite forms have attached an ending equivalent to a pronoun. ${ }^{3}$ The Balto-Slavic distinction is thus roughly opposite that of Gmc., where it is the indefinite declension that has acquired pronominal inflections, whereas the definite corresponds in its inflection to a class of nouns ( $n$-stems).

1. On the historical use of the terms 'strong' and 'weak', see $\$ 7.29$ and n. 1.

2. Perhaps not incompatible with this explanation is the idea of Hirt (1931-4: II, §81) that the weak $n$-suffix reflects a postpositive pronoun en (comparing OCS ons 'he') attached to the nom. sg. masc. of definite adjectives in use as an article. Shields (1979) proposes a particularizing nasal suffix in PIE.

3. Examples (from Prokosch 1939: §89a) are Lith. gẽras žmõgus 'a good husband', gerà žmonà 'a good wife' : geràsis žmõgus, geróji žmonà 'the good husband, the good wife'; OCS dobrъ rabı 'a good servant', dobra žena 'a good woman' : dobrъjb rabı, dobraja žena 'the good servant, the good woman'.

\subsection{Inflectional patterns}

The declension of definite adjectives is for the most part congruent with that of an-and $\bar{o} n$-stem nouns $(\$ 7.30,7.32)$ : 


\section{Go. OIcel. OE $\quad$ OS}

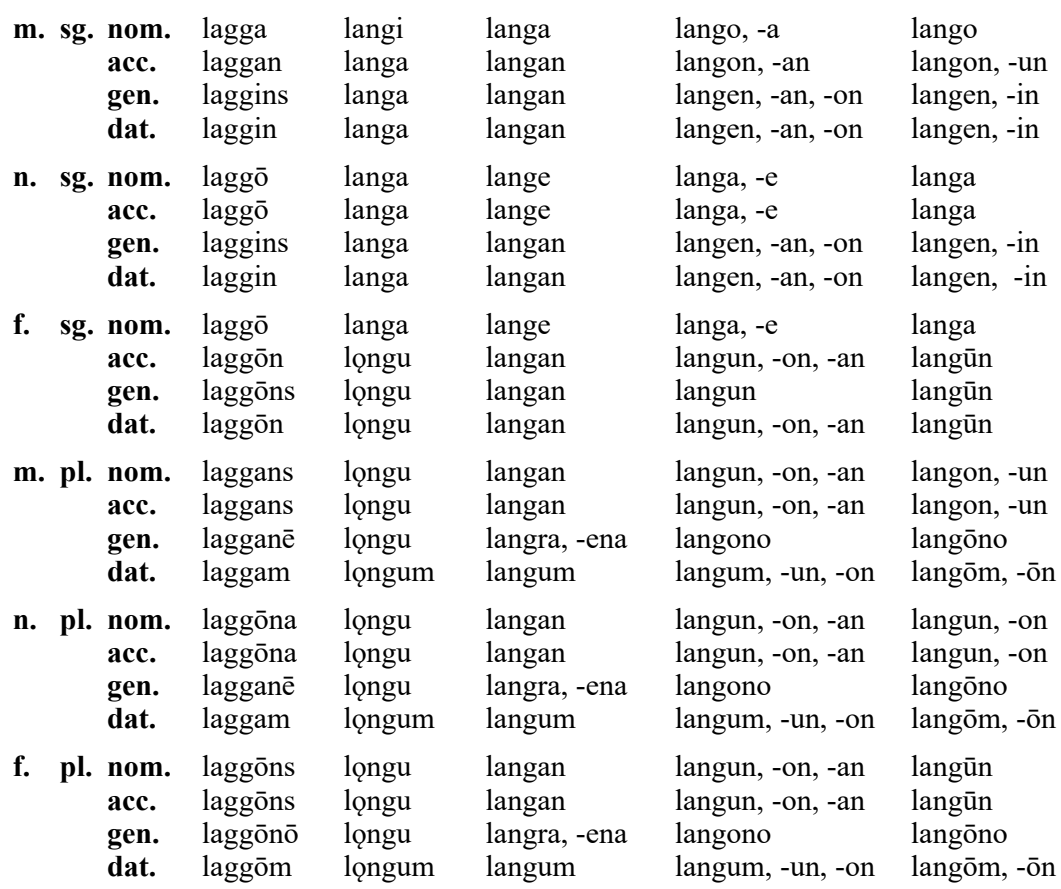

The Go. endings are identical to those of $n$-stem nouns. Aside from minor variations in $\mathrm{OS}$, the WGmc. inflections are also the same as for the nouns, except that $\mathrm{OE}$ gen. pl. $-r a$, adopted from strong inflection, is commoner than etymological -ena. In ON, too, the sg. has the same inflections as $n$-stem nouns, whereas in the plural the ending $-u$, originating in the nom./acc. fem. and neut., has spread to the masc. nouns and to all cases but the dative.

When $j a / j \bar{o}$-stems, $w a / w \bar{o}$-stems, and $i$ - and $u$-stems are given definite declension in Go., the weak ending is added to the formative element of the stem, for which $-j$ serves in the $i$ - and $u$-stems, for example nom. sg. masc. niuja 'new' (ja-stem), willja 'wild' (ja-stem), triggwa 'true' (wa-stem), hráinja 'clean' ( $i$-stem), hardja ( $u$-stem). In $\mathrm{ON}, j a / j \bar{o}$-stems have stem-final $j$ before back vowels $(a, u)$ after a light syllable or a velar consonant (e.g. nom. sg. masc. miði 'middle', rīki 'powerful', gen. miðja, ríkja), and $w a / w \bar{o}$-stems have $v$ before non-rounded vowels $(a, i$; e.g. nom. sg. masc. folvi 'pale', tryggvi 'true', pl. folu, tryggu); otherwise, just as in the strong declension, original $j a / j \bar{o}$-stems have become indistinguishable inflectionally from $a / \bar{o}$-stems. Those $i$ and $u$-stems that are inflected like $j a / j \bar{o}-$ and $w a / w \bar{o}$-stems when strong (i.e., those ending in a velar consonant) pattern like $j a / j \bar{o}$ - and $w a / w \bar{o}$-stems when weak, otherwise like $a / \bar{o}$-stems. In WGmc., $j$ of the $j a / j \bar{o}$-stems is preserved in $\mathrm{OS}$ and (written $e, i$ ) in the earliest OHG; otherwise it is lost, and the weak stem is indistinguishable from the strong, hence, e.g., nom. sg. masc. ja-stem OE mēra, OS mārio, OHG mār(e)o 'renowned'. As in the strong declension, stem-final $w$ in the WGmc. $w a$-stems is preserved after a light syllable or a vocalic stem, hence, e.g., OE gearwa, OS garwo, OHG $\operatorname{gar}(a)$ wo 'ready'. As with the corresponding $n$-stem nouns (\$7.31), OHG -in should have caused umlaut, with restoration of $a$ outside of the earliest texts. 


\subsection{The declension of participles}

Second (past, passive) participles to all verbs are inflected the same way as adjectives, with both indefinite and definite endings. First (present, active) participles were $n t$ stems in PIE, as with Gk. фépovt-, Lat. ferent-, Skt. bharant- 'bearing', and so masc. and fem. forms were not originally distinguished. Subsequently, however, a fem. declension was formed, not with nom. ${ }^{*}-\bar{a}$ but with ${ }^{*} \bar{l}$ or $*_{-}-i \bar{a}$ (see, e.g., Szemerényi 1996 : $\S 7.8 .1$ ), as with $i \bar{a}$-stem (Gmc. $j \bar{o}$-stem) nouns (\$7.17). This situation was altered considerably in Gmc. In Gothic, masc. and neut. first participles take only weak inflections - that is, they are inflected like masc. lagga, neut. laggo (\$9.8), except that beside weak masc. nom. sg. -and-a there is preserved a strong form in -and-s, an analogical formation, as PIE nom. sg. ${ }^{*}$-ent-s, ${ }^{*}$-ont-s can hardly have remained as such in PGmc. (cf. nom. sg. Gk. $-\omega v$, Lat. -ens, Skt. -an, and see $\$ 7.28$ on the nom. sg. of root-stem nouns). ${ }^{1}$ The Go. fem. declension, however, is like that of $i n$-stems (e.g. managei, $\S 7.34$ ), a change that must have started in the nom. sg. fem. *-and-ī, prompted by the use of $n$-stem inflections in the other genders. In ON, too, first participles are inflected only weak, but instead of $-u$ they take $-i$ in the nom./acc./gen. pl. of all genders, a pattern which must have spread from the fem. forms, assuming $i n$-stem inflection, as in Gothic. In WGmc. these participles may be declined either strong or weak, and when strong they take the inflections of $j a / j \bar{o}$-stem adjectives, a pattern again originating in the fem. forms.

1. Skt. also demonstrates that the $n t$-suffix originally showed quantitative ablaut alternations in addition to the qualitative one evident in Lat., Gk., and Gmc.

\section{Comparison of adjectives}

\subsection{The comparative degree}

The comparative of adjectives was formed with a suffix PIE *-ios- in the nom. and acc. (lengthened to ${ }_{-}^{-}-i \bar{o} s$ in the nom. sg. uter under Szemerényi's law, $§ 1.6 \mathrm{n} .1$ ) in alternation with $*$-ies- and, presumably in the weak cases $(\$ 7.4)$, reduced-grade $*$-is-: see Szemerényi 1996: §7.8.4. It is the last of these that was generalized in PGmc., ${ }^{1}$ yielding *-iz- under Verner’s law (§6.6). Uninflected, it was used to form adverbs, e.g. Lat. magis 'more' (cf. magnus), Go. máis 'more' < *ma-iz, mins 'less' < *minn-iz. Beside this there arose another comparative suffix *-ōz-peculiar to Gmc. and of uncertain origin. By far the most widely credited explanation is that * $-i z$ was added to Gmc. adverbs in $*_{-} \bar{o}$ to form comparatives, with subsequent development of $*_{-} \bar{o}-i z$ to ${ }^{*} \bar{o} z$ and later extension of this adverbial ${ }^{*}-\bar{o} z$ to adjectives. ${ }^{2}$ In Gothic, either ${ }^{*}-i z$ - or ${ }^{*}-\bar{o} z$ - may be added to $a / \bar{o}$-stem adjectives (but consistently one or the other), whereas the other stem classes take *-iz- only. In the other Gmc. languages, i.e. the languages with front umlaut, *-iz- became unproductive, replaced exclusively by *-ozz-, which posed no umlaut complexities, and forms derived from ${ }^{*}-i z$ - remain only as relics: see the examples below ( $\$ 9.12)$. Note that Go. stems in $j a / j \bar{o}-, i-$, and $u$ - lose the stem formative before the comparative (and superlative) suffix, e.g. alpiza 'elder', reikists 'most powerful' (ja/ō-stems), spēdiz-, spēdists (to $i$-stem *spēbs 'late'), hardiz- 'harder' ( $u$-stem). 
Adjectives in the comparative degree take only weak endings, in the case of ON the same set of endings used with first participles (\$9.9). Exclusive inflection of Gmc. comparative adjectives in the definite declension has an intriguing parallel in Greek, where to the likewise reduced-grade suffix $*$-is- is added an $n$-stem suffix to form comparative adjectives, as in $\dot{\eta} \delta i \omega v$ 'sweeter' <*sūād-is-ōn, to $\dot{\eta} \delta \dot{s} \varsigma$.

1. Prokosch (1939: §91a) regards PGmc. *-is- as a Gmc. reduction of *-ios-, but it is difficult to see how this could be. Cf. Szemerényi loc. cit.

2. Such is the explanation of Brugmann (in Brugmann \& Delbrück 1897-1916: II, 1.560-1, with refs.), who does not claim $*_{-} \bar{o}-i z>*_{-} \bar{o} z$ as a phonological development, rather $*_{-} \bar{o}-i z>*_{-}$-aiz, the diphthong of the latter then being replaced by analogy to the positive degree in ${ }^{*}-\bar{o}$. Compare Cowgill's explanation of weak verbs of the second class (§12.43). See further Kuryłowicz 1954: 252-4 and 1964: 233, also postulating an adverbial origin.

\subsection{The superlative degree}

In PIE, one method of forming the superlative was by the addition of a suffix *-to- to the comparative suffix, a method particularly common with $u$-stem adjectives, as with

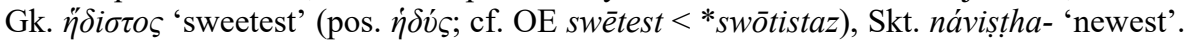
The same construction characterizes Gmc., e.g. Go. háuhists $<* x a u x-i s-t a-z$. With the rise of the new comparative suffix $*_{-} \bar{o} z$ - in PGmc., this, too, added $-t$ - to form the superlative of adjectives that took ${ }^{*} \bar{o} z$ - in the comparative degree, e.g. Go. armōst- 'poorest'.

In PIE, some adverbs formed the superlative by the addition of a suffix *-mHo-, e.g. PIE * $h_{2}$ ndh-moHo- in Skt. adhamá- (to prep. adháh 'below') and Lat. infimus 'lowest', or with an extended form of the suffix *-t-mHo-, as in Skt. ut-tama 'uppermost', Lat. ex-timus 'outermost'. A few such adverbial stems formed adjectives in Gmc., and thus there survive some superlatives in $-m$ - in Go. and OE, the Go. forms conveying either comparative or superlative sense: ${ }^{1}$ Go. aúhuma 'higher', fruma 'the former, prior, first' (= OE OS forma 'first'), innuma 'inner(most)', aftuma 'the following, next', iftuma 'the following, next', hleiduma 'left(hand)', OE hindema 'last'. These are declined weak, the Go. fem. forms taking $i n$-stem inflections (§7.34). In Go. and, more extensively, $\mathrm{OE}$ the superlative sense could be reinforced by the addition of the adj. suffix *-ist-, hence Go. aúhumists 'highest', aftumists 'last' (OE æftemest), frumists 'first' (OE fyrmest, formest, Anglian forpmest), hindumists 'hindmost', spēdumists 'last', OE innemest 'innermost', ytemest, ütemest 'outermost', norpmest 'northernmost', and so forth.

Aside from the superlatives in PGmc. *-um- (without added *-ist-), superlative adjectives may be declined strong or weak except in OHG, where they are always weak.

1. The mixture of comparative and superlative senses probably resulted from a combination of two influences, the growing opacity of $-m$ - as a superlative marker, esp. on adjectives, and the tendency not to distinguish carefully between comparative and superlative use in dyadic comparisons, which are especially relevant to locational adverbs (e.g. 'the nearest' vs. 'the nearer' of two). Although OE forma retains its superlative sense, cf. OE medemest 'most moderate', with the superlative stem medem- extended to positive medeme and comparative medemra (cf. also OS Medema-hèm in the Vita S. Willihadi).

\subsection{Distribution of suffixes}

As noted above, Go. -iz- and -ist- may be attached to adjectives of any stem class, including $a / \bar{o}$-stems, whereas $-\bar{o} z$ - and $-\bar{o} s t-$ are used with $a / \bar{o}$-stems only. Elsewhere in 
Gmc., where they had caused umlaut, *-iz- and *-ist- ceased to be productive in the early period, leaving a few comparatives and superlatives with these suffixes as relics, along with a tendency to substitute for them forms containing the suffixes in $\bar{o}$. Thus, in OIcel. the normal endings (i.e., derived from ${ }^{*}-\bar{o} z-,{ }^{*}-\overline{o s} t-$ ) in the nom. sg. masc. are comp. -ari (but simply -ri after the adj. suffix -lig-, as in fáligri 'more reserved') and superl. -astr (or weak -asti). ${ }^{1}$ The corresponding endings in WGmc. are OE -ra and -ost/-ast, ${ }^{2} \mathrm{OS}$-ora/-ara/-era and -ost (or weak -osto), OHG -ōro and -ōsto (weak only). ${ }^{3}$ In addition to adjectives with suppletive comparison ( $\$ 9.13$ ), some forms typical for the

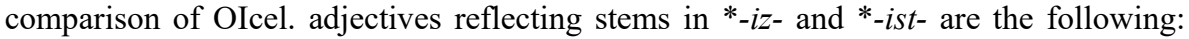
djúpr 'deep' (dýpri, dýpstr), fagr 'beautiful' (fegri, fegrstr), fár 'few' (færi,fæstr), langr 'long' (lengri, lengstr), seinn 'slow' (seinni < *seinri, seinstr), stórr 'large' (stoerri, stoerstr). For a fuller accounting, see Noreen 1970: $\S \S 438-9$, with a list of adjectives compared in both manners, i.e. with and without umlaut. The only very common OE adjectives of this sort are eald 'old' (ieldra, ieldest), geong 'young' (gingra, gingest), ${ }^{4}$ hēah 'high' (hīer(r)a, hiehst, §5.6), lang (lengra, lengest), sc(e)ort 'short' (scyrtra, scyrtest), all of which may also lack umlaut and/or have superl. in -ost. In OS and OHG the irregularities caused by the umlauting suffixes are less apparent, since only the umlaut of $a$ is indicated in the orthography, and it may be leveled out in such forms. Examples in OS reflecting *-iz- are infrequent: they occur to ald 'old', engi 'narrow', lang 'long', mildi 'mild, generous', spāhi 'wise'; also in furđiro 'greater'. ${ }^{5}$ OHG -ir-, -ist- are much more widely attested, and although there is no regular pattern to their distribution, they are almost always the rule in $j a$-stems and infrequent with stems of more than one syllable (Braune 2004a: §261). One and the same $a / \bar{o}$-stem adj. may take either these or $-\bar{o} r-$ - $-\overline{o s t}$ -

1. Rarely is $j$ or $v$ preserved in the comp. or superl. of ON $j a / j, \quad \S 9.12$ Distribution of suffixes

221

2. OE -ost- reflects -ust-< PGmc. *-ōst- with raising (and shortenıng) betore $u$ in the next syllable (§১.১), whereas OE -ast- reflects *-ōst- without raising, in cases without a following $u$ (Hogg 1992: §3.34).

3. The assertion of Krahe \& Meid (1969: II, §56) that the WGmc. superl. is declined weak only is mistaken.

4. Compare Go.juggs, comp. jühiza, showing that the PIE root was accented in the comparative.

5. OS -er- may also reflect -ir-, but the examples of -er-alternating with -or-, -ar- within paradigms cited by Gallée (1993: §353) probably reflect weakened forms of -or-.

\subsection{Suppletive comparison}

In PGmc. a few very common adjectives used a stem in the comp. and superl. degrees different from that in the positive. The attested forms are these:

Go. OIcel. $\quad$ OE $\quad$ OS $\quad$ OHG

\begin{tabular}{|c|c|c|c|c|c|}
\hline $\begin{array}{l}\text { pos. } \\
\text { comp. }\end{array}$ & $\begin{array}{l}\text { gōps 'good' } \\
\text { batiza }\end{array}$ & $\begin{array}{l}\text { góðr } \\
\text { betri }\end{array}$ & $\begin{array}{l}\text { gōd } \\
\text { bet(e)ra, }\end{array}$ & $\begin{array}{l}\text { gōd } \\
\text { betera, -ara }\end{array}$ & $\begin{array}{l}\text { guot } \\
\text { bezziro }\end{array}$ \\
\hline superl. & batists & beztr & $\begin{array}{l}\text { bet(e)st, best, } \\
\text { sēlest }\end{array}$ & bezto, besto & bezzisto \\
\hline $\begin{array}{l}\text { pos. } \\
\text { comp. } \\
\text { superl. }\end{array}$ & $\begin{array}{l}\text { leitils 'little' } \\
\text { minniza } \\
\text { minnists }\end{array}$ & $\begin{array}{l}\text { lítill } \\
\text { minni } \\
\text { minztr }\end{array}$ & $\begin{array}{l}\text { lȳtel } \\
\text { lǣssa } \\
\text { lǣst }\end{array}$ & $\begin{array}{l}\text { luttil } \\
\text { minnera, -ara } \\
\text { minnista }\end{array}$ & $\begin{array}{l}\text { luzzil } \\
\text { minniro } \\
\text { minnisto }\end{array}$ \\
\hline
\end{tabular}




\begin{tabular}{|c|c|c|c|c|c|}
\hline & Go. & OIcel. & OE & OS & OHG \\
\hline $\begin{array}{l}\text { pos. } \\
\text { comp. }\end{array}$ & $\begin{array}{l}\text { mikils 'large' } \\
\text { máiza }\end{array}$ & $\begin{array}{l}\text { mikill } \\
\text { meiri }\end{array}$ & $\begin{array}{l}\text { micel } \\
\text { māra }\end{array}$ & $\begin{array}{l}\text { mikil } \\
\text { mēro }\end{array}$ & $\begin{array}{l}\text { mihhil } \\
\text { mēr(ir)o, } \\
\text { mērōro }\end{array}$ \\
\hline superl. & máists & mestr & mǣst & mēst(o) & meisto \\
\hline $\begin{array}{l}\text { pos. } \\
\text { comp. } \\
\text { superl. }\end{array}$ & $\begin{array}{l}\text { sineigs 'old' } \\
\text { sinista }\end{array}$ & $\begin{array}{l}\text { gamall } \\
\text { ellri } \\
\text { elztr }\end{array}$ & $\begin{array}{l}\text { eald } \\
\text { ieldra } \\
\text { ieldest }\end{array}$ & $\begin{array}{l}\text { ald } \\
\text { aldiro, eldiro } \\
\text { eldist }\end{array}$ & $\begin{array}{l}\text { alt } \\
\text { altiro, eltiro } \\
\text { altisto, eltisto }\end{array}$ \\
\hline $\begin{array}{l}\text { pos. } \\
\text { comp. } \\
\text { superl. }\end{array}$ & $\begin{array}{l}\text { ubils 'bad' } \\
\text { waírsiza }\end{array}$ & $\begin{array}{l}\text { illr, vándr } \\
\text { verri } \\
\text { ve(r)str }\end{array}$ & $\begin{array}{l}\text { yfel } \\
\text { wiersa } \\
\text { wierrest }\end{array}$ & $\begin{array}{l}\text { ubil } \\
\text { wirsa } \\
\text { wirsisto, } \\
\text { wirristo }\end{array}$ & $\begin{array}{l}\text { ubil } \\
\text { wirsiro } \\
\text { wirsisto }\end{array}$ \\
\hline $\begin{array}{l}\text { pos. } \\
\text { comp. } \\
\text { superl. }\end{array}$ & & $\begin{array}{l}\text { margr 'many } \\
\text { fleiri } \\
\text { flestr }\end{array}$ & & & \\
\hline
\end{tabular}

Compare also the $\ddot{\alpha} \pi \alpha \xi \lambda \varepsilon \gamma$ ó $\mu \varepsilon v o v$ Go. iusiza 'better' (or possibly 'different': Galatians 4:1). Grammars of the individual languages should be consulted for the development of these forms, but a few general observations may be offered. Suppletive comparison is found very commonly in the IE languages for the same basic concepts expressed by these Gmc. adjectives, e.g. Lat. bonus, melior, optimus and Gk. $\dot{\alpha} \gamma \alpha \theta o ́ s, \dot{\alpha} \mu \varepsilon i v \omega v$,

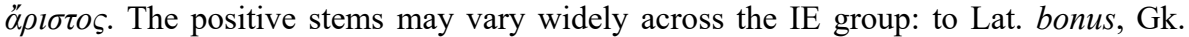
$\dot{\alpha} \gamma \alpha \theta \dot{\varsigma} \varsigma$ cf. Skt. vasu-, OIr. maith, dag-, Go. gōps. Rather, it is the comparative and superlative forms that have the securest cognates: to Go. batiza cf. Skt. bhad-rá-h 'excellent'; to Go. minniza, minnists cf. Lat. minor, minimus; to Go. máiza, máists cf. Oscan mais 'more', Umbrian fem. mestru 'larger'; to OE wierrest cf. Skt. várșișthah 'highest'. Even when the positive forms do have obvious cognates, they tend to be formed differently: to Go. mikils cf. Lat. magnus, Skt. maha- (but also Gk. fem. $\mu \varepsilon \gamma \alpha ́ \lambda \eta)$. This pattern suggests that the positive forms are generally younger than the others, and that is what might be expected, since it is likelier that a new positive form should have replaced the original, given the way that new manners of expressing basic concepts like these are some of the commonest lexical innovations in modern languages, than that suppletive stems should have been chosen for the comp. and superl. of preëxisting positives. The same development can be observed in Gmc. itself, with the substitution of ON gamall for the positive degree of 'old' (where comp. ellri= Go. alpiza, OE ieldra; the WGmc. forms show no such suppletion) and the use of vándr beside illr. ${ }^{1}$ There is, however, no scholarly consensus about these matters. ${ }^{2}$

1. OE lēssa, lǣst would appear to contradict the pattern, but plainly these are not innovative forms but old formations, as shown by their irregular form. They would originally have been close in meaning to 'smaller', 'smallest', to judge by the cognates Crimean Go. lista 'little', OHG līso 'mildly' (see also Pokorny 1959-69: I, 662), and if they were perceived as meaning the same as *minniz-, ${ }^{*}$ minnist-, there would have been no reason not to regard them as suppletive forms of $l \bar{y} t e l$, esp. since the initial consonants agree.

2. For example, in explanation of suppletive comparison Krahe \& Meid remark, "Der Grund für dieses Verhalten ist darin zu suchen, daß die durch solche Adjektiva ausgedrückten Begriffe gegenüber den durch die Steigerungsformen bezeichneten Bedeutungsdifferenzen besonders empfindlich sind, so daß sie nicht durch den gleichen Wortstamm wiedergegeben können." Cf. also Hirt (1931-4: II, §84): "Zu erklären ist die Erscheinung dadurch, daß gewisse Adjektive zunächst nicht steigerungsfähig waren, und daß anderseits zu Komparativen und Superlativen der Positiv verloren ging." 


\section{Numerals}

\section{Cardinals}

\subsection{The numerals $1-4$}

In PIE the first four cardinal numbers were fully declined as adjectives which could be used as substantives, and they continued to be declined in PGmc., though, as in most IE languages, no gender distinctions are observed outside of the nom. and acc. ('1' aside), and ' 4 ' is inflected consistently only in ON. ${ }^{1}$

1. The PIE o-stem *oinos '1' (Gk. oivós, Lat. ünus) by regular development yields Go. áins, OIcel. einn, $\mathrm{OE} \bar{a} n, \mathrm{OS}$ èn, OHG ein, declined as a Gmc. $a / \bar{o}$-stem adj.,

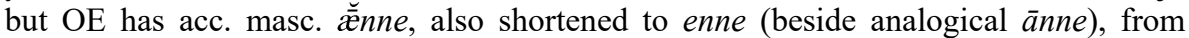
*ainin $\bar{o}^{n}$, an $i$-stem case form. ${ }^{2}$ Inflection as an $i$-stem is a Gmc. innovation, but an old one, as Go. ' 11 ' probably requires *aini- $(\$ 10.3)$. Despite the singular meaning, ' 1 ' could be inflected in the plural, in constructions like Go. pans frijondans izwis áinans 'only those loving you' (acc.) and $\mathrm{OE}$ annra gehwilc 'each one', literally 'each of ones'. In NWGmc. it may take weak inflections, usually with the meaning 'alone', ${ }^{3}$ always with that meaning in $\mathrm{ON}$, though in OHG it is inflected weak in definite constructions.

2. PIE had for ' 2 ' the form masc. *d(u)uoh, neut. (and fem.? $)^{4} * d(u)$ uoi, initial *du- appearing after a short vowel in sandhi, otherwise *duu-; cf. Lat. duo, Gk. $\delta v o$ (Homeric $\delta \dot{v} \omega$ ), Vedic Skt. $d(u) v a \bar{u} u, d(u) v a \bar{a} .^{5,6}$ It was given the dual inflections of $o$ stems (masc., neut.) and $\bar{a}$-stems (fem.), which are imperfectly known: see, e.g., Szemerényi 1996: §7.6.7. The early Gmc. paradigms are these:

Go. OIcel. OE $\quad$ OS OHG

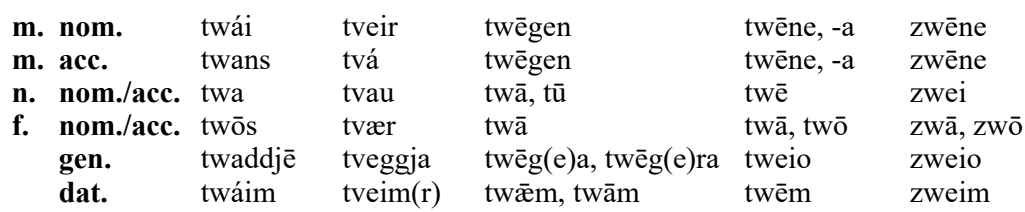

The Go. endings are identical to those of plural $a / \bar{o}$-stem adjectives attached to a stem $t w$-, except that the gen. pl. has the stem twaddj- $<* t w a j j-$, due to the Verschärfung (§6.10), the same PGmc. stem that underlies the case-form elsewhere in Gmc. ${ }^{7}$ With that one exception, the OIcel. forms are made up of a stem $t v$ - plus the same endings found in the plural of the pronoun hann (\$8.7: peir, pau, pær , etc.); the by-form dat. tveimr is analogical to brimr ' 3 '. In WGmc., where the nom. and acc. are identical, the vowel $\bar{e}$ has not been satisfactorily accounted for. The usual explanation, developed from a suggestion by Sievers (1885b: 495-6 n. 1; so, e.g., Krahe \& Meid 1969: II, §61, Euler 2013: 124) is that OE twègen is analogical to beegen 'both', which may be 
regarded as a compound of PGmc. *bō- (<PIE *bhō, as in Gk. $\ddot{\alpha} \mu \varphi \omega$, Lat. ambō 'both') and pronominal *jen-, as in OHG jenerr 'that' $(\$ 8.11)$. On the problems with this derivation, see the discussion of 'both' below. ${ }^{8}$ It cannot be that $\mathrm{OE} \bar{e}$ is the umlaut of $\bar{a}<a i$ (so, e.g., Prokosch 1939: §99a), since the umlaut of $\bar{a}$ is $\bar{x}$, and although forms with $\bar{x}$ do occur in OE, they represent a decided minority in the DOE corpus (Healey 2009): 45 $\bar{x}$ : $779 \bar{e} .{ }^{9}$ Rather, Anglian OE twēgen shows that $\bar{e}$ in WS twe gen can only be the umlaut of $\bar{o} .{ }^{10}$ In OS twene the vowel $\bar{e}$ is the regular development of $a i$, and the form can otherwise plausibly be explained as analogical to the nom./acc. pl. of ' 1 ', éne, $-a$; but this will not account for $\bar{e}$ in OHG zwēne. ${ }^{11} \mathrm{OE}$ nom./acc. fem. \& neut. twā can directly reflect $\mathrm{PIE} * d u o i$, as can neut. OS $t w \bar{e}$, OHG zwei; and OE $t \bar{u}$ (as well as OS $t w \bar{o}$, OHG $z w \bar{o}$, though the former occurs just once) can reflect PGmc. *twōz (> Go. $t w \overline{o s})$ : see $\S 4.11$. More difficult to explain are fem. OS $t w \bar{a}$, OHG $z w \bar{a}$; perhaps they align with Go. neut. twa, with lengthening under Prokosch's law (§2.5). Ross \& Berns (1992: 562, 566) suggest instead that they represent the lengthening of re-stressed *twa, the unstressed result of WGmc. ${ }^{*} t w \bar{o}<$ PGmc. ${ }^{*} t w \bar{z} z$. But WGmc. ${ }^{*}-z$ was not lost in OHG monosyllables, and so Cowgill (1985: 16-18) derives $z w \bar{a}$ from PIE uninflected *duuo, with lenghtening of final *-a. Rare OE twēg(e)a is the etymological form, although again $\bar{e}$ for expected $\bar{x}(* t w \bar{x} j-<* t w a \bar{j} j-<* t w a i j-, \S 6.10)$ remains to be explained; $t w \bar{e} g(e) r a$ has acquired the pronominal/adjectival inflection. OE $t w \bar{x} m$ is etymological, from *twaimiz, whereas twām is by analogy to $t w \bar{a}$; but cf. Ross 1954: 118, reconstructing *-muz, *-maz beside *-miz.

Closely connected with ' 2 ' is 'both', the latter being semantically a definite form of the former. The surviving forms of Go. bái are precisely parallel in structure to twái; the pronominal form of the stem seen in nom. masc. bajōps, dat. bajōpum was apparently inflected like a consonant-stem noun. ${ }^{12}$ The usual forms in the other Gmc. languages are these:

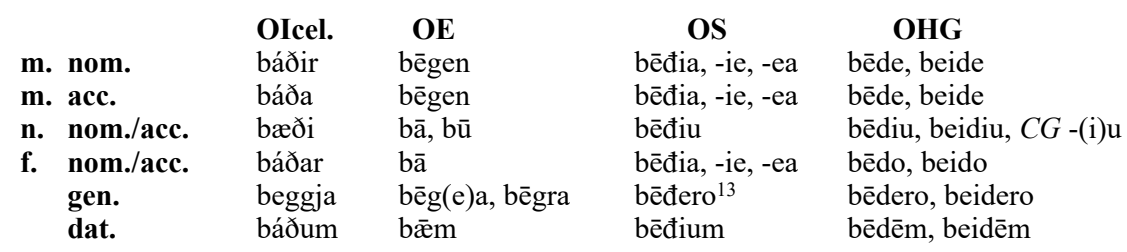

The OIcel. stem contains $b a ́-<$ acc. pl. *bans; to this was added a pronominal stem in * $b$-, and thus perhaps masc. acc. báða reflects, in effect, *bans-pans (so Prokosch 1939: $\S 99 a)$. The stem báð- is then inflected like the plural of sjá (§8.12: pessir, pessi, pessar, etc.). The umlaut in bæði resists explanation, but the discussion in $\$ 8.12$ of sjá and its development suggests some possibilities. ${ }^{14}$ Gen. beggja could be etymological, depending on how the Verschärfung is to be explained (\$6.10), and on what the shape of this stem might have been before bád- was extended through the rest of the paradigm, but more likely it is analogical to tveggja ' 2 '. It was remarked above that $\bar{e}$ in the WGmc. forms of ' 2 ' presents difficulties; the same may be said in regard to 'both'. As noted above, OE bēgen is usually explained as a compound of *bo- and pronominal *jen-; Seebold (1968: 418-21, with references) objects on a variety of grounds, among them that 'both' should combine not with the pronoun *jen- but the 'article' in * $p$ - (as in $\mathrm{ON}$, $\mathrm{OS}$, and $\mathrm{OHG})$.

3. PIE ' 3 ' was an $i$-stem *trei- $\sim *$ tri-, reflected as Skt. tráyaḥ, Gk. $\tau \rho \varepsilon \hat{\imath} \varsigma$, Lat. trēs. The usual Gmc. forms are these: 


\begin{tabular}{llllll} 
m. nom. & Go. & OIcel. & OE & \multicolumn{1}{c}{ OS } & OHG \\
m. acc. & & prír & prīe & thria, -ie, -ea & drī \\
n. nom./acc. & prija & prjá & prjúe & thria, -ie, -ea & drī \\
f. nom. & & prjár & prēo & thriu, thrū & driu \\
f. acc. & prins & prjár & prēo & thria, -ie, -ea & drīo \\
gen. & prijēe & priggja & prēora & & drīo \\
dat. & prim & prim(r) & prim & thrim & drīo \\
\end{tabular}

The Go. masc. and fem. nom. (both * preis) and fem. gen. (*prijē) and dat. (*prim) are unattested. The Go. word is declined like an $i$-stem noun, of which there are no neut. examples in Go.; neut. prija precisely reflects PIE *tri(i) $\bar{a}$ (cf. Gk. $\tau \rho i \alpha$, Lat. tria), as do the corresponding forms in the other Gmc. languages. PIE nom. masc. *treies should have produced PGmc. *pri(j)iz $>{ }^{*}$ prizz, which yields the OIcel. and OHG forms; the $\mathrm{OE}$ and $\mathrm{OS}$ equivalents show analogical addition of adj. endings to *pri-. The cognates of OIcel. priggja do not show gemination of PGmc. $j$; probably, then, it is analogical to tveggja, though some regard it as etymologically correct (e.g. Krahe \& Meid 1969: II, $\S 61$; see $\$ 6.10$ above on the Verschärfung). Certainly, OIcel. prim is analogical, whereas primr $<*$ primiz is original (cf. vinr 'friend' $<*$ winiz). Nom./acc. fem. prjár reflects the stem ${ }^{*} p r \bar{l}$ - with the addition of the adjective inflection $*_{-} \bar{o}_{R}(\S 9.2)$, and the WGmc. languages show a comparable analogical development. ${ }^{15} \mathrm{OE}$ gen. pl. prēora shows addition of the adj. ending, whereas OHG drīo is the expected equivalent of Go. prije.

4. PIE masc. $k^{w}$ etuores '4' (Skt. catvárah, Gk. $\tau \dot{\varepsilon} \sigma \sigma \alpha \rho \varepsilon \varsigma$, Attic $\tau \varepsilon ́ \tau \tau \alpha \rho \varepsilon \varsigma$, Lat. quattuor) was declined as a consonant-stem. ${ }^{16}$ The Gmc. forms (Go. fidwōr, OIcel. fjórir, OE féower, OS fi(u)war, fior, OHG fiur, with PIE $* k^{w_{-}}>*^{*} p->f-, \S 6.5$ ad fin.) for the most part show limited inflection. Go. fidwōr, with $/ ð /<$ PIE $t$ under Verner's law, is usually uninflected, though once there is a dat. fidwörim. OIcel. fjórir is inflected thus:

$\begin{array}{llll} & \text { masc. } & \text { neut. } & \text { fem. } \\ \text { nom. } & \text { fjórir } & \text { fjogur } & \text { fjórar } \\ \text { acc. } & \text { fjóra } & \text { fjogur } & \text { fjórar } \\ \text { gen. } & \text { fjogurra } & \text { fjogurra } & \text { fjogurra } \\ \text { dat. } & \text { fjórum } & \text { fjórum } & \text { fjórum }\end{array}$

That is to say, fjórir is declined the same way as the plural of gamall (\$9.3), with the same inflections and the same distribution of mono- and disyllabic stems, the remarkable difference being that the distinction between the stems fjor- and fogur- is more pronounced than that between gaml- and gamal-. The development is masc. ${ }^{*}$ fedure $\bar{e}_{R}>$

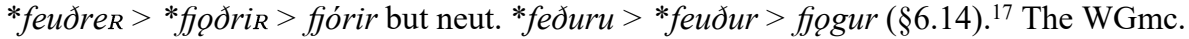
forms are usually derived from a stem altered before the application of Grimm's and Verner's laws, *kwetuór- $>* k^{w}$ ekuór- $>$ *pekuór- $>$ *fexwár- $>$ *fezwar- (Verner's law), with subsequent change of intervocalic $3 w$ to $w$ after $e(\S 6.4) .{ }^{18}$ Yet this assumption requires a stem different from that found in Gothic, and so it is more economical to derive WGmc. *feuwar from *feðwar < *feðwör; OHG fiur (and OS fior) may then be derived from the ordinal (Stiles 1985-6: 6.89-92, with references). Synthesizing these reconstructions, Stiles concludes (7.18) that '4' was inflected thus in PGmc.: nom./acc. ${ }^{*} f e ð w \bar{r}$ (from the PIE neut.), gen. *feðurô ${ }^{n}$ (from PIE * $k^{w} e t u r-;$ cf. Skt. cátur), dat. *feðurmiz. Thus, Go. and WGmc. generalized the nom./acc. stem, adding $i$-stem inflections, whereas ON standardized the oblique stem, adding $a$ - and $\bar{o}$-stem inflections. 
WGmc. '4' is usually uninflected when attributive; when predicative or substantive, in OS and OHG it is inflected as an $i$-stem, in OE as follows: nom./acc. fêow(e)re (with forms in -o in late Northumbrian), gen. fêow(e)ra, dat. fēow(e)rum. On Go. fidur-, OE fiper-, see below $(\$ 10.10)$.

1. The literature on Gmc. numerals is treated extensively in Ross \& Berns 1992. Schuppener 1996 deals mainly with numerical structures rather than the specifics of the development of individual numerals.

2. So Ross \& Berns 1992: 560-1. The $i$-stem variant is also reflected in the OE word element $\bar{x} n-(\bar{x} n l i c$ 'peerless', ānlīepe 'solitary', beside ānlic, ānliepe). Since the numerals ' 5 ' and above, as well as ' 3 ', declined as $i$-stems, it should not be surprising that ' 1 ' acquired an $i$-stem alternant. Cf. Ringe \& Taylor 2014: 18-20, positing a phonological change of *ainan $\bar{o}^{n}$ (cf. Go. áinana) to NWGmc. ${ }^{*}$ aininin $\bar{o}^{n}$.

3. Rarely can $\mathrm{OE}$ weak ānan not be explained as a late form of ānum.

4. Cf. the nom. dual neut. fem. pronoun *toi (\$8.9).

5. The PIE alternation of syllabic and nonsyllabic glides after an initial consonant in sandhi is confined to monosyllables and is commonly referred to as Lindeman's law: see Lindeman 1965.

6. For extensive references to the literature on Gmc. '2', see Strunk 1992: 194-200,

7. The unattested Go. fem. gen. probably would have been *twaddjō. Cowgill (1985) argues that Go. neut. twa reflects an uninflected dual corresponding to Gk. $\delta$ v́o (also reflected in OIcel. tvau, with analogical addition of the neut. pl. inflection $-u$ of $a$-stems), and this is possible, though the near-perfect conformity of the paradigm to that of Go. $a / \bar{o}$-stem adjectives is striking.

8. See Ross \& Berns 1992: 568-9 for discussion and references, though their solution, deriving twe gen from *twai inae, requires some unlikely phonological developments. For another view, see Bammesberger 2010.

9. Girvan (1931: 41-2) asserts that the texts with $t w \bar{x} g e n$ are all Kentish, and in Kentish $\bar{x}$ and $\bar{e}$ have fallen together, resulting in hypercorrection. It must be said that the texts are not all Kentish, but nearly all the examples outside of Kentish charters occur in just two texts, Ælfric's Lives of Saints and the Mercian portion of the gloss on the Rushworth Gospels. Girvan is thus surely right that $\bar{x}$ cannot be original, pace Ross \& Berns 1992: 568 .

10. It is true that $\bar{e}$ is commonly rounded to $\bar{x}$ after $w$ in Northumbrian, but this will not account for Mercian twoega.

11. So, e.g., Holthausen 1921: $\$ 380$ Anm. 2. Cf. Prokosch (1939: §99a; so earlier Meringer 1887: 235), assuming the OS and OHG forms were originally like the OE one: "OS [for which he must mean OHG] $\bar{e}$ was monophthongized from $a i$ at a time, when the word was still felt as a compound, and $a i$ therefore was in final position; cf. wēnec (by the side of weinec), from *wai- 'woe'.” Krahe \& Meid (1969: §61) instead reconstruct for OS tweene and OHG zwène an archaic adjectival distributive numeral PIE *duoi-noi comparable to Lat. binn 'twofold', ternī 'three at a time'; so earlier Hirt 1931-4: II, §93; see further Seebold 1968: 417. As for Seebold's own argument, despite the impressive orthographic evidence he presents to show that OE twe gen originally had a short root vowel, such an interpretation is forbidden by the counterevidence of poetic meter, which he fails to explain convincingly. His argument also demands some questionable assumptions, e.g. the change of WGmc. ${ }^{*}$-aj- to ${ }^{*}-e j$ - at an early date.

12. To the suffix $-\bar{o} p$ - Torp \& Falk (1909: 255) compare Lat. $-\bar{a} t$ - in nostrātes 'ours, of our country'. Krause (1971: 33-4) argues that the perplexing Runic baijor (Kårstad cliff inscription, ca. 450; $\mathbf{o}$ is uncertain) is a form of 'both'.

13. To OS bēđia there also occurs a gen. sg. neut. bēđies.

14. Ross \& Berns (1992: 573) reconstruct a stem with the pronoun *piu attached, but whereas this is plainly attached to the stem in OS and OHG, there is no plausible source for it in ON.

15. On OHG nom./acc. fem. drīo in particular, see Eichner 1987: 196-200.

16. Szemerényi (1996: §8.5.2) suggests PIE fem. ${ }^{*} k^{w}$ etesres, neut. ${ }^{*} k^{w}$ etuōor, masc. acc. ${ }^{*} k^{w}$ eturns, gen. $* k^{w}$ eturom, loc. ${ }^{*} k^{w}$ etursu.

17. So the handbooks of ON, as well as Stiles 1985-6: 6.97-104 (with references) and (probably) Voyles 1987: 489; Hirt (1931-4: II, §91) and Pokorny (1959-69: I, 643) instead derive the form from * $k^{w}$ etwōr, assimilated to * $k^{w} e k w o \bar{r}$ in Pre-PGmc.

18. Mottausch (2015: 286) instead reconstructs WGmc. *feuwar-, without 3 , explaining the loss of PIE $t$ as analogical to the ordinal Pre-PGmc. *péturto-, by dissimilation (cf. Skt. caturthá-). 


\subsection{The numerals $5-10$}

Numerals above ' 4 ' were indeclinable adjectives in PIE, but this changed in Gmc. In general, these numerals are undeclined when they stand before a subtantive that they qualify; otherwise (i.e., when modifying a preceding noun or when substantive) they may be inflected as $i$-stem nouns, ultimately by analogy to ' 3 ', though exceptions occur. Contradicting the rule are $\mathrm{ON}$, in which they are categorically indeclinable, and $\mathrm{OE}$, where the inflected forms are like those of ' 4 ', except that the nom./acc. of ' 5 ' may end in $-e$, or (chiefly Northumbrian) $-o$. In Gothic they take inflections only in the gen. and dat., not in the nom. or acc.

5. PIE *pénk ${ }^{w} e$ (Skt. páñca, Gk. $\pi \varepsilon ́ v \tau \varepsilon$, Lat. quinque) develops to Go. fimf, OE OS fif (\$4.11), OHG fimf, finf. On the change of $k^{w}$ to Gmc. $f$, see $\$ 6.5$ ad fin. OIcel. fimm (for expected *fif: $\$ 4.9$ ) is usually explained as analogical to related forms (e.g. fimtán ' 15 ', fimti 'fifth'), though it has also been claimed to be a phonological development: see $\$ 6.14$ n. 5 .

6. PIE *séks (Skt. șás, Gk. "̧̌̋, Lat. sex) regularly yields Go. saíhs, OIcel. sex, OE siex (from seox by palatal umlaut, §4.13), OS OHG sehs. Boutkan (1995b: 376) reconstructs PGmc. *sexse, by analogy to PIE * pénk $k^{w} e$, in order to explain why the word does not yield PNorse $\uparrow \operatorname{sex}_{R}$, but his assumption is that PGmc. final $*_{-S}$ was always voiced.

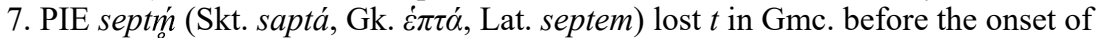
Grimm's law, giving (by Verner's law) *sebun > Go. sibun, OE seofon, and, with raising of $i$ before $u$ in OS and OHG (if not earlier, §4.4), OS sibun, OHG sibun. OIcel. sjau represents - $a u$ (borrowed from * attau ' 8 ') attached to the stem *se-. The reason for the loss of $t$ in PGmc. *sibun is probably the analogical influence of the ordinal *sep $(t) m$ tos 'seventh', in which haplology $(\$ 12.33$ n. 6) may be assumed to have induced its loss, though Sievers (1877-8: 5.119; likewise Ross \& Berns 1992: 586) argues for phonological loss of $t$ between $p$ and $m$; cf. van Helten 1905-6: 84, and, for an alternative explanation, Voyles 1987: 492-3. The retention of the final nasal consonant (with PGmc. change of final $m$ to $n, \S 6.11$ ) is also attributable to the influence of the ordinal, although other explanations are possible. ${ }^{1}$

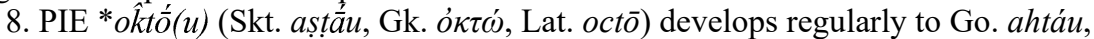
OIcel. átta (\$4.9), OE eahta (\$4.12), OS OHG ahto. The PIE word is formally a dual (referring to the fingers on two hands, thumbs aside): see Szemerényi 1996: §8.5.2 n. 14 for refs.

9. PIE *néun (Skt. náva, Gk. Évvéa (on which see Sihler 1995: 415-16), Lat. novem (with $-m$ for $-n$ by analogy to decem, but cf. Szemerényi 1960: 171-3)) corresponds to Go. niun (disyllabic, with PGmc. loss of $w$ before $u, \S 6.11$ ), OIcel. níu, OE nigon, OS nigun, OHG niun. These show several peculiarities. OIcel. níu should have become monosyllabic †njú (cf. sjá 'see' < se-a); the reason for the retention of disyllabicity is not known for certain, but perhaps $n i$ - was retained by analogy to forms like ní-tján '19', ni-tugr 'ninety years old'. ${ }^{2}$ PGmc. * niwun- should have lost $w(\$ 6.11)$, with raising of $e$ before $u$ and subsequent vowel contraction in WGmc. ${ }^{3}$ OHG niun thus appears to be etymological, whereas an inorganic 3 replaced the lost $w$ in NSGmc., probably to maintain parallelism with disyllabic NSGmc. *texan 'ten'; cf. OHG niwan '9' $(1 \times)$, likewise in agreement with OHG zehan (Braune 2004a: §271 Anm. 2). At all events, it is inadvisable to reconstruct Proto-WGmc. *newun (Euler 2013: 126).

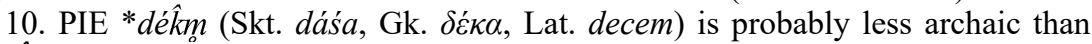

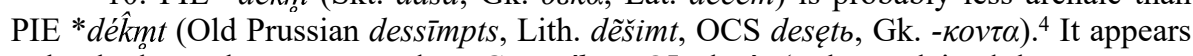
to be the latter that corresponds to Go. taihun, OIcel. tíu (to be explained the same way 
as níu above), OE tīen, OS tehan, OHG zehan, since it accounts for the retention of the final nasal consonant (§5.2). The WGmc. forms correspond not to PIE *dékmt but $* d e ́ \hat{k} o m t$, which is unparalleled as such in IE; but cf. PIE * $k m t o ́ m$ 'hundred' $<* d \hat{k} m t$ $d \hat{k} o m(t)$ and Gk. $\tau \rho \imath \dot{\alpha}-\kappa o v \tau \alpha$ ' 30 ', $\tau \varepsilon \tau \tau \alpha \rho \dot{\alpha}-\kappa o v \tau \alpha$ '40', and so forth. ${ }^{5}$ OE tīen must show umlaut originating in the inflected forms (with $i$-stem inflections, as elsewhere in Gmc.; so Brunner 1965: $\$ 129$ Anm. 6); the Mercian equivalent is thus correctly tèn. The uninflected form without umlaut is reflected in hund-tēon-tig ' 100 ' $(\S 10.5)$.

1. Final $-u n$ could, e.g., be analogical to the ending on '10', which is phonological. Hirt (1931-4: II, §91) actually reconstructs a pre-Gmc. * septnt; the approach of Ringe 2017: 105 is similar. If these numerals were inflected in PGmc., as they are in Go. and WGmc. under the conditions mentioned above, that would also explain preservation of the final nasal consonant, with analogical extension to uninflected forms; but the cogent account of the PGmc. numerals and their inflection offered by Stiles (1985-6) renders it much likelier that inflection of the numerals above ' 4 ' is a post-PGmc. development.

2. Noreen $(1970: \S 133 \mathrm{~b}, 2)$ ascribes the noncontraction to a retained degree of stress on the final vowel, Prokosch (1939: §99a) to rhythmical patterns in counting. It is unnecessary to invoke analogy, as Prokosch does, to explain the long vowel, as a stressed antevocalic long vowel would be lengthened (Prokosch's law, $\S 2.5)$. The development in nitján is *ni-u- $>*^{*} n \bar{\imath}-u$ - (Prokosch's law) $>n i$-. The same questions pertain to tíu 'ten'.

3. On *niwun- rather than *newun-, see $\S 4.4 \&$ n. 2.

4. The problem of which is older is complex and much contested: see Szemerényi 1960: 67-114 for an overview, arguing that the form with $-t$ is older.

5. Szemerényi (1960: 101) supports the view of Brugmann (in Brugmann \& Delbrück 1897-1916: II, 2.212) and others that -an in WGmc. *texan is analogical to -an-in the decads (cf. Gk. - $\kappa o v \tau \alpha$ ), whereas Voyles (1987: 489) regards it as borrowed from ' 11 '.

\subsection{The numerals 11-19}

In terms of inflection these are treated the same way as the numerals 5-10, except that no inflected forms of 13-19 appear in OS, probably due simply to lack of attestation (Stiles 1985-6: 7.3). The majority of these are unattested in Go., where numerals are commonly expressed by alphabetic characters, as in Greek $(\S 1.11)$. The relevant attested forms are these:

\begin{tabular}{|c|c|c|c|c|}
\hline Go. & OIcel. & OE & OS & OHG \\
\hline *áinlif & ellifu & enlefan & el(l)evan, -en & einlif \\
\hline twalif & tólf & twelf & twe-, twi-, twu-lif & zwelif \\
\hline 13 & prettán & prēotīene & thriu-, thrū-tein & drīzehan \\
\hline fidwōrtaíhun & fjórtán & fēowertīene & fiertein & fiorzehan \\
\hline fimftaíhun & fimtán & fiftīene & fĭftein & finfzehan \\
\hline 16 & sextán & sixtīene & se(h)stein & sehszeha \\
\hline 17 & sjaut(j)án & seofontīene & sivontein & \\
\hline 18 & át(t)ján & eahtatīene & ahto-, ahte-tein & ahtozeha \\
\hline 19 & nítján & nigontīene & nigentein & niunzeh \\
\hline
\end{tabular}

' 11 ' and ' 12 ' stand apart, being formed of ' 1 ' and ' 2 ' with a suffix $*$-lib- $<*$-lif- (by Verner's law) < PIE *likw - (cf. Gk. $\lambda \varepsilon i \pi \omega$, Lat. linquō 'leave'), i.e. 'one, two left' (after counting on ten fingers). They are thus parallel to Lith. venúo-lika, dvý-lika, with -lika as the reduced grade of liêkas 'left over'. ${ }^{1}$ Go. *áinlif is attested only as dat. áinlibim, probably reflecting *aini- rather than *aina- (cf. OE ænne $<*$ aini-, §10.1 supra), as -ais more often retained $(72 \times)$ than lost $(21 \times)$ as a composition vowel in Gothic (Krause 1968: §68), whereas the loss of $-i-$, though irregular, is more frequent. OE enlefan also 
requires *aini-, but either *aini- or *aina- will explain the remaining forms, as those with $i$-umlaut may have it because of $i$ in the second constituent. In ON there is the development $*$ aina-li $\bar{b}->* \bar{a} n$-li $\bar{b}->* \bar{a} l l i \hbar->* \bar{e} l l i \hbar->*$ elli $\bar{b}-$, with final $-u$ extended from ' 10 '. Although the stress is initial in Modern Icelandic, the change $a i>\bar{a}$ presupposes (subordinate?) stress on the second constituent (Noreen 1970: §51.1a), as in English and, in part, Dutch, though voiced $b$ in Go. áinlibim suggests initial stress only. The OE and OS forms likewise show endings borrowed from ' 10 '. ${ }^{2}$ Beside OE enlefan occur enleofan, with back mutation (\$4.8), and endlefan, with epenthetic $d$ as a result of denasalization of $n$ at the point of juncture before $l$. OIcel. tólf is lengthened from tolf $(\S 4.9)<* t w o l f$, with loss of $w$ before $o(\S 6.14)$, resulting from postconsonantal rounding of $a$ after $w$ (cf., e.g., sorta 'black dye' $<{ }^{*}$ swarto $\hat{o}^{n}$, and cf. Go. swarts 'black'). OE twelf<*twalib- is always syncopated, like, e.g., hwelc 'which' (\$8.13).

The numerals ' 13 ' to '19' are self-evidently compounds of ' 3 ' to '9' plus '10', as Go. plainly shows. This transparency is maintained in OE (where a plural suffix $-e$ is added, with umlaut from a lost $i$-stem inflection; cf. Ross \& Berns 1992: 591-2) and $\mathrm{OHG}$, whereas OS tein is a rare spelling of OS 'ten', showing loss of $h$ and weakening of $a$ to $i$ (Holthausen 1921: $\S \S 125,380$ Anm.), probably by analogy to the suffix, bearing less stress. The OIcel. forms present a number of difficulties. Various explanations have been offered for the alternation between -tán and -tján, none of them palmary. ${ }^{3}$ The latter, at least, can certainly be derived from *texan- (note the retention of final $-n)$, the form known from West Germanic. OIcel. prettán reflects *prinn-tán (\$6.14) <*prinz- (cf. Go. prins, §10.1). On fjog(u)rtán beside fjórtán, see Noreen 1970: $\S 160$ Anm. The interchange of -tán and -tján in sjaut(j)án is due to dissimilation (ibid., §295 Anm. 1); the reverse dissimilation (sautján) occurs rarely.

1. But see Bednarczuk 1999: 44 on problems with the comparison. Ringe (2017: 229-30) proposes instead to connect the second constituent with PIE *leip-, as in OE be-liffan 'remain, be left'.

2. Voyles (1987: 489-90), rather implausibly, explains the different endings in Go., ON, and WGmc. as reflecting, respectively, zero suffixation, weak participial ${ }_{-}^{*} n t$, and $o$-grade ${ }^{*}$-ont. He assumes that Go. *áinlif is actually attested, and he attributes the non-application of Verner's law to secondary stress on the second constituent. Rather, see $\$ 6.12$ on Go. final fortition.

3. The usual view is that there was a variant of PIE ' 10 ' with lengthened grade, and that this will account for both ON -tán and Go. -tēhund in the numerals ' 70 ' to ' 100 '. But there is no other evidence for such a variant, and the Go. decads are probably to be analyzed differently (see below, §10.5). Moreover, if this explanation were correct it would be peculiar that the distribution of -tán vis-à-vis -tján in the teens is the reverse of the distribution of Go. -tēhund vis-à-vis tigjus in the decads. Szemerényi (1960: 102-3 n. 155) discusses some further proposals and their weaknesses; see also Ross \& Berns 1992: 592-3.

\subsection{The lower decads, $20-60$}

In PIE, numerals above '19' were indeclinable nouns taking complements in the genitive. The Gmc. decads show a difference in the formation of the lower and the upper series. The difference was identified by J. Schmidt (1891) as a remnant of a PIE sexagesimal system of counting, Babylonian in origin, an idea even now sometimes encountered, though the prevailing view currently is that this is a peculiarity of Germanic: see, e.g., Szemerényi 1960: 2-3, Mańczak 1985a, and see further Justus 1996, Schuppener 1998, von Mengden 2005. The relevant forms of the lower decads are these: 
Go.

20

30

40

50

60
OIcel.

tuttugu

prír tigir

fjórir tigir

fimm tigir

sex tigir
OE

twēntig
prītig
fēowertig
füftig
siextig

OS

twēntig

thrītig

fiuwartig

fĭftig

sechstic

\section{OHG}

zweinzug

drīz(z)ug

fiorzug

finfzug

seh(s)zug

Go. ' 20 ' to ' 60 ' are formed by the relevant integer plus tigjus, a plural $u$-stem inflected in four cases, with the integer also inflected to the extent allowed in $\S \S 10.1-2$, e.g. acc. prins tiguns (on the basis of which nom. *preis tigjus is assumed), dat. twáim tigum. This tigjus reflects PIE * dekmt, which, when it acquired inflections in PGmc., would have formed the dat. as athematic *tezundmiz, with suffixal accent, and this would result in Go. tigum. This last form is indistinguishable from a $u$-stem dat., and on that basis the word developed $u$-stem inflections in Gothic. ${ }^{1}$ The Go. forms of these five decads are thus semantically and morphologically transparent. They do not, however, resemble the forms to be reconstructed for PIE, on which see $\$ 10.5$, where the problem is discussed.

ON tigir, an $i$-stem, corresponds to Go. tigjus. OIcel. tuttugu (early tottogo) is in origin an acc. of this same tigir, hence *twanz tizunz $>*$ twonz-tizunz $>*$ tonn-tizunn $>$ *tottizun (cf. the development of tólf, above), with replacement of $i$ by $o / u$, probably due to the surrounding vowels, leading to tottogo. ${ }^{2}$ There occurs an alternative form tvítján, like áttján, nítján but apparently multiplicative rather than additive. Later there arise indeclinables prjátigi, fjórutigi, etc.

In WGmc. the equivalent of Go. tigjus is reduced to a suffix that is indeclinable in OS and OHG (where these decads are substantives taking a complement in the gen.), whereas indeclinables are a late development in OE. Unlike the adj. suffix -ig (\$9.3), OE -tig never suffers syncope but is always a syllable even in early verse. OE OS tweentig perhaps reflects *twanz tigunz with analogical replacement of the first vowel by the vowel of '2'; remarkably, OHG has only zweinzug, never †zwēnzug. Seebold's derivation of the WGmc. forms from *twajintig- (1968: 430-2), though brilliant, is closely tied to his explanation of ' 2 ' (see above) and faces some of the same difficulties. The reason for the substitution of $u$ for $i$ in OHG -zug is unknown, but comparison is commonly drawn to OIcel. tuttugu. ${ }^{3}$

These decads are constructed the same way in Baltic: cf. Lith. dvi-dešimt '20', tris-dešimt ' 30 ', etc. On the decads in other IE languages, see below.

1. Because a single case-form may seem insufficient basis for the construction of a $u$-stem paradigm, some have supposed that the acc. pl. would also have resembled a $u$-stem form (so, e.g., Prokosch 1939: §99a), but Szemerényi (1960: 41) is right that the correct form would be *tezunduns, which will not serve. He adduces parallels to the construction of an entire paradigm on the basis of a single form. Euler (2013: $127 \mathrm{n}$. 258, with further references) misinterprets Szemerényi's argument and identifies the acc. as the case of origin for the $u$ stem forms, which Szemerényi declares to be impossible. Voyles (1987: 490) regards it as ambiguous whether the second constituent of these lower decads was originally an $i$-stem or a $u$-stem.

2. The alternative construction of a dual *twō-tugū (so Krahe \& Meid 1969: II, §64) leaves the medial geminate unexplained.

3. Streitberg (1896: $§ 167)$ derives $u$ here from PIE $ə$, i.e. $H$, and Krahe \& Meid (1969: II, §64) seem to have something similar in mind when they call -zug a "Schwundstufenbildung." But there cannot ever have been a laryngeal consonant in PIE '10'; see also $\$ 5.5$ ad fin. on $u$ as the reflex of a laryngeal. On OHG $-z u g$ see further Lühr 1977: 67. 


\subsection{The upper decads, $70-120$}

The relevant attested forms are these:

\begin{tabular}{|c|c|c|c|c|c|}
\hline & Go. & OIcel. & OE & OS & OHG \\
\hline 70 & sibuntēhund & sjau tigir & hundseofontig & antsibunta & sibunzo \\
\hline 80 & ahtáutēhund & átta tigir & hundeahtatig & antahtoda & ahtozo \\
\hline 90 & niuntēhund & níu tigir & hundnigontig & nichonte & \\
\hline 100 & taíhuntēhund & tíu tigir & hundtēontig & hund & zehanzo \\
\hline 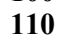 & & ellifu tigir & hundændlæftig & & \\
\hline 2 & & hundrað & hundtwelftig & & \\
\hline
\end{tabular}

ON hundrað refers to the 'great hundred', i.e. ' 120 ', a meaning in use in Scandinavia and Britain throughout the Middle Ages (see, e.g., Goodare 1993); -rað is related to Go. rapjan 'count', Lat. ratio 'computation'. Although ' 120 ' is not attested in Gothic, that a duodecimal 'hundred' was in use must not be doubted. ${ }^{1}$

Except in ON, where tigir has been extended from the lower decads, the difference between the formation of the upper and lower decads is striking, as well as the differences among the languages represented. The origin and development of this series are still intensely debated. It was once the prevailing view (not yet entirely abandoned) that the Go. words should be divided sibun-têhund, ahtáu-têhund, etc., and the second constituent derived from a lengthened-grade variant of PIE dékmt ' 10 '. ${ }^{2}$ The chief alternative view, proposed independently by Wheeler (1885: 38) and Brugmann (Brugmann \& Osthoff 1878-1910: V, 11-12) and laid out in detail by Brugmann (Brugmann \& Delbrück 1897-1916: II, 2.35-40), is that the division should be sibunte--hund, and so forth. ${ }^{3}$ Surely the latter analysis is correct: there is no evidence outside of Gmc. for PIE *de $\hat{k} m \underline{n} t$; although OE hund- (reduced in OS to and-) is prefixed rather than suffixed, its very mobility within Gmc. identifies the relevant morpheme; it has close parallels in

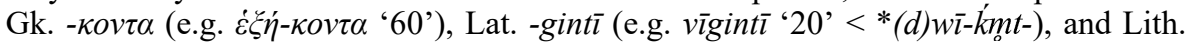
-dešimt (e.g. trìs-dešimt '30'); and Go. taihuntē-weis (on which see n. 1) shows that -tēbelongs to the first constituent of the Go. decads. There is no scholarly consensus how, precisely, $-t \bar{e}-$ arose in the Go. forms, but suggestive parallels in other IE languages are in evidence. Just as the method of forming the decads in Go. changes strikingly starting with ' 70 ', so, too, in Greek and Latin the formation changes starting at '70': in Greek and Latin, the decads to ' 60 ' add Gk. - $\kappa o v \tau \alpha$, Lat. -ginta to the corresponding cardinal digit, with a long connecting vowel, e.g. $\pi \varepsilon v \tau \eta$ ' $\kappa o v \tau \alpha$, quinnquāgintā ' 50 '; starting with ' 70 ', however, the digit changes in nature, resembling an ordinal rather than a cardinal,

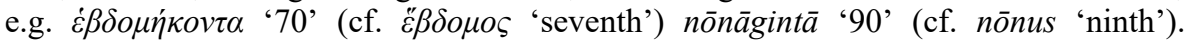
Sommer (1951) showed that the morphological change is an illusion, since initial constituents like $\dot{\varepsilon} \beta \delta o \mu$ - are not ordinals but phonological variants of cardinals (cf. $\dot{\varepsilon} \pi \tau \dot{\alpha}$ '7'), and Szemerényi (1960) showed that the apparently morphological change has a phonological starting point: the suffix *-kont-/-knnt- is derived from *dékmt/dkomt ' 10 '. The initial $d$ of *-dkomt- (or $t$, devoiced by $\hat{k}$ ) was lost, with compensatory lengthening of any immediately preceding syllabic segment. The implications of this for Germanic are conveniently summarized in Szemerényi 1996: §8.5.3:

The IE system survives in 70-90, e.g. Goth. sibuntēhund, ahtautēhund, niuntēhund. These continue the old *septinkomt, oktōkomt, newñkomt, from which first arose *seftunhand, *ahtōhand, *newunhand, preceded in the series by *fimfēhand and *sehskand; this original ending -hand was later adapted to conform with 20 and 100, thus becoming -hund in 30-90 also. Among these tens 60 stood out from the rest and 
was modified to *sehsēhund by analogy with 50. The influence of 50 and 60 led to *seftunēhund, but since in 50,60, and 80 the principle of formation was unmistakably unit $+-(\bar{e})$ hund, and 7 already had the form *sefun, *seftunēhund became *sefuntēhund, *sebuntēhund. The metathesis thus led to a formation which synchronically could only be taken as 'seven' + -téhund, and so led to the series ahtautēhund-niun-tēhund-taihan-tēhund. ${ }^{4}$

The pattern of changes thus proposed is not simple, but it accounts for the rise of Go. $-t \bar{e}$ - on a principled basis rather than as a morpheme of arbitrary derivation (cf., e.g., G. Schmidt 1970: 119, Lühr 1977: 64), and it has the particular virtue of explaining why the Go. decads are different starting at '70': $-t \bar{e}$ - originated in '70' and thus, in counting, was extended only to decads that followed in the course of counting (and see further below).

Although -hund is a suffix in Gothic, it is a prefix in OE and, in the reduced form ant-, in OS, whereas it is missing in OHG. ${ }^{5}$ The reason for its loss in OHG is that it was superfluous, the meaning of each upper decad being unambiguous even without hund attached. Explaining the WGmc. upper decads is difficult in part because OE lends no etymological assistance, the suffix -tig of the lower decads having been extended to the upper (see Pijnenburg 1992), with a similar situation in ON. Several hypotheses have been proposed: ${ }^{6}$ (1) Go. taíhunte- - is a gen. pl. 'of decads', so that taihuntēhund means 'a decad of decads', and after it were formed sibuntēhund, etc. (Brugmann in Brugmann \& Osthoff 1878-1910: V, 16; similarly Voyles 1987: 493-5). Thus, OHG sibunzo (etc.) is also a gen. plural. This hypothesis is objectionable on semantic grounds, in part because -hund cannot mean 'decad' (see Szemerényi 1960: 29-31), and at all events the OS forms cannot be genitives. ${ }^{7}$ (2) Go. sibuntē- is an ordinal, and hence sibuntēhund means 'seventh decad' (Holtzmann 1856: 217-18, revived by Rosenfeld 1955c: 385-6). There is again the semantic problem; see further the criticisms of Brugmann (Brugmann \& Osthoff 1878-1910: V, 13) and Szemerényi (1960: 31-2, 148-65). (3) WGmc. generalized not the $\bar{e}$ of PGmc. *fimféhund, as in Go., but the $\bar{o}$ of *ahtohund, and it is this that is reflected as OS $-a$, OHG -o (Szemerényi 1960: 33-8). This last is the only very plausible analysis. The OS and OHG endings could be explained instead as borrowed from weak masc. nouns, but such an analysis would leave unexplained the motive for the borrowing, and why these words are invariant rather than inflected like weak nouns. The OS and OHG forms did not remain stable: already in poetry OS sibuntig appears beside antsibunta, and the forms given above for $\mathrm{OHG}$ are those found in the earliest texts, with replacement of $-z o$ by $-z u g$ completed before the end of the $13^{\text {th }}$ century.

As for why the lower decads of Gmc. do not resemble those reconstructed for PIE, once again the explanation of Szemerényi (1960: 39-44) is particularly cogent. After the upper decads were refashioned in the manner described, they appeared to be transparent formations, made up of digit $+*-t \bar{e}-+*$-hund-. The lower decads, however, had grown morphologically opaque: the PIE forms may have been *uikkntī ' 20 ', *trîkont- '30', * $k^{w}$ etwrk̂nt- '40', *penk ${ }^{w} \bar{e} \hat{k} o n t-~ ' 50 ',{ }^{*} s(w) e k s \hat{k}$ ont- '60', which would correspond to PGmc. *wixxand-, *prixxand-, *feðurxand-, *fimfēxand-, *sexskand-, the last replaced by *sexsexund-, as above. The pressure to align the lower with the upper decads, especially starting with ' 20 ', would thus have been considerable. The Go. morpheme $-t \bar{e}$ - that arose in ' 70 ' could not be extended to the lower decads because *sexstēhund-, *fimftēhund- would have appeared to represent the ordinals *sexst-, * fimft-, making them confusing constructions, ${ }^{8}$ whereas there was no possibility of such confusion in the upper decads (to Go. ahtáutēhund cf. ahtuda 'eighth'). Moreover, there 
came into being the requirement that numerals above ' 4 ' be inflected, rendering it natural enough that there should arise a transparent combination of an inflected digit and an inflected form of ' 10 '.

1. This is evident from the use of taihundtēhund rather than hund for ' 100 ' and from the rendering fimf hundam taihuntēweis brōprē 'five hundred (decimally) brothers' for Gk. $\pi \varepsilon v \tau \alpha \kappa o \sigma i o ı \varsigma ~ \alpha \dot{\delta} \delta \lambda \varphi o \hat{\iota} \varsigma$, where taihuntēweis, literally 'ten-ty-wise', is the explanatory addition of a glossator. Note that beside taihuntēhund there occurs taihuntaihund, probably by attraction to the vowel of the initial syllable.

2. This view was defended most substantially by J. Schmidt 1891 . For concise discussion and bibliography, see Jellinek 1926: 139-40.

3. For discussion and extensive bibliography, see Szemerényi 1960: 27-44, and for subsequent studies, see Szemerényi 1996: §8.5.3 n. 4, with brief summaries. See now also von Mengden 2010.

4. This last remark is dubitable, for the reasons given above. It is unnecessary to assume a unitary morpheme tēhund to explain why $-t \bar{e}-$ was extended past ' 70 '. For support for Szemerényi's analysis, see H.F. Nielsen 1990. Instead of metathesis in *seftunēhund, Ringe (2017: 230-1) assumes that ' 7 ' bore a final *-t in PGmc. (see $§ 10.2 \mathrm{n} .1$ above), and when this consonant was lost in ' 7', *sebunt-ēhund- was reanalyzed as *sebun-tēhund- and *-tēhund- extended upward in the decads. This is an appealing idea.

5. Szemerényi (1960: 38) argues that -hund was moved because, e.g., WGmc. ${ }^{*}$ sibuntē-hund- (= Go. sibuntēhund) was in danger of being interpreted as ' 70 hundreds'.

6. On some further proposals, see Szemerénti 1960: 32-3 and Ross \& Berns 1992: 609-11.

7. The reponse of Voyles (1987: 494) to this latter objection of Szemerényi's ("word-final and unstressed OS $/ \mathrm{o} /$ could, particularly if the immediately preceding syllable was unstressed as in a form like *sibunto, often be realized as [a]") does not persuade, since - $a$ in the OS decads plainly is not an occasional form.

8. It is not plain to the present writer why Szemerényi regards the constructions 'sixth, fifth decad' as "impossible (!)" (1960: 39), but it is certainly the case that if the upper decads exerted pressure to make the first constituents in the lower decads transparent digits, constructing what would look like ordinals would run counter to that purpose. At all events, as remarked above, since -te-e- originated in ' 70 ', it would be natural enough on the basis of counting for it to be extended to following but not preceding decads.

\subsection{The higher cardinals}

Gmc. inherited from PIE a word for ' 100 ', * $k$ món $m$, doubtless from earlier *tkkm-tkóm $<$ $* d \hat{k} m-d \hat{k}$ óm, i.e. 'ten tens'. As discussed in $\S 10.5$, this was replaced by a compound belonging to the upper series of decads within a sexagesimal system of counting, but PGmc. *xunda $a^{n}$ remained as an $a$-stem neuter noun in two uses:

(1) It is used in the pl. to form multiplicatives of ' 100 ', e.g. Go. twa hunda, OE twā hund (but also twā hundred), OS twe hund (also hunderod in the Freckenhorst tax roll), OHG zwei hunt '200'. Compare, however, OIcel. tvau hundrað '240'.

(2) Outside of OHG it may be used per se in WGmc. to mean ' 100 '.

PIE probably had no word for ' 1000 ', though the Indo-Iranian and Hellenic

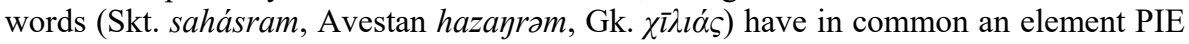
* ghéslo-. The PGmc. word is reconstructed as *pūsund-, a compound of *puss- < PIE *tū-s- (cf. Skt. tavás- 'strong', Lat. tōtus 'all', OE ge-pūf 'thriving') and *xund- '100', hence with the meaning 'strong hundred'. The construction is closely paralleled in Balto-Slavic: cf. Lith. túkštantis, OCS tysąšta, on which see Pijnenburg 1989. As '100' was originally uninflected, and PGmc. *-und- must have lost its connection to *xundearly, it is perhaps unsurprising that ' 1000 ' is inflected differently across the Gmc. languages: it is a $j \bar{o}$-stem in Gothic, an $i$-stem in ON, a neuter $a$-stem in OE, an indeclinable in OS, and either an $\bar{o}$-stem or a neut. $a$-stem in OHG. 


\section{Ordinals and varia}

\section{7 'First', 'second', and 'third'}

Except for the first three, the ordinals are all much alike, and all but 'second' and some forms of 'first' are declined weak.

'First' had no single means of expression in PIE, and so it takes a variety of forms in Gmc. The most archaic is a derivative of the PIE prepositional-adverbial stem *per- (cf. Skt. pári, Gk. $\pi \varepsilon \rho i$ ' around', Lat. per 'through') in weak grade with the suffix

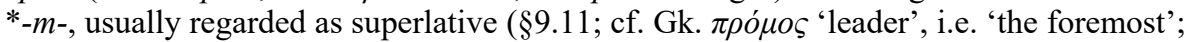
also OPruss. pirmas, Lith. pirmas 'first' $<*$ *r-m-): hence Go. fruma, OE forma, OS formo. In Gmc., at least, the original meaning of this formation was 'first' only in the sense 'the former of two', as in Gothic. To this a superlative meaning 'first' was formed by the addition of the suffix *-ist-, hence Go. frumists, OE fyrmest. The same root, without the suffix *-m-, could be used with the superlative suffix *-isto-: hence, OIcel. fyrstr, OE fyrest, OS furist may be either strong or weak, whereas OHG furisto, like other superlatives in that language, is always weak. There is also an OE (Anglian) forpmest, formally a superlative to forp 'forth', on the formation of which see §9.11. A WGmc. form is the superlative to PGmc. *airi 'early', OE ǣrest, OS èrist, OHG èristo, the last declined only weak.

'Second' is Go. anpar, OIcel. annarr, OE ōðer, OS āđar, ōđar, andar, OHG ander, taking only strong inflections. It is identical to Skt. ántara-, OPruss. antars, Lith. añt(a)ras 'other', formed to the root *an- (cf. Skt. anyá- 'other') by the addition of a comparative suffix *-ter-, as in Lat. alter 'second' (formally a comp. to alius 'other'),

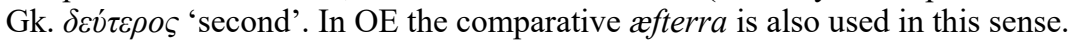

'Third' is the weak Go. pridja, OIcel. priði, OE pridda, OS thriddio, OHG dritt(i)o, reflecting PIE *tri-tio-, reflected also in Avestan Aritya-, Lat. tertius.

\section{8 'Fourth' to 'twelfth'}

These bear weak inflections and are formed by the addition of PIE *-t- to the equivalent

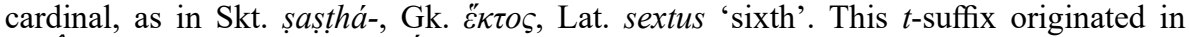
*dek̂nt-ós, reanalyzed as *dekm-tós, and in the decads containing this morpheme as a suffix, whence it could spread to the lower ordinals in some IE languages, and in 'fifth' and (probably) 'sixth' already in PIE: see Sihler 1995: 425-33. In Gmc. the suffix was extended to all ordinals above 'third', being added to the normal full-grade form of the cardinal. These ordinals are not well attested in Gothic, and in fact not all the Go. forms given below are attested in precisely this form. The relevant forms are these:

Go. OIcel. OE $\quad$ OS

4.

5. fimfta

6. saíhsta

7.

8. ahtuda

9. niunda

10. taíhunda

11. ellifti

12. fjórði

fēorða

fimti

sétti

sjaundi

átti

níundi

tíundi

enlefta

tólfti fĭfta

siexta

seofoða

eahtoða

nigoða

tēoða

ellifto, ellefta

twelfta feordo

fiorđo

fĭfto

sehsto

sivondo, sivotho

ahtođo

nigunda, niguđa

tehando, tegotho, -atho

einlifto fimfto

sehsto

sibunto

ahtodo

niunto

zehanto

zwelifto 
Go. ahtuda should perhaps be ahtūda (Szemerényi 1960: 89; cf. Stiles 1985-6: 8.12). The Go. forms (except perhaps for ahtuda: see $\$ 6.12$ on Thurneysen's law) show the effect of Verner's law except where PIE $t$ came into contact with a voiceless stop, whereas it is ambiguous whether OIcel. - $ð$ - reflects PGmc. $ð$ or $b$. In OE, wherever $d(<$ PGmc. ) might have been expected on the basis of comparison to Gothic, instead is found the reflex of PGmc. $p$. Originally (already in in PIE?) the suffix vowel bore the accent and all other syllables were in the reduced grade, e.g. ${ }^{*} k^{w} t u r-o$ - 'fourth' (cf. $* k^{w} e t w o r-$ ' 4 '), so that Verner's law should be expected to have produced $\partial$ from suffixal PIE $t$, as in Gothic. However, when the reduced-grade stems were replaced by the cardinals in their normal form, two possibilities may have arisen: (1) there may have existed doublets, alternately with original, suffixal accent and accent as normally placed on the cardinal, or (2) if these ordinals were accented the same way as the corresponding cardinals, in some instances the vowel preceding the dental suffix would have been accented (e.g. *septñ́to-, *ok̂tó(u)to-), in others not (*néunto-, *dékmto-). ${ }^{1}$ In either event, in PGmc. there would have resulted alternation between $p$ and $\delta$ under Verner's law, and there may be assumed later generalization of one or the other alternant in the individual languages. ${ }^{2}$ OS has forms like those of OE, but also alternative forms like those of Gothic. OHG feordo and ahtodo agree with the OE forms, but sibunto, niunto, zehanto seem to show extension of -t- from fimfto, sehsto, einlifto, zwelifto. OE nigoða, tēoða, OS niguđa, tegotho (the last with analogical -g-) show the NSGmc. loss of $n$ before an originally voiceless fricative (\$4.11).

1. Stiles (1985-6: 8.7-11, with references) would date the refashioning of 'fourth' and 'eighth' with accent on the syllable before *-to- prior to the application of Verner's law, but he is unable to explain why just these two should have differed in this respect.

2. Compare the explanation of Prokosch (1939: $§ 100)$, that "the rhythm of counting led to anomalous accent changes." See also Bammesberger 1986b for another explanation. Possibly OE has extended the suffix of eahtoða to the other forms with - $\delta$ - (so Euler 2013: 130), but this alone is not sufficient explanation if Go. ahtuda has $d$ by Verner's law rather than Thurneysen's.

\subsection{The higher ordinals}

The only higher ordinal attested in Go. is dat. fimftataihundin 'fifteenth'. That is to say, the word is formed like the cardinal fimftaihun, but with ordinals rather than cardinals as

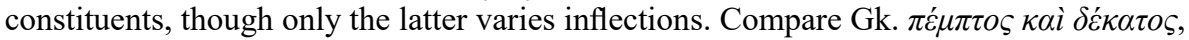
Lat. quintusdecimus 'fifteenth' (cf. $\pi \varepsilon v \tau \varepsilon \kappa \alpha i \delta \varepsilon \kappa \alpha$, quindecim ' 15'), in which both constituents are also ordinals. The earliest OHG texts follow this pattern in the teens, as well, with forms like finftazehanto 'fifteenth', sibuntozehanto 'seventeenth'; beginning with Notker there appear new formations like funfzēndo, agreeing with OIcel. fimtándi, OE fiftēoða, i.e. compounds comprising a cardinal and an attached ordinal suffix, as in the lower ordinals (and with loss of $n$ in OE, as in tēoða); no ordinals above 'eleventh' are attested in OS.

For the ordinal decads, OIcel. has tuttugandi 'twentieth', pritugandi 'thirtieth', and so forth, with - $u g$ - extended from ' 20 ' and 'twentieth', though no ordinal 'hundredth' or higher is recorded in ON. These forms coöccur with forms in 〈onde〉, i.e. -undi, apparently attesting to the occurrence of, beside normal reflexes of PIE *dékmt, NGmc. reflexes of the variant *déḱkmt found in WGmc. (§10.2; cf. Szemerényi 1960: $102-3$ n. 155). Here -andi is cognate with OE -oða, as in twēntigoða, prītigoða, etc., with variants -tegoða, -teogoða, -tiogoða, -tigpa. That is, the ending underwent the 
NSGmc. development $*_{-a n} p->{ }^{*}-\bar{a}^{n} p-.^{1}$ Synthetic ordinals for numbers higher than the decads are unrecorded in OE, for which circumlocutions are used (see Brunner 1965: $\$ 328$ ). That there actually is a semantic relation between ordinals and superlatives (cf. Sihler 1995: 427) is demonstrated by OHG zweinzugōsto, drīzugōsto, etc., with variants $-z_{0}{ }_{-},-z i g-,-z e g_{-},-z g_{-} ;$in $\mathrm{ON}$, too, -tugandi later appears as -tugti, and finally -tugasti. ${ }^{2}$ OHG 'hundredth' is zehanzugōsto; 'thousandth' is unrecorded.

1. The analyses of Cowgill (1970: 120) and Bammesberger (1986) are different. It may well be correct that $\mathrm{ON}-u n d i$ is analogical to tiundi, but this leaves -andi unexplained. Bammesberger assumes a word *tezunpwith the meaning 'decad'. It is also possible that *-tizo $p$ - throughout the decads arose by analogical extension to the following ordinals (in counting) of the desinence of NSGmc. *nizō $p$ - 'ninth'; such an explanation, at all events, seems necessary to account for OS tegotho beside OE tēoða.

2. On the relation of ordinals to superlatives cf. also the remark of Meier-Brügger (2003: 236): "In ProtoIndo-European, and naturally also later, ordinal numbers had the function of signaling the end of a series, e.g. "We traveled for nine days. But on the tenth...,."

\subsection{Varia}

Although distributive numerals are usually expressed by analytic forms in Gothic, the language preserves one synthetic distributive numeral, fem. acc. tweihnōs, dat. tweihnáim 'two each'. OE has the distributives ānlīepig 'one each' (cf. ON ein-hleypr 'single, unmarried', OS ènloppe 'single, alone', ON hlaupa 'leap') and getwinne 'two each'. OHG has the distributives einluzze, zwiske, driske, feoriske; cf. OS twisk 'double'.

Multiplicatives are formed by the addition of PGmc. *-falðaz to the cardinals, hence, e.g., Go. áinfalps, OIcel. einfaldr, OE ānfeald, OHG einfalt 'onefold, simple'; note also Go. fidurfalps 'fourfold' (not fidwōr-) $<*^{*} k^{w} e ́ t^{w}{ }_{e} r$-; cf. Skt. cátur), and cf. OE fiðer-rīce 'tetrarchy'. ${ }^{1}$ An older type of multiplicative is represented by OIcel. tvennr 'twofold', OE twinn 'double' (cf. be twēonum 'between') < *twiznaz (cf. MHG zwirn 'two-cored thread'), comparable to Lat. binni 'twofold' <*duisnoi . Cf. further OIcel. prennr, OE prinen 'threefold'.

A fraction derivable from PGmc. is Go. halba, OE healf, OS half, OHG halb ' $1 / 2$ '; with a fem. suffix, ON uses hálft (cf. OFris. helfte, halfte) or helming, masc. helmingr $<*$ halbning-. Older and used only in compounds is OE OS sām-, OHG sāmi'half' = Skt. sāmi-, Gk. $\dot{\eta} \mu l-$, Latin sēmi-. Smaller fractions are formed in ON with a masc. suffix, as in prið(j)ungr ' $1 / 3$ ', fjórðungr ' $1 / 4$ ', fimtungr ' $1 / \frac{1}{5}$ ', séttungr ' $1 / 6$ ', and so forth. OE has the fraction $t w \bar{x} d e, t w \bar{x} d \bar{x} l$ ' $2 / 3$ '; cf. OS $t w \bar{e} d i$ ' $1 / 2$ '.

Most adverbial numerals, answering the question 'how often?', are expressed analytically with a cardinal and a reflex of PGmc. *sī $p$ - 'time', but ON has tysvar, tvisvar 'twice' <*twis-wōz, also prysvar, prisvar 'thrice'; to these correspond $\mathrm{OE}$ twiwa, priwa, OS twīo, thwī(w)o, OHG zwiro(r). For 'thrice' and upward OHG attaches -stunt (an adverbial form of stunta 'time') to cardinals, e.g. driostunt 'thrice'. Note also OE ǣne 'once, one time', rarely gen. $\bar{x} n e s$, like OS ènes, OHG eines.

ON forms substantives referring to groups by attaching a fem. suffix $-d$ or $-t$ to a cardinal, thus fimt 'pentad', sétt 'sextet' $(<*$ sex(s)t-), sjaund 'septet' (with the nasal of PGmc. *sebun preserved), pritugt 'group of thirty', etc., but also tigr 'decad(e)' (sg. equivalent to Go. pl. tigjus, §10.4). Compare the ON abstract nouns eining 'unity', tvenning 'duality', prenning 'trinity'.

On 'both', see $\$ 10.1$. 
1. Stiles (1985-6: 7.15-16) explains that Gothic has eliminated the variation under Verner's law by extending the voiced $d$ of fidwōr to fidur-. Euler (2013: 126) takes the coöccurrence of LWS fyper-and Anglian feopur- to require the reconstruction of WGmc. *feupwari. However, the latter OE form shows back mutation, which fails in WS after non-labial consonants (\$4.8), and of course WGmc. eu would produce a long diphthong in OE. 


\section{Adverbs, Prepositions, Conjunctions}

\subsection{Monomorphemic adverbs}

Gmc. inherited from PIE a number of adverbs of time and place that are probably to be regarded as monomorphemic in PGmc. Adverbs of this sort in Go. include (for time) áir 'early', han 'when', pan 'then', ju 'already', nu 'now' and (for place, without motion) hèr 'here', har 'where', par 'there', faúr 'in front'. Yet certain morphological components are recognizable. These adverbs of place end in a loc. $-r$ (cf. Lith. kur 'where', Skt. tár-hi 'at that time, then', OE æfter, pider, nipor, hinder), and their initial consonantism is paralleled in related words: $h$ - in $h \bar{e} r$ reflects the $I / h e r e$ deictic particle PIE $* \hat{k}$ - seen in Lat. cis 'on this side', OIr. cé 'here, on this side', which participates in a decitic system in Gmc. (e.g. Go. hidrē 'hither', hindar 'behind', hiri 'come here!'); $h$ - in har is interrogative (cf. Go. has 'who', harjis 'which', hap 'whither'); and $p$-reflects the $i t /$ there deictic particle PIE * $t$ - used to form the PIE demonstrative *tod (Skt. tád, Gk. $\tau o$, Lat. is-tud, Go. pata), also participating in a deictic system (e.g. Go. padei 'whither, where', pannu 'therefore', pei '(so) that'). Go. han, pan can then be seen to contain a clitic particle PIE *no/ne (a form of pronominal *eno-, as in Gk. $\kappa \varepsilon \hat{\imath} v o \varsigma$ 'that (over

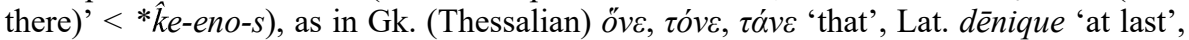
dōnec 'until'. Go. áir is generally assumed to be a locative (PIE *aieri > PGmc. *a(j)iri) of a heteroclitic stem meaning 'day, morning', as in Avestan ayarz 'day' and

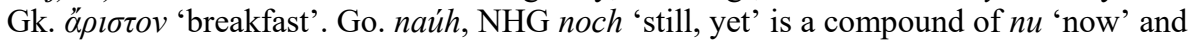
PIE * $k^{w} e>$ Lat. -que. Monomorphemic adverbs include adverbial particles like Go. interrogative $-u$, negative $n i$, affirmative $j a$, and others, for which the handbooks should be consulted.

In the other Gmc. languages, where preserved, these adverbs have developed regularly for the most part, with lengthening of final vowels when stressed (e.g. OIcel. $n u ́$, OE $n \bar{u}, g e \bar{o}$ 'formerly', also spelt $i \bar{u}$ ) and loss of final $-n$ in OIcel. pá 'then'. But WGmc. gives evidence of some alternative forms, including PGmc. * $x^{w}$ annai, *pannai (OE hwonne, ponne, OHG (h)wanne, wenne, denne) and WGmc. *xweer, *peer (OE $h w \bar{x} r, p \bar{x} r$, OS thār, OHG (h)wār, dār), with WGmc. lengthening.

\subsection{The composition of adverbial stems}

Most early Gmc. adverbs recognizably comprise more than one morpheme. One recurring suffix is PGmc. *-ai (cf. * $x^{w}$ annai, *pannai above), indicating location, ${ }^{1}$ as in Go. inna, OIcel. inni, OE inne, OS inna, OHG inna- 'within'; also Go. afta 'behind', faúra 'ahead', iupa 'above', üta 'outside', dalapa 'below', and cognates. Another is PGmc. *-ne (as in Lat. superne '(from) above'), indicating motion from a place, as in Go. aftana 'from behind', OIcel. aptan 'afterward, again', OE æftan 'behind', OS aftan 'eventually', OHG aftan '(from) behind'; also Go. innana '(from) within', ùtana 'from 
without', etc., and cognates. A suffix restricted to Gothic is $-p<\mathrm{PIE}{ }^{*}$-te (as in Gk. $\pi o^{-}$ $\sigma \varepsilon$ 'whither' $<* \pi \delta$ ' $\tau \varepsilon$; $\not 2 \lambda \lambda o-\sigma \varepsilon$ 'elsewhither'), denoting motion to a place, as in Go. aljap 'in another direction', dalap 'down'; elswhere in Gmc., motion to a place is denoted by the bare adverbial stem (perhaps originally acc.: Cercignani 1980b: 181), e.g. OE pider 'thither', $\bar{u} t$ 'out', nipor 'to below, down'. In PGmc., it is generally assumed, the ablative of adjectives could be used adverbially. The very common adverbial suffix PGmc. $*_{-} \bar{e}$ in alternation with $*_{-} \bar{o}$ is commonly said to reflect an $o$-stem ablative sg. inflection $\mathrm{PIE} *_{-} \bar{e} d \sim *_{-} \bar{o} d ;^{2}$ the former is used in Anglo-Frisian, the latter elsewhere, e.g. Go. ga-leikō, OIcel. likka, OE gelīce, OFris. līke, OS gi-līko, OHG gi-līhho 'likewise, alike'. This suffix was subsequently used to form adverbs from words other than adjectives, e.g. Go. aftarō 'behind', aúftō 'perhaps, surely', simlēe 'once', and so forth. It was added to the suffix PGmc. *_ $ð r$ - (by Verner's law related to the PIE prepositional root *ter-, as in OIr. tar, Lat. trans 'across', Go. pairh 'through') to denote, in Gothic, motion to a place $(-d r \bar{e})$ or from a place $(-d r \bar{o})$, as in hadre 'whither', hadrō 'whence', jáindrēe 'thither', jáindrō 'thence', a distinction perhaps originating in Gothic (certainly not a characteristic of PIE), since it cannot be traced elsewhere: cf., e.g. OE pider 'thither' but panon 'thence' (with PGmc. *-nē, as above).

Of these adverbial endings, certainly PGmc. $*_{-} \bar{e} \sim *_{-} \bar{o}$ was the most productive: cf., e.g., OIcel. snemma 'early', harðla 'very', OE fægre 'beautifully', hearde 'severely', OS lango 'for long', hluttro 'plainly', OHG snello 'quickly', mahtigo 'mightily'. But some more distinctive suffixes were also in use to form adverbs of manner or quality to major class words. For this purpose Go. attaches to adjectives the suffix $-b a$, not subject to Thurneysen's law (\$6.12), of uncertain derivation and unparalleled anywhere as an adverbial ending. ${ }^{3}$ In such formations the adjective usually retains the mark of its original stem class, e.g. baírhtaba 'brightly' (a/ō-stem), sunjaba 'truly' (ja/jō-stem), ana-láugniba 'secretly' ( $i$-stem), but hardaba beside harduba 'grievously' ( $u$-stem). Otherwise, adverbs of this sort are commonly formed by compounding, the most prevalent added morpheme being the stem of PGmc. *likka- 'body' (Go. leik, OIcel. lik, etc.), which is also used to form adjectives. Thus, on the commonest view, the meaning of Go. adj. samaleiks 'alike' may be assumed to have developed from *'having the same body', of liubaleiks 'dear' from * 'having a dear body' (thus explaining, in the latter instance, why the suffix appears to be meaningless: cf. OIcel. ljúfr, OE léof (etc.) 'dear': but see further $\S 8.13$ n. 7). In the only Go. adverbs with PGmc. *likka- it bears a prefix rather than being compounded with an adjective: ana-leikō 'in like manner', galeikō 'like', and otherwise it is compounded only with adjectives. The suffix is commoner in WGmc. (OE -līce, OS -līko, OHG -lìhho, with the ablative endings identified above) and in $\mathrm{ON}$, where the morpheme has been altered to -liga, ${ }^{4}$ with the alternant -lega. ${ }^{5}$ In NWGmc. the suffix may be attached to parts of speech other than adjectives (e.g. ON hófliga, to hóf 'moderation', OE werlīce to wer 'man', OHG gomilīhho to gomo 'man'), showing that Gothic reflects an older state of affairs.

It was pointed out above that PIE locative and ablative case-forms could be used adverbially. The nom./acc. sg. neuter is so used in various IE branches, including Gmc., e.g. Go. OS OHG filu, ON fjol-, OE (Northumbrian) feolu 'much, very' (cf., with ograde, Gk. neut. $\pi o \lambda \dot{v}$ and, with (probably) weak grade, Skt. purú 'very'), Go. leitil 'little', OIcel. mikit 'greatly'. Other case-forms may also serve as adverbs, e.g. Go. gen. allis 'wholly', nahts 'by night', OE dat. pl. wundrum 'marvelously': the grammars of the individual languages should be consulted for other examples and cases.

PGmc. *zōðaz 'good' forms its adverb with a different stem, Go. waila, ON vel, OE wě l, OS OHG wela, wola, which shares its root with the verb Go. wiljan 'wish, 
want'; cf. Skt. vára- 'wish'. To OE adj. lȳtel 'little' corresponds the unextended stem in adv. ly $t$ (beside ly $t l e$ ), from the $i$-stem adj. $l \bar{y} t$.

1. To Go. faúra cf. Gk. $\pi \alpha \rho \dot{\alpha}$; thus, perhaps, PGmc. *-ai reflects *-a with the addition of the deictic particle *-i (identical to the locative ending), as in *upér- $i>$ Skt. upári, OIcel. yfir 'over' (cf. Gk. vi $\pi \dot{\rho} \rho$ ). For a different analysis of such pronouns, deriving them from PIE instrumentals, see Hollifield 1980: 145-6.

2. This assumption is problematic, since the evidence for a PIE alternant $*_{-} \bar{e} d$ is poor. Kieckers (1960: 94) derives Go. $-\bar{e}$ from PIE instr. $-\bar{e}$ and assumes that the vowel somehow became trimoric in Germanic. Boutkan (1995b: 379-81), in agreement with A.W. Jones (1979: 341-7), instead explains the ending as a Gmc. innovation, with the ablatival final dental added to an instr. ending.

3. Krahe \& Meid (1969: III, §116) suggest that the suffix originated as a case-form of adjectives in PIE *-bho-, *-bhā-, but that there were Gmc. adjectives bearing this suffix remains to be shown. Kluge (1926) identifies none.

4. The change is most likely a folk etymological one, due to the resemblance to adjectives like audigr 'wealthy' (perhaps through reanalysis of some such form as *fá-likr (later fá-ligr 'reserved') to *fál-ikr), given the especially close resemblance in the nom./acc. sg. neut. (auðikt): see Noreen 1970: §248 Anm. 4.

5. Noreen (1970: $§ 145$ Anm. 4) regards the alternant -lega as mysterious, but the influence of adjectives like auðigr on the suffix (see the preceding note) adequately explains the matter, since adjectives like auðigr have the alternant auðegr, due to mixture of the PGmc. suffixes $*_{-} \bar{\imath} 3-$ and $*_{-}-a z-$.

\subsection{Regular comparison of adverbs}

The comparative of adverbs was formed in PIE with the same suffix *-is used with comparative adjectives, but left uninflected: IE examples are given in $\S 9.10$. Forms in -is are thus to be regarded as examples of the nom./acc. sg. neuter being used adverbially (cf. Go. filu, etc. above), since these cases were uninflected in consonant-stem neuters (see, e.g., §7.38). The suffix *-is (like the identical nom. sg. masc. $i$-stem noun inflection) is lost altogether in WGmc., leaving (often) only umlaut of the root vowel to mark comparative forms, though very commonly there is analogical replacement of such forms with forms bearing an overt inflection. Examples are Go. háuhis 'higher' (to háuhaba); Go. nēhis (to nēhua), OIcel. nær 'nearer'; OIcel. lengr, OE OS leng 'longer'; OIcel. betr (with umlaut after a light syllable, there being no paradigm for the adverb; cf. $\S 4.7)$, OE OS bet 'better'; OS hald, OHG halt 'more'. Surviving comparatives of this sort are few outside of Gothic, esp. in OHG. More commonly the uninflected corresponding adj. suffix ${ }^{*}-\bar{o} z$ is used, which, reflected as $-\bar{o} r$, is added in OHG even to stems that form the comparative adj. with -iro, e.g. adj. reiniro 'cleaner', festiro 'firmer', but adv. reinōr, fastōr. Examples are Go. sniumundōs 'more hastily', aljaleikōs 'otherwise'; OIcel. optar, OE oftor 'more often'; OIcel. vissuligar, OE gewislicor 'more certainly'; OIcel. djúpar, OE dēopor, OS diopor, OHG tiofōr 'deeper'.

Correspondingly, the superlative is formed with uninflected $*_{\text {-ist }}$ or $*_{-o}$ st , depending for the most part on which form of the comparative is used. The former is less frequent. There are just two examples in Gothic (and none of *-ost): frumist 'first of all', máist 'at most' (to mikilaba). Other examples include OIcel. snimst, snemst 'soonest', næst 'most nearly', lengst 'longest', OE hīehst 'highest', ǣrest 'at first', tylgest 'most firmly', OS OHG errist 'at first'. Outside of Gothic, commoner is *-osst, as in OIcel. vídast 'most widely', optast 'most often', OE fægrost 'most beautifully', gear(w)ost 'most certainly', OS wìdost 'most widely'. In OHG, once again, the comp. of the adj. and adverb may have different suffixes, e.g. hartōst 'hardest', langōst 'longest' (adj. hertisto, lengisto). 
As remarked in connection with adjectives derived from adverbs, some adverbs formed the superlative in PIE with the suffix *-mHo- (see the examples in $\$ 9.11$ ). No such adverbs survive as such in Gmc., though a number of adjectives derived from them do. In addition, in OE some superlatives with double suffixation *-m-ist- may be used both as adjectives and, when endingless, adverbs, e.g. innemest 'innermost', ufemest, yfemest 'uppermost'.

\subsection{Suppletive comparison}

As with Gmc. adjectives, a few adverbs form the comp. and superl. degrees with a stem different from that of the positive (though no suppletive comp. or superl. forms happen to be preserved in Go., except for haldis 'rather', to which no positive or superl. is attested):

OIcel.

$\begin{array}{ll}\text { pos. } & \text { gjarna 'gladly' } \\ \text { comp. } & \text { heldr, gjarnara } \\ \text { superl. } & \text { helz(t) } \\ \text { pos. } & \text { illa 'badly' } \\ \text { comp. } & \text { verr } \\ \text { superl. } & \text { ve(r)st } \\ \text { pos. } & \text { lïtt '(a) little' } \\ \text { comp. } & \text { minnr, miðr } \\ \text { superl. } & \text { minzt } \\ \text { pos. } & \text { mjok 'much' } \\ \text { comp. } & \text { meir(r) } \\ \text { superl. } & \text { mest } \\ \text { pos. } & \text { upp 'upward' } \\ \text { comp. } & \text { ofar(r), ofarmeir(r) } \\ \text { superl. } & \text { ofa(r)st } \\ \text { pos. } & \text { vel 'well' } \\ \text { comp. } & \text { betr } \\ \text { superl. } & \text { bezt, bazt }\end{array}$

OE

georne

geornor

geornost

yfle

wiers

wierst, wierrest

lȳtle, lȳt

lǣs

lǣst, lǣsest

micle

mā

mǣst

ūp, upp

ufor

ufemest, yfemest

wēl

bet, sēl

bet(e)st, best, sēlest
OS

\section{gerno}

hald

ubilo

wirs

(2)

lēs

mikilu

mēr

mēst

up

wel(a), wala, wola

bet, bat

bezt, best
OHG

gerno

halt, gernōr

gernōst

ubilo

wirs

wirsist

luzilo

min

minnist

mih(h)il

mēr

meist

uf

wel(a), wola

baz

bezist

\subsection{Prepositions}

Most Gmc. prepositions may be regarded as monomorphemic, but a small amount of compositionality can be discerned. Some of the same PIE morphemes identifiable as adverb suffixes in PGmc. can be detected in prepositions, some of which are in fact identical to deictic adverbs. The umlaut in OIcel. yfir 'over' demands PGmc. *ubiri $<$ $* u \hbar e r i=$ Skt. upári, prompting the assumption of a suffix $*_{-} i$ (identical to a locative inflection, §7.2) missing from OE ofer, Gk. vं $\varepsilon \dot{\rho} \rho$; cf. OHG ubari, ubiri beside ubar. Moreover, *-er- in PGmc. *uber(i), is suffixal (cf. the remarks about $-r$ in Go. har, par, $\S 11.1$ ): compare NWGmc. *upp- (a geminated form of *ub-: §6.9) in ON upp 'up', OE $\bar{u} p$, upp, and so forth. OIcel. fyr(r), fyri(r) 'before' is perhaps in part formed similarly (cf. OS OHG furi), though the corresponding adverb in the compar. degree (*fur-iz) has 
probably played a role, with confusion on semantic grounds. WGmc. *umbi (OE $y m b(e)$, OS OHG umbi 'about, around' is usually equated with Gk. $\alpha \mu \phi i$ 'around', although retention of the final high vowel after the heavy syllable (cf. ON um(b)) presents a difficulty. It could be that folk etymology of the desinence as equivalent to the prep. * $b \bar{l}$ led to retention of the vowel, due to the partial overlap in meaning, though Klingenschmitt (1987: 187 n. 59) argues that the cause must be phonological rather than analogical, due to retention anteconsonantally in sandhi, given the similar retention in OS OHG āno 'without', OS endi, OHG enti 'and' <*andi. See also $\$ 5.2$ n. 2 on this.

Adverbs of place from which, bearing the PIE suffix *-ne $(\S \S 1.4,6.9)$, may also be used as prepositions, often with change of meaning, as in Go. ütana weihsis 'out of the village', OIcel. útan frænda rád 'without the advice of kin', OE innan pām hūse 'inside the house'. Go. adverbs in - $p r o \bar{o}$ may be used the same way, as in ni waíhts ist ütaprō mans 'there is nothing from outside a person'.

\subsection{Conjunctions}

Most conjunctions are compounds, at least in origin, and in Gothic their constituency is usually transparent, e.g. páuhjabái 'even though' (cf. páuh 'then', jabái 'if'), swēpáuh 'indeed, however' (cf. swē 'thus' and OE sepēah). Even some of the more basic conjunctions, however, can be analyzed morphologically. Several contain a reflex of the PIE pronominal stem *io- (see §8.14), e.g. Go. jah 'and, also' (with $-h=$ Lat. -que), jappe 'whether, or' (with instr. pē, §8.10), jabái 'if' (OIcel. OS ef, OE gif, OHG ibu; cf. Go. nibái 'if not'). Although the derivation of the first constituent of Go. aíppáu 'or' (OIcel. eða, OE oððe, OS ettho, $\mathrm{OHG} e d(d) o$ ) is uncertain, it plainly contains Go. páu, one meaning of which is 'or', as in Dáupeins Iohannis uzuh himina was páu uzuh mannam 'Was John the Baptist from heaven or from humans?'. The PGmc. adverb * pana 'then' $(\$ 11.1)$ forms the basis for a number of conjunctions of varying transparency, including Go. appan 'but, however', pannu 'therefore', pandē 'inasmuch as, when, as long as, until', OE penden 'while'. The compositional conjunctions of Gothic tend not to have precise parallels elsewhere in Germanic. The number of conjunctions in $\mathrm{ON}$ is decidedly curtailed, affording no more than ten, whereas WGmc. shows a number of innovations, e.g. OE siððan 'after' < *sīp pon, swylce 'as if', and oppæt 'until' (OS unt(h)at, OHG untaz), though the last was probably not yet univerbated in early OE poetry (see Fulk 2007: 168-71). But the forms taken by conjunctions are, for the most part, more properly the study of etymology and lexicology than of morphology. 


\section{Verbs}

\section{The Proto-Indo-European Background of the Germanic Verb}

\subsection{Categories and aspects of verbs in Proto-Indo-European}

Verbs in late PIE apparently were conjugated in two voices (active, middle), ${ }^{1}$ four, or possibly five, moods (indicative, subjunctive, optative, imperative, perhaps injunctive), ${ }^{2}$ two tenses (present, preterite), ${ }^{3}$ and three aspects (as explained below). Verbs were inflected for three persons (first, second, third) in three numbers (singular, dual, plural). ${ }^{4,5}$

PIE verbs may be classified as either athematic or thematic. The terms have the same meaning they have in regard to nouns (\$7.1): between the verb stem and the inflection there appeared in a great many verbs (though not in all forms of such) a connecting vowel, referred to as the 'theme vowel' (or 'thematic vowel'), which might be either $e$ or its ablaut alternant $o$. For example, *bher- 'bear' takes the theme vowel $e$ in pres. 2 pl. *bher-e-te $>$ Gk. $\varphi \varepsilon ́ \rho \varepsilon \tau \varepsilon$ but the theme vowel $o$ in pres. 3 pl. *bher-o-nti $>$

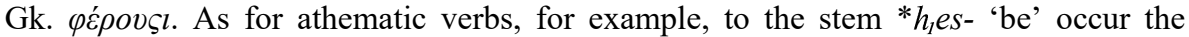
forms pres. $1 \mathrm{sg} .{ }^{*} h_{l} e s-m i>$ Skt. ásmi and $3 \mathrm{sg}$. ${ }^{*} h_{l} e s-t i>$ Skt. ásti, Gk. É $\sigma \tau i$, Lat. est, without any theme vowel. The personal inflections in the two types differed only in the first person singular present, where the thematic verbs have $*_{-} \bar{o}$ (from theme vowel $o$ plus $h_{2}$ ), as in Gk. $\varphi \varepsilon ́ \rho \omega$ 'I bear', whereas the athematic verbs have ${ }^{*}-m i$, as in Gk. $\tau i \theta \eta \mu$. For this reason the athematic verbs are sometimes referred to as $m i$-verbs. In thematic verbs the stem was invariant in its root vocalism, whereas in athematic verbs the rule was full grade in the singular and weak grade in the dual and plural of the present indicative, with accent on the inflection. Thus, for example, full-grade $* h_{l} e s$ - in

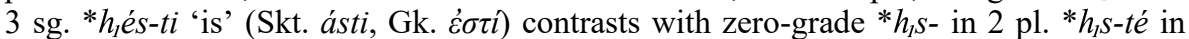
Skt. sthá and 3 pl. * $h_{1} s$-ónti in Skt. sánti.

As regards aspect, PIE verbs may be classified as either stative or eventive. When stative, verbs take the form of the perfect, which denotes a state precipitated by past developments of present import. For example, the perfect construction "She has lived in Aarhus ever since" refers to present residence due to a move made formerly, and "I have eaten" refers to an implied present situation ("I am not in need of a meal") due to past action. When eventive, a verb could take the form either of the imperfective, not indicating completion of the process or quality indicated by the verb's semantics, or of the perfective, indicating completion. The basic stem of the imperfective form is the present, whereas the basic stem of the perfective is the aorist. It should be noted that although the aorist denotes completion, it leaves unspecified an event's aspectual qualities (durative, iterative, etc.), whereas event structure is often indicated in present stems by means of affixes (see $§ 12.3$ ). Affixes also characterize the aorist stem, not on an 
aspectual but a historical basis. The oldest and simplest aorist stems are the root-stems, which might alternate between full grade in the active singular, elsewhere reduced grade. Alternatively, ${ }^{*}-s$ - might be added to the ablauting, athematic stem to form the so-called sigmatic aorist, with lengthened grade in the active singular (probably: see Szemerényi 1996: §9.4.2.1). A third alternative is that a thematized stem, with reduced grade of the root, might be used with or without reduplication to form the aorist stem.

PIE verb morphology and inflection depended to a remarkable extent on semantics (or, more precisely, Aktionsart), ${ }^{6}$ correlating to whether a verb was fundamentally imperfective (i.e., not expressing completion of an action, hence atelic; cf. Gk. $\tau \dot{\lambda} \lambda o \varsigma$ 'end') or perfective (i.e., indicating an end, hence telic). ${ }^{7}$ Atelic verbs are thus those which most commonly express continuous or habitual action, such as go, bear, and enjoy; telic verbs are those which normally express non-continuous action, such as strike, choose, and cast. An atelic verb would appear in its unmarked form as a present stem, whereas a telic verb would appear as an aorist stem - a root-aorist, to be precise, this being the simplest form of the aorist. A fundamentally atelic verb, however, might be used in a punctual sense: for example, go is non-continuous (and thus punctual) in the sentence "At midnight she went home." Likewise, a fundamentally punctual verb might be used in a durative or habitual sense, as in the sentence "His music strikes the ear as atonal." In PIE, the verb in its fundamental meaning according to its Aktionsart assumed its morphologically simplest form, and forms of the verb expressing a different aspectual meaning would require greater morphological complexity, which might be manifested in one of a number of ways. For example, atelic *leigh- 'lick' appears in simple form in athematic pres. Skt. léédhi $<$ *leigh not a simple root-aorist but the morphologically more complex $s$-aorist aliksat. Alternatively, the punctual stem might be formed by the use of a reduplicated aorist: to atelic *bheidh- in Gk. $\pi \varepsilon i \theta \omega$ 'persuade' ${ }^{8} \mathrm{cf}$. Homeric aorist $\pi \varepsilon \dot{\varepsilon} \iota \theta o v$. Conversely, to form the durative of a punctual (telic) verb, reduplication (sometimes with the vowel $i$ rather than e) ${ }^{9}$ might be employed: to punctual *dheh ${ }^{-}$'set, place' in aorist Skt. ádhām and Gk.

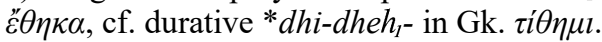

Logically, the perfect could have present or preterite tense, but there probably was no pluperfect in PIE: the pluperfect is formed differently in Gk. and Skt. and thus appears to be a post-PIE innovation. Rather, the perfect forms of PIE must have been used for both perfect and pluperfect meanings. Because the meaning of the aorist excludes any reference to event structure, the aorist stem could make no present formation, given that present reference by definition includes information about event structure. A different present stem, however, could be formed to the same root found in an aorist stem. Thus, of the present, aorist, and perfect stems, only the first was inflected for tense, its preterite being the imperfect. ${ }^{10}$

1. It is debated whether verbs inflected in the middle voice could also convey passive meaning. Fortson (2010: 90), for example, accepts the proposition and refers to the PIE middle voice as the mediopassive, whereas Beekes (2011: 252) categorically rules out passive meaning.

2. The injunctive is represented as such solely in Skt., where it occurs only in prohibitions with the negative particle $m \dot{a}$ and in series of verbs in which a preceding verb bears mood or tense marking. Thus, the injunctive is an unmarked form of the verb as regards tense and mood, as might be expected from its bearing neither an augment nor primary inflections. Historically, then, it is simply a more basic form of the verb, without the later accretions of present stems (with their primary inflections) or imperfect ones (with the augment). There also occur some augmentless imperfects in early Greek. For a succinct account of the injunctive, see Clackson 2007: 130-2.

3. On the possibility of a future tense in PIE, see Szemerényi 1996: §9.4.2.2. 
4. The categories listed here are best represented in Sanskrit and Greek, but they must be reconstructed for PIE because of relics found in other languages, e.g. the subjunctive (originally optative) forms sim and velim in Latin (which has no formal optative): see Szemerényi 1996: §9.1.

5. Reconstruction of the PIE verb system, considered fairly settled by the late nineteenth century, was upended by new information derived in the twentieth from Anatolian and Tocharian: see, e.g., Jasanoff 2003. The challenges to the older reconstruction presented by Anatolian and Tocharian are irrelevant to the Gmc. verb system, which, though simplified considerably from that of late PIE, plainly is to be derived from that system, bearing no marked resemblance to, e.g., the Hittite system: see $\$ 1.4$. The affinity of the Gmc. system to that of the classical languages is of relevance to those versions of the glottalic theory $(\S 6.2)$ that regard Gmc. as more archaic in its phonology than the classical languages.

6. For present purposes, Aktionsart may be regarded as lexical aspect, i.e. aspectual quality inherent in a verb's semantics (or the semantics of the predicate as a whole) rather than conferred by morphology or syntax (which is termed simply 'aspect'). This is the commonest understanding of the distinction between the two, though there is no general agreement about the matter: see, e.g., Bache 1982. At all events, since PIE drew distinctions on the basis of both aspect and Aktionsart, the two terms are not always easy to distinguish in contexts like the present one.

7. Note that the term 'perfective' has nothing to do with the IE perfect.

8. Initial $\pi$ - rather than $\varphi$ - as the reflex of * $b h$ - is due to Grassmann's law: see Collinge 1985: 47-61.

9. The vowel $i$ is regular in reduplicated thematic presents, as with Gk. yi $\gamma v$ vo $\alpha l$ 'become', whence it must have spread to athematic ones. The original distribution of $i$ and $e$ in reduplicated syllables is disputed (Beekes 2011: 253).

10. The imperfect is thus technically the preterite of an atelic verb. In the 'southeastern' group of IE languages (Greek, Phrygian, Indo-Iranian, Armenian) the imperfect is formed of the present stem with secondary, rather than primary, inflections (see §12.4) and prefixation of the reflex of $h_{1} e^{-}$, referred to as the aug-

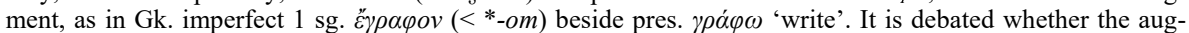
ment is an innovation of the southeastern group only or whether it is a feature lost from all other IE languages. The augment is sometimes invoked in explanation of certain Gmc. forms (see, e.g., §12.14), but there is no very secure evidence for its use in PGmc.

\subsection{Verb tenses and stems in Proto-Indo-European}

Technically, just two tenses can be reconstructed with assurance for PIE: the present and the preterite. ${ }^{1}$ The preterite, however, may take the form either of the imperfect or of the aorist. ${ }^{2}$ The imperfect stem was derived from the present stem by the addition of the augment in those languages in which the augment is found $(\S 12.1 \mathrm{n} .10)$, with secondary inflections, differentiating the imperfect from the present, which used primary inflections $(\S 12.4)$. The aorist stem usually took the augment with secondary inflections, as well. Neither the PIE imperfect stem nor the aorist is of indubitable relevance to the Germanic languages, in which the preterite stem derives instead from the PIE perfect, though some aorist inflections were perhaps added to Gmc. preterite stems $(\S 12.25)$, and the imperfect is sometimes invoked in explanation of some of the peculiarities of OE dōn 'do' and its WGmc. cognates $(\S 12.61)$; see further $\S 12.9 \mathrm{n} .1$ for references.

The perfect was not in origin a tense but an aspect of the present, originating probably in a stative construction. It nonetheless had a stem distinct from both the present and the aorist. The singular of the perfect stem was normally formed with $o$ grade of the root vowel and initial reduplication. Examples are *le-loik $k^{w}$ - in Gk. $\lambda \dot{\varepsilon} \lambda o l \pi \alpha$ 'I have left' (cf. *leik $k^{w}$ - in pres. $\lambda \varepsilon i \pi \omega$ ) and ${ }^{*} k^{w} e-k^{w} o r$ - in Skt. cakắra' 'I have made' (cf. ${ }^{*} k^{w} e r$ - in Gk. $\tau \varepsilon \dot{\rho} \rho \alpha \varsigma$ 'portent'). In the dual and plural of the perfect, however, the root took weak grade, as in Skt. cakrmá 'we have made'. Cf. also 1 sg. * $g^{w} e-g^{w} o ́ m-h_{2} e>$ Skt. jagáma 'I have gone', 2 pl. * $g^{w} e-g^{w} m-e$ > Skt. jagmá. When the verbal stem began with 
$s+$ stop, the entire cluster was reduplicated, as shown by the divergent reflexes of (non-

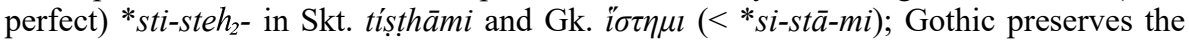
original situation in forms like ga-staí-stald 'possessed' (cf. inf. ga-staldan). ${ }^{3}$ That reduplication is not original to the formation of the perfect is probably not to be inferred from its absence from what appears to be the oldest perfect type, *uoid- $h_{2} e>*_{\text {woida }}>$ Skt. vếda, Gk. ồ $\delta \alpha$, Go. wáit 'I know': see $\$ 12.54$.

The three basic verb stems of PIE, from which the rest were derived, were thus the present, the aorist, and the perfect, of which only the first and last are indubitably preserved in Germanic.

1. Although a variety of IE languages have a synthetic future bearing the tense marker $-s-$, marking such forms as desideratives in origin, the suffixes are not uniform across the relevant languages, and they are perhaps best explained as innovations in the daughter languages: see Szemerényi 1996: §9.4.2.2 for concise discussion and references. The issue is of little import for Germanic linguistics, since no synthetic future is found in the early Germanic languages.

2. In addition, the pluperfect is the preterite of the perfect, but at all events the perfect is an aspect rather than a tense, and the supposition of a formal pluperfect in PIE is based more on logic than on the evidence of the daughter languages: the pluperfect is plainly "a much younger creation, but since the perfect - a present tense-is old, its past tense must be at least as old as the imperfect" (Szemerényi 1996: §9.4.4.1). There is no trace of an inherited pluperfect in Germanic (though cf. Kortlandt 1994b).

3. This peculiarity of reduplication is one of the factors that have prompted discussion of the phonemic status of /st, sp, sk/: see Lubbe 1987, Takahashi 1987, Suzuki 1991a, Minkova 2003: 192-237.

\subsection{Primary, secondary, and derived verbs in Proto-Indo-European}

Many PIE verbs based their present stem directly upon the root, or upon the root plus theme vowel, and these are referred to as non-derived verbs. The remainder added one or another productive affix to the present stem to express, originally, some aspectual variety. These latter are referred to as derived verbs, and stems created by such affixation were not used outside of the present. ${ }^{1}$ Aorist and perfect stems, however, might be derived from the same verb root (rather than stem), and a derived verb might share a non-present stem with a related, non-derived verb, e.g. OS stōd 'stood' as preterite to both athematic inf. stān and nasal-infixed standan.

In addition to the distinction drawn between derived and non-derived verbs, there is that between primary and secondary verbs. Primary verbs are created directly from verb roots, and so primary verbs may be either derived or non-derived. By contrast, secondary verbs, which are always derived, are created from forms other than roots, such as nouns, verbs, and even phrases, in the manner of Lat. salutāre 'greet', based on salütem dīcere 'say a greeting (literally 'health')'. Secondary verbs had no stem other than the present stem in PIE (and are thus referred to as presentia tantum), though in the daughter languages, including Gmc., means were devised to provide preterites to such verbs. ${ }^{2}$

One method of affixation in the formation of derived verbs was reduplication with the vowel $i$ in both thematic and athematic verbs, as in Skt. bibharti 'bears' < PIE *bhi-bher-ti. In thematic verbs, at least, the original significance of reduplication in the present stem was probably iteration or intensity of meaning. Germanic verbs showing reduplicated present stems are few, probably only OHG bibēn, OE beofian, ON bifa 'tremble' (cf. Skt. bi-bhe--ti 'is afraid') and OHG zittarōn, OIcel. titra 'tremble, twinkle, wink' (cf. Gk. $\dot{\alpha} \pi o-\delta l-\delta \rho \alpha \dot{\alpha}-\sigma \kappa-\omega$ 'teach not (to do)'). There is also Go. reiran 'tremble', with so-called full reduplication, i.e. reduplication of the entire root, used with 
intensives and iteratives: cf. Skt. lēlāyáti $<*$ rei-rēi-é-ti. As remarked by Prokosch (1939: §53b), these reduplicated Germanic presents all have the same meaning, suggesting that reduplication is preserved in them by reason of sound symbolism.

A number of verbs took a nasal infix in the present stem in Proto-Indo-European, usually in opposition to a non-infixed root aorist, e.g. Skt. yunákti 'joins' <*iu-né-g-ti to the root *iug-; cf. the root without the nasal infix in Skt. root aorist yojat (unusually, without augment), as well as in Lat. jugum, Go. OS juk 'yoke'. Infixation was not productive in any of the IE languages, the only preserved examples still showing alternation in Germanic being Go. OS OE standan, pret. Go. stöp, OS OE stōd, and (with suffixal rather than infixed $n$ ) Go. fraíhnan, OIcel. fregna, OE frignan 'ask', pret. sg. Go. frah, OIcel. frá (but OE frægn, with extension of $n$ to the pret.), pl. Go. frēhum, OIcel. frágum. To Go. keinan 'bud, grow' (OHG kinan) cf. pp. us-kijanata. ${ }^{3}$ In some other verbs the infix was extended to the preterite in Germanic, e.g. Go. OHG OS fähan, ON fá, OE fōn 'take' < PGmc. *fanx-ana $a^{n}$, pret. Go. faifāh (reduplicated *fe-fanx), OE fĕng (cognate with Latin pango 'fix, settle', reduplicated non-nasal perf. pe-pig-ī), and probably Go. windan 'wind' (cf. Go. ga-widan 'bind'). ${ }^{4,5}$ Frequently an $n$-infix in a verb is detectable only by comparison to related words, in Germanic or elsewhere, from which the infix is missing. An example is OE murnan 'mourn', pret. sg. mearn (whereas Go. maúrnan and OHG mornēn are weak), in comparison to PIE *(s)mer- in Skt.

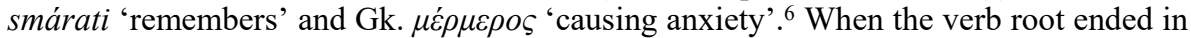
$* u$ or a laryngeal consonant, the infix plus that segment could be reanalyzed as a suffix, as in the fifth (sunṓti) and ninth (krịnăti) classes of Sanskrit verbs. Such a suffix was added to the root in OE wæcnan 'awake', pret. wōc; cf. weak Go. ga-waknan, OIcel. vakna. But the reanalyzed $n$-suffix could also be used to form verbs of the fourth weak class in Germanic $(\S \S 12.48-50))^{7}$

The present stem might be formed with reduced grade of the root and corresponding accent on the theme vowel. Such are called tudáti-presents, after the verb (meaning 'thrusts') for which the type in Sanskrit is named; cf. full-grade PIE *(s)toudin Go. stáutan, OHG stōzan, OS stōtan 'push, shove'. Germanic examples of the tudáti type are the so-called aorist presents (§12.18), e.g. OE bügan 'bend' (cf. the Skt. tudátitype bhujáti 'bends'< *bhug-é-ti) from *bhugh-ó-. ${ }^{8}$ The tudáti type expressed punctual (aorist) aspect, and hence the type might coöccur with the normal thematic type of nonpunctual aspect in the present: to punctual *grbh-ó- in Gk. $\gamma \rho \alpha \dot{\alpha} \varphi \omega$ 'write' compare durative *gérbh-o- in OE ceorfan 'carve'. When such alternative forms coexisted, one or the other was generalized in Germanic, with elimination of the punctual/durative distinction.

Most commonly, derived verbs were formed by the addition of a suffix. One such suffix frequently reflected in the IE languages is *-skéló-, as in Lat. pascō 'feed' < *pās-sḱko- (cf. pastor 'shepherd') and *prk̂k-ské- 'ask' in Skt. prccháti, Lat. poscit 'asks', OHG forscōn 'investigate'. ${ }^{9}$ It forms denominal verbs. Germanic examples include OHG wunscen, OE wȳscan 'wish' < PGmc. *wun-sk-jan- $a^{n}<{ }^{*} u n-s \hat{k}-(\mathrm{cf}$. OE wēn 'expectation') and Go. priskan, OHG drescan, OE perscan 'thresh' (cf. OE prāwan 'twist, rack'). The original meaning of the suffix *-skéló- cannot be determined with assurance: in Latin, for example, it lends inceptive aspect to verbs, whereas in Anatolian it indicates iterative or consuetudinal action, as perhaps also in Germanic - the sense that Szemerényi (1996: §9.4.1.4) ascribes to the original suffix.

Among derived verbs, the commonest suffix was *-ie/o-, which was used to form denominal and deverbal present stems. Frequently it has no discernible meaning, as with the Gmc. strong verbs with weak presents (\$12.19), but with reduced grade of the 
root and suffix accent it formed intransitive verbs, as with PIE *mn-ié- in Gk. $\mu \alpha i v \varepsilon \tau \alpha l$ 'raves' (cf. *-mon- in Skt. mányatē 'thinks', OIrish do·moiniur 'I believe'). With suffix accent it could also form denominal verbs, often transitive, with full grade of the root,

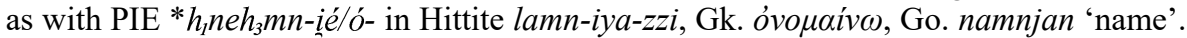
Such verbs could be formed from nouns of all stem classes, e.g. Skt. namas-yáti 'reveres' (cf. namas- 'reverence', s-stem) and śatru-yáti 'acts as an enemy' (cf. śatru'enemy', $u$-stem). As the latter example shows, $u$-stems (and $i$-stems) show the stem suffix in the weak grade. In Gmc., however, the relation between noun or adj. stem and verb is generally obscured, e.g. Go. kaúrjan 'weigh down' (not *kaúrujan; cf. $u$-stem kaúrus 'heavy'). Note that Go. hráinjan 'clean' <*xrain(i)-j-an- (cf. i-stem hráins 'clean') and matjan 'feed' <*mat(i)-j-an- (cf. $i$-stem mats 'food') are ambiguous, due to the effects of Sievers' law $(\$ 5.8)$.

This same suffix *-ie/o- could be added to other suffixes to express particular aspectual qualities in the present tense of verbs. From the perspective of Germanic linguistics, the most important such construction was that in which the verb root appeared in $o$-grade, with accent on suffixal $*_{-} e$ - (in origin the thematic vowel) followed by $*$-ie/o- to form causative or factitive verbs from both noun (adjective) and verb stems. Examples are Gk. $\delta \omega \rho \varepsilon \dot{\varepsilon} \mu \alpha l$ 'give' <*dōr-élio- (cf. $\delta \omega \rho o v$ 'gift') and Lat. moneō 'remind, warn' < *mon-éio- (cf. ON OE man 'remember'). In Greek such verbs are iterative in meaning, and so the type is commonly referred to as 'causative-iterative'. Germanic examples are Go. nasjan 'save' < PIE *nos-éío- (cf. OE nesan 'escape') and OE cemban 'comb' < PGmc. *kamb-jan- (cf. camb noun 'comb'). This is the chief source of verbs of the Germanic first weak class $(\S \S 12.34-9)$. Since PIE $*_{-} e-$ - and $*_{-i}-$ fell together as *-(i)j- in Germanic verb suffixes $(\S \S 12.34,12.38 \mathrm{n} .5)$, this type coalesced with the namnjan type (above). In NWGmc. such verbs could be formed from parts of speech other than nomina (nominals, i.e. nouns and adjectives) and verbs.

The suffix *-ie/o- might also be added to a suffix $*_{-}-h_{2}-$ which was in turn added to adjectives, in order to form so-called factitive verbs with the meaning 'cause to have the quality of the adjective'. An example is Hittite new-ahh-, Lat. renovāre 'make new' (cf. PIE *neu-o-s in Gk. véoৎ). The same construction produced primary verbs from verb roots, e.g. Lat. vorāre 'devour' $<{ }^{*} g^{w} \mathrm{or}_{-}-\mathrm{h}_{2}-\underline{\underline{i}-}$ (cf. Skt. giráti 'devours'); probably deverbal also is Lat. domāre = OHG zamōn 'tame' (cf. OHG zam adj. 'tame'). ${ }^{10}$ This is the original source of Germanic verbs of the second weak class $(\S \S 12.40-3)$.

Present stems in which $*_{-i} e / o$ - was added to the suffix $*_{-} e h_{l^{-}}\left(>*_{-} \bar{e}_{-}\right)$to form socalled stative verbs are commonest in Balto-Slavic, but the type is well represented also in Latin and Germanic, which show some striking similarities, e.g. Lat. tacēre = Go. pahan, OHG dagèn 'be silent' and Lat. silère = Go. ana-silan 'be quiet'. This is one source of Germanic verbs of the third weak class (\$12.44-7).

Likewise incorporating PIE *-ie/o-, the Gmc. suffix *-atja- was used to form denominal verbs, e.g. Go. láuhatjan, OHG lougazzen 'lighten' (cf. OE lìeg 'fire' and lieget 'lightning') and Go. swōgatjan 'sigh' (cf. OE swēg 'sound'). Such verbs are common in Old English and Old High German. ${ }^{11}$ The same suffix, from PIE *-ad-io-, serves to form verbs from $\bar{a}$-stem nouns in Greek, e.g. $\dot{\alpha} \rho \pi \dot{\alpha} \zeta \omega$ 'bear off' (cf. $\ddot{\alpha} \rho \pi \eta$ 'sickle, harpy'). ${ }^{12}$

Some other suffixes forming present stems in PIE were much less productive and show only scattered reflexes in the daughter languages, including Germanic. For ex-

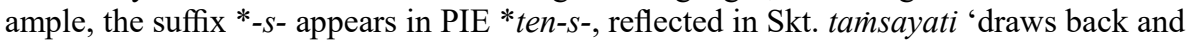
forth', Go. at-pinsan 'attract', OHG dinsan, thinsan 'drag'; cf. *ten- without the $s$ in Gk. $\tau \varepsilon i v \omega$ 'stretch' <*ten-iō. A present suffix *-t-appears in PIE *plek-t-, reflected in 
Lat. plectō $=$ OHG flehtan 'braid, interweave'; cf. unsuffixed *plek̂- in Gk. $\pi \lambda \dot{\varepsilon} \kappa \omega$, Lat. plicō 'fold'. A present suffix *-dh- appears in PIE *ghren-dh-, reflected in OE grindan 'grind'; cf. *ghrn-io- in Gk. $\chi \rho \alpha i v \omega$ 'touch lightly'. For further examples, see Brugmann \& Delbrück 1897-1916: II, 3.1.336-50, 362-79.

Although some IE present stems are reflected only in suffixed form, unsuffixed and suffixed forms to the same root could coöccur, as could forms with different suffixes attached to the same root. For example, beside normal thematic Gk. $\varphi$ '́ $\beta o \mu \alpha l$ 'be put to flight' there is the type with suffix *-éio- in $\varphi \circ \beta \varepsilon \dot{c} \omega$ 'frighten', and the double affixation

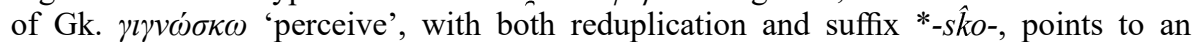

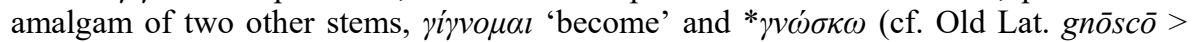
$n \bar{s} s \bar{o}$ 'become acquainted with').

1. The present stem, however, was also used to form the imperfect, although the evidence for imperfect formations in Gmc. is disputed (see $\$ 12.61$ ). Derived verbs are mistakenly opposed to primary verbs in Fortson 2010: 88, leading to some confusion.

2. As the focus here is chiefly on derived vs. non-derived verbs, it may be useful to summarize separately the derivational patterns of secondary verbs (which, again, have only present stems in PIE). Among the deverbal stems (those derived from pre-existing verbs) are causatives (with $o$-grade of the root plus *-é $i$-e/o-), as in Go. satjan < PIE *sod-éi-o-; cf. root*sed- 'sit'); iteratives (likewise with o-grade of the root plus *-éi-

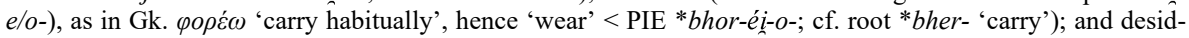
eratives, which add *-( $\left.h_{1}\right)$ se- to the verb stem, with or without reduplication, as in Lat. vis $\bar{o}$ 'seek' (orig. 'wish to see') <*ueid-so-, and reduplicated Skt. didrksati 'wishes to see' $<* d i-d r k$-se-. Among the denominal stems (including deadjectival ones) are true denominals, derived from noun stems, as in Skt. vasnayáti 'buys'

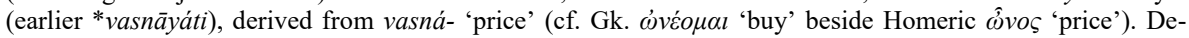
adjectival stems include statives, in which ${ }^{*}$-éh- replaces the adj. suffix ${ }^{*}$-ro- in the weak grade of stems formed under Caland's law (on which see Szemerényi 1996: §7.8.2), as in Lat. rubeō 'be red' < PIE * $h_{1} r u d h$ -

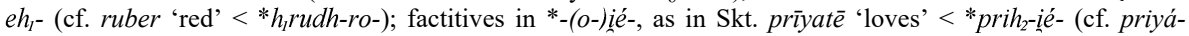

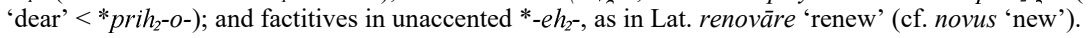

3. Another possible example is Go. weihan 'fight', if from PGmc. *winxanan (cf. Lat. vincō 'conquer', perf. $v \bar{\imath} c i$ ), though this could instead be a normal verb of the first strong class, from PIE *ueik- (Hirt 1931-4: II, 164). The latter is the simpler explanation, since the root was not accented in PIE verbs with nasal infix (though full grade, but also voicing under Verner's law, is to be found in many exceptional forms in Germanic, e.g. OE swingan 'beat' < PIE *sue-n-k- and clingan 'cling' < PIE *gle-n-k- (Pokorny 1959-69: I, 1047, 357)); cf. voicing under Verner's law in OE wīgan, OHG part. wìgant.

4. Another likely example is OHG klimban, OE climban 'climb'; cf. PIE *glēbh- in Lith. glëbiu, glëbti 'embrace'. PGmc. * piyx - in Go. peihan, OS thīhan, OHG dīhan, OE pēon 'thrive' perhaps also contains a nasal infix (but without the expected voicing under Verner's law), though the $n$ is regarded as part of the root by Pokorny (1959-69: I, 1068); Seebold (1970: 512-14) is uncertain; cf. Bammesberger 1986a: 40-1, who also points out that although the etymon of Go. leihan, ON ljá, OHG līhan, OE lèon 'lend' is probably *li- $\eta$ $x^{w}$ - (cf. Lat. linquō 'leave' and Gk. $\lambda \varepsilon i \pi \omega$ 'idem', with and without infix, respectively), PIE *leik ${ }^{w}$ - is also possible.

5. Belonging to this group are also verbs in which the infix appears to have been assimilated to a preceding

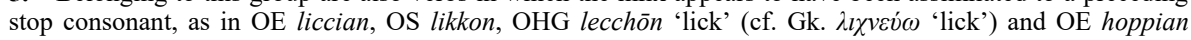
'hop' < PGmc. *xup-nō-jan- (so Hirt 1931-4: II, §130; see §6.9 supra on Kluge's law). Likewise, Germanic verbs containing $*_{-} n w$ - (cf. the Skt. type krṇóti $\left.<* k^{w} r-n e-u-t i\right)$ will show $-n n-$ as the reflex of this (§6.8). Examples are Go. rinnan 'run' and related forms (cf. Skt. rṇốti 'moves', Gk. ó $\rho v \bar{v} \mu \imath$ 'stir') and Go. winnan 'struggle' and related forms (cf. Skt. vanốti 'obtains').

6. Further examples: OE spurnan (pret. spearn) and related forms (cf. Skt. sphuráti 'kicks away'); OE hleonian 'lean' and related forms (cf. Lat. clīnō 'lean', but Skt. śráyati 'leans'); OE gīnan (strong), geonian (weak) 'gape' and related forms (cf. Lat. hiō 'gape'); OS thwingan, OHG dwingan, OIcel. pvinga 'compel' (cf. Gk. ти́коৎ 'hammer', Latvian tukstêt 'beat'); OE wringan 'wring' (and related forms; cf. Lith. veržiù, ver̃̌t $t i$ 'confine, press'); OIcel. springa, OE OS OHG springan 'leap' (cf. Gk. $\sigma \pi \varepsilon \dot{\rho} \rho \chi \omega$ 'drive, cause to hurry'); OE swingan 'beat', OS OHG swingan 'rush' (cf. Skt. svájate 'clasps'); Go. skeinan, OIcel. skina, OE scinan shine' (cf. Go. skeima, OE scimma 'light, brightness'). Others that probably ought to be included here are OE be-clenc(e)an 'hold fast', à-cwenc(e)an 'extinguish', à-timplian 'provide with spikes', (perhaps) on-ginnan 
'begin', and their Germanic cognates, along with a great many other verbs with stems ending in a nasal consonant plus a stop. See further Raith 1931.

7. For an exhaustive survey of nasal-infixed and -suffixed verbs in Gmc., see Scheungraber 2014.

8. On the lengthening of the root vowel, see $\S 12.18$. Bammesberger (1984) views the tudáti type as an innovation in Indic and Germanic; Mailhammer (2006: 8-13; 2007: 117-38), to the contrary, believes the type was rather commoner in Proto-Germanic than in the attested languages. The latter view is in accordance with the remarks of Streitberg 1896: 200 , who observes that verbs of this type must have been quite a bit commoner in PGmc., as otherwise it is difficult to explain why there is no voicing of - $p$ (reflecting PIE *-ti) in the ind. pres. pl. of verbs in OE and OS; 2 sg. $-s(: \mathrm{ON}-r<-z)$ in West Germanic may be subject to the same explanation (\$12.24). The tudáti type is discussed extensively by Mottausch (2013: 80-123), though with some weaknesses remarked by R.I. Kim (2015).

9. The last denominal, according to Bammesberger (1986a: 39-40), who also envisages a denominal derivation for PGmc. *aiskōjana ${ }^{n}>\mathrm{OE}$ āscian 'ask'; so also Ringe 2017: 186. He furthermore entertains the possibility of derivation of PGmc. *waskanan (> OE wæscan 'wash') from PIE *uod-sk- (presumably he means

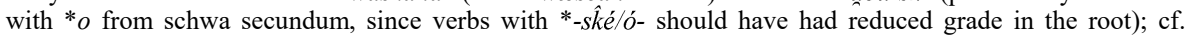
* $h_{2}$ uod- in Go. wato, ON vatn, OE wæter 'water'.

10. On the deverbal status of this form, see Szemerényi 1996: $\$ 9.4 .1 .5$, with references.

11. For OE, see Hogg \& Fulk 2011: §6.93; for OHG, see Riecke 1996: 214-50.

12. See Richter 1909: 135; Schwyzer 1977: 734.

\subsection{Personal inflections of verbs in Proto-Indo-European}

As noted above, the present-tense active endings of thematic and athematic verbs in PIE were identical except in the $1 \mathrm{sg}$., where the former had $*_{-}-*_{-} *_{-}-h_{2}$ and the latter had ${ }^{*}$-mi. The reconstruction of the inflections in the singular and in the 3 plural are not in doubt: ${ }^{1}$

$\begin{array}{ll} & \text { athematic } \\ 1 \text { sg. } & * \text {-mi } \\ 2 \text { sg. } & * \text {-si } \\ 3 \text { sg. } & * \text {-ti } \\ 3 \text { pl. } & * \text {-nti }\end{array}$

\section{thematic}

*-o $<*_{-}-\mathrm{O}-\mathrm{h}_{2}$

$*$-e-si

$*$-e-ti

*-o-nti

These inflections are referred to, somewhat confusingly, as primary endings. ${ }^{2}$ By contrast, the secondary endings, which are used in the imperfect and the aorist, as well as the optative, lack the final ${ }_{-}-i$, hence $1 \mathrm{sg} . *_{-} m, 2 \mathrm{sg}$. ${ }_{-}^{*} s$, etc.

The daughter languages are in less agreement about how the remaining present inflections should be reconstructed, but a fairly conservative reconstruction of all the present primary and secondary endings in the singular, dual, and plural is as follows: ${ }^{3}$

\begin{tabular}{|c|c|c|c|}
\hline & athematic & thematic & secondary \\
\hline $1 \mathrm{sg}$. & $*$-mi & $*_{-} \overline{\mathrm{o}}<*-\mathrm{o}-\mathrm{h}_{2}$ & $*_{-}(\mathrm{o}-) \mathrm{m}$ \\
\hline $2 \mathrm{sg}$. & $*_{\text {-si }}$ & $*_{\text {-e-si }}$ & $*_{-}(\mathrm{e}-) \mathrm{s}$ \\
\hline $3 \mathrm{sg}$. & $*_{-}$ti & $*_{\text {-e-ti }}$ & $*_{-}(\mathrm{e}-)^{t}$ \\
\hline 1 du. & *-unes/unos & *-o-unes/uos & *-(o-)ue/ūe \\
\hline 2 du. & $*$-tes & $*$-e-tes & $*_{-}(\mathrm{e}-)$ tom \\
\hline 3 du. & *-tes & $*$-e-tes & 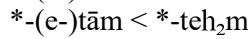 \\
\hline 1 pl. & $*_{\text {-mes }}$ & $*$-o-mes & $*_{-}(\mathrm{o}-) \mathrm{me} / \mathrm{me}$ \\
\hline 2 pl. & $*$-te(s) & $*_{\text {-e-te(s) }}$ & $*_{-}(\mathrm{e}-)$ te \\
\hline 3 pl. & $*$-nti & $*_{\text {-o-nti }}$ & $*_{-}(\mathrm{o}-) \mathrm{nt}$ \\
\hline
\end{tabular}


It is evident that the present endings in Germanic must reflect the PIE primary rather than the secondary endings. For example, Go. 3 sg. $-p$ must reflect primary *-ti, as secondary PIE *-t would have been lost altogether $(\$ 6.11)$.

The personal endings of the perfect cannot all be reconstructed with assurance, but the endings in the singular, at least, are secure: ${ }^{4}$

\begin{tabular}{|c|c|c|c|}
\hline & singular & dual & plural \\
\hline 1 & $*-h_{2} \mathrm{e}(>*-a)$ & *-úé & *-mé \\
\hline 2 & $*-\operatorname{th}_{2} \mathrm{e}$ & $?$ & $*_{-}\left(\mathrm{h}_{1}\right) \mathrm{e}^{\mathrm{s}}$ \\
\hline 3 & $*_{\text {-e }}$ & ? & $*_{\text {-rrér }}$ ? \\
\hline
\end{tabular}

The non-singular forms, in particular, have undergone extensive refashioning in the various IE branches, including Germanic.

1. The thematic inflections are here given with the preceding thematic vowel in order to show where they took $e$-grade and where $o$-grade.

2. The terminology is confusing because it should be obvious that the secondary endings are more basic, and the primary are derived from them by the addition of the hic et nunc particle ${ }^{*}-i$, here associated with present tense; the endings without $-i$ are thus associated with non-present functions. The terminology of course is predicated on the idea that the simple present tense is more basic than the imperfect or the aorist, even though the considerable majority of present stems are not basic but are derived by means of the kinds of affixation described in $\S 12.3$.

3. See Szemerényi 1996: $\S \S 9 \cdot 2 \cdot 1.1-2$. The $1 \mathrm{sg}$. secondary ending * ${ }_{-} m$ is used for both thematic and athematic stems. When the thematic vowel appears before the secondary $1 \mathrm{sg}$. ending ${ }^{*}-m$ it is of the $o$-grade: cf.

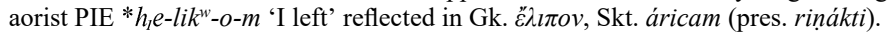

4. See, e.g., Szemerényi 1996: §9.2.3, Clackson 2007: 128, Fortson 2010: 103-4, and Beekes 2011: §18.4.2 for differing views on the reconstruction of the perfect endings..

\subsection{The middle voice in Proto-Indo-European}

The usual function of the middle voice in the IE languages is to express reflexive or reciprocal action, e.g. OIcel. verjask 'defend oneself' (cf. active verja 'defend') and berjask 'fight (each other)' (cf. berja 'strike'). ${ }^{1}$ In accordance with the reflexive function, it may also turn a transitive into an intransitive verb, as with OIcel. sýnask 'seem' (cf. sýna 'show'). The PIE middle voice may in addition have encompassed passive meaning (see $\S 12.1$ n. 1), in a manner analogous to OIcel. middle eyðask 'be depopulated' (cf. active eyða 'lay waste'). In some cases, however, IE verbs inflected for middle voice have only active meaning, and the reason for middle inflection is obscure, just as with so many deponent verbs in the classical languages, e.g. Lat. cōnor 'attempt' and sortior 'cast lots'.

The oldest middle inflections appear to have resembled those of the perfect, and common origin of the two can be explained on the basis of similar functions, the middle denoting reflexivity, out of which passive meanings commonly develop, and the perfect is probably stative in origin, denoting states of passivity (see Clackson 2007: 149-50). Over the course of time, the corresponding active inflections exerted analogical influence upon the middle ones, restructuring them so that the resemblance to the perfect inflections is difficult to discern in any single IE language, with wide differences among languages in this respect. The Germanic languages group with Indo-Iranian, Greek, and Albanian in showing mostly forms with final $*_{-} i$, apparently reformed by the addition of this element of the primary active endings to middle secondary endings. The relevant 
endings for these languages are perhaps to be reconstructed thus (following, for the most part, Szemerényi 1996: $\$ 9.2 .2 .1$ ):

\begin{tabular}{|c|c|c|}
\hline & primary & secondary \\
\hline $1 \mathrm{sg}$. & *-ai/mai & $*_{-} \overline{\mathrm{a}} / \mathrm{ma} \overline{\mathrm{a}}<*_{-}(\mathrm{m}) \mathrm{eh}_{2}$ \\
\hline $2 \mathrm{sg}$. & $*_{\text {-soi }}$ & $*_{\text {-so }}$ \\
\hline 3 sg. & $*$-toi & *-to \\
\hline 1 pl. & *-medha & *-medha \\
\hline 2 pl. & *-dhue & *-dhue \\
\hline 3 pl. & *-ntoi & *-nto \\
\hline
\end{tabular}

The dual forms in this paradigm are too uncertain to be reconstructed. No dual forms of the middle voice are reflected in Germanic.

1. Note, however, that the $\mathrm{ON}$ middle voice is a NGmc. innovation (see §12.29) unrelated etymologically to the PIE middle voice.

\subsection{The moods of Proto-Indo-European}

The indicative mood was used in PIE for factual statements and, in effect, all modalities other than commands, wishes, and counterfactuals. All the inflections examined so far have been indicative.

The imperative mood was used to express commands in both the second and third persons. The most relevant PIE imperative inflections are reconstructed as follows, where $*_{-} \varnothing$ in the $2 \mathrm{sg}$. of the athematic type indicates that the bare stem is used with no inflection, and $*_{-} e$ in the $2 \mathrm{sg}$. thematic type represents the thematic vowel itself (and so, like the athematic type, this one is technically inflectionless):

$\begin{array}{lll} & \text { athematic } & \text { thematic } \\ \text { 2 sg. } & *_{-} \varnothing, *_{\text {-dhi }} & *_{\text {-e }(-\varnothing)} \\ \text { 3 sg. } & *_{\text {-t }(\mathrm{u})} & *_{\text {-e-t }(\mathrm{u})} \\ \text { 2 pl. } & *_{\text {-te }} & *_{\text {-e-te }} \\ \text { 3 pl. } & *_{\text {-ent }(\mathrm{u})} & *_{\text {-o-nt(u) }}\end{array}$

The imperative stem is generally the same as the present stem, with few exceptions. PIE also had middle imperatives (see, e.g., Szemerényi 1996: §9.2.5), but they are of no demonstrable relevance to Germanic. On injunctives, see $\S 12.1 \mathrm{n}$. 2 , and on the so-called future imperative in *-tōd, see $\S 12.28$.

The optative mood is used chiefly in independent clauses to express wishes and related volitional modalities. On the standard view, the optative was formed by the addition of the ablauting suffix $*_{-}-i e h_{l} / h_{l} / i h_{1}$ - to each of the three basic verb stems, the present, the aorist, and the perfect $(\$ 12.1)$. In athematic verbs the root was generally in the weak grade, whereas the optative suffix was in the $e$-grade in the singular, elsewhere in the weak grade with accent on the inflection. By contrast, in thematic stems the root was the same throughout the paradigm (as usual), the thematic vowel was consistently $*_{-} O-$, and the optative suffix was in zero grade throughout. Both types, athematic and thematic, added secondary endings to the optative suffix. The pattern may be illustrated by reconstructed paradigms of the present active of athematic *hes- 'be' and thematic *bhér- 'bear' (after Fortson 2010: 107): 


\begin{tabular}{|c|c|c|}
\hline & athematic & thematic \\
\hline $1 \mathrm{sg}$. & $* h_{1} s-i e h_{1}-m$ & *bhér-o-ih $\mathrm{h}_{1}-\mathrm{m}$ \\
\hline $2 \mathrm{sg}$. & $* \mathrm{~h}_{1} \mathrm{~s}-\hat{\mathrm{ieh}} \mathrm{h}_{1} \mathrm{~s}$ & *bhér-o-îh $\mathrm{h}_{1}-\mathrm{s}$ \\
\hline 3 sg. & $* \mathrm{~h}_{1} \mathrm{~s}-\hat{\mathrm{i}} \mathrm{eh}-\mathrm{t}$ & *bhér-o-ih $\mathrm{h}_{1}-\mathrm{t}$ \\
\hline 1 pl. & $* \mathrm{~h}_{1} \mathrm{~s}-\mathrm{i} \mathrm{h}_{1}$-mé- & *bhér-o-îh $\mathrm{h}_{1}$-me- \\
\hline 2 pl. & $* \mathrm{~h}_{1} \mathrm{~s}-\mathrm{i} \mathrm{h}_{1}$-té- & *bhér-o-îh $h_{1}$-te- \\
\hline 3 pl. & ${ }^{*} \mathrm{~h}_{1} \mathrm{~s}$-ih $\mathrm{h}_{1}$-ént & *bhér-o-i $\mathrm{ih}_{1}$-ent \\
\hline
\end{tabular}

The standard view accounts well for the athematic optative. The assumption, however, that the thematic optative was formed of the theme vowel ${ }^{*}-o$ - plus optative suffix $-i h_{1}$ plus inflection faces some notable difficulties, as pointed out by Sihler (1995: §539.2). One is that appearance of the theme vowel $*_{o}$ throughout the paradigm is unparalleled. In derived forms, in fact, the theme vowel should be *e throughout, as in Gk. $\varphi \circ \beta \varepsilon \dot{\varepsilon} \omega$ 'frighten', derived from $\varphi o ́ \beta o \varsigma$ 'terror'. Another is that *-o-i $h_{l}$ - should be expected to be realized as ${ }^{*}$-oi $h_{1}$ - before an obstruent beginning the inflection, and yet there is no evidence for such a realization in the language families where the evidence should be plainest, Hellenic and Indo-Iranian. Yet Streitberg (1896: §221) is right to invoke the

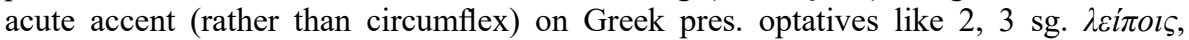
$\lambda \varepsilon i \pi o l$ as evidence that the suffix was not simply PIE *-oi- but must be regarded as, in Gmc. terms, trimoric $\left({ }^{*} o+\bar{\imath}\right.$ in his notation). ${ }^{1}$ Perhaps Clackson (2007: 136-7) is right that the postvocalic laryngeal was lost early, with compensatory lengthening, in forms like athematic $1 \mathrm{pl}$. * $h_{1} s-i h_{l}-m e ́>*$ simé '(we) are', and $\bar{\imath}$ was then extended analogically to thematic stems, e.g. *bhér-o-i-me. Certainly, PIE *-oih $m$ accounts admirably for Go. 1 sg. pres. -áu (§12.26). It is reflected as well in Skt. bhar-ēy-am 'I would bear' (which, however, has $\bar{e}$ by analogy to the rest of the paradigm) and Arcadian Gk. $\varepsilon \xi \xi \lambda \alpha v v o l \alpha$ 'I would drive out'.

The subjunctive mood, as its name implies, is used in subordinate clauses. In the few daughter languages in which the PIE subjunctive is reflected, it largely has future meaning, but presumably in PIE it also expressed any contrary-to-fact condition, a function assumed by the etymological optative in many IE languages. In PIE the subjunctive was formed by the addition of the ablauting thematic vowel to the present or aorist stem regardless of whether it was already thematic; whether the inflections added to this were primary or secondary, or a combination of the two, is a matter of dispute (see Szemerényi 1996: §9.3.1.1 for references). Thus, to athematic ind. $3 \mathrm{sg}$. * $h_{l} e ́ s-t i$ 'is' cf. subjunctive *hes-e-t(i), yielding Skt. ásti and ásat(i), respectively, and to thematic ind. $3 \mathrm{sg}$. *bhér-e-ti 'bears' cf. sj. *bhér-e-e-t(i), yielding Skt. bhárati and bhárāt $(i)$, respectively. The PIE subjunctive was lost entirely in Germanic, its functions assumed for the most part by the original optative.

1. Streitberg's observation raises a difficulty for the assumption that the laryngeal was lost in PIE in the anteconsonantal sequence *-oinh ${ }^{-}$: see Beekes 1969: 238-42, 254-5 (with references), Ringe 2017: 16-17, 43.

\subsection{Non-finite verb forms}

The non-finite verb forms to be considered are infinitives and participles, the latter either active or passive, corresponding to so-called present and past participles.

Infinitives are verbal nouns, which correspond in meaning to English infinitives (e.g. to swim) and gerunds, i.e. (in English) words in -ing serving as nouns rather than adjectives (e.g. swimming). In PIE there were several different ways to form verbal 
nouns from verb stems, and many of these formations are reflected in Germanic as nouns rather than infinitives. PIE verbal nouns could be formed by the addition of a suffix *-ti- to a verb root or stem, as with OCS $d a-t i$ 'to give', Lith. $b \dot{u}-t i$ 'to be', and

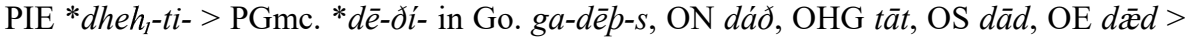
PDE deed; also PIE * gus-ti- in Go. ga-kust-s 'test', OE cyst 'choice' (cf. OE cēosan 'choose' < PIE * geus $^{-}$). Another suffix was *-tu-, as in Skt. dấ-tu-m 'to give' and PGmc. *flō-ðú- > Go. flodus, OIcel. flóð, OHG fluot, OE flòd 'flood' (cf. OE flōwan '(over)flow' and Gk. $\pi \lambda \omega \tau \sigma^{\varsigma} \varsigma$ 'flotation'). Various suffixes in *-n-were also used to form verbal nouns, e.g. *-men/mon- in Skt. vid-mán-e 'to find' (= Homeric Gk. i $i \delta \mu \varepsilon v \alpha l)$ and

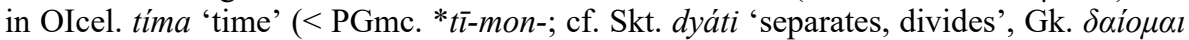
'divide, allot') beside tí , OE tīd NHG Zeit 'time' (< PGmc. *tī- $\partial \dot{a}-)$. True Germanic infinitives are neuters formed with the PIE suffix *-no- (added to the thematized stem, unlike in PIE), as in Go. bairan, ON bera, OE OS OHG beran 'to bear' < PGmc. * berana $^{n}=$ Skt. bharanam. See further $§ 12.30$.

First (active, present) participles are deverbal adjectives expressing active voice. PIE originally had separate suffixes of this kind for present and perfect verb stems, as well as a separate middle suffix, but only the suffix $-n t-$, attached to present stems, is reflected as a participial suffix in Germanic. It is in fact reflected in all the IE languages, though not always as a productive means of adjectival formation. In both athematic and thematic verbs the suffix alternated between $*_{\text {-ont }}$ and ${ }^{*}-n t$ - within the paradigm by strong and weak case (see §7.4): ${ }^{1}$ to full grade Skt. acc. sg. masc. adántam 'eating' (< $* h_{1} e d$-ont-mo) compare gen. sg. adatáh $\left(<* h_{1} e d\right.$-not-os).

From their semantics it is plain that second (passive or past) participles in *-tóand *-nó- (with weak grade of the root and no very obvious distinction in meaning) ${ }^{2}$ are not participial in origin; ${ }^{3}$ hence, they are commonly said to form verbal adjectives rather than participles. The distinction has been eliminated in most IE languages, though in Greek such verbal adjectives generally maintain their original meaning, e.g. $\sigma \tau \alpha \tau o ́ \varsigma$ 'stationary' : Skt. sthitáh, Lat. status 'having stood'. The two suffixes are differentiated in some IE branches, including Germanic, in which they form passive participles to weak and strong verbs, respectively: see §12.30. Examples are PIE *k̂klu-tó-s in Skt. śru-

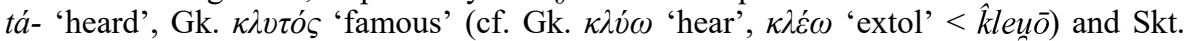
bhinná- 'split' < *bhid-nó- (cf. bhinádmi 'split').

1. Full-grade *-ont- must not be analyzed as containing the thematic vowel, as the vowel disappears in the weak cases, which is not a characteristic of the thematic vowel.

2. In Skt. the reflex of *-nó- is used only with a limited set of common verb roots ending in a vowel or a non-labial stop: see Whitney 1889: §957. In Skt. grammar these are called past passive participles, to distinguish them from participles formed to present passive stems.

3. Likewise, true participles were formed by the addition of the participial suffix to a tense stem, whereas the verbal adjectives were formed from the verb root (Brugmann \& Delbrück 1897-1916: II, 3.2.968). One semantic indication that they are not participial in origin is that their reflexes are alternately active and passive in meaning, e.g. Skt. sthitá- 'having stood' : hatá- 'having been struck'.

\subsection{Particles and the Proto-Indo-European verb}

Many PIE verbs bore clitic prefixes, usually derived from prepositions and particles. An example is PIE * prō prep. 'forward, for, before' plus *bhéreti 'bears' in Skt. pra-

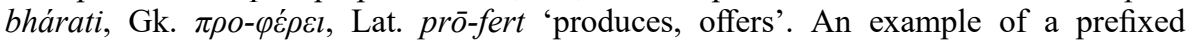
particle is *ne 'not' in Lat. ne-sciō 'do not know' and Lith. ne-seĩ-nyti 'fail to attain'. 
Some such clitic formations are to be found in Germanic, e.g. PIE *pro- in Go. fra-itan, OE fretan, OHG frezzan 'devour' and *ne in Go. nist < ni ist 'is not'. However, most Germanic verb prefixes are later innovations without directly parallel uses in the other IE languages, e.g. Go. faúra-gaggan, OE fore-gangan 'precede' and Go. faúr-gaggan, OE for-gangan 'pass by, overlook'. The two types are often difficult to distinguish. See especially Buckso 2011 on developments in Gothic; Schulte (2007: 8-10) offers an inventory of Gmc. preverbs.

\section{Germanic Verb Morphology}

\subsection{The general nature of the restructuring of the Germanic verb system}

The rather complex verb system of PIE, with its morphologically distinct aspects, tenses, and moods, was considerably simplified in Proto-Germanic. As in most other IE branches, the distinction between aspect and tense was eliminated; in Germanic, aspect was replaced by tense through the elimination of imperfect and aorist stems, the IE perfect coming to play the role of the preterite. ${ }^{1}$ A few Gmc. preterites can plausibly be related to an original, stative perfect meaning, e.g. PGmc. *laih ${ }^{w}$ 'has left behind' $>\mathrm{OE}$ lāh 'lent', but most either are resultative perfects with no obvious derivation from stative meaning or are aorist in meaning and are thus innovations, e.g. Go. haihald 'held, has held' and lailáik 'leapt'. The collapse of aorist and perfect meanings is particularly evident in verbs like Go. sat 'sat down, was sitting'. In the present system, too, aspect to a great extent grew irrelevant with the loss of productiveness in most suffixes used to form present stems. A small number of present suffixes retained their productivity, and although two of them retained their aspectual significance-causative and inchoative, employed in the first and fourth weak classes of Germanic - the more important function of the remaining productive present suffixes continued to be to provide a means of forming new verbs. Thus, a few of the most productive present suffixes of PIE continued in use, resulting in four distinct classes of so-called weak verbs. The suffixes that formed such verbs in PIE were used only to produce present stems, and thus a particular need in Germanic was a means of bringing such new formations into line with older, so-called strong verbs in respect to tense alternations. The reduction of the IE tense and aspectual systems to a binary opposition between present and preterite stems afforded an opportunity to satisfy that need, and a new method of forming the preterite for such verbs arose, by the addition of a dental suffix. The strong verbs at the same time grew more uniform in their morphological expression, for example adopting a single present stem for each verb, eliminating competitions like that between suffixed and unsuffixed stems, or between regular thematic and tudáti-type present stems (§12.18). Certainly, some archaic formations were retained, especially among verbs of high frequency, but for the most part, morphological alternatives without any obvious retained significance were replaced by a single standard: for example, although a small number of athematic verbs are still recognizable as such in Germanic, nearly all verbs adopted the morphology of thematic formations, e.g. Go. ga-teiha 'I tell, show' < PIE $*_{\text {-dei }}$ - plus thematic $*_{-} \bar{o}$ rather than athematic ${ }_{-}-m i$ (cf. athematic Skt. dí-des-t $t i$ 'shows', Gk. $\delta \varepsilon i \kappa-v \bar{v}-\mu l$ ), but athematic Go. im 'am' < *hés-mi and OHG tuom '(I) do'. ${ }^{2}$

The four moods of PIE were reduced to three in Gmc. when the formal optative assumed the functions of the original subjunctive. A few formal aorist subjunctives 
survive in pres. ind. use, as may be determined by the loss of certain pres. ind. stems

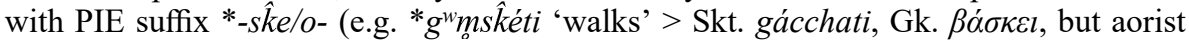
sj. * $g^{w} e ́ m-e / o-$ in Go. qiman 'come') or $n$-infix (e.g. 3 pl. pres. ind. *bhindénti $>$ Skt. bhindánti 'split', but aorist sj. *bhéid-e/o- in Go. beitan 'bite'): see Ringe 2017: 185-6.

Although the middle voice of PIE is reflected in the Gothic passive, it was almost entirely lost elsewhere in Germanic. ${ }^{3}$

1. Aorist forms must have continued in use into the WGmc. period if the WGmc. 2 sg. pret. ending $*_{-} i$ is to be derived from the aorist inflection (though this is dubitable: see $\$ 12.25$ ). The extent to which Gmc. preserves traces of the aorist is a matter of controversy: see, e.g., Dimler 1974, Mottausch 2013, and see, e.g., $\S \S 12.14,12.39,12.59,12.61,12.63$ infra.

2. In the older IE languages, finite verb forms require no explicit pronominal subject, e.g. Lat. paratus sum 'I am prepared'. The same is true of Gothic, but in the other Gmc. languages an explicit subject is required; hence tuom '(I) do'. On null subjects in the early Gmc. languages see, e.g., Harbert 2007: 221-3.

3. Austefjord (1984) discusses the simplification of the Gmc. verb system on the basis of leveling from the preterite to the present and the reverse. Hewson (2001) explores the conversion of aspect to tense in Gmc.

\subsection{Morphological restructuring of root, stem, and inflection in Proto-Germanic}

As explained in $§ 7.1$, the distinction between stem and inflection was obscured in some noun forms already by the end of the PIE period, with the result that some suffixes became unrecognizable as such and were instead analyzed as part of the inflection. This process was greatly accelerated during the PGmc. period. Among the verbs a comparable development is observable. A simple example is the incorporation of the reflex of the theme vowel into the personal endings attached to it, for instance the development of PIE 3 sg. pres. ind. *-e-ti and pl. *-o-nti to Go. $-i p$ and -and, with the result that the reanalyzed endings were generalized, extended to most verbs that had never contained a theme vowel, essentially turning what had been athematic verbs into thematic ones. ${ }^{1}$ But suffixes besides the theme vowel could also become part of the inflection. A plain example is observable in the reanalysis of verbs of the second weak class in Ingvaeonic, whereby, e.g., PIE 3 pl. pres. ind. *-éi-o-nti developed to ${ }^{*} i j a^{n} b$ in heavy-stemmed weak verbs of the first class, and from this was abstracted ${ }^{*}-j a^{n} b$, which was extended to stems of the second weak class ( $(12.43)$. With the phonological reduction of unstressed syllables, then, the suffix as a morphological category intermediate between root and inflection became, to a great extent, unrecognizable as such, and the morphology of most verbs was reduced to a matter of roots (formerly stems) and inflections.

1. For specific examples of thematization, see Bammesberger 1982a.

\section{Strong Verbs}

\section{A. STEM FORMATION}

\subsection{The general nature of strong verbs}

Strong verbs are those in which the present and the preterite are distinguished by rootinternal vowel alternations derivable from ablaut alternations in Proto-Indo-European, 
conforming, with minor deviations, to discrete patterns of alternation that are the basis for identifying seven classes of strong verbs. The one exception to the rule of ablaut alternations between present and preterite is that the majority of verbs of the seventh class in Gothic have the same root vowel in both tenses, and the two stems are instead distinguished by the addition of reduplication in the preterite: see $\$ 12.16$. Most of the distinctions among the classes, however, are due not to ablaut differences in PIE but to specifically Germanic developments of the PIE vowels.

The relevant vowel alternations are observable in the oppositions among four stems: (1) the present stem, including the indicative, the imperative, the present subjunctive ( $<$ optative), the infinitive, the active participle, and, in Gothic, the passive; (2) the preterite singular (but not, in WGmc., the $2 \mathrm{sg}$.); (3) all remaining preterite forms, including the plural, the subjunctive, and, in WGmc., the 2 sg.; and (4) the past/passive participle. The alternations in the stems of Germanic strong verbs are thus conventionally represented by four principal parts: (1) infinitive, (2) pret. 1/3 singular, (3) pret. 3 plural (as here, though instead very commonly $1 \mathrm{pl}$. in handbooks), and (4) second participle, nominative singular masculine (as here) or neuter. ${ }^{1}$ In these principal parts are observable ablaut alternations in the first six classes derivable from the following in Proto-Germanic:

(1)

$\begin{array}{ll}\text { Class I } & *_{\overline{1}} \\ \text { Class II } & *_{\mathrm{eu}} / \overline{\mathrm{u}} \\ \text { Class III } & *_{\mathrm{e}} / \mathrm{i} \\ \text { Class IV } & *_{\mathrm{e}} \\ \text { Class V } & *_{\mathrm{e}} \\ \text { Class VI } & *_{\mathrm{a}}\end{array}$

(2)

*ai

*au

$* \mathrm{a}$

$* \mathrm{a}$

$* \mathrm{a}$

$*_{\overline{0}}$
(3)

$\begin{array}{ll}*_{\mathrm{i}} & *_{\mathrm{i}} \\ *_{\mathrm{u}} & *_{\mathrm{o}} \\ *_{\mathrm{u}} & *_{\mathrm{o}} \mathrm{u} \\ \text { * }_{\bar{e}_{1}} & *_{\mathrm{o}} \\ \text { * }_{\mathrm{e}_{1}} & *_{\mathrm{e}} \\ *_{\overline{0}} & *_{\mathrm{a}}\end{array}$

1. The pp. of many verbs in OIcel. occurs only in neuter form (e.g. verit 'been'), though for consistency's sake only what would be the nom. sg. masc. form is usually given in this book (e.g. veriðr). In OHG, the citation form of the past/passive participle, given as principal part (4) of strong verbs and (3) of weak (\$12.33) is simply uninflected, whereas the nom. sg. masc. ends in $-\bar{e} r$, the neuter in $-a z(\S 9.2)$.

\subsection{Productivity}

In general, the strong verbs represent a closed, unproductive category in the attested Gmc. languages, with few additions over time. There do occur some innovations, but they often betray their status as neologisms by incomplete assimilation to strong patterns, e.g. PDE pp. shown and proven beside pret. showed, proved; and, conversely, in North American English, pret. dove beside pp. dived. Rather, in the course of the later Middle Ages strong verbs in all the Gmc. languages were extensively refashioned as weak ones or passed out of use altogether. ${ }^{1}$ The situation in the prehistoric period quite possibly was different, as there are numerous Gmc. strong verbs with no convincing IE etymology, so that they may be suspected of being additions to the strong verb inventory, perhaps from substrate languages. ${ }^{2}$ It appears that strong verbs could be added even as late as the WGmc. period, e.g. OE scrîfan, OFris. skrīva, OS skrītan, OHG skrīban 'write' (class I, OE pret. scrāff, etc.), borrowed from Lat. scrībō 'write'. ${ }^{3}$

1. Thus, for example, Krygier (1994: 59-65, 246) finds that of 367 strong verbs identified in OE, 61 are commonly inflected weak, and nearly a quarter have no reflexes after the OE period. In general, the complete 
conversion of any strong verb to a weak is infrequently attested in the early Gmc. languages before ca. 1200 , and after ca. 1600 there are about as many instances of conversion of weak to strong verbs as there are of the opposite development. For discussion and references, see Fertig 2009, 2016; also van Haeringen 1940.

2. See Mailhammer 2006. For example, a group of verb stems in gr- (e.g. OHG grīnan 'whimper', Go. grētan 'weep', OE grēotan 'weep') has no convincing IE etymology and may be derived from a substrate, if the origin is not simply onomatopoeic (Seebold 1970: 237, 241).

3. It is perhaps likelier, though, that the other WGmc. languages have borrowed the word from OE, due to Anglo-Saxon missionary efforts. Certainly, OIcel. skrifa is the result of missions to Scandinavia. That the WGmc. word is a borrowing rather than native is disputed: see, e.g., Orel 2003: 344, but cf. Seebold 1970: 420 .

\subsection{Derivation of Proto-Germanic ablaut patterns: classes I-III}

To a considerable extent, the alternations tabulated in $\$ 12.11$ are derivable from a familiar PIE pattern whereby $* e$ is the ablaut alternant in the present stem (at least in most thematic stems and in the singular of athematic ones), ${ }^{*} o$ in the perfect singular, weak grade in the perfect dual and plural, and weak grade in the verbal adjective in *-nó-. Classes I-III are almost perfectly regular in this respect. In class I, PIE *ei $>$ PGmc. $*_{i}$ and PIE $* o i>$ PGmc. ${ }^{*} a i(\S 3.4)$, and the vocalization of PIE $* i$ under reduced grade is *i, preserved as such in PGmc. In class II, PIE *eu > PGmc. *eu and PIE *ou > PGmc. *au (\$3.4); and the vocalization of *u under reduced grade is $* u$, preserved as such in PGmc, except that at least in NWGmc., in the passive participle it is lowered to $*_{o}$ before $* a$ in the next syllable ( $\left.\$ 4.3\right)$. (On the alternative vowel $* \bar{u}$ in the present stem of class II, see $\S 12.18$.) In class III, PIE *eR (where $R=/ \mathrm{r}, 1, \mathrm{~m}, \mathrm{n} /$ ) $>$ PGmc. ${ }^{*} e R$ except when $R$ is a tautosyllabic nasal consonant, in which event it becomes *iR (§4.4); PIE $* R>$ PGmc. $* a R(\$ 3.2)$; and PIE $* R$ under reduced grade is vocalized to $* R$, producing PGmc. * $u R$, except that at least in NWGmc., * $u R$ becomes * $o$ before $* a$ in the next syllable when $R$ is not a nasal consonant and no $j$ intervenes (\$3.2). The remaining strong classes show varying degrees of deviation from the ablaut patterns of the PIE perfect to be expected on the basis of the comparative IE evidence.

\subsection{Derivation of Proto-Germanic ablaut patterns: classes IV-V}

In classes IV and $\mathrm{V}$ the preterite plural shows PGmc. ${ }^{*} \bar{e}_{1}$ for expected reduced grade, and there is no consensus as to why this is so. That $*_{\bar{e}}$ is an analogical replacement for vowels reflecting original reduced grade may be inferred from the preterite-present verbs of the corresponding class types: cf. Go. pres. 1 pl. munum 'remember' and magum 'can', corresponding morphologically to preterite plurals of classes IV and V (§12.54), with the root-vowels $u$ and $a$ reflecting the expected schwa secundum (§§3.12). The commonest explanation is that the perfect stem in the preterite plural of classes IV-V has been replaced by the sigmatic aorist stem (minus the $s$ suffix) with lengthened grade of the root vowel. ${ }^{1}$ That lengthened grade in the aorist is a PIE feature rather than an innovation in individual branches of the IE family is disputed, though Szemerényi (1996: $\S \S 9.4 .2 .1(c), 6.2 .8$ Addendum 1) offers cogent reasons to regard it as of PIE origin. ${ }^{2}$ Perhaps the most serious objection to this analysis is that it is not plain what should have motivated the replacement of the perfect stem by the aorist in the preterite plural only. Accordingly, some prefer the view that ${ }^{*} \bar{e}$ originates in the verb reflected as 
Go. etan 'eat' (class V), where the Gmc. preterite would have been formed by reduplication $\left(3 \mathrm{sg} .{ }^{*} e-a t\right)$ or by the augment $\left(* e_{-}<* h_{l} e-\right)$ found in the PIE imperfect (though there is no other secure evidence for a PIE augment in Gmc.: see $\S 12.61){ }^{3}$ This explanation furnishes a plausible source for the analogical change, but it leaves unanswered the question why the change did not take place in the singular, as well as the question what in the system motivated the complete loss of the original preterite plural reduced-grade vocalism and replacement by $\bar{e}$. A more recent suggestion is that the

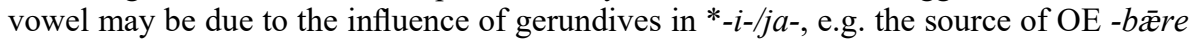
(as in OE wæstmbǣre 'fruit-bearing' and hornbǣre 'horn-bearing'): so Heidermanns 1999. On the other hand, it has been argued, as well, that $\bar{e}$ in the plural originated in the verb 'sit', with *sêt- as the regular phonological development of reduplicated perf. pl. *se-st-, and the long vowel spread analogically (Bammesberger 1994a, and see n. 3 infra). For discussion and references, see Laker 2001.

1. So, e.g., Brugmann 1913: 143-8 (and in Brugmann \& Delbrück 1897-1916: II, 3.433-5, 489-90), Guchmann 1966: 314-15.

2. Szemerényi's idea that the long vowel results from compensatory lengthening upon loss of tense-marker $*_{s}$ (under Szemerényi's law) renders it easier to believe that the sigmatic aorist should have been the source, given that ${ }^{*} s$ appears nowhere in these Gmc. preterite plurals. That there was a lengthened-grade aorist in PIE is rejected by many, e.g. Cowgill 1960: 492 n. 25, who nonetheless draws a distinction between this and long vowels of other origin in the aorist (1957: 46-52). Matzel (1970) and Meid (1971: 48-54), on the other hand, envisage PIE perfects with lengthened grade.

3. So, e.g., Mottausch 2000 and Mailhammer 2007: 67-86, both with extensive references. Some other explanations (for which they provide further bibliographical references) are the following: (1) the cause is compensatory lengthening upon loss of the root-initial consonant originating in reduplicated, zero-grade perfect plurals, e.g. PIE *bhe-bhr- > PGmc. *bēr- (so, e.g., Sihler 1995: §525.6a), PIE *se-zd- > *sēd- 'sat' (as in Lat. sēdimus; so esp. Streitberg 1896: §96; cf. the telling objections of Prokosch 1939: §57); (2) as proposed by Kuryłowicz (1956: 310-12, Kuryłowicz et al. 1968-2015: II, 290-1), the vowel length is analogical to the length in preterites of class VI. This of course leaves unexplained why the preterite singular retained a short vowel.

\subsection{Derivation of Proto-Germanic ablaut patterns: class VI}

The ablaut pattern in class VI is unlike patterns normally reconstructed for PIE verbs. Accounting for how it could have arisen in Gmc., however, is a matter of considerable difficulty, not least because analogical developments should be expected to have produced a pattern resembling one already found in the language rather than an entirely new one. The irregularities stem, moreover, not just from the vowel qualities and quantities, but also from a different distribution of variants under Verner's law, as discussed below (§12.17). An added difficulty is that because the ablaut pattern appears not to derive from PIE, identifying the source of the vowel $a$ in the present and in the second participle, and of $\bar{o}$ throughout the preterite, is subject to many uncertainties. Thus, for example, $a$ in the present may derive from PIE (1) $o$, (2) $a$, (3) ${ }_{o}$, (4) $h_{2} e$, or (5) $h_{3} e$ $(\S \S 3.1-2)$. Nearly all of these sources in fact appear to have been involved, though etymologies are not uniformly certain: ${ }^{1}$ (1) Go. faran 'go' and cognates < PIE *por- (cf. Gk. $\pi \varepsilon \rho \alpha \dot{\omega} \omega$ 'drive through'); (2) Go. skaban 'scrape' and cognates < PIE *skabh- (cf. Lat. scabo 'scratch'); (3) OE bacan 'bake' < PIE *bhag- <*bhh $h_{3}$ - (cf. Gk. $\varphi \omega ́ \gamma \omega$

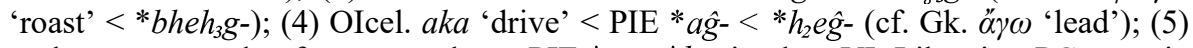
no known example of root vowel $a<$ PIE $*_{o}<{ }^{*} h_{3}$ in class VI. Likewise, PGmc. $\bar{o}$ in the preterite may derive from PIE $\bar{a}$ or $\bar{o}(\$ 3.3)$, and both appear to be actual sources in attested verbs, e.g. OE wōd (wadan 'advance'; cf. Lat. vādo 'wander') and scōp 
(scieppan 'create, form'; cf. Lat. scōpa 'twig'). Yet PGmc. * $\bar{o}$ is found in some preterites that cannot derive from PIE forms with either $\bar{a}$ or $\bar{o}$, e.g. Go. för (to faran, cf. Gk. $\pi \varepsilon \rho \alpha \dot{\alpha} \omega$ above): a lengthened $o$-grade to this root is not found in any other IE branch. Whether substrate influence might have played a role is unknowable.

Despite the uncertainties involved, certain probabilities can be established. Since the vowel $a$ in the present is polygenetic, it is probably most preterites, rather than presents, that are analogical formations. The lack of a distinction between singular and plural stem in the preterite accords with this assumption: if the need to create new preterites led to the proliferation of stems in $\bar{o}$, distinguishing between singular and plural in the preterite would have been less urgent a requirement than distinguishing between present and preterite, and presumably the model for the analogical change, whatever it was, afforded no distinction between singular and plural stems. The assumption that most preterites of class VI are of analogical origin would also explain the distribution of voicing under Verner's law in these verbs $(\$ 12.17)$. Some of the views of Prokosch (1939: §60) accord well with these probabilities. He argues that at least some of the present stems contained a (i.e. $H_{o}$ ) and were aorist in their Aktionsart, and hence of the tudáti type (\$12.18 infra). He supports this idea by reference to pairs of verbs in Latin with $a$ in the root and distinguishing perfective and imperfective action by the opposition reduced grade : full grade. Thus, compare Lat. lăbō 'waver' : lābor 'glide', and vădo 'pass through' : vādo 'wander'. ${ }^{2}$ (Many verbs of class VI would have been derived verbs - many, for instance bear a $j$-suffix — and so they would not originally have had preterites $(\$ 12.3)$, thus requiring new preterites to be formed for them in Germanic.) Although long-vowel perfects in Latin are polygenetic, and a great many of them analogical in origin (see, e.g., Sihler 1995: §525), some, at least, have their long vowel by regular phonological development (e.g. féci $<* d h e h_{1}-k$-, to faciō 'make'). Although the precise analogical model cannot be identified with assurance, it may have been similar constructions in Germanic that gave rise to the alternations in class VI. It may be tempting to assume that a very common verb such as 'stand' (PIE $*_{s t h_{2}}$ : $*^{*} s_{t} h_{2^{-}}>*$ sta- : stā-, hence OE standan : stōd) played a significant role (so, e.g., Austefjord 1987), but models such as this are dubitable because they should originally have distinguished singular and plural in both the perfect and the athematic aorist by means of ablaut. For a discussion of alternative views, with references, see Mailhammer 2007: 89-103, ${ }^{3}$ whose own solution is to suppose that the model was verbs with a root-initial laryngeal (similarly others, e.g. Schumacher 2005: 597-8), since these would have developed in Gmc. a long vowel in the reflexes of both the perfect singular and the plural, e.g. PIE perfect

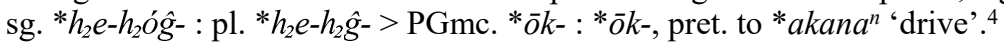

1. The following are merely examples. They are drawn from the survey of etymologies of the 46 verbs in this class provided by Mailhammer (2007: 92-7, 223-4), without cavil as to his derivations. The etymological uncertainties are considerable, as Mailhammer himself notes (2007: 93 n. 105).

2. Prokosch argues further that the aspectual distinction between perfective (reduced grade) and imperfective (full grade) was converted, by default, to a tense distinction in Germanic.

3. Mottausch (1996) and Jasanoff (2003: 66-77) also summarize the prior literature. Their views, which begin from the unusual assumption that present stems could be formed with either primary endings $\left(*_{-}-m i\right.$, etc.) or stative/perfect ones, as suggested by Hittite evidence, are critiqued by Mailhammer (2007: 98-103).

4. Cowgill (1960: 489-90) had earlier rejected explanations like Mailhammer's starting from verbs with vocalic initials, preferring the idea that the long-vowel preterites were formed by analogy to those of classes IV and V. 


\subsection{Derivation of Proto-Germanic ablaut patterns: class VII}

The defining characteristic of this class is that the verbs all differentiate preterite from present and participial stems by the device of initial reduplication in the former in Gothic, e.g. falpan, faifalp, faifalpun, falpans 'fold'. ${ }^{1}$ Given that the most direct source of the Gmc. preterite is the PIE perfect, it should be expected that reduplication was originally a feature of all PGmc. strong preterites, and it has been lost in all classes but this. The obvious explanation is that most of the verbs in class VII in Gothic show no ablaut difference between the present and the preterite stem, whereas the two are plainly differentiated in classes I-VI: reduplication was thus preserved in class VII as a tense marker that could not be dispensed with, as it could in the other classes. There are six exceptional verbs, showing an ablaut difference between present and preterite: Go. grētan 'weep', lètan 'let', ga-rēdan 'reflect upon', tēkan 'touch', saian 'sow', waian blow' (pret. sg. gaígrōt, lailōt, ga-raírōp, taitōok, saísō, pl. waíwōun). In the infinitives of the last two verbs, $a i$ is from PIE $\bar{e}$ before a vowel (§4.5), and so the ablaut pattern is underlyingly pres. $\bar{e}$ : pret. $\bar{o}$. It is not plain why the ablaut difference did not suffice to allow loss of reduplication in these six verbs, though of course if reduplication had been abandoned in these, they would not conform to the ablaut pattern of any of the first six classes.

It is a notable feature of the verbs of class VII that although they preserve an archaic feature of IE verb morphology, reduplication, the ablaut patterns they evince seem innovative, since they are difficult to derive directly from PIE. Aside from the six Gothic verbs with $\bar{e}: \bar{o}$ ablaut alternation, there are five root vowels encountered in this class in Gothic: $a$ (e.g. falpan 'fold', pret. faifalb), ${ }^{2}$ ái (e.g. háitan 'call', pret. haíháit), áu (e.g. áukan 'add', pret. aiáak), e (e.g. slēpan 'sleep', pret. saíslēp or ga-saízlēp), ${ }^{3}$ and $\bar{o}$ (e.g. hōpan, pret. haih $\bar{o} p$ ). As in class VI, the individual vowels may be the result of polygenesis: e.g., haldan must reflect the PIE $o$-grade (Brugmann 1913: 181), whereas $a$ in *fayxana $(>$ făhan) appears to be original, if not due to a laryngeal consonant (cf. Lat. pango 'fasten', Gk. $\pi \dot{\alpha} \gamma o \varsigma$ 'frost', etc.). Unlike in class VI, however, all but a few of the roots containing PGmc. $a$, $a i$, or $a u$ derive from PIE roots without either $a$ or a laryngeal consonant, and thus they present the appearance of being derived from $o$ grade ablaut variants. It is possible, then, that in a fashion complementary to that which appears likeliest in class VI, the preterites are the more original forms in class VII, and the presents formed by analogy - perhaps a likely development if the original present stems were derived and thus different from the preterite in terms of more than just ablaut (§12.3). ${ }^{4}$ The evidence of OE relic reduplicated preterites like reordon 'advised', discussed immediately below, suggests, however, that Gothic has generalized $\bar{o}$ in the preterite rairōp (and similarly in other verbs of this class), and there must originally have been alternation between full and reduced grades, since OE reordon cannot plausibly be derived phonologically from *re-rō $\partial$ - Rather, vowel alternations in the preterite in PGmc. appear to be a necessary assumption: see immediately below on Bammesberger 1986a: 62-3.

Reduplication as a mark of the preterite in class VII has generally been given up in NWGmc., for reasons detailed in $\$ 12.20$, where support is lent the view that a new method of distinguishing present and preterite stems was devised. With the rise of this new method, however, the older, reduplicated forms, grown exceptionally opaque, passed slowly out of use, so that only a few relics survive. These are commonest in OE, where they occur exclusively in texts of Anglian origin (including poetry, nearly all of which appears to have been composed originally in Anglian, though it is recorded 
almost entirely in Late West Saxon). The following preterites have been regarded as examples of such:

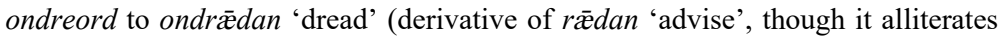
on $d$ : Hogg \& Fulk 2011: $§ 6.71$ n. 1) beside WS ondrēd

hēht to hätan 'command' beside WS hèt

leolc to lācan 'toss' beside WS lēc

leort to lǣtan 'let' beside WS lēt

reord to rē dan 'advise' beside WS rēed, but much more commonly WS weak rǣ dde

Further possible examples are Northumbrian speoft, speaft (if to spātan 'spit'), pl. beafton, beoftun (if to bēatan 'beat'), and blefla (if to blāwan 'blow'). ${ }^{5}$ The resemblance between these preterites and the reduplicated forms of Gothic is unmistakable, but the precise changes involved in their development are not obvious. Most straightforward are reord and leolc, though if these result from normal phonological developments it must be assumed (as proposed by Bammesberger 1986a: 62-3, ${ }^{6}$ supported by Mottausch 1998b: 55) that in this class Gothic has analogically extended the long vowel in the preterite, eliminating an original alternation between PGmc. sg. *re-rōp- <*re-róH$t$ - and pl. *re-rð- $<*$ re-rH-t-' (since the reflex of PIE $H_{o}$ is probably lost in all unstressed syllables in Gmc., §5.5) like that found in classes I-III. Some recourse to analogy or ad hoc phonological developments is required to explain most of the remainder, e.g. leort for expected *leolt.

A few forms that appear to be reduplicated are also preserved in Old Icelandic: gnera to gnúa 'rub', grera to gróa 'grow', rera to róa 'row', sera to sá 'sow', snera to snúa 'turn'. Some of these may represent regular phonological developments, e.g. rera

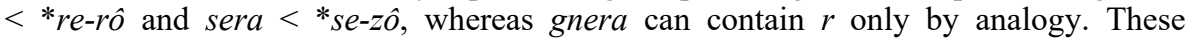
preterites all end in -era, and analogical developments must have played a role in the formation of some. See the studies cited in $\$ 12.20$ for discussion and references.

OHG forms with medial $-r$ - (e.g. biruun to büan 'dwell') are usually grouped with these relic reduplicated forms, but see $\S 12.20$.

1. On Gmc. reduplication, see Suzuki 1982, Fullerton 1991.

2. The verbs fähan 'seize' and hähan 'hang' had $a$ in the root in PGmc. before this was lengthened upon loss of the nasal consonant in *fayxana ${ }^{n}$ and *xayxana ${ }^{n}$, respectively ( $\left.\$ 4.1\right)$.

3. Given the voicing of $s$ to $z$ in ga-saizlēp, it is assumed that in at least some pret. forms of this class the reduplicative syllable was unaccented in PGmc., allowing Verner's law to apply. In other forms there is no voicing (faifalp, haihald, haihuōp, saisō, etc.). Some assume that the reduplicative syllable remained unstressed in Gothic: for references to the controversy, see Mottausch 1994: 134 n. 29.

4. Thus, for example, Brugmann (1913) argues that many Gmc. verbs of both classes VI and VII with $a$ in the root have that vowel as an innovation. This would account for the unexpected vowel in faran $(\$ 12.15)$.

5. For references to the literature on these, see Hogg \& Fulk 2011: §6.71.

6. Jasanoff (2007: 264 n. 50) objects to crediting Bammesberger with first offering this insight but cites no prior published authority.

\subsection{Verner's law in strong verbs}

It is usually assumed that voicing under Verner's law is to be expected only in the preterite plural and the passive participle of strong verbs, an expectation raised by the variable position of the accent in Sanskrit verbs $(\$ 6.6)$, and that departures from this pattern 
are the result of analogical change: so, e.g., Adamczyk 2004, and most handbooks of the early Gmc. languages. However, Prokosch (1939: §63) shows effectively that such a pattern, though impressively regular in the first three classes, is almost never what is to be found in classes V-VII (class IV being irrelevant, since the stem ends only in a sonorant consonant or, exceptionally, a stop). Prokosch's idea is that voicing of a stem-final fricative should not be expected in any form containing a full- or lengthened-grade vowel, since this must have borne the accent, and he finds that the attested alternations in classes V-VII support this assumption, with voicing in class V only in the passive participle, in class VI only in the infinitive and the passive participle, and in class VII on an irregular basis, since the class represents a mixture of accentual types. On the basis of a survey of Germanic forms he concludes that this is indeed the general pattern. The evidence, however, is difficult to reconcile with this conclusion.

He points to Go. standan, stōp, stōpum, *sta(n)dans 'stand' in support of the posited pattern in class VI. It is true that $p$ in the preterite is unlikely to be due to devoicing of $\partial(\$ 6.12)$, in view of forms like 3 pl. stōpun, 1 pl. afstōpum, 2 pl. gastōpup, 3 sg. sj. afstōpi. But there is no reason to assume on the basis of this model that the voicing in the infinitive is to be expected in the present stem of other verbs of this class, since PIE verbs with nasal infix bore suffixal accent in the dual and plural. The stem stand- plainly derives from a form with suffixal accent (PIE root $* s t h_{2}$-; cf. full grade in Lat. stâre), whereas some verbs of class VI appear to derive from roots with full-grade $a$ or $h_{2} e$, as noted above (\$12.15). Moreoever, in Old English there is to be found a consistent pattern almost precisely the opposite of the Gothic one, in *scieppan (LWS sceppan), sc(e)ōd, sc(e)ōdon, sceaðen 'injure', and in contracted verbs (those with original root-final $x, \S 12.1$ ), where $g$, which is regular in the preterite plural (e.g. slogon), is also predominant in the preterite singular slogg. Beside slog there does occur slōh (which may be due to final devoicing, §6.17), but the voiced variant is the usual one in early texts (Hogg \& Fulk 2011: $§ \S 6.65-6)$. Despite Prokosch to the contrary, $g$ is also the rule in both the preterite singular and the plural in OHG, with few exceptions: see Braune 2004a: $\$ 346$ Anm. 2, in agreement with Prokosch that $g$ in the singular must have been extended analogically from the plural. Prokosch reasons that this extension is motivated by the need to distinguish the preterite from the present, but since the ablaut difference between the preterite stem and the present was plainly sufficient to differentiate the two in classes I-III, it is difficult to see why such a change should have taken place in this class but not those. There is the added difficulty that whereas Prokosch's analysis predicts a voiceless fricative in the passive participle in class VI, instead a voiced one is consistently to be found in both North and West Germanic, and this must be quite an old situation: cf. Runic slaginar (Möjbro stone, ca. 450). ${ }^{1}$ Voicing in the last three principal parts but not the first appears also to have been the original rule for at least some verbs in class VII, to judge by OE fön, fëng, fëngon, fangen 'take' (= OIcel. fá, fekk, fengu, fenginn) and hōn, hē̄ng, hě̄ngon, hangen 'hang' and NWGmc. cognates. Yet no single pattern will explain all the verbs of class VII: for example, OE has a voiceless fricative in both pres. hwōsað 'cough' and pret. hwēos, whereas, like Gothic, it reflects only a voiced fricative in scādan 'distinguish' (Go. skáidan), in contradistinction to $\mathrm{OS}$ and $\mathrm{OHG}$, where the reflexes of voiceless fricatives are commonest (OS skēđan, OHG skeidan). Similarly, OHG shows a mixture of forms in faldan beside faltan 'fold'.

Patterns in class $\mathrm{V}$ are not much more supportive of the proposed distribution of alternants under Verner's law. In Old English, for example, the preterite plural consistently reflects a voiced fricative where Prokosch predicts a voiceless (cw̄̄don 'said', 
wǣron 'were', gefǣgon 'rejoiced'). It is true, nonetheless, that the passive participle reflects a voiced one, as predicted, in cweden 'said' and sewen, gesawen 'seen'. The passive participle of wesan 'be' is unattested in any of the earliest WGmc. languages; the later forms OFris. wes(s)en and MHG gewesen, with a voiceless fricative, are most likely analogical creations. ${ }^{2}$

Whereas it is uncertain whether there was voicing under Verner's law originally in the passive participle in class $\mathrm{V}$, the considerable preponderance of the evidence thus suggests that with that one possible exception, the pattern in this class was like that in classes I-III, whereas in class VI the commonest pattern was voicing in the preterite (sg. and pl.) and the pass. participle, and that this was also the pattern for the most secure examples of class VII. These patterns plainly have little to do with PIE vowel gradation, which thus furnishes no very good explanation for the alternants under Verner's law in classes V-VII. ${ }^{3}$

1. As Prokosch rightly observes, OIcel. pret. sg. sló (to slá 'strike') is ambiguous as to whether it reflects *slōz or *slōh (see above, §6.14).

2. In OIcel., $r$ has been extended throughout the paradigm, even to inf. vera, imp. ver(ið), and pp. verit (neut.).

3. For this reason the argument of Ringe that only the pret. sg. in class VI retained a voiceless fricative in PGmc. must be regarded as inconclusive. He reasons that since OHG heffen 'lift' is a weak present with weak grade of the root, PGmc. *xabjan- should be expected (as in OE hebban, OS hebbian), and OHG can have acquired the voiceless fricative reflected throughout the pres. only by analogy to the pret. singular (Ringe \& Taylor 2014: 100). Yet even if there were a plain correlation in class VI between assumed ablaut grade and voicing under Verner's law, it need not be the case that this verb, cognate with Lat. capiō 'take', shows weak grade of the root. Rather, this appears to be one of those instances in which full-grade $a$ must be reconstructed for PIE (\$3.1): so, e.g., Pokorny 1959-69: I, 527-8. There is, after all, the problem that PGmc. $a$ in the pres. of class VI appears to have multiple sources $(\$ 12.15)$, and very few other verbs of this class reflect voiced fricatives in the pres. in WGmc. Polygenesis of the ablaut in this class renders it inadvisable to reconstruct a single pattern of alternants under Verner's law for PGmc. The PGmc. facts appear to be irrecoverable.

\subsection{Aorist presents}

Reflexes of the PIE tudáti-type present stem, with weak grade in the root rather than $e$ (§12.3), are securely attested only in Indic and in Germanic, in regard to the latter of which they are most commonly referred to as aorist presents. In Greek, for example, the opposition between full and weak grades is regularly used to distinguish the present stem, and forms based on it, from the aorist stem, as with pres. inf. $\varphi \varepsilon v$ $\gamma \varepsilon \imath v$ 'flee' and imperfect है $\varphi \varepsilon v \gamma o v$ in opposition to aorist inf. $\varphi v \gamma \varepsilon \hat{\varepsilon} v$ and aorist $\tilde{\varepsilon} \varphi v \gamma o v .{ }^{1}$ For that reason the existence of the tudáti type in PIE has been doubted, though there is no consensus (see $§ 12.3 \mathrm{n} .8$ ). The following, whether they are inherited or post-PIE innovations, ${ }^{2}$ are commonly regarded as verbs of this type in Germanic:

Class I: Go. digandin 'made of clay' (beside full-grade inf. deigan); OIcel. vega 'fight, kill' (OHG ubar-wehan 'overcome', OE gewegan, pp. forwegen; cf. full-grade Go. weihan, OE wigan; the verb corresponds to OIr. fichid); also class V Go. bidjan 'request' and cognates (see $\$ 12.19$ infra), if this has been transferred from class I (so Osthoff 1882; cf. Seebold 1970: 92-3, Pokorny 1959-69: I, 114). ${ }^{3}$

Class II:4 Go. ga-lūkan 'shut' (OIcel. lúka, OE lūcan, OFris. lūka, OS bi-lūkan, OHG bi-lūhhan); OIcel. lúta 'bow' (OE lūtan); OIcel. súga 'suck' (OE sūgan, sūcan, OS OHG sūgan); OIcel. súpa 'sip' (OE sūpan, OFris. sūpa, MLG sūpen, OHG sūfan); OE brūcan 'use' (OFris. brūka, OS brūkan, OHG brūhhan; cf. Go. weak 
brūkjan); OE bügan 'bend' (OS būgan; cf. full-grade Go. biugan, OHG biogan); OE düfan 'dive' (MLG be-duven 'be covered'; ON dúfa is weak); OE hrūtan 'snore, make a noise' (OFris. hrüta, OS hrütan, OHG rüzan; cf. full-grade ON hrjóta); OE scūfan 'shove' (OFris. skūva, MLG schuven; cf. full-grade Go. afskiuban 'reject', OSwed. skiuva 'shove'; there also occurs OE scēofan); OE slüpan 'glide' (Fris. slüpe, MLG slüpen; cf. full-grade Go. sliupan, OHG irsliofan 'come (out)'); OE smūgan 'creep' (cf. full-grade OIcel. smjúga, MHG smiugen); OE strüdan 'plunder' (MLG stroden, OHG strutten); OE pütan 'howl' (cf. full-grade OE peotan, OIcel. pjóta, OHG diozan); OE *crūdan 'hasten' (only 3 sg. pres. crȳdeb); OE *sprūtan 'sprout' (past part. $\bar{a}$-sprotene, ME inf. sprouten); $\mathrm{OHG} *$ tūhhan 'plunge' ( $\mathrm{pp}$. betochen); and possibly $\mathrm{OE} *$ scūdan 'hurry' (?) (only pres. part. scüdende, but perhaps to the second weak class because poetic/Anglian: see Hogg \& Fulk 2011: §6.112).

Class III: OIcel. horfa 'be turned' (weak; cf. strong hverfa); OIcel. molka 'milk' (weak; cf. strong OHG melchan, Skt. mấrśtit 'wipes'); OE spurnan 'kick' (OFris. spurna (may be weak), OS bi-spurnan (strong?), OHG fir-spurnan; weak OIcel. sporna, spyrna); OE murnan 'mourn' (weak Go. maúrnan, OS mornian, OHG mornēn).

Class IV: ON koma (OE cuman, OFris. kuma, OS kuman; cf. the originally imperfective stem in Go. qiman, OHG queman) $<{ }^{*} g^{w}{ }_{e} m-;{ }^{5}$ Go. trudan 'tread' (OIcel. troða); ${ }^{6}$ Go. wulan 'seethe, rage' (no pret. attested; cf. OE weallan, OHG biwellan 'seethe' < *uel-n-?); also PGmc. *knuðanan in weak ON knoða 'knead'; cf. fullgrade strong $\mathrm{OE}$ cnedan, $\mathrm{OHG}$ knetan.

Class V: There are no aorist presents to this class, but none would be detectable, as the root vowel in an aorist stem would have been schwa secundum, which would have been reflected as a full-grade vowel (§§3.1-2). An exception is OIcel. sofa 'sleep', which could reflect either *sweb- or *sub- (see Heusler 1967: §87.2), whereas $\mathrm{OE}$ swefan is unambiguous.

Class VI: A great many of the verbs of this class are best analyzed as showing in the present the weak grade of a root containing a laryngeal consonant (see $\$ 12.15$ ).

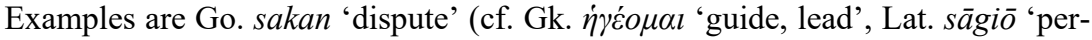
ceive quickly, feel keenly'); Go. skaban 'shave' (cf. Lith. skóbti 'gouge' and Latvian skābs 'sour', from *'sharp, cutting'); and Go. ga-daban 'beseem' (cf. Go. ga-dōfs 'becoming, fit').

There is no certain example in Class VII, where etymologies are generally insecure. ${ }^{7}$

1. But there are exceptions. For example, Gk. $\gamma \rho \alpha \dot{\varphi} \omega$ 'write' reflects * $g r b h$-ó $h_{2}$, whereas OE ceorfan 'carve' shows the full grade of the root. The former, perfective stem used in the present would originally have expressed punctual action, the latter stem durative $(\$ 12.1)$; one or the other stem was then generalized in the individual IE branches.

2. Bammesberger (1986a: \$3.3.5) outlines a process by which forms with reduced grade of the root could have been created analogically in Gmc.

3. Seebold (1970: 467-8) would add *stikanan 'stick', refashioned as a verb of class V (e.g. OS stekan), though derivatives show it to have been originally a verb of class I. Some further possibilities in English are discounted by Seebold (1966b).

4. Aorist presents of the second class have $\bar{u}$ for expected $u$ in the present stem. The commonest explanation (see, e.g., Prokosch 1939: §55) is that the vowel was lengthened by analogy to the long vowel in the present stem of the first class (and the long diphthong in the non-aorist presents of the second?). Cf. A. Campbell (1977: $§ 736(\mathrm{~b})$ ), suggesting an analogical proportion of present and preterite singular vocalism in PGmc. $\bar{l} \sim$ $a i$ (class I) : $\bar{u} \sim a u$ (class II). Because $\bar{u}$ is found also in related words, Perridon (2001, with references) argues 
for a curtailed sound change $e u>\bar{u}$. There is the further consideration to be taken into account that short $u$ in a form like *lukan should be expected to have been lowered to $o(\S 4.3)$, creating irregularities in the paradigm. For a list of aorist presents of class II, distinguishing inherited from innovative forms, see Ringe \& Taylor 2014: 39-40

5. Ringe (Ringe \& Taylor 2014: 141-2), rather, posits a NWGmc. change *kweman > *kwiman (cf. *niman 'take') $>*$ kuman.

6. WGmc. forms (OE tredan, OHG tretan) must be innovations by analogy to verbs of the fifth class (though it belongs to the fourth in Go. and OIcel.) if the PIE stem is *dreu-, as in Skt. drávati 'runs' (so Osthoff 1901: 372-3); but *dr-t-ó- is also possible, though unattested outside of Germanic. See Seebold 1970: 506.

7. A possible example is Go. skáidan 'distinguish': see Pokorny 1959-69: I, 921.

\subsection{Strong verbs with so-called weak presents}

As noted in $\S 12.3$, the suffix *-ie/o- served as one marker of present stems in PIE. ${ }^{1} \mathrm{~A}$ number of Gmc. strong verbs are formed this way, with the consequence that morphologically they are nearly identical to weak verbs of the first class in the present (§12.34), for example showing (outside of Gothic) umlaut throughout the present paradigm and (in WGmc.) gemination in originally light stems. Unlike weak verbs, however, they are not causative or iterative in meaning, and the suffix exerts no perceptible influence on the semantics of the verb. ${ }^{2}$ Moreover, the root vowel of the present stem derives from the grade normal to strong presents (i.e., $e$ in classes I-V) rather than the $o$ characteristic of the oldest stratum of causatives. Such verbs are very commonly referred to as strong verbs with weak presents, though they are sometimes called strong verbs with $j$-presents. Though the latter term is more accurate, the former, which is of long standing, is used here for the convenience of referring to other types, by contrast, simply as strong presents. The relevant verbs are these:

Class I: OIcel. blik(j)a 'gleam' (cf. suffixless OS blīkan); ${ }^{3}$ possibly OIcel. svikja beside svikva 'betray' (cf. strong pres. OS swīkan); similarly OIcel. víkja beside víkva 'turn'; possibly $\mathrm{OHG}^{*}$ in-trīhhen 'expose'. ${ }^{4}$

Class II: Possibly OIcel. flýja 'flee' (pret. fló, Noreen 1970: §488, but usually weak; cf. suffixless OE flèon < *flèohan, and cognates); ${ }^{5}$ possibly OIcel. spýja 'vomit' (pret. spjó, Noreen 1970: $§ 488$, though also with a weak pret.; but suffixless Go. speiwan, $\mathrm{OE}$ spiwan, etc., belong to the first class). ${ }^{4}$

Class III: Probably OE * gierran 'chatter, make a noise' (see Hogg \& Fulk 2011: §6.55).

Class IV: No known examples.

Class V: Go. bidjan 'request' (OIcel. biðja, OE biddan, OFris. bidda, OS biddian, OHG bitten; but cf. suffixless Go. us-bidan); OIcel. liggja 'lie' (OE licgan, OFris. lidza, OS liggian, OHG liggen, lickan; but cf. suffixless Go. ligan); OIcel. sitja 'sit' (OE sittan, OFris. sitta, OS sittian, OHG sizzen; but cf. suffixless Go. sitan); OIcel. piggja 'receive' (OE picgan); OE fricgan 'ask' (cf. Go. fraihnan and cognates); possibly OE *ā-ficgan 'fry' (see Hogg \& Fulk 2011: §6.63).

Class VI: Go. frapjan 'understand'; Go. hafjan 'lift' (OIcel. hefja, OE hebban, OFris. heva, OS hebbian, OHG heffen); Go. hlahjan 'laugh' (ON hlæja, OE hlihhan < *hliehhan); Go. ga-rapjan 'count'; Go. ga-skapjan 'create' (OIcel. skepja, OE scieppan, OFris. skeppa, OS skeppian, OHG skepfen); Go. skapjan 'harm' (OIcel. skeðja, OE sceppan beside suffixless sceaðan (see Hogg \& Fulk 2011: $\S 6.67$ n. 5); Go. wahsjan 'grow' (cf. suffixless OIcel. vaxa, OE weaxan, etc.); 
OIcel. deyja 'die' (OS dōian, OHG touwen; cf. Go. *diwan in pp. diwans); OIcel. geyja 'bark'; OIcel. k(v)efja 'dip, put into water' (in part weak; cf. suffixless OHG ir-queban 'suffocate'); OIcel. sverja (OE OS swerian, OFris. swera, OHG swerren, but cf. suffixless Go. swaran); OE stæppan, steppan 'step'6 (OFris. steppa); OS af-seffian 'perceive' (OHG in-sebben); OHG erien 'plow'?

Class VII: OE wēpan 'weep' (OFris. wēpa, OS wōpian, OHG wuofan); perhaps also OIcel. spýja (under class II above).

1. Perhaps some of these verbs bore instead the suffix *-eie/o-, or even *-eiele/o- (from *-eht-ie/o-): to OIcel. sitja cf. Lat. sederre < sed-ēe- The types coalesced in Gmc.: see §12.34.

2. This is a matter fraught with etymological uncertainties. For example, Mailhammer (2007: 92) offers reasons to reject the usual view that *waxsja- 'grow', *dauja- 'die', and *swarja- 'swear' are causative or iterative in origin.

3. WGmc. forms other than those of OS are inconclusive in this class, due to loss of $*_{-j-}$ after heavy syllables $(\S 6.15)$ and failure of umlaut to affect $\bar{l}$.

4. 3 sg. intrīhhit, the vowel seemingly originally short (Braune 2004a: $\$ 331$ Anm. 4; cf. Seebold 1970: 565).

5. Likelier is that fýja and spýja are formed by analogy to suffixless present forms (e.g. $3 \mathrm{sg}$. fýr, spýr). The latter verb is perhaps better regarded as conforming to the pattern of class VII.

6. The form stæppan (rather than the less common steppan) is generally regarded by the handbooks as more original, prompting, for example, the implausible reconstruction PGmc. ${ }^{*}$ stappana $^{n}$ (so Orel 2003: 372). Rather, $x$ in the root is due to analogical substitution of $a$ for $æ$ prior to umlaut, a change that is particularly frequent in verbs of class VI ( 4 4.7; Hogg \& Fulk 2011: §6.65).

7. The verb follows class VII in OHG, but it must originally have belonged to class VI (Braune 2004a: $\$ 350$ Anm. 5, with references).

\subsection{Preterites of class VII in Northwest Germanic}

As remarked above $(\$ 12.16)$, Gothic verbs of class VII form their preterite stem with the addition of initial reduplication, and certain preterite forms in OIcel. and by-forms in OE (e.g. leort 'let') appear to be reduplicative in origin. The usual preterites in North and West Germanic, however, show no trace of reduplication. Compare the following principal parts of a verb meaning 'let':

$\begin{array}{lllll}\text { Go. } & \text { lētan } & \text { laílōt } & \text { laílōtun } & \text { lētans } \\ \text { OIcel. } & \text { láta } & \text { lét } & \text { létu } & \text { látinn } \\ \text { OE } & \text { lǣtan } & \text { lēt } & \text { lēton } & \text { lāten } \\ \text { OS } & \text { lātan } & \text { lēt } & \text { lētun } & \text { gilētan } \\ \text { OHG } & \text { lāzan } & \text { liaz } & \text { liazun } & \text { gilāzan }\end{array}$

The NWGmc. preterites thus reflect $\bar{e}$ in the root (so-called $\bar{e}_{2}, \S 3.5$ ), and this is true of roughly half the verbs in this class, whereas nearly all the remainder reflect $\bar{e} o$, as in a verb meaning 'leap' or 'run':

$\begin{array}{lllll}\text { Go. } & \text { hláupan } & \text { haíhláup } & \text { haíhláupun } & \text { hláupans } \\ \text { OIcel. } & \text { hlaupa } & \text { hljóp } & \text { hljópu } & \text { hlaupinn } \\ \text { OE } & \text { hlēapan } & \text { hlēop } & \text { hlēopon } & \text { hlēapen } \\ \text { OS } & \text { hlōpan } & \text { hliop } & \text { hliopun } & \text { gihlōpan } \\ \text { OHG } & \text { hloufan } & \text { hliof } & \text { hliofun } & \text { gihloufan }\end{array}$

For the purpose of the present discussion, preterites like OE lèt and hlēop will be referred to as type 2 preterites (as opposed to originally reduplicated forms like OE leort, 
a type 1 preterite). How to explain the origin of the NWGmc. preterite stems of type 2, as well as the coexistence of relic reduplicated forms in $\mathrm{OE}$, has been a matter of some controversy. Approaches to the problem have taken one of four forms: ${ }^{1}$

(1) Until recently, the usual explanation, first proposed by Grimm (1822-37: I, 898-9), has been that a reduplicated form like PGmc. *xexait- ( $>$ Go. haíháit) is the etymon of both type 1 and type 2 preterites. Thus, it is assumed that in type 2 preterites there has occurred loss of a root-initial consonant (e.g. *xe-xait- $>* x e$-ait $>\mathrm{OE} h \bar{e} t$ ), or even a consonant cluster (e.g. *ste-stald- > * ste-ald- > OE stēold 'possessed', inf. stealdan), and explaining how a form such as *xe-xlaup-can have developed to OE hlēop requires some complication of the process of change.

(2) Following the lead of Brugmann 1895 and Wood 1895, some have analyzed the verbs of classes VI-VII as reflecting so-called heavy bases, in opposition to the light bases of classes $\mathrm{I}-\mathrm{V},{ }^{2}$ and their preterites have been seen as counterparts to Latin perfects like $f \bar{e} c \bar{\imath}$ 'did' and aorists like Gk. $\tilde{\varepsilon} \beta \eta v$ 'went'. Obstacles to this analysis became apparent with the acceptance of the laryngeal hypothesis $(\$ 3.1)$, when it could be seen that although many heavy bases must have contained laryngeals in PIE, not all did (e.g. the etymon of Go. faran, $\$ 12.15)$, and some of those that did could not be fitted to the Brugmann-Wood scheme, e.g. * $h_{2}$ eug- in OIcel. auka 'add', but $* h_{2} u o h_{3} g->* w \bar{o}$ - in pret. jók (however the $j$ - is to be derived on this analysis). This approach now lacks currency; Ringe (in Ringe \& Taylor 2014: 91 n. 29) calls it "wildly implausible."

(3) Under a hypothesis developed by van Coetsem (1956: 37-41 and many subsequent studies, including van Coetsem 1990, 1994, 1997), $\bar{e}_{2}$ in type 2 preterites results from a split of PIE $e i$ into $e e$ and $e i>i i$ parallel to the split of $e u$ into $e o$ and $e u>i u$. This hypothesis has met with much criticism and appears no longer to have any proponents.

(4) Under the most recent analysis, type 2 preterites were formed in NWGmc. by the insertion of $e$ into the present stem immediately before the root vowel. Thus, e.g.,

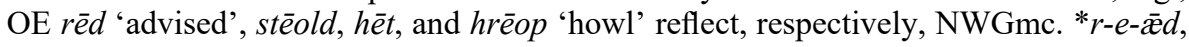

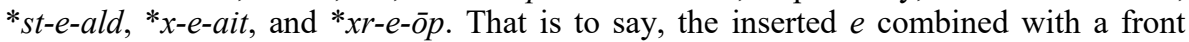
vowel or a front diphthong to produce $\mathrm{OE} \bar{e}$, but with a back vowel or a back diphthong to produce $\bar{e} o$, with comparable results in the other NWGmc. languages. The model for the analogical change was verbs without an initial consonant, e.g. *aukan, hence pret. *e-auk> OIcel. jók. The motive for the change was that due to Verner's law and some other changes, the structural relation between many present and preterite stems had grown opaque: thus, for example, since the reduplicative syllable was unaccented in PIE, the reduplicated preterite stem of PGmc. *xaitan- should have been *xezait-, and of *flokkan- 'clap', *feblōk-, not to speak of the vowel alternations posited by Bammesberger $(\$ 12.16)$. In Gothic the fricatives voiced in this fashion have for the most part been replaced by voiceless ones, but $z$ remains in ga-saízlēp 'slept' (beside saíslèp); cf. also OIcel. sera 'sowed' <*se-zô.

Explanation (4) has been fairly widely credited (references in Hogg \& Fulk 2011: $\$ 6.70$ n. 2), though some studies still adhere to explanation (1), either on a purely phonological basis ${ }^{3}$ or a largely analogical one. ${ }^{4}$ Explanation (4) offers several advantages, one of which is that in nearly every instance it accurately predicts on the basis of the present stem whether the preterite stem will contain $\mathrm{OE} \bar{e}$ or $\bar{e} O$ (with comparable results in the other NWGmc. languages). ${ }^{5}$ Another advantage is that it accounts for the coöccurrence of parallel forms like heht and hêt in Old English, the former being the inherited type, the later the innovative. A third is that it accounts for the appearance of $\bar{e}_{2}$ in NWGmc. preterites, though why it should have occurred in such an environment 
has long remained an unsolved problem (§3.5). A fourth advantage is that it provides a plausible explanation not just for the stem formation of preterites to class VII in NWGmc. but for several puzzling irregularities in NWGmc., as well (on which see Fulk 1987):

(a) The diphthong derived from PIE eu regularly develops to OIcel. jó before dental consonants, as well as $x$ and $m$ when a non-high vowel followed in the next syllable; otherwise it is reflected as $j u$ (Heusler 1967: §49). Yet in preterites of class VII, jó appears before any consonant, as in hljóp 'ran, leapt'. This is explicable if the reflex of PIE $e u$ was distinct from that of the sequence created by the insertion of $e$ before $a u$ found in NWGmc. *xl-e-aup > hljóp at the time when the reflexes of PIE eu became differentiated.

(b) The situation is similar in OHG, where, for instance, in class II, the reflex of PIE $e u$ is $i u$ in the present stem before labial and velar consonants (other than $h$ ) even when a non-high vowel followed in the next syllable; otherwise it is $e o$ or $i o$. Yet in the preterite of verbs of class VII the diphthong is $e o$, later io (ia, ie), even before labial and velar consonants, as in leof, liof 'ran', and even when a high vowel follows in the next syllable, as in every preterite form in OHG except for the 1 and $3 \mathrm{sg}$. indicative, which is endingless. Explaining (a) and (b) as independent analogical developments in OIcel. and $\mathrm{OHG}$ is methodologically suspect.

(c) In Old West Frisian the reflex of PGmc. $e u$ is regularly $i \bar{a}$ or $i \bar{e}$, whereas in preterites of class VII verbs of the type with PGmc. $a u$ or $\bar{o}$ in the present the result instead is $i \bar{o}$ (van Helten 1896: 446). Once again, the diphthong in the preterite of this class appears not to derive from PGmc. eu.

(d) It is usually assumed that PGmc. $\bar{e}_{2}(\S 3.5)$ is still preserved and spelt $\langle\mathrm{e}\rangle$ or $\langle e e\rangle$ in the earliest $\mathrm{OHG}$ records (eighth century), though already there it coöccurs with $\langle$ ea, which changes to $\langle i a\rangle$ and $\langle i e\rangle$ in the ninth century (so, e.g., Braune 2004a: §35). The assumption is thus that $\langle\mathrm{ea}\rangle$ is an intermediate stage in the development of $\bar{e}_{2}$ to $i a$ and $i e$. Although this assumption matches the evidence of manuscript spellings for a word like here, hier 'here', it derives little support from the evidence of preterites of class VII, and the spellings of the preterites of fähan 'take' and gangan 'go', in particular, suggest that in this class instead ea is the older value - as should be expected if it derives from inserted $e$ plus the root vowel $a .^{6}$

(e) A small number of preterites to verbs of class VII in OHG contain $\langle r\rangle$ of mysterious origin, which appears only on an irregular basis, and only in early texts. Thus, for example, ana-stōzan 'strike' has the preterite ana-steroz beside ana-stiez. These $r$-preterites have long been connected with the problem of the loss of reduplication in NWGmc., but any analysis along the lines of explanation (1) above must assume that the $r$ originates in the verb scrottan 'cut', with preterite ki-screrot, which is somehow to be explained as developing from NWGmc. ${ }^{*}$ ske-skraud-, and then $r$ was extended analogically to the preterites of bluozan 'sacrifice', stözan 'strike', and büan 'dwell', no matter how ill motivated such analogical change may seem. The chief difficulty, however, is that the intrusive $r$ appears in the middle of what is usually assumed to be a diphthong: -steroz, for example, is thought to derive from * steut-, though this requires the injection of $r$ into the middle of the diphthong eu. Rather, if it is assumed that -steroz derives from a NWGmc. form with $e$ infixed before the root diphthong $\left({ }^{*} s t\right.$ $e$-aut), it may be assumed that the facultative use of $\langle\mathrm{r}\rangle$ in such forms is an ad hoc means of representing the hiatus between $e$ and the root diphthong. This also explains why the forms with $\langle r\rangle$ are found only in the earliest texts, before contraction and loss of hiatus. 
(f) A number of verbs with originally vocalic stems (verba pura) have developed a stem-final $w$ of perplexing origin, especially in OE, e.g. grōwan 'grow', sāwan 'sow' (cf. OE grēne $<*_{3} r \overline{-}-n-i z$ and $s \bar{x} d$ 'seed' $<*_{s \bar{e}-} \partial-a^{n}$ ). Under explanation (4) the $-w$ may be explained as originating in some preterites of this type (Fulk 1993: 247-8): see $\S 12.22$ for details.

Jasanoff (2007: 250-2) rejects explanation (4) chiefly on the basis of the supposition that relevant verbs with a vocalic initial would have been too few in NWGmc. to serve as an adequate model for the analogical change that resulted in the insertion of $e$ before the root vowel in preterites of class VII. It is true that in some kinds of analogical change the pattern to be copied must be rather common to serve as a plausible model. Under normal circumstances we should not, for instance, expect a noun stem found only in the genitive singular to have been extended throughout a paradigm. But the present instance is of a different sort, since the motive for the analogical change was the problem that the morphology of the original, reduplicated preterite stems had grown too opaque (a point with which Jasanoff concurs, 2007: 260), as remarked above in regard to expected alternations under Verner's law, but as is more directly observable in the way relic reduplicated forms in Old English bear little resemblance to the predicted forms. The pressure to simplify preterite-formation in this class must have been great, and no matter how many or how few may have been verbs with vocalic initials in NWGmc., they were doubtless some of the few, if not the only, reduplicated verbs of this class with preterites that were still generated by regular rule. It is thus not the number of relevant verbs that is of paramount importance but the transparency of the relevant rule that made the model attractive. And it must be remembered that the reduplicating verbs are limited in number-Gothic attests to reduplicated preterites to just 14 verbs - so that a few preterites formed in regular fashion could exert outsize analogical influence on the rest. ${ }^{7}$ Comparison may be drawn to the origin of the vowel $\bar{e}$ in the pret. pl. of verbs of classes IV and V, which is now usually attributed to the analogical influence of originally reduplicated verbs with vocalic initials $(\$ 12.14)$ - an origin which, e.g., Ringe (2017: 210, 273) accepts, though he points out that there is just one verb with the requisite structure to provide the model, the verb 'eat'. Regarding the plausibility of the conversion of reduplication to infixation, the argument of Garrett 2001 about a comparable change in Yurok may be noted.

Explanation (4) thus provides solutions for a range of problems in NWGmc. phonology and morphology, whereas the competing explanations are limited in their explanatory power to preterites of class VII alone. The disadvantages to any explanation of type (1) along phonological lines should be obvious, since ad hoc phonological rules without application outside of class VII are required. Yet even chiefly morphological solutions in accordance with (1) have their drawbacks, not least of which is that they are necessarily far more complicated. For example, Jasanoff (2007: 262) argues that although stems beginning with $s+$ stop involve the entire culster in reduplication in Gothic (and, it should be added, apparently in PIE: §12.2), as in Go. ga-staí-stald, in

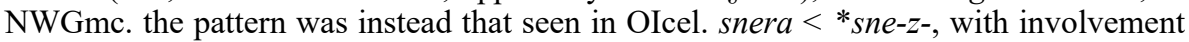
of the stop in the reduplicative syllable but loss of it in the root onset. What motivated the change in NWGmc., however, is not explained, and the counterevidence (OE speoft rather than *spest) has to be explained as analogical (to beoft, itself with an analogically induced diphthong). This different sort of reduplication would have resulted in a pret. pl. *xezlð- (to *xalðanan 'hold'), which, because of its anomalous structure, would have been altered to *held-, though this amounts to a novel sort of change regardless of whether it is regarded as a phonological or a morphological development. Many further 
analogical adjustments are required to produce the attested forms, and in no instance is such change as plainly motivated and based on as obvious an analogical model as is the unified analogical change assumed in explanation (4).

1. For bibliographical references, see Fulk 1987, esp. 159-60. For the most part, the present discussion provides references only to more recent studies.

2. Prokosch (1939: §46) defines bases as "syllables subject to gradation. A base may be a root syllable, a prefix, a suffix, an ending, or an independent particle. If under conditions of ordinary stress, its vowel is short we speak of a Light Base, if, under like conditions, it is long, we speak of a Heavy Base."

3. So Vennemann 1994b, 1997, though whether this approach can accurately be called purely phonological is rightly disputed: see D'Alquen 1997, as well as Jasanoff 2007: 252-60.

4. So Jasanoff 2007 and, in part, Ringe \& Taylor 2014: 88-92.

5. The one certain exception is OIcel. blét 'sacrificed' (for *bljót, inf. blóta); possibly also OE fĕng 'took' and hěng 'hung, hanged' (and cognates), on which see Fulk 1987: 165, 172. However, the rule might with equal justice be formulated to prescribe that the preterite is formed by inserting $e$ not into the present stem but into the stem of the passive participle, in which event these last two verbs would not be exceptions. It is naturally to be expected that analogy should have obscured some of the original regularities, and that the OE verbs should reflect a fairly conservative state of affairs: on the discrepancies between OE and OFris. and ON verbs like the reflexes of PGmc. xalðana ${ }^{n}$ 'hold', see Fulk 1987: 167-9. To the assertion of Ringe \& Taylor (2014: 91) that the only possible explanation for pret. gang 'went' in Beowulf is loss of the reduplicative syllable, cf. Fulk, Bjork, \& Niles 2014: cxlvii f.-though, to be sure, loss of the reduplicative syllable in *gegang is the likeliest explanation. Note that gang is unlikely to be a scribal substitution for *gegang at Beowulf 1316a, as the metrical type would then normally require double alliteration (see Bliss 1967: 40-3).

6. Jasanoff (2007: 251) sets aside the mass of evidence supporting this conclusion, crediting instead only the seeming counterevidence of preterites of gangan, fähan, and hähan in the OHG Isidor with $\langle\mathrm{e}\rangle$ instead of $\langle\mathrm{ea}\rangle$, which hardly seems probative.

7. About thirty such verbs can be reconstructed for PGmc., according to Ringe (2017: 279), who also rejects Jasanoff's objection and observes that all the subclasses in class 7 are small (Ringe \& Taylor 2014: 89 n. 28). This would contribute to the impression of irregularity in the other subclasses and highlight the regularity in the vowel-initial type.

\subsection{Contracted verbs}

After the loss of $/ \mathrm{x} /$ between voiced sounds in ON, OE, and OFris. $(\S \S 6.14,6.18,6.19)$ there resulted contraction of vowels rendered adjacent by this loss. In strong verbs the consequence was some notable irregularities in the present tense, where Verner's law had not voiced $x$ to $3 .{ }^{1}$ Thus, for example, OIcel. class V sjá 'see' $\left(<*^{*} \operatorname{sex}{ }^{w} a n-\right)$ has the stem sjá- in the pres. ind. 1 and 3 pl., elsewhere in the pres. sé- (pret. sá-), whereas class VI slá 'strike' (<*slaxan-) has the stem slæx- in the pres. ind. sg. and slá- elsewhere in the pres. (pret. ind. sg. sló, slótt, sló, pl. slóg-. sj. sloeg-). Common patterns in the present stem in Early West Saxon (and, in part, Kentish: see \$2.24) are like those in the verbs flēon 'flee', slēan 'strike', and fōn 'take': 1 sg. flèo, slēa, fō, 2 fliehst, sliehst, fèhst, 3 flieh $p$, slieh $p$, fêh $p$, pl. flēop, slēap, föp. In the Anglian dialects, on the other hand, forms like 2, 3 sg. slēs, slēè are normal, without $h$ (which was lost between vowels, followed by contraction: see $\S 4.13$ ), though many analogical developments are to be found, e.g. analogical re-addition of the ending in 3 pl. on-fōað: see, e.g., Hogg \& Fulk 2011: §6.66. In OFris. are found contracted forms analogous to the WS forms of OE, e.g. 3 sg. pres. tiucht, sleith/slaith <*slezp/slazb (Old West Fris. slacht), to tiā 'draw' (class II) and $s l \bar{a}$ 'strike' (class VI).

In $\mathrm{ON}$, nearly all such verbs have acquired weak preterites, e.g. pret. tjáða to tjá 'show' <*tīxan- (class I), though strong preterites and/or passive participles to these are 
sometimes preserved in old and poetic texts, e.g. pret. fló to flýja 'flee', more commonly weak pret. flóða, flǿða, or flýða. ${ }^{2}$ A number of these, like flýja (for *flóa: cf. Go. pliuhan), have developed weak presents by the addition of $-j$ - to the stem of the umlauted singular. Contracted verbs that generally retain strong preterites include, from class V, sjá 'see'; from class VI, flá 'flay', hloja 'laugh', klá 'scratch' (but originally *kleyja), slá 'strike', pvá 'wash'; and, from class VII, fá 'take'. Contraction also occurred in $\mathrm{ON}$ after loss of * $w$ in 2 sg. spýr 'vomit' (cf. Go. speiwis), with reformation of inf. *spýa to weak spýja. Compare also $2 \mathrm{sg}$. snýr and gnýr to snúa and gnúa (< ${ }^{*} s n \bar{o} w$-, *bnoww-, $\$ 3.4$ n. 5; to the latter verb, cf. Go. bnauan). There is contraction as well in the pres. ind. sg. of verba pura (\$12.22), e.g. 3 sg. sær to sá 'sow' (and similarly gróa 'grow', róa 'row', sóa 'sacrifice').

In $\mathrm{OE}$, contracted verbs retain their strong preterites. Contracted verbs of classes I and II have the same vocalism in the first principal part, and as a consequence, there is some shifting of such verbs between the two classes: for example, wrēon 'cover' of class I forms its pret. $3 \mathrm{sg}$. as wrāh (class I), but more commonly as wrēah (class II). Contracted verbs in OE include the following: class I: lēon 'grant', $\bar{a}$-sēon 'sift', tēon 'accuse', wrēon 'cover'; class II: flèon 'flee', tēon 'draw, lead'; class III: pēon 'prosper'; 3 class V: ge-fêon 'rejoice', plēon 'risk', sēon 'see'; class VI: flèan 'flay', lēan 'blame', slēan 'strike', pwēan 'wash'; class VII: fōn 'take', hōn 'hang'. Contraction upon loss of $/ \mathrm{w} /$, with the original, uncontracted values confirmed by poetic meter despite contracted spellings, is also attested in forms of rōwan 'row' and strēgan (Anglian) 'strew' (see Fulk 1992: $§ \S 119-20$ ). Contraction upon loss of $/ \mathrm{j} /$, again with a few instances of non-contracted scansion in verse, is to be found in some forms of bèon

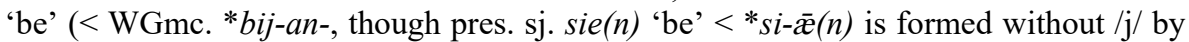
the analogical extension of $*_{-} i$ - throughout the paradigm from the singular, e.g. original WGmc. 1 sg. * sijæ $\overline{\mathfrak{e}}^{n}$ (see Hogg \& Fulk 2011: §6.148, and see $\$ 12.57$ infra).

Contracted verbs in OFris. due to loss of *h include $f \bar{a}$ ' catch', flia 'fly', $h w \bar{a}$ 'hang' (<*hōhan; cf. $d w \bar{a}$ 'do' <*do-an or *do-an, §12.61), iān 'confess', siā 'see', skīa(n) 'happen', slā 'strike', and tiā 'draw'.

1. Although Verner's law caused no voicing in the preterite singular of at least classes $I-V$, in none of the pret. sg. forms of $\mathrm{OE}$ would the voiceless fricative have appeared between voiced sounds and thus undergone deletion, whereas $* h$ in the syllable coda was lost in $\mathrm{ON}$, as in pret. $2 \mathrm{sg}$. sátt 'saw' $<$ *saht and $3 \mathrm{sg}$. sá $<$ *sah.

2. ON verbs that have lost $/ \mathrm{x} /$ and gained weak preterites include these: class I: tjá 'show', ljá 'lend'; class II: flýja 'flee', *fúa 'rot' (pp. fúinn; cf. wk. inf. fúna), lýja 'beat' (pp. lúinn), tjóa 'avail' (pp. toginn 'drawn', Noreen 1970: §488 Anm. 4); class VI: prá ‘yearn' (strong pp. in name Práinn).

3. From *bixxan $<*$ piyxan- (§4.1), with pret. sg. pāh $<*$ payx , pl. pungon.

4. From WGmc. *sexwan, hence WS pret. pl. sāwon $<* s \bar{x}(3)$ wun, but Anglian sēgon $<*$ sēj(w)un (§§6.4 ad fin., 6.6).

\subsection{The verba pura}

A number of verbs originally inflected according to class VII have the appearance of not bearing any stem-final consonant, due to loss of a PIE laryngeal consonant. Examples are Go. saian 'sow', OIcel. sá, OE sāwan, OS sāian (cf. Lith. sëju, sëti 'sow', OCS

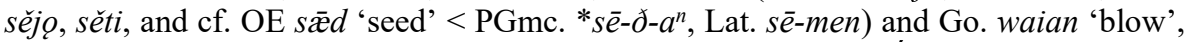
OE wāwan, OFris. waja (cf. Skt. vāti 'blows', beside $\underline{i}$-present vắyati, etc.). Lindeman (1968) offers a list of 23 verbs of this type, to which Matzel (1987) adds a number of 
roots on the basis of what he takes to be substantivized deverbal adjectives, e.g. ${ }^{*} m \bar{o}$ 'exert oneself' on the basis of Go. mōpss 'anger' (cf. Go. pp. af-mauidái 'fatigued' (weak class 1), etc.). With the exception of OE, WGmc. has almost entirely reformed these verbs to inflect according to weak class 1, and that tendency is evident in all the Gmc. languages, even in Gothic, as af-mauidái demonstrates. It is commonly assumed that such verbs acquired a stem-final $*_{-j}-$ in the pres. already in PGmc., ${ }^{1}$ but certain facts tell against that assumption. Particularly discordant with that view are OE verbs of this type, which have $-w$ - rather than *-j-, e.g. grōwan 'grow', sāwan 'sow' (cf. OFris. grōja, OS sāian); but also elsewhere in WGmc., $j$-presents are hardly uniform in these verbs, e.g. OHG sāian, sāan, sāwen, sāhen, ${ }^{2}$ casting doubt on the antiquity of the stems in $* j$. Moreover, for verbs in $\bar{o}$ most grammars reconstruct for $\mathrm{ON}$ forms with stem-final *w, e.g. flóa $<*$ flowwan $=\mathrm{OE}$ flowan 'flow' ${ }^{3}$ The evidence of both $\mathrm{ON}$ and Gothic is inconclusive. ${ }^{4}$ The $-w$ - in OE verbs like flowan is of particularly obscure origin; it is sometimes explained by reference to perfect forms like Skt. jajñá $u$ and Lat. $n \bar{o} v \bar{\imath}$ ' $k n e w$ ' (cf. OE $c n \bar{e}(o) w$ to cnāwan 'know'), but Bammesberger (1980: 17) has shown how implausible that supposition is. The account of the reformation of the reduplicating class offered above $(\$ 12.20)$ is compatible with an alternative way to account for this $w$ : it may be assumed that it developed between $\bar{o}$ and $u$ in preterites like $3 \mathrm{pl} .{ }^{*} 3 r-e-\bar{o}-u n>$ $\mathrm{OE}$ greeowon and was then generalized as part of the stem in both the pret. and the pres., whence it was extended also to the similar verbs in $\mathrm{OE} * \bar{x}(>\bar{a}$ before $w)$, e.g. ${ }^{*} s \bar{x}-\rightarrow$ $s \bar{a} w-.{ }^{5}$ On preterites to the verba pura, see Matzel 1988, Bammesberger 1991d.

1. So, e.g., Kluge 1910 and others cited by Lindeman (1968: 48 n. 1). It may be that a few such verbs originally had weak presents, and that the $j$-suffix was extended to the rest by analogy, as Lindeman argues. But Guðrún Pórhallsdóttir (1993), who finds that intervocalic $j$ was lost in PGmc. even after stressed vowels, argues persuasively that all such instances of WGmc. semivowels are innovations.

2. The treatment of intervocalic $j$ in $\mathrm{OHG}$ is not plain, but that four forms such as these could all reflect WGmc. *sǣjan, as is not uncommonly assumed, seems dubitable, especially given that forms without $\langle i\rangle$ are the norm in earlier OHG, and it is only in late OHG and MHG that $\langle i\rangle$ comes to predominate (Braune 2004a: $\S 117 \mathrm{Anm} .1)$. Note, however, that $\mathrm{OHG}$-en may derive from *-jan $(\$ 12.38)$.

3. So, e.g., Noreen 1970: $§ 235$ d, Iversen 1973: $§ 124.6$; see also the references in Lindeman 1968: 50 n. 7; cf. also Seebold 1970: 204, reconstructing *flowan for OE but *flo-e- for ON, though the latter could only be an analogical formation.

4. For the reasons, see Fulk 1993a: 249-51, anticipated in part by Kluge 1910: 108. The most careful treatments of this question are in fact tentative about how such forms are to be reconstructed, e.g. Streitberg 1896: $\S \S 91-2$.

5. Thus Fulk 1993a: 245-6. Guðrún bórhallsdóttir (1993: 114-37) points out that the same change could have occurred before the pres. ind. $1 \mathrm{sg}$. ending $*-u$.

\section{B. INFLECTION}

\subsection{A comparative paradigm of strong verb inflection}

A typical strong verb, Go. -biudan 'bid' (in ana-biudan 'bid', faúr-biudan 'forbid'), with cognates in the other earliest Germanic languages, is inflected as follows: 


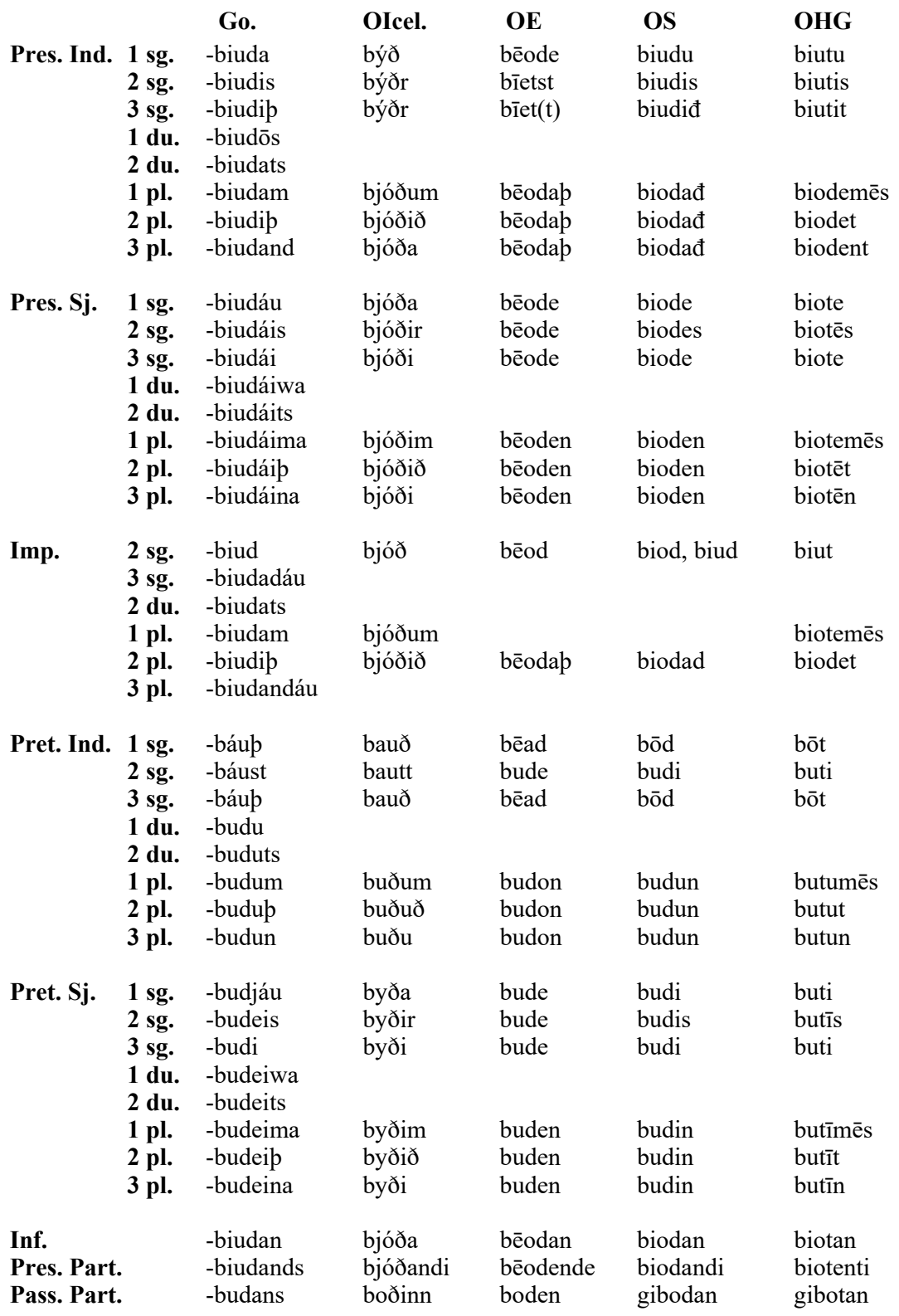

Outside of Gothic, the plural endings are used with both plural and dual subjects. In addition, inflected infinitives (also called gerunds) occur in WGmc. (\$12.30). Only in Gothic are verbs regularly inflected in the passive voice, and only in the present tense: see $\S 12.29$. 


\subsection{Inflection of the present indicative active in Proto-Germanic}

The Germanic endings of the present indicative active developed from the PIE primary thematic endings identified in $\S 12.4$, with the exceptions noted below. On verbs preserving athematic inflections, see $\S 12.55$. The endings attested in the earliest Germanic languages, with possible PGmc. antecedents (assuming unconditioned change of $e$ to $i$ in unstressed syllables, §5.5), are these:

\begin{tabular}{|c|c|c|c|c|c|c|}
\hline & Go. & OIcel. & OE & OS & OHG & PGmc. \\
\hline $1 \mathrm{sg}$. & $-a$ & $-\varnothing$ & $-e$ & $-\mathrm{u}$ & $-\mathrm{u}$ & $*_{-} \overline{0}$ \\
\hline $2 \mathrm{sg}$. & -is & $-r$ & $-s t$ & -is & $-i s(t)$ & $*_{\text {-is }}(\mathrm{i}), *_{\text {-iz(i) }}$ \\
\hline 3 sg. & $-\mathrm{ip}$ & $-r$ & $-\mathrm{p}$ & -id, -it, -iđ & - it & *-ip(i), *-ið(i) \\
\hline 1 du. & $-\overline{o s}$ & & & & & \\
\hline 2 du. & -ats & & & & & \\
\hline 1 pl. & -am & -um & $-\mathrm{ap}$ & -ad, -at, -ad & -umēs, -amēs, -emēs & *-om(i)z \\
\hline 2 pl. & $-\mathrm{ip}$ & -іð & $-a p$ & -ad, -at, -ad & -et, -at & 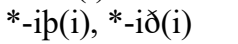 \\
\hline 3 pl. & -and & $-\mathrm{a}$ & $-a p$ & -ad, -at, -ad & -ant & *-anp(i), *-anð(i) \\
\hline
\end{tabular}

Outside of Gothic, there is umlaut of the root vowel in the second and third persons singular, e.g. 3 sg. OIcel. ferr, OE ferð (beside fær $ð, \S 12.63$ \& n. 4), OS feriđ, OHG ferit to OIcel. fara 'go', etc. Umlaut should also have occurred originally in the second person plural, but analogical developments have eliminated it everywhere, though it remains in a few forms in OHG in the early Monsee Fragments (Braune 2004a: $\$ 308$ Anm. 1). In Old Icelandic, umlaut is extended analogically to the $1 \mathrm{sg} . ;^{1}$ conversely, the PGmc. raising of $e$ before $i(\$ 4.4)$ has been eliminated in strong classes III-V, e.g. $3 \mathrm{sg}$. berr 'bears'. In OS and OHG, 1 sg. $-u$ causes raising of $e$ in the root to $i$, e.g. biru '(I) bear' to beran (§4.4). In the endings reconstructed for PGmc., a vowel in parentheses indicates one that was lost without leaving a trace in early Germanic.

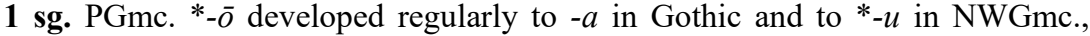
where it should have been lost in OIcel. (but preserved in Runic writu 'I carve' on the Eikeland brooch, ca. 600, and in the OIcel. middle voice, e.g. gefumk 'give' $<$ gefu + $m(i) k)$. It should also have been lost after heavy syllables in OE, but analogy has obscured the original distribution, with restoration of $-u$ (frequently becoming $-o$ ) after heavy stems in the Anglian dialects, and, in WS, replacement by -e, perhaps from the subjunctive; for references, see Hogg \& Fulk 2011: §6.11 n. 2, and cf. Holthausen 1925, A. Campbell 1977: §731(a), Suzuki 1988. Introduction of the sj. ending may have taken its initial impetus from the verb willan, the pres. ind. of which was in PGmc. formally a pret. sj. (§12.59).

2 sg. The alternation between PGmc. ${ }^{*}-i s$ and $*_{-i z}$ is a result of Verner's law (§6.6). The Gothic desinence may reflect either variant, whereas OIcel. $-r$ reflects the latter and the WGmc. endings the former. ${ }^{2}$ In OE, $-s t$ is usually said to result from resegmentation of the construction in which enclitic $p u$ followed, i.e. $-s p u>-s t u>-s t$, though it has also been argued (e.g. by Sihler 1986) that the preëxisting ending -st found in bist '(you) are' and a few pret.-pres. verbs (\$12.52) must have played a role. The earliest texts in OHG likewise have -is, later -ist, the two coöccurring in Tatian. For a thorough discussion of the competing analyses, with full bibliography, see Fertig forthcoming, where it is argued persuasively (contra Ringe in Ringe \& Taylor 2014:353-5, who rejects enclisis entirely as an explanation and attributes the change solely to analogy) that the mechanisms leading to the standardization of -st are essentially phonological in nature. Spellings like Anglian OE -esð, it may be noted, suggest at least the 
perception of $-t$ as derived from $b u$. The syncopated form $-s t$ is regular in WS after heavy stems and variable after light, occurring least frequently after stems ending in a sonorant consonant. In the Anglian dialects of $\mathrm{OE}$ the ending is regularly -est, -esð, or -es, except that syncope appears to be the norm when the pronoun is enclitic, though examples are few, as with Mercian acers $\partial u$ 'you turn away' (= EWS $* \bar{a}$-cierst $p \bar{u}$ ); syncope is variable in Kentish (see Ringe \& Taylor 2014: $\$ 7.1 .2$ for the details of Kentish). The most plausible explanation for this distribution is that syncope originated in the construction with enclitic pronoun; WS then generalized the syncopated ending, Anglian the unsyncopated. ${ }^{3}$ The addition of $-s t$ to the bare stem in OE could lead to various adjustments to some of the resulting consonant clusters, in the form of devoicing (e.g., $-g$-st $>-h s t$, i.e. $/ \mathrm{y} /+/ \mathrm{st} />/ \mathrm{xst} /$ ) and assimilation (e.g. $-p-s t>-s s t>-s t)$. For details, see Hogg \& Fulk 2011: §6.13.

3 sg. PGmc. *- $p(i)$ should have alternated with *-ið(i) under Verner's law, although the only secure evidence for this is OHG $-i t<*_{-i d}<*-i \delta,{ }^{4}$ whereas Go. is ambiguous (\$6.12), and the other Gmc. evidence demands PGmc. ${ }^{*}-i p$; cf. the $2 \mathrm{pl}$. ending, below. ON $-r$ is usually regarded as analogical to the $2 \mathrm{sg}$. ending; ${ }^{5}$ original $-i p$ is still to be found in Runic $\mathbf{b}^{\wedge}$ riutip 'breaks' (Tveito stone, Norway, ca. 625, beside $\mathbf{b}^{\wedge}$ rutR, Björketorp stone, Sweden, roughly contemporary). The introduction of the $2 \mathrm{sg}$. ending into the $3 \mathrm{sg}$. was probably the result of the syncope of $i$ in the $3 \mathrm{sg}$. inflection, leading to unwieldy final consonant clusters, as in OE (H.F. Nielsen 2000: 263). In OE, syncope is distributed the same way as in the $2 \mathrm{sg}$., and once again there could be adjustments to some consonant clusters formed when $-b$ was added directly to the stem, including devoicing (e.g. $-n g-p>-n c p$ ), assimilation (e.g. $-d-p>-t t$ ), and dissimilation (e.g. $-s-b>-s t$ ). For details, see Hogg \& Fulk 2011: §6.13.

1 du. Go. $-\overline{o s}$ possibly reflects the etymological PIE thematic ending *-o-ues, hence PGmc. ${ }^{*}$-awiz, but with analogical replacement of $*_{-} a$ - by $1 \mathrm{sg}$. $-\bar{o}$, producing PGmc. ${ }^{*}-\bar{o}(w) i z$ (Wright 1954: §287), though it has not been proved that $w$ should have been lost between an unstressed vowel and $i$ (so Ringe 2006a: 136; cf. Ringe 2017: 161, reconstructing PIE $*_{-o-u o s)}$; possibly there was the change $*_{-} \bar{o} w i z>*_{-} \bar{o} w z>-\bar{o} s$ (A.W. Jones 1979: 351). Rather, Bammesberger (1983b: 174) explains $-\overline{o s}$ as created on the analogical proportion 1 sg. pres. -am : pret. $-u m=1$ du. pres. $x$ : pret. $-\bar{u}$, hence $x={ }^{*}-\bar{o}$, with subsequent addition of $-s$ from the 2 dual.

2 du. In Go. -ats, the final cluster -ts is plainly derivable from the PIE ending *-tes, though why the result is -ts rather than *-ps is disputed. ${ }^{6}$ Neither is it known for certain why the PIE thematic vowel $*_{-}-$-, which should have developed to ${ }^{*}-i$ - in Germanic, was replaced by Gmc. *- $a$-, though this seems likeliest to be a paradigm regularization, with replacement of the reflex of PIE thematic ${ }^{*}-e$ - by that of its alternant ${ }^{*}-O-$.

1 pl. The Go. and OIcel. endings represent regular developments. ${ }^{7}$ In OHG, the form -umēs appears to be oldest, though there is mixture of endings from an early date. Final $-\bar{e} s$ in this form is difficult to explain. ${ }^{8}$ In Ingvaeonic, the $3 \mathrm{pl}$. ending has been extended throughout the plural.

2 pl. The Go. and OIcel. endings represent regular developments if it is assumed that PIE $e$ became PGmc. $i$ in unstressed syllables except before $r(\S 5.5)$; the PIE thematic ending was *-e-te. That the final consonant in PGmc. was at least sometimes voiced by Verner's law is shown by forms with an attached enclitic in Go., e.g. qibid-uh 'and you say'. OHG -at seems to show the same substitution as in the Go. 2 du., whereas the origin of -et is much disputed: see the references in Braune 2004a: $\$ 308 \mathrm{Anm}$. 1b and in Boutkan 1995b: 317-18. Beside the latter appears the expected -it in the early Monsee fragments, which is formally identical to the 3 sg., likewise causing umlaut, 
and this suggests that PIE *-ete did indeed yield PGmc. *-ip/-ið. In Ingvaeonic the $3 \mathrm{pl}$. ending has been extended throughout the plural. Possibly this was aided by a prior refashioning of $*_{-i p}$ to $*_{-} a p$ (as with OHG -at $<*_{-} a$; ; so Krahe \& Meid 1969: II, §69), but the vowel of 3 pl. $-a p$ (as explained below) must have remained long for some time.

3 pl. The PIE ending *-o-nti would normally develop to PGmc. *-and(i), yielding *-and, reflected in Go. -and, OHG -ant. But there must have been an alternant PGmc. *-anp(i) not subject to Verner's law because of stress on the inflection, as in the 2 and $3 \mathrm{sg}$. This is reflected in OIcel., showing the development $*_{-}$anp $(i)>*_{\text {-ann }}>-a$ (see Heusler 1967: $\S \S 158.2,152),{ }^{9}$ and in Ingvaeonic, where the development is $*_{-} a n p$ $>*_{-} \bar{a}^{n} p>-a p(\$ 6.17$, and see n. 4 infra). OS -ad, -at would seem to reflect PGmc. $*_{\text {-anp }}(i)$ rather than *andi, as $n$ would not have been lost in the latter in NSGmc. OS $-a t$, however, appears to be the final fortition of $-a d$, discouraging the idea that the former is merely a spelling variant of $-a d$, and final fortition tells against a development $*_{-} p>*_{-} \partial>*_{d}$ (cf. Ringe \& Taylor 2014: 160). Holthausen (1921: §405) may thus be right that the OS pl. inflections represent a mixture of the original 2 and 3 pl. endings.

1. If it is supposed that umlaut by lost $i$ did not originally affect light syllables in ON (§4.7), it must be assumed that it was extended to the 2 and $3 \mathrm{sg}$. of verbs with light stems. But almost certainly umlaut did originally apply to light syllables.

2. It is generally assumed that the unvoiced alternant was preserved in verbs of the tudati type, i.e. the Germanic aorist presents $(\S 12.3)$; see also below on the 3 pl. ending. But $-s$ - would also have remained unvoiced in verba pura such as PGmc. *dō-s(i) 'do', *3ē-s(i) 'go' and *stē-s(i). Fullerton (1975, with refs.) supports the view that * $z$ was devoiced by the voiceless initial of an enclitic pronoun. See Ringe 2017: 207-9 for an accounting of the original distribution of the variants by verb type.

3. This analysis originates with Walde (1900: 125 n. 1); see also Lōfvenberg 1949: 17-23 and Fulk 1992: $\S \S 318-21$. Ringe (in Ringe \& Taylor 2014: §7.1.2) adheres to the earlier view that only the Anglian endings are analogical, in support of his hypothesis that OE syncope occurred in more environments than has heretofore been allowed (see $\$ 5.2$ n. 4 supra).

4. OS -id, -it may represent borrowings from OHG: so Prokosch 1939: §72a. However, since there was devoicing of final obstruents in OS $(\S 6.20)$, these could both represent the alternant $*_{-} d<*_{-} \partial$ under Verner's law (so Holthausen 1921: $\$ 404$ Anm. 1). It is plain that voiced and voicless alternants coöccurred in ProtoWGmc., since leveling has taken opposite directions in OHG and OE.

5. Holland (1980, with discussion of alternative analyses) argues instead that $3 \mathrm{sg}$. $-r$ reflects an enclitic 3 sg. pronoun ${ }^{*} e_{R}$. Some others envisage a phonological change $\delta>_{R}$ : see Brøndum Nielsen 1950-7: VIII, $\S 782.1$.

6. Since the Skt. ending is -a-thah, possibly the PIE ending was *-o-tHes, and the laryngeal consonant prevented Grimm's law from applying to * $t$ in PGmc. (Krause 1968: $\$ 258$, in agreement with Stang 1949). For alternative views, see Krahe \& Meid 1969: II, §69, Wright 1954: §287 (the latter arguing that the $t$ is analogical to the $t$ in forms like Go. OIcel. 2 pl. pret. namt 'took'), K.M. Schmidt 1974, and Bammesberger $1983 \mathrm{~b}$, the last arguing (171-2) that $t$ in the suffix remained unshifted in a few athematic verbs ending in a consonant which, in contact with $t$, normally prevented the application of Grimm's law, e.g. *es- 'be' and * $3 e b$ - 'give', with subsequent generalization of $t$, as in the 2 sg. pret. Rather, Ringe (2017: 264) assumes a regular change of *- $p s$ to -ts that, he reasons, is unattested elsewhere because of paradigm regularization.

7. A comparable development is seen in the dat. plural of Gmc. $a$-stem nouns ( $\$ 7.8 a d f i n$.). That is, the PIE verb ending *-o-mes gives - am in Gothic but -um in NWGmc. (\$5.5).

8. Krahe 1958 argues that $s$ remained unvoiced in the reflex of PIE $*_{-o-m e s}$ due to suffixal accent originating in athematic verbs (cf. Skt. 1 pl. imáh $<* h_{l}$ i-més 'go'), and $i$ was then replaced by $\bar{e}$ by analogy to the 1 pl. opt. ending *-mē (> Go. sj. - $m a$ ). Bech (1962) raises weighty objections, but no more convincing is his notion of the addition of the OHG $2 \mathrm{sg}$. sj. ending -ês to the normal $1 \mathrm{pl}$. ind. in -um. The commonest assumption is that -umēs shows the incorporation of a following pronoun into the inflection: for discussion and references, see Boutkan 1995b: 313-17.

9. The idea of Boutkan (1995b: 318) that the OIcel. inflection reflects *-anði rather than *-anpi faces the objection that *-nð- should have become *-nd- in PGmc. (\$6.5), but loss of final $d$ after $n$ could not be called 
improbable. The argument of Fullerton (1974) that NSGmc. *-anp results from devoicing in *-anð, however, cannot be reconciled with the assumption that $n d$ arose already in PGmc.

\subsection{Inflection of the preterite indicative in Proto-Germanic}

The Germanic endings of the preterite indicative active developed from the PIE perfect endings identified in $\S 12.4$, with the exceptions noted below. The endings attested in the earliest Germanic languages are these:

\begin{tabular}{|c|c|c|c|c|c|c|}
\hline & Go. & OIcel. & OE & OS & OHG & PGmc. \\
\hline $1 \mathrm{sg}$. & $-\varnothing$ & $-\varnothing$ & $-\varnothing$ & $-\varnothing$ & $-\varnothing$ & $*_{-}$(a) $(\S 5.2)$ \\
\hline 2 sg. & $-\mathrm{t}$ & $-\mathrm{t}$ & $-e$ & $-\mathrm{i}$ & $-\mathrm{i}$ & $*-\mathrm{p}(\mathrm{a})$ \\
\hline 3 sg. & $-\varnothing$ & $-\varnothing$ & $-\varnothing$ & $-\varnothing$ & $-\varnothing$ & $*_{-}(\mathrm{e})$ \\
\hline $\begin{array}{l}1 \mathrm{du} . \\
2 \mathrm{du} .\end{array}$ & $\begin{array}{l}-u \\
-u t s\end{array}$ & & & & & $*-\mathrm{w}(\mathrm{e})>*_{-u}(\S 5.2)$ \\
\hline 1 pl. & -um & -um & -on & -un & -um & $*_{-\mathrm{m}}(\mathrm{e})>*_{-\mathrm{m}}>*_{\text {-um }}(\S \S 5.2,3.2)$ \\
\hline 2 pl. & $-\mathrm{up}$ & -uð & -on & -un & -ut & \\
\hline 3 pl. & -un & $-\mathrm{u}$ & -on & -un & -un & $*_{\text {-un }(\mathrm{p})}$ \\
\hline
\end{tabular}

Outside of Gothic, the plural endings are used with both plural and dual subjects. In the desinences reconstructed for PGmc., a segment in parentheses indicates one lost without leaving a trace in early Germanic. The following inflections merit discussion:

$2 \mathrm{sg}$. Gothic and OIcel. - $t$ reflect the PIE perfect ending *-th $e$ seen in Skt. -tha and Gk. $-\theta \alpha$ (as in $o \hat{i} \sigma \theta \alpha$ 'you know'; cf. also Hitt. sak-ti 'you know', sak-ta 'you knew', and Lat. vìd-is-tī 'you saw'). PIE *-th $h_{2}$ is commonly assumed to have produced PGmc. *- $b$, which, however, is nowhere found, except perhaps in OE (Anglian) (e)arð (§§12.56-7). Rather, after a fricative consonant PIE *-t would remain unshifted under Grimm's law (§6.5), as in Go. saht 'you saw' and gaft 'you gave', ${ }^{1}$ and presumably this rather common variant was generalized in East and North Gmc., if not in PGmc. (the latter possibility discounted by Heidermanns 2007: 59). This ending is found also in WGmc. in the preterite-present verbs (\$12.52), but the normal WGmc. preterite endings must reflect either $*_{-i}$ (etymological after light stems, analogical after heavy) or $*_{-} \overline{\text {. }}$. This is now usually explained as derived from PGmc. ${ }_{-}-i z$ (with loss of final $z$ after the unstressed vowel in WGmc., §6.16), reflecting the thematic vowel *-e-plus the secondary ending $*_{-}-$used in the PIE imperfect and aorist. ${ }^{2}$ The substitution of the aorist ending for the perfect one would have been well motivated, given the awkward final consonant clusters that would have resulted in some instances from the addition of final *- $b$ to a stem that already ended in a consonant cluster, and given the alternation between $*-b$ and $*$ - $t$ already mentioned (if this was not eliminated already in PGmc.), as well as further irregularities like that mentioned in $\mathrm{n}$. 1. A difficulty facing derivation of the WGmc. ending from an aorist is that in order to explain, e.g., WGmc. *tuzi(z), it is necessary to derive it from PIE *hé-duk-e-s (cf., e.g. Skt. ásicah 'you poured' (root sic-), Gk. "̌̀ $\imath \pi \varepsilon \varsigma$ 'you left'), as suffix accent, though it would explain the voicing of the root-final consonant under Verner's law, would produce final $*_{-s}$ rather than $*_{-z}$; and yet there is no secure evidence for a verbal augment anywhere in Germanic (see $\S 12.61)$. If, instead, WGmc. *tuzi is derived from an augmentless thematic aorist *duk$\dot{e}-s$ (cf. Gk. $\lambda \imath \pi \varepsilon \hat{\imath} v$, etc.), it must be assumed that final ${ }_{-s}$ was lost in WGmc. regardless of whether or not it was voiced under Verner's law, or that final $*_{-s}$ developed to $*_{-z}$ in WGmc. (and was thus lost) regardless of the original place of the accent (see §6.16). 
Grønvik (1998b: 103-11, at 104-5) raises a number of other telling objections. ${ }^{3}$ Most alternative explanations rely upon the assumption that the WGmc. ending is optative in origin. ${ }^{4}$ In PGmc. the pret. subjunctive (< optative) ending was ${ }^{*}-\bar{i}-s$ or ${ }^{*} \overline{-}-z$ (see $\S 12.27)$; if the former, it must be assumed, once again, that final $*_{-s}$ was simply lost in WGmc. In either event, the remaining $*_{-} \bar{l}$ would have been shortened, but not early enough to undergo apocope after heavy stems: cf., for instance, OHG 1 and 3 sg. pret. sj. $-i$ (see $§ 12.23$ ). This explanation thus does not require the extensive appeal to analogy required by derivation from an aorist form. ${ }^{5}$ Derivation of the $2 \mathrm{sg}$. ending from either the aorist or the perfect subjunctive will explain why the stem is in the reduced grade in WGmc. Kortlandt (1994b) derives the ending from a posited PGmc. pluperfect.

1 du. Bammesberger (1983b: 173) regards the inflectional vowel as long, composed of 'thematic' $u$ plus $w<$ PIE *-ue. If it is short, it must reflect *-ue alone.

2 du. Go. -uts has its vowel by analogy to the 1 dual and the plural endings. See Bammesberger 1983b: 172-3.

1 pl. The usual assumption (first offered by Sievers 1877-8: 5.119-21; cf. Marchand 1957b: 107-8) is that in a form like PGmc. *bid-m(e), upon loss of the final vowel the remaining postconsonantal $*_{-} m$ was syllabified and fell together with the reflex of PIE *-m as *-um. ${ }^{6}$ Since this cannot be proved, Bammesberger (1986a: 96) argues instead that PGmc. *-um has its vowel by analogy to the 3 pl. ending *-un. In OE and OS, the $3 \mathrm{pl}$. ending has been extended throughout the plural.

2 pl. The endings (outside of Ingvaeonic, where the $3 \mathrm{pl}$. ending has been substituted) must derive from PGmc. *-up, though this cannot reflect the PIE perfect ending, whatever it was $\left({ }^{*}-\left(h_{1}\right) e ́\right.$ ? $) .^{7}$ This ${ }^{*}-u p$ most likely has its vowel by analogy to the 1 and 3 pl. inflections, and perhaps its consonant derives from the pres. ind. inflection. Alternatively, this consonant could be derived from the PIE aorist inflection *-(e-)te, a possibility mentioned by Krahe \& Meid 1969: II, §73. PGmc. * ${ }^{*} u p$ is also reflected in the present of athematic and preterite-present verbs.

3 pl. The PGmc. ending must have been *-un(b) (with loss of the final consonant already in PGmc.), to be derived from PIE * ${ }^{*} n t$, which is not a perfect ending. ${ }^{8}$ Rather, $*_{-n t} t$ is an athematic secondary ending, and so used with the imperfect and the sigmatic aorist (Cowgill 1957: 48-9). ${ }^{9}$

None of these endings proves conclusively that the PIE aorist was still an inflectional category at the time the PGmc. preterite was formed, but the 3 pl. ending renders that conclusion highly probable. ${ }^{10}$ Likewise, an aorist model, insecure as it is, seems the likeliest explanation offered to date for the $2 \mathrm{sg}$. ending in WGmc., ${ }^{11}$ and it is a possible explanation, in part, for the 2 pl. ending.

1. Final $-t$ would also have resulted when $*-p$ was added to a dental consonant, producing final $-s t$, as in Go. 2 sg. pret. ana-báust to ana-biudan 'bid'. There is also, however, the possibility that the First Consonant Shift preceded the loss of the laryngeal, which prevented $t$ from shifting (so, e.g., Sihler 1986: 201): cf. $\$ 12.24$ on the pres. 2 dual inflection. Ringe (2017: 124) is probably right that laryngeals were lost before the First Sound Shift, but it does not appear to be possible to prove that anteconsonantal and postconsonantal laryngeals were lost at the same time. OE dialectal 2 sg. pres. earð, arð 'are' would appear to be the only Gmc. forms showing the shifted consonant, but it is by no means certain that $-\delta$ reflects the original perfect ending: see $§ 12.57$.

2. This idea originates with von Fierlinger 1885, supported by Loewe 1907: 267, Sverdrup 1927, 1929: 4850, Hirt 1931-4: II, §122, Prokosch 1939: §56b, Krahe \& Meid 1969: II, §73, A. Campbell 1977: §731, Brunner 1965: $\$ 364$, Hogg \& Fulk 2011: $§ 6.21$, and very many others.

3. As Grønvik points out, the assumption that $3 \mathrm{pl} .{ }^{*}-u n(p)$ is an aorist ending demands the supposition that the perfect and aorist melded in PGmc., so that the assumption of an intact aorist surviving into WGmc. makes no sense. Moreover, such a posited aorist has left no trace in North Germanic. In addition, the ending 
$*_{-i}(\mathrm{OE}-e)$ would be etymological only in strong classes 1 and 2 , as the sj. stem in all other classes would have been heavy, causing apocope of the final vowel. And although OHG ni curi 'do not' has sometimes been identified as an aorist form (so, e.g., Streitberg 1896: §214), it is more plausibly analyzed as a pret. sj. $(\$ 12.27)$.

4. So, e.g., Bammesberger 1986a: 47-8; refs. in H.F. Nielsen 2000: 245 . This idea was proposed already by Jacob Grimm: see Flasdieck (1934: 118-19), who discounts the idea and remarks that derivation from the aorist has in its favor that the aorist ending could not be added to the preterite-presents, since they are present in meaning. See also Meid 1971: 13-14. Bech (1969) argues that *-iz was taken into the pret. from the pres., and M.R. Barnes (1975) offers some refinements to this analysis, with discussion of the problem of WGmc. $*_{-z} z$.

5. Advocates of variants upon this explanation include van Helten (1893: 554; 1902: 545), Schröder (1921), Polomé (1964), Bammesberger (1986a: 47-8), Grønvik (1998b: 103-11), Euler 2013: 138-40, and Ringe \& Taylor 2014: 67-9. For a syntactic justification for the origin of the use of the pret. sj. for the ind., see Grønvik 1998b: 105-11, with references. Yet surely the original ind. inflection would not have been lost entirely had it not created paradigm irregularities, as remarked above.

6. So, e.g., Krahe \& Meid 1969: II, §73, though their idea that $-u$ - in this ending might in some instances reflect a (i.e. $H$ ) is not to be credited: see $\$ 5.5$ ad fin.

7. If the PIE inflection really was *-he, with loss of the laryngeal it would have fallen together with the $3 \mathrm{sg}$. ending, and this may have prompted the refashioning of the inflection (Boutkan 1995b: 336).

8. The PIE perfect ending almost certainly contained $r(\$ 12.4)$, though the original ending has been replaced analogically in the majority of IE branches.

9. Tops (1974: 26), building on ideas set forth by Polomé (1964) and Meid (1971), argues that the presumed PIE 3 pl. perf. inflection in $r$ was replaced by $-n t$ in the PIE period itself, and therefore the source of the Gmc. perf. ending could be the present ending. One assumes that he means by this either that the replacement did not take place in all verbs (since the $r$ ending is reflected in Hittite, Tocharian B, Sanskrit, and Latin) or that the replacement took place only in some dialects of PIE. In either event, he must mean that because the replacement took place so early, PIE phonological patterns would still have applied, and hence $/ \mathrm{nt} /$ would have been realized as *-nt. But the problem of the survival of the $r$ inflection in some IE languages tells against replacement at such an early date, and at all events, if the replacement took place so early, the distinction between primary and secondary endings would still have been observed, rendering the secondary form of the Gmc. ending difficult to explain.

10. Rather, Ringe (2017: 182-5) derives the Gmc. inflection solely from the form *dèðun 'did', which he derives from an imperfect: see $\$ 12.61$ on 'do'.

11. Assuming that the $2 \mathrm{sg}$. ending in WGmc. is aorist in origin demands that the aorist have remained in use up to the time of the separation of WGmc. from NGmc, though there is no other reason to suppose that it was preserved so late. It would indeed be surprising if it persisted so long without leaving a trace in Gothic and NGmc. that is not found also in WGmc. Considerable uncertainty thus remains.

\subsection{Inflection of the present subjunctive active in Proto-Germanic}

The Germanic endings of the present subjunctive active developed from the PIE present optative desinences. It was the PIE thematic optative that was generalized in the present tense in Gmc., which, according to the standard view (\$12.6), comprised the theme

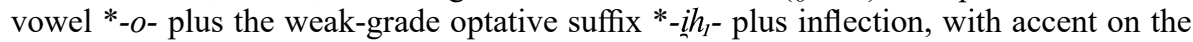
root throughout. ${ }^{1}$ In the present tense in Gmc., of the PIE athematic optative only a few relic forms are to be found. ${ }^{2}$ The normal endings attested in the earliest Germanic languages are these:

\begin{tabular}{|c|c|c|c|c|c|c|}
\hline & Go. & OIcel. & OE & OS & OHG & PGmc. \\
\hline $1 \mathrm{sg}$. & -áu & $-\mathrm{a}$ & $-e$ & $-e$ & $-e$ & $*_{\text {-a }}(\mathrm{j}) \mathrm{u}(\mathrm{n})<\mathrm{PIE} *_{-} \mathrm{oih}_{1} \mathrm{~m}_{\mathrm{n}}$ \\
\hline $2 \mathrm{sg}$ & -áis & -ir & $-e$ & -es & -ēs & $*_{\text {-aiz }}$ \\
\hline 3 sg. & -ái & $-\mathrm{i}$ & $-e$ & $-\mathrm{e}$ & $-e$ & $*_{\text {-ai }(ð)}$ \\
\hline
\end{tabular}




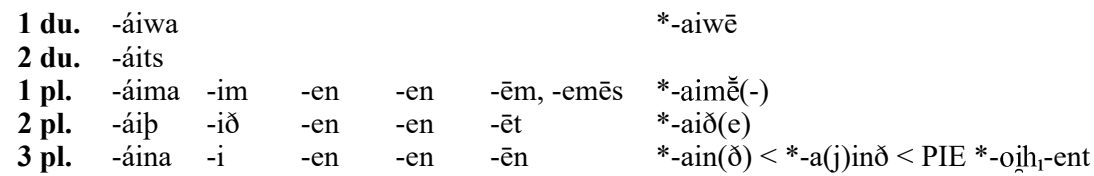

The following endings merit comment:

1 sg. PIE *-oih $m(\$ 12.4$, in line with the explanation of Paul 1877: 378) accounts admirably for Go. -áu, since the resulting PGmc. *-ajum would have lost *j between unstressed vowels ( $\$ 6.11 \mathrm{ad}$ fin.), and final $*_{-} m\left(>*_{-} n\right)$ would have been lost, as well (§6.11). There is thus no need to suppose that the emphasizing particle $*_{-} u$ that appears to underlie the $3 \mathrm{sg}$. and pl. imp. endings in Gothic $(\$ 12.28)$ is required to explain this opt. ending (so Prokosch 1939: §72c). PGmc. ${ }^{*}$-au will also explain OIcel. - $a$ (cf. átta ' 8 ' < PIE *októtu), whereas the WGmc. endings appear to reflect *-aim > *-ai(n), an early analogical formation with *-ai- derived from the remainder of the paradigm rather than an original alternant. ${ }^{3}$

2 sg. The Go., OIcel., and OE endings develop regularly. The OS and OHG endings have $-s$ on an analogical basis, under the influence, not least of all, of the athematic optative ( $\$ 12.6)$, a change perhaps motivated by the utility of re-differentiating the 2 and 3 sg. (Boutkan 1995b: 323); cf. Flasdieck 1934: 115, arguing that Anglo-Frisian has innovated.

1 du. PGmc. *-aiwē is reconstructed by comparison to, e.g., OCS ved-ě-vě 'let us lead' < PIE *uedh-o-ih $h_{1}-u \bar{e}$ (with final $-\bar{e}$ from $-e-h_{l}$ ?). Cf. Ringe 2017: 264-5.

2 du. The ending is the same as in the indicative (on the origin of which, see $\S 12.24)$ but attached to the PGmc. thematic optative suffix -ai-.

1 pl. Go. -aima agrees with, e.g., Lith. -o-mé-s in reflecting an inflection with a long vowel (and cf. the 1 dual ending, above). By contrast, the OIcel. and OHG endings presuppose an ending with a short vowel, PGmc. *-ai-mé, in agreement with Skt. $-\bar{e}-m a$ and Gk. $-o l-\mu \varepsilon v$. In NSGmc. the ending of the third person has been extended throughout the plural, as in the indicative.

2 pl. Only the Ingvaeonic endings do not result regularly, being due to extension of the 3 pl. ending throughout the plural.

3 pl. Only the Gothic ending is altered analogically, with extension of $-a$ to match the $1 \mathrm{du}$. and pl. endings. Because he does not reconstruct a laryngeal consonant, Hreinn Benediktsson (1983: 33) regards PGmc. *-ain(ð) as an analogical formation, but since $* j$ between unstressed vowels appears to have been lost in PGmc. (\$6.11 ad fin.), *-ain(ठ) may result phonologically from *-a(j)ind $<\mathrm{PIE} *_{-}$-oih $h_{l}$-ent.

1. According to the earlier view, before the discovery of laryngeal consonants (see, e.g., Streitberg 1896: $\S 221$ ), the thematic optative desinence is made up of thematic $*_{o}$ plus the $*_{\bar{\imath}}$ found in the dual and plural of athematic optatives, producing PGmc. *ôे. This requires the assumption of morphological change in some of the Gothic endings. But once a laryngeal consonant is assumed in PIE, resort to analogy is unnecessary, as nearly all the Go. endings can be derived on a phonological basis, the one exception being that Go. 3 pl. -aina must be assumed to have final - $a$ by analogy, an assumption that is necessary under any analysis. See $\$ 12.6$ on problems in the analysis of the PIE thematic pres. optative.

2. On the present subjunctive (PIE optative) in athematic verbs, see $\S 12.6$. Very likely the OE umlauted present subjunctives cyme, cymen reflect a PGmc. athematic optative, hence with suffix $*-\bar{l}$-: see Bammesberger 1982b, with references. Euler 2013: 139 regards them as aorist in origin, i.e. with punctual meaning.

3. Krahe \& Meid (1969: II, §77) justify *-ai(m) as an original alternant by comparison to Lat. $s$-im 'I be', but when the presence of a laryngeal is acknowledged it should be plain that there should have been no thematic desinence *-oim inherited from PIE. For discussion and references to alternative proposals, see A.W. 
Jones 1979: 354-9, and esp. Hreinn Benediktsson 1987. Ringe plausibly argues that because the 1 and 3 sg. pret. ind. were undifferentiated, that pattern spread to the pret. sj., and thence to the pres. sj. (Ringe \& Taylor 2014: 75-6).

\subsection{Inflection of the preterite subjunctive in Proto-Germanic}

The Germanic endings of the preterite subjunctive developed from the PIE perfect (hence athematic) optative desinences (§12.6), except that the reflex of weak-grade PIE $*_{-}-i h_{1^{-}}$of the dual and plural was extended to the singular, replacing PIE athematic $*_{-i e h}{ }^{-}$, with the possible exception of the $1 \mathrm{sg}$. The endings attested in the earliest Germanic languages are these:

Go. OIcel. OE

\begin{tabular}{|c|c|c|c|}
\hline $1 \mathrm{sg}$. & -jáu & $-a$ & $-e$ \\
\hline $2 \mathrm{sg}$. & -eis & -ir & $-e$ \\
\hline 3 sg. & $-\mathrm{i}$ & $-\mathrm{i}$ & -e \\
\hline $1 \mathrm{du}$. & -eiwa & & \\
\hline $2 \mathrm{du}$. & -eits & & \\
\hline 1 pl. & -eima & -im & -en \\
\hline 2 pl. & -eip & -¡ð & -en \\
\hline 3 pl. & -eina & $-\mathrm{i}$ & -en \\
\hline
\end{tabular}

\section{OS OHG}

$-\mathrm{i} \quad-\mathrm{i}$

-is $\quad-\overline{1} S$

$-\mathrm{i} \quad-\mathrm{i}$

$*-\overline{1}(ð)$

*-īwē

$\begin{array}{ll}\text {-in } & -\overline{1} \mathrm{~m},-\overline{\mathrm{m}} \mathrm{e} \mathrm{s} \\ \text {-in } & -\overline{\mathrm{i}} \mathrm{t} \\ \text {-in } & -\overline{\mathrm{in}}\end{array}$

(-1)
PGmc.

*-jêu $<*$-je-u(n) $<$ PIE *-ieh P $_{n}$

$*-\overline{1} \mathrm{Z}$ or *-is

*-īmĕ $(-)$

*-1ð(e)

*-în $(ð)<*$-i-inð $<*$-ih $h_{1}$-ent

In OIcel. the stem shows umlaut throughout; a few possible examples with umlaut are found in OE (see Bammesberger 1982b: 414-15). The Gmc. singular endings, with the possible exception noted below, reflect analogical PGmc. * ${ }^{*} \bar{l}-$ plus the secondary endings, as in the present. The dual forms, attested in Gothic only, reflect this PGmc. ${ }^{*} \overline{-}-$ plus the usual dual inflections. As usual in NSGmc., the 3 pl. inflection has been extended throughout the plural. Otherwise, only the following endings require comment:

$1 \mathrm{sg}$. It is usually explained that Go. -jáu reflects the optative sign *-i- extended from the dual and plural with the analogical addition of -áu on the model of the present optative (so, e.g., Krahe \& Meid 1969: II, §78). But the ending may etymologically

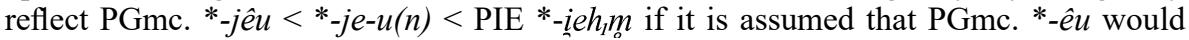
develop to Go. -áu. This development cannot be proved, but cf. the development of Go. $-a ́ u$ from PIE *-êu in the locative singular of $u$-stem nouns (\$7.25). Perhaps *-jêu would also yield OIcel. $-a$, as $* j$ would have been lost after the heavy syllable $(\$ 6.14)$ found in the stem of the pret. sj. of strong verbs other than those in classes I-II (where the syllable would have been light), though $-a$ is perhaps likelier to be analogical to the present inflection, as every other pret. sj. ending in OIcel. is identical to the corresponding present ending. Certainly, the WGmc. $1 \mathrm{sg}$. endings reflect extension of $*_{-\bar{l}}$ - from the other persons, but it is notable that $1 \mathrm{sg}$. pres. ind. OE (Anglian) willo, OS williu, OHG willu 'will' all correspond to Go. wiljáu, bearing a pret. sj. inflection on a pres. stem (§12.59), and thus supporting the assumption of PGmc. *-jêu.

2 sg. Final ${ }_{-s}$ would have remained voiceless in the PGmc. reflex of PIE *-iéh $h_{1}$ $s$. Perhaps when the reflex of $*_{-i e h} h^{-}$was replaced by $*_{-i-}$ in PGmc., the original voiceless $*_{-s}$ remained (in which event $\mathrm{OE}-e$ for $*_{-}$es would appear to be analogical). This would help to explain why the analogical pressure of athematic inflection was sufficient to induce extension of $-s$ to the corresponding present ending in OS and OHG (§12.26). Otherwise it would have to be assumed that this preterite ending in OS and $\mathrm{OHG}$ is analogical to the present ending of a small number of athematic verbs. But it is 
perhaps likelier that to analogical PGmc. *- $-\bar{l}$ - was added $-z$ (rather than $-s$ ), as in the pres. subjunctive. This would explain the curious imp. OHG ni curi 'do not' (beside later, analogically restored ni churīs, to kiosan 'choose'), which appears to be an early form of the 2 sg. pret. sj.: see, e.g., Bammesberger 1986c: 676, Euler 2013: 138.

3 pl. As in the present, the Go. ending shows extension of $-a$ from the $1 \mathrm{pl}$. inflection. Also as in the present, loss of PGmc. * $j$ between unstressed vowels adequately explains the development of PIE *-ih ${ }_{1}$-ent to PGmc. *-in( $(\partial)$, without recourse to analogy (cf. Hreinn Benediktsson 1983: 33).

\subsection{Inflection of the imperative in Proto-Germanic}

The endings attested in the earliest Germanic languages are these:

\begin{tabular}{|c|c|c|c|c|c|c|}
\hline & Go. & OIcel. & OE & OS & OHG & PGmc. \\
\hline $2 \mathrm{sg}$. & $-\varnothing$ & $-\varnothing$ & $-\varnothing$ & $-\varnothing$ & $-\varnothing$ & $*_{-}(\mathrm{e})(\S 5.2)$ \\
\hline $3 \mathrm{sg}$. & -adáu & & & & & \\
\hline du. & -ats & & & & & \\
\hline 1 pl. & $-a m$ & -um & -on & $-a$ & -amēs, -emēs, -ēm & \\
\hline $\begin{array}{l}2 \text { pl. } \\
3 \text { pl. }\end{array}$ & $\begin{array}{l}\text {-ip } \\
\text {-andáu }\end{array}$ & -ið & $-a ð$ & $-a đ$ & -et & $*_{\text {-ip }}$ \\
\hline
\end{tabular}

Only the $2 \mathrm{sg}$. and $2 \mathrm{pl}$. endings bear a relation to the PIE endings (\$12.6) transparent enough to allow reconstruction of the PGmc. endings with sufficient confidence.

2 sg. The PGmc. inflection *-e, which would have been lost consistently, reflects the PIE theme vowel with null inflection. On the imp. in athematic verbs, see $\$ 12.6$.

3 sg. Go. -adáu derives not from the PIE $3 \mathrm{sg}$. imp. *-t(u) but from what is sometimes called the future imperative (so, e.g., Szemerényi 1996: \$9.2.5), which bears a suffix in PIE *-tōd, as in OLat. estōd 'let him be' (= Gk. ě $\sigma \tau \omega)$; the Skt. reflex is -tāt. With root accent of the verb it thus would have produced PGmc. *-ðo, to which (according to the standard view) has been added an emphasizing particle, probably the same seen in Skt. pres. imp. astu, santu 'let it/them be', to produce (thematic) PGmc. *-a-ðōu $>$ Go. -adáu. Cf. Go. ahtáu 'eight' < PIE *ok̂tó̀, but see below in regard to the $3 \mathrm{pl}$. ending for some difficulties and an alternative analysis. The theme vowel $a$ in this form, however (for expected $e$ ), is by analogy to the 3 pl. imp. ending (Krause 1968: §217.4).

2 du. Go. -ats is the same ending found in the pres. ind. 2 dual, just as the $2 \mathrm{pl}$. endings are identical in the indicative and the imperative.

1 pl. The Gmc. inflections are apparently an innovation; no $1 \mathrm{pl}$. imp. ending is reconstructible for PIE. Outside of Ingvaeonic, the $1 \mathrm{pl}$. imp. ending is identical to the ind. ending, just as the $2 \mathrm{pl}$. ind. and imp. endings are identical. In OE and OS the sj. plural is the normal form used for injunctions, but OS wita ${ }^{1}$ and OE (w)uton, (w)utan, uten (also Northumbrian wutum $3 \times$ ) 'let us', apparently derived from forms of OS, OE witan 'go', suggest a separate original imp. ending even in Ingvaeonic. Possibly in these languages, too, the $1 \mathrm{pl}$. imp. ending was originally the same as the indicative, but the attested forms require the assumption of exceptional developments under low stress (see Hogg \& Fulk 2011: $\S \S 6.6,6.46$ n. 1), and so the original form of the Ingvaeonic ending cannot be determined.

2 pl. Just as in PIE, all the 2 pl. imp. inflections are identical to the indicative ones, on the development of which see $\$ 12.24$. Thus, in NSGmc. the inflection of what was originally the $3 \mathrm{pl}$. ind. is employed, since the $3 \mathrm{pl}$. ind. inflection replaced the $2 \mathrm{pl}$. 
in Ingvaeonic. The PIE 2 pl. imp. may be in origin an injunctive (so Krahe \& Meid 1969: II, §79), on which see $\$ 12.1$ n. 2 .

3 pl. The relation between Go. 3 pl. -andáu and 3 sg. -adáu has been compared to that between Skt. 3 pl. -antu $<*_{-}--n t-u$ and $3 \mathrm{sg}$. $-a t u<*_{-}-t-t-u$. Go. -andáu is commonly thought to reflect PIE *-ontōd, as in Doric Gk. $\varphi \varepsilon \rho o ́ v \tau \omega$ (but with accent on the root) with the addition of the same emphasizing particle * $u$ seen in the $3 \mathrm{sg}$. (so, e.g., Wright 1954: §289). This demands the assumption that $*_{-} u$ was not added until after the loss of the final consonant in the PGmc. reflex of PIE *-ontōd. The same must be assumed for the $3 \mathrm{sg}$. ending, and so it is not plain what the analogical model for the addition of $*-u$ could have been, given this analysis. Accordingly, Markey (1972, with refs. and discussion of alterative views) argues that, here and in the $3 \mathrm{sg}$. imp., to prevent neutralization of the distinction between the imp. and the pass. ind., -áu was added, borrowed from the pass. sj., given the semantic connections between the imperative and the subjunctive, as demonstrated, e.g., by the pret.-pres. verbs, which have no formal imperative, for which the sj. instead serves. Yet Suzuki (1984) counters that $-u$ in the pass. sj. is equally mysterious in origin, and he proposes that $-u$ is identical to the Go. interrogative suffix $-u$ (so earlier Wright 1954: §297). For discussion and references, see A.W. Jones 1979: 364-71.

On OHG ni curi, pl. ni curìt, curet see $§ 12.27$; on Go. ni ōgs pus, §12.53.

1. Holthausen (1921: $\S 408$ Anm. 3) assumes a long vowel, but a short seems likelier, given that OE wuton requires a short vowel to explain the development of the root vowel to $u$ under combinative back mutation (Hogg 1992: §5.109.1).

\subsection{The passive and middle inflections}

Only in Gothic are verbs regularly inflected in the passive voice, and only in the present tense:

Pres. Ind.

$\begin{array}{lll}1 \text { sg. -biudada } & \text { pl. } & \text {-biudanda } \\ 2 \text { sg. -biudaza } & \text { pl. } & \text {-biudanda } \\ 3 \text { sg. -biudada } & \text { pl. } & \text {-biudanda }\end{array}$

Pres. Sj.

$\begin{array}{llll}\text { sg. } & \text {-biudáidáu } & \text { pl. } & \text {-biudáindáu } \\ \text { sg. } & \text {-biudáizáu } & \text { pl. } & \text {-biudáindáu } \\ \text { sg. } & \text {-biudáidáu } & \text { pl. } & \text {-biudáindáu }\end{array}$

The category reflects the PIE middle voice, but verbs inflected this way in Gothic are purely passive in meaning. That there is no synthetic pret. passive is a consequence of there having been no perfect passive in PIE, seeing as the Gmc. preterite reflects the PIE perfect. 3 pl. -anda directly reflects PIE *-o-ntoi (\$12.5), which ending has been extended throughout the ind. plural. Its connecting vowel $a$ has been extended to the 2 and 3 sg. endings (Lühr 1978: 110), which otherwise reflect PIE *-e-soi and *-e-toi, respectively. The $1 \mathrm{sg}$. is analogical to the $3 \mathrm{sg}$.; the original ending was PIE ${ }^{*}-a i$, which is reflected in Runic haite 'I am called'.${ }^{1}$ For a very different account, beginning with dissimilar PIE endings, see Boutkan 1995b: 327-30.

The subjunctive has the same connecting vocalism -ái- as in the pres. act. subjunctive. Otherwise the endings are the same as those in the ind. passive, except for final $-a ́ u$, which is perhaps borrowed from the $1 \mathrm{sg}$. pres. ind. active; but see the discussion of the $3 \mathrm{sg}$. \& pl. imperative above ( $(12.28)$.

Aside from these Gothic forms and Runic haite, the PIE middle is formally reflected in Gmc. only in OE $1 \& 3 \mathrm{sg}$. hätte 'am/is called, was called' = Go. háitada, 
with both present and past meaning. ${ }^{2}$ Elsewhere in Gmc. the passive meaning in this verb has been assumed by active forms.

A new middle voice, used with both reflexive and passive meaning, arose in NGmc. by the addition of reflexive pronouns to verbs, e.g. 1 sg. pres. ind. * $3 r a \hbar \bar{o}+m i k$ $>$ grofumk (to grafa 'delve'), 2 sg. * $3 r a b i z+s i k>$ grefsk, 3 pl. *3raba(n) + sik $>$ grafask, 2 sg. pret. * grōft + sik $>$ grófzk. The paradigm is as follows:

\section{Indicative}

sg.

$\begin{array}{ccl}\text { Pres. } & \mathbf{1} & \text { grofumk } \\ & \mathbf{2} & \text { grefsk } \\ & \mathbf{3} & \text { grefsk } \\ \text { Pret. } & \mathbf{1} & \text { grófumk } \\ & \mathbf{2} & \text { grófzk } \\ & \mathbf{3} & \text { grófsk }\end{array}$

pl. grọfumk grafizk grafask grófumk grófuzk grófusk
Subjunctive sg. pl. grọfumk grafimk grafisk grafizk grafisk grafisk grœfumk grœfimk grœfisk grœfizk grefisk grefisk

On the development of the NGmc. middle voice, see Faarlund 2005.

1. The form is a reconstruction on the basis of two imperfect inscriptions: see Krause 1971: §103. In the sense 'am called' the OIcel. verb takes the form heite $>$ heiti; the other persons and numbers are inflected according to the pattern of heavy stems of the first weak class.

2. OE $3 \mathrm{sg}$. hæitte, in one of the so-called metrical charms, is more likely a scribal error than a reflex of *xaitiðai, i.e. the PGmc. form without substitution of the connecting vowel, as in Gothic. OE pl. hätton is analogical, possibly to weak verbs of the first class (Euler 2013: 136), but perhaps more likely to preterite-present verbs, since it may have pres. meaning but a pret. inflection.

\subsection{Formation and inflection of non-finite strong verb forms}

Of the various means of forming verbal nouns in PIE (\$12.7), addition of the suffix ${ }^{*}$-no- $\left(>\mathrm{PGmc} .{ }^{*}-n a-\right)$ to the thematic stem ending in ${ }_{-}-o$ - used in the present was the exclusive method adopted in PGmc. for the formation of infinitives. These bore the nom./acc. sg. neuter $o$-stem inflections. Hence, PIE *bher-o-no-m produces PGmc. * berana ${ }^{n}>$ Go. bairan, ON bera, OE OS OHG beran 'to bear'. ${ }^{1}$ In WGmc., a suffix *-anja- bearing ja-stem inflections was added to the bare stem to form so-called inflected infinitives (or 'gerunds'). ${ }^{2}$ These are chiefly in the dative case and usually follow the prep. OE $t \bar{o}$, OS $t e$, OHG $z a, z i$, expressing, for the most part, purpose, e.g. OE $t \bar{o}$ berenne, to beranne, ${ }^{3} \mathrm{OS}$-ann(i)a, ${ }^{4} \mathrm{OHG}$-anne. In $\mathrm{OS}$ and $\mathrm{OHG}$ there is also, though less frequently, an inflected inf. in the genitive, without a preposition, ending in OS -annias, $\mathrm{OHG}$-annes. OHG has also instr. sg. forms in -annu (et sim.), whereas dat. pl. forms in -annum are by analogy to Latin constructions. In ON there occur some innovative pret. infinitives, formed by the addition of $-u$ to the pret. stem, e.g. stóðu 'to have stood', mæltu 'to have said', knáttu 'to have known'. These originate in the preterite-present verbs (see $\$ 12.53$ n. 2).

The active (or present, or first) participle is formed by the addition of PIE *-ntto the thematic stem ending in ${ }^{*}-O$ - used in the present, with the addition of adjective inflections (§9.9). With accent on the root, PIE *-nt- yields PGmc. ${ }^{*}-n \delta->*_{-} n d-$ under Verner's law (§6.6), as in Go. bairands, OIcel. berandi, OE berende, OS berandi, OHG beranti 'bearing'. Except in ON, these take both strong and weak inflections; in ON they bear a uniform set of inflections identical to those borne by adjectives in the comparative degree (see $\S 9.9$ for details). In West Gmc. the strong forms bear $j a$ - and $j \bar{o}$ - 
stem inflections. That the inflections found on such participles differ in the three main branches of Gmc. is no doubt a consequence of original consonant-stem inflection, as in

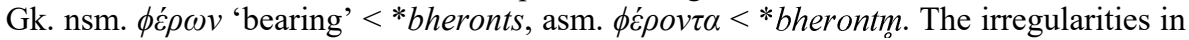
the suffix produced by such inflection would naturally have motivated morphological change.

The passive (or past, or second) participle of strong verbs is formed by the addition of thematized *-an- (in alternation with much rarer *-in-) $)^{5}$ to the PGmc. unaccented verb stem reflecting the PIE weak grade, e.g. Go. baúrans $<*$ buranaz $<* b h_{e} r-$ ón-o-s. Such participles take normal strong and weak adjective inflections.

1. PGmc. *beranan is commonly compared to Skt. bharanam. Hirt (1931-4: II, $\$ 158)$ concedes that this is a possibility, but that the Skt. form could derive instead from *bhermnom, making it more directly comparable to Gk. infinitives in - $\mu \varepsilon v \alpha l$. Indeed, under most formulations of Brugmann's law we should expect *bheronom to produce Skt. †bharānam, though the law is too insecure for this to prove the point: see Collinge 1985: 1321 . Hirt's idea that $*_{-} m n$ - would explain $*_{-} n n$ - in the WGmc. inflected infinitives discussed below does not simplify matters, since *-nn- is already explained by the ja-stem inflection of these infinitives. The PIE suffix *-men- appears to be reflected in PGmc. *ermen-/ermun- 'immense, high' (in Latinized Go. Ermeni-rīcus (name), OIcel. jormun-, OE eormen-, OHG irmin-): cf. Gk. part. ö $\rho \varepsilon v v o \varsigma$ to ö $\rho v \bar{v} \mu l$ 'stir up' (so Müllenhoff 1879).

2. Commonly this *-anja- is regarded as formed by the addition of *-ja-to the inf. in *-an-, though the basis for such a development is not easy to account for. Grønvik (1998b: 112-14) ventures a possible explanation. More commonly now the formation is regarded as unrelated to the stem of the uninflected inf:: see Los 2005, with references.

3. The form -anne is actually less frequent than etymological -enne in all OE dialects, doubtless by analogy to the uninflected infinitive, which is sometimes found after $t \bar{o}$ in poetry, rarely in prose. The same influence is probably to be seen in OS. OHG forms in -enne among strong verbs, as well as forms in -anni, seem to attest to derivation of $-n n$ - from *-nj- (Braune 2004a: $\$ 315$ Anm. 1).

4. With variants -anne, -enne, -onn(i)a, -onne.

5. Examples reflecting *-in- are Runic haitinar 'called' and early (Mercian) OE binumini 'deprived' and forleginum 'fornicated'. The alternation is paralleled in Slavic (Hirt 1931-4: II, §157). For discussion of *-an-

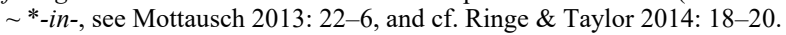

\subsection{Characteristics of the seven strong classes in the individual early Germanic languages}

Phonological and morphological changes resulted in some distinctive features of verbs in various of the seven classes in some of the early languages. Representative paradigms are offered below for strong verbs in Go., OIcel., OE, OFris., OS, and OHG. Not all of the principal parts offered below are attested as such, but the forms are not in doubt, given that the ablaut patterns are well attested. On various departures from these patterns, including consonant alternations under Verner's law, aorist presents, weak presents, and contracted verbs, see $\S \S 12.17-19$.

Class I, PGmc. (1) $\bar{i}$, (2) ai, (3) $i$, (4) $i$ : The root contains the reflex of PIE /i/, which in full grade is preceded by the root vowel. In part (1), PIE $e i>$ PGmc. $\bar{l}$, and in part (2), PIE oi > PGmc. ai (\$3.4) In NWGmc. there most likely should have been lowering of $i$ to $e$ in passive participles, due to $a$ in the following syllable, e.g. *riðanaz 'ridden' > *reðanaz, but the evidence for such a change is slender: see $\$ 4.4$. If it took place, it has been almost completely reversed on the basis of analogy, perhaps to the preterite plural. It might seem odd that analogy should have removed the effect of lowering in the passive participle in class I but not class II, but it should be remembered that $o$ in the class II participle was not a phoneme in NWGmc. but an allophone of $/ \mathrm{u} /$ 
and thus, though perhaps not immune to analogical effects (see, e.g., Steriade 2000), less disposed to them, whereas $e$ in class I would have been a phoneme. Taking into account language- or subfamily-specific sound changes, the following principal parts to Go. beitan 'bite' and cognates are representative of the ablaut patterns in the individual languages:

(1)

$\begin{array}{ll}\text { Go. } & \text { beitan } \\ \text { OIcel. } & \text { bíta } \\ \text { OE } & \text { bītan } \\ \text { OFris. } & \text { bīta } \\ \text { OS } & \text { bītan } \\ \text { OHG } & \text { bīzan }\end{array}$

(2)

báit

beit

bāt

bēt

bēt

beiz
(3)

bitun

bitu

biton

biten

bitun

bizun
(4)

bitans

bitinn

biten

biten

gibitan

gibizan

OHG verbs with stem-final $h$ or $w$ have $\bar{e}$ rather than $e i$ in the pret. sg. (\$4.17), e.g. zìhan 'accuse', zèh, zigun, gizigan.

Class II, PGmc. (1) $e u$, (2) $a u$, (3) $u$, (4) $u$ : The root contains the reflex of PIE $/ \mathrm{u} /$, which in full grade is preceded by the root vowel. In part (2), PIE ou $>$ PGmc. $a u$. Outside of Gothic, Gmc. $u$ was lowered to $o$ before $a$ in the next syllable. In OFris., on the other hand, *-in- (in alternation with much commoner *-an-: §12.30) was generalized in the pp., with resulting umlaut, e.g. WGmc. *budin- > beden, with analogical extension of $e$ to the pret. pl. (Bremmer 2009: §132). The following principal parts to Go. -biudan (in ana-biudan 'command' and faúr-biudan 'forbid') and cognates are representative of the ablaut patterns in this class:

(1)

$\begin{array}{ll}\text { Go. } & \text {-biudan } \\ \text { OIcel. } & \text { bjóða } \\ \text { OE } & \text { bēodan } \\ \text { OFris. } & \text { biāda } \\ \text { OS } & \text { biodan } \\ \text { OHG } & \text { beotan }\end{array}$

\section{(2)}

-báup

bauð

bēad

bād

bōd

bōt
(3)

-budun

buðu

budon

beden

budun

butun
(4)

-budans

boðinn

boden

beden

gibodan

gibotan

The chief variant of this ablaut pattern is represented by the aorist presents ( $\$ 12.18)$, which have $\bar{u}$ in the present stem, e.g. Go. ga-lukkan 'shut', -láuk, -lukun, -lukans. OIcel. $j o$ in the present stem occurs only before dental consonants, otherwise jú, as in fjúga 'fly', to which the pret. sg. is fló (\$4.9). ${ }^{1}$ In OS the original diphthong *eu of the present stem is preserved before $w$, as in hreuwan 'rue'. OHG has in part (2) $\bar{o}$ only before dental consonants and $h$, otherwise ou (\$4.17), e.g. liogan 'lie', loug, lugun, gilogan.

Class III, PGmc. (1) $e$, (2) $a$, (3) $u$, (4) $u$ : The stem ends in a consonant cluster, usually consisting of a sonorant plus another consonant, which may effect changes upon the preceding vowel. Typical is the paradigm of Go. hilpan 'help' and cognates:

(1)

$\begin{array}{ll}\text { Go. } & \text { hilpan } \\ \text { OIcel. } & \text { hjálpa } \\ \text { OE } & \text { helpan } \\ \text { OFris. } & \text { helpa } \\ \text { OS } & \text { helpan } \\ \text { OHG } & \text { helfan }\end{array}$

(2)

halp

halp

healp

halp

halp

half
(3)

hulpun
hulpu
hulpon
hulpen
hulpun
hulfun

(4)

hulpans

holpinn

holpen

hulpen

giholpan

giholfan

OIcel. hjálpa shows fracture followed by stress shift and lengthening (\$§4.8-9); the pret. sg. may also be hjálp, by analogy. In OE healp there is breaking (§4.13), and 
breaking also occurs in part (1) before $/ \mathrm{r} /$ or $/ \mathrm{x} /$, as in beorgan 'protect' and feohtan 'fight', though not in berstan 'burst' and perscan 'thresh', in which there is metathesis of $r$ with the root vowel. Verbs with initial $g$ - or $s c$ - show WS diphthongization by initial palatal consonant if breaking did not antecede it, thus gieldan 'pay', giellan 'yell', gielpan 'boast', *sciellan 'resound'; compare the palatalization in part (1) of OFris. ielda 'pay', gald, gulden, gulden. The vowel $u / o$ is probably analogical (i.e. not developed in, e.g., $r u<*_{r}$ : see n. 3 infra) in the pret. and pp. of OIcel. bregða 'brandish', OE frignan 'ask', stregdan 'strew', OS flehtan 'braid', and certainly of $\mathrm{OE}$ feohtan 'fight', and cognates. Another ablaut pattern in class III looks rather different, due to the effect of a nasal consonant on the root vowel (\$4.4), as demonstrated by the principal parts of Go. bindan 'bind' and cognates:

$\begin{array}{ll}\text { Go. } & \text { bindan } \\ \text { OIcel. } & \text { binda } \\ \text { OE } & \text { bindan } \\ \text { OFris. } & \text { binda } \\ \text { OS } & \text { bindan } \\ \text { OHG } & \text { bintan }\end{array}$

(2)

band

batt

band

band

band

bant
(3)

bundun

bundu

bundon

bunden

bundun

buntun
(4)

bundans

bundinn

bunden

bunden

gibundan

gibuntan

OIcel. batt develops from *bant < *band (§6.14). OE birnan 'burn' and irnan 'run' adhere to this pattern because they show metathesis of $r$ with the root vowel.

Class IV, PGmc. (1) $e$, (2) $a$, (3) $\bar{e}_{1}$, (4) $u$ : Verbs of this class generally have a single, sonorant stem-final consonant, and in those few instances in which the consonant is not a sonorant, a sonorant appears before the root vowel, thus explaining $u / o$ in the pass. part. as, probably, analogical (see n. 3 infra). Such exceptional verbs usually have a stem ending in PGmc. $k$, e.g. OHG brechan 'break', rechan 'avenge', ${ }^{2}$ sprechan 'speak', stechan 'pierce', trechan 'draw', treffan 'strike'. ${ }^{3}$ Normally, the vowel of the pp. should have been $u$ (reflecting PIE schwa secundum: $\S \S 3.1-2$ ), lowered to $o$ outside of Gothic before $a$ in the next syllable. ${ }^{4}$ OFris. $e$ in the pp. is due to umlaut (see the explanation under class II above). On Gmc. $\bar{e}_{1}$ in the pret. pl., see $\S 12.14$. The normal ablaut pattern may be illustrated by the principal parts of Go. bairan 'bear' and its cognates:

(1)

$\begin{array}{ll}\text { Go. } & \text { baíran } \\ \text { OIcel. } & \text { bera } \\ \text { OE } & \text { beran } \\ \text { OFris. } & \text { bera } \\ \text { OS } & \text { beran } \\ \text { OHG } & \text { beran }\end{array}$

(2)

bar

bar

bær

ber

bar

bar
(3)

bērun

báru

bǣron

bēren

bārun

bārun
(4)

baúrans
borinn
boren
beren
giboran
giboran

One verb shows the effect of a nasal consonant upon the root vowel similar to that observable in verbs like bindan in class III. The principal parts of Go. niman 'take' and cognates are these:

$\begin{array}{lll}\text { Go. } & \text { niman } & \text { nam } \\ \text { OIcel. } & \text { nema } & \text { nam } \\ \text { OE } & \text { niman } & \text { nam } \\ \text { OFris. } & \text { nima } & \text { nom } \\ \text { OS } & \text { niman } & \text { nam } \\ \text { OHG } & \text { neman } & \text { nam }\end{array}$

nēmun

námu

nōmon

nōmen

nāmun

nāmun numans

numinn

numen

nimen

ginoman ginoman 
OIcel. $e$ in the present stem is etymologically correct; PGmc. $e$ is, as usual, raised to $i$ in Go. (§4.5). In WGmc., the pres. stem nem- occurs in a considerable minority of forms in OS, whereas OFris. nem- is found only in the Rüstring manuscripts, where lowering of $i$ (and $u$ ) in open syllables before $a$ is the norm (Bremmer 2009: §134). Conversely, OS pp. ginuman occurs rarely. Accordingly, it is possible to explain the raising in Ingvaeonic nim- as due to analogy to verbs like bindan of class III (so Gough 1973), and the consideration that it is only in this verb that raising takes place before a heterosyllabic nasal consonant would seem to support this position. It should be noted, though, that in the instance of the corresponding back vowel, the effect of a heterosyllabic nasal consonant upon a preceding $u / o$ is well documented, as in OE fruma 'beginning' and guma 'man': see $\S 4.3$.

The very common verb 'come' belonging to this class is somewhat anomalous:

(1)

$\begin{array}{ll}\text { Go. } & \text { qiman } \\ \text { OIcel. } & \text { koma } \\ \text { OE } & \text { cuman } \\ \text { OFris. } & \text { kuma } \\ \text { OS } & \text { kuman } \\ \text { OHG } & \text { queman }\end{array}$

(2)

qam

kom/kvam

cōm

kom

quam

quam
(3)

qèmun

kómu/kvámu

cōmon

kōmen

quāmun

quāmun
(4)

qumans

kominn

cumen

kemen

gikuman, kumen

queman

Go. qiman and OHG queman represent the normal type PGmc. ${ }^{*} k^{w} e m$-, whereas the remaining present stems reflect an aorist present $* k^{w}{ }_{e} m->* k u m-$. The difference is between the action of coming (durative, full-grade) and the result of coming (aorist, weak grade: see §12.1). One or the other stem was generalized in the early languages, taking on both meanings. OIcel. inf. and pp. stem kom- is from kum- (the latter frequent in Old Norwegian) by $a$-mutation ( $\$ 4.8)$. Pret. sg. kvam is the more original form; kom shows the development of $w a$ to $o$, presumably under low stress (Heusler 1967: §87.2); and kvámu (kvómu) is the older form of the pret. pl., with development of vó to ó before retained $u$ (Noreen 1970: §77.11). In OE, cōm and cōmon correspond to more original Anglian cwōm, cwōmon; there is no consensus about the origin of the long vowel in the singular, though niman similarly has sometimes pret. sg. nom for nam (see Hogg \& Fulk 2011: $\S \S 6.59$ n. 4, 6.58 and n. 3, with references). Umlauted forms of the pres. sj. occur in some OE texts, and this may be because cuman reflects an aorist stem, to which an optative in PIE $*_{-} i h_{l^{-}}$(rather than thematic full-grade $*_{-o-i} h_{l^{-}}$) is to be expected: see Sievers 1882: 81-3 and see above, $\$ 12.26$ n. 2. OFris. kemen shows umlaut (from *kumin-: see under class II above). OHG pp. queman is analogical to the inf.; on the several variants of the OHG forms, see Braune 2004a: $\$ 340$ Anm. 3.

Class V, PGmc. (1) $e$, (2) $a$, (3) $\bar{e}_{1}$, (4) $e$ : Verbs of this class are like those of class IV, except that the stem ends in an obstruent. This explains $e$ (from schwa secundum, $\S \S 3.1-2)$ in the passive part. The normal ablaut pattern is illustrated by the principal parts of Go. mitan 'measure' and cognates:

\section{(1)}

$\begin{array}{ll}\text { Go. } & \text { mitan } \\ \text { OIcel. } & \text { meta } \\ \text { OE } & \text { metan } \\ \text { OFris. } & \text { meta } \\ \text { OS } & \text { metan } \\ \text { OHG } & \text { mezzan }\end{array}$

(2)

mat

mat

mæt

met

mat

maz
(3)

mētun

mátu

mǣton

mēten

mātun

māzun
(4)

mitans

metinn

meten

meten

gimetan

gimezzan 
An irregularity is that the pret. sg. of PGmc. *etanan 'eat' is * $\bar{e}_{I} t$ (and so also *fra-ēt to *fra-etana ${ }^{n}$ 'devour'), which, like Lat. perf. $\bar{e} d \bar{l}$, is subject to various interpretations. ${ }^{5}$ The cognates of Go. giban 'give' show a number of variants: in OE there is diphthongization by initial palatal consonant in EWS giefan (so also in be-gietan 'acquire', ongietan 'perceive'), whereas some forms in other dialects may show back mutation, hence geofan; Old West Frisian shows a variety of phonological and analogical developments (see Bremmer 2009: §135); and giban appears beside geちan in OS.

Class VI, PGmc. (1) $a$, (2) $\bar{o}$, (3) $\bar{o}$, (4) $a$ : On the origin of the ablaut pattern in this class, see $\$ 12.15$. The present stem ends in a single consonant unless the verb reflects a PIE derived stem (\$12.3), as with OE standan 'stand', wæcnan 'awake', wæscan 'wash', hebban 'raise', etc. The ablaut pattern may be illustrated by the principal parts of Go. faran 'go' and cognates:

(1)

$\begin{array}{ll}\text { Go. } & \text { faran } \\ \text { OIcel. } & \text { fara } \\ \text { OE } & \text { faran } \\ \text { OFris. } & \text { fara } \\ \text { OS } & \text { faran } \\ \text { OHG } & \text { faran }\end{array}$
(2)

fōr

fór

fōr

fōr

fōr, fuor

fuor
(3)

fōrun

fóru

fōron

fōren

fōrun, fuorun

fuorun
(4)

farans

farinn

faren

faren, ferin

gifaran

gifaran

Weak presents are numerous in this class. ${ }^{6}$ Go. standan 'stand' and cognates have the $n$ infix only in the present stem (see §12.3), and similarly, OE wæcnan 'awake' loses the $n$-suffix in pret. $w \bar{o} c, w \bar{o} c o n$ (no strong pp. attested). In OIcel., verbs with a stem-final velar (palatal) consonant have palatal mutation in the pp. (\$4.7), e.g. tekinn $<*$ takinaz, to taka 'take'. Also in OIcel., vaða has pret. óð, óðu (§6.14, later vóð, vóðu by analogy to the rest of the paradigm); similarly vaxa 'grow'. OE weaxan 'grow' has usually the ablaut pattern of a verb of class VII, but the Gmc. cognates (Go. wahsjan, OIcel. vaxa, etc.) belong to class VI (see Flasdieck 1936: 343). The pp. in OFris. may or may not show umlaut. On $\bar{o} / u o$ in the OS pret., see $\S 4.15$.

Class VII shows various ablaut patterns in Gmc., but as in class VI, the vocalism of parts (2) and (3) is the same, as is that of parts (1) and (4). In Gothic verbs with no ablaut difference between present and preterite the root vowel may be $a,{ }^{7} \bar{e}, \bar{o}, a ́ i$, or $a^{\prime} u$. The only ablaut alternation is $\bar{e}: \bar{o}$, though the former also develops to ai before a vowel, as in saian 'sow' (pret. saísō), waian 'blow'. In NWGmc. the following alternations (A-E) are attested:

$\begin{array}{ccccccc}\text { type } & \text { parts } & \text { OIcel. } & \text { OE } & \text { OFris. } & \text { OS } & \text { OHG } \\ \mathrm{A} & (1,4) & \mathrm{a} & \overline{\mathrm{x}}^{8} & \overline{\mathrm{e}} & \overline{\mathrm{a}} & \overline{\mathrm{a}} \\ & (2,3) & \mathrm{e} & \overline{\mathrm{e}} & \overline{\mathrm{e}}^{9} & \overline{\mathrm{e}} & \mathrm{ia}^{10} \\ \mathrm{~B} & (1,4) & \mathrm{o} & \overline{\mathrm{o}} & \overline{\mathrm{o}} & \overline{\mathrm{o}}, \mathrm{uo} & \text { uo } \\ & (2,3) & \mathrm{e}^{11} & \overline{\mathrm{e}} & & \text { io } & \text { io } \\ \mathrm{C} & (1,4) & \mathrm{ei} & \overline{\mathrm{a}} & \overline{\mathrm{e}} & \overline{\mathrm{e}} & \mathrm{ei} \\ & (2,3) & \mathrm{e} & \overline{\mathrm{e}} & \overline{\mathrm{e}}^{9} & \overline{\mathrm{e}} & \mathrm{ia}^{10} \\ \mathrm{D} & (1,4) & \mathrm{au}^{12} & \overline{\mathrm{e}} & \overline{\mathrm{a}} & \overline{\mathrm{o}} & \mathrm{ou}^{13} \\ & (2,3) & \text { jó } & \overline{\mathrm{e}} & \mathrm{e}, \mathrm{i}^{14} & \text { eo, io, ia } & \text { eo, io, ia, ie }\end{array}$

Verbs with PGmc. ${ }^{*} a$ in the root show a considerable variety of ablaut patterns, as illustrated by some representative verbs, OS haldan 'hold', fallan 'fall', blandan 'mix', spannan 'link', fähan 'catch' ( $<$ PGmc. *fayxana $\left.{ }^{n}\right)$ and cognates: 


$\begin{array}{ccccccc}\text { type } & \text { part } & \text { OIcel. } & \text { OE } & \text { OFris. } & \text { OS } & \text { OHG } \\ \text { E1 } & (1) & \text { halda } & \text { healdan } & \text { halda } & \text { haldan } & \text { haltan } \\ & (2) & \text { helt } & \text { hēold } & \text { hēld/hīld } & \text { held } & \text { hialt } \\ \text { E2 } & (1) & \text { falla } & \text { feallan } & \text { falla } & \text { fallan } & \text { fallan } \\ & (2) & \text { fell } & \text { fēol(1) } & \text { fōl } & \text { fell } & \text { fial } \\ \text { E3 } & (1) & \text { blanda } & \text { blandan } & & \text { blandan } & \text { blantan } \\ & (2) & \text { blett } & \text { blēnd } & & \text { blend } & \text { bliant } \\ \text { E4 } & (1) & & \text { spannan } & \text { (bonna })^{15} & \text { spannan } & \text { spannan } \\ & (2) & & \text { spēon(n) } & \text { (bēn) } & \text { spenn } & \text { spian } \\ \text { E5 } & (1) & \text { ganga } & \text { gangan } & \text { gunga } & \text { gangan } & \text { gangan } \\ & (2) & \text { gekk } & \text { gēong } & \text { gēng }(\overline{1}, o) & \text { geng } & \text { giang } \\ \text { E6 } & (1) & \text { fá } & \text { fōn } & \text { fā(n) } & \text { făhan } & \text { fāhan } \\ & (2) & \text { fekk } & \text { fĕng } & \text { fēng/fīng } & \text { feng } & \text { fiang }\end{array}$

The most striking irregularity is that whereas $\mathrm{OE}$ and OHG consistently (or almost so in the former case) show a long vowel or a diphthong in the pret., OIcel. and OS seem to contradict this pattern. OFris. appears to agree with $\mathrm{OE}$ and $\mathrm{OHG}$, but the quantity of its preterite vowels is not universally agreed upon; spellings like $\langle$ hild $\rangle$, 〈ging $\rangle$, and $\langle$ fing $\rangle$ must result from an etymological long vowel. In OIcel. there is shortening of vowels in closed syllables (§4.9); in OS there is likewise shortening before geminates, and probably before other consonant clusters (Holthausen 1921: $\$ 108$ Anm. 1). Thus, there is no obstacle to assuming original long vowels in the preterites of type E1-6, whereas the assumption of an original short vowel requires much analogical intervention to produce the attested forms of OE, OFris., and OHG. ${ }^{17}$

1. This verb acquired a weak pret. early, but similar preterites were reformed by analogy to other verbs of this class, e.g. analogical laug 'lied' beside earlier ló.

2. OHG pp. girohhan is an innovation: Go. wrikans, OIcel. rekinn, OE wrecen plainly belong to class V.

3. To OHG pp. gitroffan cf. OIcel. drepinn, whereas OE has both drepen and dropen. A verb such as Go. brikan (brak, brēkun, brukans) 'break' should be expected originally to have shown the alternation $e \sim o \sim r>$ PGmc. $e \sim a \sim u r$ (i.e., with pp. *burkanaz), and doubtless Ringe (2017: 102-3) is right that $u r$ was changed to $r u$ because in all other forms in the paradigm the vowel followed rather than preceded $r$. There is sometimes assumed instead a stem * $b h r_{e} \hat{g}_{-}^{-}$(so Pokorny 1959-69: I, 165) to account for, e.g., the equivalence of PGmc. *bruk- and Lat. frag- (as in fragilis), but *bhr $r_{e} \hat{g}$ - is not a plausible PIE form, since there is no reasonable way to explain why it is not * $b h r \hat{g}-$. Rather, Latin has innovated the same way Gmc. has (note that $r$ gives or in Lat.), on the basis of frango ' 'break' and related forms.

4. Go. $a u$ in the pp. in the given paradigm is due to lowering of $u$ before $r(\$ 4.5)$; the normal vowel of the pp. is $u$, as in trudans 'trodden'.

5. The long vowel in Latin could be due to reduplication in the perfect $* h_{l} e-h_{l} o d$ - (in alternation with * $h_{l} e-$ $h_{l} d$-; see Szemerényi 1996: $\$ 9.4 .3 b$ ) to the root $h_{l} e d-$, or it could have arisen by analogy to long-vowel perfects like ven $\bar{\imath}$ (Sihler 1995: §487). Another possibility is that it results from a stem with augment, i.e. ${ }^{*} h_{l} e-h_{l} e d-$, though the augment is otherwise unattested, or not securely attested, in either Latin or Germanic. Analogy to the plural (so Prokosch 1939: §59b n. 6), or to the long-vowel preterites of class VI, is also a possibility, although the motivation seems weak.

6. Cf. Lat. $c a p i \bar{o}$, faciō, and see $\S 12.19$.

7. Also $\bar{a}$ in $-\bar{a} h-<$ PGmc. *-ayx- (§4.1), as in fāhan 'seize' and hāhan 'hang'.

8. Non-WS è (§4.6), as in lētan 'let', rēdan 'advise'.

9. But $\bar{l}$ in the Rüstring texts $(\S 1.17)$. The situation in OFris. is thus normally like that in non-WS OE, with no contrast between pres. and pret. vocalism in verbs with $\bar{e}$ in the present.

10. Also $\langle$ e, ea, ie $\rangle$. See $\$ 3.5$.

11. For expected jó: see $\S 12.20$. The only attested example is the verb blóta 'sacrifice'. 
12. To this pattern belongs also hoggva 'hew' < *hawwan- (with Verschärfung, §6.10), pret. sg. hjó, pl. hjoggu. (So also OFris. hāwa, pret. unattested.) A more regular example is hlaupa 'leap, run', hljóp, hljópu, hlaupinn.

13. But $\bar{o}$ before $h$ or a dental consonant (§4.17), as in stōzan 'thrust'.

14. So Bremmer 2009: §137. Steller (1928: §97) has rather $\bar{e}$ beside $\bar{l}$, as in types A and C. Van Helten (1890 $\S 275$ ) indentifies the vocoid as $i a$ but says that the preterite of such verbs is unattested in Old East Frisian.

15. OFris. bonna 'summon' is given here because there is no cognate of OS spannan attested in OFris.

16. But pp. gangen, gengen, genzen, ginzen, the latter two with affrication of $/ \mathrm{g} /$.

17. For discussion and references, see Fulk 1987: 167-73, with pertinent remarks on the earliest OHG spellings of $\bar{e}_{2}$. See also $§ 12.20$ supra.

\section{Weak Verbs}

\subsection{The nature of weak verbs}

Weak verbs are distinguished from strong in that the preterite stem is differentiated from the present not by ablaut alternation but by the addition of a dental suffix, a characteristic they share with preterite-present verbs, the verb 'will' (Go. wiljan), and a few isolated verbs. They originate in certain derived verb types of PIE, of which many (the secondary verbs) originally had no discrete preterite stem $(\S 12.3)$, and thus the rise of a unified method of forming preterites to these disparate derived types should hardly be surprising. This is especially so because of the high productivity of the weak types, their constantly growing numbers reinforcing the utility of a single method of preteriteformation. Although it seems likely that the strong classes were productive in PGmc. (see §12.12), it is also likely that this productivity ceased at a relatively early date, after the initial accommodation of a number of non-IE verbs to the emerging Gmc. strong types. After that time the simpler method of suffixation used to form weak verbs assumed the burden of permitting the addition of new verbs, usually derived secondarily from strong verbs or other parts of speech. Some weak types remained productive in the historical period: thus, for example, Go. sildaleikjan 'wonder at' is plainly derived from the adj. sildaleiks 'wonderful', and Go. ga-frisahtnan 'become an example' is derived from frisahts 'example', with no parallel to either verb outside of Gothic. Certain classes, however, ceased to be productive in NWGmc. In OE, for example, new verbs were not generally added to class 1 once the morphology of the class lost transparency with the deletion of the suffix $*_{-j}$ - and the resultant morphologization of umlaut and gemination. It was in fact only class 2 that remained productive in WGmc., as shown by such neologisms as OE hüslian 'administer the Eucharist' and OHG managfaltōn 'multiply' (cf. managfalt 'numerous'). Such developments, however, were not inevitable. For example, despite the loss of phonological conditioning for some alternations in class 1, verbs continued to be added in ON, e.g. OIcel. hógværa 'appease' (cf. hógværr 'gentle') and prýða 'adorn' (cf. prúðr 'magnificent', from OE prüd, from Old French). And strong verbs could acquire weak preterites in all the NWGmc. languages.

For weak verbs just three principal parts are required to illustrate variation in the stem: (1) infinitive, (2) $3 \mathrm{sg}$. pret., and (3) pass. participle, nom. sg. masc. (as here) or neuter, or, in the case of OHG, simply uninflected (see $\S 12.11 \mathrm{n} .1$ ). 


\subsection{Origin of the dental suffix}

How the dental suffix of the weak preterite arose is far from plain. ${ }^{1}$ The most widely credited explanations derive the dental element either from (1) PIE $d h$ or from (2) PIE $t$ $>p$, which may become $\partial$ under Verner's law (§6.6):

(1) Nearly all studies that derive the dental suffix from PIE $d h$ assume that the suffix is a form of the PGmc. verb that becomes PDE do (the so-called composition

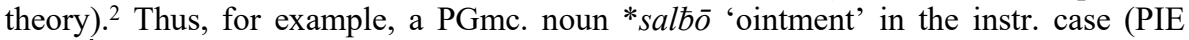
*solpā) plus a root aorist *dè(p) (PIE *dhèt), literally 'did with ointment', could be expected to have been grammaticalized as *salbōjé( $(p)$ (with $\partial$ rather than $d$ because of PGmc. phonotactics), producing Go. salbōda 'annointed', a verb of weak class 2 . The grammaticalized $\delta$-element was then extended to the other weak classes, since it represented a transparent method of forming preterites to verbs without a preterite stem (Lühr 1984: 43-4). This approach to the problem has several advantages. It is a development with obvious parallels in other IE languages, e.g. the rise of the Latin imperfect in $-b \bar{a}$-, which represents a grammaticalization of an old form ( $\bar{a}$-preterite?) to the verb 'be', with similar periphrases in other languages. ${ }^{3}$ It also offers a convenient way to explain the double appearance of a dental element in the indicative dual and plural and in all forms of the subjunctive in the preterite of weak verbs in Gothic, e.g. pret. ind. 3 pl. nasidèdun 'saved' (see the paradigm in §12.35). In such forms, -dèd- may be derived from PGmc. pret. forms of 'do' best reflected in OS and OHG, e.g. 3 pl. ind. OS dēdun, dädun and OHG tätun. ${ }^{4}$ That 'do' came to play such an important morphological role as this may explain why such an apparently basic verb was lost in East and North Gmc., its functions taken over by táujan and gørva (originally 'prepare'), respectively.

Several difficulties confront explanation (1). The most important of these is that the dental preterite of preterite-present verbs $(\S 12.54)$ and of certain weak verbs lacking PGmc. ${ }_{-}-i$ - in the preterite $(\S 12.37)$ cannot have been formed this way: see explanation (2) below. In addition, although equating the Go. suffix -dédun with the OS verb dédun seems advantageous, the equation raises questions about how a Go. inflection like - $d a$ in $1 \& 3$ sg. pret. nasida 'saved' can be equated with $1 \& 3$ sg. OS deda, OHG teta 'did'; more important still, it raises questions about how Go. -dédun can be considered equivalent to OIcel. $-ð u, \mathrm{OE}-d o n$, OS $-d u m$, OHG $-t u n .{ }^{5}$ Such posited relations seem to demand either ad hoc phonological developments or analogical restructuring in NWGmc., leading some to suppose rather that the Go. inflections may be innovations in East Gmc. (so, e.g., Jasanoff 1978b: 92 n. 76, Stiles 2010). ${ }^{6}$ Likewise, if the 3 sg. pret. ending is to be reconstructed as $*_{-} \partial \bar{e}(p)<\mathrm{PIE} * d h h_{l} t$, Go. $-d a$ is an unexpected result, since $\bar{e}_{1}$ does not yield Go. $a$ except in absolute finality: cf. PIE $-\bar{e} d>$ PGmc. ${ }^{*}-\bar{e}(t)$ in Go. hidrē 'hither' (but see $§ 11.2$ ). ${ }^{7}$

(2) Studies arguing for the derivation of the dental preterite suffix from PIE $t$ are more varied in nature, identifying numerous possible sources, including PIE inflections peculiar to particular persons and numbers (such as the 2 sg. perf. ${ }^{*}-t_{2} e$, the perf. middle $3 \mathrm{sg} . *_{-}^{*}$ tai, and the aorist middle $2 \mathrm{sg} . *_{-}$-thl $\left.\bar{e} s\right)$ or to particular tense stems (esp. PIE *-t- in forms like Lat. plectō, OHG flehtan 'plait'; cf. Lat. plicō, Gk. $\pi \lambda \dot{\varepsilon} \kappa \omega$ 'fold'). But the most widely credited approaches involve the PIE verbal adj. suffix *-to- (> PGmc. *-pa-/-ða-), as in Lat. datus 'given' and nātus 'born'. It is certainly possible that when this suffix came to mark the past participle in Gmc., its association with past action should have prompted analogical extension to the preterite. This seems the least complicated explanation for certain weak preterites which cannot derive their dental element from PIE $d h$. Most preterite-present verbs are of this sort. Thus, PGmc. *- $p$ - is 
reflected in OE cūðe 'knew how' and $\bar{u} ð e$ 'granted's < PGmc. *kunp-, *unp-, and by dissimilation it becomes $t$ (or, more plausibly, was never shifted under Grimm's law) in porfte 'needed', dorste 'dared', etc. Likewise, a number of irregular weak verbs (i.e., those of the first class with no connecting vowel in PGmc. between the root and the dental suffix, §12.37) suggest a suffix PGmc. *- $b->t$, e.g. Go. baúhta 'bought', pūhta 'seemed' (cf. infs. bugjan, bugkjan), as the preterite, if formed from the reflex of PIE $d h$, would instead be †bugda, †brangda.

Explanation (2) is anything but straightforward even for the forms it seems best to explain. If the source of the dental suffix is PIE *-tó-, the dental consonant should have developed to Gmc. $\partial$ under Verner's law, since the root vowel was unaccented in the verbal adjectives that this suffix formed. There are indeed preterite-present verbs with preterites in PGmc. $\partial$ rather than $p$ : cf. Go. munda 'thought' and skulda 'should' (3 sg. pres. man, skal), showing the expected voicing. But in most preterite-present verbs the dental suffix is voiceless, and that would be difficult to explain if the suffix originated in the past part. It is chiefly this consideration that has prompted hypotheses about derivation of the dental suffix from finite verb inflections and suffixes such as those mentioned above. Thus, for example, it is conceivable that the dental suffix in these verbs should have originated in the PIE 2 pl. aorist inflection *-te (so, e.g., Bammesberger 1986a: 75), but the motive for extension of that particular inflection is not plain. It may be instead that the accent shifted in most of the preterite-present verbs before the application of Verner's law: so Prokosch (1939: §65d), who offers the contrast between Skt. rikta- 'empty' (adj.) and riktá- 'emptied' (part.) in evidence of accent shift when tó-participles are used in non-participial function. And it is indeed true that a morphological contrast arose outside of Gothic to differentiate participles from adjectives derived therefrom: thus, for example, in ON most such participles have been reformed according to the second weak class (e.g., to pp. kunaðr cf. adj. kuðr, kunnr 'known' = Go. pp. kunps, but cf. ON pp. áttr 'owned'), and in $\mathrm{OE}$ they have been reformed as strong participles (e.g., to pp. witen cf. adj. gewiss 'certain' <*-wit-t-, §6.8; = Go. -wiss in un-wiss 'unknown'). Analogical extension of the dental suffix from the part. to the pret. would thus have to have taken place at a time when no distinction other than placement of the accent was drawn between otherwise formally identical participles and adjectives. The preterite-present verbs are an archaic category (see \$12.54), certainly much older than the preterites and past participles of weak verbs, and so even the most archaic of weak verbs may be supposed to have borrowed the dental suffix from the preterite-present verbs, thus explaining the voicelessness of the dental suffix in preterites to primary verbs like Go. pāhta, OE pōhte 'thought' (\$12.37). If this is so, however, the voiced dental suffix in all other weak verbs is hard to explain as derived from the same source.

Accordingly, most approaches to the problem of the origin of the dental preterite now favor the assumption of polygenesis, with both PIE $d h$ and $t$ playing a role. Since Go. munda and skulda show that some preterite-present verbs did have a dental suffix voiced under Verner's law, as should be expected if the suffix originated in the passive part., it may be that folk etymology led to association of that variety of the suffix with forms of 'do'.

1. For surveys of the earlier literature on the topic, see Collitz 1912 and Tops 1974. Subsequent studies include Rauch 1973, Kuryłowicz 1977, G. Schmidt 1977, Tops 1978, Shields 1982, 1988, 1997, Bammesberger 1984, 1987, 1988c, Mańczak 1984a, Birkmann 1987, Fullerton 1989, Kortlandt 1989, Pohl 1989, Rasmussen 1996, West 2001, and Hill 2004. 
2. This analysis was first proposed by Diederich von Stade no later than 1718: see Ball 1968: 163.

3. Bammesberger (1986a: 68) gives the example of Skt. gamayấm cakára 'I have brought' (literally 'I have made a causing to go'), an innovative perfect (on which see Whitney 1889: $\S \S 1070-1$ ), though he also illustrates synthetic formations by the example of $\sigma$-aorists and $\kappa$-perfects to derived verbs in Greek, e.g. $\varepsilon \dot{\pi} \alpha i \delta \varepsilon v \sigma \alpha$ and $\pi \varepsilon \pi \alpha i \delta \varepsilon v \kappa \alpha$ to $\pi \alpha l \delta \varepsilon v \dot{\omega} \omega$ 'educate'.

4. Note, however, that the origin of these forms is disputed, and the WGmc forms cannot easily be reconciled with the assumption of a root aorist: see $\S 12.61$.

5. Hill (2010) argues that the pres. of PGmc. 'do' reflected a Pre-Gmc. aorist sj. reinterpreted as a pres. ind. unaugmented imperfect, forms of which served to form the weak preterite. Since imperfects did not have optative forms of their own, such had to be created for the new weak preterites. In Go. the opt. of the strong pret of 'do' (PGmc. 3 pl. *dè $\delta \bar{l}-n t$ ) served this function, and the pret. opt. stem was extended to the ind. pl., since the pret. opt. and the ind. pl. stems are identical in strong verbs. In NWGmc., by contrast, the weak pret. opt. reflects the ind. stem in $*_{-} \partial \bar{e}$ - plus the pret. opt. sign $*_{-\bar{l}}$ - plus inflection. There is much of worth in this analysis, though it is necessarily speculative. Cf. the analysis of Stiles (2010), whereby the Go. pl. forms with $-d \bar{e}$ - are said to reflect the original $3 \mathrm{sg}$. employed as a stem, plus the original weak pl. inflections. On the idea of Kiparsky (2009) that weak preterites in OHG were still morphologically compounds, see $\$ 5.6 \mathrm{n} .10$.

6. It should be noted in defense of such ad hoc phonological changes, however, that the Gmc. languages do have a tendency to avoid the repetition of identical sounds in proximity to each other, especially in unstressed syllables, and that the means of avoiding the repetition are commonly dissimilatory, haplological, or otherwise unlike instances of regular sound change. Examples are WGmc. $/ \mathrm{v} /$ for $/ \mathrm{m} /$ in proximity to $/ \mathrm{n} /$, as in OS heban 'heaven' (cf. OS, OHG himel); the change of /j/ to / $/$ / in OE hergian 'harry < PGmc. *xarjojjanan (Hogg \& Fulk 2011: $\$ 118$ n. 2); the change of OE -odon to -edon (§5.6); and the Modern Icelandic dat. pl. inflection plus definite article -u-num [o:nYm] for expected [Y:nym]. Parallels closer to the question at hand are OHG swibogo 'arched vault' <*swibi-bogo, Old Franconian unsēr, unsero (= UG unserēr, unserero: see $\$ 8.5 \mathrm{n} .1$ ), PDE England < OE Engla land, NHG Zauberin 'sorceress' for Zaubererin, and PDE morphonology for morphophonology. Lūhr (1984: 44) explicitly attributes the change in weak preterites to haplology, as does Ringe (Ringe \& Taylor 2014: 516-17; 2017: 192-3); for further references, see Hill 2010: 417-20, with counterarguments; also Stiles 2010: 350. On irregular sound change in Gmc. and frequency of incidence, see Mańczak 1987a, and cf. Shaterian 1990, as well as Markey 1979. On haplology in particular, see Fertig 1998, 2000: $136-40$.

7. The verb ending appears to have been $*_{-} \partial \bar{x}$ in Proto-Norse, spelt -da in Runic. This explains OIcel. - $е$, later $-ð i$.

8. The pass. part. of this verb, however, is geunnen, as if the verb were strong.

\section{A. WEAK VERBS OF CLASS 1}

\subsection{Stem formation}

Aside from primary verbs lacking connecting PGmc. ${ }^{*} i$ - in the preterite $(\S 12.37)$, the earliest verbs of weak class 1 were denominal (including deadjectival) verbs in PIE *-ié/ó- and causative-iterative verbs in *-é-ie/o- (\$12.3), which two types fell together, the suffix developing to PGmc. ${ }^{*}-j i$ - and $*_{-j a}-$ or the variants *-iji- and ${ }^{*}-i j a$ - after heavy syllables under Sievers' law $(\$ 5.8) .{ }^{1}$ When deadjectival, such verbs are generally factitive in nature (i.e., with the meaning 'cause to have the quality of the adjective'), e.g. Gk. $\varphi \imath \lambda \dot{\varepsilon} \omega$ 'love' (cf. $\varphi$ í $\lambda o \varsigma$ 'dear'), Go. ga-tamjan 'tame' (cf. ON adj. tamr 'tame') and natjan 'dampen' (cf. NHG naß). The causative-iterative type, which was originally chiefly deverbal, was the more productive of the two, and in it the root vowel was usually Gmc. $a<$ PIE $o$, with accent on what was originally the theme vowel preceding the $j$-suffix, thus distinguishing verb roots in these stems from those of the primary verbs from which they were derived, which naturally had PIE $e$ in the present stem. ${ }^{2}$ 
The causative type is very frequent, e.g. Go. ga-dráusjan 'cast down' (cf. driusan 'fall),

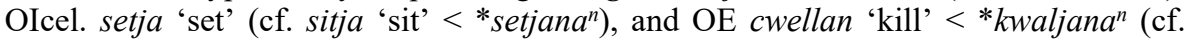
cwelan 'die'), though many exceptions to the pattern will be found. ${ }^{3}$ Examples of the iterative (or intensive-iterative) type are Go. wagjan 'shake' (cf. ga-wigan 'move') and wrakjan 'persecute' (cf. wrikan, with the same meaning). Gothic verbs of the first weak class are based on noun/adjective and verb stems only, reflecting the original situation, but in the NWGmc. languages causative-factitive verbs could be formed from adverbs, as well, as in ON yppa 'lift', OE yppan 'disclose' (cf. ON upp 'up'). It is plain that by the time preterites were formed to these verbs by the addition of the dental suffix, the suffixal element $*_{-j} j$ - originally proper to the present stem was viewed as integral, since it was carried over to the preterite stem, where it appears as ${ }^{*}-i$ - between consonants. The exception is the verbs lacking PGmc. ${ }_{-}^{-i-}$ in the preterite (\$12.37), which represent the earliest stratum in this class.

1. Cf. Kortlandt 1986, arguing that the distinction between the two types was maintained after light roots until a relatively late date.

2. Late formations aside, the exceptions with a long vowel in the root are usually otherwise explicable as regular, e.g. Go. uf-hlohjjan 'cause to laugh', with PIE *-oH- in the root, as opposed to hlahjan 'laugh', with *-H-. Weak grade in the root is also not uncommon, e.g. OIcel. bylja 'roar' (cf. bylr 'squall, gust of wind'). It is nonetheless true that in some instances PGmc. $\bar{o}$ in the root must be explained as a product of the perception that the causative stem is that of the preterite sg. of a strong verb (since both contained PIE $o>$ PGmc. $a$ ), and thus the pret. sg. stem of other strong types was adopted for the causative. The plainest instance is PGmc. *förijanan 'lead' > OIcel. forra, OS förian, OHG fuoren: cf. OIcel. pret. sg. fór to fara 'go' (Ringe 2017: 258).

3. There is a wealth of relevant types cited in Riecke 1996. Otherwise, grammars of the individual languages should be consulted.

\subsection{Inflection}

In summarizing the inflection of weak verbs of class 1 it is necessary to distinguish etymologically light stems from heavy. The patterns may be illustrated by the paradigms of Go. satjan 'set' and ON fremja, OHG fremmen 'promote' (light stems) and Go. dáiljan, OIcel. deila, OHG teilen 'deal out' (heavy stems), with OHG illustrating the general WGmc. pattern:

\begin{tabular}{|c|c|c|c|c|c|c|c|}
\hline \multirow{4}{*}{ Pres. Ind. } & \multirow{4}{*}{$\begin{array}{l}1 \text { sg. } \\
2 \text { sg. } \\
3 \text { sg. }\end{array}$} & Go. & Go. & OIcel. & OIcel. & OHG & \multirow{4}{*}{$\begin{array}{l}\text { OHG } \\
\text { teilu } \\
\text { teilis } \\
\text { teilit }\end{array}$} \\
\hline & & satja & dáilja & frem & deili & fremmu & \\
\hline & & satjis & dáileis & fremr & deilir & fremis & \\
\hline & & satjip & dáileip & fremr & deilir & fremit & \\
\hline & 1 du. & satjōs & dáiljōs & & & & \\
\hline & 2 du. & satjats & dáiljats & & & & \\
\hline & $1 \mathrm{pl}$. & satjam & dáiljam & fremjum & deilum & fremmemēs & teilemēs \\
\hline & 2 pl. & satjip & dáileip & fremið & deilið & fremmet & teilet \\
\hline & 3 pl. & satjand & dáiljand & fremja & deila & fremment & teilent \\
\hline \multirow[t]{8}{*}{ Pres. Sj. } & $1 \mathrm{sg}$. & satjáu & dáiljáu & fremja & deila & fremme & teile \\
\hline & $2 \mathrm{sg}$. & satjáis & dáiljáis & fremir & deilir & fremmēs(t) & teilēs(t) \\
\hline & 3 sg. & satjái & dáiljái & fremi & deili & fremme & teile \\
\hline & 1 du. & satjáiwa & dáiljáiwa & & & & \\
\hline & $2 \mathrm{du}$. & satjáits & dáiljáits & & & & \\
\hline & $1 \mathrm{pl}$. & satjáima & dáiljáima & fremim & deilim & fremmēm & teilēm \\
\hline & 2 pl. & satjáip & dáiljáip & fremið & deilið & fremmēt & teilēt \\
\hline & 3 pl. & satjáina & dáiljáina & fremi & deili & fremmēn & teilēn \\
\hline
\end{tabular}




\begin{tabular}{|c|c|c|c|c|c|c|c|}
\hline Imp. & $\begin{array}{l}2 \text { sg. } \\
3 \text { sg. } \\
2 \text { du. } \\
1 \text { pl. } \\
2 \text { pl. } \\
3 \text { pl. }\end{array}$ & \begin{tabular}{l}
\multicolumn{1}{c}{ Go. } \\
satei \\
satjadáu \\
satjats \\
satjam \\
satjip \\
satjandáu
\end{tabular} & $\begin{array}{l}\text { Go. } \\
\text { dáilei } \\
\text { dáiljadáu } \\
\text { dáiljats } \\
\text { dáiljam } \\
\text { dáileip } \\
\text { dáilandáu }\end{array}$ & $\begin{array}{l}\text { OIcel. } \\
\text { frem }\end{array}$ & $\begin{array}{l}\text { OIcel. } \\
\text { deil }\end{array}$ & $\begin{array}{l}\text { OHG } \\
\text { fremi }\end{array}$ & $\begin{array}{l}\text { OHG } \\
\text { teili }\end{array}$ \\
\hline Pret. Ind. & $\begin{array}{l}1 \mathrm{sg} . \\
2 \mathrm{sg} . \\
3 \mathrm{sg} . \\
1 \text { du. } \\
2 \mathrm{du} . \\
1 \mathrm{pl} . \\
2 \mathrm{pl} . \\
3 \mathrm{pl} .\end{array}$ & $\begin{array}{l}\text { satida } \\
\text { satidēs } \\
\text { satida } \\
\text { satidēdu } \\
\text { satidēduts } \\
\text { satidēdum } \\
\text { satidēdup } \\
\text { satidēdun }\end{array}$ & $\begin{array}{l}\text { dáilida } \\
\text { dáilidēs } \\
\text { dáilida } \\
\text { dáildēdu } \\
\text { dáilidēduts } \\
\text { dáilidēdum } \\
\text { dáilidēdup } \\
\text { dáildēdun }\end{array}$ & $\begin{array}{l}\text { fromoum } \\
\text { rromðuð } \\
\text { ropmðu }\end{array}$ & $\begin{array}{l}\text { deildum } \\
\text { deilduð } \\
\text { deildu }\end{array}$ & $\begin{array}{l}\text { fremita } \\
\text { fremitōs }(t) \\
\text { fremita }\end{array}$ & $\begin{array}{l}\text { teilta } \\
\text { teiltōs(t) } \\
\text { teilta }\end{array}$ \\
\hline Pret. & $\begin{array}{l}1 \text { sg. } \\
2 \text { sg. } \\
3 \text { sg. } \\
1 \text { du. } \\
2 \text { du. } \\
1 \text { pl. } \\
2 \text { pl. } \\
3 \text { pl. }\end{array}$ & $\begin{array}{l}\text { satidēdjáu } \\
\text { satidēdeis } \\
\text { satidēdi } \\
\text { satidēdeiwa } \\
\text { satidēdeits } \\
\text { satidēdeima } \\
\text { satidēdeip } \\
\text { satidēdeina }\end{array}$ & $\begin{array}{l}\text { dáilidēdjáu } \\
\text { dáilidēdeis } \\
\text { dáilidēdi } \\
\text { dáilidēdeiwa } \\
\text { dáildēdeits } \\
\text { dáilidēdeima } \\
\text { dáilidēdeip } \\
\text { dáildēdeina }\end{array}$ & $\begin{array}{l}\text { fremðim } \\
\text { fremðið } \\
\text { fremði }\end{array}$ & $\begin{array}{l}\text { deildim } \\
\text { deildið } \\
\text { deildi }\end{array}$ & $\begin{array}{l}\text { fremiti } \\
\text { fremitīs(t) } \\
\text { fremiti } \\
\text { fremitīm } \\
\text { fremitīt } \\
\text { fremitīn }\end{array}$ & $\begin{array}{l}\text { teilti } \\
\text { teiltīs(t) } \\
\text { teilti } \\
\\
\text { teiltīm } \\
\text { teiltīt } \\
\text { teiltīn }\end{array}$ \\
\hline $\begin{array}{l}\text { Inf. } \\
\text { Pres. Par } \\
\text { Pass. Par }\end{array}$ & & $\begin{array}{l}\text { satjan } \\
\text { satjands } \\
\text { satips }\end{array}$ & $\begin{array}{l}\text { dáiljan } \\
\text { dáiljands } \\
\text { dáilips }\end{array}$ & $\begin{array}{l}\text { fremja } \\
\text { fremjandi } \\
\text { fram(i)ðr }\end{array}$ & $\begin{array}{l}\text { deila } \\
\text { deilandi } \\
\text { deildr }\end{array}$ & $\begin{array}{l}\text { fremmen } \\
\text { fremmenti } \\
\text { gifremit }\end{array}$ & $\begin{array}{l}\text { teilen } \\
\text { teilenti } \\
\text { teilit }\end{array}$ \\
\hline
\end{tabular}

Outside of Gothic, the plural endings are used with both plural and dual subjects. In addition, inflected infinitives (also called gerunds) occur in WGmc. (\$12.30). In the pres. ind. and sj., Go. verbs may be inflected in the passive voice, with the same endings as in $\S 12.29$, e.g. 1 sg. pres. ind. satjada, dáiljada, etc. In Alemannic the inflectional vowel is $\bar{o}$ throughout the pret. ind. pl., hence teiltōm, teiltōt, teiltōn.

1. Earlier deilða, etc.: see $\S 6.14$.

\subsection{Variation in the stem}

Due to various phonological and analogical developments, the paradigms of these and other verbs of this class evince some irregularities. These may be discussed in respect to the individual $\mathrm{Gmc}$. branches and languages, as follows:

Gothic. The only notable irregularity in the given paradigms is that whereas the present stem of satjan is consistently satj- (with the exception only of the $2 \mathrm{sg}$. imperative: see §12.28), that of dáiljan is dáil-, rather than dáilj-, in those forms of the pres. ind. in which the corresponding inflection of the light stems has the vowel $i$; in those forms the heavy stems have instead an inflection in ei. Thus, for example, $3 \mathrm{sg}$. -eib in the heavy stems (corresponding to $-j-i p$ in the light stems) may be derived from PGmc. $*_{-i j-i b(i)}$ (with $*_{-j}$ - realized as $*_{-}-i j$ - after the heavy stem under Sievers' law, §5.8), undergoing the development $*_{-i(j) i p}>*_{-i i p}>-i \bar{p}$, spelt $-e i p(\S 12.38)$. Aside from the verbs lacking $-i$ - in the preterite ( $\$ 12.37)$, the only other variation in this class in Gothic is in verbs with stem-final $\bar{o}, i u$, or $a u$ in the present, since these vocoids appear as such 
before $-j$ - in the present, but they undergo change before $-i$ - in the preterite $(\$ 4.5)$ : to infs. stōjan 'judge', ana-niujan 'renew', and táujan 'do' cf. pret. $3 \mathrm{sg}$. ind. stauida, ananiwida, tawida.

Old Icelandic. In the present, the light stems have $-j$ - before an inflection beginning with a back vowel (as in the $j a$-stem nouns, $§ 7.11$; everywhere else the $-j$ - has been lost), and the heavy stems bear an inflection beginning with $-i$ - wherever the light stems do not bear an inflection beginning with a vowel. In the 2 and $3 \mathrm{sg}$. ind. this $-i$ - reflects $*_{\bar{\imath}}$, of the same origin as $\langle\mathrm{ei}\rangle$ in the Go. $2 \& 3 \mathrm{sg}$; the vowel is then extended to the 1 sg., to make the sg. paradigm analogous to that of strong verbs, such that deil-i- $\varnothing$, deil$i-r$ is parallel to $b i ð-\varnothing$, bi $\delta-r$. In the preterite, all the indicative endings were of sufficient weight to induce syncope of $-i-$, though earlier after heavy stems than light, resulting in phonemicization of umlaut in heavy stems, e.g. domð $i$ 'judged', but not light, e.g. fram $x(\$ 4.7) .{ }^{1}$ Both heavy and light stems show $u$-mutation in the pret. ind. plural (§4.8). In the pass. part. of light stems, -ið- should originally have alternated with - - , due to the conditions outlined in $\$ 5.6$, producing, e.g., nom. sg. masc. framiðr, fem. framið, neut. framit : masc. acc. sg. framðan, dat. fromðum, etc., but from the $12^{\text {th }}$ century the original distribution is much disrupted by analogy; likewise, where $-i$ - was not syncopated it should have caused $i$-umlaut, but this has been eliminated within the paradigm. In stems ending in $\partial$ or $t$, syncope of $i$ is carried through, e.g. gladdr 'gladdened', fluttr 'conveyed'<* $<$ laðið-, *flutið-.

Regarding patterns not observable from the paradigms in $\$ 12.35$, in those present forms in which $-j$ - remained, $g$ and $k$ were geminated at the close of a light syllable, but the resulting paradigm alternation between geminate and non-geminate was usually settled in favor of -gg- and, conversely, -k-, hence leggja 'lay', vekja 'waken'. When the preterite suffix - $\partial$ - was added to a light stem ending in $\partial$ or $t$, the result was a geminate stop, hence pret. gladdi 'gladdened', flutti 'conveyed', pp. gladdr, fluttr (as above), to gleðja, flytja. The suffix was devoiced after a fricative or a voiceless stop, as krafði [kraf $\theta \mathrm{I}]$ 'demanded' (to krefja), vakði 'wakened', in the latter instance later becoming $t$, as in vakti. Similarly, by about $900-\partial$ - developed to $d$ after a heavy stem in $l, n$, as in $d e i l \delta i>d e i l d i$, and later $\left(13^{\text {th }}-15^{\text {th }}\right.$ centuries $)$ after other heavy stems containing a sonorant consonant, e.g. dœmði 'judged', fylgði 'followed', kembði 'combed' > dœmdi, fylgdi, kembdi, and after light stems in $l, n$, as in talði, later taldi 'counted'.

West Germanic. In the given forms the stem shows throughout the paradigm umlaut of vowels capable of undergoing umlaut, though the mutation of vowels other than $a$ is not observable in OS and OHG. An exception is that there is no umlaut in OHG heavy-stemmed verbs in the pret. or in the inflected past participle. Light stems ending in a consonant other than $r$ show the effect of WGmc. gemination $(\$ 6.15)$ in all pres. forms in which $j$ had not been eliminated, i.e. all except the $2 \& 3 \mathrm{sg}$. ind. and the 2 sg. imperative. ${ }^{2}$ The $j$ causing gemination was subsequently lost except in OS and in the oldest $\mathrm{OHG}$ texts. In light stems ending in $r$ (including $r<z$ ), no gemination takes place, and $j$ remains, as in OHG OS OE nerian 'save'. ${ }^{3}$ Geminate voiced fricatives become stops, as with OS an-swebbian 'fall asleep' (cf. pp. an-swebit). The preterite suffix $*_{-} \partial$ - develops regularly to $*_{-} d$ - in WGmc. (\$6.16), and this is devoiced when in contact with a voiceless consonant, as with OE pyfte 'puffed', wyrpte 'recovered', lixte 'illuminated'. With the exceptions noted below, the general pattern in the WGmc. preterite is that $*_{-} i$ - is retained after light stems but is syncopated after heavy.

In the pres. stem in $\mathrm{OHG}$, when a geminate consonant has undergone the High German Consonant Shift $(\$ 6.21)$, the new sound is extended to forms within the paradigm that did not undergo gemination, e.g. 3 sg. ind. scepfit 'creates', setzit 'sets', 
weckit, UG wecchit 'wakes'. Outside of Bavarian, in verbs like nerian there occur stems like nerr- for neri-: see $\S 6.21$. Light stems ending in $w$ develop two forms of the stem, resulting in parallel paradigms, one with umlaut but no gemination, the other with gemination but no observable umlaut, e.g. frewen beside frauwen $>$ frouwen 'gladden' ${ }^{4}$ In early UG there is not infrequent gemination after a long vowel or diphthong, as in hörren 'hear' and teillan 'divide'. In general, the preterite suffix is -it- after light stems, - $t$ - after heavy, but in addition to cognates of verbs lacking any reflex of PGmc. *-i- in the preterite in other languages $(\$ 12.37)$ there are some principled exceptions, whereby - $t$ - is attached to light stems and there is no umlaut: such verbs include those with stems ending in $l l$ or $t t$ in the present (e.g. wellen 'choose', scutten 'pour', pret. walta, scutta), though to these verbs there also occur preterites in -it- such as welita, scutita (see Dittmer 1989). ${ }^{5}$ Likewise, preterites in $-t$ - are normal to verbs with stems that came to end in affricates in the present and (underlyingly) geminate fricatives in the preterite due to the effect of the High German Consonant Shift on voiceless geminates in the present and the corresponding non-geminate stops in the preterite, e.g. scefta, sazta, wahta (beside analogical wakta), with forms like setzida occurring in Franconian only (Schatz 1927: §472; cf. Braune 2004a: §362). Verbs like frewen/frouwen form their preterite normally (frewita), though analogical forms do occur (frouwita). In Franconian there occur some heavy stems with -it- in the preterite. As for the pass. part., light stems that always have $-i$ - in the preterite also have it in all case forms of the part., whereas both light and heavy stems without it have $-i$ - only in uninflected forms of the part., hence gisezzit, gihōrit but gisaztēr, gihōrtèr.

In OS the present suffix $-j$ - is retained and spelt $i$ after both heavy and light syllables, as with quellian 'kill', lèrian 'teach' and wređian 'support', which, like nerian, is without gemination. As in $\mathrm{OHG}$, stems ending in a dental consonant lack the connecting vowel $i$ in the preterite; they may or may not lack umlaut, as in latta, letta 'prevent' and quadda, quedda 'greet' to lettian, queddian; likewise lagda, legda 'laid' to leggian, but cf. analogical pp. gilegid. Verbs ending in a postconsonantal sonorant $l$, $n$ do not lose $-i$ - in the preterite, hence twiflida 'doubted', tēknida 'drew'. This is probably the model for other heavy-stem preterites in -id-, which are not uncommon. As in $\mathrm{OHG},-i$ - in the pass. part. of heavy stems should have been preserved only in uninflected forms, producing alternations such as gi-lērid : gi-lērdes, etc. However, in most instances, especially in the Heliand, the syncopated vowel has been restored. Rarely does analogy operate in converse fashion, producing uninflected forms like gibrand 'burnt' (inf. brennian) and gi-stild 'stilled' (stillian).

In $\mathrm{OE}$, to some present stems there are adjustments like those mentioned in $\S 12.24$ when syncopated inflections are added to the $2 \& 3 \mathrm{sg}$. pres. indicative, e.g. sentst, sent 'send(s)' (inf. sendan), brencð 'brings' (breng(e)an). Stems ending in $w$ or $h$ could undergo some significant changes, with many analogical developments: see Hogg \& Fulk 2011: $\S \S 6.97-9$ for details. Where preserved, $-i$ - in the preterite is lowered to $e$ after the earliest texts. Stems ending in a dental consonant have syncope in the preterite regardless of whether the stem is heavy or light, as with pret. sette 'set' (for expected $\dagger$ setede). Pret. legde 'laid' (inf. lecgan) follows the same pattern. As in OS, the connecting vowel is not syncopated in verbs with a stem ending in a postconsonantal sonorant consonant, e.g. timbrede 'built', LWS bȳcnedon 'signified. ${ }^{6}$ In EWS and in all late OE dialects there is a tendency for originally light stems to acquire inflections of the second weak class, under somewhat obscure circumstances (see Hogg \& Fulk 2011: §6.88), e.g. wenian 'accustom', pret. wenode, replacing wennan, wenede. 
1. The connecting vowel $-i$ - has not yet been syncopated in older Runic preterites, e.g. faihido 'I wrote' (Einang stone, $4^{\text {th }}$ cent.).

2. An exception is the OHG 2 pl., which ought not to have a geminate; the stem has been made uniform in the pl. But cf. Boutkan (1995b: 343), arguing for an inflection *-ete $>-e t$, with retention of preceding $j$ long enough to cause gemination.

3. The nonsyllabic status of this $j$ in OE is attested by the Mercian gloss on the Vespasian Psalter, wherein spellings like hergan 'praise' (cf. class 2 lufian 'love,' with syllabic $i$ ) are the norm. In poetry, too, the stem nerg- prevails, though by the end of the OE period spellings like nerig- (also in OHG) are common.

4. The stem frew-originates in the preterite and pass. part., where there was no gemination, and the stem frauw- originates in geminated forms of the present, where the development of aw in *awwja- to the diphthong au prevented any graphic representation of umlaut.

5. It is commonly stated in the handbooks that there is no umlaut in the pret. sj. of OHG verbs of this class: so, e.g., Schatz 1927: 47, Braune 2004a: $\$ 361$ Anm. 1. This is not the case: cf., e.g., in Otfrid's gospel book, 3 sg. legiti (IV, 35.13, 24), pl. legitin (III, 24.61; inf. leggen 'lay'). Rather, umlaut fails in the pret. sj. of verbs that lack the connector $-i$ - in the preterite, e.g. branti 'burned', zalti 'counted', and this is surprising because the PGmc. inflections contained $\bar{l}$. The restoration of the unmutated vowel is usually explained as due to the need to differentiate pres. and pret. stems: see Robinson 1980 for discussion and an account of alternative views.

6. Since spellings like timberde are rare and late (Hogg \& Fulk 2011: §6.96), -re- in timbrede probably does not reflect an etmologically nonsyllabic sonorant consonant made syllabic, but instead $*_{-r i-}$, as in OS.

\subsection{Verbs without $*_{-i}$ - in the preterite}

All the Gmc. languages show some verbs of weak class 1 that lack any trace of original

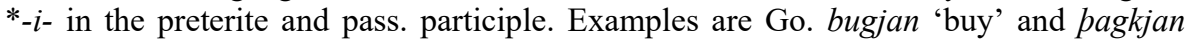
'think', prets. baúhta, pāhta < *buxta, *bayxta <*buz-t-, *bayk-t- (\$§4.1, 4.5), the last two forms with -t- unshifted by Grimm's law (§6.5). ${ }^{1}$ In Gothic the type is limited to verbs with stems ending in a velar consonant: in addition to bugjan and pagkjan, the relevant verbs are bringan 'bring' (strong pres., weak pret.), brükjan 'use', bugkjan 'seem', and waúrkjan 'make' (prets. brāhta, brühta, pühta, waúrhta). ${ }^{2}$ But not all Go. verbs ending in a velar consonant are formed this way: cf. lagjan 'lay', dragkjan 'give to drink', and many others with $-i$ - in the preterite. OIcel. soekja 'seek', yrkja 'make', pekkja 'recognize', and pykkja 'seem' are of this type, with prets. sótti, orti, pátti, pótti (§6.14; cf. Runic worahto on the Tune Stone, ca. 400); whether there were any original light-stemmed verbs of this type in NGmc. is impossible to say, since light stems normally lack both $-i$ - and umlaut in the preterite. West Germanic shows a wider variety of verbs of this type. Additions to the class include dental stems (on which see below), as well as OHG stems ending in affricates in the present but in (underlyingly geminate) fricatives in the preterite, though all these may or may not have umlaut in the pret. (§12.36). Yet WGmc. also shows this feature in some originally light stems ending in $l$, and these always lack umlaut in the preterite, so that it is not plain whether such verbs are all WGmc. additions or whether some arose earlier. ${ }^{3,4}$ Old English (as well as OHG) has a significant number of verbs of this sort with stems ending in a velar consonant (for a list, see Hogg \& Fulk 2011: §6.100) for which no evidence of formation without $*_{-i}$ is to be found in any of the few North and East Gmc. cognates, and in at least one instance such a cognate offers counterevidence: to OIcel. roekja 'heed', pret. rokkti cf. $\mathrm{OE}$ recc(e)an, rōhte. That the $\mathrm{OE}$ form could be more original, however, is a possibility suggested by the agreement of OIcel. sæekja, sótti with OE sēcean, sōhte, as against Go. sōkjan, sōkida. 
In all the WGmc. languages are to be found a few stems ending in a dental consonant that resemble verbs lacking PGmc. ${ }^{*}-i$ - in the pret., e.g. OS lettian 'hinder', pret. latta beside letta (not †letida), OHG quetten 'call', pret. quatta, OE settan 'set', pret. (Northumbrian) gesætte (WS sette). Probably analogical to OS settian 'set', pret. satta beside setta, due to the semantic resemblance, is leggian 'lay', pret. lagda (beside legda). Gallée (1993: §407) would derive such forms from PGmc., but East and North Gmc. afford no evidence of this. Still, the lack of umlaut in the pret. renders it likely that these arose in WGmc. before the onset of umlaut, though most evidence of the phenomenon has been eliminated on an analogical basis.

The securest examples of verbs lacking PGmc. ${ }^{*} i-$ in the preterite are plainly quite archaic verbs in which this irregularity persisted because of high frequency of use. The plainest sign of the antiquity of the type is that although the preterites are weak, they are formed with a suffix $*_{-}-b-\left(>*_{-} t-\right)$ instead of $*_{-} \partial_{-}$, since, for example, *buz- $\partial \bar{e}$ would produce Go. †bugda rather than baúhta. These preterites are thus formed the same way as those of the preterite-present verbs, another archaic category $(\S \S 12.51-4)$.

There is no scholarly consensus as to why ${ }_{-}-i$ - should be missing from such preterites. The verifiably oldest of these are primary verbs (so, e.g., Go. waúrkeip $=$ Avestan varazyeiti 'does, makes', and cf. Gk. $\dot{\rho} \varepsilon \dot{\varepsilon} \zeta \omega$ 'do'), which in PIE attached the *-ie/o- suffix to the present stem only. As the most archaic of the Gmc. ja-verbs, then, those like waúrkeip merely reflect the oldest state of affairs (so, e.g., Fullerton 1977: 5-7). This is an attractive analysis inasmuch as the type is plainly archaic, and since the preterite was formed with $*_{-} p$ - rather than $*_{-} \chi_{-}$, the means of forming the preterite plainly differed from the means used with later additions to weak class 1 . A disadvantage of this analysis is that it leaves unexplained why, aside from WGmc. additions to the class, it is only stems ending in a velar consonant (or a consonant, like $/ 1 /$, capable of velarity) that lack $*_{-i}-$ in the preterite. The problem is of some moment because the parallel between preterite formation in these verbs and in preterite-present verbs is an important clue to the origin of the type, yet preterites in that class with a stem-final velar are a notable minority (see $\$ 12.53$ ). Thus, an alternative analysis is that the preterite originally contained *-i-, which was lost on a phonological basis. For example, Prokosch (1939: §67c; cf. Brunner 1965: §407.3) argues that the final velar consonant was palatalized by the following $* i$, which it absorbed, though it reverted to velar articulation early enough for breaking to have taken place in forms like OE streahte 'stretched' and tealde 'counted'. Yet perhaps it is the case that the conditioning is morphological rather than phonological. Adding PIE $t$ or its reflex Gmc. $b$ as the preterite suffix to stems ending in a dental consonant (other than $s, n$ ) would have resulted in remarkable paradigm irregularities like that seen in Go. preterite-present *witan 'know' (cf. pres. 1 pl. witum), with pret. wissa, and so it should not be surprising if original, primary weak verbs of this sort without $*_{-} i$ - in the preterite were reformed to avoid this irregularity by the addition of $*_{-}-i$. It is less apparent why stems in labial consonants should have undergone a similar analogical reformation, but it is notable that among the preterite-present verbs the only stem of this type is to Go. *baúrban (cf. pres. 1 pl. paúrbum, but $1 \mathrm{sg}$. parf), whereas there are several verbs with stems ending in a velar consonant (OE dugan, *-nugan, magan, ägan). It is possible, then, that among the presumably small number of primary verbs in the earliest stages of PGmc. preterite-formation for weak and preterite-present verbs, the relatively high incidence of the alternation between pres. ${ }_{-3}$ - and pret. ${ }^{*}-x t$ ensured its acceptability, ${ }^{5}$ whereas the comparatively few stems in non-velars were all refashioned to conform to the pattern established by analogically reformed stems like pres. * sat-j- : pret. *sat-ið-. 
On the issues treated here, see further Penzl 1988c.

1. The term Rückumlaut (i.e., retrograde mutation) is sometimes used to describe this phenomenon, but there is no umlaut in Gothic, and the term is more properly reserved for those instances, discussed below, in which syncope of $i$ prior to umlaut occurred, especially in OHG. Cf. Antonsen 2002: 253.

2. Go. káupatjan 'buffet' has the pret. káupasta (but pp. káupatips), but this is plainly a phenomenon of a different order.

3. That $\mathrm{OE}$ stands closest to the original situation in WGmc. is the opinion, e.g., of Paul (1879-80: 7.143) and Prokosch (1939: $\$ 67 \mathrm{c})$. Ringe avers that there were just five verbs lacking $*_{-} i$ - in the pret. in PGmc., all with stems ending in a velar consonant (Ringe \& Taylor 2014: 71, 97-9). It is notable that the athematic verb Go. wiljan 'will' has the pret. wilda $(\S 12.58)$, which is contructed in the manner of verbs of the first weak class without $*_{-} i$ - in the preterite. A cogent argument has in fact been made that 'will' was the model for the analogical spread of the pret. irregularity to other stems in $l$ in WGmc. (Ringe \& Taylor 2014: 73-5).

4. OE cwellan 'kill', dwellan 'mislead', sellan (later syllan) 'give', stellan 'position', tellan 'count' (prets. cwealde, dwealde, etc.); OS sellian 'give', tellian 'count' (prets. salda, talda). OHG verbs of this type may or may not have both $-i$ - and umlaut. Perversely, though umlaut is usually missing from the preterite of light stems in OIcel., the pret. of selja 'give' is seldi.

5. Note that alternation between $z$ and $x$ was well established in other environments, under Verner's law, whereas that between $\hbar$ and $f$ was rarer and was presumably somewhat obscured by the change of the voiceless bilabial fricative to the latter, $\$ 6.4$ n. 3 .

\subsection{Development of the inflections of the present stem}

Under Sievers' law (§5.8), in PGmc. the stem-forming suffix in the present was $*_{-j}$ after light syllables and ${ }^{*}-i j$ - after heavy. ${ }^{1}$ On stems of more than one syllable, see $\S 2.5$. Loss of $*_{-j}$ - in the sequence $*_{-i j-i-}(\$ 6.11 \mathrm{ad}$ fin.; hence, in the $2 \& 3 \mathrm{sg}$. ind. and the 2 pl. ind.) produced a long (trimoric?) vowel, ${ }^{2}$ the difference between heavy and light stems in this respect being still observable in Gothic and ON, with 3 sg. pres. Go. -jip and $-e i p, \mathrm{ON}-r$ and $-i r$, after light and heavy stems, respectively. As for WGmc., there is no evidence of such a long vowel in the relevant forms in OHG, but there is evidence that the distinction persisted into prehistoric $\mathrm{OE}$, since a strong verb like sēon $<*$ seoxan

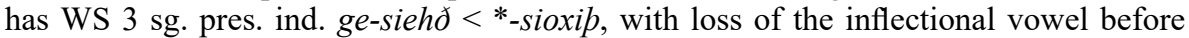
intervocalic $* x$ could be deleted, whereas a weak verb like $p \bar{y} w a n$ 'press' $<*$ pux $x i j a n$ has WS 3 sg. $p \bar{y} p<* b \bar{u} x \bar{\imath} p$, with preservation of the inflectional vowel long enough to enable loss of * $x$. Plainly, the North and West Gmc. forms show loss of $j$ before $i$ in the light desinences $*_{-j i z,}{ }_{-j} j i p$, and this change is often ascribed to PGmc., demanding the assumption that Go. $-j i s,-j i p$ are analogical re-creations, with extension of $j$ from those forms in which it was preserved before a back vowel. ${ }^{4}$ This is possible, but unless Sievers' law (\$5.8) was an active constraint at the time this morphological change took place, it would seem odd that there was no comparable paradigm regularization in the heavy stems, e.g. sōkeis, sōkeip altered to *sōkjis, ${ }^{*}$ sōkjip, since stem-final $j$ similarly in this case appeared elsewhere throughout the paradigm.

In the pres. indicative, the primary PIE thematic inflections were added to the stem-suffix $*_{-}(i) i_{-}$. After the development of PGmc. $*_{-} i j i-$ to $*_{-} \hat{\imath}^{-}$(or $*_{-i}-$ ? see $\left.\S 5.4\right)$ in the $2 \& 3 \mathrm{sg}$. and the $2 \mathrm{pl}$., the remaining instances of $*-i j$ - in the heavy stems (i.e., the instances preceding a back vowel) were reduced to $*_{-j-} .^{5}$ These changes resulted in such paradigm irregularities that it is probably best to assume morphological reanalysis, such that the remaining instances of $*_{-j}$ - were no longer treated as part of the stem but of the inflection (though Kiparsky 2000 assumes otherwise). The PGmc. inflections on heavy stems were thus these (with alternants due to Verner's law): 


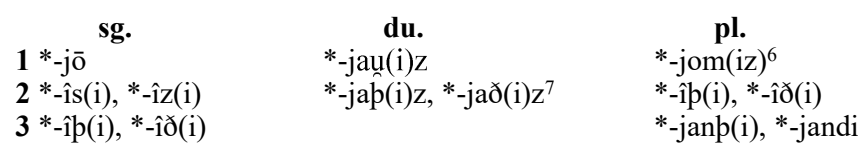

The corresponding inflections on light stems would have been the same, except for $2 \mathrm{sg}$.

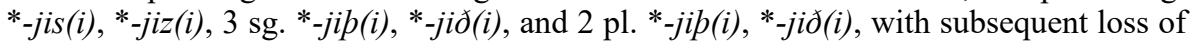
$j$ in all these $(\$ 6.11 \mathrm{ad}$ fin.). The Gothic development of the inflections is regular, aside from analogical changes in the dual like those in strong verbs $(\$ 12.24)$ and, apparently, re-introduction of $j$ in the endings just cited. The $\mathrm{ON}$ developments are likewise regular, except that the $2 \mathrm{sg}$. endings have been extended to the $3 \mathrm{sg}$., as in the strong verbs, and the vowel of the $2 \& 3 \mathrm{sg}$. has been extended analogically to the $1 \mathrm{sg}$. in heavy stems. After heavy stems, $*_{-j}$ - was regularly lost, as in the $j a$-stem nouns. Although $j$ is preserved in OS, it is lost everywhere in OE except after $r$ in light stems, whereas in OFris. it is lost even after $r$; in OHG, -ja- turns to - $e$-. As noted above, inflections with $\bar{l}$ on heavy-stemmed verbs must have replaced this with $i$ at a fairly early date in OHG but not in OE: perhaps they adopted the $i$ found in the corresponding desinences of strong verbs and light-stemmed weak verbs (but cf. Ringe \& Taylor 2014: 70-1).

As regards the subjunctive (optative), the Go. inflections are the same as for strong verbs, except without loss of $j$ in any instance, with light and heavy stems inflected identically. The situation is the same in $\mathrm{ON}$, except that $j$ is preserved only in the 1 sg. inflection -ja after light stems (- $a$ after heavy), this being the only inflection containing a back vowel. In WGmc. the subjunctive is inflected just as in the strong verbs, with inflections attached to the same stem as in the infinitive.

In the imperative, aside from the $2 \mathrm{sg}$. the attested forms are entirely comparable to those of strong verbs. In the $2 \mathrm{sg}$., PIE *-e should have been lost consistently in PGmc., leading to nuclearization of final $*_{-j}(\$ 5.2 \mathrm{ad}$ fin.) in light stems and preservation of $*_{-} i j$ as $*_{-} \bar{i}$ in heavy. Thus, Go. $-e i$ in heavy stems should originally have alternated with $*_{-} i$ in light, but analogy led to elimination of the alternation in favor of the long vowel. ${ }^{8}$ Both forms of the inflection were lost phonologically in ON. In WGmc. the inflection was preserved after light stems but lost after heavy, and this situation is reflected in OE (cf. sete 'set' < *seti : dèm 'judge'), but elsewhere in WGmc. the ending of light stems has been extended to the heavy (e.g. OFris. dèle, OS dèli, OHG teili 'divide').

The infinitive and the present participle are formed with the same suffixes as in strong verbs attached to the present stem in $-j-$. In $\mathrm{OHG}$, once again, *-ja- turns to - $e$-, hence inf. in -en and pres. part. in -enti, whereas strong verbs more commonly have -an and -anti, though there is much mixture of the variants from an early date. The same may be said of gerunds $(\$ 12.30)$.

1. Since 2 sg. Go. nasjis 'save' must derive from PIE *nos-éi-esi, Krahe \& Meid (1969: II, §85) prescribe that PGmc. *-iji- in such forms underwent development to ${ }^{*}-i i$-, which then gave ${ }^{*}-j i$ - after light stems but $*_{-}-\overline{-}$ - after heavy. It is more plausible to assume that, under Sievers' law, ${ }^{*}-i j i$ - after light stems became * ${ }_{-j} i$ before $j$ could be lost intervocalically.

2. The assumption of a trimoric vowel as the result of loss of intervocalic $j$ would explain the divergent developments in Go. 1 sg. pres. harbō 'wander' < *ōjō (\$6.11 ad fin.) and nom. sg. giba 'gift' < ${ }_{-}-\bar{o}$.

3. This evidence at first appears only circumstantial because the distinction is between strong and weak verbs rather than heavy- and light-stemmed verbs with weak presents. But there were no heavy-stemmed strong verbs with weak presents with stem-final $/ \mathrm{x} /$ comparable in structure to weak * püxijan in prehistoric $\mathrm{OE}$ (only an original light stem in hlihhan 'laugh'), and, conversely, there were no light-stemmed weak verbs 
of the first class with stems ending in $* x$ even before WGmc. gemination applied, and so all the relevant weak verbs thus had a long vowel in the pertinent inflections. A version of this analysis was offered already in Fulk 2010a. This accounts for the otherwise bewildering observation of A. Campbell (1977: §462) that a single phonological process, syncope in the $2 \& 3$ sg. pres. ind., occurred earlier in OE strong verbs than in weak. This analysis poses a difficulty for the account of weak verbs of the second class proposed by Cowgill (1959): see $\$ 12.43$ infra. Less probable seems the explanation of Hogg (1992: §7.49) that $h$ in ge-siehð has been reintroduced analogically from pret. $1 \& 3 \mathrm{sg}$. seah, especially as the same analogical development would have to be assumed to have occurred independently in Old Frisian.

4. So, e.g., Kortlandt 1986, Bammesberger 1988c, Ringe 2017: 155, 252.

5. For simplicity of presentation, this development is here treated as belonging to the PGmc. period. In actuality, it probably postdates that period, in view of Runic inf. prawijan 'desire' (? Kalleby stone, ca. 400). This form contains a light stem, but it is probably best explained as due to the analogical influence of heavy stems (of which no relevant Runic forms are attested). Compare the variation in Runic harja and harija (\$5.8).

6. See $\S 5.5$ on the development of PIE *-o-mes to Go. -am, NWGmc. -um.

7. With analogical replacement of $i$ (PIE $e$ ) by $a$ (PIE $o$ ): see $\S 12.24$.

8. Since ${ }^{*}-\bar{l}$ was shortened in Gothic ( $\left.\S 5.3\right)$, it must be assumed that Go. $-e i$ is analogical to the vowel that predominates in the pres. of heavy stems; but see $\$ 7.10$ for an alternative view.

\subsection{Development of inflections of the preterite stem}

How the preterite inflections are to be reconstructed is a question inseparable from the question of the origin of the dental preterite $(\$ 12.33)$, but certain facts can be established independently. The oldest Runic endings in the singular are $1 \mathrm{sg} .-\overline{\mathbf{o}}$ and $3 \mathrm{sg}$. $-\overline{\mathbf{e}}$ (beside hypercorrect -ai, §5.3), pointing to PGmc. ${ }_{-}^{*} \bar{o} m$ and ${ }^{*}-\bar{e} p$. The former will also account for Go. $1 \mathrm{sg}$. $-a$, though this could also derive from ${ }^{*}-\bar{e} m$, or it could be analogical to 3 sg. - $-a$ (Hirt 1931-4: II, §124). But 3 sg. $-a$ is itself difficult, since a long vowel should be expected to have been preserved as such when originally protected by a final consonant, as in the parallel instance of $\bar{o}(\S 5.3 \& \mathrm{n} .3)$. Go. 2 sg. - $\bar{e} s$ may safely be derived from PGmc. ${ }^{*}-\bar{e} s$. Thus, the likeliest reconstruction of the preterite desin-

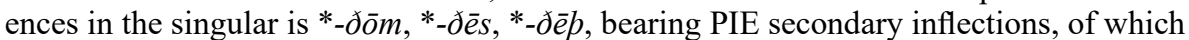
only the last raises unresolved difficulties. The Go. plural desinences -dèdum, -dèdup, -dēdun correspond exactly to the OHG pret. pl. forms of the verb 'do', i.e. tātum, tātut, tätun, providing strong evidence for the composition theory ( $\$ 12.33)$, regardless of how the OHG forms themselves are to be explained ( $\$ 12.61)$, but the sg. forms are another matter: cf. OHG $1 \& 3 \mathrm{sg}$. teta, 2 sg. tāti. Attempts to derive the sg. pret. endings from the same source as the plural (and dual, as well as all forms of the subjunctive) thus face considerable difficulties if the Gothic plural endings are considered more original than, e.g., 3 pl. OIcel. - $ð u$ and OHG -tun, even though, conversely, it seems counterintuitive to suppose that Go. innovated plural endings so different from the sg. ones. The commonest explanation for the sg. endings is that they reflect unreduplicated aorists, e.g. PIE $3 \mathrm{sg} . * d h \bar{e}$, but the $o$-quality of $1 \mathrm{sg}$. *dhom is then anomalous, as *dhèm should be expected, instead (Bammesberger 1986a: 85-6). It is not impossible, however, that the vocalism of *-dhèm, *-dhēs, *-dhêt should have been altered on the basis of the usual pattern in thematic secondary endings, ${ }^{*}$-om, ${ }^{*}$-es, ${ }^{*}$-et (so Hirt loc. cit.). ${ }^{1}$ It is at all events remarkable that the WGmc. simplex verb (OE dōn, OS dōn, duon, OHG tuon)

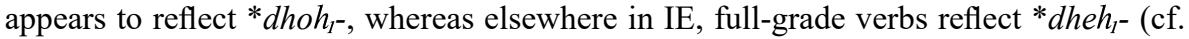
nouns Gk. $\theta \omega \mu$ ó ‘ 'heap', Lat. ab-domen 'abdomen', i.e. 'thing hidden' (ab-ditum)): see $\S 12.61$ on the explanation of Hill (2010). Note also OHG 2 sg. pret. -tōs and (principally) Alemannic 1, 2, 3 pl. -tōm, -tōt, -tōn (otherwise OHG -tum, -tut, -tun). ${ }^{2}$ 
In the subjunctive, the inflections are identical to those of strong verbs, attached to the pret. stem, which in Go. is the pret. pl. stem.

In general, the stem of the pass. part. is identical to that of the pret. sg., with the same endings as taken by strong participles. In Go. the $d$ ([ð]) of the stem is devoiced to $p$ before $s$ in the nom. sg.

1. Similarly Meid (1971: 111-12), though Krahe \& Meid (1969: II, §90) envisage ablaut variation in the sg.

2. Here the vowel $\bar{o}$ in the $2 \mathrm{sg}$., however, is best explained as analogical to the original $1 \mathrm{sg}$. ending $*_{-} \bar{o}(m)$, and $\bar{o}$ in the Alemannic pl. as analogical to the 2 sg. (Krahe \& Meid 1969: II, §90). Boutkan (1995b: 362) agrees that $\bar{o}$ in the Alemannic plural is analogical, but he derives $\bar{o}$ in the $2 \mathrm{sg}$. from the original perfect of 'do'. Cf. Hollifield 1980: 151, Ringe \& Taylor 2014: 76-7, the latter identifying $-s$ as borrowed from classes 2 and 3 , and perhaps the pres. sj.

\section{B. WEAK VERBS OF CLASS 2}

\subsection{Stem formation}

Verbs of this class bore in PIE the suffix $*_{-} \bar{a}-<*_{-} e h_{2^{-}}$, with or without the addition of *-ie/o-. Derivatives of this type were formed in two ways. (1) The suffix was attached to adjective stems to form factitive verbs-i.e., verbs with the meaning 'cause to have the quality of the adjective'. An example is Hittite newahmi 'I make new', Lat. re-novāre, $\mathrm{OE}$ nīwian (cf. Gk. véoৎ 'new' < *neu-o-s); perhaps also Go. frijōn 'love' (cf. frija'free', but also Skt. prīnấti 'pleases'). Verbs derived from nouns by this method are generally younger formations, as exact cognates in separate IE branches are uncommon. Gmc. examples are Go. fiskōn 'fish' (cf. fisks 'fish' (noun) and Lat. piscāri 'fish' (verb)) and Go. sidon 'practice' (cf. sidus 'custom'). Verbs of this type could also be formed by the addition of PIE *-ie/o- to $\bar{a}$-stem nouns, e.g. Go. karōn 'care for' (cf. kara 'anxiety') and OE eahtian 'esteem' (cf. eaht 'estimation'). ${ }^{1}$ (2) The suffix was attached to verb roots, forming primary verbs, e.g. Lat. plicāre 'fold' (cf. explicere 'unfold'), lavāre 'wash' beside lavere, and cubāre 'recline' (cf. recumbere 'recline'). It is usually assumed that factitive verbs of type (1) were originally athematic, with addition of inflections directly to the stem-forming *-ā-, as the forms of 'make new' (above) attest, whereas thematic verbs, with the addition of $*_{-} i e / o$ - to $*_{-} \bar{a}$-, were formed to both types (1) and (2). Hirt (1931-4: II, §134) argues that the relation between verbs with and without $-\bar{a}$ - under (2) parallels that between $\bar{a}$-stem and $o$-stem noun pairs like Gk. $\tau o \mu \eta \dot{~}$ 'stump' and tómoৎ 'slice', and thus verbs of type (2) are actually denominal. Many verbs resist this explanation, however, especially on semantic grounds, since, e.g., a noun *piskā (Go. fiskōn, Lat. piscāri; cf. nouns Go. fisks (a-stem) and Lat. piscis (istem)) seems unlikely. And as he points out, verbs of this type not infrequently coöccur with verbs of weak class 1, e.g. OHG mālōn beside Go. méljan 'write', and OE hatian 'hate' beside Go. hatjan, suggesting rather deverbal derivation. Yet the uncertainties about origins are considerable. In Gmc. a further source of verbs of this class is most likely preterites like *salচōðē 'anointed', if this is a compound of a noun in the instrumental case with a form of the verb 'do' (\$12.33), allowing derivation from nouns other than Gmc. $\bar{o}$-stems.

1. Denominal verbs of this type are surveyed and classified semantically by Schäfer (1984). 


\subsection{Inflection}

There is no distinction between the inflection of light and heavy stems in the second weak class, illustrated by the paradigms of Go. hwarbōn 'wander' and cognates:

Pres. Ind. 1 sg. uarbō

2 sg. huarbōs

3 sg. harbōp

1 du. huarbōs

2 du. huarbōts

1 pl. huarbōm

2 pl. huarbōp

3 pl. huarbōnd

Pres. Sj. 1 sg. harbō

2 sg. huarbōs

3 sg. huarbō

1 du. huarbōwa

2 du. huarbōts

1 pl. huarbōma

2 pl. huarbōp

3 pl. huarbōna

Imp. 2 sg. harbō

3 sg. huarbōdáu

2 du. huarbōts

1 pl. huarbōm

2 pl. huarbōp

3 pl. huarbōndáu

Pret. Ind. 1 sg. harbōda

2 sg. huarbōdēs

3 sg. huarbōda

1 du. huarbōdēdu

2 du. huarbōdēduts

1 pl. huarbōdēdum

2 pl. huarbōdēdup

3 pl. huarbōīdēdun

Pret. Sj. 1 sg. harbōdēdjáu

2 sg. huarbōdēdeis

3 sg. harbōdēdi

1 du. huarbōdēdeiwa

2 du. huarbōdēdeits

1 pl. huarbōdēdeima

2 pl. harbōdēdeip

3 pl. huarbōdēdeina

\section{Inf.}

Pres. Part.

Pass. Part.

\section{Go.}

uarbōn

huwarbōnds

huarbōps
OIcel.

hvarfa

hvarfar

hvarfar

hvorfum

hvarfið

hvarfa

hvarfa

hvarfir

hvarfi

hvarfim

hvarfið

hvarfi

hvarfa

hvọrfum

hvarfið

hvarfaða

hvarfaðir

hvarfaði

hvọrfuðum

hvọrfuðuð

hvǫrfuðu

hvarfaða

hvarfaðir

hvarfaði

hvarfaðim

hvarfaðið

hvarfaði

OE

hwearfige

hwearfast

hwearfað

hwearfiað

hwearfiað

hwearfiað

hwearfige

hwearfige

hwearfige

hwearfigen

hwearfigen

hwearfigen

hwearfa

hwearfiað

hwearfode

hwearfodest

hwearfode

hwearfodon

hwearfodon

hwearfodon

hwearfode

hwearfode

hwearfode

hwearfoden

hwearfoden

hwearfoden

hvarfa

hvarfandi

hvarfaðr

hwearfian

hwearfiende

hwearfod
OS

hwarboiu

hwarbos

hwarbod

hwarboiad

hwarboiad

hwarboiad

hwarboie

hwarbos

hwarboie

hwarboian

hwarboian

hwarboian

hwarbo

hwarboiad

(h)warbōmēs

(h)warbōt

hwarboda

hwarbodes

hwarboda

hwarbodun

hwarbodun

hwarbodun

hwarbodi

hwarbodis

hwarbodi

\section{OHG}
(h)warbōm
(h)warbōs
(h)warbōt

(h)warbōmēs

(h)warbōt

(h)warbōnt

(h)warbo

(h)warbōs

(h)warbo

(h)warbōm

(h)warbōt

(h)warbōn

(h)warbo

(h)warbōta

(h)warbōtōs

(h)warbōta

(h)warbōtum

(h)warbōtut

(h)warbōtun

(h)warbōti

(h)warbōtīs

(h)warbōti

hwarbodin

(h)warbōtīm

hwarbodin

(h)warbōtīit

(h)warbōtīn

hwarbodin

(h)warbōn

hwarboian

hwarboiandi

(h)warbōnti

gihwarbod gi(h)warbōt

Outside of Gothic, the plural endings are used with both plural and dual subjects. In addition, inflected infinitives occur in WGmc. (\$12.30). In the pres. ind. and sj., Go. verbs may be inflected in the passive voice, with the same endings as in $§ 12.29$, e.g. 1 sg. pres. ind. huarbōda, 2 sg. huarbōza, etc. 


\subsection{Morphological variation}

Some verbs in OIcel. show contraction, e.g. spá 'prophesy' < spáa $<{ }^{*}$ spaxōjana $^{n}$ and fjá 'hate' <*fijojana ${ }^{n}$.

In $\mathrm{OE},-i(g)$ - in the pres. stem reflects $*$-ojj-, e.g. inf. hwearfian $<{ }^{*} x^{w} a r b \overline{o j} a n a^{n}$, in which $*_{\bar{o}}$ is umlauted to ${ }^{*} \bar{e}$ by the following ${ }^{*} j$, and this ${ }^{*} \bar{e}$ is subsequently shortened and raised to $i$ by the influence of the following palatal sound. ${ }^{1}$ The commonest pattern is for the pres. suffix to appear as - $i$ - before $a$ (rarely -ige-) but -ig- before $e$, except in non-finite forms, though there are many exceptions, especially outside of LWS. By dissimilation, -odon is commonly changed to -edon (\$5.6). The preterite suffix is normally $-o d$ - in standard WS (early $-u d$-) but - $a d$ - in Kentish and Anglian; the former reflects *-u $\bar{u}-$-, the allomorph that appeared before $u$ in the next syllable, which was generalized in WS, whereas -ad- reflects unraised ${ }^{*}-\bar{o} d$-, generalized in the other dialects. On forms like hwearfende and tō hwearfenne (rather than -iende, -ienne) in Anglian, see Hogg \& Fulk 2011: §6.112. Contracted verbs to this class also occur in OE, e.g. sméagan 'contemplate' $<*^{*}$ smauxōjan-, 3 sg. pres. ind. smēap $<*^{*}$ smauxōp. Contraction could also occur without any loss of [x], as with frīgan 'love' $<*$ frīej- $<$ NSGmc. *frij-ōj-.

OS (with hwar-spelt 〈huar)) shows the usual variation in the spelling of inflectional vowels $(\S \S 1.18,5.6)$. In addition, -oia- may be spelt -ogea-, parallel to spellings in OE. The forms given are presumably the older ones, since they are found almost exclusively in poetry. In addition to forms in -oia- and -oie(-) there occur forms in simple $-o(-)$ that are comparable to the OHG forms, thus pres. ind. pl. hwarbod, sj. $1 \& 3 \mathrm{sg}$. hwarbo, pl. hwarbon. These are normal in prose, though they occur also in poetry, where in fact they predominate, at a rate of about 5 in 6 relevant forms. Pres. ind. $1 \mathrm{sg}$. hwarboiu does not in fact occur as such, but it is rendered certain by two forms in prose, oppraiu and likiu (Cowgill 1959: 3), as should be expected on the basis of the OE and OFris. forms, showing that the longer forms bear thematic endings $\left(1\right.$ sg. PIE $\left.{ }^{*} \bar{o}\right)$, whereas the shorter ones bear athematic ( $1 \mathrm{sg} .{ }^{*}-m i$, as in OS trūon, tholon), as in OHG. In poetry there also occur forms in -ia- (with syllabic $i$ ) for -oia-, and these forms are comparable to those encountered in Anglo-Frisian. Unlike in OHG, the stem vowel -ohas been shortened, as shown by its not infrequent lowering to $a$.

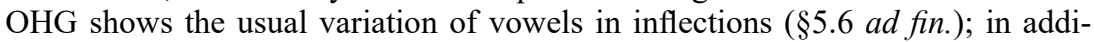
tion, -ōn may appear for $-\bar{o} m(\bar{e} s)$. In the pres. opt. there occur in UG (but also in Isidor), especially in Alemannic, longer forms of the order $1 \& 3 \mathrm{sg}$. warbō $(g) e, 2 \mathrm{sg} .-\bar{o}(g) \bar{e} s, 1$ pl. $-\bar{o}(g) \bar{e} m$, etc., where $\langle\mathrm{g}\rangle=[\mathrm{j}]$.

1. Despite the incredulity of Fullerton (1977: 50), these developments are well attested in OE, with umlaut of a vowel or diphthong by an immediately following * $j$, as in Anglian cēgan 'call' (EWS ciegan) <*kaujan-, weakening of unstressed long vowels, as of $* \bar{u}>u>o$ in the preterites of this class, and raising of weakened front vowels before palatal sounds, as in hālig 'holy' <*hālæj-<*xailaz-.

\subsection{Historical development}

Significant uncertainties attend the analysis of this class of verbs. The Go., ON, and OHG forms would appear to represent athematic conjugation, with inflections added directly to stems in PIE $* \bar{a}\left(\right.$ or $* e h_{2}$ ), whereas the longer stems of Anglo-Frisian and, in part, OS appear to be thematic, with the suffix *-ie/o-, containing the theme vowel, inserted between $* \bar{a}$ and the inflections. The OHG 1 sg. pres. ind. ending $-\bar{o} m(=\mathrm{OS}$ $-o n)$ is certainly athematic, but Go. $-\bar{o}$ and Runic $\mathbf{- \overline { \mathbf { o } }}$ are thematic, as are the endings in 
Anglo-Frisian. The earliest attempts at an explanation thus assumed the coöccurrence of thematic and athematic forms in Gmc., with mixture of the two in Ingvaeonic and generalization of the athematic elsewhere. (Compare athematic Aeolic Gk. $\tau \overline{\bar{\mu}} \mu \bar{\alpha} \mu \iota$ beside thematic Attic $\tau \bar{\mu} \mu \bar{\alpha} \omega<* \tau \bar{\imath} \mu \bar{\alpha} i \omega$ 'fear'.) Yet the required analogical changes are not uniformly well motivated, and the reason for the particular distribution of thematic and athematic forms in Ingvaeonic is difficult to perceive on this basis. It is especially hard to account for the pres. sj. forms in this fashion, since athematic optatives to stems in PIE $* \bar{a}\left(\right.$ or $\left.* e h_{2}\right)$ should have been formed by the addition of $*-i(e) h_{1}-(\$ 12.6){ }^{1}$

A revised approach by Cowgill (1959) turns conventional wisdom on its head by explaining some of the seemingly most archaic forms as innovations. Cowgill argues that PGmc. ${ }^{*} j$ was lost between any two unstressed vowels (but not if the first vowel was $* i, \S 6.11$ ad fin.), ${ }^{2}$ followed by contraction of the remaining vowels, with the result that simple $\bar{o}$ in the non-Ingvaeonic forms (as opposed to Ingvaeonic ${ }^{*}$-ojja-, ${ }^{*}$-ōji-) is the phonologically regular result of this change, whereas the longer Ingvaeonic forms are the result of an analogical change. On this analysis, alternations in heavy-stemmed verbs of the first weak class such as inf. *dōmijan, pres. sg. *domijō, *dōmis, dōmip, pret. sg. *domiðe, led to morphological reanalysis whereby the stem in these forms was perceived to be $*^{*} \overline{o m i} i$ - and the inflections $*_{-j a n} *_{-j} \bar{o}, *_{-} s,{ }_{-}-b$, and $*_{-} \partial \bar{e}$, respectively. Thereupon, these inflections were extended analogically in Ingvaeonic to stems of the

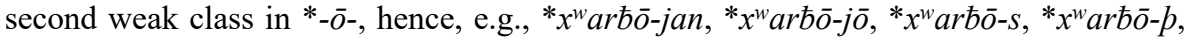
${ }^{*} x^{w}$ arb $\bar{o}-\partial \bar{x} .{ }^{3}$ This accounts brilliantly for both the Ingvaeonic and the non-Ingvaeonic forms, disposing very effectively, especially, of the problem of the pres. sj. forms, assuming that the alternative, longer sj. forms of UG are an analogical innovation, formed by the addition of the normal sj. endings of strong verbs to stems in ${ }^{*}-\bar{o}$ - in order to redifferentiate ind. and sj. forms that had fallen together. ${ }^{4}$

Attractive as Cowgill's hypothesis is, however, it faces several difficulties that are not insignificant. Although his objections and counterproposals are on the whole unpersuasive, Fullerton (1977: 49) is right to observe that it is difficult to believe that loss of $j$ and subsequent contraction in the sequence *-oji- would lead to a monophthong * $\bar{o}$ rather than a diphthong. ${ }^{5}$ A problem that Cowgill himself raises is that if the longer forms of OS (hwarboian, hwarboiad, etc., as opposed to the shorter forms hwarbon, hwarbod, etc.) are actually analogical innovations and thus the younger of the two types, it is difficult to see why the longer forms occur almost exclusively in the more conservative language of verse. ${ }^{6} \mathrm{~A}$ further problem is that reanalysis of *domijan as stem *domi- plus inflection in Ingvaeonic is complicated by developments in OE, since it was pointed out above $(\S 12.38)$ that even though a short vowel is indicated in the $2 \&$ 3 sg. pres. ind. of such verbs in OHG (for which Cowgill assumes shortening already in WGmc.), prehistoric OE seems to require a long vowel $\left({ }^{*} \bar{l} s,{ }^{*}-\bar{l} p\right)$ in order to explain the different effects of syncope in contracted strong and weak verbs, e.g. strong flieh 'flies' < fliuxib : weak $p \bar{y} \partial$ 'presses' < *būxī $p$. This consideration perhaps does not disqualify Cowgill's explanation altogether, but it renders the assumed reanalysis of the heavy-stemmed inflections less straightforward. In addition, it should be said that Cowgill's assumption is that there was no athematic inflection of such verbs in PGmc., rather than coöccurring thematic and athematic inflection. He is thus obliged to assume that the OHG $1 \mathrm{sg}$. pres. in $-\bar{o} m$ (and OS -on) is analogical to WGmc. *dom (OHG tuom, OS dōm, Anglian OE dōm) '(I) do', and though this may not be impossible, it seems dubitable that such an otherwise unproductive category of Gmc. verbs as athematic stems $(\S \S 12.55-64)$ should have exerted analogical influence of this sort. These 
problems are perhaps not insurmountable. Yet however these difficulties are to be accounted for, Cowgill's remains the only very plausible account to date.

1. For summaries of the scholarhip, see Cowgill 1959 and Fullerton 1977: 45-54. Bammesberger (1986a: 155) highlights the problem posed by the present subjunctive and argues that in this respect the second class is analogical to the first.

2. This hypothesis about the loss of $j$ between unstressed vowels had already been proposed: see Wilmanns 1893-1906: III, 86; Prokosch 1939: §54; Krahe 1948: 129, 134; see also, e.g., Krause 1968: §241. The objections of Birkhan (1974: 4-7) fail to persuade.

3. Note, however, that on this analysis no analogical change is actually required in the $2 \& 3 \mathrm{sg}$. forms, which would already have had ${ }^{*}-\bar{o} s,{ }^{*}-\bar{o} p$ on a phonological basis.

4. To the contrary, Kirschstein (1962: 109) regards the longer sj. forms as more original, even though they are UG and thus cannot very plausibly be regarded as the result of a dialect continuum with Ingvaeonic.

5. Prokosch (1939: §54) sees this as "a process akin to the loss of the second element of long diphthongs in IE," but in Gmc. such loss is characteristic only of, perhaps, PIE $\bar{e} i>$ PGmc. $\bar{e}_{2}$ and, even more tentatively, $\bar{o} u$ $>\bar{o}$; cf. especially the development of PIE $* \bar{a} i$ to PGmc. ${ }^{*} a i$ rather than ${ }^{*} \bar{o}(\S 3.4)$. Yet it should be observed that the most widely credited explanation for the PGmc. comparative suffix *-ozz is that it is contracted from $*_{-}-\overline{-}-i z$ (though the proposer of that explanation, Brugmann (in Brugmann \& Delbrück 1897-1916: II, 1.560-1) attributes the change to ${ }^{*}-\bar{o} z$ to an analogical process, not a phonological one: see $\S 9.10$ ).

6. Ringe proposes that by the $9^{\text {th }}$ cent., when the poetry was composed, the longer forms would have seemed more archaic, and that the shorter forms came to dominate later under OHG influence (Ringe \& Taylor 2104: 161). The former explanation seems uncharacteristic of early Gmc. poets' practices with regard to archaic language, the latter, then, too coincidental to seem probable. The problem persists.

\section{WEAK VERBS OF CLASS 3}

\subsection{Stem formation}

Extra-Germanic cognates to verbs of this class suggest that they were formed in PIE with a stem in $*_{-}-\bar{e}-<*_{-} e h_{l^{-}}$, with or without the addition of a thematizing suffix $*_{-i} e_{-} / o^{-}$. They would thus have been entirely parallel to verbs of weak class 2 , but with PIE $* \bar{e}$ instead of $* \bar{a}$. An example is Lat. monēre 'warn', Lith. minët 'remember', OCS mbnět $i$ 'believe', Go. munan 'remember', OHG manēn 'warn'. As the example demonstrates, some of these are deverbal and durative, but a particular use for stems of this type in PIE was to form deadjectival stative verbs with the meaning 'have the quality of the adjective'. ${ }^{1}$ An example is Lat. rubère, OCS rzdèti, OHG rotēn 'be red'. There are also factitives derived from both nouns and adjectives, preserved almost exclusively in Gothic, e.g. Go. gapiwan 'enslave' (cf. piwōs 'servants'), arman 'pity' (<*'regard as poor'; cf. arms 'poor'). The difficulties that attend accounting for the attested Gmc. forms starting from such a reconstruction, however, are even greater than in the parallel instance of class 2, as discussed in $\$ 12.43$. Especially in Ingvaeonic, a great many of these verbs are normally inflected according to weak class 1 and/or 2 . There is also the problem of how it is to be explained that PIE statives and factitives came to be inflected alike in Gmc. (on which see Ringe 2017: 205, Ringe \& Taylor 2014: 518).

1. Dishington (2010), rather, argues that the most basic verbs in this class are denominal. 


\subsection{Inflection}

Although no one verb exemplifies all the difficulties encountered in trying to account for this class, the paradigm of Go. haban 'have' and its Gmc. cognates, a deverbal formation related to Go. hafjan 'raise, bear' (= Lat. capiō), illustrates a number of the peculiarities of the type:

Go.

Pres. Ind. 1 sg. haba 2 sg. habáis

3 sg. habáip

1 du. habōs

2 du. habats

1 pl. habam

2 pl. habáip

3 pl. haband

Pres. Sj. 1 sg. habáu

2 sg. habáis

3 sg. habái

1 du. habáiwa

2 du. habáits

1 pl. habáima

2 pl. habáip

3 pl. habáina

Imp. 2 sg. habái

3 sg. habadáu

2 du. habats

1 pl. habam

2 pl. habáip

3 pl. habandáu

Pret. Ind. 1 sg. habáida

2 sg. habáidēs

3 sg. habáida

1 du. habáidēdu

2 du. habáidēduts

1 pl. habáidēdum

2 pl. habáidēdup

3 pl. habáidēdun

Pret. Sj. 1 sg. habáidēdjáu

2 sg. habáidēdeis

3 sg. habáidēdi

1 du. habáidēdeiwa

2 du. habáidēdeits

1 pl. habáidēdeima

2 pl. habáidēdeip

3 pl. habáidēdeina

Inf.

Pres. Part.

Pass. Part.

haban

habands

habáips
OIcel.

OE

hef(i)

hef(i)r

hef(i)r

hæbbe

hæfst

hæfठ

họfum

hafið

hafa

hafa

hafir

hafir

hafim

hafið

hafi

hafi

họfum

hafið

hafða

hafðir

hafði

hǫfoum

hǫfðuð

hǫfðuð

hefða

hefðir

hefði

hefoim

hefðið

hefði

habbap

hæbbe

hæbbe

hafa

\section{habbap}

habbap

hæbbe

hæbben

hæbben

hæbben

hebbiad, habbiad

hebbiad. habbiad

hebbiad, habbiad

hebbie, habbie

hebbias, habbias

hebbie, habbie

hebbian, habbian

hebbian, habbian

hebbian, habbian

habe, -a, -i

habēmēs

habēt

habēnt

habe

habēs(t)

habe

habēm, -ēn

habēt

habēn

habe

habēmēs, -ēn

habbap

hebbiad, habbiad

habēt

$\begin{array}{ll}\text { hæfde } & \text { habda, -e } \\ \text { hæfdest } & \text { habdes, -as } \\ \text { hæfde } & \text { habda, -e }\end{array}$

habēta

habētōs(t)

habēta

\section{hæfdon habdun}

hæfdon habdun

hæfdon habdun

habētum

habētut

habētun

habēti

habētīs

habēti

habētīm

habētīt

habētīn

habēn

habēnti

gihabēt

Outside of Gothic, the plural endings are used with both plural and dual subjects. In addition, inflected infinitives occur in WGmc. (\$12.30). In the pres. ind. and sj., Go. 
verbs may be inflected in the passive voice, with the same endings as in $\$ 12.29$, e.g. 1 sg. pres. ind. habada, 2 habaza, etc.

\subsection{Morphological variation}

The verb hafa is the only one of this class in OIcel. to show forms without $-i(-)$ in the pres. sg. (hef, hefr beside newer hefi, hefir), aside from segja 'say', to which seg, segr are old and rare. Many past parts. end in -aðr rather than - $r$ (-tr after a stop, as in keyptr 'bought'), e.g. brosaðr 'having smiled', and it is notable that hafa and segja show (rarely) an alternative form of the pass. part. only in older and/or poetic texts, hafat (neut.) and sagaðr. In $\mathrm{OE}$, where just four verbs are regularly inflected according to this class (habban 'have', libban 'live', secgan 'say', hycgan 'think') there is considerable variety in stems and inflections. Thus, secgan and hycgan show umlaut in the present stem (but not $2 \& 3$ sg. sægst, sægð), whereas habban and libban do not (though umlaut would be undetectable in the stem libb-, as opposed to leof-); libban lacks syncope in the $2 \& 3 \mathrm{sg}$. pres. ind. (leofast, leofad, with back mutation, §4.8), whereas the others do not (e.g. hæfst, hæfð); and to imp. sg. hafa, leofa cf. sæge, hyge. The verb hycgan is in fact indistinguishable from a verb of class 1 , except in the preterite. The Anglian forms are different, sometimes in expected ways, e.g. pres. ind. sg. hafo, hafast, hafad, but also lifg- for libb-. OFris. hebba, habba 'have', libba 'live', and sedza 'say' are inflected the same way as verbs of class 2 , so that only the stems attest to original membership in class 3. OS hebbian 'have', libbian 'live', and seggian 'say' are the only OS verbs inflected thus, and they show some of the same peculiarities as the OE verbs, including the mixture of forms with and without umlaut (e.g. inf. hebbian beside habbien; $2 \& 3$ sg. sagis, sagad beside 1 sg. seggiu, etc.), and forms alternately with $-e / a$ or $-i$ in the imp. singular. Although no pres. part is attested for hebbian or seggian, cf. libbiandi beside libbendi. Among other variants, $\mathrm{OHG}$ has in some early texts pret. hapta $<$ *habda (so also hogta, hocta 'thought'), in agreement with Ingvaeonic. The number of such verbs in OHG is notably greater than in NSGmc.: see Braune 2004a: $\S 369$ for an inventory.

\subsection{Historical development}

Although much ingenuity has been expended in the attempt, no purely phonological explanation has succeeded convincingly in deriving the attested inflectional patterns directly from the stems in PIE *-e $(-\underline{i} e / o)$ - that the extra-Germanic cognates suggest should be the starting point. ${ }^{1}$ The $\mathrm{OHG}$ forms might be accounted for in this fashion, but the great regularity of $\mathrm{OHG}$ stem-formation in $-\bar{e}$ - can only be an analogical innovation, in view of the irregularity of the stem in the other Gmc. languages, and especially in view of early OHG preterites like hapta and hogta (beside habèta, hogèta). And seeing as the most probable explanation of the Ingvaeonic verbs of weak class 2 is that they were analogically reformed after class $1(\S 12.43)$, it would be hazardous to make the Ingvaeonic forms of class 3 the basis for reconstructing the PGmc. situation. Probably, then, the best evidence for the most archaic patterns is to be found in East and North Germanic.

The Go. pres. paradigm shows - ai- in those forms in which the inflection contained PGmc. $* i<$ PIE $* e$ in other classes of verbs, otherwise $-a(-)$, and so this has the 
appearance of a regular phonological development. However, athematic PIE $*-\bar{e}$ - should not have produced non-final $a$ in Gothic (cf. nasidess : nasida, and hamme- $h$ 'to everyone' : hamma 'to whom'), much less thematic *-eie/o-, the development of which can only be guessed. Various morphological solutions have been proposed, involving analogy and/or the coöccurrence of thematic and athematic stems within the paradigm (see the counterarguments in Jasanoff 1978b: 60-7), but in neither event is it plain what forces should have produced an alternation with the appearance of being phonologically conditioned. Accordingly, Bennett (1962; cf. Jasanoff 1973: 855) proposes that the stem-final formative was not $*_{-} \bar{e}-<*_{-} e h_{1^{-}}$but the weak grade of this, hence thematic *-h $h_{1}-i e / 0-$, a structure closely paralleled in OCS verbs like $1 \mathrm{sg}$. pres. stojq 'stand', $3 \mathrm{sg}$. stojitz, corresponding to $\mathrm{OHG}^{*}$ stêm, stēt (an athematic verb, §12.64), though in this verb ${ }^{*} h_{l}\left(>\right.$ OCS $o$ ) is not suffixal. ${ }^{2}$ Though Bennett offers no extra-Germanic parallels to the weak grade of the suffix in $\bar{e}$-verbs, weak grade seems best to explain certain Balto-Slavic forms, e.g. OCS 2 pl. pres. sēdite 'sit', Lith. sëdite, as well as Gk. verbs like $\mu \alpha i v \varepsilon \tau \alpha l$ 'is mad' < * $\mu \alpha v i \varepsilon \tau \alpha l$ (cf. inf. $\mu \alpha v \hat{\eta} v \alpha l$; see Streitberg 1896: §206). ${ }^{3}$ Assuming (as Cowgill does in regard to verbs of weak class $2, \S 12.43$ ) that PGmc. ${ }^{3} j$ was lost between unstressed vowels (though not after $* i$ when a back vowel followed), the Go. pres. endings can be generated on a purely phonological basis:

\begin{tabular}{|c|c|c|c|c|c|c|c|}
\hline & PIE & & Go. & & PIE & & Go. \\
\hline Sg. 1 & $*_{-}\left(\mathrm{h}_{1} \mathrm{i}\right)-\overline{\mathrm{o}}$ & $>$ & $-a$ & Pl. 1 & *-( $\left.\mathrm{h}_{1} \mathrm{i}\right)$-omes & $>$ & -am \\
\hline 2 & *-hol $(\mathrm{i})$-esi & $>$ & -áis & 2 & *-hol $(\mathrm{i})$-ete & $>$ & -ái \\
\hline 3 & *-hon $(\hat{i})$-eti & $>$ & -áip & 3 & *-( $\left(\mathrm{h}_{1} \mathrm{i}\right)$-onti & $>$ & -and \\
\hline
\end{tabular}

Similarly, ${ }^{*} h_{1} i-$ would have been lost in all pres. forms of the subjunctive (optative) before the suffix *-oi-, resulting in the same endings as on strong verbs both active and passive; the pass. ind. endings likewise parallel those of strong verbs, which arose by the analogical changes detailed in $\S 12.29$. Note that this analysis requires that syllabic laryngeals not have been lost in all Gmc. unstressed syllables (see $\$ 5.5 \mathrm{ad}$ fin.). Thus, the suffix *-h,i-would have developed to -ái- before the dental consonant in all forms of the preterite, but *-(h,i)-o- would have produced $-a$ - in the infinitive and pres. participle. Although Bennett offers a different explanation, PIE imp. $2 \mathrm{sg} .{ }^{*}-h, i-e$ may be presumed to have produced Go. -ái regardless of whether final $*_{-} i<*_{-} e$ or $*_{-j}-$ was lost first. Bennett's hypothesis thus accounts admirably for all the Gothic forms as regular phonological developments.

By Bennett's account, his analysis also explains all the inflectional forms of this class in $\mathrm{ON}$, which in the present has $-e(-)(>-i(-)$, from *-ai-) everywhere Go. has $-a i-$, and $-a(-)$ everywhere Go. has $-a(-)$, with the exception only of 1 sg. pres. ind. $-e(>-i)$, which does not correspond to Go. $-a$. In the preterite, $*_{-} e_{-}<*_{-} a i$ - was syncopated in medial syllables when the inflection was of sufficient weight, and thus there is no connecting vowel in the ON preterite, in which all the inflections were heavy. The verbs segja 'say', pegja 'be silent' have their $-j$ - already in the earliest records by analogy to weak class $1 .{ }^{4}$ But matters are surely not so straightforward as this. The pres. ind. sg. forms 1 hef and $2 \& 3$ hefr (also seg, segr) must be old, since they are found only in archaic and poetic texts, though umlaut in such forms is difficult to explain, both because umlaut ought not to be found in light stems without preserved $i$ in the next syllable and because on this analysis there seems no plausible way to derive $\breve{l}$ in $2 \mathrm{sg}$. * $x a \hbar \check{\bar{z} z}>$ hef(i)r. It is probably best to assume an original paradigm in which syncopated forms alternated with unsyncopated, e.g. $1 \mathrm{sg} .{ }^{*} x a \bar{b}(a j) \bar{o}>* h a \hbar u$ (which would have developed to *hof if analogy had not intervened) : 2 sg. *xabiz (whatever the derivation 
of $\vec{\imath})>$ hefir, with paradigm regularization then extending umlaut throughout the sg. and leading to parallel paradigms with and without inflectional $-e(-)>-i(-)$ in the sg., the forms with $-e(-)$ coming to prevail by an early date in the literate period. Similar developments are required to explain the coöccurrence of pass. parts. in - $\delta$ - and - $a \delta$ - (the latter, in the verbs hafa and segja, at least, occurring only in early and/or poetic texts), which is comparable to (and has the same cause as) the alternation between - $\delta$ - and -i - in the pass. parts. of weak class $1(\$ 12.36)$.

The Ingvaeonic forms may be accounted for in a fashion similar to the one that Cowgill (see §12.43) devised for weak class 2 (Hogg \& Fulk 2011: §§6.124-5). That is, outside of the $2 \& 3 \mathrm{sg}$. pres. ind., the reanalyzed endings of the heavy-stemmed verbs of weak class 1 (e.g. inf. ${ }^{*}$-jan, 1-3 pl. *-jã $b$ ) were added to the present stem; but whereas the present stem in weak class 2 was perceived to end in ${ }^{*}-\bar{o}$ - (hence, e.g., NSGmc. inf. *xailaz-ō-jan > OE hālgian 'hallow', 3 sg. *xailaz-ō- $p>$ halgap), the stem in weak class 3 was perceived to end in a consonant, due to the original alternation between, e.g., PGmc. inf. *xab(aj)an- > *xab-an- and 3 sg. *xaba(j)ip(i) >*xab-aip. The result in Ingvaeonic would have been forms like the following:

\begin{tabular}{|c|c|c|c|}
\hline & $\begin{array}{l}\text { Ind. } \\
\text { * }_{\text {nnd- }}\end{array}$ & $\underset{*}{\mathbf{S j} .}$ & Imp. \\
\hline 2 & $\begin{array}{l}\text { Fab-ju }^{*} \text { *ab-ais } \\
\text { F }\end{array}$ & *aab-jaa & *xab-ai \\
\hline 3 & *xab-aip & *xab-jai & \\
\hline $\begin{array}{l}\text { pl. } \\
\text { Inf. } \\
\text { Pres. part. }\end{array}$ & $\begin{array}{l}\text { *xab-ja }{ }^{\mathrm{n}} \mathrm{p} \\
\text { *xab-jan } \text { *xab-jandī }\end{array}$ & *xab-jain & *xab-ja \\
\hline
\end{tabular}

If it is assumed that WGmc. gemination was still operative at this early date in Ingvaeonic, this will account for forms like OE habban, OFris. hebba, habba, OS hebbian, habbien. In such a paradigm umlaut would have applied everywhere but in the 2 and 3 sg. pres. ind., and this is the situation as preserved in OE libban and secgan, though umlaut has been extended analogically throughout the paradigm of hycgan and leveled out of that of habban, in the latter case perhaps to differentiate the present paradigm from that of hebban 'raise'. The imperatives OE sæge, hyge show the correct development of final -ai, whereas hafa and leofa must be explained as having acquired the imp. sg. ending of weak class 2; cf. OS imp. sg. haちe beside haba, habi, the last with the ending of weak class 1. Likewise, OE 2 \& 3 sg. leofast, leofað (as well as Anglian hafast, hafad) cannot reflect *-ais, *-aip but must bear endings borrowed from class 2 ; and there is, again, alternation among the vowels $e, a$, and $i$ in the corresponding inflections in OS, showing mixture of endings from classes 1-3. WS hæfst, $h æ f \delta$ are probably not regular developments under the conditions outlined in $\$ 12.24$ but analogical creations (unsurprisingly, given the dominant role of analogy in the formation of the 2 \& $3 \mathrm{sg}$. in $\mathrm{OE}$ ), in view of the preservation of the etymologically long inflectional vowel in the corresponding forms of weak class 2; but they conform to the pattern of adding the inflections of class 1 to the bare consonantal stem that governs the morphology of this class, even if they were formed long after the Proto-Ingvaeonic period. Similarly, neither $1 \mathrm{sg}$. pres. ind. WS hæbbe nor Anglian hafo directly reflects Ingvaeonic *xabju, which results correctly in OS hebbiu, but they show analogical developments that are already familiar from the development of these and other verbs in OE. As for the preterite, PGmc. *-ai- should not have been syncopated before the dental suffix, but given that the present stem was analyzed as ending in a consonant, it may be assumed that in Ingvaeonic the same development affected the preterite formation as the present, and 
dental suffix plus inflection were added to the consonantal present stem to form the preterite, just as in heavy-stemmed verbs of weak class 1 they were added to the present stem, which was perceived to end in *-i-, e.g. WGmc. *domi-d $\bar{x}>\mathrm{OE}$ dèmde 'judged'.

The OHG forms are then to be explained as showing analogical extension of the stem in $-\bar{e}-<*_{-}$-ai- throughout the paradigm, under the influence of the parallel stems in $-\bar{o}$ - of class 2 . That early preterites like hapta, hogta lack a connecting vowel suggests that the analogical change outlined above resulting in the Ingvaeonic preterite stem without a final vowel began already in early WGmc.

1. For an exhaustive survey of the extensive literature, see Flasdieck 1935, focusing particularly on OE. More concise accounts are offered by Bennett 1962 and Fullerton 1977: 58-9; see also Dishington 1976, Kortlandt 1990, Boutkan 1995b: 347-51.

2. On uncertainties about the development of syllabic laryngeals in Gmc. unstressed syllables, see $\S 5.5 \mathrm{ad}$ fin.

3. Yet Ringe (2017: 157-8) offers a plausible account of how $h_{1}$ can have arisen in innovative pass. participles to these verbs and spread thence to the pres.

4. Note that the lack of gemination in segja, pegja can be explained either on the assumption that a vowel has been syncopated before $j$ (so, e.g., Dishington 1978: 312, with refs.) or as due to the relatively late date at which these forms were created analogically. Kortlandt (1990: 3-4) attributes the lack of a geminate in segja (and pegja 'be silent') to the same analogical cause as in vekja, rekja, etc. ( $\$ 6.14$ supra), but that analogical process, though degeminating $k$, normally leaves $g g$ geminated (e.g. leggja 'lay'). To the contrary, Ringe (2017: 158, 163-4) supposes that *saz'sja-developed to *sazja-already in PGmc., on the assumption that rare seggja is older than segja, the latter formed by analogy to $2 \& 3$ sg. segir (so Noreen 1970: §279.1). The usual assumption, however, is that seggja is an innovation of the $12^{\text {th }}$ or $13^{\text {th }}$ cent. (so, e.g., Finnur Jónsson 1901: 109), seeing as seggja is required by the rhyme just once in skaldic verse, in a poem of no very early date (Ámundi Árnason, Lausavísa 3 (13 $3^{\text {th }}$ cent.)), whereas segja is demanded by the hending often in verse, some of it demonstrably archaic, e.g. Sigvatr Pórðarson's Nesjavísur 1 (ca. 1016). See the exhaustive discussion of relevant skaldic forms in Konráo Gíslason et al. 1875-89: II, 351-412.

\section{WEAK VERBS OF CLASS 4}

\subsection{Stem formation}

This class remains a discrete category in Gothic only. Elsewhere in Gmc. the verbs originally belonging to this group are all inflected according to one of the other weak classes, usually class 2 , though in $\mathrm{OHG}$, as a rule, they join class 3 . The most distinctive signs of this class are stems ending in $-n$ - and inchoative meaning (or 'anticausative': Scheungraber 2014: 214; or 'fientive': Ringe 2017: 200), e.g. Go. mikilnan 'be magnified' (cf. mikils 'large') and tundnan 'become lit' (cf. tandjan 'kindle'). As the examples show, these verbs may be either denominal (esp. deadjectival) or deverbal, and at least in primary verbs the root is in the weak grade, due to suffix accent in PIE. For a catalogue of relevant verbs and references to the pertinent literature, see Scheungraber 2014.

\subsection{Inflection}

With the stem in $-n$ - throughout, in the pres. these verbs are inflected precisely the way strong verbs are, and in the pret. as verbs of weak class 2 . The conjugation may be illustrated by the paradigm of Go. fullnan 'become full': 


\begin{tabular}{|c|c|c|c|}
\hline & Ind. & Sj. & Imp. \\
\hline Pres. 1 sg. & fullna & fullnáu & \\
\hline $2 \mathrm{sg}$. & fullnis & fullnáis & fulln \\
\hline $3 \mathrm{sg}$. & fullnip & fullnái & fullnadáu \\
\hline 1 du. & fullnōs & fullnáiwa & \\
\hline 2 du. & fullnats & fullnáits & fullnats \\
\hline 1 pl. & fullnam & fullnáima & fullnam \\
\hline 2 pl. & fullnip & fullnáip & fullnip \\
\hline 3 pl. & fullnand & fullnáina & fullnandáu \\
\hline Pret. 1 sg. & fullnōda & fullnōdēdjáu & \\
\hline $2 \mathrm{sg}$. & fullnōdēs & fullnōdēdeis & \\
\hline $3 \mathrm{sg}$. & fullnōda & fullnōdēdi & \\
\hline 1 du. & fullnōdēdu & fullnōdēdeiwa & \\
\hline 2 du. & fullnōdēduts & fullnōdēdeits & \\
\hline 1 pl. & fullnōdēdum & fullnōdēdeima & \\
\hline 2 pl. & fullnōdēdup & fullnōdēdeip & \\
\hline 3 pl. & fullnōdēdun & fullnōdēdeina & \\
\hline Inf. & fullnan & & \\
\hline Pres. Part. & fullnands & & \\
\hline Past Part. & fullnōps & & \\
\hline
\end{tabular}

There are no transitive verbs in this class, due to their inceptive meaning, and so they have no passive inflection.

\subsection{Historical development}

These verbs are usually compared to Skt. verbs of the prnắti 'fills' type (class 9), which have a stem ending in a laryngeal consonant preceded by a nasal infix, between the two of which there appears a full-grade vowel in the singular, though otherwise the stem is entirely in the weak grade; hence, to $3 \mathrm{sg}$. prṇấti $<* p l-n$-éhl-ti cf. 1 pl. prñimáh $<*$ * pl-n$h_{1}$-mós (with lengthening of $i<* h_{1}$ by analogy to the long vowel in the sg., according to Kuryłowicz 1956: 258). The usual assumption, then, is that because the Go. $1 \& 3$ pl. and the pres. part. contain $-n a$ - (which may be derived from $\left.{ }^{*}-n h_{r^{-}}\right)^{1}$ and which makes these forms identical to the corresponding forms of strong verbs, strong endings were leveled into the entire pres. ind., and thence into the other pres. forms. ${ }^{2}$ This seems rather a radical analogical refashioning on the basis of a slender resemblance, however, and therefore more plausible is the account of Fullerton (1971, 1977: 71-6), who points out that IE stems with what was originally infixed $-n$ - may be either thematic or athematic. For example, Skt. athematic yunákti 'joins', jinốti 'quickens', and prṇáti occur beside thematic yuñjáti, jinváti, and prnáti, respectively, the last to be derived from *pl$n-h_{l}-\dot{e}-t i$. The Skt. forms of this last correspond almost precisely, ${ }^{3}$ then, to the comparable Go. forms:

\section{PIE}

1 sg. *pl-n- $h_{1}-\overline{0}$

2 sg. *pi-n-h-é-si

3 sg. *pi-n-h-é-ti

1 pl. *pí-n-h-hó-mes

2 pl. *pl-n-h-é-t(H)e

3 pl. *pl-n-h-h-ó-nti
Skt.

prṇắmi

prnạási

prnáti

prṇấmah

prnátha

prnánánti

PGmc.
*fulnō
*fulnis(i)
*fulnip(i)
*fulnom(iz)
*fulnip(i)
*fulnanb(i)

Go.

fullna

fullnis

fullnip

fullnam

fullnip

fullnand 
A disadvantage of Fullerton's account is that it renders the Go. preterite more difficult to explain: whereas the pres. is to be derived from thematic stems, the pret. must be derived from athematic, e.g. athematic sg. stem * $p l-n$-éh $h_{1}$ or * $p l-n$-óh $h_{1}$ plus dental suffix and inflection, producing Go. fullnōda, etc. It is by no means plain why the pret. stem, before the addition of the dental suffix, should in no instance have been identical to the pres. stem, since this is unparalleled in Go. weak verbs. Fullerton posits an interesting complementary distribution, however, that lends support to the assumption of parallel thematic and athematic stems in Gmc.: in NWGmc., verbs of this sort with strong preterites have thematic present inflection, whereas those with weak preterites have, unlike Gothic, athematic presents. That is to say, a verb like OE wæcnan 'awake' (pret. $w \bar{o} c$ ) has a pres. stem ending in the equivalent of PIE thematic *-nH-o-, whereas OE hlinian 'lean' (pret. hleonode) has a pres. stem ending in the equivalent of PIE *-n-e/o$H$ - > PGmc. *-nō-. The evidence is hardly solid, especially in view of forms like OE weak wæcnian 'awake' (pret. wæcnode) parallel to strong wæcnan, giving rise to the opportunity for much analogical refashioning. But it is an important observation that whereas intransitive-inchoative verbs in $-n$ - are all weak in Gothic, and are usually so in NWGmc., a few traces of strong conjugation survive outside of Gothic, in forms with the weak grade of the root expected in primary verbs of this type, including OE murnan (pret. mearn beside weak murnde, the latter originally of weak class 3 , like Go. maúrnan (only pres. sj. forms attested), OS mornian, OHG mornēn) ${ }^{4}$ and OE spurnan (pret. spearn, also occasionally with weak pret. of class 2), OHG spurnan (pret. pl. spurnum); probably also ON gína 'yawn' (pret. gein), OE gīnan (pret. gān), beside wk. OE ginian, geonian, OS ginon. ${ }^{5}$

1. A difficulty is that in athematic verbs of this sort the 3 pl. should end in *-nH-énti (Szemerényi 1996: $\S 9.2 .1 .2$ ), which should not produce Go. -nand, as Verner's law would not apply. Since the alternant with $d$ has otherwise been generalized in Gothic (\$12.24 ad fin.), however, its appearance here may be regarded as analogical.

2. So, e.g., Prokosch 1939: §54i; Wright 1954: 160; Krause 1968: §245; Krahe \& Meid 1969: II, §88.

3. Sanskrit substitutes the athematic $1 \mathrm{sg}$. inflection for the thematic. The Go. spellings with $-l l$ - are possibly by analogy to fulls 'full'; some spellings of the Go. compound us-fullnan have just one $l$. There is the added difficulty that PGmc. *-ln- should have developed to -ll- in all forms ( $\$ 6.8)$; it may be that the Go. verb is thus largely a late (or analogically reformed) creation based on the adjective, but the example otherwise illustrates well the underlying principles of stem formation and development that Fullerton outlines for this class, and which may be assumed to have applied in other verbs like this one. Boutkan (1995b: 352-3) objects to Fullerton's claim that his explanation accounts for every Go. pres. form, since the thematic vowel should have been colored as $a$ in $3 \mathrm{sg} .{ }^{*}-n h_{2}-e-t i$. It is true that the suffix extracted from nasal-infixed nouns contained $h_{2}$ (Beekes 2011: 258), but thematic *pl-n- $h_{l}-e ́-t i$ did not (cf. Lat. complètus), and presumably some others. Certainly, analogy must have played a role in many verbs, but not necessarily all.

4. That the weak forms of this verb are of class 3 should be unsurprising, since the stem-final laryngeal in these PIE $n$-infixed stems could be of any sort. Note that in OHG, weak verbs of this sort most commonly conform to weak class 3 , whereas elsewhere weak class 2 is the commonest sort.

5. The long vowel in the strong forms is probably by analogy to other verbs of class I; cf. the lengthening in aorist presents of class II like OE brücan 'use', lücan 'close', etc., and compare unlengthened aorist presents in class I like Go. digandin (§12.18). Scheungraber (2014: 81-4) explains the long vowel otherwise. 


\section{Preterite-present verbs}

\subsection{Stem formation}

Present-tense forms of preterite-present verbs are formally and historically Gmc. preterites, i.e. PIE perfects, almost entirely identical to the preterite forms of identifiable classes of strong verbs. New, weak preterites were formed for them with a dental suffix, to which the normal preterite inflections of weak verbs were added. Thus, for example, Go. 3 sg. pres. kann 'knows' resembles a 3 sg. pret. of a strong verb of class III, with 3 pl. kunnun; the innovated 3 sg. pret. is kunpa.

\subsection{Inflection and forms}

The following paradigms of Go. mag 'can' and its Gmc. cognates may serve to illustrate the inflection of the pret.-pres. verbs. Given their semantics, in Go. no passives are preserved, and for the same reason many of these verbs have no infinitive. On imperatives, see below, §12.54. In the paradigms below an exceptional number of gaps have been filled in by reference to other verbs and expected strong and weak patterns.

\begin{tabular}{|c|c|c|c|c|c|c|}
\hline \multirow{5}{*}{ Pres. Ind. } & \multirow{5}{*}{$\begin{array}{l}1 \mathrm{sg} . \\
2 \mathrm{sg} . \\
3 \mathrm{sg} . \\
1 \text { du. }\end{array}$} & Go. & \multirow{4}{*}{$\begin{array}{l}\text { OIcel. } \\
\text { má } \\
\text { mátt } \\
\text { má }\end{array}$} & \multirow{4}{*}{$\begin{array}{l}\text { OE } \\
\text { mæg } \\
\text { meaht } \\
\text { mæg }\end{array}$} & \multirow{4}{*}{\begin{tabular}{l}
\multicolumn{1}{c}{ OS } \\
mag, mah \\
maht \\
mag, mah
\end{tabular}} & \multirow{2}{*}{$\begin{array}{l}\mathbf{O H G} \\
\mathrm{mag}\end{array}$} \\
\hline & & mag & & & & \\
\hline & & magt & & & & maht \\
\hline & & mag & & & & mag \\
\hline & & magu & & & & \\
\hline & 2. du. & maguts & & & & \\
\hline & 1 pl. & magum & megum & magon & mugun & magun, mugun \\
\hline & 2 pl. & magup & meguð & magon & mugun & magut, mugut \\
\hline & 3 pl. & magun & megu & magon & mugun & magun, mugun \\
\hline \multirow[t]{8}{*}{ Pres. Sj. } & $1 \mathrm{sg}$. & magjáu & mega & mæge & mugi & megi, mugi \\
\hline & $2 \mathrm{sg}$. & mageis & megir & mæge & mugis & megis, mugis \\
\hline & $3 \mathrm{sg}$. & magi & megi & mæge & mugi & megi, mugi \\
\hline & 1 du. & mageiwa & & & & \\
\hline & 2 du. & mageits & & & & \\
\hline & 1 pl. & mageima & megim & mægen & mugin & megin \\
\hline & 2 pl. & mageip & megið & mægen & mugin & megit \\
\hline & 3 pl. & mageina & megi & mægen & mugin & megin \\
\hline \multirow[t]{8}{*}{ Pret. Ind. } & $1 \mathrm{sg}$. & mahta & mátta & meahte & mahte & mahta \\
\hline & $2 \mathrm{sg}$. & mahtēs & máttir & meahtest & mahtes & mahtest \\
\hline & $3 \mathrm{sg}$. & mahta & mátti & meahte & mahte & mahta \\
\hline & $1 \mathrm{du}$. & mahtēdu & & & & \\
\hline & 2 du. & mahtēduts & & & & \\
\hline & 1 pl. & mahtēdum & máttum & meahton & mahtun & mahtun \\
\hline & 2 pl. & mahtēdup & máttuð & meahton & mahtun & mahtut \\
\hline & 3 pl. & mahtēdun & máttu & meahton & mahtun & mahtun \\
\hline \multirow[t]{4}{*}{ Pret. Sj. } & $1 \mathrm{sg}$. & mahtēdjáu & mætta & meahte & mahti & mahti \\
\hline & $2 \mathrm{sg}$. & mahtēdeis & mættir & meahte & mahtis & $\operatorname{mahtīs}(\mathrm{t})$ \\
\hline & $3 \mathrm{sg}$. & mahtēdi & mætti & meahte & mahti & mahti \\
\hline & $\begin{array}{l}1 \text { du. } \\
2 \text { du. }\end{array}$ & $\begin{array}{l}\text { mahtēdeiwa } \\
\text { mahtēdeits }\end{array}$ & & & & \\
\hline
\end{tabular}




\begin{tabular}{|c|c|c|c|c|c|}
\hline & Go. & OIcel. & OE & OS & OHG \\
\hline 1 pl. & mahtēdeima & mættim & meahten & mahtin & mahtīn \\
\hline 2 pl. & mahtēdeip & mættið & meahten & mahtin & mahtìt \\
\hline 3 pl. & mahtēdeina & mætti & meahten & mahtin & mahtīn \\
\hline & & mega & magan & & magan \\
\hline & $\begin{array}{l}\text { magands } \\
\text { mahts }\end{array}$ & $\begin{array}{l}\text { megandi } \\
\text { máttr }\end{array}$ & magende & & magamu \\
\hline
\end{tabular}

Go. $2 \mathrm{sg}$. pres. ind. magt is an analogical spelling for *maht. The vowel $u$ of the $2 \mathrm{pl}$. pres. ind. inflection in Go., OIcel., and OHG is by analogy to the 1 and 3 plural. OIcel. mátt(-) is from *maht(-) (\$6.14). The stem OIcel. meg- derives its umlaut by analogy to sj. forms; cf. má $<* m a h<* m a z$, like Runic Aih 'I own' = OIcel. á. Early WS meaht(-) is already frequently meht(-), due to palatal monophthongization (on which see Hogg 1992: §5.120), and in Late WS the stem is usually miht(-). ${ }^{1}$ OS OHG mug- is an analogical creation on the basis of other pret.-pres. verbs, e.g. OS skal, pl. skulun 'shall' and far-man, pl. *far-munun 'disdain'; comparable forms are to be found in Old Norwegian, OFris., and Middle English, rarely in late OE. Of similar origin are OS OHG mohtbeside maht-.

1. This miht(-) is perhaps due to the influence of the noun miht 'might', which has umlaut (so Hogg \& Fulk 2011: §6.138), though perhaps likelier it originated as a low-stress variant of meht(-) (cf., e.g., *xailaz- > *xālæz $>$ *hālez $>$ hālig 'holy'). It could represent generalization of the pret. sj. stem, in which umlaut is to be expected (as in OIcel.), but there is no umlaut in Early WS pret. sj. meahte.

\subsection{Inventory by corresponding strong class}

In most instances it is unambiguous according to which strong class the present of each Gmc. pret.-pres. verb is formed, as demonstrated by the following inventory, in which the principal parts are $2 \& 3 \mathrm{sg}$. pres. ind. (rather than the infinitive, since some such verbs have no infinitive), 3 pl. pres. ind., 1 \& 3 sg. pret., and pass. participle. The relevant verbs are Go. wáit knows', láis 'understands', dáug 'avails, is good for', gadars 'dares', kann 'knows', parf 'needs', man 'thinks' (and ga-man 'remembers'), bi$n a h$ 'is permitted' (and ga-nah 'suffices'), skal 'shall, is obliged', mag 'can', ga-mōt 'finds room', ōg 'fears', áih 'owns', OIcel. ann 'loves', mun 'will (probably)', kná 'knows (how), is able', and cognates. As usual in this book, not all of the forms listed below are actually attested; in this case a few of the more crucial unattested forms are marked as reconstructed, for clarity's sake. For the actually attested forms, see (collectively) Birkmann 1987 or (individually) Braune 2004b: §§196-203 (Gothic), Noreen 1970: §§521-5 (OIcel.); Hogg \& Fulk 2011: §§6.132-9 (OE); Gallée 1993: §§415-21 (OS); and Braune 2004a: $\S \S 371-7$ (OHG).

\begin{tabular}{lllllll} 
Class I & & Go. & OIcel. & OE & \multicolumn{1}{c}{ OS } & OHG \\
& Pres. 2 sg. & wáist & veizt & wāst & wēst & weist \\
& Pres. 3 sg. & wáit & veit & wāt & wēt & weiz \\
& Pres. 3 pl. & witun & vitu & witon & witun & wizzun \\
& Pret. 3 sg. & wissa & vissi & wisse & wissa & wissa \\
& Pass. part. & & vitaðr & witen & giwitan & giwizzan
\end{tabular}

In Go. there is also a verb láis 'I understand', to which this is the only attested form; compare the causative formation PGmc. *laiz-ij-an-> Go. láisjan, OE lǣran (etc.) 'teach'. It is usually assumed that Go. wáist develops from *uoit-th $e>$ PGmc. *wais(s) 
(§6.8), with subsequent analogical re-addition of the $2 \mathrm{sg}$. ending, though Sihler (1986) offers cogent reasons for regarding wáist as the regular reflex of *uoit-th $e$. The pass. parts. of OIcel. veit and cognates (weak in ON, strong in WGmc.) are all innovations; the original pp. *wissa- <*uittó- <*uid-tós is reflected only as an adj. stem meaning 'certain' (cf. Go. un-wiss, OIcel. vissu-ligr, OE ge-wiss, etc.). Infinitives to this verb are attested in Go. (witan), OIcel., OE, OS, and OHG. The verb Go. áih 'owns' is very commonly regarded as belonging to this class (so, e.g., Euler 2013: 165), but see below under class VII.

Class II

$\begin{array}{ll} & \text { Go. } \\ \text { Pres. } 2 \text { sg. } & \\ \text { Pres. } 3 \text { sg. } & \text { dáug } \\ \text { Pres. } 3 \text { pl. } & \\ \text { Pret. } 3 \text { sg. } & \\ \text { Pass. part. } & \end{array}$

OIcel. $\quad$ OE

OS OHG

$\begin{array}{lll}\text { dēag } & \text { dōg } & \text { toug } \\ \text { dugon } & \text { dugun } & \text { tugun } \\ \text { dohte } & & \text { tohta }\end{array}$

The form dáug is the only one attested in Gothic (2×). There is an inf. OE dugan.

\begin{tabular}{|c|c|c|c|c|c|c|}
\hline \multirow[t]{4}{*}{ CLASS III } & $\begin{array}{l}\text { Pres. } 2 \text { sg. } \\
\text { Pres. } 3 \text { sg. } \\
\text { Pres. } 3 \text { pl. } \\
\text { Pret. } 3 \text { sg. } \\
\text { Pass. part. }\end{array}$ & Go. & $\begin{array}{l}\text { OIcel. } \\
\text { annt } \\
\text { ann } \\
\text { unna } \\
\text { unni } \\
\text { unn(a)ðr }\end{array}$ & $\begin{array}{l}\text { OE } \\
\text { ann } \\
\text { unnon } \\
\text { uðde } \\
\text { unnen }\end{array}$ & -onsta & $\begin{array}{l}\text { an } \\
\text { unnun } \\
\text { onda }\end{array}$ \\
\hline & $\begin{array}{l}\text { Pres. } 2 \text { sg. } \\
\text { Pres. } 3 \text { sg. } \\
\text { Pres. } 3 \text { pl. } \\
\text { Pret. } 3 \text { sg. } \\
\text { Pass. part. }\end{array}$ & $\begin{array}{l}\text { ga-dars } \\
\text { ga-daúrsun } \\
\text { ga-daúrsta }\end{array}$ & & $\begin{array}{l}\text { dearst } \\
\text { dear } \\
\text { durron } \\
\text { dorste }\end{array}$ & $\begin{array}{l}\text {-dar } \\
\text { gi-dorsta }\end{array}$ & $\begin{array}{l}\text { gi-tarst } \\
\text { gi-tar } \\
\text { gi-turrun } \\
\text { gi-torsta }\end{array}$ \\
\hline & $\begin{array}{l}\text { Pres. } 2 \text { sg. } \\
\text { Pres. } 3 \text { sg. } \\
\text { Pres. } 3 \text { pl. } \\
\text { Pret. } 3 \text { sg. } \\
\text { Pass. part. }\end{array}$ & $\begin{array}{l}\text { kant } \\
\text { kann } \\
\text { kunnun } \\
\text { kunpa } \\
\text { kunps }\end{array}$ & $\begin{array}{l}\text { kannt } \\
\text { kann } \\
\text { kunnu } \\
\text { kunni } \\
\text { kunnaðr }\end{array}$ & $\begin{array}{l}\text { canst } \\
\text { cann } \\
\text { cunnon } \\
\text { cūðe } \\
\text {-cunnen }\end{array}$ & $\begin{array}{l}\text { kanst } \\
\text { kan } \\
\text { kunnun } \\
\text { konsta }\end{array}$ & $\begin{array}{l}\text { kanst } \\
\text { kan } \\
\text { kunnun } \\
\text { konda } \\
\text {-cunnan }\end{array}$ \\
\hline & $\begin{array}{l}\text { Pres. } 2 \text { sg. } \\
\text { Pres. } 3 \text { sg. } \\
\text { Pres. } 3 \text { pl. } \\
\text { Pret. } 3 \text { sg. } \\
\text { Pass. part. }\end{array}$ & $\begin{array}{l}\text { parft } \\
\text { parf } \\
\text { paúrbun } \\
\text { paúrfta } \\
\text { paúrfts }\end{array}$ & $\begin{array}{l}\text { parft } \\
\text { parf } \\
\text { purfu } \\
\text { purfti } \\
\text { purftr }\end{array}$ & $\begin{array}{l}\text { pearft } \\
\text { pearf } \\
\text { purfon } \\
\text { porfte }\end{array}$ & $\begin{array}{l}\text { tharft } \\
\text { tharf } \\
\text { thurbun } \\
\text { thorfta }\end{array}$ & $\begin{array}{l}\text { darft } \\
\text { darf } \\
\text { durfun } \\
\text { dorfta }\end{array}$ \\
\hline
\end{tabular}

Go. 2 sg. kant is once spelt kannt (I Corinthians 7:16). In addition to OHG onda, konda there occur gi-onsta, konsta in Otfrid. The original pass. parts. Go. kunps 'known' (OIcel. kunnr, OE cù , OS kū $d$ ) and paúrfts 'necessary' are used as common adjectives. There occur the infinitives OE OHG unnan; also Go. ga-daúrsan. Infinitives for kann occur in Go. (kunnan), OIcel., OE, and OHG; and for parf in OIcel. (burfa) and OE. WGmc. forms with $2 \mathrm{sg}$. pres. ind. $-s t$ for etymological *-t, it is usually assumed, have abstracted this desinence from * ${ }^{*}$ aist, ${ }^{*}$ darst, and ${ }^{*} m \overline{o s t} .{ }^{1}$ If this analogical replacement occurred in Proto-WGmc., it must be assumed that analogy within the paradigm prevented or eliminated the expected change *kann-st $>* k a n-s t>* k \bar{a}^{n} s t$ in NSGmc. 


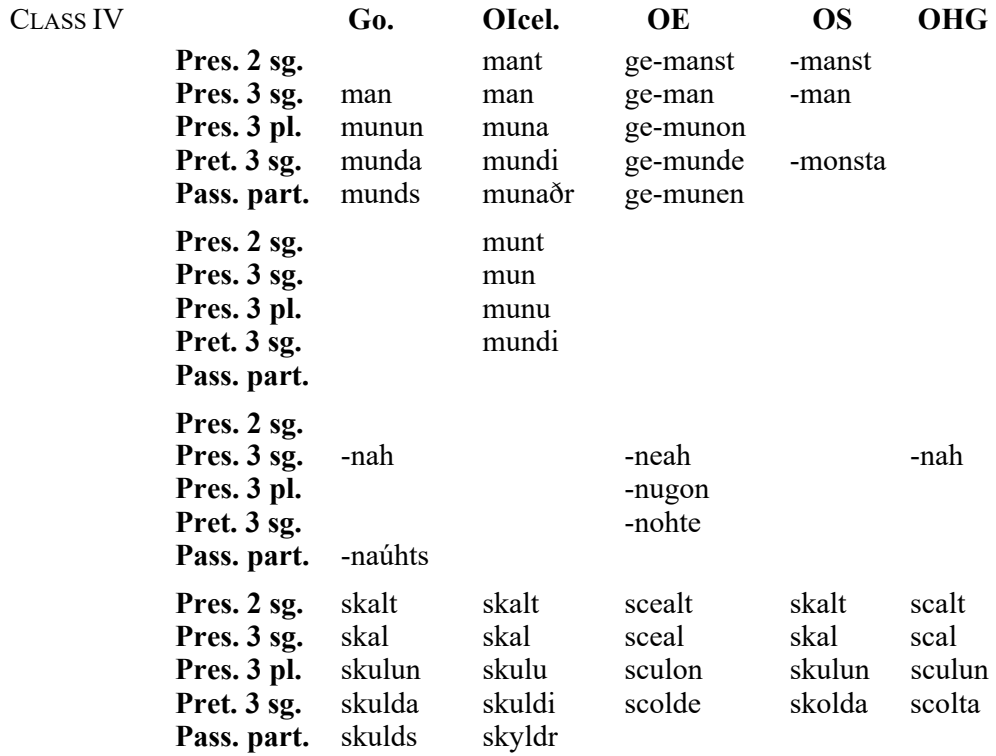

OIcel. mun 'will (probably)' is cognate with Go. munan 'intend, will', a weak verb of class 3. It was refashioned as a pret.-pres. verb in $\mathrm{ON}$ in large part because of the formal identity of some inflectional forms to those of man: see Birkmann 1987: 243-8. Note that it shows no ablaut alternation, betraying its origin as a weak verb. Go. pp. skulds has the meaning 'owing, lawful', and OIcel. skyldr (with umlaut!) 'obliged, due'. Infinitives for man occur in Go. (ga-munan), OIcel., and OE; and for skal in OIcel. (skulu, a pret. inf. in form, §12.30), OE, and OHG. OIcel. mun has the inf. munu. ${ }^{2}$

CLass V

Go. OIcel.

OE OS

OHG

$\begin{array}{ll}\text { Pres. } 2 \text { sg. } & \text { knátt } \\ \text { Pres. } 3 \text { sg. } & \text { kná } \\ \text { Pres. } 3 \text { pl. } & \text { knegu } \\ \text { Pret. } 3 \text { sg. } & \text { knátti } \\ \text { Pass. part. } & \end{array}$

$\begin{array}{llllll}\text { Pres. } 2 \text { sg. } & \text { magt } & \text { mátt } & \text { meaht } & \text { maht } & \text { maht } \\ \text { Pres. } 3 \text { sg. } & \text { mag } & \text { má } & \text { mæg } & \text { mag, mah } & \text { mag } \\ \text { Pres. } 3 \text { pl. } & \text { magun } & \text { megu } & \text { magon } & \text { mugun } & \text { magun, mugun } \\ \text { Pret. } 3 \text { sg. } & \text { mahta } & \text { mátti } & \text { meahte } & \text { mahta } & \text { mahta }\end{array}$

OIcel. kná, not pret.-pres. in origin and chiefly poetic, is cognate with $\mathrm{OE}$ cnāwan (see $\S 12.22$ on the verba pura), and its paradigm is constructed by analogy to $m a^{3}{ }^{3}$ There occurs an inf. knáttu, pret. in form (\$12.30). Although mag was certainly perceived to be of this class (to judge by the rise of the analogical stem mug- in various NWGmc. languages, §12.52), in origin it cannot have resembled strong verbs of class V: cf., e.g., Gk. $\mu \hat{\eta} \chi o \varsigma$, Doric $\mu \hat{\alpha} \chi o \varsigma$ 'means, enablement', pointing to a PIE root * $m h_{n} g h$, suggesting class VI or VII. ${ }^{4}$ Infinitives to mag occur in OIcel. (mega, pres. in form), OE, and OHG (magan, mugan). On variation and development in forms of mag and cognates, see $\S 12.52$. 


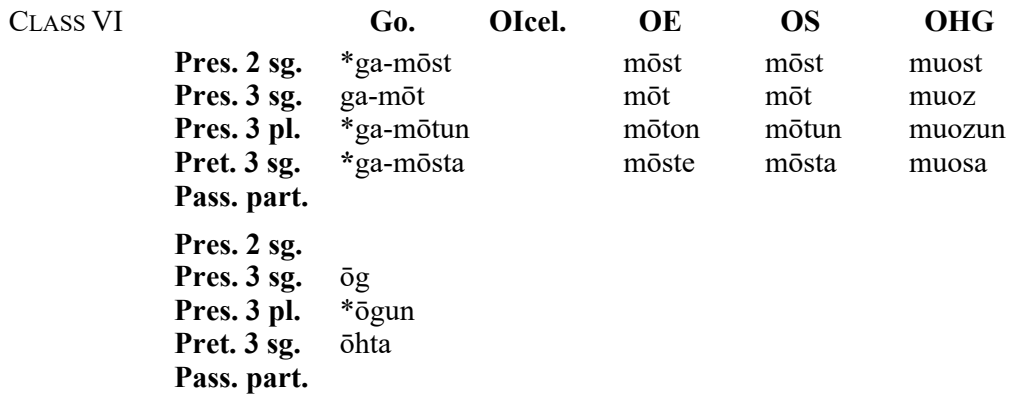

Go. pret. 3 sg. *ga-mōsta may be safely assumed on the basis of pl. mōstēdun (Mark 2:2). No inf. occurs. To Go. $\bar{g} g$ there occurs 2 sg. imp. $\bar{g} g s$ (in negated ni oggs pus) of disputed etymology, though it probably reflects a short-vowel sj. (or injunctive) PIE *agh-e-s. ${ }^{5}$ As the present system of these verbs is preterite in origin, they have no etymological imperatives, for which subjunctives are generally used. Weak grade of the root of $\bar{o} g$ appears in the negated part. un-agands 'fearless' (cf. pres. part. ogands), probably attesting not to an old ablaut alternation but to a secondary formation: cf., e.g., agis 'fright' and agjan 'frighten', and see Jacobsohn 1913: $342 \mathrm{n}$. 1. The verb does not occur in pret.-pres. conjugation outside of Go.; cf. the weak verbs OIcel. óask 'be afraid', ceja 'frighten', OE on-ēgan, on-ēgnan 'fear'.

Class VII

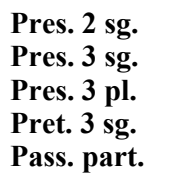

Go. OIcel.

$$
\text { átt }
$$

áih

áigun

áihta

$$
\text { á }
$$

eigu āgon

átti āhte

áttr

\begin{tabular}{lll}
\multicolumn{1}{l}{ OE } & OS & OHG \\
āhst & & \\
āh & & \\
āgon & ègun & eigun \\
āhte & êhta & \\
& &
\end{tabular}

Although $2 \mathrm{sg}$. OE $\bar{a} h s t$ is usual, there occurs an archaic $\bar{a} h t$ in Northumbrian and Early WS. Infinitives occur in Go. (fair-áihan), OIcel., OE, and OS. The original pp. OIcel. eigin '(one's) own' (indeclinable; OE āgen, OS ègan, OHG eigan) is entirely adjectival. This verb is often reckoned among those of class I, but since all other pret.-pres. verbs in classes I-IV show the expected ablaut alternation between pres. sg. \& pl., it seems likelier that it is comparable to Go. háitan 'call' and thus belongs to class VII, in which no ablaut distinction is to be expected between sg. and plural. Birkmann (1987: 74-8) reviews the arguments that have been adduced and concludes that derivation from class I is more persuasive because alternations under Verner's law are not to be expected in class VII, ${ }^{6}$ but Antonsen (1992: 97) responds that such alternations are well attested in class VII in the opposition between infs. *fayxana ${ }^{n}$ 'take', *xayxana ${ }^{n}$ 'hang' and pass. parts. *fayganaz, *xayganaz. There in fact appear to have been multiple patterns of variation under Verner's law in class VII (see §12.17), and so the evidence of Verner's law provides no reliable basis for determining the original class of this verb. Many expected forms of this verb in OS and OHG are unattested because instead are used forms of OS hebbian, OHG habèn 'have'.

1. David Fertig kindly advises that OS and OHG pret. forms like konsta, -onsta, -monsta raise doubts about this explanation, the analogical extension then being, in at least some cases, that of a stem alternation, whereby a stem-final $s$ is added before a $t$-initial suffix, on the model of (OHG) gi-tar '(I) dare', 2 sg. gi-tarst, pret. gi-torsta. 
2. The OIcel. infs. skulu, munu, and rare megu (usually mega) have $-u$ (rather than $-a$ ) due to the homomorphy of inf. and 3 pl. pres. ind. in most verbs. This is the origin of the ending $-u$ of ON pret. infinitives $(\S 12.30)$.

3. So, e.g., Noreen 1970: $§ 525$ Anm. 2, Seebold 1970: 302. This is so even though kná appears to reflect a more original stem than kunna (Eichman 1973). In one sense it should be unsurprising that a new pret.-pres. verb meaning 'know (how)' should have arisen in ON, as the PIE root with this meaning had already produced the pret.-pres. verb Go. kann and cognates. A new verb meaning 'know (how)' arose in conjunction with the restriction of ON kunna in meaning to 'know' in the sense 'have knowledge of'.

4. Bammesberger (1986a: 73) supposes rather that mag did originally belong to class $\mathrm{V}$, and that the root is to be reconstructed * $m \hat{g} h$, of which the reduced grade *mgh - produced a PGmc. *muz-reflected chiefly in OS and $\mathrm{OHG}$, and $e$-grade *megh $h$ - produced OIcel. pres. 3 pl. $m e g u$ and similar OIcel. forms.

5. So, e.g., Bammesberger 1986c, with an overview of the literature; see also Euler 1992: 24. To the argument of Jasanoff (2003: 35; not 2004) that $\overline{o g s}$ reflects a PIE pluperfect, cf. Ringe 2017: $292 \mathrm{n} .18$.

6. Go. $1 \& 3 \mathrm{sg}$. áih $(7 \times$, beside analogical áig $1 \times)$ does not prove the matter, since there is devoicing of final fricatives in Go. (\$6.12), but OIcel. $a$ is probative, as *-aih by devoicing in *-aiz produces $-\dot{e}$ rather than $-a ́$, as in sté, the more archaic form of the pret. of stiga 'step'. Cf. also Go. inf. fair-áihan.

\subsection{Historical development}

The example usually cited to illustrate how these verbs acquired present meaning is Go. wáit $=$ Skt. vếda, Gk. oî̉ $\delta \varepsilon$ 'knows' < PIE *uoidde, an unreduplicated perfect to the weakgrade stem seen in Lat. video 'see'. Since the perfect is probably stative in origin $(\S 12.5)$, and these verbs are stative in meaning, they appear to preserve an archaic state of affairs; yet even if some are Gmc. innovations, given that the perfect designates past events which are relevant to a present state ("has dreaded"), it is plain enough how the present element of its semantics should in such instances have come to dominate ("is afraid"). In actuality, wáit is the only one of these verbs in which the rationale for the word's semantic development is pellucid, though it is perhaps not too difficult to see how the sense 'have thought (and still think)' should result in 'remember' (Go. ga-man,

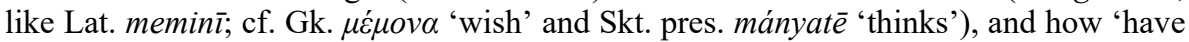
come under obligation' (cf. Old Lith. skelù 'am culpable') should result in 'shall'. These examples illustrate that the category is an ancient one, with parallel perfects in nonGermanic languages to which no present is formed, and yet the considerable majority of the Gmc. verbs have no IE parallels to pret.-pres. usage, e.g. Go. kunnan in comparison to Skt. jānắti 'knows', Gk. $\gamma \imath \gamma v \omega ́ \sigma \kappa \omega$, Lat. nōscō. Most, accordingly, appear to be Gmc. innovations. ${ }^{1}$ Go. wáit and its cognates show with particular clarity that this is an ancient category of verb, given the lack of reduplication across IE languages; but although this verb has sometimes been thought to demonstrate a more archaic perfect construction, formed before reduplication became obligatory (so, e.g., Prokosch 1939: §65), instead it seems likelier that the lack of reduplication is an innovation: see Szemerényi 1996: §9.4.3, Jasanoff 2003: $228-33 .^{2}$ One particularly interesting sign of the category's antiquity is that the pres. pl. of verbs resembling those of strong class IV has the vowel $u$ that etymology suggests should have been original, whereas strong verbs have the reflex of PGmc. $\bar{e}_{1}$ in the pret. pl.: see $\S 12.14$.

As with the verbs of weak class I lacking $*_{-i}$ - in the preterite $(\S 12.37)$, most pret.-pres. verbs form the preterite with PGmc. ${ }^{*} b<\mathrm{PIE} * t$ attached directly to the stem of the pres. (originally pret.) plural, without any connecting vowel, though in Go. skal and man the dental suffix in the preterite reflects PGmc. $* \partial$, the expected form under Verner's law if the dental suffix in this class of verbs originated in the PIE verbal adj. 
suffix *-tó-, given its accentuation: see $\S 12.33$ for discussion and a possible explanation for the voiceless variant, pertaining to the development of the original pass. participles to common adjectives and their replacement in North and West Germanic. The PGmc. dental suffix $*_{-}-p$ - (or earlier $\left.*_{-} t-\right)^{3}$ underwent further development in the consonant clusters that arose from its affixation, as follows. The regular development of *-tt- $(\S 6.8)$ is seen in Go. pret. wissa < PIE *uid-t-. In WGmc. there also occur pret. forms in which the dental suffix has been analogically reintroduced, e.g. OE wiste, OHG wista. Similarly in regard to the verb ga-mōt, OHG muosa $<$ NWGmc. ${ }^{*} m \bar{o} s s \bar{x}$ appears to reflect the original situation in the pret. $\left({ }^{*} m \bar{o} t-t-\right)$, whereas the other languages have analogically re-added the dental suffix, e.g. Go. mōstêdun. After a fricative the voiceless dental suffix appeared as $t$ and caused devoicing, if applicable, e.g. Go. ga-daúrsta and paúrfta $<*$ burb-t-. In Ingvaeonic there was loss of $* n$ before $* b$ with compensatory lengthening (§4.11) in, e.g., OE cūðe, ūðe <*kunp-, unp-. By contrast, ON shows assimilation in the pret. stems *kunp-, *unp-> kunn-, unn- (\$6.14).

Go. 2 sg. pres. ind. wáist is perhaps for *wáis $<$ PGmc. ${ }^{*}$ waiss $<*$ wait- $t<\mathrm{PIE}$ *uoid-th $e$, with re-addition of the $2 \mathrm{sg}$. pret. inflection $-t$ (but see $\$ 12.53$ in reference to Sihler 1986). In OIcel., root-final $-t$ - is re-added, as well, giving veizt (where $z t=/$ tst/). The normal reflex of the PIE 2 sg. perfect ind. inflection *-th 2 e would be - $p$ (but see $\S 12.25 \mathrm{n}$. 1 on this), but in fricative clusters $-t$ should be expected, and in Go. and ON this $-t$ has been extended analogically to stems that should have had $-b$, hence, e.g., Go. kant, skalt, ON annt, mant. The inflection is otherwise well preserved in Go. and ON, whereas in WGmc. it is found in some pret.-pres. verbs, but not all, replaced by the present inflection -st (on which see $\S 12.24$ ). ${ }^{4}$ This is an unsurprising development, given that $2 \mathrm{sg}$. $-t$ was not used in WGmc. preterites, but rather an inflection that is dubitably aorist in origin $(\$ 12.23)$, and the process was no doubt aided by forms like WGmc. *waist, *mōst, which either are etymological (again, see §12.53) or already in PGmc. had facultative analogical readdition of $*_{-} t$ to stems in $*_{-s}<*_{-s s}<*_{-t-t}$.

Since the pres. paradigm is formally preterite, and in view of the Go. endings, umlaut should be expected in the pres. sj. in North and West Gmc. It has been almost entirely removed, doubtless by analogy to strong verbs, which have no umlaut in the pres. sj., but a few relics occur, e.g. OE dyge, pyrfe (beside duge, purfe), and scyle is the usual form (beside rare scule); and the pres. sj. stem meg- is preserved in OIcel. and extended to the indicative. Etymologically there should be no umlaut in the pret. of these verbs, where the dental suffix was added to the stem without any intervening $*_{-i}$-, but again by analogy to other verbs, umlaut has been induced in OIcel. preterites.

As there was no perfect imperative in PIE, these verbs have no etymological imperative. In Go., as explained above, imp. $\overline{o g s}$ is probably sj. (opt.) in origin. In OIcel., new imperatives have been created, using the bare stem of the pres. pl. in the 2 sg., by analogy to other verbs (e.g., vit, eig), though the semantics of some prohibit imperative formation (parf, mun, má, kná). In WGmc. the sj. is generally used for the imp., though occasionally imperatives of the OIcel. type are found in Northumbrian, e.g. ge-wit 'know'.

Preterites like OHG onda, konda show $o$ for * $u$ as a result of analogy to other preterites in this class such as tohta, gi-torsta, dorfta, skolta; OS preterites like gi-onsta, konsta, for-monsta show the same influence, and they make the analogical nature of the change especially plain, transferring not only the vowel but also the stem-final $s$ from gi-dorsta (with support from mōsta; but see $\$ 12.53$ n. 1). 
1. This explanation is disputed by T. Tanaka (2011: 65-89), who regards Gmc. pret.-pres. verbs as uniformly archaic rather than (many of them) Gmc. innovations, with several members of the class no longer preserved in the recorded languages. Cf. R.I. Kim 2012. Tanaka provides a summary of alternative hypotheses (2011: 92-105).

2. To the contrary, Randall \& Jones (2015) would derive these verbs from a separate category in PIE, one of aorist roots to which stative inflections were added, so that they never showed reduplication.

3. It seems likely that at least some of the changes described here antedate the First Consonant Shift; alternatively, PIE $* t$ remained unshifted in the relevant consonant clusters.

4. $2 \mathrm{sg}$. $-t$ originally remained after a fricative or $-l-$, but not $-n-$. But archaic OE $\bar{a} h t$ gave way to $\bar{a} h s t$, and the obscuration of the original regularity in regard to $-h$ - perhaps contributed to the LWS replacement of meaht by miht.

\section{Athematic verbs}

\subsection{Inventory}

As noted above (\$12.9), athematic verbs were generally thematized in Gmc., but a small number of exceptions persist, due to frequency of use. Since the PIE inflections of thematic and athematic verbs were otherwise identical, the plainest indication of preserved athematic conjugation in Gmc. is $1 \mathrm{sg}$. pres. ind. in $-m<$ PIE $*_{-} m i$ (vs. thematic ${ }^{*}-\bar{o}$ ) though $-m$ is not an infallible diagnostic, as it may in some instances be an innovation, e.g., perhaps in OHG verbs of weak class 2. For this reason verbs of this type are sometimes referred to (as in Greek grammar) as $m i$-verbs, but also sometimes as anomalous verbs. Despite its antiquity, Go. preserves the fewest signs of athematic inflection, and WGmc. the greatest number of relevant verbs: 'be' and 'will' show traces of athematic inflection in all the Gmc. languages; 'do' and 'go' in all the WGmc. languages; and 'stand' in OS and OHG.

\subsection{The verb 'be'}

The present and preterite paradigms are based on unrelated PIE roots; the root *us in the latter also may occur in the inf., the pres. part., and the imp., and in no instance did it form an athematic verb, but only the root ${ }^{*} h_{1} s$ in the present did so. In WGmc. there is a future/consuetudinal stem (with no separate preterite) based on a third root, though the distinction between present and future/consuetudinal meaning is maintained only in OE:

\begin{tabular}{|c|c|c|c|c|c|c|c|}
\hline \multirow{8}{*}{ Pres. Ind. } & & Go. & OIcel. & OE & OS & OHG & PIE \\
\hline & $1 \mathrm{sg}$. & $\mathrm{im}$ & & eom & bium & bim, bin & $-m i$ \\
\hline & $2 \mathrm{sg}$. & is & & eart & bist & bist & $* h_{1}$ és-si \\
\hline & $3 \mathrm{sg}$. & ist & es, er & is & is, ist & ist & *hés-ti \\
\hline & $1 \mathrm{du}$. & $\begin{array}{l}\text { siju } \\
\text { sijuts }\end{array}$ & & & & & \\
\hline & 1 pl. & sijum & erum & sind(on) & sind(un) & $\operatorname{biru}(\mathrm{m})$ & $* h_{1} \mathrm{~s}$-més \\
\hline & 2 pl. & sijup & eruð & sind(on) & sind(un) & birut & $* \mathrm{~h}_{1} \mathrm{~s}$-té \\
\hline & 3 pl. & sind & eru & sind(on) & sind(un) & $\operatorname{sint}$ & ${ }^{*} \mathrm{~h}_{1} \mathrm{~s}$-énti \\
\hline
\end{tabular}




\begin{tabular}{|c|c|c|c|c|c|c|c|}
\hline Fut. Ind. & $\begin{array}{l}1 \text { sg. } \\
2 \text { sg. } \\
3 \text { sg. } \\
1 \text { pl. } \\
2 \text { pl. } \\
3 \text { pl. }\end{array}$ & Go. & OIcel. & $\begin{array}{l}\text { OE } \\
\text { bēo } \\
\text { bist } \\
\text { bið } \\
\text { bēoð } \\
\text { bēoð } \\
\text { bēoð }\end{array}$ & OS & OHG & PIE \\
\hline Pres. Sj. & $\begin{array}{l}1 \text { sg. } \\
2 \text { sg. } \\
3 \text { sg. } \\
1 \text { du. } \\
2 \text { du. } \\
1 \text { pl. } \\
2 \text { pl. } \\
3 \text { pl. }\end{array}$ & $\begin{array}{l}\text { sijáu } \\
\text { sijáis } \\
\text { sijái } \\
\text { sijáiwa } \\
\text { sijáits } \\
\text { sijáima } \\
\text { sijáip } \\
\text { sijáina }\end{array}$ & $\begin{array}{l}\text { sém } \\
\text { séð } \\
\text { sé }\end{array}$ & $\begin{array}{l}\text { sie, bēo } \\
\text { sie, bēo } \\
\text { sie, bēo } \\
\\
\text { sien, bēon } \\
\text { sien, bēon } \\
\text { sien, bēon }\end{array}$ & $\begin{array}{l}\sin \\
\sin \\
\sin \end{array}$ & $\begin{array}{l}\mathrm{sī} \\
\operatorname{sīs}(t) \\
s \overline{1} \\
\\
\operatorname{sīm} \\
\operatorname{sìt} \\
\sin \end{array}$ & $\begin{array}{l}{ }^{*} h_{1} \mathrm{~s}-i e ́ h_{1}-\mathrm{m} \\
{ }^{*} \mathrm{~h}_{1} \mathrm{~s}-\mathrm{ié} \mathrm{h}_{1}-\mathrm{s} \\
{ }^{*} \mathrm{~h}_{1} \mathrm{~s}-\mathrm{iéh} \mathrm{h}_{1}-\mathrm{t} \\
\\
{ }^{*} \mathrm{~h}_{1} \mathrm{~s}-\mathrm{ih} \mathrm{h}_{1} \text {-mé } \\
{ }^{*} \mathrm{~h}_{1} \mathrm{~s}-\mathrm{ih} \mathrm{h}_{1} \text {-té } \\
{ }^{*} \mathrm{~h}_{1} \mathrm{~s}-\mathrm{ih} \mathrm{h}_{1} \text {-ént }\end{array}$ \\
\hline Imp. & $\begin{array}{l}2 \mathrm{sg} . \\
2 \mathrm{pl} .\end{array}$ & & $\begin{array}{l}\text { ver } \\
\text { verið }\end{array}$ & $\begin{array}{l}\text { bēo, wes } \\
\text { bēoð, wesað }\end{array}$ & $\begin{array}{l}\text { wis, wes } \\
\text { wesad }\end{array}$ & $\begin{array}{l}\text { wis } \\
\text { weset }\end{array}$ & \\
\hline Pret. Ind. & $\begin{array}{l}1 \mathrm{sg} . \\
2 \mathrm{sg} . \\
3 \mathrm{sg} . \\
1 \mathrm{du} . \\
2 \mathrm{du} . \\
1 \mathrm{pl} . \\
2 \mathrm{pl} . \\
3 \mathrm{pl} .\end{array}$ & $\begin{array}{l}\text { was } \\
\text { wast } \\
\text { was } \\
\text { wēsu } \\
\text { wēsuts } \\
\text { wēsum } \\
\text { wēsup } \\
\text { wēsun }\end{array}$ & $\begin{array}{l}\text { várum } \\
\text { váruð } \\
\text { váru }\end{array}$ & $\begin{array}{l}\text { wǣron } \\
\text { wæ̋ron } \\
\text { wæron }\end{array}$ & $\begin{array}{l}\text { was } \\
\text { wāri } \\
\text { was } \\
\\
\text { wārun } \\
\text { wārun } \\
\text { wārun }\end{array}$ & $\begin{array}{l}\text { was } \\
\text { wāri } \\
\text { was } \\
\text { wārum } \\
\text { wārut } \\
\text { wārun }\end{array}$ & 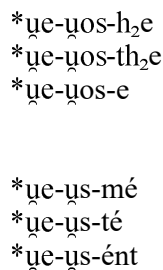 \\
\hline Pret. Sj. & $\begin{array}{l}1 \text { sg. } \\
2 \text { sg. } \\
3 \text { sg. } \\
1 \text { du. } \\
2 \text { du. } \\
1 \text { pl. } \\
2 \text { pl. } \\
3 \text { pl. }\end{array}$ & $\begin{array}{l}\text { wēsjáu } \\
\text { wēseis } \\
\text { wēsi } \\
\text { wēseiwa } \\
\text { wēseits } \\
\text { wēseima } \\
\text { wēseip } \\
\text { wēseina }\end{array}$ & $\begin{array}{l}\text { væra } \\
\text { værir } \\
\text { væri }\end{array}$ & $\begin{array}{l}\text { wǣre } \\
\text { wǣre } \\
\text { wǣre } \\
\\
\text { wǣren } \\
\text { wǣren } \\
\text { wǣren }\end{array}$ & $\begin{array}{l}\text { wāri } \\
\text { wāris } \\
\text { wāri }\end{array}$ & $\begin{array}{l}\text { wāri } \\
\text { wārīs } \\
\text { wāri } \\
\\
\text { wārīm } \\
\text { wārīt } \\
\text { wārīn }\end{array}$ & \\
\hline $\begin{array}{l}\text { Inf. } \\
\text { Pres. Part. } \\
\text { Pass. Part. }\end{array}$ & & $\begin{array}{l}\text { wisan } \\
\text { wisands }\end{array}$ & vera & $\begin{array}{l}\text { bēon, wesan } \\
\text { bēonde, } \\
\text { wesende } \\
\text { gebēon }\end{array}$ & $\begin{array}{l}\text { wesan } \\
\text { wesandi }\end{array}$ & $\begin{array}{l}\text { wesan } \\
\text { wesanti }\end{array}$ & \\
\hline
\end{tabular}

OIcel. es is an early form, replaced starting in the $13^{\text {th }}$ cent. by $e r$. The handbooks assert a $2 \mathrm{sg}$. form est that underwent the same development as es > er, but Crawford (2012) finds that est does not occur in OIcel., and that it is probably not an OWN form. ${ }^{1}$ The distinction between the pres. sj. and the future/consuetudinal sj. in $\mathrm{OE}$ is purely formal: no distinction in temporal or aspectual meaning is detectable; likewise for the imperative and non-finite forms. To WS eom correspond Mercian and Kentish eam, Northumbrian am; to WS eart correspond Mercian earð and Northumbrian arð; beside sind(on), sindun occur Anglian earon, arun. OE OS sind is commonly sint as a result of final devoicing under low stress. There occurs once OS 3 sg. pres. sj. wese. The stem wesalso appears occasionally in the pres. ind. and sj. in OHG, but it more usually has the specific meaning 'exist' or 'occur'. 
1. OIcel. ert is usually explained as having $r$ by analogy to er, but Crawford sees it as cognate with OE eart, with analogical replacement of the vowel by the $e$ found in the remainder of the OIcel. paradigm.

\subsection{Historical development of 'be'}

Many questions about the development of this verb remain unsettled. The pres. forms (excluding those in $b$-) derive from the PIE root $* h_{h} s$, which, as normal in athematic verbs, appears in the full grade in the ind. sg. $\left({ }^{*} h_{l} e ́ s-\right.$, hence $3 \mathrm{sg} .{ }^{*} h_{l} e ́ s-t i>$ Skt. ásti, Gk. $\dot{\varepsilon} \sigma \tau i$, Lat. est, Lith. est $)$ and zero grade elsewhere $\left({ }^{*} h_{s} s-\right.$, hence $3 \mathrm{pl} .{ }^{*} h_{s} s-\dot{e} n t i>$ Skt. sánti; cf. Doric Gk. évtí, Lat. sunt). These forms develop regularly in the Go. 1-3 sg. and 3 pl., ${ }^{1}$ the 1 and $2 \mathrm{pl}$. have adopted the onset si- from the $3 \mathrm{pl}$. and added the normal endings of pret.-pres. verbs, so that -j- merely fills the intervening hiatus (so, e.g., Krahe \& Meid 1969: II, §98); alternatively, sij- here may be borrowed from the sj. (so, e.g., Prokosch 1939: §75a), or the change may be attributed to the combined force of the 3 pl. and the sj. to suggest a stem $s i(j)$-. Whatever the source of the new forms, the change was well motivated, since PIE $1 \mathrm{pl} . h_{1} s$-més $>$ PGmc. ${ }^{*}$ smes and $2 \mathrm{pl}$. PIE $h_{1} s$-té $>$ PGmc. *ste would have seemed entirely anomalous within the paradigm; they are in fact eliminated in all the Gmc. languages, though not in uniform fashion. Go. 3 pl. sind is for expected $* \sin p<\mathrm{PIE} *$ sénti. It may be that the accent shifted, giving PGmc. *sinpi $>$ *sinði under Verner's law (so Prokosch 1939: §75a), but it seems likelier that the voicing arose under the low stress that this verb usually received (so Brugmann in Brugmann \& Delbrück 1897-1916: II, 3.2.635, and Bennett 1972: 109), though Brugmann also suggests the possibility of analogy to forms like Go. 3 pl. báirand.

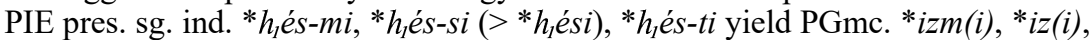
$* i s t(i)>*_{i m}(m), *_{i z}, *_{i s t}$, with early loss of $*_{-i}$ and voicing of $s$ to $z$ in the $1 \& 2 \mathrm{sg}$. because of low stress on the verb. Probably already in PGmc. (Ringe \& Taylor 2014: 518) the vowel of the sg. was extended to the pl., and the normal inflections of pret.pres. verbs supplied, resulting in $*_{i z u m} *_{i z u p}, *_{i z u n} .^{2}$ In NGmc., with the development of $*_{z}$ to $*_{R}$ and the lowering of $*_{i}$ before this (§4.9), the plural develops regularly. In the sg., ${ }^{*} i$ - is replaced by ${ }^{*} e$ - in Proto-Norse, probably a paradigm regularization on the basis of the plural (so, e.g., Prokosch 1939: §75a; Heusler 1967: §335; Noreen 1970: $\$ 532$ Anm. 1), and $2 \& 3$ sg. es is the usual form until ca. 1200, when it begins to be replaced by $e r$, doubtless again under the influence of the plural. The analogical replacement of Proto-Norse $3 \mathrm{sg}$. *ist (Runic ist, Vetteland Stone, mid- $4^{\text {th }}$ century) involves the elimination of $*_{-} t$ because of the influence of pret.-pres. inflections, in which $*_{-} t$ should be the inflection instead of the 2 singular. In the pret. pl., the stem vóru(-) (later and normalized váru(-)) changed to vóru(-) by combinative back mutation (\$4.8), and vwas then lost before $o$ (\$6.14), giving óru(-), a form required by the alliteration in some early poetry; but $o ́ r$ - was also replaced by vór- (> vár-), with $v$ - by analogy to the rest of the pret. paradigm and $g$ by analogy to other verbs of the fifth class (and the fourth), and this came to be the standard form of the stem.

The OE forms present a number of mysteries. Prokosch (1939: §75a) and many others suppose that WS eom developed by analogy to fut. bèo (Anglian biom), and Brunner (1965: §427) and Krahe \& Meid (1969: II, §98) even assume a long diphthong in the former, hence WS êom, though Middle English spellings never suggest a long vocoid, and the parallel between this supposed éom and bēo is hardly striking (there is no WS †bēom); moreover, metrical evidence tells against $\dagger \bar{e} \bar{e}$. $^{3}$ The ending on $2 \mathrm{sg}$. 
Mercian ear $\delta$, Northumbrian $\operatorname{ar} \delta$, would be the only instance in Gmc. of the regular development of PIE $*_{-}-t h_{2} e$ to the pret.(-pres.) ending *- $b$ (rather than the attested -t: see $\S 12.25)$, but it may be that it is due instead to reanalysis with an enclitic pronoun, *ar $b \bar{u}$ (so Lühr 1984: 37, though certainly WS eart must bear the pret.-pres. inflection). More perplexing is the vocalism of these forms, which derives from $* a$, a vowel that ought not to have appeared anywhere in the PGmc. paradigm. The commonest explanation is that the stem of this form (as well as Old Swedish aru 'are') reflects PIE $* h_{3}$ er-, as in Lat. orior 'arise', Gk. ó $\rho v \bar{v} \mu l$ 'arouse', formed as a Gmc. pret.-pres. verb of the class IV type, hence with PIE *or- in the pres. ${ }^{4}$ The replacement of PGmc. $3 \mathrm{sg} .{ }^{*}$ ist by is in OE (and OS) is perhaps best explained as above - that is, as due to the pervasive influence of pret.-pres. inflection on this verb, since the $3 \mathrm{sg}$. pres. in that class bears no inflection, and $-t$ would no doubt have been perceived as the inflection proper to the 2 sg. - a change perhaps abetted by sandhi environments in which *ist appeared before a word with an initial dental consonant. In the plural, as usual in Ingvaeonic, the original form of the third person has been extended throughout. ${ }^{5}$ Here -on may be added to sind by analogy to pret.-pres. verbs (though Shields 1984 argues that -on is an archaism; cf. Whitehead 1990-1). Anglian earon, arun must have its vocalism from the same source as the $2 \mathrm{sg}$. (as well as $1 \mathrm{sg}$. non-WS (e)am). Note, however, that the $2 \mathrm{sg}$. stem agrees with the plural stem, which is characteristic of WGmc. strong preterites but not of pret.pres. verbs.

The OE future and consuetudinal forms develop from the root seen in Skt. bhávati 'is, exists' (also supplying forms of 'be' in Italic, Celtic, and Balto-Slavic), which takes the form PIE *bhu-ii- (a perfective present), hence *bhu-ii-o $>$ WS beo $($ Anglian bīom $)=$ Lat. fìo 'shall be', OIr. biuu 'am accustomed to being' ${ }^{6}{ }^{6}$ Inf. bēon may be disyllabic in verse, probably with a heavy initial syllable; ${ }^{7}$ hence, Anglian bion (WS bēon $)=b \bar{i}$-on. In $2 \& 3 \mathrm{sg}$. WGmc. ${ }^{*} b i j-i s t,{ }^{8} * b i j-i b$, intervocalic $j$ was lost, producing, under the low stress usually borne by this verb, the same result as in the $2 \& 3 \mathrm{sg}$. pres. ind. of weak verbs of class 1 with an originally heavy stem (\$12.38), hence *biist, *biip $>{ }^{*} b i s t,{ }^{*} b i \bar{p}$, followed by shortening. Thematic WS bēo is no doubt a regularization of the athematic $1 \mathrm{sg}$. found elsewhere in WGmc., e.g. Anglian biom $<*$ b̆ $(j) u m<$ PIE *bhu-ii-m.

OS and OHG show a present paradigm mixing pres. and future/consuetudinal stems, without any distinction in meaning. ${ }^{9}$ There is similar mixture of paradigms in OFris. and Old Low Franconian. OHG $1 \mathrm{sg}$. bim is best explained as the reflex of PGmc. *ezm $>* i m$ under low stress, with addition of the future/consuetudinal $b$-. OS 1 sg. bium may show the same development, assuming original OS *ium $=\mathrm{WS}$ eom, or (perhaps more likely) bium = Anglian biom. The OHG $1 \& 2$ pl. are usually assumed to be formed the same way as the 1 sg., i.e. by the addition of $b$ - to assumed WGmc. $1 \mathrm{pl}$. *izum, 2 pl. *izup, comparable to the corresponding ON forms: so, e.g., Lühr 1984: 2930. There is, however, no evidence for such forms in WGmc. ${ }^{10}$

The PIE optative forms given in the paradigm should have produced a PGmc. sj. sg. stem $*^{*}(j) \bar{e}-, 1 \& 2 \mathrm{pl} . *^{*} \bar{l}$ - (i.e. before a consonant), $3 \mathrm{pl} .{ }^{*} s i(j)$ - (before a vowel). In Go. the last of these was extended throughout the paradigm and the pres. sj. inflections of strong verbs added to this. In OIcel., by contrast, the sg. forms may all be regarded as the expected developments of the PGmc. forms (assuming voicing of $*_{-s}$ in the clitic 2 sg.), and this stem was then extended to the plural. OE $\operatorname{sie}(n)^{11}$ is frequently disyllabic in poetry, where the meter never requires a heavy initial syllable (Fulk 1992: §115), and so it would appear that OE has generalized the stem *si- (abstracted from the $3 \mathrm{pl}$.) and added to this the normal pres. sj. inflections $3 \mathrm{sg} .{ }^{*}-a i(\delta)>-e$ and $3 \mathrm{pl} .{ }^{*}$-ain $(\partial)>-e n$. 
In that event it is probably safest to assume that the OS and OHG forms are the result of contraction of $* s i$ - with the normal sj. inflections.

PIE * es-, being a copula, had no imperative forms. In Go., sj. forms are used for the imperative of the verb 'be', whereas the other Gmc. languages have created imp. forms from the future/conditional stem $* b \bar{i}$ - and/or the pres. stem $*$ wes-corresponding to pret. *was- $*$ wēz-.

PIE * $h_{1} e s-$ apparently had no perfect stem; various preterites are formed to it in the individual IE languages. It forms its pret. in Gmc. from the verb *wesana ${ }^{n}$, a verb of class $\mathrm{V}$, hence with pret. sg. in $*_{-} a$ - (with loss of the reduplicative syllable) and $*_{-} \bar{e}_{1^{-}}$in the dual, the plural (and the $2 \mathrm{sg}$. in WGmc.), and throughout the subjunctive. The attested forms are entirely in line with those to be expected of a class $\mathrm{V}$ preterite. It is striking that whereas the pret.-pres. verbs that align with class $\mathrm{V}$ show the $-u$ - expected in the pres. (originally pret.) plural on an etymological basis, the verb 'be' has the reflex of PGmc. ${ }^{*}-\bar{e}_{1}-$ of mysterious origin that characterizes verbs of class $\mathrm{V}$, suggesting that the Gmc. pret. of 'be' was not formed in the earliest stratum of PGmc., as perhaps implied also by the regularity of the pret. paradigm of a verb as common as this.

None of the non-finite forms in the paradigms given above is to the PIE root $* h_{l} s$, and thus all are transparent Gmc. derivatives of the future/consuetudinal and class $\mathrm{V}$ stems. An original PIE pres. part. ${ }^{*} h_{1} s-o n t-$, however, is probably the basis for PGmc. *sanp-> OIcel. sannr, OE sōð 'true'. ${ }^{12}$

1. Assume PIE *hés-mi $>$ PGmc. ${ }^{*} e z m(i)>* e m(m)$ and $* h_{l} h^{e} s-s i>* e s(i)$. These are stressed forms; see below on unstressed *im(m), *iz.

2. Rather, Lühr (2016: 243) supposes that *-u- originated in the $1 \mathrm{pl}$., in a variant $*_{\text {-umez }}<*_{\text {-mós }}$ (her notation; but Verner's law!) comparable to *sii- beside *si-.

3. Since beeon (Anglian bìon) may be disyllabic in verse, with a heavy initial syllable, as remarked below, if eom were the result of analogy to bēom it should be expected likewise to scan this way, but it does not: cf., e.g., $n \bar{u}$ ic pus féasceaft eom (Genesis A 2176b), where è-om would be unmetrical.

4. So, e.g., Prokosch 1939: §75a and Bammesberger 1986a: 120-1. Lühr (2016: 245-7) mentions and dismisses the possibility of Scandinavian influence, offering instead several indecisive phonological explanations.

5. It is tempting to think that this verb played a significant role in promoting this change, given the difficulties posed by the original $1 \& 2 \mathrm{pl}$. forms, as pointed out above - an idea supported as well by the replacement of the $1 \& 2 \mathrm{pl}$. with forms from the original future/consuetudinal paradigm in OHG.

6. Bammesberger (1986a) assumes a similar development based on PIE *bhü- (cf., e.g., Skt. aorist $a ́ b h \bar{u} t$ to

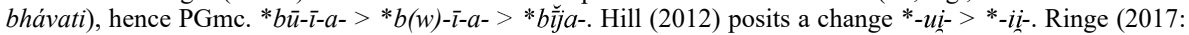
$220,293)$ reconstructs $* b h u H$ - and argues that the Gmc. forms are perfective presents.

7. Cf. drēamleas bēon (Daniel 557b), though the quantity of the first syllable of beon is ambiguous: the verse could be like sorhleas swefan (Beowulf 1672a) rather than Hröðgar lēofa (1483a).

8. It should be noted that $-t$ in OE OS OHG bist is the norm already from the time of the earliest records, whereas in strong and weak verbs the earliest texts have simple -s. Paul (1916-20: II, 192) suggests that bist is apocopated from bistu, though it is also possible that $-t$ is due to the analogical influence of pret.-pres. verbs. Rare OHG bis is explained by Braune (2004a: $\$ 379$ Anm. 1) not as an archaism but a neologism resulting from reanalysis of bistu 'you are'.

9. Lühr (2016: 244) argues that the admixture of $b$-forms originated in the 2 sg., where the addition of the pret.-pres. ending $-t$ to $* i$ w would have created a homophone of $3 \mathrm{sg}$. ist, requiring redifferentiation.

10. Another possibility is that $\mathrm{OHG} \operatorname{biru}(m)$, birut show the attachment of pret.-pres. inflections to the stem $b i$ - of the singular, with $-r$ - filling the hiatus, just as $-r$ - fills the hiatus in certain OHG verbs of class VII, e.g.

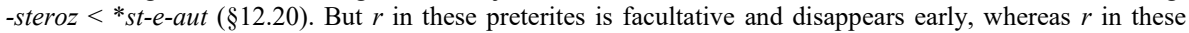
present forms is regular and persists until the thirteenth century.

11. Not $\dagger \operatorname{sige}(n)$; cf. weak verbs of class 2 in $-i(g) e n(\S 12.42)$. 
12. Bammesberger (1986a: 122) proposes a further connection to Go. sunja 'truth' and OHG suntea 'sin'.

\subsection{The verb 'will'}

The most usual attested forms of the Gmc. verb 'will' (in the original sense 'be willing, wish') are these:

\section{Go.}

Pres. Ind. 1 sg. wiljáu

2 sg. wileis

3 sg. wili

2 du. wileits

1 pl. wileima

2 pl. wileip

3 pl. wileina

Pres. Sj. 1 sg.

2 sg.

$3 \mathrm{sg}$.

1 pl.

2 pl.

3 pl.

Pret. Ind. 1 sg.

2 sg. wildēs

3 sg. wilda

1 pl. wildēdum

2 pl. wildēdup

3 pl. wildēdun

Pret. Sj. 1 sg. wildēdjáu

2 sg. wildēdeis

3 sg. wildēdi

1 pl. wildēeima

2 pl. wildēdeip

3 pl.
Inf.

Pres. Part.

Pass. Part.
OIcel.

vil

vill, vilt

vill

viljum
vilið
vilja

vilja

vilir

vili

vilim

vilið

vili

vilda

vildir

vildi

vildum

vilduð

vildu

vilda

vildir

vildi

vildim

vildið

vildi

vilja

viljandi
OE

wille

wilt

wile

willap

willap

willap

wille

wille

wille

willen

willen

willen

wolde

woldest

wolde

woldon

woldon

woldon

wolde

wolde

wolde

wolden

wolden

wolden

willan

willende
OS

williu

wili(s), wilt

wil(i), will

williad

williad

williad

willie

willies

willie

willean

willean

willean

welda

weldes

welda

weldun

weldun

weldun

weldi

weldi

weldin

weldin

weldin

willien

willeandi
OHG

willu

wili

wili

wellemēs

wellet

wellent

welle

wellēs(t)

welle

wellēm

wellēt

wellēn

wolta

woltōs

wolta

woltum

woltut

woltun

wolti

woltīs

wolti

woltīm

woltīt

woltinn

wellen

wellenti

OIcel. 1 sg. pres. ind. vilja (= Go. wiljáu) appears sometimes in poetry. As usual in OE, the 1 sg. pres. ind. may end in -o outside of WS. In Anglian, forms like walde (which may or may not coöccur with wolde) are the norm. OS has also the stem well- in the pres. and wold- in the pret. (rarely wald-), in addition to normal variation in the endings (e.g. 1 sg. pres. ind. willeo beside williu). There is a small amount of deviation from the given stems in OHG. In OE there appear some innovative imperatives, e.g. Mercian pl. willap, negated sg. nyl.

\subsection{Historical development of 'will'}

The source is the PIE root *uel(H)- reflected in Lat. volo 'wish' (with traces of athematic inflection, e.g. vult), Lith. vélmi 'wish', OCS veljo, velěti 'bid, wish', Skt. vrnnitée 
'chooses, prefers', etc. The present of this verb in Gmc. is etymologically subjunctive (PIE optative), due to polite usage: 'would like' rather than 'want'. The Go. paradigm in particular makes it plain that the pres. inflections are of the pret. sj. (\$12.27), even though the root vocalism is not that of a perfect. ${ }^{1}$ Use of the pret. sj. inflections is explicable on the basis of the observation that the pret. $\mathrm{sj}$. is associated with conditions and wishes of a particularly hypothetical nature (see, e.g., Heusler 1967: §419; Mitchell 1985: I, $\S \S 1679-81$ ), and so it may express an especial degree of politeness; but since they are attached to a present stem, it is more probable that the sj. endings are preterite because analogical to those of pret.-pres. verbs. The Go. pret. is weak and formed like the preterite of irregular verbs of weak class I (\$12.37), except that no other verb so constructed in Go. has a stem in $-l-$, as a result of which the dental suffix is always voiceless in such Go. verbs. Inf. wiljan shows that the verb has a $j$-present with PIE $e$ rather than $o$-grade of the root, like a strong verb (as should be expected on the basis of athematic inflection). Formation of the preterite of 'will' without a connecting vowel may be due to creation of the Gmc. preterite at an early date, though it could also be a late PGmc. development on the model of pret.-pres. verbs (so Krahe \& Meid 1969: II, $\S 101)$.

In OIcel. the pres. sj. forms correspond to the Go. pres. ind. ones, and a new pres. ind. paradigm has been constructed of the weak class 1 type, hence sg. $1 \mathrm{vil}, 2 \mathrm{vill}$, 3 vill, entirely parallel to 1 frem, 2 fremr, 3 fremr, etc. $(\$ 12.35){ }^{2} 2 \& 3 \mathrm{sg}$. vill $<*^{*}$ vil $l_{R}$ show assimilation under low stress (Heusler 1967: §333): cf. telr 'tell'. The OIcel. pret. likewise bears the same relation to Go. wilda, etc., that OIcel. preterites of weak class 1 bear to the corresponding Go. forms. The root vowel $-i$ - in the Go. pret. is to be expected, whereas OIcel. should have pret. ind. *velda rather than vilda, etc.; but OIcel. weak verbs of class 1 with - $i$ - in the pres. have also - $i$ - in the pret., e.g. hirða 'care for', pret. hirda. At all events, Sievers (1884: 563) may be right that the umlauted vowel has been extended from the sj.

The WGmc. verbs are somewhat less straightforwardly explained. The pres. ind. $1 \mathrm{sg}$. shows replacement of the original inflection by the normal thematic pres. ${ }^{*}-\bar{o}$, except that WS, as usual, has $-e$, which is perhaps etymological (i.e., sj.) rather than a replacement for analogical $-o(\$ 12.24)$. Beside OHG willu there occurs in some early texts wille, with what appears to be a present sj. inflection (see Boutkan 1995b: 371-2 for discussion). Otherwise, the pres. ind. sg. corresponds well to the Go. sg. forms, though obviously OE OS $2 \mathrm{sg}$. wilt has acquired its inflection from the pret.-pres. verbs. Particularly striking are OS OHG wili, since the inflection is entirely anomalous on a 2 sg. form, and yet it is etymologically correct: cf. OHG ni curi (\$12.27). In the plural, the OE OS stem will-is not etymological, but in WGmc. verbs with $j$-presents the $1 \mathrm{sg}$. and the 1-3 pl. agree in having a stem with gemination (e.g. OE $1 \mathrm{sg}$. fremme, pl. fremmað), and so the $\mathrm{pl}$. here is refashioned on that ind. pattern. A common assumption is that in addition to the PIE $e$-grade stem reflected in the pres. ind., there must be assumed a weak grade PIE *ul- > PGmc. ${ }^{*} w u l-$ to account for WGmc. ${ }^{*} w u l-\partial$ - in OE wolde, OHG wolta (with lowering of *u before a non-high vowel of the following syllable, $\$ 4.3$ ), as well as an $o$-grade PIE * uol- to account for various WGmc. forms, including OHG well$<*$ wal-j-. Thus, for example, Bammesberger (1986a: 119) reconstructs, in addition to the root aorist mentioned in $\mathrm{n}$. 1, a perfect showing the alternation sg. *(we-)wolo*(we)wlo- (his notation), providing a source for PGmc. ${ }^{*} w a l-\sim *^{*} w u l-$. Yet if it raises doubts to recognize that no other weak pret. in PGmc. added the dental suffix to a stem other than the pres. stem, it seems even more peculiar that a weak pret. should have been formed to this verb at all if there already existed perfect forms that could serve as a 
pret., since the purpose of weak suffixation was to provide preterites to verbs that otherwise had none. And yet without the assumption of a perfect, the seeming ablaut alternations are difficult to explain. But perhaps it is unnecessary to assume either PGmc. *wal- or *wul-. Bammesberger supposes that the former is demanded by Anglian walde, but this is the result of a regular Anglian phonological development between a labial consonant and covered $l$ or $r$, as in Anglian warhte 'created', margen 'morning' (Hogg 1992: §5.34). Sievers (1884: 563-4) argues that Early WS negated nelle ic 'I do not want' (beside more usual nylle ic) demands the reconstruction *niwaljai (beside *niwiljai $>$ nylle), but there is no parallel to such a development, and 2 sg. nelt cannot be explained this way. Rather, since $* y>\mathrm{OE} e$ in unstressed syllables, it is safer to assume that nelle is a normal variant of nylle under the low stress that such auxiliaries commonly received: cf. $y>e$ in gædeling 'companion' $<*^{*}$ gædyling- $<*_{3}$ aðuling-. Neither is it necessary to derive the OHG pres. pl. stem well- from *walj- (so, e.g., Krahe \& Meid 1969: II §101, Euler 2013: 177), since lowering of *will- (as in OE OS ) to well- in OHG may have originated in the sj. before $-\bar{e}$ - of the inflection, parallel to the situation in weak classes $2 \& 3$, e.g. lebeen 'live' (cf. OE libban, Anglian lifgan, and OS pret. sj. lebdin beside libdi). ${ }^{3}$ As for $\mathrm{OE}$ wolde, $\mathrm{OHG}$ wolta, these do not necessarily demand derivation from PGmc. ${ }^{*} w u l-\delta$-, since they may be the result of rhyming attraction to OE scolde, OHG skolta (and cf. the transfer of $o$ from the pret. of other pret.-pres. verbs, replacing * $u$ in OHG onda, konda, OS gi-onsta, konsta, for-monsta, $\$ 12.54$ ad fin.). OS has usually pret. welda, with the stem to be expected from dental suffixation of the present stem *wel-, since the pret. stem did not have the $*_{-i / j-\text { of the }}$ pres. For thorough discussion of the development of this verb, see Flasdieck 1937b; see also Birkmann 1987: 116-18, 157-61, etc., Ringe \& Taylor 2014: 73-5; and for a discussion of related issues that support the account suggested here, see Fertig 1999.

1. Bammesberger (1986a: 117-18) thus explains the present forms as derived from a PIE root aorist. Striking is the correspondence between Go. wileis, wili, etc., and Lat. velīs, velit.

2. The alternative 2 sg. vilt, with a pret.-pres. inflection, is actually a later form. Although this was a perfectly regular paradigm comparable to that of fremja at the time of the change, the modal use of vilja may be assumed to have continued to invite the influence of pret.-pres. inflection on the verb.

3. It is noteworthy that Northumbrian shows a pres. sj. stem well-, wæll-, beside ind. will-, which Sievers thinks demands * wal-j-, though this seems just one of several possibilities, including a development like that seen in OHG. One possible source of a stem *well- in WGmc. is confusion with the semantically similar verb PGmc. *waljana ' choose' ( $>$ OHG wellen). Such mixture of the two verbs could explain why 'choose' is not preserved in Ingvaeonic.

\subsection{The verb 'do'}

The verb 'place, cause, do' is found as such only in WGmc.:

\section{OE OFris.}

Pres. Ind. 1 sg. dō

2 sg. dēst

3 sg. dēð

1 pl. dōð

2 pl. dōð

3 pl. dōð dwē

dēst

$\operatorname{dèt}(\mathrm{h})$

dwāt(h), dwā

dwāt(h), dwā

dwāt(h), dwā

\section{OS}

dōm, duom

dōs, duos

dōd, duod

dōd, duod, duad

dōd, duod, duad

dōd, duod, duad
OLF

OHG

tōm, tuam

tōs, tuos(t)

tōt, tuat

tōmes, tuamēs

tōt, tuat

tōnt, tuant 
OE $\quad$ OFris. $\quad$ OS $\quad$ OLF $\quad$ OHG

\begin{tabular}{|c|c|c|c|c|c|c|}
\hline Pres. Sj. & $\begin{array}{l}1 \mathrm{sg} . \\
2 \mathrm{sg} . \\
3 \mathrm{sg} . \\
1 \mathrm{pl} . \\
2 \mathrm{pl} . \\
3 \text { pl. }\end{array}$ & $\begin{array}{l}\text { dō } \\
\text { dō } \\
\text { dō } \\
\text { dōn } \\
\text { dōn } \\
\text { dōn }\end{array}$ & $\begin{array}{l}\text { dwēe, dwā } \\
\text { dwēe,dwā } \\
\text { dwēe,dwā } \\
\text { dwēe,dwā } \\
\text { dwēe, dwā } \\
\text { dwē, dwā }\end{array}$ & $\begin{array}{l}\text { dōe, duo, dua, -e } \\
\text { duoas } \\
\text { dōe, duo, dua, -e } \\
\text { dōen, duon, -an } \\
\text { dōen, duon, -an } \\
\text { dōen, duon, -an }\end{array}$ & $\begin{array}{l}\text { duos } \\
\text { duo } \\
\text { duon }\end{array}$ & $\begin{array}{l}\text { tō, tue } \\
\text { tōs, tuēs } \\
\text { tō, tue } \\
\text { tûên, tuoên } \\
\text { tôt, tuēt } \\
\text { tōn, tuēn }\end{array}$ \\
\hline Imp. & $\begin{array}{l}2 \mathrm{sg} . \\
2 \mathrm{pl} .\end{array}$ & $\begin{array}{l}\text { dō } \\
\text { dōð }\end{array}$ & dwāt(h) & $\begin{array}{l}\text { dō, duo } \\
\text { dōd, duod, duad }\end{array}$ & $\begin{array}{l}\text { duo } \\
\text { duot }\end{array}$ & $\begin{array}{l}\text { tō, tua } \\
\text { tōt, tuat }\end{array}$ \\
\hline Pret. Ind. & $\begin{array}{l}1 \text { sg. } \\
2 \text { sg. } \\
3 \text { sg. } \\
1 \text { pl. } \\
2 \text { pl. } \\
3 \text { pl. }\end{array}$ & $\begin{array}{l}\text { dyde } \\
\text { dydest } \\
\text { dyde } \\
\text { dydon } \\
\text { dydon } \\
\text { dydon }\end{array}$ & $\begin{array}{l}\text { dēde } \\
\text { dēde } \\
\text { dēde } \\
\text { dēden } \\
\text { dēden } \\
\text { dēden }\end{array}$ & 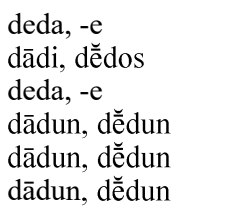 & deda & $\begin{array}{l}\text { teta } \\
\text { tāti } \\
\text { teta } \\
\text { tātum, -un } \\
\text { tātut } \\
\text { tātun }\end{array}$ \\
\hline Pret. Sj. & $\begin{array}{l}1 \mathrm{sg} . \\
2 \mathrm{sg} . \\
3 \mathrm{sg} . \\
1 \text { pl. } \\
2 \mathrm{pl} . \\
3 \mathrm{pl} .\end{array}$ & $\begin{array}{l}\text { dyde } \\
\text { dyde } \\
\text { dyde } \\
\text { dyden } \\
\text { dyden } \\
\text { dyden }\end{array}$ & $\begin{array}{l}\text { dēde } \\
\text { dēde } \\
\text { dēde } \\
\text { dēden } \\
\text { dēden } \\
\text { dēden }\end{array}$ & 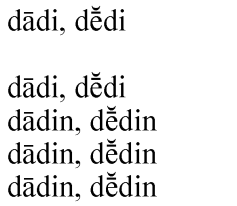 & & $\begin{array}{l}\text { tāti } \\
\text { tātīs(t) } \\
\text { tāti } \\
\text { tātīm } \\
\text { tātīt } \\
\text { tātīn }\end{array}$ \\
\hline $\begin{array}{l}\text { Inf. } \\
\text { Pres. Part. } \\
\text { Pass. Part. }\end{array}$ & & $\begin{array}{l}\text { dōn } \\
\text { dōnde } \\
\text { gedōn }\end{array}$ & $\begin{array}{l}\text { dwā(n) } \\
\text { dwān(d)e } \\
\text { (e)dēn, dīen }\end{array}$ & $\begin{array}{l}\text { dōn, duon, duan } \\
\text { gidōn, -duan, -dān }\end{array}$ & $\begin{array}{l}\text { duon, duen } \\
\text { duonda } \\
\text { gedan }\end{array}$ & $\begin{array}{l}\text { tōn, tuan } \\
\text { tōnti, tuanti } \\
\text { gitān }\end{array}$ \\
\hline
\end{tabular}

The OE forms given are WS. In Anglian there occur pret. pl. forms with the stem 〈ded (on which see below), and in poetry a pp. -dèn, which can only show umlaut (see Hogg \& Fulk 2011: §6.155), and thus it reflects the pp. suffix *-in- (§12.30). In OS the forms with $\bar{o}$ and $u o$ are phonological variants (§4.15), whereas the other forms require explanation. There is the usual variation in inflections, e.g. final $-t$ beside $-d$. The OHG forms are exceptionally various, with the phonological variants $\bar{o}$ and $u a$, but also $u o, u e$, and $u i$, at least some of which must be regarded as disyllabic. See Braune 2004a: $\S 380$ for a conspectus of forms.

\subsection{Historical development of 'do'}

Although IE cognates to this verb are not in short supply (cf., e.g., Gk. $\tau i \theta \eta \mu$ 'place', Lith. dëti, OCS déti), outside of Germanic it is only in nominal forms that $\bar{o}$-vocalism occurs, e.g. Gk. $\theta \omega \mu o ́ \varsigma$ 'heap', Lat. ab-domen. The normal PIE vocalism of verbal forms is $* \bar{e}$, which in Gmc. is reflected only in pp. OS gidān, OHG gitān (and probably OE gedōn: see Hogg \& Fulk 2011: §6.155), and probably in the OS and OHG pret. stems $d \bar{a} d-$, $t \bar{a} t$-. Hill (2004: 281-6, idem 2010: 446-8) offers an ingenious explanation: $\bar{o}$ originates in Pre-Gmc. aorist sj. forms (reanalyzed as pres. ind.) with back vowels in the inflection, subsequently undergoing contraction. Thus, for example, PIE $1 \mathrm{pl}$. *dhéh omes $>$ *dhéomes $>$ Pre-PGmc. *dhốmes, as opposed to $3 \mathrm{sg}$. *dhéh,eti $>$ *dhéeti $>$ Pre-PGmc. *dhéti. The assumption that $\bar{e}$ and $\bar{o}$ alternated in the PGmc. pres. paradigm furnishes a possible solution to certain problems pertaining to how the Gmc. 
weak preterite is to be explained ( $\$ 12.33) .{ }^{1}$ Ringe rejects Hill's account,$^{2}$ arguing instead that Gmc. 'do' does, after all, reflect a PIE stem *dhóh $h_{1}$ : cf. Hittite 3 sg. dāi 'put' $<* d h o ́ h_{1}-i$ - (so Jasanoff 1979: 88-9).

Among the peculiarities of the development of this verb in Gmc., perhaps the oddest is its metrical treatment in verse. In OE poetry the inf. and pres. forms are frequently treated in the meter as disyllabic, but never with a heavy initial syllable. ${ }^{3}$ It must be concluded that in the conservative language of OE poetry, dōn is equivalent to dǒan ${ }^{4}$ A similar scansion is demanded for $g \bar{a} n$ ' $\mathrm{go}$ ' (\$12.63), the anaphoric pronoun hie (§8.7), and the verb sie 'be' (\$12.57). This metrical evidence is reinforced by the four-stress meter of Otfrid's Evangelienbuch (863-71; on the meter, see Somers 2009: 72-82), in which duan is usually equivalent to a single stressed position, but at other times to a trochee. ${ }^{5}$ OS don, duan, duon, doen, duoan does not conform to the pattern of spellings of other words containing the reflex of PGmc $\bar{o}$ (Gallée 1993: §86 Anm. 3). Forms like the last two may show analogical re-addition of the inf. ending, ${ }^{6}$ but $d u a n$ is anomalous, and the supposition that it is to be explained as due to Frisian influence (Holthausen 1921: §95) is unpersuasive. Rather, duan may result from the disyllabic form demanded in OE and OHG poetry (though there does not appear to be any evidence for disyllabicity in OS poetry). These observations are suggestive as regards the analysis of the $\mathrm{OE}$ pret. (see below), and they forbid the supposition that the OE pres. directly reflects an athematic paradigm $1 \mathrm{sg} .{ }^{*} d \overline{o m i}, 2$ *dōsi, etc. (so, e.g., Ringe \& Taylor 2014: 369), which, in any event, would raise the expectation of umlaut throughout the present. ${ }^{7}$ Rather, it has been proposed (Fulk 1993) that at some point in time (in the Ingvaeonic period?) after the PGmc. thematization of most athematic verbs in PGmc., there was shortening of antevocalic long vowels. Certainly, when antevocalic long vowels arose later in OS, they were shortened (see §4.15). Thematization and antevocalic shortening thus explain both the metrical peculiarities of the present of 'do' and the restriction of umlaut in the pres. ind. to the 2 and $3 \mathrm{sg} .:$ cf. thematized Pre-OE $1 \mathrm{sg} . *$ do- $u, 2 * d o-i s, 3$ $*$ do-i $i, 3$ pl. *do- $a^{n} p$. This appears to be the only explanation offered to date for the disyllabic scansion of 'do' in OE poetry with a light initial syllable. The problem no doubt bears further study.

The anomalous OE pret. $d y d e$, so unlike the other WGmc. preterites, has provoked a variety of fairly desperate explanations. ${ }^{8}$ If, however, the Pre-OE pres. had a shortened stem in *dó- to which thematic inflections were added, it may be supposed that before the time of umlaut this stem was extended to the pret., since the pres. and pret. stems (before the addition of *-id- to the pret.) were usually identical in weak verbs. The usual preterite suffix plus inflections of weak class 1 were added to this, producing, e.g., $3 \mathrm{sg} . * d o-i d-\bar{x}$. If this happened at a sufficiently early date, $* d o-$ should be expected to have been realized as * $d u$-, since as late as the time of umlaut there was no $o$ before $i$ or $j$ in native words except by analogy (A. Campbell 1977: §196). Reconstructed $* d u-i d-\bar{x}$ might be expected to have produced a heavy stem, though poetic meter shows $d y d e$ to have a light initial syllable; but *-ui- produces a light syllable also in the form dryas 'wizards' < Old Irish drui-, as shown by poetic meter. ${ }^{9}$ In Anglian the pret. stem is usually $d y d$-, but in the plural there is a minority stem $d \bar{e} d-$, as well, comparable to the plural forms employed elsewhere in WGmc. ${ }^{10}$ These WGmc. pl. stems (OFris. $d \bar{e} d-$, OS $d \bar{a} d-$, OHG tāt-) appear to reflect PGmc. *dē $\delta-$, with the vowel $\left(\bar{e}_{l}\right)$ of the pp. OS gidān, OHG gitān and the IE cognates, Lith. dëti, etc. In the $1 \& 3 \mathrm{sg}$. pret. ind., however, OS and OHG have a short vowel, and OE poetry (almost all of Anglian origin) agrees with this pattern, inasmuch as the pret. sg. never scans with a heavy first syllable, whereas pl. dydon (substituted for Anglian dédon by WS scribes) frequently 
scans so (Sievers 1885b: 498-9). Given the close correspondence between the OS and OHG preterites and the pret. inflections of weak verbs in Gothic (§12.33), these forms must be old, and yet it is difficult to perceive in them any pattern inherited from PIE without much analogical disruption. The short vowel in the $1 \& 3 \mathrm{sg}$. ind. is most commonly explained on the assumption that these forms represent reduplicated perfects, PIE $1 *$ dhe-dhoh $h_{1}-a, 3 *$ dhe-dhoh $h_{1}$ e: so, e.g., Bammesberger 1991c. Flasdieck (1937a: 52) and Prokosch (1939: §75b) object that these should have produced a final trimoric vowel that would have been reflected as a long vowel in OHG. ${ }^{11}$ The alternative is to assume an augmentless imperfect (= injunctive, thus with secondary endings) $1 \mathrm{sg}$. *dhe-dhè-m, 3 *dhe-dhēt (so Wilmanns 1893-1906: 3.61; Bammesberger 1986a: 11213; Ringe 2006b: 179-96), which would correctly result in OHG teta, OS deda, though there is no secure evidence for any reflex of a PIE imperfect in Gmc. ${ }^{12}$ The vocalism of the pret. stem OS $d \bar{a} d-$, OHG tāt- is even more difficult to account for convincingly. Prokosch (1939: §75b), Ringe (2017: 182-6), Euler (2013: 172), and Lühr (2016: 255) regard it as analogical to corresponding pret. stems in strong class V, e.g. OS 2 sg. gā $\bar{b}$, pl. gā̄un (cf. 1, 3 sg. gaf) 'gave'. Bammesberger (1986a: 113-14) instead derives the long vowel in this stem from a root aorist $* d h \bar{e}-m, * d h \bar{e}-s$, etc., existing beside the injunctive and the perfect paradigms already assumed, though it is not plain why the vowel of the root aorist should have been extended to the perfect, and why not to the 1 \& 3 singular. Flasdieck (1937a: 50-3, with a brief conspectus of the relevant proposals) explains the long vowel in the OS and OHG pret. as due to rhythmic lengthening, comparable to that seen in Skt. 3 pl. perfect vā-vrt-úh 'turn' (: 3 sg. va-várt-a), avoiding a sequence of three light syllables. None of the analyses offered to date is unassailable. ${ }^{13}$

1. Cf. the explanation of Ringe (2017: 173), self-described as phonologically improbable, whereby $\bar{o}$ originates in $1 \mathrm{sg}$. imperfect *dedę (i.e. $\left.d e d \bar{e}^{n}\right)$, with lowering, backing, and rounding of the final vowel.

2. See Ringe \& Taylor 2014: 112-13. Ringe finds the development $*_{-} e h_{2} O_{-}>*_{-}-\bar{o}$ and the analogical replacement of $*_{-} \bar{e}$ - by ${ }^{*}-\bar{o}$ - within the paradigm unlikely. His other objection is more telling: if the pres. ind. reflects an aorist subjunctive, it is difficult to explain how it acquired the ending on $1 \mathrm{sg}$. *domi. But note that Hill is dealing with changes in the Pre-PGmc. period, when a greater number of verbs in ${ }^{*}-m i$ would have been preserved.

3. Examples from Beowulf: swā sceal man dōn (1172b, scanned like Wæs sēo hwīl micel 146b), but never $\dagger$ †ōn mihte (which would require a scansion like lange prāge 1257b), rather only gedōn wolde (2090b, like ond dracan fellum 2088b); cf. also swā hē nū gìt dèঠ (1058b, like ac wit on niht sculon 683b). See Fulk 1993a.

4. Spellings like $\langle$ doan $\rangle$ are in fact common in texts of non-WS origin, but it is impossible in any given instance to be certain that such spellings do not represent analogical re-addition of inflections to the contracted stem $d \bar{o}-$. A few uncontracted spellings occur in Early WS, however, and these almost certainly are archaic rather than innovative: see Hogg \& Fulk 2011: §6.154 for discussion; but cf. Flasdieck (1937a: 48), who attributes them to Anglian influence.

5. For example, the word is equivalent to a single stressed position in óba ih dúan so sámalih (III, 16.48) but to two positions in nub ér es dúan scólti énti $(\mathrm{V}, 9.36)$ and thaz drúhtin inan dúan híaz (II, 5.16).

6. By comparison, in Notker (ca. 1000) there are OHG forms that plainly show a long vowel or diphthong plus analogically re-added inflection, e.g. 2 sg. pres. sj. tûêst, tuoêst.

7. To explain athematic Anglian $d \bar{o} m$, without umlaut, it might be assumed that, as with 'be', final *-i was lost because of low stress on the verb: see Flasdieck 1937a: 46-8. In that event, however, there should be no umlaut in the pres. paradigm.

8. Prokosch (1939: §75b) supposes that $d y d e$ has $y$ by analogy to pret.-pres. subjunctives like dyge, scyle, though that pres. subjunctives should have induced such a change in pret. forms (ind. \& sj.) is dubitable. Bammesberger (1986a: 113) derives ind. $d y d e$ from a pret. sj. $* d u-d-\breve{\bar{l}}$, with $* d u$ - as an analogical replacement for $* d a-<* d z$. Prokosch objects to similar derivations on the ground that forms comparable to $\mathrm{OE} d y d e$ 
might be expected outside of $\mathrm{OE}$ if $d y d e$ were not a late analogical creation. He would thus no doubt have rejected the argument of R.I. Kim (2009) that there was already in PGmc. substitution of $u$ (from the $3 \mathrm{pl}$. inflection) for $e$, regarded as a reduplicative vowel, comparable to the substitution in Skt. perf. bu-bhód-a 'awaken'. There is no parallel to the development of unstressed $e$ to $y$ posited by Hill (2004: 280-1); the usual development is the reverse of this, as in PGmc. *3aduling- > gædyling- > gædeling 'companion'.

9. So sægde hȳ dryas wǣron (Juliana 301b), to be scanned like pāra ðe cwice hwyrfap.

10. On the evidence for the length of the vowel in Anglian $d \bar{e} d-$-, see Hogg \& Fulk 2011: §6.155.

11. Alternatively, since the stem might be either $* d \bar{o}$ - or $* d o-$, the paradigm could have arisen on an analogical basis using the stem *dedo- after the loss of the endings $*_{-} a,{ }^{*}-e$, hence with zero inflection in the $1 \& 3$ sg. There are too many uncertainties involved to establish any firm probabilities.

12. This is supposed to explain as well archaic OS $2 \mathrm{sg}$. pret. ind. dedos (beside $d \bar{a} d i$, both in poetry), though if it is to be derived from *dhe-dhess it must have its vowel by analogy, perhaps to the present, or to an assumed perfect (so Bammesberger).

13. The account of Hill (2010) concerning the rise of the weak preterite (see $\S 12.33$ ) deals with a number of issues pertaining to the development of 'do', and it has much to recommend it, though it does not specifically address the issue of how the alternation *ded- $\sim * d \bar{e} d$ - arose in the pret. ind. of 'do'. Hill's is surely the strongest case yet for crediting a Pre-PGmc. imperfect as a source. See also Lühr 2016: 250-60.

\subsection{The athematic verb 'go'}

All the older Gmc. languages attest to a PGmc. verb *3ayganan 'go' (Go. gaggan, OIcel. ganga, OE gangan, etc.), a strong verb of class VII (but with a weak pret. in Go.), its PIE root probably reflected also in reduplicated Gk. kí $\eta \mu l$ 'reach' $<* \hat{g} h i$ gheh $h_{1}-m i$. Primarily in WGmc. there are found, beside this, reflexes of a non-derived athematic paradigm to a PIE root that some regard as the same: ${ }^{1}$

\begin{tabular}{|c|c|c|c|}
\hline & \multirow[b]{2}{*}{$\begin{array}{l}1 \text { sg. } \\
2 \text { sg. } \\
3 \text { sg. } \\
1 \text { pl. } \\
2 \text { pl. } \\
3 \text { pl. }\end{array}$} & OE & \multirow[b]{2}{*}{$\begin{array}{l}\quad \text { OHG } \\
\text { gām, gān, gēm, gēn } \\
\text { gās(t), gēs(t) } \\
\text { gāt, gēt } \\
\text { gāmēs, gān, gēmēs, gēn } \\
\text { gāt, gèt } \\
\text { gānt, gēnt }\end{array}$} \\
\hline Pres. Ind. & & $\begin{array}{l}\text { gā } \\
\text { gǣst } \\
\text { ḡ̄ð } \\
\text { gāð } \\
\text { gāo } \\
\text { gāð }\end{array}$ & \\
\hline Pres. Sj. & $\begin{array}{l}1 \text { sg. } \\
2 \text { sg. } \\
3 \text { sg. } \\
1 \text { pl. } \\
2 \text { pl. } \\
3 \text { pl. }\end{array}$ & $\begin{array}{l}\text { gā } \\
\text { gā } \\
\text { gāa } \\
\text { gān } \\
\text { gān } \\
\text { gān }\end{array}$ & $\begin{array}{l}\text { gē } \\
\text { gēs }(t) \\
\text { gē } \\
\text { gēn } \\
\text { gēt } \\
\text { gēn }\end{array}$ \\
\hline Imp. & $\begin{array}{l}2 \mathrm{sg} . \\
2 \mathrm{pl} .\end{array}$ & $\begin{array}{l}\text { gā } \\
\text { gāo }\end{array}$ & gāt, gēt \\
\hline $\begin{array}{l}\text { Inf. } \\
\text { Pres. Part } \\
\text { Pass. Part }\end{array}$ & & $\begin{array}{l}\text { gān } \\
\text { gānde } \\
\text { gegān }\end{array}$ & $\begin{array}{l}\text { gān, gēn } \\
\text { gānti, gēnti }\end{array}$ \\
\hline
\end{tabular}

OFris. has the forms 3 sg. pres. ind. gēt(h), g(h)eet, pl. gät, gaet, pp. (e)gēn. In OS the only forms attested are $3 \mathrm{sg}$. pres. ind. be-gēd, inf. (-)gān, and inflected inf. te gānde; otherwise all forms are to gangan. Similarly, in OLF there is only inf. gān, beside forms of gangan. Although this stem is not attested in Wulfilan Gothic, Crimean Gothic attests to geen; and Old East Norse gā produces Swedish and Danish gå. As with OE dōn, 
Anglian forms frequently show analogical re-addition of the endings to the stem, e.g. 1 sg. ind. gaa, 2 sg. gaæs (listed by Flasdieck 1937a: 59). There is no inherited preterite to this stem: the strong pret. to gangan is used (e.g. OHG giang), except in OE, where there is a suppletive weak pret. éode, which is usually thought to be cognate with Go. iddja, the usual weak pret. (beside gaggida $1 \times$ ) to gaggan. Go. iddja is unusual in that it is the only verb to which the weak preterite inflections are added directly to the stem, without a stem-final dental consonant, hence $3 \mathrm{sg}$. iddja, 3 pl. iddjēdum, etc.

1. If the two are related, they are only distantly so: to PGmc. ${ }^{*}$ zenna ${ }^{n}<\mathrm{PIE} * \hat{g} h h_{1}$ - cf. PGmc. *zaygana ${ }^{n}<$ PIE * $\hat{g} h o n g h-;$ cf. Lith. žengiù, žeñgti 'stride'. The similarity nonetheless led to mixed paradigms in Gmc.

\subsection{Historical development of 'go'}

Forms like OE inf. gān appear to present a problem, inasmuch as WGmc. * ${ }^{*} \bar{x} n$ (< PGmc. * ${ }^{2} \bar{e}$ ) should have produced OE and OFris. *gōn (§4.12). Accordingly, there is usually reconstructed a stem $*_{3}$ ai- beside WGmc. ${ }^{*}{ }_{3} \bar{x}-$ to account for OE gān, OFris. *gān; so, e.g. Mottausch 1997, 1998a, with references; Ringe 2017: 295. Yet there is no very plausible parallel to this * $3 a i$ - outside of Anglo-Frisian. ${ }^{1}$ The non-pret. inflection of 'go' obviously closely parallels that of 'do', and just as with 'do', in OE poetry the stem is disyllabic, with, apparently, a light initial syllable (Fulk 1992: $\S \S 107-11$ ). ${ }^{2}$ Accordingly, the prehistoric OE pres. ind. may be reconstructed as thematized sg. $1 * 3 a-\bar{x}, 2$ $*_{3 a-i s, 3} *_{3} a-i p$, pl. * $3 a-\bar{a} p$. After Anglo-Frisian fronting of * $a$, umlaut, and contraction, 3 sg. *3a-ip (for example) might be expected to have developed to *gè rather than the attested $g \bar{x} \gamma$; but it may be assumed that just as in class VI, fronted * $x$ was replaced by $* a$ for the sake of paradigm regularity before umlaut applied, ${ }^{3}$ the result then being $*_{3} a$ $i p>{ }^{*} z^{x}-i p>g \bar{x} \partial$. The assumption of a short root vowel also affords the opportunity to account for the coöccurrence of the stems $g \bar{a}$ - and $g \bar{e}$ - in OHG: $g \bar{a}$ - arose in forms like inf. * $3 a-a n$, and gé- in forms like $3 \mathrm{sg}$. * $3 a-i t$, umlauted to * $3 e-i t$ and then contracted to $g \bar{e} t$, with levelling of the two variants throughout the ind. to create parallel paradigms (Hogg \& Fulk 2011: $\$ 6.157$ \& n. 2). ${ }^{4}$

OE pret. éode appears to be cognate with Go. iddja, as remarked above, both of them weak preterites, and in the relevant literature the two are most commonly associ-

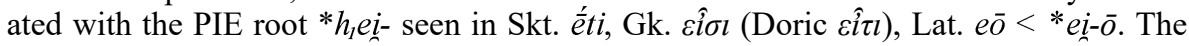
etymology is complicated by the observation of Sievers (1900: 52) that the verb is never *iode or *iade in Northumbrian but èode or éade, with about equal frequency in the gloss on the Lindisfarne Gospels, ${ }^{5}$ suggesting either a stem $\bar{e}$ - plus preterite inflections of weak class 2 or (more likely) * ${ }^{2} o$ - plus preterite inflections of weak class $3 .{ }^{6}$ A plausible explanation was devised by Cowgill (1960), arguing that although no perfect was formed to the root $* h_{l} e i$ - in PIE, perfects were created in the post-PIE period (Skt. $i y-\bar{a} y$ $a$, Lat. $i \bar{l}$ ), and in Pre-PGmc. there arose a perfect with the expected alternation between sg. *e-oi- and pl. *e-ii-. A form like 3 pl. *e-ii-nt then yielded PGmc. *ijjun, which would have developed to Go. *iddjun, but instead weak inflections were substituted for the perfect ones. What makes this explanation particularly attractive is that it plausibly explains why iddja is the only Go. verb to bear weak inflections without a stem-final dental consonant: the implication is that the stem was already perceived to be preterite, without the addition of the dental suffix, and that is explicable only if the verb represents a remodeling of an earlier preterite of a different sort. As for OE éode, this may be derived from the Pre-PGmc. sg. stem ${ }^{*} e-o i-$ on the assumption that PGmc. ${ }_{-}-j-$ (from 
* $-i-$ ) once again would have been lost between the unstressed vowels, resulting in a stem *e-o- > OE $\bar{e} o-$, to which preterite endings like those of weak class 3 were added. ${ }^{7}$ Why the present forms of this verb should have died out and been replaced by forms of * zenena $a^{n}$ and *3angana $^{n}$ is explained by Mottausch (1994) as the result of a tendency to replace excessively short words, those with much grammatical information compacted in unanalyzable forms, with longer ones, as happened to Lat. $e \bar{o}$ when some forms were replaced by those of $v \bar{a} d \bar{o}$ in late Latin, and in French, with the substitution of forms derived from Lat. ambulāre (allons, allez). ${ }^{8}$ Alternative analyses rely on the reconstruction of unlikely forms in PIE and/or unlikely phonological developments, e.g. the equation of Go. iddja and the Skt. augmented aorist áyām to the root $y \bar{a}-$ (as first argued by Möller 1879: 432 n. 1 and Kluge 1879: 124-7) and the reconstruction of an augmented, zero-grade aorist * $h_{1} e-u d h-n t$ to the root seen in Lat. vādo 'go', with the result that Go. iddja and OE éode must not be regarded as close cognates (Holthausen 1903: 342): for critiques of these and other views, see Flasdieck 1937a, Cowgill 1960, and Mottausch 1994, the last with some proposed refinements to Cowgill's analysis. A subsequent study is Schumacher 1998, proposing that to the PGmc. stem *ej- 'go' was formed a pret. $\bar{e} j$ - by analogy to *ēt- 'ate', and to this stem OE added endings of weak class 2 (but cf. n. 5 infra). See also Eichner 2005.

1. This posited $*_{3} a i$ - is assumed to have originated in the athematic pres. sj. (opt.), PIE ${ }^{*} \hat{g} h_{n} h_{-}-i e h_{1}-$ and spread to the ind. and inf.: so, e.g., Euler 2013: 174.

2. Kortlandt (1990: 8-9) earlier proposed that the OE monosyllables can best be explained as derived from disyllables, though he did not assume a light initial syllable.

3. Hence, e.g., 3 sg. færð 'goes' beside etymological and less usual ferð: so A. Campbell (1977: §§160, 194). The cause of this variation is actually disputed (see Hogg 1992: $\S 5.80 .2$, with references), but the variation itself is undeniable and thus may be expected in forms of $g \bar{a} n$ under this explanation.

4. Note that thematization of the originally athematic verb is required by this explanation, as OE $g \bar{x} \partial$, for example, cannot be derived directly from PIE * $(\hat{g} h e-) \hat{g} h h_{l}-t i$, which would produce $\mathrm{OE} * g \bar{e} \partial$. The failure of any $1 \mathrm{sg}$. form in $-m$ to be preserved in Anglian (in contrast to $d \bar{o} m$ 'do') is perhaps attributable to the observation that PGmc. ${ }^{*} \bar{e} \bar{e}-m i$ would have produced Anglian $1 \mathrm{sg} .{ }^{*} g \bar{x} m$ or (with early loss of $*_{-} i$ under low stress) *gōm, a notable paradigm irregularity.

5. Kolbe (1912: 104) gives the proportion as $\bar{e} a 117 \times: \bar{e} o 116 \times$.

6. The reason that $\bar{e}_{-}+-$-ode is less likely than $\bar{e} o-+d e$ is that -ade shows the usual vowel of the suffix in Northumbrian, next to which -ode is rare. By contrast, in the Northumbrian dialect of the gloss on the Lindisfarne Gospels, where èode and éade are about equally frequent, $\bar{e} o$ very commonly develops to $\bar{e} a$ except before $w$ or before $o$ or $u$ in the next syllable, whereas in the dialect of the Northumbrian portion of the gloss on the Rushworth Gospels, where the proportion of êod-to êad- is 98 : 9 (Lindelöf 1901: 150), the development of $\bar{e} o$ to $\bar{e} a$ is relatively infrequent.

7. Cowgill is at great pains to argue that Pre-Gmc. ${ }^{*} e-o$ - would not have contracted to ${ }^{*} \bar{e}$ or $* \bar{o}$, and although many of his points are incompatible with the analysis of NWGmc. preterites of class VII offered above $(\S 12.20)$, that analysis renders it plausible enough that $*_{-}-o-o$ - would not have contracted at an early date, and that the uncontracted PGmc. ${ }^{*} e-a$ - implicit in his account would have resulted in $\mathrm{OE} \bar{e} o$. The discussion in the preceding note, however, shows that contraction must have taken place by the time of OE itself, as the analysis of class VII would lead one to expect.

8. See also the remark above ( $\$ 8.7$ n. 1) on Einlautigkeit.

\subsection{The athematic verb 'stand'}

PGmc. *standanan 'stand', a nasal-infixed present (cf. Lat. stäre), has reflexes in all the older Gmc. languages, but in a few of them there is reflected an athematic stem entirely comparable in its inflection to OHG gān, gēn and its cognates (\$12.62). The verb is best 
attested in $\mathrm{OHG}$ (inf. stān, stēn, 1 sg. ind. stām, stēm, etc.), though forms are also infrequently attested in OFris. (3 sg. pres. ind. stēt, pl. stāt, pp. stēn), OS (inf. stān, $2 \mathrm{sg}$. pres. ind. stēs, 3 sg. stēd, stād, steid, pl. stād), OLF (inf. stān, 2 sg. imp. up-stā) and Old East Norse (cf. Danish, Swedish stå), with other forms supplied by ${ }^{*}$ standana $^{n}$. The historical development of this verb may be assumed to parallel exactly that of PGmc. $*_{3} \bar{e}(-a) n a^{n}(\S 12.63)$. For references to relevant literature, see Braune 2004a: $\S 382$ Anm. 1. 


\section{References}

For the purpose of alphabetization, diacritics on the Roman alphabet are ignored. Inessential subtitles of books have been omitted. Journal titles have been abbreviated as follows:

\begin{tabular}{|c|c|c|c|}
\hline$A b \ddot{a} G$ & $\begin{array}{l}\text { Amsterdamer Beiträge zur älteren Ger- } \\
\text { manistik }\end{array}$ & & $\begin{array}{l}\text { Deutschen, Griechischen und Latein- } \\
\text { ischen (1852-74), Beiträge zur ver- }\end{array}$ \\
\hline$A f d A$ & Anzeiger für deutsches Altertum & & gleichenden Sprachforschung auf dem \\
\hline AJGLL & $\begin{array}{l}\text { American Journal of Germanic Lin- } \\
\text { guis } \mid \text { tics and Literatures }\end{array}$ & & $\begin{array}{l}\text { Gebiete der arischen, celtischen und } \\
\text { slawischen Sprachen (1858-76), and }\end{array}$ \\
\hline$A P S$ & Acta Philologica Scandinavica & & Zeitschrift für vergleichende Sprach- \\
\hline Arkiv & Arkiv för nordisk filologi & & forschung (1968-87). The journal is \\
\hline \multirow[t]{3}{*}{$B B$} & Beiträge zur Kunde der indergerman- & & continued by $H S$. \\
\hline & ischen Sprachen (Bezzenbergers Bei- & $L B$ & Leuvense Bijdragen \\
\hline & träge) & $M G S$ & Michigan Germanic Studies \\
\hline$B S L$ & $\begin{array}{l}\text { Bulletin de la Société de Linguistique } \\
\text { de Paris }\end{array}$ & $M S S$ & $\begin{array}{l}\text { Münchener Studien zur Sprachwissen- } \\
\text { schaft }\end{array}$ \\
\hline$E L L$ & English Language and Linguistics & NOWELE & North-Western European Language \\
\hline$F L$ & Folia Linguistica & & Evolution \\
\hline$F L H$ & Folia Linguistica Historica & NTS & Norsk Tidsskrift for Sprogvidenskap \\
\hline$G L$ & General Linguistics & $P B B$ & Beiträge zur Geschichte der deutschen \\
\hline$H S$ & $\begin{array}{l}\text { Historische Sprachforschung / Histori- } \\
\text { cal Linguistics }\end{array}$ & & $\begin{array}{l}\text { Sprache und Literatur ('Pauls und } \\
\text { Braunes Beiträge'). From } 1955 \text { to } 1979\end{array}$ \\
\hline$I F$ & Indogermanische Forschungen & & two journals with the same title were \\
\hline$I J G L S A$ & $\begin{array}{l}\text { Interdisciplinary Journal for Germanic } \\
\text { Linguistics and Semiotic Analysis }\end{array}$ & & $\begin{array}{l}\text { published in Halle }(P B B(H)) \text { and Tü- } \\
\text { bingen }(P B B(T)) \text {, the latter continuing }\end{array}$ \\
\hline IncLing & Incontri linguistici & & to the present. \\
\hline$J E G P$ & $\begin{array}{l}\text { Journal of English and Germanic Phil- } \\
\text { ology }\end{array}$ & $R A S K$ & $\begin{array}{l}\text { RASK: International Journal of Lan- } \\
\text { guage and Communication }\end{array}$ \\
\hline \multirow[t]{2}{*}{$J G L$} & Journal of Germanic Linguistics. (Con- & $S A P$ & Studia Anglica Posnaniensia \\
\hline & tinues $A J G L L)$. & $S L$ & Studies in Linguistics \\
\hline JIES & Journal of Indo-European Studies & $S N$ & Studia Neophilologica \\
\hline$J L$ & Journal of Linguistics & $T P S$ & Transactions of the Philological Soci- \\
\hline \multirow[t]{3}{*}{$K Z$} & $\begin{array}{l}\text { Zeitschrift für vergleichende Sprach- } \\
\text { forschung auf dem Gebiete der indo- }\end{array}$ & & $\begin{array}{l}\text { ety. The earlier volumes are numbered } \\
\text { by year rather than volume. }\end{array}$ \\
\hline & germanischen Sprachen (1877-1967: & $Z D P$ & Zeitschrift für deutsche Philologie \\
\hline & $\begin{array}{l}\text { 'Kuhns Zeitschrift'). Earlier titles in- } \\
\text { clude Zeitschrift für vergleichende }\end{array}$ & $Z f d A$ & $\begin{array}{l}\text { Zeitschrift für deutsches Altertum und } \\
\text { deutsche Literatur }\end{array}$ \\
\hline
\end{tabular}

Adamczyk, E. 2001. Old English reflexes of Sievers' law. SAP 36.61-72.

Adamczyk, E. 2004. Grammatical change in Old English strong verbs: early traces of elimination. SAP 44.101-20.

Adamczyk, E. 2012. On the fate of the $s$-stems in West Germanic: evidence from Old English and Old High German. In Languages in contact 2011, ed. Z. Wąsik \& P. Chruszczewski, 7-25. Wrocław.

Adams, D.Q. 1985. The Indo-European word for 'apple' again. IF 90.79-82.

Adamus, M. 1962. Mutual relations between Nordic and other Germanic dialects. Germanica Wratislavensia 7.115-58.

Adrados, F.R., A. Bernabé, \& J.M. Mendoza. 2010. Manual of Indo-European linguistics. Vol. I. Leuven. 
Ament, H. 1986. Die Ethnogenese der Germanen aus der Sicht der Vor- und Frühgeschichte. In Ethnogenese europäischer Völker-Aus der Sicht der Anthropologie und Vor- und Frühgeschichte, ed. W. Bernhard \& A. Kandler-Pálsson, 247-56. Stuttgart.

Anthony, D. 2007. The horse, the wheel, and language. Princeton.

Antonsen, E.H. 1965. On defining stages in prehistoric Germanic. Language 41.19-36.

Antonsen, E.H. 1967. 'Proto-Scandinavian' and Common Nordic. Scandinavian Studies 39.1639.

Antonsen, E.H. 1969-70. Old High German and the laws of final syllables. SL 21.55-76.

Antonsen, E.H. 1972. The Proto-Germanic syllabics (vowels). In van Coetsem \& Kufner 1972: $117-40$.

Antonsen, E.H. 1975. A concise grammar of the older Runic inscriptions. Tübingen.

Antonsen, E.H. 1982. Zum Ursprung und Alter des germanischen Fuparks. In Dick \& Jankowsky 1982: 3-15.

Antonsen, E.H. 1989. Review of H.F. Nielsen 1989. Diachronica 6.287-90.

Antonsen, E.H. 1992. Review of Birkmann 1987. JEGP 91.96-7.

Antonsen, E.H. 2002. Runes and Germanic linguistics. Berlin.

Antonsen, E.H. 2007. Proto-Germanic final /-a/ in second syllables. NOWELE 52.23-9.

Antonsen, E.H., \& H.H. Hock, edd. 1991. Stæfcræft: studies in Germanic linguistics. Amsterdam.

Århammar, N.R. 2001. Grundzüge nordfriesischer Sprachgeschichte. In Munske et al. 2001: 74465.

Ásgeir Blöndal Magnússon. 1989. Íslensk orðsifjabók. [Reykjavík.]

Askedal, J.O., H. Bjorvand, \& J.E. Knirk, edd. 2010. Zentrale Probleme der Erforschung der älteren Runen. Frankfurt a.M.

Askedal, J.O., \& H.F. Nielsen, edd. 2015. Early Germanic languages in contact. Amsterdam.

Atkinson, Q., G. Nicholls, D. Welch, \& R. Gray. 2005. From words to dates: water into wine, mathemagic or phylogenetic inference? TPS 103.193-219.

Austefjord, A. 1984. Zur Gestaltung des germanischen Tempussystems. IF 89.160-8.

Austefjord, A. 1987. Das präterale $\bar{o}$ der 6. Ablautreihe des Germanischen. IF 92.168-71.

Austin, W.M. 1946. A corollary to the Germanic Verschärfung. Language 22.109-11.

Bache, C. 1982. Aspect and Aktionsart: towards a semantic distinction. JL 18.57-72.

Baesecke, G. 1918. Einführung in das Althochdeutsche. Munich.

Bahnick, K.R. 1973. The determination of stages in the historical development of the Germanic languages by morphological criteria. The Hague.

Baldi, P. 1983. An introduction to the Indo-European languages. Carbondale.

Baldi, P., ed. 1990. Linguistic change and reconstruction methodology. Berlin.

Ball, C.J.E. 1968. The Germanic dental preterite. TPS 1968, 162-88.

Bammesberger, A. 1975. Die Flexion der altenglischen Abstrakta auf -ð(u). KZ 89. 283-90.

Bammesberger, A. 1980. Das Präteritalparadigma einiger 'reduplizierender' Verben im Urgermanischen. In Lautgeschichte und Etymologie: Akten der VI. Fachtagung der Indogermanischen Gesellschaft, Wien, 24.-29. September 1978, ed. M. Mayrhofer et al., 1-21. Wiesbaden.

Bammesberger, A. 1982a. Einige $e$-stufige Präsentien des Urgermanischen und ihr Verhältnis zu indogermanischen athematischen Wurzelaoristen. PBB 104.339-44.

Bammesberger, A. 1982b. Der Optativ bei athematischen Verbalstämmen im Altenglischen. Anglia 100.413-18.

Bammesberger, A. 1983a. The weak forms of the Germanic $r$-stem paradigm. JIES 11.105-16.

Bammesberger, A. 1983b. Zur Herkunft der Dualendungen im gotischen Verbalsystem. PBB 105.169-76.

Bammesberger, A. 1984. Die urgermanischen Aoristpräsentien und ihre indogermanischen Grundlagen. In Das Germanische und die Rekonstruktion der indogermanischen Grundsprache, ed. J. Untermann \& B. Brogyanyi, 1-24. Amsterdam.

Bammesberger, A. 1985. Die Endung für Nom. Akk. Pl. bei altenglischen $u$-Stämmen. Anglia 103.365-70.

Bammesberger, A. 1986a. Der Aufbau des germanischen Verbalsystems. Heidelberg. 
Bammesberger, A. 1986b. On the Germanic decads from '20' to ' 60 '. In Brogyanyi \& Krömmelbein 1986: 3-8.

Bammesberger, A. 1986c. Gotisch (ni) ogs (pus) und althochdeutsch ni kuri. In Etter 1986: 6737.

Bammesberger, A. 1987. Das Paradigma der $\bar{e}$-verben im Urgermanischen. PBB 109.341-9.

Bammesberger, A. 1988a. Der indogermanische Aorist und das germanische Präteritum. In Jazayery \& Winter 1988: 55-62.

Bammesberger, A., ed. 1988b. Die Laryngaltheorie und die Rekonstruktion des indogermanischen Laut- und Formensystems. Heidelberg.

Bammesberger, A. 1988c. The paradigm of ja-verbs in Germanic. JIES 16.233-9.

Bammesberger, A. 1990. Die Morphologie des urgermanischen Nomens. Heidelberg.

Bammesberger, A. 1991a. Ingvaeonic sound changes and the Anglo-Frisian runes. In Bammesberger 1991b: 389-408.

Bammesberger, A., ed. 1991b. Old English runes and their continental background. Heidelberg.

Bammesberger, A. 1991c. On the morphology of Old Frisian deda. In Bammesberger 1991b: 305-8.

Bammesberger, A. 1991d. Das Präteritum der verba pura und ahd. ier-/eor-/er-. PBB 113.22-7.

Bammesberger, A. 1994a. Dehnstufe und Reduplikation im Urgermanischen. In Bopp-Symposium 1992 der Humboldt-Universität zu Berlin, ed. R. Sternemann, 15-20. Heidelberg.

Bammesberger, A. 1994b. The Development of the runic script and its relationship to Germanic phonological history. In Swan, Mørck, \& Jansen Wesvik 1994: 1-25.

Bammesberger, A. 1996. Frisian and Anglo-Saxon rules: from the linguistic angle. ABäG 45.1523.

Bammesberger, A. 2000. Urgermanisch *mann-: Etymologie und Wortbildung. Studia Etymologica Cracoviensia 5.7-12.

Bammesberger, A. 2001. -um (>-on) as marker of the instrumental singular in Old English and Old Frisian. Neophilologus 85.287-90.

Bammesberger, A. 2007. Runic names in -warijaz. NOWELE 53.13-18.

Bammesberger, A. 2010. Gothic tweihna-, Old English twegen, and some further formations with Gmc. *twi. NOWELE 58/59.323-42.

Bandle, O. 1973. Die Gliederung des Nordgermanischen. Basel. Rpt. Tübingen 2011.

Bandle, O. (main editor), K. Braunmuller, E.-H. Jahr, A. Karker, H.P. Naumann, \& U Teleman, edd. 2002-5. The Nordic Languages: an international handbook on the history of the North Germanic languages. 2 vols. Berlin.

Banta, F. 1980. Proto-Germanic short o. MGS 6.17-39.

Barber, P.J. 2013. Sievers' law and the history of semivowel syllabicity in Indo-European and ancient Greek. Oxford.

Barnes, M.P. 2009. The origins of the younger fupark: a review of recent and less recent research. NOWELE 56/57.123-42.

Barnes, M.P. 2012. Runes: a handbook. Woodbridge.

Barnes, M.R. 1975. On the origin of the West Germanic second singular preterite. SN 47.275-84.

Barnes, M.R. 1999. Old High German umlaut. In Carr, Harbert, \& Zhang 1999: 239-46.

Barrack, C.M. 1998. Sievers' law in Germanic. New York.

Barrack, C.M. 2010. Sievers' law in Gothic: a response to Pierce. JGL 22.255-76.

Bazell, C.E. 1937. IE final unaccented $\bar{e}$ in Germanic. JEGP 36.1-9.

Bech, G. 1962. Die Entstehung der ahd. Verbalendung -mēs. SN 34.195-211.

Bech, G. 1963. Die Entstehung des schwachen Präteritums. Copenhagen.

Bech, G. 1969. Über die gotischen Gen.Pl.-Endungen. Lingua 23.55-65.

Bechtel, F. 1885. Über die urgermanische Verschärfung von $j$ und v. Nachrichten der Akademie der Wissenschaften in Göttingen (Phil.-Hist. Klasse) 6.235-9.

Beck, H., ed. 1986. Germanenprobleme in heutiger Sicht. Berlin.

Beck, H., ed. 1989. Germanische Rest- und Trümmersprachen. Berlin.

Beckwith, C.I. 2007. On the Proto-Indo-European obstruent system. HS 120.1-19. 
Bednarczuk, L. 1982-3. The ethnolinguistic situation in prehistorical North-East Europe. Annali del Seminario di Studi dell'Europa Orientale 1.69-83.

Bednarczuk, L. 1999. Germanic and North Indo-European. In Vielfalt der Sprachen: Festschrift für Aleksander Szulc zum 75. Geburtstag, ed. M. Kłańska \& P. Wiesinger, 37-50. Vienna.

Beekes, R.S.P. 1969. The development of the Proto-Indo-European laryngeals in Greek. The Hague.

Beekes, R.S.P. 1972. Germanic Verschärfung and no laryngeals. Orbis 21.327-36.

Beekes, R.S.P. 1985. The origins of the Indo-European nominal inflection. Innsbruck.

Beekes, R.S.P. 1988. The pronominal genitive singular in Germanic and Proto-Indo-European. PBB 110.1-5.

Beekes, R.S.P. 1989. The Indo-Iranain ending *-āsas and its Germanic cognates. In Heller et al. 1989: 29-44.

Beekes, R.S.P. 2011. Comparative Indo-European linguistics: an introduction. $2^{\text {nd }}$ ed. Amsterdam. Translated from Vergelijkende taalwetenschap. Een inleiding in de vergelijkende Indoeuropese taalwetenschap, Utrecht, 1990.

Beeler, M.S. 1966. Proto-Germanic [i] and [e]: one phoneme or two? Language 42.473-4.

Beeler, M.S. 1979. North-West Germanic -um = Gothic -am. In Linguistic method: essays in honor of Herbert Penzl, ed. I. Rauch \& G.F. Carr, 509-14. The Hague.

Behagel, O., ed. 1984. Heliand und Genesis. $9^{\text {th }}$ ed. rev. B. Taeger. Tübingen.

Benediktsson see Hreinn Benediktsson

Bennett, W.H. 1962. The parent suffix in Germanic weak verbs of class III. Language 38.135-41.

Bennett, W.H. 1964. Gothic spellings and phonemes: some current interpretations. In Taylor Starck Festschrift, 19-27. The Hague.

Bennett, W.H. 1968. The accentuation of Gothic ga-. In Germanic studies in honor of Edward Henry Sehrt, ed. F.A. Raven et al., 53-60. Coral Gables.

Bennett, W.H. 1969. Pre-Germanic /p/ for Indo-European /kw/. Language 45.243-7.

Bennett, W.H. 1972. Prosodic features in Proto-Germanic. In van Coetsem \& Kufner 1972: 100 16.

Bennett, W.H. 1978. The Germanic reflex of Indo-European /a/ in originally medial syllables. In Jazayery, Polomé, \& Winter 1978: 3.13-18.

Bergmann, R., H. Tiefenbach, \& L. Voetz, edd. 1987. Althochdeutsch. Heidelberg.

Bermúdez-Otero, R. 2015. The life cycle of High Vowel Deletion in Old English: from prosody to stratification and loss. Handout to paper presented at the $9^{\text {th }}$ Studies in the History of the English Language Conference (SHEL-9), Vancouver, 5 June 2015. http://www.bermudezotero.com/SHEL9.pdf. Last accessed 21 May 2017.

Bernharðsson see Haraldur Bernharðsson

Bethge, R. 1900. Konsonantismus des Urgermanischen. In Dieter 1900: 162-92.

Bezzenberger, A. 1880. Die verwandtschaftliche Gruppierung der altgermanischen Dialekte. Nachrichten von der K. Gesellschaft der Wissenschaften und der Georg-Augusts-Universität zu Göttingen, 152-5.

Binnig, W. 1999. Gotisches Elementarbuch. $5^{\text {th }}$ ed. Berlin.

Bird, N. 1982. The distribution of Indo-European root-morphemes. Wiesbaden.

Birkhan, H. 1974. Das germanische starke Adjektiv. In Strukturen und Interpretationen: Studien zur deutschen Philologie gewidmet Blanka Horacek zum 60. Geburtstag, ed. A. Ebenauer, F.P. Knapp, \& P. Krämer, 1-24. Vienna.

Birkmann, T. 1987. Präteritopräsentia: Morphologische Entwicklungen einer Sonderklasse in den altgermanischen Sprachen. Tübingen.

Birnbaum, H. 1984. Zu den ältesten lexikalischen Lehnbeziehungen zwischen Slaven und Germanen. Wiener Slawistischer Almanach 13.7-21.

Bjorvand, H. 1987. Holt og holtar: om utviklingen av det indoeuropeiske kollektivum i norrønt på sammenlignende grunnlag. Oslo.

Bjorvand, H. 1991. Der Genitiv Singular der indoeuropäischen o-Stämme. IF 96.96-117.

Bliss, A.J. 1967. The metre of 'Beowulf'. Rev. ed. Oxford. 
Boer, R.C. 1916. Over den samenhang der klankverschuivingen in de Germaansche dialecten. Neophilologus 1(2), 103-11.

Boer, R.C. 1924. Oergermaansch handboek. $2^{\text {nd }}$ ed. Haarlem.

Born, R. 1980. Disintegration and reintegration: the history of the verbal ablaut from ProtoGermanic to Modern German. LB 69.385-444.

Bosworth, J., \& T.N. Toller. 1882. An Anglo-Saxon Dictionary. Oxford.

Bouckaert, R., et al. 2012. Mapping the origins and expansion of the Indo-European language family. Science 337 (no. 6097), 957-60.

Boutkan, D.F.H. 1992. Old English -ur/-or in the $r$ - and $s$-stems. NOWELE 20.3-26.

Boutkan, D.F.H. 1995a. Altgermanisch 'Held' und die Entwicklung von unbetontem *e im Altnord- und Westgermanischen. ABäG 41.1-7.

Boutkan, D.F.H. 1995b. The Germanic 'Auslautgesetze'. Amsterdam.

Boutkan, D.F.H. 1996. A concise grammar of the Old Frisian dialect of the First Riustring Manuscript. Odense.

Boutkan, D.F.H. 1998. On the form of North European substrate words in Germanic. HS 111.102-33.

Boutkan, D.F.H. 1999. Pregermanic fish in Old Saxon glosses: on alleged ablaut patterns and other formal deviations in Gmc. substratum words. $A B \ddot{a} G$ 52.11-26.

Boutkan, D., \& S.M. Siebenga. 2005. Old Frisian etymological dictionary. Leiden.

Braune, W. 1874a. Die altslovenischen Freisinger Denkmäler in ihrem Verhältnisse zur ahd. Orthographie. $P B B$ 1.527-34.

Braune, W. 1874b. Zur Kenntnis des Fränkischen und zur hochdeutschen Lautverschiebung. PBB $1.1-56$

Braune, W. 1876. Über die Quantität der althochdeutschen Endsilben. PBB 2.125-67.

Braune, W. 2004a. Althochdeutsche Grammatik. 15 $5^{\text {th }}$ ed. rev. I. Reiffenstein. Tübingen.

Braune, W. 2004b. Gotische Grammatik. 20th ed. rev. F. Heidermanns. Tübingen.

Bremer, O. 1886. Germanisches ē. PBB 11.1-76.

Bremer, O. 1900. Ethnographie der germanischen Stämme. In Paul 1900-9: III, 735-959.

Bremer, O. 1903. Urgerm. $a$ in unbetonter Silbe. IF 14.363-7.

Bremmer, R.H., Jr. 1982. Old English - Old Frisian: the relationship reviewed. In Philologia Frisica anno 1981, 79-90. Ljouwert.

Bremmer, R.H., Jr. 2005. Old Frisian fule and felo 'much; many': an idiosyncrasy in Germanic and Frisian perspective. NOWELE 46/47.31-40.

Bremmer, R.H., Jr. 2008. North-Sea Germanic at the cross-roads: the emergence of Frisian and Hollandish. NOWELE 54/55.279-308.

Bremmer, R.H., Jr. 2009. An Introduction to Old Frisian. Amsterdam.

Bremmer, R.H., Jr., \& A. Quak, edd. 1992. Zur Phonologie und Morphologie des Altniederländischen. Odense.

Brink, L. 2004. PIE feature synchronism and word division in Verner's law. In Per aspera ad asteriscos, ed. A. Hyllested et al., 81-93. Innsbruck.

Brinkmann, H. 1951. Zur Erforschung des Frühgermanischen. Zeitschrift für Mundartforschung 20.207-17.

Britton, D., ed. 1996. English historical linguistics 1994. Amsterdam.

Brogyanyi, B. \& T. Krömmelbein, edd. 1986. Germanic dialects: linguistic and philological investigations. Amsterdam.

Brøndum Nielsen, J. 1950-7. Gammeldansk grammatik i sproghistorisk fremstilling. $2^{\text {nd }}$ ed. 8 vols. Copenhagen.

Brosman, P.W., Jr. 1971. Romance evidence and Gothic ggw. IF 76.165-73.

Brugmann, K. 1895. Der präteritale Bildungstypus ahd. hiaz aisl. hét und ahd. liof aisl. hlióp. IF $6.89-100$.

Brugmann, K. 1913. Zu den Ablautverhältnissen der sogenannten starken Verba des Germanischen. IF 32.179-95.

Brugmann, K. 1914. Der gotische Genitivus Pluralis auf -ēe. IF 33.272-84. 
Brugmann, K., \& B. Delbrück. 1897-1916. Grundriss der vergleichenden Grammatik der indogermanischen Sprachen. $2^{\text {nd }}$ ed. 5 vols. Strassburg.

Brugmann, K., \& H. Osthoff. 1878-1910. Morphologische Untersuchungen auf dem Gebiete der indogermanischen Sprachen. 6 vols. Leipzig.

Brunner, K. 1965. Altenglische Grammatik nach der Angelsächsischen Grammatik von Eduard Sievers. $3^{\text {rd }}$ ed. Tübingen.

Buckso, John M. 2011. Preverbs and idiomatization in Gothic. New York.

Bugge, S. 1855. Die Formen der geschlechtslosen persönlichen Pronomina in den germanischen Sprachen. KZ 4.241-56.

Bülbring, K. 1902. Altenglisches Elementarbuch, I: Lautlehre. Heidelberg.

Calabrese, A. 1994. Sievers' law in Gothic: a synchronic analysis with some notes on its diachronic development. The Linguistic Review 11.49-94.

Calder, D.G. \& T.C. Christy, edd. 1988. Germania: comparative studies on the old Germanic languages and literatures. Wolfeboro, N.H.

Callender, C. 2007. The progression of West Germanic gemination. IJGLSA 12.187-222.

Callender, C. 2012. Neogrammarian sound change, lexical diffusion, and the Second Consonant Shift. NOWELE 64/65.37-75.

Callender, C. 2017. Borrowing, incomplete lexical diffusion and the High German tenues shift. NOWELE 70.57-72.

Cameron, A., A.C. Amos, A.diP. Healey, et al., edd. 2016. Dictionary of Old English: A to H. http://tapor.library.utoronto.ca/doe/ (by subscription). Last accessed 18 May 2017.

Campbell, A. 1947. West Germanic problems in the light of modern dialects. TPS 1947, 1-14.

Campbell, A. 1972. A dictionary of Old English: enlarged addenda and corrigenda. Oxford.

Campbell, A. 1977. Old English grammar. Reprinted from the corrected sheets of the $1^{\text {st }}$ ed. (1959). Oxford.

Campbell, J. 1982. The lost centuries: 400-600. In The Anglo-Saxons, ed. J. Campbell, 20-44. Ithaca.

Cardona, G., \& N.H. Zide, edd. 1987. Festschrift for Henry Hoenigswald on the occasion of his seventieth birthday. Tübingen.

Carr, G.F., W.E. Harbert, \& L. Zhang, edd. Interdigitations: essays for Irmengard Rauch. New York.

Casaretto, A. 2000. Korpussprachen und Produktivität: Einige Überlegungen zu den gotischen $s$ Stämmen. HS 113.210-38.

Casaretto, A. 2004. Nominale Wortbildung der gotischen Sprache. Heidelberg.

Cathey, J. 1970. A reappraisal of 'Holtzmann's law'. Studia Linguistica 24.56-63.

Cathey, J. 2000. Old Saxon. Munich.

Cercignani, F. 1979. The reduplicating syllable and internal open juncture in Gothic. KZ 93.12632.

Cercignani, F. 1980a. Alleged Gothic umlauts. IF 85.207-13.

Cercignani, F. 1980b. Early 'umlaut' phenomena in the Germanic languages. Language 56.12636.

Cercignani, F. 1984. The enfants terribles of Gothic 'breaking': hiri, aippau, etc. JIES 12.315-44.

Chang, W., et al. 2015. Ancestry-constrained phylogenetic analysis supports the Indo-European steppe hypothesis. Language 91.194-244.

Clackson, J. 2007. Indo-European linguistics. Cambridge.

Clark Hall, J.R. 1960. A Concise Anglo-Saxon Dictionary. $4^{\text {th }}$ ed. rev. H.D. Meritt. Cambridge.

Cleasby, R., \& G. Vigfusson. 1957. An Icelandic-English dictionary. Rev. ed., with a supplement by W.A. Craigie. Oxford.

Collier, L.W. 1987. The chronology of $i$-umlaut and breaking in Pre-Old English. NOWELE 9.33-45.

Collinge, N.E. 1985. The laws of Indo-European. Amsterdam.

Collitz, H. 1905. Das Analogiegesetz der westgermanischen Ablautsreihen. Modern Language Notes 20.65-8.

Collitz, H. 1912. Das schwache Präteritum und seine Vorgeschichte. Göttingen. 
Colman, F. 1994. Old English stress: amorphous? In English historical linguistics 1992, ed. F. Fernández et al., 65-79.

Connolly, L.A. 1977. Indo-European $i>$ Germanic $e$ : an explanation by the laryngeal theory. $P B B(T)$ 99.173-205, 333-58.

Connolly, L.A. 1979. $\bar{e}_{2}$ and the laryngeal theory. $P B B(T)$ 101.1-29.

Connolly, L.A. 1980. 'Grammatischer Wechsel' and the laryngeal theory. IF 85.96-123.

Connolly, L.A. 1983. Germanic -r-preterites. JIES 11.325-38.

Connolly, L.A. 1999. On identifying laryngeal reflexes in Germanic. AJGLL 11.205-22.

Cook, A.S. 1894. A glossary of the Old Northumbrian gospels. Halle.

Cordes, G. 1973. Altniederdeutsches Elementarbuch. Heidelberg.

Cordes, G., \& D. Möhn, edd. 1983. Handbuch zur niederdeutschen Sprach- und Literaturwissenschaft. Berlin.

Cornish, J.L. 2007. The role of accent correlates in the history of Germanic: Verner's law and unstressed vowel reduction and loss. Ph.D. thesis. State Univ. of New York at Buffalo.

Cowan, H.K.J. 1957. De Oudnederlandse (Oudnederfrankische) Psalmenfragmenten. Leiden.

Cowgill, W. 1957. The Indo-European long-vowel preterites. Ph.D. thesis. Univ. of Michigan, Ann Arbor.

Cowgill, W. 1959. The inflection of the Germanic ō-presents. Language 35.1-15.

Cowgill, W. 1960. Gothic iddja and Old English èode. Language 36.483-501.

Cowgill, W. 1965. Evidence in Greek. In Evidence for laryngeals, ed. W. Winter, 142-80. The Hague.

Cowgill, W. 1970. Italic and Celtic superlatives and the dialects of Indo-European. In IndoEuropean and the Indo-Europeans, ed. G. Cardona, H.M. Hoenigswald, \& A. Senn, 113-53. Philadelphia.

Cowgill, W. 1985. PIE * duuo '2' in Germanic and Celtic, and the nom.-acc. dual of non-neuter $o$ stems. MSS 46.13-28.

Crawford, J. 2012. Old Norse-Icelandic (pú) est and (pú) ert. Arkiv 127.13-17.

Dahl, I. 1938. Substantival inflexion in early Old English. Lund.

Dal, I. 1932. Die germanischen Pronominalkasus mit n-Formans. Oslo.

Dal, I. 1934. Zur Geschichte der ia-Stämme im Westgermanischen. NTS 7.243-52.

Dal, I. 1983. Altniederdeutsch und seine Vorstufen. In Cordes \& Möhn 1983: 69-97.

d'Alquen, R.J.E. 1974. Gothic ai and au. The Hague.

d'Alquen, R.J.E. 1988. Germanic accent, grammatical change and the laws of unaccented syllables. Frankfurt a.M.

d'Alquen, R.J.E. 1997. Non-reduplication in Northwest Germanic: the problem that will not go away. In Germanic studies in honor of Anatoly Liberman, ed. K.G. Goblirsch et al. [NOWELE 31/32], 69-91. Odense.

Davis, G.W. 1999. Rounding the corner: progress in Old High German linguistics at the turn of the century. Diachronica $16.335-55$.

Davis, G.W. \& G.K. Iverson. 1994. pl-in Gothic. HS 107.155-64.

Davis, G.W. \& G.K. Iverson. 1996a. Gothic $p l-:$ a response to Woodhouse. HS 109.276-8.

Davis, G.W. \& G.K. Iverson. 1996b. The Verschärfung as feature spread. In Germanic linguistics: syntactic and diachronic, ed. R.L. Lippi-Green \& J.C. Salmons, 103-20. Amsterdam.

De Decker, F. 2011. Stang's law and the Indo-European word for 'cow'. IF 116.42-59.

Denton, J.M. 1998. Phonetic prespectives on West Germanic consonant gemination. AJGLL $10.201-35$.

Devleeschouwer, J. 1985-6. Zum uralischen Substrat des Gallischen und des Urgermanischen, II. Onoma 28.20-34. [Part I (1971) is on Gaulish only.]

Dick, E.S., \& K.R. Jankowsky, edd. 1982. Festschrift für Karl Schneider zum 70. Geburtstag am 18. April 1982. Amsterdam.

Dickhoff, E. 1913. Der Unterschied im Gebrauch von gotisch uns und unsis. ZfdA 54.466-74.

Dieter, F., ed. 1900. Laut- und Formenlehre der altgermanischen Dialekte. Leipzig.

Dimler, G.R. 1974. The development of the aorist in the Germanic verbal system: a survey of opinion. Semasia 1.95-102. 
Dishington, J. 1976. Functions of the Germanic $\bar{e}$-verbs: a clue to their formal prehistory. Language 52.851-65.

Dishington, J. 1978. Arguments for an ai/ja-paradigm in the 3rd weak class of Proto-Germanic. IF 83.301-23.

Dishington, J. 2010. The Caland system and the Germanic third weak verb class. HS 123.297317.

Dittmer, A. 1989. Das Präteritum der althochdeutschen schwachen Verben I, -it- oder -t-? Kopenhagener Beiträge zur germanistischen Linguistik 25.23-44.

Donaldson, B.C. 1983. Dutch: a linguistic history of Holland and Belgium. Leiden.

Donhauser, K., et al. 2011. Referenzkorpus Altdeutsch. http://www.deutschdiachrondigital.de/. Last accessed 20 May 2018.

Draye, L. 1986. Niederländisch und Germanisch: Bemerkungen zu Theo Vennemanns neuer Lautverschiebungstheorie aus niederländischer Sicht. PBB 108.180-9.

Draye, L. 1990a. Wellentheorie und Entfaltungstheorie: Methodisches zur Lautverschiebungsdiskussion. In Sprache in der sozialen und kulturellen Entwicklung, ed. R. Grosse, 323-7. Berlin.

Draye, L. 1990b. Zur Konditionierung der westgermanischen Konsonantendehnung. LB 79.17384.

Dresher, B.E., \& A. Lahiri. 1991. The Germanic foot: metrical coherence in Old English. Linguistic Inquiry 22.251-86.

Durie, M. 1996. Early Germanic umlaut and variable rules. In The comparative method reviewed, ed. M. Durie \& M.D. Ross, 112-34. New York.

Düwel, K. 1983. Runenkunde. $2^{\text {nd }}$ ed. Stuttgart.

Düwel, K., ed. 1998. Runeninschriften als Quellen interdisziplinärer Forschung. Berlin.

Dyen, I. 1990. The homomeric argument for a Slavo-Germanic subgroup of Indo-European. In Baldi 1990: 385-90.

Ebbinghaus, E.A. 1990. The question of Visigothic runic inscriptions re-examined. GL 30.20714.

Ebbinghaus, E.A. 1991. The vowel of the Gothic reduplicating syllable. GL 31.177-9.

Edgerton, F. 1934. Sievers' law and Indo-European weak grade vocalism. Language 10.235-65.

Edgerton, F. 1943. The Indo-European semivowels. Language 19.83-124.

Edgerton, F. 1962. The semivowel phonemes of Indo-European: a reconsideration. Language 38.352-9.

Eichman, T.L. 1973. The development of Gmc. *kann-. ABäG 5.1-10.

Eichner, H. 1987. Zu den geschlechtigen Nominativformen des Kardinalzahlworts 'drei' im Althochdeutschen. In Bergmann et al. 1987: 190-200.

Eichner, H. 2005. Etymologische Notiz zu gotisch iddja und altenglisch ēode 'ging'. In Indogermanica: Festschrift Gert Klingenschmitt, ed. G. Schweiger, 71-2. Taimering.

Einarsson see Stefán Einarsson

Elert, C.-C. 1997. Språket i södra Skandinavien under bronsåldern: finskugriskt, baltiskt, germanskt eller...?. In Studier i svensk språkhistoria. 4. Förhandlingar vid fjärde sammankomsten för svenska språkets historia, Stockholm 1-3 november 1995, ed. P. Åström, 77-86. Stockholm.

Erdmann, P.H. 1972. Suffixal $j$ in Germanic. Language 48.407-15.

Ernst, P., \& G. Fischer. 2001. Die germanischen Sprachen im Kreis des Indogermanischen. Vienna.

Eska, J. 1988. The origin of the Gothic genitive plural in -ē. IF 93.186-96.

Etter, A., ed. 1986. O-o-pe-ro-si: Festschrift für Ernst Risch zum 75. Geburtstag. Berlin.

Eulenburg, K. 1904. Zum Wandel des idg. o im Germ. IF 16.35-40.

Euler, W. 1985. Gab es ein ostgermanisches Sprachgebiet in Südskandinavien? (Zur Frage gotisch-ostgermanischer Runeninschriften in Südschweden und Dänemark). NOWELE 6.322.

Euler, W. 1992. Modale Aoristbildungen und ihre Relikte in den alteuropäischen Sprachen. Innsbruck. 
Euler, W. 1997. Die Beziehungen zwischen den italischen, germanischen und baltischen Sprachgruppen. Res balticae 1997, 103-18.

Euler, W. 2002. Die Herausbildung von Übergangsdialekten und Sprachgrenzen: Überlegungen am Beispiel des Westgermanischen und Nordischen. Innsbruck.

Euler, W. 2013. Das Westgermanische: Von der Herausbildung im 3. bis zur Aufgliederung im 7. Jahrhundert. Berlin.

Euler, W., \& Badenheuer, K. 2009. Sprache und Herkunft der Germanen: Abriss des Protogermanischen vor der Ersten Lautverschiebung. Hamburg.

Faarlund, J.T. 2005. From clitic to affix: on the history of Scandinavian reflexive verbs. NOWELE 46/47.53-72.

Fagan, S.M.B. 1989. Geminates in intensive and iterative Germanic class II weak verbs. $P B B$ 111.35-58.

Fairfax, E. 2014. The twisting path of runes from the Greek alphabet. NOWELE 67.173-230.

Falluomini, C. 2014. Zum gotischen Fragment aus Bologna. ZfdA 143.281-305.

Fertig, D. 1998. The ge-participle prefix in Early New High German and the modern dialects. AJGLL 10.237-78.

Fertig, D. 1999. Stem-vowel changes in the German modals. Diachronica 16.233-60.

Fertig, D. 2000. Morphological change up close. Tübingen.

Fertig, D. 2009. Are strong verbs really dying to fit in? Handout. http://www.acsu.buffalo.edu/ \%7Efertig/PubsTalks/GLAC15Handout.pdf. Accessed 26 March 2018.

Fertig, D. 2013. Analogy, plain and simple: the development of exceptions to Sievers' law in Gothic and umlaut alternations in Old Norse short-stem class-I weak verbs. Slides from a presentation at the $21^{\text {st }}$ International Conference on Historical Linguistics, Oslo. http://www. acsu.buffalo.edu/ \%7Efertig/PubsTalks/ICHL2013Talk.pdf. Accessed 22 March 2018.

Fertig, D. 2016. Spreading like wildfire: morphological variation and the dynamics of the great English verb regularization. Handout. http://www.acsu.buffalo.edu/\%7Efertig/PubsTalks/St PetersburgAnglisticaTalk2016.pdf. Accessed 26 March 2018.

Fertig, D. Forthcoming. Morphological change through phonological analogy: $2 \mathrm{SG}-s \rightarrow-s t$ and related developments in Germanic. To appear in JGL.

Fierlinger, J. von. 1885. Zur deutschen Conjugation. KZ 27.430-41.

Filppula, M., \& J. Klemola, edd. 2009. Re-evaluating the Celtic hypothesis. Special issue of ELL $13.155-334$.

Finazzi, R.B., \& P. Tornaghi. 2013. Gothica Bononiensia: Analisi linguistica e filologica di un nuovo documento. Aevum 87.113-155. [English translation in IJGLSA 19.1-57.]

Findell, M. 2012. Phonological evidence from the continental runic inscriptions. Berlin.

Finnur Jónsson. 1901. Det norsk-islandske skjaldesprog. Copenhagen.

Flasdieck, H.M. 1930. Zur Geschichte der femininen ō-Flexion im Westgermanischen. IF 48.5366.

Flasdieck, H.M. 1934. Die zweite Person des Singulars im ae. Verbalsystem. Anglia 58.113-21.

Flasdieck, H.M. 1935. Untersuchungen über die germanischen schwachen Verben III. Klasse (unter besonderer Berücksichtigung des Altenglischen). Anglia 59.1-192.

Flasdieck, H.M. 1936. Die reduplizierenden Verben des Germanischen (unter besonderer Berücksichtigung des Altenglischen). Anglia 60.241-365.

Flasdieck, H.M. 1937a. Ae. dōn und gān. Anglia 61.43-64.

Flasdieck, H.M. 1937b. Das Verbum wollen im Altgermanischen (unter Berücksichtigung des Ae.). Anglia 61.1-42.

Förstemann, E. 1869. Alt-, mittel-, neuurdeutsch. KZ 18.161-86.

Fortson, B.W., IV. 2010. Indo-European language and culture: an introduction. $2^{\text {nd }}$ ed. Chichester.

Fourquet, J. 1948. Les mutations consonantiques du germanique. Paris.

Franck, J. 1971. Altfränkische Grammatik. $2^{\text {nd }}$ ed. rev. R. Schützeichel. Göttingen.

Frey, E. 1989. Worttrennung und Silbenstruktur des Gotischen mit besonderer Berücksichtigung der Skeireins. IF 94.272-93.

Friesen, O. von. 1901-6. Till den nordiska språkhistorien. 2 vols. Uppsala. 
Frings, T. 1932. Germania Romana. Halle.

Fritzner, J., et al. 1954. Ordbog over det gamle norske sprog. 4 vols. Oslo. [Vols. 1-3 are a reprint of the $2^{\text {nd }}$ ed. of 1886-96; Vol. 4 is a supplement by F. Hødnebø.]

Fromm, H. 1957-8. Die ältesten germanischen Lehnwörter im Finnischen. ZfdA 88.81-101, 21140, 299-324.

Fulk, R.D. 1987. Reduplicating verbs and their development in Northwest Germanic. PBB 109.159-78.

Fulk, R.D. 1988. PIE *a in Germanic unstressed syllables. In Bammesberger 1988b: 153-77.

Fulk, R.D. 1989. An eddic analogue to the Scyld Scefing story. Review of English Studies n.s. 40.313-22.

Fulk, R.D. 1992. A history of Old English meter. Philadelphia.

Fulk, R.D. 1993a. Old English dōn, dyde and the verba pura in Germanic. IF 98.241-51.

Fulk, R.D. 1993b. Paradigm regularization and the Verschärfung. In Comparative-historical linguistics: Indo-European and Finno-Ugric, ed. B. Brogyanyi \& R. Lipp, 341-51. Amsterdam.

Fulk, R.D. 1998a. The chronology of Anglo-Frisian sound changes. In Approaches to Old Frisian philology, ed. R.H. Bremmer, Jr., et al. [AbäG 49], 139-54.

Fulk, R.D. 1998b. The role of syllable structure in Old English quantitative sound changes. NOWELE 33.3-35.

Fulk, R.D. 2002. Conditions for the voicing of Old English fricatives, II: morphology. ELL 6.81104.

Fulk, R.D. 2005. Review of S. Suzuki, The metre of Old Saxon Poetry. JGL 17.149-53.

Fulk, R.D. 2007. Some emendations and non-emendations in Beowulf (verses 600a, 976a, 1585b, 1663b, 1740a, 2525b, 2771a, and 3060a). Studies in Philology 104.159-74.

Fulk, R.D. 2008. English as a Germanic language. In A companion to the history of the English language, ed. H. Momma \& M. Matto, 142-9. Chichester.

Fulk, R.D. 2009a. Anglian dialect features in Old English anonymous homiletic literature: a survey, with preliminary findings. In Studies in the history of the English language IV: empirical and analytical advances in the study of English language change, ed. S. Fitzmaurice \& D. Minkova, 81-100. Berlin.

Fulk, R.D. 2009b. Morphology and diachrony in A Grammar of Old English and the Dictionary of Old English. In Constructing a world one word at a time: papers on the Dictionary of Old English project, ed. M. J. Toswell [Florilegium 26], 15-35.

Fulk, R.D. 2010a. Phonological and morphological change in the development of Old English contracted verbs. Keynote address, Germanic Linguistics Annual Conference 16, May 1, University of Wisconsin-Milwaukee.

Fulk, R.D. 2010b. The roles of phonology and analogy in Old English high vowel deletion. TPS 108.126-44.

Fulk, R.D. 2012. An introduction to Middle English. Peterborough, Ont.

Fulk, R.D. 2014. An introductory grammar of Old English, with an anthology of readings. Tempe.

Fulk, R.D., R.E. Bjork, \& J.D. Niles, edd. 2014. Klaeber's 'Beowulf'. 4th ed. Reprinted with corrections. Toronto.

Fullerton, G.L. 1971. The source of the Germanic fourth weak conjugation. Language 47.375-80.

Fullerton, G.L. 1974. The development of obstruents in four Germanic endings. Linguistics $130.71-82$.

Fullerton, G.L. 1975. Grimm's Law and the WGmc. 2sg. verb ending -s. Linguistics 145.87-102.

Fullerton, G.L. 1977. Historical Germanic verb morphology. Berlin.

Fullerton, G.L. 1983. The Gothic genitive plural: an analysis of morphological structure. MGS 9.113-28.

Fullerton, G.L. 1989. The Germanic weak nonpresent formations. PBB 111.59-80.

Fullerton, G.L. 1991. Reduplication and the prosody of ancient Germanic. PBB 113.1-21.

Fullerton, G.L. 1992. PIE. syllabification and Gmc. nominal inflection. In Rauch, Carr, \& Kyes 1992: 81-95. 
Gabriel, E. 1969. Die Entwicklung der althochdeutschen Vokalquantitäten in den oberdeutschen Mundarten. Graz.

Gade, K.E. 1995. The structure of Old Norse 'dróttkvætt' poetry. Ithaca.

Gallée, J.H. 1993. Altsächsische Grammatik. $3^{\text {rd }} \mathrm{ed}$. rev. by H. Tiefenbach. Tübingen.

Gamkrelidze, T.V. 1990. Diachronic typology and reconstruction: the 'archaism' of Germanic and Armenian in light of the glottalic theory. In Language typology 1987: systematic balance in language, ed. W.P. Lehmann, 57-65. Amsterdam.

Gamkrelidze, T.V., \& V.V. Ivanov. 1973. Sprachtypologie und die Rekonstruktion der gemeinindo-germanischen Verschlüsse. Phonetica 27.150-6.

Gamkrelidze, T.V., \& V.V. Ivanov. 1995. Indo-European and the Indo-Europeans. Berlin. [Trans. J. Nichols from Indoevopejskij jazyk i indoevropejcy, Tbilsi, 1984.]

Garrett, A. 2001. Reduplication and infixation in Yurok: morphology, semantics, and diachrony. International Journal of American Linguistics 67.264-312.

Gąsiorowski, P. 1997. The Phonology of Old English stress and metrical structure. Frankfurt a.M.

Gąsiorowski, P. 2006. A shibboleth upon their tongues: early English /r/ revisited. SAP 42.63-76.

Gimbutas, M. 1997. The Kurgan Culture and the Indo-Europeanization of Europe: selected articles from 1952 to 1993 . Washington.

Girvan, R. 1931. Angelsaksisch Handboek. Trans. E.L. Deuschle. Haarlem.

Gíslason, see Konráo Gíslason

Goblirsch, K.G. 1991. Germanic ai and au in Anglo-Frisian. ABäG 33.17-23.

Goblirsch, K.G. 1999. The types of gemination in West Germanic. In Rauch \& Carr 1999: 57-75.

Goblirsch, K.G. 2005. Lautverschiebungen in den germanischen Sprachen. Heidelberg.

Goblirsch, K.G. 2015. Aspiration und Lautverschiebung: Zur Typologie des Niederländischen. NOWELE 68.187-225.

Goering, N. 2016. The linguistic elements of Old Germanic metre. D.Phil. thesis, University of Oxford.

Goering, N. Forthcoming. (Proto-)Germanic alliterative verse: linguistic limits on a cultural phenomenon. To appear in Interrogating the 'Germanic', ed. J.M. Harland, M. Friedrich, \& N. Gunn. Berlin.

Goodare, J. 1993. The long hundred in medieval and early modern Scotland. Proceedings of the Society of Antiquaries of Scotland. 123.395-418.

Gordon, E.V. 1957. An introduction to Old Norse. $2^{\text {nd }}$ ed. rev. A.R. Taylor. Oxford.

Görtzen, Jens. 1998. Die Entwicklung der indogermanischen Verbindungen von dentalen Okklusiven mit besonderer Berücksichtigung des Germanischen. Innsbruck.

Gough, J.V. 1973. Old English cuman and niman. English Studies 54.521-5.

Graaf, T. de, \& P. Tiersma. 1980. Some phonetic aspects of breaking in West Frisian. Phonetica 37.109-20.

Graff, E.G. 1840. Althochdeutscher Sprachschatz oder Wörterbuch der althochdeutschen Sprache. 7 vols. Berlin. Rpt. Darmstadt 1963.

Gray, R.D., \& Q.D. Atkinson. 2003. Language-tree divergence times support the Anatolian theory of Indo-European origin. Nature 426.435-9.

Green, D.H. 1998. Language and history in the early Germanic world. Cambridge.

Gretsch, M. 2006. A key to Ælfric's Standard Old English. Leeds Studies in English n.s. 37.16177.

Griepentrog, W. 1995. Die Wurzelnomina des Germanischen und ihre Vorgeschichte. Innsbruck.

Grimm, J. 1822-37. Deutsche Grammatik. 4 vols. Göttingen.

Grimm, J. 1848. Geschichte der deutschen Sprache. Leipzig.

Grønvik, O. 1981. Runene på Tunesteinen. Oslo.

Grønvik, O. 1983. Die dialektgeographische Stellung des Krimgotischen. Oslo.

Grønvik, O. 1995. Über die Herkunft der Krimgoten und der Goten der Völkerwanderungszeit: eine sprachlich-kritische Beurteilung der Gotenfrage. In Drei Studien zum Germanischen in alter und neuer Zeit, ed. J.O. Askedal, H. Bjorvand, \& O. Grønvik, 69-93. Odense. 
Grønvik, O. 1998a. Runeninschriften als Quelle für die ältere Sprachgeschichte. In Düwel 1998: 576-82.

Grønvik, O. 1998b. Untersuchungen zur älteren nordischen und germanischen Sprachgeschichte. Frankfurt a.M.

Grønvik, O. 2010. Nordische Merkmale in der Sprache der älteren Runeninschriften. In Askedal et al. 2010: 115-35.

Guchmann, M.M. 1966. Glagol v germanskich jazykach. In Guchmann et al. 1962-6: IV, 124 434. [The verb in the Germanic languages.]

Guchmann, M.M., È.A. Makaev, et al., edd. 1962-6. Sravnitel'naja grammatika germanskich jazykov. 5 vols. Moscow. [A comparative grammar of the Germanic languages.]

Guðrún Pórhallsdóttir. 1993. The development of intervocalic *j in Proto-Germanic. Ph.D. thesis, Cornell Univ.

Guinet, L. 1981. Essai de datation de la gémination consonantique du westique. Études Germaniques 36.56-7.

Guinet, L. 1982. Les emprunts gallo-romans au germanique (du ler à la fin du 5e siècle). Paris.

Gutenbrunner, S. 1951. Historische Laut- und Formenlehre des Altisländischen. Heidelberg.

Gütter, A. 2013. Frühe Belege für den Umlaut von. Ahd. /u/, /ō/ und/ū/. PBB 133.1-13.

Gysseling, M. 1987. Substratwörter in den germanischen Sprachen. NOWELE 10.47-62.

Haak, W., et al. 2015. Massive migration from the steppe is a source for Indo-European languages in Europe. bioRxiv Feb. 10. http://biorxiv.org/content/early/2015/02/10/013433. Last accessed 24 Feb. 2015.

Hachmann, R. 1970. Die Goten und Skandinavien. Berlin.

Hachmann, R., G. Kossack, \& H. Kuhn. 1962. Völker zwischen Germanen und Kelten. Neumünster.

Hackstein, O. 2002. Uridg. *CH.CC $>*$ C.CC. HS 115.1-22.

Hahmo, S.-L., T. Hofstra, A.D. Kylstra, \& O. Nikkilä. 1991-2012. Lexikon der älteren germanischen Lehnwörter in den ostseefinnischen Sprachen. Amsterdam.

Hale, M., \& C. Reiss. 2008. The phonological enterprise. Oxford.

Hall, T.A. 2004. On the nongemination of $/ \mathrm{r} /$ in West Germanic twenty-one years later. FLH 25.211-34.

Ham, W.H. 1997-8. A new approach to an old problem: gemination and constraint reranking in West Germanic. Journal of Comparative Germanic Linguistics 1.225-62.

Hammerich, L.L. 1955. Die germanische und die hochdeutsche Lautverschiebung, II: Worin besteht die hochdeutsche Lautverschiebung? PBB(T) 77.165-203.

Hamp, E.P. 1959. Final syllables in Germanic and the Scandinavian accent system. SL 13.29-48.

Hamp, E.P. 1979. The North-European word for 'apple'. Zeitschrift für celtische Philologie 37.158-66.

Hamp, E.P. 1985. On criteria for Northwest Germanic. Lingua Posnaniensis 27.7-11.

Hamp, E.P. 1990. The Germanic $r$-stem nominative singular. HS 103.102-3.

Hansen, B.S.S. 2015. The outcome of PIE *\#Hi- and *\#Hu- in Germanic. IF 120.31-76.

Haraldur Bernharðsson. 2001. Verner's law in Gothic. Ph.D. thesis. Cornell Univ.

Harbert, W. 2007. The Germanic languages. Cambridge.

Harðarson see Jón Axel Harðarson

Harm, V. 2013. 'Elbgermanisch', 'Weser-Rhein-Germanisch' und die Grundlagen des Alhochdeutschen. NOWELE 66.79-99.

Hartmann, M. 2013. Anlautendes idg. * $g^{w h}$ - und $* g^{\prime h} u$ - im Germanischen. International Journal of Diachronic Linguistics and Linguistic Reconstruction 10.1-25.

Haudry, J. 1981. Les deux flexions de l'adjectif en germanique. BSL 76.191-200.

Haugen, E. 1969. Phonemic indeterminacy and Scandinavian umlaut. FL 3.107-19.

Haugen, E. 1970. The language history of Scandinavia: a profile of problems. In The Nordic languages and modern linguistics, ed. Hreinn Benediktsson, 41-86. Reykjavík.

Haugen, O.E., ed. 2013a. Handbok i norrøn filologi. Bergen.

Haugen, O.E. 2013b. Norröne Grammatik im Überblick. Hamburg. 
Healey, A.diP. 2009. Dictionary of Old English web corpus. Toronto. http://tapor.library. utoronto.ca/doecorpus/ (by subscription). Last accessed 18 May 2017.

Heather, P.J. 1996. The Goths. Oxford.

Heather, P.J., \& J. Matthews. 1991. The Goths in the fourth century. Liverpool.

Heidermanns, F. 1993. Etymologische Wörterbuch der germanischen Primäradjektive. Berlin.

Heidermanns, F. 1999. Die germanische Adjektive auf -i-/-ja- und ihr indogermanischer Hintergrund. In 'Grippe', 'kamm' und Eulenspiegel: Festschrift für Elmar Seebold zum. 65 Geburtstag, ed. W. Schindler \& J. Untermann, 145-76. Berlin.

Heidermanns, F. 2007. Zum Präteritum der starken Verben im Gotischen. In Beiträge zur Morphologie, ed. H. Fix, 57-68. Odense.

Heller, K., O. Panagl, \& J. Tischler, edd. 1989. Indogermanica Europaea. Graz.

Hermann, G. 1978. Le problème de l'Ingvéonien. A propos d'un livre de Paolo Ramat. Études germaniques 33.298-304.

Hesselman, B. 1945. Omljud och brytning $i$ de nordiska språken. Stockholm.

Heusler, A. 1967. Altisländisches Elementarbuch. $7^{\text {th }}$, unrev. ed. Heidelberg.

Hewson, J. 2001. Aspect and tense from PIE to Germanic. In Watts et al. 2001: 73-82.

Hiersche, R. 1963. Germ. got. pō/ an. pau Ntr. Pl. = ai. $t \bar{a}(u)$ Masc. Du. aus idg. ${ }^{*} t \bar{o}(\underline{u}) . K Z$ 78.155-60.

Hiersche, R. 1984. Indoarisch-germanische Isoglossen und die Ausgliederung des Germanischen. In Studia linguistica et philologica. Festschrift für Klaus Matzel zum sechzigsten Geburtstag, ed. H.-W. Eroms, B. Gajek, \& H. Kolb, 87-97. Heidelberg.

Hill, E. 2003. Untersuchungen zum inneren Sandhi des Indogermanischen. Bremen.

Hill, E. 2004. Das germanische Verb für 'tun' und die Ausgänge des germanische schwachen Präteritums. Sprachwissenschaft 29.257-303.

Hill, E. 2010. A case study in grammaticalized inflectional morphology: origin and development of the Germanic weak preterite. Diachronica 27.411-58.

Hill, E. 2012. Die Entwicklung von $* u$ vor unsilbischem $* i$ in den indogermanischen Sprachen Nord- und Mitteleuropas: Die Stammsuppletion bei $u$-Adjektiven und das Präsens von 'sein'. NOWELE 64/65.5-36.

Hilmarsson see Jörundur Hilmarsson

Hines, J. 1995. Focus and boundary in linguistic varieties in the North-West Germanic continuum. In Friesische Studien II, ed. V.F. Faltings, A.G.H. Walker, \& O. Wilts, 35-62. Odense.

Hirt, H. 1894. Grammatische Miscellen. PBB 18.519-30.

Hirt, H. 1931-4. Handbuch des Urgermanischen. 3 vols. Heidelberg.

Hock, H.H. 1973. On the phonemic status of Germanic $e$ and $i$. In Issues in linguistics, ed. B.B. Kachru et al., 319-51. Urbana.

Hock, H.H. 1986. Principles of historical linguistics. Berlin.

Hoffmann, K. 1955. Vedisch 'gamati'. MSS 7.89-92.

Höfler, O. 1955-56. Stammbaumtheorie, Wellentheorie, Entfaltungstheorie. $P B B(T)$ 77.30-66, 424-76.

Hofmann, D. 1995. Zur Monophthongierung von germanisch ai und au im Altfriesischen und in seinen Nachbarsprachen. In Lingua Theodisca, ed. J. Cajot et al., 23-36. Münster.

Hofstra, T. 1976. Zum Germanisch des 1. nachchristlichen Jahrhunderts. LB 65.149-66.

Hogg, R.M. 1979. Analogy and phonology. JL 15.55-85.

Hogg, R.M. 1992. A grammar of Old English, I: phonology. Oxford: Blackwell.

Hogg, R.M. 1996. Tertiary stress in Old English: some reflections on explanatory inadequacy. In Britton 1996: 3-12.

Hogg, R.M., \& R.D. Fulk. 2011. A grammar of Old English, II: morphology. Chichester: WileyBlackwell.

Hogg, R.M., \& C.B. McCully. 1987. Metrical phonology. Cambridge.

Holland, G.B. 1980. On the origin of $3^{\text {rd }}$ sg. $-r$ in Old Norse. In Klar, Langdon, \& Silver 1980: 347-55.

Hollifield, P.H. 1979. Final $* \bar{o}$ in monosyllables in North and West Germanic. Die Sprache 25.54-6. 
Hollifield, P.H. 1980. The phonological development of final syllables in Germanic. Die Sprache 26.19-53, 145-78.

Hollifield, P.H. 1984. Raising in unaccented syllables in Germanic. Die Sprache 30.29-72.

Hollifield, P.H. 1985. On the phonological development of monosyllables in West Germanic and the Germanic words for 'who' and 'so'. IF 90.196-206.

Holsinger, D.J., \& J.C. Salmons. 1999. Toward 'a complete analysis of the residues': on regular vs. morpholexical approaches to OHG umlaut. In The emergence of the modern language sciences, ed. S.M. Embleton et al., II, 239-53. Amsterdam.

Holthausen, F. 1891. Review of Georg Holz, Urgermanisches geschlossenes $\overline{\mathrm{e}}$ und verwandtes: Beitrag zur Laut- und Flexionslehre des Germanischen. AfdA 17.185-9.

Holthausen, F. 1903. Etymologien. IF 14.339-42.

Holthausen, F. 1921. Altsächsisches Elementarbuch. $2^{\text {nd }}$ ed. Heidelberg.

Holthausen, F. 1925. Grammatisches. Englische Studien 60.119-20.

Holthausen, F. 1974. Altenglisches etymologisches Wörterbuch. $3^{\text {rd }}$, unrev. ed. Heidelberg.

Holthausen, F. 1985. Altfriesisches Wörterbuch. $2^{\text {nd }}$ ed. rev. D. Hofmann. Heidelberg.

Holtzmann, A. 1835. Review of H.F. Massmann, Skeireins. Heidelberger Jahrbücher der Literatur 28.854-63.

Holtzmann, A. ed. 1836. Isidori Hispalensis de nativitate Domini, passione et resurrectione, etc. Karlsruhe.

Holtzmann, A. 1856. Über das deutsche Duodecimalsystem. Germania 1.217-23.

Holtzmann, A. 1870. Altdeutsche Grammatik, I: Die specielle Lautlehre. Leipzig.

Hopper, P.J. 1973. Glottalized and murmured occlusives in Indo-European. Glotta 7.141-66.

Hopper, P.J. 1975. The syntax of the simple sentence in Proto-Germanic. The Hague.

Hopper, P.J. ed. 1977. Studies in descriptive and historical linguistics. Amsterdam.

Hopper, P.J. 1990. A glottalic interpretation of the Germanic EXPRESSIVE GEMINATION. In Development and diversity: language variation across time and space, ed. J.A. Edmondson et al., 85-93. Dallas.

Howe, S. 1996. The personal pronouns in the Germanic languages. Berlin.

Howell, R.B. 1991a. Modern evidence for ancient sound changes: Old English breaking and Old High German epenthesis revisited. In Antonsen \& Hock 1991: 103-13.

Howell, R.B. 1991b. Old English breaking and its Germanic analogues. Tübingen.

Howell, R.B., \& J.C. Salmons. 1997. Umlautless residues in Germanic. AJGLL 9.83-111.

Hreinn Benediktsson. 1963. Some aspects of Nordic umlaut and breaking. Language 39.409-31.

Hreinn Benediktsson. 1983. The Germanic subjunctive: a morphological review. NOWELE 1.3159 .

Hreinn Benediktsson. 1987. The 1st singular preterite subjunctive in Germanic. In In Honor of Ilse Lehiste / Ilse Lehiste pühendusteos, ed. R. Channon \& L. Shockey, 307-21. Dordrecht.

Huld, M.E. 1986. On the unacceptability of the Indo-European voiced stops as ejectives. $I F$ 91.67-78.

Hutterer, C.J. 1975. Die germanischen Sprachen. Budapest.

Hutton, J. 1998a. The development of secondary stress in Old English. In Historical linguistics 1995, ed. R.M. Hogg \& L. van Bergen, 115-30. Amsterdam.

Hutton, J. 1998b. Stress in Old English, giet ongean. Linguistics 36.847-85.

Hyman, L. 2006. Word-prosodic typology. Phonology 23.225-57.

Isakson, B. 2000. The emergence of a Scandinavian language: development until around 900. NOWELE 36.3-43.

Isakson, B. 2002. How primary was the OHG primary umlaut? NOWELE 41.99-104.

Iversen, R. 1973. Norrøn grammatikk. $7^{\text {th }}$ ed. rev. E.F. Halvorsen. Oslo.

Iverson, G.K., G.W. Davis, \& J.C. Salmons. 1996. Blocking environments in Old High German umlaut. FLH 15.131-48.

Iverson, G.K., \& J.C. Salmons. 1996. The primacy of primary umlaut. PBB 118.69-86.

Iverson, G.K., \& J.C. Salmons. 2012. Paradigm resolution in the lifecycle of Norse umlaut. JGL 24.101-31.

Jacobsohn, H. 1913. Got. ogs, lat. vel. KZ 45.342-8. 
Jakobson, R. 1958. Typological studies and their contribution to historical comparative linguistics. In Proceedings of the eighth International Congress of Linguists, ed. E. Sivertsen, 17-25. Oslo.

Janda, R.D. 1998. German umlaut: morpholexical all the way down from OHG through NHG: two Stützpunkte for Romance metaphony. Rivista di linguistica 10.163-232.

Janko, J. 1906. Über germanisch $\bar{e}_{2}$ und die sog. reduplizierenden Praeterita. IF 20.229-316.

Jasanoff, J. 1973. The Germanic third weak class. Language 49.850-70.

Jasanoff, J. 1978a. Observations on the Germanic Verschärfung. MSS 37.77-90.

Jasanoff, J. 1978b. Stative and middle in Indo-European. Innsbruck.

Jasanoff, J. 1979. The position of the hi-conjugation. In Hethitisch und Indogermanisch, ed. E. Neu \& W. Meid, 79-90. Innsbruck.

Jasanoff, J. 1980. The nominative singular of $n$-stems in Germanic. In Klar et al. 1980: 375-82.

Jasanoff, J. 1983. Reply to Schmalstieg and Kortlandt. JIES 11.187-90.

Jasanoff, J. 2002. The nom. sg. of Germanic $n$-stems. In Wedel \& Busch 2002: 31-46.

Jasanoff, J. 2003. Hittite and the Indo-European verb. Oxford.

Jasanoff, J. 2004. Acute vs. circumflex: some notes on PIE and Post-PIE prosodic phonology. Harvard Working Papers in Linguistics 8.19-31.

Jasanoff, J. 2007. From reduplication to ablaut: the class VII strong verbs of Northwest Germanic. HS 120.241-84.

Jazayery, M., \& W. Winter, edd. 1988. Languages and cultures: studies in honor of Edgar C. Polomé. Berlin.

Jellinek, M.H. 1891a. Beiträge zur Erklärung der germanischen Flexion. Berlin.

Jellinek, M.H. 1891b. Germanisch $\bar{e}_{2}$. PBB 15.297-301.

Jellinek, M.H. 1895. Zur Lehre von den langen Endsilben. ZfdA 39.125-51.

Jellinek, M.H. 1926. Geschichte der gotischen Sprache. (Grundriss der germanischen Philologie I, 1.) Berlin.

Johansson, K.F. 1890. Morphologische Studien III. BB 16.121-70.

Johnsen, S. 2005. The historical derivation of Gothic $a b a$ and its $n$-stem anomalies. HS 118.25162.

Johnsen, S. 2011. The development of voiced labiovelars in Germanic. In Proceedings of the 20th annual UCLA Indo-European Conference, ed. S.W. Jamison et al., 232-41. Bremen.

Jón Axel Harðarson. 1989. Die ōn-Feminina des Germanischen und der Gen. Plur. anord. kvinna/kvenna. Acta Linguistica Hafniensia 21.79-93.

Jón Axel Harðarson. 2005. Der geschlechtige Nominativ Singular und der neutrale NominativAkkusativ Plural der $n$-Stämme. In Sprachkontakt und Sprachwandel, ed. G. Meiser \& O. Hackstein, 215-36. Wiesbaden.

Jónsson see Finnur Jónsson

Jones, A.W. 1979. Gothic final syllables. Ph.D. thesis. Univ. of North Carolina, Chapel Hill.

Jones, M.J. 2002. More on the 'instability' of dental fricatives: Gothic pliuhan 'flee' and Old English fleon 'flee'. Word 53.1-8.

Jordan, R. 1974. Handbook of Middle English grammar: phonology. Trans. \& rev. E.J. Crook. The Hague.

Jörundur Hilmarsson. 1991. On $\bar{e}_{2}$ in Germanic. Acta Linguistica Hafniensia 23.33-47.

Joseph, B.D. 1985. Proto-Indo-European consonantism: methodological and further typological concerns. In Papers from the 6th International Conference on Historical Linguistics, ed. J. Fisiak, 313-21. Amsterdam.

Jungandreas, W. 1949. Geschichte der deutschen und der englishen Sprache, I. $2^{\text {nd }}$ ed. Göttingen.

Jungandreas, W. 1974. Nord-, Ost- und Westgermanischen im 1. Jahrhundert nach Chr. Geb. LB $63.197-214$.

Justus, C.F. 1996. Numeracy and the Germanic upper decades. JIES 24.45-80.

Kallio, P. 1997. Uralic substrate features in Germanic? Suomalais-ugrilaisen seuran aikakauskirja = Journal de le Société Finno-ougrienne 87.123-30.

Karg-Gasterstädt, E., et al. 1968-. Althochdeutsches Wörterbuch. Currently to $R$ (17 March 2017). Berlin. 
Karstien, C. 1921. Die reduplizierten Perfekta des Nord-und Westgermanisch. Giessen.

Karstien, C. 1930. Germanische Sprachen. In Sachwörterbuch der Deutschkunde, II, 1126-8. Leipzig.

Kastovsky, D. 1995. Morphological reanalysis and typology: the case of the German $r$-plural and why English did not develop it. In Historical linguistics 1993, ed. H. Andersen, 227-38. Amsterdam.

Kastovsky, D., \& A. Szwedek, edd. 1986. Linguistics across historical and geographic boundaries. 2 vols. Berlin.

Katz, J. 1998. Studies in Indo-European personal pronouns. Ph.D. thesis. Harvard University.

Kausen, E. 2012. Die indogermanischen Sprachen. Hamburg.

Kehrein, W., \& R. Weise, edd. 1998. Phonology and morphology of the Germanic languages. Tübingen.

Kieckers, E. 1960. Handbuch der vergleichenden gotischen Grammatik. $2^{\text {nd }}$ unrev. ed. Munich. [Orig. pub. 1928.]

Kilbury, J. 1975. Structure and restructuring in Proto-Germanic verbal ablaut. LB 64.347-53.

Kim, R.I. 2009. On the prehistory of Old English dyde. In De comoun peplis language, ed. M. Krygier \& L. Sikorska, 9-22. Frankfurt a.M.

Kim, R.I. 2012. Review of T. Tanaka 2011. Kratylos 57.204-8.

Kim, R.I. 2015. Review of Mottausch 2013. Kratylos 60.89-95.

Kim, Y. 2001. Prosody and $i / j$ alternation in Gothic. JGL 13.97-130.

Kiparsky, P. 1971. Phonological change. Bloomington, Ind.

Kiparsky, P. 1998. Sievers' law as prosodic optimization. In Mir curad: studies in honor of Calvert Watkins, ed. J. Jasanoff et al., 345-60. Innsbruck.

Kiparsky, P. 2000. Analogy as optimization. In Analogy, Levelling, Markedness, ed. A. Lahiri, 15-46. Berlin.

Kiparsky, P. 2006. Syncope, umlaut, and prosodic structure in early Germanic. Unpublished manuscript, Stanford University. [Cited by Iverson \& Salmons 2012.]

Kiparsky, P. 2009. The Old High German weak preterite. in On inflection, ed. P.O. Steinkrüger \& M. Krifka, 107-24. Berlin.

Kirschstein, B. 1962. Sprachliche Untersuchungen zur Herkunft der ahd. Isidor-überstezung, inbesondere zur 'Murbacher These'. $P B B(T)$ 84.5-122.

Kjellmer, G. 1995. Unstable fricatives: on Gothic pliuhan and Old English flèon. Word 46.20723.

Klar, K., M. Langdon, \& S. Silver, edd. 1980. American Indian and Indo-European studies: papers in honor of Madison S. Beeler. The Hague.

Klein, T. 1977. Studien zur Wechselbeziehung zwischen alsächsischem und althochdeutschem Schreibwesen und ihrer sprach- und kulturgeschichtlichen Bedeutung. Göppingen.

Klein, T. 1992. Zu horna und zur sprachlichen Einordnung der Gallehus-Inschrift. PBB 114.21226.

Klein, T. 2013. Zum r-Plural im Westgermanischen. NOWELE 66.169-96.

Kleiner, Y. 1999a. Fernassimilation: Germanic palatal umlaut and breaking. In Carr, Harbert, \& Zhang 1999: 93-106.

Kleiner, Y. 1999b. Syllables, morae and boundaries. IJGLSA 4.1-17.

Klingenschmitt, G. 1987. Erbe und Neuerung beim germanischen Demonstrativpronomen. In Bergmann, Tiefenbach, \& Voetz 1987: 169-89.

Kluge, F. 1879. Beiträge zur Geschichte der germanischen Conjugation. Strassburg.

Kluge, F. 1882. Sprachhistorische Miscellen. PBB 8.506-39.

Kluge, F. 1884. Die germanische Consonantendehnung. $P B B$ 9.149-86.

Kluge, F. 1886. Zur altgermanischen Sprachgeschichte. $P B B$ 11.557-62.

Kluge, F. 1908. Gotische Miszellen. Zeitschrift für deutsche Wortforschung 10.64-5.

Kluge, F. 1910. Gotisch saiwan, waian = ags. sáwan, wáwan. In Festschrift für Wilhelm Viëtor, 106-8. Marburg.

Kluge, F. 1913. Urgermanisch: Vorgeschichte der altgermanischen Dialekte. $3^{\text {rd }}$ ed. Strassburg. 
Kluge, F. 1926. Nominale Stammbildungslehre der altgermanischen Dialekte. $3^{\text {rd }}$ ed. rev. L. Sütterlin \& E. Ochs. Halle.

Knapp, F.P. 1974. Wiederum germanisches $\bar{e}_{2}$. $P B B(T)$ 96.207-40.

Köbler, G. 1989. Gotisches Wörterbuch. Leiden.

Köbler, G. 2014a. Altfriesisches Wörterbuch. $4^{\text {th }}$ ed. http://www.koeblergerhard.de/ afrieswbhinw.html. Last accessed 3 August 2017.

Köbler, G. 2014b. Althochdeutsches Wörterbuch. $6^{\text {th }}$ ed. http://www.koeblergerhard.de/ ahdwbhin.html. Accessed 23 August 2016.

Köbler, G. 2014c. Altniederfränkisches Wörterbuch. $5^{\text {th }}$ ed. http://www.koeblergerhard.de/ anfrkwbhinw.html. Last accessed 27 July 2017.

Köbler, G. 2014d. Altsächsisches Wörterbuch. $5^{\text {th }}$ ed. http://www.koeblergerhard.de/ aswbhinw.html. Last accessed 15 July 2016.

Köbler, G. 2014e. Gotisches Wörterbuch. $4^{\text {th }}$ ed. http://www.koeblergerhard.de/gotwbhin.html. Last accessed 3 August 2017.

Kock, A. 1888. I-omljudet och den samnordiska förlusten af ändelsevokaler. Arkiv 4.141-62. Trans. T.L. Markey as 'I-umlaut and the Common Norse loss of final vowels', in On dating phonological change, ed. T.L. Markey, 1-19 (Ann Arbor, 1978).

Kock, A. 1898. Der $a$-Umlaut und der Wechsel der Endvocale $a: i(e)$ in den altnordischen Sprachen. PBB 23.484-554.

Kögel, R. 1880. Über einige germanische Dentalverbindungen. PBB 7.171-201.

Koivulehto, J. 1977. Germanisch-finnische Lehnbeziehungen: drei Wörter mit fi. -aav- $\sim$ urgerm. -aww- > urn. -aggw-. Finnisch-ugrische Forschungen 42.132-47.

Koivulehto, J. 1986. Die Sieverssche Regel im Lichte der germanisch-finnischen Lehnbeziehungen. In Brogyanyi \& Krömmelbein 1986: 249-94.

Koivulehto, J. 1999. Verba mutuata. Ed. K.Ph. Ruppel. Helsinki.

Koivulehto, J. 2002. Contact with Finno-Ugric languages. In Bandle et al. 2002: 583-94.

Koivulehto, J., \& T. Vennemann. 1996. Der finnische Stufenwechsel und das Vernersche Gesetz. PBB 118.163-182.

Kolbe, T. 1912. Die Konjugation der Lindisfarner Evengelien. Bonn.

Konráo Gíslason et al., edd. 1875-89. Njála. 2 vols. Copenhagen.

Kortlandt, F. 1978. On the history of the genitive plural in Slavic, Baltic, Germanic, and IndoEuropean. Lingua 45.281-300.

Kortlandt, F. 1986. The Germanic first class of weak verbs. NOWELE 8.27-31.

Kortlandt, F. 1988. Proto-Germanic obstruents. AbäG 27.3-10.

Kortlandt, F. 1989. The Germanic weak preterit. $A b \ddot{a} G$ 28.101-9.

Kortlandt, F. 1990. The Germanic third class of weak verbs. NOWELE 15.3-10.

Kortlandt, F. 1991. Kluge's law and the rise of Proto-Germanic geminates. AbäG 34.1-4.

Kortlandt, F. 1993. Old High German umlaut. ABäG 37.19-20.

Kortlandt, F. 1994a. On breaking. NOWELE 24.15-19.

Kortlandt, F. 1994b. The Proto-Germanic pluperfect. AbäG 40.1-5.

Kortlandt, F. 1997. Labials, velars and labiovelars in Germanic. NOWELE 30.45-50.

Kortlandt, F. 2001. The origin of the Goths. AbäG 55.21-5.

Kortlandt, F. 2005. The inflexion of the Indo-European $\bar{a}$-stems in Germanic. $A B \ddot{a} G 60.1-4$.

Kortlandt, F. 2006a. Germanic $\bar{e}_{1}$ and $\bar{e}_{2}$. NOWELE 49.51-4.

Kortlandt, F. 2006b. The inflexion of the Germanic $n$-stems. NOWELE 48.3-7.

Kortlandt, F. 2007. Gothic gen. pl. -e. HS 120.237-40.

Kortlandt, F. 2008. Anglo-Frisian. NOWELE 54/55.265-78.

Kossinna, G. 1936. Ursprung und Verbreitung der Germanen in vor- und frühgeschichtlicher Zeit. $3^{\text {rd }}$ ed. Leipzig.

Kostakis, A. 2015. Height, frontness and the special status of $/ \mathrm{x} /, / \mathrm{r} /$ and $/ 1 /$ in Germanic language history. Ph.D. thesis. Indiana Univ., Bloomington.

Kotin, M.L. 2012. Gotisch: im (diachronischen und typologischen) Vergleich. Heidelberg.

Kraehenmann, A. 2003. Quantity and prosodic asymmetries in Alemannic. Berlin. 
Krahe, H. 1948. Historische Laut- und Formenlehre des Gotischen. Zugleich eine Einführung in die germanische Sprachwissenschaft. Heidelberg.

Krahe, H. 1954. Sprache und Vorzeit: Europäische Vorgeschichte nach dem Zeugnis der Sprache. Heidelberg.

Krahe, H. 1958. Die ahd. Personalendung -mēs. IF 63.55-60.

Krahe, H. 1964. Unsere älteste Flußnamen. Wiesbaden.

Krahe, H. 1966-9. Indogermanische Sprachwissenschaft. 2 vols. Berlin.

Krahe, H. 1967. Historische Laut- und Formenlehre des Gotischen. $2^{\text {nd }}$ ed. rev. Elmar Seebold. Heidelberg. [Cf. Krahe 1948.]

Krahe, H., \& W. Meid. 1969. Germanische Sprachwissenschaft. 3 vols. Berlin.

Krause, W. 1966. Die Runeninschriften im älteren Futhark. With contributions by H. Jankuhn. 2 vols. Göttingen.

Krause, W. 1968. Handbuch des Gotischen. $3^{\text {rd }}$ ed. Munich.

Krause, W. 1971. Die Sprache der urnordischen Runeninschriften. Heidelberg.

Kretschmer, P. 1932. Die Urgeschichte der Germanen und die germanische Lautverschiebung. Wiener prähistorische Zeitschrift 19.269-80.

Krogh, S. 1996. Die Stellung des Altsächsischen im Rahmen der germanischen Sprachen. Göttingen.

Kroonen, G. 2008. The origin of Gothic izwis. NOWELE 53.3-11.

Kroonen, G. 2011. The Proto-Germanic n-stems. Amsterdam.

Kroonen, G. 2013a. Etymological dictionary of Proto-Germanic. Leiden.

Kroonen, G. 2013b. Non-Indo-European root nouns in Germanic: evidence in support of the agricultural substrate hypothesis. In A linguistic map of prehistoric northern Europe, ed. R. Grünthal \& P. Kallio, 239-60. Helsinki.

Krygier, M. 1994. The disintegration of the English strong verb system. Frankfurt a.M.

Krygier, M. 1997. Theory recycling: the case of $i$-umlaut. SAP 31.117-21.

Kuhn, H. 1929. Das Füllwort of-um im Altwestnordischen. Göttingen.

Kuhn, H. 1933. Zur Wortstellung und -betonung im Altgermanischen. PBB 57.1-109. Rpt. in Kuhn 1969-72: 1.18-103.

Kuhn, H. 1944. Review of the first edition (1944) of Maurer 1952. AfdA 63.4-13.

Kuhn, H. 1952. Review of Schwarz 1951. Anzeiger für deutsches Altertum und deutsche Literatur $66.45-52$.

Kuhn, H. 1955-6. Zur Gliederung der germansichen Sprachen. ZfdA 86.1-47.

Kuhn, H. 1969-72. Kleine Schriften. 3 vols. Berlin.

Kümmel, M.J. 2015. On the lengthened grade in the nominative singular. IF 120.279-95.

Kuryłowicz, J. 1927. a indoeuropéen et $h$ hittite. In Symbolae grammaticae in honorem Joannis Rozwadowski, ed. W. Taszycki \& W. Doroszewski, I, 95-104. Krakow.

Kuryłowicz, J. 1949. Latin and Germanic metre. English and Germanic Studies 2.34-8.

Kuryłowicz, J. 1954. Remarques sur le comparatif (germanique, slave, v. indien, grec). In Sprachgeschichte und Wortbedeutung [ed. G. Redard], 251-7. Bern.

Kuryłowicz, J. 1956. L'apophonie en indo-européen. Wrocław.

Kuryłowicz, J. 1958. L'accentuation des langues indo-européennes. Wrocław.

Kuryłowicz, J. 1964. The inflectional categories of Indo-European. Heidelberg.

Kuryłowicz, J. 1967. The Germanic Verschärfung. Language 43.445-51.

Kuryłowicz, J. 1968. Die Flexion der germanischen schwachen Femininstämme. In Studien zur Sprachwissenschaft und Kulturkunde: Gedenkschrift für Wilhelm Brandenstein, ed. M. Mayrhofer, 85-91. Innsbruck.

Kuryłowicz, J. 1977. Zum germanischen Dentalpräteritum. Kwartalnik Neofilologiczny 24.333-8.

Kuryłowicz, J., M. Mayrhofer, W. Cowgill, C. Watkins, A. Bammesberger, \& T. Lindner. 19682015. Indogermanische Grammatik. 4 vols. Heidelberg.

Kuzmenko, Ju.K. 1991. Fonologičeskaja évolucija germanskich jazykov. Leningrad. [The phonological evolution of the Germanic languages.]

Kuzmenko, Ju.K. [Kusmenko, Ju.K.] 1994. Skandinavische Diphthongierungen. In Arbeiten zur Skandinavistik, ed. H. Schottmann, 139-46. Münster. 
Kyes, R.L., ed. 1969. The Old Low Franconian psalms and glosses. Ann Arbor.

Kyes, R.L 1983. Dictionary of the Old Low and Central Franconian psalms and glosses. Tübingen.

Kylstra, A.D. 1983. Zum Alter des ‘älteren’ Umlauts im Germanischen. ABäG 19.1-6.

Lahiri, A. 2000. Hierarchical restructuring in the creation of verbal morphology in Bengali and Germanic: evidence from phonology. In Analogy, leveling, markedness, ed. A. Lahiri, 71123. Berlin.

Laker, N.J. 2001. The lengthened grade in the Germanic $4^{\text {th }}$ and $5^{\text {th }}$ class strong verbs. In Watts et al. 2001:19-27.

Lane, G.S. 1936. The labiovelars before $\bar{o}$ in Germanic. JEGP 35.17-26.

Lane, G.S. 1963. Bimoric and trimoric vowels and diphthongs: laws of Germanic finals again. JEGP 62.155-70.

Lane, G.S. 1978. Some remarks on reconstructed Germanic. In Linguistic and literary studies in honor of Archibald A. Hill, ed. M.A. Jazayery et al., III, 117-22. Lisse.

Langbroek, E. 2015. So viel geschrieben, so wenig geblieben. Eine neue Entdeckung: unbekannte altfriesische Psalmglossen. $A B \ddot{a} G$ 74.135-46.

Lange, K.-P. 2003. Der westfränkische Ursprung der 2. Lautverschiebung. IncLing 26.99-118.

Lasch, A. 1914. Mittelniederdeutsche Grammatik. Halle.

Lass, R. 1986. Words without etyma: Germanic ‘tooth'. In Kastovsky and Szwedek 1986: I, 47382.

Lass, R. 1994. Old English: a historical linguistic companion. Cambridge.

Lass, R. 1999. Phonology and morphology. In The Cambridge history of the English language, III: 1476-1776, ed. R. Lass, 56-187.

Laur, W. 1984. Ingwäonisch: eine zutreffende Benennung für eine Sprachgruppe? In Miscellanea Frisica $:$ in nije bondel Fryske stúdzjes = een nieuwe bundel Friese studies $=$ a new collection of Frisian studies, ed. N.R. Århammar et al., 21-33. Assen.

Laur, W. 1988. Hochgermanisch und Niedergermanisch: Bedenken gegenüber einer neuen Theorie zur Zweiten Lautverschiebung. Sprachwissenschaft 13.118-50.

Laur, W. 1990. Zur Frage nach frühen Unterschieden zwischen Nordgermanisch und Westgermanisch. Sprachwissenschaft 15.197-225.

Lauttamus, T. 1992. Grimm's law: a functional-structuralist approach to the first German consonant shift. In Studia linguistica Careliana, ed. J. Niemi, 51-78. Joensuu.

Lechner, W. 2008-9. Protogermanisch. http://users.uoa.gr/\%7Ewlechner/HIST2008b\%2004.pdf. Accessed 23 March 2018.

Lehmann, W.P. 1952. Proto-Indo-European phonology. Austin.

Lehmann, W.P. 1954. Old English and Old Norse secondary preterites in -r-. Language 30.20210.

Lehmann, W.P. 1966. The grouping of the Germanic languages. In Ancient Indo-European dialects, ed. H. Birnbaum \& J. Puhvel, 13-27. Berkeley.

Lehmann, W.P. 1967. The Gothic genitive plural $-\bar{e}$ : focus of exercises in theory. In Papers in linguistics in honor of Léon Dostert, ed. W. Austin, 108-11. The Hague.

Lehmann, W.P. 1972. Proto-Germanic syntax. In van Coetsem \& Kufner 1972: 239-68.

Lehmann, W.P. 1985. Indogermanisch-Germanisch-Deutsch: Genealogische Einordnung und Vorgeschichte des Deutschen. In Sprachgeschichte. Ein Handbuch zur Geschichte der deutschen Sprache und ihrer Erforschung, ed. W. Besch, O. Reichmann, \& S. Sonderegger, 949-62. Berlin.

Lehmann, W.P. 1986. A Gothic etymological dictionary, based on the third edition of 'Vergleichendes Wörterbuch der gotischen Sprache' by Sigmund Feist. Leiden.

Lehmann, W.P. 1993. Theoretical bases of Indo-European linguistics. London.

Leskien, A. 1876. Die Declination im Slavisch-Litauischen und Germanischen. Leipzig.

Lewickij, V. 1996. Ablautentgleisungen im Germanischen. Naukovyj visnyk Černivec'koho universytetu. Črnivci 2, Hermans'ka filolohija 1996, 3-8.

Liberman, A. 1982. Germanic accentology, I: the Scandinavian languages. Minneapolis. [No more published.] 
Liberman, A. 1987. Complementary distribution as a tool of phonological analysis with a note on the $e$ sounds in Old High German. GL 27.173-88.

Liberman, A. 1990a. The phonetic organization of early Germanic. AJGLL 2.1-22.

Liberman, A. 1990b. Some debatable questions of Germanic prosody. AJGLL 2.149-58.

Liberman, A. 1991. Phonologization in Germanic: umlauts and vowels shifts. In Antonsen \& Hock 1991: 125-38.

Liberman, A. 1994. Scandinavian phonology. Scandinavian Studies 66.231-67. [Review article on Kuzmenko 1991.]

Liberman, A. 1998. Toward a theory of West Germanic breakings. IJGLSA 3.63-119.

Liberman, A. 2001. Review of Schulte 1998. Alvíssmál 10.85-8.

Liberman, A. 2010. Verner's law. NOWELE 58/59.381-425.

Lindelöf, U. 1901. Die südnordumbrische Mundart des 10. Jahrhunderts. Bonn.

Lindeman, F.O. 1964. Les origines indo-européennes de la 'Verschärfung' germanique. Oslo.

Lindeman, F.O. 1965. La Loi de Sievers et le début du mot en indo-européen. NTS 20.38-108.

Lindeman, F.O. 1968. Bemerkungen zu den germanischen Verbalstämmen auf $-\bar{e},-\bar{o}$. NTS 22.4871.

Lindeman, F.O. 1987. Introduction to the 'laryngeal theory'. Oslo.

Lippi-Green, R.L., ed. 1992. Recent developments in Germanic linguistics. Amsterdam.

Lloyd, A.L. 1961. Indo-European unstressed short $e$ in Germanic. Modern Language Notes $76.847-51$.

Lloyd, A.L. 1966. Is there an $a$-umlaut of $i$ in Germanic? Language 42.738-45.

Lloyd, A.L., et al. 1988-. Etymologisches Wörterbuch des Althochdeutschen. 6 vols. to date (10 June 2017: $A-P)$. Göttingen.

Lockwood, W.B. 1955. An introduction to Modern Faroese. Copenhagen.

Loewe, R. 1907. Das starke Präteritum des Germanischen. KZ 40.266-351.

Loewe, R. 1918. Der germanische Pluraldativ. KZ 48.76-99.

Loewe, R. 1933. Germanische Sprachwissenschaft. $4^{\text {th }}$ ed. 2 vols. Berlin.

Löfvenberg, M.T. 1949. On the syncope of the Old English present endings. Essays and Studies on English Language and Literature 1. Uppsala.

Looijenga, T. 2003. Texts and contexts of the oldest Runic inscriptions. Leiden.

Los, B. 2005. The rise of the to-infinitive. Oxford.

Lötzsch, R. 1987. Die These von der baltoslawisch-germanischen Spracheinheit in der Geschichte der Slawistik, Baltistik und Indoeuropäistik. In History and historiography of linguistics: papers from the fourth international conference on the history of the language sciences (ICHoLS IV), ed. H.-J. Niederehe \& K. Koerner, II, 737-46. Amsterdam.

Lubbe, H.J. 1987. Onset $s p$-, st- and sk- in Germanic languages: cluster or phoneme? SA Tydskrif vir Taalkunde/SA Journal of Linguistics 5/2.75-99.

Lühr, R. 1976. Germanische Resonantengemination durch Laryngal. MSS 35.73-92.

Lühr, R. 1977. Die Dekaden '70-120' im Germanischen. MSS 36.59-71.

Lühr, R. 1978. Die Kontinuante der urindogermanischen Medialflexion im Germanischen. MSS 37.109-20.

Lühr, R. 1980. Zu einem urgermanischen Lautgesetz. In Mayrhofer, Peters, \& Pfeiffer 1980: 24859.

Lühr, R. 1984. Reste der athematischen Konjugation in den germanischen Sprachen. In Untermann \& Brogynayi 1984: 25-90.

Lühr, R. 1988. Expressivität und Lautgesetz im Germanischen. Heidelberg.

Lühr, R. 2016. Indogermanistik und Germanistik. HS 129.233-63.

Luick, K. 1914-40. Historische Grammatik der englischen Sprache. Leipzig. [Only Vol. I completed; rpt. Stuttgart, Oxford, \& Cambridge, Mass. 1964.]

Lutz, A. 1985. Die Worttrennung am Zeilenende in altenglischen Handschriften: Phonologische Betrachtungen zu Claus-Dieter Wetzels gleichnamigem Buch. IF 90.227-38.

Lutz, A. 1986. The syllabic basis of word division in Old English manuscripts. English Studies 67.193-210. 
Lutz, A. 1991. Phonotaktisch gesteuerte Konsonantenveränderungen in der Geschichte des Englischen. Tübingen.

Luxner, B. 2015. Notkers Anlautgesetz und das altalemannische Plosivsystem. Sprachwissenschaft 40.377-411.

Magnússon see Ásgeir Blöndal Magnússon

Mahlow, G. 1888. Die langen Vokale a e in den europaeischen Sprachen. Berlin.

Mailhammer, R. 2006. On the origin of the Germanic strong verb system. Sprachwissenschaft 31.1-52.

Mailhammer, R. 2007. The Germanic strong verbs: foundations and development of a new system. Berlin.

Makaev, È.A. 1962. Ponjatie obščgermaskogo jazyka i ego periodijacija. In Guchmann et al. 1962-6: I, 114-24. [The concept of the Proto-Germanic language and its periodization.]

Makaev, È.A. 1996. The language of the oldest runic inscriptions. Stockholm. [Trans. of Jazyk drevnejšich runičeskich nadpisej (Moscow, 1965).]

Mallory, J.P. 1989. In search of the Indo-Europeans: language, archaeology and myth. London.

Mallory, J.P., \& D.Q. Adams, edd. 1997. The encyclopedia of Indo-European culture. London.

Mallory, J.P., \& D.Q. Adams. 2006. The Oxford introduction to Proto-Indo-European and the Proto-Indo-European world. Oxford.

Mańczak, W. 1982. Kamen die Goten aus Skandinavien? IF 87.127-37.

Mańczak, W. 1984a. Das germanische Dentalpräteritum. KZ 97.99-112.

Mańczak, W. 1984b. Origine méridionale du gothique. Diachronica 1.79-102.

Mańczak, W. 1985a. IE numerals and the sexagesimal system. In Papers from the $6^{\text {th }}$ International Conference on Historical Linguistics, ed. J. Fisiak, 347-52. Amsterdam.

Mańczak, W. 1985b. On the position of Germanic among Indo-European languages again. In Pieper \& Stickel 1985: 563-9.

Mańczak, W. 1986a. L'habitat primitif des Goths. FLH 7.371-80.

Mańczak, W. 1986b. Germanic and other Indo-European languages. In Kastovsky \& Szwedek 1986: I, 491-500.

Mańczak, W. 1987a. Frequenzbedingter unregelmässiger Lautwandel in den germanischen Sprachen. Wrocław.

Mańczak, W. 1987b. On the Ausgliederung of the Germanic languages. JIES 15.1-17.

Mańczak, W. 1990. La restriction de la règle de Verner à la position médiane et le sort du $s$ final en germanique. HS 103.92-101.

Mańczak, W. 1996. Les étymons protogermaniques sont-ils en $*_{-z}$ ou en $*_{-s}$ ? Studia Etymologica Cracoviensia 1.39-42.

Mańczak, W. 1998. Sur l'habitat primitif des Goths. Lingua Posnaniensis 40.125-30.

Mańczak, W. 1999. Revision der Vernerschen Regel. In Linguam amicabilem facere Ludovico Zabrocki in memoriam, ed. J. Bańczerowski \& T. Zgołka, 219-22. Poznań.

Mańczak, W. 2000. Relations entre le germanique, le slave, le balte et le latin. Lingua Posnaniensis 42.99-106.

Marchand, J.W. 1956. Dialect characteristics in our Gothic MSS. Orbis 5.141-51.

Marchand, J.W. 1957a. Germanic short * $i$ and *e: two phonemes or one? Language 33.346-54.

Marchand, J.W. 1957b. Notes on the origin of some Gothic inflectional endings. Modern Language Notes 72.107-10.

Marchand, J.W. 1957c. The Proto-Germanic long stops. GL 2.51-69.

Marchand, J.W. 1959. Über ai, au im Gotischen. $P B B(H)$ 81.436-55.

Marchand, J.W. 1973. The sounds and phonemes of Wulfila's Gothic. The Hague.

Marchand, J.W. 1991. The sound-shift revisited-or Jacob Grimm vindicated. In Antonsen \& Hock 1991: 139-46.

Markey, T.L. 1972. Gothic imperatives in -au. Studia Linguistica 26.42-7.

Markey, T.L. 1976. Germanic dialect grouping and the position of Ingvæonic. Innsbruck.

Markey, T.L. 1979. Review of H. Birkhan, Das 'Zipfische Gesetz', das schwache Präteritum und die germanische Lautverschiebung (Vienna, 1979). MGS 5.238-45.

Markey, T.L. 1981. Frisian. The Hague. 
Markey, T.L. 1982. Reflexivity and Gmc. *se-l-b- 'self'. Sprachwissenschaft 7.348-58.

Markey, T.L. 1986. Social spheres and national groups in Germania. In Beck 1986: 248-66.

Markey, T.L. 1988a. The Celto-Germanic 'Dog/Wolf'-champion and the integration Pre-/Non-IE ideals. NOWELE 11.3-30.

Markey, T.L. 1988b. The laryngeal theory and aspects of Germanic phonology. In Bammesberger 1988b: 313-26.

Markey, T.L., R.L. Kyes, \& P.T. Roberge. 1977. Germanic and its dialects, III: bibliography and indices. Amsterdam. [No more published.]

Marold, E., \& C. Zimmermann, edd. 1995. Nordwestgermanisch. Berlin.

Massmann, H.F. 1841. Gotthica minora. ZfdA 1.294-393.

Matzel, K. 1962. Anlautendes $p l$ - und $f$ - im Gotischen. Die Sprache 8.220-37.

Matzel, K. 1970. Zum System der starken Verben im Germanischen. In Añjati: papers on Indology and Buddhism. A Felicitation volume presented to Oliver Hector de Alwis Wijsekera on his sixtieth birthday, ed. Jayadeva Tilakari, 172-81. Peradenyia, Ceylon.

Matzel, K. 1982-3. Zum gotischen Interrogativ- und Indefinitpronomen ho. KZ 96.119-26.

Matzel, K. 1987. Zu den verba pura des Germanischen. KZ 100.146-203.

Matzel, K. 1988. On the origin of the dental preterit of the verba pura. In Calder \& Christy 1988: 29-44.

Maurer, F. 1952. Nordgermanen und Alemannen. $3^{\text {rd }}$ ed. Bern.

Mayrhofer, M., M. Peters, \& O.E. Pfeiffer, edd. 1980. Lautgeschichte und Etymologie: Akten der VI. Fachtagung der Indogermanischen Gesellschaft. Wiesbaden.

McCray, S. 1983. Der Umlaut im Althochdeutschen (AHD). ZDP 102.115-20.

McCully, C.B. 1992. The phonology of resolution in OE word-stress and metre. In Evidence for Old English, ed. F. Colman, 117-41. Edinburgh.

McCully, C.B., \& R.M. Hogg. 1990. An account of Old English stress. JL 26.315-39.

McFadden, T. 2003. On the pronominal origins of the Germanic strong adjective inflection. MSS 63.53-82.

Mees, B. 2002. The Bergakker inscription and the beginnings of Dutch. ABäG 56.23-6.

Mees, B. 2006. Early Rhineland Germanic. NOWELE 49.13-49.

Meid, W. 1971. Das germanische Praeteritum. Innsbruck.

Meid, W. 1984. Bemerkungen zum indogermanischen Wortschatz des Germanischen. In Untermann \& Brogyanyi 1984: 91-112.

Meid, W. 1986. Hans Kuhns 'Nordwestblock'-Hypothese: Zur Problematik der 'Völker zwischen Germanen und Kelten'. In Beck 1986: 183-212.

Meid, W. 1987. Germanische oder indogermanische Lautverschiebung? In Bergmann et al. 1987: $3-11$.

Meier-Brügger, M. 2003. Indo-European linguistics. Berlin. (Tr. C. Gertmenian from Indogermanische Sprachwissenschaft, $8^{\text {th }}$ ed., Berlin, 2001.)

Meillet, A. 1908. Les dialectes indo-européens. Rpt. 1922. Paris.

Meillet, A. 1922. Caractères générales des langues germaniques. Paris.

Melchert, H.C. 1987. PIE velars in Luvian. In Studies in memory of Warren Cowgill, ed. C. Watkins, 182-204. Berlin.

Melchert, H.C. 1989. New Luvo-Lycian isoglosses. HS 102.23-45.

Melchert, H.C. 1994. Anatolian historical phonology. Amsterdam.

Mengden, F. von. 2005. How myths persist: Jacob Grimm, the long hundred and duodecimal counting. In Englische Sprachwissenschaft und Mediävistik, ed. G. Knappe, 201-21. Frankfurt a.M.

Mengden, F. von. 2010. Cardinal numbers: Old English from a cross-linguistic perspective. Berlin.

Meringer, R. 1887. Beiträge zur Geschichte der indogermanischen Deklination. KZ 28.217-39.

Merlingen, W. 1986. Indogermanisch, Germanisch und die Glottis. PBB 108.321-32.

Meyer, H. 1901. Über den Ursprung der germanischen Lautverschiebung. ZfdA 45 (n.s. 33) 10127. 
Mikkola, J.J. 1924. Die Verschärfung des intervokalischen $j$ und $w$ im Gotischen und Nordischen. In Streitberg Festgabe, 267-71. Leipzig.

Mildenberger, G. 1986. Die Germanen in der archäologischen Forschung nach Kossina. In Beck 1986: 310-20.

Milroy, J. 1982. On the problem of historical interpretation: Verner's law in Gothic. In Papers from the fifth International Conference on Historical Linguistics, ed. A. Ahlqvist, 223-9. Amsterdam.

Minkova, D. 1996. Verse structure as evidence for prosodic reconstruction in Old English. In Britton 1996: 13-37.

Minkova, D. 2003. Alliteration and sound change in early English. Cambridge.

Mitchell, B. 1985. Old English Syntax. 2 vols. Oxford.

Möller, H. 1879. Epenthese vor $k$-Lauten im Germanischen als Wirkung des velaren oder palatalen Charakters des Wurzelauslauts. KZ 24.427-522.

Möller, H. 1880. Zur Declination: germanisch $\bar{a} \bar{e} \bar{o}$ in den Endungen des Nomens und die Entstehung des $o\left(a_{2}\right)$. PBB 7.482-547.

Möller, H. 1911. Vergleichendes indogermanisch-semitisches Wörterbuch. Göttingen.

Moltke, E. 1985. Runes and their origin. Copenhagen.

Morgenroth, W. 1965. Der Genitiv pluralis im Gotischen. PBB(H) 87.328-36.

Moriciniec, N. 1984. Was sint althochdeutsche Dialekte? In Festschrift für Lauri Sepännen zum 60. Geburtstag, ed. A. Jäntti \& O. Salminen, 207-12. Tampere.

Morris, R.L. 1988. Runic and Mediterranean epigraphy. Odense.

Mossé, F. 1956. Manuel de la langue gotique. Paris.

Mottausch, K.-H. 1994. Idg. *hlei- 'gehen' im Germanischen. HS 107.123-40.

Mottausch, K.-H. 1996. Germanisch gangan 'gehen' und die starken Verben mit $a$ aus *o. HS 109.76-109.

Mottausch, K.-H. 1997. Germanisch gä-/gai- 'gehen'. KZ 110.252-71.

Mottausch, K.-H. 1998a. 'Gehen' und 'stehen' im Germanischen. HS 111.134-62.

Mottausch, K.-H. 1998b. Die reduplizierenden Verben im Nord- und Westgermanischen: Versuch eines Raum-Zeitmodells. NOWELE 33.43-91.

Mottausch, K.-H. 2000. Das Präteritum der 4. und 5. starken Verbklassen im Germanischen. NOWELE 36.45-58.

Mottausch, K.-H. 2001. Gotisch - $(u) h$ und ein vergessenes Lautgesetz. NOWELE 38.37-47.

Mottausch, K.-H. 2011. Der Nominalakzent im Frühurgermanischen. Hamburg.

Mottausch, K.-H. 2013. Untersuchungen zur Vorgeschichte des germanischen starken Verbs. Hamburg.

Mottausch, K.-H. 2015. Review of Euler 2013. ABäG 74.284-9.

Moulton, W.G. 1954. The stops and spirants of early Germanic. Language 30.1-42.

Moulton, W.G. 1977. Secondary stress in Germanic alliterative verse. In Hopper 1977: 393-404.

Moulton, W.G. 1986. Die Vennemannsche Lautverschiebungstheorie. PBB 108.1-15.

Moulton, W.G. 1987. On vowel length in Gothic. In Cardona \& Zide 1987: 281-91.

Much, R. 1887. Germanische Dative aus der Römerzeit. ZfdA 31.354-8.

Much, R. 1893. Die Südmark der Germanen. $P B B$ 17.1-136.

Much, R. ed. 1967. Die Germania des Tacitus. $3^{\text {rd }}$ ed., rev. H. Jankuhn. Heidelberg.

Müllenhoff, K. 1879. Irmin und seine Brüder. ZfdA 23.1-23.

Müllenhoff, K. 1900. Deutsche Altertumskunde, IV. Berlin.

Müller, S. 2007. Zum Germanischen aus laryngaltheoretischer Sicht, mit einer Einführung in die Grundlagen. Berlin.

Munske, H.H., et al., edd. 2001. Handbuch des Friesischen / Handbook of Frisian studies. Tübingen.

Murray, R.W. 1986. Urgermanische Silbenstruktur und die westgermansiche Konsonantengemination. $P B B$ 108.333-56.

Murray, R.W. 1988. Phonological strength and early Germanic syllable structure. Munich.

Murray, R.W. 1991. Early Germanic syllable structure revisited. Diachronica 8.201-38. 
Murray, R.W. 1998. Old problems, new approaches, and optimizing preferences: a reply to Ham (1998). Journal of Comparative Germanic Linguistics 2.221-37.

Murray, R.W., \& T. Vennemann. 1983. Sound change and syllable structure in Germanic phonology. Language 59.514-28.

Must, G. 1952. The Gothic genitive plural in -e. Language 28.218-21.

Must, G. 1953. The genitive singular of $o$-stems in Germanic. Language 29.301-5.

Myrvoll, K.J. 2015. Zum Ursprung des Dativs Singular auf $-u$ der altwestnordischen $\bar{o}$-Stämme. IF $120.153-75$.

Nakao, T. 1986. Metathesis. In Kastovsky \& Szwedek 1986: 1.547-56.

Nakhleh, L., T. Warnow, D. Ringe, \& S.N. Evans. 2005. A comparison of phylogenetic reconstruction methods on an Indo-European dataset. TPS 130.171-92.

Naumann, H.-P., ed. 2004. Alemannien und der Norden: Internationales Symposium vom 18.-20. Oktober 2001 in Zürich. Berlin.

Nedoma, R. 2005. Urnordisch - $a$ im Nominativ Singular der maskulinen $n$-Stämme. NOWELE 46/47.155-91.

Neidorf, L., \& R.J. Pascual. 2014. The language of Beowulf and the conditioning of Kaluza's law. Neophilologus 98.657-73.

Neri, S. 2003. I sostantivi in -u del gotico. Innsbruck.

Nielsen, H.F. 1975. Morphological and phonological parallels between Old Norse and Old English. Arkiv 90.1-18.

Nielsen, H.F. 1976. A list of morphological and phonological parallels between North and West Germanic. APS 31.96-116.

Nielsen, H.F. 1984. A note on the origin of Old English breaking and back mutation. $A B \ddot{a} G$ $22.73-81$.

Nielsen, H.F. 1985. Old English and the continental Germanic languages. $2^{\text {nd }}$ ed. Innsbruck.

Nielsen, H.F. 1989. The Germanic languages: origins and early dialectal interrelations. Tuscaloosa. (Trans. from De germanske sprog. Baggrund og grupperung, Odense, 1979.)

Nielsen, H.F. 1990. The Old English and Germanic decades. In Nordic conference for English Studies 4, ed. G. Caie, I, 105-17. Copenhagen.

Nielsen, H.F. 1991. Unaccented vowels in runic Frisian and Ingvaeonic. In Bammesberger 1991b: 299-303.

Nielsen, H.F. 1994a. Ante-Old Frisian: a review. NOWELE 24.91-136.

Nielsen, H.F. 1994b. Ingerid Dal's 1896-1985 views on Old Saxon in the light of new evidence. In Swan, Mørck, \& Jansen Westvik 1994: 195-212.

Nielsen, H.F. 1994c. On the dialectal split of Ingvaeonic West Germanic from the early runic language of Scandinavia. In Runische Schriftkultur in kontinental-skandinavischer und -angelsäsischer Wechselbeziehung, ed. K. Düwel, 117-27. Berlin.

Nielsen, H.F. 1996. Developments in Frisian runology: a discussion of Düwel \& Tempel's runic corpus from 1970. ABäG 45.123-30.

Nielsen, H.F. 1998a. The continental backgrounds of English and its insular development until 1154. Odense.

Nielsen, H.F. 1998b. The linguistic status of the early runic insriptions of Scandinavia. In Düwel 1998: 539-55.

Nielsen, H.F. 2000. The early runic language of Scandinavia. Heidelberg.

Nielsen, H.F. 2004. Friedrich Maurer and the dialectal links of Upper German to Nordic. In Naumann 2004: 12-28.

Nielsen, H.F. 2009. Language change in the runic inscriptions of Denmark between 500 and 700. RASK 30.3-15.

Nielsen, K.M. 1975. The position of Proto-Scandinavian in the Germanic language group. APS 30.1-16.

Nielsen, K.M. 1978. Junggrammatische und phonologische Umlauttheorien. APS 32.21-34.

Nilsson, T. 1996. Notationes germanicae I-IX. Studia Etymologica Cracoviensia 1.49-62.

Nordmeyer, G. 1935. Gothic initial pl-. Language 11.216-19.

Noreen, A. 1894. Abriss der urgermanische Laulehre. Strassburg. 
Noreen, A. 1904. Altnordische Grammatik, II: Altschwedische Grammatik, mit Einschluss des Altgutnischen. Halle: Niemeyer.

Noreen, A. 1970. Altnordische Grammatik, I: Altisländische und altnorwegische Grammatik. $5^{\text {th }}$, unrev. ed. (rpt. of $4^{\text {th }}$ ed. of 1923). University, Ala.

Normier, R. 1977. Idg. Konsonantismus, germ. 'Lautverschiebung' und Vernersches Gesetz. KZ 91.171-218.

Noske, R. 2012. The Grimm-Verner chain shift and Contrast Preservation Theory. In Phonological explorations: empirical, theoretical and diachronic issues, ed. B. Botma \& R. Noske, 6386. Berlin.

Novembre, J. 2015. Human evolution: ancient DNA steps into the language debate. Nature 522.164-5.

Nowak, A. 2011. Völker zwischen Germanen und Kelten und die Festlegung der Rheingrenze. Munich.

Odenstedt, B. 1990. On the origin and early history of the runic script. Uppsala.

Odenstedt, B. 1991. Review of Morris 1988. In Bammesberger 1991b: 359-87.

Oettinger, N. 1997. Grundsätzliche Überlegungen zum Nordwest-Indogermanischen. IncLing $20.93-111$.

Orel, V. 2003. A handbook of Germanic etymology. Leiden.

Osthoff, H. 1878. Der Gen. Plur. im Germanischen. In Osthoff \& Brugmann 1878-1910: I, 23290.

Osthoff, H. 1882. Got. bidjan, griech. $\pi \varepsilon i \theta \omega$ und verwandtes. $P B B$ 8.140-6.

Osthoff, H. 1886. Die neueste Sprachforschung und die Erklärung des indogermanischen Ablauts. Heidelberg.

Osthoff, H. 1901. Etymologische Parerga. Leipzig.

Osthoff, H., \& K. Brugmann. 1878-1910. Morphologische Untersuchungen auf dem Gebiete der indogermanischen Sprachen. 6 vols. Leipzig.

Paddock, H. 1996-7. Grimm's law as a response to functional asymmetry. Linguistica Atlantica 18/19.109-20.

Page, B.R. 1997. Articulatory phonology as a tool for explanation in historical phonology: the case of stop epenthesis in Germanic. In Rauch \& Carr 1997: 175-88.

Page, B.R. 1998. Verner's law. PBB 120.175-93.

Page, B.R. 2013. Notker's Anlautgesetz and the neutralization of contrasts. $P B B$ 135.515-34.

Page, R.I. 1996. On the baffling nature of Frisian rules. ABäG 45.131-50.

Painter, R.K., \& J.E. Dery. 2014. An acoustic investigation of $r$-umlaut in Old Norse. JGL 26.156-81.

Panieri, L. 2012-13. Eine neue phonetische Hypothese zum primären Umlaut von germ. */a/ im Althochdeutschen. Linguistik Online 53.85-98. Electronic pub.

Panieri, L. 2013. Überlegungen zur nordischen Entwicklung von germ.*/( $\overline{\mathrm{e}}_{1} /$ in Endsilbe. $A B \ddot{a} G$ 70.25-450.

Panieri, L. 2015. Einige Fälle von allophonischem Wechsel von germ. */o/ in unbetonter Silbe. $A B \ddot{a} G$ 74.23-43.

Pascual, R.J. 2016. Old English metrical history and the composition of Widsið. Neophilologus 100.289-302.

Paul, H. 1877. Die Vocale der Flexions- und Ableitungs-Silben in den aeltesten germanischen Dialecten. PBB 4.315-475.

Paul, H. 1879. Zur Geschichte des germanischen Vocalismus. PBB 6.1-256.

Paul, H. 1879-80. Beiträge zur Geschichte der Lautentwickelung und Formenassociation. PBB $6.538-60,7.105-70$.

Paul, H. ed. 1900-9. Grundriss der germanischen Philologie. 3 vols. $2^{\text {nd }}$ ed. rev. K. von Amira et al. Strassburg.

Paul, H. 1916-20. Deutsche Grammatik. 5 vols. Halle.

Pedersen, H. 1951. Die gemeinindoeuropäischen und die vorindoeuropäischen Verschlusslaute. Copenhagen.

Peeters, C. 1971. A phonemic definition of IE $b h, d h, g h . K Z 85.1-4$. 
Penzl, H. 1985. Zur gotischen Urheimat und Ausgliederung der germanischen Dialekte. IF 90.147-67.

Penzl, H. 1986a. Althochdeutsch. Bern.

Penzl, H. 1986b. Zu den Methoden einer neuen germanischen Stammbaumstheorie. PBB 108.1629.

Penzl, H. 1988a. Can Proto-Germanic be reconstructed as a 'natural' language? In Calder \& Christy 1988: 1-8.

Penzl, H. 1988b. The horn of Gallehus and the subgrouping of the Germanic languages. In Jazayery \& Winter 1988: 489-508.

Penzl, H. 1988c. Der Rückumlaut in den germanischen Sprachen. In Gentry 1988: 99-109.

Penzl, H. 1989. Die Gallehusinschrift: Trümmer der nordisch-westgermanischen Ursprache. In Beck 1989: 87-96.

Penzl, H. 1996. Ist das nordisch-westgermanische Runengermanisch das 'Ur-Altenglische'? NOWELE 27.137-45.

Perridon, H. 2001. On the origin of $\bar{u}$ in verbs of the type lūkan. In Watts et al. 2001: 29-37.

Petersen, C.T., ed. 2003. Bibliographia gotica amplificata. CD-ROM. Darmstadt.

Petersen, H.P. 2002. Verschärfung in Old Norse and Gothic. Arkiv 117.5-27.

Peterson, L. 1998. A critical survey of the alleged East Germanic runic inscriptions of Scandinavia. In Düwel 1998: 556-75.

Petracco Sicardi, G. 1977. La seconda mutazione consonantica negli antroponimi di origine longobarda. In Studi di filologia germanica e di letteratura tedesca in onore di Nicola Accolti Gil Vitale, ed. G. Bolognesi \& G. Sichel, 7-20. Genoa.

Petrikovits, H. von. 1985. Fragen der Ethnogenese aus der Sicht der römischen Archäologie. In Studien zur Ethnogenese (= Abhandlungen der Rheinisch-Westfalischen Akademie der Wissenschaften, Bd. 72), 101-32. Opladen.

Philippson, E.A. 1954. Neuere Forschungen zum Westgermanenproblem und zur Ausgliederung der germanischen Stämme. Symposium 8.18-32.

Pieper, U., \& G. Stickel, edd. 1985. Studia linguistica diachronica et synchronica: Werner Winter sexagenario anno MCMLXXXIII. Berlin.

Pierce, M. 2002. Was Gothic syllabification phonologically or morphologically conditioned? IF $107.241-9$.

Pierce, M. 2004. The syllabification of consonant + semivowel clusters in Proto-Germanic. $H S$ $117.86-96$.

Pierce, M. 2006. Syllable structure and Sievers' law in Gothic. JGL 18.275-320.

Pierce, M. 2013. Syllable weight in Gothic. IF 118.213-26.

Pietersen, L. 1978. Die Zukunft des Friesischen. MGS 4.165-76.

Pijnenburg, W.J.J. 1989. Eine germanisch-baltoslawische Isoglosse. HS 102.99-106.

Pijnenburg, W.J.J. 1992. Neuerungen im westgermanischen Dekadensystem, mit besonderer Berücksichtigung des Niederländischen. $A B \ddot{a} G$ 36.31-8.

Pisani, V. 1930. Ein Kapitel der gotischen Auslautgesetze. IF 48.67-71.

Pohl, H.-D. 1989. Zur Herkunft des germanischen Präteritums. In Heller et al. 1989: 193-207.

Pokorny, J. 1959-69. Indogermanisches etymologisches Wörterbuch. 2 vols. Bern.

Polenz, P. von. 2009. Geschichte der deutschen Sprache. 10 $0^{\text {th }}$ ed. rev. N.R. Wolf. Berlin.

Polomé, E. 1949. A West Germanic reflex of the Verschärfung. Language 25.182-9.

Polomé, E. 1959. Théorie 'laryngale' et germanique. In Mélanges de linguistique et de philosophie Fernand Mossé in memoriam, 357-402. Paris.

Polomé, E. 1964. Diachronic development of structural patterns in the Germanic conjugation system. In Proceedings of the ninth International Congress of Linguists, Cambridge, Mass., August 27-31, 1962, ed. H. G. Lunt, 870-80. The Hague.

Polomé, E. 1970. Remarks on the problem of the Germanic Verschärfung. In Linguistique contemporaine: hommage à Eric Buyssens, 177-90. Brussels.

Polomé, E. 1982a. The dialectal position of Germanic within West-Indo-European. Proceedings of the XIIIth International Congress of Linguists 13.733-42. 
Polomé, E. 1982b. Germanic as an archaic Indo-European language. In Dick \& Jankowsky 1982: 51-9.

Polomé, E. 1983. Celto-Germanic isoglosses (revisited). JIES 11.281-98.

Polomé, E. 1985. Methodological approaches to the ethno- and glottogenesis of the Germanic people. In Entstehung von Sprachen und Völkern: Glotto- und ethnogenetische Aspekte europäischer Sprachen, ed. P.S. Ureland, 45-70. Tübingen.

Polomé, E. 1986a. The non-Indo-European component of the Germanic lexicon. In Etter 1986: 661-72.

Polomé, E. 1986b. Some comments on Germano-Hellenic lexical correspondences. In Aspects of language: studies in honour of Mario Alinei, ed. N. Århammar et al., I, 171-98. Amsterdam.

Polomé, E. 1987a. Initial PIE * $g^{w} h$ - in Germanic. In Cardona \& Zide 1987: 303-13.

Polomé, E. 1987b. Who are the Germanic people? In Proto-Indo-European: the archaeology of a linguistic problem, ed. S.N. Skomal \& E. Polomé, 216-44. Washington.

Polomé, E. 1988. Are there traces of laryngeals in Germanic? In Bammesberger 1988b: 383-414.

Polomé, E. 1989. Substrate lexicon in Germanic. NOWELE 14.53-73.

Polomé, E. 1992a. Germanic, Northwest-Indo-European and Pre-Indo-European substrates. In Lippi-Green 1992: 47-55.

Polomé, E. 1992b. Zur Chronologie des Germanischen. In Rekonstruktion und relative Chronologie: Akten der VIII. Fachtagung der indogermanischen Gesellschaft, Leiden, 31. August-4. September 1987, ed. R.S.P. Beekes et al., 55-73. Innsbruck.

Polomé, E. 1993. Prehistoric linguistic contacts in Northern Europe and their reflexes in the lexicon. In Lingue e culture in contatto nel mondo antico e altomedievale: atti dell'VII convegno internazionale di linguisti: tenuto a Milano nei giorni 10-12 settembre 1992, ed. R.B. Finazzi \& P. Tornaghi, 25-62. Brescia.

Polomé, E. 1994. Proto-Germanic and the reconstruction of Proto-Indo-European. NOWELE 23.3-40.

Polomé, E. 1997. How Indo-European is Germanic? In Rauch \& Carr 1997: 197-206.

Porzig, W. 1954. Die Gliederung des indogermanischen Sprachgebiets. Heidelberg.

Probert, P., \& A. Willi, edd. 2012. Laws and rules in Indo-European. Oxford.

Prokosch, E. 1912. Forchhammers Akzenttheorie und die germanische Lautverschiebung. JEGP 11.1-9.

Prokosch, E. 1918-19. Die indogermanischen 'mediae aspiratae'. Modern Philology 15.621-8, 16.99-112, 325-36, 543-52.

Prokosch, E. 1939. A comparative Germanic grammar. Philadelphia.

Quak, A. 1981. Zur Sprache der sogenannten Wachtendonckschen Psalmen. Niederdeutsches Jahrbuch 104.7-21.

Quak, A., \& J.M. van der Horst. 2002. Inleding Oudnederlands. Leuven.

Raith, J. 1931. Die englischen Nasalverben. Leipzig.

Ramat, P. 1981. Einführung in das Germanische. Tübingen.

Ramat, G.A., \& P. Ramat, edd. 1998. The Indo-Eruopean Languages. London.

Randall, W., \& H. Jones. 2015. On the early origins of the Germanic preterite-presents. TPS 113.137-76.

Ranke, F., \& D. Hofmann. 1988. Altnordisches Elementarbuch. $5^{\text {th }}$ ed. Berlin.

Rasmussen, J.E. 1983. Two phonological issues in Germanic. Acta Linguistica Hafniensia $18.201-19$.

Rasmussen, J.E. 1989. On the North Germanic treatment of -eww-. Arkiv 104.1-9.

Rasmussen, J.E. 1990. Germanic Verschärfung: tying up loose ends. In Historical linguistics 1987: papers from the $8^{\text {th }}$ International Conference on Historical Linguistics, ed. H. Andersen \& K. Koerner, 425-41. Amsterdam.

Rasmussen, J.E. 1996. On the origin of the Germanic weak preterite. Copenhagen Working Papers in Linguistics 4.161-8.

Ratkus, A. 2015. Gothic possessives, adjectives, and other modifiers in -ata. JGL 27.238-307.

Ratkus, A. 2018. Greek $\dot{\alpha} \rho \chi \varepsilon \rho \varepsilon v ́ \varsigma$ in Gothic translation: linguistics and theology at a crossroads. NOWELE 71.3-34. 
Rauch, I. 1973. The Germanic dental preterite: language origin and linguistic attitude. IF 77.21533.

Rauch, I. 1992. The Old Saxon Language. New York.

Rauch, I. 1999. Feature spreading in Old High German and Old Saxon: umlaut, monophthongization, pragmatics. In Rauch \& Carr 1999: 201-9.

Rauch, I., \& G.F. Carr, edd. 1997. Insights in Germanic linguistics, II: classic and contemporary. New York.

Rauch, I., \& G.F. Carr, edd. 1999. New insights in Germanic linguistics. New York.

Rauch, I., G.F. Carr, \& R.L. Kyes, edd. 1992. On Germanic linguistics. Berlin.

Reid, T.G. 1990. The lack of $i$-mutation in short-stemmed, syncopated forms in Old Icelandic. NOWELE 15.23-48.

Renfrew, C. 1987. Archaeology and language: the puzzle of Indo-European origins. London.

Renfrew, C. 2002. The Indo-European problem and the exploitation of the Eurasian steppes: questions of time depth. In Complex societies of Central Eurasia from the $3^{\text {rd }}$ to the $1^{\text {st }}$ millennium BC: regional specifics in light of global models, ed. K. Jones-Bley \& D. G. Zdanovich, 3-20. Washington.

Repanšek, L. 2012. Remarks on the development of [the] 'Anglo-Frisian' vowel system. NOWELE 64/65.77-90.

Restelli, G. 1984. Goti, tedeschi, longobardi: rapporti di cultura e di lingua. Brescia.

Riad, T. 1992. Structures in Germanic prosody. Ph.D. thesis. Univ. of Stockholm.

Riad, T. 2004. Syllabification and word division in Gothic. JGL 16.173-202.

Richter, J. 1909. Ursprung und analogische Ausbreitung der Verben auf $-\alpha \zeta \omega$. Leipzig.

Riecke, J. 1996. Die schwachen jan-Verben des Althochdeutsches. Göttingen.

Ringe, D. 1984. Germanic $\bar{e}_{2}$ and $r$. Die Sprache 30.138-55.

Ringe, D. 1998. Some consequences of a new proposal for subgrouping the IE family. Proceedings of the twenty-fourth annual meeting of the Berkeley Linguistics Society: special session on Indo-European subgrouping and internal relations, 32-46. http://journals. linguisticsociety.org/proceedings/index.php/BLS/article/view/1251/1035. Last accessed 15 July 2016.

Ringe, D. 2002. Syncopated present indicative forms in Old English. In Wedel \& Busch 2002: $125-56$.

Ringe, D. 2006a. From Proto-Indo-European to Proto-Germanic. Oxford.

Ringe, D. 2006b. A sociolinguistically informed solution to an old historical problem: the Gothic genitive plural. TPS 104.167-206.

Ringe, D. 2012. Cladistic principles and linguistic reality: the case of West Germanic. In Probert \& Willi 2012: 33-42.

Ringe, D. 2017. $2^{\text {nd }}$ ed. of Ringe 2006a. Oxford.

Ringe, D., \& A. Taylor. 2014. The development of Old English. Oxford.

Ringe, D., T. Warnow, \& A. Taylor. 2002. Indo-European and computational cladistics. TPS $100.59-129$.

Ritter, R.-P. 1984. Ein mögliches finnisches Zeugnis für germanische Resonantengemination durch Laryngeal. MSS 43.183-6.

Ritter, R.-P. 2002. Towards determining the terminus ante quem of the beginning of Protogermanic-Finnic contacts. In Finno-Ugrians and Indo-Europeans, ed. R. Blokland \& C. Hasselblatt, 319-26. Maastricht.

Rix, H. 2001. Lexikon der indogermanischen Verben. $2^{\text {nd }}$ ed. Wiesbaden.

Roberge, P. 1988. Those Gothic spirants again. IF 88.109-55.

Robinson, O.W. 1980. An exception to OHG umlaut. In Klar, Langdon, \& Silver 1980: 449-60.

Robinson, O.W. 1992. Old English and its closest relatives. Stanford.

Roelands, K. 1989. Die Vokalsenkung vor $h$ und $r$, der Velarumlaut und die Brechung im Germanischen. $A B \ddot{a} G 29.177-86$.

Rooth, E. 1974. Das Vernersche Gesetz in Forschung und Lehre 1875-1975. Lund.

Rösel, L. 1962. Die Gliederung der germanischen Sprachen nach dem Zeugnis ihrer Flexionsformen (= Erlanger Beiträge zur Sprach- und Kunstwissenschaft, Bd. 11). Nuremberg. 
Rosenfeld, H.-F. 1955a. Ingwäonisch he, hi und das germanische Demonstrativpronomen. Zeitschrift für Mundartforschung 23.74-110.

Rosenfeld, H.-F. 1955b. Ingwäonisch he, hi und das Personalpronomen im Germanischen. Forschungen und Fortschritte 29.150-6.

Rosenfeld, H.-F. 1955c. Zur sprachlichen Gliederung des Germanischen. Zeitschrift für Phonetik und allgemeine Sprachwissenschaft 8.365-89.

Ross, A.S.C. 1954. Contributions to the study of U-flexion. TPS 1954, 85-128.

Ross, A.S.C., \& J. Berns. 1992. Germanic. In Indo-European numerals, ed. J. Gvozdanovič, 555716. Berlin.

Rot, S. 1988. On Germanic-Eastern Slavic language contacts. In Hungaro-Slavica 1988: Internationaler Slavistenkongress Sofia, 14.-22. September 1988, ed. P. Király \& A. Hollós, 191201. Budapest.

Rowe, C. 2003. The problematic Holtzmann's law in Germanic. IF 108.258-66.

Rübekeil, L. 2002. Diachrone Studien zur Kontaktzone zwischen Kelten und Germanen. Vienna.

Russ, C.V.J. 1978. Historical German phonology and morphology. Oxford.

Russ, C.V.J. 1996. Umlaut in Frisian and the Germanic languages: some thoughts on its genesis and development. NOWELE 28/29.501-12.

Russom, G. 2001. Metrical evidence for subordinate stress in Old English. JGL 13.39-64.

Salmons, J.C. 1987. Another word on lexical data and genetic relatedness. JIES 15.381-4.

Salmons, J.C. 1990. Accent and syllabification in early Germanic: a response to Liberman. AJGLL 2.137-48.

Salmons, J.C. 1992. Northwest Indo-European Vocabulary and Substrate Phonology. In Perspectives on Indo-European Language, Culture and Religion: Studies in Honor of Edgar C. Polomé, ed. R. Pearson, 2265-79. Washington.

Salmons, J.C. 1993. The glottalic theory: survey and synthesis. McLean, Va.

Salmons, J.C. 1994. Umlaut and plurality in Old High German: some problems with a natural morphology account. Diachronica $11.213-29$.

Salmons, J.C. 2012. A history of German. Oxford.

Salmons, J.C., \& G.K. Iverson. 1993. Gothic $p l-\sim f$ - variation as lexical diffusion. Diachronica $10.87-96$.

Sanders, R.H. 2010. German: biography of a language. Oxford.

Sanjosé Messing, A. 1986. ${ }^{+} \mathrm{T}^{\mathrm{h}}-{ }^{+} \mathrm{T}^{\prime}-{ }^{+} \mathrm{D}$ ? Kritische Anmerkungen zu Vennemanns Rekonstruktion des vor-germanischen Konsonantensystems. PBB 108.172-9.

Santesson, L. 1989. En blekingsk blotinskrift: en nytolkning av inledningsraderna på Stentoftenstenen. Fornvännen 84.221-9.

Sapir, E. 1921. Language: an introduction to the study of speech. New York.

Saussure, F. de. 1879. Mémoire sur le système primitif des voyelles dans les langues indo-européennes. Leipzig.

Scardigli, P. 1978. Stand und Aufgaben der Langobardenforschung. Einleitende Bemerkungen. Jahrbuch für internationale Germanistik 10.56-62.

Scardigli, P. 1987. Der germanische Anteil am indogermanischen Wortschatz und anderes. In Studien zum indogermanischen Wortschatz, ed. W. Meid, 218-26. Innsbruck.

Schäfer, C. 1984. Zur semantischen Klassifizierung germanischer denominaler ôn-Verben. Sprachwissenschaft 9.356-83.

Schaffner, S. 2001. Das Vernersche Gesetz und der innerparadigmatische grammatische Wechsel im Nominalbereich. Innsbruck.

Schatz, J. 1907. Altbairische Grammatik. Göttingen.

Schatz, J. 1927. Althochdeutsche Grammatik. Göttingen.

Schenker, W. 1971. -es/-os-Flexion und -es/-os-Stämme im Germanischen. PBB(T) 93.46-59.

Scherer, W. 1995. Zur Geschichte der deutschen Sprache. Amsterdam. [Orig. pub. 1868, Berlin.]

Scheungraber, C. 2013.Wurzelauslautvariationen bei westgermanischen Nasalinfixverben. In The sound of Indo-European 2, ed. R. Sukač \& O. Šefčik, 252-645. Munich.

Scheungraber, C. 2014. Die Nasalpräsentien im Germanischen. Innsbruck.

Schindler, J. 1975. L'apophonie des thèmes indo-européens en -r/n. BSL 70.1-10. 
Schirmunski, V. 1965. Über die altgermanischen Stammesdialekte. Acta Linguistica Academiae Scientiarum Hungaricae 15.1-36.

Schleicher, A. 1860. Die deutsche Sprache. Stuttgart.

Schlerath, B. 1995. Bemerkungen zur Geschichte der -es-Stämme im Westgermanischen. In Verba et structurae: Festschrift für Klaus Strunk, 249-64. Innsbruck.

Schlimpert, G. 1985. Methodologische Probleme des germanisch-slawisch-deutschen Sprachkontaktes. In Beiträge zur Onomastik: Vorträge der Teilnehmer aus der DDR auf dem XV. Internationalen Kongreß für Namenforschung Karl-Marx-Universität Leipzig, 13.-17. August 1984, ed. E. Eichler et al., II, 328-32. Berlin.

Schmalsteig, W.R. 1994. A note on possible parallel development of certain Germanic and Baltic verbs with the suffix *-n-. GL 34.191-4.

Schmid, W.P. 1986. Alteuropa und das Germanische. In Beck 1986: 155-67.

Schmid, W.P. 1987. 'Indo-European' — 'Old European' (on the reexamination of two linguistic terms). In Skomal \& Polomé 1987: 322-38.

Schmid, W.P. 1989. Zu den germanisch-baltischen Sprachbeziehungen: die Komparative der Adjektive. In Heller et al. 1989: 241-50.

Schmidt, C., R. Nedoma, \& K. Düwel. 2011. Die Runeninschrift auf dem Kamm von Frienstedt, Stadt Erfurt. Die Sprache 49.123-86.

Schmidt, G. 1970. Zum Problem der germanischen Dekadenbildung. KZ 84.98-136.

Schmidt, G. 1973. Die iranischen Wörter für 'Tochter' und 'Vater' und die Reflexe des interkonsonantischen $H($ (a) in den idg. Sprachen. $K Z$ 87.36-83.

Schmidt, G. 1977. Das germanische schwache Präteritum mit idg. -dh-. KZ 90.262-70.

Schmidt, G. 1978. Stammbildung und Flexion der indogermanischen Personalpronomina. Wiesbaden.

Schmidt, J. 1872. Die Verwandtschaftsverhältnisse der indogermanischen Sprachen. Weimar.

Schmidt, J. 1889. Die Pluralbildungen der indogermanischen Neutra. Weimar.

Schmidt, J. 1891. Die Urheimat der indogermanen und das europäische Zahlsystem. Berlin.

Schmidt, K.H. 1963. Dativ und Instrumental im Plural. Glotta 41.1-10.

Schmidt, K.H. 1984. Keltisch und Germanisch. In Untermann \& Brogyanyi 1984: 113-53.

Schmidt, K.H. 1986. Keltisch-germanische Isoglossen und ihre sprachgeschichtlichen Implikationen. In Beck 1986: 231-47.

Schmidt, K.H. 1991. The Celts and the ethnogenesis of the Germanic people. HS 104.129-52.

Schmidt, K.M. 1974. The Gothic dual second person *-ts. Linguistics 130.83-6.

Schrijver, P.C.H. 2004. Early developments of the vowel systems of North-West-Germanic and Saami. In Language in prehistoric Europe, ed. A Bammesberger \& T. Vennemann, 195-226. Heidelberg. [First issued 2003.]

Schrijver, P.C.H. 2011. The High German consonant shift and language contact. In Language contact in times of globalization, ed. M. Norde et al., 217-49. Amsterdam.

Schrijver, P.C.H. 2014. Language contact and the origins of the Germanic languages. New York.

Schröder, E. 1898. Zur Vorgeschichte der germanischen -ll- und -li-, -mm- and -m-. ZfdA 42.5971.

Schröder, E. 1921. Die 2. Pers. Sg. Perf. st. Flexion im Westgermanischen. IF 39.224.

Schrodt, R. 1976. Die germanische Lautverschiebung und ihre Stellung im Kreise der indogermanischen Sprachen. $2^{\text {nd }}$ ed. Vienna.

Schrodt, R. 1989. Neue Forschungen zur germanischen Lautverschiebung - ein Fall von Paradigmenwechsel? In Vennemann 1989: 137-52.

Schuhmann, R. 2011. Zum analogischen Ausgleich bei den got. ja-Stämmen. In Indogermanistik und Linguistik in Dialog, ed. T. Krisch \& T. Lindner, 508-16. Wiesbaden.

Schuhmann, R. 2014. Einführung in das Altsächsische. http://www.academia.edu/1739714/ Einf\%C3\%BChrung_in_das_Alts\%C3\%A4chsische. Last accessed 25 May 2018.

Schulte, M. 1998. Grundfragen $\bar{d}$ er Umlautphonemisierung. Berlin.

Schulte, M. 2000a. Reduktion und Synkope im Spiegel der Runeninschriften. NOWELE 37.3-24.

Schulte, M. 2000b. Zur Transfersensitivität phonetish-phonologischer Prozesse am Beispiel des Sieversschen Gesetzes. ABäG 54.137-50. 
Schulte, M. 2003. Early Nordic language history and modern runology: with particular reference to reduction and prefix loss. In Historical linguistics 2001: selected papers from the 15th International Conference on Historical Linguistics, Melbourne, 13-17 August 2001, ed. B.J. Blake \& K. Burridge, 391-402. Amsterdam.

Schulte, M. 2004. The Germanic foot in Ancient Nordic resolution and related matters revisited. NOWELE 45.3-24.

Schulte, M. 2007. Präverbierung in den prosodischen Systemen des Altgermanischen. NOWELE $50 / 51.5-42$.

Schulte, M. 2009. The Scandinavian runic reform: a sound notion or a research dogma? NOWELE 56/57.143-63.

Schulte, M. 2011. The rise of the Younger Fupark: the invisible hand of change. NOWELE 60/61.45-68.

Schumacher, S. 1998. Eine alte Crux, eine neue Hypothese: gotisch iddja, altenglisch èode. Die Sprache 40.161-78.

Schumacher, S. 2005. 'Langvokalische Perfekta' in indogermanischen Einzelsprachen und ihr grundsprachlicher Hintergrund. In Sprachkontakt und Sprachwandel: Akten der XI. Fachtagung der Indogermanischen Gesellschaft, 17.-23. September 2000, ed. G. Meiser \& O. Hackstein, 592-626. Wiesbaden.

Schuppener, G. 1996. Germanische Zahlwörter: sprach- und kulturgeschichtliche Untersuchungen insbesondere zur Zahl 12. Leipzig.

Schuppener, G. 1998. Einschnitte bei den indogermanischen Zehnerzahlen. In Sprache und Kultur der Indogermanen, ed. W. Meid, 293-321. Innsbruck.

Schutz, R., ed. 2007-14. Kernerman Nederlands Leerderswoordenboek. http://www.woorden. org/woord/Oudnederlands. Last accessed 16 April 2018.

Schützeichel, R. 1976. Die Grundlagen des westliches Mitteldeutschen. $2^{\text {nd }}$ ed. Tübingen.

Schützeichel, R. 2006. Althochdeutsches Wörterbuch. $6^{\text {th }}$ ed. Berlin.

Schwarz, E. 1951. Goten, Nordgermanen, Angelsachsen: Studien zur Ausgliederung der germanischen Sprachen. Bern.

Schwarz, E. 1971. Die Herkunftsfrage der Goten. In Zur germanischen Stammeskunde, ed. E. Schwarz (Darmstadt, 1972), 287-308.

Schwerdt, J. 2000. Die 2. Lautverschiebung: Wege zu ihrer Erforschung. Heidelberg.

Schwerdt, J. ed. 2002. Die Kontroverse um die 2. Lautverschiebung. Frankfurt a.M.

Schwyzer, E. 1977. Greichische Grammatik auf der Grundlage von Karl Brugmanns Greichischer Grammatik. $5^{\text {th }}$, unrev. ed. Vol. 1. Munich.

Seebold, E. 1966a. Die Geminata bei gm. kann, ann und anderen starken Verben. KZ 80.273-83.

Seebold, E. 1966b. Die ae. schwundstufigen Präsentien (Aoristpräsentien) der ei-Reihe. Anglia 84.1-26.

Seebold, E. 1967. Die Vertretung idg. $g^{u} h$ im Germanischen. KZ 81.104-33.

Seebold, E. 1968. Ae. twegen und ahd. zwēne 'zwei'. Anglia 86.417-36.

Seebold, E. 1970. Vergleichendes und etymologisches Wörterbuch der germanischen starken Verben. The Hague.

Seebold, E. 1972. Das System der indogermanischen Halbvokale. Heidelberg.

Seebold, E. 1980. Etymologie und Lautgesetz. In Mayrhofer, Peters, \& Pfeiffer 1980: 431-84.

Seebold, E. 1982. Der Übergang von idg. - $w$ - zu gm. -k- und -g-. IF 87.172-94.

Seebold, E. 1984. Das System der Personalpronomina in den frühgermanischen Sprachen. Göttingen.

Seebold, E. 1986. Die Konstituierung des Germanischen in sprachlicher Sicht. In Beck 1986: 168-82.

Seebold, E. 2004. Alemannisch und Nordgermanisch: Kritierien und Grundlagen für eine sprachgeschichtliche Beurteilung. In Naumann 2004: 1-11.

Seebold, E. 2013. Die Aufgliederung der germanischen Sprachen. NOWELE 66.55-77.

Sehrt, E.H. 1925. Vollständiges wörterbuch zum Heliand und zur altsächsischen Genesis. Göttingen. 
Sehrt, E.H. 1930. Der Genitive Plural auf $-\bar{e}$ im Gotischen. In Studies in honor of Hermann Collitz, 95-100. Baltimore.

Seip, D.A. 1919. Review of A. Kock, Umlaut und Brechung im Altschwedischen (Lund, 191116). Maal og Minne 1919 (no. 2), 85-90.

Sen, S.K. 2000. * $k^{w}$ in Gothic. NOWELE 36.67-8.

Sen, S.K. 2002. Heteroclisis in Gothic. NOWELE 40.105-7.

Seymour, R.K. 1968. A bibliography of word formation in the Germanic languages. Durham, N.C.

Seynnaeve, J. 1987. On the morpheme structure function of the consonant germination in West Germanic. $L B$ 76.433-46.

Shaterian, A. 1990. Review of Mańczak 1987a. Diachronica 7.121-7.

Shields, K.C., Jr. 1979. Some remarks about the origin of the Germanic weak adjectival declension and the neuter plural. FL 13.201-13.

Shields, K.C., Jr. 1982. The origin of the Germanic dental preterite: a new proposal. LB 71.42740.

Shields, K.C., Jr. 1984. OE sind(on): its Germanic and Indo-European origins. AbäG 22.1-9.

Shields, K.C., Jr. 1985. Gothic meina and related Germanic forms. MGS 11.62-70.

Shields, K.C., Jr. 1988. The Indo-European origins of the Germanic third weak class. LB 77.4356.

Shields, K.C., Jr. 1997. Typological plausibility and the deictic origin of of the Germanic dental preterite. $L B 86.125-9$.

Shields, K.C., Jr. 2001. The Germanic personal pronoun accusatives in $*_{-} k$ and their Indo-European origins. $P B B$ 123.343-52.

Shields, K.C., Jr. 2006. On the origin of OHG nom.-acc. pl. masc.-fem. - $\bar{a}$. ABäG 61.27-36.

Siebs, T. 1901. Geschichte der friesischen Sprache. In Paul 1900-9: 1152-1464.

Sievers, E. 1875. Kleine Beiträge zur deutschen Grammatik. 3. Die starke Adjektivdeclination. $P B B$ 2.98-124.

Sievers, E. 1877-8. Zur Accent- und Lautlehre der germanischen Sprachen. PBB 4.522-39, 5.63163.

Sievers, E. 1882. Das Verbum 'kommen'. PBB 8.80-9.

Sievers, E. 1884. Kleine Beiträge zur deutschen Grammatik. 11-12. PBB 9.561-8.

Sievers, E. 1885a. Grundzüge der Phonetik. $3^{\text {rd }}$ ed. Leipzig.

Sievers, E. 1885b. Zur Rhythmik des germanischen Alliterationsverses. PBB 10.209-314, 451545.

Sievers, E. 1892. Grammatische Miscellen. PBB 16. 235-65.

Sievers, E. 1893. Altgermanische Metrik. Halle.

Sievers, E. 1895. Germanisch $l l$ aus dl. IF 4.335-40.

Sievers, E. 1900. Zum angelsächsischen Vokalismus. Leipzig.

Sievers, E. 1903. An Old English grammar. Boston. (Trans. A.S. Cook from the $3^{\text {rd }}$ ed. of Angelsächsische Grammatik, Halle, 1898.)

Siewierska, A. 2013. Gender distinctions in independent personal pronouns. In The world atlas of language structures online, ed. M.S. Dryer \& M. Haspelmath. http://wals.info/chapter/44. Accessed 24 March 2018.

Sihler, A.L. 1986. Germanic second person endings in -st. MSS 47.193-215.

Sihler, A.L. 1995. New comparative grammar of Greek and Latin. Oxford.

Simmler, F. 1974. Die westgermanische Konsonantengemination im Deutschen unter besonderer Berücksichtung des Althochdeutschen. Munich. http://digi20.digitale-sammlungen.de/de/fs1/ object/goToPage/bsb00042535.html?pageNo=1. Last accessed 3 Dec. 2016.

Simms, D.P.A. 2017. The Old English name of the $s$-rune and 'sun' in Germanic. JGL 29.26-49.

Skomal, S.N., \& E.C. Polomé, edd. 1987. Proto-Indo-European: the archaeology of a linguistic problem. Studies in honor of Marija Gimbutas. Washington.

Smith, H.L., Jr. 1941. The Verschärfung in Germanic. Language 17.93-8.

Smith, J. 1976. Mittel- und Niederfränkisches in den Wachtendonckschen Psalmen. Niederdeutsches Wort 16.63-74. 
Smith, L.C. 1996. Vennemann's bifurcation theory of the Germanic and German consonant shifts. Calgary Working Papers in Linguistics 18.67-75.

Snædal, M. 2002. The $i$-stem adjectives in Gothic. IF 107.250-67.

Snædal, M. 2011. Gothic 〈ggw〉. Studia Linguistica Universitatis Iagellonicae Cracoviensis 128.145-54.

Snyder, W.H. 1989. Verwandtschaftsverhältnisse der germanischen Sprachen: Wortbildung und Sprachgeschichte. Sprachwissenschaft 14.421-39.

Solmsen, F. 1897. Vermischte Beiträge zur griechischen Etymologie und Grammatik. KZ 34.53660.

Somers, K.W. 2009. From phonology to syntax: pronominal cliticization in Otfrid's 'Evangelienbuch'. Tübingen.

Sommer, F. 1924. Zur venetischen Schriftsprache. IF 42. 90-132.

Sommer, F. 1951. Zum Zahlwort. Munich.

Spurkland, T. 1998. Runic inscriptions as sources for the history of the Scandinavian languages in the Middle Ages. In Kehrein \& Weise 1998: 592-600.

Stang, C.S. 1949. A quoi correspond en germanique le th sanscrit? NTS 15.335-42.

Stang, C.S. 1972. Lexikalische Übereinstimmungen zwischen dem Slavischen, Baltischen und Germanischen. Oslo.

Stearns, MacD., Jr. 1989. Das Krimgotisch. In Beck 1989: 175-94.

Stechow, A. von. 1986. Notizien zu Vennemanns Anti-Grimm. PBB 108.159-71.

Stedje, A. 1987. Warum nur in Germanischen? Altes und Neues zum Ablaut der starken Verben. Studier i modern språkvetenskap 8.96-113.

Stefán Einarsson. 1945. Icelandic: grammar, texts, glossary. Baltimore.

Steller, W. 1928. Abriss der altfriesischen Grammatik. Halle (Saale).

Steriade, D. 2000. Paradigm uniformity and the phonetics-phonology boundary. In Papers in laboratory phonology 5, ed. M. Broe \& J. Pierrehumbert, 313-34. Cambridge.

Stiles, P.V. 1984. On the interpretation of Older Runic swestar on the Opedal Stone. NOWELE 3.3-48.

Stiles, P.V. 1985-6. The fate of the numeral ' 4 ' in Germanic. NOWELE 6.81-104, 7.3-27, 8.325.

Stiles, P.V. 1988. Gothic nominative singular brōpar 'brother' and the reflexes of Indo-European long vowels in the final syllables of Germanic polysyllables. TPS 86.115-43.

Stiles, P.V. 1995. Remarks on the 'Anglo-Frisian' thesis. In Friesische Studien II, ed. V.F. Faltings et al., 177-220. Odense.

Stiles, P.V. 1996. Old English uncet and incit. NOWELE 28/29.557-68.

Stiles, P.V. 2004. Place-adverbs and the development of Proto-Germanic long $\bar{e}_{1}$ in early West Germanic. In Etymologie, Entlehnungen und Entwicklungen, ed. I. Hyvärinen et al., 385-96. Helsinki.

Stiles, P.V. 2010. The Gothic extended forms of the dental preterite endings. NOWELE 58/59.343-66.

Stiles, P.V. 2012. Older Runic evidence for North-West Germanic $a$-umlaut of $u$ (and the converse of Polivanov's law). In Probert \& Willi 2012: 43-60.

Stiles, P.V. 2013. The pan-West Germanic isoglosses and the sub-relationships of West Germanic to other branches. NOWELE 66.5-38.

Stockwell, R.P., \& C.W. Barritt. 1951. Some Old English graphemic-phonemic correspondences-æ, ea and a. Washington.

Streitberg, W. 1892. Zur germanischen Sprachgeschichte. Strassburg.

Streitberg, W. 1893. Review of the $1^{\text {st }}$ ed. of Kluge 1913. Anzeiger für indogermanische Sprachund Altertumskunde: Beiblatt zu den Indogermanischen Forschungen 2.44-52.

Streitberg, W. 1896. Urgermanische Grammatik. Heidelberg.

Streitberg, W. 1910. Gotisches Elementarbuch. $3^{\text {rd }}$ ed. Heidelberg.

Streitberg, W. 1927. Germanisch: Allgemeiner Theil und Lautlehre. Berlin.

Streitberg, W., ed. 2000. Die gotische Bibel. $7^{\text {th }}$ ed. rev. P. Scardigli. 2 vols. Heidelberg. 
Streitberg, W., V. Michels, \& M.H. Jellinek. 1936. Die Erforschung der indogermanischen Sprachen, II: Germanisch. Berlin.

Strid, J.P. 2010. The origin of the Goths from a topolinguistic perspective: a short proposal. NOWELE 58/59.443-52.

Strid, J.P. 2014. Retracing the Goths. In Wulfila 311-2011: international symposium, ed. A. Kaliff \& L. Munkhammar, 41-54. Uppsala.

Strøjer, L. 1984. Aspects of West Saxon breaking. In English historical linguistics: studies in development, ed. N.F. Blake \& C. Jones, 1-11. Sheffield.

Strunk, K. 1992. War auch das andere Horn gemeint? Horn B von Gallehus und Fragen des Duals. PBB 114.179-211.

Suphi, M. 1988. Old English stress assignment. Lingua 75.171-202.

Suzuki, S. 1982. A metrical approach to Gothic reduplication. Linguistics 20.587-609.

Suzuki, S. 1984. On the Gothic innovation whereby $-u$ was extended to the 3 pres. imp. and the opt. mediopassive. IF 89.169-78.

Suzuki, S. 1985. The role of syllable structure in Old English poetry. Lingua 67.97-119.

Suzuki, S. 1986. Syllable theory and Old English verse: a preliminary observation. In Kastovsky \& Szwedek 1986: I, 651-7.

Suzuki, S. 1988. On the $1 \mathrm{sg}$. pres. ind. ending $-u$ and high vowel deletion in Anglian and other West Germanic languages. IF 93.210-24.

Suzuki, S. 1989. On determining the sonority value of $/ \mathrm{w} /$ relative to $/ \mathrm{r} /$ and $/ \mathrm{l} /$ in early West Germanic. FLH 10.21-34.

Suzuki, S. 1991a. Germ. /sp/,/st/, /sk/ und /skw/ als Lautgruppen. ABäG 33.1-8.

Suzuki, S. 1991b. The Germanic Verschärfung: a syllabic perspective. JIES 19.163-90.

Suzuki, S. 1992. Toward an explanatory account of Thurneysen's law in Gothic. PBB 114.28-46.

Suzuki, S. 1994. Breaking, ambisyllabicity, and the sonority hierarchy in Old English. Diachronica $11.65-93$.

Suzuki, S. 2004. The metre of Old Saxon Poetry: the remaking of alliterative tradition. Cambridge.

Svennung, J. 1972. Jordanes und die gotische Stammsage. In Studia Gotica, ed. U.E. Hegberg, 20-56. Stockholm.

Svensson, J. 1944. Diftongering med palatalt förslag $i$ de nordiska språken. Lund.

Sverdrup, J. 1927. Der Aorist im germanischen Verbalsystem und die Bildung des starken Präteritums. In Festskrift til Hjalmar Falk, 30 desember 1927, fra elever, venner og colleger, ed. E.W. Selmer, 296-330. Oslo.

Sverdrup, J. 1929. Der Aorist im germanischen Verbalsystem und die Bildung des starken Präteritums. NTS 2.5-96.

Swan, T., E. Mørck, \& O. Jansen Westvik, edd. 1994. Language change and language structure: older Germanic languages in a comparative perspective. Berlin.

Syrett, M. 1994. The unaccented vowels of Proto-Norse. Odense.

Syrett, M. 1998. On Sievers' law, and its converse, in North Germanic. NOWELE 34.75-98.

Szemerényi, O.J.L. 1956. Latin $r \bar{e} s$ and the Indo-European long-diphthong stem nouns. $K Z$ $73.490-514$.

Szemerényi, O.J.L. 1960. Studies in the Indo-European system of numerals. Heidelberg.

Szemerényi, O.J.L. 1996. Introduction to Indo-European linguistics. Oxford: Clarendon. (Trans. from Einführung in die vergleichende Sprachwissenschaft, $4^{\text {th }}$ ed., Darmstadt, 1990.)

Takahashi, T. 1987. Germ. /sk, sk, sp, st/ als Monophoneme. Sprachwissenschaft 12.157-65.

Tanaka, T. 2011. A morphological conflation approach to the historical development of preteritepresent verbs. Fukuoka. Available at: https://www.academia.edu/9357716/A_Morphological_ Conflation_Approach_to the_Historical_Development_of_Preterite-Present_Verbs Old_English_Proto-Germanic_and_Proto-Indo-European?auto=download. Āccessed 11 May $201 \overline{7}$.

Tanaka, Y. 1970. A proposed hypothesis for Holtzmann's law. La linguistique 6.65-80.

Taylor, M.E. 1989. Old High German monophthongization: a theoretical solution. Lingua 78.2336. 
Pórhallsdóttir see Guðrún Pórhallsdóttir

Tiefenbach, H. 2010. Altsächsisches Handwörterbuch / A Concise Old Saxon Dictionary. Berlin.

Tiersma, P. 1983. The nature of phonological representation: evidence from breaking in Frisian. JL 19.59-78.

Tiersma, P. 1986. Comments on the development of breaking. Us Wurk 35.1-11.

Tischler, J. 1978. Neu- und wiederentdeckte Zeugniss des Krimgotischen. Innsbruck.

Tischler, J. 1989. Zum Langobardischen. In Beck 1989: 195-209.

Toller, T.N. 1921. An Anglo-Saxon Dictionary: Supplement. Oxford.

Tops, G.A.J. 1974. The origin of the Germanic dental preterite: a critical research history since 1912. Leiden.

Tops, G.A.J. 1978. The origin of the Germanic dental preterit: von Friesen revisited. In Recent developments in historical phonology, ed. J. Fisiak, 349-71. The Hague.

Torgilsvedt, T. 2009. Klassifisering av langobardisk språk og en ny forklaring på konsonantovergangene i langobardisk. Norsk Lingvistik Tidsskrift 27.314-27.

Torp, A., \& H.S. Falk. 1909. Wortschatz der germanischen Sprachen. Göttingen.

Trager, G.L., \& H.L. Smith. 1950. A chronology of Indo-Hittite. SL 8(3).61-70.

Trautmann, R. 1906. Germanische Lautgesetze in ihrem sprachgeschichtlichen Verhältnis. Kirchhain.

Trautmann, R. 1925. Suum cuique. KZ 53.89-90.

Twaddell, W.F. 1963. Graphical alternation in Old Saxon suffixes. Monatshefte für deutschen Unterricht, deutsche Sprache und Literatur 55.225-8.

Udolph, J. 1990. Die Stellung der Gewässernamen Polens innerhalb der alteuropäischen Hydronymie. Heidelberg.

Udolph, J. 1994. Namenkundliche Studien zum Germanenproblem. Berlin.

Untermann, J. 1989. Sprachvergleichung und Sprachidentität: methodische Fragen im Zwischenfeld von Keltisch und Germanisch. In Beck 1989: 211-39.

Untermann, J., \& B. Brogyanyi, edd. 1984. Das Germanische und die Rekonstruktion der indogermanischen Grundsprache. Amsterdam.

Unwerth, W. von. 1910. Zur Geschichte der indogermanischen es/os-Stämme in den germanischen Dialekten. $P B B$ 36.1-42.

Vaan, M. de. 2012. The metathesis of suffixal -sl- to - $l s$ - in West Germanic. NOWELE 64/65.91103.

Vaan, M. de. 2014. The emergence of Dutch: consonant changes until 1200. NOWELE 66.3-22.

van Bree, C. 1977. Leerboek voor de historische grammatica van het Nederlands. Groningen.

van Coetsem, F. 1949. Le renforcement des semivoyelles intervocaliques en germanique $(\mathrm{j} / \mathrm{jj}>\mathrm{jj}$ $>$ gotique $d d j$ etc.). $L B$ 39.41-78.

van Coetsem, F. 1956. Das System der starken Verba und die Periodisierung im älteren Germanischen. Amsterdam.

van Coetsem, F. 1970. Zur Entwicklung der germanischen Grundsprache. In Sprachgeschichte (Kurzer Grundriss der germanischen Philologie, I), ed. L.E. Schmitt, 1-93. Berlin.

van Coetsem, F. 1990. Ablaut and reduplication in the Germanic verb. Heidelberg.

van Coetsem, F. 1994. The vocalism of the Germanic parent language. Heidelberg.

van Coetsem, F. 1997. Reconditioning and umlaut in Germanic, and the question of $\bar{e}_{2}$. NOWELE 31/32.423-37.

van Coetsem, F., \& H. Kufner, edd. 1972. Toward a grammar of Proto-Germanic. Tübingen.

van Coetsem, F., \& S. McCormick. 1982. Old High German umlaut and the notion of optimal patterning. ABäG 17.23-7.

van der Hoek, M. 2007. The origin of Gothic hiri. NOWELE 52.9-22.

van der Meer, G. 1985. Frisian 'breaking'. Groningen.

van der Rhee, F. 1976. Die hochdeutsche Lautverbschiebung in den langobardischen Gesetzen:

Datierung, Umfang, orthographische Wiedergabe. Neophilologus 60.397-411.

van der Rhee, F. 1977. Palatalisierung, Mouillierung und Assibilierung von urgerm. /k/ im Altenglischen und Altfriesischen. Us Wurk 26.33-44. 
van der Rhee, F. 1978. Die Erforschung des Langobardischen: kurzer Überblick über die Forschungsprobleme. Jahrbuch für Internationale Germanistik 10.77-86.

van Haeringen, C.B. 1940. De taaie levenskracht van het sterke werkwoord. De Nieuwe Taalgids 34.241-55.

van Helten, W. 1889. Zur Lexicologie und Grammatik des Altostfriesischen. PBB 14.232-88.

van Helten, W. 1890. Altostfriesische Grammatik. Leeuwarden.

van Helten, W. 1891. Grammatisches. $P B B$ 15.455-88.

van Helten, W. 1893. Grammatisches. $P B B$ 17.550-72.

van Helten, W. 1896. Grammatisches. $P B B$ 21.437-98.

van Helten, W. 1902. Grammatisches. PBB 28.497-569.

van Helten, W. 1905-6. Zum germanischen Zahlwort. IF 18.84-126.

van Helten, W. 1908. Zu germanischen $\bar{e}_{2}, \bar{e}_{1}$. IF 23.92-117.

van Helten, W. 1909. Grammatisches. $P B B$ 35.273-305.

van Helten, W. 1910. Grammatisches. $P B B$ 36.435-515.

van Loon, J. 1986. Die umgelauteten Diphthonge des Gemeingermanischen. IF 91.259-65.

van Wijk, N. 1907-8. Germanisches. IF 22.250-66.

Vennemann, T. 1984a. Bemerkungen zum frühgermanischen Wortschatz. In Studia linguistica et philologica. Festschrift für Klaus Matzel zum sechzigsten Geburtstag, ed. H.-W. Eroms, B. Gajek, \& H. Kolb, 105-19. Heidelberg.

Vennemann, T. 1984b. Hochgermanisch und Niedergermanisch: Die Verzweigungstheorie der germanisch-deutschen Lautverschiebungen. $P B B$ 106.1-45.

Vennemann, T. 1987a. Betrachtung zum Alter der Hochgermanischen Lautverschiebungen. In Bergmann et al. 1987: 29-53.

Vennemann, T. 1987b. Muta cum liquida: Worttrennung und Syllibierung im Gotischen. ZfdA 116.165-204.

Vennemann, T. 1988a. Die innergermanische Lautverschiebung und die Entstehung der germanischen und deutschen Dialekte. In Jazayery \& Winter 1988: 749-61.

Vennemann, T. 1988b. Preference laws for syllable structure and the explanation of sound change. Berlin.

Vennemann, T., ed. 1989. The new sound of Indo-European. Berlin.

Vennemann, T. 1991. The relative chronology of the High Germanic Consonant Shift and the West Germanic anaptyxis. Diachronica $8.45-57$.

Vennemann, T. 1994a. Dating the division between High and Low Germanic. In Language change and language structure, ed. T. Swan, 271-303. Berlin.

Vennemann, T. 1994b. Zur Entwicklung der reduplizierenden Verben im Germanischen. PBB 116.167-221.

Vennemann, T. 1997. The development of reduplicating verbs in Germanic. In Insights in Germanic linguistics II, ed. I Rauch \& G. Carr, 297-336. Berlin.

Vennemann, T. 2013. Griechisch, lateinisch, etruskisch, karthagisch?: zur Herkunft der Runen. In LautSchriftSprache, ed. E. Glaser et al., 47-81. Zurich.

Verner, K. 1877. Eine Ausnahme der ersten Lautverschiebung. KZ 23.97-130.

Versloot, A. 2014. Methodological reflections on the emergence of Old Frisian. NOWELE 66.2349.

Vinogradov, A.Ju., \& M.I. Korobov. 2015. Gotskie graffiti iz Mangupskoj baziliki. Srednie veka 76(3-4), 57-75. [Gothic graffiti from the Mangup basilica.] http://www.gotica.de/ boranicum.pdf. English summary at http://languagehat.com/medieval-gothic-graffiti-from-thecrimea/. Last accessed 10 July 2016.

Vinogradov, A.Ju., \& M.I. Korobov. 2016. Gotische Graffito-Inschriften aus der Bergkriem. ZfdA 145.141-57.

Voyles, J.B. 1968. Gothic and Germanic. Language 44.720-46.

Voyles, J.B. 1971. The problem of West Germanic. FL 5.117-50.

Voyles, J.B. 1981. Gothic, Germanic and Northwest Germanic. Wiesbaden.

Voyles, J.B. 1987. The cardinal numbers in Pre- and Proto-Germanic. JEGP 86.487-95. 
Voyles, J.B. 1988. Early Germanic changes in unstressed word-final syllables: problems and ramifications. Lingua 76.63-90.

Voyles, J.B. 1989a. Bifurcational Germanic and glottonic Indo-European. PBB 111.16-34.

Voyles, J.B. 1989b. Laryngeals in Germanic. AJGLL 1.17-52.

Voyles, J.B. 1992. Early Germanic grammar: pre-, proto-, and post-Germanic languages. San Diego.

Voyles, J.B. 1996. A footnote and bibliography to Herbert Penzl's 'Zum Beweismaterial für den $i$-Umlaut im Nordisch-Westgermanischen'. AJGLL 8.289-91.

Voyles, J.B. 1999. A reply to Professor Connolly's 'On identifying laryngeal reflexes in Germanic'. AJGLL 11.223-9.

Voyles, J.B. 2005. The 'conundrum' of Old Norse $i$-umlaut: a reply to Iverson and Salmons. JGL 17.265-77.

Voyles, J.B., \& C.M.Barrack. 2009. An introduction to Proto-Indo-European and the early IndoEuropean languages. Bloomington.

Vries, Jan de. 1962. Altnordisches eymologisches Wörterbuch. Rev. ed. Leiden.

Vykypěl, B. 2001. Eine bohemistische Bemerkung zur Datierung der ersten germanischen Lautverschiebung. In Beiträge der Europäischen Slavistischen Linguistik (Polyslav) IV, ed. K. Böttger et al., 198-205. Munich.

Wackernagel, J. 1868. Sprache und Sprachdenkmäler der Burgunden. In Geschichte der burgundisch-romanischen Königreichs, ed. C. Binding, 329-404. Leipzig.

Wackernagel, J. 1892. Über ein Gesetz der indogermanischen Wortstellung. IF 1.333-436.

Wade, Nicholas. 2015. The tangled roots of English. The New York Times 24 Feb., sec. D, 1, 6.

Wadstein, E. 1892. Eine vermeintliche Ausnahme von der $i$-Umlautsregel im Altnordischen. $P B B$ 17.412-34.

Wadstein, E., ed. 1899. Kleinere altsächsische Sprachdenkmäler mit Anmerkungen und Glossar. Norden.

Wagner, N. 1986a. Die völkerwanderungszeitliche Germanenbegriff. In Beck 1986: 130-54.

Wagner, N. 1986b. Um die Endung von ahd. $\operatorname{tag} a(-\bar{a})$. ZfdA 115.37-48.

Wagner, N. 1989. Der Stammesname der Salier und die 'westgermanische' Konsonantengemination. ZfdA 118.34-42.

Wagner, N. 2006. Zu got. $h, q$ und ai, au. HS 119.286-91.

Wagner, N. 2011. Einiges zu germanischen $s$-Stämmen, auch in Personennamen sowie zu mhd. tamer, temer stN. Beiträge zur Namenforschung 46.287-95.

Walde, A. 1897. Die Verbindung zweier dentale und tönendes $z$ im indogermanischen. $K Z$ 34.461-536.

Walde, A. 1900. Die germanischen Auslautgesetze. Halle.

Walkden, G. 2014. Syntactic reconstruction and Proto-Germanic. Oxford.

Waterman, J.T. 1976. A history of the German language. Rev. ed. Seattle.

Watts, S., J. West, \& H.-J. Solms, edd. 2001. Zur Verbmorphologie germanischer Sprachen. Tübingen.

Wedel, A.R., \& H.-J. Busch, edd. Verba et litterae: explorations in Germanic languages and German literature. Newark, Del.

Wells, C.J. 1987. German: a linguistic history to 1945. Oxford.

Wessén, E. 1958. Isländsk grammatik. Lund.

Wessén, E. 1968. Die nordischen Sprachen. Berlin.

West, J. 1990. The evidence for the German fourth class of weak verbs. German Life and Letters 43.191-8.

West, J. 2001. The Newcastle Germanic weak verbs project: conjecture on the weak preterite. In Watts et al. 2001: 51-61.

Wetzel, C.-D. 1981. Worttrennung am Zeilenende in altenglischen Handschriften. Frankfurt a.M.

Wheeler, B.I. 1885. Der griechische Nominalaccent. Strassburg.

Whitehead, B.N. 1990-1. On the transfer of the preterite verbal endings to the present tense of 'to be' in Germanic. Copenhagen Working Papers in Linguistics 1.83-6.

Whitney, W.D. 1889. Sanskrit grammar. $2^{\text {nd }}$ ed. Cambridge, Mass. 
Wiedemann, O. 1892. Der Dativus Singularis der germanischen Sprachen. KZ 31.479-84.

Wienold, G. 1967. On umlaut in Gothic. Orbis 16.185-96.

Wiik, K. 1995. Finno-Ugric prosodic substrata in the Germanic languages and vice versa. In ICPhS 95: proceedings of the XIIIth International Congress of Phonic Sciences, Stockholm, Sweden, 13-19 August, 1995, ed. K. Elenius \& P. Branderud, 4.168-71.

Wiik, K. 1997. The Uralic and Finno-Ugric phonetic substratum in Proto-Germanic. Linguistica Uralica 33.258-80.

Wilmanns, W. 1893-1906. Deutsche Grammatik: Gotisch, Alt-, Mittel- und Neuhochdeutsch. 3 vols. Strassburg.

Wodtko, D., B. Irslinger, \& C. Schneider. 2008. Nomina im indogermanischen Lexikon. Heidelberg.

Wolfram, H. 1979. Geschichte der Goten. Munich.

Wood, F.A. 1895. Verner's law in Gothic. Chicago.

Wood, F.A. 1923. Morphological notes. Studies in Philology 20.99-109.

Woodhouse, R. 1995. Gothic $p l-$. HS 108.102-3.

Woodhouse, R. 1997. Germanic implosives, Bartholomae's law, Germanic aspirates and consonant shifts. $P B B$ 119.374-98.

Woodhouse, R. 1998a. Gothic $p l-<* t(t)$ : filling in some gaps, plus a note on VLat. $b l$ - in Castilian. HS 111.296-304.

Woodhouse, R. 1998b. Verner's and Thurneysen's laws in Gothic as evidence for obstruent development in early Germanic. PBB 120.194-222.

Woodhouse, R. 2000. Gothic $p l$ - : $f$ - variation is due to ablaut, not interdialectal borrowing. Studia Etymologica Cracoviensia 5.145-7.

Woodhouse, R. 2003. Gothic siuns, the domain of Verner's law and the relative chronology of Grimm's, Verner's and Kluge's laws in Germanic. PBB 125.207-22.

Wrede, F. 1886. Über die Sprache der Wandalen. Strassburg.

Wright, J. 1954. Grammar of the Gothic language. $2^{\text {nd }} \mathrm{ed}$. with a supplement to the grammar by O.L. Sayce. Oxford.

Wright, J., \& M.E. Wright. 1925. Old English grammar. $3^{\text {rd }}$ ed. Oxford.

Wulf, F. 1985. Zu den Sproßvokalen des Althochdeutschen. Wissenschaftliche Zeitschrift der Wilhelm-Pieck-Universität Rostock 34(4).40-2.

Zgusta, L. 1955. Conclusive evidence in historical linguistics. Archiv Orientální 23.184-204.

Zimmer, H. 1876. Ostgermanisch und Westgermanisch. ZfdA 19.393-462.

Zoëga, G.T. 1910. A concise dictionary of Old Icelandic. Oxford.

Zupitza, E. 1896. Die germanischen Gutturale. Berlin. 


\section{Index verborum}

Numbers in boldface indicate the location of paradigms and/or extended discussion of forms. Numbers in italics indicate the location of principal parts of verbs. The order of languages indexed is as follows (with number of page or initial page in parentheses):

NON-INDO-EUROPEAN LANGUAGES. Northern European (p. 376); Finnish (p. 376).

PROTO-INDO-EUROPEAN (p. 376).

ANATOLiAN. Hittite (p. 379).

TOCHARIAN B (p. 379).

INDO-IRANIAN. Sanskrit (p. 379); Avestan (p. 381); Middle Persian (p. 381).

ARMENiAn (p. 381).

BALTIC. Old Prussian (p. 381); Lithuanian (p. 381); Latvian (p. 381).

SLAVIC. Old Church Slavonic (p. 381); Slovene (p. 381); Serbian (p. 382); Czech (p. 382); Russian (p. 382).

HELLENIC. Greek (p. 382).

ITALIC. Oscan (p. 384); Umbrian (p. 384); Latin (p. 384); French (p. 385).

Celtic. Prehistoric Celtic (p. 385); Gaulish (p. 385); Irish (p. 386); Welsh (p. 386).

Albanian (p. 386).

VENETIC (p. 386).

GERMANIC. Pre-Proto-Germanic (p. 386); Proto-Germanic (p. 386); Gothic (p. 389); Burgundian, Vandalic, and other East Germanic (p. 395); Northwest Germanic (p. 395); Runic (p. 000); Proto-Norse (p. 395); Old (West) Norse / Old Icelandic (p. 396); Old Norwegian (p. 401); Modern Icelandic (p. 401); Faroese (p. 401); Old East Norse (p. 401); Gutnish (p. 402); Swedish (p. 402); Danish (p. 402); West Germanic (reconstructed) (p. 402); West Germanic (non-Runic) (p. 402); North Sea Germanic (Ingvaeonic) (p. 402); Anglo-Frisian (p. 402); Old English (p. 402); Middle English (p. 410); Present-Day English (p. 410); Old Frisian (p. 410); Modern Frisian (p. 412); Old Saxon (p. 412); Middle Low German (p. 415); New Low German (p. 415); Old Low Franconian (p. 415); Dutch (p. 415); Old High German (p. 415); Middle High German (p. 420); New High German (p. 420).

\section{NON-INDO-EUROPEAN LANGUAGES}

\section{Northern European}

sblu 1.5

skib- 1.5

Finnish

kulta 5.2

kuningas 1.7

lammas 7.38

ratsas 5.8 n. 2

rengas 1.7

tiuris $1.7,5.2 \mathrm{n} .5$

\section{Proto-Indo-EuRoPeAN}

Inflected forms are lemmatized under their root, usually given in $e$-grade, regardless of the grade actually cited in the text. aĝ-12.15, ấgós 7.6

ägh-e-s 12.53

an- 10.7

aieri 5.2 n. 2, 6.11, 11.1

aies 6.11

apo 6.4

bend- $n-6.4$

bu-s- 6.4

bhāgheūom 7.25

bhāgós 3.3

bheh ${ }_{1}-3.2$

bheh $h_{2} u d-, b h_{2} u-d-3.4$

bheh $h_{3}$-, $b h_{n} h_{3}-12.15$

bhelgh- 3.2

bhendh-, bhndh- 3.2, 4.4, 6.5

bher- 3.1, 6.4, 12.1, 12.3 n. 2,

12.6, bhi-bher-ti 12.3, bher-e-ti 4.4, 12.8, bhere-te 5.2, 12.1, bher-o-nti 12.1, bhe-bhr- 12.14 n. 3 , bhr-t-3.1, bhor-éi-o- 12.3 n. 2 , bheront- 12.30 , bher-o-no-m, bher-ón-o-s
12.30, bhermnom 12.30

n. 1

bherH $\hat{g}_{-}$, , bhrHh- 5.5, 6.5

bheudh- 3.4, bhudh- 6.8, bhudhnt 5.2, bhudh-men4.3

bheid-12.9, bhindénti 12.9,

bhid-nó- 12.7

bheidh-12.1, bhidh-nnt, bheidh-o-ihl- $t$

6.11

bhlē- 3.3

bhleh $u_{1}$ - bhlh ${ }_{1} u^{-} 3.4$

bhlendh- 6.5

bhlo- 3.3

-bho-, -bhā- 11.2 n. 3

bhō 10.1

bhrāter- 3.6, 6.5, 7.36, bhrấtr-, bhrá̀tr- 7.36

bhrô- 3.6 n. 1, 12.31 n. 3

bhrgh- 3.2

bhrūg- 3.3

bhruH- 3.1, 3.3 
bhug-ó-, -é-ti 12.3

bhuh ${ }^{-}$, bhü- 3.3, 6.4

bhu-ii-, bhü-, bhuh $12.57 \&$ n. 6

dakku- 3.2

de 8.2

deh $h_{2}$ iuer-, $d h_{2}$ iwer- 3.4, 6.4

$\operatorname{deh}_{2} p-3.2$

dékm(t) 6.4, 8.2, 10.2, 10.4, $10.5,10.9$, dékomt 10.2,

10.9, de $\hat{k}$ mt 10.5, de k̂ntos 10.8

deuk-, hié-duk-e-s, duk-é-s 12.25

deik $\hat{k}^{-6.4}, 12.9$

deiu-o-so 7.8

$d \bar{l}-t-3.3$

dllh $h_{2} g h o ́-3.3, d l h_{2}-n-g h-6.5$

dngh- 6.5

dreu-, dr-t-ó- 12.18 n. 6

$d r \hat{k}-, d i-d r \hat{k}-s e-12.3$

$d(u) u \bar{o}(-) 3.3,6.4,10.1$, duиo $10.1, d(u) u o-i(-) 6.4,10.1$ \& n. 11, duoi-Hou 6.10, duisnoi $6.8,10.10$

dheht- 3.2, 3.3, 12.1, 12.39,

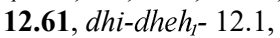
dheht 5.4, 12.33, dheh-k12.15, dhe h-ti- 12.7

dheub- 6.4

dh $\hat{g h}$-m-on- 7.27 n. 2

$d \mathrm{dnh}_{1^{-}} 3.3$

dhrs- 6.4, 6.5

dhubh- 3.2

$\operatorname{dhug}(h) h_{2}$ tér- 5.5, 7.35 n. 2

dhur- 3.2, 6.4

-enko-, -nko- 3.6

ékuos 7.8, -osio 7.8, 8.10

eno- 8.7, 8.11, 11.1, no, ne 11.1

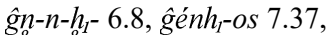
genh $h_{1}$-es- 6.6, 7.1, 7.37, genht-e-tōr- 7.1

geus- 3.4, 12.7, ĝus-ti- 12.7

$\hat{g}_{n e h}{ }_{3^{-}}, \hat{g}_{n} n h_{3^{-}}-3.3,6.4, \hat{g}_{n} n h_{3^{-}}$ neh ${ }_{2}$-ti 6.4, ğñtós 3.1, 3.3

gneu-, gonu- 6.4

gombh- 6.5

$\hat{g} r h_{1} n-3.3$

ghaiso- 6.4

ghans- 6.4

$\hat{g} h \bar{e}-$, $\hat{g} h e h_{1^{-}} 3.3,12.62$ n. 1 , 12.63 n. 1 , ghi-ghheh ${ }_{1}-m i$ 12.62, ( $\hat{g} h e-) \hat{g h e h} h_{1}-t i$
12.63 n. 4

gheh $u-m-3.4$

ghengh-, ghongh- 6.5, 12.62 n. 1

ghéslo- 10.6

ghleh -3.2

ghleu-ri- 6.10

ghltom 5.2

ghwōtjo- 6.4

gal- 6.4

glehl bh- 3.3, glm $\bar{n} b h-3.3$

gle-n-k-12.3 n. 3

gloi- 6.4

gnu-t-néh -6.9

grbh-, gerbh- 3.2, 6.4, 12.3, $12.18 \mathrm{n} .1$

grd-, grod-néh $h_{2}-6.9$

ghaido- 3.4

ghleu- 6.4

ghostis 6.4, 6.5

ghrbh-néh - ti 6.9

ghreh $u-$, ghreh ${ }_{1} u-n o-3.4$

ghren-dh-, ghrn-io- 12.3

ghrū- 3.3

$g^{w}$ em-, $g^{w} m-3.2,6.4,12.9$, $12.18, g^{w}$ msk̂kéti $12.9, g^{w} e-$ $g^{w}{ }^{\prime} m-h_{2} e, g^{w} e-g^{w} m-\dot{e}$ $12.2, g^{w} m-t-i s-3.2$

$g^{w} e n-6.4,7.33, g^{w} e ́ n-h_{2}, g^{w} n-$ éh $h_{2}-S 7.4$

$g^{w}$ etu- 4.4

$g^{w} i h_{3} u-4.3,6.3$

$g^{w}$ oh $_{1} u d h-3.4$

$g^{w}$ or-eh $_{2}-\underline{i}-12.3$

$g h^{w} n-t i-s 6.4$

$g h^{w} r-n-w-6.4$

$h_{1} e d-12.31$ n. $5, h_{1} e-h_{1} o d-$ $h_{l} e-h_{l} d-, h_{l} e-h_{l} e d-12.31 \mathrm{n}$. 5, $h_{1}$ ed-nt-os 12.7, $h_{1} d n t$ 3.2, 7.28, $h_{l}$ dont- 7.28

$h_{l}$ e $\hat{g o H}, h_{l}$ e gom 8.2, mei 8.5

(h) eh $h_{1} u d h^{-} 3.4$

$h_{1}$ eng $^{w}-, h_{1} n^{w} \bar{e} n 6.4$

$h_{1} e s-12.1,12.6,12.56-7$, $h_{1}$ es-mi 6.8, 12.1, 12.9, $h_{1}$ es-si, esi 6.8, hies-ti 3.1, 5.2 n. $2,12.1, h_{l} s^{-} t e ́, h_{l} S^{-}$ ónti 12.1

$h_{l}$ ei- $12.63, h_{l} i$-més $12.24 \mathrm{n} .8$

$h_{1}$ neh ${ }_{3} m n-i e ́-,-i o-12.3$

$h_{1} \circ g h^{w}-i-6.4$

$h_{1}$ rudh- 3.2, 6.8, 12.3 n. 2, $h_{1}$ roudhos 3.4

$h_{l}$ reg $^{w}-6.4, h_{l}$ reg $^{w}$-es- 6.6 $h_{2} e \hat{g}^{-}, a \hat{g}^{-}-3.1,12.15, h_{2} e-$ $h_{2} \hat{o}^{-}-, h_{2} e-h_{2} \hat{g}^{-} 12.15$, $h_{2}$ eĝ́ós 7.6

$h_{2}$ egros 6.4

$h_{2} e g h^{w}-n-6.4$

$h_{2}$ engh- 6.5

$h_{2}$ ent- 3.1

heug- 6.4, 12.20

$h_{2} e^{\text {igh }}{ }^{w}-3.4$

$\left(h_{2}\right)$ maur- 3.4

$h_{2} m b h i(-)$ 1.4, 3.2, 6.5

$h_{2 n}$ dh-mHo- 9.11

$h_{2} u l h_{2}-n-e h_{2} 3.3,6.8$

h2uod- 12.3 n. 9 , uod-sk- 12.3

n. 9, h2uód-r, $h_{2} u d-n-7.42$

\& n. 1

$h_{3} e k^{w}-3.1$

$h_{3}$ er- 12.57

$h_{3} e r b h-3.1$

$h_{3} e-z d$-os 6.11

(h) migh- 3.2

is 8.6

-is(-) $9.10 \& \mathrm{n} .1$

$\hat{k}$ (-) 8.7 \& n. 2, 9.11, 11.1, ke-eno-s 8.7, 11.1

$\hat{k} e h_{2} d-3.2$

kel- 3.2

kerdhiiéso 5.8

$\hat{k} i-3.4, \hat{k} \bar{e} i-r-3.4$

klep- 6.4

k̂leu-ō 3.1, klu-tós 6.4, 12.7

kntóńm 3.2, 6.1, 6.4, 6.11, $10.2,10.6$

$\hat{k} o h_{l}-3.4, \hat{k} h_{1}-\dot{i}-n-3.4$

kueit-nó- 6.9

kan- 3.2

kap-tó-s 6.5

kāp- 3.3

kap-ōl- 6.4

kar- 6.4

kaunos 3.4

$\mathrm{keh}_{2} \mathrm{i}-3.4$

$\mathrm{keh}_{2}$-ro- 6.4

$\mathrm{keh}_{2} \mathrm{u}-3.4$

$\mathrm{keh}_{2}$ ulā 3.4

$k h_{2} d h-n e ́ h_{2}-6.9$

$k h_{1} i d-3.4$

kld- $i-5.8$ n. 2

kléh-t-, klh $h_{2}$-tó- 3.6

klem- 4.4

klh-tó- 6.8

klt- 3.2

kneh $h_{2}-m-6.8$

knk- 3.2 
kom- 2.2 n. 2

koriéso 5.8

kuzdh- 6.11

$-k^{w} e 6.5$ n. 2, 11.1

$k^{w} e k^{w} l o-6.15$ n. 6

$k^{w} e r-, k^{w} e-k^{w}$ or- 12.2, $k^{w} r-n e ́-$ $u$ - $t i 12.3$ n. 5

$k^{w}$ etūôr,$k^{w}$ etuor- 3.1 n. 6 , $7.36,10.1 \&$ n. 16, 10.8, $k^{w}$ tur-ó- $10.8, k^{w} e ́ t^{w}{ }_{e} r-$ 10.10

$k^{w} i s, k^{w} i d$ 8.13, $k^{w}-\dot{e}$-so 7.8 , $8.10, k^{w}$ od 6.4

$k^{w} o, k^{w} o d, k w o h_{2} \mathbf{8 . 1 3}$

$k^{w}$ olsos 6.5 n. 2

$k^{w}$ oter-, $k^{w}$ eter- $6.4, k^{w}$ oteréd 6.11

labh- 6.9

legh- 3.2, 6.4

leh $h_{2}$ - 3.4

leubh- 6.4

leuk- 6.4

leî̀gh-, -ti 12.1, lighh-néh- 6.9

leik $k^{w}-3.4,6.4,12.2,12.3$ n. 4, $l k^{w}-10.3, h_{l} e-l i k^{w}-o-m$

12.4 n. 4 , le-loik $k^{w}-12.2$

leip- $6.4,10.3$ n. 1

lig- 3.3

lipar- 3.2

$\ln g h^{w}-6.5$

lob-néh -6.9

loigh -6.4

mầtēr, mà́ter- 3.3

$m \bar{e}-3.2$

med- 6.4

medhu- 3.2, 4.4, 6.4

medh-io- 4.4, 6.4

$m_{e} \hat{g}-, m_{e} \hat{g}-e l-4.4$

men- 7.27 n. 2

-men-, -mon- vb. suffix 12.7, $12.30 \mathrm{n} .1$

mēn-on-m 7.1

meigh 6.5

mei-os 8.5

meit-on- 6.8

$m h_{2} g h 12.53$ \& n. 3

$m h_{2} k r o ́ s ~ 7.8$

-mHo- 9.11, 11.3, -t-mHo-

9.11

mit-to- 6.8

mizdhó- 3.5, 6.11

mld- 3.2

$m l h_{3} d h-3.3$

$m n-i e ́-12.3$ mnt- 6.4

mori 5.2

mūs 3.3

n- 3.2

nas-, nās- 3.1

ne 5.2, 5.5, 12.8

$-n \bar{e} 11.5$

nébhos, nebhés-os, nebhés- $h_{2}$

7.37 n. 2

$n e g h^{w}-r-6.4$

-néh $h_{2}-6.6,6.9$

neh $h_{2} u-6.3$, neh $_{2} u-s-3.4$

népōt- 6.4, 6.11

néun 6.11, 10.2, néunto- 10.8, neuñरिomt 10.5

neu-o-s 12.3

$n i-z d-o-3.6,6.11$

-no- 6.9 n. 5, 12.7, 12.13, 12.30

$n^{2} \operatorname{gog}^{w}-6.4$

$n o k^{w}-t-6.5$

nos-éio- 12.3, nos-éi-esi $12.38 \mathrm{n} .1$

oino- $3.4,8.11,10.1$

ok̂t $t \bar{o}(u)$ 3.2, 5.6, 6.5, 10.2, 12.26, 12.28, ok tố(u)to10.8, ok̂tôkomt 10.5

-ont-, - nt- vb. suffix $12.7 \& \mathrm{n}$. 1

$p \bar{a}-3.3$

pa-n-k- 4.1

ped-, pod-, pōd 3.1, 6.4, 7.1, 7.27, 7.28 \& n. 3, pod-m 7.1

pek̂k- 6.4

$p_{e} k^{w}$-tos $3.1 \& \mathrm{n} .7$

pénk $^{w}$ e 6.5, 10.2

per-10.7, pr-m- 10.7

pērsn- 4.2

$p h_{2}$ tếr, phón $t e ́ r-6.6,7.2,7.4$,

7.31, ph $h_{2} t$-ér-m, $p h_{2} t$-r-ós

7.4, $\mathrm{ph}_{2}$ trs $s, p h_{2}$ tr-i 7.36

piH-uon- 3.1

pisk- 3.2, 6.5

plek $\hat{k}$-, ple $\hat{k}-t-12.3$

pleūo 6.13

$p l h_{1}-3.2, p l-n-h_{l}-e ́-t i \mathbf{1 2 . 5 0} \&$

n. 3, plh $h_{1}-i s-3.4$, ploh $h_{1}$-nó-

3.3, 6.8, pelh $-n-6.8$,

pelh $-u-3.2,4.4$

plok-t- 6.13

plukós 6.13

pnk-t- 4.1

prih $_{2}-0-$, - ié- 12.3 n. 2 pondh-, pndh- 3.1

pónt-oh $-s$, pnt- $h_{2}$-és 7.4

por- $6.4,12.15$

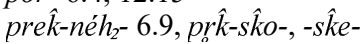

$6.5,12.3$

prō, pro- 12.8

$r \bar{e} \hat{g}-1.4$

reng- 4.4

rei-rēi-é-ti 12.3

re-róH-t-, re-rH-t-' 12.16

rog- 6.4

roup- 3.4, rup-néh- 6.9

sal- 3.2

saus- 3.4

sed- 3.1, 3.2, 4.3, 6.4, 6.11,

12.3 n. 2, sed-io- 4.4 ,

sod-éi-o- 12.3 n. 2 , se-zd-

12.14 n. 3, sed-t- 6.8, ni-

$z d-o-3.6,6.11, h_{3} e-z d-o s$

6.11

seh $_{I^{-}}$, se-sóh $h_{1}-e$ 5.4

$\mathrm{seh}_{2} \mathrm{i}-3.4$

séks 10.2

sek $^{w}-3.1,6.4$

sem-, som 8.9

sengh $^{w}-6.5$

septín 10.2, septm-tos 10.2 ,

10.8, septī $\hat{k}$ komt 10.5

-ske-, -sk̂ko- 6.5, 12.3, 12.9

$s \hat{k i h} h^{-} 6.5$

skabh- 6.5, 12.15

slak-t- 6.5

slēb- 6.4

slibro- 6.3

(s)mer- 12.3

(s)neubh- 6.5

(s)noigh $h^{w}-6.4$

so $5.2,8.8,8.9,8.10 \&$ n. 8 ,

8.13 , tom $6.11,7.8$, toso, tósio 7.8, 8.10, tósieh ${ }_{2}$ s

8.10 n. 2, teso 8.10 , toi 7.8 , 10.1 n. 4 , tosmi 8.10 , tio8.10, $\operatorname{tod} 8.8,8.13$, sā 8.8, 8.10, siā 8.10, so-k $k^{w}$ e 5.2 solpá̀ 12.33

spr- $n-6.5$

sroum- 6.11

steh $2^{-}$, sth $_{2^{-}}$3.1, 3.2, 6.5,

12.15, sti-steh $_{2}-12.2$

stel- 4.3

(s)teigh-, stēigh- 3.4, 4.3, 6.4 sti- 3.2

(s)toud- 12.3

suâd-is-ōn 9.10 
s(u)e 8.4, seu 8.5

$s(u) e d h-4.4$

sue-n-k-12.3 n. 3

suesōr 1.6 n. $1,7.36$

sūi 3.3

sūōd 2.5 \& n. 2, 6.11

tag-néh ${ }_{2}-6.9$

-te 11.2

tenk- 4.1, 4.4

ten-s- 12.3

ter- 11.2

(te)trapedia 7.17

-ti- vb. suffix 12.7

tng-, tong- 4.1, 6.4

-tó- vb. suffix 12.7, 12.33, 12.54

tog-, (s)teg- 6.4

trei- $6.4,10.1, \operatorname{tri}-, \operatorname{tri}(i) \bar{a}$ 10.1

tri-tio- 10.7

trn- 3.2

trs- 3.2

tiu, ti 8.3, teu 8.5

-tu- vb. suffix 12.7

$t \bar{u} s-10.6$

upéri $11.2 \mathrm{n} .1$

uedh-o-ih $h_{1}-\underline{u} \bar{e} 12.26$

uegh- 3.2, 6.4, uegh-io- 4.4

uel(H)-, uol $(H)-12.59$

uel-n- 12.18

uen-, uenis 4.4

uêntos 4.2

uert- 6.4

ues- 12.56-7

ueik- $6.4,12.3$ n. 3

uei-l- $l$ ue $\bar{i}-l-3.4$

uid-, uoid-h $h_{2}$, uoida 5.2,

12.2 , uoid-the, uoit-th 2

12.53, uoide 3.4, 5.2,

12.54, ueid-so- 12.3 n. 2 , uid-tó-s, uitstós 6.8, $12.53,12.54$

$u l k^{w}-3.2,6.5,7.1,7.17$

uobhs- 6.5

-ie-, -io- vb. suffix $12.3 \& \mathrm{n}$. 2, 12.34, -ad-io- 12.3

-ieh $h_{l^{-}},-i h_{l^{-}},-o-i h_{l^{-}}$opt. suffix $12.6,12.31$

io- pron. 8.11 n. $3,8.13,8.14$, $11.6, i e-8.11,8.14$

ịé $k^{w}-r-, \underline{i} k^{w}-n-7.4$

-īoss, -ios-, $-i s-9.10$

ing - 12.3, ingom 4.3, 7.1, inu$n$-g- 6.5, inu-né-g-ti 12.3

$\underline{i n} H_{n} t-5.6$

\section{AnAtolian}

Hittite

dāi 12.61

hant-s 3.1

harapp- 3.1

kwis, kwid 8.13

lamniyazzi 12.3

neku- 6.5

newahh-12.3, newahmi 12.40

sak-ti, sak-ta 12.25

ug, amug 8.2

yukan 7.1

watar, witenas 7.42

\section{ToChaRIAN B}

skiyo 6.5

wes 8.2

\section{INDO-IRANIAN}

Sanskrit

$a-3.2$

á 8.10 n. 2

abhi(-) 6.5, abhi-tah 3.2

adántam, adatáh 12.7, datáh 3.2

adháh 9.11

adhamá- 9.11

agnè, agnayē, agnayah 7.21

ahám 8.2, máyi 8.5, āvá-, nah, vayám 8.2

áhi- 6.4

ajáh 7.6

ájrah 6.4

ántara- $8.15,10.7$

anyá- 10.7

ápa 6.4

apataram 5.5

ásmi 12.1, ási 6.8, ásti 12.1, 12.57, sthá 12.1, sánti

$12.1,12.57$, astu, santu 12.28

asmái 8.7

asțấu $6.5,10.2$

áśvah 7.8, -asya 7.8, 8.10

aśvānām 7.14

ätíh 5.5

ávyah 7.21 babhrúh 4.8

badhná̀ti 6.5 , baddháh 3.2

bhadráh 9.13

bándhuh 3.2

budh-, bó̀dhati 3.4

bhárati 6.4, 12.6, bibharti 12.3, bharēyam 12.6, bhárāt(i) 12.6, bhárant-

7.17, 9.9, bharanam 12.7, 12.30 n. 1, pra-bhárati 12.8

bibhēti 12.3

bhinádmi 12.7, bhindánti 12.9 , bhinná- 12.7

bhrājatē 6.5

bhrắtar- 6.5

bhrüh 3.3

bhü-, bhávati 6.4, 6.10, 12.57

\& n. 6 , ábhūt 3.3, 12.57

n. 6

bu-bhód-a 12.61 n. 8

bhujáti 12.3

bhürja- 5.5

cátuspad 9.1 n. 1

caturthá- $10.1 \mathrm{n} .18$

catvắrạ 6.5, 10.1, cátur 10.1

chāyá 6.5

dāpayati 3.2

dáśa $6.4,10.2$

datáh 3.2

dầtum 12.7

dēvár- 3.4, 6.3, 7.35 n. 3

dēvī, -ìm 7.17, dēvyāh $7.17 \mathrm{n}$. 1

didești 12.9

didrkșati 12.3 n. 2

dīrghá- 3.3

drávati 12.18 n. 6

duhitár- 5.5

duráh 3.2

d(u)váa (u) 3.3, 3.4, 6.4, 10.1, dváyōh 6.10

dyáti 12.7

dyauh 7.17

dham-, dhmā-táh, dhami-táh 3.3

dhắrā 3.2

dháyati 6.10, dhāya- 3.2

dhrsnốti 6.4, 6.5

dhvánati 6.5

éti 12.63, imáh 12.24 n. 8, iy$\bar{a} y-a 12.63$

gámati 3.2, gácchati 12.9, jagáma, jagmá 12.2, gáti-h 
3.2, gamayấm cakára 12.33 n. 3

giráti 12.3

grbhṇấti 6.9

ghrṇốti 6.4

hamisáh 6.4

hatá- 12.7 n. 3 , hatịh 6.4

hếṣas- 6.4

id-am 8.10 n. 2

jámbhah 6.5

jánah, jánasah 7.37

jānà̃ti $6.4,12.54$, jajñáa

12.22, jātáh 3.3

jấnu 6.4

jánghā 6.5

játu 4.4

jihvấ 6.5

jinốti, jinváti 12.50

jūváh 6.3

jūrṇah, jīrnah 3.3

kád 6.4

káh, káa, kím 8.13

kákatē 3.2

kapấla- 6.4

karkara- 6.4

katará- 6.4, 8.13

kētú- 3.4

krnồti 12.3 n. 5, cakắra 12.2

krándati 4.4

krīnáati 12.3

lēlāyáti 12.3

lihati 6.4, lédhi, alikșat 12.1

lồtam, lồtram 3.4

lúbhyati 6.4

mádhu- 4.4, 6.4

mádhyah 6.4

maha- 9.13

mánu- 6.8, 7.27 n. 2

mányate $12.3,12.54$

má̀rśti 12.18

mātár-3.3, 7.35 n. 1, mätrbhis

méhati 6.5

mìdhá- 3.5

mrdnāti 3.2

mūrdhán- 3.3

mú̀s- 3.3

ná $2.5,5.5$

nagnáh 6.4

ná kaś-caná 8.15 \& n. 10

naktam 6.5

nāma 7.30 n. 3, -āni 7.31

namas- 12.3 , namasyáti 12.3

nápāt 6.4, 6.11 nás 3.1

nầuh 3.4

náva $6.11,10.2$

náviștha- 9.11

néma- 9.2

nīạ́h 4.3

páliknī 7.17

panthāh, patháh 7.4

páñca $6.5,10.2$

payka- 4.1

pári 10.7

pārșnih 4.2

parút 5.6

páśu- 6.4

pát, p $\breve{\bar{a} d-6.4, ~ 7.28, ~ p a d-i ~ 6.5, ~}$ pat-sú 6.5

pitár-6.6, 7.35 n. 1, pitúr 7.36

pivvan- 3.1

prccháti 12.3, prcchá 6.5

prīnáti 12.40

priyá- $6.10,12.3$ n. 2, prīyatē 12.3 n. 2

prnấti $6.8,12.50$, prnááti 12.49

pürña- 3.3

purú(-) 3.2, 11.2

púrva- 9.2

rájạ̣ 7.37

rájani- 6.4

rājñah 7.4 n. 1, 7.31, rājñ̄e 7.31

rinákti, áricam 12.4 n. 4 , rikta-, riktá- 12.33

rjyati 6.4

rnōti $6.8,12.3$ n. 5 , rnváti 6.8

rōká- 6.4

rōpayati 3.4

rudhirá- 3.2

sá 6.11, tám 6.11, 7.8, tád 9.2, 11.1, tásmāi 6.8 , tấm 6.11 sad-6.4, sattá- 3.2, 6.8

sahásram 10.6

sāmí- 10.10

saptá 10.2

sic-, ásicah 12.25

smárati 12.3

sprnồti 6.5

sphuráti 12.3 n. 6

stighnōti 6.4

sthagayati 6.4

sūnóh 7.25

sunồti 12.3

svá- 8.4 svadhấ 4.4

svájatē 12.3

svásar-, svásr- 6.11

śānah 3.4

śatám 6.4

śatru-, śatruyáti 12.3

śvētá-, śvítna-, śvitnyá- 6.9

śráyati 12.3 n. 6

śrutáh $6.4,12.7$

șás 10.2

șașthá- 10.8

tamsayati 12.3

tár-hi 11.1

tavás- 10.6

tíṣthāmi 12.2, sthitá- 3.1, 3.2, $6.5,12.7 \& \mathrm{n} .3$

tráyah 6.4, 10.1

trínam 3.2

trísyati 3.2

tudáti $12.3 \&$ n. $8,12.9$,

$12.18,12.24$ n. 2

tvám 8.3, tvád, tvé 8.3

ubhnấti 6.5

üdhar 3.4

upári 11.2, 11.5

ùrṇā 3.3, 6.8

usrá- 6.11

ușāh 1.12 n. 1

ut-tama 9.11

váhati 6.4

vahyá- 4.4

vanốti 12.3 n. 5

vānt- 4.2

vára- 11.2

várșișthah 9.13

vártati 6.4, 6.6, va-várt-a 6.1,

12.61, va-vrt-imá, vart-

āná- 6.6, vā-vrt-úh 12.61

vasnayáti 12.3 n. 2

vasu- 9.13

vāti, vắyati 12.22

váyati 6.10

vid-, véda 3.4, 12.2, 12.54, vittáh 6.8, vid-mán-ē 12.7

vidyá 7.17

vrkah $3.2,6.5,7.1$

vrkìh, vrkyàm 7.17

vrnìté 12.59

yā-, áyām 12.63

yáh, yấ, yad 8.14

yáknah 7.4

yunákti 12.3, 12.50, yuñjáti 12.49 , yojat 12.3, yugám 7.1 
Avestan

ayarz $6.11,11.1$

azam 8.2

bandayaiti 4.4, 6.5

frā-ymat 3.2

hazayrom 10.6

hizvā 6.5

mazga 6.11

$m \check{\bar{l}} \mathrm{~d} d a-6.11$

sādra- 3.2

saēni- 3.4

satom 6.1

Oritya- 10.7

vawžaka- 6.5

varazyeiti 12.35

Middle Persian

drang 6.5

\section{Armenian}

ost 6.11

ti 3.3

\section{BALTIC}

Old Prussian

antars 10.7

balsinis 3.2

deiwas $7.8,8.10$

dessimpts 10.2

es 8.2

gorme 6.4

knapios 1.5 n. 5

massais 1.4

pirmas $1.4,10.7$

Lithuanian

Forms are Modern Lithuanian unless otherwise marked.

añt(a)ras 10.7

ántis 5.5

áugu, áugti 6.4

aušrà 1.12 n. $1,6.11$

blendžiù, blệsti 6.5

bút 12.7

dañgiškas 1.4

(-)dẽsimt 10.2, 10.5

dët $i 2.61$ dubùs 6.4

duris 6.4

dvì-dešimt 10.4

dvý-lika 10.3

esst 12.57

eš (Old) 8.2, mùdu, vè-du 8.2, vẽdo (Samogitian) 8.2

gẽras žmõgus, gerà žmonà, geràsis žmõgus, geróji žmonà $9.7 \mathrm{n} .3$

glabóti 3.3

gláudoti (Old) 6.4

glëbiu, glëbti 3.3, 12.3 n. 4

gniutúoti 6.9

grưdau, grúdžiu 3.3

kanapës $1.5 \mathrm{n} .5$

katràs 8.13

káuju, kóviau, káuti 3.4, 6.10

kur̃ 11.1

lemia 1.4 , lèmé 1.4

liẽkas 10.3

lizdas 4.3

lýg, lýgus 3.3, 8.13 n. 7

medùs 3.2

miglà 3.2

minëti 12.44

mótè $7.35 \mathrm{n} .1$

núogas 6.4

pa-žìntas 3.3

pilnas 3.3

pinù, pinti 6.3

pirmas 10.7

raupaĩ 3.4

rëžiu, rëžti 4.4

sëdite 12.47

sëju, sëti 12.22

sekù 3.2

skelù (Old) 12.54

skóbti 12.18

slãbnas (Samogitian) 6.4

slepia 1.4 , slépe 1.4

styrstù, stỹrti 3.3

šis 8.7

támisra- 6.3

tamsùs 6.8

tamui 8.10

tenkù, tèkti 4.1, 4.4

treñkti 4.1

tris-dešimt 10.4, 10.5

tù 2.4

túkštantis 10.6

úoga 3.2

vapsvà 6.5

$v \dot{e}-d u 1.4$ vélmi 12.59

venúo-lika 10.3

veržiù, veřžti 12.3 n. 6

vilkas 6.5

žengiù, žeñgti 6.5, $12.62 \mathrm{n} .1$

Latvian

blendu 6.5

es 8.2

kãrs 6.4

kàuns 3.4

skabrs 6.5

skābs 12.18

\section{SlaVIC}

Old Church Slavonic

česo $7.8,8.10$

dati 12.7

debelb 6.8

desętb 10.2

děti 12.61

dobrz rabz, dobra žena, dobrbjь rabъ, dobraja žena 9.7 n. 3

glagolati 6.4

gostb 6.4, gosti 7.21

ime 7.30 n. 3

(j)azb 8.2

konopljá 1.5 n. 5

ležati 6.4

mbněti 12.44

mbzda 3.5, 6.11

mozgb 6.11

опъ 9.7 n. 2

rzděti 12.44

sēdite 12.47

sějo, sěti 12.22

sb 8.7

skotb 6.9

slověnbskъ 1.4

smokva 6.9

stoja, stojitb 12.47

tèmb, tomb 8.10

tysašta 10.6

veděvě 12.26

veljo, veléti 12.59

voziti 3.2

žena 6.4

Slovene

$m \hat{\imath}-d v a 8.2$ 
Serbian

rüpa 3.4

Czech

brh 3.2

Russian

глина 6.4

жена 7.33

\section{Hellenid}

Greek

Forms are Attic unless otherwise marked.

$\dot{\alpha}-3.2$

$\dot{\alpha} \gamma \alpha \theta \dot{\varsigma} \varsigma, \dot{\alpha} \mu \varepsilon i v \omega v, \not ́ \alpha \imath \sigma \tau o \varsigma$ 9.13

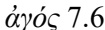

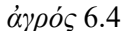

$\ddot{\alpha} \gamma \chi \omega 6.5$

$\ddot{\alpha} \gamma \omega 12.15$

$\dot{\alpha} \gamma \hat{\omega} v,-o \varsigma 7.33$ n. 1

$\dot{\alpha} \delta \dot{\eta} v 6.4$

$\ddot{\alpha}-l \sigma \tau \circ \varsigma 6.8$

$\alpha \hat{i} \sigma \chi \circ \varsigma 3.4$

$\dot{\alpha} \lambda \eta \theta \operatorname{\varepsilon in}$ (Ionic) 7.17

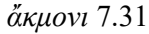

$\not \ddot{\alpha} \lambda$ os, $\ddot{\alpha} \lambda \lambda \circ 9.2$

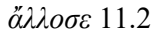

$\dot{\alpha} \lambda \varsigma 3.2$

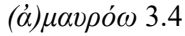

ג厶uvós 6.4

$\dot{\alpha} \mu \phi i \quad 5.2$ n. 2, 6.5, 11.5

$\ddot{\alpha} \mu \varphi \omega 10.1$

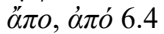

$\dot{\alpha} \pi \circ \delta$ $\delta \delta \rho \alpha \dot{\sigma} \kappa \omega 12.3$

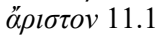

$\dot{\alpha} \rho \pi \dot{\alpha} \zeta \omega 12.3$

$\ddot{\alpha} \rho \pi \eta 12.3$

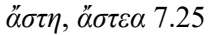

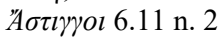

ä $\tau \tau \alpha 6.9$

$\alpha \hat{v} \circ \varsigma$ (Homeric) 3.4

$\alpha \dot{\tau} \tau \hat{\omega} v 2.1$

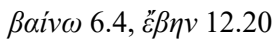

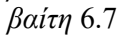

$\beta \alpha \sigma l \lambda \varepsilon \dot{s} \varsigma, \beta \alpha \sigma l \lambda \varepsilon \hat{v} 5.4$ n. 2

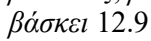

$\beta \lambda \omega \theta \rho o ́ \varsigma 3.3$

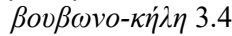

$\beta \dot{\omega} \omega 6.4$

$\gamma \varepsilon 8.2, \dot{\varepsilon} \mu \dot{\varepsilon} \gamma \varepsilon 8.2$

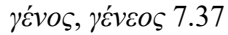

$\varepsilon \varepsilon \dot{\omega} \omega 3.4$

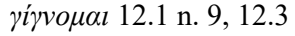

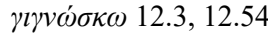

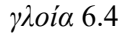

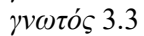

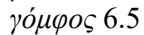

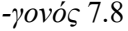

jóvv 6.4

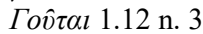

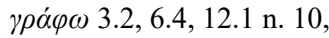

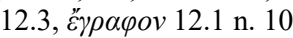

Гv́$\theta \omega v \varepsilon \varsigma 1.12$ n. 3

$\Delta \alpha \gamma \iota \sigma \theta \alpha \hat{\imath} \circ \varsigma 7.37$ n. 5

$\delta \bar{\alpha} \dot{\rho} \rho 6.3,7.35$ n. 3

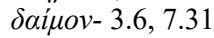

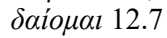

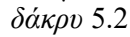

$\delta \alpha \pi \alpha v \alpha \dot{\omega} \omega 3.2$

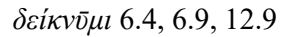

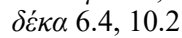

$\delta \varepsilon \dot{\varepsilon} \mu \omega 6.11$

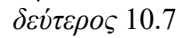

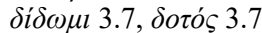

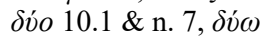

(Homeric) 3.3, 6.4

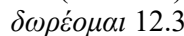

ह̈ 8.4

$\dot{\varepsilon} \beta \delta о \mu \dot{\kappa} \kappa$ ov $\tau \alpha 10.5$

$\varepsilon \ddot{\beta \delta о \mu о \varsigma ~} 10.5$

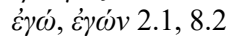

है $\theta$ o५ 4.4

हi 8.14

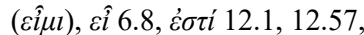
Év $v i$ (Doric) 12.57, है $\sigma \tau \omega$ 12.28

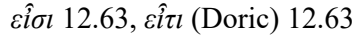

$\varepsilon \hat{i}-\tau \alpha 8.14$

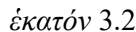

(દ) $\kappa \varepsilon \hat{\imath} v o \varsigma ~ 8.7,8.8,11.1$

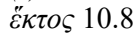

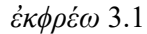

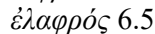

évvย́a 10.2

है $\xi 10.2$

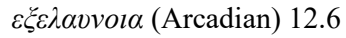

$\dot{\varepsilon} \xi \dot{\eta}$ - $\kappa o v \tau \alpha 10.5$

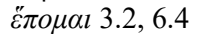

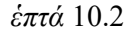

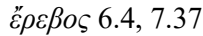

ع̈ $\rho \varepsilon v \theta \circ \varsigma 6.8$

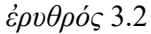

ह̈ $\sigma \pi \varepsilon \rho \circ \varsigma 1.12 \mathrm{n} .1$

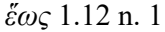

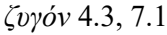

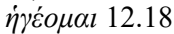

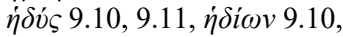

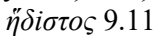

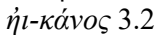

$\dot{\eta} \mu l-10.10$

$\dot{\eta} \pi \alpha \rho 7.4$

$\theta \varepsilon \hat{\alpha} \varsigma 5.4$

$\theta \varepsilon o \hat{v} 5.2$

$\theta \varepsilon \rho \mu o ́ \varsigma ~ 6.4$

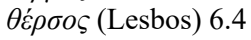

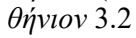

Өoós 3.2

$\theta v \gamma \alpha \dot{\tau} \eta \rho, \theta v \gamma \alpha \tau \varepsilon ́ \rho-5.5,7.35$ n. 2

$\theta \dot{v} \rho \bar{\alpha}$ (Homeric) 3.2, 6.4

$\theta \omega \mu o ́ \varsigma ~ 3.3,12.39,12.61$

iлvós 6.9

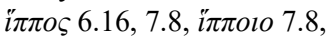
8.10

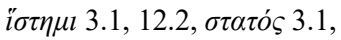
$3.2,12.7$

$-\imath \sigma \tau \circ \varsigma 6.5$

$\kappa \alpha \lambda \imath \alpha \dot{\alpha} 3.2$

$\kappa \alpha \dot{v v} \alpha \beta \imath \varsigma 1.5$ n. 5

$\kappa \hat{\eta} \delta o \varsigma 3.2$

$\kappa \eta \dot{\lambda} \eta 3.4$

$\kappa \hat{\eta} \pi \circ \varsigma$, Doric $\kappa \hat{\alpha} \pi \circ \varsigma 3.3$

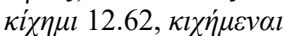

(Homeric) 3.3

$\kappa \lambda \varepsilon \dot{\varepsilon} \omega, \kappa \lambda v \tau o ́ \varsigma$ 6.4, 12.7

$\kappa \lambda \dot{\varepsilon} \pi \tau \omega 6.4$

$\kappa \lambda \imath \tau ı \kappa o ́ \varsigma ~ 2.1$

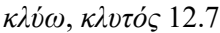

$\kappa v \dot{\mu \eta} 6.8$

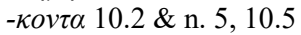

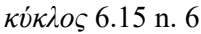

кррлкко́v 6.19

$\kappa \hat{\omega}$ vos 3.4

$\lambda \bar{\alpha} i \bar{\alpha}$ (Doric), $\lambda \eta \ddot{i \eta}$ (Ionic) 3.4

$\lambda \alpha \varphi \dot{\sigma} \sigma \sigma \omega 6.9$

$\lambda \varepsilon i \pi \omega$ 3.4, 6.4, 10.3, 12.2,

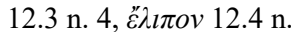

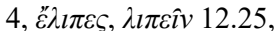

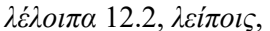
$\lambda$ віілол 12.6

$\lambda \varepsilon i \chi \omega \omega .4$

$\lambda \dot{\chi} \chi о \varsigma ~ 6.4$

$\lambda \imath \pi \alpha \rho o ́ \varsigma ~ 3.2,4.3$

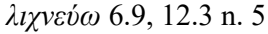




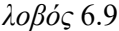

$\lambda o ́ \chi o \varsigma 3.2$

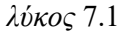

$\Lambda \omega \check{\delta} \delta \mathrm{l} 1.11 \mathrm{n} .6$

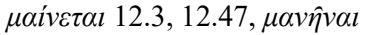
12.47

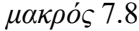

$\mu \varepsilon \gamma \alpha \dot{\lambda} \eta 9.13$

$\mu \varepsilon \dot{\delta} \delta$ o $\alpha \mathrm{l} 6.4$

$\mu \dot{\varepsilon} \theta v$ 3.2, 4.4, 6.4

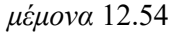

$\mu \varepsilon \dot{\rho} \mu \varepsilon \rho о \varsigma 12.3$

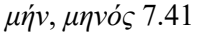

$\mu \dot{\eta} \tau \eta \rho$ 3.3, $7.35 \mathrm{n} .1$

$\mu \hat{\eta} \tau \iota \varsigma 3.3$

$\mu \hat{\eta} \chi o \varsigma 12.53, \mu \hat{\alpha} \chi o \varsigma$ (Doric) 12.53

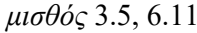

veípel (Homeric) 6.4

vÉ

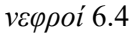

vทे $\sigma \alpha \alpha 5.5$

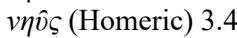

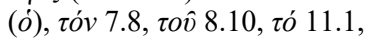

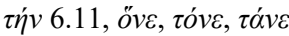
(Thessalian) 11.1

ö $\delta \varepsilon 8.8$

ő

oî่ $\delta$, oî $\delta \varepsilon 3.4,12.2,12.54$, oî $\sigma \theta \alpha 12.25, i \delta \mu \varepsilon v \alpha l$ (Homeric) 12.7

oivó 10.1

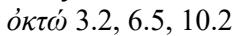

ó $\mu i \gamma \lambda \eta 3.2$

он $\mu \varphi \dot{~} 6.5$

óvouaivw 12.3

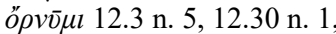

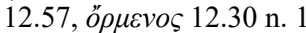

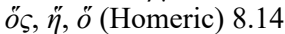

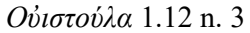

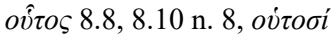
8.10 n. 8

ö $\phi ı \varsigma 6.4$

ó $\varphi \rho \hat{v} \varsigma 3.3$

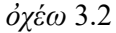

о̆чонол 3.1

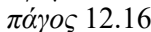

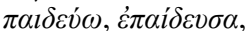
$\pi \varepsilon \pi \alpha i \delta \varepsilon v \kappa \alpha 12.33$ n. 3

$\pi \alpha \rho \alpha ́ 11.2$ n. 1

$\pi \alpha \tau \dot{\rho} \rho$ 6.6, 7.2, $\pi \alpha \tau \dot{\varepsilon} \rho \alpha$ 5.3,

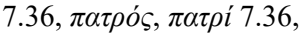
$\pi \alpha \tau \dot{\rho} \rho \omega \nu$ 7.36, $\pi \alpha \tau \rho \hat{\omega} v$ (Homeric) 7.36 $\pi \varepsilon i \theta \omega$ 12.1, $\pi \dot{\pi} \pi \imath \theta o v$

(Homeric) 12.1

$\pi \dot{\lambda} \lambda \alpha \varsigma 6.8$

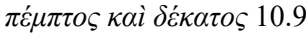

$\pi \varepsilon v \theta \varepsilon \rho o ́ \varsigma ~ 4.4$

$\pi \dot{\varepsilon} v \tau \varepsilon 6.5,10.2$

$\pi \varepsilon v \tau \varepsilon \kappa \alpha i \delta \varepsilon \kappa \alpha 10.9$

$\pi \varepsilon v \tau \eta \dot{\kappa о \nu \tau \alpha ~} 10.5$

$\pi \varepsilon ́ \pi \circ v \theta \alpha$ 3.1, हैं $\alpha$ $\alpha$ ov 3.1

$\pi \varepsilon \rho \alpha \dot{\alpha} 12.15$

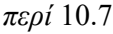

$\pi \dot{\rho} \rho v \sigma l 5.6$

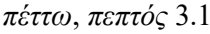

$\pi \varepsilon \dot{\theta} \theta$ онал 3.4

$\pi \dot{\eta} \chi \varepsilon \omega v 7.25$

$\pi \lambda \dot{\varepsilon} \kappa \omega 12.3,12.33$

$\pi \lambda \varepsilon \dot{\varepsilon} \omega 6.13$

$\pi \lambda \omega \tau o ́ \varsigma 12.7$

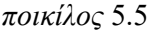

$\pi о \imath \mu \varepsilon ́ v-3.6$

$\pi o ́ \lambda l \varsigma, \pi o ́ \lambda l ~ 7.21, \pi o ́ \lambda \eta \ddot{~}$

(Homeric) 7.23

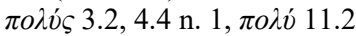

$\pi о \rho \varepsilon \dot{\omega} \omega 6.4$

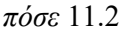

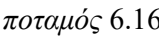

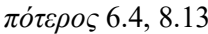

$\pi \circ u ́ \varsigma, \pi \circ \delta-6.4,7.28$ n. 3 , $\pi \delta ́ \delta \alpha$ 7.1, $\pi \delta ́ \delta \varepsilon \varsigma 7.27$

$\pi \rho \dot{\theta v \rho o v ~} 4.3$

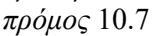

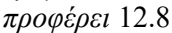

$\dot{\rho} \varepsilon \dot{\zeta} \zeta \omega 12.37$

$\dot{\rho} \varepsilon \hat{v} \mu \alpha 6.11$

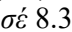

$\sigma \bar{\imath} \gamma \dot{\eta} 3.3$

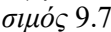

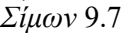

$\Sigma \kappa \alpha v \delta i \alpha 1.12$ n. 3

$\sigma \kappa l \bar{\alpha} 6.5$

$\sigma \pi \varepsilon \dot{\rho} \rho \omega 12.3$ n. 6

$(\sigma) \tau \dot{\varepsilon} \gamma \circ \varsigma 6.4$

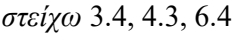

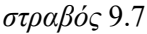

$\Sigma \tau \rho \alpha \dot{\beta} \omega \nu$ 9.7

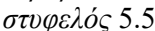

бó 2.5

ธova $\omega \omega \gamma \hat{\eta} 1.11$

$\tau \varepsilon \hat{\imath}-\delta \varepsilon$ (Doric) 7.8 n. 9, 8.10

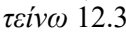

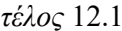

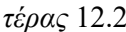

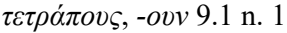

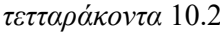

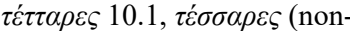
Attic) 10.1

$\tau \eta-\delta \varepsilon$ (Thera) 5.3, 7.8 n. 6 , 8.10

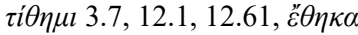

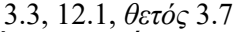

$\tau \bar{\mu} \mu \bar{\alpha} \omega 12.43, \tau \overline{\bar{\nu}} \mu \bar{\alpha} \mu l$ (Aeolic) 12.43

$\tau \bar{\mu} \mu \dot{\eta}^{7} 7.13$

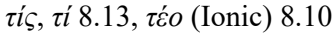

$\tau о \mu \eta \dot{~} 12.40$

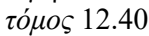

$\tau \rho \alpha ́ \pi \varepsilon \zeta \alpha 3.1$ n. 6, 7.17, - $\alpha \nu$

7.17

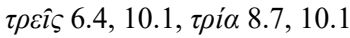

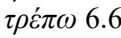

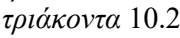

$\tau \rho о \pi \dot{~} 6.6$

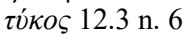

$\tau \dot{\phi} \phi \omega 3.2$

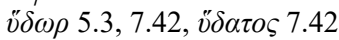

vं $\pi \dot{\varepsilon} \rho 11.2$ n. 1, 11.5

vंлó 6.9

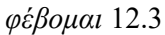

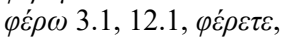

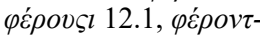

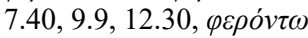

(Doric) 12.28

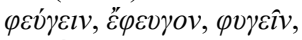

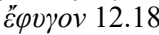

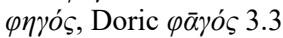

$\varphi \imath \lambda \dot{\varepsilon} \omega 12.34$

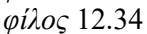

$\varphi \lambda \alpha \hat{v} \rho \circ \varsigma, \varphi \alpha \hat{v} \lambda o \varsigma 3.4$

$\varphi \lambda \dot{v} \alpha \varphi \circ \varsigma 3.3$

$\varphi о \beta \varepsilon ́ \omega 12.6$

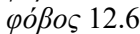

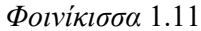

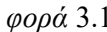

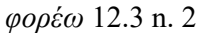

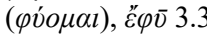

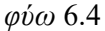

$\varphi \omega ́ \gamma \omega 12.15$

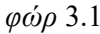

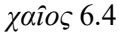

$\chi \alpha v \lambda_{l}$-ó $\delta o v \tau-3.4$

$\chi \dot{\eta} v 6.4$

$\chi \bar{l} \lambda \imath \dot{\alpha} \varsigma 10.6$

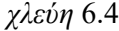

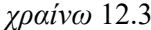

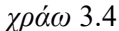

$\chi \omega \dot{\rho} \bar{\alpha} 7.13$

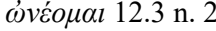


ITALIC

Oscan

mais 9.13

paastores 3.3

Umbrian

mestru 9.13

natine 1.4

Latin

abditum 12.39

abdomen 3.3, 12.39, 12.61

ad 6.11

aes 1.4

aеvum 8.15 n. 8

agnus 6.4

alius $9.2,10.7$, aliud 9.2

alter 10.7

ambō 10.1

ambulāre 12.63

anas, anatis 5.5

angō 6.5

ante 3.1

aqua $1.4 \mathrm{n.} 9$

asininus 8.5

atta 6.9

augeō 6.4

aurora 1.12 n. 1

auscultō 3.2

bēta 3.5

bìn $1.4,6.8,10.1$ n. 11 , 10.10

bis 1.4

bonus, melior, optimus 9.13

bōs 4.11

cannabis 1.5 n. 5

canō 3.2

capiō 12.17 n. $3,12.31$ n. 6 , 12.45 , captus 6.5

caput 1.4 n. 9

cārus 6.4

castra 4.13, 5.6

Catō, -ōnis 9.7

catus 9.7

caupō 6.19

celō 3.2

centum 3.2, 6.1, 6.4

Cimbri 6.7

cis 3.4, 8.7, 11.1

clepō 6.4 clēricus 3.3

clìnō 12.3 n. 6

cognātus 7.1

collum 1.4 n. 9

commūnis 6.6

complètus $12.50 \mathrm{n} .3$

co(n)- 6.6

concipiō 6.6

conjugō 6.6

cōnor 12.5

conveniō 6.6

coquō, coctus 3.1

cubāre 12.40

cum 6.11, quom (Old) 6.11

decem 10.2

défendō 4.4

dēnique 11.1

dèns, dent- 3.2, 7.28

dīcōo 6.4

dīvus 4.8

(dō, dāre), datus 12.33

domāre 12.3

donec 11.1

duo $6.4,10.1$

ea, eam 8.7

$\bar{e} d \bar{\imath} 12.31 \&$ n. 5

egō 8.2, egomet 8.2 , nōs 8.2

$e \bar{o}, i \bar{\imath} 12.63$

equus 7.8

explicere 12.40

extimus 9.11

extrā 1.4

faciō 12.15, 12.31 n. 6 , fêc $\bar{\imath}$ $3.3,12.15,12.20$

fāgus 3.3

fêmina 3.2

femur, feminis 7.42

ferō 6.4, ferent- 9.9

ferveō 6.8

flōreō 3.3

formus 6.4

fragilis $12.31 \mathrm{n} .3$

frūctus 3.3

generis 6.6, 7.1

genitōris 7.1

gentis 7.1

genus, generis 7.37

-gintī, -gintā 10.5

Gotones 1.12 n. 3

Graecus 3.5, 6.7

grāmen 1.4 n. 9

grānum 3.3

haedus 3.4

Hasdingi, Asdingi 6.11 n. 2 hērēs 3.3

hic 8.8

hiō 12.3 n. 6

hostis 6.4

idem 8.10 n. 2

ignis, ignī 7.21

ille 8.8

imāgō 3.3

in- 3.2, en-(Old) 3.2

infimus 9.11

inguen 6.4

is 8.15

iste 8.8 , istum 6.11 , istud 11.1

jugum 4.3, 7.1, 12.3

jungō, junxī, junctus 6.5

juvent- 5.6, juventūt- 1.4

labō 12.15

lābor 12.15

lambō 6.9

lāna 3.3, 6.8

lavāre 12.40

lavere 12.40

lèvir 3.4

levis 6.5

libet 6.4, lubet (Old) 6.4

limus 1.4 n. 9

lingō 6.9

lingua 1.4 n. 9, 6.5, 7.13, dingua (Old) 1.4 n. 9, 6.5

linquō 10.3, 12.3

longus 6.5

lupus $6.5,7.1$

lū $x 6.4$

magis 9.10

magnus $4.4,9.10,9.13$

māter 3.3

meditor 6.4

medius 4.4, 6.4

memin̄̄ 12.54

mēnsis 7.41

mentum 6.4

mêtior 3.3

meus 8.5

minor, minimus 9.13

molina 4.7

mollis 3.2

monē̄ 12.3, monēre 12.44

mūs 3.3

nāpus 3.3

nāris 3.1

nātus 3.1, 3.3, 12.33, gnātus

(Old) $3.1,3.3$

natiōne 1.4

nāvis 6.3 
nefās 5.5

nefrōnēs (Praenestine) 6.4

nepōs, nepōt- 3.1, 6.4, 7.41

neptis 3.1

neque 8.15

nesciō 5.5

nìdus 4.3, 6.11

ninguit 6.4

niveus 6.4

nōman $7.30 \mathrm{n} .3$

nōnāgintā 10.5

nōnus 10.5

nōscō 6.4, 12.3, 12.54, gnōscō (Old) 12.3, nōvi 12.22

noster 8.13

nostrātes $10.1 \mathrm{n} .12$

novem $6.11,10.2$

novus $12.3 \mathrm{n} .2$

nox, noctem 6.5

nūbō, nūpsi, nūptus 6.5

octō $3.2,10.2$

oleum 4.7

orbus 3.1

orior 12.57

Ostrogoti, Austro- 1.11 n. 6, $1.12 \mathrm{n} .1$

pālus 3.3

pangō 4.1, 12.3, 12.16, pepiḡ $\bar{\imath}$ 12.3

pāscō 3.3

pater 6.6

pecū 6.4

per 10.7

perna 4.2

pēs, ped- $6.4,7.28$ \& n. 3

pascāri 12.40

piscis $3.2,6.5,12.40$

plectō $6.13,12.3,12.33$

plēnus $3.3,6.8$

plicō 12.3, 12.33, plicāre

12.40

pluit 6.13

plüs 3.4, plous, ploerume

$$
\text { (Old) } 3.4
$$

portō 6.4

poscit 12.3

prēsbyter 3.5

prōfert 12.8

quattuor 3.1 n. 6, 6.5, 10.1

-que 6.5 n. 2, 8.15 n. 9, 11.1, 11.6

quī, quae, quod $8.12,8.13$ \& n. 1 quindecim 10.9

quinque $6.5,10.2$

quintusdecimus 10.8

quis, quid 8.13

quod 6.4, 6.11

quoque $8.13 \mathrm{n} .1$

ratio 10.5

recumbere 12.40

relinquō 6.4

renovāre 12.3 \& n. $2,12.40$

rogō 6.4

Rōmāni 3.3

rubeō 12.3 n. 2, rubēre 12.44

rubor $3.2,6.8$

Rufō, -ōnis 9.7

rufus 9.7

rumpō 6.9

rüfus 3.4

saccus 6.9

sāgiō 12.18

sal 3.2

salutāre 12.3

scabō $6.5,12.15$

schola $3.2 \mathrm{n} .1$

scōpa 12.15

scrībō 12.12

sēcūrus 5.6

sēdēs 3.1

sedeō 4.3, 6.4, sedēre 12.19

n. 1, sēdimus 1.4 , sessus 3.2

sēmen 12.22

sēmi- 10.10

sentiō 6.8

septem 10.2

sequor $3.2,6.4$

sermō, -ōnem 7.33 n. 1

sessiō 6.8

sex 10.2

sextus 10.8

silère 1.4, 12.3

Silva Bācenis 3.3 n. 3

sōror 6.11

sortior 12.5

spernō 6.5

stō 6.5, stāre 3.2, 12.64, status $3.2,12.7$

strāta 4.6 n. 2

suad (Old) 6.11

sum 12.9 n. 2 , est, sunt 12.57 , fiō 12.54, sim 12.1 n. 4, estōd 12.28

superne 1.4, 8.2, 11.2

suus 8.4 tacēre $1.4,12.3$

tangō 6.9

tēgula 4.15

tenuis 6.8

ternī $10.1 \mathrm{n} .11$

tertius 10.7

Teutones 6.7

thèca 3.5

tongeō 4.1, 6.4

tōtus 10.6

trans 1.2

trēs 6.4, 10.1, tria 8.7, 10.1

Turicum 6.21

-umnia 6.11

ūnus 3.4, 10.1, oinos (Old) 3.4

vadō 12.15

vādo $12.15,12.63$

vehō 6.4

veniō 6.4

ventus 4.2

vertō 6.4

vesper $1.12 \mathrm{n} .1$

videō 12.54, vīsus 1.4, 6.8

vīgintī 10.5

vincō $6.4,12.3$ n. 3 , vīc $\bar{\imath} 12.3$

n. 3

Visigoti 1.12 n. 1

vīsō 12.3 n. 2

volō 12.59 , vult 12.57 , velim 12.1 n. 4

vorāre 12.3

French

allons, allez 12.63

flanc 6.11 n. 2

\section{Celtic}

Prehistoric Celtic

rig- 1.4

Volcae (Latinized) 3.2 n. 1

Gaulish

ambactus 1.4

isarno- 1.4 
Irish

Forms are Old Irish unless

otherwise marked.

ás 3.3

ben $6.4,7.4$, mná 7.4

benn 6.4

betha, -ad 1.4

bith 4.3

biuu 12.57

bolg 3.2

breth 3.1

cacht 6.5

cé 11.1

celid 3.2

dag- 9.13

domain 6.4

drui- 12.61

dub 3.2

fiuss 1.4

iasc, èisc 6.5

il 4.4

i-nnocht 6.5

lán 3.3

lige 6.4

maith 9.13

mí-, mis(s)- 6.8

mid 4.4

net (Middle) 4.3

slacc (Middle) 6.5

tar 11.2

teng 6.5

tíagu 6.4

Welsh

Forms are Modern Welsh unless otherwise marked.

bannog 6.4

canu 3.2

de(h)ongl (Middle) 6.5

deigr 3.2

dwfn 6.4

galw 6.4

gnawd (Middle) 3.3

$g \hat{w} r 4.3$

\section{Albanian}

kanep 1.5 n. 5

\section{VENETIC}

eхo 8.2, meхo $1.4,8.2$
GERMANIC

Pre-Proto-Germanic

dhếti, dhốmes 12.61

$e$-oin- $e$-ii- 12.63

$g^{w}$ ow- 4.11

$k^{w} e k w \overline{o r} 10.1$ n. 17

$k^{w} i k^{w} a z 6.4$

péturto- $10.1 \mathrm{n} .18$

septnt $10.2 \mathrm{n} .1$

Proto-Germanic

afteraz 5.5

azisôn $\hat{o}^{n} 5.6$

aзjō 6.18

$\bar{a}^{n}$ xtinaz 4.7 n. 17

axtō 4.9

axtōxand 10.5

$a x^{w} \bar{O} 4.8$

-ai $11.2 \& \mathrm{n} .1$

aix(e) 4.9

aimurjo $^{n} 4.7$

ainaz 8.15, 10.3, aini-10.1,

10.3 ainino $^{n} 10.1$ \& n. 2

ain̄̄zaz 8.15

aini-lib- 10.3

airi 10.7

airuz 4.9

aiskōjana $^{n} 12.3$ n. 9

aiwa 4.8

aiwaz 4.9

aiw-3i-līk-az 8.15

aiwin- 4.9

a(j)iri $6.11,11.1$

$a(j) i z-6.11$

akana $^{n}, \overline{o k}-12.15$

akraz 6.15

ala-maxtīzaz 5.6

ansuz 1.13, 4.9

anperaz 4.11, 5.2 n. 8, 5.5, anperō 5.5, anperaiz $\hat{o}^{n}$

$9.2 \mathrm{n.} 3$

апидi- 5.5

$a \eta k^{w} \hat{O} 7.30$

arwō 7.18

-asnō, -aznō 6.8

attini 5.2

abaljaz 5.6

auðagō 5.6

bаðјаz 4.7

bаðwō 6.14, 6.16

balbijanan $^{n} 4.7$ band 12.31

bannjō 7.17

baykiz 4.7, baykijum 6.18

bariz 4.7 \& n. 8

batiza- 2.4 n. 5

bauzijanan $^{n} .7$

baumaz 1.9 n. 5

bebruz 4.8

berana $^{n} 12.7,12.30$ \& n. 1 , biripi 4.4, buranaz 12.30

веиðапа ${ }^{n} 4.14$, ьијип(p) 5.2

b̆ 5.6

biððipi 5.2

bið-m(e) 12.25

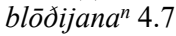

bnōw- 12.21

bō- 10.1

bōkiz 4.7

bōsmaz 6.8 n. 2

bōtijanan $^{n} 4.7$

brayxtēp, brā $\bar{n}^{n} x t \bar{e} 4.1$

brekan- 3.6 n. 1, burkanaz $12.31 \mathrm{n} .3$

brewana $^{n}$, brau 6.10

brinwanan $^{n} 6.8$

briutiz(i) 4.7

brōpēr, brōper- 6.14, $7.35 \mathrm{n}$. 4, 7.36, brōpē, brōor(u)7.36

brūðiz 4.7, 5.6

brūki(j)ip(i) 4.7

brukiz $3.6 \mathrm{n} .1$

brunjō 4.7

$b \bar{u}-12.57$ n. 6

buzjana $^{n} 4.7$

burz- 7.28

burzun 5.2 n. 6

burilijaz 5.8

-buts- 6.8

dazaz 5.2, 7.37 n. 5, daza ${ }^{n}$

5.6, dazōsiz 6.16, dazomz

$5.2 \mathrm{n} .7$

daza-werkan 5.6

dai-j-ana ${ }^{n} 6.10$

dail-iðе̄(p) 6.14

dailiz 4.7

dauja- 12.19 n. 2

даира-, даида- 6.6

$d \bar{e}-ð \dot{i}-12.7$

deuzan $^{n} 4.13$

diubul- 5.6

diupijana $^{n} 4.7$

diuriz $1.7,5.2$ n. 5

dōzazō, $-a z 7.38$ 
dōmijana ${ }^{n}$, dōmij- 4.7, 12.43

dō-ana ${ }^{n} 1.9, d \bar{o}-s(i) 12.24 \mathrm{n}$.

2, dēðиn 12.25 n. 10, dēðīnt- 12.33 n. 5 , -ðе̄(p) $5.3,5.4,12.33,12.39$

$-\bar{e},-\bar{o},-\partial r \bar{e},-\partial r \bar{o} 11.2$

éuraz 4.8

eちurôn 5.6

ej-, $\bar{e} j-12.63$

ek(a), ik 5.5, 8.2, mez 2.5, wetu 4.4 n. 3 , wē $4.13 \mathrm{n}$.

4, unswé $6.7 \mathrm{n} .9$

ermen-, ermun- 12.30 n. 1

es-, $s-, i z-12.57$

etana $^{n}, \bar{e} t 12.31,12.63$

faðе̄ $r$, faðеr- 4.7, 5.3, 5.5

fayxana $^{n}$, fă $^{n} x_{n n a}$ 2.3, 4.1,

4.11, 4.13, 4.17, 12.3,

12.16 \& n. 3, 12.31,

12.53, fän $x i z, f \bar{a}^{n} x i p 4.7$, $f \bar{a}^{n}$ xum 4.8, fayganaz 12.53

$\left(\right.$ farana $\left.^{n}\right)$, farō 5.3, farip(i)

4.7, 5.2, faran- 5.6

fawō 6.16, 9.5, fawum(i)z 9.5

fastunjaz 5.8

feðurxand- 10.5

feðwōr 8.3, 10.1

fel-n-, fell- 6.8

fextana $^{n} 4.13$

fexu 5.2

felôz 4.4 n. 1

fijōjanan $^{n} 12.42$

filu 5.2

fimfēxand- 10.5

fimfila $^{n} 4.9$

fimft- 10.5

finxlō, fin $\imath^{n} \overline{l o} 4.13$

fliuxip 12.43, flauz 4.9

flō-ðú- 12.7

flōkan-, feblōk- 12.20

fōtiz 7.28

fra-etana $^{n}$, fra-èt 12.31

framiza- 5.2 n. 6

freusana $^{n} 4.13$

frij-jo 6.10

frijōnd- 4.13 \& n. 6

fülipō 4.7

ful-n-, full- 6.8, full-iðè( $(p)$

6.14

fuyxtaz, $\bar{u}^{n} x t a z 4.1$

funsaz 4.11

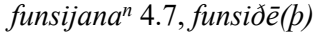

6.14 fur $(x)$ sk- 6.5

furiz 11.5

3a-, 3i- $2.2 \&$ n. 2

заðuling- 12.59, 12.61 n. 8

заiðwa ${ }^{n} 5.2$

zamalō 4.8

3ansiz 4.7

3aygana $^{n} 12.62$ \& n. 1, 12.63

3arwaz 5.2

3arwijana 4.7

3astiz 4.7, -inz 6.14

зе̄-ana ${ }^{n}$, उēna ${ }^{n} 12.62$ n. 1 ,

12.63, zē-mi 12.63 n. 4,

ze-s(i) 12.24 n. $2,{ }^{*} 3 a i-$

$12.63 \mathrm{n} .1$

зеБапа ${ }^{n} 12.24$ n. 6 , заБ(e)

4.13, zё̄un (b) 4.13

зебо̄ 5.3

3i- $x^{w}$ arjaz 8.15

3i-xwaperaz 8.15

зlaðiðе̄(p) 4.7, 6.14

Jlauwaz 9.5

зо̄ðaz 11.2

zrabis(i) 5.5, zrabepe 5.5

зraђō 3.6, 9.2

उrōniz 12.20

उиðіnijo ${ }^{n} 5.8$

3ulpan 4.3, 5.2

3umini 5.2

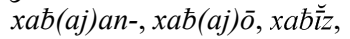
xaђa(j)ip(i) 12.47

xabjan- 12.17 n. 3

xaちukaz 4.8

xafō 4.8

xaftunjō 5.8

xaxtuz 4.9

xailaz- 12.42 n. 1, 12.52 n. 1 , xailazō 5.5

xaitan-12.20, xe-xait, xezait12.20, xaitiðai 12.29 n. 2

xalðana $^{n} 12.20$ \& n. 5, xalðip(i) 4.7

xananu $^{n} 3.6$, xaninaz 3.6

xanduz 5.6

xanô $^{n} 5.6$

xayxana $^{n}$ 6.6, 12.16 n. 3, 12.53, xayganaz 12.53

xarjaz 5.6

xarjōjana $^{n} 6.15$ n. 7, $12.33 \mathrm{n}$. 6

xaux-is-ta-z 9.11

xauzijana $^{n} 4.7$, xauziðē(p)

4.7, 5.6, xauziðaz 5.6

xe-xlaup- 12.20 xerotaz 4.8

xirðijaz 4.7 n. 14, xirði(j)i

5.6, xerðija $a^{n} 5.6$

xlaxtraz 4.13, 5.6 n. 7

xlaupiz(i) 4.7

xleumaz 4.9

$x l \bar{p} p-3.6$

xrain(i)jan- 12.3

xreygaz 1.7

xreusana $^{n} 6.8$

- xruza $^{n} 6.6$

xruz-l- 6.8

хизіz 4.14

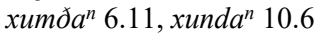

xupnōjan- 12.3 n. 5

$x^{w}$ annai $11.1,11.2$

$x^{w}$ ar 4.6 n. 2

$x^{w}$ arbōjana $^{n} 12.42$

$x^{w}$ arjaz $8.13,8.14,8.15$

$x^{w}$ aperaz 8.15

$x^{w} a z$ 8.13, $x^{w}$ és 7.8 \& n. 4

$x^{w} i$-likkaz 8.13 n. 7

¿ððalō 5.6

-īz-, -az- 11.2 n. 5

ijjun 12.63

$-i l-5.5$

in 2.5

-ing-, -ung- 3.6

irzijaz 4.7

isern- 8.2 n. 10

-ipō 4.7

-iz(-), -ōz(-), -ist-, -ōst- 9.10

\& nn. $1 \& 2,9.11,9.12$

$i z-l i \bar{k}$-az 8.15

jainaz, jenaz $8.7,8.11$ \& n. 2,

$8.12,8.14,10.1$

jēran 6.14

joka ${ }^{n}$,jukum 4.3 n. 2

juзиnp- 5.6

juygaz 6.14, juךx-iz- 6.6

kambjan- 12.3

karlingō 4.7

kastrō 4.13

katilaz 4.7

kaujan- 12.42 n. 1

kerlaz 4.13

keusanan $^{n}$ 4.5, 4.9, kiusip(i) 4.7

klaijō (klajjō?) 4.10

$k^{2 n u ð a n a^{n} 12.18}$

knusjana $^{n}$ 4.3, 6.8

knupan- 6.9

knuzlijana $^{n} 6.8$

kuniggaz 1.7 
kunja $^{n}$ 4.7, 5.2, 5.6

(kunnan-), kunp-12.33, 12.54

kustiz 4.7

küpijanan 4.7

$k^{w}$ aljana $^{n} 12.34$

$k^{w} \bar{o}-4.11$

$k^{w} \bar{O} \overline{-}-6.5$

$k^{w}$ em-, kum- 12.31, $k^{w}$ umenaz 5.5

$k^{w}$ umiz 5.2

lazjanan $^{n} 4.7$

laibō 5.3

laiðō 6.6

laipjána $^{n} 3.6$

laizijana $^{n} 4.7,6.6,12.53$

laizō 6.6

lambezō 5.5, 7.37

layg-iz 6.18

laubijanan $^{4} .7$

lauður- 6.14

lauziz 4.7

lausaz 6.14

lèswō 7.18

leub- 3.6, 4.9, 4.14

leuzanan 4.9

likk $a^{n} 8.13$ n. 7, 11.2

līkaz 8.13 \& n. 7

ligx $^{w}-12.3$ n. 4, laih ${ }^{w} 12.9$

linxtaz 4.13

liuxtijana $^{n}$ 4.5, 4.7

liznō- 6.6

lūtilaz 1.9, lūtilō 5.6, lais-iz$\hat{o}^{n} 6.16$

mazwī 5.3, 7.16

maipma- 5.6 n. 7

malwijanan $^{n} .8$

manaz(az), manazum(iz) 5.6

manw-, mann- 6.8, mannaz

7.27 n. 2, manniz 7.28

maygijana $^{n} 6.18$

mari, mariz 5.2, 7.19

mat(i)jan- 12.3

maplan $^{n} 4.9$

meins 8.5

mēnōpi 5.2

mēriz $4.6 \mathrm{n} .4$

metōjana $^{n} 5.5$

$\operatorname{mixs}(t)-4.13$

mikil- 4.4, 6.18

miluki 5.2

minniz-, minnist- 9.13 n. 1

$m \bar{o}-12.22$

$m \overline{o t}-t-6.9$

muniz 4.7 murzanaz, murzin- 3.6, 4.7

mūsiz 4.7

nasja- 3.1

naziðе 5.6

nautīnō 5.6

nawiz 4.7

$-n \bar{e} 11.2$

ne-aiw-mann- 8.15

newun(-), niwun(-) 4.4 n. 2, $10.2 \& \mathrm{n} .3$

newunxand 10.5

ni 5.2, 5.5

niujaz 4.10 \& n. 1

niwiljai, niwaljai 12.59

plixti- 4.14

raiðijaz 5.8 n. 2

raiðō 3.6

raizijana $^{n} 6.6$

razna $^{n} 6.8$

(rēðana $\left.{ }^{n}\right), r e-r o ̄ p-, r e-r \partial-, r e-$ rōð- 12.16

rēðijaz 6.15

rïðana ${ }^{n}$ 3.6, riðanaz 12.31

rixtijanan 4.9

rīkijan 5.2, 5.6

rinwana $^{n} 6.8$

(rō-ana $\left.{ }^{n}\right)$, re-rô 12.16

sa 5.2, 8.10, po $\bar{o}^{n} 5.3$, paimiz 8.9

sajjaz 7.11

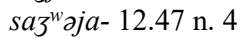

sairan $^{n} 4.9$

sakja $^{n} 4.7$

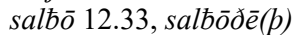

$12.33,12.40$

samanōjana $^{n} 5.6$

sandi(j)iz(i) 4.7

sanpaz $6.14,12.57$

sarwan $^{n}$ 5.6, sarwō 7.12

-satan 3.6

satjana $4.7,12.37$, satið12.37

$s \bar{e}-a n a^{n} 4.5$ \& n. 3, se-zô 5.4, 12.16

$s \bar{e} \partial a^{n} 12.20,12.22$

seftunxand 10.5

sexs 10.2

sexskand- 10.5

sexst- 10.5

sex $^{w} a^{n} a^{n} 1.8$ n. $2,4.13,6.6$, 12.21, (-) six $x^{w} i p(i)$ 4.7, 4.13, $\operatorname{sax}^{w}(e) 2.5$, sē ${ }^{w} u n(b) 1.8$ n. 2, 6.6, sez $^{w}$ an- 6.6 sēmô 7.30

setjana $^{n} 12.34$

sètō 3.6

sibun(-) 4.4, 4.8, 10.2, 10.5

simle $^{n} 5.3$ n. 3

sinwō 7.18

sing $^{w}$ ana $^{n} 4.8$

sitjanan $^{n} 3.1$, se-st- 12.14

sīp- 10.10

skab- 6.9

-skariðaz 4.7

skeranan $^{n} 4.13$

slaxana $^{n} 4.13,12.21$

slazipō 6.16

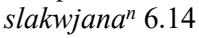

smauxōjan-, smauxōp 12.42

snaiwaz 7.12

snōw- 12.21

sōkijanan 4.7 , sōki(j)iz(i) 4.7

spaxōjanan $^{n} 12.42$

spakin- 4.7

spurjanan $^{n} 4.7$

stadin $^{n} 4.7$

staðlaz 6.8

stapulaz 6.8

stainomiz $5.2 \mathrm{n} .7$

standana $^{n} 12.64$

stappana $^{n} 12.19$ n. 6

$\left(s t \bar{e}-a n a^{n}\right), s t \bar{e}-s(i) 12.24$ n. 2

ste-stald- 12.20

stikana $^{n} 12.18$ n. 3

stigk $^{w}$ ana $^{n} 4.8$

stōiðé(p) 4.5

straujanan $^{n} 4.10$ \& n. 1

stulanaz 4.3

$s \bar{u}-4.11$

sundan 4.3

sunuz 5.6

swa 2.5 \& n. $2,4.6,8.13$ n. 6

swarja- 12.19 n. 2

swartô $^{n} 10.3$

sweb-, sub- 12.18

swestèr 5.6, 7.8

swōtistaz 9.11

swum- $-a^{n} 6.11$

takinaz 12.31

tanpiz, tān $\overline{b i z}^{2} .7$

teзunp- 10.9 n. 1

texan-10.3, tezunduns $10.4 \mathrm{n}$.

1, tezundmiz 10.4

téuxana ${ }^{n} 6.6$

$t \bar{l}$-ðá- 12.7

tīxan-12.21

tì-mon- 12.7 
tīwaz 4.8

treuwō (trewwō?) 4.10

trumjanan $^{n} 4.3$

-tuzô 6.6

tungōn(i) 5.6

twai 6.10, twōz, twajj/twaij10.1, twaimiz 6.10, 10.1, twaijōn 6.10

twalib- 10.3

twanz tizunz 10.4

twiznaz $6.8,10.10$

pana adv. 11.6

pankō 4.8

pannai 11.1, 11.2

par 4.6 n. 2

pauh 4.9

peuxa $^{n} 4.9$

pimz-, pimsiza- 6.8 n. 2

pinxana $^{n}$, pi ${ }^{n}$ xana $^{n}$ 4.1, 4.4, 12.3 n. $4,12.21$ n. 3 , payx 12.21 n. 3

- ріuð̄̄ 4.7

piujōz 4.7

prawō 4.10

prīxand- 10.5

pri(j)iz, prīz 10.1, prinz- 10.3, primiz 10.1

prinxana $^{n}$, prì $^{n} x$ ana $^{n}$ 4.1, 6.6

(b) $), 3 \check{\bar{e}} 4.13$

pūxijan-12.38, pūxīp 12.38, 12.43

bunw- 6.8

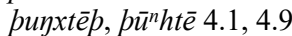

purb-t- 12.54

püsund- 10.6

ubil- 4.7

uђer(i), ubiri 5.6, 11.5

un- 3.2

under 5.2, 5.5

(unnan-), unp- 12.33, 12.54

waðlō- 6.8

waznaz 4.14

waxsja- 12.19 n. 2

wai- $10.1 \mathrm{n} .11$

wais(s) $12.53,12.54$

wakiðе̄(p) 4.7

waljana $^{n} 12.59$ n. 3

watōr 5.3

wap $(u) l-6.8$

wesana $^{n}$, was-, wēz- 12.57

wext- 8.15

wēniz 4.7

wēnijanan $^{n} 4.7$

werpana $^{n} 6.14$ $\left(\right.$ wesana $\left.^{n}\right)$, es- 12.24 n. 6, imm(i) 6.8 , wērun(b) 4.8

wizana $^{n} 4.3$ n. 4

wixand- 10.5

wixtiz 4.9

winxana $^{n} 12.3$ n. 3

winiz 4.7, 5.6

wirsiz 6.12

wissa- 12.53

$\left(\right.$ witana $\left.^{n}\right)$, wait 8.15

worxtē 6.14

wrìtō 5.3

wrōt-, wurt- 7.28 n. 4

wulfaz 6.14

wulgīz 7.17

wul-n-, wull- 6.8

wundanaz 4.3

wunskjana $^{n} 12.3$

wundraz 5.6

wurkijana $^{n} 6.18$

Gothic

Preterite-present verbs are indexed unprefixed.

aba 7.42, abne, abnam 7.30 n. 2

af 6.4

af-leipan 3.6

af-mauidái 12.22

af-rád 5.7

af-skiuban 12.18

af-stōpum, -stōpi 12.17

afta 11.2

aftarō 5.5, 11.2

aftra 2.4, 6.14

aftuma, aftumists 9.11

aggwus 6.5, 9.6, aggwjana 9.6

agis 12.53

agjan 12.53

aha $1.9,7.1$, -in 1.9

ahs 6.15

ahtáu 3.2, 4.9, 6.5, 6.14, 10.2

ahtáutēhund 10.5

ahtuda 10.5, 10.8

aha 1.4 n. 9, 4.8

-áihan (fairr-), áih, áig 6.6, $12.53 \& n .6$, áigands, áihands 6.6

áihts 4.17

áinaha 8.15 n. 7

áinfalps 10.10 áinhvarjizuh 8.15

*áinlif 4.15, 10.3, -libim 10.3

áins 3.4, 8.11 n. 3, 8.15, 10.1, áinans 10.1

áin(s)hun 8.15

áir 4.17, 6.11, 11.1

áirinōn 4.9

áirus 4.9

áibei $7.35 \mathrm{n} .1$

aíppáu 4.5 n. 1, 8.15, 11.6

áiw 4.15

áiwiski 3.4

áiws $4.9,8.15$ n. 8

áiz 1.4, 6.11

ajukdūps 1.4

akran 3.2

akrs 6.4, 6.15

alds $1.11 \mathrm{n} .7,6.12$

aljaleikōs 11.3

aljap 11.2

aljis 8.15

alls 8.15 , allis 11.2

alpeis 6.6, alpiza 6.14, 9.10, 9.13

ana 6.14

ana-biudan see -biudan

ana-busns 6.8

ana-láugniba 11.2

ana-leikō 11.2

ana-niujan,-niwida 12.35

ana-silan 1.4, 12.3

and 5.7

and (a)- 5.7

andbahteis, -jis 5.8

anses (Latinized) 4.9

ansts $6.11,7.22$, -ái 2.4

anpar 5.2 n. 8, 5.5, 6.12,

$6.22,8.2,8.13,8.15$,

10.7 , -ans 6.14

apel (Crimean) 6.15

aqizi 6.6 n. 5, 7.37 n. 2

arbáips 5.6

arbjis 5.8

arma-hairts 2.2

arman 12.44

arms 12.44

armōst- 9.11

asts 6.11

at 6.11

atta 6.9, 7.1, attin 5.2

at-pinsan 12.3

at-uh-ban-gaf 2.2

appan 11.6

aúftō 11.2 
áugjan 6.15

áugō 4.12, 4.17, 7.30, -ōna

$$
6.14
$$

aúhns 1.9

aúhsnē 7.30, 7.31

aúhuma, aúhumists 9.11

áuk 4.12, 4.17

áukan 6.4, 12.16, aiáuk 12.16

ásō 6.6

-ba 11.2

bagms 1.9

bái 4.5 n. $3,8.15,10.1$

bairan 4.5, 6.4, 12.7, 12.30, 12.31, baírip 5.2, baíram 5.5, bart 1.9, bērjáu 1.9 , baírands, baúrans 12.30 baírgan 4.8

bairhtaba 11.2

bairhts 6.5

bajōps 4.5 n. 3, 8.15, 10.1, bajōpum 10.1

balgs 3.2

bandi 3.6, 5.8, 7.16, 9.3

bandwa, -wōs 7.18

bandwō, -ái 7.33

bandwjan 2.3, 6.14

barizeins 4.7 \& n. 8

barn 4.13

bauan 1.9, 6.4

baúrgs 6.12, 7.27, 7.30, baúrg 5.2

(beidan), beidip 5.2, beidái 6.11 , bidun 6.11

beitan 12.9, 12.31

bidjan 1.4, 6.11, 6.15, 12.18, 12.19, bap 6.11, bēdun 1.4

bi-láigōn 6.4

bi-leiban 3.6

bindan 3.6, 4.4, 6.5, 12.31, bindáina 6.14 , bundans 3.2

-biudan (ana-, faúr-) 3.4, 12.23, 12.29, 12.31, -báust 12.25 n. 1, -budun 4.5, 5.2, -budans 4.5

biugan 12.18

bi-pe $7.8,8.10$

bláupjan 3.4

bliggwan 1.11, 6.10

blinds 6.5

blōpis 6.6

bnauan 12.21

bōka 4.17 brannijana 4.7

briggan, brāhta 4.1, 12.37

brikan $12.31 \mathrm{n} .3$

brinnan 6.4, 6.8

brōpar 3.6, 6.5, 6.22, 7.35, 7.36, brōpr 3.6, 5.2, brōprjus 2.3, 7.36

brūkjan 3.3, 12.18, 12.37, brūkeip 4.7, brūhta 12.37

brunjō 4.7

bugjan 4.7, 12.33, 12.37, baúhta $12.33,12.37$

daddjan 3.2, 6.10

dags 4.12, 5.2, 7.10, dagis 1.9, 5.2, dagōs 5.3, 6.16, dagē 5.4

dáiljan 6.14, 6.15, 12.35, 12.36

dáils 4.7

dalapa 11.2

daúhtar 5.5, 7.35 \& n. 1, daúhtrjus 1.9

dáupeins $7.34 \mathrm{n} .1$

dáupjan 7.34 n. 1

daúr 6.4

-daúrsan (ga-), -dars 6.4, 6.5, 12.53,-daúrsta 12.54

dáups 6.6, 6.22

dáupus 4.17

-dèd-, -dédun 12.33, 12.39

deigan 12.18, digandin 12.18, 12.50 n. 5

dēbs 7.23

diups 6.4

*diwan, diwans 12.19

dōmjan 4.7, dōmidēdun 1.8

dōms 3.3

dragkjan 12.37

-drēe,-drō 11.2

driusan 12.34

$d u 5.3$

*dugan, dáug 12.53

$-\bar{e},-\bar{o} 11.2 \& \mathrm{n} .2$

ei 8.14

eisarn 1.4

Ermenirīcus (Latinized)

$12.30 \mathrm{n} .1$

etan 12.14

fadar 4.12, 5.3, 5.5, 6.6, 7.35

fadreinam 2.4

Faffo (non-Wulfilan) 6.9 n. 2

faginōn 6.6

fähan 2.3, 4.1, 6.6, 12.3, $12.16 \&$ n. $2,12.31$ n. 7 , faifāh 12.3

fahēps 6.6

faíhu 5.2, 6.4, 7.24

fair- 2.2 n. 5, 6.6

fairneis 6.8

fairra 6.8

fairzna 4.2

falpan $12.16 \&$ n. 1, faifalp $4.5 \mathrm{n} .1$

faran 6.4, 12.15, 12.20, 12.31, fara 5.3, farip 4.7, 5.2, fōr 12.15

farjan 6.15

fastubni 5.8 n. 4, 6.12

faúr(a) 5.7, 11.1, 11.2 \& n. 1

faúr(a)- 2.2 n. 5, 5.7, 6.6

faúra-gaggan 12.8

faúr-biudan see-biudan

faúr-dammjan 6.8

faúr-gaggan 12.8

*fáus, fawái 8.15, 9.5

féra 3.5

fidur-10.1

fidurfalps 10.10 \& n. 1

fidwōr 4.9, 5.3, 6.5, 7.36, $10.1,10.10$ n. 1 , -im 10.1

fidwōrtaihun 10.3

fidwōr tigjus 10.4

filhan 6.6

filu 5.2, 11.2, 11.3

fimf 6.4 n. 3, 6.5, 10.2

fimfta 10.8

fimftaíhun 10.3, 10.9

fimftataíhundin 10.9

fimf tigjus 10.4

finpan 6.14

fiskōn 12.40

fisks 3.2, 6.5, 12.40

flahta 6.13

flödus 6.13, 12.7

fōdjan 3.3

fön, funins 1.9, 7.27, 7.42, funin 7.42

fōtus 4.17, 6.4, 7.28, -u, -uns 7.28

fra- 6.6

fraihnan 6.6, 6.9, 12.3, 12.19, frah, frēhum 12.3

fra-itan 12.8, -itip 1.11

fram 6.14

fram-ganga 5.7

framis $5.2 \mathrm{n} .6$

frapjan 12.19

fra-waírpan 6.6 
fra-wardjan 6.6

fra-wrōhjan 5.7

freihals 7.7

frija- 12.40

frijōn 6.10, 12.40

frijōndi 5.3, 7.17

frijōnds 7.3 n. 3, 7.39, $7.40 \mathrm{n}$. 1

frisahts 12.32

frōps, frōdis 9.3

fruma 9.11, 10.7, frumists

$9.11,10.7,11.3$

fulgins 6.6

fulhsnja 2.4

(-)fullnan (us-) 1.9, 12.49,

12.50 \& n. 3

fulls 3.3, 6.8, 12.50 n. 3

Fwnikiska 1.11

ga-bundi 3.6

ga-daban 12.18

ga-dēps 3.3, 12.7

ga-dōfs 12.18

ga-dráusjan 12.34

ga-faúrs 6.12

ga-frisahtnan 12.32

gagg 6.5

gaggan 12.62

ga-haftjan 6.6

gáidw 4.12, 5.2, 7.12

gáits 3.4

ga-juka 6.6

ga-kusts 12.7

ga-láubjan 3.6, 4.7

ga-leikō 5.4, 11.2

ga-leiks 8.13

ga-lūkan 12.18, 12.31

ga-máins 6.6

ga-malwjan 4.8

ga-nisan 3.6

ga-nōhs 6.6

ga-qiman 6.6

ga-qumps 3.2

ga-ráidjan 5.7

ga-rapjan 12.19

ga-rēdan, ga-raírōp 12.16

ga-skafts 6.5

ga-skapjan 12.19

ga-staldan 12.2, ga-stai-stald

$12.2,12.20$

ga-stōpup 12.17

gasts 1.9, 5.2, 6.4, 6.5, 7.20,

gast 7.3 n. 3

ga-tamjan 12.34

ga-teihan 6.4, -teiha 12.9 ga-piwan 12.44

ga-wagjan 3.2

ga-waknan 12.3

ga-widan 12.3

ga-wigan 6.4

gazds 6.14

geen (Crimean) 3.3, 12.62

giba 5.3, 5.4, 7.14

giban 6.5, 6.12, 12.31, gaf 4.13, 6.12, gaft 12.25, gēbun 4.13

glaggwō 6.10

gōps, gōdis 6.12, 9.3, 9.13, gōdana 6.14, batiza, batists 9.13

gras 1.4 n. 9, 6.19

grētan 12.12 n. 2, 12.16, gaígrōt 12.16

gudisks 1.4

gulp 6.17, gulpa 6.6 n. 7

gulpeina 5.6, -áim 5.6

guma 7.27 n. 2, 7.30, gumin 5.2

* Guti-Skandia 1.12

haban 1.9, 6.6, 12.45, habáis 5.4, habái 2.4

hafjan 6.6, 12.19, 12.45

-hafts 6.5

hähan 12.16 n. $2,12.31$ n. 7

háidus 3.4

hairdeis 2.3, 5.8 \& n. 1, 7.10, haírdi 5.6 \& n. 1 , haírdjōs 5.8

haírtō 4.8, 5.4

háitan 3.4 \& n. 3, 12.16, haíháit 4.5 n. 1, 12.16, 12.20, háitans 5.2, háitada 5.3

halba 10.10

halbs 6.12

haldan 4.13, 6.14, haihald $12.9 \&$ n. 3

haldis 11.4

hals 1.4 n. 9, 6.5 n. 2

hana 3.2, -an, -ins 3.6

handus 5.2, handu 7.28

hardaba, -uba 11.2

hardus 2.3 n. 1, 4.13, 6.4, 9.6, hardjana 2.3 n. 1, hardja 9.8, hardiz- 9.10

harjis $2.3,5.8 \&$ nn. $1 \& 3$, 7.10, 9.3, hari 5.6 n. 1

hatis 3.2, 5.2, 7.37

hatjan 12.40 háubip 1.5

háuhaba, háuhis 11.3

háuhs 4.13, 4.17, háuhists

9.11

háuns 3.4

háusjan 4.7

hawi 6.10

hazeins 5.8

hazjan 6.6, hazei $5.6 \mathrm{n} .1$

hèr 3.4, 3.5, 8.2 n. 9, 11.1

hidrē 3.4, 5.3 \& n. 3, 5.4, $11.1,12.33$

hilpan 12.31, halp 4.13

himins 1.9, 6.11

himma, hina, hita 8.12

hindana 8.5

hindar 8.5, 11.1

hindumists 9.11

hiri 4.5 n. 1, 11.1, hirjats, hirjip 4.5 n. 1

hlahjan 12.19

hláifs, hláibis 6.12

hláiwasnōs 6.8

hláupan 12.20

hleiduma 9.11

hlifan 6.4

hlütrs 6.15

hōrs 6.4

hráinjan 12.3

hráins 9.6, 12.3, hráinja 9.8

hraiw 4.9

hrings 1.7

huggrjan 6.6

hührus 5.6, 6.6

hulps 3.2, 6.14, 6.17

hulundi 3.2

-hun 8.15

hund $6.4,6.11,-a 10.6$

-hund 10.5

huzd 6.11

hadrē 5.3, 11.2

hadrō 11.2

han 11.1

har 3.5 n. 2, 11.1

hwarbōn 12.41, harbō 12.38 n. 2, harbōda 5.6

harjis, -ata 8.13, 8.15, 11.1, harjamma 8.15

harjizuh 8.15 , harjammēh 8.15

has, ha, hō 6.4, 6.11, 8.13

\& n. $5,8.15,11.1$, hana, han 8.10 , hamma 5.3, $7.8,8.10,8.15,12.47$ 
hashun 8.15

hap 11.1

hapar 5.6, 6.4, 8.2, 8.13, 8.15

haparuh 8.15

hapō $6.5 \mathrm{n} .2$

haprō 1.4

hazuh 8.10, 8.13, 8.15, hanōh 8.10, hammēh

5.3, 7.8, 8.10, 8.15,

12.47, hanzuh $8.13,8.15$

heits 6.9

hi-leiks 8.13, 8.15

hōpan 6.5, 12.16, haíhōp $12.16 \&$ n. 3

Ibba (non-Wulfilan) 6.9 n. 2

ibns 6.11

-ida, -ipa 6.12

iftuma 9.11

*igqar 8.5

ik 8.2, mik 1.4, mis 2.5, uns

6.7 n. 9 , ikei 8.14

in 6.14

inna 11.2

innana $6.14,11.2$

innuma 9.11

is $1.9, \mathbf{8 . 7}, 8.14,8.15$

iupa 11.2

iusiza 9.13

-iz-, -ōz-, -ōst- 9.12, -ists 6.5, 9.12

izwar 8.5

ja 11.1

jabái 11.6

-jah 11.6

jáinar 8.2

jáindrē 5.4, 11.2

jáindrō 11.2

jáins 8.2, 8.7, 8.8, 8.11 \& n. 3

jappē 7.8, 11.6

ju 11.1

juggs, jūhiza 6.6, 9.12 n. 4

juk 12.3

kara 12.40

karōn 12.40

káupatjan, káupasta, káupatips 12.37 n. 2

kaúrjan 12.3

kaúrn $3.3,-a 1.9$

kaúrus 12.3

keinan, us-kijanata 12.3

kinnus 7.21

kiusan 3.4, 4.5, 4.7

kniu 6.4, 7.12 *knōps, knōdái 3.3

Krēks 3.5, 6.7

kunds 3.1

kuni 2.5, 5.2

kunnan, kann 6.3, 6.4, 12.51, $12.53 \& n .3$, kant 12.54, kunnun, kunpa 12.51

kunps 3.3, 12.33

lagjan 6.14, 6.15, 12.37

laggs $6.5,9.2,9.8$, lagga, $-\bar{o}$ 9.9

láiba 5.3

(láikan), lailáik 12.9

láisjan 4.7, 12.53

lambiz- 4.7

lasiw-s 9.5

lats 4.12

láuhatjan 12.3

láuhmuni 4.7

Lauidjái 1.11 n. 6

láun 3.4

láus, láusis 9.3

leihts 4.13

leihan 3.4, 6.4, 6.6, 12.3 n. 4, laíhans 4.5

leik 11.2

leitil 11.2

leitils 1.9, 6.15, 9.13, minniza, minnists 9.13

lētan 3.5, 12.16, 12.20, laílōt 12.16

libáin- 5.6

ligan $6.4,12.19$

*lisan, láis 6.6, 12.53

lista 9.13 n. 1

liubaleiks 11.2

liufs 3.6, 6.4, 9.3, liubis 9.3

liuhap 6.4

liuhtjan 4.5, 4.7

lubáin- 5.6

lubō 3.6

*magan, mag 6.12, 12.14, 12.52, 12.53, magt 6.12, mahta 6.12

magus 5.3

mahts 6.14

maihstus 6.5

máis 9.10

máipms 6.15

Mammo (non-Wulfilan) $6.9 \mathrm{n}$. 2

managei 1.4, 5.3, 7.34, 9.9

manags $2.3 \mathrm{n} .1,8.15$

mana-sēps 7.27 n. 2 manna $6.8,7.21,7.27,7.30$, 8.15

mannahun 8.15

marei 7.20

matjan 12.3

mats 12.3

mapl 4.9

maúrnan 12.3, 12.18, 12.50

mawi 5.3, 5.8, 7.16

meins 8.2

mēl 3.3

mēljan 12.40

mèna 4.12, -an 7.1

mēnōps 5.6, 7.41, -um 7.28

-mērs $1.8 \mathrm{n} .1$

mēsa 3.5

midjis 6.4, 9.4

mikilaba, máist 11.3

mikileis 5.8 n. 1, mikileip 5.8

mikilnan 12.48

mikils 6.18, 9.13, 12.48, máiza 9.13, máists 4.9, 9.13

miluks 4.8

mins $1.4,9.10$

missa- 6.8

mitan 6.4, 12.31

mitōn 5.5

mizdo 3.5, 4.17, 6.11

*mōdar 7.35 \& n. 1

*-mōtan (ga-), -mōt 12.53, 12.54, mōstēdun 12.54

mōps 12.22

munan class 3 vb. 12.53

(-)munan ( $\mathrm{ga}$-), (-)man pret.pres. vb. $12.33,12.44$, $12.53,12.54$, типит 12.14 , munda 12.33

muns 4.7

munps 6.4, 6.17

nahts $6.5,11.2$

namnjan 12.3

namō 6.11 n. 6, 7.30, namna 7.30

naqaps $6.4,6.15$

naseins 5.8

nasjan 3.6, 6.6, 6.15, 12.3, nasjis $12.38 \mathrm{n} .1$, nasjip

5.8 , nasida, nasidēs

12.47, nasidēdun 12.33

natjan 12.34

naúh 11.1

*-naúhan (bi-, ga-), -nah 12.53 
nawis 5.2

$n \bar{e} 2.5$

nēhva, nēhis 11.3

ni 2.5, 5.2, 5.5, 8.15, 11.1, ni pé haldis 5.3, 8.10, ni hashun, ni mannahun, ni áin(s)hun, ni waihts 8.15

ni-áiw 4.8

nibái 11.6

nih 8.15

niman $1.4,12.31$, namt 12.24 n. 6 , nётип 1.4

niujis 6.15 n. 2, niuja 9.8

niun $6.11,10.2$

niunda 10.8

niuntēhund 10.5

пи 2.2

-ōdus, -ōpus 6.12

*ōgan, ōg $12.53 \&$ \&. 4, ni ogs pus 12.28, 12.53, 12.54

Oppa (non-Wulfilan) 6.9 n. 2 páida 6.7

qairrus 6.8

qiman 3.6, 6.4, 6.5 n. 3, 12.9, 12.18, 12.31, qimip $1.4 \mathrm{n}$. 12, qēmun 4.12

qinō 6.4, 7.32, 7.33, -ōns 7.33

*qius, qiwa- 6.3, 9.5, qiwái 9.5

qipid-uh 12.24

qums 3.6, 5.2

raihts 6.14

-ráips 4.12

rapjan 10.5

ráups $3.4,4.15$

razn $6.8,6.14$

reiki 5.2

(reiks adj.), reikists 9.10

reiks noun 1.4, 7.27, reik, reikis 7.28

reiran 12.3

-rēps $1.8 \mathrm{n} .1$

Riggo (non-Wulfilan) 6.9 n. 2 rinnan $6.8,12.3$ n. 5

riqis $6.4,6.12,6.14,7.37$, riqizis $6.12,7.37$

Rūmōneis 3.3

sa pron. $2.5 \&$ n. $2,5.2,8.10$, 8.14 , pana $6.11,7.8,8.7$, 8.12 , pis 8.7 , pamma 6.8 , 8.7, pe 5.3, 7.8, 11.6, pei 8.9, pái 7.8, 9.2, pata 8.12, 11.1, sō 5.3, pō 5.3,
6.11, pizái 1.9, 8.7, pizōs 1.9, 8.7, pái 3.5, pizō 1.9, saei, panei, pizei,

pammei, pizēei, pizáiei

8.14

$s a-h 5.2$

sagqjan 3.6

saian 4.5, 12.16, 12.22,

12.31, saiip, saijip $4.5 \mathrm{n}$.

3, saísō 5.4, 12.16 \& n. 3, 12.31

saíhs 10.2

saíhsta 10.8

saihs tigjus 10.4

saíhan 3.2, 6.4, 6.15, sái

4.17, sah 2.5, saht 12.25

(sa)hazuh saei, sahazuh izei, patahuah pei 8.15

sáir 3.4, 4.9

sakan 12.18

sakjō 6.15

sakkus 6.9

salbōda 12.33

saljan 6.15

salt 3.2

sama 9.7

samaleiks 11.2

sandjan 6.14, sandeis 4.7, sandida 4.7

satjan $4.7,6.15,12.3$ n. 2 ,

12.35, 12.36, satjis $5.8 \mathrm{n}$. 1

sabs, sadis 9.3

saúhts 6.14

sauil $1.9,7.42$ n. 2

seins 8.5

sētum 1.4

sibja 6.15

sibun $4.8,10.2$

sibuntēhund 10.5 \& n. 5

sidōn 12.40

sidus 12.40

siggwan 1.8, 1.11, 6.16

sigqan 3.6, 4.8

sik 8.4

silba $8.15,9.7$

sildaleikjan 12.32

sildaleiks 12.32

simle 5.3, 11.2

sineigs, sinista 9.13

sipōneip 5.8

sitan $6.4,12.19$

skaban $6.5,6.9,12.15,12.18$

skadus 5.2 skáidan $12.17,12.18 \mathrm{n} .7$

skalk 7.3 n. 3, 7.8 n. 12

skaman 6.11

skanda 6.11

skapjan 6.15

skatts 6.9

skapjan 12.19

skeima 12.3 n. 6

skeinan $6.5,12.3$ n. 6

*skulan, skal 12.33, 12.53,

12.54 , skalt 12.54 , skulda 12.33

skulds 12.53

slahan 6.5

slēpan 6.4, 12.16, saíslēp

12.16, 12.20, ga-saízlēp

12.16 \& n. $3,12.20$

sliupan 12.18

smakka 6.9

snáiws 6.4, 7.12, -is 4.17

sniumundōs 11.3

snutrs $6.15,6.21$

sōkjan 4.7, 4.17, 12.37, sōkeis

4.7, $5.8 \mathrm{n} .1,12.38$,

sōkeip 5.8, 12.38, sōkei

5.6 n. 1, sōkida 12.37

speiwan 12.19 , speiwis 12.21

*spēps, spēdiz-, spēdists, spēdumists 9.10

spinnan 6.3

stáins 1.9, 4.17, 5.2, stáina

5.3, stáinans 5.2 , stáinam 5.5

staírnō 4.13

standan $6.5,12.3,12.17$,

12.31, stō $p 12.3$

staps 3.2

stáutan 12.3

steigan $3.4,6.4$

stibna 6.11 n. 6

stigqan 4.8

stilan 4.5

stōjan 12.36, stōjis 5.8 n. 1, stauida 4.5 \& n. $3,12.34$

striks 3.6

sums 8.15

sund 6.11

sunja 12.57 n. 12

sunjaba 11.2

sunus 7.24, sипu 7.3 n. 3, -áu

1.9 , sunjus 5.6

swa 2.5 \& n. 2, 6.11, 8.15

*-swairban (af-, bi-) 6.12, -swarb 1.11 n. 7, 6.12 
swa-leiks $8.13,8.15$ \& n. 3 swaran 12.19

swarts 10.3

swē 2.5 \& n. 2, 11.6

swēpáuh 11.6

swèrs 6.12

swēs 8.4

swiltan, swultun 6.11

swistar 2.4, 6.11, 7.35

swnagōgē 1.11

swōgatjan 12.3, swōgateip

$$
5.8
$$

tagr 3.2, 5.2, 6.15

taihun $6.4,10.2$

taíhunda 10.8

taíhuntēhund, -taíhund $105 \&$ n. 1

taíhuntēweis 10.5 \& n. 1

táiknjan 6.9

talzeinái 2.4

tandjan 12.48

táujan, tawida $1.9,12.35$

-tēhund 10.3 n. 3, 10.5

tēkan, taitōk 12.16

tigjus 10.3 n. 3, 10.4, 10.10, tigum, tiguns 10.4

timbrjan 6.11

triggws 9.5 , triggwa 9.8

trudan 12.18 , trudans 12.31 n. 4

tuggō 1.4 n. 9, 6.5, 7.32

tulgus 3.3, 9.6

tundnan 12.48

*tunpus 3.2, 7.28

twái 4.12, 6.4, 10.1 \& n. 7, twōs 3.3, twaddjē 6.10 tweihnōs, tweihnáim 10.10 twái tigjus, twáim tigum 10.4 twalif $4.9,10.3$

padei 11.1

pagkjan 4.8, 6.4, 6.14, 12.37, pāhta 12.37

paháins 5.6

pahan 1.4, 12.3

pairh 11.2

pairh- 6.6

pan 2.2, 11.1

pana-máis 8.10

pandē 11.6

рапnи 11.1, 11.6

par 3.5 n. 2, 11.1

pat-ei 8.14

páu 11.6

páuh 4.9, 6.14, 11.6 páuhjabái 11.6

* paúrban, parf 6.6, 12.37, 12.53, parft 6.12, paúrbum 6.6, 12.37, paúrfta 12.54

paúrfts 12.53

paúrnus 3.2, 6.8, 6.22, -uns

$$
2.4
$$

pé-ei 7.8, 8.14

pei 7.8 n. 9, 8.10, 8.14 \& n. 5, 11.1

peihan 4.1, 4.4, 12.3 n. 4

peins 8.5

pishazuh saei, pishah pei, pishah patei 8.15

piudan 7.8 n. 12

*pius, piwis 1.9, 7.12, piwōs 12.44

piwi 4.9, 7.16, piujōs 4.7, 7.16

plaúhs 6.13

pliuhan 6.13, 12.21

preihan 4.1, 6.6

* preis 10.1, prija 6.4

*preis tigjus, prins tiguns 10.4

pridja 10.7

prija 8.7

priskan 12.3

-prō 11.5

prūtsfill 6.8

pu 2.5 n. 2, 8.3, igqis 6.4, buei, pukei, izwizei 8.14

pugkjan, pūhta 4.1, 12.33, 12.37

$-u 11.1$

ubils, waírsiza 9.13

-ubni, -ufni 6.11, 6.12

uf 5.7

$u f-5.7$

uf-blēsan 3.3

uf-hlōhjan 12.34 n. 2

uf-rakjan 6.4

*ugkar 8.5

-uh $2.2,6.5$ n. $2,8.12,8.15$

ühtwō 6.14

undar 5.2, 8.5

unsar 8.5

un-weis 6.9

un-wiss $12.33,12.53$

us-bidan 12.19

us-kijanata 12.3

us-nu-gibip 2.2

*usskáus, usskawái 9.5 üta 11.2

ütana 1.4, 8.2, 11.2, 11.5

ütaprō 11.5

-uzi, -usi 6.12

Wacca (non-Wulfilan) 6.9 n. 2

-waddjus 6.10

wagjan 12.34

wahsjan 12.19, 12.31

waian $12.16,12.22,12.31$,

waíwōun 12.16

waihts 8.15

waila $4.5 \mathrm{n} .1,11.2$

wair $6.12,7.7$

waíra-leikō 8.13 n. 7

wairs 6.12

waírpan 6.4

waírps 4.13

watō, watins 1.9, 7.30, 7.42,

12.3 n. 9 , watnam 7.30

(waírpan), waúrpun 4.5

waldufni 6.12

waúrd 6.12, 7.7

waúrkjan 6.5, 6.14, 12.37, waúrkeip 12.37, waúrhta $1.13,6.5,12.37$

waúrms 6.14

waúrstwa 2.4

waúrts $7.28 \mathrm{n} .4$

weiha 9.7

weihan 4.3 n. 4, 6.4, 6.6, 12.3 n. $3,12.18$

weihs 9.7

weitwōds 7.41

wiljan $11.2,12.32,12.37$ n. 3 , 12.58-9, wilda 12.37 n. 3, wiljáu 12.27

wilpeis $6.17,9.4$, wilpja 9.8

windan 12.3

winds 4.2

wintrus 5.6, wintrái 2.4

wisan 12.56-7, im 1.9, 6.8, 12.9

wit 1.4

witáibs 5.6

*witan, wáit 3.4, 5.2, 6.8, $12.2,12.53,12.54$, wáist

12.54, wissa $6.8,12.54$

witubni 6.12

wōds 6.14

wōpjan 6.14

wrakja 7.16

wrakjan 12.34

wrikan 12.34 , wrikans 12.31

n. 2 
wulan 12.18

wulfs 3.2, 6.5 \& n. 4, 7.7

wulla $3.3,6.8,6.11$

wundufni 6.12

Xristus 1.11

-zna, -sna 6.12

Burgundian, Vandalic, and other East Germanic

awings (Runic) 7.8

-mir(is) $1.8 \mathrm{n} .1$

-rid 1.8 n. 1

Northwest Germanic

e-auk 12.20

3a-, 3i- 8.15

$x$-e-ait 12.20

$x r-e-\bar{o} p 12.20$

iðwiz 8.3

knaちa-, knappa- 6.9

$k^{w}$ iman 12.18 n. 5

mirkwiz 4.8

mōss $\bar{x} 12.54$

niman 12.18 n. 5

ob- 6.9

$r-e-\bar{x} d 12.20$

Segimerus 4.4

Segimundus 4.4

ske-skraud- 12.20

st-e-ald 12.20

st-e-aut $12.20,12.57$ n. 10

pekkuz 4.8

upp- $6.9,11.5$

Runic

$A f^{a} t_{R} 6.14$

Aih 4.9, 12.52

alja- $8.15 \mathrm{n} .1$

alugod 1.14 n. 1

arbijano $7.30 \mathrm{n} .1$

awings 7.8

$b^{4}$ riutip, $b^{4}$ ruts 12.24

boso 7.31

dohtri $_{R}$ 1.9, 4.7, 7.36

ek, -(e)ka 8.2, ik 8.2 n. 3

fahido, fahide 4.9 \& n. 1 , faihido 12.35 n. 1

-gastiR 1.9, 7.21

gibu, gAf 6.14

godagas 1.9 haite 12.29, haitinar 5.2,

12.30 n. 5

hakupo $7.25 \mathrm{n} .1$

-halaiban 1.9

har(i)ja 5.8, 12.38 n. 5

haukopuR 5.5

hide $_{R^{-}}, h_{A i d_{R^{-}}} 6.14 \mathrm{n} .1$

hnabdas $7.8 \mathrm{n} .1$

holtijaz 5.8 \& n. 2, 6.11, 7.11

horna 4.3

ist 12.57

kaba 1.14 n. 1, 5.6 n. 6

kepan 7.8

kuni-mu[n]diu 1.9, 7.25

kunni 6.15

-kurne 1.9

lapu 7.15

leubo 7.31

magu 7.25

makija 5.8

- mArAz 4.9

-mariR 4.6 n. 4, 5.2 n. 5, 9.6

niuhagestumR 4.7 n. 4

runo 5.3

saira 4.9 n. 1

SAR 8.14 n. 1

sasi, susi, patsi, pita 8.12

slaginar 12.16

stabA 5.2

stain 4.9, staina 1.9, 4.9, 5.2

swaba-harjaR 5.8

swestar 5.3, 5.6, 5.8 n. 4, 7.36

talgidai 5.3

tawido 1.9 , tawide 5.3 n. 3 , 5.6

$\operatorname{uini}_{R} 5.2$ n. 5

$u_{i p_{R}} 6.14$ n. 3

upin 6.14 n. 3

pewar 1.9, 7.8

prawijan 12.38 n. 5

walhakurne 7.8

$w^{a}$ ritu 5.3

-warijaR 5.8 \& n. 5

waruR 5.2 n. 5

welA- 6.14 n. 4

woduride 7.8

-wol ${ }^{A} f_{R} 1.13$

wor $^{a}$ hto $1.13,12.37$

wraita $5.2 \mathrm{n} .1$

writu 12.24

wul(a)f- 6.14

wurte, wortaa, worte 6.14
Proto-Norse

ainazar 5.6

ajjan 4.7

allum 4.8

anlaibaz 4.9

annran(n) 6.14

āttau 10.2

auRōn 4.7

æin(t)-gi(n), æitt-gi (West

Norse) 4.9, 8.15

berzan 4.8

-berzu 7.14

blindōstaR 5.6

brōpris 7.36

dazaR 5.6

doxtriR 4.7

fallin-R 6.14

fanp 6.6

fari $_{R} 4.7$, farana $_{R} 5.6$

feðurēe, $-u 10.1$

felu- 4.9

ferup 5.6

fјодriR 4.9, дедиги 6.14

gaira $_{R} 4.9$

gamalar, gamalanu $^{n} 5.6$

gastiR 5.6 N. 7

gātu 4.8

geち̋̄m(e) 5.6, gā̄un 5.6

geђи 7.14

glad- 6.14

glaR 4.7

grōbìme 5.6

hail $-R 6.14$

haitanas, haitan $\bar{x}_{R} 5.6$, hait $\bar{x}$ 5.6

hānR 8.7

heltum 4.8

herta 4.8

hleuran $^{n} 4.7$

iuzar- 8.5

iulu 8.5

jāran 1.13

juygistōm 5.6

komiR 4.7

$k \bar{u}_{R} 4.7$

kuRun 4.9

$k^{w} æ i k^{w}$ - (West Norse) 4.8

lātiR 4.7

laus-R 6.14

lìtil-R 6.14

mazuR 5.6

$\operatorname{manôR} 5.6$ 
mirkwi 4.8

$m i_{R} 4.9$

nahtu 4.8

nerwa- 4.8

ne wæit ek hwerr, ne wæit ek hwat (West Norse) 8.15

reru 4.8

sakjar 6.14

skeldu 4.8

staina $^{n} 5.6$

staina-warija 5.8

strīkwan 4.8

suniuR 5.6

swestǣ $r$ 5.6, 7.8, swistrik 4.9

-tezuR 4.8

paz̄̄nôn 5.6

pakku 4.8

pa $\bar{a}_{R} 4.7$

biwiR 4.9

pōh 1.14 n. 4, 4.9, 6.14

prinn-tán 10.3

punran 4.9, 8.5

witaiðaR 5.6

wōðanaR 5.6

wulpe 6.6

Old (West) Norse / Old

Icelandic

á 6.14, á milli, á miðli 6.14

-aðr 9.3

af 6.4

aka 12.15

akarn 3.2

akr 6.4, 6.15

(aldr adj.), ellri 6.14

aldr noun 7.7

allr 4.8, 8.15, ollum 4.8

annarr 5.2 n. 8, 5.5, 8.15,

10.7, aðra 6.14, onnur

5.5 n. 8, annarr hvárr

8.15

aptan 11.2

ár $1.13,6.14$

-ari, -astr 9.12

arna, árna 4.9

árr, órr 4.9

áskunnr 3.3

áss 4.9

ást, óst 7.22

at conj. 8.14

at prep. 6.11

átta 3.2, 6.5, 6.14, 10.2,

12.26 átta tigir 10.5

átti 10.8

át(t)ján 10.3, 10.4

auðigr, auðikt 11.2 n. 4, -egr

$$
11.2 \text { n. } 5
$$

auga 1.14 n. $3,7.30,-u 6.14$

auka 6.4, 12.20, jók 4.9, 12.20

ax 6.15

æja 4.7, áði 4.7

ær 7.28

ævi 4.9

bаð 3.2

báðir $\mathbf{1 0 . 1}$

barn 3.6, born 7.8, 8.10

beiða 6.14

beina 6.14

bekkjar 6.14

bekkr 4.7, 7.20, bekkja(r), bekks, bekkjum 7.20, bekkja 7.21

ben, benjar 5.8, 7.16

benda 6.14

bera 3.6, 6.4, 12.7, 12.30, 12.31 , berr 12.24 , berum 5.5 , bart 1.9 , bæra 1.9 , berandi 12.30

Bergelmir 4.7 n. 8

berja, berjask 12.5

berr 4.7 n. 8

biða 4.4 \& n. 6, bíð(r) 12.35, beðinn 4.4 \& n. 6

biðja 4.4 n. 6, 6.15, 12.19

bifa 12.3

binda 4.4, 6.5, 12.31, bindi 6.14, batt 1.14, 6.14, 9.3, bitt, bind 6.14

bita 12.31

bjár 1.14

bjarga 4.8

bjartr 6.5

bjóða 3.4, 12.23, 12.31

blanda 12.31

blása 3.3

blauðr 3.4

blika, blikja 12.19

blindr 6.5, -astr 5.6

blóta 12.20 n. 5, 12.31 n. 11, blét 12.20 n. 5

bogna 7.30 n. 2

bók 3.3, 7.27

bólginn 4.9

bóndi 7.39 \& n. 1

Borgundar holmr 1.11 n. 2 boð, boðvar 6.14

bol 7.12

brádfengr 9.6

bregða 12.31

brenna 6.4

brinna 6.8

brjóta 4.7, brýtr 4.7

bróðir 6.5, 6.14, 7.35, brøðr 5.2, 7.35 n. 4, 7.36,

bróður 7.36

brúðlaup, brullaup 4.9

brún 3.3

brynja $4.7,7.32$

búa $1.9,2.4,3.3,3.4$ n. $5,6.4$

burdr 3.6

byggja, byggva 3.4 n. 5, 6.10

bylja 12.34 n. 2

bylr $12.34 \mathrm{n} .2$

dáð 3.3, 12.7, dóð, dáðir 7.23

dagr 5.2, 5.6, 6.14, dags 6.14, dagar 5.3, 6.16

dalr 6.14

dammr 6.8

dapi 6.8

deila $6.14,6.15, \mathbf{1 2 . 3 5}$, deili(r) 12.35, deilði

12.35 , deildi $6.14,12.35$

deyja 12.19

djúpr 6.4, 9.12, dýpri, dýpstr 9.12

dómr 3.3

dóttir 7.35 n. 2, doetr 4.7, $7.35 \mathrm{n} .4$

dœета 4.7, dømði, domdi 12.35

dregg 7.16

drekka 6.14

drengir, $-i 1.14$

drepinn $12.31 \mathrm{n} .3$

dreyma 1.14 n. 3

dúfa 12.18

dupt 3.2

dý 3.3

dynr 6.5

dyrð, dýrð 4.9

dyrr 6.4

dýrr 4.9, 9.6

edda 4.9

eða 11.6

ef 11.6

egg 7.16, eggjar 5.8, eggju(m) 7.16

eggja 4.15

еіða 4.9 
eiga, á 1.9, 4.9, 12.52, 12.53 \& n. 6, áttr 12.33, eig 12.54

eigin 12.53

einhleypr 10.10

einigr 5.6

eining 10.10

einn $3.4,8.15,9.3,10.1$, einn hverr, ein hver, eitt hvert 8.15

eir 6.11

eitthvat 8.15

ellifti 10.8

ellifu 10.3

ellifu tigir 10.5

ek 1.14, 5.5, 8.2, mér 4.9, vit

1.14 n. 2 , vér $1.14 \&$ n. 2 ekki 4.9

ekkja 1.4

engi 8.15 \& n. 9, e(i)nskis 6.14

er, es pron. $8.14 \& \mathrm{n} .1$

ér, pér 1.14

erfiði 9.2 n. 3

ey 4.8

еуða, eyðask 12.5

eygja 6.15

eyra $4.7,6.6$

fá 12.3, 12.17, 12.21, 12.31, fær 4.7, fóm, fóum, fáum 4.8

faðir 4.7, 5.3, 5.5, 6.6, 7.36, foður 7.35, 7.36, feðr

$7.35 \&$ n. $4,7.36$

fagr 6.14, 9.3, 9.12, fagrar

9.3, fegri, fegstr 9.12

falda 6.14

fáligr 11.2 n. 4, fáligri 9.12

falla 12.31, fallinn 6.14

fár 8.15, 9.3, 9.12, færi, fæstr 9.12

fara $2.5,6.4,12.24,12.31$,

12.34 n. 2, fer 5.3, ferr

4.7, 12.24, farir 6.16, fór

12.34 n. 2 , farinn 5.6

fé 6.4, fjár 7.24

fengr 6.6

-fengr 9.6

ferja 6.15

fifl 4.9

fimm $6.4,6.5,6.14$ n. $5,10.2$

fimm tigir 10.4

fimt 10.10

fimtán 6.14 n. 5, 10.2, 10.3 fimtándi 10.9

fimti 10.2, 10.8

fimtungr 10.10

finna 6.14, fann, fundu 6.6, fundinn 9.3

finn, finum 4.9

fiskr 3.2, 6.5

fjá 12.42

fjall 6.8, foll 7.8

fjandi 1.14

fjórði 10.8

fjórðungr 10.10

fjórir 4.9, 6.14, 10.1, fjogur 6.14

fjórir tigir 10.4

fórtán, fjog(u)rtán 10.3

fjórutigi 10.4

fol(-) 2.4, 4.4 \& n. 1, 4.8, 11.2

flá 12.21

fleygr 9.6

flúga, fló 12.31

flód 12.7

flugr 6.13

flýja $6.13,12.19$ \& n. 5, 12.21

\& n. 2, flýr 12.19 n. 15 , fló 4.9, 12.19, 12.21, flóða, flǿða, flýða 12.21

flytja, flutti, fluttr 12.35

fódr 3.3

fótr 6.4 , fótar 7.27 , foetr 7.28

fólk 4.9

folr, fols, folvan 9.5, folvi, folu 9.8

fora 12.34 n. 2

frá 6.14

frændi, fríendr 7.39 n. 1

fregna, frá, frágum 12.3

fremja $6.15,12.35,12.59 \mathrm{n}$. 2, frem(r) 12.59, framdi, framið(r), framit, framðan, fromðum 12.35

Frigg 6.10

frú, frúr 7.32

frýja 5.7

*fúa, fúinn 12.21 n. 2

fullr 6.8

fúna $12.21 \mathrm{n} .2$

funi $1.9,7.42$

fúss 4.7

fylgði, fylgdi 12.35

(fylla), fylldi 6.14

fyr $(r)$, fyri(r) 11.5

fyrstr 10.7 fýsa 4.7, fýsti 6.14

gaddr 6.14

gamall 5.6, 9.3, 9.13, gamlan

5.6, gomul 4.8, ellri, elztr

9.13

ganga 4.7, 12.31, 12.62, gekk

6.14 , genginn 4.7, gakk,

gang 6.14

gangr 6.5

gás 6.4

Gautar 1.12

gefa 2.4, 6.14, gefem, gefim

5.6, gáfu 5.6, gefumk

12.24

gefandi, gefendr 7.40

geg(i)n 4.7

geirr 4.9, 6.4

geit 3.4

gestr 5.2, 5.6 n. 7, 6.4, 7.20, gesti 6.14

geta $4.8 \mathrm{n} .1$

geyja 12.19

gin 4.3

gina, gein 12.50

Gísli 6.17

gjalda 6.14 , galt 6.14 , gjalt, gjald 6.14

gjarna, heldr, gjarnara, helz $(t) 11.4$

gjof 5.3 \& n. 2, 7.14

(glaðr), glatt 6.14

glámr 3.2

glan 3.2

glær 3.2

gleðja 12.35, gladdi 4.7, 6.14, 12.35 , gladdr 12.35

gler $4.7,6.6$

(g) likr 3.3

Glíru-Halli 8.2 n. 5

gloggr, gløggr 6.10

glý 6.4

gnúa 1.14, 12.16, 12.21, gnýr

12.21 , grera 12.16

gnyðr 4.7

gódr 4.9, 9.13, góðan 6.14, gott 4.9, betri, beztr 9.13

gorr 5.2

gotu 5.6

gótu, gátu 4.8

gørsimi $\mathbf{7 . 3 4}$

gørva 1.9

grafa 12.29, grefr 5.5, grafid 5.5, grofim 5.6, grafask 12.29 
gras 3.2

greiða 5.7

gripeð, -et, gripoð, -ot 1.14 n. 2

grjón 3.4

gróa $3.2,12.21$

gróf 3.6

grof $3.6,7.14,9.2$

guð, gоð 4.8

guðr, gunnr 6.4

gull 4.3, 6.6 n. 7, 6.14, 6.17

gullna 5.6

gumi 7.30, guma 4.3

hafa 12.45, hef(i) 12.46,

12.47, hef(i)r 5.4, 12.46, 12.47

haddr $6.11 \mathrm{n} .1$

halda $6.14,12.31$

hálft 10.10

háls 4.9, 6.5 n. 2

hampr $1.5 \mathrm{n} .5$

hani $3.2,7.31$ n. 8 , hana 7.31 n. 8

hann 1.9, 8.7, 8.11, 10.1, peir

9.2, 10.1, pau 10.1, pær

4.7, 10.1, pæim 1.14 n. 3

haptr 6.5

harðliga 8.13 n. 7, harðla 11.2

hardr 6.4, 9.6

hatr 3.2

háttr 4.9

haull 3.4

heðan 4.3

heðra 5.3

hefja 12.19

heiði, heiðar 5.8

heiðr 6.14 n. 1, 7.16

heilagr 5.6, heilug 5.5 n. 8

heill 6.14, 9.3, heilan, heillar 9.3

hein 3.4

heita 3.4, heite, heiti 5.3, 5.6,

$12.29 \mathrm{n}$. 1, hét 3.5 , heitins

5.6, heitner, heitnir 5.6

helju 7.16

helming $(r) 10.10$

hér 3.4, 3.5

heyra 4.7 , heyrdi 4.7

hiðra, heðra 4.3

himinn 1.9, 6.11, 7.7

hinn $1.8,8.8,8.11$, hit(t), hin

$8.8,8.11$

hirða, hirda 12.59

hirðir 7.11 hjálmr 4.9

hjálpa 12.31

hjarta 4.8

hjoltum 4.8

hjørt, hirti 7.24

hlass 6.8 \& n. 1

hlaupa 1.14 n. 2, 4.7, 4.17, 10.10, 12.20, 12.31 n. 12, hleypr 4.7, hljóp 4.9, 12.20

hljómr 4.9

hlogiligr 8.13 n. 7

hloja 12.21

hlýr 4.7

hniga 1.14 n. 2

hóf 11.2

hófliga 11.2

hógværa 12.32

hógværr 12.32

hollr 3.2, 6.14, 6.17

horfa 12.18

hósti 6.14

hofuð 1.4 n. 9, 1.5

hogg 7.12

hoggva 3.4, 6.10, 12.31 n. 12

hond 5.2, 7.24, hendi 7.24

horr 7.12

hrafn 7.7

hræ 4.9

hringr $1.7,1.14$ n. 2

hrjósa 6.8

hrolla 6.8

hundrað 10.5, 10.6

hungr 3.2

hvaðarr 5.6, 6.4

hvar 8.13

hvarfa 12.41, hvarfaða 5.6

hvárr 8.13, 8.15

hvár(r)gi, hvárungi, hvár(i)gum 8.15

hvár(r)tveggja 8.15

hvatr $6.5 \mathrm{n} .2$

hvatvetna 8.15

hvé 8.10 n. $5,8.13$

hverfa 12.18

hverr 1.14 n. $2, \mathbf{8 . 1 3}, 8.15$, hvat $6.4,6.11$

hver(r)gi, hvatki, hverjungi, hverigum 8.15

hví 8.10 \& nn. 5 \& 11

hvilikr 8.13

hvitr 6.9

i 2.5, 6.14, i fjord 5.6, i gær 1.14 illa, verr, ve(r)st 11.4

illr, verri, ve(r)str 9.13

Ingibjorg 7.14

-inn 9.3

innan 6.14

inni 11.2

iss 7.7

jarl 6.14, 7.7

járn 8.2 n. 10

jól 8.5

jokull 7.7

jormun- $12.30 \mathrm{n} .1$

júgr 3.4, 8.5

kalla 6.4 , kallask 1.14

kambr 6.5

kappi 6.14

kati 1.5

kembði, kembdi 12.35

kerling 4.7, 7.14

ketill 4.7

kirja, kirkna 7.32

kjósa 3.4, 4.9, 6.6, køru, kuru $4.9,6.6$

klá 12.21

kleppr 6.14

knáttu, kná 12.30, $12.53 \&$ \&. $3,12.54$

knoða 12.18

knylla 6.8

koma 4.3, 4.8, 6.4, 6.11, 12.31, kømr 4.7

kona, kvenna, kvinna 7.32

konungr 3.6

korn 3.3

kœnn, kœnan, kænnar 9.3

krabbi 6.9

krefja, krafði 12.35

kroppinn 1.14

krota 6.9

kuðr, kunnr 12.33, 12.53, 12.54

kunna, kann 6.4, 6.8, 12.53 \& n. 3, kunaðr 12.33

kvefja, kefja 12.19

kveykva, kveikja 4.8

kvikr 6.3

kylr 4.7

kyn 5.2, 7.11 \& n. 4

kýr 4.7, 4.11, 6.16 n. 5, 7.28, kú 4.11

langr 6.5, 9.2, 9.8, lengri, lengstr 9.12

láta 3.5, 4.7, 12.20, lætr 4.7, lét 3.5 
laun 3.4

(-)lauss 2.2, 6.14

leggja 6.14, 6.15, 12.35, 12.47 n. 4, leginn 3.2

leif 5.3

leiga 6.6

lemja 4.7

lemd 4.7

lengr, lengst 11.3

lifr $3.2,4.3$

liggja 6.4, 12.19, lig $(g) r 6.14$

-liga, -lega 11.2 \& n. 5

-ligr $9.3,9.12$

lik 11.2

lika 5.4, 11.2

likkr 8.13

lítill 1.9, 4.9, 6.14, 6.15, 9.13, litinn 9.3, litt 4.9, minni, minztr 9.13

litt, minnr, miðr, minzt 11.4

ljá $6.4,6.6,12.3$ n. 4, 12.21

ljúfr 4.9, 6.4, 6.14, 11.2, ljúft 6.14

ljúga 4.9, ló, laug 12.31 n. 1

lod 7.14

lond 1.14

lúka 12.18

lúta 12.18

lýja, lúinn 12.21 n. 2

lykja 6.14

maðr 6.14, 7.27, 7.28, manni 6.14 , menn 7.28

mál 3.3, 4.9

mánaðr 7.41

manar 5.6

mangr 8.15

$\operatorname{man}(n)$ gi 8.15

máni 4.12

margr 9.13 , fleiri 3.4 n. 2, 9.13 , flestr 9.13

máttr 6.14

mækja 7.11

mæltu 12.30

mærr 9.6

mega, má 12.52, $12.53 \& n n$. $2 \& 4,12.54$

(melja), malði 6.14

mergr 6.11

meta $6.4,12.31$

meyrr 3.4

miðr 4.4, 6.4, 9.4, miði, miðja 9.8

míga 6.5

mikill 4.4, 9.13, mikinn 9.3, mikit 11.2, meiri 9.13, mestr 4.9, 9.13

minn, mín- 8.2, 8.5, 8.11

mis- 6.8

mistr 3.2

mjólk 4.8

mjoðr 4.4, 6.4, 7.24

mjok, meir(r), mest 11.4

mjotuðr 5.5

móðir 3.3, 7.35 n. 1, тюðr 7.35 n. 4

molka 12.18

motti 6.14

mogr 5.5

mork, merkr 7.28 \& n. 2

mølva 4.8

muna, man 12.3, 12.53, mant 12.54

типпr, тиґг 6.4

типи, тип $12.53 \&$ n. 2, 12.54

mús 3.3, mýss 4.7

mylna 4.7

myrginn, morginn 4.7

myrkr 4.8

nafn 6.11 n. 6

nár 4.7

nátt $6.5,7.28$ n. 2 , nótt 7.28

n. 2

nauðr, nаuð 7.17, 7.22

naust 3.4

nær, næst 11.3

né 2.5

nefi 6.4

neinn 8.15

nekkverr, nøkkverr, nekkvarr, nøkkvarr, nekkvat, nøkkvat, nakkvat 8.15

nema vb. 12.31, namt 12.24 n. 6

nes 3.1

niðr 7.11, niðjar 6.14

nítján 10.2 \& n. 2, 10.3, 10.4

nitugr 10.2

níu 10.2

níundi 10.8

níu tigir 10.5

nótt 4.8

nokkvi 6.3

nøkkviðr 6.4, 6.14

nú 11.1

nýra 6.4

óask 12.53

Óðinn 5.6, 6.14 n. 3 óðr 6.14

ok noun 4.3

okkarr 8.5

Óláfr, Áleifr 4.9

optar 11.3

ord 7.7

ormr 6.14

ótta 6.14

ó, á noun 4.8

ongr, øngr 6.5, 9.6

or, - var 7.18

økkr 6.4

øx, ox 6.6 n. 5

ogja 12.53

жра 6.14, жрðі, жpti 6.14

pinni 6.4

posi 6.4

prúdr 12.32

рrýða 12.32

rann $6.8,6.14$

rauðr 3.4

rauf 3.4

ræði 6.15

regn 6.9

reið 3.6

rekinn 12.31 n. 2

rekja $6.4,6.14,12.47$ n. 4

rétta 4.9

réttr 6.14

ríða 3.6

riki 7.11

rikr 9.4, riki, rikja 9.8

róa $12.16,12.21$, rera 12.16 , røru 4.8

róta 6.14

rostu 7.22

røk(k)r, rokkr 6.4, 6.14, 7.37, røk $(k) r s 7.37$

rœkja, rokti 12.37

ruppa 6.9

sá pron. 2.5, 5.2, 8.10, $8.14 \mathrm{n}$. 1, sú 5.3, pá 6.11, peiri

1.9, peirar $1.9, \operatorname{peir}(r) a$

1.9 , peim 8.13

sá vb. 12.16, 12.21, 12.22, sær 12.21, sera 1.14, 5.4, $12.16,12.20$

safna, samna 6.11 n. 6

salt 3.2

saman 6.11 n. 6

samr 8.14

sannr 6.14, 9.3, 12.57, sannrar 9.3

sár 4.9 
segja $12.46,12.47 \&$ n. 4 , seggja 12.47 n. 4, seg, segr 12.46, 12.47, segir 12.47 n. 4, sagaðr 5.6 n. $5,12.46$

seinn, seinri, seinstr 9.12 sekja 6.14 n. 6

sekr 6.14 n. 6 selja $6.14,6.15,12.37$ n. 4 , seldi 12.37 n. 4

sem $1.14,8.14$

senda 6.14 , sendir 4.7

sess 6.8

setja $4.7,6.15,12.34$, setinn 3.2

sétt 10.10

sétti 10.8

séttungr 10.10

sex 10.2

sextán 10.3

sex tigir 10.4

siðr 4.4

sik 8.4

sinn 8.5

sitja 4.4, 6.4, $12.19 \&$ n. 1 , 12.34

sjá pron. 8.12 \& n. 3, 10.1, pessir, pessi, pessar 10.1 sjá vb. 1.14, 6.4, 10.2, 12.21 \& $n .1$, sá 2.5

sjálfr 4.9, 8.15, 9.7

sjau 10.2

sjaund 10.10

sjaundi 10.8

sjau tigir 10.5

sjaut(j)án, sautján 10.3

skafa $6.5,6.9$

skáld 4.9

Skáney 6.14

skeðja 12.19

skepja $6.15,12.19$

skera 4.13

skina $6.5,12.3$ n. 6

skip 1.5, 4.3

skira 4.9

Skirnir 4.9

skjoldu 4.8

skrifa 12.12 n. 3

skulu, skal $12.53 \&$ n. 2, skaltu 2.5

skyldr 12.53

slá 12.17 n. 1, 12.21, sló 6.6, 12.17 n. 1 , slógu 6.6

sláttr 6.5 slikr 8.15

slokkva 6.14

smjúga 12.18

snemma 11.2 , snimst, snemst 11.3

snjór, snær 6.4

snotr 6.15

snúa $6.3,12.16,12.21$, snýr 12.21, snera $6.3,12.16$, 12.20

sofa $4.9,12.18$

sóa 12.21

sól 1.9

sótt 6.14

sorta 10.3

sokkva 6.14

sokum 1.14 n. 2

sœkja 4.7, 6.14, 12.37, sœkir 4.7, sótti 12.37

sotr 6.14

spá, spáa 12.42

spakr 4.7, spaka 5.3 n. 2

spekd, -t $4.7 \&$ n. 8

spor 4.7

sporna $6.5,12.18$, spyrna 12.18

spretta 'cause to spring' 6.14

spretta 'spring' 6.14

springa 12.3 n. 6

spýja 12.19 \& n. 5, 12.21, spjó 12.19 \& n. 5, spýr 12.19 n. $5,12.21$

spyrja 4.7

staðr 3.2, stað 4.7

standa 6.5 , stóðu 12.30

(steinn), stein 5.2, 5.5, steinar 8.10 , steinum 5.5

(stela), stolinn 4.3

stíga 3.4, 4.3, 6.4, 12.53 n. 6 , sté 12.53 n. 6

stigi, stegi 4.3

stirðna 1.9

stjarna 6.8

stórr 4.9, 9.12, storri, storstr 9.12

støkkva 4.8

straumr 6.11

strýkva, strýkja 4.8

súga 12.18

sumr 8.15

sund $4.3,6.11$

sunr, sonr 4.8, 7.24, sonar 4.8, synir 5.6

súpa 12.18 súrr, súrrar 9.3

svá $2.5,8.15$

svefn 1.14 n. 2, 6.9

sverja 12.19

svíkja 12.19

sýna, sýnask 12.5

syngva 1.8, 4.8, 6.5, 6.14, 6.16 , song 6.4

sýr 7.28

syster, systir 5.6 \& n. 4, 6.11, 7.8, systr 4.9

tafn 3.2

taka, tekinn 4.7, 12.31

tal 4.7

tamr 12.34

-tán, -tján 10.3 \& n. 3

tár 6.15

teðr, tennr 7.28 , tonn $7.28 \mathrm{n}$. 2

teikna 6.9

(telja), talði 4.7, 12.35, taldi 12.35

tíð $3.3,12.7$

tigr 10.10, tigir 10.4, 10.5

tíma 12.7

timbra 6.11

titra 12.3

tíu $6.4,10.2$ \& n. 2

tíundi $10.8,10.9$ n. 1

tíu tigir 10.5

tjá $6.4,12.21 \&$ n. 2, tjáða 12.21

tjóa, toginn 12.21 n. 2

tólf $4.9,10.3,10.4$

tólfti 10.8

-tøgr 4.8

troða 12.18

tryggr, tryggs, tryggvan 9.5, tryggvi, tryggu 9.8

-tugandi, -tugti, -tugasti 10.8

tunga $6.5,7.32$

tuttugandi

tuttugu, tottogo 10.4

tveir 6.4, 9.2, 10.1 \& n. 7, tveggja 6.10

tvenning 10.10

tvennr, tvinnr 1.4, 6.8, 10.10

tvitján 10.4

Týr 4.8

tysvar, tvisvar 10.10

pá adv. 11.1

pagnar 5.6

pak 6.4

pegja 12.47 \& n. 4 
pekkja 6.4, 6.14, 12.37, pátti 12.37

piggia 12.19

pinn 4.9, 8.5, 8.11, 9.3, pínum 4.9

bjó 4.9

pjokkr 4.8

pjóta 12.18

*bōh, pó 1.14 n. 4, 4.9, 6.14

bórr 4.9, 8.5

Dorsteinn 4.9

pokk 4.8

prá, Práinn 12.21 n. 2

prenning 10.10

prennr 10.10

prettán 10.3

priði 10.7

prið(j)ungr 10.10

prír 6.4, 10.1

prír tigir 10.4

pritøgr 4.8

prítugandi 10.9

prítugt 10.10

prjátigi 10.4

prong 6.6

prongr 9.5

prysvar, prisvar 10.10

pú $2.5,8.3,-t u 2.5$

punnr 6.8, 6.14

purfa, parf 12.53, 12.54

pvá 12.21

p(v)ilikr 8.10, 8.15

pvinga 12.3 n. 6

pýjar 4.7

pykkja 6.14, 12.37, pótti 4.9, 12.37

úlfr 4.9, 6.5, 6.14, 7.7

$u m(b) 3.2,5.2,11.5$

undir 5.2, 5.5, $5.6 \mathrm{n} .3$

ungr 6.14, yngstr, yngstum 5.6

unna, ann 12.53, annt 12.54, pret. unn- 12.54

upp 11.4, 11.5, 12.34, ofar(r), ofarmeir(r), ofa(r)st 11.4

urt 7.28 n. 4

útan 11.5

uxafóts 7.28

uxi, oxi, yxn, øxn, øxna, ухпит, øхпит 7.30, ухпа $7.30,7.33$

vаðа 12.31

vakna 12.3

(valda), olli, valdinn 6.6 vándr, verri, ve(r)str 9.13

vanr 6.14

varmr 6.4

várr $8.2,8.5$, várn 9.3

vath $1.9,7.42,12.3$ n. 9 , vatr 7.42

vaxa $12.19,12.31$

vættki 8.15

vættr 4.9, 8.15

vega 'fight' 4.3, 6.6, 12.18

vega 'lift' 6.4

veggr 6.10

vekja $4.7,6.14,12.35,12.47$

n. $4, v a k \partial i,-t i 4.7,12.35$

vel 11.4, betr 11.3, 11.4, bezt, bazt 11.4

vél 3.4

véla 6.14 n. 4

(velja), valði 6.14

venja 6.15

vera 12.17 n. $2, \mathbf{1 2 . 5 6}-7$, em 1.9, eru 4.9, óru, vóru, váru 4.8 , væri 1.14 , ver, verið 12.17 n. 2 , verit 12.11 n. $1,12.17$ n. 2 , *veriðr 12.11 n. 1

verða $6.4,6.14$, orðinn 6.5

verja, verjask 12.5

verk 4.13

verr 4.3

víðast 11.3

víðka 6.14

viðr 6.14

vigg 4.4

víkja, víkva 12.19

vilja 12.58-9

villisauðr 9.4

villr 6.17, 9.4

vindr 4.2

vinr 4.4, 7.20, 10.1

vissuligr 12.53

vissuligar 11.3

vita, veit 3.4, 12.53, veizt

12.54, vissa 6.8 , vitaðr

5.6, vit 12.54

vitr, vitrar 9.3 , vitri 7.42

vond, vendi 7.14

yðvarr 8.5

yfir 5.6, 11.2 n. $1,11.5$

ykkarr 8.5

$y \lg r 7.17$

ýmiss, ymsir 4.9

урра 12.34

yrkja $6.14,12.37$, orti 12.37
Old Norwegian

gripir, -ið, -it, gripur, -иð, -ut 1.14 n. 2

hværr, hvarr 1.14 n. 2

kum- 12.31

laugur-dagr 6.14

loupa 1.14 n. 2

níga $1.14 \mathrm{n} .2$

ringr 1.14 n. 2

sakum 1.14 n. 2

svemn 1.14 n. 2

vér, mér 1.14 n. 2

vit, mit 1.14 n. 2

Modern Icelandic

aðrar 2.4

akrar 2.4

betri 2.4

epli 2.4

katlar 2.4

klifra 2.4

miklan 2.4

seðlar 2.4

sitja 2.4

skopra 2.4

stírur 3.3

vökva 2.4

Faroese

glisa 8.2 n. 5

glisa 8.2 n. 6

sum 8.14 n. 2

Old East Norse

ænkia 1.14

bant 1.14

by ar 1.14

drængiar, -ia 1.14

drōma 1.14 n. 3

fiande 1.14

gā 12.62

gnōa 1.14

iak, iæk 1.14, vì(r) 1.14

$\bar{\imath}$ gār 1.14

$\bar{l}(r) 1.14,8.3$

kallas(s) 1.14

kō 1.14

krumpin 1.14

land 1.14

ø̄ga 1.14 n. 3 
sāpe 1.14

sēa 1.14

sum 1.14

pār 8.10

pēm 1.14 n. 3

vāre 1.14

$v \bar{\imath}(r) 8.2$

Gutnish

Old Gutnish unless otherwise marked.

auga 1.14 n. 3

droyma 1.14 n. 3

ōar 8.5, euar (Modern) 8.5

sina 8.4

paim 1.14 n. 3

Swedish

Old Swedish unless otherwise marked.

\section{aru 12.57}

bóa 1.9

dæggia 6.10

gå (Modern) 12.62

hū 9.2

klimper 6.14

skiuva 12.18

stå (Modern) 12.64

sum, som 8.14 n. 2

Danish

Old Danish unless otherwise marked.

gå (Modern) 1.9, 12.62

sem, sæm, sum, som 8.14 n. 2

stå (Modern) 1.9, 12.64

West Germanic

(reconstructed)

aggju 6.18

$a k r, a k k r \bar{x} 6.15$

bij-ist, bij-ip 12.57

bi-linnan 5.7

bi-ütan 5.7

budin- 12.31

dinkwa 4.8

dōmid $\bar{x} 12.47$ dōn, do-an 1.8, 4.14, dōm

$$
12.43
$$

feuwar 8.3

fimf 4.11

zalzunum 7.31

zans 4.11

3 $\bar{x}-$, 3ai- 12.63 \& n. 2

зеби 5.6

$x \bar{a}^{n} x a n 4.14$

xlūtr, xlütras 6.15

$x^{w} \bar{e} r 11.1$

jelokôn 4.8 n. 9

kirikôn $^{n} 6.19$

klipōd̄̄ 4.8

mannja $^{n} 7.11$ n. 5

mǣrja 4.7 n. 17

mōst 12.54

ræð̄ 6.15

saz3ja 7.11

sǣjan 12.22

$\operatorname{sex}^{w}$ an $4.14,12.21$ n. $4, \operatorname{sex}^{w} u$ 4.8, sǣзwun $12.21 \mathrm{n} .4$

sibunt $\bar{x}-$ hund- 10.5 n. 5

siz 8.10

slaxan 4.14

talljan 4.7 n. 2

texan 10.2 n. 5

tuzi $(z) 12.25$

pe 8.14 n. 5

pèr 11.1

piudjan 4.17

praygwaz 9.5

prawu 7.18

umbi 11.5

waist 12.54

wesan, bij-an-12.21, sijæ $\overline{\mathfrak{x}}^{n}$, $s i-\bar{x}(n) 12.21$

West Germanic (non-Runic)

Aflims 1.14 n. 1

Alateiviae 4.4 n. 4

Ariovistus 5.5

Gabims 1.14 n. 1

Hludana 4.3 n. 1

Langobardi 5.5

Nehalennia 4.4

Vatvims 1.14 n. 1

North Sea Germanic

(Ingvaeonic)

frij-ōj- 12.42

xabjan 12.47 xailaz-ōjan, - $\bar{o} p 12.47$

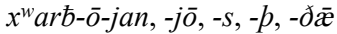
12.43

$k \bar{a}^{n}$ st 12.53

nizōp- 10.9 n. 1

nizun $4.8,10.2$

texan 10.2

-tizōp- 10.9 n. 1

üser- 8.2

Anglo-Frisian

$\bar{a}$-zi-hwæðer- 8.15 n. 8

3i-a-a-hwæðer- 8.15

piss-, pitt- 8.12

Old English

Preterite-present verbs are indexed unprefixed.

$\bar{a} 8.15 \mathrm{n} .8$

* $\bar{a}$-cierst pū 12.24, acers ðu (Mercian) 12.24

$\bar{a}$-cwenc(e)an 12.3 n. 6

$\bar{a} d l 5.6$

*a-ficgan 12.19

ägan, āh 12.37, 12.53

aggen 12.53

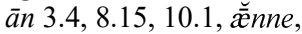
enne, ānne, ānra 10.1, ānum, ānan 10.1 n. 3

andswarian 2.2

andswaru 2.2

ānfeald, -es 2.2, 10.10

ānga $8.15 \mathrm{n} .7$

anwald, -wold 5.6

$\bar{a} r$ 'bronze' 6.11

$\bar{a} r$ 'messenger' 4.9

arn 6.8

äscian 12.3 n. 9

$\bar{a}$-seolcan 4.13

$\bar{a}$-sēon 12.21

$\bar{a}$-timplian $12.3 \mathrm{n} .6$

ätor, attor 4.15

àwiht, äuht, āht 8.15

æcer $6.4,6.15$ \& n. 5

æces (Mercian) 6.6 n. 5, 6.15, 7.37 n. 2

æðele 5.6

æftan 11.2

æftemest 9.11

after 5.5, 11.1

æfpunca 5.7 
$\bar{x} g$ 7.37, $\bar{x} g r a 4.15$

$\bar{x} g-8.15$

$\bar{x} g h w \bar{a} 8.15$

ǣghwæder 8.15

ฉ̄ghwilc 8.15

$\bar{x} l c$ 8.15, ylc (Mercian) 8.15

n. $6, \bar{x}$ fre $\bar{x} l c 8.15$ n. 6

ælmihtig 5.6

ǣmyrge, $\bar{x}$ merge 4.7

$\bar{x} n-, \bar{a} n-10.1, \bar{x} n l i c, \bar{x} n l \bar{l} e p e$, ānlic, ānliepe $10.1 \mathrm{n.} 1$, ānlīepig 10.10

żne, $\bar{x}$ nes 10.10

₹̄nig 8.15

æppel 6.15

xpplede 5.6

$\bar{x} r 5.2$ n. 2, ǣ rest 10.7

xt 6.11

ætgæd(d)re 6.18

$\bar{x}$ wisc 3.4

bacan 3.2, 12.15

Balth- 6.17

bæc 6.18

-bǣre 12.14

beadu 6.16

bēag 4.7

bēam 1.9, 4.12

bearn $4.13,6.19$

bearu 7.12

bēatan 3.4, 12.16, beoftun

(Northumbrian) 12.16, bēaten 3.4

be-clenc(e)an 12.3 n. 6

be-gān 5.7

bēgen 10.1, bū 4.11

be-gietan 12.31

be-līfan $10.3 \mathrm{n} .1$

bencum 6.18

be-nemnan 5.7

bēodan 3.4, 6.16, 12.23, 12.31, budon 4.5, 5.2, boden 4.5

beofian 12.3

beofor 4.8

beorgan 12.31, burgon 3.2

beorht 6.5

beornan, birnan $6.4,6.8$

beran 4.5, 6.4 12.7, 12.30, 12.31, birð 4.4, b̄̄re 1.9, berende, tō berenne, tō beranne 12.30

bere $4.7 \& \mathrm{n} .8$

berstan 12.31

be-sciered 4.7 bēte 3.4

bet $(t)$ re 6.18

bì, be 5.7 , be twēonum 10.10

bidan 6.16

biddan $6.15,12.19$

biegan 4.7, bēgan (Anglian) 4.7

bieldan 4.7

bigenga 5.7

binama 5.7

bindan 4.4, 6.5, 12.31

bi-numini (Mercian) $12.30 \mathrm{n}$. 5

birnan 12.31

bìtan 12.31

blandan 12.31

blāwan 12.16, blefla (Northumbrian) 12.16

blæc, blaces 9.3

blēað 3.4

blind 6.5

blinnan 5.7

blod 6.6

blōwan 3.3

b̄̄c 3.3, 7.27, 7.28, bēc 4.7, 7.28, bōce 7.28

bōcere 4.7, 5.6

bōs $(u) m 6.8$ n. 2

botm 4.3, 5.6

brecan 3.6

bregdan 6.17

brēmel, brembel 6.11 n. 4

(bringan), breng(e)an, brenco 12.35

brōgna 7.30 ก. 2

brōpor 6.5, 7.35, $7.36 \mathrm{n} .1$, brēðer 5.2, gebrōðor 8.15

brū $3.1,3.3$

brūcan 3.3, 4.4 n. 5, 12.18, 12.50 n. 5 , brȳyst 5.6, brūcest (Anglian) 5.6, brī̄đ 4.7, 5.6, brūcep (Anglian) 5.6

bryce adj. 9.6

bryce noun 3.6

brȳd 4.7, 5.6

būan 3.3, 6.4

būgan $12.3,12.18$

burg, burh 1.16 n. 2, 6.17, burga $6.17 \mathrm{n} .1$

bütan 5.7

bycgan 4.7

bȳcnedon (LWS) 12.35

bydel 5.6 byrele 5.8 \& n. 4

byrgen $(n) 6.8$

camb 6.5

cæppe 6.21

cēace 6.19

ceald 4.13, 6.18, cald

(Anglian) 4.13

cealf, cealfr- 7.37, cælf, calfer- (Mercian) 7.37, calfur (Mercian) 7.37,

7.38 \& n. 2, calferu

(Mercian) 7.38 n. 2

ceallian 6.4

cēap 6.19

ceaster 4.13, 5.6, -caestir 5.6

cemban 12.3

cempa 6.14

cèn 3.5

Céol(l)a, Cēol- 6.9

ceorfan 6.4, 12.3, $12.18 \mathrm{n} .1$

ceorl 4.13, 6.18

cēosan 3.4, 4.5, 12.7, cīest

4.7, cēs (LWS) 4.13

cìegan 12.42 n. 1, cēgan

(Anglian) $12.42 \mathrm{n} .1$

cirice 6.18, 6.19

clawu, -e 7.18 n. 1

clāg 4.10, 6.4

climban 12.3 n. 4 , clumdon 3.3

clingan 12.3

clipian, cleopian 4.8 , cleopode 4.8, cliopode

(Northumbrian) 4.8

cnāwan, cnēe(o)w 12.22,

12.53

cnedan 12.18

cnēo(w) 6.4

cniht 4.13

cnōsl 3.3

cnotta 6.9

chyllan 6.8

chyssan $4.3,6.8$

crabba 6.9

Crēcas 3.5

*crūdan, crȳdep 12.18

$c \bar{u} 4.11,6.16 \mathrm{nn} .1 \& 5$

cuman 3.2, 4.3, 4.8, 6.4, 6.11, $12.18,12.31, c(w) \overline{o m o n}$

4.11 , cymen 5.5

cunnan, cann 6.4, 12.53, cūðe $12.33,12.54$

cūp $3.3,12.53$

cwēad 3.4 
(cweðan), cwǣdon, cweden 12.17

cwelan 12.34

cwellan 12.34, 12.37 n. 4 , cwealde 12.37 n. 4

cwene 6.4, 7.32

сwicu 6.4, сисu, cwic, cucone, cucune, cwicne, cucne 9.6

-cwida 5.4 n. 4

cỹðan 4.7

cyning 1.7, 3.6

cynn $4.7,5.6,6.15,7.11$

cyrf 3.2

cyst $4.7,12.7$

darod 3.2

daru 3.2

$d \bar{x} d 12.7$

dæg 4.12, 5.2, 5.6, 6.17, dagas $4.13,5.3,6.16$, daga 5.4

dægweorc 5.6

$d \bar{x} l 4.7$

dæelan 6.15

dēad 6.6

dēmde 12.47 , dēm 12.38

Dene, Deniga 7.20

Denisc 5.6, 6.18, -um 6.18

dēofol 5.6

dēop 6.4

dēopor 11.3

dēor 1.7, 4.13, 5.2 n. 5

dīc, dīcum 6.18

*dīepan, LWS dȳpan 4.7

dile, dili 7.11 n. 5

docga 6.9

(dohtor), dohter (Mercian) 7.35

dōm 3.3

dōn 12.2, 12.39, 12.60-1, dōm (Anglian) 12.43, 12.63 n. 4

dor $4.3,6.4$

dēg (Northumbrian) 3.6, 7.37 \& n. 5, 7.38, dōgor 3.6, 7.37, 7.38 \& n. 2, dōgore 7.38

drepen, dropen 12.31 n. 3

drincan 6.14

dryas 12.61

düfan 4.4 n. $5,12.18$

dugan, dēag 12.37, 12.53, dyge, duge 12.54

*durran, dear 6.4, 6.5, 12.53, dorste 12.33 duru $3.2,7.25$ n. 3

dwellan, dwealde 12.37 n. 4

dyne 6.5

ðarf (Northumbrian) 4.13

éac 4.12

ēacian 6.4

Ead-6.9, Eadbald 4.12, Ead(d)a 6.9, Eadgilse

6.17

èadig, èadigu, ēad(e)gum 5.6

èage 4.12, 7.30, ège (LWS) 4.13

eahta 4.13, 6.5, 10.2, ehta (LWS) 4.13

eahtatīene 10.3

eahtian 12.40

eahtoða 10.8

eald 6.6, 9.12, 9.13, ieldra, ieldest $9.12,9.13$

eall 4.13, 8.15, all (Anglian) 4.13

ealu 7.41

èanian 6.4

éar 6.15, whher

(Northumbrian) 6.15,

6.18

ēare 6.6

earfop, -ep 5.6, -epe 9.2 n. 3

earm-heort 2.2

Eastron, -un 6.11, 7.33

ecg 6.18

ef(e)sian 5.6

efn, emn 6.11 n. 6

eg(e)sa 5.6

egle 9.6

el- $8.15 \mathrm{n} .1$

ele 4.7 , ale (Northumbrian)

4.7

eln 5.6

endelēas $2.2 \mathrm{n} .7$

enge 6.5, 9.6

Engle 1.16, Engla land 12.33

n. 6

enlefan, enleofan, endlefan 10.3

enlefta 10.8

eofor 4.8 , eofore 5.6

eofora 5.6

Eorcon-, -un- 5.6

еоrðu (Northumbrian) 5.5, 7.33

ēored 4.13

eormen- $12.30 \mathrm{n} .1$

éower 8.5 ermða (Mercian) 7.15

esst 6.11, 7.22

fäcen 5.6 \& n. 13

fāh 9.7

faran 4.7, 5.6, 6.4, 12.31, færo, fearu (Anglian) 5.3, færठ 4.7, 12.24, $12.63 \mathrm{n}$. 3, ferd 12.24, 12.63 n. 3, fare 6.16 , faren(-) 5.6 \& n. 11

farr (Northumbrian) 4.13

faru 2.5

fatu 5.8

fæder 4.11, 5.3, 6.6, 6.16, 7.35, 7.36 n. 1, fæd(e)res 7.35, -(e)ras 7.35, 7.36, feadur (Mercian) 7.35, 7.36, -fadur, fador (Northumbrian) 7.35, 7.36

fægre 11.2

fæstenn 5.8 \& n. 4, 6.11

fēa 6.16, 8.15, fēam, fēawum 9.5

feallan 12.31

fearh, færh, ferh 4.13

fela 4.4 \& n. 1, feolu

(Northumbrian) 4.4 n. 1 , $9.6,11.2$

fell 6.8

-felth 6.17

feoh 6.4

feohtan 4.13, 12.31

fēol, fìl 4.13

fêondlic 8.13 n. 7

fēorða 10.8

fêower 5.3, 5.5, $\mathbf{1 0 . 1}$

fêowertiene 10.3

fêowertig 10.4

ferian 6.15

fiellan 5.8

fiersn 4.2

fif $4.11,6.5,6.17,10.2$

fîfta 10.8

fiftēoða 10.9

fiftiene 10.3

fîftig 10.4

finc 6.18

fir (e) n 5.6

fisc 3.2, 6.5, 6.19

fiper-10.1, fyðer- (LWS)

10.10 n. 1 , feopur- 10.10

n. 1, fiðerfōt- 9.1 n. 1 , fiðerrīce 10.10 
flǣsc 6.19

flèan 12.21

flèoge, flège 4.13

flèon 6.13, 12.19, 12.21, fliehd 12.43

flōd 6.13, 12.7

flowan 12.7, 12.22

fōðor, fōd(d)or 3.3

foldu (Northumbrian) 5.5, 7.33

fōn 4.13, 12.3, 12.17, 12.21, 12.31 , fēng $12.3,12.20 \mathrm{n}$. 5 , fangen 4.1

for-gangan 12.8

for-leginum (early) 12.30 n. 5 forma, fyrmest, formest 9.11

\& n. 1, 10.7, forpmest

(Anglian) 9.11, 10.7

forst, frost 6.8

forp 10.7, forpmest (Anglian) 10.7

fōt 6.4

frætwa 7.18

freces 6.18

freme 9.6

fremman 6.15 , fremme, fremmad 12.59

frēond 4.13 \& n. 6, 7.39, frīend $5.2 \mathrm{n} .7$

fretan 12.8

fricc(e) a 6.9

fricg(e)an 12.19

frìgan 12.42

frignan 12.3, 12.31, frægn 12.3

frogga 6.9

fruma $4.3,12.31$

fugl 5.6 n. 8

füht 4.1

fül 4.7

fultum, fulteam 2.2

furlang $2.2 \mathrm{n} .8$

füs 4.11

$f \bar{y} l p$, fèlp 4.7

$f \bar{y} r 1.9,7.42$

fyrest 10.7

gād 'goad' 6.14

gād 'lack' 4.12, 5.2

galgu (Northumbrian Runic) $5.5,7.31,7.33$

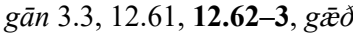
4.13

gang 6.5

gangan 12.31, 12.62, gang 12.20 n. 5 gār 6.4

gāst, ḡ̄st 7.37

gāt 3.4

gædeling $12.59,12.61$ n. 8

ge-, gi- 5.7

gēac 4.12

(gēar), gēr (LWS) 4.13

gearu 5.2, 9.5, gearone, gearwes 9.5 , gearwa 9.8

Géatas 1.12

ge-fā 9.7

ge-fēon 12.21, ge-fǣgon 12.17

(ge-)fyrn 9.6 n. 2

ge-hror 6.6

ge-hwā 8.15, ge-hwām 8.13 n. 7, ge-hw̄̄re, -hwāre (LWS) 8.13 n. 3

ge-hwæðer 8.15

ge-hwelc 8.15

ge-līc 3.3

ge-lìce 5.4, 11.2

ge-myne 9.6

ge-nesan 6.6

ge-nōg- 6.6

geō, $i \bar{u} 11.1$

geос 4.3

geogup 5.6

geol(o)ca 4.8 n. 9

* geon, geonre 8.11 \& n. 2

geong, gingra 9.12 , ging(e)sta 5.6, 9.12

geonian 12.3 n. 6

georne, geornor, geornost 11.4

gēotan 6.17

ge-sæt 3.6

ge-pēode, ge-piode 4.7

ge- $p \bar{u} f 10.6$

ge-wegan 4.3 n. 4, 4.4, 12.18

(ge-)welhwilc 8.15

ge-wislicor 11.3

ge-wiss $12.33,12.53$

giefan 4.13, 6.5, 12.31, geofan (non-WS) 12.31, giefst 5.6, gefest

(Anglian) 5.6, giefð 5.6, gefep (Anglian) 5.6, geaf, gef 4.13, 6.17, gēafon 4.13

giefu 5.3, 7.14, giefe 5.4, gyf-, gif- (LWS) 7.14, ge(o)f(Anglian) 7.14

gieldan $6.17,12.31$ giellan 12.31

gielpan 12.31

gierd 7.16

* gierran 12.19

giest 4.7, 5.2, 5.6, 6.4, 7.20

gif 11.6

gīnan 12.3 n. 6, 12.50

ginian, geonian 12.50

glæs 6.6

glēaw 6.10, 9.5, glēawne 9.5

glēo 6.4

gōd 9.13, gōdne 5.6, bet(e)ra

5.6, 9.13, -an 2.4, sēlra,

sella 9.13, bet(e)st, best,

sēlest 9.13

gold 4.3, 6.6 n. 7, 6.17

gōma 3.4

gōs 4.11, 6.4, gēs 4.7, ḡ̄es

(Anglian) 4.7

grēne 12.20

grēotan 12.12 n. 2

grindan 12.3

grōwan 3.2, 12.20, 12.22, grēowon 12.22

grūt 3.3

gū 6.4

guma 4.3, 7.30, 12.31

gyden 5.8 n. 4 , - 5.8

gyldnum 5.6

habban 12.45, 12.46, 12.47, hæbbe 12.47, hafo

(Anglian) 12.46, hæfst, hæfठ 12.46, 12.47,

hafas(t) (Anglian) 5.4,

12.46, 12.47, hafad

12.46, 12.47, hafa 12.46,

12.47, næbbe 5.7 n. 2

hād 3.4

hādswāpe 6.11

hafoc 4.8, heafoc (Mercian)

4.8

$h \bar{a} d r-, h \bar{x} d r-6.14$

hafola 6.4

hafu, -o 4.8, heafu (Mercian) 4.8

hālig 6.17, 9.3, 12.42 n. 1, 12.52 n. 1, hālge,

$h \bar{a} \lg u(m) 6.17$

hālor 7.37

hamm 6.8

hana 3.2

hand 5.6, hond (Mercian)

4.12

hard 9.6 
hātan 3.4, 12.16, hĕht

(Anglian) 12.16, hèt 3.5, 12.16, 12.20, hātte 5.3, 12.29, hätte, hätton 12.29 n. 2

hatian 12.40

hæft 6.5

hæftenn 5.8

$h \bar{x} l 7.37$

hæle 7.41

hættian 6.9

$h \check{\bar{e}} 1.9,1.10$ n. $6,8.7,8.10$, hèo 4.10, 8.10, hie 12.61, heora 4.8

hēafod 1.5, hēafudu (Mercian) 2.5, 5.8

hēah 4.13, 9.3, 9.12, hēh (Anglian \& LWS) 4.13, hēas 9.3, hìer(r)a, hìehst 9.12, hiehsta 5.6

hēala 3.4

healdan $4.13,12.31$

healf 10.10

heals $6.5 \mathrm{n} .2$

hēan 3.4

heard $4.13,6.4$

hearde 11.2

Heardingas 6.11 n. 2

hēawan 3.4, 6.10

hebban 12.17 n. 3, 12.19, $12.31,12.47$

helan 3.2

helpan 12.31, healp 4.13

hennep $1.5 \mathrm{n} .5$

heofon 1.9, 6.11, -es 2.4

heofoncund 3.3

heolstor, helustras 5.6

heorde $6.11 \mathrm{n} .1$

heorot 4.8

hèr 3.4, 3.5

here 5.6, 7.11, -heri $7.11 \mathrm{n} .3$

heretoga 6.6

hergian 6.15 n. 7, 12.33 n. 6

hergan (Mercian) 12.35 n. 3

hete 5.2

hettend 2.2 n. $8,5.2$ n. 7 , -e 7.39

hider $3.4,4.3,5.3$

hieg 6.15 n. 2

hielt 4.7

(hìeran), hīerde 5.6, hīered 5.6

hierde 4.7 n. 14, 5.6, 7.11, hiorde, heorde (Anglian) 4.7 n. 14 hindema 9.11

hinder 11.1

hladan 3.6

hläford, -ard 5.6

hlāw, hlǣw 7.37

hlæd 3.6

hlæst 6.8 \& n. 1

hleahtor 4.13, $5.6 \mathrm{n} .7$

hlēapan 12.20

hleonian 12.3 n. 6

*hliehhan, hlihhan 12.19, 12.38 n. 3

hlimman 4.4

hlinian, hleonode 12.50

hlōð 3.6

hlūd 6.4

hlütor, hluttor 6.15, 6.18

hñ̄gde 4.15

hōcor 7.37

hōd 6.9

hold 3.2, 6.17

hōn 12.17, 12.21, hēng 12.20 n. 5

hoppian 12.3 n. 5

hord 6.11

hōre 6.4

hornb̄̄re 12.14

hrafn, hramn 6.11 n. 6

hrāw hrǣ $w 7.37$

hrēð, hrōð(o)r(-) 7.37

hrēop 12.20

hrēosan 6.6

hrōfæ 7.8

hrūtan 12.18

$h \bar{u} 4.11$

hund num. 3.2, 6.4, 6.11, 10.6 , hundred 10.6

hundændlæftig 10.5

hundeahtatig 10.5

hundnigontig 10.5

hundseofontig 10.5

hundtēontig 10.5

hundtwelftig 10.5

hüs 7.8

hüslian 12.32

hwā 8.13, hwæt 6.4, 6.11, hwon 8.10, swā hwā swā 8.15

hwæt 9.2, hwatu 9.2, hwatost 2.5

hwæder 5.3, 6.5

hwæðer 5.6, 8.13, swā hwæðer (swā), swæðer 8.15 $h w \bar{x} r 8.2$ n. 9, 8.13, 11.1

hwæthwugu 8.15

hwearfian 12.41

hwelc, hwilc 5.6, 8.13, $8.15 \mathrm{n}$.

3, 10.3, swā hwilc swā

8.15

hweohhol, (-)hweohle(s) 6.15

n. 6

hwergen 8.15

hwīl 8.13, hwȳl (LWS) 8.13

hwilchwugu 8.15

hwïtc(w)udu 4.4

hwonne 11.1

*hwōsan 6.5, hwōsad, hwēos 12.17

hwōsta 6.14

-hwugu, -hwegu, -hwigu 8.15

$h w \bar{y}, h w \bar{\imath} 8.10$ n. 11

hycgan, hyge 12.46

hyge noun 6.17

hyse, hysses 7.11 n. 5

$\bar{l}-8.15$

ic 5.5, 8.2, mё 1.10 n. $6,2.5$, wit 4.4 n. 3 , wē 4.13 n. 4

idages 8.15

ìdelu 5.6 \& n. 13, ìdlan 5.6

ierre 4.7, iorre, eorre (non-

WS) 4.7

iewan, ēawan 6.15

ifig 2.3

ilca 8.15

incer 8.5

innan 11.5

inne 11.2

innemest 9.11, 11.3

irnan 12.31

ìsīðes 8.15

lācan, lēe 12.16, leolc

(Anglian) 12.16

lād 6.6

lāf 5.3

lām 1.4 n. 9

lamb 7.37, lomb (Mercian)

4.12, lomber (poetic) 7.38

n. 2, lombur, lomberu

(Mercian) 7.38 n. 2

lang 6.5, 9.2, 9.8, long

(Mercian) 4.12, lengra,

lengest 9.12

lār 6.6, 7.14

læcc(e)an, lāhte, lāxhte 6.15

læedan 3.6

læppa 6.9

lēran 4.7, 6.6, 12.53 
lās noun 7.18, lāswe 6.16, lǣs $s(w) u m 7.18$

læt 4.12

lǣtan 3.5, 6.3, 12.16, 12.20, lètan (non-WS) $12.31 \mathrm{n}$. 8, leort (Anglian) 6.3, 12.16, 12.20, lèt 3.5, $12.16,12.20$

lèan noun 3.4

lēan vb. 12.21

-lēas $2.2 \mathrm{n} .7$

lēaðor 6.14

lecgan 6.15 , legde 12.35

leng $6.18,11.3$

lēof $6.4,11.2$

lèoht, līoht adj. 4.13

lèoht noun 6.4

lēon 6.4, 6.6, 12.3 n. 4, 12.21, lāh 12.9

leornian, liornian 6.6, 6.8, 6.11

lēosan 4.8, 6.6

libban, leofast, leofad, leofa 12.46, 12.47, 12.59, lifg(Anglian) 12.46, 12.59

liccian 12.3 n. 5

-lìce 11.2

licg(e)an 6.4, 12.19, legen 3.2 lìan 6.6

lìeg 4.7, 12.3, lèg (Anglian) 4.7

lieget 12.3

līehtan 4.5, 4.7

lifen 5.6

lifer 3.2, 4.3

lixxte 12.35

lücan $12.18,12.50$ n. 5

lufen 5.6

lufian 12.35 n. 3

lungor 6.5

lütan 12.18

lyre 6.6

lỳt 9.6 n. 2, 11.2, 11.4, lȳtle

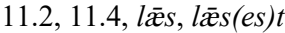
11.4

lȳtel 1.9, 5.5, 6.15, 9.13, 11.2, lyttel 6.15, 6.18, lỳtelu (Mercian) 5.6, lēssa 6.16, $8.12,9.13$ \& n. 1 , lǣst $9.13 \&$ n. 1 magan, mæg 12.37, 12.52 \&

n. 1, 12.53, meaht 12.54, miht (LWS) 12.54

manig 5.6, 8.15, 9.3, manges 9.3, man(i)gum 5.6 $\operatorname{man}(n) 6.8,6.14,7.27$, menn 7.28

manna(n) 7.27

$m \bar{a} p(p) m$ (LWS) 6.15, 6.18

$m \bar{x} d 5.6,-e 7.18$

m̄̄g, māgas 4.13

$m æ g(e) p 7.41$

mǣgwlite 3.3

mǣra 9.8

mearh 4.13, 6.11, 6.18, méares $4.13,6.18$

medem-, -e, -ra, -est $9.11 \mathrm{n} .1$

medu, meodo 3.2, 4.4

(meltan), multon 3.2

mene 7.11 n. 5

meng(e)an 6.18, 6.19

menigu 7.34

meol(o)c 4.8, 5.6, milc

(Anglian) 5.2

meord, mēd 3.5, 6.11

me(o)tod 5.5

meoxen, mixen 4.13

metan 12.31

mere 5.2

metan 6.4

micel 4.4, 5.5, 6.18, 9.3, 9.13, mic(c)les 5.6, 6.15 n. 6,

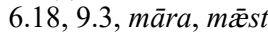
9.13

micle $11.4, m \bar{a} 6.16 \mathrm{nn} .1 \&$ 5, 11.4, m̄̄st 11.4

midd 4.4, 6.4, 9.4

mihtig 5.6

$\min 8.2,8.5$

mirce 1.8 n. 2

mis- 6.8

mist 3.2

mōdor 3.3, 7.35 \& n. 1, mōdru, $-a 7.35$

molda 3.3

mōna 4.12

mōnað 7.41

morgen, mergen 3.6, 4.7, myrgen- 3.6 n. 2, margen (Anglian) 12.59

*mōtan, mōt 12.53

moppe 6.14

mйð 6.4, 6.17

-munan (ge-), (-)man 12.3, 12.53

murnan 12.3, 12.18, 12.50, mearn, murnde 12.50

$m \bar{u} s 3.3$

myne 4.7 myrge 9.6

(nā), nā ðе̄ raðor 5.3

naca 6.3

nacod 6.4, 6.14, 6.15

nama 5.4, noma (Mercian)

4.12, naman 5.6

nān 8.15

nāthwelc 8.15

nāthwā, nāthwæt 8.15

nāwiht, nāuht, nāht 8.15

nāwper 8.15

$n \bar{x}$ dre, næddre 6.18

n̄̄nig (non-WS) 8.15

$n \bar{x} p 3.3$

ne $2.5,5.2$

$n \bar{e} 2.5$

nēah 4.13, nēh (Anglian) 4.13

nefa $6.4,6.11$

nerian $6.6,6.15,12.35$, ner(i)g- 12.35 n. 3, -nerige

$6.15 \mathrm{n} .3$, nerede 5.6

nesan 12.3

nest 3.6, 4.3, 6.11

nètenu, nētna, nētnum (with Anglian $\bar{e}) 5.6$

niehst(a) 4.7

niewe 4.10

nigoða 10.8

nigon 4.4 n. 2, 10.2

nigontīene 10.3

niht, neaht 6.5

niman 12.31

niper, nipor 4.3, 11.1, 11.2

niwwian 12.40

norðerne 8.5 , norpmest 9.11

nordweard 2.2

nōse 3.1

$n \bar{u} 11.1$

*-nugan (be-, ge-), -neah $12.37,12.53$

одðе 11.6

öðer 4.11, 5.2 n. 8, 5.5, 8.15, 10.7, ōderu (Mercian)

7.38 n. 2

ōðerhwīle 8.15

of, ob 6.17

ofen 1.9

ofer, ofær 5.5, 11.5

oftor 11.3

of-pync(e)an 5.7

ombeht 1.4

ondrǣ dan, ondrēd 12.16, ondreord (Anglian) 12.16 on-ēgan 12.53 
on-ēgnan 12.53

on-gietan 12.31

on-ginnan 12.3 n. 6

$\overline{o s} 1.13$

op-gān 5.7

oppæt 11.6

oppe, eppa 4.5 n. 1, 8.15

oxa, cexen, exin, exen, oxna, oxnum 7.30

pāl 3.3

Peohtas 4.13

pinn 6.4

plēon 12.21

pusa, posa 6.4

pyfte 12.35

-ra, $-\bar{o} s t-,-\bar{a} s t-9.12 \& \mathrm{n} .2$, -ust- 9.12 n. 2

rāp 4.12

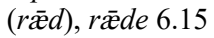

rǣंdan 12.16, rēdan (non-

WS) 12.31 n. $8, r \bar{x} d d e$

12.16, rēd 12.16, 12.20,

reordon (Anglian) 12.16

rǣंe 5.8 n. 2 ,

rǣran 6.6

rēad 3.4

recc(e)an 'care' 6.15, 12.37, rōhte $6.15,12.37$

recc(e)an 'stretch' 6.4

rīce (noun) 5.2, 7.11

riht 4.13

rinc 4.4

rinnan 6.8

rīsan 6.6

rōwan 12.21

rudu 3.2

sacu 4.7

salor 7.37

sām- 10.10

samhwilc 8.15

samnian 5.6

sār 3.4, 4.9

sārlic 5.6

sāwan 12.20, 12.22, tō sāwenne 1.9

sæcc 4.7, 6.15

$s \bar{x} d 12.20,12.22$

$s \bar{x} t 3.6$

scādan 12.17

sceacga 6.9

(sceadu), sceadwa 5.2

sc(e)afan 6.5

sceaft 6.19

sc(e) and 6.11 scēap 6.9

sceatt 6.9

scēawian 4.15

Scedenig 6.14

sc(e)ort, scyrtra, scyrtest

scērero 7.37

* sciellan 12.31

scieppan $6.15,12.19$

scieran 4.13

*scieppan, LWS sceppan

$$
12.17,12.19
$$

scima 12.3 n. 6

scinan $6.5,12.3$ n. 6

scipu $7.7,7.8$

scōl 6.18

scolu $3.2 \mathrm{n} .1$

scop 6.18

scrīfan, scrā 12.12

scrūd 7.27

*scūdan, scūdende (poetic) 12.18

scüfan, scēofan 12.18

sculan, sceal 6.18, 12.53, scyle, scule 12.54

$s \breve{\bar{e}} 2.5, \mathbf{8 . 1 0}, 8.13,8.14,9.2$, pone $6.11,7.8, p \bar{x} m 8.14$

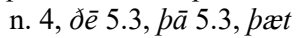

8.11 , sēo 8.7

sealf, salb 6.17

sēar 3.4

searo, $-u$ 5.6, 7.12

Seaxan 1.16, Seaxe 7.20

sēcan 4.7, 6.18, sēcp 6.18. sēc $7.21 \mathrm{n} .2$

$\operatorname{secg} 7.11 \&$ n. 2

secgan $6.19,12.46,12.47$, sægst, sægð, sæge 12.46

sele 7.37

self(a) 8.15, seolf (non-WS) 4.13

sellan $6.15,12.37$ n. 4, syllan (LWS) 12.37 n. 4

sendan 12.35 , sentst, sent

12.35 , sende 4.7

seofoða 10.8

seofon 4.8, 10.2, sifun-

(Mercian) 4.4, siofu

(Northumbrian) 4.8

seofontīene 10.3

seolh 4.13

sēon 1.8 n. 2, 4.13, 6.4, 6.6, $6.18,12.38$, sēo 4.8 , gesiehठ 4.7, 4.13, $12.38 \mathrm{n}$. 3, siohð 4.7, 4.13, seah
12.38 n. 3, sāwon 1.8 n.

2, 4.13, 12.21 n. 4, sēgon

(Anglian) 6.6, 12.21 n. 4, ge-sawen 4.13, sewen

12.17, segen (Anglian)

6.6

sess 6.8

setl 3.6

settan $4.7,6.15,12.37$, sette

$12.35,12.37$, -sætte

(Northumbrian) 12.37, sete 12.38

sepēah 11.6

sibb 6.15

sidu 4.4

siððan, seoppan 4.8, 6.16,

$8.10,11.6$

siex, seox 10.2

siexta 10.8

siextig 10.4

sigan 6.17

sige 7.37

sigor 7.37

$\operatorname{sim}(b)$ le 5.3 n. 3

$\sin 8.5$

singan $1.8,6.5,6.16$

sinnan 6.8

sinu 7.18

sittan 4.4, 6.4, 12.19, seten

3.2

sixtīene 10.3

slǣpan 6.4

slēan 4.13, 12.21, slōg, slōh, slogon 12.16

slieht $6.5,6.16$

slipor 6.3

slüpan 12.18

smeorwum, smerum 6.16

smūgan 12.18

smylte, smolt 9.6

smippe 6.22

snā(w) 6.4, 7.12

snot(t)or 6.15

sōð 12.57

spannan 12.31

spātan 12.16, speoft, speaft

(Northumbrian) 12.16, 12.20

speru 7.20

spic, spec 4.3

spinnan 6.3

spiwan 12.19

sprǣce 6.19

springan 12.3 n. 6 
* sprūtan, $\bar{a}$-sprotene 12.18

spurnan, spornan $6.5,12.3 \mathrm{n}$.

$6,12.18,12.50$, spearn

12.50

staðol 6.6, 6.8

stalu 3.6

stān 5.2, stānum 5.5

standan 6.5, 6.6, 12.3, 12.15, 12.31, stōd 12.3, 12.15

stæppan, steppan 12.19 \& n. 6

stealdan, stēold 12.20

steall 6.8

stefn, stemn 6.11 n. 6

stelan 3.6, 4.5

stellan 12.37 n. 4

steorra 4.13, 6.8

stigan 3.4, 6.4

strǣt 4.6 n. 2

strēam 6.11

stregdan 12.31

strenge 7.34, 9.6, strang 9.6

streng $p u$ 7.34

strīcan 3.6, 4.8

*strīegan 4.10 \& n. 1 , strēgan (Anglian) 4.10, 12.21

strūdan 12.18

sū $6.16 \mathrm{n} .1$

sūgan, sūcan 12.18

sum 8.15

sund 6.11

sunne 1.9

sипи 5.6, 7.24

sūpan 12.18

swä 2.5, 4.6 \& n. $1,8.13$ n. 6 ,

$8.15, s w \bar{x}, s w \bar{e} 4.6$ n. 1 ,

8.13 n. 6

swēr $r(e) 9.6$

swǣs 8.4

swefan 4.9, 12.18

swēg 12.3

swelc, swilc 8.15

sweotole 5.6

swerian 12.19

swēte, swōt 9.6, swētest 9.11

swice 9.6

sw⿳亠丷冖̆ian, swugian 3.3

swilce conj. 11.6

swimman 6.11

swingan 6.11, 12.3 nn. $3 \& 6$, $s(w)$ ungen 6.11

swōt 6.14

synn, e 7.16 tācor $3.4,6.3$

tǣe $(e)$ an 6.9

tǣcnan 6.9

teagor $5.2 \&$ n. 3

tellan 4.7 n. 2, 5.8, 12.37 n. 4

tēoða $10.8,10.9 \& \mathrm{n} .1$

tèon class I 6.4, 12.21

tēon class II 6.6, 12.21

ticcen 6.9

tìd $3.3,12.7$

tīen 6.4, 10.2, tēn (Mercian) 10.2

-tigoða, -tegoða, -teogoða, -tiogoða, -tigpa 10.9

timbran 6.11, timbrede 12.35 \& n. 6, timberde $12.35 \mathrm{n}$. 6

tō 5.3, 12.30

tōweard, -ward 5.6

tredan 12.18

trēo 4.10

trēow 4.10

trymman 4.3

tulge 3.3, 9.6

tunge $6.5,7.32$

tūsc 6.18

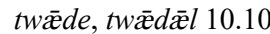

twēgen 10.1 \& n. 11, tū 4.11, twā $4.12,6.4$

twelf 5.6, 10.3

twelfta 10.8

twēntig 10.4

twēntigoða 10.9

twin $6.11 \mathrm{n} .1$

twinn $6.8,10.10$

twiwa 10.10

paccian 6.9

panon 11.2

pæc 6.4

$p \bar{x} r 8.2$ n. $9,11.1$

pæt conj. 8.14

pætte 8.14

pe, pē pron. $8.14 \&$ nn. $3 \& 4$

pearf adj. 9.7

pearfa 9.7

péaw 4.15

begn 6.9

penc(e)an 6.4, pōhte 4.1

penden 11.6

pēod 4.7

pēon 4.4, 12.3 n. 4, 12.21, pāh 12.21 n. 3, pungen $4.1,12.21 \mathrm{n} .3$

pēow, -es 4.10 n. 1, 6.10, 7.12 perscan $12.3,12.31$

p $\breve{\bar{e} s} \mathbf{8 . 1 2}, 8.15, p \bar{y} s 8.15$

picce 1.8 n. 2

picg(e)an 12.19

pider 11.1, 11.2

pin 8.5

ponne 11.1

prāwan 12.3

prēa 4.10, $7.18 \mathrm{n} .1$

prēotīene 10.3

pridda 10.7

prīe $6.4, \mathbf{1 0 . 1}$

prinen 10.10

prītig 10.4

prītigoða 10.9

priwa 10.10

prosm 6.8

p $\breve{\bar{u}} 2.5,8.3,12.24$, gìe 4.13

pungen 4.1

punor 6.11, punres 4.9

purfan, pearf 12.53, porfte

12.33, pyrfe, purfe 12.54

purst 3.2

pus 8.15

pütan, pēotan 12.18

pwēal 4.13

pwèan 12.21

pweorh, pwēores 9.3

pȳmel $6.11 \mathrm{n} .4$

pync(e)an 4.1

bynne 6.8

pyrre 9.6

pyslic, puslic, pyllic, pullic 8.15

pȳwan, $p \bar{y} p 12.38$

unblēoh 3.4

uncer 8.5

under 5.2, 5.5

unnan, ann $6.11,12.53, \bar{u} ð e$ $12.33,12.54$

üp, upp, 11.4, 11.5, ufor 11.4, ufemest, yfemest 11.3, 11.4

üre, ūser 8.5

üt 11.2

üteweard 5.6

üpgenge 5.7

waðol 6.8

wāg, wāg 6.10

wagian 3.2

wāwan 12.22

wæcnan $12.3,12.31,12.50$,

$w \overline{o c} 12.3,12.50$

wæcnian, wæcnode 12.50 
wæfs, wæsp, wæps 6.5

wæscan 12.3 n. $9,12.31$

wæstmb̄̄re 2.3, 12.14

wæter 1.9, 5.3, 5.6, 7.42, 12.3 n. 9

Wealh- 3.2 n. 1

weallan 12.18

weallian 6.8

-weard, -ward 5.6

wearm 6.4

weax, wæx 4.13

weaxan 12.19

wèðe 6.4

wefan 6.5

weft 6.5

wegan 6.4

wël 4.5 n. 1, 11.2, bet 11.3 , 11.4, sēl, bet(e)st, best, sēlest 11.4

Wēlund 3.4

wēn $4.7,12.3$

wennan $6.15,12.35$, wenian, wenede, wenode 12.35

weorc, werc 4.13

weord 4.13

weorðan 2.4 n. 6, 6.4, wurdon 4.5

we(o)rod 2.5, 5.6, 5.8

wepan 12.19

wēpen (Mercian) 5.6

wer 2.4 n. $6,4.3,11.2$

werlice 11.2

wesan $12.17, \mathbf{1 2 . 5 6}-7$, bēon

12.21, (e)ard (Anglian)

12.25 \& n. 1, si(o)ndon

4.8, bēo (m) 1.9, $\operatorname{sie}(n)$

12.21, 12.61, nis 5.7 n. 2

wìdra, widdra 6.18

wìgan 4.4, 12.3 n. 3, 12.18,

for-wegen (or under gewegan?) 4.3 n. 4, 4.4,

12.18

wiht 8.15

wìl 3.4

wilde $6.17,9.4$

willan 12.24, 12.58-9, willo (Anglian) 12.27

wind 4.2

(windan), wunden 4.3

wine 4.4, 4.7, 5.6, 7.20, winiga 7.21

winter, wintru 7.25

-wintre 9.6

wiss 6.9 wīsdōmes 2.2

wise 6.8

wiss 6.8

witan, wāt 3.4, 12.53, wisse 6.8 , wiste $6.8,12.54$, witen 12.33

wìtan 12.28

wlacu, wlæc 9.6

wōh 4.15

word 5.8, 7.7

-wracu 5.4 n. 4

wrecen 12.31 n. 2

wrēon 12.21, wrāh, wrēah 12.21

wringan 12.3 n. 6

wrixl 4.13

wrōtan 6.14

wudu, widu 4.8

wulf $6.5,6.17,7.7$

wull 6.8

wundrum 11.2

(w)uton, -an, uten $12.28 \& \mathrm{n}$. 1 , wutum (Northumbrian) 12.28

wyrc(e)an 6.18 , warhte

(Anglian) 12.59

uyrdi (Northumbrian) 7.22, 7.23

wyrpte 12.35

wyrt 7.28 n. 4

wȳscan 12.3

yfel 5.5, 9.3, 9.13, yfelu 9.3, wiersa, wierrest 9.13

yfle, wiers, wier(re)st 11.4

$y m b(e) 3.2,5.2$ n. $2,11.5$

yppan 12.34

ytemest, ütemest 9.11

Middle English

зиие 4.13

hor 4.8

lappen 6.9

seothen 4.8

souen, seoue(ne) 4.8

sprouten 12.18

steken 4.3 n. 4

pō3 4.9, 6.14

yiven 6.5

Present-Day English

absolute $6.6 \mathrm{n} .2$

absolve 6.6 n. 2 beadle 5.6

bear 12.1

beseech 6.18

bramble $6.11 \mathrm{n} .4$

cast 12.1

chocolate $1.5 \mathrm{n} .5$

choose 12.1

deed 12.7

do 12.33

dove, dived 12.12

either 8.15 n. 8

England 12.33 n. 6

enjoy 12.1

every 8.15 n. 6

exact 2.2 n. 2

examine $6.6 \mathrm{n} .2$

execute 2.2 n. 2, 6.6 n. 2

exercise 2.2 n. $2,6.6$ n. 2

exert 2.2 n. 2, 6.6 n. 2

exile 6.6 n. 2

exist $6.6 \mathrm{n} .2$

exit 6.6 n. 2

go 12.1

grand $4.2 \mathrm{n} .1$

grant 4.2 n. 1

lather 6.14

loud $4.2 \mathrm{n} .1$

lout 4.2 n. 1

morpho(pho)nology $12.33 \mathrm{n}$. 6

of $6.6 \mathrm{n} .2$

off $6.6 \mathrm{n} .2$

potato $1.5 \mathrm{n} .5$

proved, proven 12.12

seek 6.18

sere 3.4

showed, shown 12.12

somewhat 8.15 n. 5

strike 12.1

swimming, to swim 12.7

thimble $6.11 \mathrm{n} .4$

though 1.14 n. 4

thunder $6.11 \mathrm{n} .4$

tomato $1.5 \mathrm{n} .5$

wile 3.4

yon $8.8,8.11$ n. 2

Old Frisian

achta 3.2, 4.12, 5.6

àge 4.12

āhwedder 8.15

$\bar{a} k 4.12$

ald 4.12 
$\bar{a} n, \bar{e} n 4.12$

bām 4.12

bed 4.7

bera 12.31

berch, berge 6.17

bēta 4.7

biāda 4.14, 12.31

bidda 12.19

binda 12.31

binna 6.19

bita 12.31

bonna $12.31 \& n .15$

bōs(e)m 6.8

brēed 4.7, 5.6

bren, bern 6.19

breida 6.17

brochte 4.11

brūka 12.18

dei $4.12,6.17$

deiwerch 5.6

dèl, deil 4.7

dēle 12.38

diunk 4.8

diūpa 4.7

dōm 3.3

$d w \bar{a}(n) 4.14,6.19,12.21$, 12.60-1

ègan 12.53

ekker 6.15

ellik, e(l)k 8.15

elmechtich 5.6

èn, $\bar{a} n 6.19$

ēnich 8.15

ethele 5.6

$f \bar{a}(n) 12.21,12.31$

falla 12.31

fara 5.6, 12.31, faren(-) 5.6 \& n. 11

feder 4.12

fèth 4.7

fif 4.11

fiower, fiuwer 5.5

fisk 6.19

fiuchta 4.14

fläsk 6.19

fliā 6.13, 12.21

fule, fula 3.2

gād 4.12

gāk 4.12

* gān 12.62-3

gers 6.19

gife 5.3, 5.4

gōdne 5.6

gold 6.17 gōs 4.11

grōja 12.22

gunga $12.31 \& n .16$

halda 12.31

hām, hèm 4.12

hana 3.2

hāwa 12.31 n. 12

hebba, habba 12.46, 12.47

hei 4.14, 6.17

helfte, halfte 10.10

helich, -lega 6.17

helpa 12.31

hèr, hīr 3.5 n. 2

hēra 4.7

heva 12.19

$h \bar{\imath} 1.9,8.7, \sin 8.7$

himel, himul 6.11

hlūd 6.4

hold 6.17

hona 5.6

hond 4.12

hrūta 12.18

hū, huō 4.11

hwā 4.14, 12.21

hwelk, hwe-lik 8.13

hwona 6.19

iāhweder, āider 8.15

iān 12.21

iāta 6.17

idiges 8.15

ielda $6.17,12.31$, gulden 6.17

iena 8.11

iest 5.6

ieva 6.5 , ief 6.17

ieve 5.6

(ik), mī 8.2, *wit, *unk 8.2

iogethe 5.6

kāp 6.19

kenne 4.7

kest 4.7

kètha 4.7

klāth, klèth 4.12

klāy 4.10

$k \bar{u} 4.11$

kūđ 12.53

kuma 12.18, 12.31, kōmen

$$
4.12
$$

lappa 6.9

ledza 4.7

lēra 4.7

let 4.12

lèva 4.7

liāf 4.14

libba 12.46 lidza $6.19,12.19$

līke 5.4

livere 3.2, 4.3

lomb 4.12

long 4.12

lüka 12.18

mede 3.2

mendza 6.19

meta 12.31

mōdar 3.3

mōna 4.12, 5.6

monige 5.6

nān, nēn 4.12

nerede 5.6

ni, ne 5.2, 5.5

nima, nem- 12.31

niugen 4.8

noma $4.12,5.6$

other 4.11

plecht 4.14

quād 3.4

quik, quec 4.3

rāp 4.12

Rümiska, -eska 5.6

rīke 5.6

$s \bar{a} 4.6$

salt 4.12

sax 4.12

sedza $6.19,12.46$

sē 3.4

siā 4.14, 12.21, siuchst 4.14, sēgon, sēn 6.6 n. 4

side 4.4

siga 6.17

sitta 12.19

si(u)gun 6.19

skeft 6.19

skeppa 12.19

skia(n) 12.21

skrīva 12.12

skūva 12.18

slā 4.12, 4.14, 12.21, sleith, slaith, slacht 12.21

somnia, samenia 5.6

sprētse 6.19

spurna 12.18

* stān 12.64

steppa 12.19

sulih, sulik, selik 8.15

Sunnandei 6.19

süpa 12.18

swart 4.12

swera 12.19

tēth 4.7 
tiā, tiucht 12.21

tiuche 4.14

tō 5.3

tunga 6.19

twa 4.12

thes 8.10

thö́chte 4.1

(th $\breve{\bar{u}})$, *jit, *iunk 8.3

tsiāk 6.19

tsiurke 6.19

waja 12.22

warm 4.12

was $4.12 \mathrm{TO} \mathrm{BE}$, wes(s)en 12.17

wein 4.14

wēldich, -ech 5.6

wēna 4.7

wēpa 12.19

wer- 4.3

wilde 6.17

wind 4.2

Modern Frisian

junk (North) 8.3

slüpe (West) 12.18

stīr (East) 3.3

unk (North) 8.3

\section{Old Saxon}

For the purpose of alphabetization, the character $b$ is regarded as equivalent to $v$. Preteritepresent verbs are indexed unprefixed.

acus, accus 6.6 n. 5, 6.15

ađali 5.6

af 6.4

af-seffian 12.19

aftan 11.2

ahar 6.15

ahto $3.2,6.5,10.2$

ahtođo 10.8

ahtotein, ahte- 10.3

akkar 6.4, 6.15

al 8.15

alajung 5.6

alamahtig 5.6

ald, old 4.15, 6.6, 9.3, 9.12,

9.13 , aldiro, eldiro, eldist

9.13

alowaldand 5.6

andwurdi, -wirdi 4.7 n. 17 āno 11.5

anst $\mathbf{7 . 2 2}$

an-swebbian, an-swebit 12.35

antahtoda 10.5

antsibunta 10.5

appul 6.15

at 6.11

bath 3.2

bed, beddi 7.11

bēđia $\mathbf{1 0 . 1} \&$ n. 13

beraht 6.5

beran $4.5,6.4,12.7,12.24$, 12.30, 12.31, biru 12.24, birid 4.4, bāri 1.9, berandi 12.30 , te berann(i)a, -annias 12.30

beuwo 7.12

bìdan 6.16

biddian $6.15,12.19$

bi-lūkan 12.18

bindan 4.4, 6.5, 12.31

biodan 3.4, 6.16, 12.23, 12.31 , budun 4.5

bi-spurnan 12.18

bìtan 12.31

blandan 12.31

blikkan 12.19

blind 6.5

blōd 6.6

blōjan 3.3

bōsom 6.8 n. 2

brāwon, brāhon 7.18

brennian, -brand 12.35

breost 4.15

(bringan), brāhte 4.11, 4.15

brinnan $6.4,6.8$

brōđar, bruođar, -er 4.15, $6.5,7.35$

brūd 5.6

brūkan 3.3, 12.18

bū 7.12

bügan 12.18

burg, burch, burga 6.17

bütan 5.7

cō 4.11

dād 12.7

dag 5.2, 5.6, daga, -e 5.6, dagos, -as 5.3, 6.16, dago 5.4

dèlian 6.15 , dēli 12.38

dilli 7.11 n. 5

diop 6.4

diopor 11.3

diubal, diubul 5.6 dōd 6.6

dōian 12.19

dōm 3.3

dōn, duan, duon, doan 4.15, 12.39, 12.60-1, dōm 12.43, deda, dèdun, dādun 12.33

dōperi 5.6

dor, dur 4.3, 6.4

*dugan, dogg 12.53

dumb, dump 6.20

*durran, gi-dar 12.53, gidorsta 12.54

ef 11.6

$\bar{e}$ gan, *ēh 12.53

e(g)islikk 6.20

egiso 5.6

egi-thassa 6.4

êhtin 4.7 n. 17

ei(i)ero 4.15

eli- 8.15 n. 1

el(l)evan, -en 4.15, 10.3

ellifto, ellefta 10.8

èn $3.4,8.15,10.1$

endi 11.5

èn-di-hweđar 8.15

ēnes 10.10

ènig 8.15 \& $\mathrm{n}$.

engi $6.5,9.6,9.12$

énlōpe 10.10

eo, io 4.15

$\bar{e} r$ 6.11, érist 10.7, 11.3

etan $6.15,6.21$

ettar 4.15

ettho 11.6

euwa 8.5

ebur 4.8

fadar 5.3, 5.6, 6.16

fähan 12.3, 12.31

fallan 12.31

fao 8.15

faran 6.4, 12.31, faru 5.3, ferid 12.24, fares 6.16

fastunnia 5.8 n. 4, 6.11

fehu, ve 4.15, 5.2, 6.4, 7.24

ferah, farah 4.15

ferian 6.15

fersna 4.2

fiertein 10.3

fif $4.11,6.5,10.2$

fíftein 10.3

fîftig 10.4

fífto 10.8

filu 4.4, 4.8, 5.2, 9.6, 11.2 
fiordo 10.8

fisk 6.5

fiskari 5.6

fiur 7.42

fi(u)war 5.3, 10.1, fior 10.1

fiuwartig 10.4

flehtan 12.31

fliogan 4.15

fliohan 6.13

förian 12.34 n. 2

formo, - a 9.11, 10.7

fōt 6.4

frato(h)o 7.18

fremmian 6.15

friund 7.39

furdiro 9.12

furist 10.7

furi 11.5

füs 4.11

fūsid, fisid 4.7 n. 17

(-)gān 3.3, 12.62-3

gang 6.5

gangan 12.31

gans 4.11

garo 5.2, 9.5, garu, garowes

9.5 , garwo 9.8

gast $6.4,7.20$

ge(g)in 6.20

gēr 6.4

gerdia 7.16

gerno 11.4, hald 11.3, 11.4

gèt 3.4

gebа 5.3 \& n. 1, 5.4, 7.14,

7.28, -u 7.28, gaf, gā̄i, -un 12.61

geban, giban 12.31, gaf 6.17, ie-givan 6.20

gi-, $i-6.20$

gi-hwe 8.15

gi-hweđar 8.15

gi-hwilīk 8.15, -hwilīkies 6.20

gi-līk 3.3

gi-līko 5.4, 11.2

gi-mahalda, gi-mālda 4.15

gi-nōg 6.6

ginon 12.50

gi-rādi 6.15

gi-sellian 6.15

gi-walt 6.20

gi-wennian 6.15

glas 6.6

glau $6.10,9.5$, glauwan 9.5

gōd 9.13, gōdan(a) 5.6, betera, -ara, bezto, besto 9.13 gold 4.3, 6.6 n. 7, 6.17

gōs, gās 6.4

graБи 7.7, 7.8

gūđea 6.4

guто, goто 4.3, 7.30, gumon, -un 5.5

haft 6.5

haldan 12.31

half 10.10

hals 6.5 n. 2

hanap $1.5 \mathrm{n} .5$

hand 5.6, handi, hendi 4.7

hano 3.2

hard 6.4, 9.6

hauwan 6.10

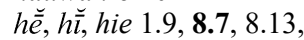
im(u) 1.18

hebbian 12.17 n. 3, 12.19 ,

12.45, 12.46, 12.47, habbien 12.46, 12.47, hebbiu 12.47, habes, -as 5.4, haちe, haちa, habi 12.47

hèlag 9.3, hēlagon, hēlagumu 1.18

helan 3.2

helid 7.41

helpan $6.21,12.31$

hēr, hīr, hier 3.4, 3.5 \& n. 2, $4.15,8.7$

heri 5.6, $7.11 \mathrm{n} .1$

herta 6.21

hētan 3.4, hēt 3.5

heti 5.2

heban 5.6, 6.11, 12.33 n. 6 , hebenes 5.6

himil $6.11,12.33$ n. 6

hinan(a) 8.7

hirdi $\mathbf{7 . 1 1}$

hiu-diga 8.7

hlopan 12.20

hlüd 6.4

hluttar 6.15

hluttro 11.2

hneihida 4.15

hōhan, hoan 6.20

hōi 6.15

hol 9.3

hold 3.2, 6.17

holt 6.21

hord 6.11

(hōrian), hōrda, -hōrid 5.6

hōba 3.3

hōbid 1.5 hоби 7.8

hreuwan 4.15, 12.31

hringodi 5.6

hrütan 12.18

$h \bar{u}, h u \bar{o} 4.11$

hugi 6.17

hund num. 6.4, 6.11, 10.5, 10.6 , hunderod 10.6

hunger 5.6

hüs 7.8

hwan 6.11

hwār 8.13

hwarboian 12.41, 12.43, hwarboiu, hwarbo 12.42, hwarbon, hwarbod, 12.42, 12.43, hwarboiad 12.43

hwē 8.13, hwat 6.4, 6.11, 6.21, sō hwē sō 8.15

hweđar 6.4, 8.13, sō hweđar sō 8.15

hwergin 8.15

hwilik 8.13

ieldan 6.20

ik 5.5, 6.21, 8.2, wit 4.4 n. 3

inka 8.5

inna 11.2

io-gi-hwē 8.15

io-gi-hwelīk 8.15

io-hweđar 8.15

io-wiht 8.15

iungaro, giungaro 6.20

juguđ 5.6

juk $4.3,12.3$

kiennian 6.20

kiēsur 6.20

kiosan 3.4, 6.6

kneo, knio 6.4, 7.12, kneohon 7.12

korn 6.21

kuman 6.4, 6.11, 12.18, 12.31, quāmun 4.12

*kunnan, kan 12.53, konsta $12.54,12.59$

kunni 5.6

lang $6.5,9.2,9.8,9.12$

lango 11.2

lappo 6.9

lātan 3.5, 4.15, 12.20, lèt 3.5, $4.15 \mathrm{n} .1$

lèdian 6.6

leggian 6.15, 12.35, 12.37, legda, lagda, 12.35, 12.37, -legid 12.35 
lēm 4.15

leng 11.3

lēra 7.14

lèrian, -lērid, -lērdes 12.35

lès 11.4

lettian, letta, latta 12.35 , 12.37

lēta 5.3

libbian, libbiandi, libbendi 12.46, libdi, lebdin 12.59 līđan 6.6

liggian $6.4,12.19$

lìhan 3.4, 6.4, 6.6

līkiu 12.42

-līko 11.2

likkon 6.9

linon $6.8,6.11 \mathrm{n.} 1$

liof 6.4

lioht noun 6.4

lōn 4.15

lungar 6.5

luttil 6.15, 9.13, minnera, -ara, minnista 9.13

*magan, mag 12.52, 12.53 \& n. 3

makon 6.21

manag 8.15

$\operatorname{man}(n) 6.8,7.27,7.28$

māno 4.12, 4.15

man-slahta 6.5

marg 6.11

mārio 9.8

mēda 3.5

Medema-hēm 9.11 n. 1

mēđom- 5.6 n. 7

menigi, -o 7.34

mennisk-, mannisk 4.7

méri 4.7 n. 17

metan $6.4,12.31$

metod 5.5

middi 6.4

mikil 4.4, 9.13, mēro, mēst(o) 9.13

mikilu 11.4, mēr 6.16 n. 5, 11.4, mēst 11.4

mildi 9.12

miluk 4.8

$\min 8.5$

mis- 6.8

mōdar $3.3,7.35$ n. 1

mornian 12.18, 12.50

*mōtan, mōt 12.53, mōsta 12.54

mūđ 6.4, 6.17, mund 6.17 *-munan (far-), -man 12.52, $12.53, *-$ munun 12.52 , for-monsta $12.54,12.59$

$m \bar{u} s 3.3$

naht $6.5,7.27$, nahta 7.28

nēn 8.15

neo-man, nio-man 8.15

neo-wiht, ni-wiht 8.15

nerian $6.15,12.35$

neбo 6.4, 6.11

neweđar 8.15

ni, ne 5.2, 5.5

nichonte 10.5

nigèn, negēn 8.15

nigentein 10.3

nigun 10.2

nigunda, niguđa 10.8

niman, nem- 12.31

niuwi 4.10, 6.15

ōđar, ōđer, āđar 4.11, 5.2 n. $8,5.5,8.15,10.7$

ođđarhweđar 8.15

òga, - $\mathbf{7 . 3 0}$

ogian 6.15

ōkian 6.4

oppraiu 12.42

ora 6.6

-(o)ra, -ara, -era, -ost(o) 9.12 \& n. 5

oban(a) 6.9

penning 6.21

pinn 6.4

punt 6.20

queddian, quedda, quadda 12.35

quellian 12.35

quena 6.4

quik, quec- 4.3

rīki 5.2, 7.11

rink 4.4

rinnan 6.8

rōd $3.4,4.15$

sāian 12.22

salt 3.2

sām- 10.10

saro 5.6

scolu 4.3

$\operatorname{segg}(i) 7.11 \&$ n. 1

sehan 3.2, 6.4, sihu 4.8

sehs 10.2

se(h)stein 10.3

sehsto 10.8

sechstic 10.4

seggian, seggiu, sagis, sagad 12.46 self, selb- 8.15

sellian, salda 12.27 n. 4

(sendan), sanda 4.7

sè (o), sēwes 5.6

sēr 3.4

settian 6.15, 6.21, 12.37, setta, satta 12.37

sibbia 6.15

sidu 4.4

sikur, -or 5.6

$\operatorname{sim}($ b) la 5.3

$\sin 8.5$

singan $1.8,6.5,6.16$

sittian 3.1, 4.4, 6.4, 12.19, $-\operatorname{setan} 3.2$

sivondo, sivotho 10.8

sivontein 10.3

sibun $5.6,10.2$

skaban 6.5

skado 7.12

skāp 6.9

skauwon 4.15

skēđan 12.17

skeppian 6.15, 6.21, 12.19

skinan 6.5

skip 6.21

skrīban 12.12

*skulan, skal 12.52, 12.53, skulun 12.52

släpan 6.4, 6.15, 6.21

snīđan 6.6

sō 4.6, 8.15

(sōkian), sōki 7.21 n. 2

spāhi 9.12

spannan $12.31 \& n .15$

springan 12.3 n. 6

spurnan 6.5

stān $3.2,12.3, \mathbf{1 2 . 6 4}$

standan $6.5,12.3$, stōd, stuod $4.15,12.3$

stark 6.21

stekan $12.18 \mathrm{n} .3$

stelan 4.5 , stolen 4.3

stēn 4.15, stēnum 5.5

sterro 6.8

stīgan 3.4, 6.4

stillian, -stild 12.35

stōtan 12.3

strōm 6.11

sūgan 12.18

sulik 8.15

sum 8.15

sипи 5.6, 7.24

suster, soster 4.15 
swerian 12.19

swīkan 12.19

swingan 12.3 n. 6

swiri 7.11 n. 1

te 12.30

tehan $6.4,10.2$, tein 10.3

tehando 10.8 , tegotho, -atho $10.8,10.9$ n. 1

tēknida 12.35

tellian, talda 12.37 n. 4

tìd 3.3

tieglan 4.15

tìhan 6.4

timbrian 6.11

tiohan 6.6, 6.21

tō 5.3

treuwa 4.10

treo, trio 4.10, 6.10, 7.12, trewe 6.10 , treuиes 7.12

truon 12.42

tulgo 3.3, 9.6

tunga, - e 6.5, 7.32

tweedi 10.10

twelif, twi-, twu- 10.3

twēne 10.1 \& n. 11

twēntig 10.4

twīflida 12.35

twīo 10.10

twisk 10.10

thār 11.1

tharf 7.14

that conj. 8.14

thau 4.15

thĕ dem. pron. 8.10, 8.12, 9.2, themu 8.13 , thia, thiu 8.7

the rel. pron. 8.14

thenkian 6.4, 6.21

*these, thit(t), thius $\mathbf{8 . 1 2}$, thesaro, -oro 5.6

thīhan $4.4,12.3$ n. 4

thimm $6.3,6.8$ \& n. 2

thin 8.5

thinclīk 6.20

thiodan 5.6

tholon 12.42

thria $6.4, \mathbf{1 0 . 1}$

thriddio 10.7

thritig 10.4

thriutein, thrū- 10.3

th $\breve{\bar{u}} 2.5,8.3, e u, i u 4.15$

*thurban, tharf 12.53

thwingan 12.3 n. 6

thwì $(w)$ o 10.10

umbi $3.2,5.2$ n. $2,11.5$ undar, under 5.2

unka 8.5

*unnan, *ann, gi-onsta 12.53 , $12.54,12.59$

unt(h)at 11.6

up 11.4

uppan 6.9

urlagu 7.20

üsa 8.5

ubil, wirsa, wirsisto, wirristo 9.13

ubilo, wirs 11.4

wagian 3.2

wāh 4.15

warm 6.4

wastom, -um 5.6

watar, water 5.3

wegan 6.4

wekkian 6.21

wela, wola 11.2 , wala 11.4 , bet 11.3, 11.4, bat, bezt, best 11.4

wesan 12.56-7, bium 1.9

wer 4.3

(werđan), wurdun 4.5

wìdost 11.3

wigg 4.4

wiht 8.15

wildi 6.17

willien 12.58-9, williu 12.27

wind 4.2

wini 4.4, 5.6, 7.20, winies, winios 7.21

wintar 5.6

wis 6.9

wiss 6.8

wita 12.28

witan, wèt 3.4, 12.53, wissa 6.8

wìtan 12.28

wōđi 6.4

wōpian 12.19

word 7.7

wređian 12.35

wulf $6.5,7.7$

wurt 7.28 n. 4

Middle Low German

be-duven 12.18

dese 8.12

gōs 4.11

jene 8.11

jük 8.3 klei 4.10

krabbe 6.9

lever 4.3

naket 6.15

schuven 12.18

slüpen 12.18

stroden 12.18

süpen 12.18

New Low German

jewen 6.5

kat 1.5

Old Low Franconian

duon, duen 12.60-1

fuot 4.16

he, hie, her 8.7

hiera 4.16

mērra 4.16

öra 4.16

ouga 4.16

sēo 4.16

sia 8.7

sig, sil 8.4 n. 1

stān $\mathbf{1 2 . 6 4}$

wì wir 6.16

Dutch

Middle unless otherwise marked.

geven (Modern) 6.5

hède $6.11 \mathrm{n} .1$

\section{Old High German}

Preterite-present verbs are indexed unprefixed.

achus, acchus 6.6 n. 5

ackar 6.15

aftan 11.2

after 5.5

ahto $3.2,6.5,10.2$

ahtodo 10.8

ahtozehan 10.3

ahtozo 10.5

akar, ackar 6.4

al 8.15

alamahtīg 5.6

alt 6.6, 9.13, altiro, eltiro, altisto, eltisto 9.13 
ana-stōzan, -stiez 12.20, -steroz $12.20,12.57$ n. 10

ander, andar 4.11, 5.2 n. 8, $5.5,6.22,8.15,10.7$

āno 11.5

ansi- 4.9

anst $4.7 \mathrm{n} .12,7.22$

apful 6.15

ast 6.11

az 6.11

bad 3.2

bāen, bājan 3.2

balg 3.2

be de, beide $\mathbf{1 0 . 1}$

beotan 4.17, 12.31, biutu, biut 4.17

beraht 6.5

beran $6.4,6.21,12.7,12.24$, $12.30,12.31$, peran 6.21 , biru 4.4, 12.24, birit 4.4, berumēs 5.5 , bāri 1.9, beranti $12.30, z a, z i$ beranne, -annes, -annu(m) 12.30

$\operatorname{bet}(t) i 7.11 \&$ n. 5

biaza 3.5

bibēn 12.3

bi-jehan 5.7

büjiht 5.7

bi-līban 5.7

bi-lūhhan 12.18

bintan 4.4, 6.5, 12.31

biogan 12.18

biotan 3.4, 6.15, 6.21, 12.23, biodan 6.21 , gi-botan 4.5

bìtan 6.16

bitten 6.15, 6.21, 12.19, bidden 6.21

bi-wellan 12.18

bizan 12.31

blantan 12.31

blāsan 3.3

blint 6.5 , blintēer 8.2

bliuwan 1.11

bluojen, bluowen 3.3

bluot 6.6

bluozan 12.20

bodam 4.3

boum 4.12

brechan 12.31

brennen 4.7, branta 4.7, branti 12.35 n. 5

(bringan), brāhte 4.11

brinnan 6.4, 6.8 brūhhan 3.3, 12.18

bruoder 6.5, 6.22, 7.35, -o 7.36

brūt 5.6

büan 6.4, 12.16, 12.20, biruun 12.16

buoh 4.17, boohhum, buochum 6.15

buosum 6.8

$c(h)$ - see $k(h)$ -

dagēn 12.3

dah 6.4

dar 11.1

daz conj. 8.14

de rel. pron. 8.14

deh-, theh- 8.15

deh(h)ein, theh(h)ein, thihhein, dohein, thohhein 8.15

denken 6.4, 6.21, denchen, $t$ (h)enchen, $t(h)$ enken 6.21

denne 11.1

der pron. 8.7 n. $4, \mathbf{8 . 1 0}, 8.12$, 9.2, дети 8.7, 8.13, 9.2, dat 6.21 n. 2, diu 8.7, daz 9.2, deru 1.9, dera 1.9, dero 1.9

dese, -ēr 8.12, 9.2, desero 5.6 dìhan $4.4,12.3$ n. 4

din, $-\bar{e} r 1.4,8.5$

dinsan, thinsan 12.3

diozan 12.18

diuten 4.17 n. 1

dohhein̄̄g, thihheinīg 8.15

dorn 6.22

dranc 9.5

drawa, drowa, drouwa, drō 7.18

drescan 12.3

drī $6.4,10.1$ \& n. 15

driske 10.10

dritt(i)o 10.7

drīzehan 10.3

drīzugōsto 10.9

drīz(z)ug 10.4

$d \check{\bar{u}} 2.5, \mathbf{8 . 3}$, dir, ir 8.7 n. 4

dunni 6.8

*durfan, (-)darf (bi-) 12.53, dorfta 12.54

durst 3.2

dwingan 12.3 n. 6

ebur 4.8

eburo 5.6 eddes-, ettes- 8.15

eddeslīh 8.15

eddeswelīh 8.15

eddeswer 8.15

ed(d)o 4.5 n. 1, 11.6

egi-dehsa 6.4

egiso 5.6

ehir 6.15

ēht 4.17

*eigan, *eih, eigun 12.53

eigan adj. 12.53

eimuria 4.7

ein $3.4,8.15,10.1$

eines 10.10

einfalt 10.10

einlif 10.3

einlifto 10.8

einluzze 10.10

eli- 8.15

engi 6.5

enti 11.5

eo-gi-līh 8.15

er pron. $1.9,8.7 \&$ n. $4,8.10$, $8.13,9.2$, inan 8.13 , it $6.21 \mathrm{n} .2$

$\bar{e} r$ 'bronze' 6.11

$\bar{e} r$ 'early' 4.17, éristo 10.7

erien 12.19

èrist 11.3

ezzan $6.15,6.21$

fāhan $4.17,12.3,12.20 \& \mathrm{n}$. $7,12.31$

faldan, faltan 12.17

fallan 12.31

far $(a) h 4.13$

faran 6.4, 12.31, faru 5.3, ferit 12.24, farēs 6.16

fastōr 11.3

fatar, fater 5.3, 5.5, 6.6, 6.16, 7.35 , fateres, $-e,-\overline{\bar{a}} 7.35$

feginōn 6.6

feordo 10.8

feoriske 10.10

ferien, ferren 6.15

ferro, ferio 6.8, 6.15

fersana 4.2

festiro 11.3

fiara 3.5

fihu, fehu, -o 4.4, 5.2, 6.4, 7.24

filu 4.4, 4.8, 5.2, 9.6, 11.2

fimf $4.11,6.4$ n. $3,6.5,10.2$, finf 10.2

fimfto 10.8 
finftazehanto, funfzēndo 10.9

finfzehan 10.3

finfzug 10.4

fiorzehan 10.3

fiorzug 10.4

firni 6.8

fir-sinnan 6.8

fir-spurnan 12.18

fisc 3.2, 6.5

fiur 7.42, 10.1, fuir, vugir

$$
7.42
$$

flehtan 12.3, 12.33

flioga 4.13

fliohan 6.13

fluot 12.7

fö $(h)$, fao 8.15

forhta, forahta, forohta 5.6

forsca 6.5

forscōn 12.3

fragēn 6.6

fremmen $6.15,12.35$

frezzan 12.8

frido 7.24

Frīja 6.10

friunt 7.39

frouwen, frauwen, frewen, frewita, frouwita 12.35 \& n. 4

fūht 4.1

füir, fiur 1.9

funcho 7.42

funs 4.11

fuoren 12.34 n. 2

fuotar 3.3

fuoz 4.17, 6.4

fur-, for-, fir-, fer- 2.2 n. 5

furi 11.5

gān, gēn 1.9, 3.3, 12.62-3, 12.64

gang 6.5

gangan 1.9, 12.20 \& n. 7, 12.31

gans 6.4

garawen 4.7

garo 5.2, 9.5, gar(a)wes 9.5, $\operatorname{gar}(a)$ wo 9.8

garwēer, garawēr 5.6

gast 6.4, 7.20

geba 5.3 \& n. 1, 5.4, 7.14

geban 6.5, 6.21 \& n. 3, kepan

6.21 , gevan 6.21 n. 3 , gab, gaf 6.21 n.3, gigeban 4.4

geiz 3.4 gèr 6.4

gerno 11.4, halt 11.3, 11.4, gernōr, gernōst 11.4

gerta $\mathbf{7 . 1 6}$

gi-burien, -burren 6.15

gi-fehan 6.6

gift 6.5

gi-(h)wedar 8.15

gi-(h)welīh 8.15

gi-līh 3.3, 8.15

gi-līhho 5.4, 11.2

gi-loubo 5.7

gi-nuog 6.6

gi-rāti, ke-rāttes 6.15

gi-sellio 6.15 n. 7

giumo 3.4

gi-wennen 6.15

gi-wissi 1.4, 6.8

glas 6.6

glau 9.5, glauwēr 6.10, glauwan 9.5

gold 4.3, 6.6 n. 7

gomilīhho 11.2

gomo 7.30, 11.2, gomon, -un 5.5

(graban), grebis 5.5, grabet 5.5

grātidu 7.14

grīnan 12.12 n. 2

gruene 4.7

gund- 6.4

guomo 3.4

guot 9.13, guotan 5.6, bezziro, bezzisto 9.13

habēn 2.2 n. 9, 12.45, hapta

12.46, 12.47, habēta 12.47

haft 6.5

hāhan 6.6, 12.20 n. 7

halb 10.10

hals 6.5 n. 2

haltan 12.31

hamallus (Latinized) 6.6

ham-èdii (Latinized) 6.6

hamma 6.8

hanaf 1.5 n. 5

hano 3.2

hant 5.6

hart 6.4, 9.6, hertisto 11.3

hartōst 11.3

haspil 6.21

haz 3.2

heffen 12.17 n. 3, 12.19

heit 3.4 -heit 1.8

heiz(z)an 3.4, 6.15, hiaz 3.5

helan 3.2

help(f)an, helfan $6.21,12.31$

hengen 6.6

hèr, hear, hiar, hier 3.4, 4.17, 12.20

heri 5.6, heriun, herrun 6.14

herza 6.21

himil 1.9, 6.11

hirti 7.11

(h) last 6.8

hleo, lē, hlēwes 7.12

hloufan 12.20

hluttar, (h)lütar 6.15

hogta 12.46, 12.47, hocta

12.46, hogèta 12.47

hōh 4.17, hōhī, hōhīno, hōhīm 5.6 n. 14

hōla 3.4

hold 3.2

holz 6.21

(hōren), hōrren 12.35, hōrta

5.6, -hōrit 5.6, 12.35,

-hōrtēr 12.35

horo 7.12

hort 6.11

houwan 3.4, 6.10

houwi $6.15,7.11$, hewi 7.11

(h) rucki 6.21, 7.11

hunt num. 6.4, 6.11, 10.6

huoba 3.3

hūs 7.8

(h) wanne, wenne 11.1

(h) wār 8.13, 11.1

(h) warbōn $\mathbf{1 2 . 4 1}$

(h) wedar 8.13

(h) welīh 8.13, welīh, walīh

8.15 n. 3, sō welīh sō 8.15

(h) wer 8.7 n. 4, 8.10, 8.13,

(h)waz 6.4, 6.11, 6.21, wat 6.21

ibilo 4.7

ibu 11.6

ih 5.5, 6.21, 8.2, mir $1.10 \mathrm{n}$.

$6,2.5,8.7$ n. 4 , wir 8.7 n.

4, uns 6.7 n. 9

inna- 11.2

in-sebben 12.19

*in-trīhhen 12.19 , intrīhhit

12.19 n. 4

io-wergin 8.15

io-wiht 8.15

-ir-, -ist- 9.12 
irmin- $12.30 \mathrm{n} .1$

ir-queban 12.19

ir-sliofan 12.18

iuwerēr, iuwēr, iuwaz, iuwu $8.5,9.2$

jenēr $8.11,10.1$

joh 4.3

jugund 5.6

kallōn 6.4

kamb 6.5

kerban 6.4

chapf 6.21

chindiliu 7.8

$k$ (h)orn, chorn 6.21

kien- 3.5

kinan 12.3

kiosan 3.4, 12.27, churun 4.9, ni curi $12.26,12.27, n i$ churīs 12.26, ni curīt, curet 12.28

klimban 12.3 n. 4

kneo, knio 6.4

knetan 12.18

knodo 6.9

knōt, knuot 3.3

knussen 6.8

korn 3.3

krazzōn 6.9

crebiz 6.9

kund 3.3

kuningin 7.16

kunnan, kan 6.4, 6.11, 12.53, konda 12.54, 12.59

kunni 5.6

kunst 6.11

kuo 4.11

kuri 7.22

ladungu 7.14

lamb 3.6, 4.7, 7.37, lembir 3.6, $4.7,5.5$

lang, langēr 6.5, 9.2, 9.8, lengisto 11.3

langōst 11.3

lāzan 3.5, 12.20, liaz 3.5

lebara 4.3

lebēn 12.59

lecchōn 12.3 n. 5

leggen 6.15, 12.35 n. 5, legiti, legitin 12.35 n. 5

leiba $5.3 \mathrm{n} .1$

leoht, lioht noun 4.17, 6.4

lèra 7.14

liggen 6.4, 12.19, lickan 12.19 līhan 3.4, 6.4, 6.6, 12.3 n. 4, gi-liwan 4.5

-līhho 11.2

limmit 4.4

liob 6.4

liogan 12.31

lirnèn, lernēn 6.8

lìso $9.13 \mathrm{n} .1$

liuhten 4.17

liuten 4.7

lōn 3.4

loufan 4.17

lougazzen 12.3

luft 6.21

lungar 6.5

lüt 4.7, 6.4

luzilo, min, minnist 11.4

luzzil 6.15, 9.13, minniro, minnisto 9.13

magar 7.8

magad 7.41

magan, mag 12.52, 12.53 \& n. 3

mahhōn 6.21

mahtīg 4.7

māl 3.3

mālōn 12.40

manag 8.15

managfalt 12.32

managfaltōn 12.32

manēn 12.44

$\operatorname{man}(n) 6.8,7.27,7.28$, manno 8.15

māno 4.12

mānōt 7.41

mār $(e)_{o} 9.8$

marg 6.11

melchan 12.18

menigī(n) 5.3, 7.34

meri 7.20

metu, meto 3.2, mito 4.4

mezzan 6.4, 12.31

miata, mieta 3.5, 4.17

mīdan 6.8

mihhil adj. 4.4, 9.13, mēr(ir)o, mērōro, meisto 9.13

mih(h)il adv., mēr, meist 11.4 miluh 4.8

$\min ,-\bar{e} r 1.4,8.5$

miscen 6.21

missa-, missi- 6.8

mitti 4.4, 6.4

morgan 4.7 mornēn 12.3, 12.18, 12.50

mund 6.4

muoter $3.3,7.35$ \& n. 1

*muоz(z)an, тиоz 12.53, mиоsа $6.9,12.54$

$m \bar{u} s 3.3$

nackut, nackot, nachut 6.4, 6.15

naht $6.5,6.21,7.27$

namo 5.4

neman 12.31

neo-man, nio-man 8.15

nerien, nerren, nergen 6.15 \& n. $7,12.35$

nest 4.3, 6.11

nevo, nefo 6.4, 6.11

ni 5.5

nih- 8.15

nihheinīg, nohheinīg 8.15

nioro 6.4

niun, niwan 10.2

niunto 10.8

niunzehan 10.3

niuwi 4.10

*-nugan (gi-), -nah 12.53

obana 6.9

ora 6.6

ouga $4.17,7.30$

ougen, auckan 6.15

ouh 4.17

ouhhōn 6.4

p(f)enning 6.21

pfin 6.4

pfluog 1.5

pfoso 6.4

priester 3.5

quec 4.3, 6.3

queman, coman $6.4,12.18$, 12.31 , quimit $1.4 \mathrm{n} .12$ quena $6.4,7.32$

rechan 12.31 , gi-rohhan 12.31 n. 2

reiniro 11.3

renōr 11.3

rīchi 5.2, 7.11

rihten 4.9

rinc 4.4

rinnan 6.8

(rītan), reit 4.17

ropfōn 6.9

rosomo 6.8

rōt 3.4

rotèn 12.44

rūzan 12.18 
sāian, sāan, sāwen, sāhen 12.22

salz 3.2

samanōn 5.6

sāmi- 10.10

saro 5.6

(sāwan), zi sāwenne 1.9

secka 6.15

sehan $3.2,6.4,6.15$, sehhan

6.15, sihu 4.8, sē 4.17

sehs 10.2

sehsto 10.8

sehszehan 10.3

seh(s)zug 10.4

selah 4.13

selb 8.15

sellen 6.15

sêr 3.4

sezzen, setzen $6.15,6.21$, setzit, sazta, setzida, -sezzit, -saztēer 12.35

sibun $4.8,10.2$

sibunto 10.8

sibuntozehanto 10.9

sibunzo 10.5

$\operatorname{sih} 8.4$

$\sin ,-\bar{e} r 1.4,8.5$

singan 1.8, 6.5, 6.16

sipp(e)a 6.15, 6.21

situ 4.4

sizzen, sitzen 4.4, 6.4, 12.19, -sezzan 3.2

skaban $6.5,6.9$

scāf 6.9

-schaft 1.8

scama 6.21

scanta 6.11

skeidan 12.17

scepfen, skepfen 6.15, 6.21, 12.19 , skeppen 6.21 , scepfit, scefta 12.35

skif 6.21

skinan 6.5

skola 4.3

scolan, scal 12.53, skolta $12.54,12.59$

scouwunc 7.14

skrīban 12.12

scrōtan, ki-screrot $6.3,12.20$

scutten, scutta, scutita 12.35

slachta 6.5

släf(f)an 6.4, 6.15, 6.21

slag 7.20

sleffar 6.3 smitta 6.22

snello 11.2

sneo 6.4 , snēwes 4.17

snottar $6.15,6.21$

spinnan 6.3

sprehhan 6.21, 12.31

springan $12.3 \mathrm{n} .6$

spurnan $6.5,12.50$, spurnum 12.50

sō 4.6, 8.15

spannan 12.31

stān, stēn 1.9, 3.2, 12.64,

*stèm, stēt 12.47

stantan $1.9,6.5$

$\operatorname{star}(a)$ ch 6.21

stat 3.2

stechan 12.31

stein 4.17, 6.21, steinum 5.5

stelan 4.5, stilu 4.4, gi-stolan 4.3

sterro, sterno 6.8

steteo 7.22

stiaga $3.4,3.5$

stigan 3.4, 3.5, 6.4, 6.21, stīcan 6.21, gi-stigan 4.4 stōzan 12.3, 12.20, $12.31 \mathrm{n}$. 13

strengi, strang 9.6

stroum 6.11

strutten 12.18

stunta, -stunt 10.10

süfan 12.18

sūgan 12.18

sulīh 8.15

sum 8.15

sumilīh 8.15 n. 5

sun, sunu 5.6, 7.24

suntea, suntia, sunte 7.16, 12.57 n. 12

suohhen 4.17 , suochi $7.21 \mathrm{n}$. 2

swāgur 7.35 n. 1

swār(i) 9.6

swehur 7.35 n. 3

swerren 12.19

swibogo 12.33 n. 6

swigar 7.35 n. 3

swìgēn 3.3

swingan 12.3 n. 6

tag 5.2, 5.6, tages 5.5, 7.8, tagā 6.16, tago 5.4

tagarōt 7.37 n. 5

tagawerk 5.6

tahar 6.15 tapfar 6.8

tàt $3.3,12.7$

teil 4.7

teilen 12.35, teillen 12.35 , teili 12.38

tilli 7.11

tiof 6.4

tiofōr 11.3

tiufal 5.6 \& n. 10, tiufales, tiuflun 5.6 n. 10

tocchōn 6.9

tōd 4.17, 6.22

tohter, dohter 6.21

tor $4.3,6.4$

tōt 6.6

touwen 12.19

trechan 12.31

treffan 12.31, gi-troffan 12.31 n. 3

tretan 12.18 n. 6

triuwa 4.10

troistest 4.7

trūēn 6.21

tuft 3.2

*tugan, toug 12.53, tohta 12.54

*tūhhan, be-tochen 12.18

-tum 1.8

tuni 6.5

tuom 3.3

tuon, tuan, tōn 12.39, 12.60-

1, tuom 12.9 \& n. 2 ,

12.43 , teta, tātun 12.33 ,

12.39, tāti, tātum, tātut

12.39

Tuonouwa 3.3

turi $3.2,7.22$

*-turran (gi-), -tar 6.4, 12.53, gi-torsta 12.54

ubar, ubari, ubiri 11.5

ubar-wehan 12.18

ubil, wirsiro, wirsisto 9.13

ubilo, wirs, wirsist 11.4

uf 11.4

üffana 6.9

umbi $3.2,5.2$ n. 2, 11.5

unnan, an 12.53, onda 12.54, 12.59

unsēlic 4.7

unserēr, unsēer, unsaz, unsu, unser(er)o 8.5, 9.2, 12.33

n. 6

untar 5.2

untaz 11.6 
wadal 6.8

wagōn 3.2

Walha 3.2 n. 1

warm 6.4

wazzar 5.3

wedar 6.4

wegan 6.4

wec(c)hen, wecken 6.21, weckit, wecchit, wahta, wakta 12.35

wel(a) 4.5 n. 1, 11.2, 11.4, wola $11.2,11.4, \mathrm{baz}$, bezist 11.4

wellen athematic vb. 12.58-9, willu 12.27

wellen weak vb. $12.35,12.59$

n. 3, walta, welita 12.35

wēnec, weinec $10.1 \mathrm{n} .11$

werdan 6.4

werp(f)an 6.21

wesan 12.56-7, bim 1.9, ist 6.21

Wialant 3.4

wigant 12.3 n. 3

wìhan 6.6

wiht 8.15

willeo 6.15

wini $4.4,5.6,7.20$

wint 4.2

wiss 6.9

wīsa 6.8

wiz(z)an, weiz 3.4, 12.53, wissa 6.8 , wista 12.54

wolf $6.5,7.7$

wort 7.7 , wortu 7.8

wunscen 12.3

wuofan 12.19

wurz 7.28 n. 4

zahar 3.2

zam 12.3

zamōn 12.3

zan(d) 7.28

zannēn 6.8

zehan $6.4,10.2$

zehanto 10.8

zehanzo 10.5

zehanzugōsto 10.9

zeigōn 6.6

zeihinen 6.9

zeihhur 3.4, 6.3, 7.35 n. 1

(zellen), zalti 12.35 n. 5

ziahha 3.5

zicchī, zikkīn 6.9

ziga 6.9 zìhan 6.4, 6.6, 12.31

zimberen 6.11

ziohan 6.21

zìt 3.3

zittarōn 12.3

-zug 10.4 \& n. 3, 10.9, -zog-, -zig-, -zeg-, -zg- 10.9

zunga $6.5,7.32$, zungūn 5.6

zиo 5.3

zweinzug 10.4

zweinzugōsto 10.9

zwelif 10.3

zwelifto 10.8

zwēne 10.1 \& n. 11, zwei

8.10 , zwei(i)o $6.10,8.2$

zwiro(r) 10.10

zwiske 10.10

Middle High German

ackeran 3.2

eintweder 8.15

ez, enc, enker 8.3

gewesen 12.17

gloube 5.7

grūz 3.3

kōt, quāt, kāt 3.4

kraft 4.7 n. 12

sprinzen 6.14

swinken, swingen 6.15 n. 9

zwirn 10.10

New High German

Apfel 6.21

Beichte 5.7

bleiben 5.7

Brüder 7.35 n. 4

dumpf 3.3

ez, enc, enker (Bavarian)

$$
8.3
$$

irgend 8.15

jener 8.8

Kot 3.4

länten, länden (High

Alemannic) 6.15 n. 9

machen 6.21

Mütter 7.35 n. 4

naß 12.34

Schatz 6.9

Stiege 3.4

stier 3.3

Töchter 7.35 n. 4

Väter 7.35 n. 4
Zauberin 12.33 n. 6

Zeit 12.7

Zürich 6.21

Zwirn 6.11 n. 1 
Fulk's Comparative Grammar offers an overview of and bibliographical guide to the study of the phonology and the inflectional morphology of the earliest Germanic languages, with particular attention to Gothic, Old Norse / Icelandic, Old English, Old Frisian, Old Saxon, and Old High German, along with some attention to the more sparsely attested languages. The sounds and inflections of the oldest Germanic languages are compared, with a view to reconstructing the forms they took in Proto-Germanic and comparing those reconstructed forms with what is known of the Indo-European protolanguage. Students will find the book an informative introduction and a bibliographically instructive point of departure for intensive research in the numerous issues that remain profoundly contested in early Germanic language history.

\section{John Benjamins Publishing Company}

